\title{
Synthese, biologische Evaluation und Untersuchung des Wirkmechanismus neuartiger Duocarmycin-Analoga für eine selektive Krebstherapie
}

\author{
Dissertation \\ zur Erlangung des Doktorgrades \\ der Mathematisch-Naturwissenschaftlichen Fakultäten \\ der Georg-August-Universität zu Göttingen
}

vorgelegt von

Birgit Krewer

aus Bitburg

Göttingen 2008 
D7

Referent:

Prof. Dr. Dr. h. c. L. F. Tietze

Korreferent:

Prof. Dr. U. Diederichsen

Tag der mündlichen Prüfung: $\quad$ 22. Januar 2009 
Die vorliegende Arbeit wurde in der Zeit von August 2005 bis August 2008 im Institut für Organische und Biomolekulare Chemie der Universität Göttingen unter der Leitung von Prof. Dr. Dr. h. c. L. F. Tietze angefertigt.

Mein besonderer Dank gilt Herrn Prof. Dr. Dr. h. c. L. F. Tietze für die interessante Themenstellung, die Gestaltungsfreiheit, die Bereitstellung eines vorbildlich ausgestatteten Arbeitsplatzes, sein stetes Interesse am Fortgang dieser Arbeit sowie für die zahlreichen Diskussionen und Anregungen. 

Meiner Familie 

Der Fortschritt lebt vom Austausch des Wissens.

Albert Einstein 



\section{INHALTSVERZEICHNIS}

INHALTSVERZEICHNIS

Allgemeiner TeIL

1 Einleitung .................................................................................................................... 1

2 Grundlagen der Tumorentstehung und des Tumorwachstums ..................... 3

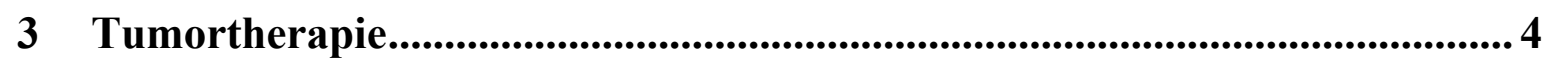

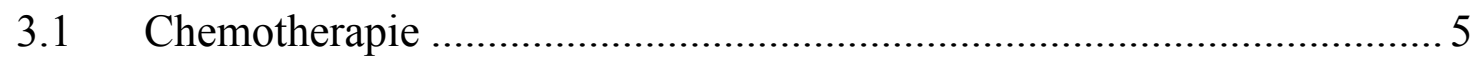

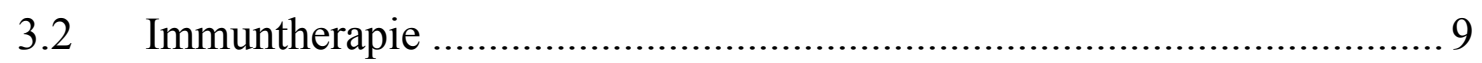

3.3 Selektive Krebstherapie mittels reversibel detoxifizierter Prodrugs........ 12

3.4 Präklinische und klinische In-vivo-Studien zur selektiven Tumortherapie nach dem ADEPT-Konzept..................................................... 15

4 CC-1065, Duocarmycine und Yatakemycin ....................................................... 17

4.1 Analoga des Antibiotikums CC-1065 und der Duocarmycine ............... 20

4.2 Untersuchung des Wirkmechanismus des Antibiotikums CC-1065, der Duocarmycine und ihrer Analoga .................................................... 25

4.3 seco-Verbindungen und Prodrugs einiger Analoga des Antibiotikums CC-1065 und der Duocarmycine............................................................ 30

5 Fluoreszenzmikroskopie und Optical Imaging ….............................................34

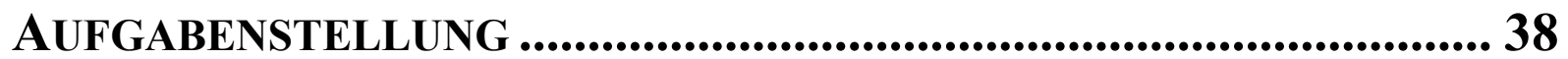

1 Stand der Forschung zu Beginn der Arbeit ....................................................38

2 Zielsetzung der Arbeit ........................................................................................ 40

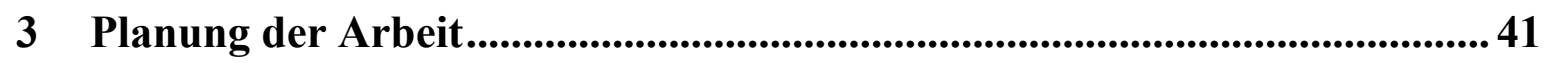

3.1 Synthese neuer Duocarmycin-Analoga .................................................... 41

3.2 Untersuchung der Wechselwirkung verschiedener DuocarmycinAnaloga mit DNA, RNA und Peptiden 
3.3 In-vitro-Untersuchungen des Wirkmechanismus an lebenden Zellen ....45

DARSTELLUNG DER ERGEBNISSE.............................................46

1 Synthese der anti-Methyl-seco-CBI-Derivate ...................................................46

1.1 Synthese des anti-Methyl-seco-CBI-Hydrochlorids ( $1 S, 10 R)-34 a$ mit einer $N, N$-Dimethylaminoethoxyindol (DMAI)-Seitenkette.

1.2 Versuche zur Synthese des anti-Methyl-seco-CBI-Derivates $\mathbf{5 0}$ mit einer $N, N, N$-Trimethylammoniumethoxyindol (TMAI)-Seitenkette .......47

1.3 Synthese des dechlorierten (1S)-Methyl-seco-CBI-Derivates (1S)-49 mit einer $N, N$-Dimethylaminoethoxyindol (DMAI)-Seitenkette

2 Synthese der seco-CBI-DMAI-Derivate .57

2.1 Synthese der seco-CBI-Hydrochloride 56a mit einer $N, N$-Dimethylaminoethoxyindol (DMAI)-Seitenkette.

2.2 Synthese des seco-CBI-Galactosides (1S)-54a mit einer $N, N$-Dimethylaminoethoxyindol (DMAI)-Seitenkette

3 Synthese des seco-CBI-MPI-Hydrochlorids .66

3.1 Synthese des seco-CBI-Hydrochlorids (1S)-56b mit einer $N$-Methylpiperidinylmethoxy (MPI)-Seitenkette .66

4 Synthese der fluoreszenzmarkierten anti-Methyl-seco-CBI-DMAI-

Derivate. .70

4.1 Synthese des fluoreszenzmarkierten anti-Methyl-seco-CBI-DMAIProdrugs $(1 S, 10 R)-\mathbf{7 5}$ .71

4.2 Synthese des fluoreszenzmarkierten anti-Methyl-seco-CBI-DMAIHydrochlorids $(1 S, 10 R)-\mathbf{7 6}$ .76

5 In-vitro-Zytotoxizitäten der neuen Analoga .................................................80

5.1 Der HTCFA-Test zur Bestimmung der Zytotoxizität ...............................80

5.2 Der MTT-Test zur Bestimmung der Zytotoxizität................................... 81

5.3 In-vitro-Zytotoxizität (HTCFA) der (1S)-seco-CBI-DMAI-Derivate......83 
5.4 Vergleich der In-vitro-Zytotoxizität (HTCFA) der seco-CBI-DMAI-

Derivate 56a und der anti-Methyl-seco-CBI-DMAI-Derivate 34a .

5.5 Vergleich der In-vitro-Zytotoxizität (HTCFA) des seco-CBI-MPIHydrochlorids $(1 S)$-56b und des $(1 S, 10 R)$-anti-Methyl-seco-CBIMPI-Hydrochlorids $(1 S, 10 R)-\mathbf{3 4 b}$. 86

5.6 In-vitro-Zytotoxizität (HTCFA) des dechlorierten Methyl-seco-CBIDMAI-Analogons (1S)-49.

5.7 In-vitro-Zytotoxizität (HTCFA) verschiedener DNA-bindender Einheiten.

5.8 In-vitro-Zytotoxizität (MTT) der fluoreszenzmarkierten anti-Methylseco-CBI-DMAI-Derivate.

6 Untersuchung der Wechselwirkung neuer Duocarmycin-Analoga mit DNA, RNA und Glutathion mittels Massenspektrometrie.

6.1 Wechselwirkung des seco-Drugs $(+)-(1 S, 10 R)-34 a$ mit den DNA-

Oligonukleotiden ds-60 und ON-1 (ds-60).

6.2 Wechselwirkung des seco-Drugs (-)-(1R,10S)-34a mit den DNA-

Oligonukleotiden ds-60 und ON-1 (ds-60).

6.3 Wechselwirkung des Prodrugs $(+)-(1 S, 10 R)-33 a$ mit den DNA-

Oligonukleotiden ds-60 und ON-1 (ds-60).

6.4 Wechselwirkung verschiedener seco-Drugs und Prodrugs mit dem

DNA-Oligonukleotid ds-60

6.5 Wechselwirkung der seco-Drugs $(+)-(1 S, 10 R)-34 \mathbf{a},(+)-(1 S, 10 R)-$

34b, $(+)-(1 S)-56 \mathbf{a}$ und $(+)-(1 S)-56 \mathbf{b}$ mit den DNA-Oligonukleotiden ds-60 - ds-69

6.6 Wechselwirkung des seco-Drugs (+)-(1S,10R)-34a mit dem RNA-

Oligonukleotid ds-59.

6.7 Wechselwirkung des seco-Drugs $(+)-(1 S, 10 R)-34 a$ mit dem Tripeptid Glutathion.

6.8 Wechselwirkung der fluoreszenzmarkierten Analoga mit dem DNA-

Oligonukleotid ds-60. 
7 Untersuchung der Wechselwirkung neuer Duocarmycin-Analoga mit

DNA mittels HPLC

7.1 Vergleich der Alkylierung des Oligonukleotides ds-60 durch

(+)-(1S,10R)-34a in Wasser und Phosphatpuffer (pH 7)

7.2 Vergleich der Alkylierung des Oligonukleotides ds-60 durch

$(+)-(1 S, 10 R)-\mathbf{3 4} \mathbf{a},(+)-(1 S, 10 R)-\mathbf{3 4 b},(+)-(1 S)-56 \mathbf{a}$ und $(+)-(1 S)-56 \mathbf{b} \ldots 148$

7.3 Untersuchung der Wechselwirkung weiterer Duocarmycin-Analoga mit dem DNA-Oligonukleotid ds-60.

8 Untersuchung der Wechselwirkung neuer Duocarmycin-Analoga und anderer Zytostatika mit DNA-Oligonukleotiden mittels

CD-Spektroskopie. 159

8.1 Untersuchung der Wechselwirkung des seco-Drugs (+)-(1S,10R)-34a mit dem DNA-Oligonukleotid ds-60.

8.2 Untersuchung der Wechselwirkung der seco-Drugs 34a, des Prodrugs $(+)-(1 S, 10 R)-33 a$ sowie des dechlorierten Analogons

$(+)-(1 S)-\mathbf{4 9}$ mit verschiedenen DNA-Oligonukleotiden. 166

8.3 Kinetik der Wechselwirkung des seco-Drugs (+)-(1S,10R)-34a mit verschiedenen Oligonukleotiden

8.4 Untersuchung der Wechselwirkung verschiedener seco-Drugs mit dem Oligonukleotid ds-60

9 Untersuchung der Aufnahme verschiedener Zytostatika in Zellen mittels CD-Spektroskopie 184

9.1 CD-Spektroskopie an Zellen 185

9.2 CD-Spektroskopie mit den seco-Drugs (+)-(1S,10R)-34a,b und (+)-(1S)-56a,b präinkubierter Zellen

9.3 CD-Spektroskopie isolierter zellulärer DNA aus mit den seco-Drugs $(+)-(1 S, 10 R)-\mathbf{3 4 a}, \mathbf{b}$ und $(+)-(1 S)-\mathbf{5 6} \mathbf{a}, \mathbf{b}$ präinkubierten Zellen

9.4 CD-spektroskopische Untersuchung der Aufnahme des fluoreszenzmarkierten seco-Drugs $(1 S, 10 R)-76$ in Zellen. 
9.5 CD-spektroskopische Untersuchung der Aufnahme anderer Zytostatika in Zellen

10 Untersuchung der Fluoreszenzeigenschaften und der zellulären Aufnahme fluoreszenzmarkierter anti-Methyl-seco-CBI-DMAI-Derivate..... 201

10.1 Fluorimetrische Untersuchung der fluoreszenzmarkierten Analoga .... 201

10.2 Untersuchung der zellulären Aufnahme fluoreszenzmarkierter antiMethyl-seco-CBI-DMAI-Derivate.

ZUSAMMENFASSUNG

EXPERIMENTELLER TEIL

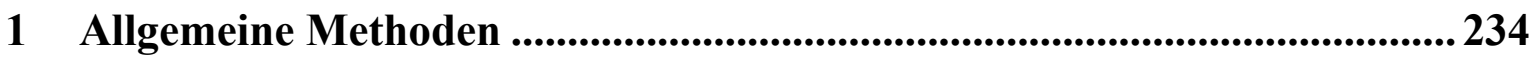

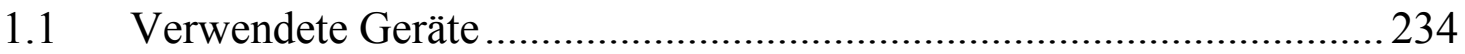

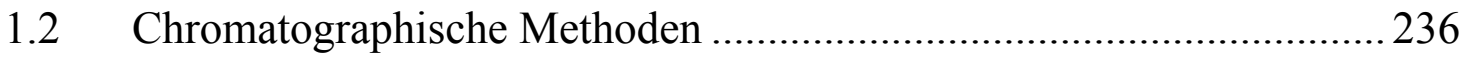

1.3 Materialien und Geräte für HPLC-MS-Messungen ...............................237

1.4 Materialien und Geräte zur Untersuchung der Wechselwirkung von Zytostatika mit DNA, RNA und Glutathion ........................................ 238

1.5 Materialien für In-vitro-Zytotoxizitätstests und In-vitro-Mechanismusstudien.

2 Synthese der anti-Methyl-seco-CBI-Derivate.

2.1 Trennung der Enantiomere von rac-\{(1S,10R)-5-Benzyloxy-3-(tertbutyloxycarbonyl)-1-(10-chlor-ethyl)-1,2-dihydro-3H-benz[ $e]$ indol $\}$ (rac-44)

$2.2(+)-\{(1 S, 10 R)-5-$ Benzyloxy-1-(10-chlor-ethyl)-3-[(5-(2- $(N, N-$ dimethylamino)ethoxy)indol-2-yl)carbonyl]-1,2-dihydro-3Hbenz $[e]$ indol $\}((+)-(1 S, 10 R)-47)$ 246

$2.3(+)-\{(1 S, 10 R)-1-(10-C h l o r-e t h y l)-3-[(5-(2-(N, N-$ dimethylamino $)-$ ethoxy)indol-2-yl)carbonyl]-5-hydroxy-1,2-dihydro-3 $\mathrm{H}$ benz $[e]$ indol-Hydrochlorid $\}((+)-(1 S, 10 R)-\mathbf{3 4 a})$. 
$2.4(-)-\{(1 R, 10 S)-5-B e n z y l o x y-1-(10-c h l o r-e t h y l)-3-[(5-(2-(N, N-$ dimethylamino)ethoxy)indol-2-yl)carbonyl]-1,2-dihydro-3Hbenz $[e]$ indol $\} \quad((-)-(1 R, 10 S)-47)$ 248

2.5 (1R,10S)-5-Benzyloxy-1-(10-Chlor-ethyl)-3-[(5-(2- $(N, N, N-$ trimethylammonium)ethoxy)-indol-2-yl)carbonyl]-1,2-dihydro-3Hbenz $[e]$ indol-Iodid $((1 R, 10 S)-70)$ 250

$2.6(+)-\{(1 S, 10 R)-5-B e n z y l o x y-1-(10-C h l o r-e t h y l)-3-[(5-(2-(N, N, N-$ trimethylammonium)ethoxy)-indol-2-yl)carbonyl]-1,2-dihydro-3Hbenz[e]indol-Iodid $\}((+)-(1 S, 10 R)-70)$ 251

2.7 (1S)-1-(10-Hydroxy-ethyl)-3-[(5-(2-( $N, N$-dimethylamino)-ethoxy)indol-2-yl)carbonyl]-1,2-dihydro-3H-benz[e]indol-5-yl]- $\beta$-Dgalactopyranosid (85a)

3 Synthese des dechlorierten Methyl-seco-CBI-DMAI-Derivates 253

3.1 (-)-\{(1S)-5-Benzyloxy-3-(tert-butyloxycarbonyl)-1-ethyl-1,2dihydro-3H-benz $[e]$ indol $\}((-)-(1 S)-45)$ 253

3.2 rac-\{5-Benzyloxy-3-(tert-butyloxycarbonyl)-1-ethyl-1,2-dihydro$3 H$-benz $[e]$ indol $\}(r a c-45)$ 255

3.3 Trennung der Enantiomere von rac-\{5-Benzyloxy-3-(tertbutyloxycarbonyl)-1-ethyl)-1,2-dihydro-3H-benz[e]indol\} (rac-45) ...256

$3.4(+)-\{(1 S)-5-B e n z y l o x y-3-[(5-(2-(N, N$-dimethylamino $)$ ethoxy $)$ indol2-yl)carbonyl]-1-ethyl-1,2-dihydro-3H-benz[e]indol\} ((+)-(1S)-48) ...258

$3.5(+)-\{(1 S)-3-[(5-(2-(N, N$-dimethylamino $)$ ethoxy $)$ indol-2-yl)carbonyl]1-ethyl)-5-hydroxy-1,2-dihydro-3H-benz[e]indol\} ((+)-(1S)-49)........259

4 Synthese der seco-CBI-DMAI-Derivate 260

4.1 rac-\{3-(tert-Butyloxycarbonyl)-1-chlormethyl-5-hydroxy-1,2dihydro-3H-benz[e]indol\} $(r a c-55)$ 260

4.2 Trennung der Enantiomere von rac-\{3-(tert-Butyloxycarbonyl)-1chlormethyl-5-hydroxy-1,2-dihydro-3H-benz[e]indol\} (rac-55) 
4.3 rac-\{1-Chlormethyl-3-[(5-(2-( $N, N$-dimethylamino)ethoxy)indol-2yl)-carbonyl]-5-hydroxy-1,2-dihydro-3H-benz[e]indolHydrochlorid\} (rac-56a) 263

$4.4 \quad(-)-\{(1 R)-1-$ Chlormethyl-3-[(5- $(2-(N, N-$ dimethylamino)ethoxy)indol-2-yl)carbonyl]-5-hydroxy-1,2-dihydro$3 H$-benz $[e]$ indol-Hydrochlorid $\}((-)-(1 R)-\mathbf{5 6 a})$

$4.5 \quad(+)-\{(1 S)-1-C h l o r m e t h y l-3-[(5-(2-(N, N$-dimethylamino $)$ ethoxy $)$ indol2-yl)carbonyl]-5-hydroxy-1,2-dihydro-3H-benz[ $e]$ indolHydrochlorid $\}((+)-(1 S)-56 \mathbf{a})$ 265

4.6 (1S)-[1-Chlormethyl-3-[(5-(2-( $N, N$-dimethylamino)ethoxy)indol-2yl)-carbonyl]-1,2-dihydro-3H-benz[e]indol-5-yl]-2,3,4,6-tetra- $O$ acetyl- $\beta$-D-galactopyranosid ((1S)-73) 268

4.7 (-)-\{(1S)-1-Chlormethyl-3-[(5-(2-( $N, N$-dimethylamino)ethoxy)indol2-yl)carbonyl]-1,2-dihydro-3 $H$-benz[ $e]$ indol-5-yl]- $\beta$-Dgalactopyranosid $\}((-)-(1 S)-54 a)$

5 Synthese des (1S)-seco-CBI-MPI-Drugs .271

$5.1(+)-\{(1 S)-1-(10-C h l o r m e t h y l)-5-h y d r o x y-3-[(5-(1-m e t h y l p i p e r i d i n-4-$ yl-methoxy)indol-2-yl)carbonyl]-1,2-dihydro-3H-benz[e]indolHydrochlorid $\}((+)-(1 S)-\mathbf{5 6 b})$

6 Synthese der fluoreszenzmarkierten anti-Methyl-seco-CBI-DMAI-

Derivate. .273

6.1 (-)-\{3-[4-(5-(4-Dimethylaminophenyl)oxazol-2yl)benzolsulfonylamino]propionsäure-[(1S,10R)-1-(10-chlor-ethyl)3 -[(5-(2-( $N, N$-dimethylamino)ethoxy)indol-2-yl)carbonyl]-5- $O-\beta$-Dgalactopyranosyl-1,2-dihydro-3H-benz[e]indol-7-ylmethyl]amidtrifluoracetat $\}((-)-(1 S, 10 R)-\mathbf{7 5})$

6.2 3-[4-(5-(4-Dimethylaminophenyl)oxazol-2-yl)benzolsulfonylamino]propionsäure-[(1S,10R)-1-(10-chlor-ethyl)-3-[(5-(2-(N,Ndimethylamino)ethoxy)indol-2-yl)carbonyl]-5-hydroxy-1,2-dihydro$3 H$-benz[e]indol-7-ylmethyl]amid-Hydrochlorid $((1 S, 10 R)-76)$ 
7 Untersuchung der Wechselwirkung verschiedener DuocarmycinAnaloga mit DNA, RNA und Glutathion mittels Massenspektrometrie...278

7.1 AAV 7.1: Allgemeine Arbeitsvorschrift zur massenspektrometrischen Untersuchung der Wechselwirkung verschiedener Duocarmycin-Analoga mit einzel- oder doppelsträngigen DNAOligonukleotiden 278

7.2 AAV 7.2: Allgemeine Arbeitsvorschrift zur massenspektrometrischen Untersuchung der Wechselwirkung verschiedener Duocarmycin-Analoga mit einzel- oder doppelsträngigen DNAOligonukleotiden im Verhältnis $n: 1(n=1,2,5)$. 278

7.3 AAV 7.3: Allgemeine Arbeitsvorschrift zur Bestimmung des Anteils alkylierter DNA

7.4 Massenspektrometrische Untersuchung der Wechselwirkung des seco-Drugs $(+)-(1 S, 10 R)-34$ a mit DNA-Oligonukleotiden.

7.5 Massenspektrometrische Untersuchung der Wechselwirkung des seco-Drugs (+)-(1S,10R)-34a mit dem RNA-Oligonukleotid ds-59 .....290

7.6 Massenspektrometrische Untersuchung der Alkylierung des Tripeptides Glutathion durch das seco-Drug $(+)-(1 S, 10 R)-34 a$

7.7 Massenspektrometrische Untersuchung der Wechselwirkung des seco-Drugs $(+)-(1 S, 10 R)-34 \mathbf{b}$ mit DNA-Oligonukleotiden.

7.8 Massenspektrometrische Untersuchung der Wechselwirkung des seco-Drugs (+)-(1S)-56a mit DNA-Oligonukleotiden

7.9 Massenspektrometrische Untersuchung der Wechselwirkung des seco-Drugs (+)-(1S)-56b mit DNA-Oligonukleotiden

7.10 Massenspektrometrische Untersuchung der Wechselwirkung anderer seco-Drugs mit den Oligonukleotiden ds-60 und ON-1 (ds-60). 309

7.11 Massenspektrometrische Untersuchung der Wechselwirkung der Methyl-seco-CBI-Hydrochloride $(1 S, 10 R)-\mathbf{3 4 a},(1 S, 10 R)-\mathbf{3 4 e}$, $(1 S, 10 R)-34 \mathbf{c}$ und $(1 S, 10 R)-34 d$ mit dem DNA-Oligonukleotid ds-60 im Vergleich 
7.12 Massenspektrometrische Untersuchung der Wechselwirkung verschiedener Prodrugs mit den DNA-Oligonukleotiden ds-60 und

ON-1 (ds-60).

7.13 Massenspektrometrische Untersuchung der Wechselwirkung fluoreszenzmarkierter Duocarmycin-Analoga mit der DNA ds-60 .......316

8 Untersuchung der Wechselwirkung neuer Duocarmycin-Analoga mit DNA-Oligonukleotiden mittels HPLC. 318

8.1 AAV 8.1: Allgemeine Arbeitsvorschrift zur Untersuchung der Wechselwirkung neuer Duocarmycin-Analoga mit doppelsträngigen DNA-Oligonukleotiden mittels HPLC. 318

8.2 AAV 8.2: Allgemeine Arbeitsvorschrift zur Untersuchung der Wechselwirkung neuer Duocarmycin-Analoga mit doppelsträngigen DNA-Oligonukleotiden im Verhältnis 1:1 mittels HPLC. 318

8.3 AAV 8.3: Allgemeine Arbeitsvorschrift zur Untersuchung der Wechselwirkung neuer Duocarmycin-Analoga mit doppelsträngigen DNA-Oligonukleotiden in Phosphatpuffer mittels HPLC

8.4 AAV 8.4: Allgemeine Arbeitsvorschrift zur Untersuchung der Wechselwirkung neuer Duocarmycin-Analoga mit doppelsträngigen DNA-Oligonukleotiden mittels semi-präparativer HPLC gefolgt von ESI-FTICR-Massenspektrometrie

8.5 Kinetik der Wechselwirkung des seco-Drugs $(+)-(1 S, 10 R)-34 a$ mit ds-60 im Verhältnis 1:1 in Wasser und in Phosphatpuffer

8.6 Untersuchung der Wechselwirkung des seco-Drugs (+)-(1S,10R)-34a mit ds-60 im Verhältnis 1:1 nach Inkubation in Phosphatpuffer mittels semi-präparativer HPLC gefolgt von ESI-FTICR-MS 320

8.7 Untersuchung der Wechselwirkung des seco-Drugs (+)-(1S,10R)-34a mit ds-60 im Verhältnis 1:1 nach $24 \mathrm{~h}$ Inkubation bei $25^{\circ} \mathrm{C}$ und $2 \mathrm{~h}$ Erhitzen auf $95^{\circ} \mathrm{C}$ mittels semi-präparativer HPLC gefolgt von ESIFTICR-MS

8.8 Untersuchung der Wechselwirkung des seco-Drugs $(+)-(1 S, 10 R)-\mathbf{3 4 a}$ mit ds-60 im Verhältnis 1:1 bis 5:1 in Wasser und Phosphatpuffer ..... 323

8.9 Untersuchung der Wechselwirkung des seco-Drugs $(+)-(1 S, 10 R)-34 a$ 
mit ds-60 im Verhältnis 5:1 nach $24 \mathrm{~h}$ Inkubation in Phosphatpuffer mittels semi-präparativer HPLC gefolgt von ESI-FTICR-MS.

8.10 Kinetik der Wechselwirkung der seco-Drugs (+)-(1S,10R)-34a, $(+)-(1 S, 10 R)-34 \mathbf{b},(+)-(1 S)-56 \mathbf{a}$ und $(+)-(1 S)-56 \mathbf{b}$ mit ds-60 im Verhältnis $1: 1$ in Phosphatpuffer.

8.11 Untersuchung der Wechselwirkung des seco-Drugs $(+)-(1 S, 10 R)-34 a$ mit DNA-Oligonukleotiden im Verhältnis 1:1 in Wasser und Phosphatpuffer

8.12 Untersuchung der Wechselwirkung des seco-Drugs $(+)-(1 S, 10 R)-34 \mathbf{b}$ mit DNA-Oligonukleotiden im Verhältnis 1:1

8.13 Untersuchung der Wechselwirkung des seco-Drugs (+)-(1S)-56a mit DNA-Oligonukleotiden im Verhältnis $1: 1$

8.14 Untersuchung der Wechselwirkung des seco-Drugs (+)-(1S)-56b mit DNA-Oligonukleotiden im Verhältnis 1:1

8.15 Untersuchung der Wechselwirkung weiterer Duocarmycin-Analoga mit DNA-Oligonukleotiden

9 Untersuchung der Wechselwirkung neuer Duocarmycin-Analoga und anderer Zytostatika mit DNA-Oligonukleotiden mittels CD-

Spektroskopie.

9.1 AAV 9.1: Allgemeine Arbeitsvorschrift zur Untersuchung des CD von Zytostatika in Phospatpuffer $\left(\mathrm{pH} 7, T=25^{\circ} \mathrm{C}\right)$

9.2 AAV 9.2: Allgemeine Arbeitsvorschrift zur Untersuchung des CD von Zytostatika in $\mathrm{PBS}\left(\mathrm{pH} 7.4, T=37^{\circ} \mathrm{C}\right)$.

9.3 AAV 9.3: Allgemeine Arbeitsvorschrift zur Untersuchung der Wechselwirkung von Zytostatika mit einzel- oder doppelsträngigen DNA-Oligonukleotiden mittels CD-Spektroskopie

9.4 CD nach Inkubation der Wirkstoffe in Phophatpuffer $(\mathrm{pH} 7) \ldots \ldots \ldots \ldots . . . . .333$

9.5 CD nach Inkubation der Wirkstoffe in PBS ( $\left.\mathrm{pH} 7.4, T=37^{\circ} \mathrm{C}\right) \ldots \ldots \ldots . .334$

9.6 Untersuchung der Wechselwirkung von Zytostatika mit einzel- oder doppelsträngigen DNA-Oligonukleotiden mittels CD-Spektroskopie...335 
10 Untersuchung der Aufnahme verschiedener Zytostatika in Zellen

mittels CD-Spektroskopie.

10.1 AAV 10.1: Allgemeine Arbeitsvorschrift zur Messung des CD

intakter Zellen nach vorheriger Inkubation mit Zytostatika

10.2 AAV 10.2: Allgemeine Arbeitsvorschrift zur Isolation zellulärer

DNA, zur Bestimmung des Anteils toter Zellen und zur Messung des

CD der isolierten DNA nach vorheriger Inkubation der Zellen mit Zytostatika

10.3 CD-Spektren unbehandelter Zellen in Suspension

10.4 Untersuchung der zellulären Aufnahme des seco-Drugs

$(+)-(1 S, 10 R)-\mathbf{3 4 a}$

10.5 Untersuchung der zellulären Aufnahme des seco-Drugs (+)-(1S)-56a. 358

10.6 Untersuchung der zellulären Aufnahme des seco-Drugs

$(+)-(1 S, 10 R)-34 b$

10.7 Untersuchung der zellulären Aufnahme des seco-Drugs (+)-(1S)-56b 361

10.8 Untersuchung der zellulären Aufnahme des fluoreszenzmarkierten seco-Drugs $(1 S, 10 R)-76$

10.9 Untersuchung der zellulären Aufnahme von Doxorubicin (11)............ 364

10.10 Untersuchung der zellulären Aufnahme von Mitomycin C (99) .......... 365

11 Untersuchung der Fluoreszenzeigenschaften und der zellulären Aufnahme fluoreszenzmarkierter anti-Methyl-seco-CBI-DMAI-

Derivate

11.1 Charakterisierung der Fluoreszenzeigenschaften von anti-Methylseco-CBI-DMAI-Derivaten

11.2 Fluoreszenzmikroskopische Untersuchung der Aufnahme und intrazellulären Verteilung fluoreszenzmarkierter anti-Methyl-secoCBI-DMAI-Derivate 368

11.3 Fluoreszenzmikroskopische Untersuchung der zeitlichen Änderung der Intensität der Hoechst 33342 (40)-Fluoreszenz während und nach Inkubation von Zellen mit anti-Methyl-seco-CBI-DMAI-Derivaten ... 370 
12 Ergänzende Untersuchungen

12.1 Untersuchung der Löslichkeit verschiedener Duocarmycin-Analoga in Applikationsmedien.

12.2 Kinetik der Zyklisierung des seco-Drugs $(+)-(1 S, 10 R)-34 \mathbf{a}$ in Wasser (pH 7).

12.3 Untersuchung der enzymatischen Spaltung fluoreszenzmarkierter Prodrugs mittels HPLC-MS

12.4 Bestimmung der Schmelztemperatur doppelsträngiger DNA nach Inkubation mit $(+)-(1 S, 10 R)-\mathbf{3 4 a}$

ANHANG 378

1 Abkürzungen und Akronyme...............................................................378

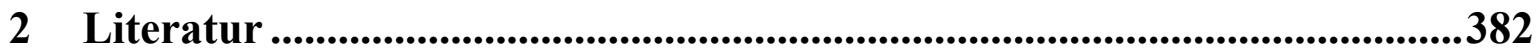

3 Danksagung...........................................................................................................401

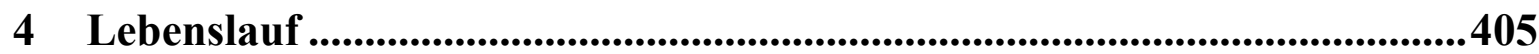




\section{Allgemeiner Teil}

\section{$1 \quad$ Einleitung}

Seit dem Beginn der menschlichen Zivilisation wurden viele wirksame Heilmethoden und Arzneimittel zur Krankheitsbehandlung entwickelt. Obwohl mit diesen bereits viele Erfolge erzielt werden konnten, ist eine selektive Therapie bestimmter schwerer Erkrankungen auch heute noch nicht möglich. Die Entwicklung neuer und selektiv wirkender Therapiemethoden sowie Medikamente stellt daher eine der großen Herausforderungen unserer Zeit dar.

Paul Ehrlich, ein deutscher Chemiker, Arzt, Serologe und Immunologe gilt als einer der Begründer der Chemotherapie und erhielt für seine Leistungen im Feld der Immunologie im Jahre 1908 den Nobelpreis für Medizin. ${ }^{1,2}$ Auf der Basis seiner Untersuchungen zur selektiven Anfärbung von Bakterien formulierte er die Idee, dass eine gezielte Bekämpfung von Krankheitserregern ohne Schädigung des Patienten möglich sei, wenn toxische Wirkstoffe mit spezifisch an die Erreger bindenden Substanzen kombiniert würden., ${ }^{1,3}$ Diese selektiven Heilmittel bezeichnete er als monotrope Substanzen und beschrieb sie bildlich als

“...charmed bullets which strike only those objects for whose destruction they have been produced...". 4

Heute wird in Anlehnung an diese Vorstellung der Begriff Wunderkugeln (magic bullets) zur Beschreibung aller Wirkstoffe verwendet, die eine selektive Toxizität für bestimmte Krankheitserreger oder Tumorzellen aufweisen.

Das 1909 von Paul Ehrlich und seinem Mitarbeiter Alfred Bertheim entwickelte Arsphenamin (1), das unter dem Markennamen Salvarsan ${ }^{\circledR}$ (heilendes Arsen) zur Bekämpfung der Syphilis und anderer Infektionskrankheiten in den Handel kam, war das bis dato erste spezifisch wirkende Chemotherapeutikum (Abb. 1). ${ }^{5}$

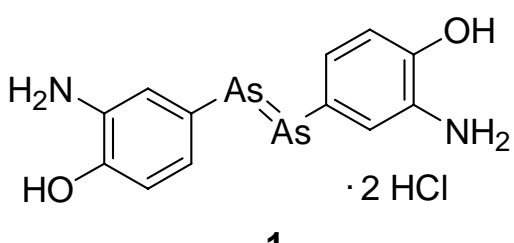

1

Abb. 1. Arsphenamin $\left(\right.$ Salvarsan ${ }^{\circledR}, 1$ ), eine organische Arsenverbindung zur selektiven Therapie bakterieller Infektionskrankheiten. 
Allgemeiner Teil

Es folgte die Entwicklung zahlreicher anderer Medikamente auf chemischer Basis, mit denen viele bis dahin tödlich verlaufende Infektionskrankheiten gezielt und wirksam bekämpft werden konnten.

Während die meisten Infektionskrankheiten in der heutigen Zeit effektiv behandelt werden können, stellen Tumorerkrankungen trotz beachtlicher Fortschritte mit etwa $13 \%$ aller Sterbefälle weltweit immer noch eine der häufigsten Todesursachen dar. ${ }^{6}$ In den Industrienationen sind Krebserkrankungen nach den Herz-Kreislauf-Erkrankungen sogar die zweithäufigste Todesursache und für etwa $25 \%$ der Todesfälle verantwortlich. ${ }^{7}$ Ziel der Krebsforschung ist daher die Entwicklung effizienterer Therapien. Diese sollen in Anbetracht der oft starken Nebenwirkungen herkömmlicher Behandlungsmethoden nicht nur wirksamer, sondern auch selektiver sein. ${ }^{8}$

Klassische Tumor-Chemotherapeutika richten ihre zytotoxische Wirkung zumeist gegen alle Zellen mit einer hohen Zellteilungsrate. Zu diesen Zellen gehören ein Teil der Krebszellen, aber auch Zellen sich stetig regenerierender Gewebe wie des Knochenmarks, des Magen-Darm-Traktes und der Haarfollikel. Die herkömmlichen Chemotherapien verursachen daher eine Reihe unerwünschter Nebenwirkungen wie Störungen im Blutbild, Immunschwäche, Entzündungen des Magen-Darm-Traktes und Haarverlust. Selektive Krebstherapien basieren stattdessen auf genotypischen oder phänotypischen Unterschieden zwischen malignen und gesunden Zellen und erlauben so eine gezielte Tötung der entarteten Zellen ohne Beeiträchtigung gesunder Zellen.

Ein in diesem Zusammenhang im Arbeitskreis von L. F. Tietze bearbeiteter Ansatz ist die Synthese und Untersuchung reversibel detoxifizierbarer Chemotherapeutika, die zur selektiven Behandlung von Krebserkrankungen eingesetzt werden können. ${ }^{9}$ Die Selektivität der Therapie basiert auf der Verwendung spezifisch an Krebszellen bindender Antikörper. Diese Antikörper sind kovalent mit einem Enzym verknüpft, welches eine verabreichte, weitgehend untoxische Verbindung selektiv im Tumorgewebe in den zugehörigen zytotoxischen Wirkstoff umwandelt. Die Begrenzung der zytotoxischen Wirkung auf das Tumorgewebe erhöht hierbei sowohl die Effizienz als auch die Selektivität der Therapie.

Die vorliegende Arbeit wurde im Rahmen der Entwicklung einer selektiven Krebstherapie angefertigt und beschäftigt sich mit der Synthese, der biologischen Evaluation und der Aufklärung des Wirkmechanismus einer Klasse neuer Anti-Tumor-Wirkstoffe und ihrer fluoreszenzmarkierten Analoga. 


\section{Grundlagen der Tumorentstehung und des Tumorwachstums}

Prinzipiell kann die Tumorentstehung (Cancerogenese) als eine Störung der normalen Regulation der Proliferation von Körperzellen aufgefasst werden. Maligne Tumoren mit ihrer Tendenz zum nicht regulierten Wachstum entstehen dann, wenn zur Proliferation führende Signale permanent aktiv sind, der Übergang in einen nicht mehr teilungsfähigen Zellzustand verhindert ist oder eine Apoptose, ${ }^{10}$ d.h. ein programmierter und nicht nekrotischer Zelltod, trotz starker DNA-Schäden nicht erfolgen kann.

Diese Fehlregulation basiert auf Veränderungen in wichtigen zellulären Genen, die für die Proliferationsregulation verantwortlich sind. ${ }^{11}$ Als Ursachen werden spontane, vererbte oder durch chemische Substanzen (z.B. polyzyklische aromatische Kohlenwasserstoffe, Nitrosamine, aromatische Amine, halogenierte Kohlenwasserstoffe, Asbest) ${ }^{12,13}$ oder physikalische Einflüsse (z.B. UV-Licht, radioaktive Strahlung) ${ }^{14}$ verursachte Mutationen, chronische Entzündungen ${ }^{15}$ sowie der Einbau viraler Gene ${ }^{16,17}$ in das menschliche Genom diskutiert. Von der Mutation betroffen sind zumeist Protoonkogene, welche das Zellwachstum fördern, und Tumorsuppressorgene, die in gesunden Zellen das Zellwachstum hemmen und bei DNA-Schäden die Zellteilung verhindern oder eine Apoptose einleiten. ${ }^{18}$

Angesichts der mehrfachen Kontroll- und Steuerungsmechanismen des Zellstoffwechsels muss in einer Zelle mehr als eine Mutation erfolgen, damit sich ein Tumor manifestieren kann.

Die Umwandlung von Protoonkogenen in Onkogene durch Mutationen führt zur verstärkten Aktivität der entsprechenden Proteine und damit zu einem erhöhten Wachstumsstimulus. ${ }^{19}$ Ein Beispiel dafür ist das Ras-Onkogen. ${ }^{16}$ Reagiert das RasProtein durch eine Mutation im entsprechenden Gen nicht mehr auf Deaktivatoren, so bleibt es dauerhaft aktiv und fördert die Zellteilung. Allerdings reicht die Mutation eines Protoonkogens zu einem Onkogen allein nicht zur Tumorentstehung aus; zusätzlich müssen die Tumorsuppressorgene durch Veränderungen inaktiviert worden sein. Ein bekanntes Beispiel eines Tumorsuppressorgens ist das p53-Gen, das in mehr als der Hälfte aller menschlichen Tumoren Mutationen aufweist. ${ }^{16,20}$ Die durch p53 kontrollierten Faktoren hemmen in gesunden Zellen den Eintritt in die S-Phase des Zellzyklus (Phase der DNA-Synthese) im Fall von DNA-Schädigungen und ermöglichen dadurch eine DNA-Reparatur. Ist die Reparatur nicht möglich, so wird durch die p53-Proteine eine Apoptose eingeleitet. 
Die Tumorentwicklung erfolgt in mehreren Phasen: In der ersten Phase, auch Initiierungsphase genannt, treten Veränderungen am Genom auf, die fortan an die Tochterzellen weitergegeben werden. Makroskopisch ist noch keine Veränderung sichtbar, da es sich nur um wenige Zellen handelt. Nach einer längeren Latenzzeit, die mehrere Jahre betragen kann, beginnt die Promotionsphase, die durch vermehrte Zellproliferation und ein Sichtbarwerden von Zell- und Kernatypien gekennzeichnet ist. In der dritten Phase, der Progressionsphase, tritt eine Tumormanifestation auf. Im Folgenden entscheidet sich dann, ob es sich um einen gutartigen (benignen) oder einen bösartigen (malignen) Tumor handelt. Benigne Tumoren wachsen am Ort ihrer Entstehung als kompakter Zellverband. Sie verdrängen zwar das umliegende Gewebe, sind aber im Gegensatz zu den malignen Tumoren nicht invasiv, nicht destruktiv und bilden keine Tochtergeschwülste (Metastasen). Es handelt sich also um eine Geschwulst, die bei entsprechender Zugänglichkeit ohne größere Gefahr chirurgisch entfernt werden kann. Im Gegensatz dazu wachsen maligne Tumoren unkontrolliert und haben die Tendenz, in benachbartes Gewebe zu invadieren und dieses dabei zu zerstören. Durch Infiltration in Blut- und Lymphgefäße breiten sich maligne Zellen außerdem im gesamten Körper aus und können sich an verschiedenen Stellen (z. B. Lymphknoten, Leber, Lunge, Knochenmark) festsetzen und Metastasen bilden. ${ }^{21}$ Diese Implantationsphase wird durch die Versorgung der Metastasen mit Blutgefäßen (Vaskularisierung) abgeschlossen.

\section{Tumortherapie}

Die Vielfalt der Krankheitsbilder erfordert individuelle Therapiekonzepte. ${ }^{22}$ Als Konsequenz der Komplexität einer Krebserkrankung stellen die meisten heute angewandten klinischen Behandlungsmethoden Kombinationen verschiedener Ansätze dar. Bei soliden, gut zugänglichen und klar umgrenzten Tumoren ist eine operative Entfernung des entarteten Gewebes die Methode mit den besten Heilungschancen und geringsten Nebenwirkungen. Ist der Tumor schwer zugänglich oder betrifft er lebenswichtige Strukturen, so ist eine Strahlenbehandlung (z. B. Radiotherapie mit RöntgenStrahlung oder radioaktiven Isotopen) angemessen. In einem fortgeschritteneren Stadium, in dem es bereits zur Metastasenbildung gekommen ist oder die Gefahr einer Metastasierung besteht, erfolgt zumeist eine umgehende Chemotherapie. Als relativ neue Methoden gewinnen die Hormontherapie, ${ }^{23}$ die Immuntherapie $^{24}$ sowie die Therapie mit Angiogenesehemmern ${ }^{25}$ und Kinaseinhibitoren ${ }^{26}$ an Bedeutung. 


\subsection{Chemotherapie}

Im Fall einer aufgetretenen oder befürchteten Metastasierung sowie im Fall systemischer oder unzugänglicher Tumoren ist die Chemotherapie die wichtigste Behandlungsmethode, wenn sie auch oftmals mit schweren Nebenwirkungen wie Störungen des Blutbildes, Immunschwäche, Schleimhautentzündungen (Mukositis), Fieber, Übelkeit, Erbrechen, Haarausfall (Alopezie) sowie Infertilität verbunden ist. Im Laufe einer Chemotherapie werden der erkrankten Person Medikamente verabreicht, die sich über die Blutbahn im gesamten Körper verteilen und so alle Zellen erreichen können. Chemotherapeutika wirken auf menschliche Zellen zytostatisch, d.h., sie hindern die Zellen an der Vermehrung, oder sogar zytotoxisch, d.h., sie bewirken das Absterben der Zellen. Aufgrund ihrer Wirkmechanismen schädigen die meisten Substanzen bevorzugt schnell proliferierende Zellen. Hierzu gehören der Großteil der Krebszellen, aber auch nicht maligne Zellen wie Knochenmarks-, Haarwurzel- oder Schleimhautzellen. Die Schädigung dieser Zellen verursacht die geschilderten typischen Nebenwirkungen.

Der Lebenszyklus aller eukaryoten Zellen beginnt mit einer Teilung (Mitose) und hört mit der erneuten Teilung wieder auf. Die Zeit zwischen den Teilungen wird in verschiedene Phasen eingeteilt und als Zellzyklus bezeichnet. Zum Verständnis der Wirkweise verschiedener Chemotherapeutika soll im Folgenden der Zellzyklus (Abb. 2) kurz erläutert werden. Nach einer erfolgten Zellteilung in der Mitosephase (M) treten proliferierende Zellen in die $\mathrm{G}_{1}$-Phase (Wachstumsphase) des Zellzyklus ein, während der die Zelle wächst und ihre Bestandteile synthetisiert. Infolge noch unbekannter Stimuli können Zellen aus der $\mathrm{G}_{1}$-Phase reversibel in die $\mathrm{G}_{0}$-Phase (Ruhephase) eintreten, in der sie zwar aktiv sind, eine Vermehrung aber ausgeschlossen ist. Unter dem Einfluss verschiedener Wachstumsfaktoren treten Zellen aus der $\mathrm{G}_{1}$-Phase in die S-Phase (Synthesephase) ein, in der die Replikation der DNA erfolgt. Nach einer oft recht kurzen $\mathrm{G}_{2}$-Phase erfolgt dann die Trennung des doppelten Chromosomensatzes und die Teilung in zwei Tochterzellen in einer erneuten Mitosephase (M).

Der Großteil der menschlichen Zellen befindet sich gewöhnlich in der $\mathrm{G}_{0}$-Phase (Ruhephase), in der sie für die meisten Zytostatika nicht zugänglich sind. Da maligne Entartungen jedoch durch eine gesteigerte Proliferationsrate gekennzeichnet sind, befinden sich nur etwa 10\% der Tumorzellen in der Ruhephase. Die meisten malignen Zellen können daher durch Chemotherapeutika geschädigt werden. 


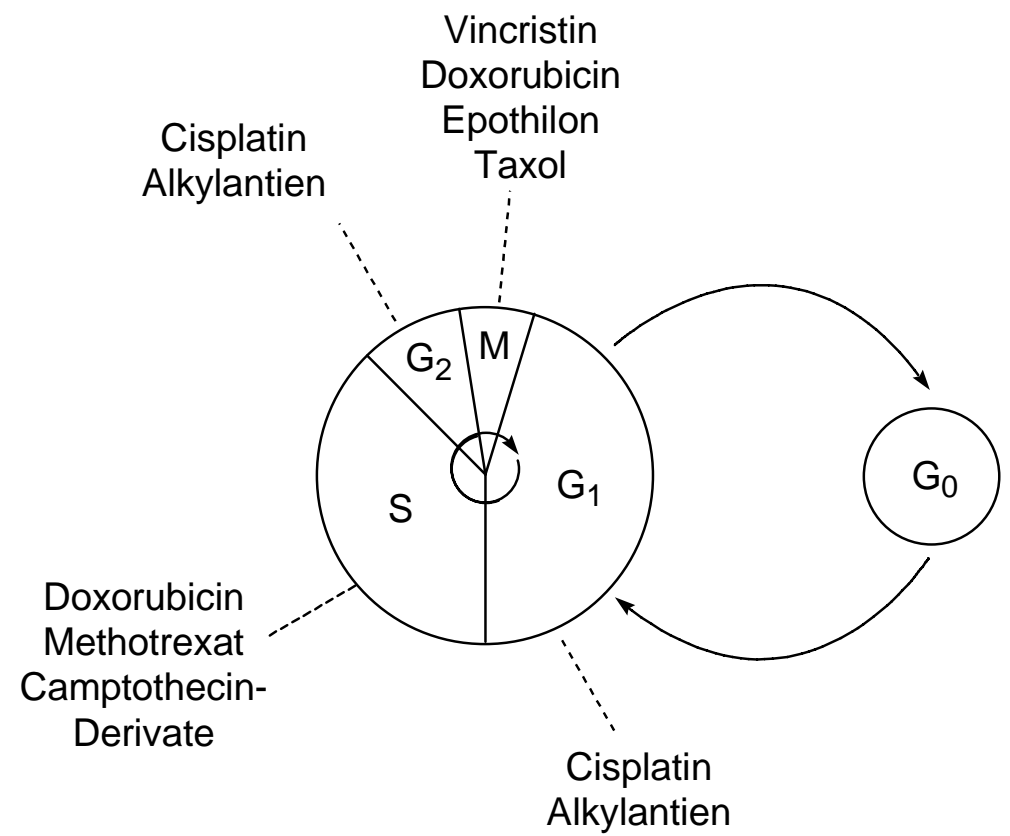

Abb. 2. Der Zellzyklus mit Beispielen für Chemotherapeutika und deren Angriffspunkte.

Die bisher bekannten und in der Tumortherapie eingesetzten Zytostatika werden gemäß ihrer Wirkmechanismen in die Klassen Alkylantien, Antimetaboliten, Mitosehemmstoffe, Topoisomerase-Hemmstoffe und zytostatische Antibiotika eingeteilt.

Die Alkylantien stellen eine zahlenmäßig bedeutende, strukturell sehr vielfältige Klasse äußerst reaktiver Substanzen dar, die in der Regel phasenunspezifisch wirken. Nach einer eventuell vorhergehenden Aktivierung des Medikamentes zum Carbokation reagiert der Wirkstoff insbesondere mit Nukleinsäuren unter Ausbildung kovalenter Bindungen. Als Folge treten Quervernetzungen der DNA, abnorme Basenpaarungen oder Strangbrüche auf, die eine Replikation verhindern und schließlich zum Zelltod führen. Wichtige Vertreter dieser Substanzklasse (Abb. 3) sind beispielsweise das Cyclophosphamid (2), das zu den Stickstoff-Lost-Derivaten zählt. ${ }^{27}$ Verbindung 2 ist eine in vitro nahezu untoxische Substanz, die erst durch Biotransformationen im Körper in den eigentlichen Wirkstoff 3 überführt wird (Giftung).<smiles></smiles>

Cyclophosphamid (2)

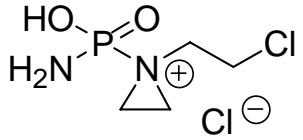

3

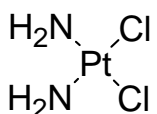

Cisplatin (4)

Abb. 3. Beispiele für Alkylantien. 
Auch Metallkomplexe wie Cisplatin (4) werden zu der Klasse der Alkylantien gezählt. ${ }^{28} \mathrm{Zu}$ einer Gruppe besonders wirksamer Alkylantien gehören weiterhin das Antibiotikum CC-1065, die Duocarmycine, das Yatakemycin sowie Derivate und Analoga der genannten Verbindungen (s. Kap. 4).

Die Klasse der Antimetaboliten repräsentiert strukturelle Analoga körpereigener Stoffwechselbausteine, die als Antagonisten an die Stelle der eigentlichen Metaboliten treten. Hierdurch können wichtige Enzyme gehemmt oder funktionsuntüchtige Makromoleküle synthetisiert werden. Als Beispiel (Abb.4) sei der Folsäureantagonist Methotrexat (5) genannt, der als falsches Substrat die Bildung von Tetrahydrofolsäure verhindert, die wiederum als Intermediat der Purinsynthese essentiell für eine Zellproliferation ist. ${ }^{29}$

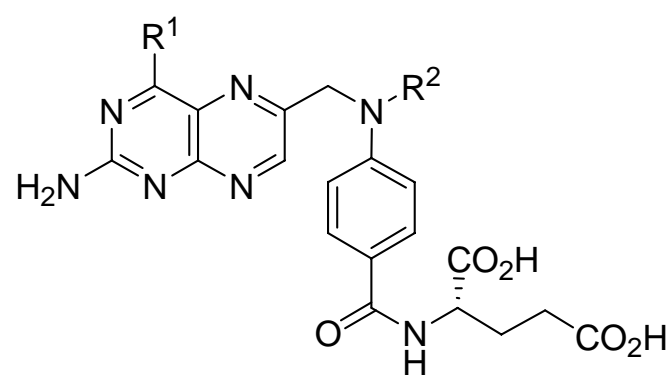

Methotrexat (5): $\mathrm{R}^{1}=\mathrm{NH}_{2}, \mathrm{R}^{2}=\mathrm{CH}_{3}$

Folsäure (6): $\quad \mathrm{R}^{1}=\mathrm{OH}, \mathrm{R}^{2}=\mathrm{H}$

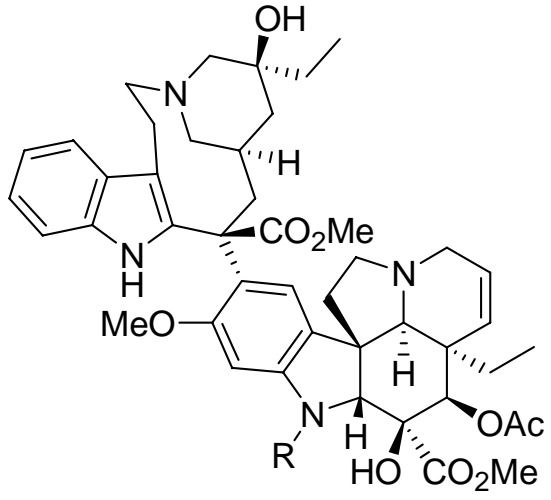

Vincristin (7): $\mathrm{R}=\mathrm{CHO}$

Vinblastin (8): $\mathrm{R}=\mathrm{CH}_{3}$

Abb. 4. Beispiele für Antimetaboliten (5) und Mitosehemmstoffe (7, 8).

Mitosehemmstoffe wirken, wie am Namen zu erkennen, in der Mitosephase des Zellzyklus. Die entsprechenden Chemotherapeutika binden an die $\beta$-Einheit des Tubulindimers und hemmen dadurch entweder den Aufbau der Kernspindeln (z. B. Colchicin, Vincristin (7), Vinblastin (8), Abb. 4) ${ }^{30}$ oder blockieren ihren Abbau (Taxol, Epothilon). ${ }^{31}$ Eine Kern- und Zellteilung ist dann nicht mehr möglich.

Eine weitere Gruppe von Chemotherapeutika sind die Hemmstoffe der Topoisomerasen I und II. Die zur Replikation notwendige Entwindung der DNA führt zu einer Verdrillung des DNA-Stückes. Durch die körpereigenen Topoisomerasen wird die Verdrillung aufgehoben, indem die DNA-Stränge vorübergehend unterbrochen und nach erfolgter Replikation wieder zusammengefügt werden. Die Hemmung dieser Enzyme und insbesondere die Blockade ihrer Dissoziation von der DNA führt dazu, 
Allgemeiner Teil

dass Strangbrüche auftreten, die schließlich den Zelltod bewirken. Typische Vertreter dieser Substanzgruppe sind Derivate des Alkaloids Camptothecin (9) (Abb. 5).

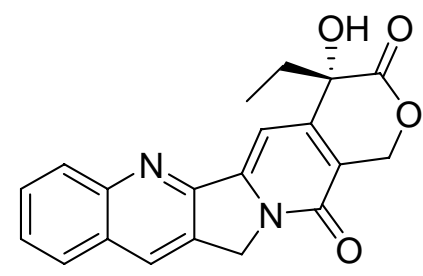

Camptothecin (9)

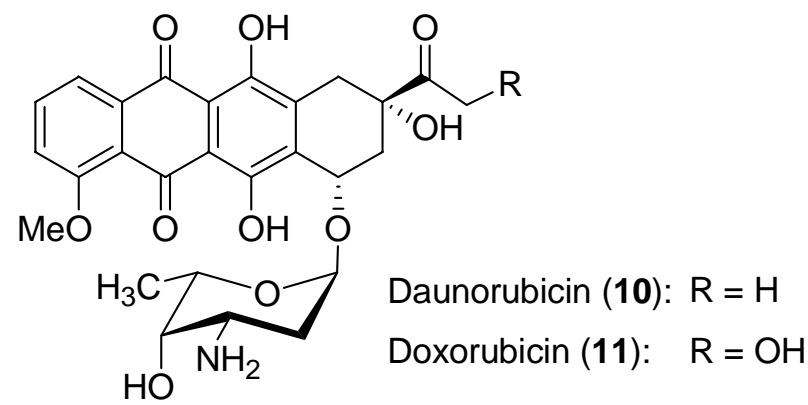

Abb. 5. Beispiele für Topoisomerase-Hemmstoffe (9) und zytostatische Antibiotika (10, 11). isolierten Anthracycline Daunorubicin (10) und Doxorubicin (11) (Abb. 5). Ihre zytostatische Wirkung ist besonders ausgeprägt in der S-Phase des Zellzyklus. Sie interkalieren in die DNA und hemmen so die Nucleinsäuresynthese oder inhibieren die DNA- und RNA-Synthese, indem sie durch Radikalbildung Doppelstrangbrüche verursachen. $^{32}$

Die Behandlung maligner Tumoren mit Chemotherapeutika hat insbesondere in Fällen schwer zugänglicher Tumoren oder bei Metastasenbildung zur Verbesserung der Behandlungsmöglichkeiten beigetragen. Neben dem Auftreten zum Teil schwerer akuter Nebenwirkungen, die unter Umständen den Abbruch einer Therapie erfordern, sind die Spätfolgen wie eine Induktion von Sekundärtumoren, eine Schädigung des Knochenmarks, ein Auftreten von Lungenfibrosen oder eine Immundefizienz gravierende Nachteile einer Chemotherapie. Ein weiteres Problem stellen Resistenzentwicklungen der Tumoren gegen einzelne Zytostatika oder Gruppen von Chemotherapeutika dar, die als natürliche Folge der Selektion resistenter Zellen während einer Behandlung auftreten. ${ }^{33}$ Die nicht mehr oder nur noch vermindert auf die Chemotherapeutika ansprechenden Zellen sind z. B. in der Lage, das Zytostatikum innerhalb der Zelle zu entgiften, dieses nicht aufzunehmen oder es nach der Aufnahme wieder in den extrazellulären Raum abzugeben.

Aufgrund der Notwendigkeit chemotherapeutischer Behandlungen, der starken Nebenwirkungen eines Großteils der bekannten Medikamente sowie dem Auftreten von Resistenzen gegen viele bekannte Wirkstoffe ist eine stete Weiterentwicklung im Bereich der Chemotherapeutika notwendig. 


\subsection{Immuntherapie}

Im Rahmen einer Immuntherapie wird das eigene Immunsystem zur Zerstörung entarteter Zellen angeregt bzw. es werden Instrumente der Immunabwehr genutzt, um gezielt Tumorzellen zu schädigen. Jede Zelle weist auf ihrer Oberfläche ein für sie charakteristisches Muster von Antigenen auf, welches aus Glykolipiden, Glykoproteinen und Proteinen besteht und als Glykokalyx bezeichnet wird (Abb. 6). ${ }^{34}$ Die individuelle Zelloberfläche dient der Erkennung körpereigener Zellen und der Steuerung des Zusammenschlusses gleicher Zellen zu Geweben und Organen. Des Weiteren ermöglicht sie die Kommunikation zwischen Zellen (z.B. Teilungshemmung bei Erreichen einer bestimmten Organgröße) sowie die Erkennung von Botenstoffen, entarteten Zellen und pathogenen Keimen.

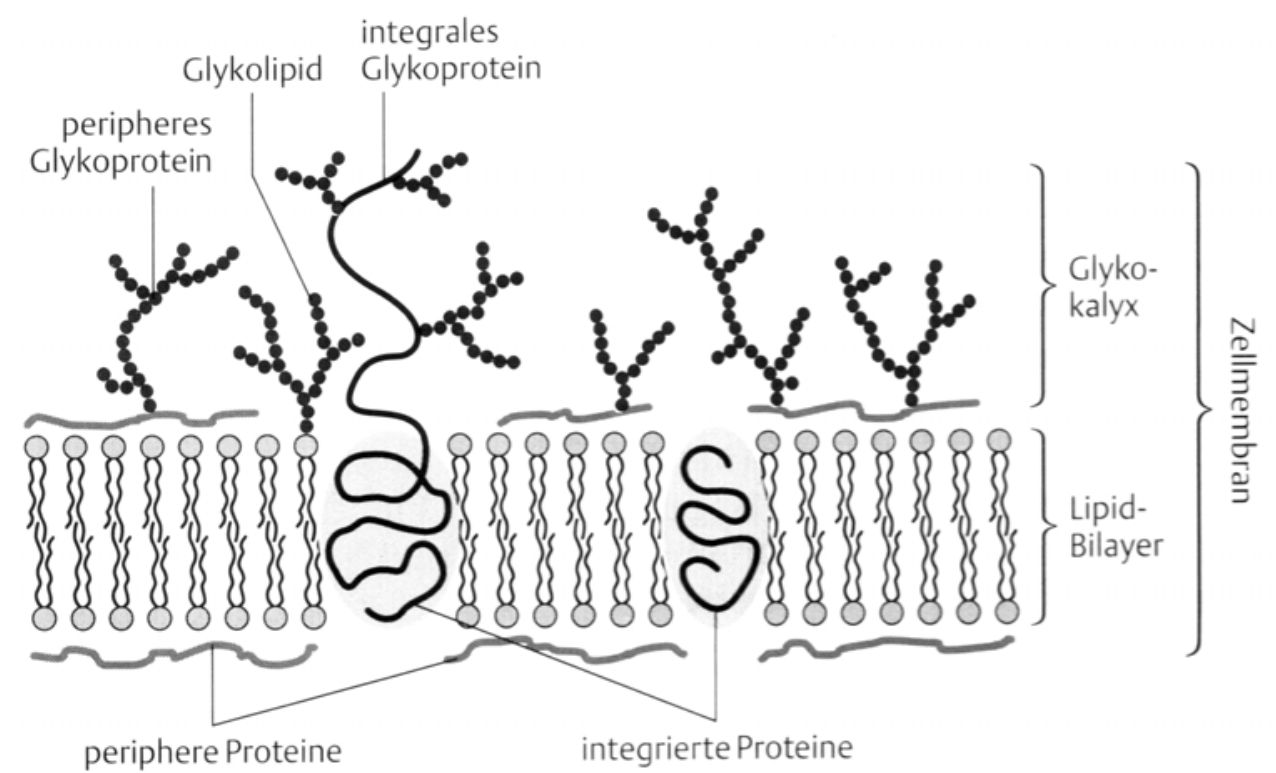

Abb. 6. Modell der Zellmembranstruktur nach H. Plattner und J. Hentschel. ${ }^{34}$

Veränderungen im Inneren einer Zelle spiegeln sich im Allgemeinen auch an ihrer Oberfläche wider, da die Zellmembranen ständig erneuert werden und ein Teil der intrazellulären Bestandteile auf der Oberfläche exponiert wird. Spezielle Glykokalyxbestandteile, die für Tumorzellen charakteristisch sind, werden als tumorassoziierte Antigene bezeichnet und stellen den zentralen Ansatzpunkt einer Immuntherapie dar. ${ }^{35}$ In der Regel ist das menschliche Immunsystem in der Lage, Tumorzellen aufgrund ihrer fremdartigen Antigene zu entdecken und zu eliminieren. Dieser Kontrollmechanismus versagt jedoch, wenn die präsentierten Antigene den übrigen Zellen zu ähnlich sind, sie in zu geringer Zahl auf der Oberfläche der Tumorzellen vorhanden 
sind, sie nicht gut zugänglich sind oder wenn die Immunzellen aufgrund fehlender Ankerstrukturen nicht mehr an die Tumorzellen binden können.

Eine wichtige Rolle bei der Immuntherapie spielen monoklonale Antikörper, die selektiv an tumorassoziierte Antigene binden können und mit deren Hilfe Krebszellen gezielt markiert und abgetötet werden können. ${ }^{36}$ Diese 1975 von C. Milstein und G. F. Köhler erstmals hergestellten Verbindungen sind mittlerweile standardmäßig mit Hilfe der Hybridomtechnik zugänglich ${ }^{37}$ und können über kovalente Bindungen mit biologisch aktiven Substanzen verknüpft werden, um diese gezielt an einen Tumor heranzuführen. Ein Beispiel dieser Konjugate ist die Kupplung monoklonaler Antikörper mit Zytokinen, z. B. dem Interleukin-2 (IL-2), zu Immunzytokinen, die am Tumor die körpereigene Immunabwehr auslösen (Abb. 7,(A)). ${ }^{38,39}$ Ein weiteres Beispiel ist die Verknüpfung der Antikörper mit T-Lymphozyten, welche zu einer direkten Zytolyse der Tumorzelle führt $(\mathbf{B}) .^{40}$ Ein anderer Ansatz, die körpereigene Abwehr gegen Krebszellen zu aktivieren, ist die Verschmelzung der Krebszellen mit Antigen-präsentierenden Zellen. Die daraus entstehenden Hybride exprimieren auf ihrer Oberfläche verstärkt tumorassoziierte Antigene und aktivieren somit zytotoxische Lymphozyten (CTL), die - alarmiert durch die Tumorantigen-präsentierenden Hybride - Tumorzellen mit den gleichen Antigenen abtöten. ${ }^{41}$ Ein analoger Effekt wird durch das Beladen dendritischer Zellen (DZ) mit Tumorproteinen, -peptiden oder -DNA erzielt $(\mathbf{C}){ }^{42}$ Ein weiterer wichtiger Ansatz in der Immuntherapie ist die Verwendung von Toxin-Immunkonjugaten (E), in denen der Antikörper als selektiver Transporter für zytotoxische Substanzen eingesetzt wird. ${ }^{43}$ Hierbei wird die Spezifität monoklonaler Antikörper für tumorassoziierte Antigene genutzt, um eine Schädigung gesunder Zellen durch die verwendeten Toxine möglichst gering zu halten. Ein Beispiel für ein bereits zur Therapie zugelassenenes Toxin-Immunkonjugat ist Mylotarg, ein Konjugat aus dem zytotoxischen Naturstoff Calicheamicin und einem Antikörper gegen CD33. ${ }^{44}$ Im Rahmen des ADEPT-Konzeptes (ㅁntibody-Directed Enzyme Prodrug Therapy) werden Antikörper-Enzym-Konjugate verwendet, die in der Lage sind, ein reversibel detoxifiziertes Zytostatikum (Prodrug) selektiv an der Krebszelle in seine toxische Form (Drug) zu überführen (D). ${ }^{45}$ Im Gegensatz zu den direkt an die Antikörper gekoppelten Toxinen (E) weist das ADEPT-System den Vorteil auf, dass nur eine relativ niedrige Konzentration von Immunkonjugaten notwendig ist, denn in der Regel besitzen die Enzyme eine hohe Aktivität und können eine große Anzahl von Prodrugmolekülen direkt am Tumor in das entsprechende Toxin überführen. Zusätzlich ergibt sich durch die Diffusion des nicht an den Antikörper gebundenen 
Zytostatikums ein Effekt auf die umliegenden Tumorzellen (bystander effect), welche nicht unbedingt über das gleiche Antigen verfügen müssen. ${ }^{46}$ Weiterhin ist eine Kupplung radioaktiver Isotope $\left({ }^{131} \mathrm{I},{ }^{90} \mathrm{Y}\right)$ mit Antikörpern möglich (F). Dieser Ansatz wird nicht nur zur Therapie, sondern auch in der Diagnostik verwendet und ermöglicht u. a. die Lokalisation von Metastasen im Körper. ${ }^{47}$

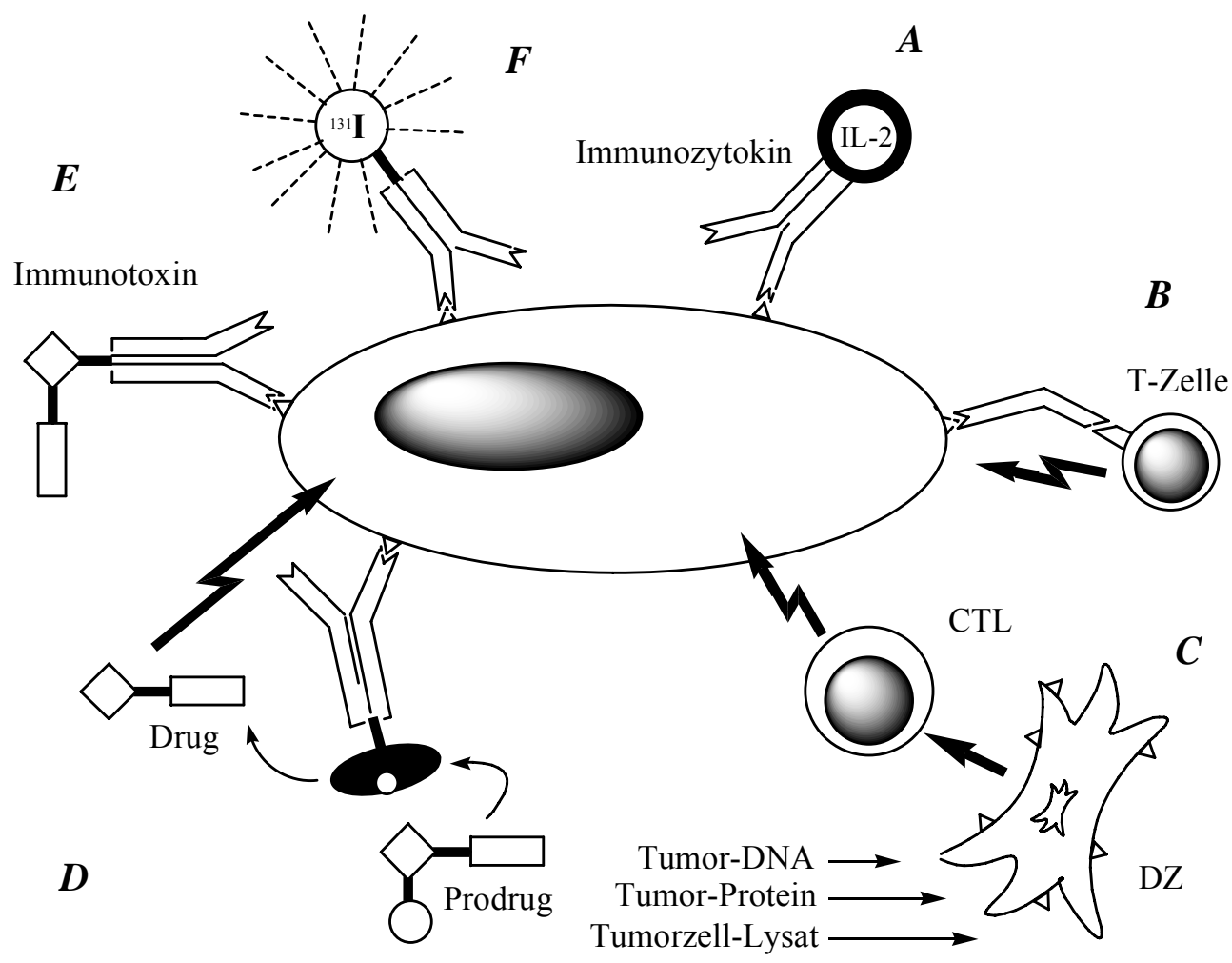

Abb. 7. Immuntherapien maligner Tumoren. A Immunozytokine, B Antikörpervermittelte Tumorzytolyse, C Aktivierung von zytotoxischen Lymphozyten (CTL) durch dendritische Zellen (DZ), D Enzymvermittelte Umwandlung von Prodrugs in Drugs (ADEPT), E Immunotoxin, F Antikörper-Radioisotopen-Konjugat.

Der Großteil der vorgestellten Ansätze zur Immuntherapie nutzt Antikörper als wichtigstes Instrument. Es ist möglich, monoklonale Antikörper in ausreichender Menge herzustellen, Antikörper murinen Ursprungs lösen allerdings im Patienten eine Immunantwort aus. Die Verwendung humanisierter oder humaner Antikörper bzw. Antikörperfragmente stellt eine vielversprechende Alternative dar. ${ }^{36}$ Problematischer ist die Tatsache, dass Zellen verschiedener Krebsarten unterschiedliche Antigenmuster präsentieren, die sich darüber hinaus in jedem Individuum unterscheiden. Für optimale Therapieerfolge müssten die Antikörper demzufolge individuell auf die tumorassoziierten Antigene der jeweiligen Patienten abgestimmt werden, was nicht praktikabel ist. 
Allgemeiner Teil

\subsection{Selektive Krebstherapie mittels reversibel detoxifizierter Prodrugs}

Viele Chemotherapien verursachen aufgrund einer ungenügenden Differenzierung zwischen gesundem und malignem Gewebe schwere Nebenwirkungen. Es wurden daher neue Konzepte entwickelt, die genotypischen und phänotypischen Eigenschaften von Tumorzellen ausnutzen, um eine höhere Selektivität der Behandlung zu erreichen. Ein wichtiger Ansatz ist die gezielte Aktivierung reversibel detoxifizierter Prodrugs direkt an ihrem Wirkort (Abb. 8).

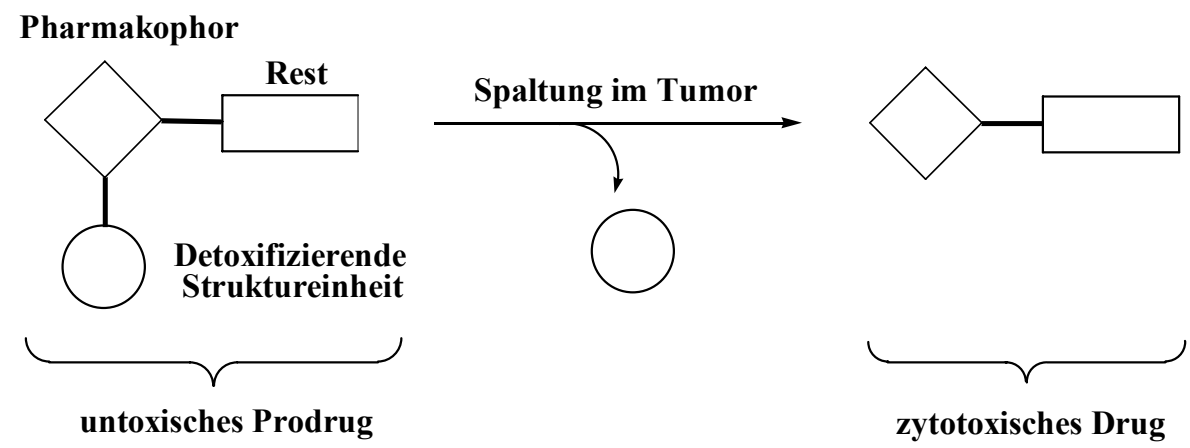

Abb. 8. Darstellung des Konzeptes reversibel detoxifizierter Prodrugs.

Bereits 1930 konnte $O$. Warburg durch In-vitro-Untersuchungen zeigen, dass der $\mathrm{pH}$ Wert im Tumorgewebe signifikant erniedrigt ist. ${ }^{48}$ Ursache hierfür ist die auf eine gesteigerte anabolische und mitotische Aktivität der Krebszellen zurückzuführende erhöhte anaerobe Glykolyserate. Durch einen verlangsamten Abtransport des Lactats aus dem Tumorgewebe aufgrund eines nur unzureichend ausgebildeten vaskulären und lymphatischen Systems wird die Milchsäure angereichert und somit der $\mathrm{pH}-$ Wert innerhalb des Tumorgewebes gesenkt. ${ }^{49}$ Die Glykolyserate der malignen Zellen ist außerdem stark von der extrazellulären Glucosekonzentration abhängig, da im Gegensatz zur Normalzelle die Aufnahme von Glucose nicht von zellulären Kontrollmechanismen gesteuert wird. ${ }^{50}$ Dadurch ist es möglich, unter hyperglykämischen Bedingungen, also unter exogener Glucosezufuhr, eine für therapeutische Zwecke nutzbare Absenkung des $\mathrm{pH}$-Wertes um durchschnittlich 1.2 Einheiten (von $\mathrm{pH} \cong 7.4$ auf 6.2) zu erreichen, die über einen Zeitraum von 24 Stunden konstant bleibt. ${ }^{51}$ Hierauf aufbauend entwickelte L.F. Tietze das Konzept der säurelabilen acetalischen Prodrugs, die erst im Tumorgewebe säurekatalysiert zum aktiven Toxin hydrolysiert werden und das gesunde Gewebe im Idealfall nicht schädigen. ${ }^{9}$ Als mögliche Prodrugs wurden zunächst Acetalglykoside von Ketonen untersucht, wie z. B. das Ketophosphamid BE-1 (12). ${ }^{52}$ Unter Säurekatalyse hydrolysiert dieses unter Abspaltung 
von Glucose (13) und Methanol zum Keton 14 (Abb. 9). Wie beim aktivierten Cyclophosphamid (s. Kap. 3.1) entsteht aus letzterem durch Metabolisierung über die Friedmannsäure 15 das Aziridiniumion 3 als eigentlich alkylierende Spezies. Das BE-1 (12) ist bei pH 6.2 an Mammakarzinomzellen der Marshall-Ratte (M1R) um den Faktor 17 toxischer als unter normalen physiologischen Bedingungen (pH 7.4). Ein Analogon des BE-1 (12), bei dem die primäre Hydroxygruppe an C-6 des Zuckers mit dem Wirkstoff das Acetal bildet, ist sogar bei pH 6.2 um den Faktor 100 toxischer als bei $\mathrm{pH} 7.4 .^{52}$

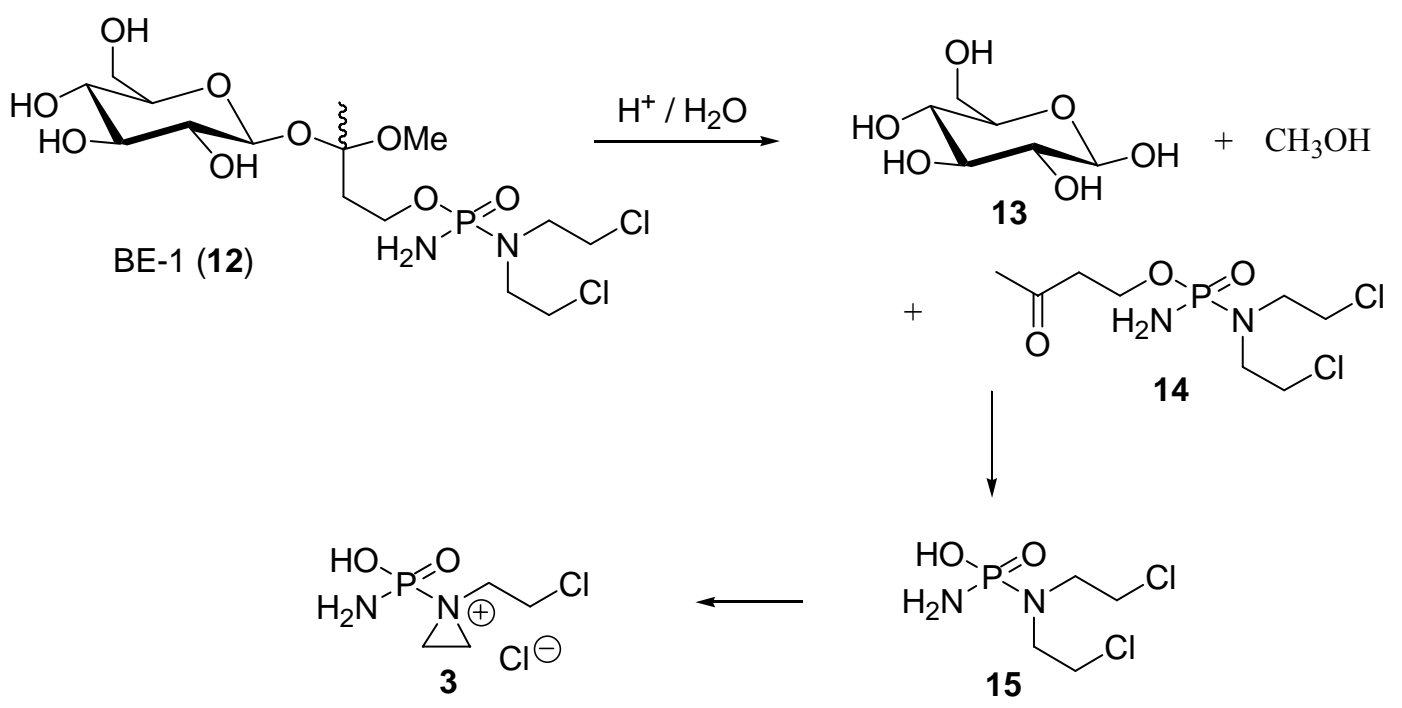

Abb. 9. Säurekatalysierte Aktivierung des acetalischen Prodrugs BE-1 (12).

Das erstmals von K. D. Bagshaw beschriebene ADEPT-Konzept nutzt AntikörperEnzym-Konjugate, die direkt am Tumor eine Umwandlung des untoxischen Prodrugs in das Drug bewirken und somit eine hohe Selektivität bewirken. ${ }^{53,54}$ Die Therapie erfolgt in zwei Schritten. Zunächst wird eine bestimmte Menge eines AntikörperEnzym-Konjugates appliziert, welches durch die Blutbahn im gesamten Organismus verteilt wird. Das Konjugat bindet an spezifische Antigene auf Tumorzelloberflächen oder wird vom Körper abgebaut oder ausgeschieden. ${ }^{55}$ Wenn sich das ungebundene Antikörper-Enzym-Konjugat nicht mehr im Blutstrom nachweisen lässt, erfolgt die Applikation des Prodrugs. Das möglichst untoxische Prodrug wird ebenfalls im gesamten Organismus verteilt und aufgrund des idealerweise nur an der Tumoroberfläche in Form des Antikörper-Enzym-Konjugates vorhandenen Enzyms gezielt im Tumorgewebe toxifiziert. Das freigesetzte Drug entfaltet dann nach Penetration durch die Zellmembran seine zytotoxische Wirkung, während das Enzym an der Außenseite der Tumorzelle weiterhin aktiv bleibt und weitere Prodrug-Moleküle aktivieren kann (Abb. 10). Die zytotoxische Wirkung des Drugs beschränkt sich hierbei nicht nur auf 
die Krebszellen, an die das Antikörper-Enzym-Konjugat gebunden hat, sondern auch auf benachbarte Krebszellen, die das Drug durch Diffusion im Tumorgewebe erreichen kann. So können auch die Zellen abgetötet werden, die nicht über tumorassoziierte Antigene verfügen.

Ein Vorteil dieses Konzeptes liegt in der vergleichsweise niedrigen Konzentration von Immunkonjugaten, die für eine effektive Bekämpfung der Tumorzellen notwendig sind, da Enzyme in der Regel eine hohe Aktivität besitzen und in der Lage sind, eine große Anzahl von Prodrug-Molekülen in das jeweilige Toxin zu überführen.

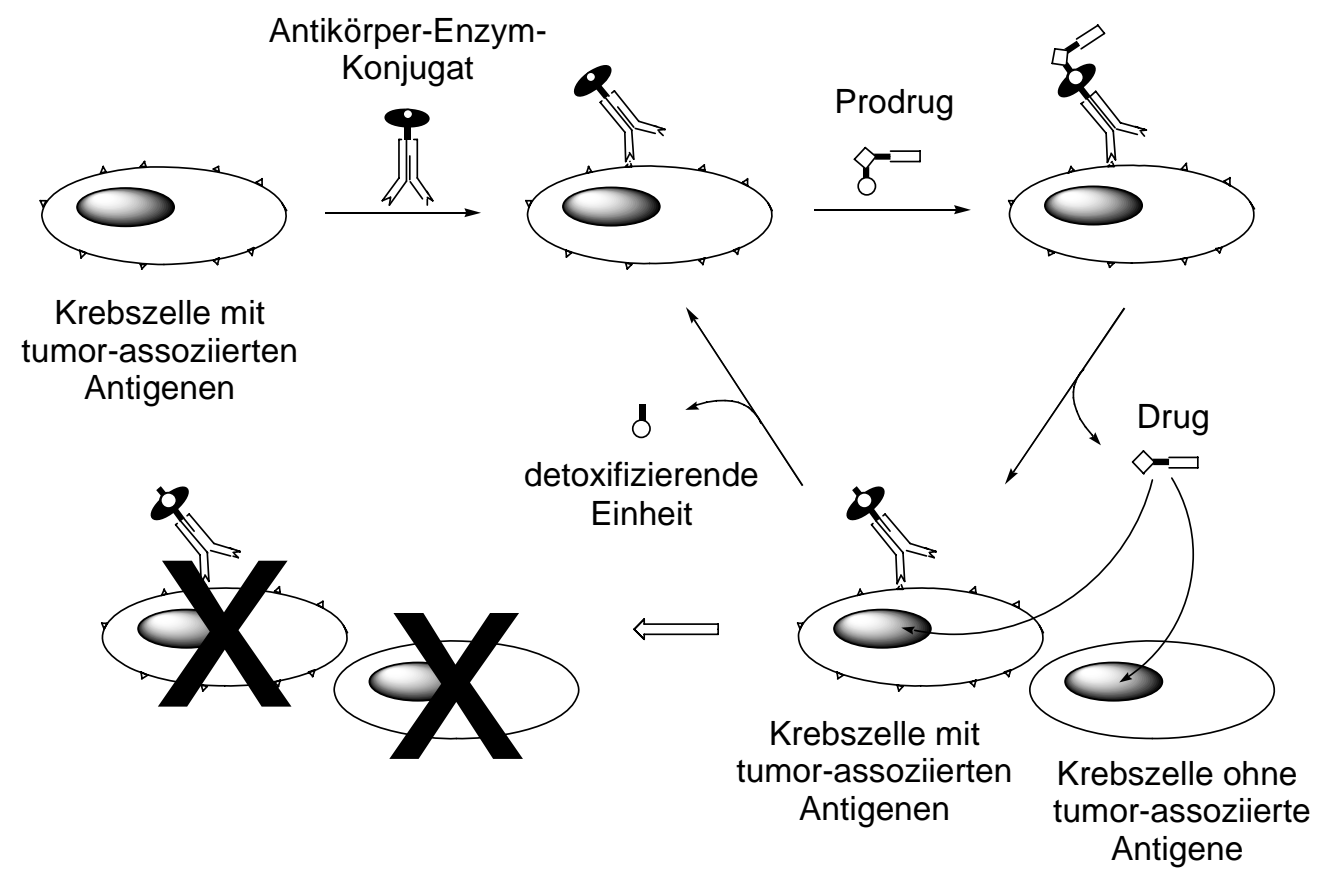

Abb. 10. Schematische Darstellung des ADEPT-Konzeptes.

Als Einschränkung gilt, dass eine Spaltung der Prodrugs durch körpereigene Enzymsysteme nicht erfolgen darf, da ansonsten die Selektivität der Therapie vermindert oder aufgehoben wäre. Die für eine Anwendung im Rahmen des ADEPT-Konzeptes geeigneten Enzyme sind unter anderem Peptidasen wie Carboxypeptidase G2, ${ }^{56}$ alkalische Phosphatase,${ }^{57} \beta$-Glucuronidase, ${ }^{58}$ Galactosidase,${ }^{59}$ Nitroreduktasen ${ }^{60}$ oder auch $\beta$-Lactamase ${ }^{61}$. Nachteile der bisher bekannten Prodrugs sind oftmals ein zu geringer Zytotoxizitätsunterschied zwischen dem Drug und dem Prodrug oder eine zu geringe Zytotoxizität des gebildeten Drugs. Als Richtlinie bei der Entwicklung von Verbindungen für das ADEPT-Konzept gilt, dass der $Q I C_{50}$-Wert $\left(Q I C_{50}=I C_{50}\right.$ (Prodrug) $/ I C_{50}$ (Prodrug in Anwesenheit des Enzyms)) $>1000$ sein sollte und die Zytotoxizität des zugrundeliegenden Drugs einen $I C_{50}$-Wert (Toxinkonzentration, bei der das Zellwachstum um 50\% unterbunden wird) $<10 \mathrm{nM}$ aufweisen sollte. ${ }^{9 e}$ 
Ein weiterer Ansatz im Rahmen einer gezielten Behandlung maligner Tumoren stellt die Prodrug-Monotherapie dar. ${ }^{62}$ Diese basiert auf dem Vorliegen von tumorassoziierten Enzymen, die in der Lage sind, ein detoxifiziertes Prodrug unter Freisetzung des korrespondierenden Drugs zu spalten. Ein mögliches Enzym ist z. B. $\beta$-D-Glucuronidase, die in erhöhten Konzentrationen in nekrotischen Bereichen von Tumorgeweben nachgewiesen werden konnte. ${ }^{63}$ Alternativ können auch Konjugate aus Wirkstoffen und tumorspezifischen Liganden für eine selektive Krebstherapie verwendet werden. Hier kommt es nach einer selektiven Bindung des Liganden an einen Rezeptor auf der Tumorzelloberfläche zu einer Internalisierung des Konjugates und zu einer folgenden intrazellulären Freisetzung des Toxins. ${ }^{64}$

\subsection{Präklinische und klinische In-vivo-Studien zur selektiven Tumor- therapie nach dem ADEPT-Konzept}

Erste präklinische In-vivo-Studien zur Evaluierung des ADEPT-Konzeptes erfolgten 1989 durch K. D. Bagshawe et al. an Nacktmäusen mit einem etablierten humanen Chorionkarzinom (CC3), einem chemisch synthetisierten Konjugat des $\mathrm{F}(\mathrm{ab})_{2}$ antihCG Antikörpers, dem Enzym Carboxypeptidase G2 (CP G2) sowie dem durch CP G2 aktivierbaren Prodrug CMDA (16, Abb. 11) ${ }^{65}$ In neun der zwölf Mäuse konnte in dieser Studie bei nur geringer Beeinträchtigung des Wohlergehens der Tiere ein kompletter Rückgang der Tumoren beobachtet werden. ${ }^{66}$

Weitere präklinische Untersuchungen dieser und anderer Forschergruppen mit verschiedenen Tumormodellen und entsprechend angepassten Antikörper-Enzym-Konjugaten folgten und belegten die Wichtigkeit der Kontrolle des Enzymspiegels im Blut sowie des richtigen Zeitpunktes der Prodrug-Gabe. ${ }^{67}$ Erfolgte die Prodrug-Applikation zu früh, so war die Konzentration des ungebundenen Antikörper-Enzym-Konjugates im Blut noch zu hoch und die Tiere starben an den Folgen der systemischen Aktivierung des Prodrugs zum Drug. Erfolgte die Prodrug-Gabe nach einer zu langen Clearance-Periode, war die systemische Toxizität zwar gering, der Effekt auf das Tumorwachstum jedoch auch, da die Konzentration des Konjugates sowohl im Blut als auch im Tumorgewebe unter eine Mindestkonzentration gefallen war.

In einer Folgestudie wurde daher $19 \mathrm{~h}$ nach der Gabe des Antikörper-EnzymKonjugates ein inaktivierender Antikörper gegen das Antikörper-Enzym-Konjugat verabreicht, um dessen Konzentration im Blut effektiv und frühzeitig zu senken. Der 
inaktivierende Antikörper war glykosidiert, um eine schnelle Aufnahme in die Leber und einen konsekutiven Abbau zu ermöglichen. So sollte eine Deaktivierung bereits an den Tumor gebundener Konjugate verringert werden. Das ungebundene AntikörperEnzym-Konjugat konnte effektiv inaktiviert werden, so dass eine Applikation des Prodrugs wenige Stunden nach der Gabe des inaktivierenden Antikörpers zu einer signifikanten Wachstumshemmung in zwei verschiedenen Tumormodellen führte. ${ }^{68}$

In einer kürzlich im Arbeitskreis $F$. Alves durchgeführten präklinischen Studie, in der ein neues und sehr vielversprechendes von L. F. Tietze et al. synthetisiertes Prodrug ${ }^{69}$ zum Einsatz kam, konnte aufgrund der schnellen Clearance des Antikörper-EnzymKonjugates aus dem Blut und der gleichzeitig immer noch hohen Konzentration des Konjugates im Tumorgewebe auf die Gabe eines inaktivierenden Antikörpers verzichtet werden. ${ }^{70}$ Hierbei konnte in einem Mammakarzinommodell (MDA-MB231) durch zwei Therapiezyklen eine signifikante Hemmung des Tumorwachstums im Vergleich zu den Kontrolltieren erreicht werden, deren Tumorwachstum um einen Faktor 1.7 höher lag. In dem ebenfalls untersuchten Lymphommodell (A20) war der Erfolg der Therapie noch weitaus ausgeprägter. Hier war das Tumowachstum in nichttherapierten Tieren um einen Faktor 3.6 höher als in der therapierten Gruppe.

Auf der Basis eines Drei-Phasen-Therapieschemas (1. Anti-Körper-Enzym-Konjugat, 2. Enzym-inaktivierender Antikörper, 3. Prodrug) erfolgte 1995 die erste klinische Studie nach dem ADEPT-Konzept. ${ }^{71}$ Von acht behandelten Patienten mit fortgeschrittener Tumorerkrankung konnte bei vier Patienten ein partielles Ansprechen der Therapie und bei einem Patienten ein Rückgang der Tumormasse aller Tumoren mit Ausnahme einer Geschwulst um mehr als 50\% beobachtet werden. Allerdings hatte das aus dem Prodrug CMDA (16) (Abb. 11) entstehende Drug eine Plasma-Halbwertszeit von bis zu 30 Minuten, ${ }^{72}$ weshalb es aus dem Tumor hinausdiffundierte und eine Myelosuppression verursachte. Dies wurde in weiteren Studien bestätigt, weshalb das neue Prodrug ZD2767P (17) (Abb. 11) entwickelt wurde, aus dem nach enzymatischer Aktivierung ein Drug mit einer sehr kurzen Halbwertszeit generiert wird. ${ }^{73,74}$
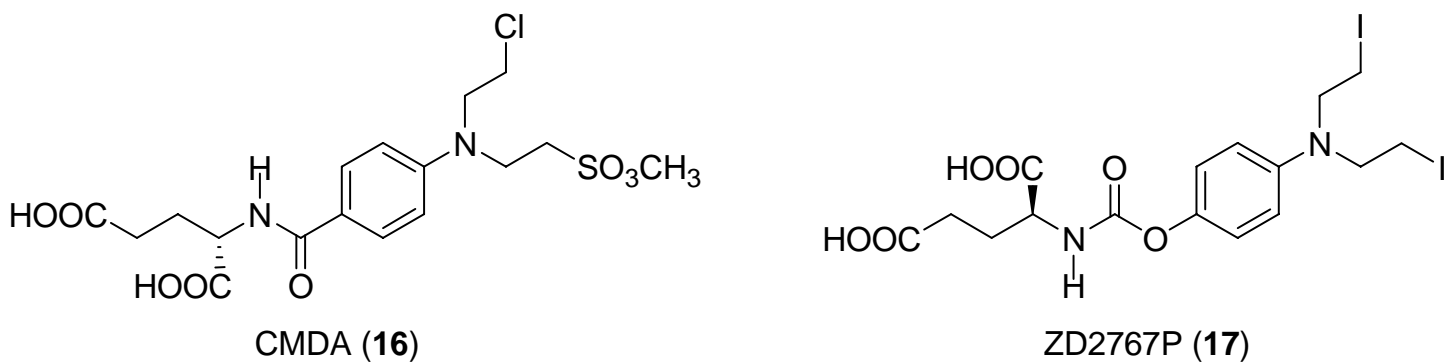

Abb. 11. In klinischen ADEPT-Studien eingesetzte, durch CP G2 aktivierbare Prodrugs. 
Derzeit durchgeführte klinische Studien basieren auf dem binären Ansatz ohne Nutzung eines inaktivierenden Antikörpers. Sie erfolgen mit dem neuen Prodrug ZD2767P (17) und einem mannosylierten Antikörper-Enzym-Fusionsprotein, ${ }^{75}$ dessen Clearance aus dem Blut durch eine schnelle Aufnahme über Mannoserezeptoren in die Leber begünstigt wird. Hierbei konnten bereits gute Ergebnisse erzielt werden: Bei einem Patienten reduzierte sich der Tumordurchmesser um 10\% und bei 11 der 28 Patienten schritt das Tumorwachstum nicht voran. ${ }^{76}$

Insgesamt lässt sich festhalten, dass das ADEPT-Konzept für eine selektive Tumortherapie geeignet ist, dass jedoch noch Verbesserungsbedarf hinsichtlich folgender Punkte besteht, um eine selektive und effiziente Therapie zu ermöglichen:

1. Der Anteil am Tumor gebundenen Konjugates im Verhältnis zum Anteil des ungebundenen Konjugates im Blut muss erhöht werden.

2. Die Immunogenität des Konjugates muss verringert werden, um mehrere Therapiezyklen ohne ausgeprägte Immunisierung der Patienten gegen das Antikörper-Enzym-Konjugat zu ermöglichen.

3. Es müssen neue und effektivere Prodrugs entwickelt werden mit einem hohen Zytotoxizitätsunterschied zwischen dem Prodrug und dem Drug, einer hohen Zytotoxizität des Drugs und einer kurzen Plasma-Halbwertszeit des Drugs.

\section{CC-1065, Duocarmycine und Yatakemycin}

Das Antibiotikum (+)-CC-1065 (18) wurde 1978 von Mitarbeitern der UpjohnCompany erstmals aus Kulturen von Streptomyces zelensis isoliert. ${ }^{77}$ Bei den durchgeführten Screenings zeigte es sowohl in vitro als auch in vivo eine enorm hohe Zytotoxizität, eine breitgefächerte antibiotische Wirksamkeit und eine starke Antitumoraktivität. ${ }^{78}$ Die außergewöhnliche Struktur des (+)-CC-1065 setzt sich aus drei substituierten Pyrrolo[2,3-e]-indol-Einheiten zusammen, die jeweils über Amidbindungen miteinander verknüpft sind (Abb. 12). Die DNA-bindenden Segmente B und $\mathbf{C}$ bestehen aus identisch substituierten 1,2-Dihydro-3H-pyrrolo-[3,2-e]-indolSystemen, die mit PDE-I und PDE-II bezeichnet werden. Das pharmakophore Segment A, auch als CPI (Cyclopropapyrroloindol) bezeichnet, weist eine Spirocyclopropyl-cyclohexadienon-Struktur auf. Aus anderen Streptomycetenstämmen konnten strukturverwandte Verbindungen wie die Duocarmycine ${ }^{79}$ (z.B. Duocarmycin SA (19)) 
sowie das Yatakemycin ${ }^{80}(\mathbf{2 0})$ isoliert werden. 20 stellt mit einem $I C_{50}$-Wert von nur 3 pM derzeit eines der potentesten Zytostatika dar. Innerhalb der Zytostatika werden die genannten Verbindungen in die Klasse der Alkylantien (s. Kap. 3.1) eingeordnet.

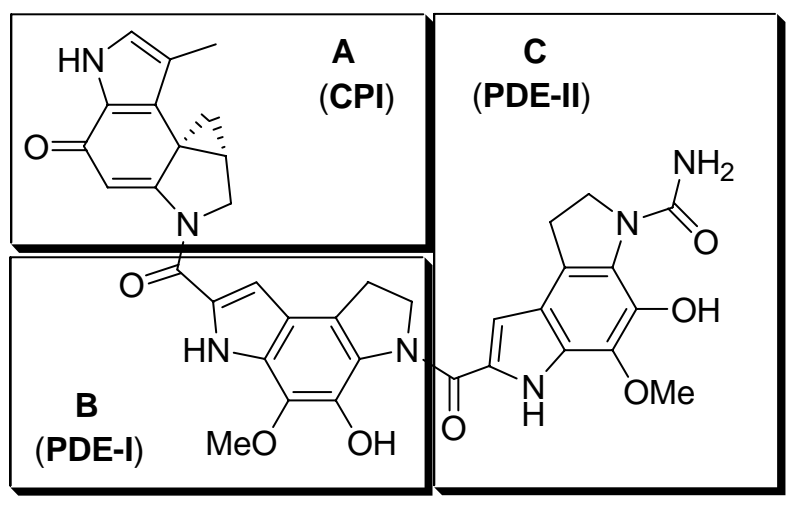

(+)-CC-1065 (18)

$\mathrm{IC}_{50}: 20 \mathrm{pM}(\mathrm{L} 1210)$

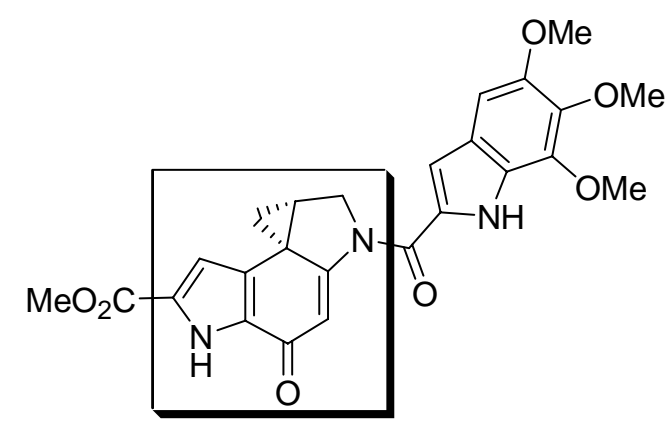

(+)-Duocarmycin SA (19) IC 50 : 10 pM (L1210)

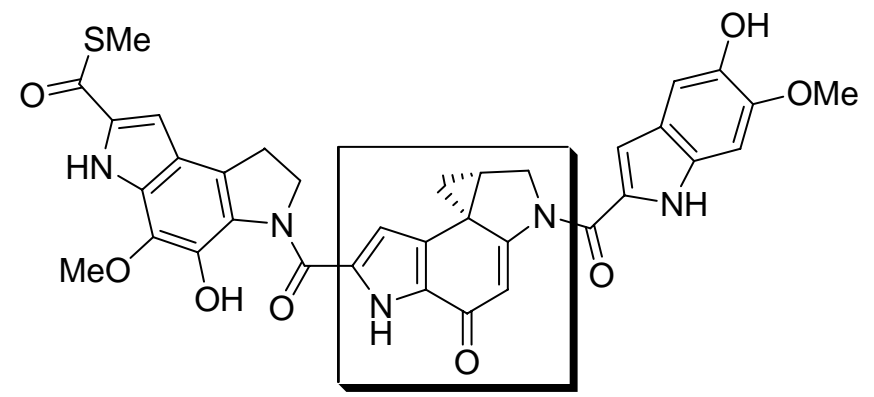

(+)-Yatakemycin (20)

$\mathrm{IC}_{50}$ : 3-5 pM (L1210)

Abb. 12. Die Alkylantien (+)-CC-1065 (18), (+)-Duocarmycin SA (19) und (+)-Yatakemycin (20).

Die zytotoxische Wirkung des CC-1065 (18) und analoger Verbindungen beruht vermutlich auf einer sequenzspezifischen DNA-Alkylierung durch eine Addition des Adenin- $N-3$ in der kleinen Furche doppelsträngiger, AT-reicher DNA an das am niedrigsten substituierte Kohlenstoffatom der Cyclopropyleinheit (Abb. 13). Die lipophile Innenseite der gekrümmten Struktur des CC-1065 und seiner Analoga begünstigt hierbei eine Wechselwirkung mit den Nucleobasen der DNA und die hydrophile Außenseite stabilisiert die Einlagerung in die kleine Furche durch Wechselwirkungen mit den polaren Funktionalitäten des DNA-Rückgrates.

Im Verlauf der Untersuchungen des CC-1065 und der Duocarmycine wurden mehrere Hypothesen über den Ursprung der beobachteten Alkylierungsselektivität aufgestellt. Das von L. H. Hurley vertretene Alkylierungsmodell postuliert eine Protonierung der Carbonylfunktion an C-4 durch eine günstig angeordnete Phosphatgruppe im flexiblen 
DNA-Rückgrat, wodurch sich die Konformation der DNA ändert und das nucleophile $N$-3-Atom in einen günstigen Abstand zum elektrophilen Zentrum des Wirkstoffs gelangt. ${ }^{81}$ Gegen dieses Alkylierungsmodell spricht jedoch u.a., dass auch Strukturanaloga, die an C-4 keine Carbonylgruppe tragen, die gleichen alkylierenden Eigenschaften und Selektivitäten besitzen, sowie die Tatsache, dass sich die DNAKonformation bei einer Bindung des Drugs nicht signifikant verändert. ${ }^{82}$
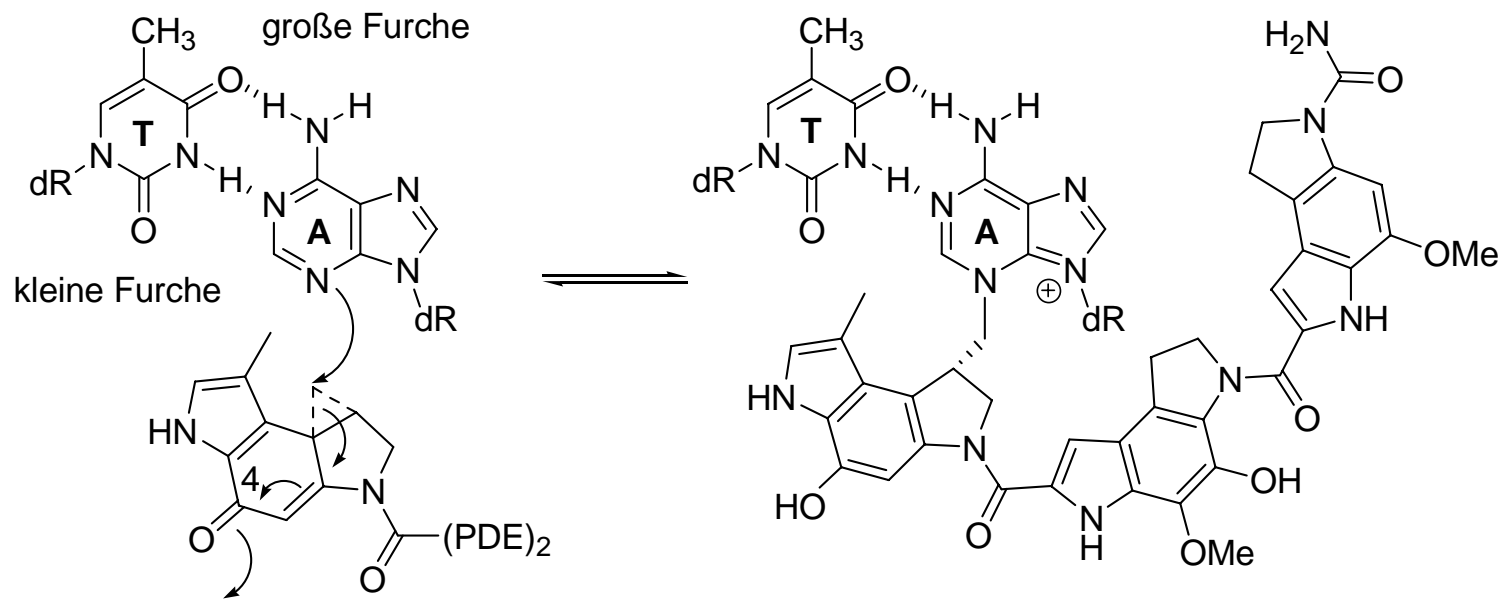

Abb. 13. Mechanismus der DNA-Alkylierung durch CC-1065 (18).

D. L. Boger hingegen vertritt das Modell der konformativen Aktivierung, bei dem eine DNA-bindende Untereinheit, die in starrer Weise über eine Amidbindung an das Pharmakophor angeknüpft ist, tief in die kleine Furche der DNA eindringt und dort über Wasserstoffbrücken-Bindungen an AT-reiche Sequenzen bindet. ${ }^{83}$ Diese formerkennende nicht-kovalente Bindung und Fixierung der Seitenkette führt zu einer Verdrillung der Amidbindung, wodurch die vinyloge Amidstabilisierung des Enons aufgehoben und die Reaktivität bezüglich eines nucleophilen Angriffs erhöht wird.

Nach neueren DFT-Berechnungen ${ }^{84}$ kann davon ausgegangen werden, dass die Aufhebung der vinylogen Amidstabilisierung (konformative Aktivierung) nicht entscheidend für die hohe Reaktivität der Wirkstoffe gegenüber doppelsträngiger DNA ist, da Verbindungen mit sehr unterschiedlicher Reaktivität eine ähnliche Verdrillung der Amidbindung aufweisen. Stattdessen erniedrigen vermutlich nicht-kovalente Wechselwirkungen der Wirkstoffe mit funktionellen Gruppen in der kleinen Furche der DNA die Aktivierungsenergie im Vergleich zur Reaktion mit einem Nukleophil in Lösung. ${ }^{85}$ Ergebnisse kombinierter Molekular-Dynamik- und Quantenmechanik/MolecularModelling-Studien ergaben zudem, dass eine Polarisierung der Wirkstoffe durch die Wechselwirkung mit der DNA sowie ein Proximitätseffekt eine wichtige Rolle bei der Aktivierung der Drugs in der kleinen Furche doppelsträngiger DNA spielen. ${ }^{82}$ 


\subsection{Analoga des Antibiotikums CC-1065 und der Duocarmycine}

Trotz enorm hoher Zytotoxizität $\left(I C_{50}=20 \mathrm{pM}\right)$ ist CC-1065 (16) wegen der im Tierversuch an Mäusen beobachteten verzögerten letalen Hepatotoxizität, die mit einer starken Veränderung der Mitochondrien einhergeht, nicht für eine klinische Anwendung geeignet. ${ }^{86}$ Die Duocarmycine sind indes aufgrund einer hohen Myelotoxizität in therapeutisch wirksamen Dosen nicht als Therapeutika einsetzbar. Die Untersuchungen verschiedener natürlicher und synthetischer Analoga der Verbindungen ergab eine ähnlich hohe Zytotoxizität. Zudem erwiesen sich einige Analoga zwar ebenfalls als myelotoxisch, jedoch nicht als hepatotoxisch. ${ }^{87}$ Die lethale Hepatotoxizität ist demnach ein Charakteristikum der Originalstruktur und nicht des Wirkmechanismus. ${ }^{88}$

In allen natürlich vorkommenden (CPI, DA, DSA) und synthetisierten (z. B. CI, CBI, CBQ, CPyI, MCBI, MCCPI) pharmakophoren Gruppen findet sich die Spirocyclopropyl-cyclohexadienon-Struktur des CI-Grundgerüstes wieder (Abb. 14).

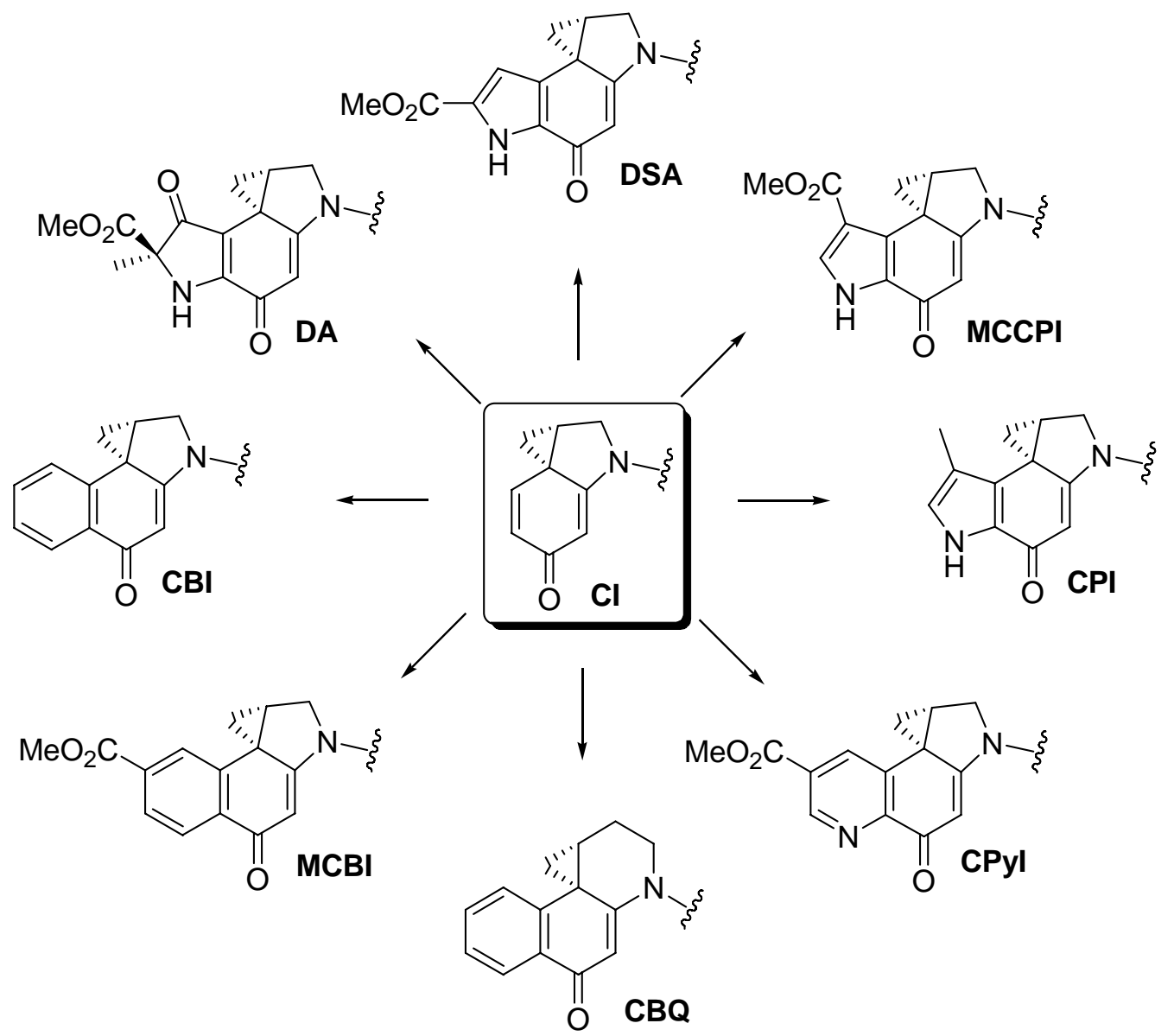

Abb. 14. Analoga des CC-1065 mit der pharmakophoren CI-Einheit. 
Untersuchungen der elektronischen und sterischen Einflüsse auf die Alkylierungseffizienz und Zytotoxizität zahlreicher Analoga ergaben eine parabolische Beziehung zwischen der Solvolysestabilität dieser pharmakophoren Moleküleinheit und der Zytotoxizität. ${ }^{89}$ Verbindungen mit einer höheren chemischen Stabilität weisen eine stärkere zytotoxische Aktivität auf, was möglicherweise auf einen effizienteren Transport des Wirkstoffs an seinen Wirkort zurückgeführt werden kann. Sind die Verbindungen jedoch zu stabil, so nimmt die Zytotoxizität wieder ab. Obwohl diese Wirkstoffe ihren Zielort wahrscheinlich in höherer Konzentration erreichen als die instabileren Analoga, sind sie aufgrund einer ebenfalls niedrigeren Reaktivität gegenüber der Zielstruktur weniger wirksam.

Neben der Variation der pharmakophoren Gruppe wurde auch die als DNA-bindende Einheit bezeichnete Substruktur des CC-1065 und verwandter Verbindungen systematisch untersucht, indem verschiedene Analoga synthetisiert und biologisch getestet wurden. ${ }^{88,90}$ Tabelle 1 zeigt einige ausgewählte Beispiele dieser Studien mit den pharmakophoren Gruppen DSA, CPI und CBI (Abb. 14) sowie verschiedenen DNA-bindenden Einheiten.

Anhand dieser Strukturvariationen und der daraus resultierenden In-vitro-Zytotoxizitäten konnten einige charakteristische Struktur-Wirkungsbeziehungen gefunden werden. Während die C-6- und C-7-Methoxysubstituenten des TMI z. B. nur geringfügig zur biologischen Aktivität beitragen, ist die C-5-Methoxygruppe essentiell für eine hohe Wirksamkeit (Tab. 1, Einträge 1-3). Die Bisindol-Derivate (Einträge 4 und 5) zeigen eine um den Faktor drei bis sechs höhere Zytotoxizität als die TMI-Derivate. Mit zunehmender Größe der DNA-bindenden Struktureinheit nimmt folglich die Zytotoxizität zu. Analoga ohne DNA-bindende Struktureinheit sind zudem etwa 1000bis 10000 -fach weniger wirksam als der entsprechende Naturstoff, was die Rolle der DNA-bindenden Einheit unterstreicht (Eintrag 6).

Des Weiteren wurde herausgefunden, dass der Pyrrolring im CPI durch einen Benzolring ausgetauscht werden kann (CBI-Analoga), wodurch die Ringspannung herabgesetzt und eine höhere Stabilität sowie eine gesteigerte Zytotoxizität erreicht werden kann (Eintrag 5). ${ }^{91}$ 
$I C_{50}(\mathrm{L1210})[\mathrm{pM}]$

DNA-bindende Einheit

DSA CPI

CBI

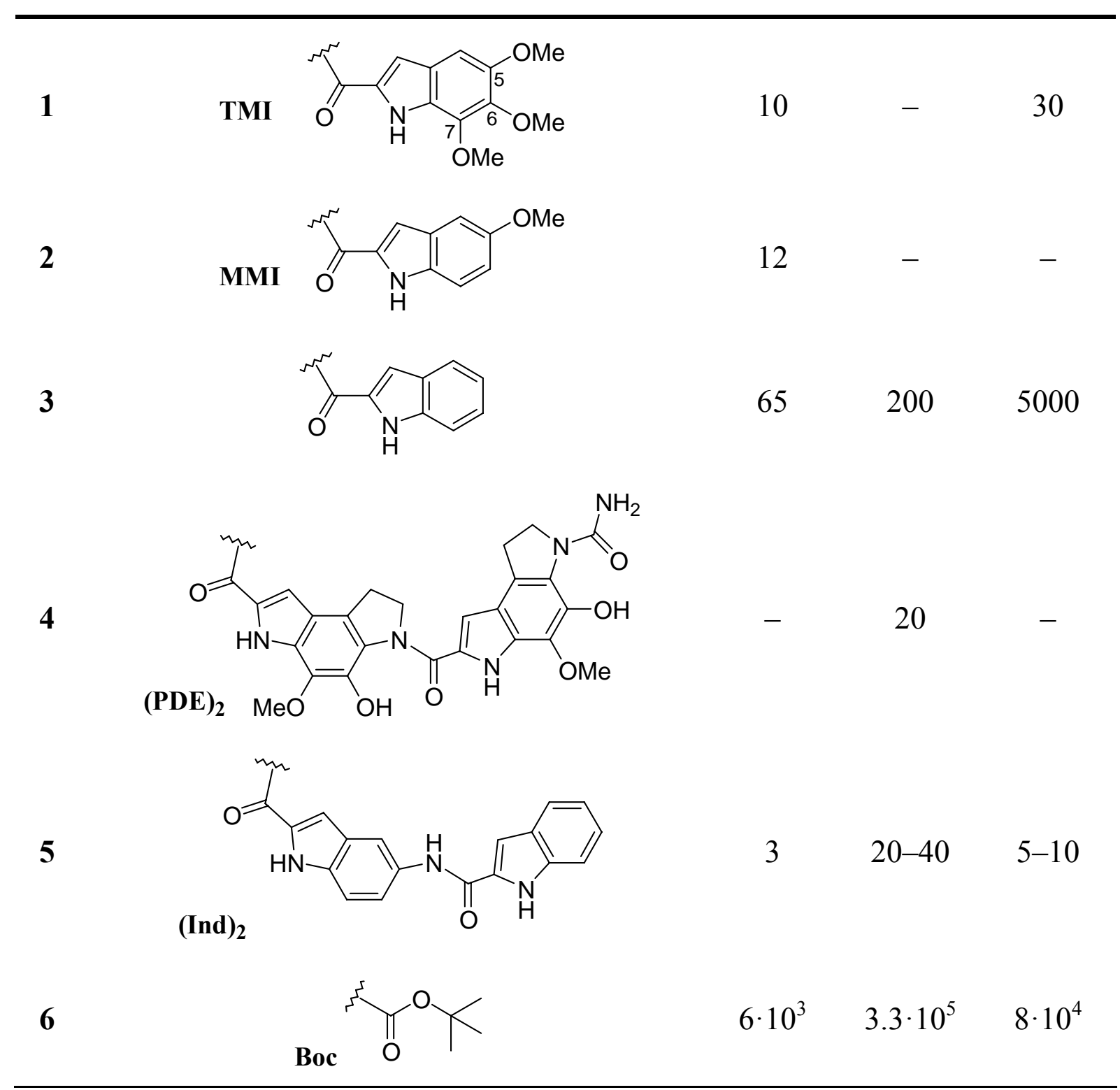

Tab. 1. Einfluss der DNA-bindenden Struktureinheit auf die Antitumoraktivität von DSA-, CPI- und CBI-Analoga.

Vergleichende Studien zwischen Verbindungen gleicher Konstitution aber unterschiedlicher Konfiguration ergaben weiterhin, dass die jeweiligen Verbindungen mit unnatürlicher Konfiguration weniger toxisch (z.B. Duocarmycine) oder ähnlich toxisch (z.B. CC-1065) sind wie die entsprechenden Enantiomere mit natürlicher Konfiguration. ${ }^{92}$ Bei Duocarmycin A (21, Abb. 15) war beispielsweise das $(+)$-Enantiomer um einen Faktor 110 toxischer als das (-)-Enantiomer. 


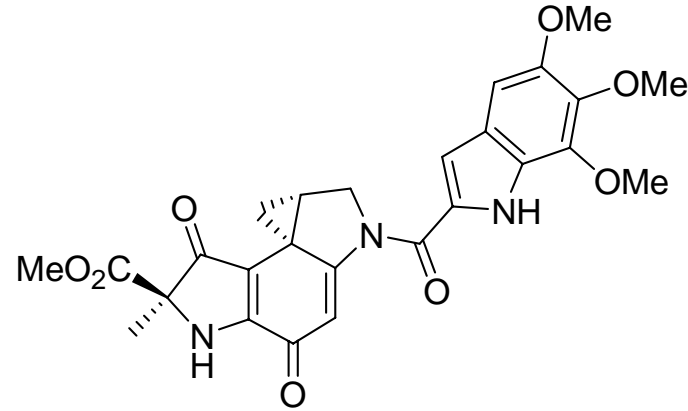

$(+)$-Duocarmycin A ((+)-21)

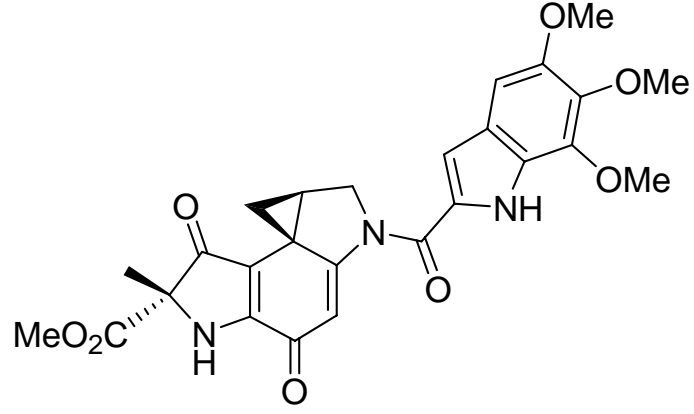

(-)-Duocarmycin A ((-)-21)

Abb. 15. Die Duocarmycine (+)-Duocarmycin A ((+)-21) und (-)-Duocarmycin A ((-)-21).

Wirkstoffe mit einer DNA-bindenden Einheit und natürlicher Konfiguration des Pharmakophors alkylieren ein Adenin am 3'-Ende einer AT-reichen Region, während die Analoga mit der entsprechenden unnatürlichen Konfiguration ein Adenin am 3'-Ende des komplementären Stranges alkylieren. ${ }^{88}$ Dies ergibt sich aus der entgegengesetzten Orientierung der Drugs in der gleichen AT-reichen DNA-Bindungsstelle. Die unnatürlichen Enantiomere bilden zudem weniger stabile nicht-kovalente DNAAddukte und die kovalente Bindung ist zu einem höheren Grad reversibel. Erst eine Erhöhung der Zahl der DNA-bindenen Einheiten ermöglicht es, die Zytotoxizität und DNA-Alkylierungseffizienz der unnatürlichen Enantiomere zu erhöhen. ${ }^{87 \mathrm{c}}$ Beide Enantiomere von Sandwich-Analoga wie Yatakemycin (20), die über DNA-bindende Einheiten auf beiden Seiten des Pharmakophors verfügen, alkylieren ein Adenin in der Mitte einer AT-reichen Sequenz des gleichen Stranges. ${ }^{93}$

Aufgrund überragender Ergebnisse in In-vitro-Untersuchungen wurden mit den synthetischen Analoga Adozelesin (22), ${ }^{94}$ Carzelesin (23), ${ }^{95}$ Bizelesin (24) ${ }^{96}$ und KW-2189 (25) ${ }^{97}$ klinische Studien durchgeführt (Abb. 16). Während Adozelesin (22) die pharmakophore Einheit von CC-1065 (18) enthält, stellen die übrigen Verbindungen seco-Formen dar, aus denen sich das reaktive Drug mit einer Cyclopropylgruppe erst in situ durch Zyklisierung bildet. Carzelesin (23), KW-2189 (25) sowie einige Analoga ${ }^{98}$ sind zudem Prodrugs mit einer schützenden Carbamoyl-Gruppe an der phenolischen Hydroxyfunktion. Diese Schutzgruppe wird in vivo von unspezifischen Plasmacarboxylesterasen abgespalten und so die toxische seco-Form erzeugt. ${ }^{99}$ Die Schutzgruppe dient im Wesentlichen der Verbesserung pharmakokinetischer Eigenschaften und im Fall von KW-2189 (25) zudem einer Erhöhung der Wasserlöslichkeit durch die Möglichkeit einer Salzbildung, ermöglicht aufgrund der Instabilität jedoch keinen Einsatz dieser Verbindungen in einer selektiven Krebstherapie. ${ }^{100}$ 
Bizelesin (24) ist ein Bisalkylans mit einer sehr hohen Zytotoxizität von 1 pM (L1210) und verfügt über zwei pharmakophore Einheiten, die über ein DNA-bindendes Bisindol miteinander verknüpft sind. ${ }^{101}$<smiles>Cc1c[nH]c2c1C(=O)C=C1N(C(=O)c3cc4cc(NC(=O)c5cc6ccccc6o5)ccc4[nH]3)C[C@@H]3C[C@@]123</smiles><smiles>CCNc1ccc2cc(C(=O)Nc3ccc4[nH]c(C(=O)N5C[C@@H](CCl)c6c5cc5oc(=O)[nH]c6=c-c=c-c=c-c6c(C)c[nH]c6-5)cc4c3)oc2c1</smiles>

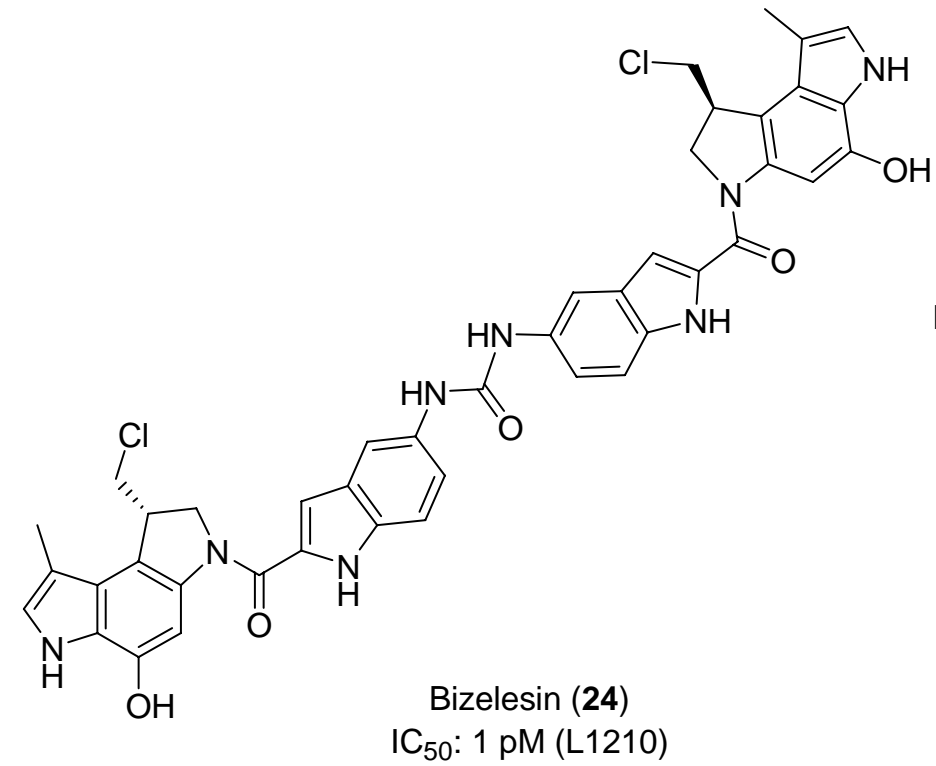<smiles>COc1cc2cc(C(=O)N3C[C@@H](CBr)c4c3cc(OC(=O)N3CCN(C)CC3)c3[nH]c(C)c(C(=O)O)c43)[nH]c2c(OC)c1OC</smiles>

Abb. 16. Wirkstoffe, die in klinischen Phasen getestet wurden: Adolzelesin (22), Carzelesin (23), Bizelesin (24) and KW-2189 (25).

Obwohl mit allen Wirkstoffen signifikante Anti-Tumor-Wirkungen erzielt werden konnten, wurden die klinischen Studien für alle Kandidaten mit Ausnahme von Bizelesin (24) eingestellt, da die Myelotoxizität der Wirkstoffe bei Verabreichung in therapeutischen Dosen zu ausgeprägt war. ${ }^{94-97}$ 


\subsection{Untersuchung des Wirkmechanismus des Antibiotikums CC-1065, der Duocarmycine und ihrer Analoga}

Der Wirkmechanismus des CC-1065, der Duocarmycine und ihrer Analoga war Ziel vieler eingehender Untersuchungen, denen zufolge vermutlich die sequenzspezifische Alkylierung in AT-reichen Regionen doppelsträngiger DNA die hohe Zytotoxizität bedingt. ${ }^{102}$ Die kleine Furche AT-reicher DNA ist tiefer und enger als die kleine Furche GC-reicher DNA-Abschnitte und eine stärkere Stabilisierung der WirkstoffDNA-Komplexe in AT-reichen DNA-Abschnitten könnte die Sequenzselektivität erklären. ${ }^{103}$

Gemäß einer Studie an Pyrrol-Imdiazol-CBI-Konjugaten verursachen Unterschiede in der Sequenzselektivität der DNA-Alkylierung Unterschiede in der biologischen Aktivität. ${ }^{104}$ AT-Regionen spielen eine bedeutende Rolle in der Initiierungsphase der Replikation und Translation, während GC-reiche Regionen bedeutend sind für die Regulation der Genexpression. ${ }^{105}$ Selektive Bindung an AT-reiche DNA in Promoteroder Enhancer-Regionen genomischer DNA kann die Genexpression betroffener Gene verändern, indem sie beispielsweise das Binden von Transkriptionsfaktoren verhindert, die Affinität der Transkriptionsfaktoren stark erhöht oder neue Bindungsstellen schafft. ${ }^{106}$ So konnte gezeigt werden, dass CC-1065 die Bindung des TATA-Boxbindenen Proteins an seine Erkennungssequenz verhindert. ${ }^{107}$ Zudem wurde nachgewiesen, dass AT-reiche DNA-Regionen (auch als AT-Inseln bezeichnet) als MatrixAnknüpfungsstellen (matrix attachment regions, MARs) dienen, die die DNA-Struktur beeinflussen und Kernaktivitäten wie DNA-Replikation und Transkription steuern. ${ }^{108}$ Das hoch toxische Analogon Bizelesin (24) verursacht beispielsweise hohe Anteile an Strangbrüchen in verschiedenen bekannten AT-Inseln. AT-reiche Regionen in den Regulatorregionen krebsassoziierter Gene (wie c-myc) konnten zudem als Zielstrukturen AT-sequenzspezifischer Wirkstoffe ermittelt werden. ${ }^{109}$ Nach Inkubaton von Zellen (CEM) mit Bizelesin (24) konnte des Weiteren eine Inhibierung der PCRReaktion AT-reicher DNA-Regionen beobachtet werden. Die Behandlung von Zellen in Zellkultur mit Bizelesin und Amino-CBI-Derivaten gefolgt von zeit- und konzentrationsabhängigen Untersuchungen der aus den Zellen isolierten DNA und RNA des Gens c-myc (hoher Anteil AT in der Starterregion ORI des Gens (61\%) und der MARRegion (76\%)) mittels PCR-Stopp-assay bzw. Reverse-Transcriptase-PCR ergab zudem eine mit der Alkylierung korrelierende Verringerung der Genexpression. ${ }^{110}$ 
Die Bindung von CC-1065 und Duocarmycinen verursacht nur eine sehr geringe Änderung der DNA-Struktur. Da eine Änderung in der Helix- und Chromatinstruktur wichtige Erkennungsmerkmale für DNA-Reparatur-Enzyme darstellt, könnte die Einlagerung der Furchenbinder schlecht als DNA-Schädigung erkannt und daher unzureichend repariert werden. ${ }^{111}$ Der nicht reparable Schaden oder Strangbrüche, die in Folge einer durch die Drugbindung behinderten DNA-Reparatur entstehen könnten, könnten neben einer Beeinträchtigung der DNA-Funktion ${ }^{112}$ als Apoptose-Auslöser wirken. ${ }^{113}$

In vitro wird die DNA-Synthese durch CC-1065 etwa zehnfach stärker gehemmt als die RNA-Synthese und diese wiederum stärker als die Proteinsynthese (Tab. 2). ${ }^{114}$ Hierbei ist die zur Hemmung der DNA-Synthese notwendige Dosis jedoch höher als die für Zellen lethale Dosis, die nur 0.02 nM beträgt. Daher können neben einer DNAAlkylierung andere Ursachen für die hohe Zytotoxizität nicht ausgeschlossen werden. Dies wird unterstützt durch die Beobachtung, dass Zellen in der S-Phase des Zellzyklus am unempfindlichsten gegen CC-1065 sind, während Zellen in der $\mathrm{G}_{2}$ - und MPhase empfindlich reagieren. So blockiert CC-1065 Zellen bereits in niedrigen Dosen in der $\mathrm{G}_{2}$ - und M-Phase, während die S-Phase erst bei sehr hohen Drug-Konzentrationen blockiert wird. ${ }^{115}$

\begin{tabular}{cc}
\hline Inhibition & $\boldsymbol{E D}_{\mathbf{5 0}}[\mathbf{n M}]$ \\
\hline DNA-Synthese & $5.7-8.5$ \\
RNA-Synthese & $71.1-85.3$ \\
Proteinsynthese & $>711$ \\
\hline
\end{tabular}

Tab. 2. Effektive Dosis zur halbmaximalen Hemmung wichtiger Biomolekülsynthesen durch CC-1065 (18) in Zellen.

W. C. Krueger et al. ${ }^{116}$ untersuchten die Wechselwirkung des CC-1065 und einiger Analoga mit Kalbs-Thymus-DNA und doppelsträngigen poly(dI-dC)-Sequenzen mittels CD-Spektroskopie und der Messung von DNA-Schmelzkurven. Sie bestimmten zusätzlich den Anteil nicht kovalent gebundenen Wirkstoffs durch Phenolextraktion und untersuchten die Stabilität der DNA-Addukte hinsichtlich verschieden langer Inkubationszeiten und des Verdaus durch Schlangengift-Phosphodiesterase I (SVDP). Hierbei stellten Sie fest, dass die Bindung von CC-1065 und vieler Analoga an doppelsträngige DNA zu einem intensiven induzierten CD-Signal 
(ICD) führt. Die Größe des CD-Signals korreliert hierbei nicht notwendigerweise mit der Größe der Bindungsaffinität, meist ist jedoch das CD-Signal bei höherer Bindungsaffinität intensiver. Eine höhere Bindungsaffinität bedingt zudem eine höhere Schmelztemperatur $\left(\Delta T_{\mathrm{m}}\right)$ der DNA. Nicht-kovalent gebundenes CC-1065 hat nur eine geringe Duplex-Stabilisierung zur Folge, d.h. es verursacht nur einen geringen Anstieg der Schmelztemperatur. Kovalent gebundenes CC-1065 verursacht stattdessen eine starke Erhöhung der Schmelztemperatur. Gebundene Moleküle schützen den Doppelstrang zudem vor Abbau durch DNA-abbauende Enzyme. Durch diese Studien wurde des Weiteren nachgewiesen, dass die Moleküle mit unnatürlicher Konfiguration schwächer an DNA binden als jene mit natürlicher Konfiguration, was vermutlich die Ursache ihrer geringeren Zytotoxizität darstellt.

In der Folge wurde eine Serie von Untersuchungen zur Bindung an Kalbs-ThymusDNA, poly $(\mathrm{dA} \cdot \mathrm{dT})-\mathrm{DNA}$ und poly $(\mathrm{dG} \cdot \mathrm{dC})$-DNA mit CC-1065 und verschiedenen Analoga zunehmender Kettenlänge durchgeführt (Tab. 3). ${ }^{117}$

\begin{tabular}{|c|c|c|c|c|c|c|c|}
\hline \multirow[b]{2}{*}{ Verbindung } & \multirow[b]{2}{*}{$I C_{50}[\mathrm{nM}]$} & \multicolumn{2}{|c|}{$\begin{array}{c}\text { Kalbsthymus- } \\
\text { DNA }\end{array}$} & \multicolumn{2}{|c|}{$\begin{array}{c}\text { Poly(dA-dT)- } \\
\text { DNA }\end{array}$} & \multicolumn{2}{|c|}{$\begin{array}{c}\text { Poly(dG-dC)- } \\
\text { DNA }\end{array}$} \\
\hline & & $\begin{array}{l}\triangle C D \\
\text { [mgrad] }\end{array}$ & $\begin{array}{l}\Delta T_{\mathrm{m}} \\
{\left[{ }^{\circ} \mathrm{C}\right]}\end{array}$ & $\begin{array}{l}\triangle C D \\
\text { [mgrad] }\end{array}$ & $\begin{array}{l}\Delta T_{\mathrm{m}} \\
{\left[{ }^{\circ} \mathrm{C}\right]}\end{array}$ & $\begin{array}{l}\triangle C D \\
{[\text { mgrad] }}\end{array}$ & $\begin{array}{l}\Delta T_{\mathrm{m}} \\
{\left[{ }^{\circ} \mathrm{C}\right]}\end{array}$ \\
\hline CC-1065 & $0.021-0.050$ & 305 & 25 & 358 & 43 & 27 & 2 \\
\hline U-68,415 & 0.015 & 94 & 14 & 122 & 17 & 0 & 0 \\
\hline U-66,694 & 0.41 & 40 & 10 & 47 & 7 & 0 & 0 \\
\hline U-68,819 & 1.6 & 13 & 9 & 20 & 4 & 0 & - \\
\hline U66,664 & 17.4 & 0 & 2 & 0 & 5 & 0 & - \\
\hline
\end{tabular}

Tab. 3. Zytotoxizitäten $\left(I C_{50}\right)$ sowie Änderungen der Intensität des CD-Signals $(\triangle C D)$ und der DNA-Schmelztemperatur $\left(\Delta T_{\mathrm{m}}\right)$ nach Inkubation verschiedener DNA mit CC-1065 und ausgewählten Analoga.

Hierbei ergab sich ein Zusammenhang zwischen der Zytotoxizität und den gemessenen Parametern $\triangle C D, \Delta T_{\mathrm{m}}$ und $U V$ (letzteres ist nicht dargestellt). Je toxischer, umso stärker waren die beobachteten Veränderungen der genannten Parameter. Dieser Effekt war für Kalbs-Thymus-DNA ungefähr so groß wie für poly(dA·dT)-DNA, während für 
poly(dG·dC)-DNA kein signifikanter Effekt beobachtet werden konnte. Alle Verbindungen binden demnach bevorzugt an AT-reiche DNA-Regionen. Dies konnte durch weitere Messungen bestätigt werden. Allgemein korreliert die Zytotoxizität von CC-1065-Derivaten jedoch nur qualitativ und nicht quantitativ mit ihrer Fähigkeit zur Bindung an DNA. ${ }^{118}$

Netropsin, ein bekannter Binder der kleinen Furche doppelsträngiger DNA, kann die Bindung von CC-1065 verringern und wird selbst aus der DNA freigesetzt, wenn diese nach Netropsin mit CC-1065 inkubiert wird. Die Ergebnisse dieser und weiterer Konkurrenzexperimente mit Netropsin belegen, dass CC-1065 in der kleinen Furche doppelsträngiger DNA bindet. ${ }^{119}$

Als Ursache des starken induzierten CD-Signals postulierten W. C. Krueger und M. D. Prairie das Vorliegen eines inhärent dissymmetrischen Chromophors, bei dem das konjugierte System aus Elektronen des CC-1065 durch die Bindung in der kleinen Furche der DNA in eine rechtshändige helikale Form gezwungen wird. ${ }^{120,121}$ Eine chirale elektronische Anregung, die über das ganze Molekül delokalisiert ist, bedingt nach dieser Annahme das typische CD-Signal. Je stärker das CD-Signal, desto stärker sind dabei die DNA-Drug-Wechselwirkungen, die die helikale Konformation des Moleküls stabilisieren. Für diese Theorie spricht, dass CC-1065 und seine Analoga in Puffer nur ein schwaches CD-Signal zeigen, welches bei Bindung an doppelsträngige DNA jedoch sehr stark wird. Zudem ist die Intensität des Signals abhängig von der Anzahl fusionierter Ringe im bindenden Molekül und die Wellenlänge des ICD korreliert mit den Absorptionsbanden des Moleküls. Neueren Untersuchungen zufolge wird das induzierte CD-Signal allerdings durch eine Kopplung der elektronischen Übergänge des Liganden mit denjenigen der DNA-Basen verursacht. ${ }^{122}$

Die CD-spektroskopischen Untersuchungen wurden in der Folge für Oligonukleotide verschiedener Länge und Basensequenz durchgeführt und es wurden weitere interessante Beobachtungen gemacht. ${ }^{123}$ So verändert sich das CD-Spektrum in der Nähe der elektronischen Anregungen $(\lambda=290-450 \mathrm{~nm})$ in Abhängigkeit von der Zeit: Das Maximum verlagert sich mit zunehmender Inkubationszeit zu kürzeren Wellenlängen (hypsochrome Verschiebung: $\lambda=392 \mathrm{~nm} \rightarrow \lambda=371 \mathrm{~nm}$ ). Das induzierte CDSignal nimmt weiterhin mit zunehmender Olionukleotidlänge und zunehmender Anzahl an Basen neben dem 5'-Ende der Bindungsposition zu. Dies wurde darauf zurückgeführt, dass längere Oligomere eine stabilere B-Form der DNA ausbilden und somit CC-1065 besser binden können. Der Übergang der nicht-kovalent gebundenen 
Form zur kovalent gebundenen Form ist zudem abhängig von der Art der Nukleobasen und ihrer Sequenz im Oligonukleotid. ${ }^{124}$ Bei DNA-Polymeren wurde ein intensives CD-Signal mit einem Maximum nach einer Stunde Inkubation erreicht. Bei längerer Inkubation trat eine Verschiebung des Maximums zu kürzeren Wellenlängen durch Übergang der nicht-kovalenten in eine kovalente Bindung auf. Bei DNA-Oligomeren erfolgte ein schnellerer Übergang der nicht-kovalenten zur kovalenten Bindung, da kein Maximum bei $\lambda=390 \mathrm{~nm}$, sondern direkt bei etwa $\lambda=370 \mathrm{~nm}$ auftrat.

Um die natürliche Situation in einer Zelle besser untersuchen zu können, wurden CC-1065 und ausgewählte Analoga mit Chromatin, Kalbs-Thymus-DNA und Histonen inkubiert. ${ }^{125}$ Sowohl die Form als auch der Zeitverlauf des induzierten CD-Signals sind bei Inkubation von CC-1065 oder eines Analogons mit Chromatin ähnlich zu denjenigen bei Inkubation mit DNA, die Intensität des ICD ist bei Inkubation mit Chromatin jedoch geringer als mit DNA und der Anteil kovalent gebundenen Wirkstoffs ist ebenfalls geringer. CC-1065 bindet zudem nur sehr schwach und unspezifisch an Histone und diese Bindung verursacht kein ICD-Signal. Präinkubation von CC-1065 mit DNA verringert die Zytotoxizität erheblich, Präinkubation mit Chromatin weniger und die mit Histonen gar nicht.

Die Zytotoxizität von CC-1065 nach Präinkubation mit möglichen zellulären Bindungspartnern wurde in der Folge mit Kalbs-Thymus-DNA, Hefen-RNA und humanem Serum-Albumin untersucht. ${ }^{126}$ Hierbei wurde eine starke Abnahme der Zytotoxizität nach Präinkubation mit DNA und hohen Mengen Albumin gefunden, die bei Albumin auf eine unspezifische und reversible Bindung zurückgeführt werden kann. Eine unspezifische Bindung ist wahrscheinlich auch die Ursache für die schwache Inhibition von Thymidinkinase durch CC-1065. Eine Inhibition der DNAPolymerase- $\alpha$-Aktivität konnte ebenfalls festgestellt werden, wurde aber auf das durch CC-1065-Bindung veränderte DNA-Templat zurückgeführt. Hierbei verursacht CC-1065 bei Raumtemperatur und $37^{\circ} \mathrm{C}$ keine Strangbrüche, jedoch bei Erhitzen auf $70{ }^{\circ} \mathrm{C}$ und höher.

Bizelesin (24) bewirkt aufgrund zweier Alkylierungseinheiten pro Molekül in Zellen und Zell-Lysaten eine Bisalkylierung doppelsträngiger DNA. ${ }^{127}$ In Zellen, aber nicht in Zell-Lysaten, zeigte CC-1065 (18), das nur über eine Alkylierungseinheit verfügt, ebenfalls eine Bisalkylierung, die bei Adozelesin (22) nicht beobachtet werden konnte. ${ }^{127}$ Neuesten Untersuchungen zufolge sind die Wirkstoffe weiterhin in der Lage, DNA zu alkylieren, die in Nucleosomen organisiert ist. ${ }^{128}$ 


\section{3 seco-Verbindungen und Prodrugs einiger Analoga des Antibiotikums CC-1065 und der Duocarmycine}

Die entsprechenden seco-Verbindungen der CC-1065- und Duocarmycin-Analoga zeigen im Allgemeinen ähnliche Toxizitäten und Selektivitäten wie die Spirocyclopropylverbindungen. ${ }^{9 e, 52 a, 88}$ Es wird daher angenommen, dass aus den seco-Verbindungen der Cyclopropanring in situ über eine Winstein-Aryl-3'-Spirozyklisierung gebildet wird und erst dann eine Alkylierung der DNA stattfindet (Abb. 17). ${ }^{129}$

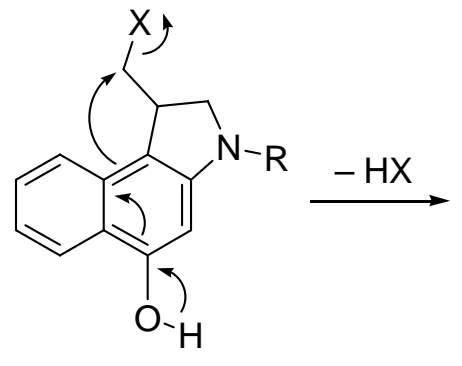

$26 a$

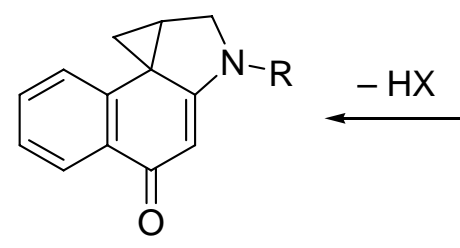

CBI

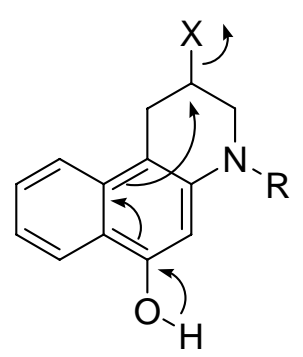

26b

Abb. 17. Winstein-Aryl-3'-Spirozyklisierung der seco-CBI-Derivate 26a und 26b.

Die Blockade der phenolischen Hydroxyfunktion oder einer entsprechenden Aminofunktion bei verwandten Aminoanaloga, die für den gezeigten Spirozyklisierungsmechanismus von essentieller Bedeutung ist, sollte demzufolge untoxische Vorstufen (Prodrugs) liefern. ${ }^{130}$

W. A. Denny und Mitarbeiter synthetisierten verschiedene Prodrugs für die Nutzung im Rahmen einer Gene-directed Enzyme Prodrug Therapie (GDEPT), indem sie die für die biologische Aktivität der Verbindungen wichtige Aminofunktionalität in ein Carbamat umwandelten. ${ }^{131}$ So kann beispielsweise das Prodrug 27 durch im Tumor exprimierte Nitroreduktase in das entsprechende seco-Drug 29 umgewandelt werden, nachdem die Krebszellen selektiv mit einem Vektor so genetisch verändert (transfiziert) worden sind, dass sie das aktivierende Enzym Nitroreduktase produzieren (Abb. 18). ${ }^{132}$ Das Prodrug 27 ist allerdings nur etwa 20-fach stärker toxisch gegen Nitroreduktase-exprimierende transfizierte SKOV-3 Zellen als gegen die entsprechenden nicht-transfizierten Zellen. In einem Versuch, den $Q I C_{50}$ der Prodrugs zu erhöhen, entwickelte dieselbe Gruppe zwölf neue 4-Nitrobenzyl-Carbamat-Prodrugs. ${ }^{133}$ Die biologische Untersuchung lieferte jedoch nur unbefriedigende Werte mit $Q I C_{50^{-}}$ Werten von bis zu 87, da die Prodrugs nicht vollständig durch das in transfizierten Zellen exprimierte Enzym aktiviert werden. 


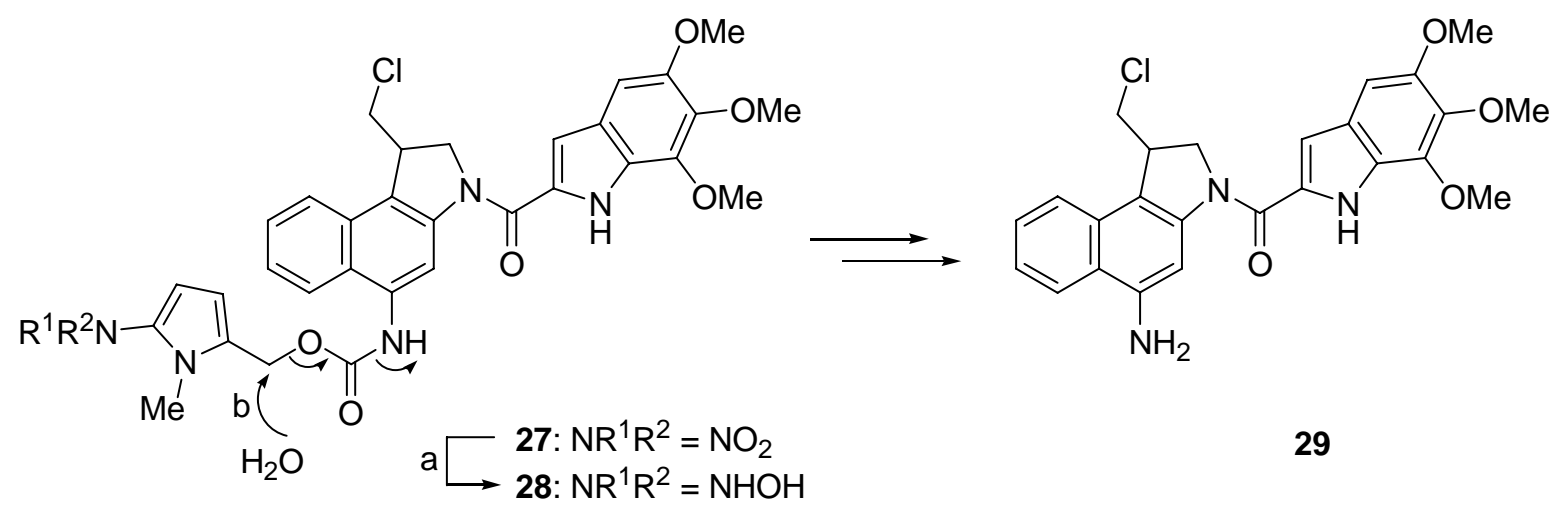

Abb. 18. Prodrug 27, das durch in Krebszellen exprimierte Nitroreduktase zu 28 reduziert wird (a), welches in situ zum toxischen seco-Drug 29 hydrolysiert (b).

Die Entwicklung analoger Prodrugs durch W. A. Denny et al. und D. L. Boger et al., die im sauerstoffarmen Tumorgewebe zu den zytotoxischen Analoga aktiviert werden sollten, ergab aufgrund einer unvollständigen In-situ-Aktivierung oder einer Instabilität der Prodrugs ebenfalls nur $Q I C_{50}$-Werte $<100 .^{134}$

Y. Wang et al. synthetisierten Prodrugs, die ihre zytotoxische Wirkung durch eine Bindung an Serum-Albumin oder eine Konjugation mit natürlichen Fettsäuren bevorzugt im Tumorgewebe entfalten sollten. ${ }^{135}$ Hierbei konnte für erstere trotz niedriger $Q I C_{50}$ Werte von $<150$ gute In-vivo-Ergebnisse erzielt werden. Die Konjugation mit der Fettsäure DHQ ergab jedoch keine signifikanten Unterschiede zwischen der Wirkung des Prodrugs und des entsprechenden seco-Drugs ohne Fettsäure.

Andere Arbeitsgruppen entwickelten Prodrugs, indem sie die DNA-bindende Untereinheit der Moleküle derivatisierten und sich so eine geringere Affinität zur Bindung an DNA erhofften. ${ }^{136}$ Beispiele dieser Art von Prodrugs sind die peracetylierten Glucuronsäure-Methylester $\mathbf{3 0}^{137}$ und das $\beta$-Lactam $\mathbf{3 2}^{138}$ (Abb. 19). Die Prodrugs 30 waren allerdings nur etwa 5.5-fach und das Prodrug 32 nur etwa 10 -fach geringer toxisch als ihre entsprechenden seco-Drugs. Dies ist entweder auf eine ungenügende Stabilität der detoxifizierenden Einheit oder auf das auch im Prodrug vorhandene freie Pharmakophor zurückzuführen. Mit Antikörper-Drug-Konjugaten, in denen der jeweilige Antikörper über eine abspaltbare Abstandseinheit mit dem DNA-bindenden Molekülteil ${ }^{139}$ oder dem Pharmakophor ${ }^{140}$ des Duocarmycin-Derivates verbunden ist, konnten indes gute Ergebnisse erzielt werden. Das jeweilige seco-Drug wird hierbei durch enzymatische Abspaltung des Antikörpers und der Abstandseinheit nach einer 
Bindung des Konjugates an die Tumorzellen auf der Tumorzelloberfläche oder innerhalb der Tumorzellen freigesetzt.
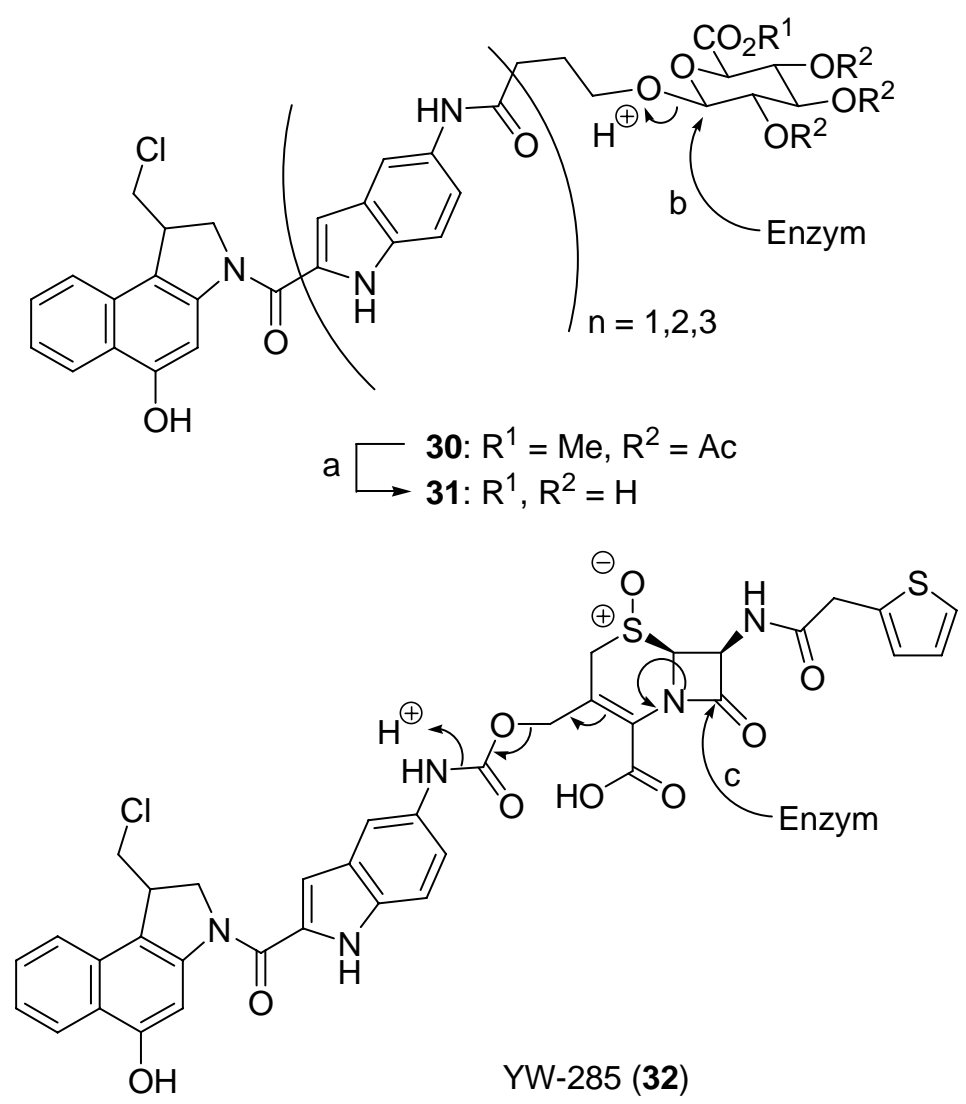

Abb. 19. Prodrugs, die durch Modifikation der DNA-bindenden Einheit detoxifiziert werden. Die peracetylierten Glucuronsäure-Methylester 30 werden durch unspezifische Carboxylatesterasen in die entsprechenden Glucuronide 31 umgewandelt (a), welche durch $\beta$-Glucuronidase selektiv im Tumorgewebe zu den entsprechenden seco-Drugs aktiviert werden (b). Die Aktivierung des $\beta$-Lactams 32 erfolgt durch $\beta$-Lactamase (c).

In den letzten Jahren gelang im Arbeitskreis L. F. Tietze die Synthese verschiedener Analoga des CC-1065 und der Duocarmycine, deren biologische Wirksamkeit getestet wurde. ${ }^{9,141}$ Hierbei konnte mit dem reversibel durch Glykosidierung detoxifizierten anti-Methyl-seco-CBI-DMAI- $\beta$-D-Galactosid (1S,10R)-33a (Abb. 20) ein hervorragendes Ergebnis erzielt werden. ${ }^{69}$ Hervorzuheben ist insbesondere der außerordentlich hohe Unterschied der Zytotoxizitäten des Prodrugs und des Prodrugs in Anwesenheit des aktivierenden Enzyms mit einem $Q I C_{50}$-Wert von 4800 gegenüber humanen Bronchialkarzinomzellen der Linie A549. Zudem ist die Zytotoxizität des durch enzymatische Spaltung aus dem Prodrug gebildeten seco-Drugs $(1 S, 10 R)-34 a$ mit einem $I C_{50}$-Wert von $0.75 \mathrm{nM}$ relativ hoch. 

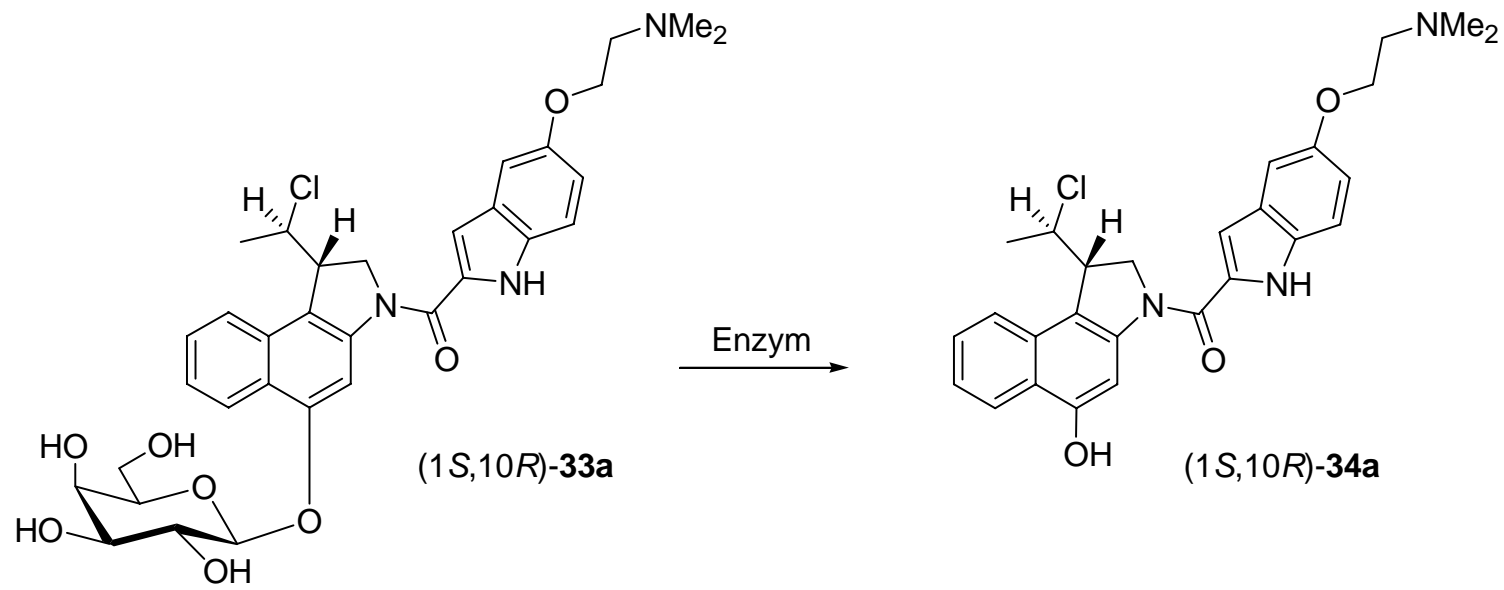

Abb. 20. Anti-Methyl-seco-CBI-DMAI-Verbindungen für eine selektive Tumortherapie nach dem ADEPT-Konzept. Aktivierung des galactosidischen Prodrugs $(1 S, 10 R)-33 a$ zu dem entsprechenden seco-Drug $(1 S, 10 R)$-34a durch $\beta$-D-Galactosidase.

Basierend auf den exzellenten Ergebnissen mit $(1 S, 10 R)-33 \mathbf{a}$ und $(1 S, 10 R)-34 \mathbf{a}$ wurden in der Folge Derivate mit dem gleichen DNA-Binder aber anderen Zuckerbausteinen synthetisiert. ${ }^{141 \mathrm{~h}, 142} \mathrm{Zu}$ diesen gehören sehr vielversprechende Prodrugs wie das $\alpha$-D-Mannosid $(1 S, 10 R)$-35 sowie die $\beta$-D-Glucuronide $(1 S, 10 R)-36$ und $(1 S, 10 R)-37$ (Abb. 21). ${ }^{58 \mathrm{a}}$ Die Prodrugs werden unter Enzymkatalyse zum seco-Drug $(1 S, 10 R)$-34a (Abb. 20) aktiviert. Aufgrund seines hohen $Q I C_{50}$-Wertes von 4500 und seiner hohen Stabilität in Zellkulturmedien ist das Mannosid $(1 S, 10 R)-35$ hervorragend geeignet für eine ADEP-Therapie. Das Glucuronid $(1 S, 10 R)-\mathbf{3 6}\left(Q I C_{50}=700\right)$ und insbesondere dessen Methylester $(1 S, 10 R)-37\left(Q I C_{50}=1600\right)$ eignen sich stattdessen für den Einsatz in einer Prodrug-Monotherapie (PMT).
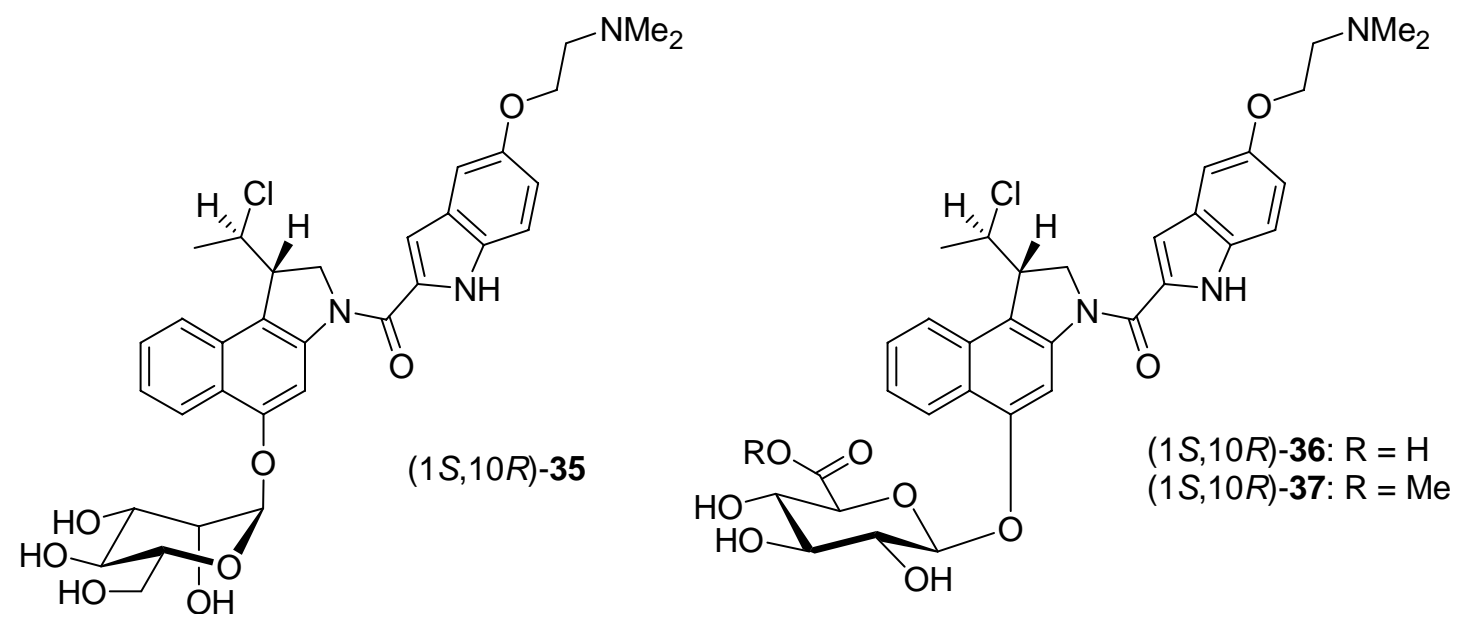

Abb. 21. $\alpha$-D-Mannosid (1S,10R)-35, $\beta$-D-Glucuronid $(1 S, 10 R)$-36 und der entsprechende $\beta$-D-Glucuronsäuremethylester $(1 S, 10 R)$-37 für den Einsatz in ADEPT oder PMT. 


\section{$5 \quad$ Fluoreszenzmikroskopie und Optical Imaging}

Fluoreszenzmikroskopie ist eine spezielle Form der Lichtmikroskopie, bei der im zu untersuchenden Präparat befindliche fluoreszierende Stoffe (Fluorochrome) mit Licht einer bestimmten Wellenlänge zum Leuchten angeregt werden. ${ }^{143}$ In der Forschung wird die Fluoreszenzmikroskopie dazu genutzt, von Natur aus fluoreszierende (autofluoreszierende) Verbindungen, synthetisch hergestellte Konjugate oder durch Gentransfektion mit einem Fluorochrom markierte Verbindungen in Zellen sichtbar zu machen. Bei zusätzlicher Anfärbung zellulärer Substrukturen wie des Kerns oder der Membranen lassen sich so Rückschlüsse über die Lokalisation der Verbindungen in fixierten oder lebenden Zellen sowie in fixierten Geweben ziehen.

Bei der Auswahl gleichzeitig verwendeter Fluorochrome muss darauf geachtet werden, dass die Anregungswellenlängen oder die Emissionswellenlängen sich so stark voneinander unterscheiden, dass die Fluoreszenzen verschiedener Verbindungen getrennt voneinander wahrgenommen werden können. Heute stehen zur gleichzeitigen Detektion verschiedenster Verbindungen eine Vielzahl von Fluorochromen mit unterschiedlichen Anregungs- und Emissionsmaxima zur Verfügung. ${ }^{144}$

Bekannte Beispiele für Autofluoreszenz sind Chlorophyll und das Grün-Fluoreszierende Protein (GFP), ${ }^{145}$ das gentechnisch mit beliebigen Zellproteinen fusioniert werden kann und es so erlaubt, die markierten Proteine zu lokalisieren und ihre Interaktion mit anderen Proteinen oder Zielstrukturen zu untersuchen. ${ }^{146}$ Als Fluorochrome für die Fluoreszenzmarkierung von Antikörpern oder Molekülen mit Aminofunktionen eignen sich z.B. das grün fluoreszierende Fluorescein-Derivat Fluoresceinisothiocyanat (FITC) (38) oder Dapoxyl ${ }^{\circledR}$-Derivate wie D10162 (39) (Abb. 22). Dapoxyl ${ }^{\circledR}$-Derivate fallen hierbei durch eine ausgeprägte Umgebungsabhängigkeit (Lösungsmittel, pH etc.) der Fluoreszenzemission und einen starken Stokes-Shift zwischen dem Absorptions- und Emissionsmaximum auf. ${ }^{147}$

Zur Anfärbung des Zellkerns lebender Zellen eignen sich diverse Farbstoffe wie z.B. Hoechst 33342 (40, Abb. 22). 40 ist ein Vertreter einer Familie von BisbenzimidFarbstoffen, die in der kleinen Furche doppelsträngiger DNA binden und in gebundener Form intensiv blau fluoreszieren. ${ }^{148}$ Auch zur Färbung stoffwechselaktiver Mitochondrien stehen diverse Fluoreszenzverbindungen wie der rot fluoreszierende MitoTracker $^{\circledR}$ Deep Red 633 FM (41) zur Verfügung (Abb. 22). ${ }^{149,150}$ 
<smiles>O=C(O)c1cc(N=C=S)ccc1-c1c2ccc(=O)cc-2oc2cc(O)ccc12</smiles>

FITC (38)

Absorption: $\lambda_{\max }=490 \mathrm{~nm}$

Emission: $\quad \lambda_{\max }=520 \mathrm{~nm}$

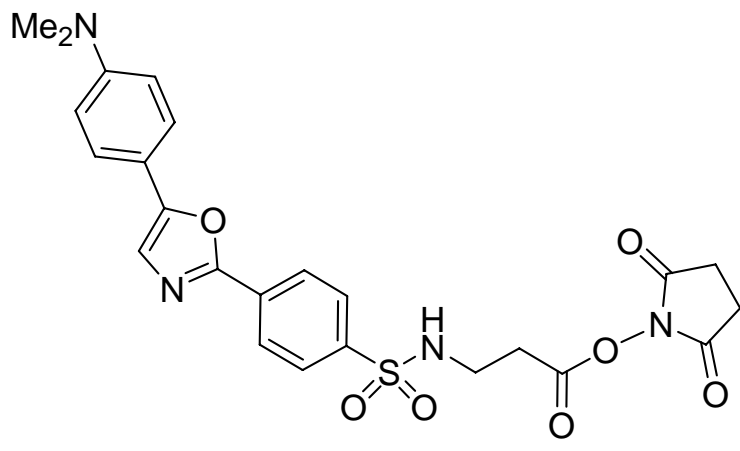

D10162 (39)

Absorption: $\lambda_{\max }=373 \mathrm{~nm}$

Emission: $\quad \lambda_{\max }=574 \mathrm{~nm}$

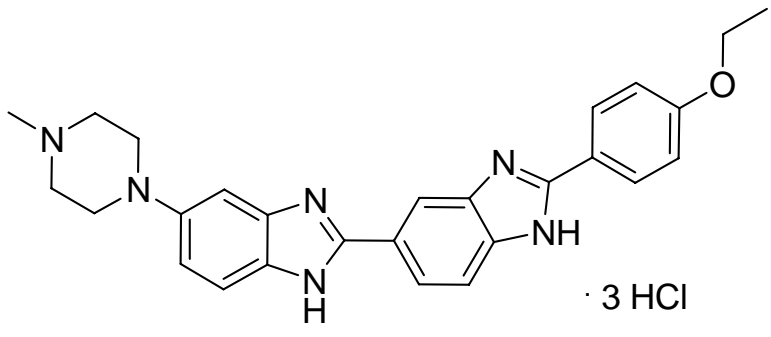

Hoechst 33342 (40)

Absorption: $\lambda_{\max }=346 \mathrm{~nm}$

Emission: $\quad \lambda_{\max }=460 \mathrm{~nm}$<smiles>CN1C(=CC=CC=CC(=O)C2(C)C(Cl)=C(C=CC=CCCl)C2(C)C)c2ccccc21</smiles>

Mitotracker Deep Red 633 FM (41)

Absorption: $\lambda_{\max }=644 \mathrm{~nm}$

Emission: $\quad \lambda_{\max }=665 \mathrm{~nm}$

Abb. 22. Die Fluoreszenzfarbstoffe FITC (38) und D10162 (39), der fluoreszierende Zellkernfarbstoff Hoechst 33342 (40) und der fluoreszierende Mitochondrienfarbstoff MitoTracker $^{\circledR}$ Deep Red 633 FM (41).

Im Rahmen der Vorbereitung präklinischer ADEPT-Studien gelang im Arbeitskreis $F$. Alves die Untersuchung der Bindungskinetik fluoreszenzmarkierter Antikörper- $\beta$-DGalactosidase-Konjugate in vitro. ${ }^{151}$ Mittels konfokaler Laser-Scanning-Mikroskopie konnte beispielsweise gezeigt werden, dass das verwendete FITC-markierte antiuPAR- $\beta$-D-Galactosidase-Konjugat bereits nach 30 Minuten spezifisch an das in Mammakarzinomzellen (MDA-MB-231) hoch exprimierte Antigen uPAR bindet, die Bindung bis zu 30 Stunden Inkubation zunimmt und danach bis zu 65 Stunden stabil bleibt (Abb. 23). Des Weiteren blieben die Zellen bis zu einer Inkubationszeit von 65 Stunden vital und es fand keine Internalisierung des Konjugates statt. Das antiuPAR- $\beta$-D-Galactosidase-Konjugat eignet sich diesen In-vitro-Untersuchungen zufolge sehr gut für eine Anwendung im Rahmen des ADEPT-Konzeptes. 


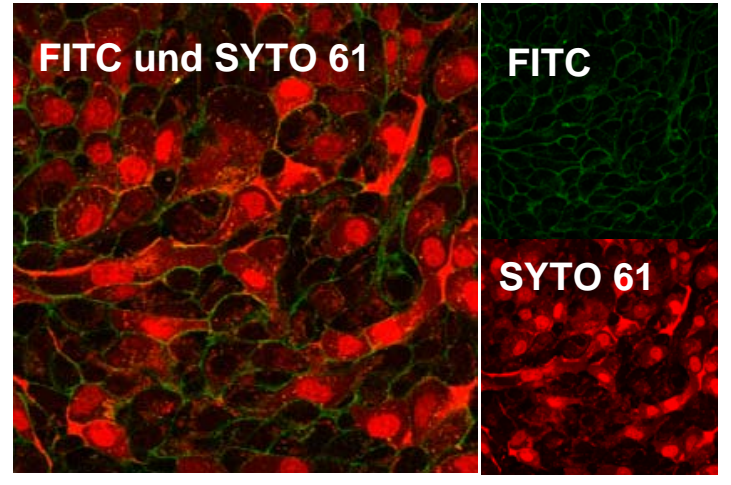

Abb. 23. Bindung des FITC-markierten anti-uPAR- $\beta$-D-Galactosidase-Konjugates (grün) an die Zellmembranen von MDA-MB-231-Zellen in vitro. Die DNA der Zellkerne und die RNA im Zytosol wurden mit Syto 61 (rot) angefärbt.

Optical Imaging ist eine auf Lichtemission beruhende Methode der molekularen Bildgebung und dient der Detektion von Verbindungen oder Reaktionen in vitalen Zellen, Geweben oder Organismen. ${ }^{152,153}$ Optical Imaging ist hervorragend dazu geeignet, Vorgänge in lebenden Organismen zu studieren und komplexe Mechanismen wie die Cancerogenese in vivo aufzuklären. ${ }^{154}$ Zudem kann es zur Optimierung neuer Therapiekonzepte in der präklinischen und klinischen Forschung eingesetzt werden und zu einem Einsparen von Versuchstieren beitragen.

Im Fluorescence Optical Imaging werden Fluoreszenzfarbstoffe wie Derivate des Cy5.5 (42, Abb. 24) durch eine externe Lichtquelle angeregt und die Fluoreszenzemission der angeregten Moleküle wird gemessen. Hierbei werden meist Farbstoffe mit einer Absorptions- und Emissionswellenlänge im roten bzw. infraroten Bereich (650-900 nm) verwendet, da Licht dieser Wellenlänge eine wesentlich bessere Gewebepenetration aufweist als kurzwelligere Strahlung und die Autofluoreszenz der untersuchten Gewebe in diesem Wellenlängenbereich niedriger ist. ${ }^{155}$

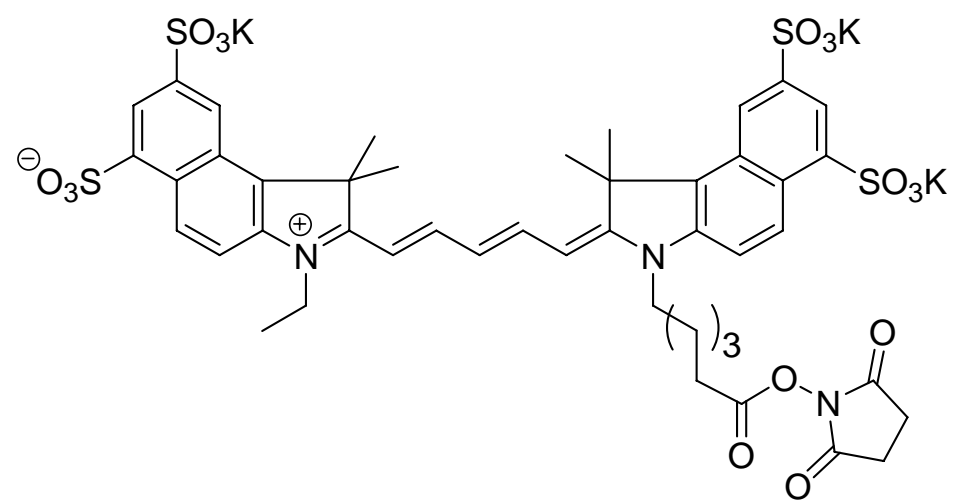

Cy5.5 (42)

Absorption: $\lambda_{\max }=675 \mathrm{~nm}$

Emission: $\quad \lambda_{\max }=694 \mathrm{~nm}$

Abb. 24. Der Fluoreszenzfarbstoff Cy5.5 (42) für Anwendungen im Optical Imaging. 
Im Bioluminescence Imaging wird stattdessen die Lumineszenz gemessen, die bei der enzymatischen Aktivierung eines speziellen Luziferin-Substrates erzeugt wird. Die Aktivierung geschieht mittels eines lichtgenerierenden Enzyms (Luziferase), dessen Gen in das Zielgewebe transfiziert werden muss. Diese Methode zeichnet sich durch eine sehr hohe Spezifität aus, da meist nur ein sehr schwaches Hintergrundsignal zu verzeichnen ist. Im Vergleich zur Fluoreszenz ist die Intensität jedoch niedriger, was durch eine längere Messzeit ausgeglichen werden muss.

Eine Konjugation der Farbstoffe mit kleinen Molekülen, Antikörpern oder AntikörperEnzym-Konjugaten ermöglicht es, die Wirkweise der Komponenten eines ADEPTKonzeptes wie des Antikörper-Enzym-Konjugates und des Prodrugs in vivo zu untersuchen und so ein optimales Therapieschema zu entwickeln. So konnten $F$. Alves et al. nach erfolgversprechenden In-vitro-Untersuchungen (vide supra) die Bindung Cy5.5-markierter Antikörper-Enzym-Konjugate mittels Optical Imaging an einem eXplore Optix System auch in vivo untersuchen (Abb. 25). ${ }^{151}$ Hierbei wurden nach der Applikation des Konjugates (Abb. 25, B-J) starke spezifische Fluoreszenzsignale ausschließlich im Tumorbereich (rechte Brustdrüse) gemessen. In anderen Bereichen messbare Fluoreszenz (Darmbereich, nativer Scan (A)) konnte anhand der unterschiedlichen Fluoreszenzlebensdauer eindeutig als unspezifische Hintergrundfluoreszenz klassifiziert werden. Die Messungen zeigen deutlich, dass die Bindung des Konjugates nach 3-7 Tagen maximal ist und bis zum 11. Tag wieder abnimmt. Hieraus ergibt sich, dass das Prodrug in einem Zeitraum von 7 Tagen nach der Applikation des Antikörper-Enzym-Konjugates verabreicht werden sollte.
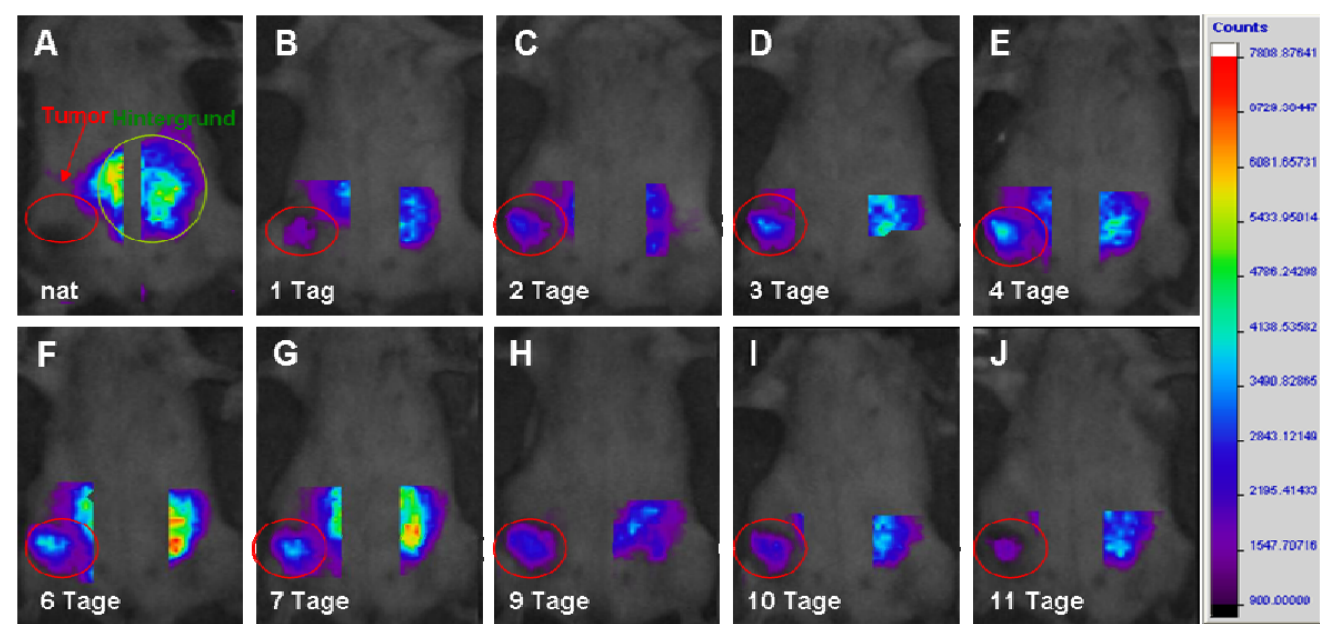

Abb. 25. Zeitabhängige Bindung des Cy5.5-markierten anti-uPAR- $\beta$-D-GalactosidaseKonjugates an MDA-MB-231-Tumorzellen in SCID-Mäusen. A: nativer Scan vor der Verabreichung des Cy5.5-markierten anti-uPAR- $\beta$-D-Galactosidase-Konjugates, B-J: Scans zu den angegebenen Zeitpunkten nach Applikation des anti-uPAR- $\beta$-D-Galactosidase-Konjugates. 


\section{Aufgabenstellung}

\section{Stand der Forschung zu Beginn der Arbeit}

Die Behandlung maligner Tumoren mit den derzeit zur Verfügung stehenden Chemotherapeutika ist im Allgemeinen mit starken Nebenwirkungen verbunden. Diese sind darauf zurückzuführen, dass klassische Chemotherapeutika nicht selektiv Tumorzellen erkennen und abtöten, sondern dass sie von allen Zellen mit hoher Proliferationsrate aufgenommen werden und in diesen Zellen ihre zytotoxische Wirkung entfalten. Es wurden daher neue Konzepte entwickelt, die genotypische und phänotypische Eigenschaften von Tumorzellen ausnutzen, um eine gezielte Bekämpfung der Krebszellen zu ermöglichen ohne die Normalzellpopulation zu beeinträchtigen.

Ein vielversprechender Ansatz zur selektiven Krebstherapie ist die Antibody-directed Enzyme Prodrug Therapie (ADEPT), bei der in therapeutischen Dosen untoxische Verbindungen (Prodrugs) gezielt im Tumorgewebe enzymatisch in hochtoxische Wirkstoffe (Drugs) umgewandelt werden. ${ }^{54}$ Die selektive Giftung der Prodrugs im Tumorgewebe erfolgt durch Enzyme, die kovalent an einen monoklonalen Antikörper gekoppelt sind, der selektiv an tumor-assoziierte Antigene bindet. Therapeutisch erfolgt die Applikation der Prodrugs mit ausreichendem zeitlichem Abstand nach der Applikation der entsprechenden Antikörper-Enzym-Konjugate, um eine Aktivierung der Prodrugs im Blut zu vermeiden.

Ein Ziel bei der Entwicklung neuer Wirkstoffe für den Einsatz in einer ADEPTherapie ist ein möglichst hoher Zytotoxizitätsunterschied zwischen den Prodrugs und den aus ihnen enzymatisch freigesetzten Drugs, d.h. ein hoher $Q I C_{50}$-Wert, sowie eine hohe Zytotoxizität der entstehenden zytotoxischen Wirkstoffe.

Mit den in den letzten Jahren im Arbeitskreis L. F. Tietze synthetisierten anti-Methylseco-CBI-Verbindungen $(+)-(1 S, 10 R)-33 a-e$ und $(+)-(1 S, 10 R)-34 a-e$ (Abb. 26) konnten hohe Zytotoxizitätsunterschiede von bis zu 4800 zwischen den Prodrugs und den aus ihnen gebildeten seco-Drugs bzw. Drugs erzielt werden. ${ }^{69,156}$ Die Zytotoxizität der Drugs war allerdings weit geringer als diejenige der zugrunde liegenden Naturstoffe.

Erste Untersuchungen zum Wirkmechanismus ergaben, dass das aus dem seco-Drug $(+)-(1 S, 10 R)-34 \mathbf{a}$ in situ enstehende Drug 43a sehr effizient und selektiv ein doppelsträngiges synthetisches DNA-Oligonukleotid alkyliert. ${ }^{157}$ Der Wirkmechanismus in Zellen sowie die Wechselwirkung anderer Analoga mit DNA wurden bisher nicht 
untersucht. Es wurde allerdings vermutet, dass die unterschiedliche Reaktivität gegenüber DNA für die beobachteten Zytotoxizitätsunterschiede verantwortlich sein könnte. Zur In-vitro-Untersuchung des Wirkmechanismus der Verbindungen war ein FITCmarkiertes Derivat des Prodrugs $(+)-(1 S, 10 R)-33$ a synthetisiert worden. ${ }^{141 \mathrm{f}}$

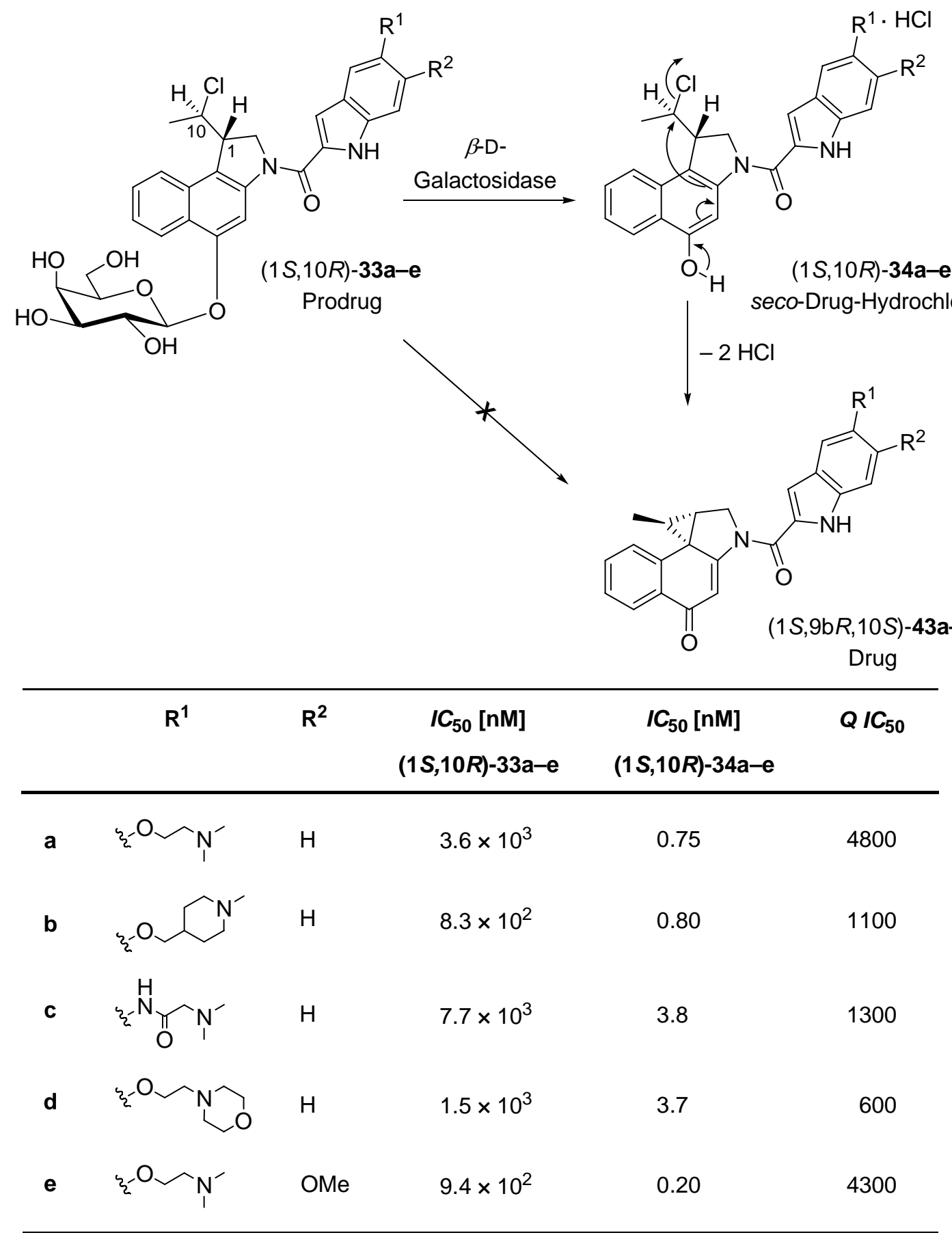

Abb. 26. Anti-Methyl-seco-CBI-Verbindungen $(+)-(1 S, 10 R)-33 \mathbf{a}-\mathbf{e}$ und $(+)-(1 S, 10 R)-34 \mathbf{a}-\mathbf{e}$, ihre In-vitro-Zytotoxizitäten ( $I C_{50}$-Werte) und die $Q I C_{50}$-Werte der Prodrugs. Die Prodrugs werden enzymatisch zu den entsprechenden seco-Drugs umgewandelt, welche unter $\mathrm{HCl}$ Abspaltung zu den reaktiven Drugs $(1 S, 9 \mathrm{~b} R, 10 S)-\mathbf{4 3 a}-\mathbf{e}$ weiterreagieren. 


\section{Zielsetzung der Arbeit}

Ziel der vorliegenden Arbeit war die Synthese neuer Duocarmycin-analoger enantiomerenreiner seco-Drugs mit hoher Zytotoxizität und der entsprechenden weniger zytotoxischen diastereomerenreinen Produgs für einen Einsatz im Rahmen des ADEPTKonzeptes. Des Weiteren sollte die Wechselwirkung der Verbindungen mit Oligonukleotiden und anderen in Frage kommenden zellulären Zielstrukturen im Hinblick auf eine Rationalisierung der Zytotoxizitätsunterschiede unterschiedlicher Vertreter dieser Verbindungsklasse untersucht werden. Weitere Zielsetzungen waren die Bestimmung der In-vitro-Zytotoxizität der neuen Wirkstoffe und die Aufklärung des Wirkmechanismus der Derivate und ihrer fluoreszenzmarkierten Analoga in vitro.

Zunächst sollten von dem anti-Methyl-seco-CBI-DMAI-Derivat (+)-(1S,10R)-34a größere Mengen für In-vivo- und In-vitro-Studien hergestellt werden. ${ }^{141 f, 157} \mathrm{Zu}$ Vergleichszwecken war dann ein Analogon mit einer $N, N, N$-Trimethylamino- anstelle einer $N, N$-Dimethylamino-ethoxyindol (DMAI)-Seitenkette ${ }^{158}$ zu synthetisieren.

Aufbauend auf Arbeiten von F. Major ${ }^{141 \mathrm{f}}$ und J. M. von Hof $^{159}$ war die Synthese neuer enantiomerenreiner seco-Drugs und eines diastereomerenreinen Prodrugs mit einem seco-CBI-Grundgerüst und dem bereits in 33a und 34a verwendeten DMAI-DNABinder geplant. Erwartet wurde eine hohe Zytotoxizität der neuen seco-Drugs sowie ein hoher $Q I C_{50}$-Wert des Prodrugs. Weiterhin sollten ein (1S)-seco-CBI-Derivat mit dem aus 34b bekannten Methylpiperidinylmethoxyindol (MPI)-DNA-Binder und ein dechloriertes (1S)-Methyl-seco-CBI-DMAI-Analogon hergestellt werden.

Zum Verständnis der Struktur-Wirkungs-Beziehungen und des Wirkmechanismus war weiterhin ein Vergleich der Reaktivität und Zytotoxizität der neuen Verbindungen mit denjenigen bekannter Analoga geplant. Mit ausgewählten Verbindungen sollte dann die Wechselwirkung mit synthetischen Analoga möglicher zellulärer Zielstrukturen wie DNA, RNA und kleinen Peptiden untersucht werden. Die zelluläre Aufnahme und Wirkweise der Verbindungen war abschließend mit einer neu zu entwickelnden Methode an lebenden Zellen zu untersuchen.

Es war weiterhin geplant, zum besseren Verständnis des Wirkmechanismus der Verbindungen ein fluoreszenzmarkiertes Prodrug und ein fluroeszenzmarkiertes secoDrug mit einem anti-Methyl-seco-CBI-DMAI-Grundkörper zu synthetisieren und die zelluläre Aufnahme dieser Verbindungen in vitro mittels Fluoreszenzmikroskopie zu untersuchen. 
Aus diesen Überlegungen ergaben sich die folgenden Teilaufgaben:

- Synthese des enantiomerenreinen anti-Methyl-seco-CBI-DMAI-Derivates

- Synthese des enantiomerenreinen dechlorierten anti-Methyl-seco-CBI-DMAIAnalogons als Referenzsubstanz für die analytischen Untersuchungen

- Synthese neuer enantiomeren- bzw. diastereomerenreiner seco-CBI-Derivate mit DMAI- und MPI-Seitenkette

- Synthese neuer fluoreszenzmarkierter anti-Methyl-seco-CBI-Verbindungen

- Untersuchung der Wechselwirkung verschiedener Prodrugs und seco-Drugs mit einzel- und doppelsträngiger DNA, RNA und Peptiden

- In-vitro-Untersuchung der Zytotoxizität der neuen Verbindungen an verschiedenen Krebszelllinien

- In-vitro-Untersuchung des Wirkmechanismus verschiedener seco-Drugs an lebenden Zellen

- In-vitro-Untersuchung des Wirkmechanismus fluoreszenzmarkierter Analoga an lebenden Zellen

\section{Planung der Arbeit}

\subsection{Synthese neuer Duocarmycin-Analoga}

Die Synthese der anti-Methyl-seco-CBI-Derivate sollte aufbauend auf bekannten Synthesestrategien unter Nutzung bereits vorhandener Bausteine sowie unter Einbeziehung einer Enantiomeren-Trennung erfolgen (Abb. 27). ${ }^{141 f, 157}$

So war zur Synthese des Benzylethers (1S,10R)-47 geplant, eine $N$-Boc-Entschützung und eine Kupplung des freien sekundären Amins von $(1 S, 10 R)-\mathbf{4 4}$ mit dem Indolcarbonsäure-Hydrochlorid 46a durchzuführen. Die Synthese des dechlorierten Derivates (1S)-48 sollte analog nach einer vorhergehenden Dehalogenierung von $(1 S, 10 R)-\mathbf{4 4}$ zu (1S)-45 erfolgen. Eine Debenzylierung der Zwischenprodukte (1S,10R)-47 bzw. (1S)-48 würde dann die Zielverbindungen $(1 S, 10 R)-34 a$ bzw. (1S)-49 liefern. Im Fall der Synthese des seco-Drugs (1S,10R)-50 mit einer $N, N, N$ Trimethylamino-Funktionalität ginge der Benzyl-Entschützung eine selektive $N$-Methylierung der DMAI-Seitenkette in $(1 S, 10 R)-47$ voraus. 


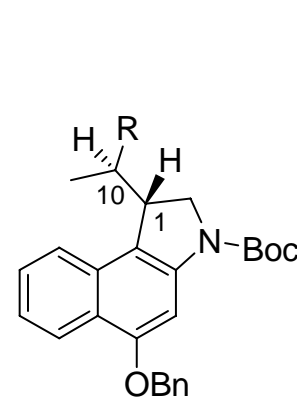<smiles>CN(C)CCOc1ccc2[nH]c(C(=O)O)cc2c1</smiles>

1. N-Boc-Entschützung

2. Kupplung mit $46 \mathbf{a}$<smiles>[R]CCOc1ccc2[nH]c(C(=O)N3C[C@@H](C([R])C)c4c3cc([R3])c3ccccc43)cc2c1</smiles>

(1S,10R)-44: $\mathrm{R}=\mathrm{Cl}$ (1S)-45:<smiles></smiles>

Dehalogenierung

Benzyl-Entschützung
$(1 S, 10 R)-47: R^{1}=\mathrm{Cl}, \mathrm{R}^{2}=\mathrm{NMe}_{2}, \mathrm{R}^{3}=\mathrm{Bn}$

(1S)-48: $\quad R^{1}=H, R^{2}=N^{2} e_{2}, R^{3}=B n$

(1S,10R)-34a: $\mathrm{R}^{1}=\mathrm{Cl}, \mathrm{R}^{2}=\mathrm{NMe}_{2} \cdot \mathrm{HCl}, \mathrm{R}^{3}=\mathrm{H}$

(1S)-49: $\quad R^{1}=H, R^{2}=N_{2 M e}, R^{3}=H$

1. N-Methylierung

2. Benzyl-Entschützung

Abb. 27. Geplante Synthese der anti-Methyl-seco-CBI-Verbindungen (1S,10R)-34a, (1S)-49 und $(1 S, 10 R)-\mathbf{5 0}$.

Die Synthese des fluoreszenzmarkierten anti-Methyl-seco-CBI-DMAI-Prodrugs 52 sollte ausgehend von dem bekannten Intermediat 51 ${ }^{141 \mathrm{f}}$ durch Kupplung mit einem Fluoreszenzfarbstoff erfolgen (Abb. 28). Es war hierbei darauf zu achten, einen kleinen und unpolaren Fluorophor mit einer hohen Fluoreszenzquantenausbeute auszuwählen, um die Membranpenetration der Verbindungen nicht zu behindern und gute Signalintensitäten zu erreichen. Zur Vermeidung einer Fluoreszenzlöschung war eine aliphatische Abstandseinheit zwischen dem Pharmakophor und dem Fluorophor einzufügen. Aus dem fluoreszenzmarkierten Prodrug 52 sollte dann durch Abspaltung des Zuckers das entsprechende fluoreszenzmarkierte seco-Drug $\mathbf{5 3}$ gewonnen werden.

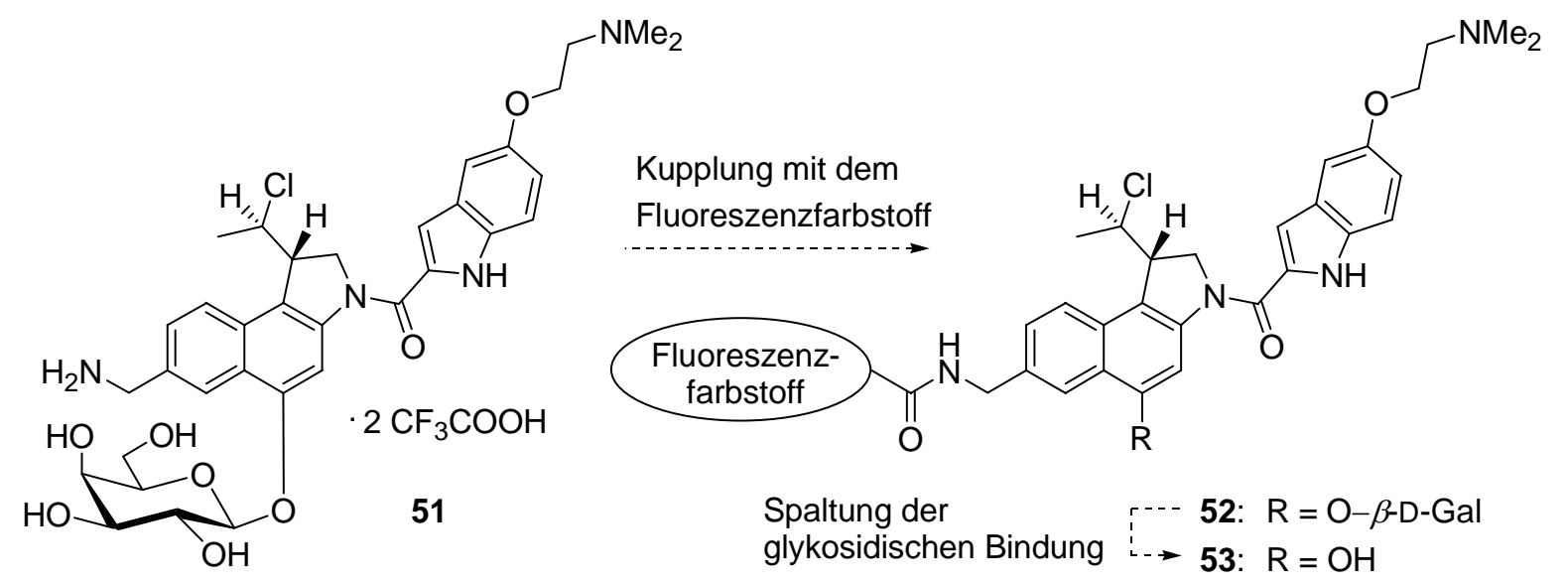

Abb. 28. Synthese der fluoreszenzmarkierten anti-Methyl-seco-CBI-Derivate $\mathbf{5 2}$ und $\mathbf{5 3}$. 
Die retrosynthetische Analyse der neuen (1S)-seco-CBI-Verbindungen mit DMAIbzw. MPI-DNA-bindender Komponente ist in Abb. 29 dargestellt. Es war geplant, das seco-CBI-DMAI-Prodrug (1S)-54a ausgehend von rac-57 zu synthetisieren. Einer Benzylentschützung des bekannten Bausteins rac-57 sollte hierbei eine Trennung der Enantiomere von rac-55 mittels präparativer HPLC an chiraler stationärer Phase folgen. Das enantiomerenreine Intermediat (1S)-55 sollte dann nach der Trichloracetimidat-Methode von R. R. Schmidt ${ }^{160}$ glykosidiert werden und nach der Entschützung des sekundären Amins mit der DNA-bindenen Indoleinheit 46a gekuppelt werden. Abschließend war eine Entschützung der Zuckereinheit vorgesehen.

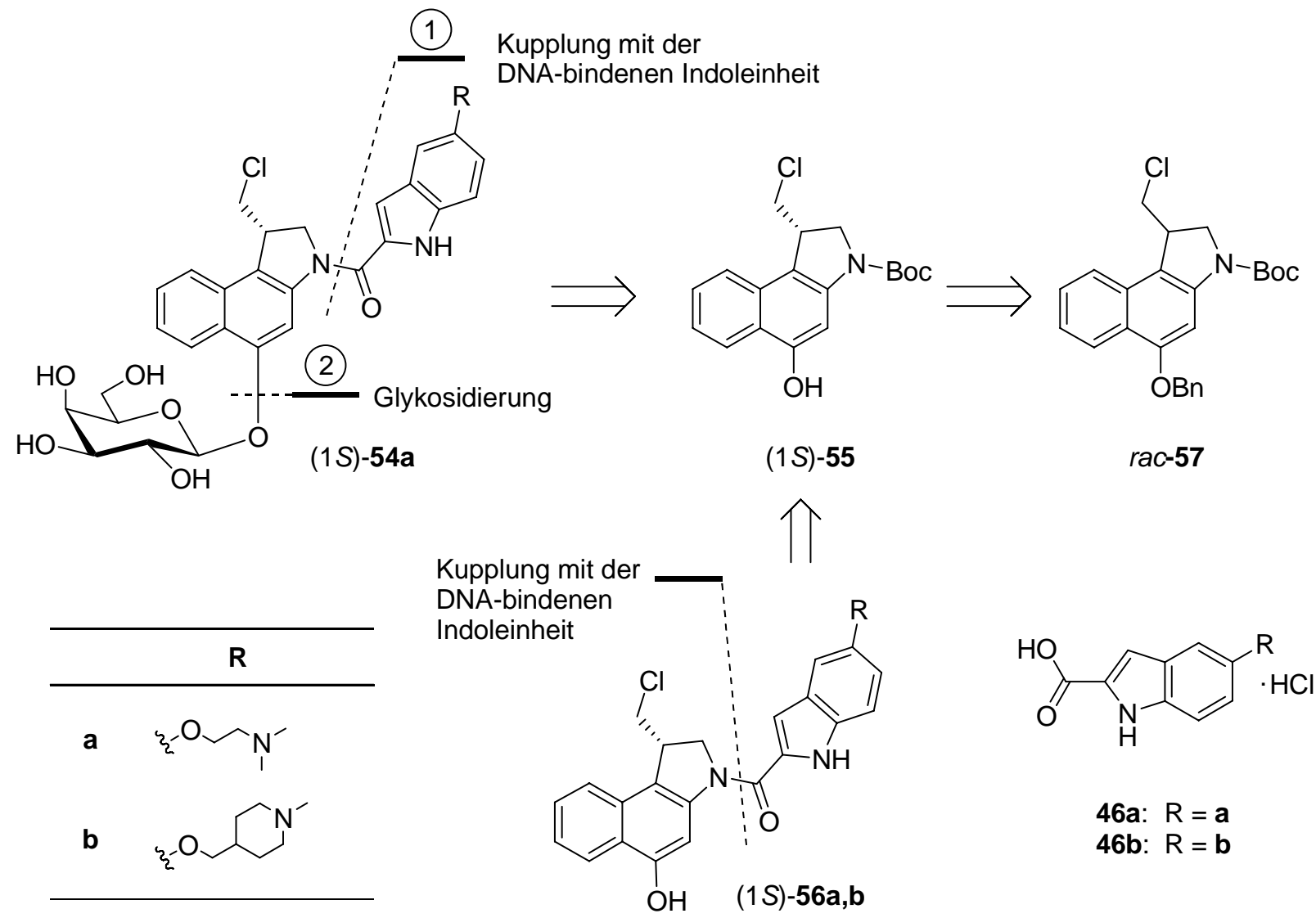

Abb. 29. Retrosynthetische Analyse der seco-CBI-Verbindungen mit DMAI-DNA-bindender Seitenkette (54a und 56a) sowie MPI-DNA-bindender Seitenkette (56b).

Die seco-Drug-Hydrochloride (1S)-56a,b und das unnatürliche Enantiomer (1R)-56a waren abweichend $\mathrm{zu}$ der sonst üblichen Synthesestrategie nicht ausgehend vom enantiomerenreinen Boc-geschützten Benzylether 57, sondern vom entsprechenden freien Phenol 55 durch direkte Kupplung mit der jeweiligen DNA-bindenen Indoleinheit darzustellen, da $\mathbf{5 5}$ im Gegensatz zu 57 mittels präparativer HPLC an chiraler stionärer Phase (Chiralpak ${ }^{\circledR}$ IA) enantiomerenrein erhalten werden kann. 


\subsection{Untersuchung der Wechselwirkung verschiedener Duocarmycin- Analoga mit DNA, RNA und Peptiden}

Auf der Basis der mit dem seco-Drug-Hydrochlorid (+)-(1S,10R)-34a und dem doppelsträngigen DNA-Oligonukleotid ds-60 (Abb. 30) bereits durchgeführten ESI-HRMSUntersuchungen zur Alkylierungseffizienz und Sequenzselektivität ${ }^{157}$ sollten umfangreichere Studien der Umsetzung einer Reihe anderer Wirkstoffe mit verschiedenen Analoga zellulärer Zielstrukturen erfolgen. Hierzu waren zehn unterschiedliche synthetische doppelsträngige DNA-Oligonukleotide, ein einzelsträngiges DNA-Oligonukleotid, ein doppelsträngiges RNA-Oligonukleotid und ein Peptid auszuwählen. Die Untersuchungen waren mit Hilfe von hochauflösender Massenspektrometrie, Chromatographie und CD-Spektroskopie durchzuführen.

Als Peptid wurde das Tripeptid Glutathion (58, Abb. 30) ausgewählt, da dessen Reaktion mit Wirkstoffen oft für deren Inaktivierung in Zellen verantwortlich gemacht wird. ${ }^{161}$ Glutathion (58) verfügt über eine nukleophile Thiol- und Aminofunktionalität.<smiles>NC(CCC(=O)NC(CS)C(=O)NCC(=O)O)C(=O)O</smiles>

58 $\left.\begin{array}{ll}\text { 5'-CGG UCA AUU AGU CGG-3' (ON-1) } \\ \text { 3'-GCC AGU UAA UCA GCC-5' (ON-2) }\end{array}\right\}$ ds-59

$$
\begin{aligned}
& \left.\begin{array}{ll}
\text { 5'-CGG CAA TTA TTG CCG-3' } & (\mathrm{ON}-1) \\
\text { 3'-GCC GTT AAT AAC GGC-5' } & (\mathrm{ON}-2)
\end{array}\right\} \text { ds-65 } \\
& \left.\begin{array}{ll}
\text { 5'-CCG GCT ATT AGG CCG-3' } & (\mathrm{ON}-1) \\
\text { 3'-GGC CGA TAA TCC GGC-5' } & (\mathrm{ON}-2)
\end{array}\right\} \text { ds-66 } \\
& \left.\begin{array}{l}
\text { 5'-CCA TAA AGC TTT TTG C-3' (ON-1) } \\
\text { 3'-GGT ATT TCG AAA AAC G-5' (ON-2) }
\end{array}\right\} \text { ds-67 } \\
& \left.\begin{array}{ll}
\text { 5'-CGG CTT ATA TGA CCG-3' } & \text { (ON-1) } \\
\text { 3'-GCC GAA TAT ACT GGC-5' } & (\mathrm{ON}-2)
\end{array}\right\} \text { ds-68 } \\
& \left.\begin{array}{ll}
\text { 5'-TGG CTG CGA GCA CCT-3' } & (\mathrm{ON}-1) \\
\text { 3'-ACC GAC GCT CGT GGA-5' } & (\mathrm{ON}-2)
\end{array}\right\} \text { ds-69 }
\end{aligned}
$$

Abb. 30. Das Tripeptid Glutathion (58), das doppelsträngige RNA-Oligonukleotid ds-59 und die doppelsträngigen DNA-Oligonukleotide ds-60 - ds-69. Das Präfix „„ds-“ dient zur Kennzeichnung doppelsträngiger DNA- oder RNA-Oligonukleotide. Zur Bezeichnung der entsprechenden einzelsträngen Oligonukleotide dienen die Abkürzungen ON-1 (Oligonukleotid geringerer Molmasse) bzw. ON-2 (Oligonukleotid höherer Molmasse). 
Die DNA- und RNA-Oligomere sollten eine Mindestlänge von 15 Basen bzw. Basenpaaren aufweisen und über mindestens sechs GC-Paare verfügen, um eine ausreichende Stabilität des Doppelstranges in Lösung zu gewährleisten. Des Weiteren war die Basenfolge so zu variieren, dass eine Aussage über die Sequenzselektivität der Alkylierung durch die getesteten Duocarmycin-Analoga möglich sein sollte. Nach den genannten Kriterien wurden das doppelsträngige RNA-Oligonukleotid ds-59 sowie die doppelsträngigen DNA-Oligonukleotide ds-60-ds-69 (Abb. 30) ausgewählt. Die DNA-Doppelstränge ds-60 - ds-68 verfügen im Gegensatz zu ds-69 über eine ATreiche Region von mindestens vier Basenpaaren und die Basenfolge der ausgewählten RNA (ds-59) entspricht nahezu der Sequenz des DNA-Doppelstranges ds-60. Es erfolgte lediglich der Austausch einer Base am Ende der Sequenz und der für einen Wechsel von DNA auf RNA typischen Austausch der Nukleobase Thymin gegen Uracil. Als einzelsträngiges DNA-Oligonukleotid sollte der reaktivere Einzelstrang ON-1 (ds-60) des Oligonukleotides ds-60 dienen.

\subsection{In-vitro-Untersuchungen des Wirkmechanismus an lebenden Zellen}

Die Untersuchung des Wirkmechanismus der fluoreszenzmarkierten Analoga sollte mittels konfokaler Laser-Scanning-Mikroskopie an lebenden Zellen erfolgen und die Messungen in Zusammenarbeit mit Dr. Mišo Mitkovski am Max-Planck-Institut für experimentelle Medizin durchgeführt werden. Für die Studien der analogen nichtmarkierten Verbindungen an lebenden Zellen war geplant, eine neue Methode zu entwickeln.

Insgesamt sollten die In-vitro-Untersuchungen Aufschluss über die zelluläre Aufnahme und den intrazellulären Wirkort der Verbindungen geben und so zur Rationalisierung der Zytotoxizität der Wirkstoffe beitragen. 


\section{DARSTELLUNG DER ERGEBNISSE}

\section{Synthese der anti-Methyl-seco-CBI-Derivate}

\subsection{Synthese des anti-Methyl-seco-CBI-Hydrochlorids $(1 S, 10 R)-34$ a mit einer $N, N$-Dimethylaminoethoxyindol (DMAI)-Seitenkette}

Zur Synthese des enantiomerenreinen seco-Drugs war eine präparative HPLC des Vorläufers rac-44 an chiraler stationärer Phase notwendig, da sich klassische Methoden der Racematspaltung wie Salzbildung oder Derivatisierung mit enantiomerenreinen Reagenzien aufgrund der Emfindlichkeit des entsprechenden freien Amins von 44 als nicht erfolgreich erwiesen hatten. ${ }^{162}$ Die Nutzung einer präparativen Säule des Typs Chiralpak ${ }^{\circledR}$ IA erlaubte hierbei eine effiziente Trennung von je $50 \mathrm{mg}$ $(0.11 \mathrm{mmol})$ des racemischen Benzylethers rac-44 pro Injektion in weniger als zehn Minuten $(\alpha($ Quotient der Retentionszeiten $)=2.05)$. Die entsprechenden Enantiomere $(+)-(1 S, 10 R)-\mathbf{4 4}$ und $(-)-(1 R, 10 S)-\mathbf{4 4}$ (Abb. 31) wurden so in $99.9 \%$ ee erhalten.

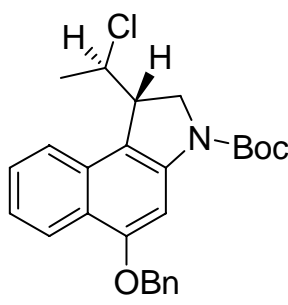

rac-44

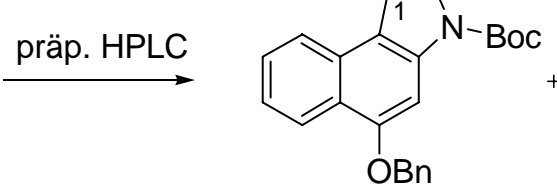

$(+)-(1 S, 10 R)-44$

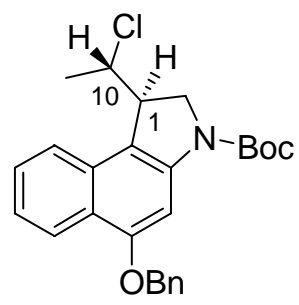

$(-)-(1 R, 10 S)-44$

Abb. 31. Trennung der Enantiomere von rac-44.

Im nächsten Schritt erfolgte die Einführung der $N, N$-Dimethylaminoethoxyindol (DMAI)-Seitenkette. ${ }^{141 f, 157}$ Hierzu wurde in einem ersten Schritt die säurelabile tertButyloxycarbonyl-Gruppe (Boc) in $\mathbf{4 4}$ mit $4 \mathrm{M} \mathrm{HCl}$ in Essigester abgespalten und danach eine Kupplung mit DMAI- $\mathrm{CO}_{2} \mathrm{H} \cdot \mathrm{HCl}$ (46a) unter Aktivierung der Carbonsäure mit dem aus der Peptidchemie bekannten wasserlöslichen Carbodiimid-Derivat $\mathrm{EDC} \cdot \mathrm{HCl}^{163}$ durchgeführt (Abb. 32). Zur abschließenden Abspaltung der Benzylschutzgruppe in $(+)-(1 S, 10 R)-47$ wurde das Kupplungsprodukt zunächst mit $4 \mathrm{M} \mathrm{HCl}$ in Essigester in das entsprechende Hydrochlorid überführt und anschließend durch katalytische Transferhydrierung mit Palladium auf Aktivkohle und Ammoniumformiat als Wasserstoffquelle ${ }^{164}$ debenzyliert. Das enantiomerenreine seco-Drug-Hydrochlorid $(+)-(1 S, 10 R)-34 a$ wurde so in einer Gesamtausbeute von $68 \%$ über drei Stufen erhalten. 


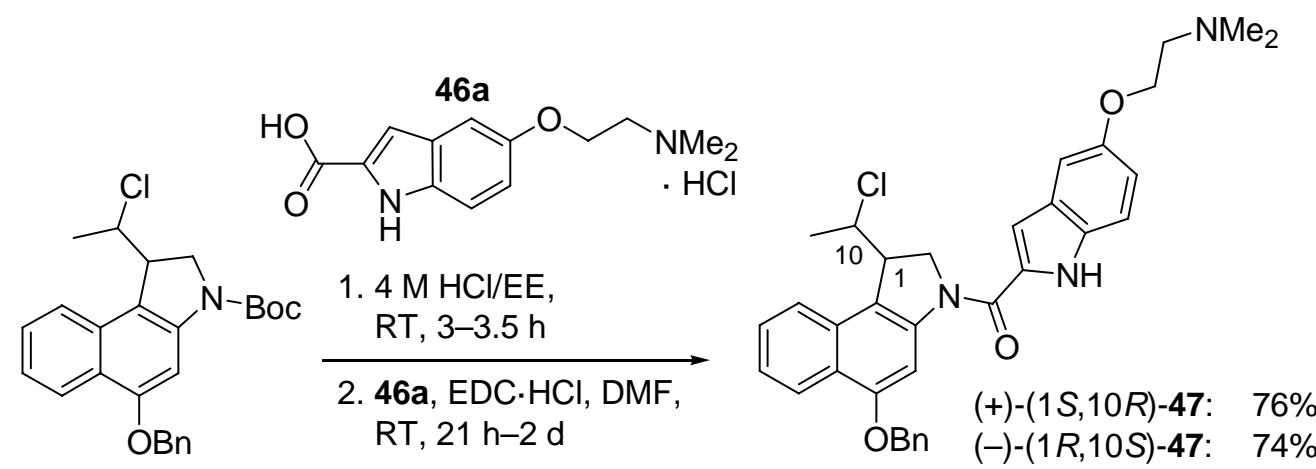

(+)-(1S,10R)-44

$(-)-(1 R, 10 S)-44$

1. $4 \mathrm{M} \mathrm{HCl} / \mathrm{EE}, \mathrm{RT}, 2 \mathrm{~h}$

2. $\mathrm{Pd} / \mathrm{C}, \mathrm{NH}_{4} \mathrm{HCO}_{2}$ (aq),

$\mathrm{THF}, 40^{\circ} \mathrm{C}, 2 \mathrm{~h}$

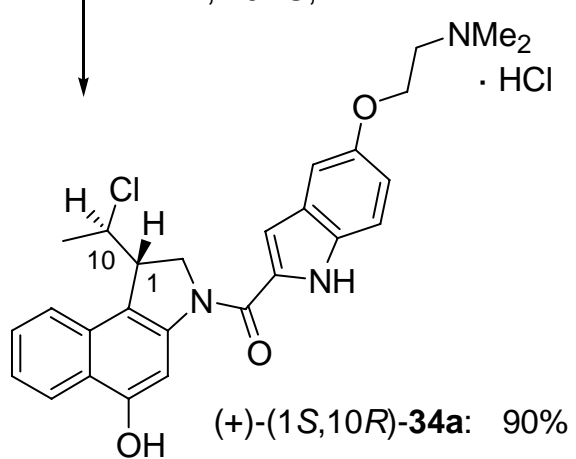

Abb. 32. Kupplung mit der DMAI-Seitenkette und Debenzylierung zu (+)-(1S,10R)-34a.

\subsection{Versuche zur Synthese des anti-Methyl-seco-CBI-Derivates 50 mit einer $N, N, N$-Trimethylammoniumethoxyindol (TMAI)-Seitenkette}

Die Synthese der enantiomerenreinen seco-Drugs mit einer TrimethylammoniumiodidFunktionalität in der Seitenkette sollte ausgehend von den entsprechenden Benzylethern 47 oder den seco-Drugs 34a durch selektive Methylierung der DimethylaminoGruppe und eine eventuell anschließende Debenzylierung erfolgen (Abb.33). Auf diese Weise sollten zu erwartende Probleme bei der Aufreinigung der entstehenden quartären Ammoniumsalze auf die letzten Syntheseschritte beschränkt werden.

Nach dem ersten Ansatz erfolgte eine selektive Methylierung der DimethylaminoGruppe der Seitenkette in 47 durch Methyliodid unter Erhitzen auf $60-100{ }^{\circ} \mathrm{C}$ im Mikrowellenreaktor gefolgt vom Quenchen des überschüssigen Methyliodides mit Methanol (Abb. 33). Bei Verwendung eines dreifachen Überschusses an Methyliodid wurden $(+)-(1 S, 10 R)-70$ und $(1 R, 10 S)-70$ in einer sehr guten Ausbeute von 94\% erhalten. 

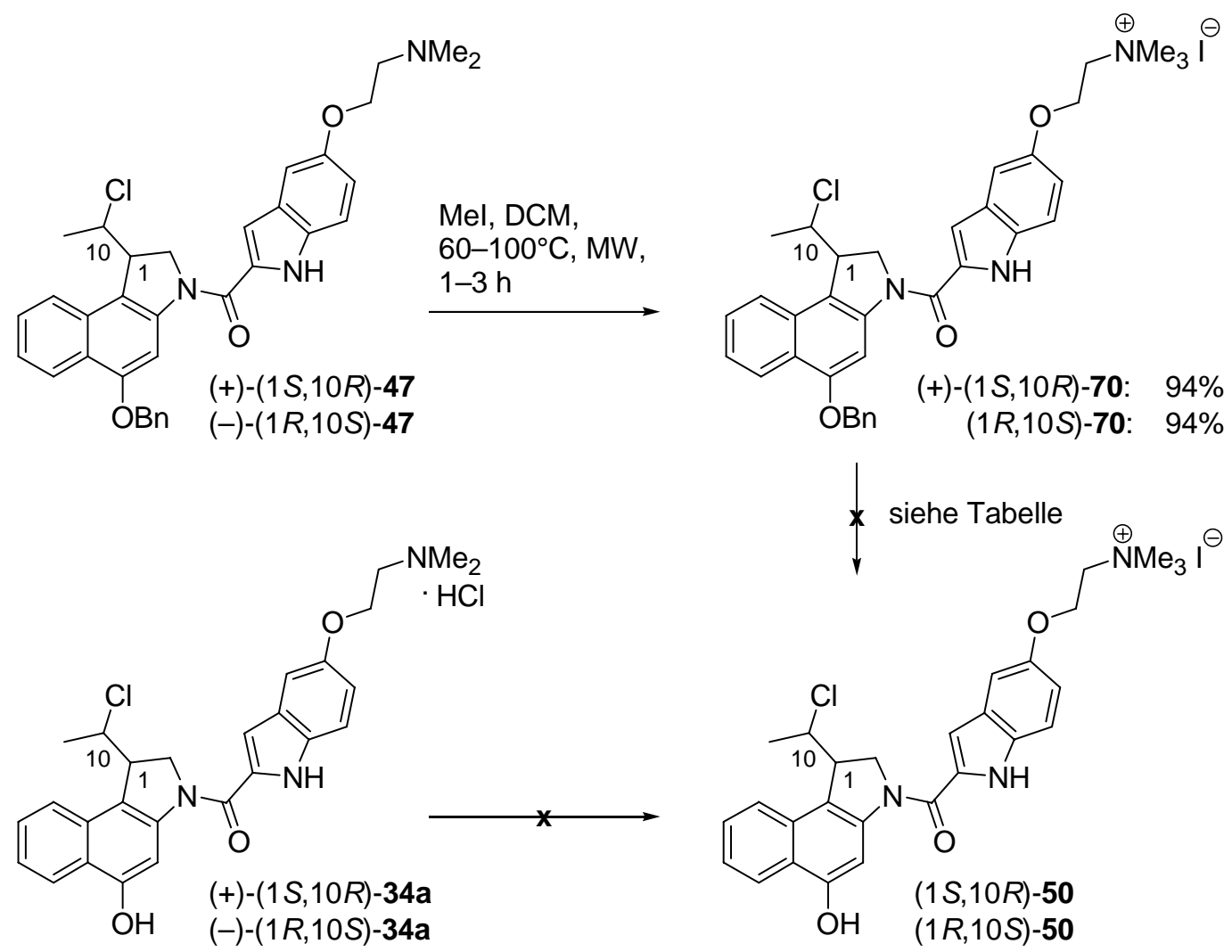

Abb. 33. Versuche zur Synthese des TMAI-seco-Drugs (1S,10R)-50.

\begin{tabular}{|c|c|c|}
\hline Nr. & Bedingungen & Ergebnis \\
\hline 1 & $\mathrm{H}_{2}, \mathrm{Pd} / \mathrm{C}(0.2$ Äq.), $\mathrm{MeOH}, 3 \mathrm{~d}$ & Edukt \\
\hline 2 & $\mathrm{H}_{2}, \mathrm{Pd} / \mathrm{C}(0.8$ Äq. $), \mathrm{MeOH}, 28 \mathrm{~h}$ & Edukt \\
\hline 3 & $\mathrm{H}_{2}(28 \mathrm{psi}), \mathrm{Pd} / \mathrm{C}$ (0.5 Äq.), MeOH/THF (2:1), $8 \mathrm{~h}$ & Edukt \\
\hline 4 & $\mathrm{HCOOH}, \mathrm{Pd} / \mathrm{C}(0.4$ Äq.), MeOH, 40 min & Edukt \\
\hline 5 & $\mathrm{HCOOH}, \mathrm{Pd} / \mathrm{C}$ (0.8 Äq.), MeOH, $28 \mathrm{~h}$ & Edukt \\
\hline 6 & $\mathrm{HCOOH}, \mathrm{Pd} / \mathrm{C}$ (1.0 Äq.), $\mathrm{MeOH}, 40^{\circ} \mathrm{C}, 24 \mathrm{~h}$ & Zersetzung \\
\hline 7 & 1,4-Cyclohexadien, $\mathrm{Pd} / \mathrm{C}$ (1.0 Äq.), MeOH, 48 h & Edukt \\
\hline 8 & $\mathrm{NH}_{4} \mathrm{HCO}_{2}, \mathrm{Pd} / \mathrm{C}$ (0.7 Äq.), MeOH, $1 \mathrm{~h}$ & Edukt \\
\hline 9 & $\mathrm{NH}_{4} \mathrm{HCO}_{2}, \mathrm{Pd} / \mathrm{C}(0.7$ Äq.), MeOH/THF (1:1), $6 \mathrm{~h}$ & Edukt \\
\hline 10 & $\mathrm{H}_{2}, \mathrm{NH}_{4} \mathrm{HCO}_{2}, \mathrm{HCOOH}, \mathrm{Pd} / \mathrm{C}(0.7$ Äq. $), \mathrm{MeOH}, 30^{\circ} \mathrm{C}, 24 \mathrm{~h}$ & Edukt \\
\hline
\end{tabular}

Tab. 4. Versuche zur Benzylentschützung der TMAI-Derivate 70. 
Die anschließend notwendige Debenzylierung konnte jedoch durch Verwenden typischer, mit dem Edukt und Produkt verträglicher Transferhydrierungs-Bedingungen nicht erreicht werden (Tab. 4). Eine Erhöhung der Katalysatormenge (Einträge 2, 5 und 6) oder des Wasserstoffpartialdruckes (Eintrag 3) führte ebensowenig zum Erfolg wie die Zugabe von Säure (Einträge 4-6, 8-10), die Nutzung einer anderen Wasserstoffquelle (Einträge 4-6, 7, 8-9, 10) oder eine Variation des Lösungsmittelgemisches. Dies ist vermutlich auf eine Vergiftung des Katalysators durch das Edukt zurückzuführen und konnte bei einer Reihe analoger Benzylether ebenfalls beobachtet werden. ${ }^{141}$

Es wurde daher versucht, die Produkte durch direkte Methylierung der seco-Drugs 34a herzustellen, allerdings erwies sich dies als ebenfalls nicht erfolgreich, da 34a ohne Base nicht methyliert werden konnte und 34a bei Zugabe ausreichender Mengen Base schnell zum entsprechenden Drug 43a zyklisierte und in der Folge ein nicht zu trennendes Produktgemisch entstand. Aufgrund dieser Ergebnisse wurden die Untersuchungen zur Synthese der seco-Drugs 50 mit TMAI-Seitenkette eingestellt.

\subsubsection{Diskussion ausgewählter spektroskopischer Daten der Verbindung $(+)-(1 S, 10 R)-70$}

In Abbildung 34 ist das ${ }^{1} \mathrm{H}-\mathrm{NMR}-$ Spektrum von $(+)-(1 S, 10 R)-70$ mit der entsprechenden Zuordnung dargestellt. Im Hochfeldbereich resonieren die $11-\mathrm{H}_{3}$-Protonen bei $\delta=1.65$ als Dublett mit einer Kopplungskonstante von $J=6.6 \mathrm{~Hz}$. Das charakteristische Singulett bei $\delta=3.22$ kann den drei Methylgruppen der $\mathrm{NMe}_{3}{ }^{+}$Funktionalität zugeordnet werden. Sowohl die im Vergleich zur $\mathrm{NMe}_{2}$-Gruppe des analogen seco-Drugs $(+)-(1 S, 10 R)$-34a $(\delta=2.81)$ zum Tieffeld hin verschobene Resonanz als auch das Auftreten eines Singuletts für 9 Protonen zeigt, dass die Methylierung selektiv an der Dimethylamino-Funktion der Seitenkette stattgefunden hat. Die Methylenprotonen 2"- $\mathrm{H}_{2}$ resonieren ebenfalls leicht tieffeldverschoben im Vergleich zu den analogen Protonen von $(+)-(1 S, 10 R)-34 \mathbf{a}(\delta=3.47)$ bei $\delta=3.83$ als zentriertes Multiplett. Weitere zentrierte Multipletts können bei $\delta=4.25$ für das Proton $1-\mathrm{H}$ sowie bei $\delta=4.49$ für die Methylenprotonen $1 "-\mathrm{H}_{2}$ beobachtet werden. Etwas weiter zu tiefem Feld verschoben resonieren die diastereotopen Protonen 2- $\mathrm{H}_{\mathrm{a}}$ und $2-\mathrm{H}_{\mathrm{b}}$ sowie $10-\mathrm{H}$. $2-\mathrm{H}_{\mathrm{a}}$ resoniert bei $\delta=4.62$ als Dublett vom Dublett mit einer Kopplungskonstante von $J=11.0 \mathrm{~Hz}$ für die geminale Kopplung zu 2- $\mathrm{H}_{\mathrm{b}}$ und einer Kopplungskonstante von $J=2.4 \mathrm{~Hz}$ für die vicinale Kopplung zum Proton 1-H. Die 
geminale Kopplungskonstante von $J=11.0 \mathrm{~Hz}$ findet sich in dem Triplett bei $\delta=4.77$ für $2-\mathrm{H}_{\mathrm{b}}$ wieder. Bei $\delta=4.81$ resoniert $10-\mathrm{H}$ als Dublett vom Quartett mit einer Kopplungskonstante von $J=6.6 \mathrm{~Hz}$ für die Kopplung zu den Methylprotonen und einer Kopplungskonstante von $J=2.4 \mathrm{~Hz}$ für die Kopplung zum Proton 1-H. Die Methylenprotonen der Benzylschutzgruppe resonieren als zentriertes Multiplett bei $\delta=5.31$.

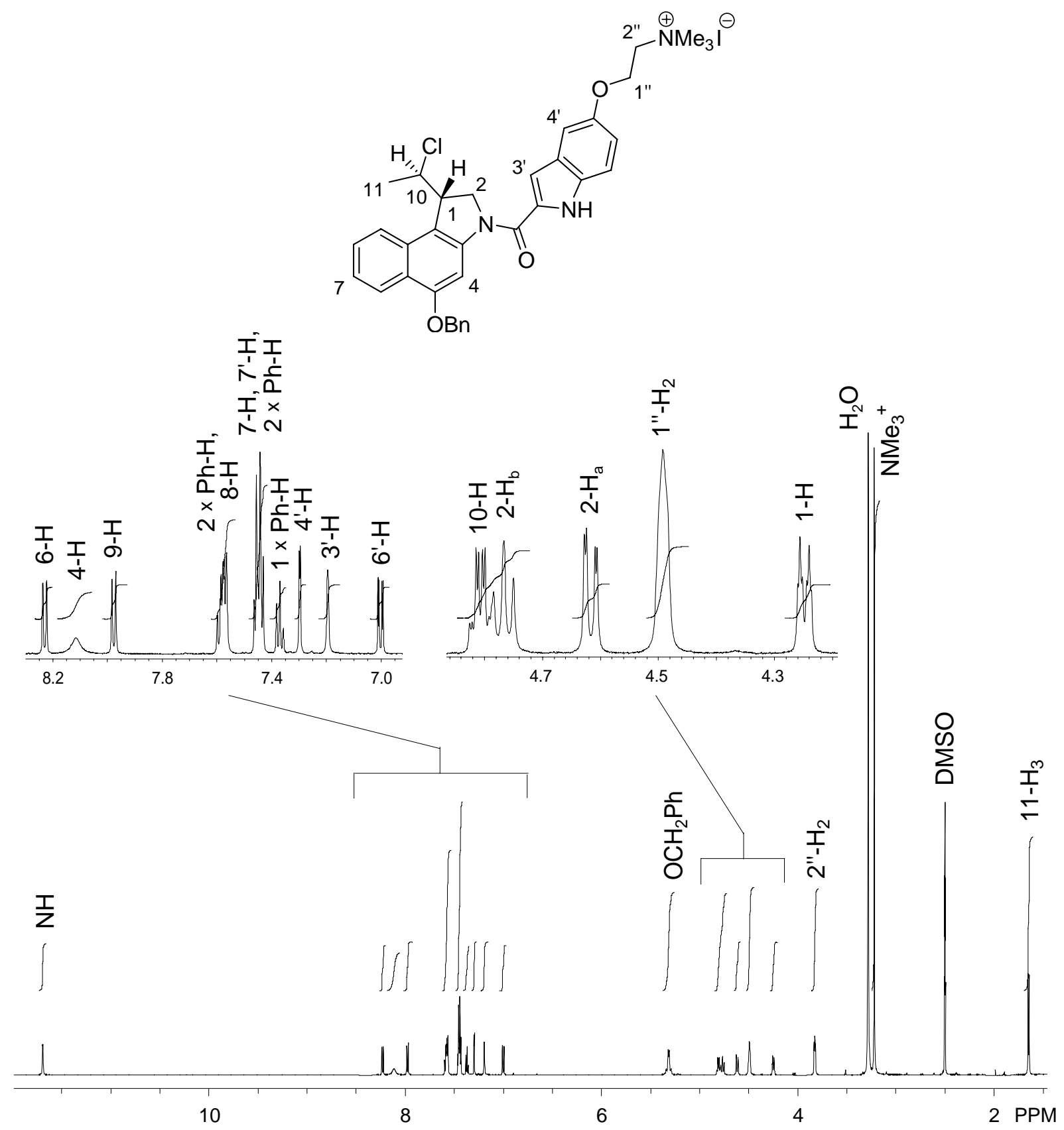

Abb. 34. ${ }^{1}$ H-NMR-Spektrum $\left(300 \mathrm{MHz}\right.$, DMSO-d $\left.\mathrm{d}_{6}\right)$ der Verbindung $(+)-(1 S, 10 R)-70$.

Im Aromatenbereich resoniert 6'-H als Dublett vom Dublett $\left(J_{o}=9.0 \mathrm{~Hz}, J_{m}=2.4 \mathrm{~Hz}\right)$ bei $\delta=7.00$. Bei $\delta=7.20$ resoniert 3'-H als Dublett mit einer Kopplungskonstante von $J=1.8 \mathrm{~Hz}$ zum Indol-NH. Bei $\delta=7.30$ folgt ein Dublett mit einer Kopplungs- 
konstante von $J_{m}=2.2 \mathrm{~Hz}$, welches dem 4'-H zuzuordnen ist und bei $\delta=7.37$ ein zentriertes Multiplett, das einem Phenylproton entspricht. 7- $\mathrm{H}$ und 8-H resonieren zusammen mit zwei Phenylprotonen in einem Multiplett bei $\delta=7.43-7.47$. Das Signal für 7'-H bildet zusammen mit den Signalen der restlichen zwei Phenylprotonen ein Multiplett bei $\delta=7.55-7.61$. Die verbleibenden Signale der aromatischen Protonen sind die Dubletts $\left(J_{0}=8.2 \mathrm{~Hz}\right)$ bei $\delta=7.98$ und 8.23, die dem 9-H bzw. 6-H entsprechen, sowie das breite Singulett bei $\delta=8.12$, welches dem 4-H zuzuordnen ist. Charakteristisch ist darüber hinaus das breite Singulett bei $\delta=11.7$ für das Indol-NH.

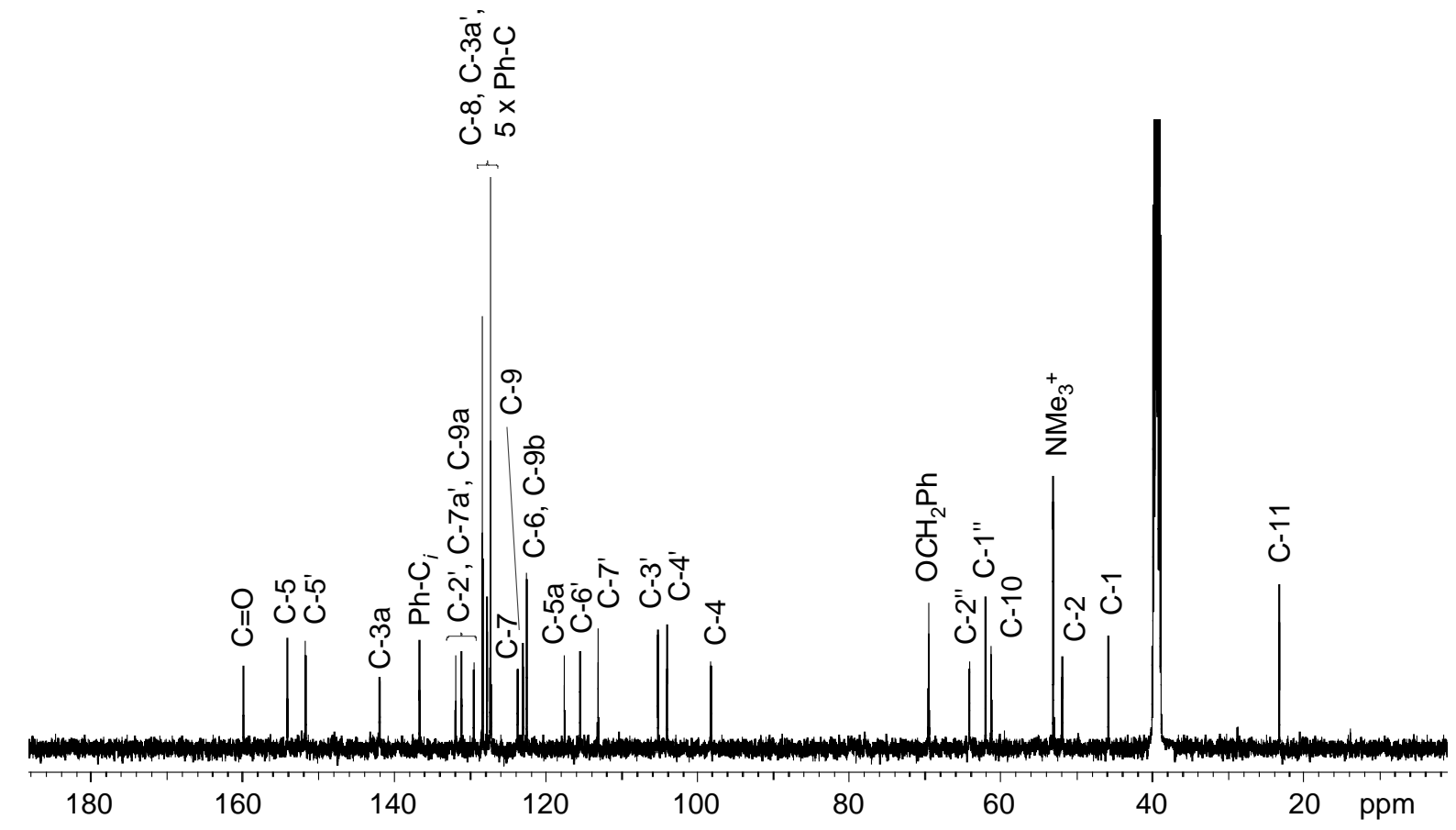

Abb. 35. ${ }^{13} \mathrm{C}-\mathrm{NMR}-$ Spektrum (75 MHz, DMSO-d $\left.\mathrm{d}_{6}\right)$ der Verbindung (+)-(1S,10R)-70.

Im ${ }^{13} \mathrm{C}-\mathrm{NMR}-$ Spektrum von $(+)-(1 S, 10 R)-34 \mathbf{a}$ ist das Signal für $\mathrm{C}-11$ erwartungsgemäß im Hochfeld bei $\delta=23.4$ zu beobachten (Abb. 35). Etwas weiter zu tiefem Feld verschoben resonieren die für Indoline charakteristischen Kohlenstoffe C-1 und C-2 bei $\delta=45.9$ bzw. 52.0. Im Vergleich zur Resonanz der $\mathrm{NMe}_{2}$-Gruppe des analogen seco-Drugs $(+)-(1 S, 10 R)-34 \mathbf{a}(\delta=42.8)$ deutlich zum Tieffeld hin verschoben kann das Signal für die drei Methylgruppen der $\mathrm{NMe}_{3}{ }^{+}$-Funktionalität bei $\delta=53.2$ beobachtet werden. Es folgt das Signal für C-10 bei $\delta=61.4$. In diesem Bereich resonieren außerdem C-1" und C-2" bei $\delta=62.1$ bzw. 64.2. Vor allem die Resonanz des C-2" ist hierbei deutlich im Vergleich zum analogen seco-Drug (+)-(1S,10R)-34a $(\delta=55.4)$ zum Tieffeld hin verschoben. Bei $\delta=69.6$ ist das Signal für den MethylenKohlenstoff der Benzylschutzgruppe zu beobachten. Die drei am weitesten tieffeldver- 
schobenen Signale können dem Carbonylkohlenstoffatom $(\delta=160.0)$, C-5 $(\delta=154.2)$ und C-5' $(\delta=151.8)$ zugeordnet werden. Die übrigen Signale der aromatischen Kohlenstoffatome konnten durch ein HSQC-Spektrum bzw. mit Hilfe von Inkrementrechnungen zugeordnet werden.

Im ESI-Massen-Spektrum von $(+)-(1 S, 10 R)$-70 ist bei $m / z 582.3$ das Signal für das Molekülion nach Iodidverlust $[\mathrm{M}-\mathrm{I}]^{+} \mathrm{zu}$ beobachten. Darüber hinaus entspricht der durch hochauflösende ESI-Massenspektrometrie gewonnene Wert dem berechneten Wert von $m / z 582.2518$ für das [M-I] ${ }^{+}$-Ion. Markante Signale im IR-Spektrum sind die breite Schwingungsbande für NH bei $3417 \mathrm{~cm}^{-1}$ sowie die Carbonylbande der Amidbindung bei $1623 \mathrm{~cm}^{-1}$.

\subsection{Synthese des dechlorierten (1S)-Methyl-seco-CBI-Derivates (1S)-49 mit einer $N, N$-Dimethylaminoethoxyindol (DMAI)-Seitenkette}

Das für die Untersuchung des Wirkmechanismus der anti-Methyl-seco-CBI-DMAIDerivate benötigte enantiomerenreine dechlorierte (1S)-Methyl-seco-CBI-DMAIAnalogon (+)-(1S)-49 wurde in Anlehnung an die Synthese des entsprechenden racemischen Gemisches dargestellt. ${ }^{157}$ Im Vorfeld war hierzu eine entsprechende Racematspaltung und eine Identfikation des $(1 S)$-Enantiomers erforderlich.

Zunächst wurde eine kleine Menge des enantiomerenreinen Chlorids $(+)-(1 S, 10 R)-44$ mit Tris(trimethylsilyl)silan (TTMSS) und AIBN als Radikalstarter in Toluol in $87 \%$ Ausbeute reduktiv zu (-)-(1S)-45 dehalogeniert (Abb. 36). Um (-)-(1S)-45 in größeren Mengen darzustellen, wurde das diastereomere Enantiomerengemisch $\mathrm{rac}-\mathbf{4 4} / \mathrm{rac}-\mathbf{7 1}$ unter denselben Bedingungen in 87\% Ausbeute $\mathrm{zu}$ rac-45 dechloriert und anschließend eine präparative Trennung der Enantiomere durch HPLC an chiraler stationärer Phase (Chiralpak ${ }^{\circledR}$ IA, $\alpha=1.5$ ) durchgeführt. Hierbei konnten $34 \mathrm{mg}$ (84 $\mu \mathrm{mol})$ des Racemates pro Injektion getrennt werden und das gewünschte Enantiomer (-)-(1S)-45 wurde eindeutig durch Vergleich der Retentionszeiten und des Drehwertes identifiziert (Abb. 37). 


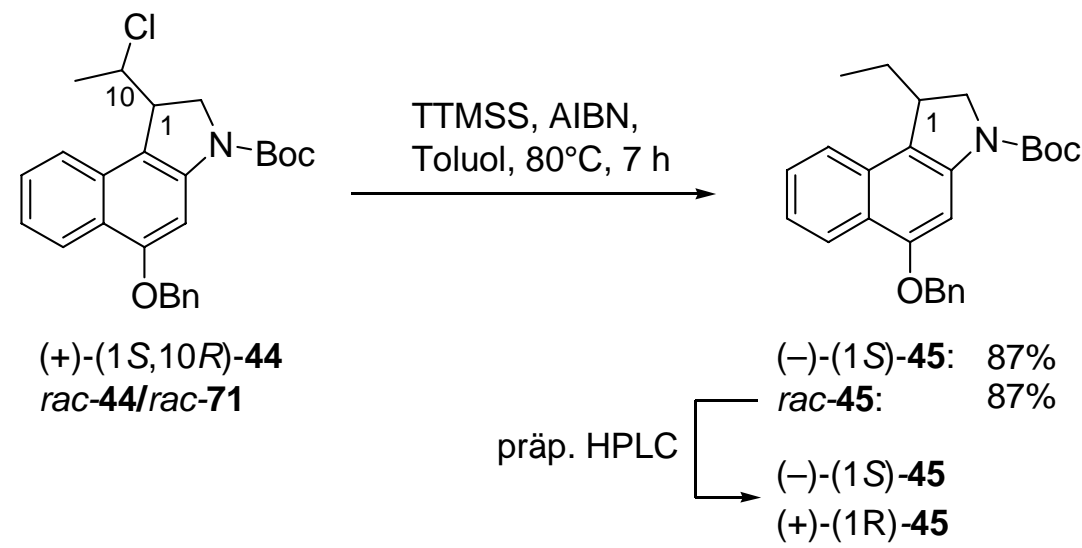

Abb. 36. Reduktive Dechlorierung zum Ethylderivat 45 und präparative Enantiomerentrennung von rac-45.

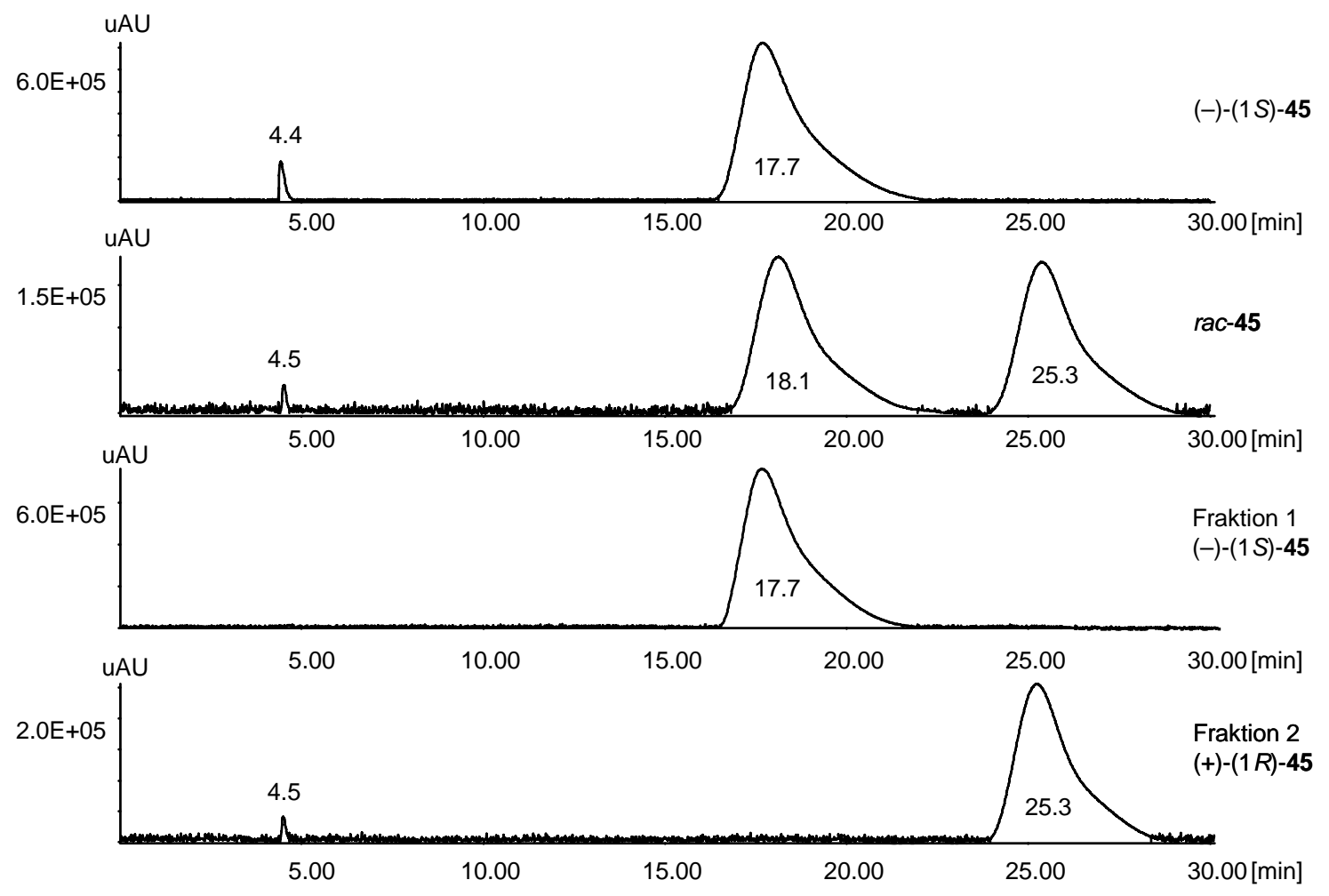

Abb. 37. Chromatgogramme der analytischen HPLC-Trennungen von (-)-(1S)-45, rac-45 und der Fraktionen 1 und 2 der präparativen HPLC-Trennung von rac-45.

Die Einführung der DMAI-Seitenkette in (-)-(1S)-45 erfolgte nach Abspaltung der säurelabilen Boc-Gruppe mit $4 \mathrm{M} \mathrm{HCl}$ in Essigester und anschließender Kupplung mit DMAI-CO ${ }_{2} \mathrm{H} \cdot \mathrm{HCl}$ (46a) unter Aktivierung mit $\mathrm{EDC} \cdot \mathrm{HCl}$ in $95 \%$ Ausbeute (Abb. 38). Eine abschließende Debenzylierung von (+)-(1S)-48 mit Pd auf Aktivkohle und Ammoniumformiat als Wasserstoffquelle lieferte das enantiomerenreine dechlorierte Methyl-seco-CBI-DMAI-Analogon (+)-(1S)-49 in 96\% Ausbeute. 


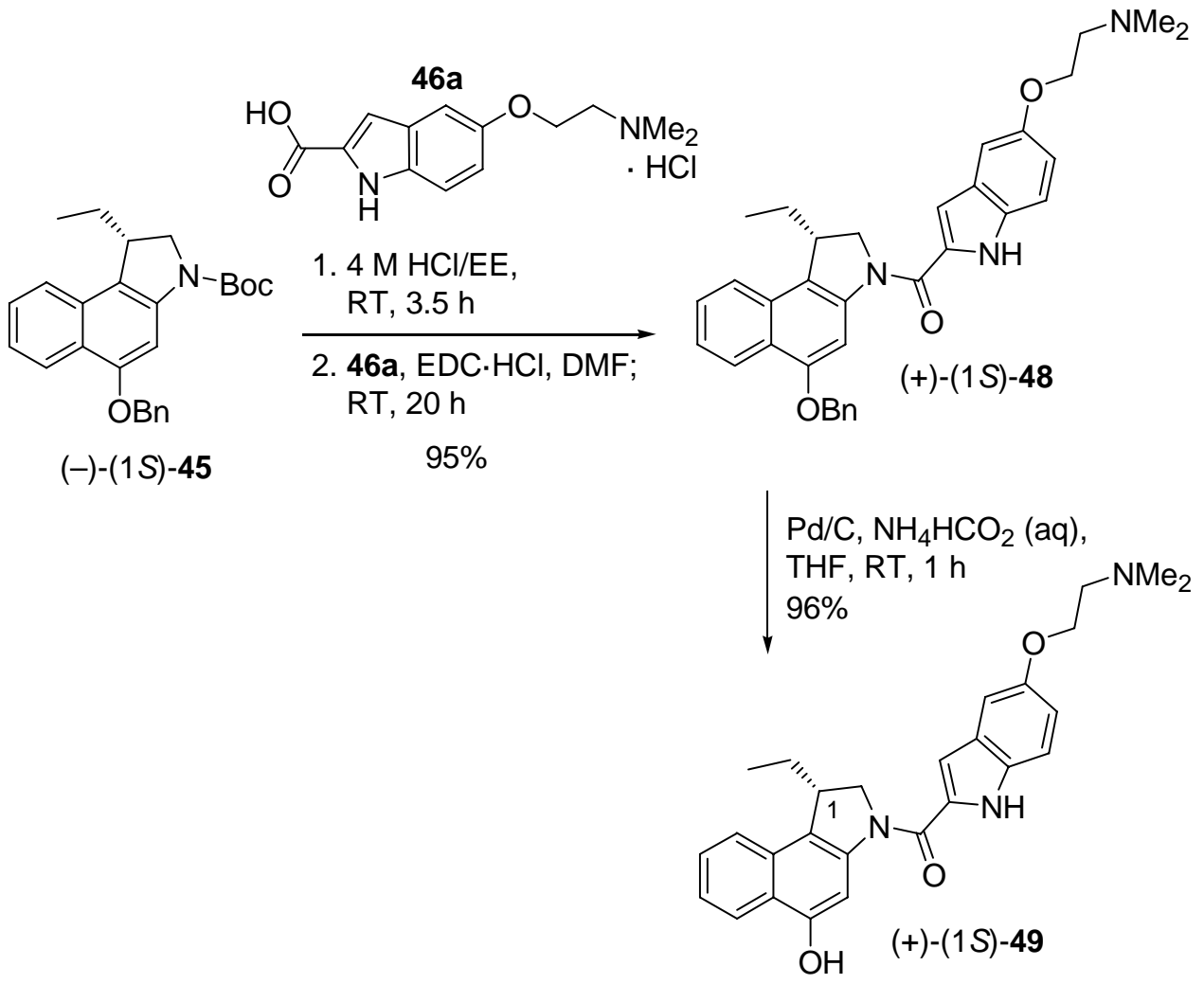

Abb. 38. Kupplung mit der DMAI-Seitenkette und Debenzylierung zu (+)-(1S)-49.

\subsubsection{Diskussion ausgewählter spektroskopischer Daten der Verbindung $(+)-(1 S)-49$}

In Abbildung 39 ist das ${ }^{1} \mathrm{H}-\mathrm{NMR}-$ Spektrum der dechlorierten Vergleichsverbindung $(+)-(1 S)-49$ mit der entsprechenden Zuordnung dargestellt.

Die Methylprotonen an C-11 resonieren bei $\delta=0.84$ als charakteristisches Triplett mit einer Kopplungskonstante von $J=7.4 \mathrm{~Hz}$ zu den Methylenprotonen 10- $\mathrm{H}_{2}$. Die Multipletts dieser diastereotopen Protonen sind bei $\delta=1.51-1.66\left(10-\mathrm{H}_{\mathrm{a}}\right)$ bzw. bei $\delta=1.75-1.89\left(10-\mathrm{H}_{\mathrm{b}}\right)$ zu beobachten. Das Singulett bei $\delta=2.35$ kann den Protonen der $\mathrm{NMe}_{2}$-Funktionalität zugeordnet werden. Die beiden Methylenprotonen 2"- $\mathrm{H}_{2}$ resonieren bei $\delta=2.81$ als Triplett mit einer Kopplungskonstante von $J=5.8 \mathrm{~Hz}$. Diese Kopplungskonstante findet sich im Triplett bei $\delta=4.12$ wieder, welches den Methylenprotonen 1"- $\mathrm{H}_{2}$ zugeordnet werden kann. Bei $\delta=3.74$ ist das Signal für 1-H als zentriertes Multiplett zu beobachten. Die charakteristischen Signale der diastereotopen Protonen des Indolinsystems $2-\mathrm{H}_{\mathrm{a}}$ und $2-\mathrm{H}_{\mathrm{b}}$ sind stattdessen im tieferen Feld $\mathrm{zu}$ erkennen. $2-\mathrm{H}_{\mathrm{a}}$ resoniert als Dublett vom Dublett bei $\delta=4.32$ mit der geminalen Kopplungskonstante $J=10.6 \mathrm{~Hz}$ und der vicinalen Kopplungskonstante $J=2.0 \mathrm{~Hz}$. 
2- $\mathrm{H}_{\mathrm{b}}$ weist ein Dublett vom Dublett bei $\delta=4.68$ mit den Kopplungskonstanten $J=10.6 \mathrm{~Hz}$ für die geminale Kopplung und $J=9.6 \mathrm{~Hz}$ für die vicinale Kopplung auf.

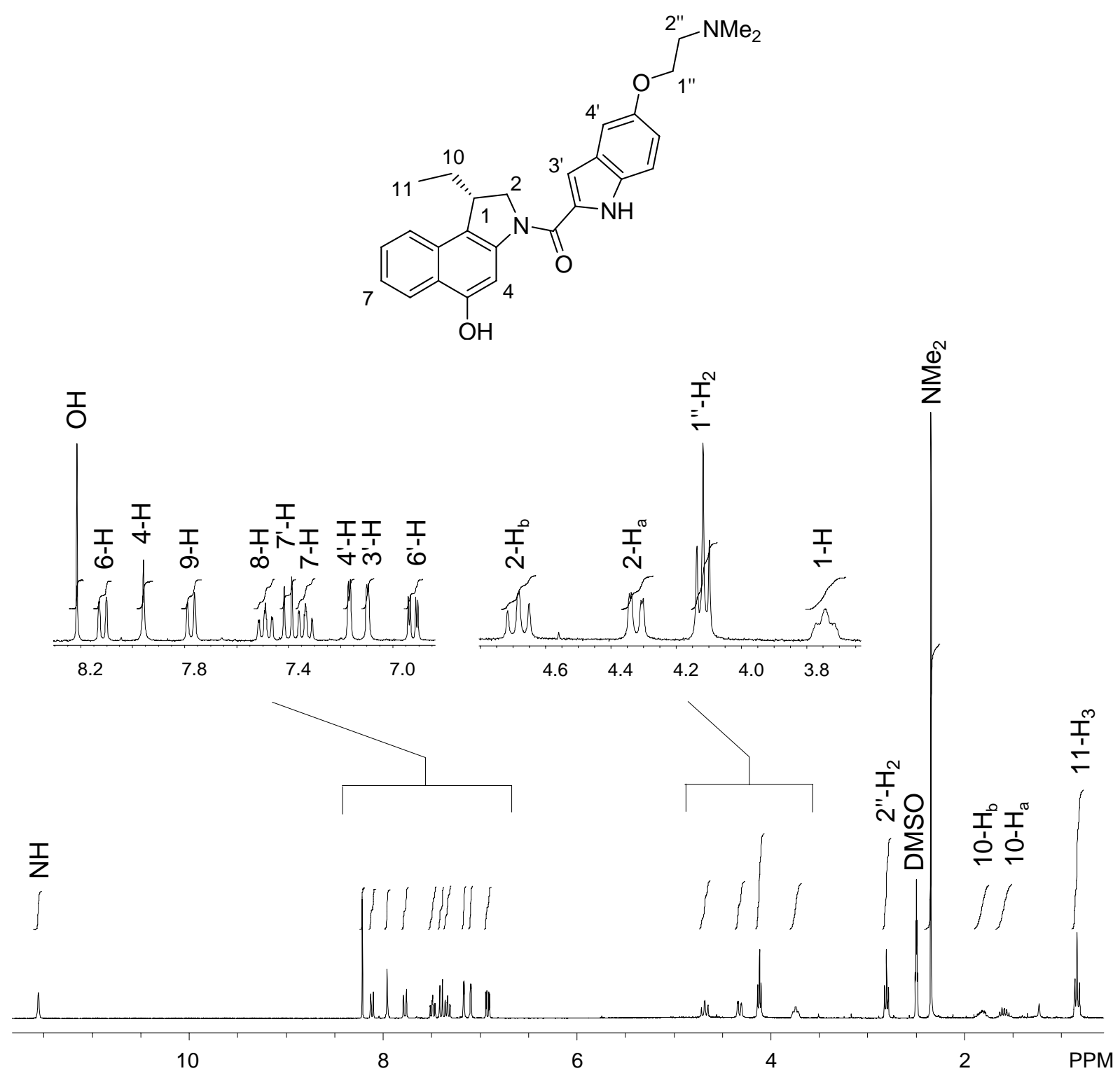

Abb. 39. ${ }^{1} \mathrm{H}-\mathrm{NMR}-$ Spektrum $\left(300 \mathrm{MHz}\right.$, DMSO-d $\left.\mathrm{d}_{6}\right)$ der Verbindung $(+)-(1 S)-\mathbf{4 9}$.

Im Aromatenbereich des Protonenspektrums von (+)-(1S)-49 resoniert 6'-H als Dublett vom Dublett bei $\delta=6.92 \mathrm{mit}$ den Kopplungskonstanten $J_{o}=9.0 \mathrm{~Hz}$ und $J_{m}=2.2 \mathrm{~Hz}$. Das Signal des 3'-H liegt als Dublett bei $\delta=7.10$ mit einer Kopplungskonstante von $J=1.8 \mathrm{~Hz}$, die für die Kopplung mit dem Indol-NH kennzeichnend ist. Bei $\delta=7.17$ kann das Dublett des 4'-H mit einer Kopplungskonstante von $J_{m}=2.4 \mathrm{~Hz}$ beobachtet werden. 7-H und 8-H resonieren als Dubletts von Dubletts mit $J_{o}=8.4 \mathrm{~Hz}$ bei $\delta=7.33$ und 7.49. Zwischen diesen beiden Tripletts ist ein Dublett mit $J_{o}=9.0 \mathrm{~Hz}$ bei $\delta=7.40$ zu beobachten, welches dem 7'-H zuzuordnen ist. Die verbleibenden Signale der aromatischen Protonen sind die Dubletts $\left(J_{o}=8.4 \mathrm{~Hz}\right)$ bei $\delta=7.78$ und 8.12, die dem 9-H 
bzw. 6-H entsprechen, sowie das Singulett bei $\delta=7.96$, welches dem 4-H zuzuordnen ist. Die höchsten chemischen Verschiebungen weisen ein Singulett für das OH-Proton bei $\delta=8.2$ und das breite Singulett der NH-Gruppe bei $\delta=11.6$ auf.

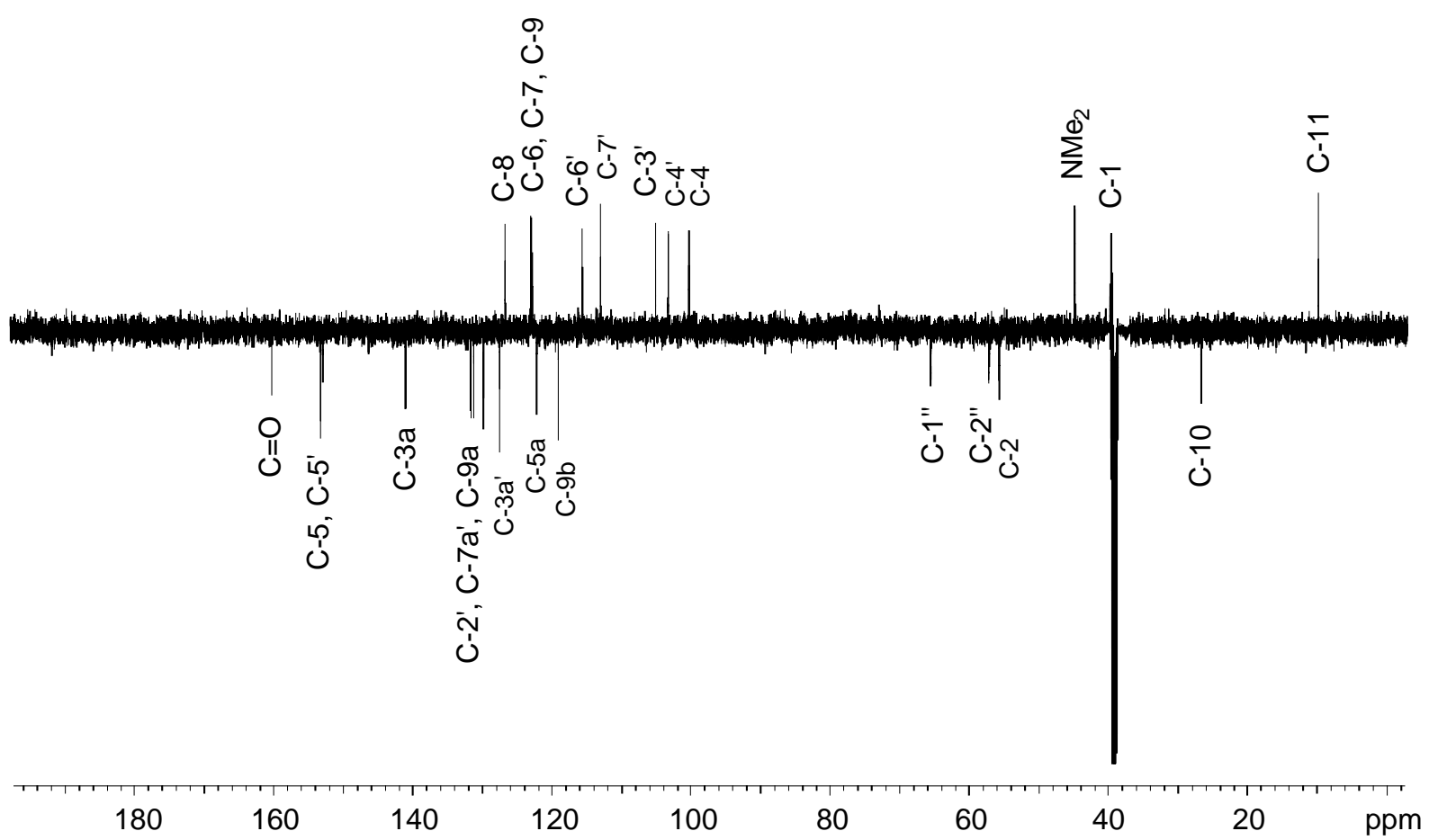

Abb. 40. APT $-{ }^{13}$ C-NMR-Spektrum (75 MHz, DMSO- $\left.\mathrm{d}_{6}\right)$ der Verbindung $(+)-(1 S)-49$.

Im ${ }^{13} \mathrm{C}-\mathrm{NMR}-$ Spektrum der Verbindung (+)-(1S)-49 (Abb. 40) resoniert C-11 erwartungsgemäß im Hochfeld bei $\delta=10.4$. Etwas weiter zu tiefem Feld verschoben liegt das Signal des C-10 $(\delta=27.1)$. Zwischen den für Indoline charakteristischen Signalen der Kohlenstoffatome C-1 und C-2 bei $\delta=39.9$ bzw. $\delta=56.0$ tritt das Signal der $\mathrm{NMe}_{2}$-Kohlenstoffe auf $(\delta=45.0)$. Die Kohlenstoffe C-2" und C-1" resonieren bei $\delta=57.3$ bzw. $\delta=65.7$. Die drei am weitesten tieffeldverschobenen Signale sind dem Carbonylkohlenstoffatom $(\delta=160.0)$ und den Kohlenstoffatomen C-5 und C-5' $(\delta=152.7$ bzw. $\delta=153.1)$ zuzuordnen. Die übrigen Signale der aromatischen Kohlenstoffatome konnten mittels eines HSQC oder mit Hilfe von Inkrementrechnungen den entsprechenden Kohlenstoffatomen zugeordnet werden.

Das ESI-Massen-Spektrum von (+)-(1S)-49 zeigt das Signal der protonierten Verbindung $[\mathrm{M}+\mathrm{H}]^{+}$bei $m / z$ 444.2. Eine ESI-HRMS-Messung bestätigte den berechneten Wert von $m / z 444.2282$ für die Masse des protonierten (+)-(1S)-49 $[\mathrm{M}+\mathrm{H}]^{+}$. Charakteristische Banden im IR-Spektrum sind die breite Schwingungsbande für NH um $3406 \mathrm{~cm}^{-1}$ sowie die Carbonylbande der Amidbindung bei $1651 \mathrm{~cm}^{-1}$. 


\section{Synthese der seco-CBI-DMAI-Derivate}

Die anti-Methyl-seco-CBI-Prodrugs mit DMAI-Seitenkette (33a) weisen einen sehr hohen Zytotoxizitätsunterschied in Ab- und Anwesenheit des aktivierenden Enzyms auf, die Zytotoxizität der entsprechenden seco-Drugs ist mit etwa $0.75 \mathrm{nM}$ für das aktivere Enantiomer $(+)-(1 S, 10 R)$-34a aber nicht so hoch wie diejenige der Duocarmycine. Im Rahmen dieser Arbeit wurden zur Steigerung der Zytotoxizität der seco-Drugs daher auch die enantiomerenreinen bzw. diasteromerenreinen seco-CBI-Derivate mit einer Chlormethyl- anstelle einer 1-Chlorethyl-Seitenkette synthetisiert und evaluiert.

\subsection{Synthese der seco-CBI-Hydrochloride 56a mit einer $N, N$-Dimethyl- aminoethoxyindol (DMAI)-Seitenkette}

Vorversuche zur Darstellung enantiomerenreiner seco-CBI-Derivate hatten ergeben, dass die Enantiomere des Benzylethers rac-57 nicht mittels präparativer HPLC an einer chiralen stationären Phase des Typs Chiralpak ${ }^{\circledR}$ IA getrennt werden können. ${ }^{159}$ Das entsprechende freie Phenol rac-55 kann jedoch zur Racemattrennung genutzt werden. In einem ersten Schritt wurde daher rac-57 in bis zu 97\% Ausbeute mittels katalytischer Transferhydrierung zum entsprechenden Phenol debenzyliert (Abb. 41). Hierbei musste der Reaktionsverlauf sorgfältig mittels Dünnschichtchromatographie verfolgt werden, um eine reduktive Dehalogenierung des Produktes nach erfolgter Debenzylierung zu vermeiden. Im Anschluss wurden pro Injektion $18.4 \mathrm{mg}(55 \mu \mathrm{mol})$ des Phenols rac-55 mittels präparativer HPLC an chiraler stationärer Phase (Säule: Chiralpak ${ }^{\circledR}$ IA, $\left.\alpha=1.3\right)$ in die Enantiomere (-)-(1S)-55 und (+)-(1R)-55 getrennt, die so mit jeweils $99.9 \%$ ee erhalten wurden.

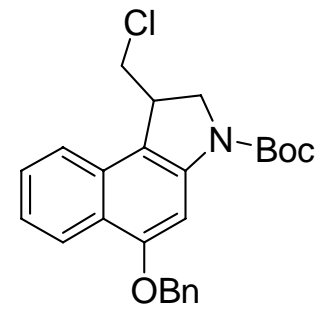

rac-57

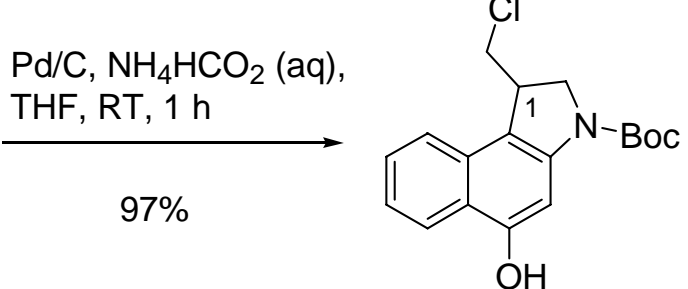

präp. HPLC $\begin{aligned} & \text { rac-55 } \\ & (-)-(1 S)-55 \\ & (+)-(1 R)-55\end{aligned}$

Abb. 41. Debenzylierung zum Phenol rac-55 und präparative Trennung der Enantiomere. 
Um nach der Trennung der Enantiomere eine erneute Schützung der phenolischen Hydroxygruppe $\mathrm{zu}$ vermeiden, erfolgte die Synthese der seco-CBI-Hydrochloride nicht ausgehend vom Benzylether 57 sondern vom Phenol 55. Zunächst wurde hierzu die Boc-Schutzgruppe in $\mathbf{5 5}$ mit $4 \mathrm{M} \mathrm{HCl}$ in Essigester abgespalten und anschließend das erhaltene sekundäre Amin unter Aktivierung mit $\mathrm{EDC} \cdot \mathrm{HCl}$ mit dem DMAICarbonsäure-Hydrochlorid (46a) gekuppelt (Abb. 42). Um eine Zyklisierung zu den entsprechenden Drugs zu vermeiden, wurde nach der Kupplung auf die sonst übliche basische Aufarbeitung verzichtet. Stattdessen wurde die Reaktionsmischung mit konzentrierter Salzsäure versetzt und das Rohprodukt anschließend säulenchromatographisch gereinigt. Die seco-CBI-DMAI-Verbindungen 56a konnten so in sehr guten Ausbeuten von 89 - 98\% erhalten werden. Für die In-vivo-Studien wurde (+)-(1S)-56a zudem mittels präparativer HPLC gereinigt.

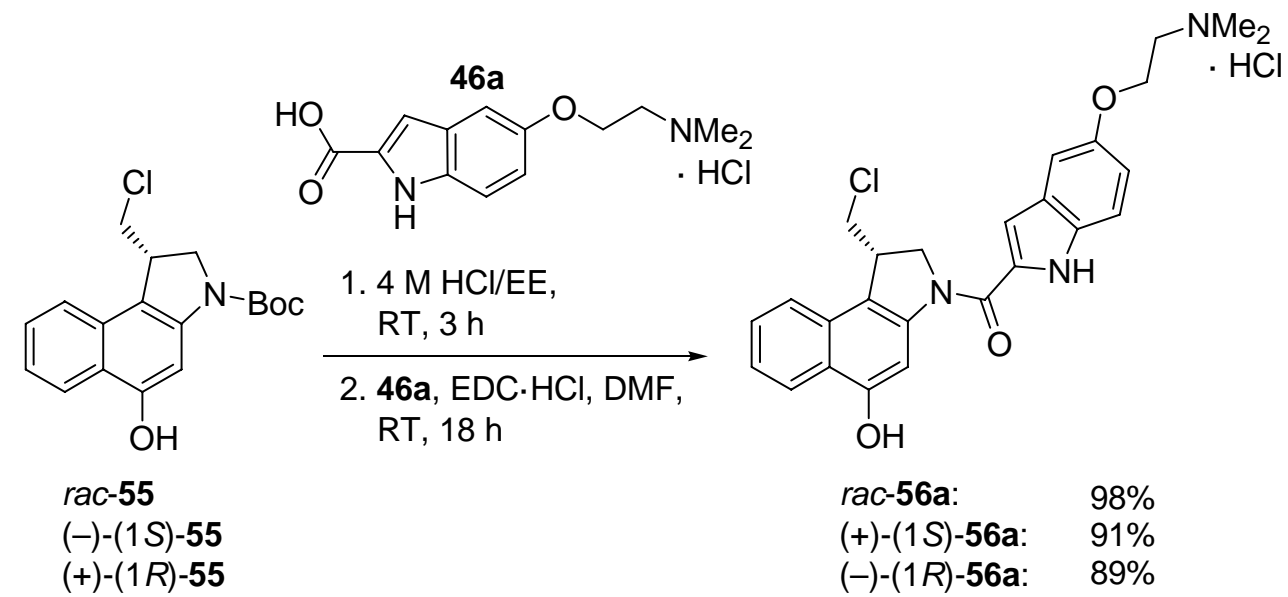

Abb. 42. Kupplung mit dem DMAI-DNA-Binder zu den seco-CBI-DMAI-Derivaten 56a.

\subsubsection{Diskussion ausgewählter spektroskopischer Daten des seco-Drug-Hydro- chlorids $(+)-(1 S)-56 a$}

In Abbildung 43 ist das ${ }^{1} \mathrm{H}-\mathrm{NMR}-$ Spektrum von $(+)-(1 S)-\mathbf{5 6} \mathbf{a}$ mit der entsprechenden Zuordnung dargestellt.

Im Hochfeldbereich des Spektrums resonieren die beiden Methylgruppen der $\mathrm{NMe}_{2}-$ Funktionalität als Singulett bei $\delta=2.86$. Die beiden Methylenprotonen 2"- $\mathrm{H}_{2}$ resonieren bei $\delta=3.52$ als Triplett mit einer Kopplungskonstante von $J=5.0 \mathrm{~Hz}$. Diese Kopplungskonstante findet sich im Triplett bei $\delta=4.38$ wieder, welches den Methylenprotonen 1"- $\mathrm{H}_{2}$ zuzuordnen ist. Bei $\delta=4.22$ ist das Signal für $1-\mathrm{H}$ als 
zentriertes Multiplett zu beobachten. Darüber hinaus sind die charakteristischen Signale der diastereotopen Protonen $10-\mathrm{H}_{\mathrm{a}}$ und $10-\mathrm{H}_{\mathrm{b}}$ bei $\delta=3.85$ bzw. $\delta=4.03$ jeweils als Dublett vom Dublett zu sehen. Die geminale Kopplungskonstante beträgt $J=11.2 \mathrm{~Hz}$ und die vicinalen Kopplungskonstante $J=8.0 \mathrm{~Hz}\left(10-\mathrm{H}_{\mathrm{a}}\right)$ bzw. $J=3.0 \mathrm{~Hz}$ $\left(10-\mathrm{H}_{\mathrm{b}}\right)$. Weiter zu tiefem Feld verschoben resonieren die diasterotopen Protonen 2- $\mathrm{H}_{\mathrm{a}}$ und $2-\mathrm{H}_{\mathrm{b}}$ jeweils als Dublett vom Dublett bei $\delta=4.55$ bzw. $\delta=4.79$ mit einer geminalen Kopplungskonstante von $J=10.8 \mathrm{~Hz}$ und einer vicinalen Kopplungskonstante von $J=1.6 \mathrm{~Hz}\left(2-\mathrm{H}_{\mathrm{a}}\right)$ bzw. $J=9.6 \mathrm{~Hz}\left(2-\mathrm{H}_{\mathrm{b}}\right)$.
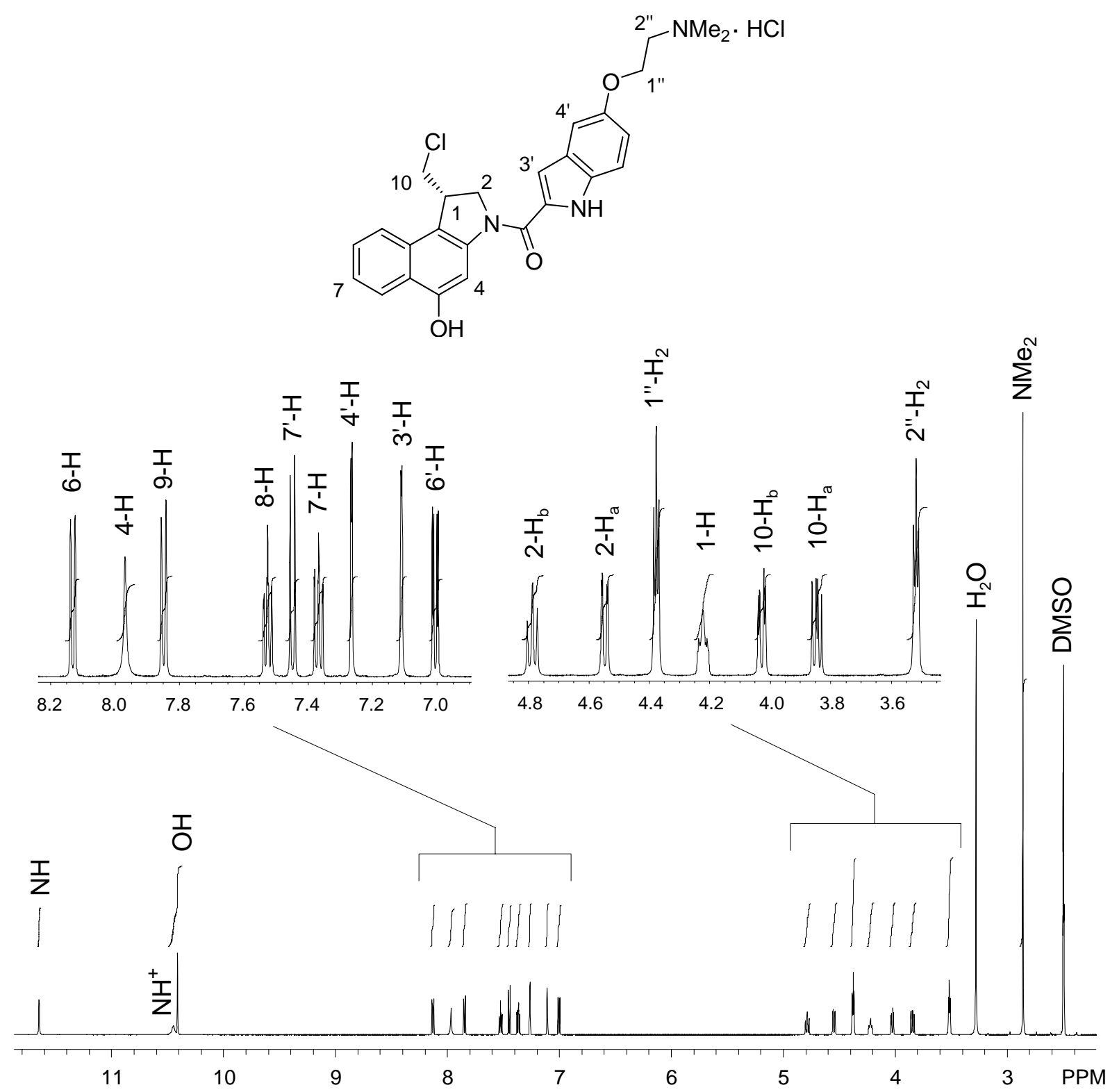

Abb. 43. ${ }^{1} \mathrm{H}-\mathrm{NMR}-$ Spektrum (300 MHz, DMSO-d $\left.\mathrm{d}_{6}\right)$ des seco-Drugs (+)-(1S)-56a.

Im Aromatenbereich des Protonenspektrums von (+)-(1S)-56a resoniert das 6'-H als Dublett vom Dublett $\left(J_{o}=9.0 \mathrm{~Hz}, J_{m}=2.2 \mathrm{~Hz}\right)$ bei $\delta=7.01$. $3^{\prime}-\mathrm{H}$ resoniert als 
Singulett mit angedeuteter Dublett-Struktur aufgrund einer Kopplung zum Indol-NH bei $\delta=7.11$. Bei $\delta=7.27$ ist ein Dublett mit einer Kopplungskonstante von $J_{m}=2.2 \mathrm{~Hz}$ zu beobachten, welches dem 4'-H zuzuordnen ist. 7-H und 8-H resonieren als Dubletts von Dubletts mit $J_{o}=7.6 \mathrm{~Hz}$ bei $\delta=7.37 \mathrm{bzw}$. 7.53. Zwischen diesen beiden Signalen liegt ein Dublett mit $J_{o}=9.0 \mathrm{~Hz}$ bei $\delta=7.45$, das dem 7'-H entspricht. Die verbleibenden Dubletts $\left(J_{o}=8.4 \mathrm{~Hz}\right)$ bei $\delta=7.85$ und $\delta=8.13$ sind 9-H bzw. 6-H und das breite Singulett bei $\delta=7.97$ dem Proton $4-\mathrm{H}$ zuzuordnen. Bei tiefem Feld resonieren weiterhin $\mathrm{OH}$ bei $\delta=10.41$ und NH bei $\delta=11.65$ jeweils als Singulett und $\mathrm{NH}^{+}$bei $\delta=10.45$ als breites Singulett.

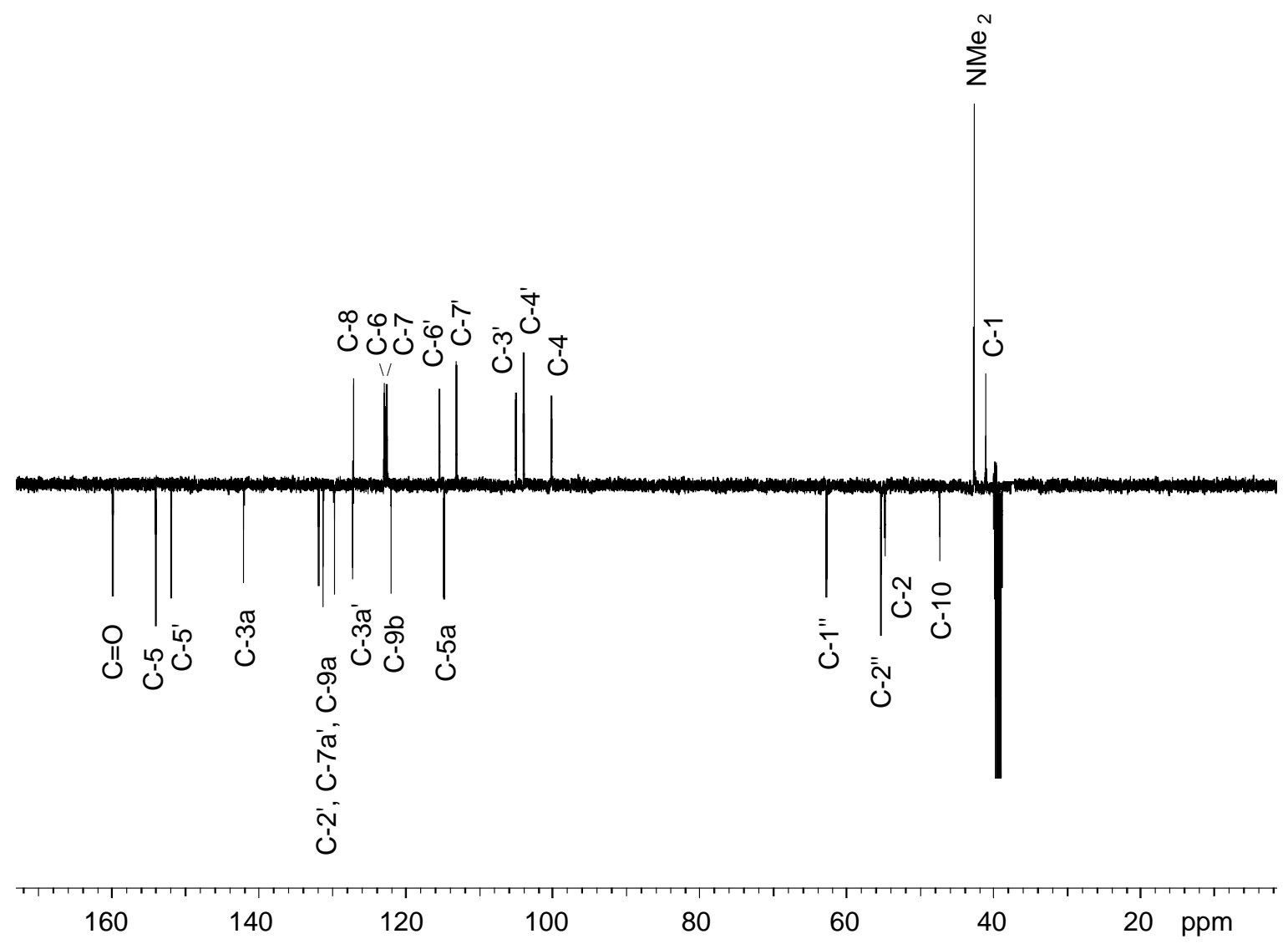

Abb. 44. ${ }^{13} \mathrm{C}-\mathrm{NMR}-$ Spektrum (125 MHz, DMSO-d $\left.\mathrm{d}_{6}\right)$ des seco-Drugs (+)-(1S)-56a.

Im ${ }^{13} \mathrm{C}-\mathrm{NMR}-S p e k t r u m$ von $(+)-(1 S)$-56a ist das Signal für C-1 im Hochfeld bei $\delta=41.2$ zu beobachten (Abb. 44). Etwas weiter zu tiefem Feld verschoben resonieren die Methylgruppen der $\mathrm{NMe}_{2}$-Funktionalität bei $\delta=42.8$. Darüber hinaus sind die für Indoline charakteristischen Signale für C-10 und C-2 bei $\delta=47.5$ bzw. 54.9 zu finden. In diesem Bereich resonieren außerdem C-2" und C-1" bei $\delta=55.4$ bzw. 62.9. Die drei am weitesten tieffeldverschobenen Signale können dem Carbonylkohlenstoffatom $(\delta=160.0)$, C-5 $(\delta=154.1)$ und C-5' $(\delta=152.0)$ zugeordnet werden. Die übrigen 
Signale der aromatischen Kohlenstoffatome konnten mit einem HSQC-Spektrum bzw. mit Hilfe von Inkrementrechnungen zugeordnet werden.

Das ESI-Massen-Spektrum von (+)-(1S)-56a zeigt das Signal des seco-Drug-Hydrochlorids nach Chlorid-Abspaltung [M-Cl] ${ }^{+}$bei $\mathrm{m} / z 464.2$ (rel. Intensität: 100) und das Dimer $[2 \mathrm{M}-2 \mathrm{Cl}+\mathrm{H}]^{+}$bei $\mathrm{m} / z 926.8$ (rel. Intensität: 30 ). Eine ESI-HRMS-Messung bestätigte den berechneten Wert von $\mathrm{m} / \mathrm{z} 464.1736$ für die Masse des seco-DrugHydrochlorids nach Chlorid-Abspaltung $[\mathrm{M}-\mathrm{Cl}]^{+}$. Charakteristische Banden im IR-Spektrum sind die breite Schwingungsbande für $\mathrm{NH}$ um $3406 \mathrm{~cm}^{-1}$ sowie die Carbonylbande der Amidbindung bei $1623 \mathrm{~cm}^{-1}$.

\subsection{Synthese des seco-CBI-Galactosides (1S)-54a mit einer $N, N$-Dimethyl- aminoethoxyindol (DMAI)-Seitenkette}

Die Darstellung von Alkylglykosiden gelingt in der Regel mit den etablierten Methoden nach B. Helferich, ${ }^{165}$ E. Fischer ${ }^{166}$ oder W. Königs - E. Knorr. ${ }^{167}$ Aufgrund der geringeren Nukleophilie aromatischer Hydroxyverbindungen sind diese Verfahren allerdings nicht in gleichem Maße für die Synthese von Arylglykosiden geeignet. Alternative Glykosidierungsmethoden stellen die Verwendung von $O$-silylierten Glykosiden nach L. F. Tietze ${ }^{168}$ oder die Glykalmethode nach S. J. Danishefsky ${ }^{169}$ dar. Als besonders leistungsfähig zur Darstellung von Glykosiden des CC-1065 oder der Duocarmycine haben sich die von $R$. R. Schmidt entwickelten Trichloracetimidate als Glykosyldonoren etabliert. ${ }^{160}$ Ausgehend von den entsprechenden Kohlenhydraten sind die Glykosyldonoren in insgesamt drei Stufen durch Schützen der Hydroxyfunktionen, selektive Entschützung am anomeren Zentrum sowie abschließende Transformation in das Trichloracetimidat durch Umsetzung mit Trichloracetonitril und DBU zugänglich. ${ }^{141,170}$

Zur Synthese des Galactosides (-)-(1S)-54a mit der natürlichen (1S)-Konfiguration wurde in Anlehnung an bereits durchgeführte Galactosid-Synthesen ${ }^{141 \text { f } 159}$ das Phenol (-)-(1S)-55 mit dem tetraacetylgeschützen $\alpha$-Trichloracetimidat der D-Galactose (72) unter Lewis-Säure-Katalyse mit $\mathrm{BF}_{3} \cdot \mathrm{OEt}_{2}$ in Anwesenheit von Molekularsieb (4 $\AA$ ) bei $-10{ }^{\circ} \mathrm{C}$ umgesetzt (Abb. 45). Nach drei Stunden wurde die Boc-Schutzgruppe am sekundären Amin durch Zugabe von weiteren drei Äquivalenten $\mathrm{BF}_{3} \cdot \mathrm{OEt}_{2}$ bei $20^{\circ} \mathrm{C}$ in 5.5 Stunden abgespalten. 

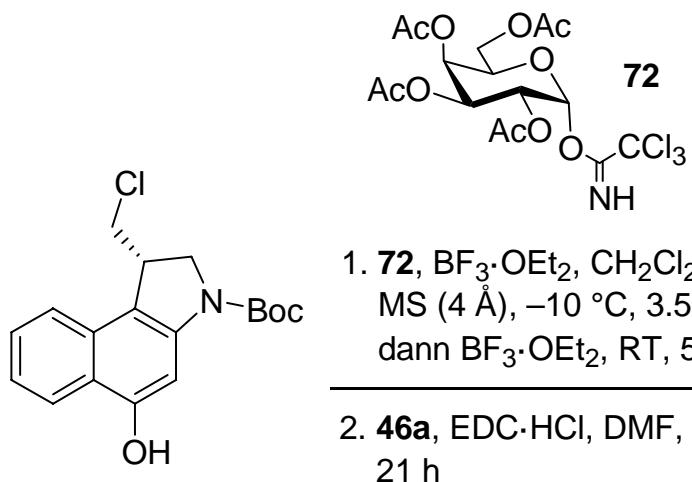

1. 72, $\mathrm{BF}_{3} \cdot \mathrm{OEt}_{2}, \mathrm{CH}_{2} \mathrm{Cl}_{2}$, $\mathrm{MS}(4 \AA),-10^{\circ} \mathrm{C}, 3.5 \mathrm{~h}$ dann $\mathrm{BF}_{3} \cdot \mathrm{OEt}_{2}, \mathrm{RT}, 5.5 \mathrm{~h}$

2. 46a, EDC. $\mathrm{HCl}, \mathrm{DMF}, \mathrm{RT}$, $21 \mathrm{~h}$

$(-)-(1 S)-55$<smiles></smiles>

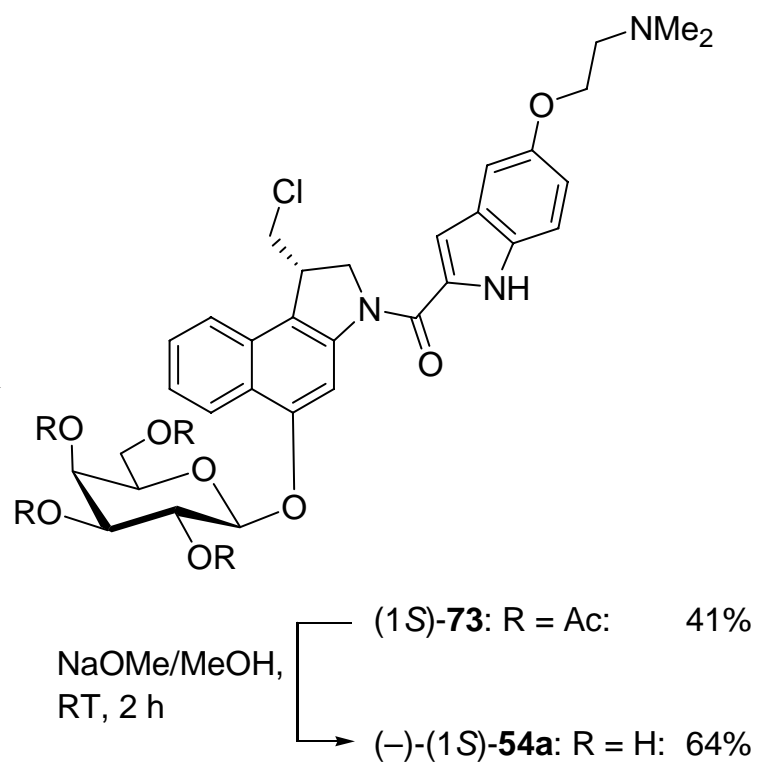

Abb. 45. Synthese des seco-CBI-DMAI- $\beta$-D-Galactosides (-)-(1S)-54a.

Auf eine Reinigung des Amins wurde aufgrund seiner Instabilität verzichtet. Stattdessen wurde das Lösungsmittel bei $30^{\circ} \mathrm{C}$ in vacuo entfernt und die ungereinigte Verbindung in Gegenwart von $\mathrm{EDC} \cdot \mathrm{HCl}$ mit dem DMAI-Carbonsäure-Hydrochlorid (46a) gekuppelt. Durch den Einsatz des $\alpha$-Trichloracetimidates entstand unter Nachbargruppenbeteiligung der Acetylgruppe an C-2 in 72 selektiv das $\beta$-D-Galactosid (1S)-73. Abschließend wurden die Acetylgruppen an der Galactoseeinheit unter basenkatalysierter Solvolyse nach der Methode von Zemplén ${ }^{171}$ abgespalten und auf diese Weise das gewünschte Galactosid (-)-(1S)-54a in einer Gesamtausbeute von $26 \%$ über drei Stufen erhalten.

\subsubsection{Diskussion ausgewählter spektroskopischer Daten des Galactosides $(-)-(1 S)-54 a$}

In Abbildung 46 ist das ${ }^{1} \mathrm{H}-\mathrm{NMR}-$ Spektrum des Galactosides (-)-(1S)-54a mit der entsprechenden Zuordnung dargestellt.

Die beiden Methylgruppen der $\mathrm{NMe}_{2}$-Funktionalität resonieren als Singulett bei $\delta=2.24$ und die Methylenprotonen 2"- $\mathrm{H}_{2}$ als Triplett mit einer Kopplungskonstante von $J=6.0 \mathrm{~Hz}$ bei $\delta=2.66$. Im Spektrum folgen die Signale für die Protonen der $\beta$-DGalactose, deren Zuordnung mittels eines COSY und eines HSQC-Spektrums erfolgte. Bei $\delta=3.47$ resoniert das axial orientierte $3 "$ '-H als Dublett vom Dublett mit den Kopplungskonstanten $J_{a x, a x}=9.8 \mathrm{~Hz}$ und $J_{a x, e q}=3.0 \mathrm{~Hz}$. Bei $\delta=3.53-3.58$ ist ein Multiplett für 5"'-H und 6"'- $\mathrm{H}_{\mathrm{a}} \mathrm{zu}$ beobachten. 
Ebenfalls als Multipletts resonieren 6"'- $\mathrm{H}_{\mathrm{b}}$ bei $\delta=3.64-3.69$ sowie 4 "'-H und 2"'-H bei $\delta=3.76-3.83$. Im letztgenannten Multiplett ist deutlich die Struktur eines Dubletts vom Dublett mit zwei ähnlichen Kopplungskonstanten zu erkennen, das dem axial orientierten 2"'-H zuzuordnen ist, sowie die Struktur eines Dubletts vom Dublett für das äquatorial angeordnete 4"'-H. Das 1"'-H am anomeren Zentrum resoniert als Dublett mit einer charakteristischen Kopplungskonstante von $J_{a x, a x}=7.8 \mathrm{~Hz}$ bei $\delta=4.93$.
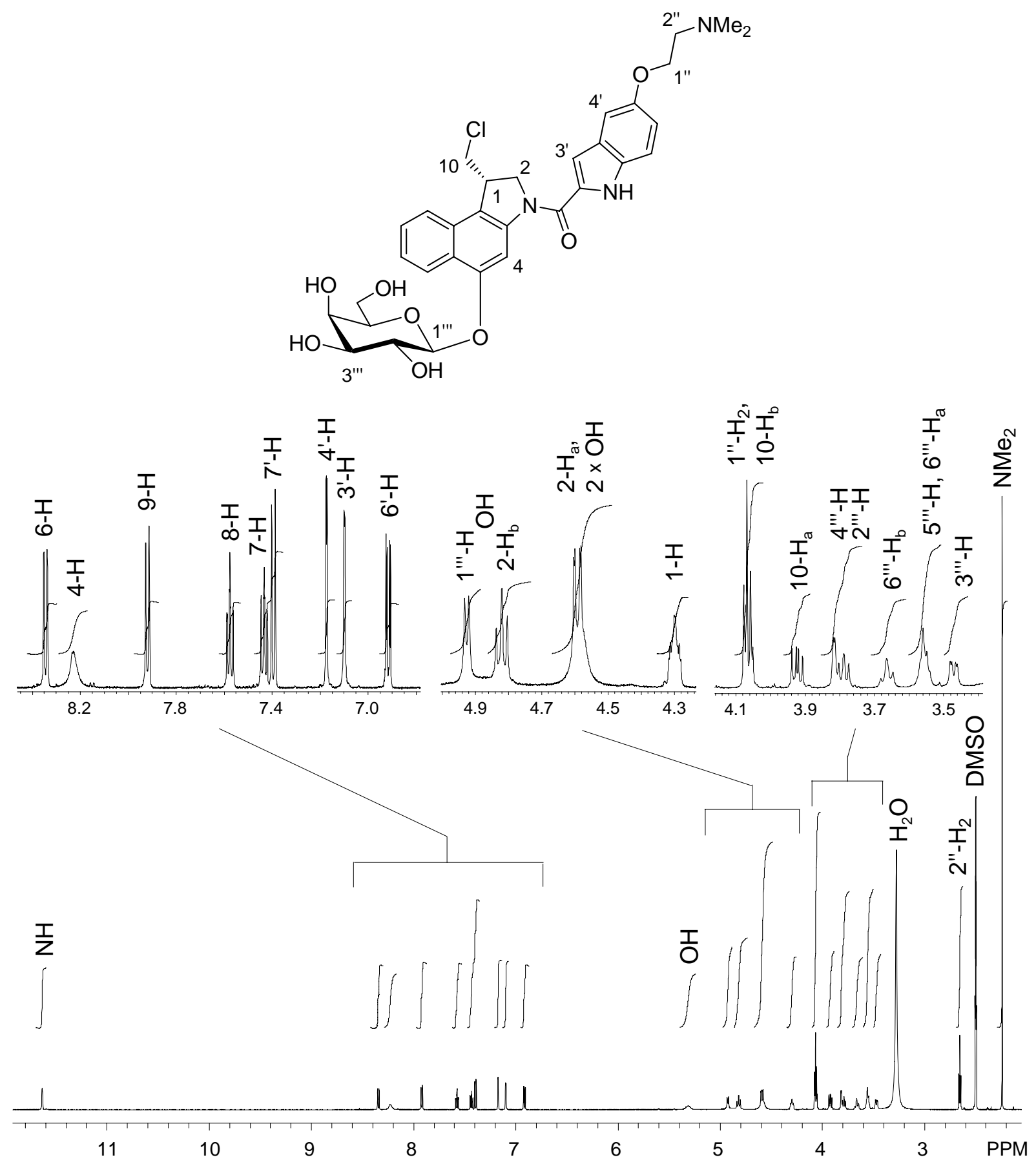

Abb. 46. ${ }^{1} \mathrm{H}-\mathrm{NMR}-$ Spektrum $\left(300 \mathrm{MHz}\right.$, DMSO-d $\left.\mathrm{d}_{6}\right)$ des Prodrugs (-)-(1S)-54a. 
Bei $\delta=3.92$ resoniert $10-\mathrm{H}_{\mathrm{a}}$ als Dublett vom Dublett mit den Kopplungskonstanten $J=11.2 \mathrm{~Hz}$ für die geminale Kopplung und $J=7.6 \mathrm{~Hz}$ für die vicinale Kopplung. $\mathrm{Zu}$ tieferem Feld verschoben folgen ein Multiplett bei $\delta=4.05-4.08$ für die Methylenprotonen 1"- $\mathrm{H}_{2}$ und das $\mathrm{zu} 10-\mathrm{H}_{\mathrm{a}}$ diastereotope Methylenproton $10-\mathrm{H}_{\mathrm{b}}$ sowie ein zentriertes Multiplett bei $\delta=4.30$ für 1-H. Im Bereich $\delta=4.5-5.0$ resonieren drei der vier OH-Protonen des Zuckerbausteins, deren Signale aufgrund chemischer Austauschprozesse jedoch stark verbreitert sind und zudem die Signale anderer Protonen überlagern. Das vierte Hydroxyproton resoniert als breites Singulett bei $\delta=5.31$. Bei $\delta=4.55-4.61$ resoniert das Methylenproton 2- $\mathrm{H}_{\mathrm{a}}$ zusammen mit zwei der Hydroxyprotonen als Multiplett. Bei $\delta=4.82$ ist das Signal des $\mathrm{zu} 2-\mathrm{H}_{\mathrm{a}}$ diastereotopen Protons $2-\mathrm{H}_{\mathrm{b}}$ als Dublett vom Dublett mit Kopplungskonstanten von $J=10.8 \mathrm{~Hz}$ und $J=9.6$ $\mathrm{Hz}$ zu beobachten.

Im Aromatenbereich resoniert das 6'-H als Dublett vom Dublett bei $\delta=6.92$ mit den Kopplungskonstanten $J_{o}=9.0 \mathrm{~Hz}$ und $J_{m}=2.6 \mathrm{~Hz}$. Bei $\delta=7.10 \mathrm{kann}$ ein Dublett für 3'-H mit einer Kopplungskonstante von $J=2.0 \mathrm{~Hz}$ zum Indol-NH und bei $\delta=7.17$ ein Dublett für 4'-H $\left(J_{m}=2.6 \mathrm{~Hz}\right)$ beobachtet werden. Es folgt ein Dublett bei $\delta=7.40 \mathrm{mit}$ einer Kopplungskonstante von $J_{o}=9.0 \mathrm{~Hz}$, das dem 7'-H zugeordnet werden kann. 7-H und 8-H resonieren als Dubletts von Dubletts $\left(J_{o}=8.6 \mathrm{~Hz}\right)$ bei $\delta=7.43 \mathrm{bzw}$. $\delta=7.58$. 9-H resoniert als Dublett $\left(J_{o}=8.6 \mathrm{~Hz}\right)$ bei $\delta=7.92$. Das breite Singulett bei $\delta=8.23$ kann dem 4-H und das Dublett bei $\delta=8.35\left(J_{o}=8.6 \mathrm{~Hz}\right)$ dem $6-\mathrm{H}$ zugeordnet werden. Die am weitesten tieffeldverschobene Resonanz stellt das Singulett für NH bei $\delta=11.63$ dar.

Im ${ }^{13}$ C-NMR-Spektrum des Galactosides (-)-(1S)-54a (Abb. 47) ist im Hochfeld bei $\delta=41.2$ das Signal des Kohlenstoffatoms C-1 zu sehen, gefolgt vom Signal der $\mathrm{NMe}_{2}-$ Kohlenstoffe bei $\delta=45.5$ und dem Signal des C-10 bei $\delta=47.4$. Das Kohlenstoffatom C-2 des Indolingerüstes resoniert bei $\delta=54.9$ und die Kohlenstoffatome C-2" und C-1" der Seitenkette bei $\delta=57.8$ bzw. $\delta=66.3$. Die Signale aller Kohlenstoffatome der $\beta$-D-Galactose sind mit Ausnahme des anomeren C-1"' $(\delta=102.1)$ im Bereich von $\delta=59.5$ (C-6"') bis $\delta=75.1$ (C-5"') zu beobachten. Die drei am weitesten tieffeldverschobenen Signale sind dem Carbonylkohlenstoffatom $(\delta=160.2)$ und den Kohlenstoffatomen C-5 und C-5' ( $\delta=153.7$ bzw. $\delta=153.0)$ zuzuordnen. Die übrigen Signale der aromatischen Kohlenstoffatome konnten mittels eines HSQC-Spektrums oder mit Hilfe von Inkrementrechnungen den entsprechenden Kohlenstoffatomen zugeordnet werden. 


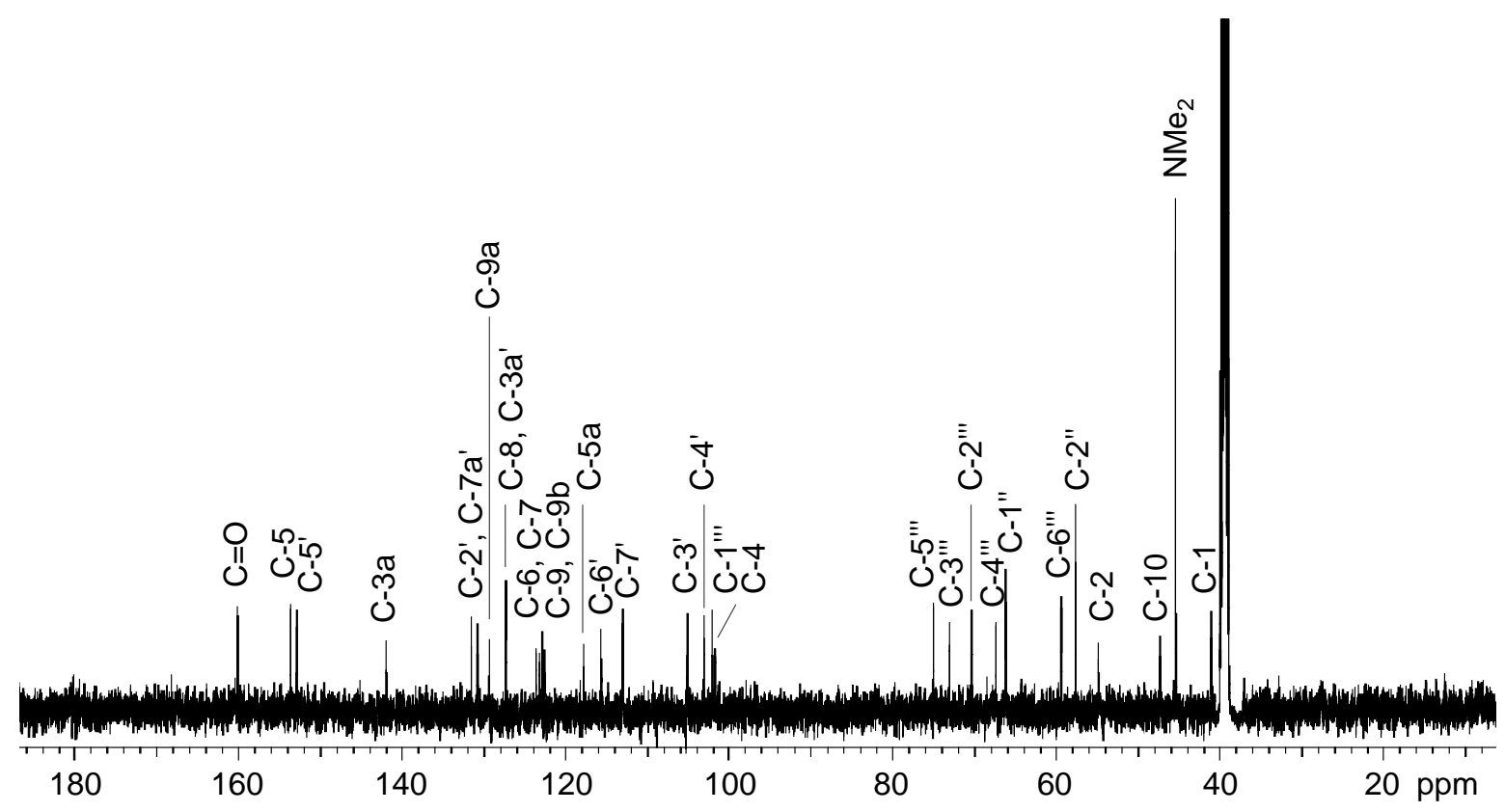

Abb. 47. ${ }^{13} \mathrm{C}-\mathrm{NMR}-$ Spektrum (125 MHz, DMSO-d 6 ) des Prodrugs (-)-(1S)-54a.

Das ESI-Massen-Spektrum von (-)-(1S)-54a zeigt als Basispeak die protonierte Verbindung $[\mathrm{M}+\mathrm{H}]^{+}$bei $m / z 626.2$ (rel. Intensität: 100). Darüber hinaus treten folgende dimere Spezies auf: $[2 \mathrm{M}+\mathrm{H}]^{+}$bei $m / z 1252.8$ (rel. Intensität: 36 ), $[3 \mathrm{M}+2 \mathrm{H}]^{2+}$ bei $\mathrm{m} / z$ 939.4 (rel. Intensität: 21 ) und [2M+Na] $]^{+}$bei $\mathrm{m} / z 1257.0$ (rel. Intensität: 14). Eine ESI-HRMS-Messung bestätigte den berechneten Wert von $\mathrm{m} / z 626.2269$ für die Masse des protonierten Galactosides $[\mathrm{M}+\mathrm{H}]^{+}$. Charakteristische Banden im IR-Spektrum sind die breite Schwingungsbande für NH um $3407 \mathrm{~cm}^{-1}$ sowie die Carbonylbande der Amidbindung bei $1624 \mathrm{~cm}^{-1}$. 


\section{Synthese des seco-CBI-MPI-Hydrochlorids}

\subsection{Synthese des seco-CBI-Hydrochlorids (1S)-56b mit einer $N$-Methyl- piperidinylmethoxy (MPI)-Seitenkette}

Für vergleichende Untersuchungen des Effektes der DNA-Binder und des Pharmakophores auf die Zytotoxizität und den Wirkmechanismus wurde zusätzlich zu dem anti-Methyl-seco-CBI-DMAI-Hydrochlorid (+)-(1S,10R)-34a, dem seco-CBI-DMAIHydrochlorid (+)-(1S)-56a und dem bekannten anti-Methyl-seco-CBI-MPI-Hydrochlorid $(+)-(1 S, 10 R)-34 \mathbf{b}^{141 \mathrm{f}}$ das seco-CBI-MPI-Hydrochlorid $(+)-(1 S)-56 \mathbf{b}$ synthetisiert.

Im ersten Schritt der zweistufigen Synthese wurde die Boc-Schutzgruppe an der Aminofunktionalität von (-)-(1S)-55 mit $4 \mathrm{M} \mathrm{HCl}$ in Essigester abgespalten und im zweiten Schritt das erhaltene freie Amin unter Aktivierung mit $\mathrm{EDC} \cdot \mathrm{HCl}$ mit dem MPI-Carbonsäure-Hydrochlorid (46b) gekuppelt (Abb. 48). Um eine Zyklisierung zum entsprechenden Drug zu verhindern, wurde die Reaktionsmischung nach der Kupplung mit konzentrierter Salzsäure versetzt und das Rohprodukt anschließend säulenchromatographisch sowie mittels präparativer HPLC gereinigt. Das seco-CBIMPI-Hydrochlorid (+)-(1S)-56b konnte auf diese Weise in insgesamt 63\% Ausbeute erhalten werden.

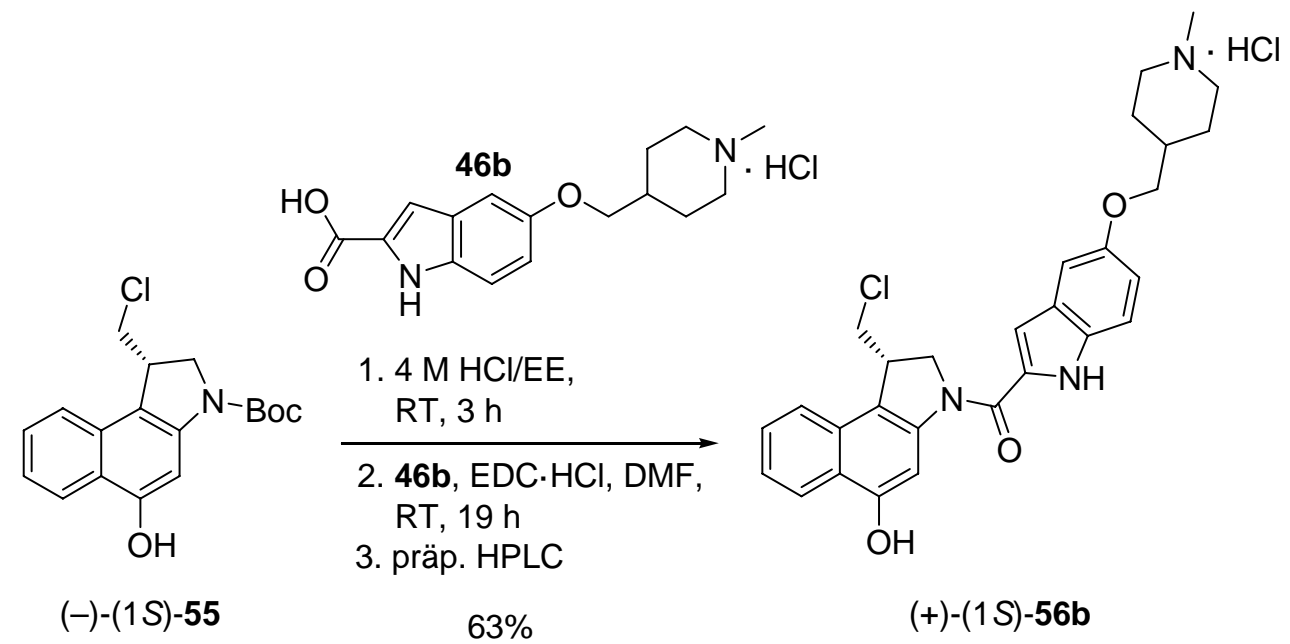

Abb. 48. Kupplung mit dem DNA-Binder zu dem seco-CBI-MPI-Hydrochlorid (+)-(1S)-56b. 


\subsubsection{Diskussion ausgewählter spektroskopischer Daten des seco-Drug-Hydro- chlorids $(+)-(1 S)-56 b$}

In Abbildung 49 ist das ${ }^{1}$ H-NMR-Spektrum des seco-Drugs (+)-(1S)-56b mit der entsprechenden Zuordnung dargestellt.

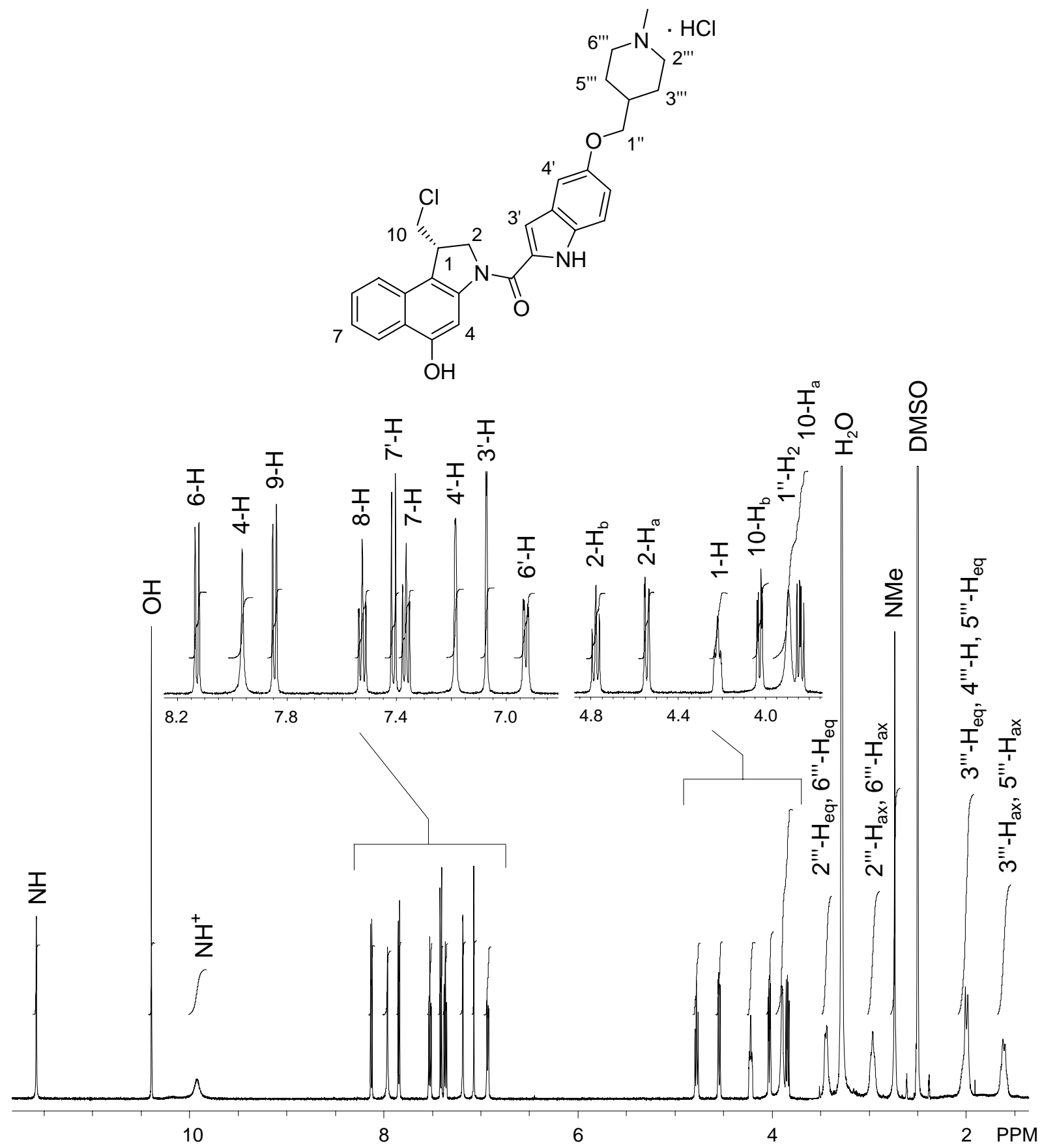

Abb. 49. ${ }^{1} \mathrm{H}-\mathrm{NMR}-$ Spektrum (600 MHz, DMSO-d $\left.{ }_{6}\right)$ des seco-Drugs (+)-(1S)-56b.

Am weitesten ins Hochfeld verschoben resonieren die axial angeordneten Protonen 3"'- $\mathrm{H}_{\mathrm{ax}}$ und 5 "'- $\mathrm{H}_{\mathrm{ax}}$ des Piperidingerüstes in Form eines zentrierten Multipletts bei $\delta=1.61$. Bei $\delta=1.93-2.08$ sind die Signale des Protons 4"'-H sowie der equatorial 
angeordneten Protonen 3"'- $\mathrm{H}_{\mathrm{eq}}$ und 5"'-- $\mathrm{H}_{\text {eq }}$ des Piperidingerüstes als Multiplett zu beobachten. Es folgt das Singulett bei $\delta=2.44$ für die Methylgruppe der NMeFunktionalität. Bei $\delta=2.97$ resonieren die axial angeordneten Protonen 2"'- $\mathrm{H}_{\mathrm{ax}}$ sowie $6 " '-\mathrm{H}_{\mathrm{ax}}$ und bei $\delta=3.44$ die äquatorial angeordneten Protonen 2 "'- $\mathrm{H}_{\mathrm{eq}}$ sowie 6"'- $\mathrm{H}_{\mathrm{eq}}$ des Piperidingerüstes als zentrierte Multipletts. Im Bereich mittlerer chemischer Verschiebungen resoniert $10-\mathrm{H}_{\mathrm{a}}$ bei $\delta=3.84$ als Dublett vom Dublett mit einer geminalen Kopplungskonstante von $J=11.3 \mathrm{~Hz}$ und einer vicinalen Kopplungskonstante von $J=7.8 \mathrm{~Hz}$. Es folgt ein zentriertes Multiplett bei $\delta=3.90$ für die Methylenprotonen 1"- $\mathrm{H}_{2}$ sowie bei $\delta=4.03$ ein Dublett vom Dublett für $10-\mathrm{H}_{\mathrm{b}}$ mit der geminalen Kopplungskonstante von $J=11.3 \mathrm{~Hz}$ und einer vicinalen Kopplungskonstante von $J=3.3 \mathrm{~Hz}$. $1-\mathrm{H}$ resoniert bei $\delta=4.22$ als zentriertes Multiplett. Es folgen die Signale der diasterotopen Protonen $2-\mathrm{H}_{\mathrm{a}}(\delta=4.55)$ und $2-\mathrm{H}_{\mathrm{b}}(\delta=4.78)$, die jeweils als Dublett vom Dublett resonieren. Die geminale Kopplungskonstante beträgt $J=10.8 \mathrm{~Hz}$ und die vicinale Kopplungskonstante $J=2.0 \mathrm{~Hz}\left(2-\mathrm{H}_{\mathrm{a}}\right)$ bzw. $J=9.4 \mathrm{~Hz}$ $\left(2-\mathrm{H}_{\mathrm{b}}\right)$.

Im Aromatenbereich resoniert das 6'-H als Dublett vom Dublett $\left(J_{o}=9.0 \mathrm{~Hz}\right.$, $J_{m}=2.2 \mathrm{~Hz}$ ) bei $\delta=6.93$. Es folgen das Singulett für 3 '-H bei $\delta=7.07$ und das Dublett mit $J_{m}=2.2 \mathrm{~Hz}$ für $4 '-\mathrm{H}$ bei $\delta=7.19$. Weiter tieffeldverschoben resonieren $7-\mathrm{H}$ und 8 - $\mathrm{H}$ als zentrierte Multipletts bei $\delta=7.37$ bzw. $\delta=7.53$. Dazwischen ist bei $\delta=7.41$ ein Dublett für das Proton 7'-H mit $J_{o}=9.0 \mathrm{~Hz}$ zu beobachten. Ebenfalls als Dublett resoniert 9-H bei $\delta=7.85$ mit einer Kopplungskonstante von $J_{o}=8.4 \mathrm{~Hz}$. Es folgen ein breites Singulett bei $\delta=7.96$ für $4-\mathrm{H}$ sowie ein Dublett mit $J_{o}=8.4 \mathrm{~Hz}$ bei $\delta=8.13$ für 6-H. Die $\mathrm{NH}^{+}$-Protonen resonieren als breites Singulett bei $\delta=9.93$ und die Protonen der Hydroxyfunktion als Singulett bei $\delta=10.4$. Am weitesten im tiefen Feld ist das Singulett des Indol-NH bei $\delta=11.6$ zu beobachten.

Im ${ }^{13} \mathrm{C}-\mathrm{NMR}-$ Spektrum von (+)-(1S)-56b (Abb. 50) resonieren im Hochfeld die Kohlenstoffe des Piperidingerüstes C-3"' und C-5"' bei $\delta=26.0$ sowie C-4"' bei $\delta=32.7$. Etwas weiter zu tiefem Feld verschoben sind die für Indoline charakteristischen Signale für C-1, C-10 und C-2 bei $\delta=41.2,47.4$ bzw. 54.9 zu beobachten. In diesem Bereich resonieren zudem die Methylgruppe der NMe-Funktionalität bei $\delta=42.7$, die verbleibenden Kohlenstoffatome des Piperidingerüstes C-2"' und C-6"' $(\delta=53.1)$ sowie C-1" $(\delta=71.6)$. Die drei am weitesten tieffeldverschobenen Signale können C-5' $(\delta=152.9)$, C-5 ( $\delta=154.1)$ und dem Carbonylkohlenstoff $(\delta=160.1)$ zugeordnet werden. Die Signale der aromatischen Kohlenstoffatome wurden durch ein HSQC-Spektrum bzw. mit Hilfe von Inkrementrechnungen zugeordnet. 


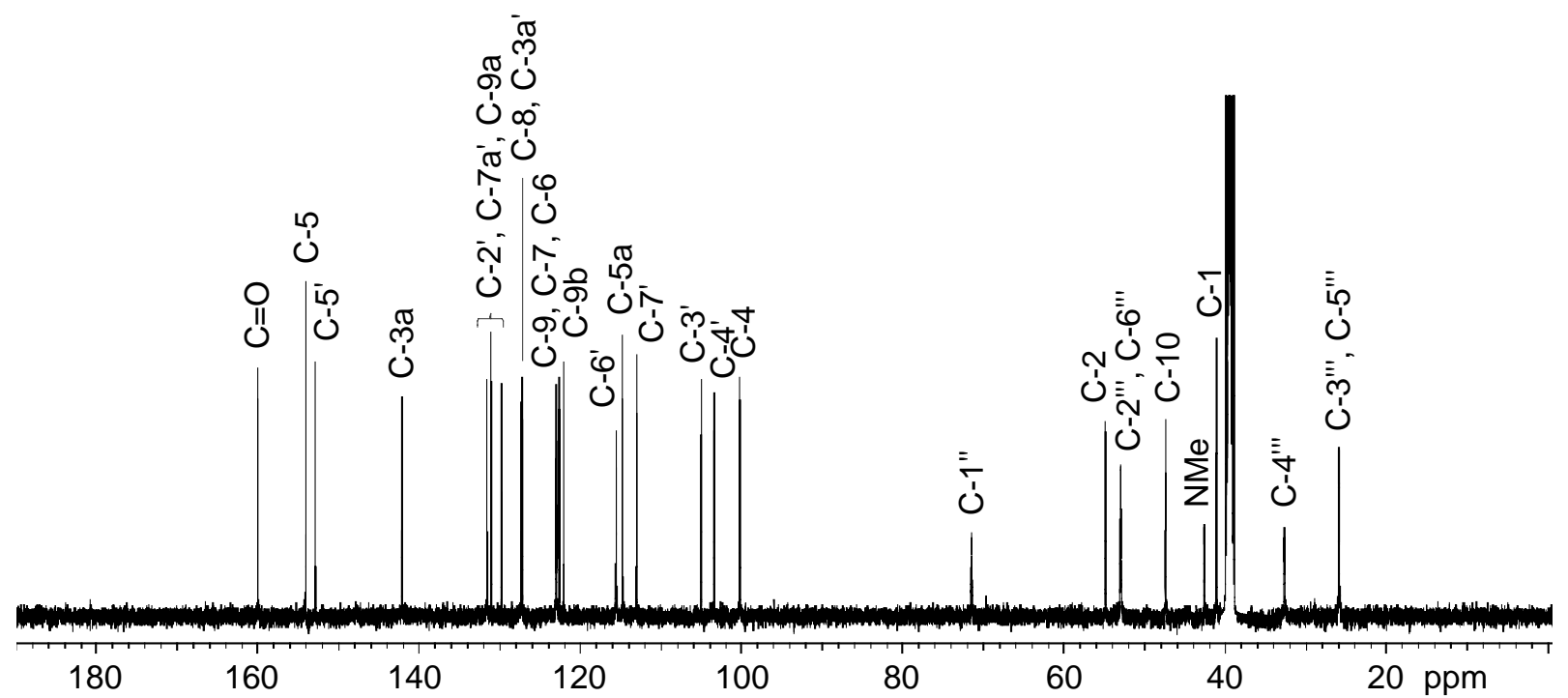

Abb. 50. ${ }^{13}$ C-NMR-Spektrum (125 MHz, DMSO-d $\left.\mathrm{d}_{6}\right)$ des seco-Drugs (+)-(1S)-56b.

Das ESI-Massen-Spektrum von (+)-(1S)-56b zeigt als Basispeak das Signal des secoDrug Hydrochlorids nach Abspaltung des Chlorids [M-Cl] ${ }^{+}$bei $m / z 504.2$ (rel. Intensität: 100). Darüber hinaus ist die dimere Spezies [2M-HCl-Cl] $]^{+}$bei $m / z 1007.4$ (rel. Intensität: 17) $\mathrm{zu}$ beobachten. Eine ESI-HRMS-Messung bestätigte den berechneten Wert von $m / z 504.2049$ für das Kation $[\mathrm{M}-\mathrm{Cl}]^{+}$. Charakteristische Banden im IR-Spektrum sind die breite Schwingungsbande für $\mathrm{NH}$ um $3405 \mathrm{~cm}^{-1}$ sowie die Carbonylbande der Amidbindung bei $1624 \mathrm{~cm}^{-1}$. 


\section{Synthese der fluoreszenzmarkierten anti-Methyl-seco-CBI- DMAI-Derivate}

Kürzlich gelang im Arbeitskreis L.F. Tietze die Synthese des fluoreszenzmarkierten Prodrugs (1S,10R)-74 (Abb. 51). ${ }^{141 \mathrm{f}}$ Ausgehend von dem für diese Synthese genutzten Substrat (-)-(1S,10R)-51 (Abb. 52) mit einer primären Aminofunktionalität in der Seitenkette an C-7, sollte über eine Kupplung mit NHS-aktivierten Farbstoffen die Synthese weiterer fluoreszenzmarkierter Prodrugs möglich sein.

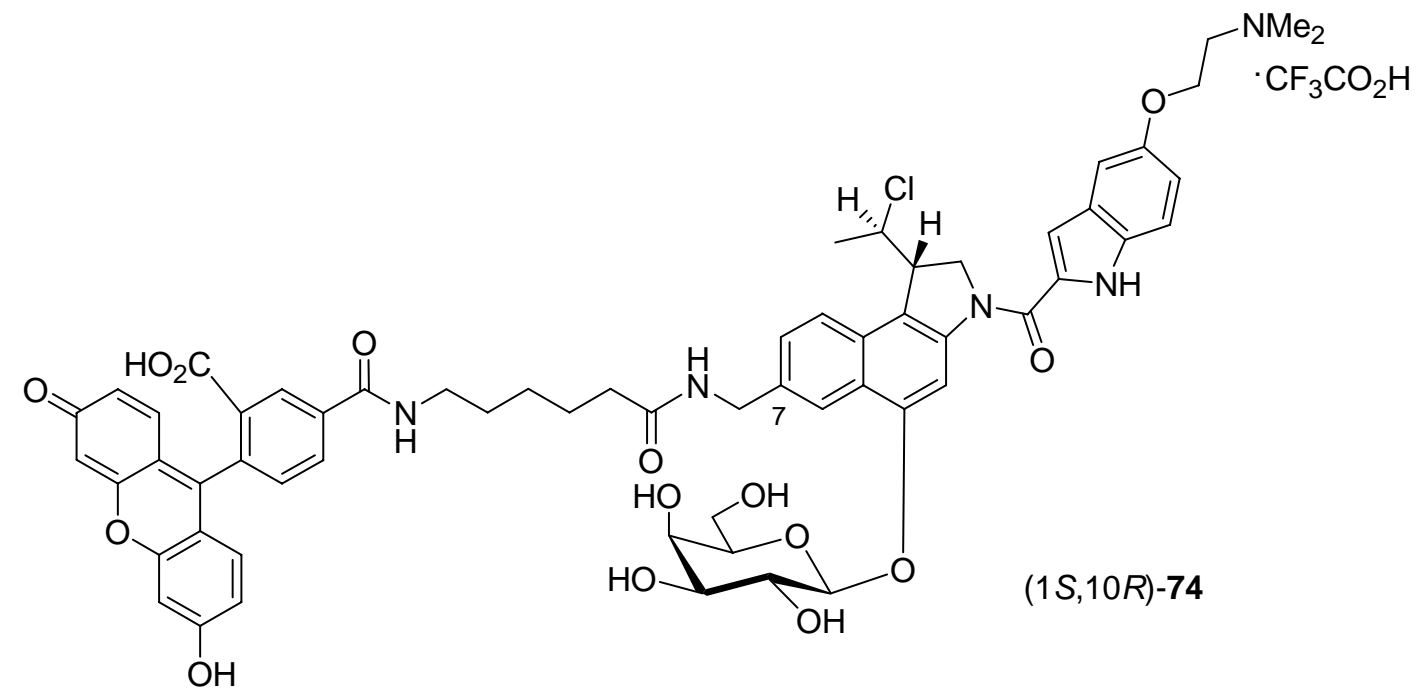

Abb. 51. Fluoreszenzmarkiertes Prodrug $(1 S, 10 R)-74$.

Im Rahmen dieser Arbeit wurde auf der Basis des Amins (-)-(1S,10R)-51 ein neues fluoreszenzmarkiertes Prodrug und aus diesem das erste fluoreszenzmarkierte secoDrug synthetisiert (Abb. 52). Als Farbstoff diente hierbei das kommerziell erhältliche NHS-aktivierte Dapoxyl ${ }^{\circledR}$-Derivat D10162 (39) der Firma Invitrogen. Eine aliphatische Abstandseinheit diente zu Trennung des Fluorophors vom Pharmakophor und verhindert so eine intramolekulare Fluoreszenzlöschung.

Dapoxy ${ }^{\circledR}$-Derivate weisen einen hervorragenden Extinktionskoeffizienten von 26000 und eine hohe Fluoreszenzquantenausbeute in organischen Lösungsmitteln auf, während die Fluoreszenz in Wasser gering ist. ${ }^{147}$ Zudem ist die Fluoreszenzemission der Derivate sehr stark von der Umgebung abhängig. Während das Maximum der Fluoreszenzemission in Methanol bei etwa $574 \mathrm{~nm}$ liegt, erfolgt die Emission in polareren Lösungsmitteln bei höherer Wellenlänge und in unpolareren Lösungsmitteln bei deutlich niedrigeren Wellenlängen (Beispiele: $\lambda_{\mathrm{em}}=615 \mathrm{~nm}$ (Acetonitril/Wasser $=1: 1), 580 \mathrm{~nm}$ (Acetonitril), $554 \mathrm{~nm}$ (Aceton), $515 \mathrm{~nm}$ (Chloroform) und $436 \mathrm{~nm}$ 
(Hexan)). Mit einem Anregungsmaximum von etwa $373 \mathrm{~nm}$ ist so der Unterschied zwischen den Absorptionsmaxima und den Fluoreszenzemissionsmaxima, der auch als Stokes-Shift bezeichnet wird, in organischen Lösungsmitteln mit etwa $200 \mathrm{~nm}$ sehr groß.

\subsection{Synthese des fluoreszenzmarkierten anti-Methyl-seco-CBI-DMAI- Prodrugs (1S,10R)-75}

Die Kupplung des Fluoreszenzfarbstoffs 39 mit dem primären Amin (-)-(1S,10R)-51 erfolgte in Gegenwart von Hünig-Base in DMF bei Raumtemperatur (Abb. 52). Nach einer Reaktionszeit von $9 \mathrm{~h}$ sowie einer nachfolgenden Reinigung mittels präparativer HPLC (Kromasil 100 C18) und Trocknung durch Lyophilisation wurde das fluoreszenzmarkierte glykosidische Prodrug $(-)-(1 S, 10 R)-\mathbf{7 5}$ als gelber Feststoff in einer sehr guten Ausbeute von 89\% erhalten.
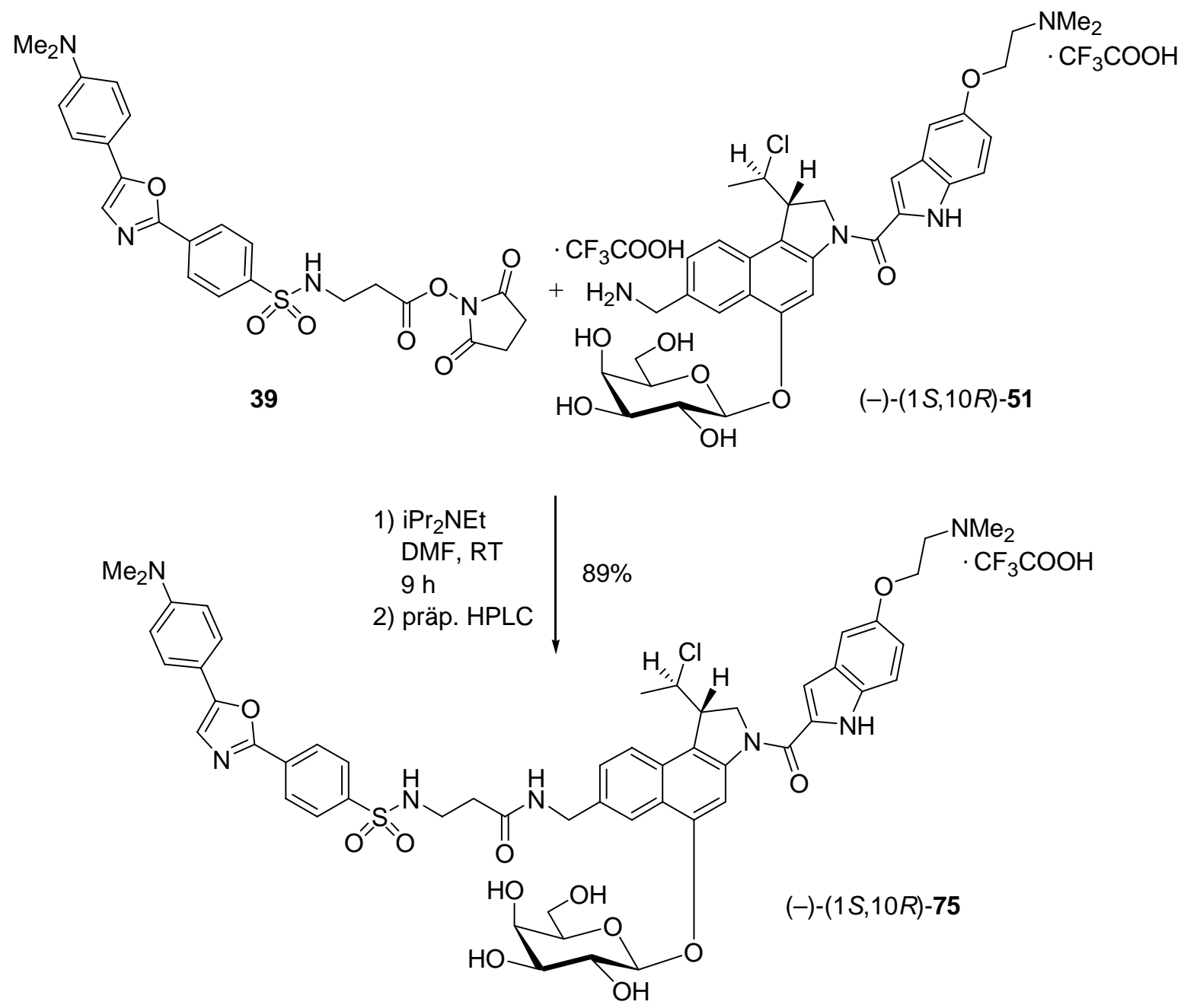

Abb. 52. Kupplung des Galactosides (-)-(1S,10R)-51 mit dem NHS-aktivierten Fluoreszenzfarbstoff D10162 (39) zum fluoreszenzmarkierten Prodrug (-)-(1S,10R)-75. 


\subsubsection{Diskussion ausgewählter spektroskopischer Daten von $(-)-(1 S, 10 R)-75$}

In Abbildung 53 ist das bei $80{ }^{\circ} \mathrm{C}$ in DMSO- $\mathrm{d}_{6}$ aufgenommene ${ }^{1} \mathrm{H}$-NMR-Spektrum des fluoreszenzmarkierten Prodrugs (-)-( $(S, 10 R)-75$ mit der entsprechenden Zuordnung dargestellt. Bei der gewählten Temperatur von $80^{\circ} \mathrm{C}$ erfolgt der H,D-Austausch bei den OH-Gruppen der $\beta$-D-Galactoseeinheit so schnell, dass die Signale dieser Protonen in dem abgebildeten Spektrum nicht beobachtet werden können. Hierdurch kommt es zu einer Vereinfachung des Spektrums.

Im Hochfeldbereich des Spektrums ist ein Dublett bei $\delta=1.63$ mit der Kopplungskonstante $J=6.6 \mathrm{~Hz}$ für die Methylprotonen $11-\mathrm{H}_{3}$ zu beobachten. Weiterhin sind ein Triplett bei $\delta=2.40$ mit $J=7.4 \mathrm{~Hz}$ für die $2^{\mathrm{S}}-\mathrm{H}_{2}$-Protonen und ein Triplett bei $\delta=3.14$ mit der gleichen Kopplungskonstante für die $3^{\mathrm{S}}-\mathrm{H}_{2}$-Protonen der aliphatischen Abstandseinheit zu finden; letzteres ist partiell vom Signal des Wassers überlagert. Die Methylgruppen der Dimethylaminofunktionalitäten resonieren als Singuletts bei $\delta=2.93\left(2 "-\mathrm{NMe}_{2}\right)$ bzw. $\delta=2.98\left(12^{\#}-\mathrm{NMe}_{2}\right)$.

Die Protonen der $\beta$-D-Galactose-Einheit mit Ausnahme des anomeren 1"'-H resonieren bei $\delta=3.40-3.90$. Ihre Zuordnung erfolgte mit Hilfe eines COSY-Spektrums. Bei $\delta=3.48$ resoniert 3'"-H als Dublett vom Dublett mit den Kopplungskonstanten $J_{a x, a x}=9.6 \mathrm{~Hz}$ und $J_{a x, e q}=3.2 \mathrm{~Hz}$. Das benachbarte Multiplett bei $\delta=3.52-3.57$ wird durch eine Überlagerung des Signals für 5 "'-H und des Signals für die Methylenprotonen 2"- $\mathrm{H}_{2}$ verursacht. Bei $\delta=3.60$ bzw. $\delta=3.69$ resonieren die beiden diastereotopen Protonen an C-6"' jeweils als Dublett vom Dublett mit einer geminalen Kopplungskonstante von $J=10.6 \mathrm{~Hz}$ und den vicinalen Kopplungskonstanten $J=5.5 \mathrm{~Hz}\left(6^{\prime \prime \prime}-\mathrm{H}_{\mathrm{a}}\right)$ bzw. $J=7.2 \mathrm{~Hz}\left(6^{\prime \prime}-\mathrm{H}_{\mathrm{b}}\right)$. Bei $\delta=3.81-3.86$ folgt ein Multiplett für 2"'-H und 4"'-H. Das anomere 1"'-H resoniert bei $\delta=4.92$ als Dublett mit einer für die $\beta$-glykosidische Bindung charakteristischen Kopplungskonstante von $J_{a x, a x}=7.8 \mathrm{~Hz}$.

Bei $\delta=4.20$ ist das dem 1-H zuzuordnende Dublett vom Triplett mit den Kopplungskonstanten $J=9.4 \mathrm{~Hz}$ und $J=2.6 \mathrm{~Hz}$ zu beobachten. In Richtung stärkerer chemischer Verschiebung folgt bei $\delta=4.36$ ein Triplett mit einer Kopplungskonstante von $J=5.0 \mathrm{~Hz}$ für die Methylenprotonen $1 "-\mathrm{H}_{2}$ sowie ein zentriertes Multiplett bei $\delta=4.42$ für die Methylenprotonen $12-\mathrm{H}_{2}$. 


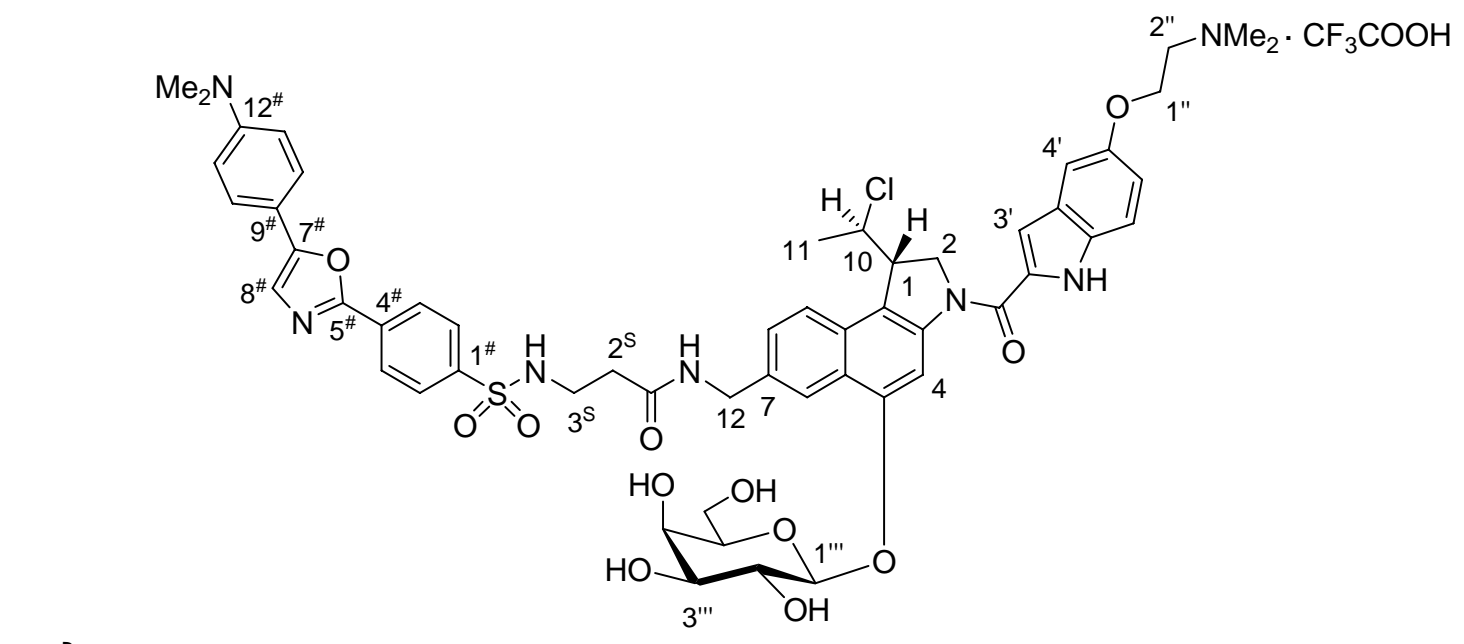

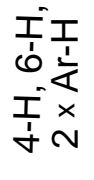
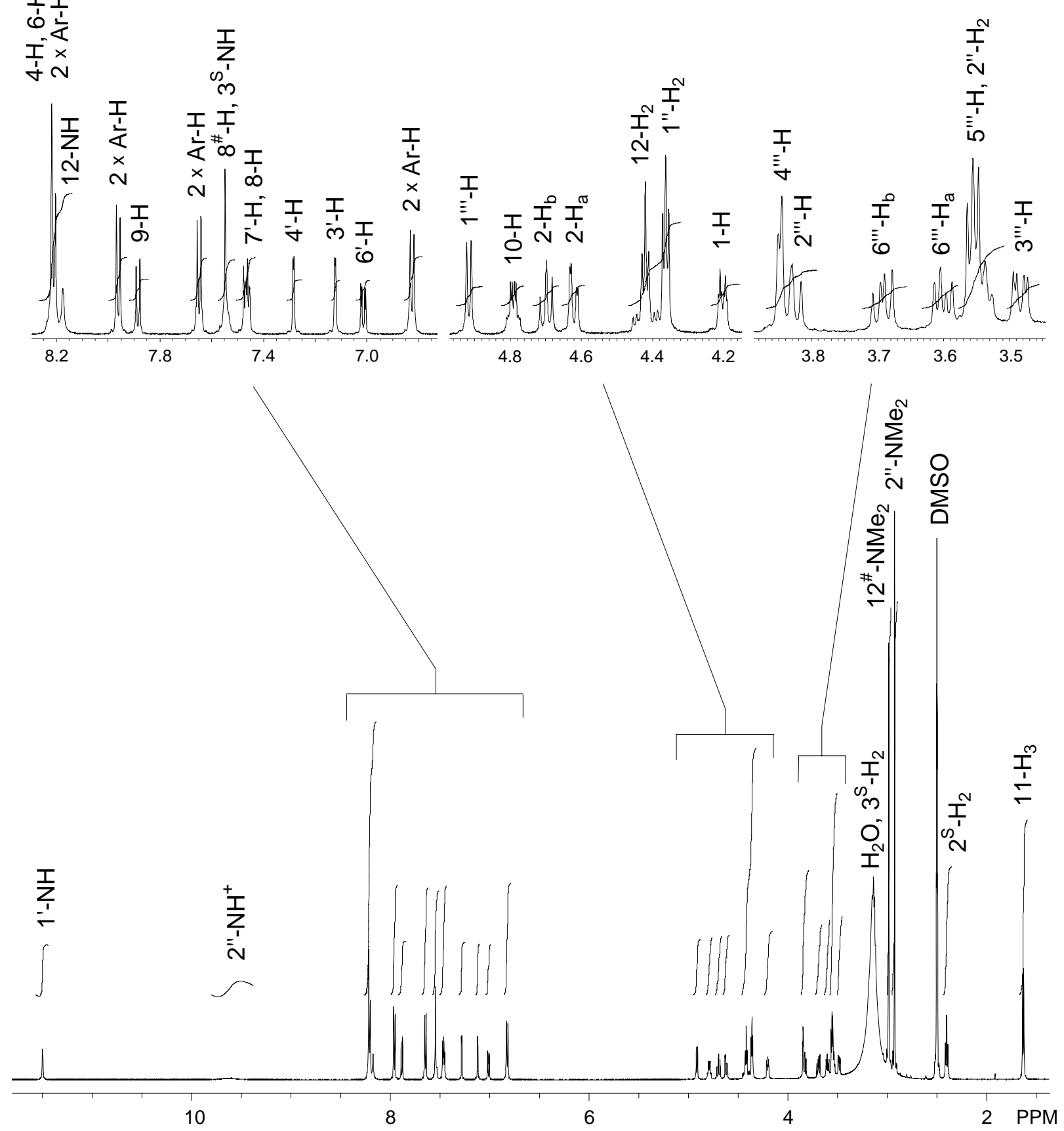

Abb. 53. ${ }^{1} \mathrm{H}-\mathrm{NMR}-\mathrm{Spektrum}\left(600 \mathrm{MHz}, \mathrm{DMSO}-\mathrm{d}_{6}, 80^{\circ} \mathrm{C}\right)$ des Prodrugs $(-)-(1 S, 10 R)-75$. 
Die diastereotopen Protonen 2- $\mathrm{H}_{\mathrm{a}}$ und 2- $\mathrm{H}_{\mathrm{b}}$ resonieren als Dubletts von Dubletts bei $\delta=4.62$ bzw. $\delta=4.70$ mit einer geminalen Kopplungskonstante von $J=11.0 \mathrm{~Hz}$ und einer vicinalen Kopplungskonstante von $J=2.6 \mathrm{~Hz}\left(2-\mathrm{H}_{\mathrm{a}}\right)$ bzw. $J=9.4 \mathrm{~Hz}\left(2-\mathrm{H}_{\mathrm{b}}\right)$. Des Weiteren ist für $10-\mathrm{H}$ ein Dublett vom Quartett mit Kopplungskonstanten von $J=6.6 \mathrm{~Hz}$ (Kopplung zu $11-\mathrm{H}_{3}$ ) und $J=2.6 \mathrm{~Hz}$ (Kopplung zu 1-H) bei $\delta=4.79 \mathrm{zu}$ beobachten.

Im Aromatenbereich können 4 Dubletts mit einer Kopplungskonstante von $J=9.0 \mathrm{~Hz}$ beobachtet werden, die jeweils 2 Aryl-Protonen zugeordnet werden können. Beginnend im Hochfeldbereich zeigen die Signale eine chemische Verschiebung von $\delta=6.83, \delta=7.65, \delta=7.96$ und $\delta=8.20-8.23$. Das am stärksten hochfeldverschobene Signal hat aufgrund der Überlagerung mit 4-H und 6-H die Struktur eines Multipletts. Ebenfalls als Multipletts resonieren 7 ' $-\mathrm{H}$ und 8 -H bei $\delta=7.45-7.48$ sowie $3^{\mathrm{S}}-\mathrm{NH}$ und $8^{\#}-\mathrm{H}$ bei 7.54-7.56. 6'-H resoniert als Dublett vom Dublett $\left(J_{o}=9.0 \mathrm{~Hz}\right.$ und $\left.J_{m}=2.2 \mathrm{~Hz}\right)$ bei $\delta=7.01,4^{\prime}-\mathrm{H}$ als Dublett $\left(J_{m}=2.2 \mathrm{~Hz}\right)$ bei $\delta=7.28$ und $3^{\prime}-\mathrm{H}$ als Dublett bei $\delta=7.12$ mit einer charakteritischen Kopplungskonstante von $J_{m}=2.0 \mathrm{~Hz}$ für die Kopplung zum Indol-NH. Charakteristisch sind darüber hinaus die breiten Singuletts bei $\delta=8.18$ für $12-\mathrm{NH}$ und $\delta=9.64$ für $\mathrm{NH}^{+}$sowie das Singulett bei $\delta=11.5$ für das Indol-NH (1'-NH).

Im ${ }^{13} \mathrm{C}-\mathrm{NMR}$-Spektrum von (-)-(1S,10R)-75 (Abb. 54) kann erwartungsgemäß das Signal für C-11 im Hochfeld bei $\delta=23.4$ beobachtet werden. Es folgen die Kohlenstoffatome der Abstandseinheit $\mathrm{C}-2^{\mathrm{S}}(\delta=35.5)$ und $\mathrm{C}-3^{\mathrm{S}}(\delta=38.7), \mathrm{C}-12(\delta=42.5)$ sowie die Signale der Dimethylaminofunktionalitäten bei $\delta=40.1\left(12^{\#}-\mathrm{NMe}_{2}\right)$ bzw. $\delta=42.9\left(2 "-\mathrm{NMe}_{2}\right)$. Darüber hinaus sind die für Indoline charakteristischen Signale für C-1, C-2 und C-10 bei $\delta=46.0,52.0$ und $61.4 \mathrm{zu}$ beobachten. Im Hochfeld resonieren außerdem C-2" und C-1" bei $\delta=55.7$ bzw. 62.7. Die Signale aller Kohlenstoffatome der $\beta$-D-Galactose-Einheit sind mit Ausnahme des anomeren C-1"' $(\delta=102.1)$ im Bereich von $\delta=59.5$ (C-6"') bis $\delta=75.2$ (C-5"') zu beobachten. Die drei am weitesten tieffeldverschobenen Signale sind dem Carbonylkohlenstoffatom $2^{\mathrm{S}}$-CO $(\delta=169.6)$, dem Carbonylkohlenstoffatom der Trifluoressigsäure $(\delta=160.0)$ sowie dem 1'-CO zusammen mit C-5 $5^{\#}(\delta=157.5)$ zuzuordnen. Etwas weiter zu hohem Feld verschoben folgen die Signale von C-5 $(\delta=153.4)$, C-5' $(\delta=152.7)$, $\mathrm{C}-12^{\#}(\delta=152.0)$ und $\mathrm{C}-7^{\#}(\delta=150.5)$. Die übrigen Signale konnten mit einem HSQC-Spektrum bzw. mit Hilfe von Inkrementrechnungen zugeordnet werden. 


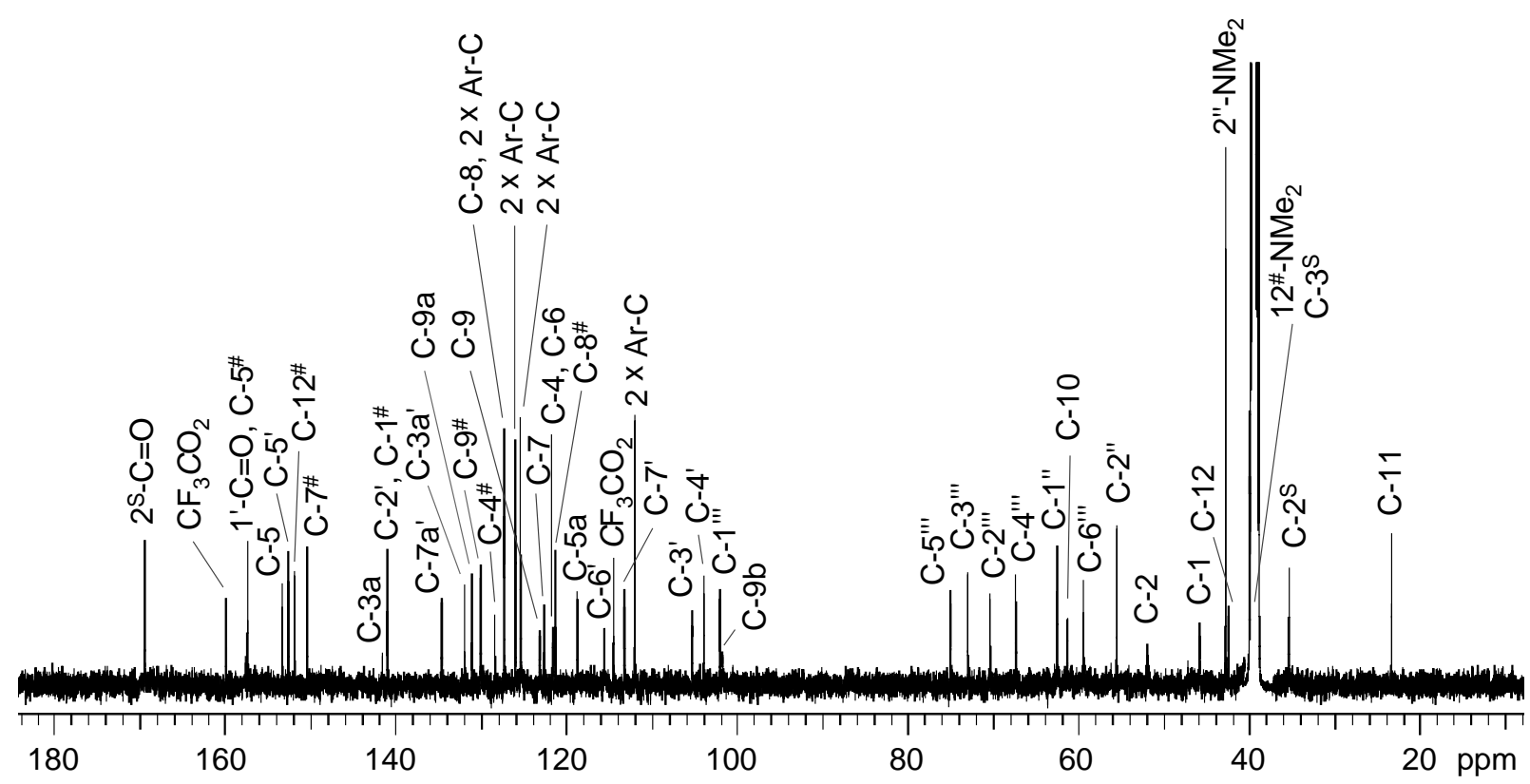

Abb. 54. ${ }^{13}$ C-NMR-Spektrum (125 MHz, DMSO-d 6 ) des Prodrugs (-)-(1S,10R)-75.

Das ESI-Massen-Spektrum von (-)-(1S,10R)-75 zeigt bei $\mathrm{m} / \mathrm{z} 1066.4$ einen Peak mit der relativen Intensität von $100 \%$, der dem $\left[\mathrm{M}-\mathrm{CF}_{3} \mathrm{CO}_{2}\right]^{+}$-Ion zugeordnet werden kann. Darüber hinaus sind die beiden doppelt geladenen Ionen $\left[\mathrm{M}-\mathrm{CF}_{3} \mathrm{CO}_{2}+\mathrm{H}\right]^{2+}$ mit m/z 533.7 (rel. Intensität: 80) sowie das durch Zuckerabspaltung im Massenspektrometer entstehende $\left[\mathrm{M}-\mathrm{CF}_{3} \mathrm{CO}_{2}-\mathrm{C}_{6} \mathrm{H}_{11} \mathrm{O}_{5}+\mathrm{H}\right]^{2+}$ mit $\mathrm{m} / z 452.7$ (rel. Intensität: 41) zu beobachten. Eine ESI-HRMS-Messung bestätigte den berechneten Wert von $m / z 1166.3782$ für die Masse des $\left[\mathrm{M}-\mathrm{CF}_{3} \mathrm{CO}_{2}\right]^{+}$-Ions. Charakteristische Banden im IR-Spektrum sind die breite Schwingungsbande für $\mathrm{NH}$ um $3406 \mathrm{~cm}^{-1}$ sowie die Carbonylbanden der Amidbindungen bei 1675 und $1616 \mathrm{~cm}^{-1}$. 


\subsection{Synthese des fluoreszenzmarkierten anti-Methyl-seco-CBI-DMAI- Hydrochlorids (1S,10R)-76}

Die Synthese des fluoreszenzmarkierten seco-Drugs $(1 S, 10 R)-\mathbf{7 6}$ sollte ausgehend vom entsprechenden fluoreszenzmarkierten Prodrug (-)-(1S,10R)-75 durch Abspaltung der Zuckereinheit erfolgen. Eine Spaltung der glykosidischen Bindung war mit Wasser/Essigsäure oder Wasser/Trifluoressigsäure bei Raumtemperatur nicht erfolgreich und führte bei höheren Temperaturen $\left(50{ }^{\circ} \mathrm{C}-70{ }^{\circ} \mathrm{C}\right)$ zunächst zu einem Austausch des Chloratoms gegen eine Hydroxyfunktion und erst danach zur Abspaltung der Zuckereinheit. Mit wasserfreier $4 \mathrm{M} \mathrm{HCl}$ in Essigester konnte nach 20 Stunden bei Raumtemperatur zwar eine partielle Glykosidspaltung beobachtet werden, es trat jedoch zusätzlich eine durch den Essigester bedingte Acylierung an einer nukleophilen Molekülfunktionalität auf. Die Darstellung des seco-Drugs $(1 S, 10 R)$-76 gelang schließlich mit einer Mischung aus konzentrierter wässriger $\mathrm{HCl}$ in $\mathrm{MeOH}$ bei Raumtemperatur (Abb. 55).
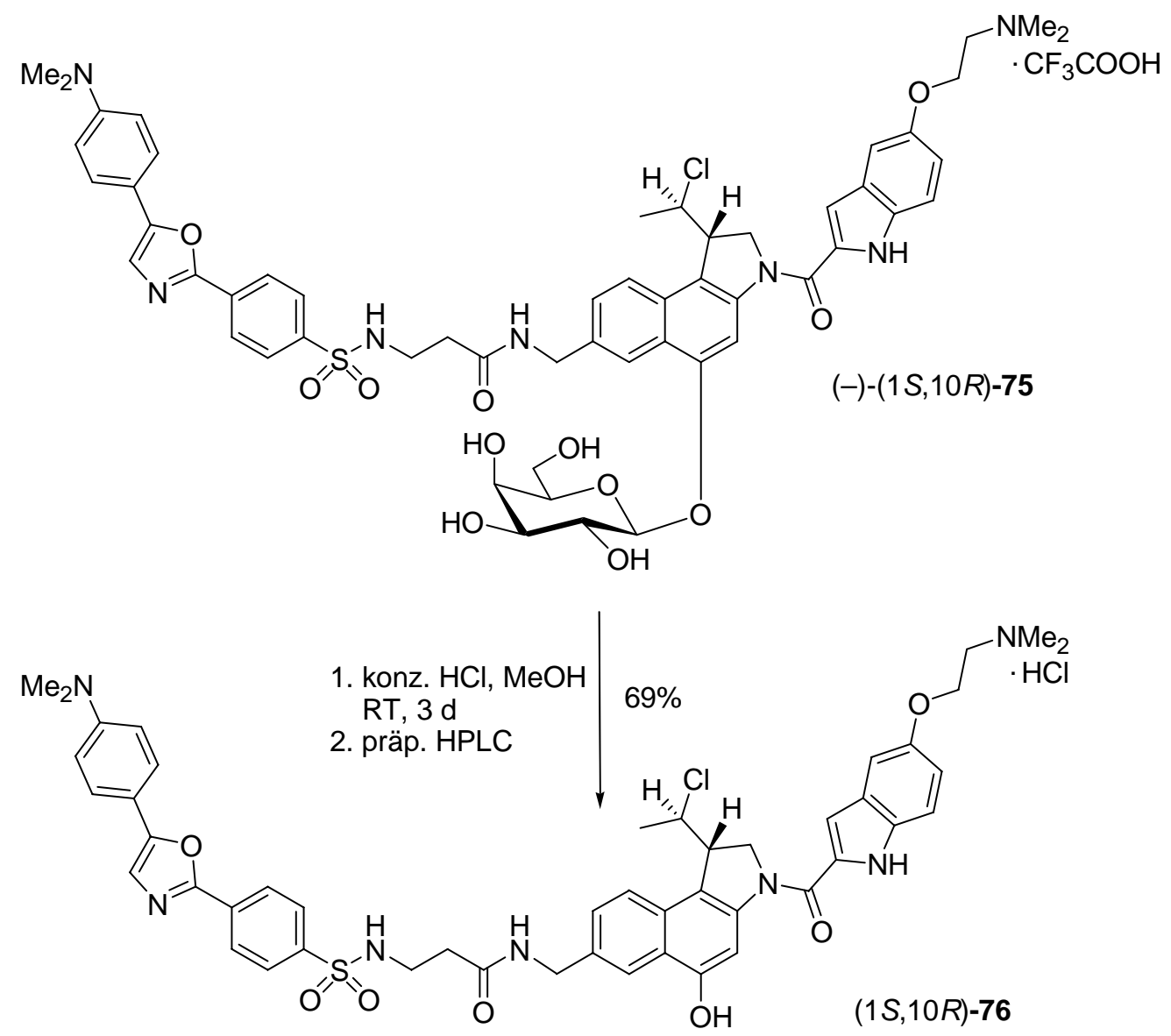

Abb. 55. Abspaltung der Zuckereinheit im fluoreszenzmarkierten Prodrug (-)-( $1 S, 10 R)-75$ zum entsprechenden fluoreszenzmarkierten seco-Drug $(1 S, 10 R)-\mathbf{7 6}$. 
Interessanterweise stellte sich hierbei ein Gleichgewicht zwischen dem Edukt und dem Produkt ein, das auch durch Zugabe weiterer Säure nicht in Richtung des Produktes verschoben werden konnte. Bei zu langer Reaktionszeit begann zudem eine Zersetzung des seco-Drugs. Das Produkt wurde daher mittels präparativer HPLC vom Edukt und den Nebenprodukten getrennt, das Edukt erneut den gleichen Reaktionsbedingungen unterworfen und von der enstehenden Mischung mittels präparativer HPLC das Produkt vom Edukt getrennt. Die Vereinigung der Produktfraktionen lieferte $(1 S, 10 R)-76$ in $69 \%$ Ausbeute.

\subsubsection{Diskussion ausgewählter spektroskopischer Daten des seco-Drugs $(1 S, 10 R)-76$}

In Abbildung 56 ist das bei $80{ }^{\circ} \mathrm{C}$ in DMSO- $\mathrm{d}_{6}$ aufgenommene ${ }^{1} \mathrm{H}-\mathrm{NMR}-$ Spektrum des fluoreszenzmarkierten seco-Drugs $(1 S, 10 R)$-76 mit der entsprechenden Zuordnung dargestellt.

Im Hochfeldbereich des Spektrums ist zunächst das charakteristische Dublett bei $\delta=1.61 \mathrm{mit}$ der Kopplungskonstante $J=6.7 \mathrm{~Hz}$ für die Methylprotonen $11-\mathrm{H}_{3} \mathrm{zu}$ beobachten. Es folgt ein Triplett bei $\delta=2.37$ mit einer Kopplungskonstante von $J=7.2 \mathrm{~Hz}$, welches den $2^{\mathrm{S}}-\mathrm{H}_{2}$-Protonen der aliphatischen Spacereinheit zugeordnet werden kann. Die gleiche Kopplungskonstante findet sich im Dublett vom Triplett bei $\delta=3.07$ wieder, das den $3^{\mathrm{S}}-\mathrm{H}_{2}$-Protonen der Abstandseinheit zuzuordnen ist. Zusätzlich kann für diese Protonen eine Kopplung zum Proton der benachbarten NHFunktionalität mit $J=6.0 \mathrm{~Hz}$ beobachtet werden. Zwischen den Signalen der genannten Methylenprotonen resonieren die Methylgruppen der beiden Dimethylaminofunktionalitäten. Hierbei resoniert 2"- $\mathrm{NMe}_{2}(\delta=2.88)$ durch die Kopplung der Methylprotonen zum $\mathrm{NH}^{+}$als Dublett und $12^{\#}-\mathrm{NMe}_{2}(\delta=2.98)$ als Singulett. Es folgen zwei zentrierte Multipletts für 2"- $\mathrm{H}_{2}(\delta=3.54)$ und 1-H $(\delta=4.14)$ sowie ein Multiplett bei $\delta=4.33-4.41$ für $1 "-\mathrm{H}_{2}$ und 12- $\mathrm{H}_{2}$. Im Bereich mittlerer chemischer Verschiebung kann zudem für 2- $\mathrm{H}_{\mathrm{a}}$ bei $\delta=4.56$ ein Dublett vom Dublett mit $J=11.0 \mathrm{~Hz}$ für die geminale Kopplung und $J=2.0 \mathrm{~Hz}$ für die vicinale Kopplung beobachtet werden. Das zu 2- $\mathrm{H}_{\mathrm{a}}$ diastereotope Proton $2-\mathrm{H}_{\mathrm{b}}$ resoniert zusammen mit 10-H als Multiplett bei $\delta=4.68-4.76$. 

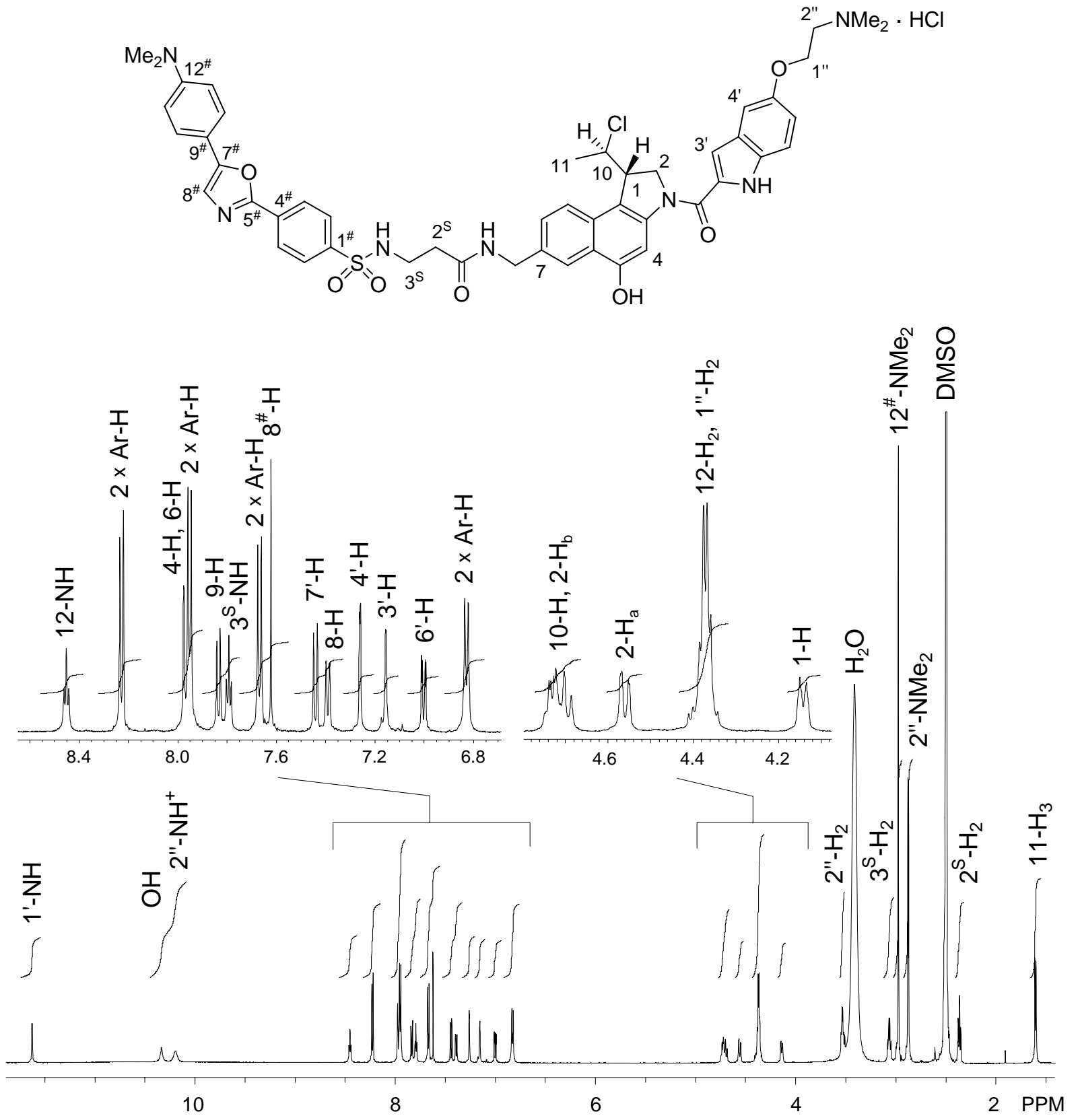

Abb. 56. ${ }^{1} \mathrm{H}-\mathrm{NMR}-S p e k t r u m\left(600 \mathrm{MHz}, \mathrm{DMSO}_{6} \mathrm{~d}_{6}\right)$ des seco-Drugs $(1 S, 10 R)-76$.

Im Aromatenbereich sind 4 Dubletts mit einer Kopplungskonstante von $J=8.8 \mathrm{~Hz} \mathrm{zu}$ beobachten, die jeweils 2 Aryl-Protonen zugeordnet werden können. Beginnend im Hochfeldbereich zeigen die Signale eine chemische Verschiebung von $\delta=6.83$, $\delta=7.67, \delta=7.94-7.99$ (Multiplett durch Überlagerung mit 4-H und 6-H) bzw. $\delta=8.23$. 6 '- $\mathrm{H}$ resoniert als Dublett vom Dublett mit $J_{o}=9.0 \mathrm{~Hz}$ und $J_{m}=2.4 \mathrm{~Hz}$ bei $\delta=7.00,4^{\prime}-\mathrm{H}$ resoniert als Dublett mit $J_{m}=2.4 \mathrm{~Hz}$ bei $\delta=7.26$ und 7'-H als Dublett mit $J_{o}=9.0 \mathrm{~Hz}$ bei $\delta=7.44$. Das Signal für $3^{\prime}-\mathrm{H}$ kann bei $\delta=7.16$ als Dublett mit einer charakteritischen Kopplungskonstante von $J=1.8 \mathrm{~Hz}$ für die Kopplung zum Indol-NH beobachtet werden. Des Weiteren zeigt 8 -H bei $\delta=7.39$ ein Dublett vom 
Dublett $\left(J_{o}=8.5 \mathrm{~Hz}\right.$ und $\left.J_{m}=1.4 \mathrm{~Hz}\right), 9-\mathrm{H}$ bei $\delta=7.84$ ein Dublett $\left(J_{o}=8.5 \mathrm{~Hz}\right)$ und $8^{\#}$-H bei $\delta=7.62$ ein Singulett. Das Sulfonamidproton $3^{\mathrm{S}}-\mathrm{NH}$ resoniert bei $\delta=7.79$ als Triplett mit einer Kopplungskonstante von $J=6.0 \mathrm{~Hz}$ zu den Methylenprotonen $3^{\mathrm{S}}-\mathrm{H}_{2}$. 12-NH resoniert bei $\delta=8.45$ ebenfalls als Triplett mit einer Kopplungskonstante von $J=6.0 \mathrm{~Hz} z u$ den Methylenprotonen an 12- $\mathrm{H}_{2}$. Charakteristisch sind darüber hinaus die breiten Singuletts bei $\delta=10.2$ und 10.3 für $\mathrm{OH}$ bzw. $\mathrm{NH}^{+}$sowie das Singulett bei $\delta=11.6$ für das Indol-NH (1'-NH).

Das ESI-Spektrum von (1S,10R)-76 zeigt bei $m / z 904.3$ einen Peak mit der relativen Intensität von $100 \%$, der dem $[\mathrm{M}-\mathrm{Cl}]^{+}$-Ion zuzuordnen ist. Eine ESI-HRMS-Messung bestätigte zudem den berechneten Wert von $\mathrm{m} / z$ 904.3254 für die Masse des [M-Cl] ${ }^{+}$ Ions. 


\section{In-vitro-Zytotoxizitäten der neuen Analoga}

Zur Bestimmung der In-vitro-Zytotoxizität der neuen Verbindungen wurden von $\mathrm{Dr}$. Ingrid Schuberth, Anja Herdlitschke und Angela Rübeling in der Abteilung für Zellbiologie des Institutes für Organische und Biomolekulare Chemie In-vitro-Untersuchungen durchgeführt. Die Bestimmung der Zytotoxizität erfolgte hierbei nach dem

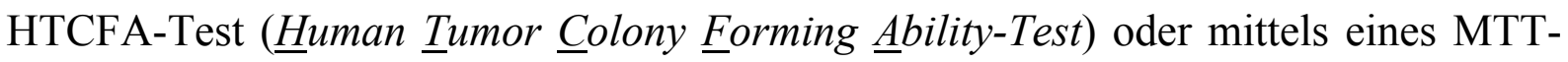
Tests (3-(4,5-Dimethylthiazol-2-yl)-2,5-diphenyltetrazoliumbromid).

\subsection{Der HTCFA-Test zur Bestimmung der Zytotoxizität}

Um die zytotoxische Wirkung der neu synthetisierten Substanzen auf adhärent wachsende humane Tumorzellen zu untersuchen, erfolgte ein Klonogenitätstest, der sich an den HTCFA-Test anlehnt und die Proliferationsfähigkeit von einzelnen Zellen widergibt (Abb. 57). Als Zelllinie diente das adhärent wachsende humane Bronchialkarzinom der Linie A549. Die Aussaat der Tumorzellen erfolgte aus einer Stammkultur, in der sie in einem Kulturmedium (DMEM mit Zusatz von 10\% fötalem Kälberserum, $44 \mathrm{mM} \mathrm{NaHCO}$ und $4 \mathrm{mM}$ Glutamin) bei $37{ }^{\circ} \mathrm{C}$ und $7.5 \% \mathrm{CO}_{2}$-Begasung in Luft permanent gehalten wurden, in Konzentrationen von $10^{2}$ bis $10^{4}$ Zellen in 6-well Multischalen. Nach 24 Stunden wurde das Kulturmedium entfernt, die Zellen einmal mit dem serumfreien Inkubationsmedium UltraCulture gewaschen und die Zellen anschließend in diesem Medium 24 Stunden mit zehn bis zwölf verschiedenen Konzentrationen (drei dekadische Größenordnungen) der $\mathrm{zu}$ testenden Substanz inkubiert. Diese wurde vorher frisch in einer DMSO-Stammlösung angesetzt und mit dem Inkubationsmedium verdünnt, so dass in den Näpfen letztlich eine DMSOKonzentration von $1 \%$ vorlag. Nach Entfernen der Testsubstanz und einem weiteren Waschgang mit dem Kulturmedium wurden die verbliebenen Zellen 12 Tage in normalem Kulturmedium kultiviert. Anschließend wurde dieses entfernt, die gebildeten Klone wurden getrocknet, mit Löffler's Methylenblau angefärbt und ab einer Klongröße von ca. $500 \mu \mathrm{m}$ makroskopisch ausgezählt. Die Bestimmung der relativen Klonbildungsraten erfolgte anhand der in Abbildung 57 angegebenen Formel, wobei sich die Klonzahl des Kontrollversuches aus unbehandelten Zellen ergab und gleich $100 \%$ gesetzt wurde. Die Freisetzung der zytotoxischen Verbindungen aus den Prodrugs erfolgte durch Zugabe von $4.0 \mathrm{U} / \mathrm{mL} \beta$-D-Galactosidase. Jede Versuchsreihe wurde in der Regel mindestens dreimal als Duplikat durchgeführt, um reproduzierbare Testergebnisse zu erhalten. 


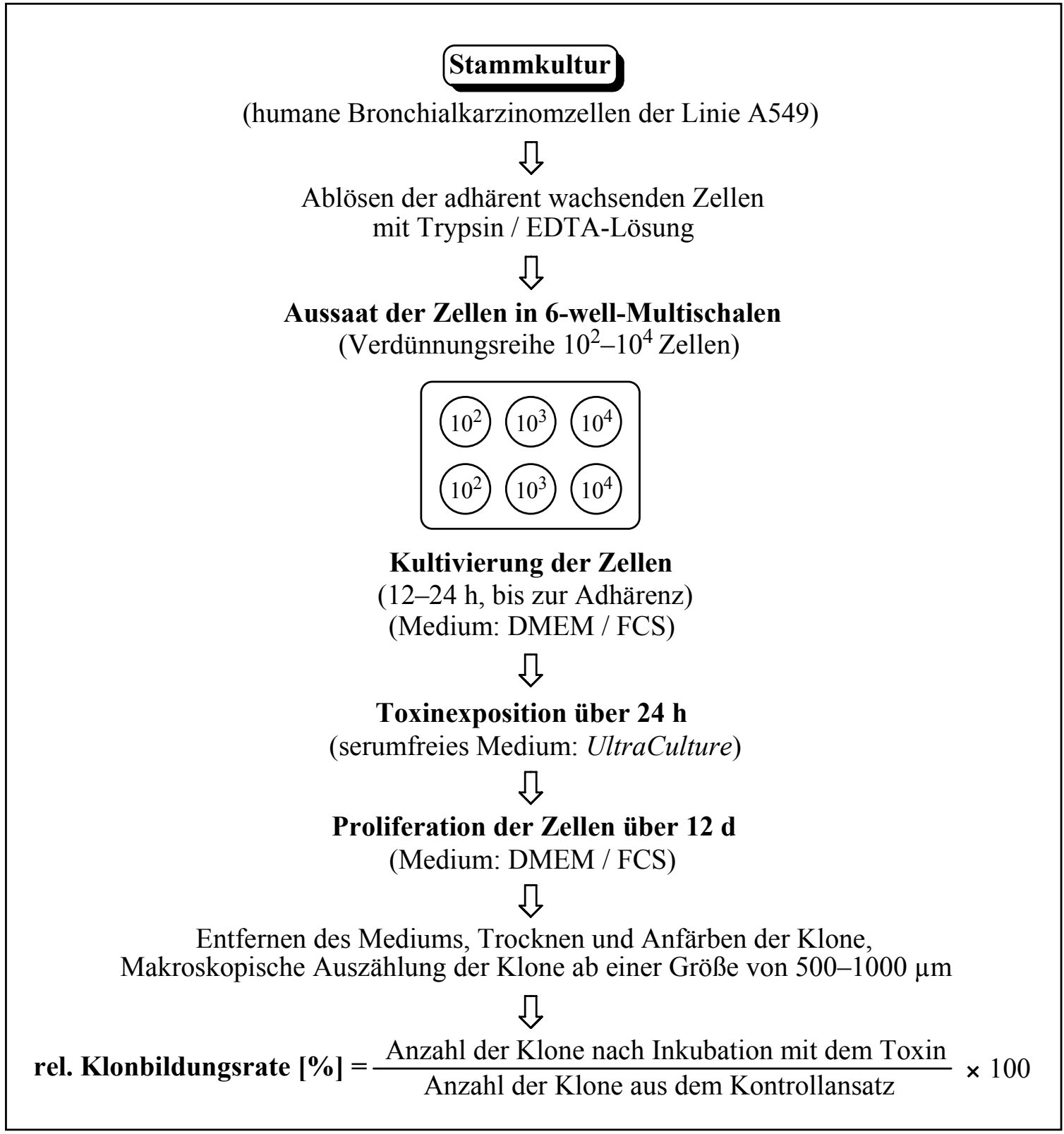

Abb. 57. Schematische Darstellung des HTCFA-Tests, modifiziert nach I. Schuberth.

\subsection{Der MTT-Test zur Bestimmung der Zytotoxizität}

Um die zytotoxische Wirkung der neu synthetisierten Substanzen auf adhärent und nicht adhärent wachsende humane Tumorzellen zu untersuchen, erfolgte eine Bestimmung der Vitalität der Zellen nach Toxinexposition mittels eines modifizierten MTT-Tests (Abb. 58). MTT-Tests beruhen auf der irreversiblen enzymatischen Reduktion des gelben Tetrazoliumsalzes MTT (3-(4,5-Dimethylthiazol-2-yl)-2,5diphenyltetrazoliumbromid, 77) zu dem blau-violetten wasserunlöslichen Formazan 78, die in lebenden und somit stoffwechselaktiven Zellen stattfindet (Abb. 59). ${ }^{172}$ 


\section{Stammkultur}

(humane Lymphomzellen der Linie HL-60 oder humane Bronchialkarzinomzellen der Linie A549)

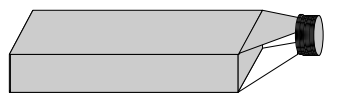

$$
\text { 凡 }
$$

Zellzählung und Aussaat der Zellen

(in $50 \mu 1$ Medium (serumfrei) in 96-well Multischale)

$$
\text { ת }
$$

Zugabe des Toxins in verschiedenen Konzentrationen (in $50 \mu \mathrm{l}$ Medium (serumfrei))

凡

Toxinexposition über $72 \mathbf{h}$

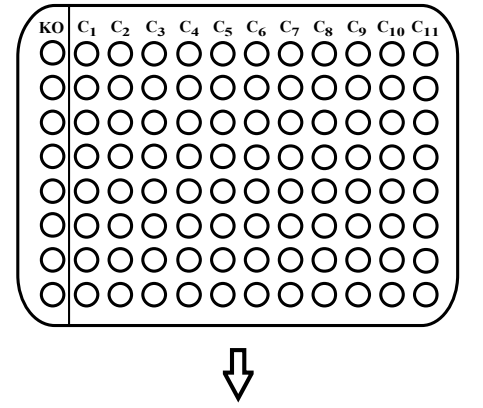

Zugabe des MTT-Reagenzes

(mit einer Endkonzentration von $0.5 \mathrm{mg} / \mathrm{ml}$ )

凸

nach 4h Abstoppen mit Solubilisierungslösung und Lösen der Formazan-Kristalle über Nacht bei $37^{\circ} \mathrm{C}$

』

\section{Photometrische Auswertung}

durch Messung der Absorption bei $\lambda=580 \mathrm{~nm}$ gegen $\lambda=650 \mathrm{~nm}$

Abb. 58. Schematische Darstellung des MTT-Tests, modifiziert nach I. Schuberth.<smiles>CC1N=C(N(N=Nc2ccccc2)n2nc(-c3ccccc3)cc2Br)SC1C</smiles>

MTT (77)<smiles>CC1N=C(N=NC(=NNc2ccccc2)c2ccccc2)SC1C</smiles>

78

Abb. 59. Reduktion des gelben MTT (77) zum blauen Formazan 78 in lebenden Zellen. 
Nach Lyse der Zellen kann die Absorption von 78 in einem Photometer bei einer Wellenlänge von $580 \mathrm{~nm}$ bestimmt werden. Da die gemessene optische Dichte bei dieser Wellenlänge dem Anteil lebender, stoffwechselaktiver Zellen direkt proportional ist, kann so der Anteil lebender Zellen in einer Probe bestimmt werden.

\subsection{In-vitro-Zytotoxizität (HTCFA) der (1S)-seco-CBI-DMAI-Derivate}

Die In-vitro-Zytotoxizität der neuen (1S)-seco-CBI-DMAI-Derivate (-)-(1S)-54a und $(+)-(1 S)$-56a wurde mittels eines HTCFA-Tests an humanen Bronchialkarzinomzellen (A549) ermittelt (Abb. 60). Die Bestimmung der relativen Klonbildungsrate erfolgte hierbei für das Prodrug (1S)-54a in Abwesenheit (o. E.) und in Anwesenheit (m. E.) des aktivierenden Enzyms $\beta$-D-Galactosidase, um den Zytotoxizitätsunterschied zwischen dem Prodrug und dem aus diesem in situ generierten seco-Drug, d.h. den $Q I C_{50}$-Wert, zu bestimmen.

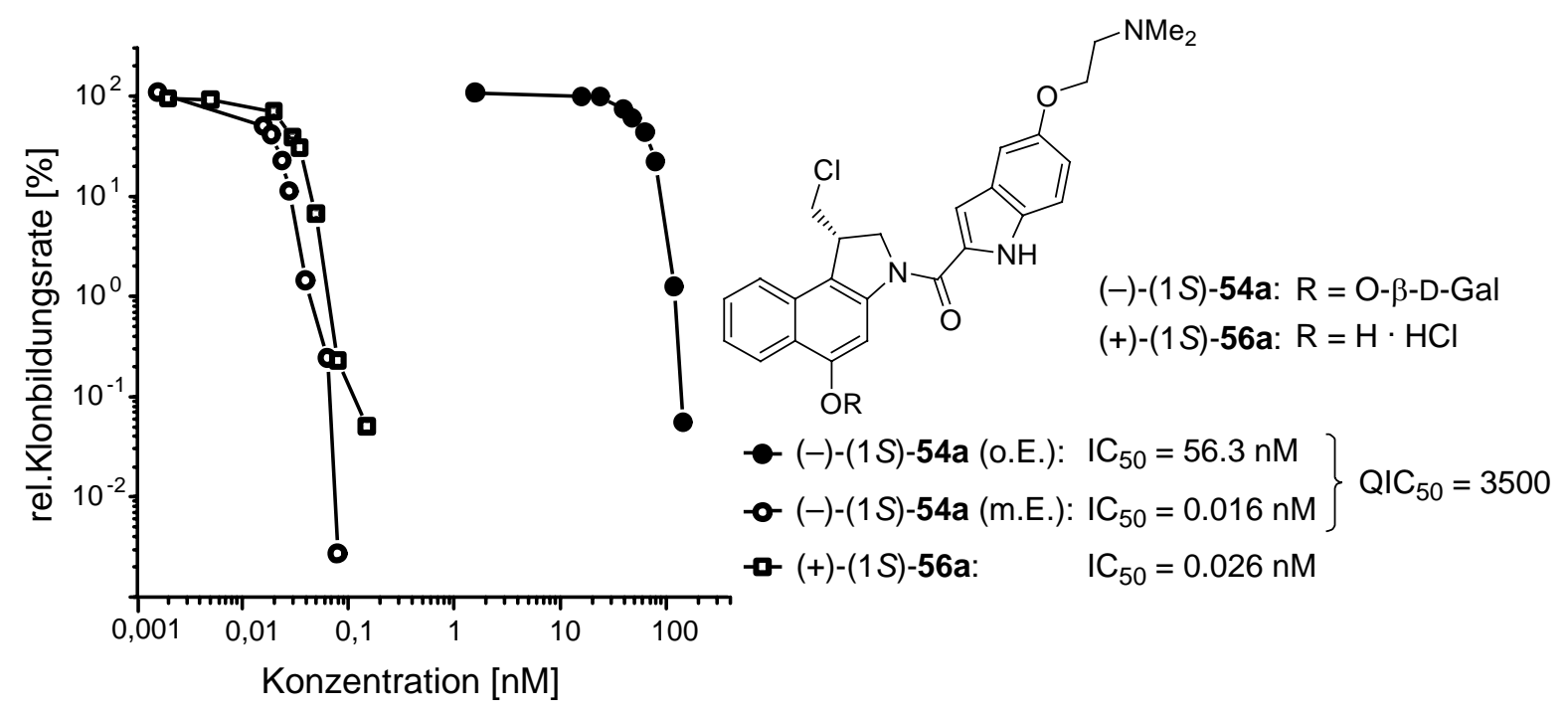

Abb. 60. In-vitro-Zytotoxizität (A549) des seco-CBI-DMAI-Galactosides (-)-(1S)-54a und des seco-CBI-DMAI-Hydrochlorides $(+)-(1 S)-56 a$. o. E. $=$ ohne Enzym, m. E. = mit Enzym.

Bei diesen Untersuchungen konnte für das diastereomerenreine Prodrug (-)-(1S)-54a ein hoher $Q I C_{50}$-Wert von 3500 bei einer gleichzeitig sehr hohen Zytotoxizität des Prodrugs in Anwesenheit des aktivierenden Enzyms mit einem $I C_{50}$ von $0.016 \mathrm{nM}$ ermittelt werden (Abb. 60). ${ }^{173}$ Das entsprechende seco-Drug (+)-(1S)-56a zeigt mit einem $I C_{50}$-Wert von $0.026 \mathrm{nM}$ eine ähnliche Zytotoxizität wie das Prodrug in Anwesenheit von $\beta$-D-Galactosidase. Dies bestätigt die reversible Detoxifizierung des Prodrugs durch die Zuckereinheit, die Stabilität der Prodrugs unter den Versuchs- 
bedingungen sowie die Nicht-Beeinträchtigung der Enzymaktivität durch das Edukt, das Produkt oder Intermediate.

Aufgrund der hervorragenden 3500-fachen Detoxifizierung durch die Galactose-Einheit sowie die sehr hohe Zytotoxizität des entsprechenden seco-Drugs ist das Prodrug (-)-(1S)-54a sehr gut für einen Einsatz im Rahmen einer ADEP-Therapie geeignet.

Die besonderen Vorzüge von (-)-(1S)-54a als Tumortherapeutikum werden durch einen Vergleich seiner In-vitro-Zytotoxizität in Anwesenheit von $\beta$-D-Galactosidase mit der von $(+)-(1 S, 10 R)-33 a$ sowie den in der Tumortherapie verwendeten Arzneimitteln Doxorubicin (11), Melphalan (79) und Carmustin (80) deutlich (Abb. 61).
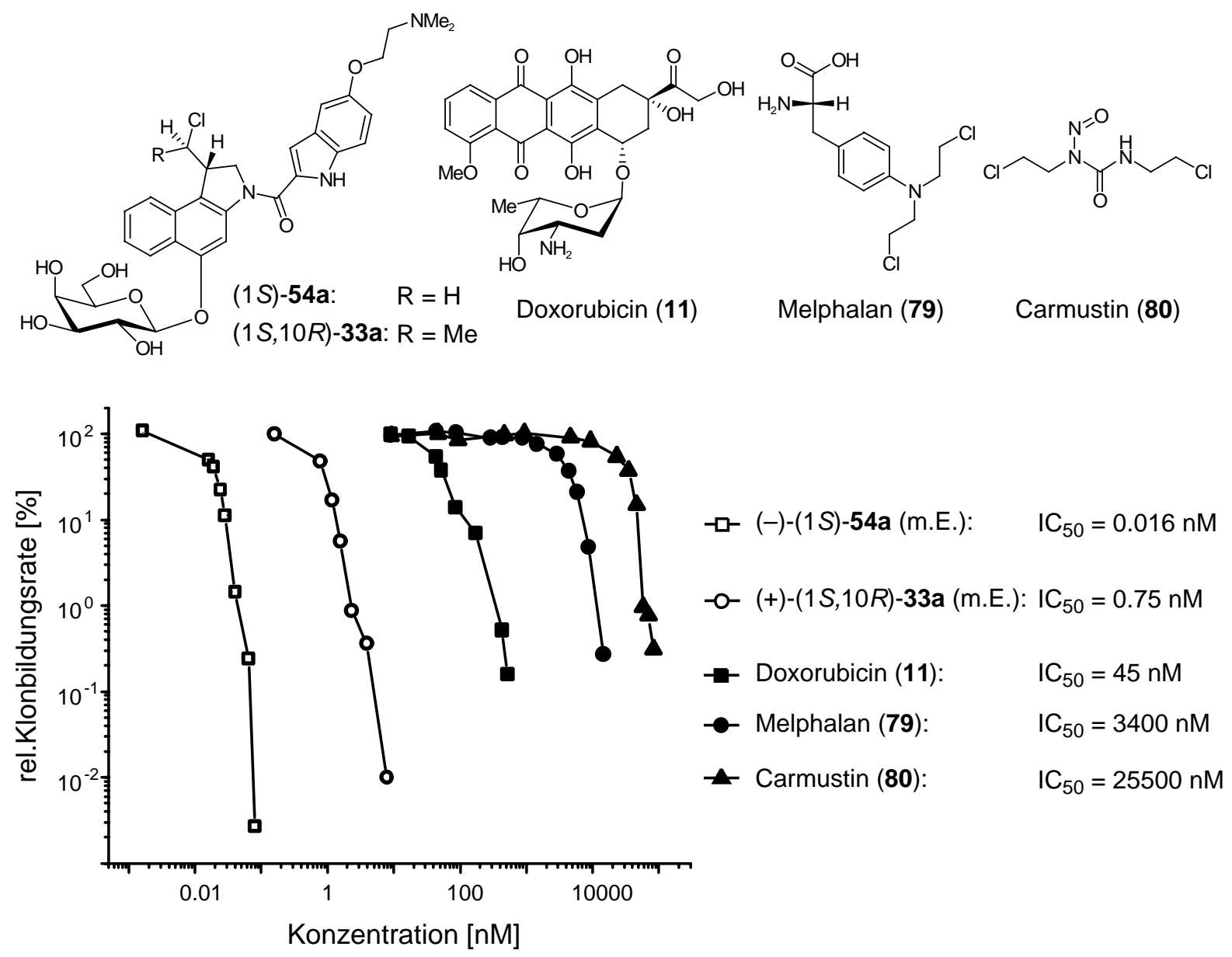

Abb. 61. In-vitro-Zytotoxizität (A549) der Galactoside (-)-(1S)-54a und (+)-(1S,10R)-33a in Anwesenheit des aktivierenden Enzyms (m. E.) sowie der klinisch verwendeten Zytostatika Doxorubicin (11), Melphalan (79) und Carmustin (80).

In dem durchgeführten HTCFA-Test an humanen Bronchialkarzinomzellen (A549) weist (-)-(1S)-54a in Anwesenheit von $\beta$-D-Galactosidase eine wesentlich höhere bio- 
logische Wirksamkeit auf als alle anderen Verbindungen (bis zu $1.6 \cdot 10^{6}$-fach) und könnte somit eine effizientere Therapie erlauben. Aufgrund der selektiven Freisetzung des seco-Drugs im Tumorgewebe würden hierbei zudem die Nebenwirkungen im Vergleich zu konventionellen Therapien auf ein Minimum reduziert.

\subsection{Vergleich der In-vitro-Zytotoxizität (HTCFA) der seco-CBI-DMAI- Derivate 56a und der anti-Methyl-seco-CBI-DMAI-Derivate 34a}

Zur Untersuchung des Effektes der Stereozentren sowie der Methylgruppe bzw. des Wasserstoffs an C-10 wurde die In-vitro-Zytotoxizität der neuen enantiomerenreinen seco-CBI-DMAI-Hydrochloride (+)-(1S)-56a und (-)-(1R)-56a sowie der analogen enantiomerenreinen anti-Methyl-seco-CBI-DMAI-Hydrochloride $\quad(+)-(1 S, 10 R)-34 \mathbf{a}$ und $(-)-(1 R, 10 S)-34 \mathbf{a}$ mittels eines HTCFA-Tests an humanen Bronchialkarzinomzellen (A549) bestimmt (Abb. 62).

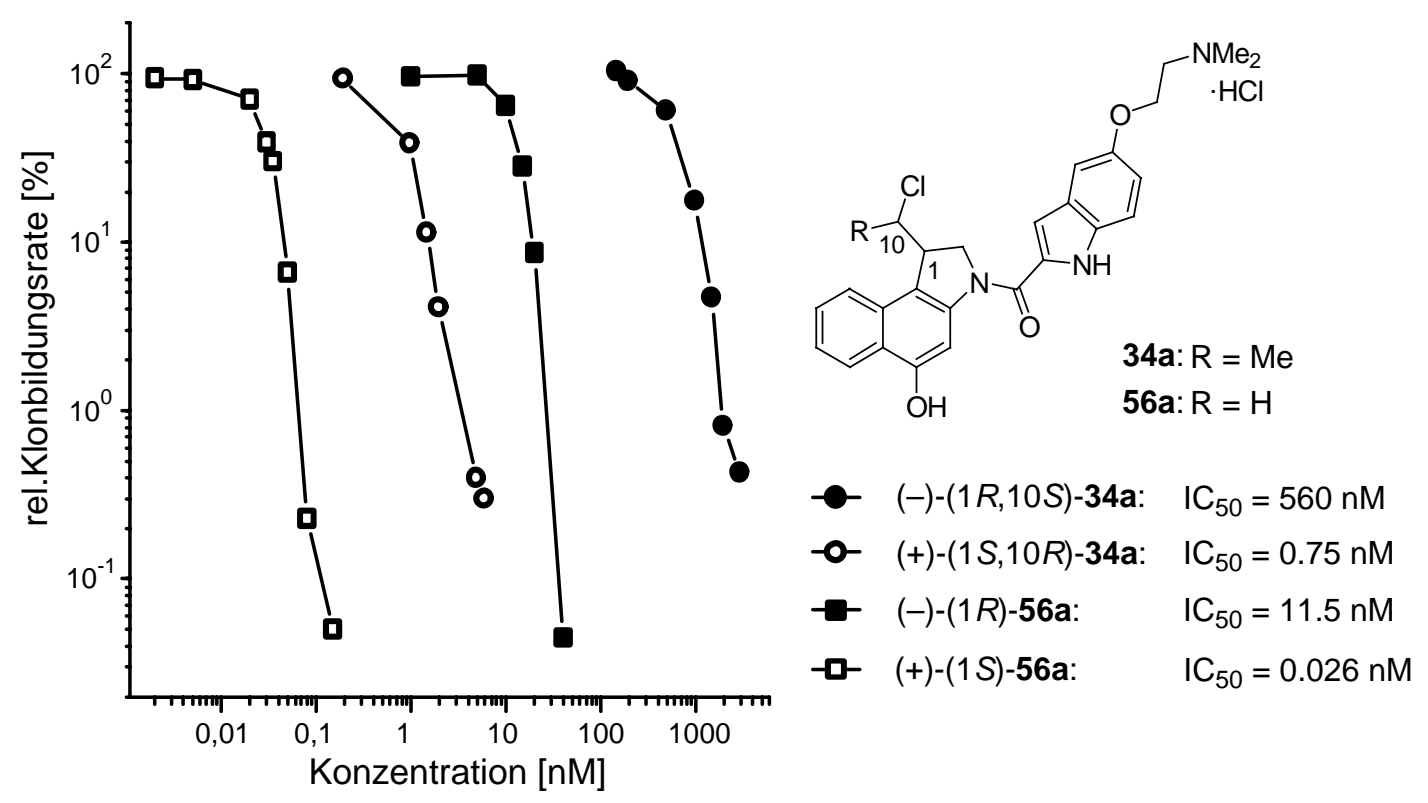

Abb. 62. In-vitro-Zytotoxizität (A549) der anti-Methyl-seco-CBI-DMAI-Hydrochloride 34a und der seco-CBI-DMAI-Hydrochloride 56a.

Die anti-Methyl-seco-CBI-DMAI-Derivate 34a $\left(I C_{50}=560 \mathrm{nM}\right.$ bzw. $\left.I C_{50}=0.75 \mathrm{nM}\right)$ sind etwa 40-fach geringer toxisch als die entsprechenden seco-CBI-DMAI-Derivate 56a $\left(I C_{50}=11.5 \mathrm{nM}\right.$ bzw. $\left.I C_{50}=0.026 \mathrm{nM}\right)$. Das Vorhandensein einer Methylgruppe an C-10 bedingt somit eine starke Verringerung der Zytotoxizität. Des Weiteren sind die seco-Drugs mit der natürlichen (1S)-Konfiguration etwa 500-fach toxischer als die Enantiomere mit der unnatürlichen $(1 R)$-Konfiguration. 


\subsection{Vergleich der In-vitro-Zytotoxizität (HTCFA) des seco-CBI-MPI- Hydrochlorids (1S)-56b und des (1S,10R)-anti-Methyl-seco-CBI-MPI- Hydrochlorids (1S,10R)-34b}

Um den Einfluss der DNA-bindenden Einheit und der Methylgruppe bzw. des Wasserstoffs an C-10 zu untersuchen, wurde die In-vitro-Zytotoxizität des neuen enantiomerenreinen seco-CBI-MPI-Hydrochlorids $(+)-(1 S)-56 \mathbf{b}$ und des enantiomerenreinen anti-Methyl-seco-CBI-DMAI-Hydrochlorids $(+)-(1 S, 10 R)-34 \mathbf{b}$ mittels eines HTCFATests an humanen Bronchialkarzinomzellen (A549) bestimmt (Abb. 63).

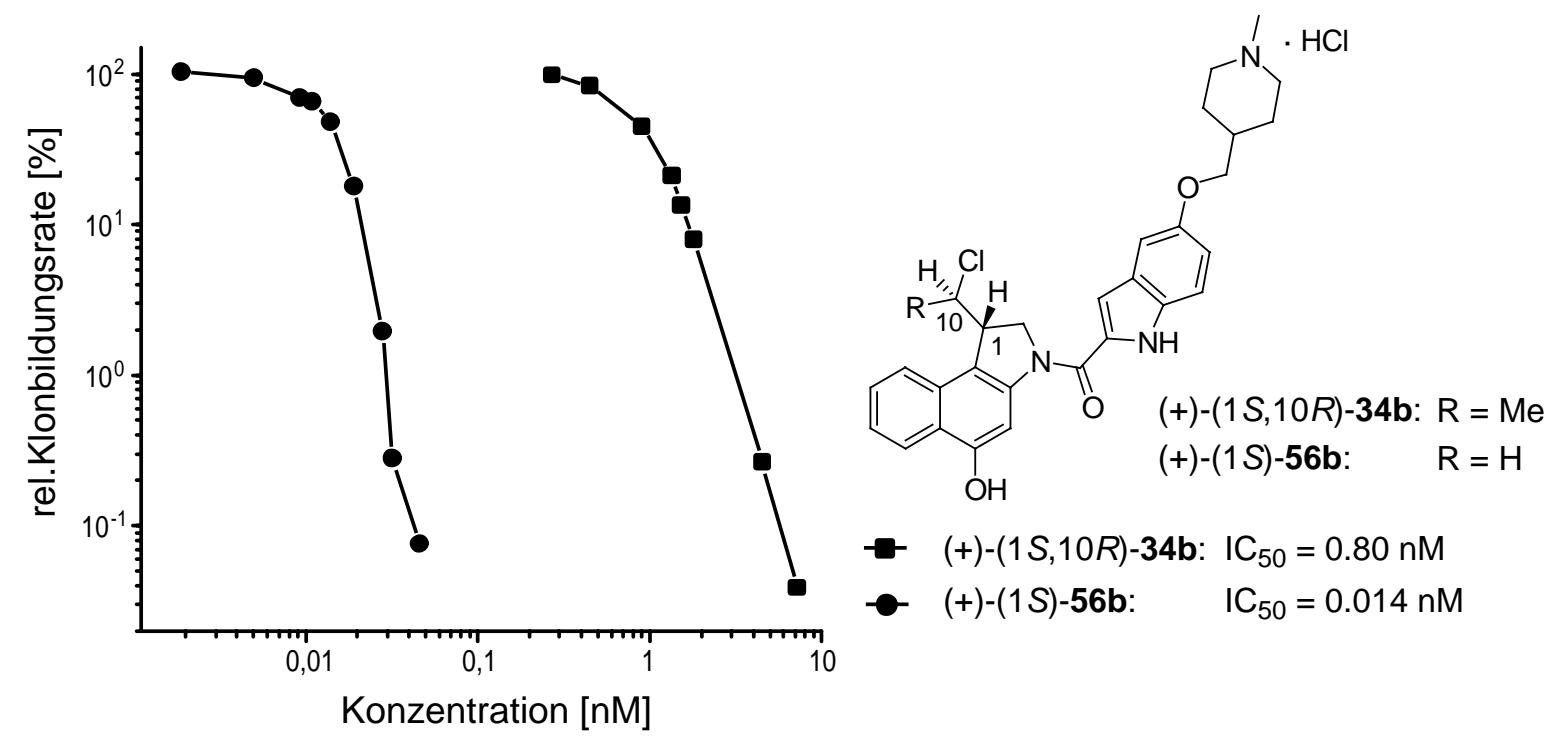

Abb. 63. In-vitro-Zytotoxizität (A549) des seco-CBI-MPI-Hydrochlorids (+)-(1S)-56b und des anti-Methyl-seco-CBI-MPI-Hydrochlorids $(+)-(1 S, 10 R)-\mathbf{3 4 b}$.

Mit dem enantiomerenreinen seco-CBI-MPI-Hydrochlorid (+)-(1S)-56b ist die Darstellung eines der zytotoxischsten CBI-Derivate gelungen. Mit einem $I C_{50}$ von nur $0.014 \mathrm{nM}$ ist es etwa so toxisch wie das entsprechende seco-CBI-DMAI-Hydrochlorid $(+)-(1 S)$-56a $\left(I C_{50}=0.026 \mathrm{nM}\right)$ und etwa 60 -fach zytotoxischer als sein Analogon $(+)-(1 S, 10 R)-34 \mathbf{b}$ mit einer Methylgruppe an C-10 $\left(I C_{50}=0.80 \mathrm{nM}\right) .(+)-(1 S, 10 R)-\mathbf{3 4 b}$ wiederum ist etwa so zytotoxisch wie das entsprechende anti-Methyl-seco-CBIDMAI-Hydrochlorid (+)-(1S,10R)-34a. Die DNA-bindenden Einheiten MPI und DMAI haben demzufolge einen sehr ähnlichen Einfluss auf die Zytotoxizität, während der Austausch einer Methylgruppe durch ein Wasserstoffatom die Zytotoxizität unabhängig von der DNA-bindenden Einheit deutlich erhöht. 


\subsection{In-vitro-Zytotoxizität (HTCFA) des dechlorierten Methyl-seco-CBI- DMAI-Analogons (1S)-49}

Um den Einfluss des Chloratoms an C-10 auf die Zytotoxizität zu bestimmen, wurde die In-vitro-Zytotoxizität des neuen enantiomerenreinen dechlorierten Methyl-secoCBI-DMAI-Analogons $(+)-(1 S)-49$ im Vergleich zu jenen der enantio- bzw. diastereomerenreinen DMAI-Derivate $(+)-(1 S, 10 R)-\mathbf{3 3 a},(+)-(1 S, 10 R)-34 \mathbf{a}$ und $(+)-(1 S)-\mathbf{5 6 a}$ mittels eines HTCFA-Tests an humanen Bronchialkarzinomzellen (A549) bestimmt (Abb. 64).

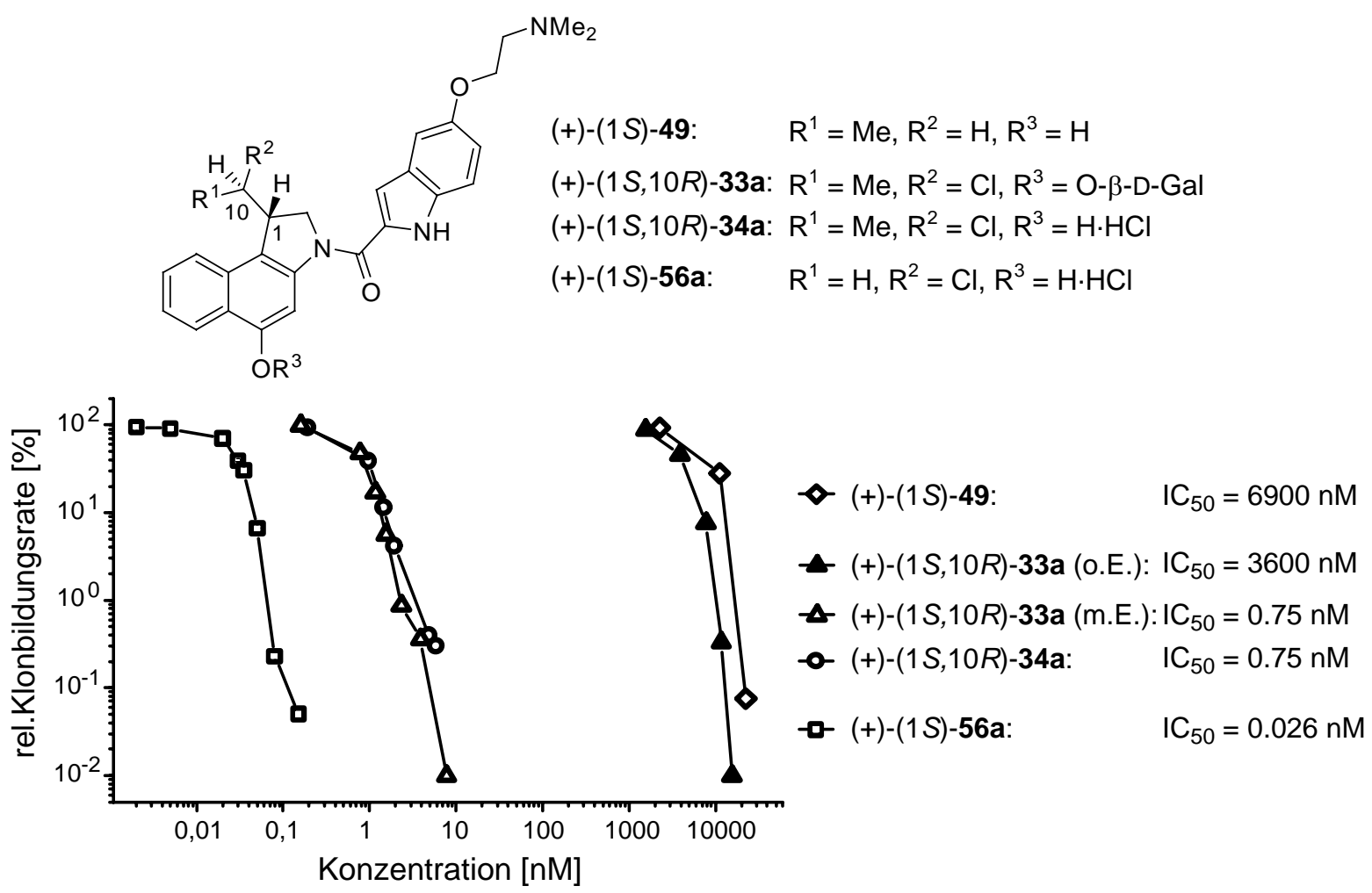

Abb. 64. In-vitro-Zytotoxizität (A549) des dechlorierten Methyl-seco-CBI-DMAI-Analogons $(+)-(1 S)-49$ sowie der DMAI-Derivate $(+)-(1 S, 10 R)-33 \mathbf{a},(+)-(1 S, 10 R)-34 \mathbf{a}$ und $(+)-(1 S)-56 \mathbf{a}$. o. E. $=$ ohne Enzym, m. E. = mit Enzym.

$(+)-(1 S)-49$ verfügt im Gegensatz zu allen anderen bisher getesten Derivaten nicht über ein Chloratom. Somit kann weder eine Winstein-Zyklisierung unter Bildung des alkylierenden Drugs noch eine direkte Alkylierung zellulärer Strukturen erfolgen. $(+)-(1 S)-49$ ist mit einem $I C_{50}$ von $6900 \mathrm{nM}$ etwa zweifach geringer toxisch als das analoge Prodrug $(+)-(1 S, 10 R)-33 \mathbf{a}\left(I C_{50}=3600 \mathrm{nM}\right)$ und zeigt eine deutlich geringere Zytotoxizität als die seco-Drugs (+)-(1S,10R)-34a und (+)-(1S)-56a. Die dennoch zu beobachtende Zytotoxizität könnte durch eine entropisch begünstigte, nicht-kovalente 
Einlagerung in die kleine Furche doppelsträngiger DNA unter Verdrängung von Wasser hervorgerufen werden, welche die DNA-Funktion beeinträchtigt. Die etwas höhere Zytotoxizität des Prodrugs $(+)-(1 S, 10 R)-33 a$ im Vergleich zu (+)-(1S)-49 könnte durch eine zusätzliche geringfügige kovalente Reaktion mit der DNA erklärt werden.

\subsection{In-vitro-Zytotoxizität (HTCFA) verschiedener DNA-bindender Ein- heiten}

Um den Einfluss der DNA-bindenden Einheiten zu untersuchen, wurde die In-vitroZytotoxizität der DNA-bindenden Indole DMAI (46a), MPI (46b), DAI (81), MEI (82) und DMMI (83) mittels eines HTCFA-Tests an humanen Bronchialkarzinomzellen (A549) bestimmt (Abb. 65). ${ }^{174}$
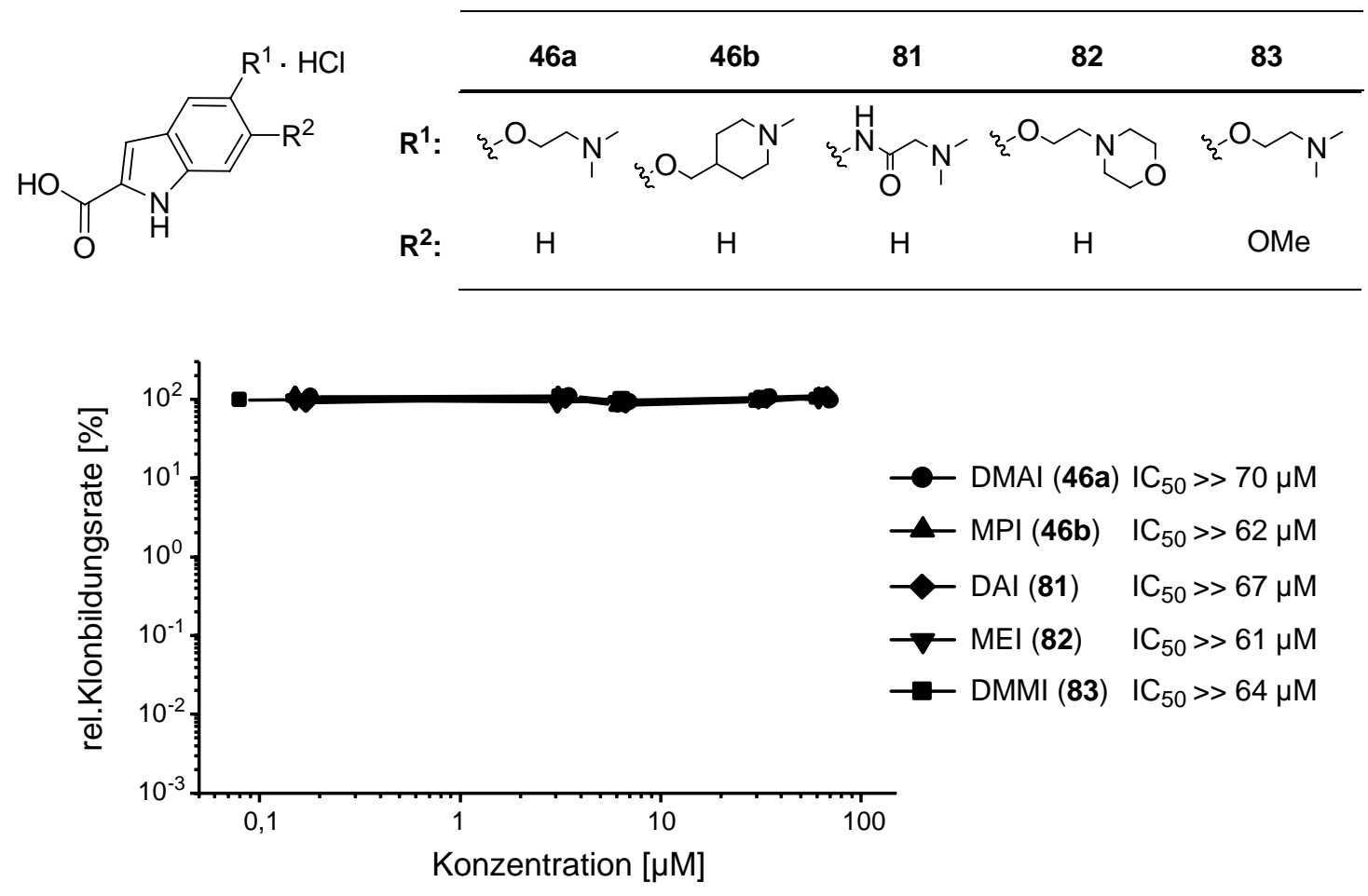

Abb. 65. In-vitro-Zytotoxizität (A549) der DNA-bindenden Einheiten 46a,b und 81-83.

Alle DNA-bindenden Einheiten weisen ohne Bindung an die pharmakophore Einheit eine nur sehr niedrige Zytotoxizität auf $\left(I C_{50}>>60 \mu \mathrm{M}\right)$. Diese ist sogar weit geringer als die Zytotoxizität des dechlorierten Methyl-seco-CBI-DMAI-Analogons (+)-(1S)-49 mit deaktiviertem Pharmakophor $\left(I C_{50}=6.9 \mu \mathrm{M}\right)$. Sollte die Zytotoxizität der Duocarmycin-Analoga tatsächlich durch eine Bindung an zelluläre DNA verursacht sein, so würde dies bedeuten, dass die Kupplung der DNA-bindenden Einheit mit einem Pharmakophor die Affinität der Verbindung im Vergleich zu den Einzelkomponenten 
stark erhöht, denn auch das Pharmakophor alleine weist eine deutlich geringere Zytotoxizität auf (s. Kap. 4.1).

\subsection{In-vitro-Zytotoxizität (MTT) der fluoreszenzmarkierten anti-Methyl- seco-CBI-DMAI-Derivate}

Die In-vitro-Zytotoxizität des neuen fluoreszenzmarkierten anti-Methyl-seco-CBIDMAI-Prodrugs (-)-(1S,10R)-75 wurde zunächst mittels eines HTCFA-Tests an humanen Bronchialkarzinomzellen (A549) ermittelt. Die Bestimmung der relativen Klonbildungsrate erfolgte hierbei in Abwesenheit und in Anwesenheit des aktivierenden Enzyms $\beta$-D-Galactosidase, um den Zytotoxizitätsunterschied zwischen dem Prodrug und dem aus diesem in situ generierten seco-Drug, d.h. den $Q I C_{50}$-Wert, zu bestimmen.

Leider betrug der $Q I C_{50}$ nur 3, da das Prodrug in Anwesenheit von $\beta$-D-Galactosidase $\left(I C_{50}=800 \mathrm{nM}\right)$ nur marginal toxischer war als in Abwesenheit des Enzyms $\left(I C_{50}=2200 \mathrm{nM}\right)$. In einer HPLC-MS-basierten Versuchsreihe zur Aktivierung des Prodrugs konnte selbst unter Einsatz sehr hoher Enzymmengen $(1500 \mathrm{U} / \mathrm{mL})$ keine Abspaltung der Galactose in $(-)-(1 S, 10 R)-\mathbf{7 5}$ beobachtet werden, was den niedrigen $Q I C_{50}$ erklärt. Obwohl die Zytotoxizität des fluoreszenzmarkierten Prodrugs derjenigen des analogen nicht-markierten Prodrugs $(+)-(1 S, 10 R)-33 a$ sehr ähnlich ist, bewirkt die Fluoreszenzmarkierung an $\mathrm{C}-7$ offensichtlich eine Behinderung der enzymatischen Aktivierung. Dies konnte in einer Reihe von HPLC-MS-Experimenten zur Aktivierung des an C-7 mit FITC markierten Prodrugs (1S,10R)-74 bestätigt werden, das ebenfalls bei Verwendung üblicher Enzymkonzentrationen nicht zum entsprechenden seco-Drug umgewandelt wurde.

Für das fluoreszenzmarkierte Prodrug (-)-(1S,10R)-75 und das seco-Drug $(1 S, 10 R)-76$ wurde die Zytotoxizität in einem MTT-Test an humanen Bronchialkarzinomzellen (A549) und humanen Lymphomzellen (HL-60) bestimmt (Abb. 66). Aufgrund von Löslichkeitsproblemen von $(-)-(1 S, 10 R)-75$ konnte hierbei der $I C_{50}$-Wert bei Verwendung von A549-Zellen nicht genau bestimmt werden. Mit einem Wert von $I C_{50}>7700 \mathrm{nM}$ ist das Prodrug (-)-(1S,10R)-75 mindestens 53-fach geringer toxisch gegenüber humanen Bronchialkarzinomzellen der Linie A549 als dessen seco-Drug $(1 S, 10 R)-76 \quad\left(I C_{50}=144 \mathrm{nM}\right)$, das durch nicht-enzymatische Spaltung aus diesem hergestellt worden war. Diese Werte sind vergleichbar mit jenen der analogen nichtfluoreszenzmarkierten Verbindungen $\quad(+)-(1 S, 10 R)-33 a \quad\left(I C_{50}=7950 \mathrm{nM}\right) \quad$ und 
$(+)-(1 S, 10 R)-34 \mathbf{a}\left(I C_{50}=10 \mathrm{nM}\right)$, bei denen im MTT-Test an Zellen der Linie A549 ein $Q I C_{50}$ von etwa 800 beobachtet wird.

Der MTT-Test auf Basis humaner Lymphomzellen der Linie HL-60 lieferte einen $Q I C_{50}$-Wert von 174 für die fluoreszenzmarkierten Analoga (-)-(1S,10R)-75 $\left(I C_{50}=2230 \mathrm{nM}\right)$ und $(1 S, 10 R)-76\left(I C_{50}=12.8 \mathrm{nM}\right)$. Aufgrund der höheren Zytotoxizität der fluoreszenzmarkierten Verbindungen gegenüber HL-60-Zellen im Vergleich zu Zellen der Linie A549 konnte mit geringeren Konzentrationen gearbeitet werden und das vorher beschriebene Löslichkeitsproblem trat nicht auf. Die entsprechenden nicht-markierten Verbindungen $(+)-(1 S, 10 R)-33 \mathbf{a}\left(I C_{50}=685 \mathrm{nM}\right)$ und $(+)-(1 S, 10 R)-34 \mathbf{a}\left(I C_{50}=1.3 \mathrm{nM}\right)$, bei denen im MTT-Test an Zellen der Linie HL-60 ein $Q I C_{50}$ von etwa 530 beobachtet wird, wirkten auf HL-60-Zellen ebenfalls stärker toxisch als auf Zellen der Linie A549.
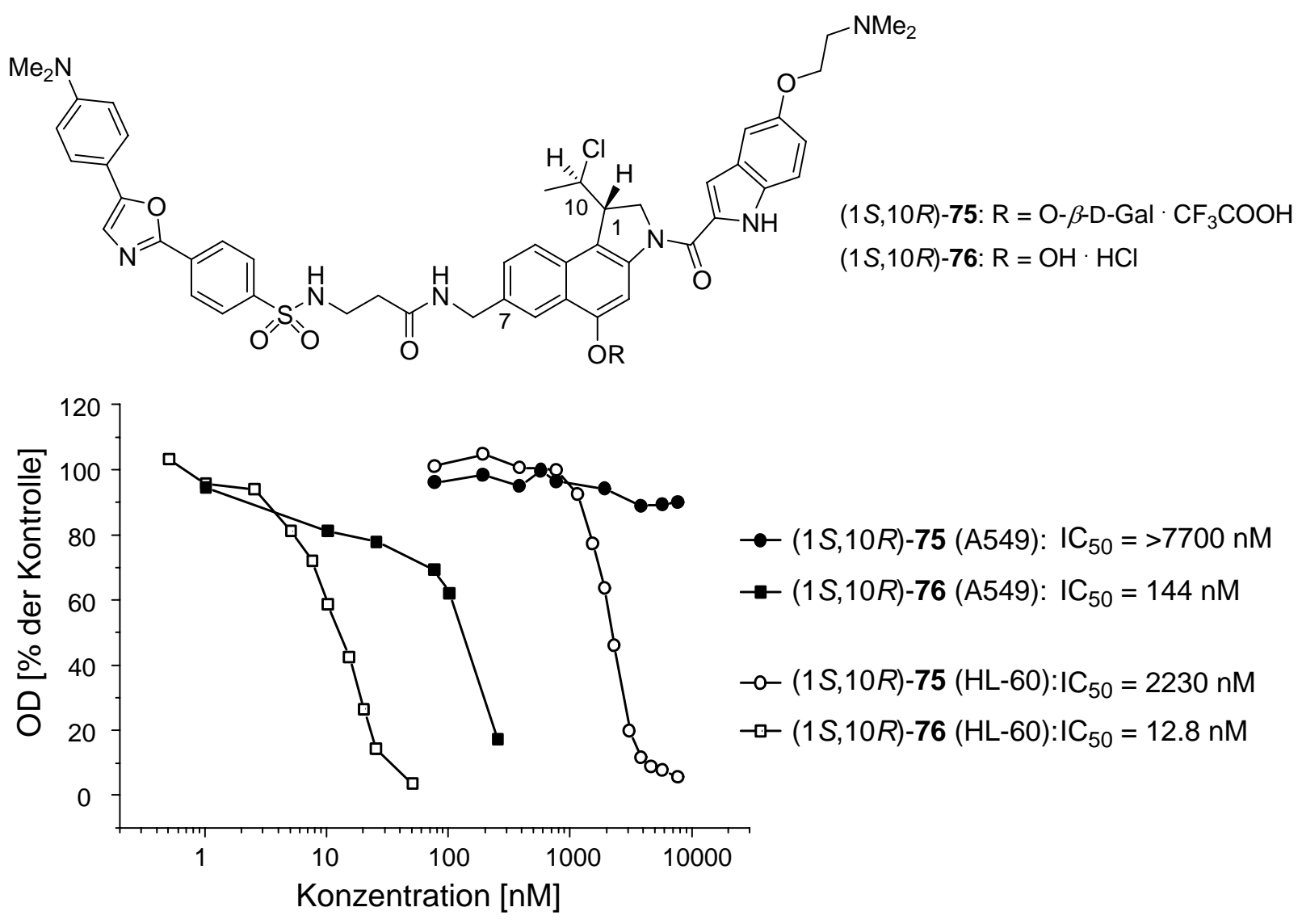

Abb. 66. In-vitro-Zytotoxizität (HL-60 und A549) des fluoreszenzmarkierten Prodrugs $(-)-(1 S, 10 R)-\mathbf{7 5}$ und des fluoreszenzmarkierten seco-Drugs $(1 S, 10 R)-\mathbf{7 6}$. 


\section{Untersuchung der Wechselwirkung neuer Duocarmycin- Analoga mit DNA, RNA und Glutathion mittels Massen- spektrometrie}

Bisherige Studien zum Wirkmechanismus des CC-1065, der Duocarmycine und ihrer Analoga ergaben, dass die Wirkstoffe sehr reaktiv gegenüber doppelsträngiger DNA sind und nur eine geringe Reaktivität gegenüber RNA und Proteinen zeigen (Kap. 4.2).

Im Allgemeinen verläuft die für die CC-1065-Analoga charakteristische DNAAlkylierung durch Addition des $\mathrm{N}-3$ von Adenin an das am wenigsten substituierte Kohlenstoffatom des Cyclopropanringes des Zytostatikums. Dies geschieht bevorzugt innerhalb bestimmter Bindungsstellen in der kleinen Furche doppelsträngiger DNA, in denen eine Folge der Nukleobasen Adenin (A) und Thymin (T) auftritt. ${ }^{175}$ Die Sequenzselektivität wird hierbei wahrscheinlich durch die stärkere nicht-kovalente Bindung der Substrate an AT-reiche Regionen innerhalb der schmaleren und tieferen kleinen Furche ${ }^{176}$ und durch die Zugänglichkeit der Alkylierungsstelle gesteuert. Die Untersuchung kürzerer und längerer Analoga des CC-1065 führte zu der Erkenntnis, dass die Selektivität gut mit der Größe des Zytostatikums und der daher notwendigen Länge der Bindungsstelle korreliert. ${ }^{177}$ Die Bindungstelle für $(+)$-Duocarmycin-SA (19) erstreckt sich über eine 3.5 Basenpaare lange DNA-Region von der Adenin- $N$-3Alkylierungsstelle in 3' $\rightarrow$ 5'-Richtung über die benachbarten zwei bis drei 5'-Basen (z.B. 5'-AAA스). Bei der Bindung ist die hydrophobe Seite des Substrates in die kleine Furche eingebettet und die polaren funktionellen Gruppen zeigen nach außen. (+)-Duocarmycin-SA (19) alkylierte in allen untersuchten DNA-Abschnitten ein Adenin, welches von zwei 5'-A- oder 5'-T-Basen flankiert war (Tab. 5). ${ }^{83,88}$ Darüber hinaus dominierten als dritte 5'-Base $A$ und $T$ deutlich gegenüber $\mathrm{G}$ (Guanin) und $\mathrm{C}$ (Cytosin). Außerdem wurde herausgefunden, dass sich Bindungsstellen hoher und niedriger Affinität in diesem Punkt unterscheiden. Für die dem alkylierten Adeninrest benachbarte 3'-Base konnte eine zusätzliche Präferenz für Purinbasen $(\mathrm{Pu})$ gegenüber Pyrimidinbasen (Py) nachgewiesen werden.

\begin{tabular}{ccccccccc}
\hline Zytostatikum & $5^{\prime}$ & 4 & 3 & 2 & 1 & $\mathbf{0}$ & -1 & $3^{\prime}$ \\
\hline $\begin{array}{c}\text { (+)-Duocarmycin SA (19) } \\
\text { (+)-CC-1065 (18) }\end{array}$ & & A/T $>$ G/C & A/T $>$ G/C & A/T & A/T & A & Pu > Py & \\
\hline
\end{tabular}

Tab. 5. Bevorzugte Nukleobasen in der Umgebung der Alkylierungsstelle (0). 
Eine ähnliche Präferenz wurde für CC-1065 (18) gefunden, allerdings muss aufgrund der größeren DNA-bindenden Einheit die AT-reiche Region im Fall von 18 um ein Basenpaar länger sein als für 19 (Tab. 5).

Im Rahmen dieser Arbeit wurden zur Bestimmung der Alkylierungseffizienz und der Sequenzselektivität verschiedener neuer Duocarmycin-Analoga die in Abb. 67 dargestellten DNA-Oligonukleotide ausgewählt.

\begin{tabular}{|c|c|c|c|c|c|}
\hline 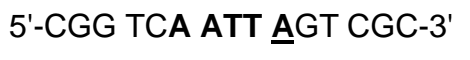 & $(\mathrm{ON}-1)\}$ & \multirow{2}{*}{ ds -60} & 5'-CGG CAA TT $\underline{A}$ TTG CCG-3' & $(\mathrm{ON}-1)\}$ & \\
\hline 3'-GCC AGT TAA TCA GCG-5' & $(\mathrm{ON}-2)\}$ & & 3'-GCC GTT AAT AAC GGC-5' & $(\mathrm{ON}-2) \int$ & \\
\hline 5'-TCG CCG GTC AAT TAGG-3' & $(\mathrm{ON}-1)]$ & \multirow{2}{*}{ ds-61 } & 5'-CCG GCT ATT AGG CCG-3' & $(\mathrm{ON}-1)]$ & \multirow{2}{*}{ ds-66 } \\
\hline 3'-AGC GGC CAG TTA ATC-5' & $(\mathrm{ON}-2)\}$ & & 3'-GGC CGA TAA TCC GGC-5' & $(\mathrm{ON}-2)\}$ & \\
\hline 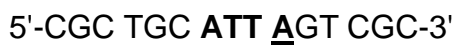 & $(\mathrm{ON}-1)\}$ & \multirow{2}{*}{ ds-62 } & 'TT TTG C-3' & $(\mathrm{ON}-1)]$ & \multirow{2}{*}{ ds-67 } \\
\hline 3'-GCG ACG TAA TCA GCG-5' & $(\mathrm{ON}-2)\}$ & & 3'-GGT ATT TCG $\underline{A} A A$ AACG-5' & $(\mathrm{ON}-2)\}$ & \\
\hline 5'-CGC TCG AAT TGG CGC-3' & $(\mathrm{ON}-1)\}$ & \multirow{2}{*}{ ds-63 } & 5'-CGG CTT ATA TGA CCG-3' & $(\mathrm{ON}-1)\}$ & \multirow{2}{*}{ ds-68 } \\
\hline 3'-GCG AGC TTA ACC GCG-5' & $(\mathrm{ON}-2)\}$ & & 3'-GCC GAA TAT ACT GGC-5' & $(\mathrm{ON}-2)\}$ & \\
\hline 5'-CGC GCT AAA & $(\mathrm{ON}-1)$ & \multirow{2}{*}{ ds-64 } & 5'-TGG CTG CGA GCA CCT-3' & $(\mathrm{ON}-1)$ & \multirow{2}{*}{ ds-69 } \\
\hline '-GCG CGA TTT TCT GGC-5' & $(\mathrm{ON}-2)\}$ & & 3'-ACC GAC GCT CGT GGA-5' & $(\mathrm{ON}-2)\}$ & \\
\hline
\end{tabular}

Abb. 67. Basensequenzen der doppelsträngigen DNA-Oligonukleotide ds-60 - ds-69.

Das Oligonukleotid ds-60 verfügt über eine AT-reiche Region von fünf Basenpaaren in der Mitte des synthetischen DNA-Doppelstranges. Am 3'-Ende der AT-reichen Region befindet sich ein Adenin im Einzelstrang ON-1, das durch Duocarmycin SA (19) alkyliert werden kann. ${ }^{178}$ Der DNA-Doppelstrang ds-61 weist die gleiche ATreiche Region am Ende des DNA-Doppelstranges auf. Aufgrund einer geringeren Stabilisierung der Enden eines Doppelstranges könnte hier die typische Struktur der großen und kleinen Furche innerhalb der AT-Basenfolge und somit die Alkylierungeffizienz verändert sein im Vergleich zu ds-60. Mit vier Basenpaaren ist die AT-reiche Region in ds-62 um ein Basenpaar kürzer als in ds-60 und ds-61 und sollte so eine Aussage darüber erlauben, ob bereits vier konsekutive Adenin- oder Thyminbasen eine Alkylierung ermöglichen. Während ds-62 über ein Adenin am 3'-Ende der AT-reichen Region verfügt, sind die Basen in ds-63 so vertauscht, dass kein 3'-A vorhanden ist. Mit diesem Oligonukleotid sollte geprüft werden, ob eine Alkylierung an einer anderen als der 3'-A-Position möglich ist.

In den Oligonukleotiden ds-64-ds-68 konkurrieren zwei oder mehr mögliche Bindungspositionen miteinander. Die entsprechenden Adenine befinden sich jeweils 
am 3'-Ende einer mindestens vier Basenpaare langen AT-reichen Region. Die bevorzugte Alkylierung einer Base in ds-64 sollte eine Aussage darüber erlauben, ob die Duocarmycin-Analoga allgemein die Base Adenin oder Thymin in 5'-Richtung bezüglich der Alkylierungsstelle bevorzugen. Durch die Bestimmung der Alkylierungsposition in ds-65, ds-66 und ds-67 sollte zudem geklärt werden, ob Adenin oder Thymin an der ersten (ds-65), zweiten (ds-66) bzw. dritten (ds-67) Nachbarposition in 5'-Richtung der Bindungsstelle bei sonst identischer Basenfolge die Reaktion begünstigen. Zusätzlich enthalten die letztgenannten Oligonukleotide weitere mögliche Bindungsstellen. Das Oligonukleotid ds-69 verfügt als einziges Beispiel der ausgewählten DNA nicht über eine AT-reiche Region und sollte damit die Frage beantworten, ob diese für eine Alkylierung wirklich notwendig ist. Um einen Vergleich der Reaktivität der Duocarmycin-Analoga bezüglich doppel- und einzelsträngiger DNA zu erlauben, wurden ausgewählte Derivate zusätzlich mit dem reaktiveren Einzelstrang ON-1 des Doppelstranges ds-60 umgesetzt.

In mit den Duocarmycin-Analoga behandelten Zellen könnte eine Alkylierung zellulärer RNA oder eine Detoxifizierung durch eine Reaktion mit Glutathion (58) erfolgen. ${ }^{161}$ Um die Wahrscheinlichkeit dieser Möglichkeiten abzuschätzen, wurde das seco-Dug (+)-(1S,10R)-34a mit dem doppelsträngigen RNA-Ologonukleotid ds-59 und mit Glutathion (58) umgesetzt.

$\left.\begin{array}{ll}\text { 5'-CGG UCA AUU AGU CGG-3' } & (\mathrm{ON}-1) \\ \text { 3'-GCC AGU UAA UCA GCC-5' } & (\mathrm{ON}-2)\end{array}\right\}$ ds-59

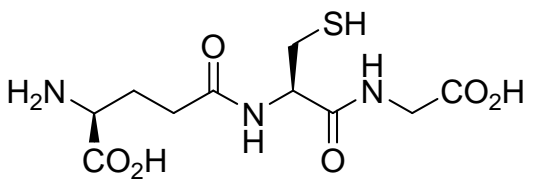

58

Abb. 68. Basensequenz des doppelsträngigen RNA-Oligonukleotides ds-59 und Struktur des Tripeptides Glutathion (58).

Im Rahmen der dieser Arbeit vorausgehenden Diplomarbeit wurde zur Untersuchung der Wechselwirkung des seco-Drugs $(+)-(1 S, 10 R)-34 \mathbf{a}$ und des doppelsträngigen DNA-Oligonukleotides ds-60 eine auf direkten ESI-HRMS-Messungen basierende, neue und effiziente Methode zur Bestimmung der Sequenzselektivität und Alkylierungseffizienz entwickelt. Im Rahmen der vorliegenden Arbeit wurde diese Methode zur Untersuchung der Reaktion einer Reihe neuer Duocarmycin-Analoga mit verschiedenen DNA- und RNA-Oligonukleotiden angewandt. Die ESI-HRMSMessungen erfolgten direkt aus der mit Methanol verdünnten Reaktionslösung ohne eine chromatographische Reinigung und Anreicherung der alkylierten DNA, die bisher 
bei analogen Messungen erforderlich war. ${ }^{179}$ Neben der Detektion der alkylierten Einzelstränge konnte durch eine Variation der Messbedingungen eine Fragmentierung der Addukte im Bereich der Alkylierungsstelle induziert werden. Anhand der Fragmente konnte die jeweilige Bindungsstelle eindeutig bestimmt werden. ${ }^{180}$ Gegenüber konventionellen Methoden zur Strukturanalyse von DNA-Drug-Komplexen wie z.B. NMR-Spektroskopie ${ }^{181}$ und Röntgenstrukturanalyse ${ }^{182}$ oder klassischen molekularbiologischen Untersuchungen ${ }^{183}$ wie PCR-Stop-Assay, DNAseI-Footprinting und PAGE nach thermisch induziertem Strangbruch weist die gewählte Vorgehensweise deutliche Vorteile auf, da sie wesentlich schneller ist (molekularbiologische Ansätze), nur niedrige Konzentrationen benötigt werden (NMR) und die Addukte zudem nicht kristallin sein müssen (Röntgenstrukturanalyse). Ein Nachteil der massenspektrometrischen Methode ist jedoch, dass nur DNA-Fragmente mit einer Molmasse von maximal $10^{4} \mathrm{~g} / \mathrm{mol}$ untersucht werden können.

Die massenspektrometrischen Untersuchungen der Reaktionsmischungen mit DNAoder RNA-Oligonukleotiden erfolgten im negativen Ionenmodus, da die Oligonukleotide aufgrund der sauren Phosphatgruppen im DNA-Rückgrat bevorzugt negativ geladene Ionen bilden. Sowohl in Lösung als auch desolvatisiert wird ein Anteil der negativen Ladungen durch Natriumionen oder Ammoniumionen neutralisiert. Während die Ammoniumionen bei der Desolvatation unter Abgabe eines Protons an einen Phosphatrest in Form von Ammoniak entfernt werden, bleiben die Natriumionen an die Oligonukleotide gebunden. Werden die Oligonukleotide als Natriumsalze eingesetzt, ist daher eine charakteristische Natriumadduktverteilung in den Massenspektren zu beobachten.

Die neue Methode und die resultierenden Ergebnisse sollen zunächst exemplarisch am Beispiel der Wechselwirkung des seco-Drugs $(+)-(1 S, 10 R)-34 a$, des entsprechenden Prodrugs $(+)-(1 S, 10 R)-33$ a sowie des enantiomeren seco-Drugs $(-)-(1 R, 10 S)-\mathbf{3 4 a}$ mit dem DNA-Doppelstrang ds-60 vorgestellt werden (Abb. 69). Im Folgenden werden dann die Ergebnisse der Untersuchungen dieser sowie weiterer Verbindungen mit DNA, RNA und Glutathion diskutiert.

Allgemein zyklisieren alle untersuchten seco-Drugs in wässrigem Medium schnell zu den entsprechenden Drugs, die in Abwesenheit geeigneter Nukleophile durch Wasser hydrolysiert und somit inaktiviert werden. Sowohl die seco-Drugs als auch die entsprechenden Prodrugs können zudem durch eine direkte nukleophile Substitution des Chloratoms durch eine Hydroxygruppe inaktiviert werden. 
Abbildung 69 zeigt die Struktur des seco-Drugs 34a, des Drugs 43a, des Prodrugs 33a sowie der entsprechenden Hydrolyseprodukte 84a bzw. 85a.

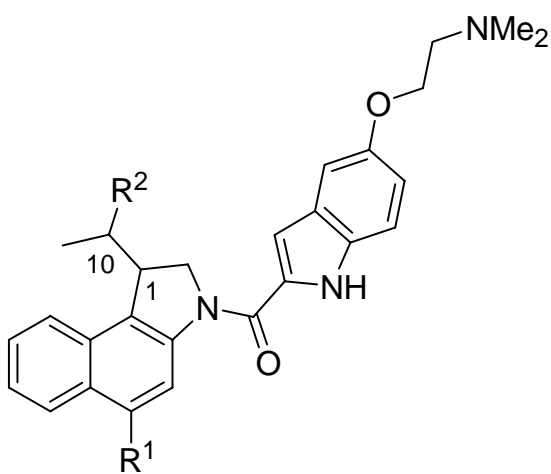

34a: $\mathrm{R}^{1}=\mathrm{OH}, \mathrm{R}^{2}=\mathrm{Cl} \cdot \mathrm{HCl}$

84a: $R^{1}=\mathrm{OH}, \mathrm{R}^{2}=\mathrm{OH}$

33a: $\mathrm{R}^{1}=\mathrm{O}-\beta-\mathrm{D}-\mathrm{Gal}, \mathrm{R}^{2}=\mathrm{Cl}$

85a: $\mathrm{R}^{1}=\mathrm{O}-\beta-\mathrm{D}-\mathrm{Gal}, \mathrm{R}^{2}=\mathrm{OH}$

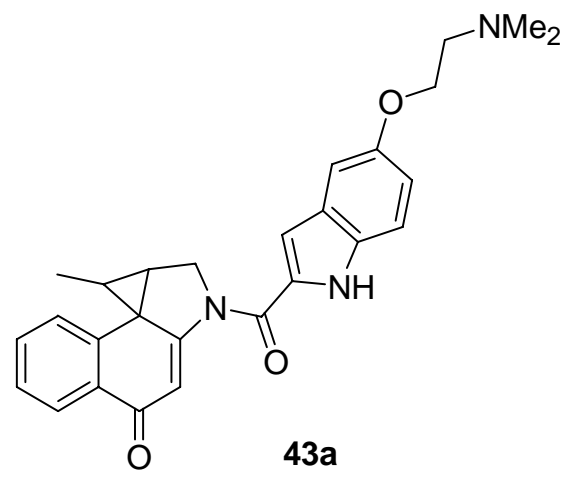

$\left.\begin{array}{ll}\text { 5'-CGG TCA ATT AGT CGC-3' } & (\mathrm{ON}-1) \\ \text { 3'-GCC AGT TAA TCA GCG-5' } & (\mathrm{ON}-2)\end{array}\right\}$ ds-60

Abb. 69. Struktur des DNA-Doppelstranges ds-60, des seco-Drugs 34a, des Drugs 43a, des Prodrugs 33a sowie der entsprechenden Hydrolyseprodukte 84a und 85a.

\subsection{Wechselwirkung des seco-Drugs $(+)-(1 S, 10 R)-34 a$ mit den DNA- Oligonukleotiden ds-60 und ON-1 (ds-60)}

Zur Untersuchung einer möglichen Adduktbildung des seco-Drugs (+)-(1S,10R)-34a mit dem doppelsträngigen DNA-Oligonukleotid ds-60 wurde eine Lösung des Natrium-Salzes der DNA in Wasser mit einer Lösung des Drugs in DMSO versetzt. Die molaren Verhältnisse des Drugs zur doppelsträngigen DNA betrugen 1:1 bis 5:1. Kurz nach dem Ansetzen und nach 24 Stunden Inkubation bei $25{ }^{\circ} \mathrm{C}$ wurden direkte ESI-HRMS-Messungen der Reaktionslösungen durchgeführt. Abbildung 70 zeigt die Massenspektren der Reaktionsmischung im Verhältnis $1: 1$ nach $t=0 \mathrm{~h}$ und $t=24 \mathrm{~h}$ Inkubation. Zur einfacheren Auswertung wurden die Massenspektren zudem dekonvoliert, d.h. es erfolgte eine computergestützte Umrechnung der Signale der mehrfach geladenen Ionen zu Signalen der entsprechenden neutralen Spezies (Abb. 71-73).

Während zum Zeitpunkt $t=0 \mathrm{~h}$ (Abb. 70a) nur die beiden DNA-Einzelstränge $\mathbf{O N - 1}$ und ON-2 sowie das seco-Drug $(+)-(1 S, 10 R)-34 a$ und das in situ aus diesem entstehende Drug 43a nachgewiesen wurden, konnte nach $24 \mathrm{~h}$ die Alkylierung des DNA-Einzelstranges $\mathbf{O N - 1}$ zu ON-1* durch das Drug 43a festgestellt werden (Abb. 70b). 

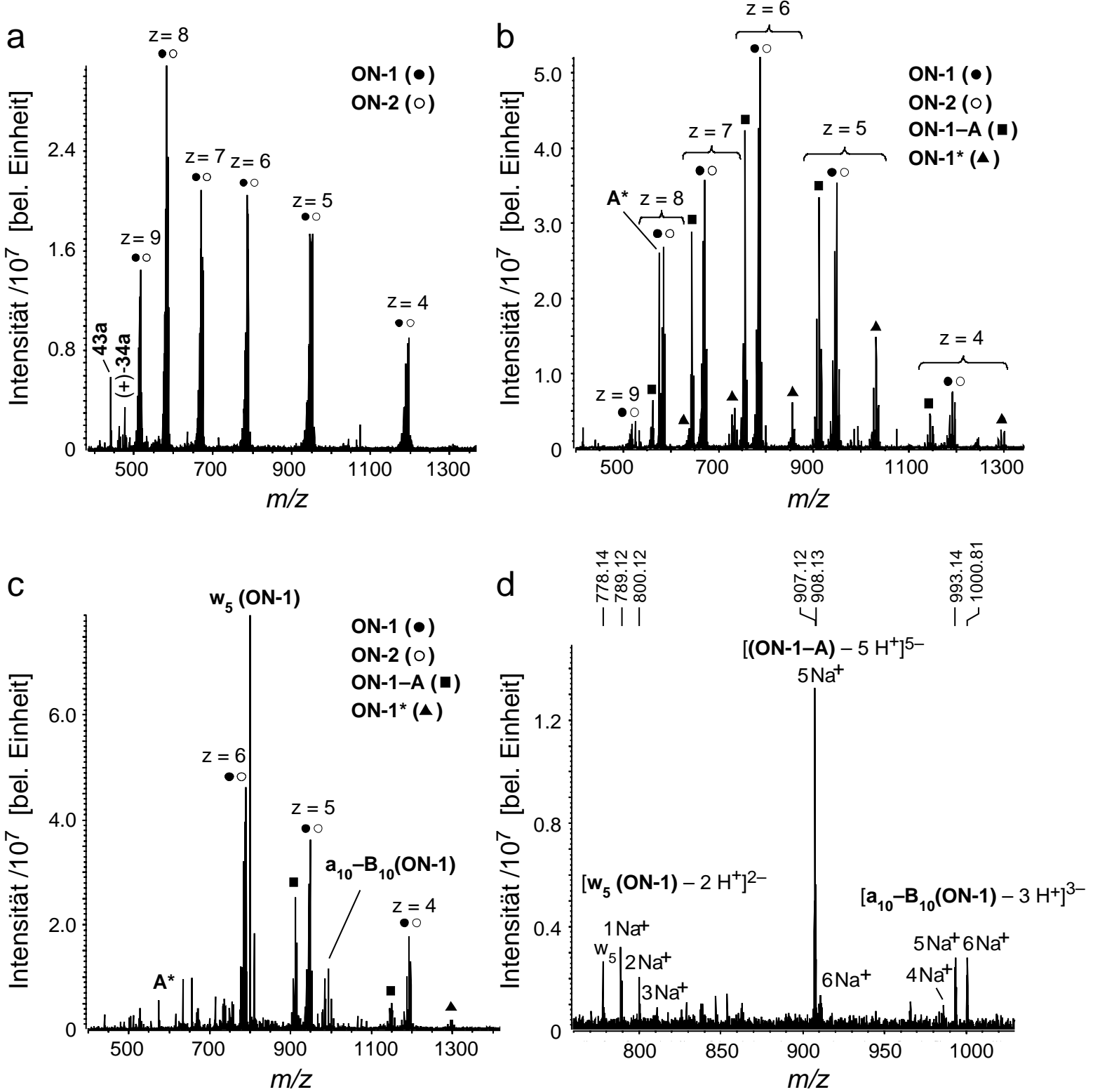

Abb. 70. Massenspektren nach Inkubation des DNA-Oligonukleotides ds-60 mit dem secoDrug (+)-(1S,10R)-34a im Verhältnis 1:1. a) $0 \mathrm{~h}$ Inkubation, $U_{\mathrm{C}}=-100 \mathrm{~V}$; b) $24 \mathrm{~h}$ Inkubation, $U_{\mathrm{C}}=-100 \mathrm{~V}$; c) $24 \mathrm{~h}$ Inkubation, $U_{\mathrm{C}}=-150 \mathrm{~V}$; d) $24 \mathrm{~h}$ Inkubation, CID-MS/MS. z: Betrag der Ladung der negativ geladenen Ionen.

Zudem konnten der Einzelstrang ON-1 nach Abspaltung der Nukleobase Adenin (ON-1-A) sowie das durch das Drug alkylierte Adenin $\mathbf{A}^{*}$ detektiert werden (Abb. 70b). Eine Erhöhung der Kapillarausgangsspannung (CapExit Voltage, $U_{\mathrm{C}}$ ) von $U_{\mathrm{C}}=-100 \mathrm{~V}$ auf $U_{\mathrm{C}}=-150 \mathrm{~V}$ führte zur Fragmentierung des alkylierten Stranges ON-1* und des primären Spaltproduktes ON-1-A mittels Capillary-Skimmer-Dissoziation $(\mathrm{CSD})^{180}$ innerhalb der ESI-Quelle zu den zwei sekundären Spaltprodukten $\mathbf{a}_{10}-\mathbf{B}_{10}(\mathbf{O N}-1)$ und $\mathbf{w}_{5}(\mathbf{O N}-1)$ (Abb. 70c). Diese Fragmentierung konnte durch ein CID-MS/MS-Experiment (CID = Collison Induced Dissociation $),{ }^{180}$ bei dem ON-1-A 
isoliert und dann durch Stöße mit einem Inertgas (Argon) fragmentiert wurde, bestätigt werden (Abb. 70d).

Die Abbildungen 71a und 72a zeigen die DNA-Oligonukleotide nach $0 \mathrm{~h}$ Inkubation.

a

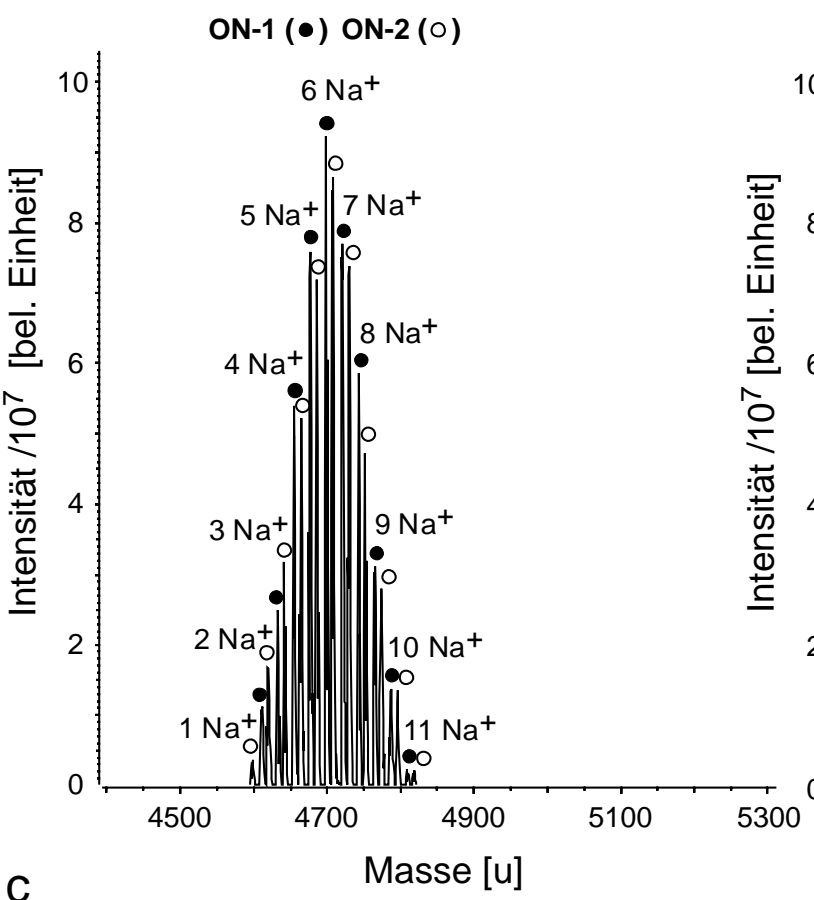

C

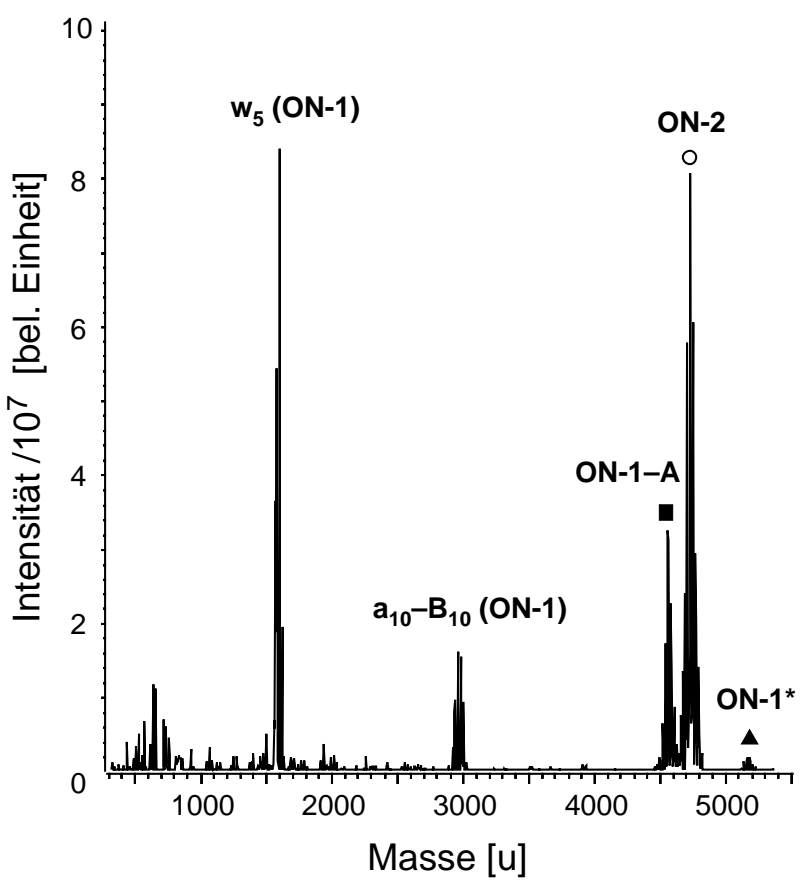

b ON-1 (•) ON-2 (O)

$6 \mathrm{Na}^{+}$

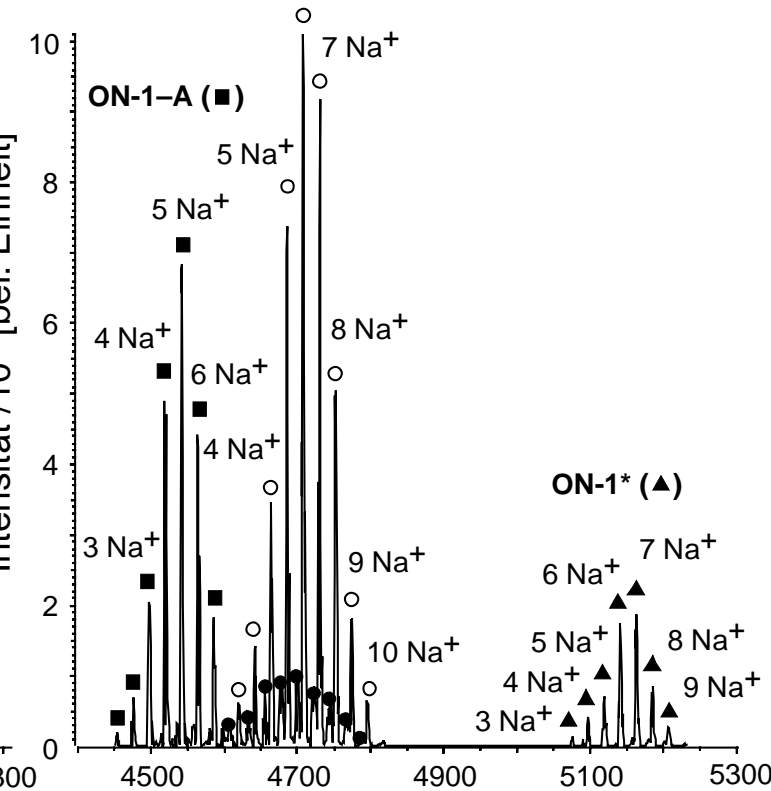

Masse $[u]$ 

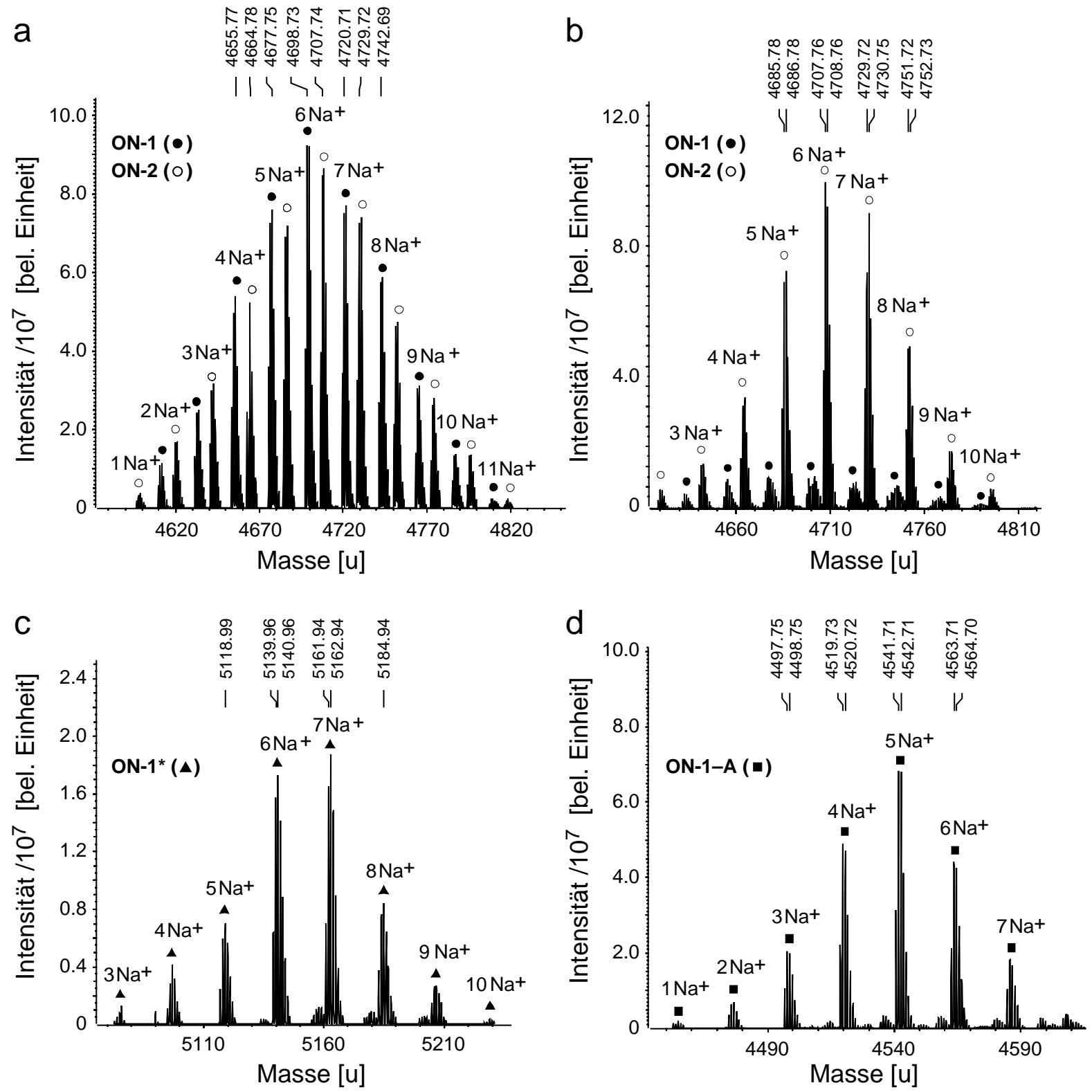

Abb. 72. Dekonvolierte Massenspektren nach Inkubation des DNA-Oligonukleotides ds-60 mit dem seco-Drug (+)-(1S,10R)-34a im Verhältnis 1:1. $U_{\mathrm{C}}=-100 \mathrm{~V}$. a) $0 \mathrm{~h}$ Inkubation, Vergrößerung von Abb. 71a; b-d) 24 h Inkubation, Vergrößerungen von Abb. 71b.

Deutlich sind sowohl die Natriumadduktverteilung sowie das Isotopenmuster jedes Natriumadduktes zu erkennen. Zudem haben $\mathbf{O N}-1$ und $\mathbf{O N - 2}$ etwa die gleiche Intensität. Nach $24 \mathrm{~h}$ Inkubation (Abb. $71 \mathrm{~b}$ und $72 \mathrm{~b}$ ) ist die Intensität des Oligonukleotides ON-1 stark verringert gegenüber der Intensität des Oligonukleotides ON-2. Zudem sind die Natriumaddukte des durch das Drug 43a alkyierten Oligonukleotides ON-1* sowie dieses Oligonukleotides nach Abspaltung der Nukleobase Adenin, d.h. des primären Spaltproduktes $\mathbf{O N}-\mathbf{1}-\mathbf{A}, \quad \mathrm{zu}$ erkennen (Abb. 71b, 72c und 72d). Die Abbildungen 71c und 73b zeigen die Natriumaddukte 
der bei erhöhter Kapillarspannung $\left(U_{\mathrm{C}}=-150 \mathrm{~V}\right)$ erhaltenen sekundären Spaltprodukte $\mathbf{a}_{\mathbf{1 0}}-\mathbf{B}_{\mathbf{1 0}}(\mathbf{O N}-\mathbf{1})$ und $\mathbf{w}_{\mathbf{5}}(\mathbf{O N}-\mathbf{1})$ des alkylierten Oligonukleotides. Die durch das Drug 43a modifizierte Nukleobase Adenin $\left(\mathbf{A}^{*}\right)$ sowie geringe Mengen des restlichen Drugs 43a sind in Abbildung 73a zu sehen. Alle Zuordnungen erfolgten durch Vergleich der experimentell ermittelten Masse mit der berechneten exakten Masse der Verbindungen (Tabellen der gefundenen und berechneten Massen: s. Experimenteller Teil, Kap. 7).
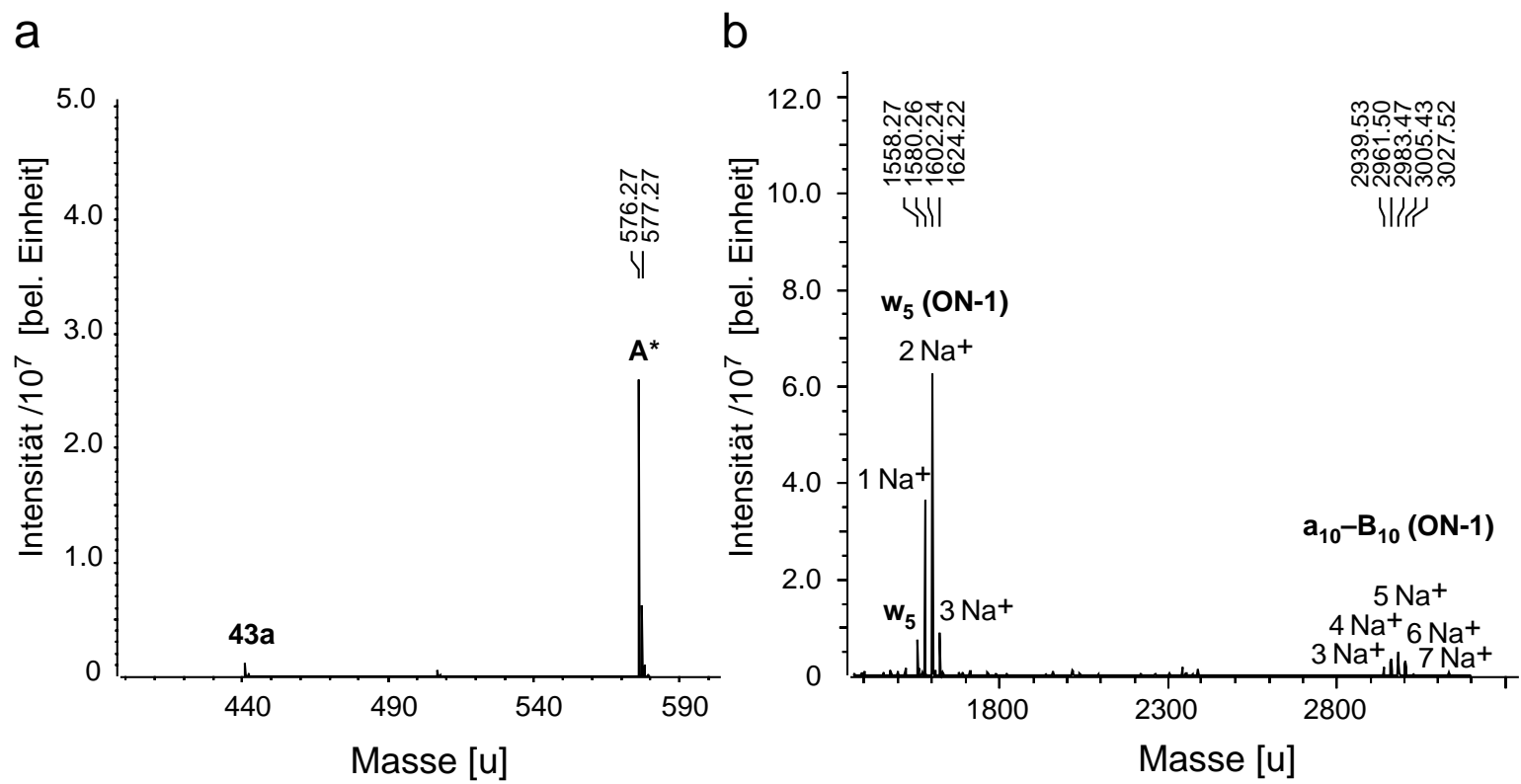

Abb. 73. Dekonvolierte Massenspektren nach Inkubation des DNA-Oligonukleotides ds-60 mit dem seco-Drug $(+)-(1 S, 10 R)-34 a$ im molaren Verhältnis 1:1. $24 \mathrm{~h}$ Inkubation, $U_{\mathrm{C}}=-150$ V. a) $43 \mathbf{a}$ und $\mathbf{A}^{*}$, b) $\mathbf{w}_{\mathbf{5}}(\mathbf{O N}-\mathbf{1})$ und $\mathbf{a}_{\mathbf{1 0}}-\mathbf{B}_{\mathbf{1 0}}(\mathbf{O N}-\mathbf{1})$.

Die Messergebnisse belegen, dass nach einer schnellen Zyklisierung des seco-Drugs $(+)-(1 S, 10 R)-34 \mathbf{a}$ zum Drug 43a eine Einlagerung in die kleine Furche der doppelsträngigen DNA stattfindet. Anschließend erfolgt eine Alkylierung des Adenins am 3'-Ende der AT-reichen Sequenz des Oligonukleotides ON-1 unter Entstehung des kovalenten Adduktes ON-1* (Abb. 74).

Die Bindung des Drugs schwächt die $N$-glykosidische Bindung zwischen der Nukleobase Adenin und der angrenzenden Desoxyribose des Zucker-Phosphat-Rückgrates. ${ }^{180}$ Dies führt unter den Ionisierungsbedingungen im Massenspektrometer unter intermediärer Nachbargruppenbeteiligung des Sauerstoffatoms der Desoxyribose in ON-1* zu einer thermischen 1,2-Eliminierung der modifizierten Base $\mathbf{A}^{*}$ (Abb. 75). ${ }^{180}$ 


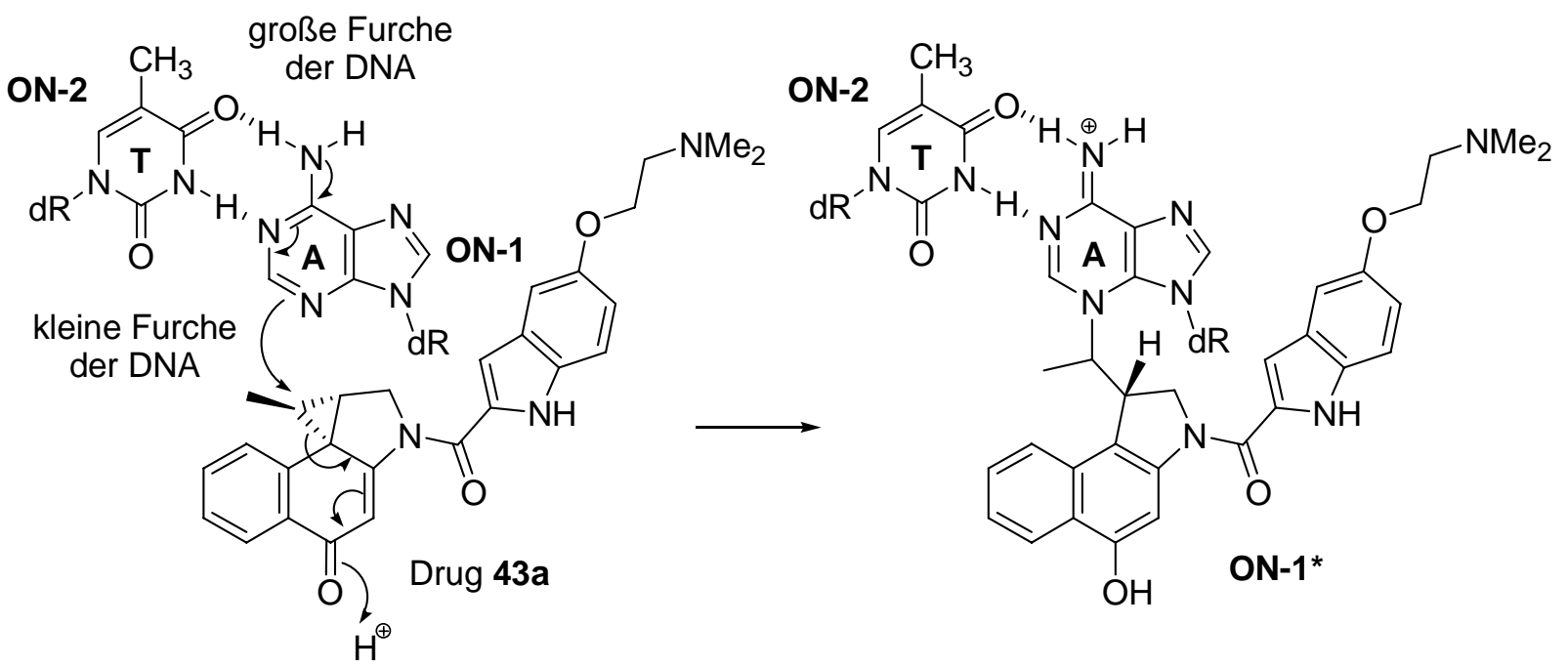

Abb. 74. Alkylierung der Nukleobase Adenin im DNA-Oligonukleotid ON-1 durch das Drug 43a unter Bildung des kovalenten Adduktes ON-1*.<smiles>CC(C1CN(C(=O)c2cc3cc(OCCN(C)C)ccc3[nH]2)c2cc(O)c3ccccc3c21)n1cnc(N)c2ncnc1-2</smiles>

ON-1*<smiles>O=P(O)(O)OC1C=COC1COP=S</smiles>

ON-1-A<smiles>CNCCOc1ccc2[nH]c(C(=O)N3CC(C(C)n4cnc(N)c5ncnc4-5)c4c3cc(O)c3ccccc43)cc2c1</smiles>

$A^{*}$<smiles>O=[R16]c1ccc(COP(=O)(O)O[Na])cc1</smiles>

Abb. 75. Fragmentierung des alkylierten Oligonukleotides $\mathbf{O N}-\mathbf{1}^{*}$ in das primäre Spaltprodukt ON-1-A und die alkylierte Base A* sowie Strangbruch in ON-1-A unter Bildung der charakteristischen sekundären Spaltprodukte $\mathbf{a}_{\mathbf{1 0}}-\mathbf{B}_{\mathbf{1 0}}(\mathbf{O N}-\mathbf{1})$ und $\mathbf{w}_{\mathbf{5}}(\mathbf{O N}-\mathbf{1})$.

Das gebildete Spaltprodukt ON-1-A zerfällt unter erhöhter Kapillarausgangsspannung $\left(U_{\mathrm{C}}=-150 \mathrm{~V}\right)$ in der ESI-Quelle in die sekundären Spaltprodukte $\mathbf{a}_{\mathbf{1 0}}-\mathbf{B}_{\mathbf{1 0}}(\mathbf{O N}-\mathbf{1})$ und $\mathbf{w}_{\mathbf{5}}(\mathbf{O N}-\mathbf{1})$, die eindeutig belegen, dass die Alkylierung an der Base $\mathrm{A}_{10}$ im Oligonukleotid ON-1 von ds-60 stattgefunden hat (Abb. 76). 


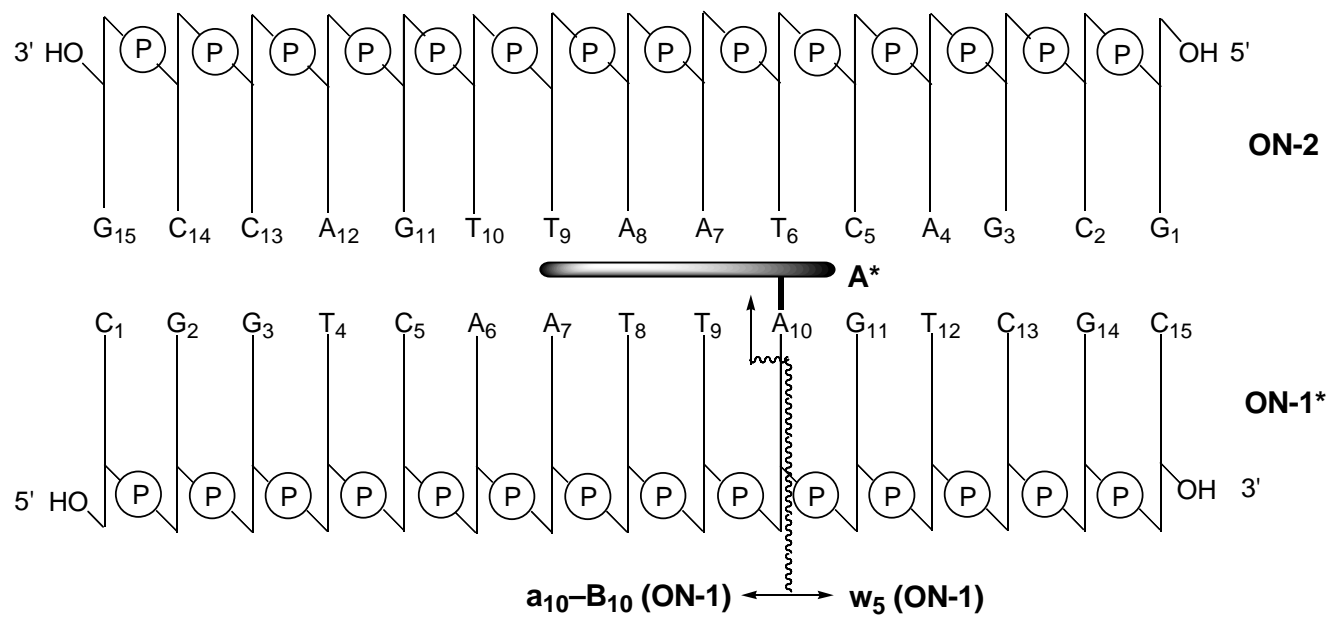

Abb. 76. Fragmentierung des alkylierten Oligonukleotides $\mathbf{O N - 1} *$ in $\mathbf{A}^{*}, \mathbf{a}_{10}-\mathbf{B}_{\mathbf{1 0}}$ und $\mathbf{w}_{\mathbf{5}}$.

Bei einem Verhältnis von (+)-(1S,10R)-34a / ds-60 = 1:1 wurde fast ausschließlich das Adenin $\mathrm{A}_{10}$ des Oligonukleotides ON-1 alkyliert (Abb. 73a). Bei einem 5:1-Verhältnis konnte eine nahezu quantitative Alkylierung des Oligonukleotides ON-1 an $\mathrm{A}_{10}$ unter zusätzlicher partieller Alkylierung von Guanin festgestellt werden (Abb. 77). Dies äußert sich durch das Auftreten der alkylierten Nukleobase Guanin $\left(\mathbf{G}^{*}\right)$. Aufgrund der geringen Signalintensität der DNA-Einzelstränge bei hohem Drug-Anteil ließen sich das an Guanin alkylierte Oligonukleotid sowie die genaue Bindungsposition nicht identifizieren.

a

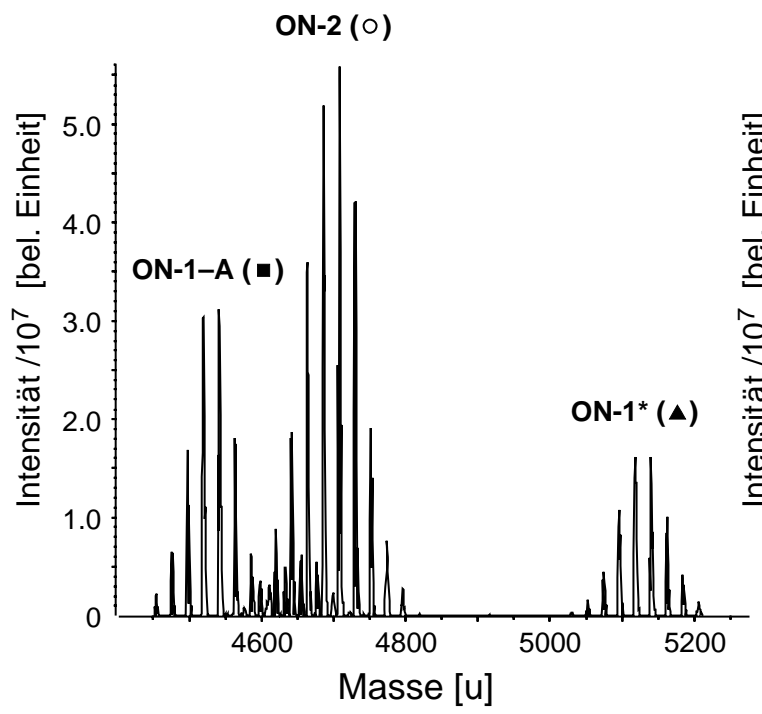

b

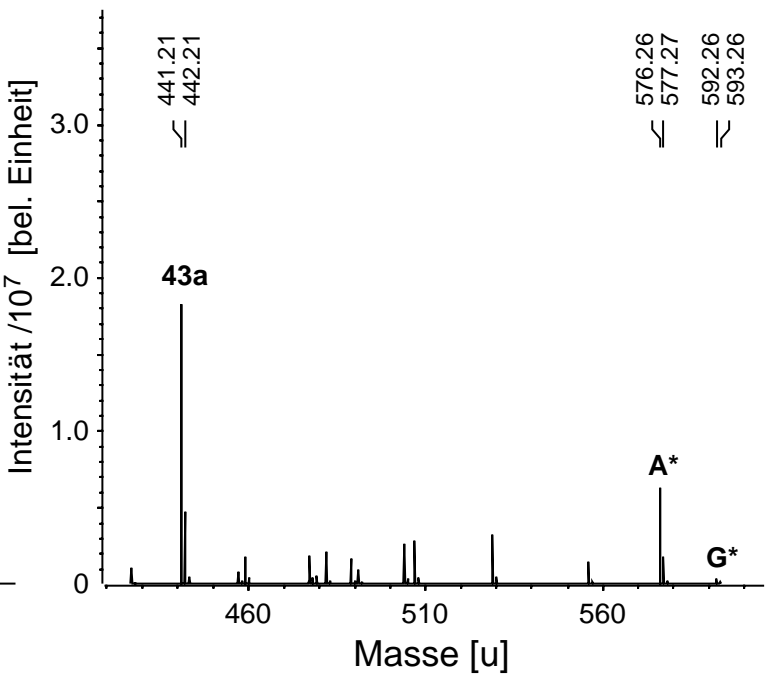

Abb. 77. Dekonvolierte Massenspektren nach Inkubation des DNA-Oligonukleotides ds-60 mit dem seco-Drug (+)-(1S,10R)-34a im molaren Verhältnis 1:5. a) $24 \mathrm{~h}$ Inkubation, $U_{\mathrm{C}}=-100 \mathrm{~V}$; b) $24 \mathrm{~h}$ Inkubation, $U_{\mathrm{C}}=-150 \mathrm{~V}$. 
Im Folgenden wurde untersucht, ob primär durch nicht-kovalente Wechselwirkungen gebildete Komplexe von ds-60 mit dem seco-Drug (+)-(1S,10R)-34a bzw. dem in situ aus diesem generierten Drug 43a massenspektrometrisch nachgewiesen werden können. ${ }^{184}$ Der Anteil des im Massenspektrometer sichtbaren Doppelstranges konnte hierbei signifikant erhöht werden, wenn die Reaktionslösung nach dem Ansetzen mit einer Mischung aus Wasser, Ammoniumacetat $(10 \mathrm{mM})$ und Isopropanol versetzt und unter milden Bedingungen $\left(T=100{ }^{\circ} \mathrm{C}, U_{\mathrm{C}}=-80 \mathrm{~V}\right)$ vermessen wurde (Abb. 78).

In keinem Fall konnten bei den durchgeführten Messungen Komplexe, die durch nichtkovalente Wechselwirkungen zwischen dem seco-Drug $(+)-(1 S, 10 R)-34 \mathbf{a}$ und dem DNA-Doppelstrang ds-60 verursacht worden sein könnten, beobachtet werden. Stattdessen war deutlich eine Spezies zu detektieren, deren Masse dem nichtkovalenten oder kovalenten Addukt aus ds-60 und dem Drug 43a entspricht (ds-60 $\left.{ }^{(*)}\right)$.
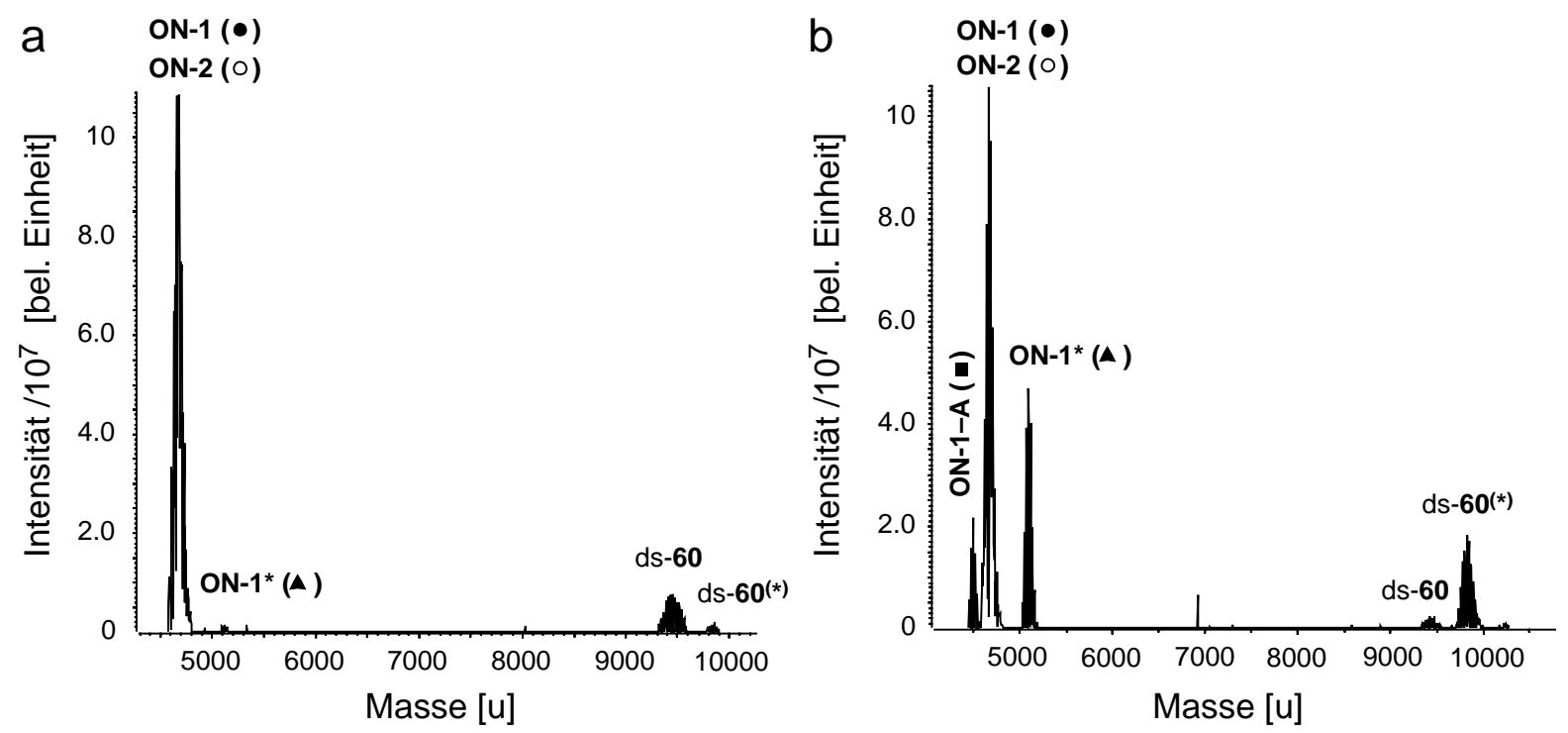

Abb. 78. Dekonvolierte Massenspektren nach Inkubation des DNA-Oligonukleotides ds-60 mit dem seco-Drug (+)-(1S,10R)-34a im molaren Verhältnis $1: 1$ in $\mathrm{H}_{2} \mathrm{O} /$ aq. $\mathrm{NH}_{4} \mathrm{OAc} /$ $i \operatorname{PrOH}=3: 1: 1$ zur Untersuchung nicht-kovalenter Wechselwirkungen. $U_{\mathrm{C}}=-80 \mathrm{~V}$. a) $15 \mathrm{~min}$ Inkubation, b) $3 \mathrm{~h}$ Inkubation.

Um die Geschwindigkeit der Alkylierungsreaktion in Wasser abzuschätzen, wurden kinetische Untersuchungen durchgeführt, indem in stündlichem Abstand nach dem Ansetzen einer 1:1-Mischung des seco-Drugs (+)-(1S,10R)-34a mit dem DNA-Oligonukleotid ds-60 massenspektrometrische Untersuchungen durchgeführt wurden. Abbildung 79 zeigt die zeitabhängige Alkylierung des Oligonukleotides ON-1 des Doppelstranges ds-60 in Wasser. 


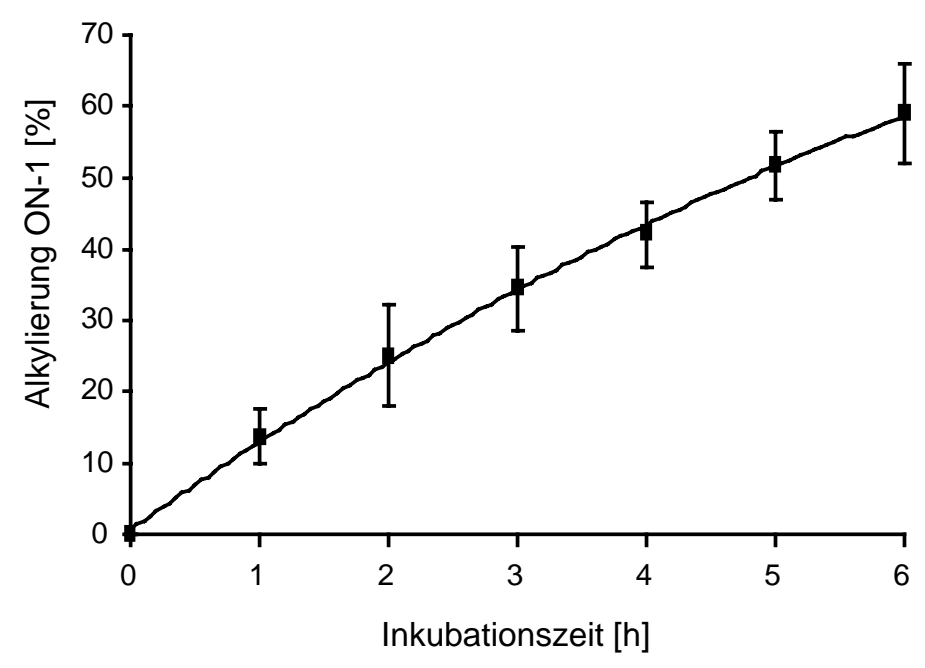

Abb. 79. Massenspektrometrisch bestimmte zeitabhängige Alkylierung des Oligonukleotides ON-1 im DNA-Doppelstrang ds-60 bei Inkubation mit dem seco-Drug (+)-(1S,10R)-34a im molaren Verhältnis ds-60/(+)-(1S,10R)-34a=1:1. Aufgetragen wurden jeweils die Mittelwerte \pm Standardabweichungen (Triplikate).

Die Alkylierungsrate beträgt etwa 10\% pro Stunde mit einer etwas höheren Geschwindigkeit zu Beginn der Reaktion und einer niedrigeren Umsatzrate bei längerer Inkubationsdauer.

Der Anteil des umgesetzten Oligonukleotides ON-1 zu einem bestimmten Zeitpunkt $t$ wurde bestimmt, indem die Peakhöhen eines jeden Natriumadduktes beider Oligonukleotide durch Division zueinander in Beziehung gesetzt wurden (s. AAV 7.3). Dieses Verfahren wurde für je zwei bis vier Messungen desselben Reaktionsansatzes angewandt und die Mittelwerte je dreier Reaktionsansätze wurden erneut gemittelt. Der Anteil $A^{\mathrm{t}}$ des umgesetzten Oligonukleotides zur Zeit $t$ errechnet sich somit gemäß:

$$
A^{t}=1-\frac{\overline{Q^{t}}}{\overline{Q^{0}}}
$$

mit: $\overline{Q^{t}}=$ Mittelwert des Quotienten der Intensitäten von ON-1 zu ON-2 zum Zeitpunkt $t$, $\bar{Q}^{0}=$ Mittelwert des Quotienten der Intensitäten von ON-1 zu ON-2 zum Zeitpunkt $t=0 \mathrm{~h}$.

Um zu überprüfen, ob das angewandte Verfahren zur Berechnung des Anteils des alkylierten Einzelstranges durch die Dekonvolution der Spektren nicht verfälscht wird, wurde für mehrere Messungen eine analoge Berechnung für alle Ladungszustände der Einzelstränge in den Rohspektren durchgeführt und der Mittelwert dieser Berech- 
nungen mit dem Mittelwert aus den dekonvolierten Spektren verglichen. In allen Fällen war die Differenz der so erhaltenen Mittelwerte kleiner als die Standardabweichung des Mittelwertes der jeweiligen Werte. Die Methode kann demzufolge als hinreichend genau betrachtet werden.

Wurde das Oligonukleotid ds-60 mit dem seco-Drug $(+)-(1 S, 10 R)-34 a$ im molaren Verhältnis ds-60 / (+)-( $(1 S, 10 R)-\mathbf{3 4 a}=1: 1$ oder 1:4 umgesetzt, so konnte nach 24 Stunden Inkubation eine Alkylierung von etwa $75 \%$ beobachtet werden. In einem Verhältnis ds-60 / (+)-(1S,10R)-34a = 1:2 war die Alkylierung bei gleichbleibender Selektivität der Alkylierungsposition signifikant erniedrigt und betrug nur etwa 50\%. Im Vergleich dazu war der Anteil des alkylierten Einzelstranges ON-1 bei Umsetzung im molaren Verhältnis ds-60 / (+)-( $(1 S, 10 R)-34 \mathbf{a}=1: 5 \mathrm{mehr}$ als $90 \%$ und es konnte eine zusätzliche Alkylierung an Guanin festgestellt werden. Die Alkylierungseffizienz und -selektivität ist somit vom molaren Verhältnis zwischen der DNA und dem secoDrug abhängig. Die Verringerung der Alkylierungseffizienz in Anwesenheit von zwei Äquivalenten des seco-Drugs könnte durch eine gleichzeitige Einlagerung zweier Drug-Moleküle in die kleine Furche der AT-reichen Region des doppelsträngigen Oligonukleotides verursacht sein, die zu einer Behinderung der Alkylierungsreaktion führt (vide infra).

Nachdem eine selektive und effiziente Alkylierung des DNA-Doppelstranges ds-60 nachgewiesen werden konnte, wurde die Alkylierung des Einzelstranges ON-1 (ds-60) mit der gleichen Methode untersucht (Abb. 80). Hierbei wurde das Ammoniumsalz der DNA eingesetzt.

Im Gegensatz zum Doppelstrang ds-60, bei dem das Oligonukleotid ON-1 nahezu quantitativ alkyliert wurde, betrug die Alkylierung nur circa 20\%, wenn das gleiche Oligonukleotid als Einzelstrang vorlag. Sowohl die wesentlich geringere Alkylierung als auch das hier zu beobachtende Auftreten des Hydrolyseproduktes 84a, das mangels geeigneter Nukleophile durch Addition von Wasser an das Drug 43a oder durch eine Chlorsubstitution im seco-Drug 34a entstand, belegen die wesentlich höhere Reaktivität des Wirkstoffs gegenüber doppelsträngiger DNA. Die Einlagerung in den DNA-Doppelstrang senkt demzufolge merklich die Aktivierungsenergie der Alkylierungsreaktion ab. 


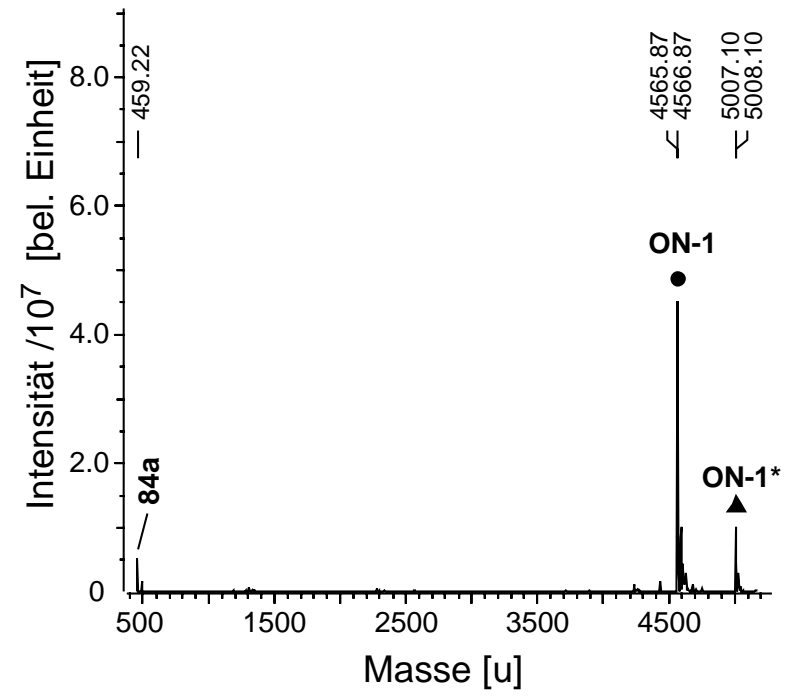

Abb. 80. Dekonvoliertes Massenspektrum nach $24 \mathrm{~h}$ Inkubation des DNA-Oligonukleotides ON-1 (ds-60) mit dem seco-Drug (+)-(1S,10R)-34a im Verhältnis 1:1.

Neben der beschriebenen Verringerung der Alkylierungseffizienz war zudem eine starke Erniedrigung der Sequenzselektivität zu beobachten: Neben $\mathrm{G}_{3}$ und $\mathrm{A}_{7}$ wurden weitere Nukleobasen durch 43a alkyliert, deren Position jedoch aufgrund der geringen Signalintensität der entsprechenden Fragmente nicht ermittelt werden konnte.

\subsection{Wechselwirkung des seco-Drugs (-)-(1R,10S)-34a mit den DNA- Oligonukleotiden ds-60 und ON-1 (ds-60)}

Das zu $(+)-(1 S, 10 R)-34$ a enantiomere seco-Drug $(-)-(1 R, 10 S)$-34a zeigt in In-vitroUntersuchungen eine wesentlich geringere Zytotoxizität als $(+)-(1 S, 10 R)-34 a$ (s. Kap. 5).

Wurde ds-60 mit $(-)-(1 R, 10 S)-34 a$ in den molaren Verhältnissen 1:1 bis 1:5 inkubiert, so konnte in allen Fällen nur eine sehr schwache Alkylierung an Guanin und Adenin festgestellt werden (Abb. 81). Interessanterweise wurden hierbei beide Oligonukleotide alkyliert, da sowohl die alkylierten Einzelstränge $\mathbf{O N}-1 *$ und $\mathbf{O N}-2 *$ als auch die nach Abspaltung von Adenin entstehenden Fragmente ON-1-A und ON-2-A beobachtet werden konnten. Während das zu erwartende alkylierte Adenin $\mathbf{A}^{*}$ nicht detektiert werden konnte, war das analog modifizierte Guanin $\mathbf{G}^{*}$ in einigen Spektren schwach zu erkennen (nicht dargestellt). Die genaue Alkylierungsposition konnte aufgrund der geringen Intensität der Addukte nicht festgestellt werden. 

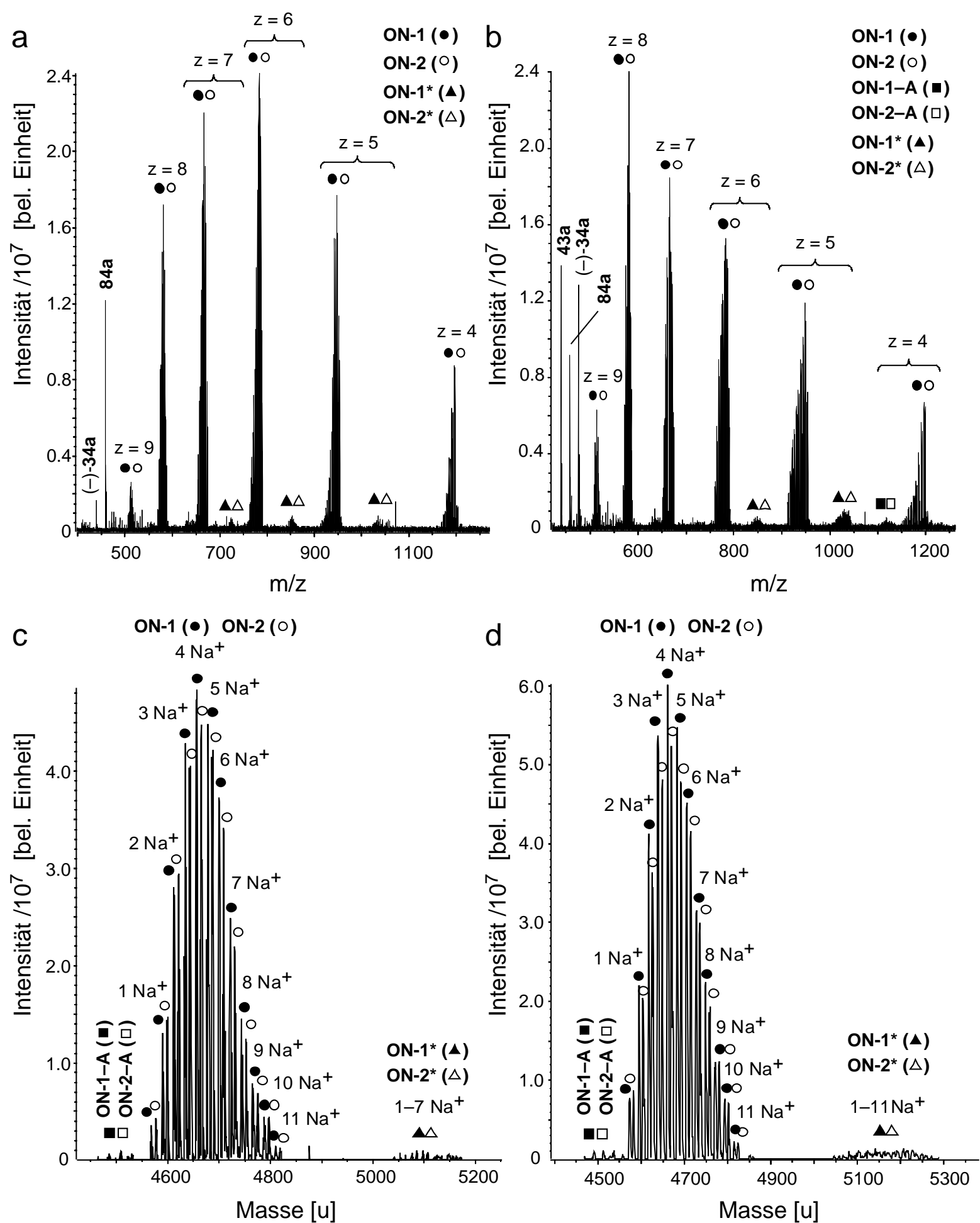

Abb. 81. Massenspektren (a,b) und dekonvolierte Massenspektren (c,d) nach 24 h Inkubation des DNA-Oligonukleotides ds-60 mit dem seco-Drug (-)-(1R,10S)-34a im molaren Verhältnis $1: 1(\mathrm{a}, \mathrm{c})$ und $1: 5(\mathrm{~b}, \mathrm{~d}) . U_{\mathrm{C}}=-100 \mathrm{~V}$.

Eine Umsetzung des seco-Drugs $(-)-(1 R, 10 S)$-34a mit dem einzelsträngigen Oligonukleotid ON-1 (ds-60) ergab, dass auch die Alkylierung des DNA-Einzelstranges mit weniger als 10\% Alkylierung nur sehr gering war (Abb. 82). 


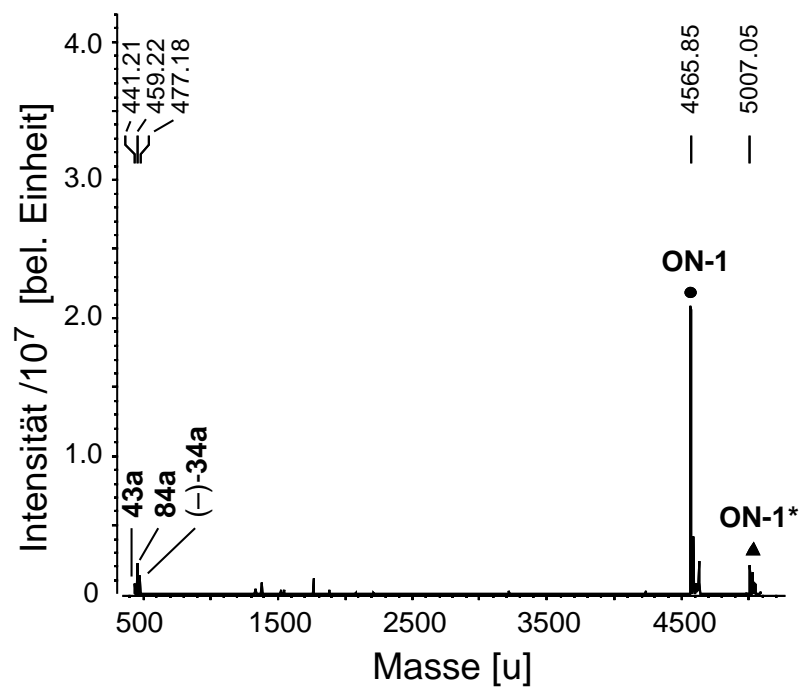

Abb. 82. Dekonvolierte Massenspektren nach $24 \mathrm{~h}$ Inkubation des DNA-Oligonukleotides ON-1 (ds-60) mit dem seco-Drug (-)-(1R,10S)-34a im molaren Verhältnis 1:1.

Aufgrund der geringeren Reaktivität des seco-Drugs mit unnatürlicher Konfiguration an C-1 bezüglich der DNA ist in allen Umsetzungen das Signal des Hydrolyseproduktes 84a des Wirkstoffs klar zu erkennen (Abb. 81 und 82). Auch Spuren des seco-Drugs 34a und des Drugs 43a sind nach 24 h Inkubation noch zu detektieren.

Die dargestellten Ergebnisse lassen somit den Schluss zu, dass die niedrigere Zytotoxzität des unnatürlich konfigurierten seco-Drugs $(-)-(1 R, 10 S)$-34a auf einer ineffizienteren Alkylierung der zellulären DNA beruhen könnte.

\subsection{Wechselwirkung des Prodrugs $(+)-(1 S, 10 R)-33 a$ mit den DNA- Oligonukleotiden ds-60 und ON-1 (ds-60)}

Wie das seco-Drug $(-)-(1 R, 10 S)-\mathbf{3 4 a}\left(I C_{50}=560 \mathrm{nM}\right)$ mit unnatürlicher Konfiguration an C-1 ist auch das Prodrug $(+)-(1 S, 10 R)-33 a\left(I C_{50}=3600 \mathrm{nM}\right)$ mit natürlicher Konfiguration weit weniger toxisch als das seco-Drug $(+)-(1 S, 10 R)-34 \mathbf{a}\left(I C_{50}=0.75 \mathrm{nM}\right)$. Dies lässt sich ebenfalls mit einer geringeren Alkylierungseffizienz erklären:

Abbildung 83 zeigt die Spektren der Inkubation des Prodrugs $(+)-(1 S, 10 R)-33 a$ mit ds-60. Nach 24 Stunden kann bei einem molaren Verhältnis ds-60 / (+)-(1S,10R)-33a $=1: 1$ nahezu keine Alkylierung (Abb. 83a,c) und im molaren Verhältnis von 1:5 nur eine maximal 10-\%ige Alkylierung (Abb. 83b,d) beobachtet werden. Die geringere 
Zytotoxizität korreliert demzufolge auch in diesem Fall mit einer geringeren Alkylierungseffizienz.
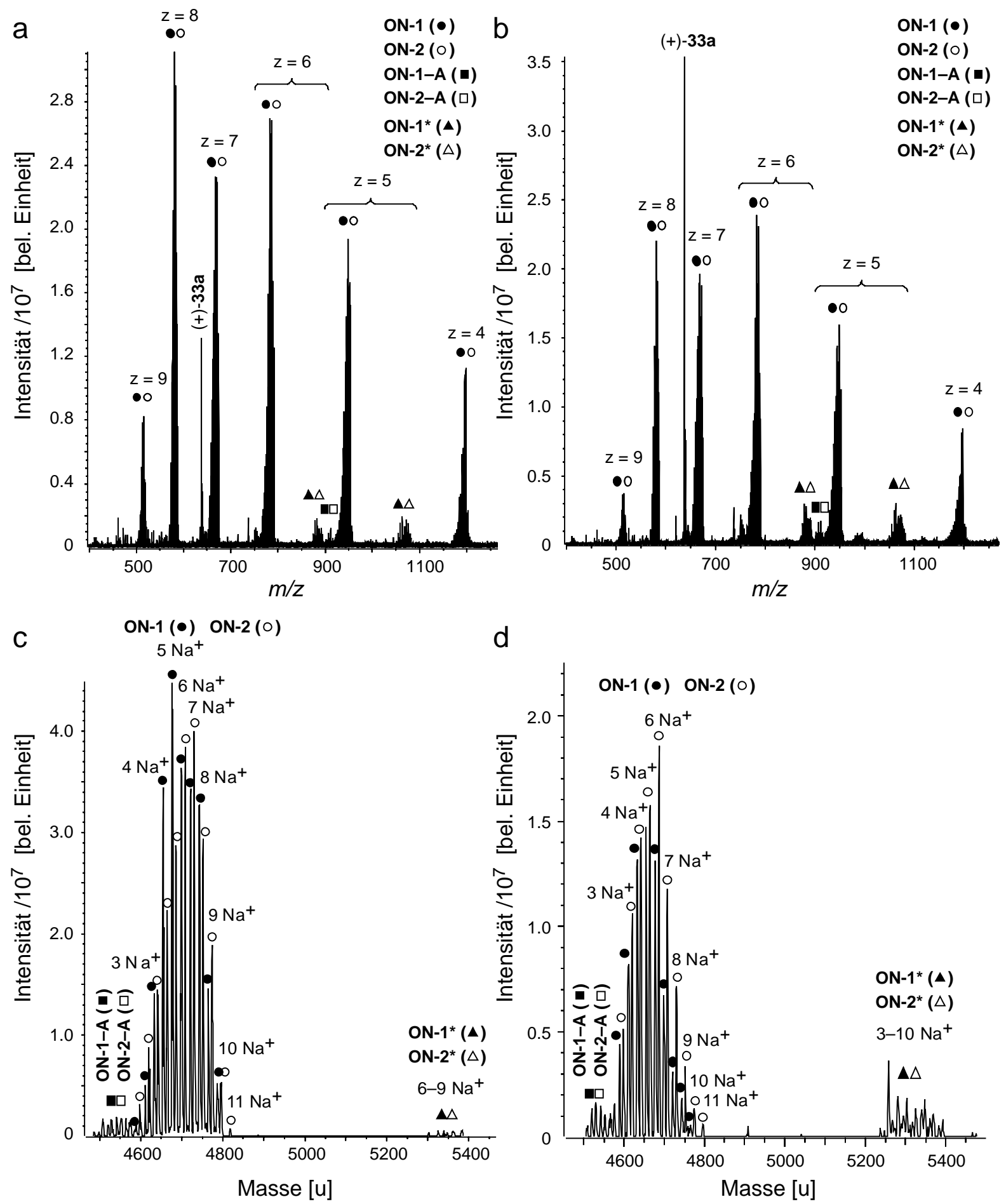

Abb. 83. Massenspektren (a,b) und dekonvolierte Massenspektren (c,d) nach $24 \mathrm{~h}$ Inkubation des DNA-Oligonukleotides ds-60 mit dem Prodrug $(+)-(1 S, 10 R)-33 a$ im molaren Verhältnis 1:1 (a,c) und 1:5 (b,d). $U_{\mathrm{C}}=-100 \mathrm{~V}$. 
Weiterhin werden beide Oligonukleotide durch das Prodrug alkyliert, was sich am Auftreten der alkylierten Einzelstränge $\mathbf{O N}-\mathbf{1}^{*}$ und $\mathbf{O N}-\mathbf{2}^{*}$ sowie ihrer primären Spaltprodukte $\mathbf{O N - 1 - A}$ und $\mathbf{O N - 2 - A}$ belegen lässt (Abb. 83).

Die Fragmentierung der primären Spaltprodukte mittels CSD durch eine Erhöhung der Kapillarausgangsspannung auf $U_{\mathrm{C}}=-150 \mathrm{~V}$ lieferte hauptsächlich vier sekundäre Spaltprodukte (Abb. 84b) sowie das durch $(+)-(1 S, 10 R)-33 a$ alkylierte Adenin (A*, Abb. 84a).
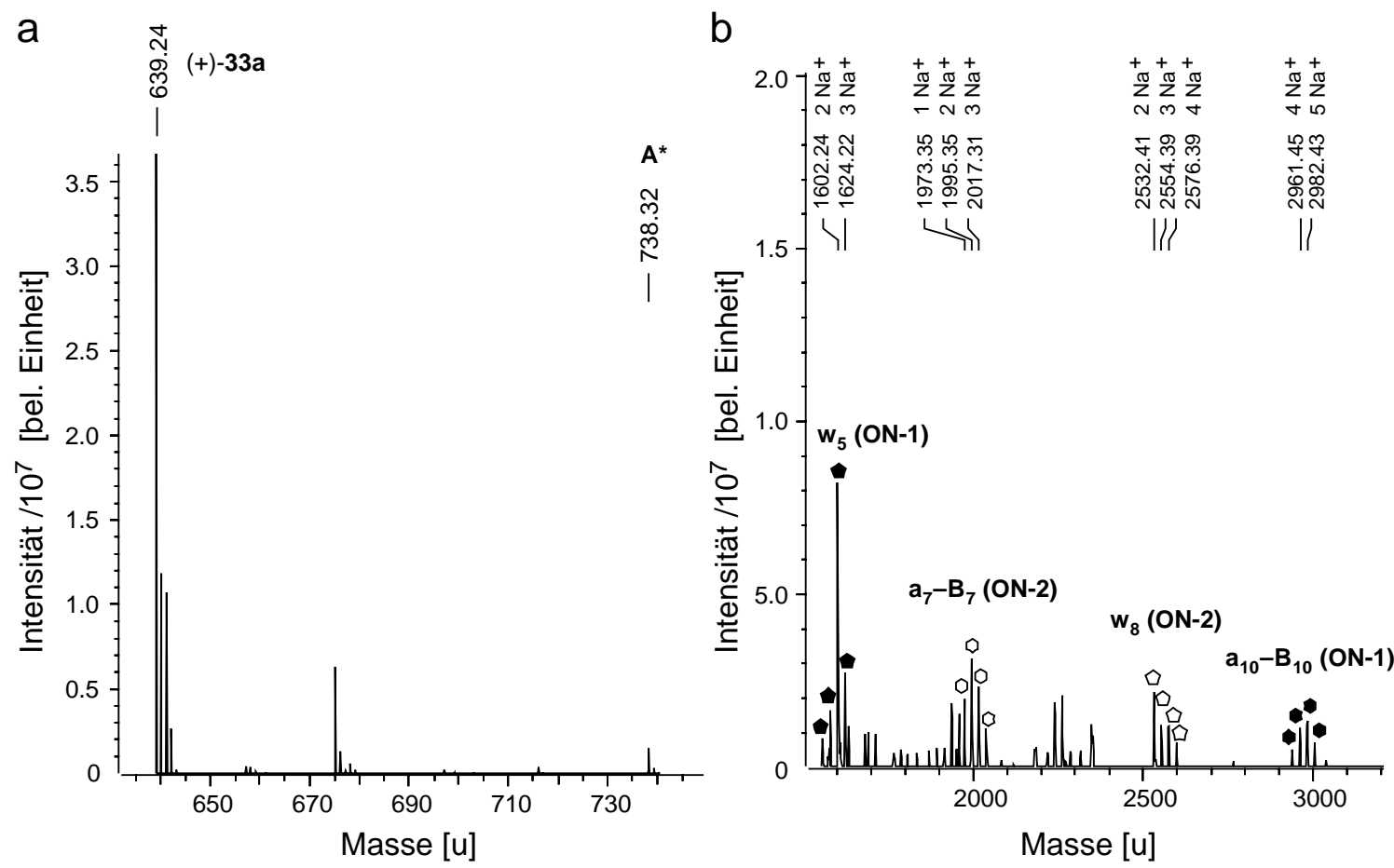

Abb. 84. Dekonvolierte Massenspektren nach Inkubation des DNA-Oligonukleotides ds-60 mit dem Prodrug $(1 S, 10 R)$-33a im molaren Verhätnis 1:1. 24 h Inkubation, $U_{\mathrm{C}}=-150 \mathrm{~V}$.

Die sekundären Spaltprodukte $\mathbf{a}_{10}-\mathbf{B}_{\mathbf{1 0}}(\mathbf{O N}-\mathbf{1})$ und $\mathbf{w}_{\mathbf{5}}(\mathbf{O N}-1)$ belegen eindeutig, dass eine Alkylierung an der Nukleobase $\mathrm{A}_{10}(\mathrm{ON}-1)$ stattgefunden hat (Abb. 84 und 85). Die zusätzlich zu beobachtenden sekundären Spaltprodukte $\mathbf{a}_{7}-\mathbf{B}_{7}(\mathbf{O N}-2)$ und $\mathbf{w}_{\mathbf{8}}(\mathbf{O N}-2)$ belegen weiterhin, dass auch an der Nukleobase $A_{7}(\mathrm{ON}-2)$ eine Alkylierung erfolgt ist (Abb. 84 und 85).

Diese Alkylierungspositionen weisen darauf hin, dass sich das Prodrug in der gleichen Orientierung in die kleine Furche des AT-reichen Abschnittes der doppelsträngigen DNA einlagert wie das aus dem entsprechenden seco-Drug $(+)-(1 S, 10 R)-34$ a gebildete Drug 43a. 


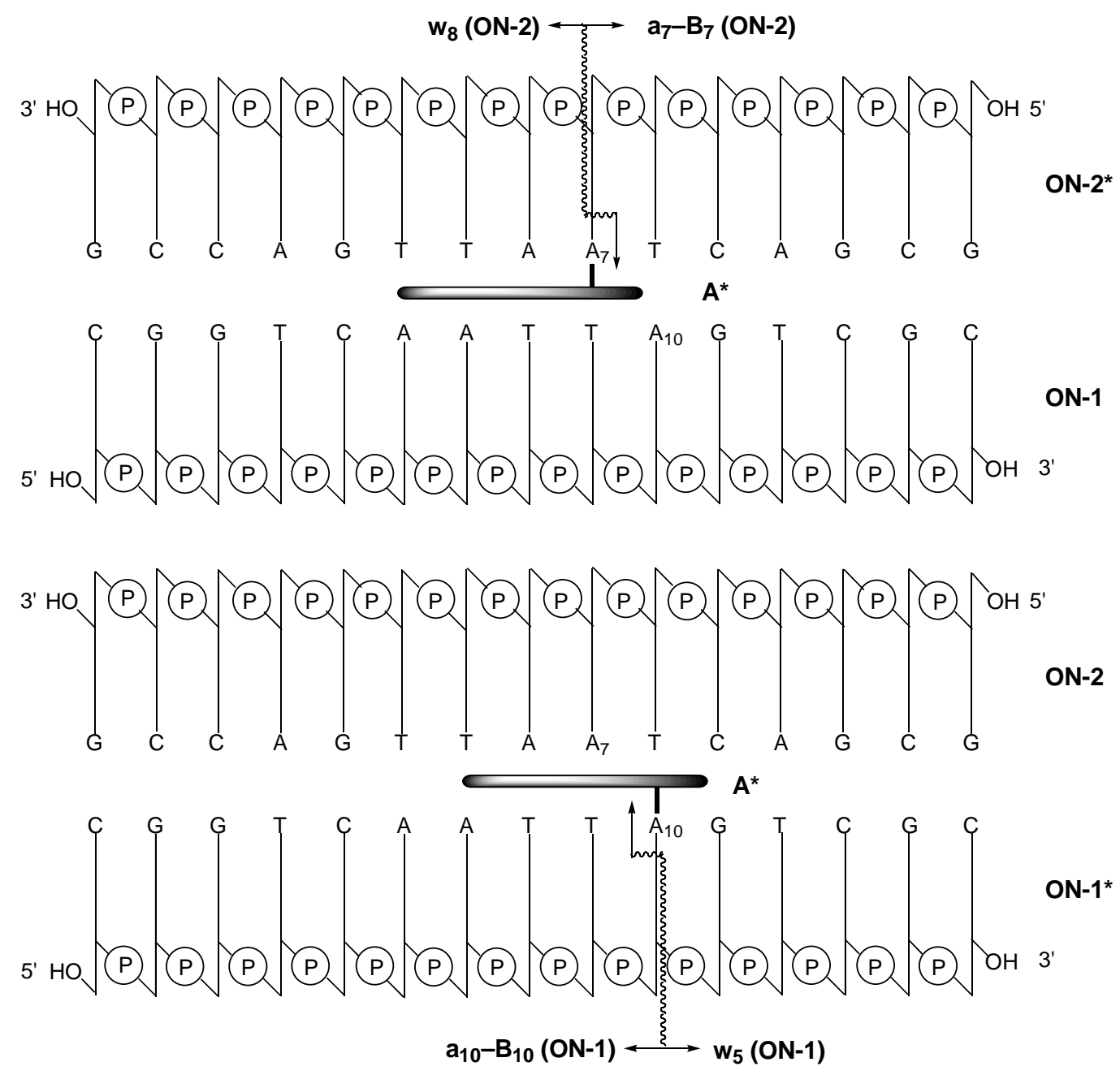

Abb. 85. Fragmentierung des alkylierten Oligonukleotides $\mathbf{O N - 2} *$ in $\mathbf{A}^{*}, \mathbf{a}_{7}-\mathbf{B}_{7}$ und $\mathbf{w}_{\mathbf{8}}$ bzw. des alkylierten Oligonukleotides $\mathbf{O N}-\mathbf{1} *$ in $\mathbf{A}^{*}, \mathbf{a}_{\mathbf{1 0}}-\mathbf{B}_{\mathbf{1 0}}$ und $\mathbf{w}_{\mathbf{5}}$.

Im Gegensatz zu (+)-(1S,10R)-34a bzw. 43a kann die Alkylierung des Prodrugs allerdings nur durch eine direkte Reaktion der DNA-Nukleobasen mit der 1-Chlorethyl-Funktionalität des Moleküls erfolgen, da eine Winstein-Zyklisierung durch die Galactoseeinheit verhindert wird (Abb. 86).

Die Flexibilität der 1-Chlorethyleinheit ermöglicht hierbei nach der Einlagerung des Prodrugs in die kleine Furche der AT-reichen Region der doppelsträngigen DNA die Alkylierung jeweils einer der beiden sich schräg gegenüberliegenden Basen $\mathrm{A}_{10}$ (ON-1) bzw. $\mathrm{A}_{7}(\mathrm{ON}-2)$ (Abb. 85 und 86). 

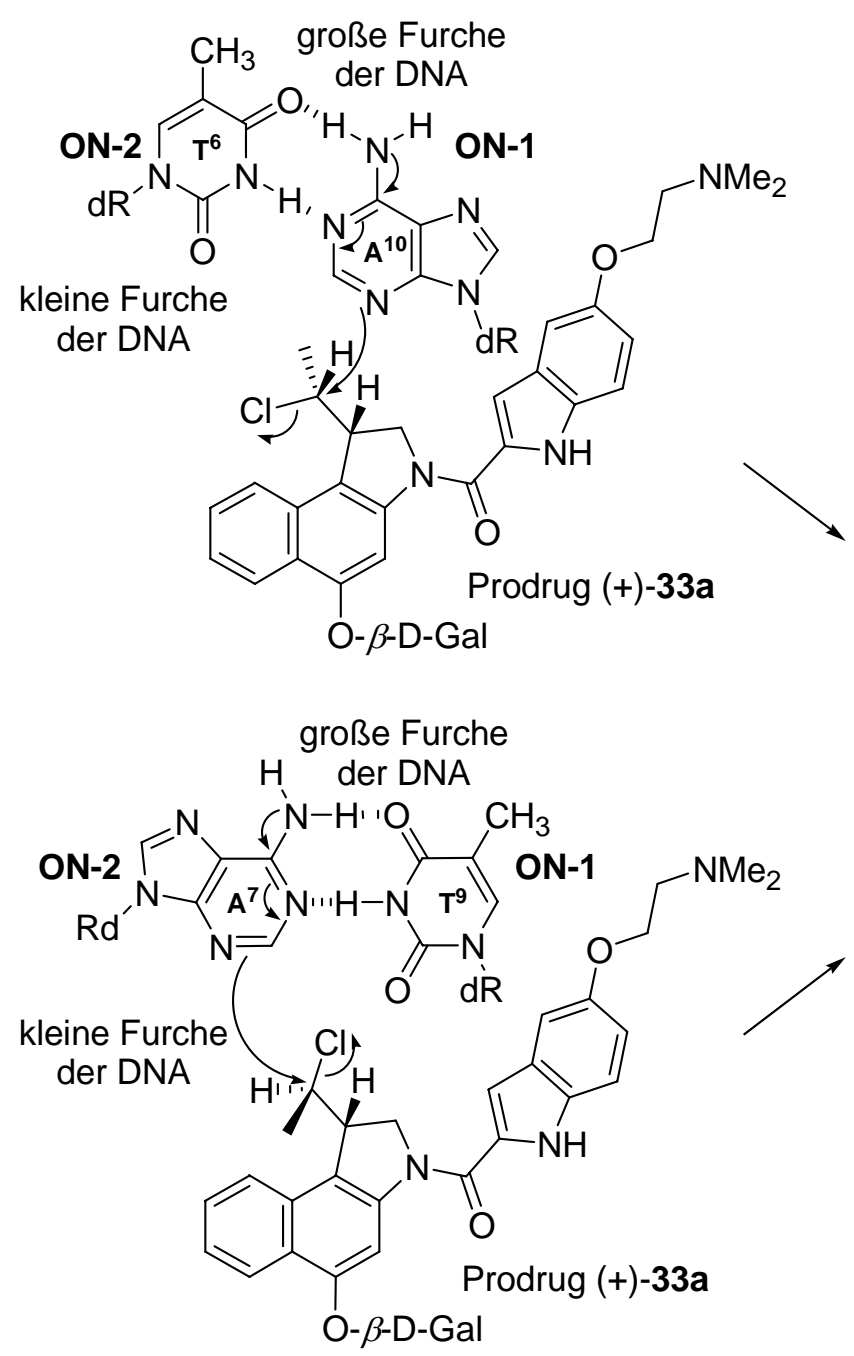

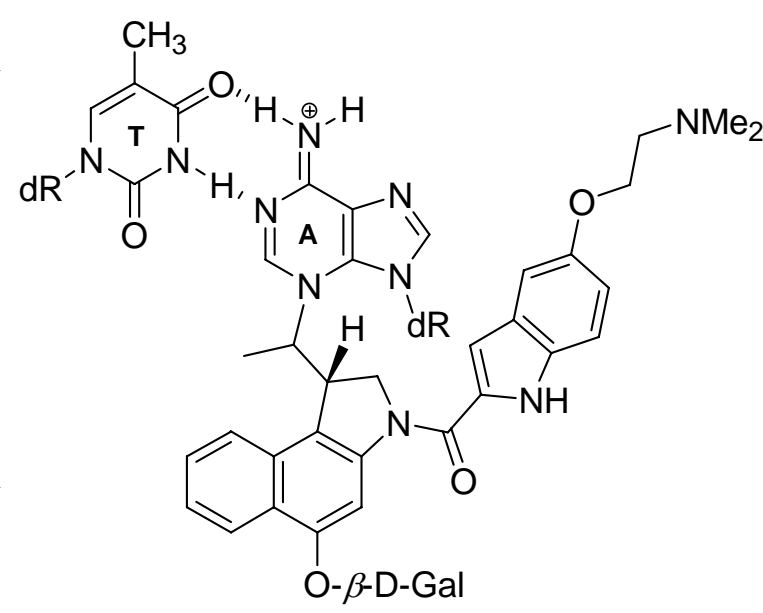

ON-1* bzW. ON-2*

Abb. 86. Alkylierung der Nukleobase Adenin durch das Prodrug $(+)-(1 S, 10 R)-33 a$ : Elektrophiler Angriff am Adenin- $N-3$ unter Bildung des kovalenten Adduktes ON-1* bzw. ON-2*.

Dass die Alkylierung der gleichen DNA durch das seco-Drug $(+)-(1 S, 10 R)-34 a$ nicht an den Nukleobasen $A_{10}(\mathrm{ON}-1)$ und $A_{7}(\mathrm{ON}-2)$, sondern nur an $A_{10}(\mathrm{ON}-1)$ erfolgt, belegt die These, dass die Reaktion mit der DNA erst nach einer Zyklisierung des seco-Drugs mit der 1-Chlorethyl-Einheit zum entsprechenden Drug 43a mit der räumlich weniger flexiblen elektrophilen Cyclopropyleinheit erfolgt.

Bei einer Umsetzung des Prodrugs $(+)-(1 S, 10 R)$-33a mit dem einzelsträngigen DNAOligonukleotid ON-1 (ds-60) konnte eine marginale Alkylierung zu ON-1* und eine etwas ausgeprägtere Bildung des unspezifischen nicht-kovalenten Adduktes ON-1 $\cdot(+)-(1 S, 10 R)-33 a$ beobachtet werden (Abb. 87). Erneut korreliert demzufolge die Alkylierungseffizienz mit der Zytotoxizität. 


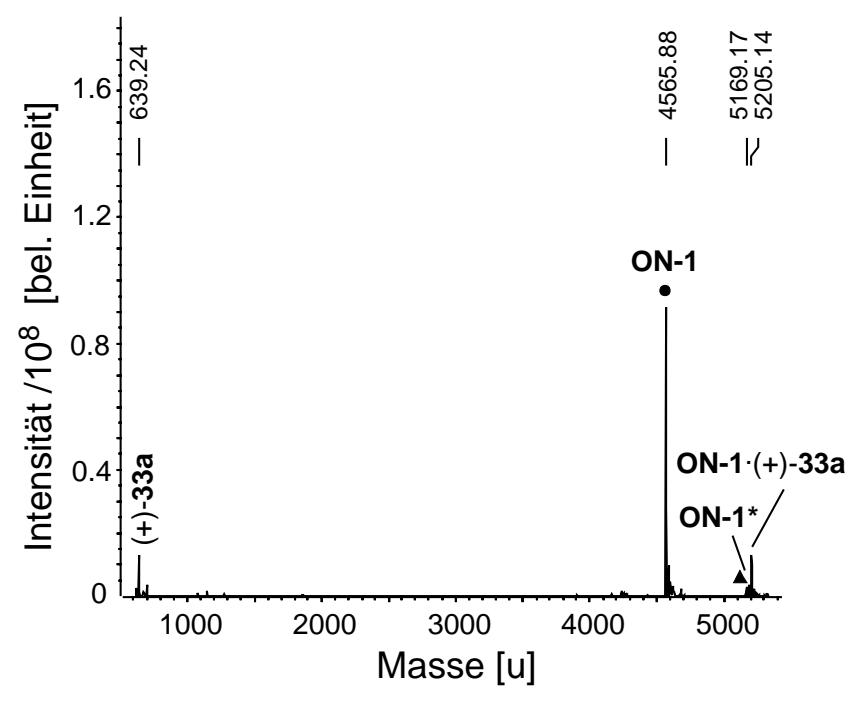

Abb. 87. Dekonvoliertes Massenspektrum nach Inkubation des DNA-Oligonukleotides ON-1 (ds-60) mit dem Prodrug (+)-(1S,10R)-33a im molaren Verhätnis 1:1 nach $24 \mathrm{~h}$ Inkubation.

\subsection{Wechselwirkung verschiedener seco-Drugs und Prodrugs mit dem DNA-Oligonukleotid ds-60}

Wie bereits diskutiert, korreliert die geringere Alkylierungseffizienz des Prodrugs $(+)-(1 S, 10 R)-33$ a und des seco-Drugs $(-)-(1 R, 10 S)$-34a sehr gut mit der geringeren Zytotoxizität dieser Verbindungen in In-vitro-Experimenten im Vergleich zu $(+)-(1 S, 10 R)-34 \mathbf{a}$.

Um zu überprüfen, ob eine höhere Alkylierungseffizienz verschiedener Vertreter dieser Wirkstoffklasse allgemein mit einer höheren Zytotoxizität verbunden ist, wurde der DNA-Doppelstrang ds-60 mit einer Vielzahl analoger seco-Drugs und einem weiteren Prodrug inkubiert. Die jeweiligen Reaktionslösungen wurden nach $t=0 \mathrm{~h}$ und $t=24 \mathrm{~h}$ Inkubation mittels direkter ESI-HRMS-Messungen im negativen Ionenmodus untersucht.

Abbildung 88 zeigt die Strukturen der zunächst untersuchten Methyl-seco-CBI-Hydrochloride 34a-e, der entsprechenden Drugs 43a-e sowie der Hydrolyseprodukte 84a-e. Die Alkylierungseffizienz dieser seco-Drugs bezüglich des doppelsträngigen DNAOligonukleotides ds-60 bei einem 1:1-Verhältnis des Wirkstoffs zur DNA, die mittels CSD bestimmte Alkylierungsposition sowie die In-vitro-Zytotoxizitäten bezüglich humaner Bronchialkarzinomzellen der Linie A549 sind in Tabelle 6 dargestellt. 


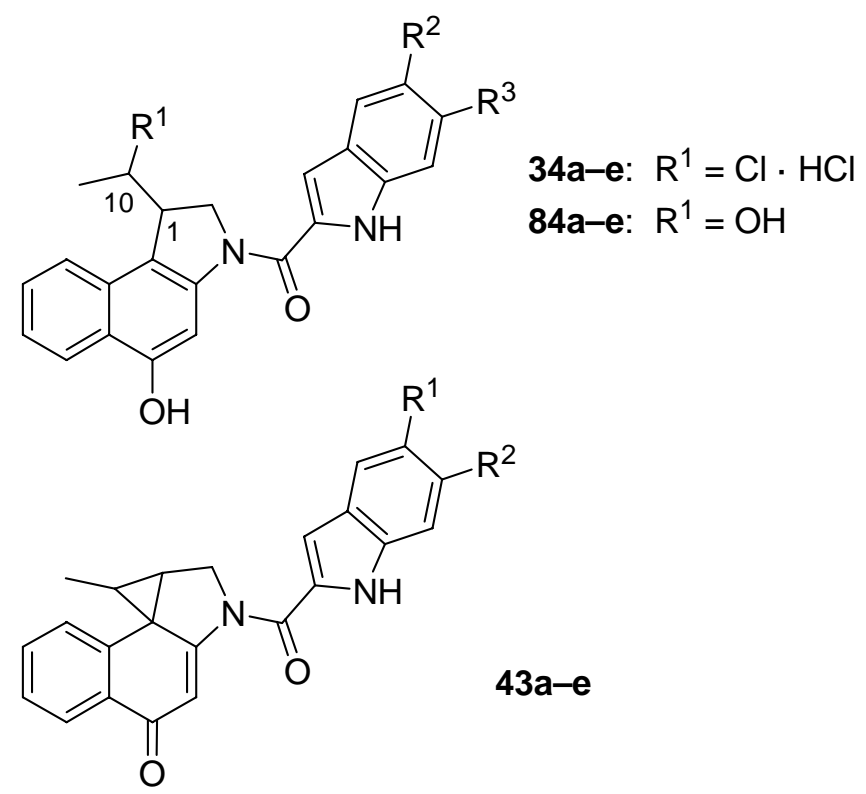

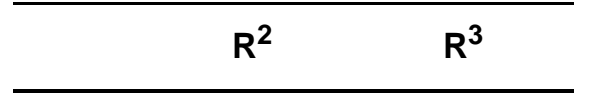

a<smiles>CNCCO[12CH3]</smiles>

$\mathrm{H}$

b<smiles>CCOCC1CCN(C)CC1</smiles>

c

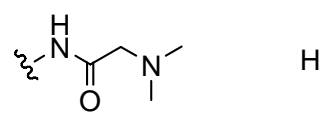

d<smiles>CCOCCN1CCOCC1</smiles>

e

OMe

Abb. 88. Methyl-seco-CBI-Hydrochloride 34a-e, die entsprechenden Drugs 43a-e sowie die Hydrolyseprodukte 84a-e.

\begin{tabular}{cccc}
\hline seco-Drug & $\boldsymbol{I C}_{\mathbf{5 0}} \mathbf{( \mathbf { A 5 4 9 } ) [ \mathbf { n M } ]}$ & Alkylierung ds-60 [\%] & Alkylierungsposition \\
\hline$(+)-(1 S, 10 R)-\mathbf{3 4 a}$ & 0.75 & 75 & $\mathrm{~A}_{10}(\mathrm{ON}-1)$ \\
$(+)-(1 S, 10 R)-\mathbf{3 4 b}$ & 0.8 & 53 & $\mathrm{~A}_{10}(\mathrm{ON}-1)$ \\
$(+)-(1 S, 10 R)-34 \mathbf{c}$ & 3.8 & 93 & $\mathrm{~A}_{10}(\mathrm{ON}-1)$ \\
$(+)-(1 S, 10 R)-34 d$ & 3.7 & 57 & $\mathrm{~A}_{10}(\mathrm{ON}-1)$ \\
$(+)-(1 S, 10 R)-34 \mathbf{c}$ & 0.20 & 90 & $\mathrm{~A}_{10}(\mathrm{ON}-1)$ \\
\hline
\end{tabular}

Tab. 6. Zytotoxizitäten der Methyl-seco-CBI-Derivate (+)-(1S,10R)-34a-e, Anteil der durch die entsprechenden Drugs verursachten Alkylierung des DNA-Doppelstranges ds-60 bei einer Umsetzung in einem 1:1-Verhältnis der DNA zum Wirkstoff sowie Alkylierungsposition.

Alle Methyl-seco-CBI-Hydrochloride alkylieren mit hoher Selektivität das Adenin $\mathrm{A}_{10}$ des DNA-Oligonukleotides ON-1 und zeigen somit trotz eines leicht variierten DNAbindenden Molekülteils die gleiche Sequenzselektivität bezüglich des DNA-Oligonukleotides ds-60. Obwohl alle seco-Drugs die DNA mit hoher Effizienz alkylieren $(53 \%-93 \%)$, gibt es signifikante Unterschiede im prozentualen Anteil des umgesetzten Oligonukleotides. (+)-(1S,10R)-34e zeigt eine der höchsten Alkylierungseffizienzen und in vitro an humanen Bronchialkarzinomzellen der Linie A549 die höchste Zytotoxizität. Eine ebenso hohe Alkylierungseffizienz zeigt jedoch das secoDrug (+)-(1S,10R)-34c, welches in der Gruppe der untersuchten seco-Drugs die 
geringste Zytotoxizität aufweist. Ein Vergleich dieser sowie der weiteren Alkylierungseffizienzen mit den entsprechenden Zytotoxizitäten zeigt, dass die Alkylierungseffizienz nicht quantitativ mit der Zytotoxizität der Wirkstoffe korreliert. Da die Alkylierung bei (+)-(1S,10R)-34a-e jedoch signifikant höher ist als diejenige der weniger zytotoxischen Verbindungen $(+)-(1 S, 10 R)-33 \mathbf{a}$ und $(-)-(1 R, 10 S)-\mathbf{3 4 a}$ (s. Kap. 6.2 und Kap. 6.3), besteht ein grober qualitativer Zusammenhang zwischen der Alklylierungseffizienz und der Zytotoxizität.

Die Alkylierung der Methyl-seco-CBI-Hydrochloride wurde in der Folge auch in Form von Konkurrenzexperimenten untersucht, um die relative Alkylierungseffizienz besser beurteilen zu können. Hierbei wurden $(+)-(1 S, 10 R)-\mathbf{3 4 \mathbf { e }},(+)-(1 S, 10 R)-34 \mathbf{c}$ oder $(+)-(1 S, 10 R)-34 d$ gleichzeitig mit $(+)-(1 S, 10 R)-34 a$ und dem DNA-Oligonukleotid ds-60 inkubiert. Die relative Alkylierungseffizienz wurde an der Signalintensität der alkylierten Nukleobase Adenin ( $\left.\mathbf{A}^{*}\right)$ bzw. der Höhe der Peaks des alkylierten Oligonukleotides $\left(\mathbf{O N}-\mathbf{1}^{*}\right)$ abgeschätzt. Tabelle 7 zeigt die Ergebnisse der Vergleichsstudie.

\begin{tabular}{ccccc}
\hline seco-Drug $\mathbf{x}$ & seco-Drug $\mathbf{y}$ & $\mathbf{d s - 6 0}: \mathbf{x}: \mathbf{y}$ & $\begin{array}{c}\text { Alkylierung } \\
\text { ON-1 (ds-60) [\%] }\end{array}$ & Produktverhältnis \\
\hline$(1 S, 10 R)-34 a$ & $(1 S, 10 R)-34 \mathbf{e}$ & $1: 1: 1$ & 98 & $\mathbf{A}^{*}(\mathbf{3 4 a})<\mathbf{A}^{*}(\mathbf{3 4 e})$ \\
& & $1: 0.5: 0.5$ & 99 & \\
$(1 S, 10 R)-34 a$ & $(1 S, 10 R)-34 \mathbf{c}$ & $1: 1: 1$ & 93 & $\mathbf{A}^{*}(\mathbf{3 4 a})<\mathbf{A}^{*}(\mathbf{3 4 c})$ \\
& & $1: 0.5: 0.5$ & 82 & \\
$(1 S, 10 R)-34 a$ & $(1 S, 10 R)-\mathbf{3 4 d}$ & $1: 1: 1$ & 88 & $\mathbf{A}^{*}(\mathbf{3 4 a})>\mathbf{A}^{*}(\mathbf{3 4 d})$ \\
& & $1: 0.5: 0.5$ & 56 & \\
& & $1: 1.2: 1.2$ & 86 & \\
\hline
\end{tabular}

Tab. 7. Anteil der nach $24 \mathrm{~h}$ Inkubation von je zwei seco-Drugs mit dem doppelsträngigen DNA-Oligonukleotid ds-60 verursachten Alkylierung und Intensitätsverhältnisse der alkylierten Nukleobase Adenin ( $\left.\mathbf{A}^{*}\right)$.

In allen Fällen konnte eine effiziente Alkylierung des Oligonukleotides ON-1 am Adenin $\mathrm{A}_{10}$ festgestellt werden. Die Alkylierungseffizienz war im Fall der seco-Drugs $(+)-(1 S, 10 R)-34 \mathbf{e}$ und $(+)-(1 S, 10 R)-34 \mathbf{c}$ wie erwartet höher als die Alkylierungseffizienz des seco-Drugs $(+)-(1 S, 10 R)-\mathbf{3 4 a}$; die des seco-Drugs $(+)-(1 S, 10 R)-\mathbf{3 4 d}$ hingegen war kleiner. 
Zur Überprüfung der Hypothese, dass ein qualitativer Zusammenhang zwischen der Alkylierungseffizienz und der Zytotoxizität bestehe, wurde eine Untersuchung der Reaktivität der seco-CBI-Hydrochloride 56a,b und des Prodrugs 54a bezüglich des DNA-Doppelstranges ds-60 durchgeführt (Abb. 89, Tab. 8).<smiles>[R]CC1CN(C(=O)c2cc3cc([R])ccc3[nH]2)c2cc([R])c3ccccc3c21</smiles>

56a,b: $\mathrm{R}^{1}=\mathrm{Cl} \cdot \mathrm{HCl}, \mathrm{R}^{2}=\mathrm{OH}$

87a,b: $\mathrm{R}^{1}=\mathrm{OH}, \mathrm{R}^{2}=\mathrm{OH}$

54a: $\quad \mathrm{R}^{1}=\mathrm{Cl}, \mathrm{R}^{2}=0-\beta$-D-Gal

88a: $\quad \mathrm{R}^{1}=\mathrm{OH}, \mathrm{R}^{2}=\mathrm{O}-\beta$-D-Gal

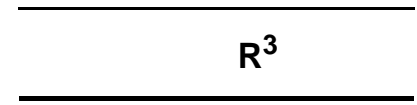

a $\quad \xi_{2}^{-O} \sim_{1}^{-}$

$86 a, b$

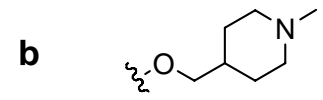

Abb. 89. seco-CBI-Derivate 56a,b, die entsprechenden Drugs 86a,b und die Hydrolyseprodukte 87a,b sowie das seco-CBI-DMAI-Prodrug 54a und dessen Hydrolyseprodukt 88a.

\begin{tabular}{cccc}
\hline Verbindung & $\boldsymbol{I C}_{\mathbf{5 0}} \mathbf{( A 5 4 9 )}[\mathbf{n M}]$ & Alkylierung ds-60 [\%] & Alkylierungsposition \\
\hline$(+)-(1 S)-56 a$ & 0.026 & $46(\mathrm{n}=1)$ & $\mathrm{A}_{10}(\mathrm{ON}-1)$ \\
$(-)-(1 R)-56 \mathbf{a}$ & 11.5 & $41(\mathrm{n}=1)$ & $\mathrm{A}_{7}(\mathrm{ON}-2)$ \\
$(-)-(1 S)-54 \mathbf{a}$ & 56.3 & keine Alkylierung $(\mathrm{n}=1,5)$ & - \\
\hline$(+)-(1 S)-56 b$ & 0.014 & $28(\mathrm{n}=1)$ & $\mathrm{A}_{10}(\mathrm{ON}-1)$ \\
\hline
\end{tabular}

Tab. 8. Zytotoxizitäten der seco-CBI-Wirkstoffe, Anteil der durch diese verursachten Alkylierung des DNA-Doppelstranges ds-60 nach $24 \mathrm{~h}$ Inkubation bei einer Umsetzung in einem molaren Verhältnis der DNA zum Wirkstoff von 1:n $(n=1,5)$ sowie Lage der Alkylierungsposition.

Das seco-Drug $(+)-(1 S)-56 \mathbf{b}$ zeigt nach 24 Stunden Inkubation trotz seiner hohen Zytotoxizität nur eine vergleichsweise niedrige Alkylierungseffizienz von $28 \%$. Wie erwartet ist jedoch die Alkylierungseffizienz der seco-Drugs 56a deutlich höher als jene des Prodrugs (-)-(1S)-54a. Bei (-)-(1S)-54a konnte sogar in einem DNA / Wirkstoff-Verhältnis von 1:5 keine Alkylierung beobachtet werden. Stattdessen trat die 
Bildung unspezifischer Addukte auf, bei denen im Massenspektrometer bis zu vier Prodrug-Moleküle mit den Oligonukleotiden assoziierten.

Erstaunlicherweise sind die Alkylierungseffizienzen der enantiomeren seco-Drugs $(+)-(1 S)$-56a und (-)-(1R)-56a sehr ähnlich, obwohl (-)-(1R)-56a eine geringere Zytotoxizität aufweist als $(+)-(1 S)-56 a$. Das seco-Drug $(+)-(1 S)-56 a$ alkyliert zwar wie erwartet das Oligonukleotid $\mathbf{O N}-1$ an der Nukleobase $\mathrm{A}_{10}$ und das seco-Drug $(-)-(1 R)-56 \mathbf{a}$ das Oligonukleotid ON-2, allerdings erfolgt die Reaktion durch $(-)-(1 R)-56 \mathbf{a}$ in Ermangelung eines geeigneten Adenins nicht am 3'-Ende der ATreichen Sequenz, sondern schräg gegenüber der Alkylierungsstelle des (1S)-Enantiomers in der Nähe des 5'-Endes der AT-reichen Region an $\mathrm{A}_{7}$ (Abb. 90).

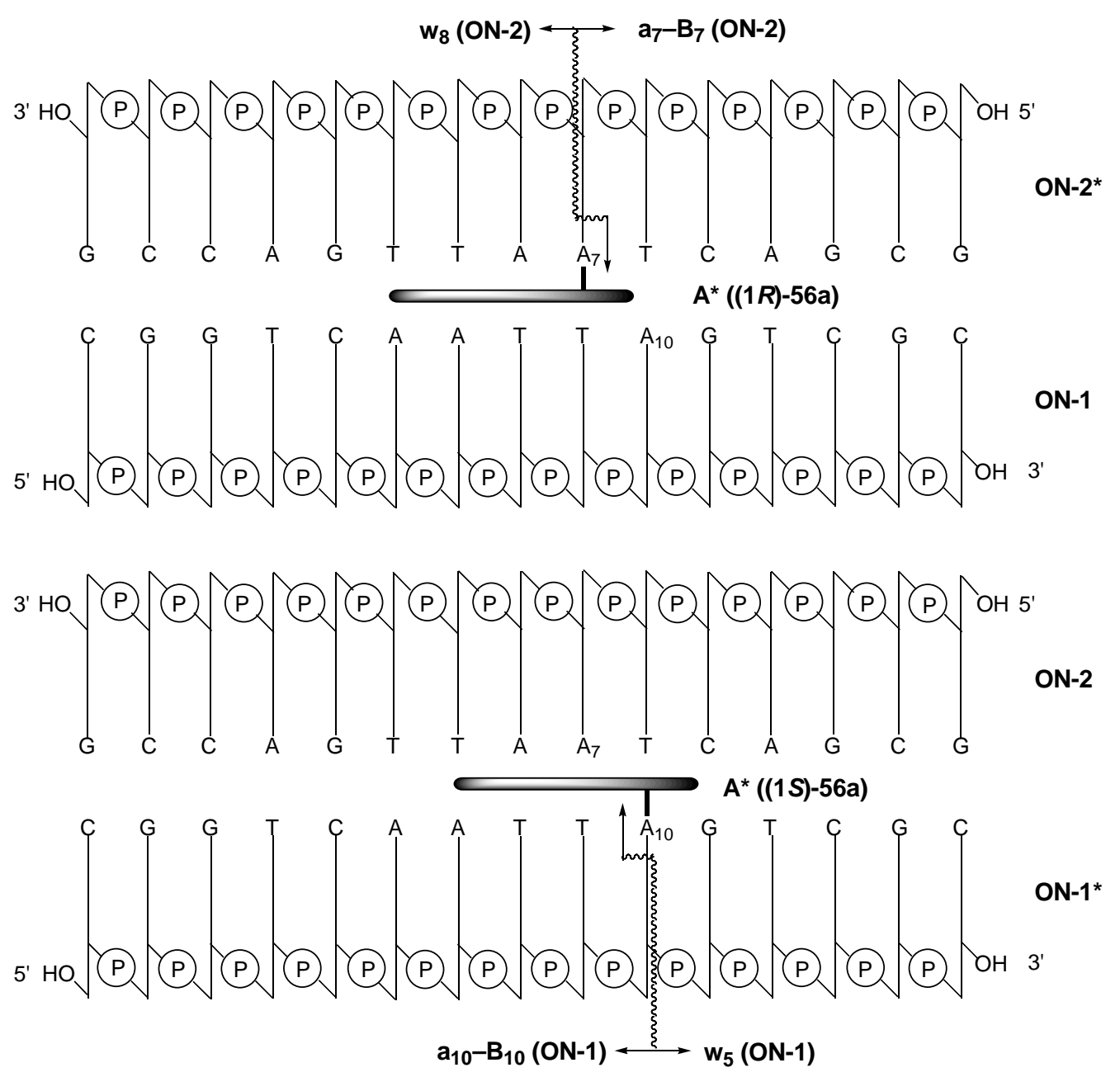

Abb. 90. Fragmentierung des alkylierten Oligonukleotides $\mathbf{O N - 2} *$ in $\mathbf{A}^{*}, \mathbf{a}_{7}-\mathbf{B}_{7}$ und $\mathbf{w}_{\mathbf{8}}$ bzw. des alkylierten Oligonukleotides $\mathbf{O N}-\mathbf{1} *$ in $\mathbf{A}^{*}, \mathbf{a}_{\mathbf{1 0}}-\mathbf{B}_{\mathbf{1 0}}$ und $\mathbf{w}_{5}$.

Diese Beobachtung und der Vergleich mit den Ergebnissen der Untersuchungen der analogen Methyl-seco-CBI-DMAI-Verbindungen lassen zwei Schlussfolgerungen zu: 
Erstens zyklisieren die seco-Drugs 56a vor der Alkylierung zu den entsprechenden Drugs und alkylieren aufgrund der Starrheit des Cyclopropylsystems nur jeweils ein Oligonukleotid. Zweitens erfolgt die Einlagerung in die kleine Furche für beide Enantiomere in der gleichen Orientierung, da die beiden Oligonukleotide am gleichen Ende der AT-reichen Region alkylieren und nicht jeweils am 3'-Ende der AT-reichen Basenfolge des jeweils komplementären Stranges. Das Drug des $(1 R)$-Enantiomers verhält sich somit anders als das analoge (-)-Duocarmycin SA ((-)-21). Im Gegensatz zu den Naturstoffen ist vermutlich der sterische Anspruch des aus (-)-(1R)-56a geformten Drugs geringer oder die Flexibilität des Moleküls größer, was eine unerwartete Einlagerung in die DNA erlaubt.

Neben den seco-CBI-Derivaten wurde die Alkylierungseffizienz zweier CI-Derivate untersucht, da diese eine geringe In-vitro-Zytotoxizität aufweisen und daher eine nur schwach ausgeprägte DNA-Alkylierung verursachen sollten. Die von $F$. Colunga synthetisierten seco-CI-DMAI-Drugs (+)-89 und (-)-89 zeigten in In-vitro-Zytotoxizitätsstudien eine Zytotoxizität von $I C_{50}=1.0 \mu \mathrm{M}((+)-89)$ bzw. $I C_{50}=0.48 \mu \mathrm{M}$ $((-)-89)\left(\right.$ Abb. 91). ${ }^{141 \mathrm{~g}}$
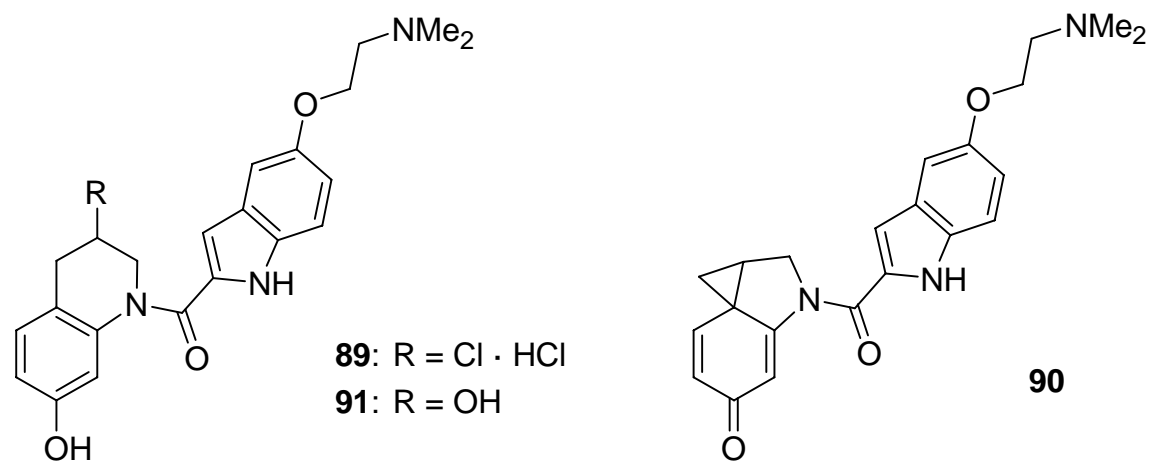

Abb. 91. Struktur der seco-CI-DMAI-Drugs 89, der entsprechenden Drugs 90 sowie der Hydrolyseprodukte 91.

Eine Überprüfung der DNA-Alkylierungseffizienz der Verbindungen ergab, dass sogar bei einem fünffachen Überschuss beider Enantiomere bezüglich des DNA-Doppelstranges ds-60 keine Alkylierung beobachtet werden konnte. Nach $24 \mathrm{~h}$ Inkubation waren beide Enantiomere der seco-Drugs 89 zwar nahezu vollständig zu den entsprechenden Drugs 90 zyklisiert, das Hydrolyseprodukt 91 konnte jedoch ebenso wenig wie das DNA-Addukt nachgewiesen werden. Dies weist darauf hin, dass die geringe Zytotoxizität der Wirkstoffe durch eine zu hohe Stabilität der Drugs 90 
bedingt ist, die eine Reaktion mit den intrazellulären Zielstrukturen wie der DNA verhindert und somit die Wirksamkeit minimiert.

Insgesamt zeigen die Ergebnisse, dass eine Abschätzung der Zytotoxizität analoger Wirkstoffe durch eine massenspektrometrische Untersuchung erfolgen kann, da zytotoxische seco-Drugs eine hohe Alkylierungseffizienz zeigen, während weitaus weniger zytotoxische seco-Drugs oder Prodrugs nicht oder nur schwach alkylierend wirken. Dass die Untersuchungen keine quantitativen Aussagen ermöglichen, könnte durch die Tatsache begründet sein, dass die Studien nur mit ausgewählten synthetischen DNAOligonukleotiden erfolgten und die Struktur dieser DNA nicht exakt der Struktur zellulärer DNA entspricht, die als Chromatin mit Proteinen assoziiert und strukturell hoch organisiert vorliegt. Weiterhin war der Inkubationszeitraum bei Experimenten mit Oligonukleotiden auf 24 Stunden begrenzt während die Zellen nach einer 24-stündigen Toxinexposition jeweils bis zu 12 Tage kultiviert wurden. Bereits in die Zellen penetrierter Wirkstoff hatte somit eine längere Zeit zur Entfaltung der Wirkung bis eine Messung des Effektes stattfand als derselbe Wirkstoff im Fall der massenspektrometrischen Untersuchungen an Oligonukleotiden. 
6.5 Wechselwirkung der seco-Drugs $(+)-(1 S, 10 R)-34 \mathrm{a},(+)-(1 S, 10 R)-34 \mathrm{~b}$, $(+)-(1 S)-56 a$ und $(+)-(1 S)-56 b$ mit den DNA-Oligonukleotiden ds-60 ds-69

Zur Untersuchung des Einflusses der DNA-bindenden Einheit und des Pharmakophors auf die Sequenzselektivität und die Alkylierungseffizienz wurden die seco-Drugs $(+)-(1 S, 10 R)-\mathbf{3 4 a},(+)-(1 S, 10 R)-\mathbf{3 4} \mathbf{b},(+)-(1 S)-\mathbf{5 6} \mathbf{a}$ und $(+)-(1 S)-56 \mathbf{b}($ Abb. 92) mit den DNA-Oligonukleotiden ds-60-ds-69 sowie ON-1 (ds-60) umgesetzt und für jede Kombination die Alkylierungseffizienz und Alkylierungsposition bestimmt.

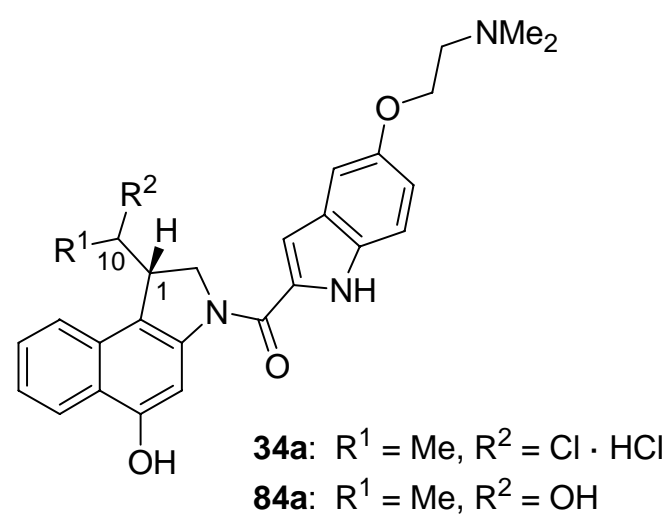

56a: $\mathrm{R}^{1}=\mathrm{H}, \mathrm{R}^{2}=\mathrm{Cl} \cdot \mathrm{HCl}$

87a: $R^{1}=H, R^{2}=O H$

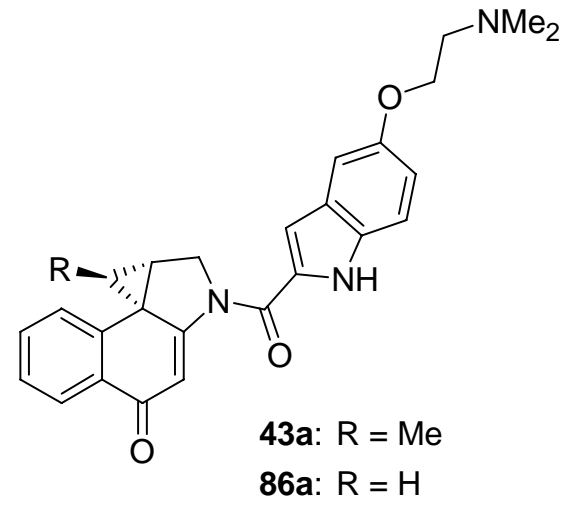

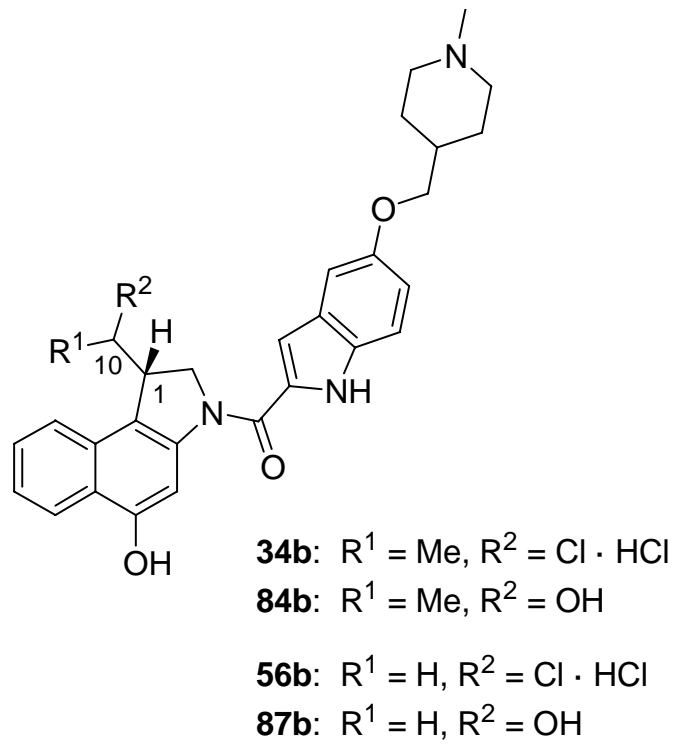

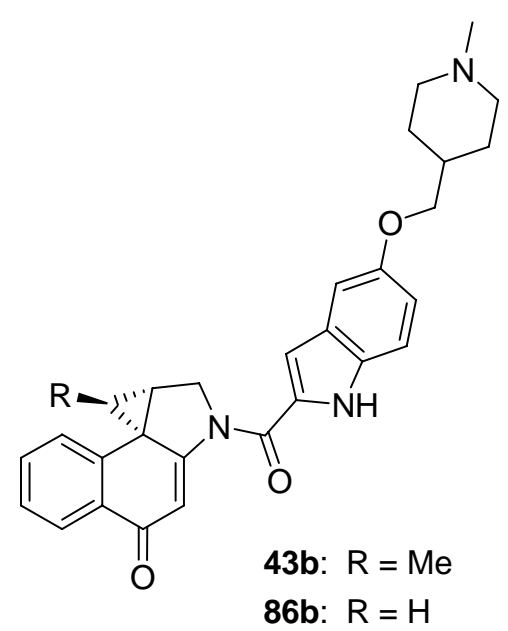

Abb. 92. Methyl-seco-CBI- und seco-CBI-Hydrochloride mit DMAI- oder MPI-DNAbindender Einheit sowie deren entsprechende Drugs und Hydrolyseprodukte.

Die Ergebnisse werden im Folgenden für die jeweiligen DNA-Oligonukleotide im Vergleich präsentiert und diskutiert. 
Werden die genannten seco-Drugs mit dem DNA-Oligonukleotid ds-60 für $24 \mathrm{~h}$ inkubiert, so alkylieren alle Wirkstoffe selektiv das Adenin $\mathrm{A}_{10}$ des Oligonukleotides ON-1 am 3'-Ende der AT-reichen Sequenz (Abb. 93, Tab. 9). Hierbei zeigt (+)$(1 S, 10 R)$-34a bei einer 1:1-Umsetzung die höchste Alkylierungseffizienz (75\%), gefolgt von den seco-Drugs $(+)-(1 S, 10 R)-34 \mathbf{b}$ und $(+)-(1 S)-56 \mathbf{a}$, die mit 53\% bzw. $46 \%$ etwa die gleiche Reaktivität aufweisen. $(+)-(1 S)-56 \mathbf{b}$ alkyliert ds-60 mit $28 \%$ Umsatz nach 24 Stunden vergleichsweise schwach.

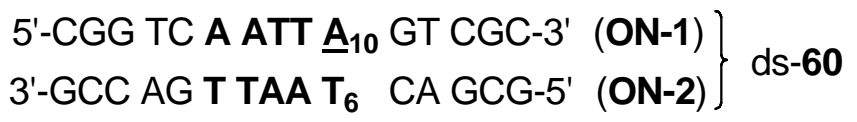

Abb. 93. Basensequenz des DNA-Oligonukleotides ds-60 und Position der Alkylierung durch die Methyl-seco-CBI- und seco-CBI-Derivate mit DMAI- oder MPI-DNA-bindender Einheit.

\begin{tabular}{ccc}
\hline seco-Drug & Alkylierung ds-60 [\%] & Alkylierungsposition \\
\hline$(+)-(1 S, 10 R)-\mathbf{3 4 a}$ & $75(50)$ & $\mathrm{A}_{10}(\mathrm{ON}-1)$ \\
$(+)-(1 S, 10 R)-\mathbf{3 4 b}$ & 53 & $\mathrm{~A}_{10}(\mathrm{ON}-1)$ \\
$(+)-(1 S)-\mathbf{5 6 a}$ & $46(55)$ & $\mathrm{A}_{10}(\mathrm{ON}-1)$ \\
$(+)-(1 S)-56 \mathbf{b}$ & 28 & $\mathrm{~A}_{10}(\mathrm{ON}-1)$ \\
\hline
\end{tabular}

Tab. 9. Anteil der durch die entsprechenden Drugs verursachten Alkylierung des DNADoppelstranges ds-60 bei einer Umsetzung im Verhältnis DNA / seco-Drug = 1:1 (bzw. 1:2) nach $24 \mathrm{~h}$ Inkubation sowie Alkylierungsposition.

Die Alkylierungseffizienz des Methyl-seco-CBI-DMAI-Derivates (+)-( $(S, 10 R)-34 a$ nimmt bei einer Umsetzung mit dem DNA-Oligonukleotid im 1:2- statt 1:1-Verhältnis der DNA zum Wirkstoff von 75\% auf 50\% Alkylierung ab. Bei dem analogen secoCBI-DMAI-Derivat (+)-(1S)-56a ist dies nicht der Fall; hier nimmt der Anteil alkylierter DNA von $46 \%$ auf $55 \%$ zu, wenn der seco-Drug-Anteil in der Reaktionsmischung verdoppelt wird.

Werden die seco-Drugs mit dem reaktiveren Einzelstrang ON-1 des Doppelstranges ds-60 inkubiert, so kann im Fall der Methyl-seco-CBI-Verbindungen (+)-(1S,10R)-34a und (+)-(1S,10R)-34b eine weniger als 25\%-ige und für die seco-CBI-Hydrochloride $(+)-(1 S)-56 \mathbf{a}$ und $(+)-(1 S)-56 \mathbf{b}$ keine Alkylierung detektiert werden (Abb. 94, Tab. 10). Die Vielzahl der Spaltprodukte weist hierbei auf eine sehr unselektive Alkylierung an Guanin und Adenin mit einer leichten Präferenz für $G_{3}$ und $A_{7}$ hin. Sowohl die 
Reaktivität als auch die Selektivität nehmen beim Übergang vom DNA-Doppelstrang zum DNA-Einzelstrang demzufolge stark ab, da im Einzelstrang keine stabilisierenden Wechselwirkungen durch eine Einlagerung in die kleine Furche möglich sind.

\section{5'-CGG $\underline{G}_{3}$ TC A $\underline{A}_{7}$ TT A GTC GC-3' ON-1 (ds-60)}

Abb. 94. Basensequenz des DNA-Oligonukleotides ON-1 (ds-60) und bekannte Positionen der Alkylierung durch die Methyl-seco-CBI- und seco-CBI-Derivate mit DMAI- oder MPIDNA-bindender Einheit.

\begin{tabular}{ccc}
\hline seco-Drug & Alkylierung ON-1 (ds-60) [\%] & Alkylierungsposition \\
\hline$(+)-(1 S, 10 R)-34 a$ & $<20$ & u.a. $\mathrm{G}_{3}$ und $\mathrm{A}_{7}$ \\
$(+)-(1 S, 10 R)-34 b$ & $<25$ & nicht bestimmbar \\
$(+)-(1 S)-56 a$ & keine Alkylierung & - \\
$(+)-(1 S)-56 b$ & keine Alkylierung & - \\
\hline
\end{tabular}

Tab. 10. Anteil der durch die entsprechenden Drugs verursachten Alkylierung des DNAEinzelstranges ON-1 (ds-60) bei einer Umsetzung im Verhältnis DNA / seco-Drug = 1:1 nach $24 \mathrm{~h}$ Inkubation sowie Alkylierungspositionen.

Befindet sich die AT-reiche Region am Ende des DNA-Doppelstranges wie in ds-61 (Abb. 95), so ist die Alkylierung durch die seco-Drugs (+)-(1S,10R)-34a und $(+)-(1 S)-56 a$ mit DMAI-DNA-bindender Einheit schwächer, diejenige der seco-Drugs $(+)-(1 S, 10 R)-34 \mathbf{b}$ und $(+)-(1 S)-56 \mathbf{b}$ mit MPI-DNA-bindender Einheit hingegen etwas stärker als die Alkylierung des DNA-Doppelstranges ds-60 (Abb. 93), bei dem die gleiche AT-reiche Region in der Mitte des Doppelstranges liegt (Abb. 95, Tab. 11). Dies weist darauf hin, dass die DMAI-haltigen seco-Drugs zur effizienten Alkylierung eine engere kleine Furche benötigen als die MPI-haltigen seco-Drugs. Bei letzteren könnte die am Ende eines DNA-Doppelstranges etwas erweiterte kleine Furche aufgrund des höheren Platzbedarfes des Methylpiperidino-Substituenten vorteilhaft sein. Alle seco-Drugs alkylieren selektiv das Adenin $\mathrm{A}_{14}$ am 3'-Ende der AT-reichen Sequenz und erneut ist die Alkylierungseffizienz im Fall der 1:2-Umsetzung für $(+)-(1 S, 10 R)-34 a$ geringer als im Fall der 1:1-Umsetzung. 


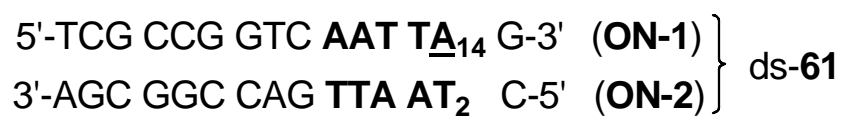

Abb. 95. Basensequenz des DNA-Oligonukleotides ds-61 und Position der Alkylierung durch die Methyl-seco-CBI- und seco-CBI-Derivate mit DMAI- oder MPI-DNA-bindender Einheit.

\begin{tabular}{ccc}
\hline seco-Drug & Alkylierung ds-61 [\%] & Alkylierungsposition \\
\hline$(+)-(1 S, 10 R)-34 \mathbf{a}$ & $60(40)$ & $\mathrm{A}_{14}(\mathrm{ON}-1)$ \\
$(+)-(1 S, 10 R)-34 \mathbf{b}$ & 66 & $\mathrm{~A}_{14}(\mathrm{ON}-1)$ \\
$(+)-(1 S)-56 \mathbf{a}$ & 9 & $\mathrm{~A}_{14}(\mathrm{ON}-1)$ \\
$(+)-(1 S)-56 b$ & 31 & $\mathrm{~A}_{14}(\mathrm{ON}-1)$
\end{tabular}

Tab. 11. Anteil der durch die entsprechenden Drugs verursachten Alkylierung des DNADoppelstranges ds-61 bei einer Umsetzung im Verhältnis DNA / seco-Drug = 1:1 (bzw. 1:2) nach $24 \mathrm{~h}$ Inkubation sowie Alkylierungsposition.

Wird die AT-reiche Region von fünf Basenparen (ds-60) auf vier Basenpaare (ds-62) verringert, so beeinflusst dies die Alkylierungseffizienz nur marginal (Abb.96, Tab. 12).

$$
\left.\begin{array}{ll}
5^{\prime}-\text { CGC TGC ATT } \underline{A}_{10} \text { GT CGC-3' } & (\mathrm{ON}-1) \\
\text { 3'-GCG ACG TAA } \text { T }_{6} \text { CA GCG-5' } & (\mathrm{ON}-2)
\end{array}\right\} \text { ds-62 }
$$

Abb. 96. Basensequenz des DNA-Oligonukleotides ds-62 und Position der Alkylierung durch die Methyl-seco-CBI- und seco-CBI-Derivate mit DMAI- oder MPI-DNA-bindender Einheit.

\begin{tabular}{ccc}
\hline seco-Drug & Alkylierung ds-62 [\%] & Alkylierungsposition \\
\hline$(+)-(1 S, 10 R)-34 \mathbf{a}$ & $55(30)$ & $\mathrm{A}_{10}(\mathrm{ON}-1)$ \\
$(+)-(1 S, 10 R)-34 b$ & 67 & $\mathrm{~A}_{10}(\mathrm{ON}-1)$ \\
$(+)-(1 S)-56 \mathbf{b}$ & 29 & $\mathrm{~A}_{10}(\mathrm{ON}-1)$ \\
$(+)-(1 S)-56 b$ & 32 & $\mathrm{~A}_{10}(\mathrm{ON}-1)$ \\
\hline
\end{tabular}

Tab. 12. Anteil der durch die entsprechenden Drugs verursachten Alkylierung des DNADoppelstranges ds-62 bei einer Umsetzung im Verhältnis DNA/ Wirkstoff=1:1 (bzw. 1:2) nach $24 \mathrm{~h}$ Inkubation sowie Alkylierungsposition. 
Während die DMAI-seco-Drugs $(+)-(1 S, 10 R)-34 a$ und $(+)-(1 S)$-56a eine leicht verminderte Alkylierungseffizienz zeigen, nimmt jene der MPI-seco-Drugs $(+)-(1 S, 10 R)-34 \mathbf{b}$ und $(+)-(1 S)-56 \mathbf{b}$ geringfügig zu. Die Sequenzselektivität bleibt jedoch erhalten, was an der einheitlichen Alkylierung des Adenins $A_{10}$ im Oligonukleotid ON-1 abgelesen werden kann. An $A_{8}(\mathrm{ON}-2)$, das am 3'-Ende einer AT-reichen Sequenz von drei Basenpaaren liegt, findet keine Reaktion statt. Somit ist eine Folge von mindestens vier AT-Basen für eine erfolgreiche Sequenzerkennung, eine nicht-kovalente Bindung und eine nachfolgende Reaktion unter Ausbildung einer kovalenten Bindung für die vier untersuchten Wirkstoffe notwendig.

Liegt kein Adenin am 3'-Ende der AT-reichen Sequenz von vier Basenpaaren, wie es bei ds-63 der Fall ist, so findet nur durch $(+)-(1 S)-56 \mathbf{b}$ eine signifikante Alkylierung statt (Abb. 97, Tab. 13). Hierbei wird hauptsächlich das Oligonukleotid ON-1 alkyliert. Weder die Bindungsposition noch die Art der alkylierten Nukleobase konnte durch Fragmentierung des alkylierten Einzelstranges ermittelt werden. Bei den anderen seco-Drugs wurde eine geringfügige Alkylierung der Nukleobase Guanin festgestellt, da das entsprechende alkylierte Guanin $\mathbf{G}^{*}$ detektiert werden konnte. Die exakte Alkylierungsposition konnte jedoch aufgrund der geringen Alkylierung ebenfalls nicht bestimmt werden. Auch Duocarmycin SA alkyliert Guanin in geringem Maße, wenn kein Adenin am 3'-Ende der AT-reichen Sequenz vorhanden ist. ${ }^{185}$

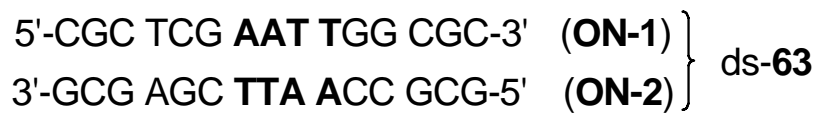

Abb. 97. Basensequenz des DNA-Oligonukleotides ds-63.

\begin{tabular}{ccc}
\hline seco-Drug & Alkylierung ds-63 [\%] & Alkylierungsposition \\
\hline$(+)-(1 S, 10 R)-34 \mathbf{a}$ & gering $(\mathrm{n}=1,2)$ & $\mathrm{G}$ \\
$(+)-(1 S, 10 R)-34 \mathbf{b}$ & gering & $\mathrm{G}$ \\
$(+)-(1 S)-56 \mathbf{a}$ & gering & $\mathrm{G}$ \\
$(+)-(1 S)-56 \mathrm{~b}$ & 32 & ON-1
\end{tabular}

Tab. 13. Anteil der durch die entsprechenden Drugs verursachten Alkylierung des DNADoppelstranges ds-63 bei einer Umsetzung im Verhältnis DNA / seco-Drug =1:1 (bzw. 1:2) nach $24 \mathrm{~h}$ Inkubation sowie Alkylierungsposition. 
Die wie im Fall der DNA-Oligonukleotide ds-60 - ds-62 bei ds-63 auftretende etwa $30 \%$-ige Alkylierung durch $(+)-(1 S)-56 \mathbf{b}$ weist eindeutig darauf hin, dass zur erfolgreichen Alkylierung doppelsträngiger DNA durch $(+)-(1 S)$-56b kein Adenin in 3'-Position einer AT-reichen Sequenz vorhanden sein muss. Ist ein entsprechendes 3'-Adenin jedoch vorhanden, so erfolgt die Alkylierung selektiv dort.

Um zu überprüfen, ob eine generelle Bevorzugung der Nukleobase Adenin oder Thymin in 5'-Richtung des alkylierten Adenins zu beobachten ist, wurden die secoDrugs mit dem DNA-Oligonukleotid ds-64 umgesetzt (Abb. 98, Tab. 14)

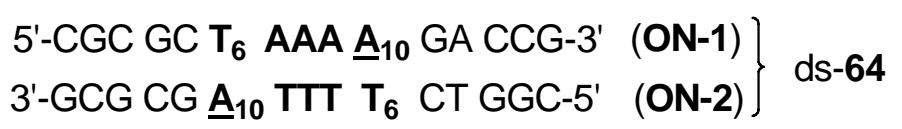

Abb. 98. Basensequenz des DNA-Oligonukleotides ds-64 und Position der Alkylierung durch die Methyl-seco-CBI- und seco-CBI-Derivate mit DMAI- oder MPI-DNA-bindender Einheit.

\begin{tabular}{ccc}
\hline seco-Drug & Alkylierung ds-64 & Alkylierungsposition \\
\hline$(+)-(1 S, 10 R)-\mathbf{3 4 a}$ & $\mathrm{ON}-1 / \mathrm{ON}-2 \sim 4: 1(\mathrm{n}=1,2)$ & $\mathrm{A}_{10}(\mathrm{ON}-1)>>\mathrm{A}_{10}(\mathrm{ON}-2)$ \\
$(+)-(1 S, 10 R)-34 b$ & $\mathrm{ON}-1 / \mathrm{ON}-2 \sim 1: 1$ & $\mathrm{~A}_{10}(\mathrm{ON}-1) \sim \mathrm{A}_{10}(\mathrm{ON}-2)$ \\
$(+)-(1 S)-56 \mathbf{a}$ & $\mathrm{ON}-1 / \mathrm{ON}-2 \sim 1: 1$ & $\mathrm{~A}_{10}(\mathrm{ON}-1) \sim \mathrm{A}_{10}(\mathrm{ON}-2)$ \\
$(+)-(1 S)-56 b$ & $6 \%$ & $\mathrm{~A}_{10}(\mathrm{ON}-1)$ \\
\hline
\end{tabular}

Tab. 14. Anteil der durch die entsprechenden Drugs verursachten Alkylierung des DNADoppelstranges ds-64 bei einer Umsetzung im Verhältnis DNA / seco-Drug = 1:1 (bzw. 1:2) nach 24 h Inkubation sowie Alkylierungsposition.

Während (+)-(1S)-56b nur das von weiteren Adeninen flankierte $\mathrm{A}_{10}(\mathrm{ON}-1)$ alkyliert, kann bei $(+)-(1 S, 10 R)$-34a eine zusätzliche Alkylierung des von Thymin flankierten $\mathrm{A}_{10}(\mathrm{ON}-2)$ beobachtet werden; $(+)-(1 S, 10 R)-\mathbf{3 4 b}$ sowie $(+)-(1 S)$-56a zeigen keine Bevorzugung gegenüber drei Adenin-Basen oder drei Thymin-Basen. Für (+)-(1S)-56b ist die Alkylierungseffizienz mit 6\% nur sehr gering. Für die anderen seco-Drugs kann aufgrund der Alkylierung beider Oligonukleotide der Anteil der umgesetzten Oligonukleotide nicht bestimmt werden, da es sich bei dem angewandten Verfahren zur Berechnung der prozentualen Alkylierung (s. Experimenteller Teil, AAV 7.3) um ein relatives Verfahren handelt. 
In ds-65 wird die potentiell als Nukleophil geeignete Nukleobase $\mathrm{A}_{9}$ im Oligonukleotid ON-1 in 5'-Richtung von einem Thymin und im Oligonukleotid ON-2 von einer Adenin-Base flankiert (Abb. 99). Die folgenden und vorhergehenden Basenpaare sind jeweils identisch. Im Oligonukleotid ON-2 kann weiterhin $\mathrm{A}_{8}$ alkyliert werden, da es sich ebenfalls am 3'-Ende einer AT-reichen Sequenz von mindestens vier Basenpaaren befindet. Zudem wird $A_{8}(\mathrm{ON}-1)$ im Gegensatz $z u$ den beiden $A_{9}$-Basen in der 3'-Richtung von Adenin und damit einer Purinbase flankiert. Hierin liegt womöglich auch die Ursache dafür, dass $\mathrm{A}_{8}(\mathrm{ON}-2)$ von allen seco-Drugs bevorzugt alkyliert wird (Tab. 15). Neben $A_{8}(\mathrm{ON}-2)$ wird zudem $A_{9}(\mathrm{ON}-2)$ alkyliert, während an $\mathrm{A}_{9}(\mathrm{ON}-1)$ keine Reaktion detektiert werden kann. Dies zeigt, dass Adenin an der ersten Position in 5'-Richtung der Alkylierungsstelle gegenüber Thymin bevorzugt wird.

$$
\left.\begin{array}{ll}
\text { 5'-CGG CAA } \mathbf{T}_{7} \boldsymbol{T}_{8} \mathbf{A}_{9} \text { TTG CCG-3' } & (\mathbf{O N}-1) \\
\text { 3'-GCC GTT } \underline{\mathbf{A}}_{9} \underline{\mathbf{A}}_{8} \mathbf{T}_{7} \text { AAC GGC-5' } & (\mathbf{O N}-2)
\end{array}\right\} \text { ds-65 }
$$

Abb. 99. Basensequenz des DNA-Oligonukleotides ds-65 und Position der Alkylierung durch die Methyl-seco-CBI- und seco-CBI-Derivate mit DMAI- oder MPI-DNA-bindender Einheit.

\begin{tabular}{ccc}
\hline seco-Drug & Alkylierung ds-65 [\%] & Alkylierungsposition \\
\hline$(+)-(1 S, 10 R)-\mathbf{3 4 a}$ & $30(18)$ & $\mathrm{A}_{8}(\mathrm{ON}-2) / \mathrm{A}_{9}(\mathrm{ON}-2) \sim 4: 1$ \\
$(+)-(1 S, 10 R)-\mathbf{3 4 b}$ & 20 & $\mathrm{~A}_{8}(\mathrm{ON}-2)>\mathrm{A}_{9}(\mathrm{ON}-2)$ \\
$(+)-(1 S)-56 \mathbf{a}$ & 17 & $\mathrm{~A}_{8}(\mathrm{ON}-2)>\mathrm{A}_{9}(\mathrm{ON}-2)$ \\
$(+)-(1 S)-56 \mathbf{b}$ & 13 & $\mathrm{~A}_{8}(\mathrm{ON}-2) \sim \mathrm{A}_{9}(\mathrm{ON}-2)$ \\
\hline
\end{tabular}

Tab. 15. Anteil der durch die entsprechenden Drugs verursachten Alkylierung des DNADoppelstranges ds-65 bei einer Umsetzung im Verhältnis DNA / seco-Drug = 1:1 (bzw. 1:2) nach $24 \mathrm{~h}$ Inkubation sowie Alkylierungsposition.

Unterscheiden sich zwei mögliche Alkylierungspositionen in der zweiten in 5'-Richtung benachbarten Base bei sonst identischer Basensequenz (Abb. 100), so wird auch in dieser Position Adenin gegenüber Thymin bevorzugt (Tab. 16). Das Oligonukleotid ds-66 wird daher bevorzugt am Adenin $\mathrm{A}_{10}(\mathrm{ON}-2)$ im Vergleich zu $\mathrm{A}_{10}(\mathrm{ON}-1)$ alkyliert. An der am 3'-Ende einer drei Basenpaare langen AT-reichen Sequenz befindlichen Base $\mathrm{A}_{8}(\mathrm{ON}-2)$ kann darüber hinaus erneut keine Alkylierung festgestellt werden. 


\section{$\left.\begin{array}{lll}5^{\prime}-C C G ~ G C ~ T_{6} & \text { ATT } \underline{A}_{10} \text { GG CCG-3' } & (\text { ON-1) } \\ 3^{\prime}-G G C ~ C G ~ \underline{A}_{10} \text { TAA T }_{6} & \text { CC GGC-5' } & (\mathrm{ON}-2)\end{array}\right\}$ ds- 66}

Abb. 100. Basensequenz des DNA-Oligonukleotides ds-66 und Position der Alkylierung durch die Methyl-seco-CBI- und seco-CBI-Derivate mit DMAI- oder MPI-DNA-bindender Einheit.

\begin{tabular}{ccc}
\hline seco-Drug & Alkylierung ds-66 & Alkylierungsposition \\
\hline$(+)-(1 S, 10 R)-34 a$ & $\mathrm{ON}-1 / \mathrm{ON}-2 \sim 1: 2(\mathrm{n}=1,2)$ & $\mathrm{A}_{10}(\mathrm{ON}-2)>\mathrm{A}_{10}(\mathrm{ON}-1)$ \\
$(+)-(1 S, 10 R)-34 b$ & $\mathrm{ON}-1 / \mathrm{ON}-2 \sim 1: 2$ & $\mathrm{~A}_{10}(\mathrm{ON}-2)>\mathrm{A}_{10}(\mathrm{ON}-1)$ \\
$(+)-(1 S)-56 \mathbf{a}$ & $\mathrm{ON}-1 / \mathrm{ON}-2 \sim 1: 1$ & $\mathrm{~A}_{10}(\mathrm{ON}-2) \sim \mathrm{A}_{10}(\mathrm{ON}-1)$ \\
$(+)-(1 S)-56 \mathbf{b}$ & $\mathrm{ON}-1 / \mathrm{ON}-2 \sim 1: 3$ & $\mathrm{~A}_{10}(\mathrm{ON}-2)>\mathrm{A}_{10}(\mathrm{ON}-1)$ \\
\hline
\end{tabular}

Tab. 16. Anteil der durch die entsprechenden Drugs verursachten Alkylierung des DNADoppelstranges ds-66 bei einer Umsetzung im Verhältnis DNA / seco-Drug = 1:1 (bzw. 1:2) nach $24 \mathrm{~h}$ Inkubation sowie Alkylierungsposition.

Unterscheiden sich die zwei Basenfolgen in der dritten der Alkylierungsposition in 5'-Richtung benachbarten Base wie beispielsweise 5'-TAAA-3' versus 5'-AAAA-3' in ds-67 (Abb. 101), so kann nur noch eine sehr leichte Bevorzugung der Nukleobase Adenin gegenüber Thymin beobachtet werden (Tab. 17). Im Fall des seco-Drugs $(+)-(1 S, 10 R)-34 a$ kann zudem eine Reaktion an den Basen $\mathrm{A}_{6}(\mathrm{ON}-2)>\mathrm{A}_{6}(\mathrm{ON}-1)$ detektiert werden, die die Bevorzugung von Adenin gegenüber Thymin an der zweiten Nachbarposition zur Bindungsstelle bestätigt.

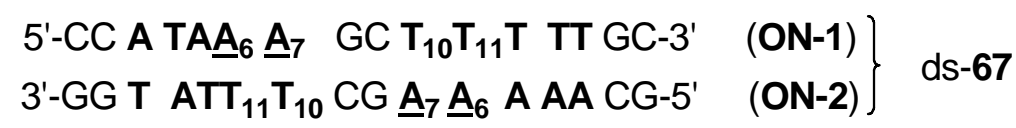

Abb. 101. Basensequenz des DNA-Oligonukleotides ds-67 und Position der Alkylierung durch die Methyl-seco-CBI- und seco-CBI-Derivate mit DMAI- oder MPI-DNA-bindender Einheit. 


\begin{tabular}{ccc}
\hline seco-Drug & Alkylierung ds-67 & Alkylierungsposition \\
\hline$(+)-(1 S, 10 R)-34 \mathbf{a}$ & $\mathrm{ON}-2>\mathrm{ON}-1$ & $\mathrm{~A}_{7}(\mathrm{ON}-2)>\mathrm{A}_{7}(\mathrm{ON}-1)>\mathrm{A}_{6}(\mathrm{ON}-2)>\mathrm{A}_{6}(\mathrm{ON}-1)$ \\
$(+\mathrm{n}=1,2)$ & $\mathrm{A}_{7}(\mathrm{ON}-2) \sim \mathrm{A}_{7}(\mathrm{ON}-1)$ \\
$(+)-(1 S)-56 \mathbf{a}$ & gering & $\mathrm{A}$ \\
$(+)-(1 S)-56 \mathbf{b}$ & $\mathrm{ON}-2 \sim \mathrm{ON}-1$ & $\mathrm{~A}_{7}(\mathrm{ON}-2) \sim \mathrm{A}_{7}(\mathrm{ON}-1)$ \\
\hline
\end{tabular}

Tab. 17. Anteil der durch die entsprechenden Drugs verursachten Alkylierung des DNADoppelstranges ds-67 bei einer Umsetzung im Verhältnis DNA / seco-Drug = 1:1 (bzw. 1:2) nach 24 h Inkubation sowie Alkylierungsposition.

Um die generelle Bevorzugung einer die Alkylierungsstelle in 3'-Richtung flankierenden Purinbase $(A, G)$ gegenüber einer Pyrimidinbase $(C, T)$ bei sonst gleicher Basenfolge zu beurteilen, wurde ds-68 ausgewählt (Abb. 102).

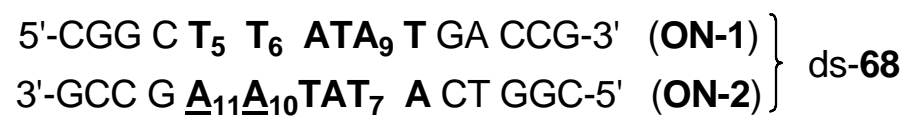

Abb. 102. Basensequenz des DNA-Oligonukleotides ds-68 und Position der Alkylierung durch die Methyl-seco-CBI- und seco-CBI-Derivate mit DMAI- oder MPI-DNA-bindender Einheit.

\begin{tabular}{ccc}
\hline seco-Drug & Alkylierung ds-68 [\%] & Alkylierungsposition \\
\hline$(+)-(1 S, 10 R)-34 \mathbf{a}$ & $77(58)$ & $\mathrm{A}_{10}(\mathrm{ON}-2) \sim \mathrm{A}_{11}(\mathrm{ON}-2)$ \\
$(+)-(1 S, 10 R)-34 \mathbf{b}$ & 82 & $\mathrm{~A}_{10}(\mathrm{ON}-2)>>\mathrm{A}_{11}(\mathrm{ON}-2)$ \\
$(+)-(1 S)-56 \mathbf{a}$ & 21 & $\mathrm{~A}_{10}(\mathrm{ON}-2)>>\mathrm{A}_{11}(\mathrm{ON}-2)$ \\
$(+)-(1 S)-56 b$ & 30 & $\mathrm{~A}_{10}(\mathrm{ON}-2)$
\end{tabular}

Tab. 18. Anteil der durch die entsprechenden Drugs verursachten Alkylierung des DNADoppelstranges ds-68 bei einer Umsetzung im Verhältnis DNA / seco-Drug = 1:1 (bzw. 1:2) nach 24 h Inkubation sowie Alkylierungsposition.

Das über ein benachbartes Thymin verfügende $A_{9}(\mathrm{ON}-1)$ wird nicht alkyliert, während das von einem Adenin flankierte $\mathrm{A}_{10}(\mathrm{ON}-2)$ eine hervorragende Bindungsstelle darstellt (Tab. 18). Neben $\mathrm{A}_{10}(\mathrm{ON}-2)$ kann zudem eine teils ausgeprägte 
Alkylierung an $\mathrm{A}_{11}(\mathrm{ON}-2)$ beobachtet werden, das ebenfalls über eine in 3'-Richtung flankierenden Purinbase verfügt, bei der es sich in diesem Fall um Guanin handelt.

Werden die seco-Drugs mit einer doppelsträngigen DNA ohne AT-reiche Region inkubiert, so kann in allen Fällen nur eine sehr schwache Alkylierung an Guanin und/oder Adenin festgestellt werden, die an mehreren Nukleobasen nicht näher bestimmbarer Position erfolgt (Abb. 103, Tab. 19). Lediglich im Fall von (+)-(1S)-56b kann aufgrund der Fragmente eine Alkylierung an $\mathrm{A}_{12}(\mathrm{ON}-1)$ nachgewiesen werden.

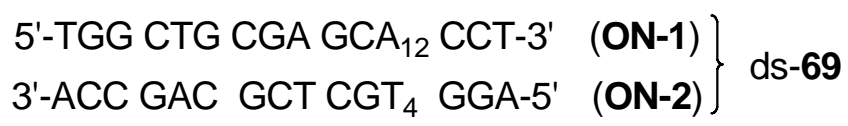

Abb. 103. Basensequenz des DNA-Oligonukleotides ds-69 und Position der Alkylierung durch die Methyl-seco-CBI- und seco-CBI-Derivate mit DMAI- oder MPI-DNA-bindender Einheit.

\begin{tabular}{ccc}
\hline seco-Drug & Alkylierung ds-69 [\%] & Alkylierungsposition \\
\hline$(+)-(1 S, 10 R)-34 \mathbf{a}$ & gering & $\mathrm{G}$ \\
$(+)-(1 S, 10 R)-34 b$ & gering & $\mathrm{G}>>\mathrm{A}$ \\
$(+)-(1 S)-56 \mathbf{a}$ & gering & $\mathrm{A}$ \\
$(+)-(1 S)-56 \mathbf{b}$ & gering & u.a. $\mathrm{A}_{12}(\mathrm{ON}-1)$ \\
\hline
\end{tabular}

Tab. 19. Anteil der durch die entsprechenden Drugs verursachten Alkylierung des DNADoppelstranges ds-69 bei einer Umsetzung im Verhältnis DNA / seco-Drug = 1:1 (bzw. 1:2) nach $24 \mathrm{~h}$ Inkubation sowie Alkylierungsposition.

Die in einem Inkubationszeitraum von 24 Stunden beobachtete niedrigere Alkylierungseffizienz der zytotoxischeren seco-CBI-Hydrochloride (+)-(1S)-56a,b im Vergleich zu den weniger zytotoxischen Methyl-seco-CBI-Derivaten $(+)-(1 S, 10 R)-34 \mathbf{a}, \mathbf{b}$ kann auf die höhere Stabilität des unsubstituierten Cyclopropylsystems in ersteren zurückgeführt werden. So sind sowohl in Zellkulturmedium als auch in PBS als Lösungsmittel die CBI-Drugs deutlich stabiler gegenüber Hydrolyse als die entsprechenden Methyl-CBI-Drugs. ${ }^{157,159}$ Die Reaktion zum kovalenten DNA-Addukt erfolgt daher mit einer niedrigeren Geschwindigkeit, weshalb nach 24 Stunden Inkubation die Reaktion noch nicht beendet ist. 
Insgesamt ergeben sich aufgrund der Ergebnisse der vorgestellten Untersuchungen die folgenden Präferenzen für eine DNA-Alkylierung durch die seco-Drug-Hydrochloride $(+)-(1 S, 10 R)-34 \mathbf{a},(+)-(1 S, 10 R)-34 \mathbf{b},(+)-(1 S)-56 \mathbf{a}$ und $(+)-(1 S)-56 \mathbf{b}$ (Tab. 20):

- Doppelsträngige DNA wird wesentlich effizienter alkyliert als einzelsträngige DNA.

- Bevorzugt alkyliert wird ein Adenin am 3'-Ende einer AT-reichen Sequenz von mindestens vier Basenpaaren.

- Adenin wird an der ersten, zweiten und dritten Position in 5'-Richtung der Alkylierungsposition gegenüber Thymin bevorzugt.

- DMAI-seco-Drugs bevorzugen bei sonst identischer Basenfolge eine AT-reiche Region von fünf Basenpaaren, MPI-seco-Drugs von vier Basenpaaren.

- Purinbasen $(\mathrm{Pu})$ werden an der ersten Position in 3'-Richtung der Alkylierungsposition bevorzugt gegenüber Pyrimidinbasen (Py).

\begin{tabular}{ccccccccc}
\hline Alkylantien & 5 & 4 & 3 & 2 & 1 & $\mathbf{0}$ & -1 & $3^{\prime}$ \\
\hline$(1 S, 10 R)-\mathbf{3 4 a},(1 S)-\mathbf{5 6 a}$ & $\mathrm{A} / \mathrm{T}>\mathrm{G} / \mathrm{C}$ & $\mathrm{A}>\mathrm{T}$ & $\mathrm{A}>\mathrm{T}$ & $\mathrm{A}>\mathrm{T}$ & $\mathbf{A}$ & $\mathrm{Pu}>\mathrm{Py}$ & \\
$(1 S, 10 R)-\mathbf{3 4 b},(1 S)-\mathbf{5 6 b}$ & $\mathrm{G} / \mathrm{C}>\mathrm{A} / \mathrm{T}$ & & & & & & \\
\hline
\end{tabular}

Tab. 20. Bevorzugte Basen in der Umgebung der Alkylierungsstelle.

Des Weiteren konnte für das seco-Drug (+)-(1S,10R)-34a für alle DNAOligonukleotide eine Verringerung der Alkylierungseffizienz nachgewiesen werden, wenn das seco-Drug in einem zweifachen molaren Überschuss anstelle einer äquimolaren Menge mit den DNA-Oligonukleotiden inkubiert wurde. Dieses Phänomen wurde mittels CD-Spektroskopie und HPLC weiter untersucht (vide infra).

Nachdem für alle seco-Drugs eine Alkylierung doppelsträngiger DNA nachgewiesen werden konnte, wurde in der Folge die Alkylierung eines doppelsträngigen RNAOligonukleotides und des Tripeptides Glutathion für das seco-Drug $(+)-(1 S, 10 R)-\mathbf{3 4 a}$ untersucht. 


\subsection{Wechselwirkung des seco-Drugs $(+)-(1 S, 10 R)-34 a$ mit dem RNA- Oligonukleotid ds-59}

RNA liegt im Gegensatz zu DNA in Zellen hauptsächlich in Form von Einzelsträngen vor. Diese bilden jedoch über intramolekulare Wasserstoffbrückenbindungen partiell auch Doppelstränge aus. Zur Untersuchung der Wechselwirkung des seco-Drugs $(+)-(1 S, 10 R)-34$ a mit RNA-Oligonukleotiden wurde ein doppelsträngiges RNA-Oligonukleotid ausgewählt, da die Reaktivität gegenüber doppelsträngiger RNA im Vergleich zu einzelsträngiger RNA erhöht sein könnte. Die Basenfolge der ausgewählten RNA ds-59 stimmt nahezu mit der des DNA-Doppelstranges ds-60 überein (Abb. 104). Es erfolgte lediglich die Variation einer Base am Ende der Sequenz und der für einen Wechsel von DNA auf RNA typischen Austausch der Nukleobase Thymin gegen Uracil. Sollte (+)-(1S,10R)-34a in der Lage sein, doppelsträngige RNA analog zu DNA zu alkylieren, so würde eine Reaktion am Adenin $\mathrm{A}_{10}(\mathrm{ON}-1)$ von ds-59 erfolgen.
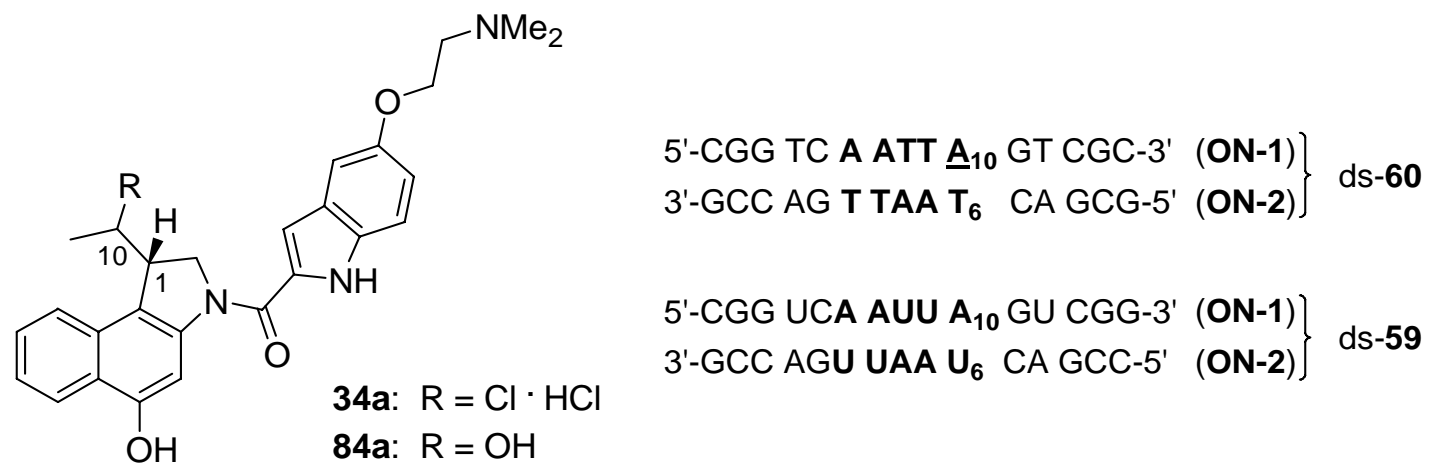

Abb. 104. seco-Drug-Hydrochlorid (+)-(1S,10R)-34a, dessen Hydrolyseprodukt 84a sowie die Basensequenzen des DNA-Oligonukleotides ds-60 und des RNA-Oligonukleotides ds-59.

RNA-abbauende Enzyme sind ubiquitär vorhanden, weshalb im Gegensatz zum Umgang mit DNA bei den durchgeführten Versuchen auf die Verwendung RNAse-freier Utensilien und Lösungsmittel geachtet wurde.

Wurde ds-59 mit $(+)-(1 S, 10 R)-34 a$ inkubiert, so konnte bei einem molaren Verhältnis von ds-59/(+)-(1S,10R)-34a = 1:1 nach 24 Stunden Inkubation keine Alkylierung festgestellt werden (Abb. 106 a,c). Stattdessen wurde (+)-(1S,10R)-34a nahezu quantitativ zu dem entsprechenden Hydrolyseprodukt 84a umgesetzt.

Bei einem fünffachen Überschuss des seco-Drugs konnte nach 24 Stunden Inkubation eine weniger als 10\%-ige Alkylierung beider RNA-Oligonukleotide an Guanin 
beobachtet werden (Abb. 106b,d). Aufgrund der geringen Intensität der Fragmente konnte die genaue Position der Bindung hierbei nicht ermittelt werden.

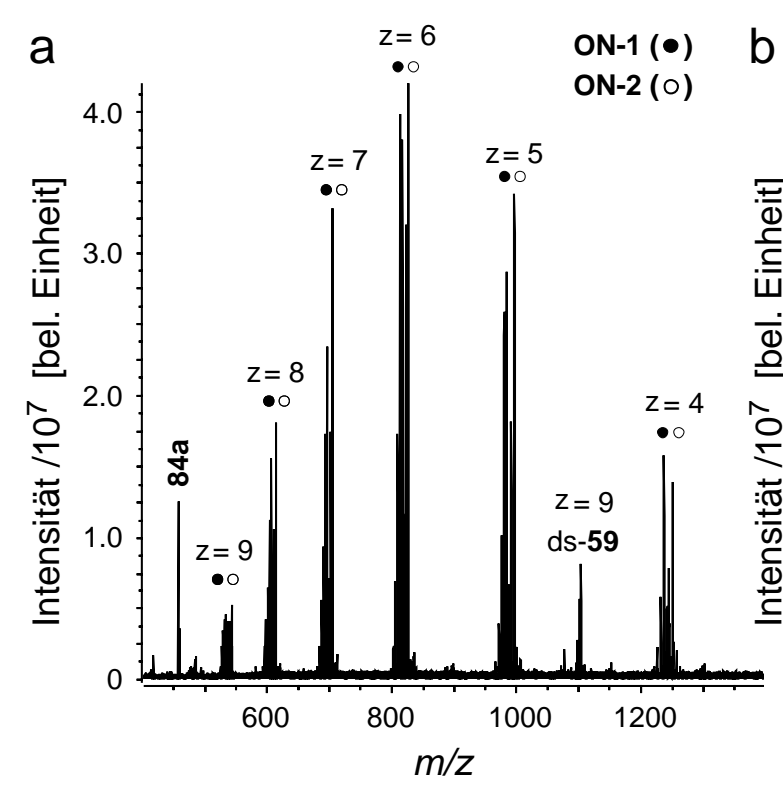

ON-1 (•) ON-2 (O)

C

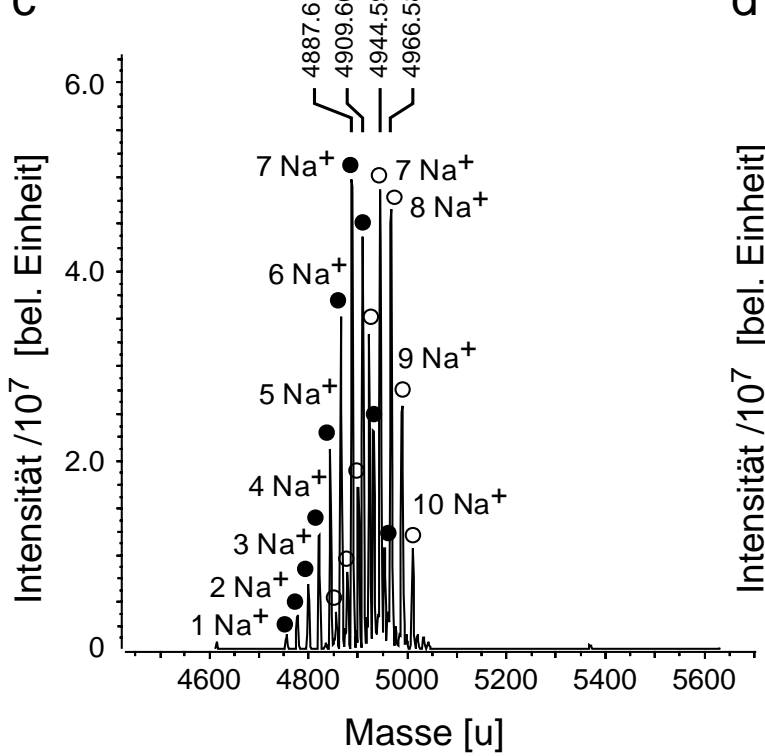

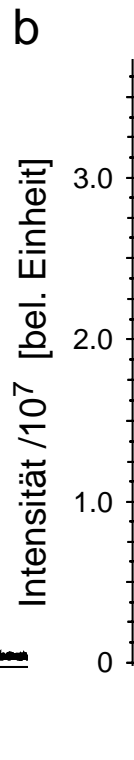

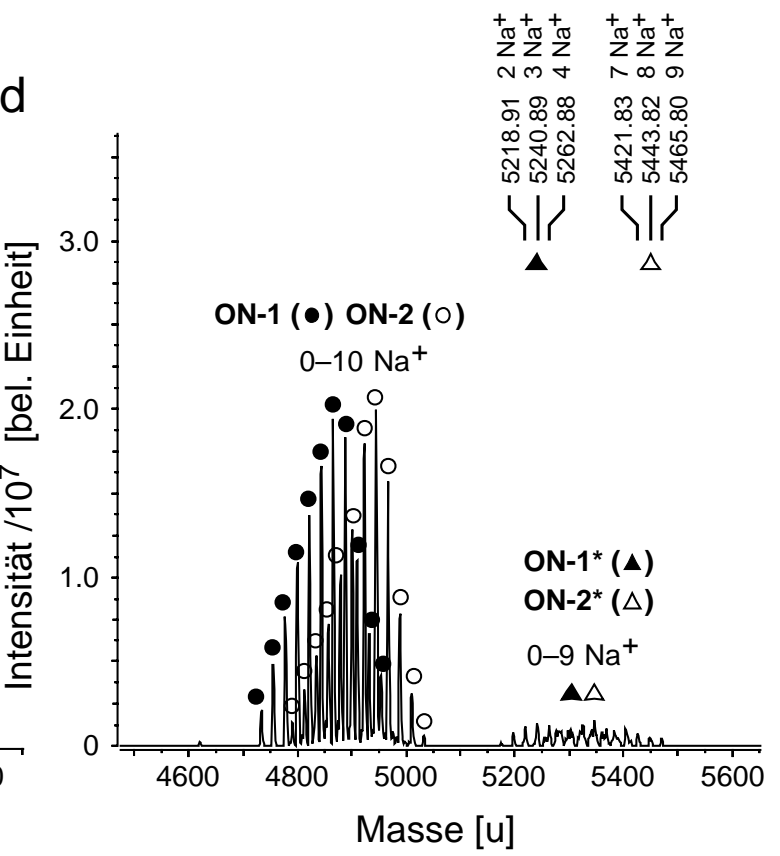

Abb. 106. Massenspektren (a,b) und dekonvolierte Massenspektren (c,d) nach $24 \mathrm{~h}$ Inkubation des RNA-Oligonukleotides ds-59 mit dem seco-Drug (+)-(1S,10R)-34a im molaren Verhältnis 1:1 $(\mathrm{a}, \mathrm{c})$ und 1:5 (b,d). $U_{\mathrm{C}}=-100 \mathrm{~V}$.

Neben dem Hydrolyseprodukt 84a und dem alkylierten Guanin $\left(\mathbf{G}^{*}\right)$ konnten weiterhin Spuren des seco-Drugs 34a und des Drugs 43a detektiert werden (Abb. 107a). Auch der RNA-Doppelstrang ds-59 und unspezifische Addukte des seco-Drugs mit dem RNA-Doppelstrang wurden nachgewiesen (Abb. 107b). 


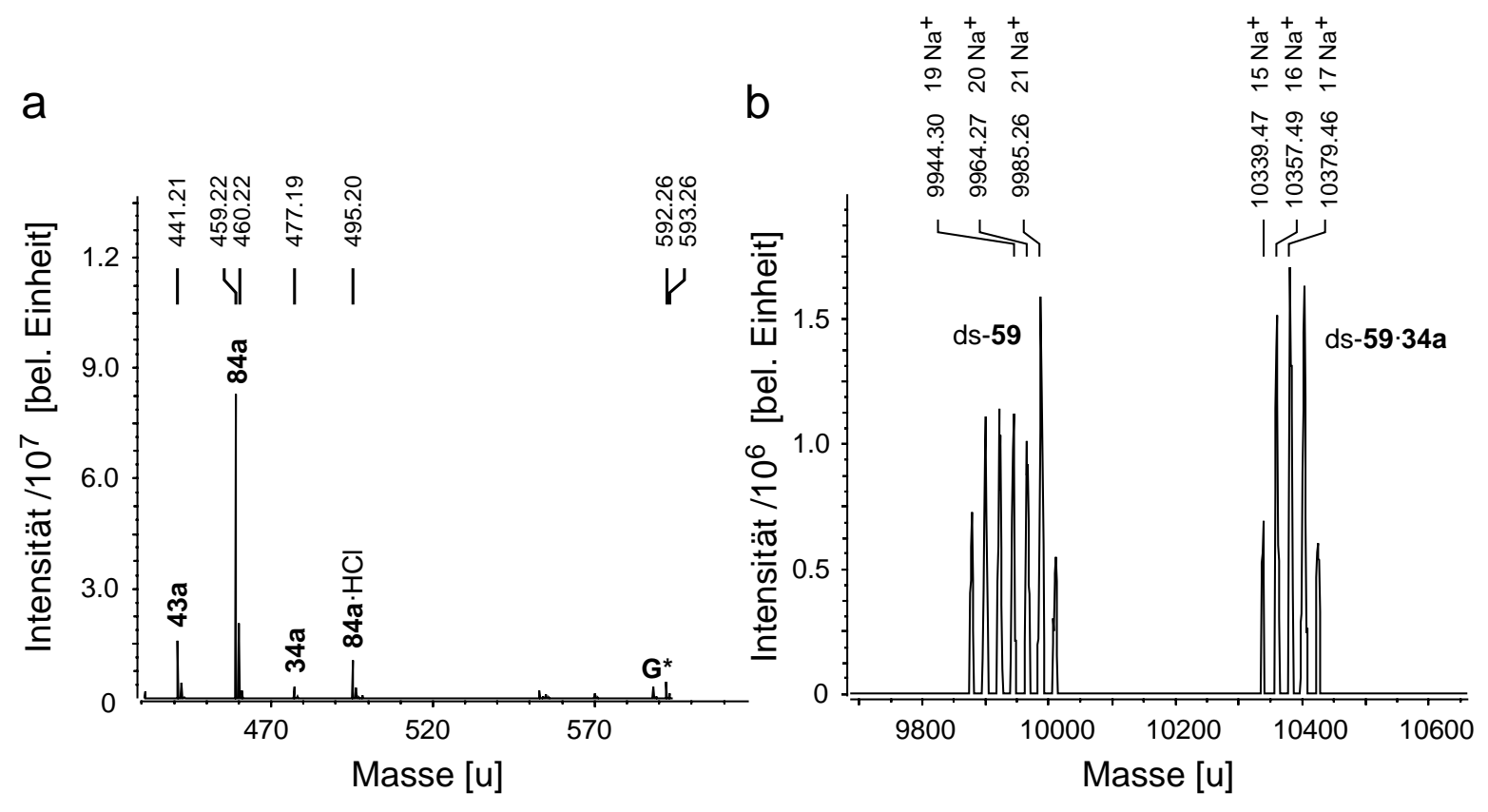

Abb. 107. Dekonvolierte Massenspektren nach Inkubation des RNA-Oligonukleotides ds-59 mit dem seco-Drug $(+)-(1 S, 10 R)-34 a$ im molaren Verhältnis 1:5 nach $24 \mathrm{~h}$ Inkubation. a) $U_{\mathrm{C}}=-150 \mathrm{~V}$, b) $U_{\mathrm{C}}=-100 \mathrm{~V}$.

Die Reaktivität des seco-Drugs gegenüber doppelsträngiger RNA ist somit wesentlich geringer als jene gegenüber doppelsträngiger DNA. Zudem unterscheidet sich die Sequenzselektivität, was darauf zurückgeführt werden kann, dass RNA-Doppelstränge in Lösung üblicherweise keine B-DNA-Doppelhelix mit einer charakteristischen großen und kleinen Furche ausbilden, sondern in einer flexiblen randomisierten Konformation vorliegen.

\subsection{Wechselwirkung des seco-Drugs $(+)-(1 S, 10 R)-34$ a mit dem Tripeptid Glutathion}

Das Tripeptid Glutathion (58, Abb. 108) dient in Zellen als endogenes Antioxidans und zur Entgiftung toxischer Substanzen, die über elektrophile Struktureinheiten verfügen. Dies betrifft auch zu therapeutischen Zwecken eingesetzte Wirkstoffe. Vermittelt durch das Enzym Glutathion-S-Transferase, aber auch unkatalysiert, werden die Elektrophile durch Reaktion mit der nukleophilen Thiolfunktion zu Thioethern inaktiviert. ${ }^{186}$ Abbildung 108 zeigt dies am Beispiel der Inaktivierung des seco-Drugs $(+)-(1 S, 10 R)-34 \mathbf{a}$ zum Addukt 58*. Die für Säugetierzellen übliche intrazelluläre Glutathionkonzentration beträgt $0.1-10 \mathrm{mM}{ }^{187}$ Glutathion ist somit das häufigste niedermolekulare Thiol in Tierzellen. ${ }^{188}$ 
<smiles>NC(CCC(=O)NC(CS)C(=O)NCC(=O)O)C(=O)O</smiles>

58

Oxidation

0.5<smiles>N[C@@H](CCC(=O)N[C@@H](CSSC[C@H](NC(=O)CC[C@H](N)C(=O)O)C(=O)NCC(=O)O)C(=O)NCC(=O)O)C(=O)O</smiles><smiles>[R]C(C)(C)[R](Cl)Cl</smiles>

$-2 \mathrm{HCl}$<smiles>[R]C[C@H](NC(=O)CC[C@H](N)C(=O)O)C(=O)NCC(=O)O</smiles>

58*<smiles>[R]=CC1(C(C)C)c2c(cc(O)c3ccccc23)N(C(=O)c2cc3cc(OCCNC)ccc3[nH]2)C[C@H]1C(C)C</smiles>

92

Abb. 108. Glutathion (58), Reaktion mit dem seco-Drug-Hydrochlorid (+)-(1S,10R)-34a $(\mathrm{R}-\mathrm{Cl} \cdot \mathrm{HCl})$ zum kovalenten Addukt 58* sowie Oxidation von 58 zum Disulfid 92.

Glutathion eignet sich aufgrund seiner reaktiven Thiolgruppe, seiner freien Aminogruppe sowie der für Peptide üblichen Säurefunktionen und Säureamidbindungen ideal als Modell für die Untersuchung der Alkylierung von Peptiden durch das seco-Drug $(+)-(1 S, 10 R)-34 a$. Um eine Oxidation des Thiols 58 zum Disulfid 92 durch Luftsauerstoff in Wasser als Lösungsmittel zu verhindern (Abb. 108), wurde bei den entsprechenden Umsetzungen unter Schutzatmosphäre gearbeitet. ${ }^{189}$

Glutathion (58) wurde im molaren Verhältnis 2000:1 bis 1:5 mit dem seco-Drug $(+)-(1 S, 10 R)-34 a$ in Wasser umgesetzt (Tab. 21). Hierbei wurden niedrige bis sehr hohe Glutathion-Konzentrationen einschließlich der physiologischen Konzentrationen (0.1-10 mM) getestet und die Reaktionsmischungen nach 24 Stunden Inkubation massenspektrometrisch im positiven Ionenmodus untersucht.

Während bis zu einem 200-fachen Überschuss des Tripeptides keine Reaktion detektiert wurde, fand bei einem 2000-fachen Überschuss an Glutathion eine sehr geringe Reaktion mit dem seco-Drug (+)-(1S,10R)-34a bzw. dem aus diesem in situ gebildeten Drug 43a unter Bildung des alkylierten Peptides 58* statt (Abb. 108 und Abb. 109). Der Hauptteil des seco-Drugs wurde jedoch mangels geeigneter Reaktionspartner zum inaktivierten Hydrolyseprodukt 84a (Abb. 105) umgesetzt. 


\begin{tabular}{ccc}
\hline Konzentration 58 & $\mathbf{5 8} /(+)-(\mathbf{1 S , 1 0 R})-\mathbf{3 4 a}$ & Verbindungen $(\mathbf{I}[\%])$ \\
\hline $100 \mathrm{mM}$ & $2000: 1$ & $\mathbf{5 8}(100), \mathbf{8 4 a}(8), \mathbf{9 2}(5), \mathbf{5 8} *(0.8)$ \\
$10.0 \mathrm{mM}$ & $200: 1$ & $\mathbf{5 8}(100), \mathbf{8 4 a}(14), \mathbf{9 2}(3)$ \\
$1.00 \mathrm{mM}$ & $20: 1$ & $\mathbf{5 8}(100), \mathbf{8 4 a}(47), \mathbf{9 2}(9)$ \\
$0.10 \mathrm{mM}$ & $2: 1$ & $\mathbf{8 4 a}(100), \mathbf{5 8}(23), \mathbf{9 2}(3)$ \\
$0.10 \mathrm{mM}$ & $1: 1$ & $\mathbf{8 4 a}(100), \mathbf{5 8}(10), \mathbf{9 2}(3)$ \\
$50.0 \mu \mathrm{M}$ & $1: 2$ & $\mathbf{8 4 a}(100), \mathbf{5 8}(5), \mathbf{9 2}(1)$ \\
$10.0 \mu \mathrm{M}$ & $1: 5$ & $\mathbf{8 4 a}(100), \mathbf{5 8}(3), \mathbf{9 2}(1)$ \\
\hline
\end{tabular}

Tab. 21. Konzentration an Glutathion, molares Verhältnis zum seco-Drug (+)-(1S,10R)-34a sowie massenspektrometrisch detektierte Verbindungen und deren relative Intensitäten (Intensität des jeweils intensivsten Ions $=100 \%$ ) nach $24 \mathrm{~h}$ Inkubation in Wasser.

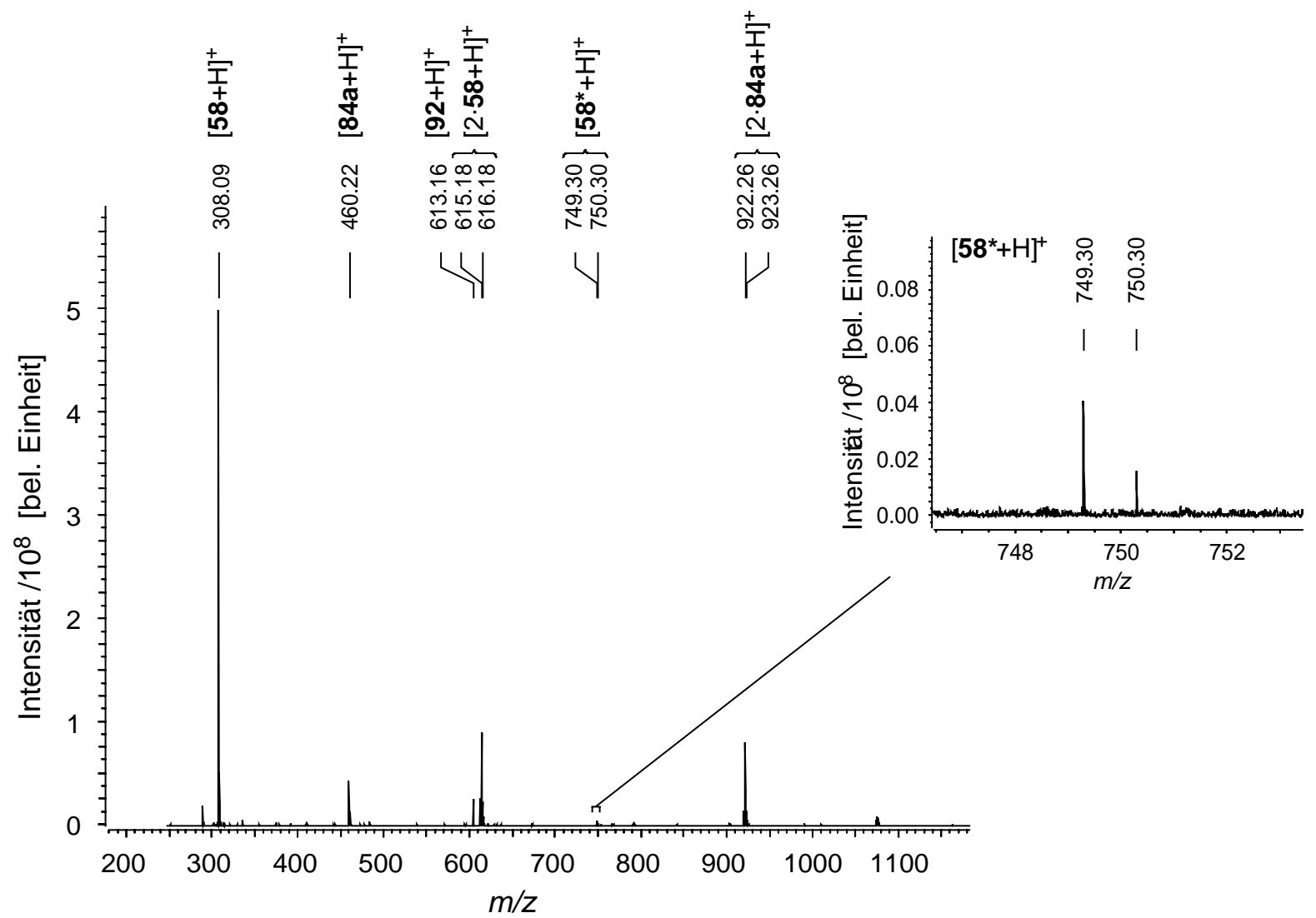

Abb. 109. Massenspektrum nach 24 h Inkubation von 58 mit $(+)-(1 S, 10 R)-34 a$ im molaren Verhältnis 2000:1.

Die Versuche zeigen, dass das seco-Drug (+)-(1S,10R)-34a zwar eine Reaktion mit dem Tripeptid Glutathion eingehen kann, dass die hierfür notwendigen Konzentrationen jedoch weit über den beobachteten Konzentrationen in Säugetierzellen liegen. Die Untersuchungen stützen daher die These, dass die Alkylierung zellulärer DNA für die Zytotoxizität der Duocarmycin-Analoga verantwortlich ist. 


\subsection{Wechselwirkung der fluoreszenzmarkierten Analoga mit dem DNA- Oligonukleotid ds-60}

Die fluoreszenzmarkierten anti-Methyl-seco-CBI-DMAI-Analoga (-)-(1S,10R)-75 und $(1 S, 10 R)$-76 (Abb. 110) weisen eine geringere Zytotoxizität auf als die entsprechenden nicht-fluoreszenzmarkierten Analoga (s. Kap. 5.8). Weiterhin kann das Prodrug $(-)-(1 S, 10 R)-75$ enzymatisch nicht zum entsprechenden seco-Drug aktiviert werden. Um zu überprüfen, ob die Fluoreszenzmarkierung die DNA-bindenden Eigenschaften der Verbindungen beeinflusst, wurde die Alkylierungseffizienz und Sequenzselektivität nach der Umsetzung mit dem DNA-Oligonukleotid ds-60 massenspektrometrisch untersucht.

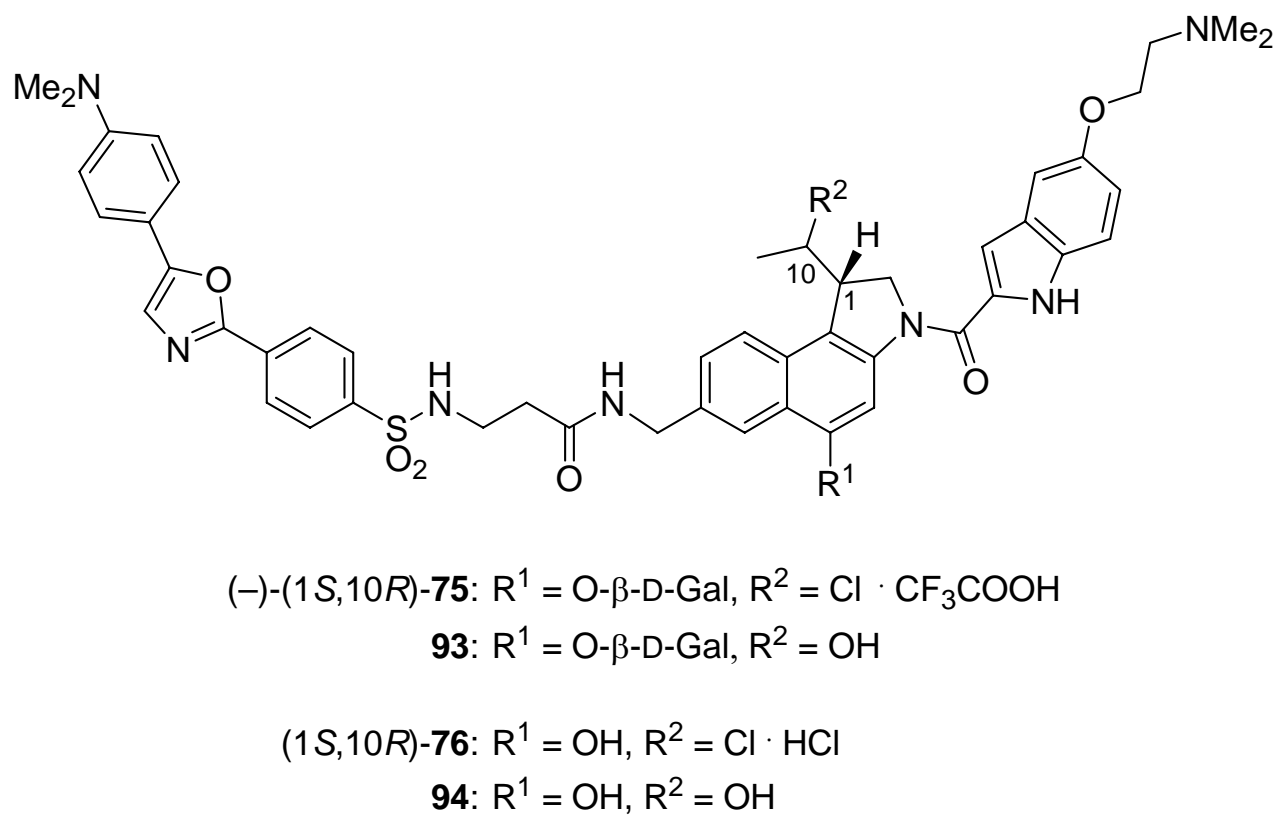

Abb. 110. Fluoreszenzmarkierte anti-Methyl-seco-CBI-DMAI-Analoga (-)-( $1 S, 10 R)-75$ und $(1 S, 10 R)-76$ sowie entsprechende Hydrolyseprodukte

Während das Prodrug (-)-(1S,10R)-75 das doppelsträngige DNA-Oligonukleotid auch in einem fünffachen Überschuss nicht alkyliert, konnte für das seco-Drug $(1 S, 10 R)$-76 eine Alkylierung des Adenins an $\mathrm{A}_{10}$ des Oligonukleotides ON-1 beobachtet werden. Obwohl die Alkylierungseffizienz mit etwa 20\% Alkylierung bei Umsetzung im Verhältnis Wirkstoff / DNA $=1: 1$ wesentlich niedriger ist als diejenige des analogen nicht-fluoreszenzmarkierten seco-Drugs $(+)-(1 S, 10 R)-34 a$ (75\%), war eine selektive Alkylierung dennoch möglich. Die Fluoreszenzmarkierung an C-7 verringert somit zwar die Alklylierungseffizienz, verhindert die Alkylierung aber nicht und beeinflusst auch nicht die Sequenzselektivität. 


\section{Untersuchung der Wechselwirkung neuer Duocarmycin- Analoga mit DNA mittels HPLC}

Die in Kapitel 6 beschriebene neue ESI-FTICR-MS-basierte Methode zur Untersuchung der Wechselwirkung verschiedener Duocarmycin-Analoga mit DNA-Oligonukleotiden gibt Aufschluss über die Alkylierungseffizienz und Sequenzselektivität verschiedener Alkylantien, wenn die Reaktionen in Wasser als Lösungsmittel durchgeführt werden. Werden Phosphatpuffer als Lösungsmittel verwendet, so können die Reaktionslösungen nicht ohne Aufarbeitung untersucht werden, da die Pufferbestandteile eine effiziente Ionisierung der $\mathrm{zu}$ beobachtenden Spezies verhindern. Zusätzlich zu den direkten ESI-HRMS-Messungen wurden daher HPLC-Untersuchungen zu den Wechselwirkungen verschiedener Duocarmycin-Analoga mit DNAOligonukleotiden in Wasser und Phosphatpuffer als Lösungsmittel durchgeführt. Diese werden im Folgenden diskutiert.

Die untersuchten Duocarmycin-Analoga und deren Derivate einschließlich der kovalenten und nicht-kovalenten Verbindungen mit Oligonukleotiden absorbieren im Gegensatz zu reinen Oligonukleotiden Licht der Wellenlänge $\lambda=350 \mathrm{~nm}$. Die Auswertung der HPLC-Messungen erfolgte daher durch Integration der Absorptionsspur bei $\lambda=350 \mathrm{~nm}$. Der ungefähre Anteil jeder Spezies wurde hierbei über den prozentualen Anteil des entsprechenden Integrals am Gesamtintegral abgeschätzt. Die Zuordnung der Spezies zu bestimmten Molekülen erfolgte durch den Vergleich der HPLC-Retentionszeiten und UV-Absorptionsspektren mit denen parallel in Wasser durchgeführter HPLC-MS-Messungen, durch ESI-FTICR-Untersuchungen der mittels semipräparativer HPLC isolierten Verbindungen und unter Berücksichtigung der UVAbsorption der Nukleobasen bei $\lambda=260 \mathrm{~nm}$.

\subsection{Vergleich der Alkylierung des Oligonukleotides ds-60 durch $(+)-(1 S, 10 R)-34 a$ in Wasser und Phosphatpuffer (pH 7)}

Zunächst wurde die Wechselwirkung des seco-Drugs $(+)-(1 S, 10 R)-34 a$ mit dem DNAOligonukleotid ds-60 in Wasser und Phosphatpuffer (pH 7) untersucht (Abb. 111). Bei den gewählten HPLC-Bedingungen hatte ds-60 eine Retentionszeit von etwa 18 Minuten und das seco-Drug $(+)-(1 S, 10 R)$-34a eine Retentionszeit von 40 Minuten. Das Drug 43a eluierte nach 37 Minuten und das entsprechende Hydrolyseprodukt 84a nach 35 Minuten. 
$\left.\begin{array}{ll}\text { 5'-CGG TCA ATT AGT CGC-3' } & (\mathrm{ON}-1) \\ 3 '-G C C \text { AGT TAA TCA GCG-5' } & (\mathrm{ON}-2)\end{array}\right\}$ ds-60
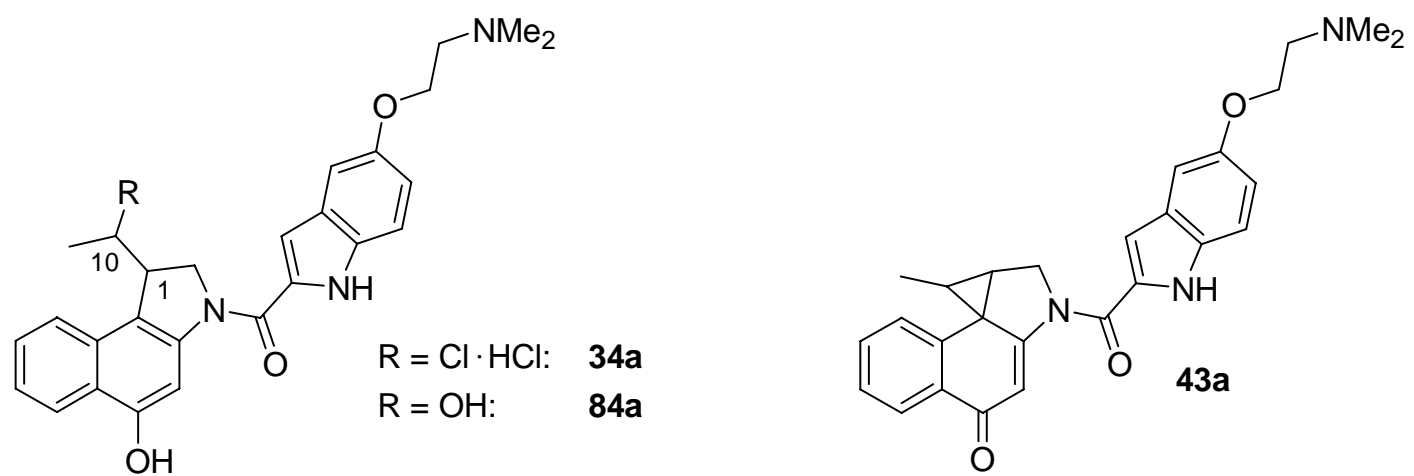

Abb. 111. Struktur des seco-Drugs 34a, des Drugs 43a und des entsprechenden Hydrolyseproduktes 84a sowie Basensequenz des DNA-Doppelstranges ds-60.

Wurde das seco-Drug (+)-(1S,10R)-34a mit dem DNA-Oligonukleotid ds-60 im 1:1Verhältnis in Wasser inkubiert, so konnte eine schnelle Zyklisierung des seco-Drugs zum entsprechenden Drug 43a beobachtet werden (Abb. 112, Tab. 22). Das entstehende Drug reagierte zügig mit dem DNA-Doppelstrang zu dem Addukt ds-60(*) weiter. Dies kann an der Zunahme der Absorption bei $\lambda=350 \mathrm{~nm}$ im Bereich der Retentionszeit der DNA von 18 Minuten abgelesen werden. Bereits nach vier Stunden Inkubation konnte weder ungebundenes seco-Drug, ungebundenes Drug noch Hydrolyseprodukt 84a detektiert werden. Das gesamte seco-Drug hatte somit zum Addukt ds-60 ${ }^{(*)}$ abreagiert, dessen Retentionszeit der Retentionszeit der DNA ds-60 zu Beginn des Experimentes entspricht (Abb. 113).

\begin{tabular}{cccc}
\hline $\boldsymbol{t}[\mathbf{h}]$ & $\mathbf{d s - 6 0}^{(*)}[\mathbf{\%}]$ & $\mathbf{4 3 a}[\%]$ & $(\mathbf{1 S}, \mathbf{1 0 R})-34 \mathbf{a}[\%]$ \\
\hline 0 & - & 17 & 83 \\
1 & 59 & 8 & 33 \\
2 & 87 & - & 13 \\
3 & 96 & - & 4 \\
4 & 100 & - & - \\
\hline $\boldsymbol{t}_{\mathbf{R}}[\mathbf{m i n}]$ & 18.3 & 36.7 & 40.4 \\
\hline
\end{tabular}

Tab. 22. Prozentualer Anteil der Verbindungen und Retentionszeiten $t_{\mathrm{R}}$ nach Inkubation des DNA-Oligonukleotides ds-60 mit (+)-(1S,10R)-34a in Wasser (pH 7). 


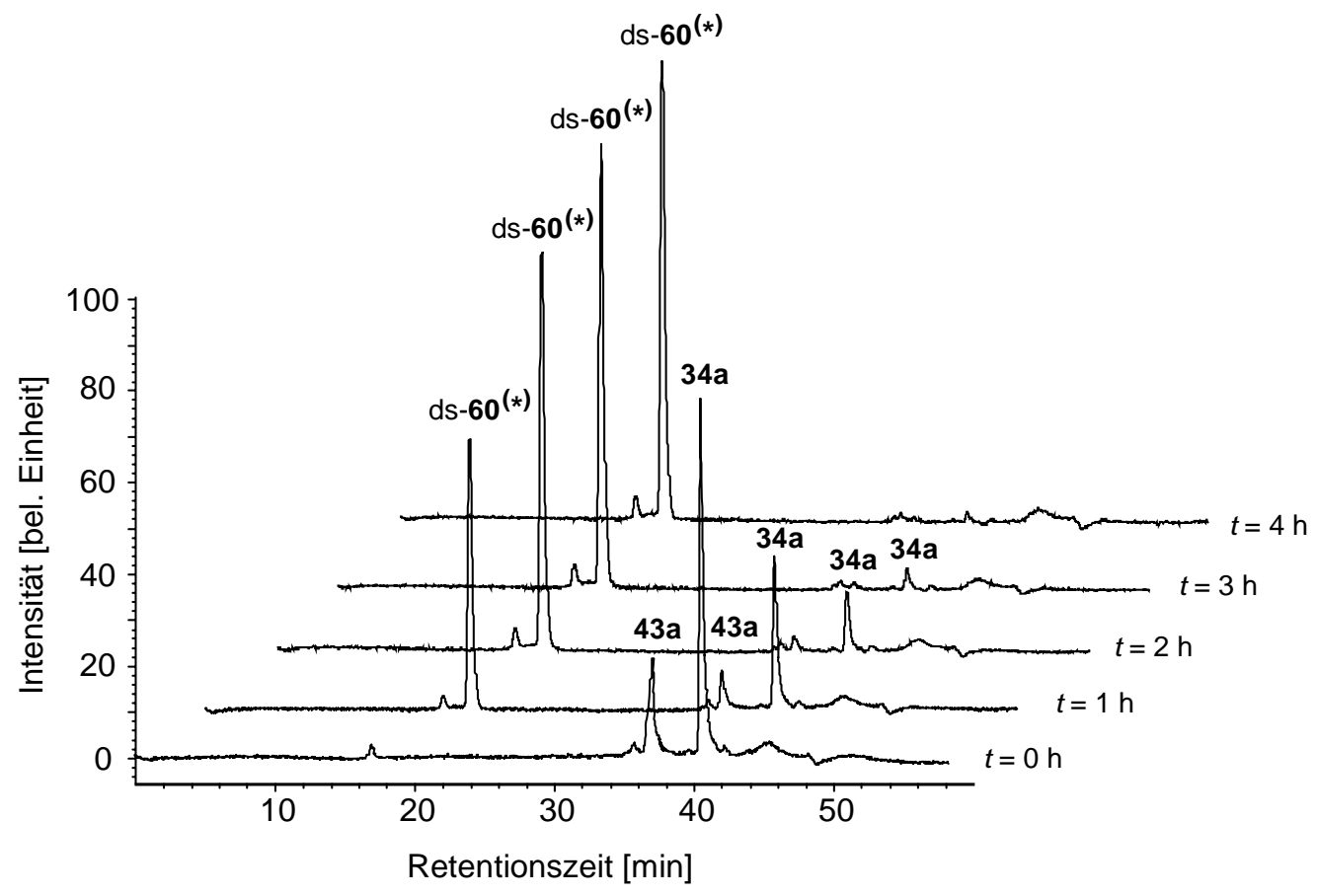

Abb. 112. HPLC-Chromatogramme der Reaktionslösungen nach Inkubation des DNA-Oligonukleotides ds-60 mit (+)-(1S,10R)-34a in Wasser (pH 7). $\lambda=350 \mathrm{~nm}$.

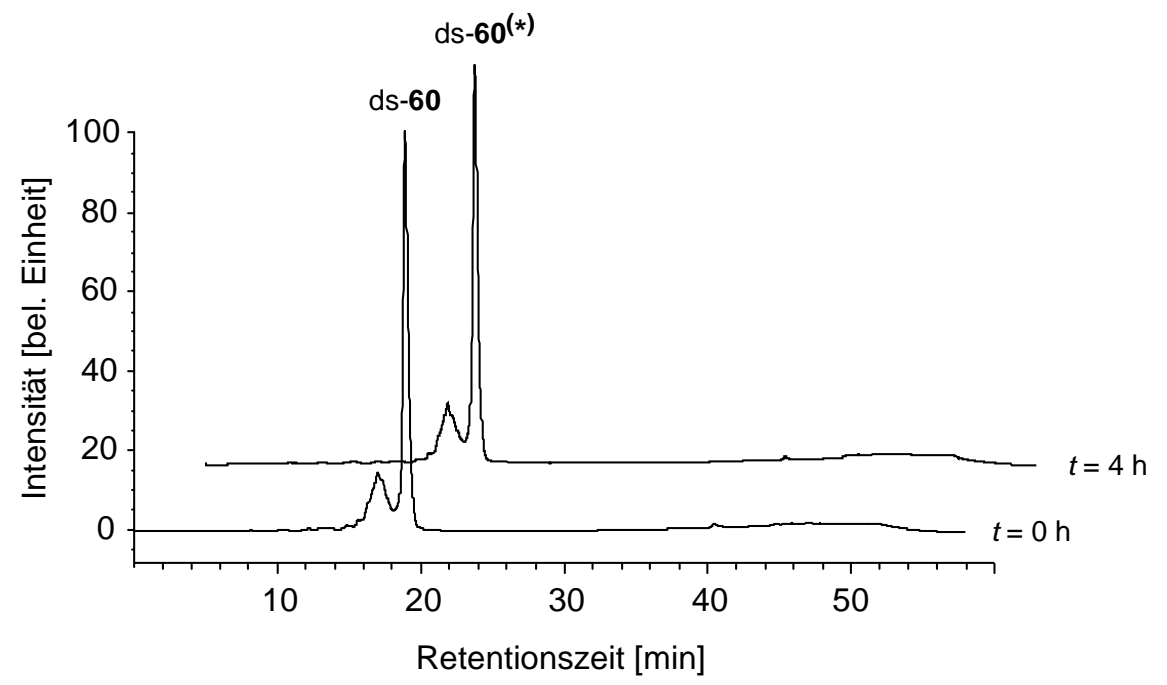

Abb. 113. HPLC-Chromatogramme der Reaktionslösungen nach Inkubation des DNA-Oligonukleotides ds-60 mit (+)-(1S,10R)-34a in Wasser (pH 7). $\lambda=260 \mathrm{~nm}$.

$\mathrm{Da}$ in massenspektrometrischen Untersuchungen nachgewiesenen wurde, dass die Alkylierung in Wasser mit einer Geschwindigkeit von etwa 10\% pro Stunde erfolgt (Kap. 6.1), handelt es sich bei dem beobachteten Addukt ds-60 ${ }^{(*)}$ zunächst vorwiegend um einen nicht-kovalenten Komplex des Drugs mit der DNA, dessen kovalenter Anteil mit längerer Inkubationszeit zunimmt. Somit bleiben unter den gewählten chromatographischen Bedingungen sowohl die nicht-kovalenten Wechselwirkungen zwischen 
den Oligonukleotiden als auch jene zwischen dem Wirkstoff und den Oligonukleotiden erhalten. Die identische Retentionszeit lässt zudem vermuten, dass die Einlagerung des Drugs in die kleine Furche der DNA die Struktur des DNA-Doppelstranges nicht gravierend verändert.

Wurde eine analoge Untersuchung in Phosphatpuffer als Lösungsmittel durchgeführt, erfolgten sowohl die Zyklisierung des seco-Drugs zum Drug als auch die anschließende Einlagerung des Drugs in die DNA schneller (Abb. 114, Tab. 23). Nach zwei Stunden Inkubation war bereits das gesamte seco-Drug zu ds-60 ${ }^{(*)}$ umgesetzt.

\begin{tabular}{cccc}
\hline $\boldsymbol{t}[\mathbf{h}]$ & $\mathbf{d s}^{-60^{(*)}}[\mathbf{\%}]$ & $\mathbf{4 3 a}[\mathbf{\%}]$ & $\mathbf{( 1 S , 1 0 R )}-\mathbf{3 4 a}[\mathbf{\%}]$ \\
\hline 0 & - & 26 & 74 \\
1 & 85 & 6 & 9 \\
2 & 100 & - & - \\
3 & 100 & - & - \\
4 & 100 & - & - \\
\hline $\boldsymbol{t}_{\mathbf{R}}[\mathbf{m i n}]$ & 18.9 & 36.7 & 40.4 \\
\hline
\end{tabular}

Tab. 23. Prozentualer Anteil der Verbindungen und Retentionszeiten $t_{\mathrm{R}}$ nach Inkubation des DNA-Oligonukleotides ds-60 mit (+)-(1S,10R)-34a in Phosphatpuffer (pH 7).

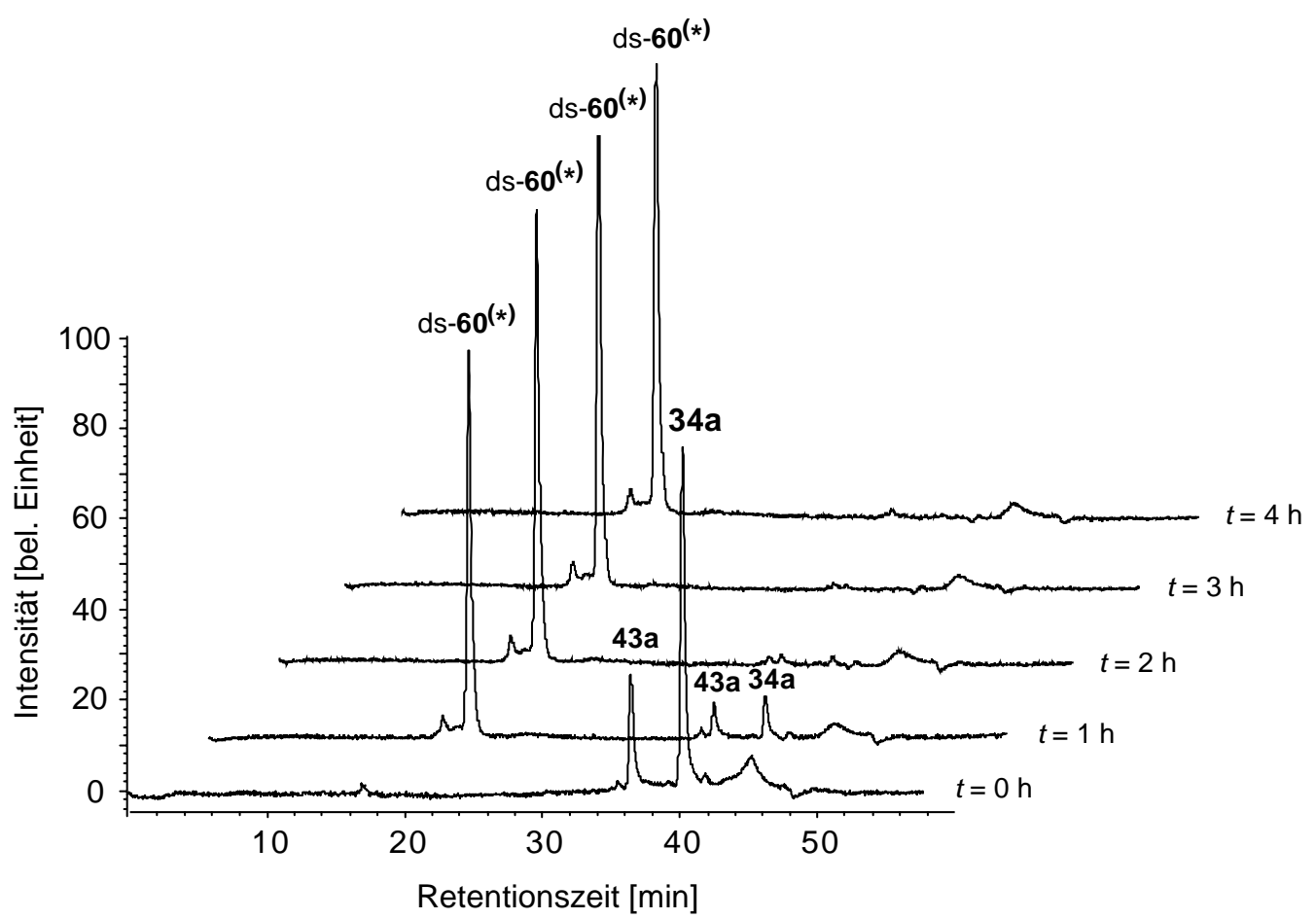

Abb. 114. HPLC-Chromatogramme der Reaktionslösungen nach Inkubation des DNA-Oligonukleotides ds-60 mit $(+)-(1 S, 10 R)-34 a$ in Phosphatpuffer $(\mathrm{pH} 7) . \lambda=350 \mathrm{~nm}$. 
Um zu überprüfen, ob die Pufferkomponenten auch die kovalente Reaktion mit dem DNA-Oligonukleotid beschleunigen, wurden die Reaktionsprodukte der entsprechenden Reaktionslösungen nach einer Stunde bzw. nach fünf Stunden Inkubation in Phospatpuffer $(\mathrm{pH} 7)$ mittels semi-präparativer HPLC isoliert und massenspektrometrisch untersucht.

Tabelle 24 zeigt die Ergebnisse für den isolierten DNA- bzw. DNA-Addukt-Peak ds- $\mathbf{6 0}^{(*)}$ mit $t_{\mathrm{R}}=18 \mathrm{~min}$.

\begin{tabular}{ccccc}
\hline ds-60 & Summenformel & $\begin{array}{c}\text { berechnete } \\
\text { Masse [u] }\end{array}$ & $\begin{array}{c}\text { gefundene } \\
\text { Masse [u] }\end{array}$ & Intensität [\%] \\
\hline ON-1 (ds-60) & $\mathrm{C}_{146} \mathrm{H}_{185} \mathrm{O}_{89} \mathrm{~N}_{55} \mathrm{P}_{14}$ & 4565.80 & 4565.83 & 88 \\
ON-2 (ds-60) & $\mathrm{C}_{146} \mathrm{H}_{184} \mathrm{O}_{87} \mathrm{~N}_{58} \mathrm{P}_{14}$ & 4574.80 & 4575.84 & 100 \\
ON-1* (ds-60, 34a) & $\mathrm{C}_{173} \mathrm{H}_{212} \mathrm{O}_{92} \mathrm{~N}_{58} \mathrm{P}_{14}$ & 5007.00 & 5007.01 & 4 \\
ON-1-A (ds-60) & $\mathrm{C}_{141} \mathrm{H}_{180} \mathrm{O}_{89} \mathrm{~N}_{50} \mathrm{P}_{14}$ & 4430.74 & 4430.75 & 4 \\
\hline
\end{tabular}

Tab. 24. Relative Intensitäten (Intensität des intensivsten Ions $=100 \%$ ) bei ESI-HRMS der Spezies ds-60 ${ }^{(*)}$ (HPLC-Peak mit $t_{\mathrm{R}}=18 \mathrm{~min}$ ) nach $t=1 \mathrm{~h}$ Inkubation des DNA-Doppelstranges ds-60 mit $(+)-(1 S, 10 R)-34 a$ im molaren Verhältnis 1:1 in Phosphatpuffer $(\mathrm{pH} 7)$.

Nach einer Stunde Inkubation konnten im Peak des Adduktes ds-60 $\mathbf{0}^{(*)}$ die beiden Oligonukleotide ON-1 und ON-2, das alkylierte Oligonukleotid ON-1* und selbiges nach Verlust der alkylierten Nukleobase Adenin, d.h. ON-1-A, nachgewiesen werden (Tab. 24). Die etwa 10\%-ige Intensitätsverringerung des ON-1 im Vergleich zu ON-2 weist hierbei auf eine etwa 10\%-ige Alkylierung durch das Drug 43a hin. Zudem beweisen diese Messungen, dass sowohl die unveränderte DNA als auch der alkylierte Doppelstrang die gleiche Retentionszeit aufweisen.

Nach fünf Stunden Inkubation konnten im Peak des Adduktes ds-60 $0^{(*)}$ die beiden Oligonukleotide $\mathbf{O N}-1$ und $\mathbf{O N}-2$, das alkylierte Oligonukleotid nach Verlust der Nukleobase Adenin, d.h. ON-1-A, und die Fragmente $\mathbf{w}_{\mathbf{5}}(\mathbf{O N}-\mathbf{1})$ und $\mathbf{d}_{\mathbf{9}}(\mathbf{O N}-\mathbf{1})$ nachgewiesen werden (Tab. 25). Die Alkylierung des Oligonukleotides beträgt etwa 50\%, da die Intensität von ON-1 um 50\% geringer ist als jene von ON-2. 


\begin{tabular}{ccccc}
\hline ds-60 & Summenformel & $\begin{array}{c}\text { berechnete } \\
\text { Masse [u] }\end{array}$ & $\begin{array}{c}\text { gefundene } \\
\text { Masse [u] }\end{array}$ & Intensität [\%] \\
\hline ON-1 (ds-60) & $\mathrm{C}_{146} \mathrm{H}_{185} \mathrm{O}_{89} \mathrm{~N}_{55} \mathrm{P}_{14}$ & 4565.80 & 4565.87 & 53 \\
ON-2 (ds-60) & $\mathrm{C}_{146} \mathrm{H}_{184} \mathrm{O}_{87} \mathrm{~N}_{58} \mathrm{P}_{14}$ & 4574.80 & 4574.87 & 100 \\
$\mathbf{O N - 1 - A ~ ( d s - 6 0 ) ~}$ & $\mathrm{C}_{141} \mathrm{H}_{180} \mathrm{O}_{89} \mathrm{~N}_{50} \mathrm{P}_{14}$ & 4430.74 & 4430.80 & 4 \\
$\mathbf{w}_{5}(\mathbf{O N}-1$ (ds-60)) & $\mathrm{C}_{48} \mathrm{H}_{63} \mathrm{O}_{32} \mathrm{~N}_{18} \mathrm{P}_{5}$ & 1558.25 & 1557.95 & 10 \\
$\mathbf{d}_{9}(\mathbf{O N}-1$ (ds-60)) & $\mathrm{C}_{88} \mathrm{H}_{133} \mathrm{O}_{56} \mathrm{~N}_{32} \mathrm{P}_{9}$ & 2792.46 & 2792.50 & 3 \\
\hline
\end{tabular}

Tab. 25. Relative Intensitäten (Intensität des intensivsten Ions $=100 \%$ ) bei ESI-HRMS der Spezies ds-60 ${ }^{(*)}$ (HPLC-Peak mit $t_{\mathrm{R}}=18 \mathrm{~min}$ ) nach $t=5 \mathrm{~h}$ Inkubation des DNA-Doppelstranges ds-60 mit $(+)-(1 S, 10 R)-34 a$ im molaren Verhältnis 1:1 in Phosphatpuffer ( $\mathrm{pH} 7)$.

Das Vorkommen der Spezies ON-1*, ON-1-A und der Spaltprodukte $\mathbf{w}_{5}(\mathbf{O N}-\mathbf{1})$ und $\mathbf{d}_{9}$ (ON-1) ist ein eindeutiger Beweis dafür, dass die Alkylierung auch im Phosphatpuffer selektiv am Adenin $\mathrm{A}_{10}(\mathrm{ON}-1)$ erfolgt (Abb. 115). Dass sich das Fragment $\mathbf{d}_{\mathbf{9}}(\mathbf{O N}-1)$ anstelle des bei Fragmentierung im Massenspektrometer beobachteten Fragmentes $\mathbf{a}_{10}-\mathbf{B}_{\mathbf{1 0}}(\mathbf{O N}-1)$ (Abb. 75) bildet, weist zudem auf eine andersartige Fragmentierung des alkylierten Oligonukleotides in wässriger Lösung hin.

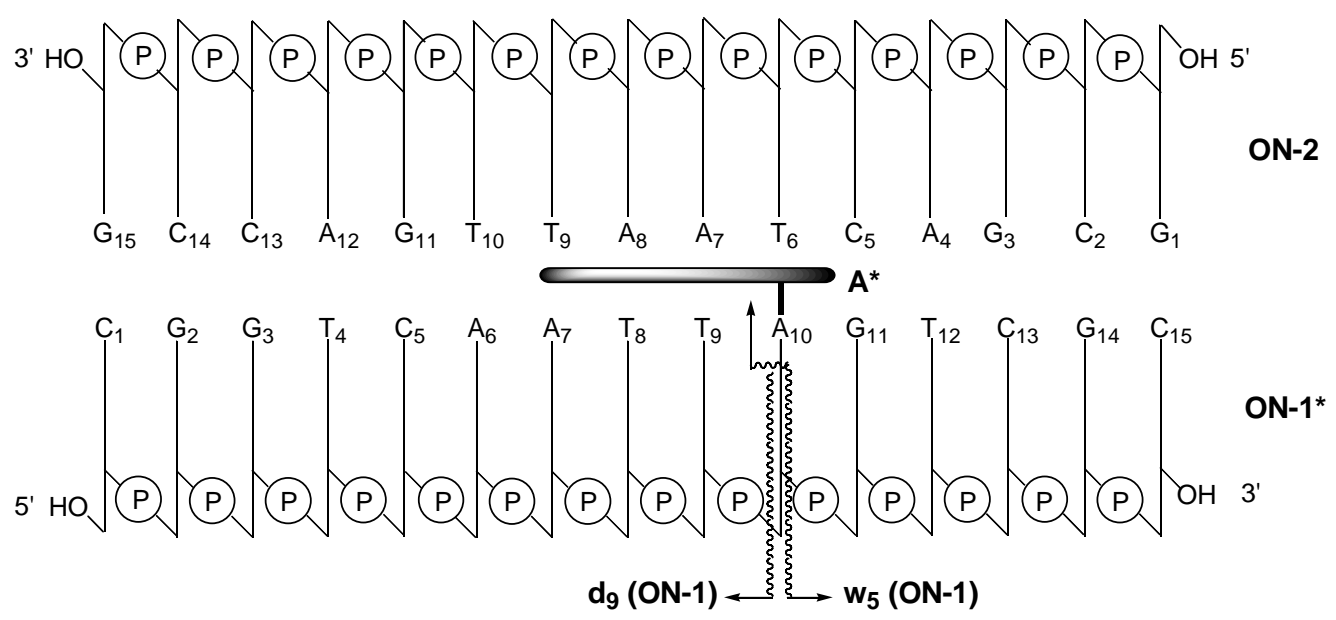

Abb. 115. Fragmentierung des alkylierten Oligonukleotides $\mathbf{O N}-\mathbf{1}^{*}$ in $\mathbf{A}^{*}$, $\mathbf{d}_{9}$ und $\mathbf{w}_{\mathbf{5}}$ in wässrigem Phosphatpuffer ( $\mathrm{pH} 7$ ).

Da die Intensität der Spaltprodukte nicht sehr hoch war, wurde zur Bestätigung der Alkylierungsposition und der andersartigen Fragmentierung in Lösung im Vergleich zur Fragmentierung in der ESI-Quelle ein weiteres Experiment durchgeführt. Hierbei wurde die Reaktionslösung aus ds-60 und $(+)-(1 S, 10 R)-34 a$ im 1:1-Verhältnis nach 
24 Stunden Inkubation in Wasser zwei Stunden auf $95{ }^{\circ} \mathrm{C}$ erhitzt, um eine thermische Depurinierung der alklyierten Nuleobase Adenin im wässrigen Milieu zu bewirken.

Die erhaltenen Produkte wurden dann mittels semi-präparativer HPLC isoliert und massenspektrometrisch analysiert. Abbildung 116 zeigt das HPLC-Chromatogramm mit der durch Massenspektrometrie erfolgten Zuordnung der Spezies (Tabellen der gefundenen und berechneten Massen: s. Experimenteller Teil, Kap. 8.7).

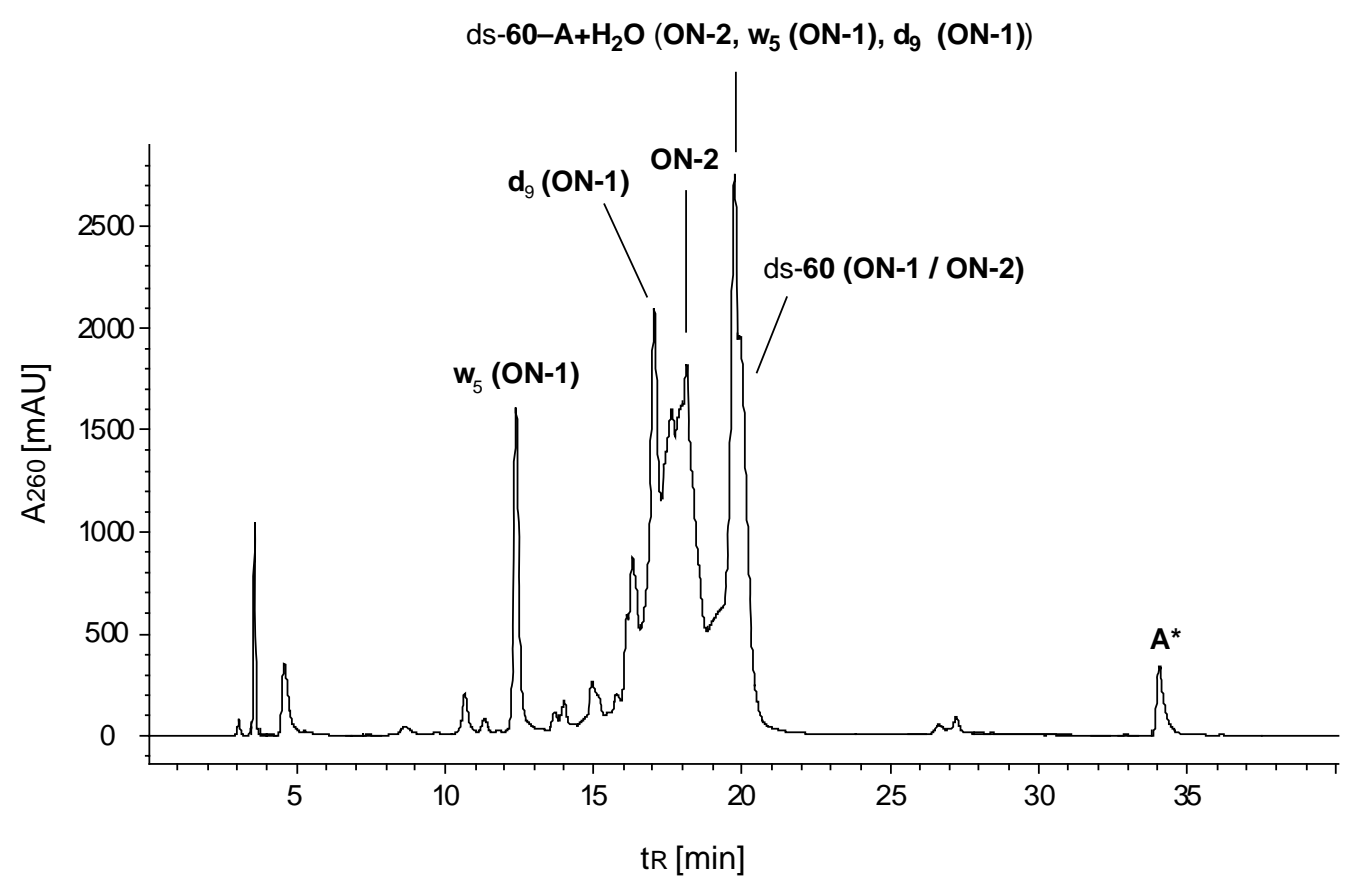

Abb. 116. HPLC-Chromatogramm der Reaktionslösung nach $24 \mathrm{~h}$ Inkubation des DNAOligonukleotides ds-60 mit (+)-(1S,10R)-34a im Verhältnis $1: 1$ in Wasser $\left(T=25^{\circ} \mathrm{C}\right)$ gefolgt von $2 \mathrm{~h}$ Erhitzen der Reaktionsmischung auf $95^{\circ} \mathrm{C}$.

Neben einer Reihe durch das Erhitzen entstandener unspezifischer Fragmente konnten eindeutig die sekundären Spaltprodukte $\mathbf{w}_{\mathbf{5}}(\mathbf{O N}-1)$ und $\mathbf{d}_{\mathbf{9}}(\mathrm{ON}-1)$ sowie das einzelsträngige Oligonukleotid ON-2 nachgewiesen werden. Bei einer Retentionszeit ähnlich der Retentionszeit des Doppelstranges ds-60 (ON-1 / ON-2) wurden zudem $\mathbf{O N}-\mathbf{2}, \mathbf{w}_{\mathbf{5}}(\mathrm{ON}-\mathbf{1})$ und $\mathbf{d}_{\mathbf{9}}(\mathbf{O N}-\mathbf{1})$ detektiert. Da diese Verbindungen einzeln eine geringere Retentionszeit aufweisen und $\mathbf{O N}-\mathbf{1}^{*}$ im Massenspektrometer anders fragmentiert, entspricht dieser Peak dem alkylierten Doppelstrang nach Verlust der Nukleobase Adenin, d.h. ds-60-A+ $+\mathbf{H}_{2} \mathbf{O}$, entsprechend $\mathbf{O N}-\mathbf{1}-\mathbf{A}+\mathbf{H}_{2} \mathbf{O} / \mathbf{O N}-2$. Bei einer Retentionszeit von 34 Minuten wurde zudem $\mathbf{A}^{*}$ nachgewiesen. Eine Alkylierung an $\mathrm{A}_{10}(\mathrm{ON}-1)$ ist demzufolge eindeutig belegt. 
Die Fragmentierung in Lösung (Abb. 117) verläuft somit etwas anders als diejenige im Massenspektrometer, bei der $\mathbf{O N}-\mathbf{1}-\mathbf{A}, \mathbf{a}_{\mathbf{1 0}}-\mathbf{B}_{\mathbf{1 0}}(\mathbf{O N}-\mathbf{1})$ und $\mathbf{w}_{\mathbf{5}}(\mathbf{O N}-\mathbf{1})$ entstehen (Abb. 75). Im ersten Schritt wird in Lösung unter intermediärer Beteiligung der Sauerstoffs der Desoxyriboseeinheit die alkylierte Nukleobase $\mathbf{A}^{*}$ abgespalten und Wasser greift nukleophil an (Abb. 117). Im primären Spaltprodukt $\mathbf{O N}-\mathbf{1}-\mathbf{A}+\mathbf{H}_{\mathbf{2}} \mathbf{O}$ stellt sich dann ein Gleichgewicht zwischen der geschlossenen Halbacetalform der Desoxyribose und der entsprechenden offenen Aldehydform ein. Aus letzterer erfolgt unter 1,2-Eliminierung des charakteristischen sekundären Fragmentes $\mathbf{w}_{\mathbf{5}}(\mathbf{O N}-\mathbf{1})$ ein Strangbruch unter Bildung des $\alpha, \beta$-ungesättigten Aldehydes 95 .

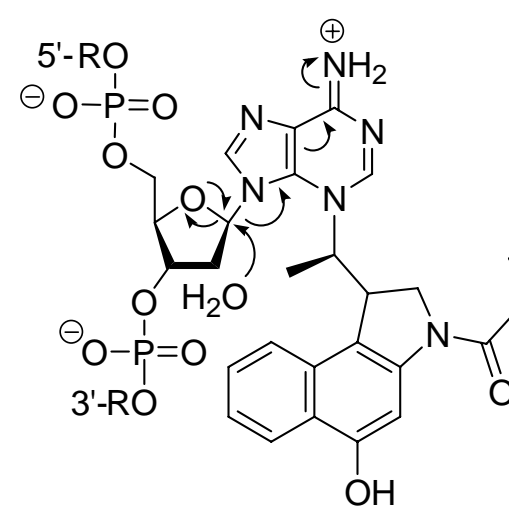

ON-1*

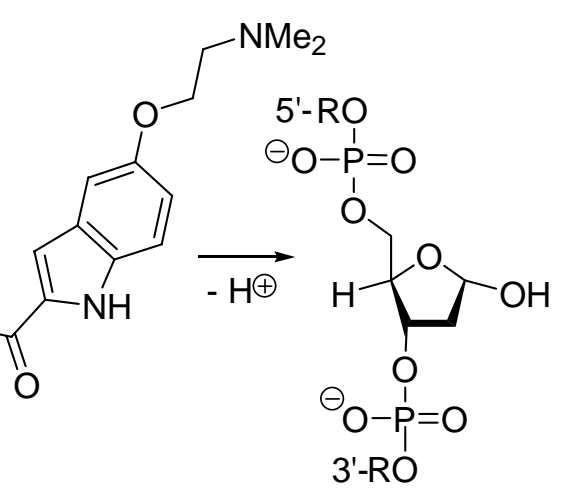

$\mathrm{ON}-1-\mathrm{A}+\mathrm{H}_{2} \mathrm{O}$<smiles>CNCCOc1ccc2[nH]c(C(=O)N3CC([C@H](C)n4cnc(N)c5ncnc4-5)c4c3cc(O)c3ccccc43)cc2c1</smiles>

$A^{*}$

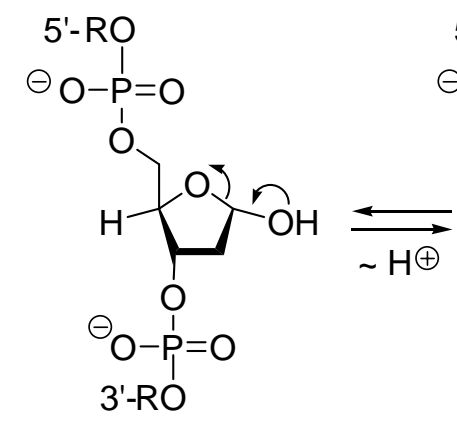

$\mathrm{ON}-1-\mathrm{A}+\mathrm{H}_{2} \mathrm{O}$

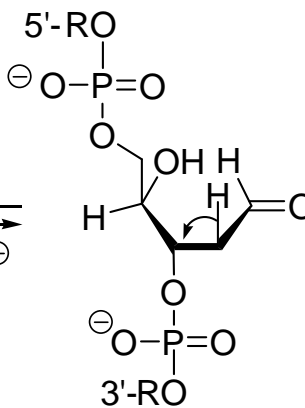

$\mathrm{ON}-1-\mathrm{A}+\mathrm{H}_{2} \mathrm{O}$

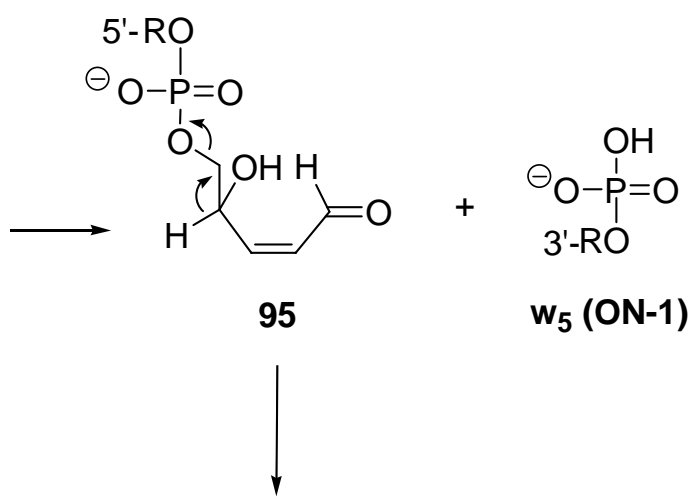

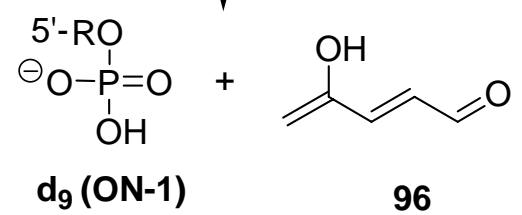

Abb. 117. Fragmentierung des alkylierten Oligonukleotides $\mathbf{O N}-1 *$ in das primäre Spaltprodukt $\mathbf{O N}-1-\mathbf{A}+\mathbf{H}_{2} \mathbf{O}$ und die alkylierte Base $\mathbf{A}^{*}$, Strangbruch in $\mathbf{O N}-\mathbf{1}-\mathbf{A}+\mathbf{H}_{2} \mathbf{O}$ unter Bildung des charakteristischen sekundären Spaltproduktes $\mathbf{w}_{\mathbf{5}}(\mathbf{O N}-\mathbf{1})$ und des Intermediates 95, das zu d9 (ON-1) und 96 fragmentiert. 
Der Aldehyd 95 wiederum zerfällt unter 1,2-Eliminierung in das charakteristische Fragment $\mathbf{d}_{\mathbf{9}}(\mathbf{O N}-1)$ und das Enol 96. $\mathbf{O N}-\mathbf{1}-\mathbf{A}+\mathbf{H}_{2} \mathrm{O}$ kann hierbei aufgrund seiner Instabilität nicht massenspektrometrisch nachgewiesen werden. Stattdessen entsteht aus restlichem ON-1* im Massenspektrometer das Fragment ON-1-A.

Der Erhalt der nicht-kovalenten Wechselwirkungen zwischen den Oligonukleotiden des Doppelstranges ds-60 sowie zwischen dem Drug 43a und dem DNA-Doppelstrang während der analytischen HPLC wurde in der Folge dazu genutzt, die postulierte Einlagerung zweier Drug-Moleküle pro Doppelstrang (s. Kap. 7) nachzuweisen. Hierzu wurde der Doppelstrang ds-60 sowohl in Wasser als auch in Phosphatpuffer mit dem seco-Drug $(+)-(1 S, 10 R)-34 \mathbf{a}$ in den molaren Verhältnissen 1:1 bis 1:5 für 24 Stunden inkubiert. Die Reaktionsmischungen wurden anschließend mittels analytischer HPLC untersucht.

Bei einer 1:1-Umsetzung in Wasser reagierte innerhalb von 24 Stunden nahezu das gesamte seco-Drug (+)-(1S,10R)-34a mit der DNA zu dem nicht-kovalenten bzw. kovalenten Addukt ds-60 ${ }^{(*)}$ (Tab. 26). Bei einer 1:2-Umsetzung reagierten 90\%, während 10\% zum Hydrolyseprodukt 84a inaktiviert wurden. Dies zeigt, dass nahezu zwei Äquivalente des Drugs an den DNA-Doppelstrang banden. Die Retentionszeiten der freien DNA und beider DNA-Addukte waren hierbei erstaunlicherweise gleich.

\begin{tabular}{|c|c|c|c|c|}
\hline$(1 S, 10 R)-34 a / d s-60$ & $\begin{array}{c}d s-60^{(*)}(34 a) \\
{[\%]} \\
\end{array}$ & $\begin{array}{c}d s-60 * *(34 a) \\
{[\%]} \\
\end{array}$ & $\begin{array}{l}43 a \\
{[\%]}\end{array}$ & $\begin{array}{l}84 a \\
{[\%]}\end{array}$ \\
\hline $1: 1$ & 99 & - & - & 1 \\
\hline $2: 1$ & 90 & - & - & 10 \\
\hline $3: 1$ & 71 & 2 & - & 27 \\
\hline $4: 1$ & 55 & 3 & - & 42 \\
\hline $5: 1$ & 46 & 3 & - & 51 \\
\hline$t_{\mathrm{R}}[\min ]$ & 18.3 & 25.0 & - & 35.6 \\
\hline
\end{tabular}

Tab. 26. Prozentualer Anteil der Verbindungen und Retentionszeiten $t_{\mathrm{R}}$ nach $24 \mathrm{~h}$ Inkubation des DNA-Oligonukleotides ds-60 mit (+)-(1S,10R)-34a in Wasser (pH 7).

Wurde der Überschuss des seco-Drugs bis auf das fünffache erhöht, so banden jeweils etwa zwei der bis zu fünf Äquivalente. Zudem traten geringe Spuren eines doppelt alkylierten Oligonukleotides ds-60** auf, welches eine deutlich höhere Retentionszeit aufwies. Da in ds-60** beide Bindungen zu dem Drug kovalent sind, ist die Konformation des Doppelstranges vermutlich signifikant verändert. 
In Phosphatpuffer als Medium war die Zyklisierung des seco-Drugs (+)-(1S,10R)-34a zum Drug 43a schneller. Vermutlich lagerten daher bis zu zwei Äquivalente des Drugs in den Doppelstrang ein, ohne dass das Drug durch Hydrolyse inaktiviert wurde (Tab. 27). Wurde der Überschuss des seco-Drugs auf drei bis fünf Äquivalente erhöht, so banden jeweils etwa zwei der bis zu fünf Äquivalente unter Ausbildung des nichtkovalenten bzw. kovalenten Adduktes ds-60 ${ }^{(*)}$. Mit höherem Drug-Überschuss nahm zudem merklich der Anteil des doppelt alkylierten Doppelstranges ds-60** zu. Die Reaktivität des Wirkstoffs ist demzufolge in Puffer gegenüber der Reaktion in Wasser erhöht.

\begin{tabular}{ccccc}
\hline $\mathbf{1 S}, \mathbf{1 0 R})-\mathbf{3 4 a}$ / ds-60 & $\begin{array}{c}\mathbf{d s - 6 0}^{(*)}(\mathbf{3 4 a}) \\
{[\%]}\end{array}$ & $\begin{array}{c}\mathbf{d s - 6 0}^{(* *)}(\mathbf{3 4 a}) \\
{[\%]}\end{array}$ & $\begin{array}{c}\mathbf{4 3 a} \\
{[\%]}\end{array}$ & $\begin{array}{c}\mathbf{8 4 a} \\
{[\%]}\end{array}$ \\
\hline $1: 1$ & 100 & - & - & - \\
$2: 1$ & 100 & - & - & - \\
$3: 1$ & 73 & 15 & - & 12 \\
$4: 1$ & 53 & 27 & - & 20 \\
$5: 1$ & 43 & 32 & - & 26 \\
\hline $\boldsymbol{t}_{\mathbf{R}}[\mathbf{m i n}]$ & 18.4 & 25.1 & - & 35.5 \\
\hline
\end{tabular}

Tab. 27. Prozentualer Anteil der Verbindungen und Retentionszeiten $t_{\mathrm{R}}$ nach $24 \mathrm{~h}$ Inkubation des DNA-Oligonukleotides ds-60 mit (+)-(1S,10R)-34a in Phosphatpuffer (pH 7).

Um zu beweisen, dass es sich bei dem Peak mit einer Retentionszeit von 25 Minuten tatsächlich um den doppelt alkylierten Doppelstrang ds-60** handelte, wurde eine Mischung des DNA-Oligonukleotides ds-60 mit (+)-(1S,10R)-34a im Verhältnis 1:5 24 Stunden in Phosphatpuffer inkubiert, mittels semi-präparativer HPLC aufgetrennt und das Eluat des interessierenden Peaks mit Hilfe hochauflösender Massenspektrometrie untersucht (Tab. 28).

\begin{tabular}{ccccc}
\hline ds-60**(34a) & Summenformel & $\begin{array}{c}\text { berechnete } \\
\text { Masse [u] }\end{array}$ & $\begin{array}{c}\text { gefundene } \\
\text { Masse [u] }\end{array}$ & $\begin{array}{c}\text { Intensität } \\
{[\%]}\end{array}$ \\
\hline ON-2 (ds-60) & $\mathrm{C}_{146} \mathrm{H}_{184} \mathrm{O}_{87} \mathrm{~N}_{58} \mathrm{P}_{14}$ & 4574.80 & 4574.84 & 100 \\
$\mathbf{O N - 1 * * ( d s - 6 0 , 3 4 a )}$ & $\mathrm{C}_{200} \mathrm{H}_{239} \mathrm{O}_{95} \mathrm{~N}_{61} \mathrm{P}_{14}$ & 5448.21 & 5448.29 & 29 \\
$\mathbf{w}_{\mathbf{5}}(\mathbf{O N - 1}$ (ds-60)) & $\mathrm{C}_{48} \mathrm{H}_{63} \mathrm{O}_{32} \mathrm{~N}_{18} \mathrm{P}_{5}$ & 1558.25 & 1558.26 & 25 \\
\hline
\end{tabular}

Tab. 28. Intensitäten bei ESI-HRMS der Spezies ds-60** (HPLC-Peak mit $t_{\mathrm{R}}=25 \mathrm{~min}$ ) nach $24 \mathrm{~h}$ Inkubation des DNA-Doppelstranges ds-60 mit $(+)-(1 S, 10 R)-\mathbf{3 4 a}$ im molaren Verhältnis 1:5 in Phosphatpuffer ( $\mathrm{pH} 7)$. 
Hierbei konnten sowohl das doppelt alkylierte Oligonkleotid ON-1** als auch das unveränderte Oligonukleotid ON-2 detektiert werden. Aufgrund der mehrfachen Alkylierung zerfiel $\mathbf{O N}-1 * *$ während der massenspektrometrischen Untersuchung in viele Fragmente, von denen als einziges $\mathbf{w}_{\mathbf{5}}(\mathbf{O N}-\mathbf{1})$ deutlich zu erkennen war.

Insgesamt ergaben die Untersuchungen der Wechselwirkungen des DNA-Oligonukleotides ds-60 mit (+)-(1S,10R)-34a, dass die Zyklisierung zum Drug und dessen nicht-kovalente Einlagerung in den Doppelstrang sehr schnell erfolgt und die anschließende Ausbildung einer kovalenten Bindung deutlich langsamer ist. In Puffer als Lösungsmittel bildet sich das nicht-kovalente Addukt etwas schneller als in Wasser. Dies ist im Wesentlichen wohl darauf zurückzuführen, dass die Zyklisierung zum Drug im Puffer schneller ist als in Wasser. Die Reaktion zum kovalenten Alkylierungsprodukt erfolgt jedoch mit etwa $10 \%$ pro Stunde in beiden Lösungsmitteln etwa gleich schnell. Weiterhin können sowohl in Wasser als auch in Puffer etwa zwei Drug-Moleküle an einen DNA-Doppelstrang binden. Eine dadurch verursachte Aufweitung der kleinen Furche oder eine sterische Behinderung könnte die Verringerung der Alkylierungseffizienz bei einer Inkubation mit einem zweifachen Überschuss an seco-Drug erklären (s. Kap. 6.1).

Die Bindung des Naturstoffs CC-1065 (18) an doppelsträngige DNA führt zu einer Erhöhung der Schmelztemperatur doppelsträngiger DNA und somit zu einer Stabilisierung des DNA-Doppelstranges (s. Kap. 4.2). Wurde das doppelsträngige DNAOligonukleotid ds-60 mit dem seco-Drug $(+)-(1 S, 10 R)$-34a im Verhältnis 1:1 inkubiert, so konnte nach einer 24-stündigen Inkubation eine geringfügige Erhöhung der Schmelztemperatur der DNA gleichbedeutend mit einer Verschiebung des Wendepunktes der Schmelzkurven von $T_{\mathrm{m}}=56{ }^{\circ} \mathrm{C}$ (ds-60) auf $T_{\mathrm{m}}=59{ }^{\circ} \mathrm{C}$ (ds-60/(+)$(1 S, 10 R)-34 \mathbf{a}=1: 1)$ und somit ebenfalls eine Stabilisierung des DNA-Doppelstranges beobachtet werden (Abb. 118).

Beide Kurven zeigen den typischen sigmoidalen Kurvenverlauf der als Hyperchromizität bezeichneten relativen UV-Absorptionszunahme in Abhängigkeit von der Temperatur. Die Zunahme der UV-Absorption der Nukleobasen wird durch die kooperative Entstapelung der Basen infolge des Aufbrechens des geordneten DNADoppelstranges in die Einzelstränge hervorgerufen. Die Schmelztemperatur entspricht hierbei der halbmaximalen Hyperchromizität und somit der Temperatur, bei der die Hälfte der DNA in Form von Einzelsträngen vorliegt. 


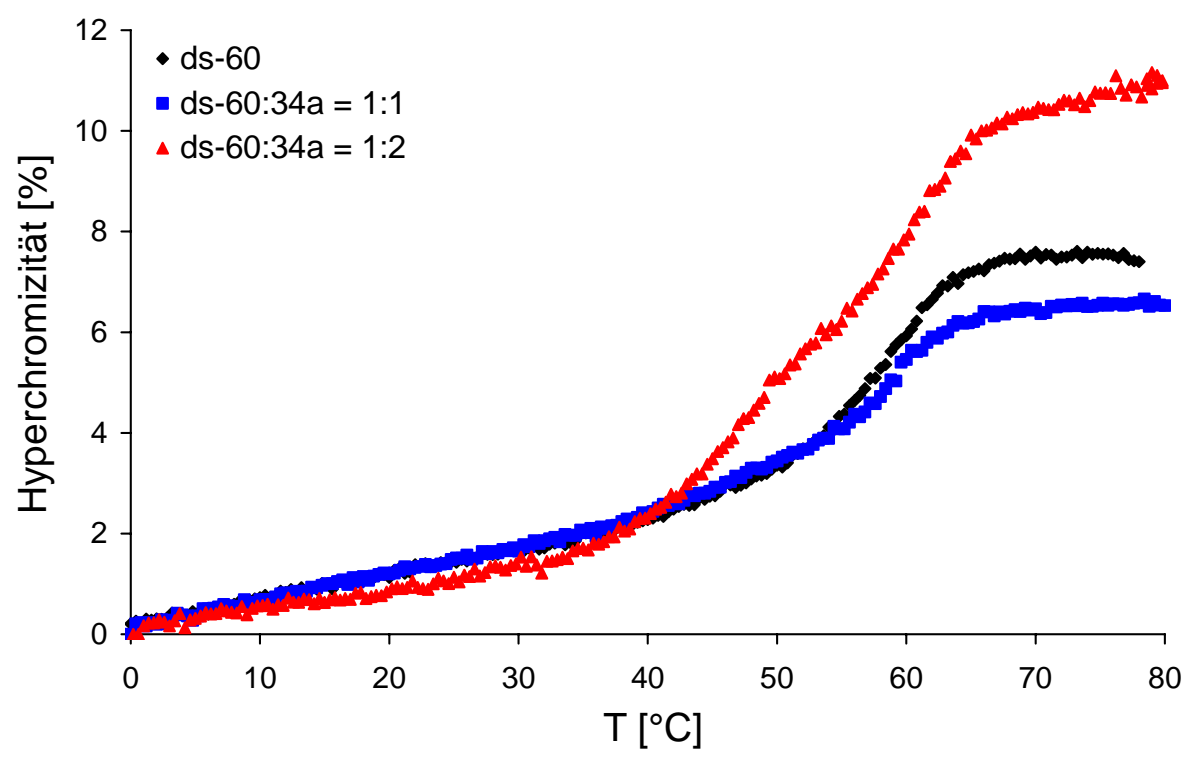

Abb. 118. Temperaturabhängige relative UV-Absorption (Hyperchromizität) des doppelsträngigen DNA-Oligonukleotides ds-60 oder einer Mischung von ds-60 und dem seco-Drug $(+)-(1 S, 10 R)-34 a$ im molaren Verhältnis 1:1 bzw. 1:2 nach 24-stündiger Inkubation in wässrigem Phosphatpuffer ( $\mathrm{pH} 7$ ). Die Konzentration des doppelsträngigen DNA-Oligonukleotides betrug jeweils $6 \mu \mathrm{M}$.

Die Schmelzkurve bei Inkubation des doppelsträngigen DNA-Oligonukleotides ds-60 mit dem seco-Drug $(+)-(1 S, 10 R)-34 a$ im molaren Verhältnis 1:2 weist im Gegensatz $\mathrm{zu}$ den bereits diskutierten Kurven einen doppelt-sigmoidalen Verlauf auf, d.h. es treten zwei kooperative Übergänge und damit zwei Wendepunkte $\left(T_{\mathrm{m}}=47^{\circ} \mathrm{C}, 61^{\circ} \mathrm{C}\right)$ auf. Dies kann auf das Vorliegen zweier Spezies in der Reaktionslösung zurückgeführt werden: Die erhöhte Schmelztemperatur ist vermutlich auf die Stabilisierung des Doppelstranganteils zurückzuführen, der mit dem aus $(+)-(1 S, 10 R)-34 a$ in situ entstehenden Drug zu einem kovalenten Addukt abreagiert hat (etwa 50\%, s. Kap. 6.5). Die erniedrigte Schmelztemperatur des zweiten DNA-Doppelstranganteils ist dann ein Indiz für eine Destabilisierung, die durch die Einlagerung zweier Äquivalente des Drugs in die anderen DNA-Doppelstränge verursacht wird. Diese Oligonukleotide haben vermutlich nicht zu einem kovalenten Addukt weiterreagiert, da zwei eingelagerte Moleküle des Drugs die Furchengeometrie verändern und eine günstige Anordnung der Reaktanden für die Alkylierungsreaktion verhindern. 


\subsection{Vergleich der Alkylierung des Oligonukleotides ds-60 durch $(+)-(1 S, 10 R)-34 \mathrm{a},(+)-(1 S, 10 R)-34 \mathrm{~b},(+)-(1 S)-56 \mathrm{a}$ und $(+)-(1 S)-56 \mathrm{~b}$}

Die seco-CBI-Derivate (+)-(1S)-56a,b sind etwa 30-60-fach toxischer als die Methylseco-CBI-Verbindungen $(+)-(1 S, 10 R)-34 a, b$. Allerdings alkylieren die seco-CBIDerivate doppelsträngige DNA innerhalb einer Inkubationszeit von 24 Stunden mit geringerer Effizienz als die Methyl-seco-CBI-Derivate (s. Kap. 6.5, Abb. 119). HPLCbasierte Untersuchungen sollten die Frage klären, ob sich die seco-Drugs in ihrer Zyklisierungsgeschwindigkeit und/oder der Geschwindigkeit der Bildung nichtkovalenter oder kovalenter Addukte mit der DNA unterscheiden.
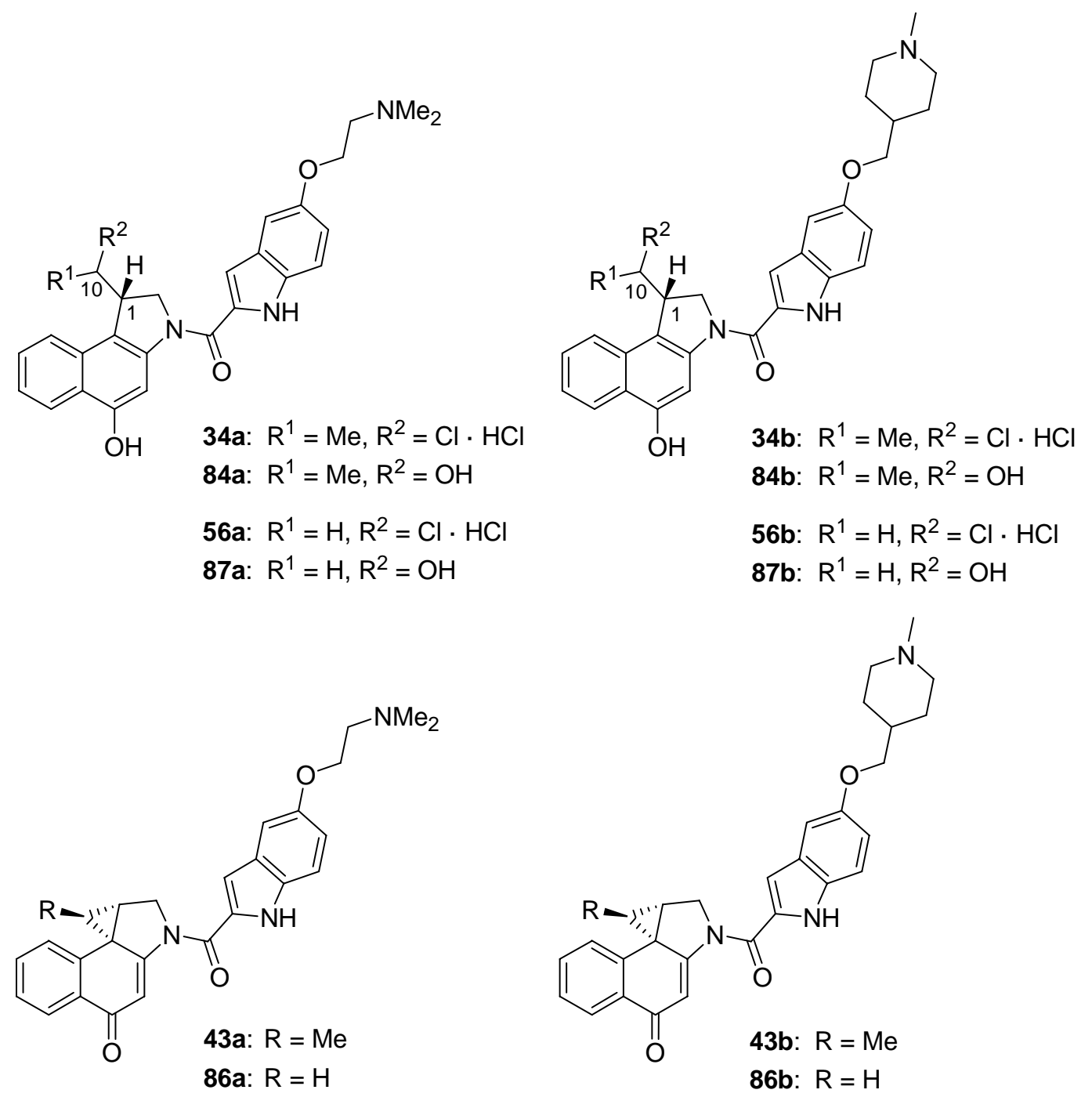

Abb. 119. Methyl-seco-CBI- und seco-CBI-Derivate mit DMAI- oder MPI-DNA-bindender Einheit sowie deren entsprechende Drugs und Hydrolyseprodukte.

Zunächst wurde die Kinetik der Wechselwirkung der seco-Drugs mit dem DNAOligonukleotid ds-60 in Phosphatpuffer $(\mathrm{pH} 7)$ für ein 1:1-Verhältnis der Wirkstoffe 
zur DNA untersucht. Tabelle 29 zeigt die relativen Intensitäten der seco-Drugs, Drugs und kovalenten bzw. nicht-kovalenten DNA-Addukte für einen Inkubationszeitraum von bis zu sechs Stunden.

$$
\text { (+)-(1S,10R)-34a: }
$$

\begin{tabular}{cccc}
\hline $\boldsymbol{t}[\mathbf{h}]$ & $\mathbf{d s - 6 0}^{(*)}(\mathbf{3 4 a})[\%]$ & $\mathbf{4 3 a}[\%]$ & $\mathbf{( 1 S , 1 0 R ) - 3 4 a ~ [ \% ] ~}$ \\
\hline 0 & - & 22 & 78 \\
2 & 100 & - & - \\
4 & 100 & - & - \\
6 & 100 & - & - \\
\hline $\boldsymbol{t}_{\mathbf{R}}[\mathbf{m i n}]$ & 20.4 & 39.2 & 43.3 \\
\hline
\end{tabular}

$(+)-(1 S, 10 R)-\mathbf{3 4 b}$ :

\begin{tabular}{cccc}
\hline $\boldsymbol{t}[\mathbf{h}]$ & $\mathbf{d s - 6 0}^{(*)}(\mathbf{3 4 b})[\%]$ & $\mathbf{4 3 b}[\mathbf{\%}]$ & $\mathbf{( 1 S , 1 0 R ) - 3 4 b ~ [ \% ]}$ \\
\hline 0 & - & 11 & 89 \\
2 & 100 & - & - \\
4 & 100 & - & - \\
6 & 100 & - & - \\
\hline $\boldsymbol{t}_{\mathrm{R}}[\mathbf{m i n}]$ & 20.1 & 42.7 & 46.5 \\
\hline
\end{tabular}

$(+)-(1 S)-56 a:$

\begin{tabular}{cccc}
\hline $\boldsymbol{t}[\mathbf{h}]$ & $\mathbf{d s - 6 0}^{(*)} \mathbf{( 5 6 a )}[\mathbf{[ \% ]}$ & $\mathbf{8 6 a}[\mathbf{\%}]$ & $\mathbf{( 1 S )}-\mathbf{5 6 a}[\mathbf{\%}]$ \\
\hline 0 & - & 26 & 74 \\
2 & 35 & 20 & 45 \\
4 & 67 & 14 & 19 \\
6 & 88 & 0 & 12 \\
\hline $\boldsymbol{t}_{\mathbf{R}}[\mathbf{m i n}]$ & 18.8 & 40.9 & 46.0 \\
\hline
\end{tabular}

$(+)-(1 S)-56 \mathbf{b}$ :

\begin{tabular}{|c|c|c|c|}
\hline$t[\mathrm{~h}]$ & ds-60 $0^{(*)}(56 b)[\%]$ & $86 b[\%]$ & $(1 S)-56 \mathrm{~b}[\%]$ \\
\hline 0 & - & 24 & 76 \\
\hline 2 & 29 & 20 & 51 \\
\hline 4 & 49 & 17 & 34 \\
\hline 6 & 62 & 19 & 19 \\
\hline$t_{\mathrm{R}}[\min ]$ & 18.6 & 44.4 & 49.9 \\
\hline
\end{tabular}

Tab. 29. Prozentualer Anteil der Verbindungen und Retentionszeiten $t_{\mathrm{R}}$ nach Inkubation des DNA-Oligonukleotides ds-60 mit den Methyl-seco-CBI-Derivaten $(+)-(1 S, 10 R)-\mathbf{3 4 a}, \mathbf{b}$ und den seco-CBI-Derivaten $(+)-(1 S)-\mathbf{5 6 a}, \mathbf{b}$ in Phosphatpuffer $(\mathrm{pH} 7)$. 
Während die beiden Methyl-seco-CBI-Derivate $(+)-(1 S, 10 R)-34 \mathbf{a}, \mathbf{b}$ innerhalb von zwei Stunden vollständig zu den jeweiligen nicht-kovalenten bzw. kovalenten DNAAddukten ds-60 ${ }^{(*)}$ umgesetzt wurden, war die Bildung der entsprechenden DNAAddukte im Fall der seco-CBI-Derivate $(+)-(1 S)$-56a,b deutlich langsamer und nach sechs Stunden noch nicht abgeschlossen. Bemerkenswert war, dass die seco-CBIHydrochloride $(+)-(1 S)-56 \mathbf{6}, \mathbf{b}$ ähnlich wie die anti-Methyl-seco-CBI-Hydrochloride $(+)-(1 S, 10 R)-34 a, b$ direkt nach dem Ansetzen der Reaktionslösungen im Puffer sehr schnell zu den entsprechenden Drugs zyklisierten, so dass innerhalb der kurzen Zeit ( $<$ fünf Minuten) bis zum Start der HPLC-Messungen eine bis zu 25\%-ige Umsetzung zum entsprechenden Drug erfolgt war. Während die anti-Methyl-seco-CBI-Hydrochloride $(+)-(1 S, 10 R)-\mathbf{3 4 a}, \mathbf{b}$ in den folgenden zwei Stunden vollständig zu nicht-kovalenten und kovalenten Addukten mit der DNA abreagierten, war dies für die seco-CBIHydrochloride $(+)-(1 S)-\mathbf{5 6 a}, \mathbf{b}$ nicht der Fall. Hier waren nach zwei Stunden noch etwa 50\% seco-Drug zu beobachten und nach sechs Stunden immer noch etwa 15\%. Auch das Drug konnte bis zu sechs Stunden nach dem Beginn der Inkubation noch nachgewiesen werden.

Da das seco-CBI-Derivat (+)-(1S)-56a in HPLC-MS-Studien in Abwesenheit der DNA in Phosphatpuffer ( $\mathrm{pH}$ 7.4) innerhalb von einer Stunde zu nahezu 90\% zyklisierte, ${ }^{159}$ muss die hier beobachtete erniedrigte Zyklisierungsgeschwindigkeit auf die Anwesenheit der DNA zurückzuführen sein. Eine Erklärung hierfür könnte sein, dass die secoCBI-Derivate $(+)-(1 S)-56 \mathbf{5 a}, \mathbf{b}$ mit der DNA eine nicht-kovalente Wechselwirkung eingehen können und die dabei auftretenden stabilisierenden Wechselwirkungen die Zyklisierungsgeschwindigkeit verringern. Dies wäre im Einklang mit der Beobachtung, dass die Zyklisierung bezüglich des seco-Drugs bimolekular abläuft. ${ }^{157}$ Eine Bindung an die DNA würde in diesem Fall die Wechselwirkung zweier seco-Drugs und somit die Zyklisierung beeinträchtigen.

Weiterhin scheint die Affinität der CBI-Drugs 86a,b zur DNA geringer zu sein als diejenige der Methyl-CBI-Drugs 43a,b, da der Anteil des nicht-kovalenten bzw. kovalenten DNA-Adduktes ds-60 ${ }^{(*)}$ trotz vorhandenen freien Drugs bei ersteren nur langsam anstieg. Die geringere Affinität könnte weiterhin zu einer partiellen Aufhebung der nicht-kovalenten Wechselwirkungen während der HPLC-Messung führen. Auch eine höhere Reversibilität der kovalenten Reaktion der CBI-Drugs 86a,b versus der Methyl-CBI-Drugs 43a,b mit dem DNA-Doppelstrang ist denkbar. So wurde bereits beschrieben, dass weniger reaktive Duocarmycin-Analoga weniger stabile und damit stärker reversible DNA-Addukte bilden. ${ }^{190}$ 
Um genauere Aussagen treffen zu können, wurden die seco-Drugs mit den DNADoppelsträngen ds-60 - ds-69 (Abb. 120) für 24 Stunden im 1:1-Verhältnis inkubiert und die Reaktionslösungen im Anschluss mittels analytischer HPLC untersucht.

\begin{tabular}{|c|c|c|c|c|c|}
\hline 5'-CGG TCA ATT AGT CGC-3' & $(\mathrm{ON}-1)$ & \multirow{2}{*}{ ds- 60} & 5'-CGG CAA TTA TTG CCG-3' & (ON-1) & \multirow{2}{*}{ ds-65 } \\
\hline 3'-GCC AGT TAA TCA GCG-5' & $(\mathrm{ON}-2)$ & & 3'-GCC GTT AAT AAC GGC-5' & $(\mathrm{ON}-2)$ & \\
\hline 5'-TCG CCG GTC AAT TAG-3' & $(\mathrm{ON}-1)$ & \multirow{2}{*}{ ds-61 } & TT ATT AGG & $(\mathrm{ON}-1)$ & \multirow{2}{*}{ ds -66} \\
\hline 3'-AGC GGC CAG TTA ATC-5' & $(\mathrm{ON}-2)$ & & 3'-GGC CGA TAA T CC GGC-5' & $(\mathrm{ON}-2)]$ & \\
\hline 5'-CGC TGC ATT AGT CGC-3' & $(\mathrm{ON}-1)$ & \multirow{2}{*}{ ds-62 } & 5'-CCA TAA AGC TTT TTG C-3' & $(\mathrm{ON}-1)\}$ & \multirow{2}{*}{ ds- 67} \\
\hline 3'-GCG ACG TAA TCA GCG-5' & $(\mathrm{ON}-2)$ & & 3'-GGT ATT TCG AAA AAC G-5' & $(\mathrm{ON}-2)\}$ & \\
\hline 5'-CGC TCG AAT TGG CGC-3' & $(\mathrm{ON}-1)$ & \multirow{2}{*}{ ds-63 } & 5'-CGG CTT ATA TGA CCG-3' & $(\mathrm{ON}-1)]$ & \multirow{2}{*}{ ds-68 } \\
\hline 3'-GCG AGC TTA ACC GCG-5' & $(\mathrm{ON}-2)$ & & 3'-GCC GAA TAT ACT GGC-5' & $(\mathrm{ON}-2)\}$ & \\
\hline 5'-CGC GCT A & & \multirow{2}{*}{ ds-64 } & G CGA GCA & $(\mathrm{ON}-1)\}$ & \multirow{2}{*}{ ds -69} \\
\hline 3'-GCG CGA TTT T CT GGC-5' & (ON-2) & & CGT GGA-5' & $(\mathrm{ON}-2)]$ & \\
\hline
\end{tabular}

Abb. 120. Basensequenz der doppelsträngigen DNA-Oligonukleotide ds-60 - ds-69.

Zunächst wurde $(+)-(1 S, 10 R)-34 a$ mit den DNA-Oligonukleotiden ds-60 - ds-69 in Wasser und Puffer umgesetzt (Tab. 30). Nach 24 h Inkubation konnten hierbei in allen Reaktionsansätzen weder das seco-Drug $(+)-(1 S, 10 R)$-34a noch das Hydrolyseprodukt 84a detektiert werden.

\begin{tabular}{c|ccc|ccc}
\hline \multirow{2}{*}{$\mathbf{d s}$} & \multicolumn{3}{|c|}{ Inkubation in Wasser } & \multicolumn{3}{c}{ Inkubation in Phosphatpuffer } \\
\cline { 2 - 7 } & $\mathbf{d s}^{(*)} \mathbf{( 3 4 a )}[\mathbf{\%}]$ & 43a [\%] & $\mathbf{3 4 a}[\%]$ & $\mathbf{d s}^{(*)} \mathbf{( 3 4 a )}[\%]$ & 43a [\%] & 34a [\%] \\
\hline ds-60 & 100 & - & - & 100 & - & - \\
ds-61 & 98 & 2 & - & 97 & 3 & - \\
ds-62 & 99 & 1 & - & 98 & 2 & - \\
ds-63 & 36 & 64 & - & 24 & 76 & - \\
ds-64 & 99 & 1 & - & 99 & 1 & - \\
ds-65 & 73 & 27 & - & 97 & 3 & - \\
ds-66 & 97 & 3 & - & 99 & 1 & - \\
ds-67 & 100 & - & - & 99 & 1 & - \\
ds-68 & 99 & 1 & - & 100 & - & - \\
ds-69 & 37 & 63 & - & 45 & 55 & - \\
\hline
\end{tabular}

Tab. 30. Prozentualer Anteil der Verbindungen nach $24 \mathrm{~h}$ Inkubation des jeweiligen DNAOligonukleotides mit dem seco-Drug $(+)-(1 S, 10 R)-34 \mathbf{a}$ in Wasser oder Puffer $(\mathrm{pH} 7)$. 
Bis auf die DNA-Doppelstränge ds-63, ds-65 und ds-69 hatte der Wirkstoff fast vollständig zu dem jeweiligen nicht-kovalenten bzw. kovalenten Addukt $\mathbf{d s} \mathbf{s}^{(*)}$ abreagiert. Dass im Fall der geringen Addukt-Bildungen keine Hydrolyse des Drugs zu 84a beobachtet werden konnte, könnte durch eine schwache stabilisierende Wechselwirkung des Drugs mit den DNA-Oligonukleotiden ds-63, ds-65 und ds-69 erklärt werden, die zwar für die Ausbildung einer kovalenten Bindung nicht ausreichte, aber dennoch effektiv eine Hydrolyse der Wirkstoffe verhinderte. Die nicht-kovalenten Wechselwirkungen besonders schwach gebundener Drug-Moleküle könnten dann während der HPLC-Analyse aufgebrochen worden sein.

Das Oligonukleotid ds-63 verfügt zwar über eine AT-reiche Region von vier Basenpaaren, aber nicht über ein geeignetes Adenin am 3'-Ende dieser Basenfolge und somit nicht über ein geeignetes Nukleophil. Das Oligonukleotid ds-69 weist keine AT-reiche Region auf und daher erfolgt weder eine Aktivierung noch eine Alkylierung. Bei ds-65 ist der Anteil nur schwach gebundenen Drugs mit 27\% nur in Wasser, nicht aber in Puffer erhöht. Als einziges Oligonukleotid verfügt dieser Doppelstrang über eine sehr lange AT-reiche Sequenz von sieben Basenpaaren, die für den beobachteten Effekt verantwortlich sein könnte.

Da bis auf ds-65 keine signifikanten Unterschiede zwischen der Inkubation in Wasser und Puffer beobachtet werden konnten, erfolgten die Umsetzungen der anderen secoDrugs nur in Wasser. Tabelle 31 zeigt die Ergebnisse für $(+)-(1 S, 10 R)-\mathbf{3 4 b}$.

\begin{tabular}{|c|c|c|c|}
\hline ds & $d s^{(*)}(34 b)[\%]$ & $43 \mathrm{~b}[\%]$ & $34 \mathrm{~b}[\%]$ \\
\hline ds-60 & 97 & 1 & 2 \\
\hline ds-61 & 89 & 2 & 9 \\
\hline ds-62 & 96 & 4 & - \\
\hline ds-63 & 38 & 62 & - \\
\hline ds-64 & 96 & 1 & 3 \\
\hline ds-65 & 60 & 40 & - \\
\hline ds-66 & 97 & 3 & - \\
\hline ds-67 & 97 & 1 & 2 \\
\hline ds-68 & 99 & 1 & - \\
\hline ds-69 & 60 & 40 & - \\
\hline
\end{tabular}

Tab. 31. Prozentualer Anteil der Verbindungen nach $24 \mathrm{~h}$ Inkubation des jeweiligen DNAOligonukleotides mit dem Methyl-seco-CBI-Derivat $(+)-(1 S, 10 R)-34 \mathbf{b}$ in Wasser $(\mathrm{pH} 7)$. 
Insgesamt sind die Ergebnisse für $(+)-(1 S, 10 R)-34 \mathbf{a}$ und $(+)-(1 S, 10 R)-34 \mathbf{b}$ sehr ähnlich. So konnte bei einer Inkubation von $(+)-(1 S, 10 R)-34 \mathbf{b}$ mit ds-63, ds-65 und ds-69 ebenfalls eine signifikante Menge des Drugs 43b in der Reaktionslösung nachgewiesen werden. Bei einer Inkubation des seco-Drugs $(+)-(1 S, 10 R)-\mathbf{3 4 b}$ mit ds-61 konnte nach 24 Stunden zusätzlich eine signifikante Menge des unveränderten secoDrugs $(+)-(1 S, 10 R)-34 \mathbf{b}$ detektiert werden. Aufgrund der Endposition der AT-reichen Sequenz und der damit vermutlich veränderten Furchengeometrie könnte es bei diesem Oligonukleotid zu einer nicht-kovalenten Wechselwirkung zwischen dem seco-Drug und der DNA gekommen sein, sodass dieses einlagern konnte und stabilisiert wurde, aufgrund der nur schwachen Wechselwirkungen teilweise jedoch wieder freigesetzt wurde. Das Addukt von 43b mit ds-65 war zudem weniger stabil und jenes mit ds-69 stabiler als die entsprechenden Addukte des analogen Drugs 43a. Dies weist auf eine leicht unterschiedliche Stabilisierung der nicht-kovalenten Addukte der verschiedenen Drugs mit den Doppelsträngen hin.

Um den Einfluss der Methylgruppe zu untersuchen, wurden die seco-CBI-Derivate (+)-(1S)-56a,b mit den DNA-Oligonukleotiden ds-60 - ds-69 in Wasser inkubiert. Die Ergebnisse der Untersuchungen mit beiden seco-CBI-Derivate ähneln einander (Tab. 32 und Tab. 33). Ihre Wechselwirkung mit DNA unterscheidet sich jedoch deutlich von jener der analogen Methyl-seco-CBI-Verbindungen $(+)-(1 S, 10 R)-\mathbf{3 4 a}$,b.

\begin{tabular}{ccccc}
\hline ds & Fragmente [\%] & ds $^{(*)} \mathbf{( 5 6 a )}[\%]$ & $\mathbf{8 6 a}[\%]$ & $\mathbf{5 6 a}[\%]$ \\
\hline ds-60 & - & 99 & - & 1 \\
ds-61 & - & 87 & - & 13 \\
ds-62 & - & 92 & - & 8 \\
ds-63 & - & 17 & 68 & 15 \\
ds-64 & - & 41 & - & 59 \\
ds-65 & 30 & 53 & 13 & 4 \\
ds-66 & 13 & 73 & 11 & 3 \\
ds-67 & - & 95 & - & 5 \\
ds-68 & 15 & 83 & - & 2 \\
ds-69 & - & 18 & 53 & 29 \\
\hline
\end{tabular}

Tab. 32. Prozentualer Anteil der Verbindungen nach 24-stündiger Inkubation des jeweiligen DNA-Oligonukleotides mit dem seco-CBI-Derivat (+)-(1S)-56a in Wasser (pH 7). 


\begin{tabular}{ccccc}
\hline ds & Fragmente [\%] & $\mathbf{d s}^{(*)} \mathbf{( 5 6 b )}[\%]$ & $\mathbf{8 6 b}[\%]$ & $\mathbf{5 6 b}[\%]$ \\
\hline ds-60 & - & 52 & 3 & 45 \\
ds-61 & - & 81 & 2 & 17 \\
ds-62 & - & 78 & 3 & 19 \\
ds-63 & - & 13 & 68 & 19 \\
ds-64 & - & 34 & 3 & 63 \\
ds-65 & 17 & 48 & 8 & 27 \\
ds-66 & 7 & 84 & 2 & 7 \\
ds-67 & - & 67 & 3 & 30 \\
ds-68 & 6 & 70 & 3 & 21 \\
ds-69 & - & 26 & 41 & 33 \\
\hline
\end{tabular}

Tab. 33. Prozentualer Anteil der Verbindungen nach 24-stündiger Inkubation des jeweiligen DNA-Oligonukleotides mit dem seco-CBI-Derivat (+)-(1S)-56a in Wasser ( $\mathrm{pH} 7)$.

Bei Umsetzung der DNA mit den seco-CBI-Hydrochloriden (+)-(1S)-56a,b konnten kleine DNA-Fragmente bei niedrigen Retentionszeiten für die Oligonukleotide ds-65, ds-66 und ds-68 nachgewiesen werden, deren prozentualer Anteil bei $(+)-(1 S)-56 \mathbf{a}$ (Tab. 32) etwas höher war als bei (+)-(1S)-56b (Tab. 33). Zudem wurden bei mehreren Oligonukleotiden noch signifikante Mengen an seco-Drug nachgewiesen, obwohl dieses normalerweise innerhalb weniger Stunden vollständig zum entsprechenden Drug zyklisieren sollte. Die Basensequenz des Oligonukleotides hatte offensichtlich einen großen Einfluss auf die Stabilität der seco-Drugs, die demzufolge eine spezifische, stabilisierende Wechselwirkung mit den Oligonukleotiden eingehen konnten. Am höchsten war der Anteil des seco-Drugs bei dem DNA-Oligonukeotid ds-64, bei dem nahezu 60\% der seco-Drugs nach 24 Stunden nicht zum Drug zyklisiert waren. Unerwartet hoch war der Anteil beider Wirkstoffe auch bei ds-69 und, insbesondere für $(+)-(1 S)-\mathbf{5 6 b}$, zusätzlich bei vielen weiteren DNA-Oligonukleotiden. Dieser hohe Prozentsatz an seco-Drug erklärt auch die unerwartet niedrige Alklyierungseffizienz der seco-CBI-Hydrochloride $(+)-(1 S)-\mathbf{5 6 a}, \mathbf{b}$, da die Alkylierung im Allgemeinen erst nach der Zyklisierung zum Drug erfolgt (s. Kap. 6).

Interessanterweise korreliert die Stabilität der seco-Drugs zudem mit der Zytotoxizität der Verbindungen: Je höher der Anteil nicht zyklisierten, durch Wechselwirkung mit der DNA stabilisierten seco-Drugs, umso toxischer ist der Wirkstoff. Die zytotoxischeren Wirkstoffe verfügen zudem über ein weniger Hydrolyse-empfindliches 
Drug und werden so in geringerem Maße inaktiviert, was ebenfalls zu einer Erhöhung der Zytotoxizität beiträgt. Insgesamt könnte die höhere Zytotoxizität der seco-CBIHydrochloride $(+)-(1 S)-56 \mathbf{a}, \mathbf{b}$ im Vergleich zu den Methyl-seco-CBI-Hydrochloriden $(+)-(1 S, 10 R)-34 a, b$ daher durch eine langsamere, aber aufgrund einer geringeren Inaktivierung stärker ausgeprägte Alkylierung der zellulären DNA verursacht werden.

\subsection{Untersuchung der Wechselwirkung weiterer Duocarmycin-Analoga mit dem DNA-Oligonukleotid ds-60}

Die Ausbildung nicht-kovalenter und kovalenter Addukte mit dem doppelsträngigen DNA-Oligonukleotid ds-60 wurde in der Folge für weitere ausgewählte seco-Drugs und einige Prodrugs im Verhältnis des Wirkstoffs zur DNA von 1:1 und 5:1 ermittelt (Abb. 121).

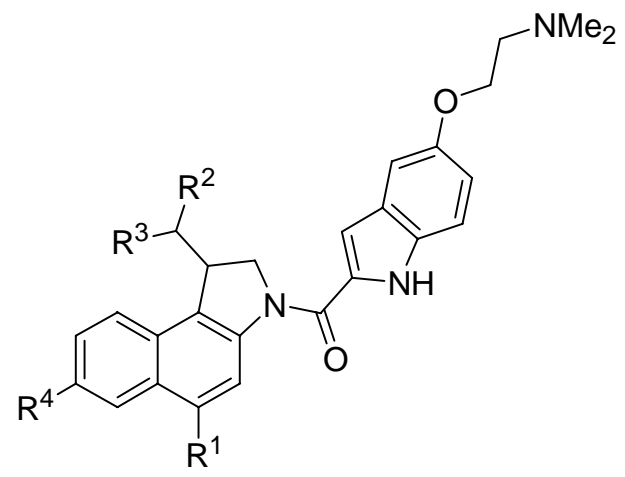

34a: $\mathrm{R}^{1}=\mathrm{OH} \cdot \mathrm{HCl}, \mathrm{R}^{2}=\mathrm{Cl}, \mathrm{R}^{3}=\mathrm{CH}_{3}, \mathrm{R}^{4}=\mathrm{H}$

84a: $R^{1}=\mathrm{OH}, \mathrm{R}^{2}=\mathrm{OH}, \mathrm{R}^{3}=\mathrm{CH}_{3}, \mathrm{R}^{4}=\mathrm{H}$

33a: $\mathrm{R}^{1}=\mathrm{O}-\beta$ - D-Gal, $\mathrm{R}^{2}=\mathrm{Cl}, \mathrm{R}^{3}=\mathrm{CH}_{3}, \mathrm{R}^{4}=\mathrm{H}$

85a: $\mathrm{R}^{1}=\mathrm{O}-\beta$-D-Gal, $\mathrm{R}^{2}=\mathrm{OH}, \mathrm{R}^{3}=\mathrm{CH}_{3}, \mathrm{R}^{4}=\mathrm{H}$

49: $\mathrm{R}^{1}=\mathrm{OH}, \mathrm{R}^{2}=\mathrm{H}, \mathrm{R}^{3}=\mathrm{CH}_{3}, \mathrm{R}^{4}=\mathrm{H}$

56a: $\mathrm{R}^{1}=\mathrm{OH} \cdot \mathrm{HCl}, \mathrm{R}^{2}=\mathrm{Cl}, \mathrm{R}^{3}=\mathrm{H}, \mathrm{R}^{4}=\mathrm{H}$

87a: $R^{1}=\mathrm{OH}, \mathrm{R}^{2}=\mathrm{OH}, \mathrm{R}^{3}=\mathrm{H}, \mathrm{R}^{4}=\mathrm{H}$

54a: $\mathrm{R}^{1}=\mathrm{O}-\beta-\mathrm{D}-\mathrm{Gal}, \mathrm{R}^{2}=\mathrm{Cl}, \mathrm{R}^{3}=\mathrm{H}, \mathrm{R}^{4}=\mathrm{H}$

88a: $R^{1}=O-\beta-D-G a l, R^{2}=O H, R^{3}=H, R^{4}=H$

76: $\mathrm{R}^{1}=\mathrm{OH} \cdot \mathrm{HCl}, \mathrm{R}^{2}=\mathrm{Cl}, \mathrm{R}^{3}=\mathrm{CH}_{3}, \mathrm{R}^{4}=$ Dapoxylderivat

94: $\mathrm{R}^{1}=\mathrm{OH}, \mathrm{R}^{2}=\mathrm{OH}, \mathrm{R}^{3}=\mathrm{CH}_{3}, \mathrm{R}^{4}=$ Dapoxylderivat

75: $\quad \mathrm{R}^{1}=\mathrm{O}-\beta$-D-Gal $\cdot \mathrm{CF}_{3} \mathrm{COOH}, \mathrm{R}^{2}=\mathrm{Cl}, \mathrm{R}^{3}=\mathrm{CH}_{3}, \mathrm{R}^{4}=$ Dapoxylderivat

93: $\quad \mathrm{R}^{1}=\mathrm{O}-\beta$-D-Gal, $\mathrm{R}^{2}=\mathrm{OH}, \mathrm{R}^{3}=\mathrm{CH}_{3}, \mathrm{R}^{4}=$ Dapoxylderivat 43a: $\mathrm{R}^{1}=\mathrm{CH}_{3}, \mathrm{R}^{2}=\mathrm{H}$

86a: $R^{1}=H, R^{2}=H$

97: $\mathrm{R}^{1}=\mathrm{CH}_{3}, \mathrm{R}^{2}=$ Dapoxylderivat

$\left.\begin{array}{l}\text { 5'-CGG TCA ATT AGT CGC-3' (ON-1) } \\ \text { 3'-GCC AGT TAA TCA GCG-5' (ON-2) }\end{array}\right\}$ ds-60

Abb. 121. Strukturen ausgewählter Verbindungen und ihrer Hydrolyseprodukte sowie Basensequenz des DNA-Oligonukleotides ds-60. 
Zunächst wurde ds-60 mit dem Enantiomer (-)-(1R,10S)-34a mit unnatürlicher Konfiguration für 24 Stunden inkubiert (Tab. 34). Hierbei wurde bei einem Verhältnis Wirkstoff / DNA = 1:1 keine Adduktbildung beobachtet. Stattdessen wurde der Wirkstoff vollständig zum Hydrolyseprodukt 84a inaktiviert. Bei einem fünffachen Überschuss des seco-Drugs wurde der größte Teil des Wirkstoffs zum Hydrolyseprodukt umgesetzt, es konnten allerdings auch Spuren einer Adduktbildung zu ds-60 ${ }^{(*)}$ sowie ein signifikanter Anteil des seco-Drugs detektiert werden. Dieses Ergebnis entspricht den Resultaten der massenspektrometrischen Untersuchungen (s. Kap. 6.2).

\begin{tabular}{cccc}
\hline $\mathbf{( 1 R , 1 0 S ) - 3 4 a ~ / ~ d s - 6 0 ~}$ & ds-60 $^{(*)}(\mathbf{3 4 a})[\%]$ & $\mathbf{8 4 a}[\%]$ & $(\mathbf{1 R , 1 0 S ) - 3 4 a ~ [ \% ]}$ \\
\hline $1: 1$ & - & 100 & - \\
$5: 1$ & 8 & 73 & 19 \\
\hline
\end{tabular}

Tab. 34. Prozentualer Anteil der Verbindungen nach $24 \mathrm{~h}$ Inkubation des DNA-Oligonukleotides ds-60 mit dem Methyl-seco-CBI-Derivat (-)-(1R,10S)-34a in Wasser (pH 7).

Analog wurde die Adduktbildung für das Prodrug $(+)-(1 S, 10 R)-33 a$ untersucht (Tab. 35). Neben unverändertem Edukt konnten nach 24-stündiger Inkubation etwa gleiche Teile Hydrolyseprodukt 85a und Addukt ds-60 ${ }^{(*)}$ nachgewiesen werden. Die wesentlich geringere Adduktbildung als jene des entsprechenden seco-Drugs $(+)-(1 S, 10 R)-34$ a korreliert auch hier mit der geringeren Zytotoxizität des Prodrugs und den Ergebnissen der massenspektrometrischen Untersuchungen (s. Kap. 6.2).

\begin{tabular}{cccc}
\hline $\mathbf{( 1 S , 1 0 R ) - 3 3 a ~ / ~ d s - 6 0 ~}$ & ds-60 $^{(*)}(\mathbf{3 3 a})[\%]$ & $\mathbf{8 5 a}[\%]$ & $(\mathbf{1 S}, \mathbf{1 0 R})-33 a[\%]$ \\
\hline $1: 1$ & 12 & 12 & 76 \\
$5: 1$ & 14 & 17 & 69 \\
\hline
\end{tabular}

Tab. 35. Prozentualer Anteil der Verbindungen nach $24 \mathrm{~h}$ Inkubation des DNA-Oligonukleotides ds-60 mit dem Methyl-seco-CBI-Prodrug (+)-(1S,10R)-33a in Wasser (pH 7).

Das dechlorierte Methyl-seco-CBI-DMAI-Analogon (+)-(1S)-49 stellt ein Modell für das seco-Drug (+)-(1S,10R)-34a dar. Im Gegensatz zu diesem verfügt (+)-49 allerdings nicht über ein Chloratom und kann somit weder zyklisieren noch DNA alkylieren. Die Umsetzung mit ds-60 zeigte selbst bei einem fünffachen Wirkstoffüberschuss keine signifikante Adduktbildung (Tab. 36), weshalb (+)-(1S,10R)-34a vermutlich erst in Form seines Drugs 43a eine stabile Wechselwirkung mit dem DNADoppelstrang ausbildet. 


\begin{tabular}{ccc}
\hline $\mathbf{( 1 S ) - 4 9} / \mathbf{d s - 6 0}$ & ds-60 $^{(*)} \mathbf{( 4 9 )}[\%]$ & $(\mathbf{1 S )}-\mathbf{4 9}[\mathbf{\%}]$ \\
\hline $1: 1$ & - & 100 \\
$5: 1$ & 1 & 99 \\
\hline
\end{tabular}

Tab. 36. Prozentualer Anteil der Verbindungen nach $24 \mathrm{~h}$ Inkubation des DNA-Oligonukleotides ds-60 mit dem dechlorierten Methyl-seco-CBI-Analogon (1S)-49 in Wasser (pH 7).

Zum Vergleich der Wechselwirkungen verschiedener seco-CBI-DMAI-Derivate mit dem DNA-Oligonukleotid ds-60 wurden neben dem seco-Drug (+)-(1S)-56a (Tab. 32) das hierzu enantiomere seco-Drug (-)-(1R)-56a sowie das Prodrug (1S)-54a mit dem Oligonukleotid ds-60 inkubiert. Das seco-Drug (-)-(1R)-56a reagierte zu einem signifikanten Anteil mit der DNA zu dem Addukt ds-60 ${ }^{(*)}$ (56a) (Tab. 37), prozentual war der Umsatz aber deutlich geringer als der des toxischeren (1S)-Enantiomers. Dieses reagiert im 1:1-Verhältnis mit ds-60 zu 99\% zum Addukt.

\begin{tabular}{cccc}
\hline $\mathbf{( 1 R ) - 5 6 a ~ / ~ d s - 6 0 ~}$ & $\mathbf{d s - 6 0}^{(*)} \mathbf{( 5 6 a )}[\%]$ & $\mathbf{8 6 a}[\%]$ & $(\mathbf{1 R ) - 5 6 a ~ [ \% ] ~}$ \\
\hline $1: 1$ & 49 & 28 & 23 \\
$5: 1$ & 33 & 29 & 38 \\
\hline
\end{tabular}

Tab. 37. Prozentualer Anteil der Verbindungen nach $24 \mathrm{~h}$ Inkubation des DNA-Oligonukleotides ds-60 mit dem seco-CBI-Derivat (-)-(1R)-56a in Wasser ( $\mathrm{pH} 7)$.

Das im Vergleich zu (+)-(1S)-56a deutlich untoxischere Prodrug (-)-(1S)-54a reagierte weder im 1:1-Verhältnis noch bei einem fünffachen Überschuss zu einem Addukt (Tab. 38). Des Weiteren konnte keine Hydrolyse und somit Inaktivierung des Prodrugs festgestellt werden, weshalb (-)-(1S)-54a sehr gut für eine therapeutische Applikation in wässriger Lösung geeignet sein sollte.

\begin{tabular}{ccccc}
\hline $\mathbf{( 1 S ) - 5 4 a ~ / ~ d s - 6 0 ~}$ & ds-60 $^{(*)}(\mathbf{5 4 a})[\%]$ & $\mathbf{8 8 a}[\%]$ & $(\mathbf{1 S})-54 a[\%]$ \\
\hline $1: 1$ & - & - & 100 \\
$5: 1$ & - & - & 100 \\
\hline
\end{tabular}

Tab. 38. Prozentualer Anteil der Verbindungen nach $24 \mathrm{~h}$ Inkubation des DNA-Oligonukleotides ds-60 mit dem seco-CBI-Prodrug (-)-(1S)-54a in Wasser (pH 7).

Auch für die seco-CBI-DMAI-Derivate besteht demzufolge ein eindeutiger Zusammenhang zwischen der Adduktbildung und der Zytotoxizität. 
Abschließend wurde die Wechselwirkung der fluoreszenzmarkierten Analoga mit dem DNA-Oligonukleotid ds-60 untersucht, um eine Aussage über möglicherweise durch den Fluoreszenzfarbstoff veränderte Bindungsaffinitäten treffen zu können.

Das fluoreszenzmarkierte Prodrug (-)-(1S,10R)-75 wurde innerhalb der 24-stündigen Inkubation mit ds-60 in Wasser weder hydrolysiert, noch fand eine Bindung an die doppelsträngige DNA statt (Tab. 39).

\begin{tabular}{cccc}
\hline $\mathbf{( 1 S , 1 0 R ) - 7 5 / ~ d s - 6 0 ~}$ & ds-60 $^{(*)}(\mathbf{7 5 )}[\%]$ & $\mathbf{9 3}[\%]$ & $(\mathbf{1 S}, \mathbf{1 0 R})-75[\%]$ \\
\hline $1: 1$ & - & - & 100 \\
$5: 1$ & - & - & 100 \\
\hline
\end{tabular}

Tab. 39. Prozentualer Anteil der Verbindungen nach $24 \mathrm{~h}$ Inkubation des jeweiligen DNAOligonukleotides mit dem Methyl-seco-CBI-Prodrug (-)-(1S,10R)-75 in Wasser (pH 7).

Das seco-Drug $(1 S, 10 R)$-76 hingegen, welches anteilig zum entsprechenden Drug 97 zyklisierte, bildete mit ds-60 nicht-kovalente bzw. kovalente Addukte. Der Anteil des Adduktes betrug bei einer 1:1-Umsetzung des Wirkstoffs mit der DNA etwa 20\%. Dieser Wert entspricht exakt dem massenspektrometrisch bestimmten Anteil kovalent gebundenen Wirkstoffs. Bei einer Erhöhung der seco-Drug-Menge auf fünf Äquivalente wurden zwar nur 12\% des Wirkstoffs an die DNA gebunden, bezüglich der DNA entspricht dies jedoch einer etwa 66\%-igen Umsetzung.

\begin{tabular}{cccc}
\hline $\mathbf{( 1 S , 1 0 R ) - 7 6 / d s - 6 0}$ & ds-60 $^{(*)}(\mathbf{7 6})[\%]$ & $\mathbf{9 7}[\mathbf{\%}]$ & $\mathbf{( 1 S , 1 0 R ) - 7 6 ~ [ \% ] ~}$ \\
\hline $1: 1$ & 23 & 19 & 58 \\
$5: 1$ & 12 & 19 & 69 \\
\hline
\end{tabular}

Tab. 40. Prozentualer Anteil der Verbindungen nach $24 \mathrm{~h}$ Inkubation des jeweiligen DNAOligonukleotides mit dem Methyl-seco-CBI-Derivat (1S,10R)-76 in Wasser (pH 7).

Mit bis zu 40\% Zyklisierung zum entsprechenden Drug innerhalb der Inkubationszeit von $24 \mathrm{~h}$ ist die Zyklisierungsgeschwindigkeit stark erniedrigt gegenüber derjenigen des analogen nicht-fluoreszenzmarkierten seco-Drugs, bei dem mehr als $90 \%$ innerhalb der ersten 30 Minuten zum Drug zyklisieren. Die Effizienz der DNAAlkylierung durch $(1 S, 10 R)-76$ ist wahrscheinlich vor allem wegen dieser langsameren Zyklisierung merklich verringert. Die Fluoreszenzmarkierung an C-7 bewirkt somit zwar eine schwächere DNA-Alkylierung, verhindert diese aber nicht. 


\section{Untersuchung der Wechselwirkung neuer Duocarmycin- Analoga und anderer Zytostatika mit DNA-Oligonukleotiden mittels CD-Spektroskopie}

Circular-Dichroismus (CD) ist eine spektroskopische Methode, die auf der differentiellen Absorption rechts- und links-zirkular polarisierten Lichtes durch chirale oder chiral gestörte Chromophore basiert, in deren Folge linear polarisiertes Licht elliptisch polarisiert wird. ${ }^{191}$ Messgröße des Circular Dichroismus ist die Elliptizität $\theta$ in grad, ${ }^{192}$ die in die molare Elliptizität $[\theta]$ in grad $\cdot \mathrm{cm}^{2} \cdot \mathrm{dmol}^{-1}$ umgerechnet werden kann (2). ${ }^{191}$

$$
[\theta]=\frac{100 \cdot \theta}{c \cdot l}\left[\mathrm{grad} \cdot \mathrm{cm}^{2} \cdot \mathrm{dmol}^{-1}\right]
$$

mit: $\theta=$ Elliptizität [grad], $c=$ Konzentration $\left[\mathrm{mol} \cdot \mathrm{l}^{-1}\right], l=$ Pfadlänge $[\mathrm{cm}]$.

Das CD-Spektrum einer Substanz hat eine charakteristische Form und kann zur Bestimmung der absoluten Konfiguration der Verbindung verwendet werden. ${ }^{191}$ Zudem stellt die CD-Spektroskopie eine geeignete Methode zur Untersuchung der Struktur und Konformation von Biomolekülen sowie intermolekularer Wechselwirkungen dar. So kann die Bildung eines kovalenten oder nicht-kovalenten Komplexes eines Wirkstoffs mit DNA zu einem starken, induzierten CD-Signal (ICD) des gebundenen Wirkstoffs führen, das durch die Kopplung elektronischer Übergangsmomente des Wirkstoffs und der Nukleobasen der DNA in der asymmetrischen Bindungsstelle verursacht wird. ${ }^{122,193}$ Die Wechselwirkung des Antibiotikums CC-1065 (18) mit DNA führt beispielsweise durch eine Einlagerung des Wirkstoffs in die kleine Furche des DNA-Doppelstranges zu einem starken induzierten CD-Signal (s. Kap. 4.2). Eine ähnliche Veränderung des CD-Spektrums wurde auch für die neuartigen, im Rahmen dieser Doktorarbeit untersuchten Duocarmycin-Analoga vermutet. Sollten die Verbindungen ein signifikantes CD-Signal induzieren, so könnte dieses zur Untersuchung der Bindungskinetik und der Affinität der Wirkstoffe zu verschiedenen DNA-Oligonukleotiden genutzt werden. 


\subsection{Untersuchung der Wechselwirkung des seco-Drugs $(+)-(1 S, 10 R)-34 a$ mit dem DNA-Oligonukleotid ds-60}

Das CD-Spektrum doppelsträngiger DNA-Oligonukleotide wie das des Doppelstranges ds-60 (Abb. 122) weist eine für B-Form-DNA typische negative Bande mit einem Minimum um $\lambda=240 \mathrm{~nm}$ und eine positive Bande mit einem Maximum um $\lambda=270 \mathrm{~nm}$ auf (Abb. 123). ${ }^{191}$
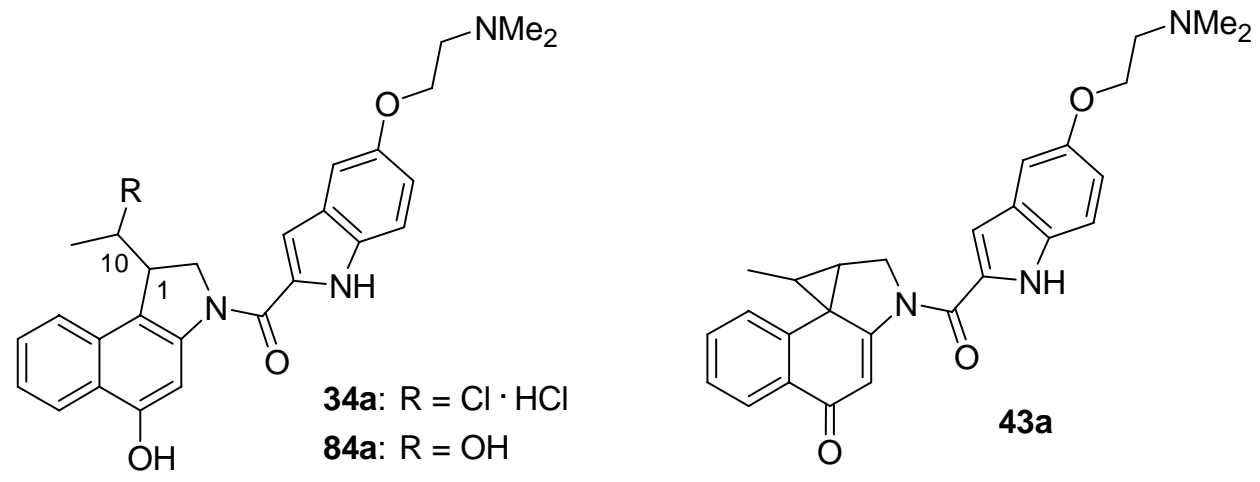

$$
\left.\begin{array}{ll}
\text { 5'-CGG TCA ATT AGT CGC-3' } & \text { (ON-1) } \\
\text { 3'-GCC AGT TAA TCA GCG-5' } & \text { (ON-2) }
\end{array}\right\} \text { ds-60 }
$$

Abb. 122. Struktur des seco-Drug-Hydrochlorids 34a, des Drugs 43a und des entsprechenden Hydrolyseproduktes 84a sowie Basensequenz des DNA-Oligonukleotides ds-60.

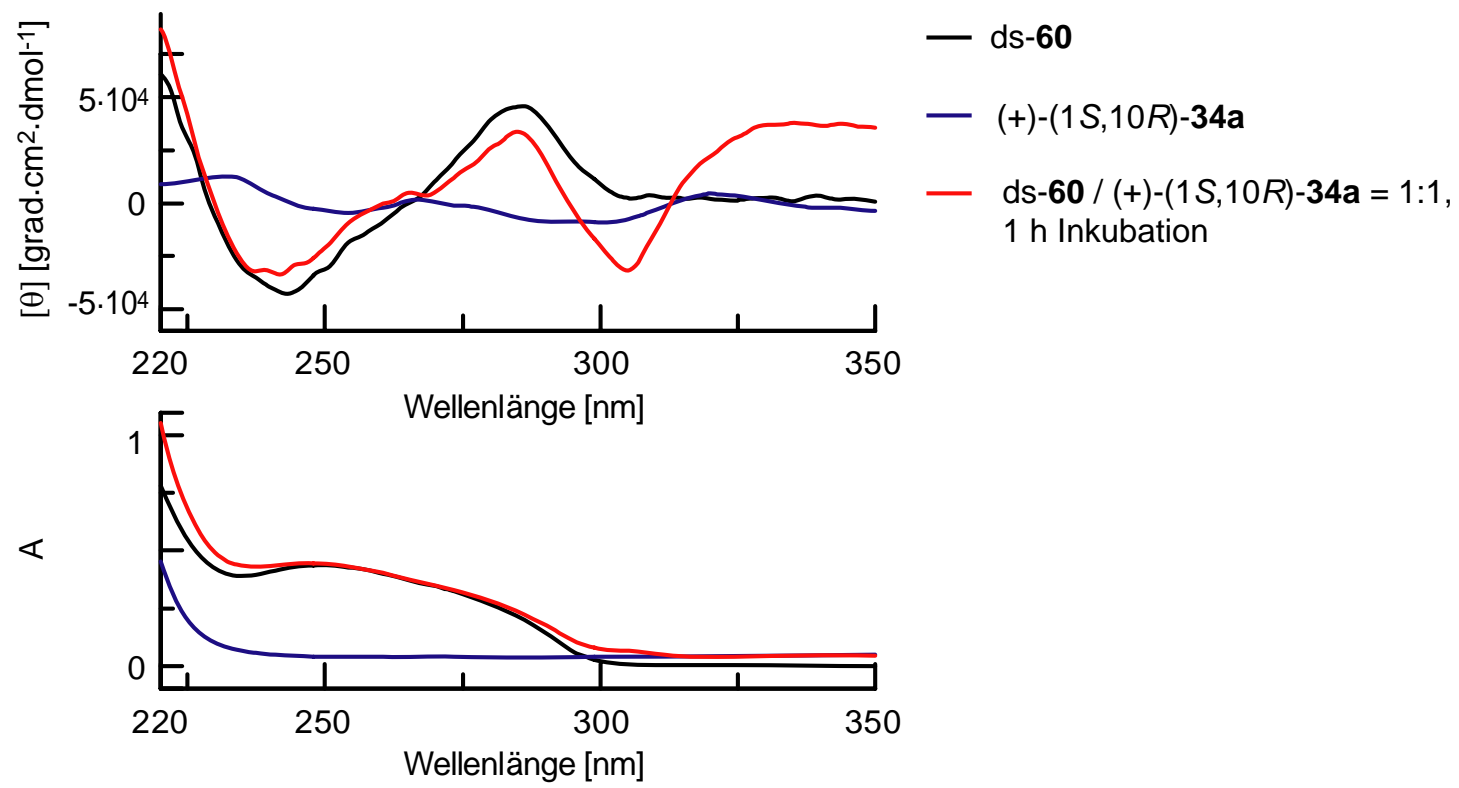

Abb. 123. CD-Spektren und Absorptionsspektren des Oligonukleotides ds-60, des secoDrug-Hydrochlorids $(+)-(1 S, 10 R)-34 a$ sowie einer Mischung des Oligonukleotides ds-60 mit dem seco-Drug-Hydrochlorid $(+)-(1 S, 10 R)-34 a$ im Verhältnis 1:1 in Phosphatpuffer $(\mathrm{pH} 7)$. 
Grundlage des CD ist die UV-Absorption der im chiralen DNA-Molekül befindlichen Nukleinsäuren im Bereich von $\lambda=200-300 \mathrm{~nm}$, die durch $\pi \rightarrow \pi^{*}$ Übergänge der planaren Purin- und Pyrimidin-Basen verursacht wird. Oberhalb von $\lambda=300 \mathrm{~nm}$ ist aufgrund der ausbleibenden Absorption kein signifikantes CD-Signal zu beobachten.

Messungen des Circular-Dichroismus nach Inkubation des synthetischen DNA-Oligonukleotides ds-60 mit dem Methyl-seco-CBI-DMAI-Hydrochlorid (+)-(1S,10R)-34a ergaben ein signifikantes, induziertes CD-Signal mit einer negativen und einer positiven Bande oberhalb von $\lambda=300 \mathrm{~nm}$ (Abb. 123). Nach einer Stunde Inkubation lag das Minimum des induzierten CD-Signals (ICD) bei $\lambda=305 \mathrm{~nm}$ und das Maximum bei $\lambda=335 \mathrm{~nm}$. Eine Lösung des seco-Drugs der gleichen Konzentration verursachte indes nur ein sehr schwaches CD-Signal mit einem Minumum bei $\lambda=290 \mathrm{~nm}$ und einem Maximum bei $\lambda=320 \mathrm{~nm}$ (Abb. 123).

Für die Untersuchung der zeitabhängigen Änderung des CD-Signals wurde das DNAOligonukleotid ds-60 mit (+)-(1S,10R)-34a inkubiert. Die Ergebnisse zeigen, dass das ICD ab Beginn der Inkubation zunehmend intensiver wurde und nach etwa einer Stunde seine höchste Intensität erreichte (Abb. 124). Das Maximum der positiven Bande verschob sich hierbei von $\lambda=320 \mathrm{~nm}$ zu $\lambda=335 \mathrm{~nm}$.

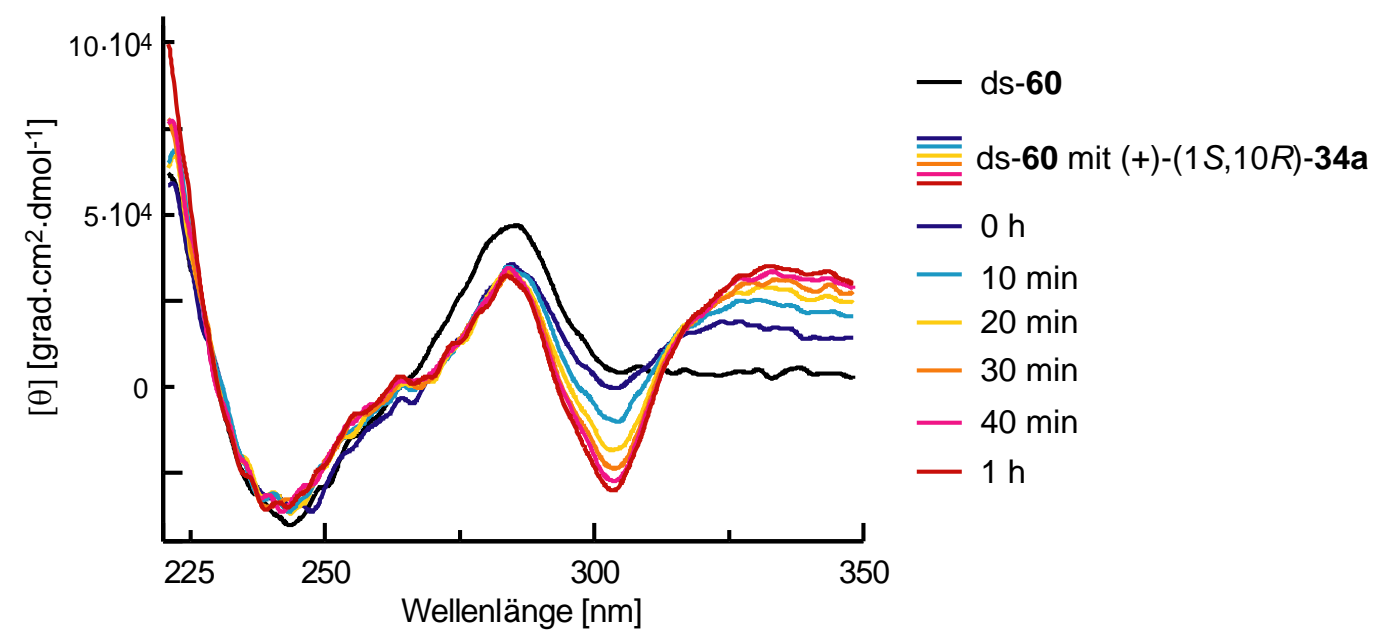

Abb. 124. CD-Spektren des DNA-Oligonukleotides ds-60 sowie einer Mischung von ds-60 mit dem seco-Drug-Hydrochlorid (+)-(1S,10R)-34a im Verhältnis 1:1 in Puffer (pH 7).

Da das seco-Drug 34a in Puffer innerhalb einer Stunde nahezu vollständig zu dem entsprechenden Drug 43a zyklisiert, welches für die Alkylierung der DNA verantwortlich ist (Kap. 6), reflektiert die Zunahme des induzierten CD-Signals vermutlich 
die Einlagerung des Drugs in den DNA-Doppelstrang. Die Alklyierung erfolgt mit einer Geschwindigkeit von etwa 10\% pro Stunde (s. Kap. 6.1), das CD-Spektrum verändert sich jedoch ab einer Inkubationszeit von einer Stunde kaum mehr. Die Signale der nicht-kovalenten und der kovalenten Wechselwirkungen des Drugs mit der DNA sind demnach sehr ähnlich. Die Verschiebung des Maximums von $\lambda=325 \mathrm{~nm}$ zu $\lambda=335 \mathrm{~nm}$ kann daher nur durch eine Erhöhung des Anteils des in der DNA nichtkovalent und kovalent gebundenen Drugs im Vergleich zum freien Drug erklärt werden.

Die Vermutung, dass die Einlagerung des Wirkstoffs in die DNA in Form des Drugs erfolgt, wird durch die Ergebnisse von Molecular-Modelling-Studien unterstützt, die in Zusammenarbeit mit Dr. Andrea Elsner durchgeführt wurden. Die Berechnungen basieren auf der Struktur eines kovalenten Adduktes zwischen Duocarmycin SA (19) und einem doppelsträngigen Oligonukleotid mit einer zu ds-60 analogen AT-reichen Sequenz (5'-d(GTCAATTÁGTC)-3'). ${ }^{178}$ Mit dem Programm MacroModel ${ }^{194}$ (Kraftfeld: Amber $)^{195}$ wurde eine Energieminimierung der nicht-kovalenten und kovalenten Komplexe der DNA mit dem seco-Drug und dem Drug in Wasser durchgeführt. Während für das seco-Drug mit dem DNA-Doppelstrang kein stabiler nicht-kovalenter Komplex modelliert werden konnte, ergab die Optimierung eines analogen Komplexes mit dem Drug stabile nicht-kovalente und kovalente Addukte (Abb. 125).
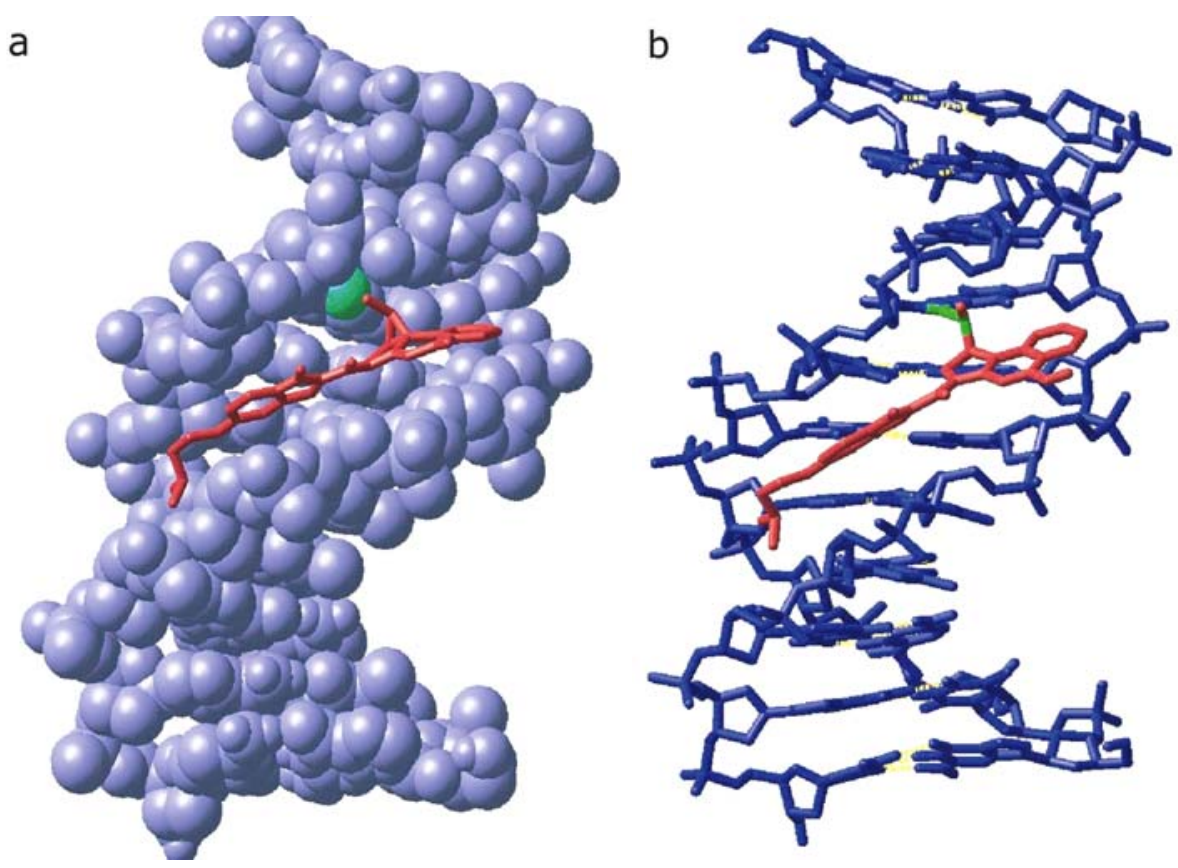

Abb. 125. Modell des nicht-kovalenten (a) und kovalenten (b) Adduktes des Drugs 43a mit

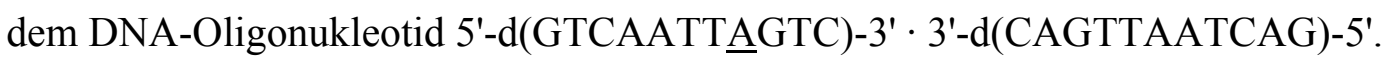


Im nicht-kovalenten Addukt (Abb. 125a) lagert sich das Drug (rot) unter leichter Verdrillung der Amidbindung zunächst tief in die kleine Furche der doppelsträngigen DNA (blau) ein. Das reaktive Cyclopropyl-Kohlenstoffatom des Pharmakophors kommt hierdurch in der Nähe des Adenin- $N$-3-Atoms (grün) zu liegen, an dem in der Folge die Alkylierung stattfindet. Der Abstand zwischen beiden Atomen beträgt in dieser Geometrie etwa 4 Å.

Im kovalenten Addukt (Abb. 125b) ist die Verdrillung der Amidbindung im Drug stärker ausgeprägt, die Produktbildung führt jedoch nicht zu einer signifikanten Veränderung der Geometrie des DNA-Doppelstranges. Diese geringe Strukturveränderung könnte erklären, warum die Retentionszeiten des DNA-Doppelstranges und des DNADrug-Adduktes bei HPLC-Untersuchungen nahezu identisch sind (s. Kap. 7).

Zur Bestätigung der These, dass das ICD durch die Einlagerung des Drugs und nicht des seco-Drugs in den DNA-Doppelstrang verursacht wird, wurden weitere Experimente durchgeführt. Zunächst wurde die zeitliche Änderung des CD-Signals gemessen, nachdem das seco-Drug $(+)-(1 S, 10 R)-34$ a zuvor eine Stunde im Puffer präinkubiert worden war und daher zu mehr als $90 \%$ bereits zu 43a zyklisiert war. Das Ergebnis dieser Messung wurde mit jenem verglichen, das ohne vorherige Präinkubation des seco-Drugs (+)-(1S,10R)-34a erhalten wurde (Tab. 41).

Als Maß der Intensität des induzierten CD-Signals wurde die als $\triangle I C D$ bezeichnete Differenz der Elliptizität an den Kurvenmaxima gewählt, d.h. der Elliptizität bei $\lambda=335 \mathrm{~nm}$ und $\lambda=305 \mathrm{~nm}$, da die Differenz dieser Werte zuverlässigere Aussagen über die Veränderung der Intensität des CD-Signals konsekutiver Messungen erlaubt als die Bestimmung des CD-Signals bei einer Wellenlänge (3).

$$
\Delta I C D=\theta(\lambda=335 \mathrm{~nm})-\theta(\lambda=305 \mathrm{~nm})
$$

mit: $\theta=$ Elliptizität [mgrad].

Das induzierte CD-Signal ist im Fall der Präinkubation des seco-Drugs bereits unmittelbar nach dem Mischen mit der DNA mit $\triangle I C D=1.6 \mathrm{mgrad}$ sehr hoch und erreicht bereits nach einer halben Stunde Inkubation das Maximum von 4 mgrad. Das ICD ohne vorherige Präinkubation ist mit $\triangle I C D=0.8 \mathrm{mgrad}$ hingegen deutlich geringer und nimmt in der Folge auch langsamer zu. Dies unterstützt die These, dass das ICD durch die Einlagerung des Drugs hervorgerufen wird. 


\begin{tabular}{ccc}
\hline $\begin{array}{c}\text { Inkubationszeit } \\
{[\mathrm{h}]}\end{array}$ & $\begin{array}{c}\Delta I C D \text { [mgrad] } \\
\text { (nach } \mathbf{1} \text { h Präinkubation } \\
\text { des seco-Drugs in Puffer) }\end{array}$ & $\begin{array}{c}\Delta I C D \text { [mgrad] } \\
\text { (ohne Präinkubation des } \\
\text { seco-Drugs in Puffer) }\end{array}$ \\
\hline 0 & 1.6 & 0.8 \\
0.5 & 4.0 & 2.5 \\
4.0 & 4.0 & 3.4 \\
\hline
\end{tabular}

Tab. 41. Zeitabhängige Änderung der Intensität des induzierten CD-Signals einer Mischung des Oligonukleotides ds-60 mit dem seco-Drug-Hydrochlorid (+)-(1S,10R)-34a im Verhältnis 1:1 in Phosphatpuffer mit/ohne vorherige 1-stündige Präinkubation des seco-Drugs im Puffer.

Im Puffer zyklisiert das seco-Drug schneller zum Drug als in wässriger Lösung (s. Kap. 7). Das induzierte CD-Signal sollte daher bei einer Inkubation in Wasser langsamer zunehmen, wenn das ICD durch die Drug- und nicht die seco-Drug-Einlagerung hervorgerufen wird. Der DNA-Doppelstrang ds-60 wurde daher einmal in Wasser und einmal in Phosphatpuffer für jeweils zwei Stunden mit dem seco-Drug Hydrochlorid $(+)-(1 S, 10 R)-34 \mathbf{a}$ inkubiert. Im Anschluss wurden beide Lösungen mit Phosphatpuffer verdünnt und unmittelbar danach $\mathrm{CD}$-spektroskopisch untersucht (Tab. 42).

\begin{tabular}{ccc}
\hline $\begin{array}{c}\text { Inkubationszeit } \\
{[\mathrm{h}]}\end{array}$ & $\begin{array}{c}\Delta \text { ICD [mgrad] } \\
\text { (Inkubation in Puffer) }\end{array}$ & $\begin{array}{c}\Delta \text { ICD [mgrad] } \\
\text { (Inkubation in Wasser) }\end{array}$ \\
\hline 2 & 2.8 & 1.4 \\
\hline
\end{tabular}

Tab. 42. Intensität des induzierten CD-Signals einer Mischung des Oligonukleotides ds-60 mit dem seco-Drug-Hydrochlorid $(+)-(1 S, 10 R)-34 a$ im Verhältnis 1:1 in Phosphatpuffer nach $2 \mathrm{~h}$ Inkubation in Phosphatpuffer ( $\mathrm{pH} 7)$ oder Wasser.

Das ICD war nach zwei Stunden Inkubation im Puffer mit $\triangle I C D=2.8$ mgrad doppelt so groß wie das nach Inkubation in Wasser $(\triangle I C D=1.4 \mathrm{mgrad})$. Dies ist ein weiteres Indiz dafür, dass das Drug und nicht das seco-Drug in die kleine Furche der DNA eingelagert wird und das induzierte CD-Signal verursacht.

HPLC-Messungen hatten ergeben, dass bis zu zwei Drug-Moleküle an den DNADoppelstrang ds-60 binden (s. Kap. 7.1). Dieses Ergebnis sollte mittels CD-spektroskopischer Untersuchungen bestätigt werden. $(+)-(1 S, 10 R)-34$ a wurde daher im 1:1Verhältnis mit ds-60 gemischt und bis zum 5:1-Verhältnis von $(+)-(1 S, 10 R)-34 a$ zu 
ds-60 nach einer jeweils zweistündigen Inkubation in Phosphatpuffer (pH 7) mit einem weiteren Äquivalent seco-Drug versetzt. Hierbei wurde jeweils sofort nach der Zugabe des seco-Drugs, nach einer Stunde sowie nach zwei Stunden ein CD-Spektrum aufgezeichnet. Tabelle 43 zeigt die Zunahme des $\triangle I C D$ in dem zweistündigen Zeitintervall nach der Zugabe jeweils eines seco-Drug-Äquivalentes.

\begin{tabular}{cc}
\hline ds-60 / (+)-(1S,10R)-34a & $\Delta$ ICD $(\mathbf{2}$ h) $-\boldsymbol{\Delta ~ I C D ~}(\mathbf{0}$ h $)[\mathbf{m g r a d}]$ \\
\hline $1: 1$ & 5.29 \\
$1: 2$ & 4.86 \\
$1: 3$ & 1.23 \\
$1: 4$ & 0.12 \\
$1: 5$ & 0.00 \\
\hline
\end{tabular}

Tab. 43. Intensitätszunahme des induzierten $\mathrm{CD}$-Signals einer Mischung des Oligonukleotides ds-60 mit dem seco-Drug-Hydrochlorid (+)-( $(1 S, 10 R)$-34a im Verhältnis 1:1 bis 1:5 in Phosphatpuffer $(\mathrm{pH} 7)$ innerhalb von je $2 \mathrm{~h}$ Inkubation nach der Zugabe jeweils eines Äquivalentes an $(+)-(1 S, 10 R)$-34a.

Die Messungen bestätigen, dass zwei Äquivalente des Wirkstoffs an ein DNAMolekül binden, da die Zunahme des $\triangle I C D$ bei Zugabe eines ersten und zweiten Äquivalentes des seco-Drugs 34a um jeweils etwa $5 \mathrm{mgrad}$ zunimmt. Die Zugabe weiterer seco-Drug-Äquivalente führt stattdessen nur zu einer leichten bis keiner Zunahme des $\triangle I C D$, die auch dadurch verursacht sein kann, dass das Binden der zwei Äquivalente nach einer zweistündigen Inkubation noch nicht beendet war.

Distamycin A (98, Abb. 126) bindet in der kleinen Furche doppelsträngiger DNA in AT-reichen Regionen in einem monomeren oder dimeren Bindungsmodus. ${ }^{196}$<smiles>Cn1ccc(NC(=O)c2cc(NC(=O)c3cc(NC(=O)c4cc(NCCC(=N)N)cn4C)cn3C)cn2C)c1</smiles>

Abb. 126. Distamycin A (98).

In GC-reichen DNA-Abschnitten stellt eine in die kleine Furche ragende Aminogruppe der Nukleobase Guanin ein sterisches Hindernis. Da die kleine Furche GC-reicher 
DNA zudem generell weiter ist, ist die Stabilisierung der Wechselwirkung zwischen dem Drug und der DNA durch hydrophobe Wechselwirkungen mit den Wänden der kleinen Furche nicht so ausgeprägt wie in AT-reichen Abschnitten der DNA.

Weiterhin lagern sich Duocarmycin-Analoga mit einer als Haarnadel bezeichneten DNA-bindenden Polyamideinheit so in die kleine Furche doppelsträngiger DNA ein, dass zwei Abschnitte der Polyamidkette nebeneinander in der kleinen Furche zu liegen kommen. ${ }^{104,197}$ Distamycin A (98) und Duocarmycin A (21) können zudem nebeneinander in der kleinen Furche doppelsträngiger DNA binden. ${ }^{198}$

Wie diese Beispiele zeigen, können Furchenbinder auch im dimeren Bindungsmodus in der kleinen Furche Platz finden. Zwei Moleküle des Drugs 43a könnten also nebeneinander, versetzt, mit der gleichen oder mit umgekehrter Orientierung in der kleinen Furche der AT-reichen DNA-Region einlagern. Eine Bindung in der großen Furche der DNA oder in GC-reichen Abschnitten der kleinen Furche kann jedoch wie bei Distamycin A (98) nicht ausgeschlossen werden. ${ }^{200,196}$

\subsection{Untersuchung der Wechselwirkung der seco-Drugs 34a, des Prodrugs $(+)-(1 S, 10 R)-33 a$ sowie des dechlorierten Analogons (+)-(1S)-49 mit verschiedenen DNA-Oligonukleotiden}

Um zu untersuchen, ob das seco-Drug $(+)-(1 S, 10 R)-34 a$ bzw. das aus diesem in situ generierte Drug 43a auch an GC-reiche DNA-Abschnitte bindet, wurden vergleichende Messungen einer 1:1-Umsetzung des seco-Drugs mit den DNA-Oligonukleotiden ds-60 und ds-69 (Abb. 127 und 128) in Phosphatpuffer als Lösungsmittel durchgeführt. Weiterhin erfolgten CD-spektroskopische Untersuchungen der Interaktion des dechlorierten Methyl-seco-CBI-DMAI-Analogons (1S)-49, des zum secoDrug $(+)-(1 S, 10 R)-34 \mathbf{a}$ enantiomeren seco-Drugs $(-)-(1 R, 10 S)-34 \mathbf{a}$ und des Prodrugs $(+)-(1 S, 10 R)-33 a$ mit dem DNA-Doppelstrang ds-60 (Abb. 127 und Abb. 128).

Während die Wechselwirkung des seco-Drugs (+)-(1S,10R)-34a mit dem DNA-Oligonukleotid ds-60 ein signifikantes CD-Signal induziert, dessen Intensität mit zunehmender Inkubationsdauer ansteigt (Abb. 124), kann ein analoges ICD bei der Inkubation des seco-Drugs $(+)-(1 S, 10 R)-34 a$ mit dem DNA-Oligonukleotid ds-69 nicht beobachtet werden (Abb. 128a). Bei $\lambda=305 \mathrm{~nm}$ und $\lambda=320 \mathrm{~nm}$ wird lediglich ein schwaches CD-Signal detektiert, dessen Intensität sich im Laufe mehrerer Stunden nicht signifikant verändert. 

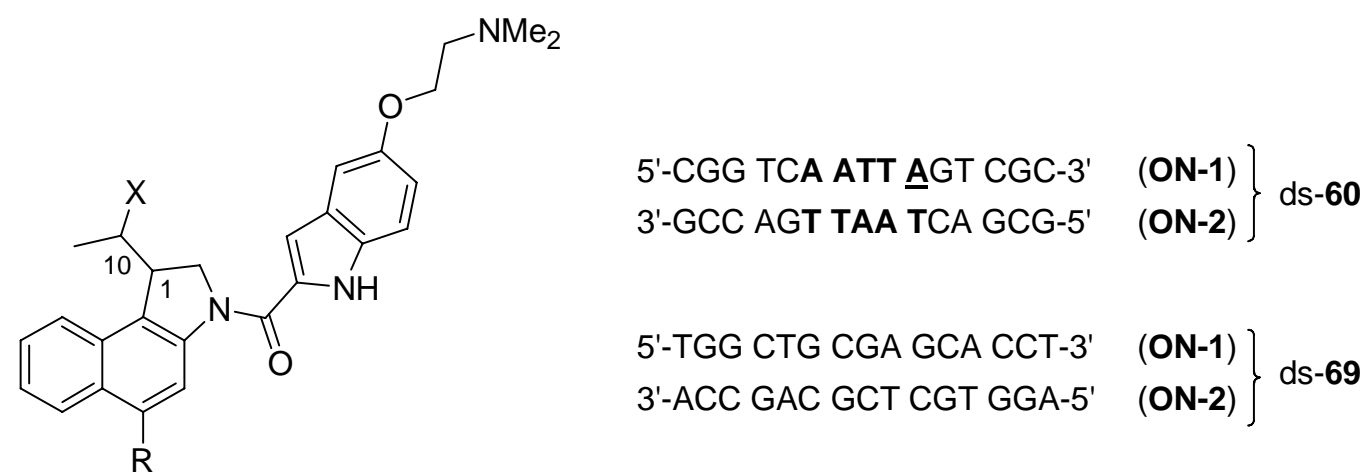

34a: $\mathrm{R}=\mathrm{OH} \cdot \mathrm{HCl}, \mathrm{X}=\mathrm{Cl}$

33a: $\mathrm{R}=\mathrm{O}-\beta-\mathrm{D}-\mathrm{Gal}, \mathrm{X}=\mathrm{Cl}$

49: $\mathrm{R}=\mathrm{OH}, \mathrm{X}=\mathrm{H}$

Abb. 127. Strukturen ausgewählter Verbindungen und DNA-Oligonukleotide.
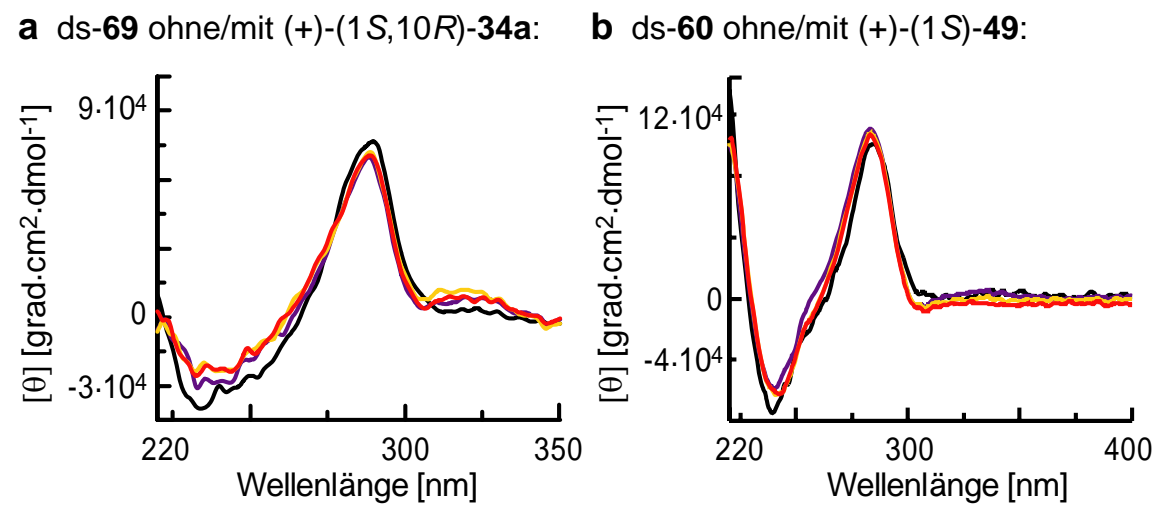

- ds-60 oder ds-69

$\equiv \mathrm{ds}-60$ oder ds-69 mit Wirkstoff:

$-0 \mathrm{~h}$

$-1 \mathrm{~h}$

$-4 \mathrm{~h}$

$-(+)-(1 S, 10 R)-33 a$

C ds-60 ohne/mit (+)-(1S,10R)-33a:

d ds-60 ohne/mit (-)-(1R,10S)-34a:
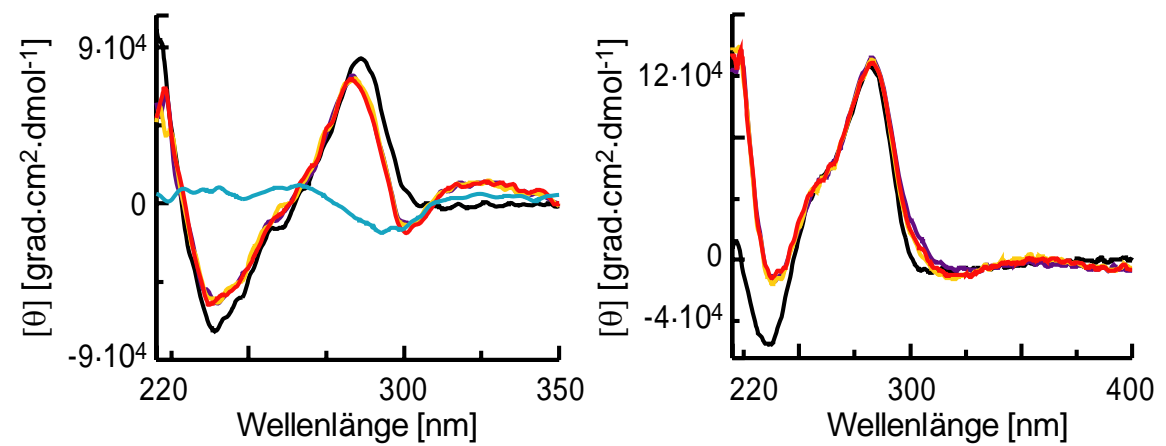

Abb. 128. CD-Spektren der Oligonukleotide ds-60 bzw. ds-69 sowie einer Mischung dieser mit $(+)-(1 S, 10 R)-34 \mathbf{a},(+)-(1 S)-49,(+)-(1 S, 10 R)-33 \mathbf{a}$ oder $(-)-(1 R, 10 S)-34 \mathbf{a}$ im Verhältnis $1: 1$ in Phosphatpuffer (pH 7).

Die ab dem Start der Inkubation im Vergleich zum CD-Signal des seco-Drugs $(+)-(1 S, 10 R)-34 \mathbf{a}$ zu beobachtende leichte Verschiebung des Minimums von $\lambda=290 \mathrm{~nm}$ zu $\lambda=305 \mathrm{~nm}$ könnte hierbei auf eine schwache und unmittelbar eintretende Wechselwirkung des seco-Drugs mit der DNA hinweisen. Die Ergebnisse 
zeigen aufgrund des fehlenden induzierten CD-Signals jedoch deutlich, dass keine Einlagerung des Drugs in die kleine Furche des GC-reichen Doppelstranges stattfindet. Dies korreliert mit der massenspektrometrisch nachgewiesenen sehr geringen und unselektiven Alkylierung dieses Doppelstranges durch das seco-Drug bzw. das aus diesem gebildete Drug. Vermutlich wird eine Einlagerung des Drugs in die kleine Furche des GC-reichen Doppelstranges ds-69 durch eine in die Furche ragende Aminogruppe der Nukleobase Guanin verhindert (Abb. 129).
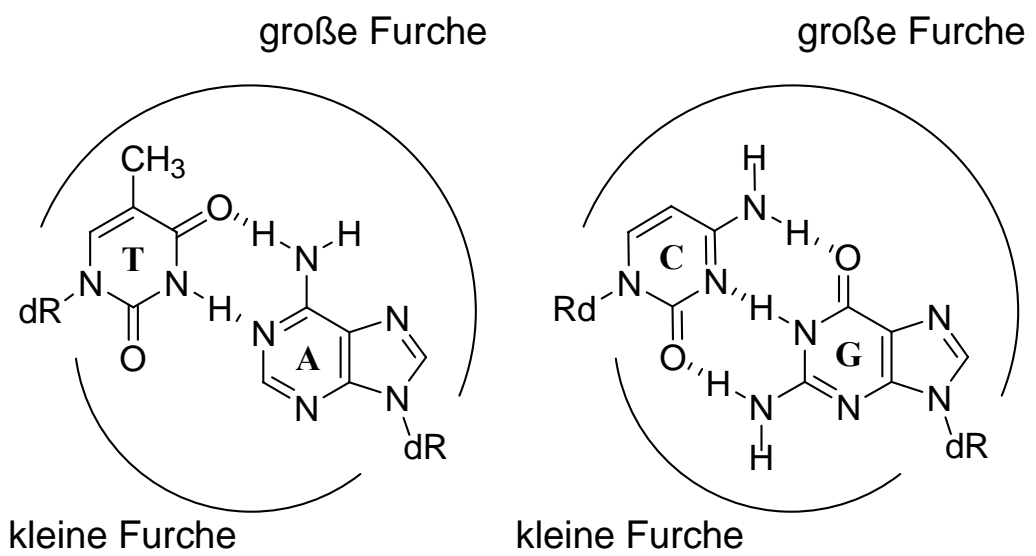

Abb. 129. Schematische Darstellung der großen und kleinen Furche in AT- bzw GC-reichen Abschnitten doppelsträngiger DNA.

Wird das dechlorierte Methyl-seco-CBI-DMAI-Analogon (+)-(1S)-49 mit dem DNAOligonukleotid ds-60 inkubiert, so kann trotz des vorhandenen AT-reichen DNAAbschnittes kein signifikantes induziertes CD-Signal beobachtet werden (Abb. 128b). Die um $\lambda=308 \mathrm{~nm}$ und $\lambda=330 \mathrm{~nm}$ detektierbaren sehr schwachen CD-Banden verändern sich im Laufe der Inkubationszeit nicht signifikant. (+)-(1S)-49 verfügt im Vergleich zu $(+)-(1 S, 10 R)-34 a$ bei sonst übereinstimmender Struktur nicht über ein Chloratom in der Seitenkette und kann daher nicht zu einem Drug zyklisieren. Die Ergebnisse stützen daher die These, dass das ICD im Wesentlichen durch die Wechselwirkung des Drugs und nicht des seco-Drugs mit der DNA verursacht wird.

Analog kann bei einer Umsetzung des Prodrugs (+)-( $1 S, 10 R)-33 a$ mit dem DNAOligonukleotid ds-60 im molaren Verhältnis 1:1 weder ein signifikantes induziertes CD-Signal noch eine zeitliche Veränderung des CD-Signals detektiert werden (Abb. 128c). Die zu beobachtenden CD-Banden mit einem Minimum bei $\lambda=305 \mathrm{~nm}$ und einem Maximum bei $\lambda=325 \mathrm{~nm}$ werden durch das Prodrug $(+)-(1 S, 10 R)-33 a$ selbst bzw. durch eine schwache Wechselwirkung des Prodrugs mit dem DNADoppelstrang verursacht. Letztere könnte hierbei sowohl für die geringfügige 
Verschiebung des Minimums als auch für eine schwache Intensitätserhöhung bei Inkubation des Prodrugs (+)-(1S,10R)-33a mit dem DNA-Oligonukleotid verantwortlich sein.

Das seco-Drug (-)-(1R,10S)-34a zeigt eine geringere Alkylierungseffizienz und Zytotoxizität als sein natürlich konfiguriertes Enantiomer (+)-(1S,10R)-34a (s. Kap. 6.2). Das bei Inkubation von (-)-(1R,10S)-34a mit dem DNA-Oligonukleotid ds-60 beobachtete schwache CD-Signal mit einem Minimum bei $\lambda=320 \mathrm{~nm}$ und einem Maximum bei $\lambda=354 \mathrm{~nm}$ sowie das Ausbleiben eines induzierten CD-Signals sind Hinweise darauf, dass die geringe Reaktivität dieses Enantiomers gegenüber doppelsträngiger DNA durch eine ungünstigere Wechselwirkung des aus $(-)-(1 R, 10 S)-34 \mathbf{a}$ entstehenden Drugs mit der DNA verursacht wird (Abb. 128d).

\subsection{Kinetik der Wechselwirkung des seco-Drugs $(+)-(1 S, 10 R)-34$ a mit verschiedenen Oligonukleotiden}

Die Lage des Minimums bei $\lambda=305 \mathrm{~nm}$ (genauer bei $304.5 \mathrm{~nm}$ ) verschiebt sich im Fall der Inkubation des seco-Drugs $(+)-(1 S, 10 R)-34 a$ mit den DNA-Oligonukleotiden nach dem Start der Inkubation nicht signifikant. Die zeitliche Veränderung dieses CDSignals wurde daher zur Untersuchung der Kinetik der Wechselwirkung des secoDrugs $(+)-(1 S, 10 R)-34 a$ mit den DNA-Doppelsträngen ds-60 und ds-69 sowie mit dem Oligonukleotid ON-1 (ds-60) verwendet.

Zunächst erfolgte eine Umsetzung des seco-Drugs $(+)-(1 S, 10 R)-34 a$ mit dem DNADoppelstrang ds-60 im molaren Verhältnis 1:1 in Phosphatpuffer (pH 7) (Abb. 130).

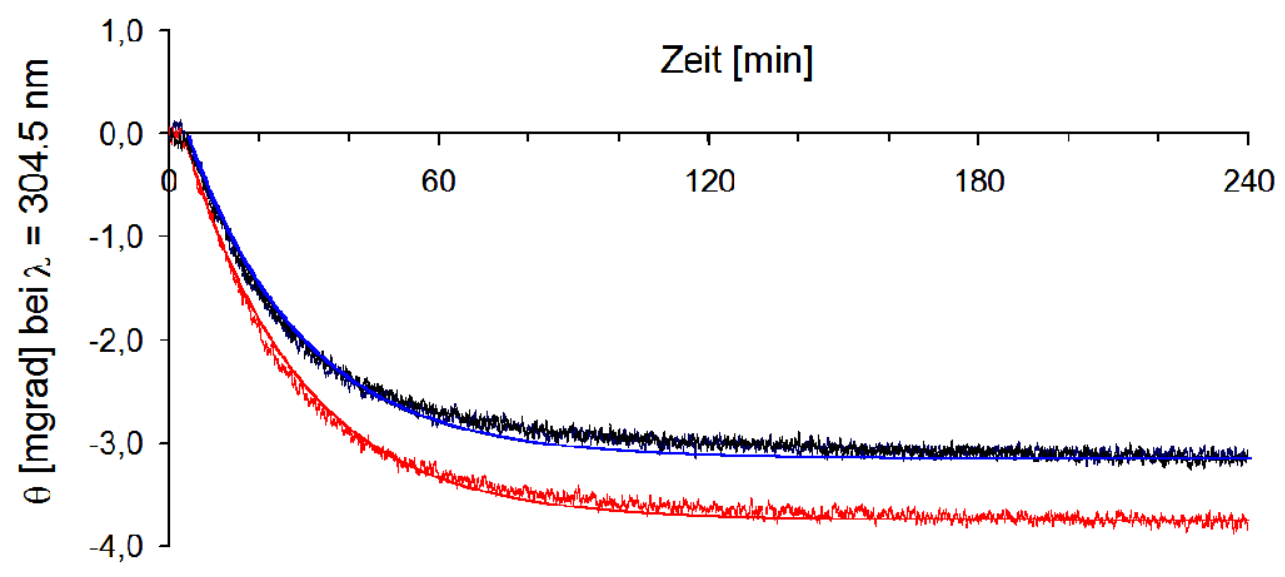

Abb. 130. Kinetik der Wechselwirkung des seco-Drugs (+)-(1S,10R)-34a mit dem DNAOligonukleotid ds-60 im Verhältnis 1:1 in Phosphatpuffer (Messung als Triplikat). 
Nach einer sehr kurzen Stagnation des CD-Signals zu Beginn der Messung (etwa vier Minuten) konnte eine schnelle Zunahme der Intensität des negativen CD-Signals beobachtet werden. Eine Sättigung trat nach etwa 60-80 Minuten bei etwa -3 mgrad ein. Die Kurvenanpassung mittels einer Exponentialfunktion (4) ergab eine gute Übereinstimmung mit den experimentellen Daten dreier Messungen für eine Zerfallskonstante von $k=(0.039 \pm 0.002) \mathrm{min}^{-1}$. Dies entspricht laut (5) einer Halbwertszeit von etwa 18 Minuten für den nicht gebundenen Wirkstoff. Das heißt, dass nach etwa 18 Minuten bereits die Hälfte des Wirkstoffs in Form des Drugs an den DNA-Doppelstrang gebunden hatte.

$$
\left(\theta_{\max }-\theta_{\min }\right) \cdot\left(1-e^{-k t}\right)+\theta_{\min }
$$

mit: $\quad \theta_{\min }=$ Elliptizität zu Beginn der Inkubation [mgrad]

$\theta_{\max }=$ Elliptizität am Ende der Inkubation [mgrad]

$k=$ Zerfallskonstante $\left[\mathrm{min}^{-1}\right]$

$t=$ Inkubationszeit [min]

$$
t_{1 / 2}=\frac{\ln 2}{k}
$$

mit: $\quad t_{1 / 2}=$ Halbwertszeit [min]

Wurde (+)-(1S,10R)-34a mit dem DNA-Doppelstrang ds-60 in Wasser inkubiert, so veränderte sich das CD-Signal im Laufe der vierstündigen Inkubation nur um $-(0.4 \pm 0.2)$ mgrad. Da in Wasser die Zyklisierung des seco-Drugs zum Drug langsamer erfolgt als in Puffer, bestätigt dies ebenfalls die These, dass das induzierte CD-Signal durch die Einlagerung des Drugs und nicht des seco-Drugs verursacht wird.

Wurde der DNA-Doppelstrang ds-60 mit einem zweifachen Überschuss des secoDrugs $(+)-(1 S, 10 R)$-34a in Puffer inkubiert, so nahm die Intensität des negativen CDSignals bei $\lambda=304.5 \mathrm{~nm}$ nach einer anfänglichen Stagnation von etwa vier Minuten mit einer ähnlichen Geschwindigkeit $\mathrm{zu}$ wie bei einer Inkubation im molaren Verhältnis der DNA zum Wirkstoff von 1:1 (Abb. 131). Die nach (3) bestimmte Zerfallskonstante betrug $k=(0.035 \pm 0.004) \mathrm{min}^{-1}$ und die Halbwertszeit etwa 20 Minuten. Die Elliptizität nach vier Stunden Inkubation betrug etwa -5 mgrad und damit etwas weniger als das Doppelte des Wertes nach einer 1:1-Inkubation. Demnach bindet das Drug in einem binären Modus, wenn es im Überschuss in der Reaktions- 
lösung vorhanden ist. Dies bestätigt die mittels Massenspektrometrie (s. Kap. 7) und HPLC (s. Kap. 8) gewonnenen Erkenntnisse.

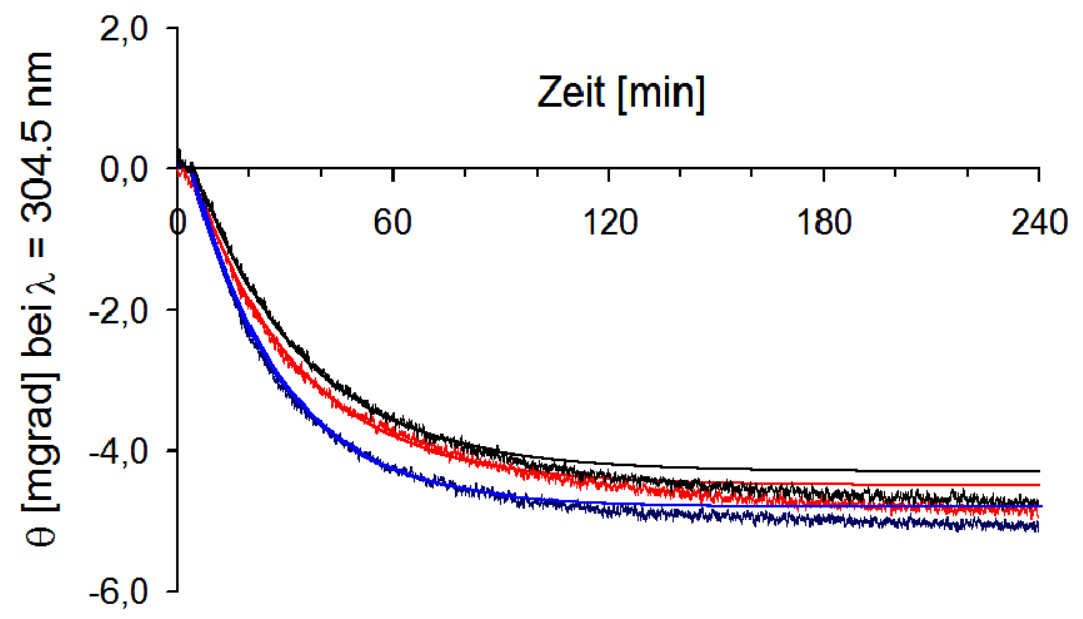

Abb. 131. Kinetik der Wechselwirkung des seco-Drugs (+)-(1S,10R)-34a mit dem DNAOligonukleotid ds-60 im molaren Verhältnis 2:1 in Phosphatpuffer (Messung als Triplikat).

Zur Klärung der Frage, ob beide Äquivalente des Drugs mit etwa der gleichen Geschwindigkeit an den DNA-Doppelstrang binden, wurde ds-60 zunächst mit einem Äquivalent des seco-Drugs $(+)-(1 S, 10 R)-34$ a versetzt und nach einer vierstündigen Inkubation ein weiteres Äquivalent des seco-Drugs zu der Reaktionslösung pipettiert. Abbildung 132 zeigt die zeitliche Veränderung des CD-Signals bei $\lambda=304.5 \mathrm{~nm}$ nach sequentieller Zugabe des ersten und zweiten Äquivalentes $(+)-(1 S, 10 R)-34 \mathbf{a}$. Deutlich ist eine jeweils schnelle Intensitätszunahme des CD-Signals zu erkennen, die eine Bindung beider Äquivalente des seco-Drugs an die DNA erneut verdeutlicht. Nach Zugabe des ersten Äquivalentes $(+)-(1 S, 10 R)$-34a erreichte das CD-Signal einen Wert von etwa -3 mgrad und nach der Zugabe des zweiten Äquivalentes einen Wert von circa -5 mgrad. Dies entspricht den Ergebnissen der bereits diskutierten Messungen.

Die nach (3) bestimmte Zerfallskonstante beträgt für die Zugabe des ersten Äquivalentes $(+)-(1 S, 10 R)-34 \mathbf{a} k=(0.032 \pm 0.005) \mathrm{min}^{-1}$ und die Halbwertszeit somit etwa 22 Minuten. Nach Zugabe des zweiten Äquivalentes seco-Drug nimmt die Zerfallskonstante einen Wert von $k=(0.024 \pm 0.001) \mathrm{min}^{-1}$ an und die Halbwertszeit beträgt somit etwa 29 Minuten. Das zweite Äquivalent bindet somit zwar immer noch sehr schnell, aber mit einer leicht verringerten Geschwindigkeit im Vergleich zum ersten Äquivalent. 


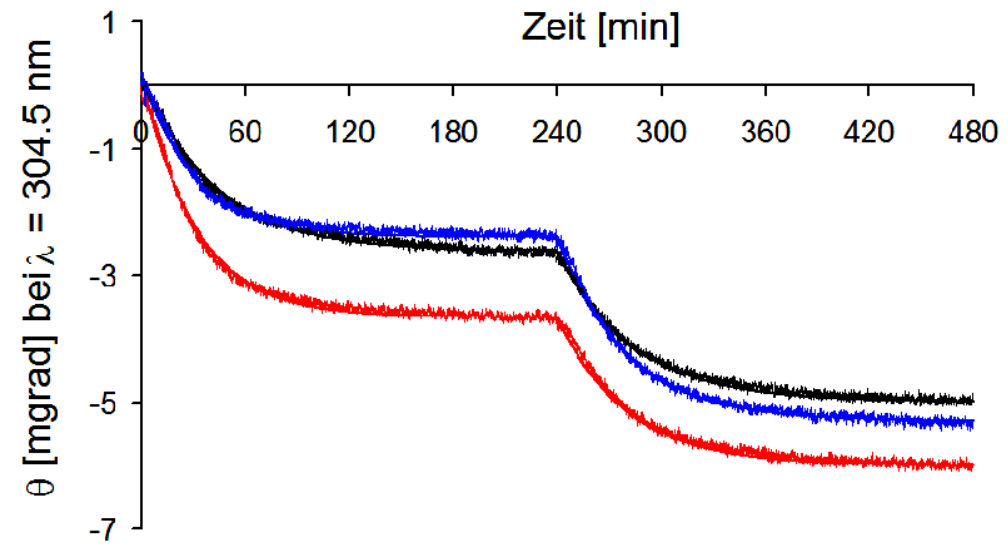

Abb. 132. Kinetik der Wechselwirkung des seco-Drugs (+)-(1S,10R)-34a mit dem DNAOligonukleotid ds-60. Zugabe eines ersten Äquivalentes (+)-34a zum Zeitpunkt $t=0$ min und eines zweiten Äquivalentes (+)-34a zum Zeitpunkt $t=240 \mathrm{~min}$. (Messung als Triplikat).

Warum es bei Inkubation des seco-Drugs $(+)-(1 S, 10 R)-\mathbf{3 4 a} \mathrm{zu}$ einem anfänglich nahezu konstanten Wert des CD-Signals bei $\lambda=304.5 \mathrm{~nm}$ kommt, wurde darauf zurückgeführt, dass das Drug zunächst durch Zyklisierung aus dem seco-Drug generiert werden muss, bevor die Interaktion mit der DNA erfolgen kann. Zur Überprüfung dieser These wurde die zeitliche Veränderung des CD-Signals bei Inkubation des seco-Drugs in Puffer in Abwesenheit von DNA untersucht (Abb. 133).

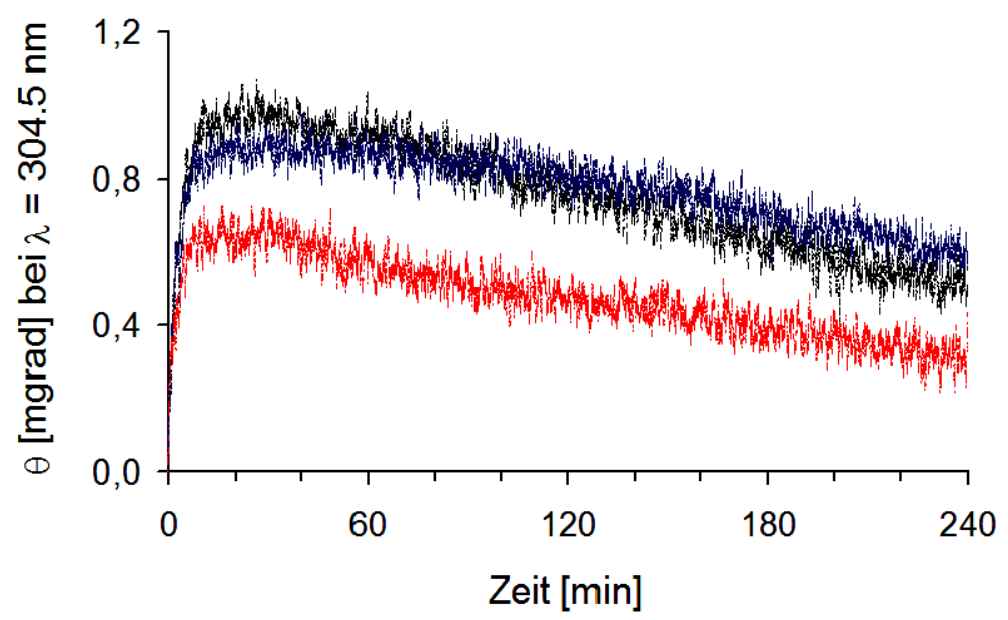

Abb. 133. Kinetik der Zyklisierung des seco-Drugs (+)-(1S,10R)-34a in Phosphatpuffer und dessen anschließenden Hydrolyse (Messung als Triplikat).

Im Gegensatz zu dem negativen CD-Signal bei einer Inkubation des seco-Drugs $(+)-(1 S, 10 R)-34 a$ mit dem DNA-Oligonukleotid ds-60 konnte bei der Inkubation des seco-Drugs im Puffer $\lambda=304.5 \mathrm{~nm}$ ein positives CD-Signal beobachtet werden. Dessen Intensität stieg sehr schnell an und erreichte nach 20-30 Minuten ein 
Maximum von etwa 0.9 mgrad. Danach sank die Intensität stetig ab und erreichte nach etwa vier Stunden die Häfte des Maximalwertes. Da das seco-Drug in Puffer innerhalb von 30 Minuten zu mehr als 90\% zum Drug zyklisiert und das Drug nach seiner Entstehung langsam im Puffer hydrolysiert wird, entspricht die anfängliche Zunahme des CD-Signals höchstwahrscheinlich der Zyklisierung des seco-Drugs zum Drug und die anschliessende Hydrolyse der Abnahme der Intensität dieses Signals.

Das positive CD-Signal nahm in den ersten vier Minuten am stärksten zu. Die Stagnation der Intensitätszunahme des negativen CD-Signals bei einer Inkubation des secoDrugs (+)-( $(S, 10 R)-34 a$ mit dem DNA-Oligonukleotid ds-60 kann demzufolge durch die Zyklisierung des seco-Drugs zum Drug verursacht sein. Hierbei gleicht die Zunahme des positiven CD-Signals, das durch die Entstehung des Drugs verursacht wird, die Zunahme des negativen CD-Signals, das durch die Einlagerung bereits entstandenen Drugs in den DNA-Doppelstrang verursacht wird, zunächst aus, bis dann die zunahme des negativen ICD überwiegt.

Das induzierte negative CD-Signal wurde auf die Wechselwirkung des Drugs mit doppelsträngiger DNA zurückgeführt und sollte bei einer Inkubation des seco-Drugs $(+)-(1 S, 10 R)-34 a$ mit einzelsträngiger DNA wie dem Oligonukleotid ON-1 (ds-60) somit nicht beobachtet werden können.

Diese Vermutung wurde durch die zeitabhängige Änderung des CD-Signals bei $\lambda=304.5 \mathrm{~nm}$ im Laufe einer vierstündigen Inkubation des Oligonukleotides ON-1 (ds-60) mit dem seco-Drug (+)-(1S,10R)-34a im Verhältnis 1:1 bestätigt (Abb. 134).

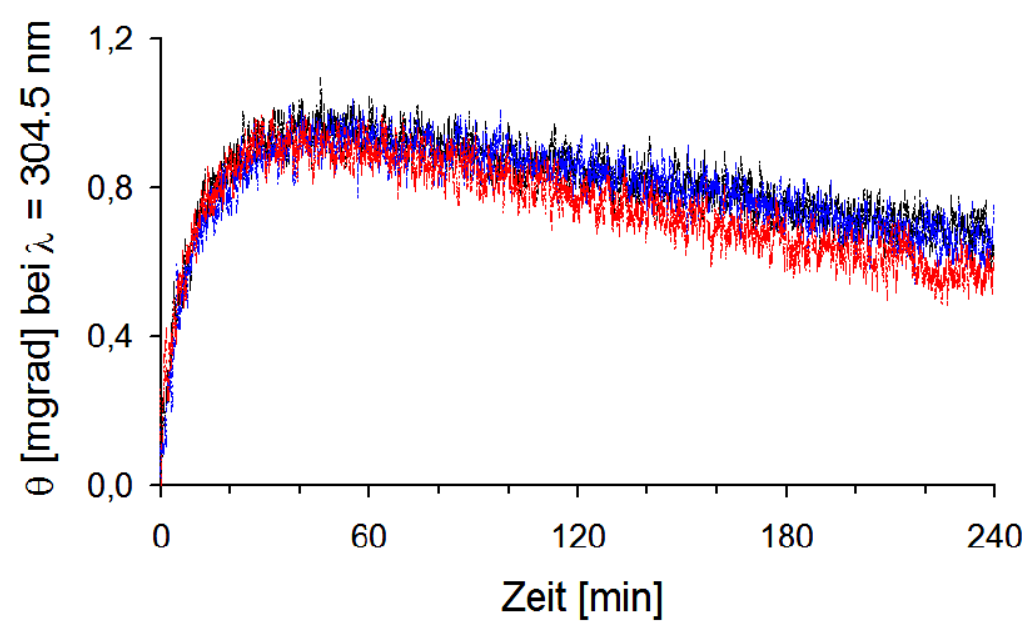

Abb. 134. Kinetik der Wechselwirkung des seco-Drugs (+)-(1S,10R)-34a mit dem einzelsträngigen DNA-Oligonukleotid ON-1 (ds-60) in Phosphatpuffer (Messung als Triplikat). 
Hierbei konnte analog zu den Messungen des seco-Drugs in Abwesenheit von DNA lediglich eine schnelle Intensitätszunahme eines positiven CD-Signals bis zu einem Maximum von etwa 0.9 mgrad sowie eine Abnahme innerhalb der nächsten 3 Stunden auf etwa die Hälfte des Maximalwertes beobachtet werden.

Bei einer Inkubation des seco-Drugs $(+)-(1 S, 10 R)-34 a$ mit dem DNA-Doppelstrang ds-69 wurde im Wellenlängenbereich von $\lambda=220-350 \mathrm{~nm}$ kein induziertes CD-Signal beobachtet (Abb. 128c). Dementsprechend konnte bei einer Inkubation dieses DNAOligonukleotides mit $(+)-(1 S, 10 R)$-34a nur die für eine Zyklisierung des seco-Drugs zum Drug charakteristische Zunahme des CD-Signal bei $\lambda=304.5 \mathrm{~nm}$ auf etwa $0.8 \mathrm{mgrad}$ und dessen nachfolgende Abnahme beobachtet werden (Abb. 135). Diese Messungen bestätigen, dass das Drug nur eine sehr schwache Wechselwirkung mit dem GC-reichen DNA-Doppelstrang eingeht.

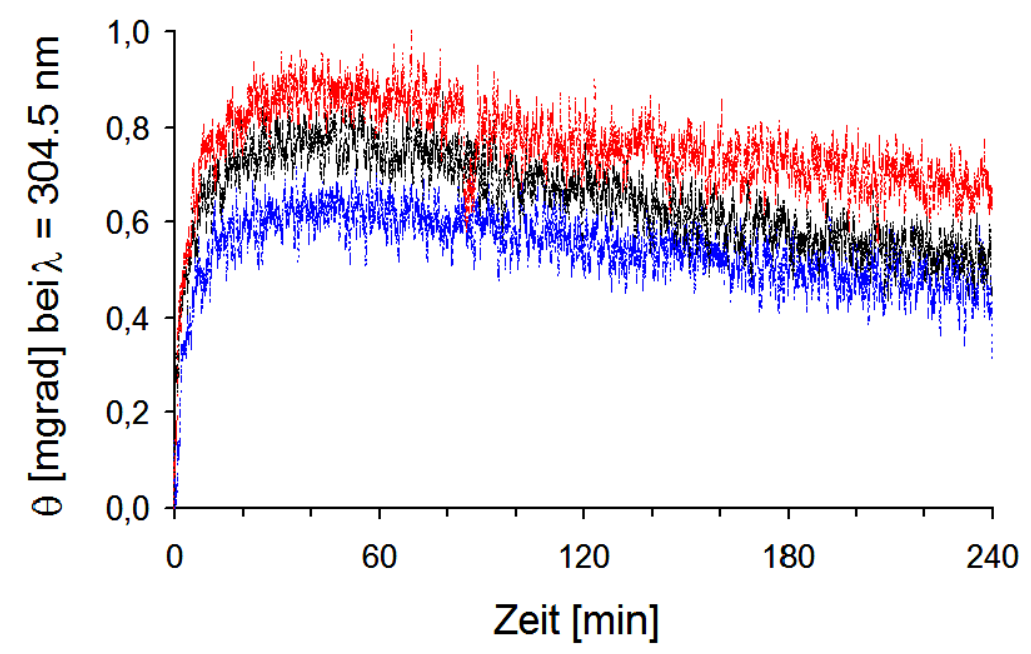

Abb. 135. Kinetik der Wechselwirkung des seco-Drugs (+)-(1S,10R)-34a mit dem DNAOligonukleotid ds-69 in Phosphatpuffer (Messung als Triplikat).

Das zu $(+)-(1 S, 10 R)-34 a$ enantiomere seco-Drug $(-)-(1 R, 10 S)-34 a$ zeigte ein Minimum bei $\lambda=320 \mathrm{~nm}$ anstelle des Minimums bei $\lambda=305 \mathrm{~nm}$. Wurde die zeitliche Veränderung dieses Signals nach dem Beginn einer Inkubation des seco-Drugs $(-)-(1 R, 10 S)-34$ mit dem DNA-Oligonukeotid ds-60 untersucht, so wurde ein negatives CD-Signal aufgezeichnet. Die Intensität dieses CD-Signals nahm in den ersten 20 Minuten schnell bis auf etwa -0.4 mgrad zu und in den folgenden Stunden sank die Intensität auf etwa die Hälfte des Maximalwertes ab. Sowohl der Kurvenverlauf als auch das im Vergleich zur Zyklisierung des seco-Drugs (+)-(1S,10R)-34a umgekehrte, negative Vorzeichen des CD-Signals weisen darauf hin, dass das CD- 
Signal durch eine Zyklisierung des seco-Drugs $(-)-(1 R, 10 S)-34 a$ zum entsprechenden Drug sowie dessen nachfolgender Hydrolyse verursacht wird. Die Geschwindigkeit der Umsetzung entspricht hierbei etwa derjenigen des entsprechenden Enantiomers $(+)-(1 S, 10 R)-34 a$. Eine Wechselwirkung mit der DNA ist nicht zu erkennen.

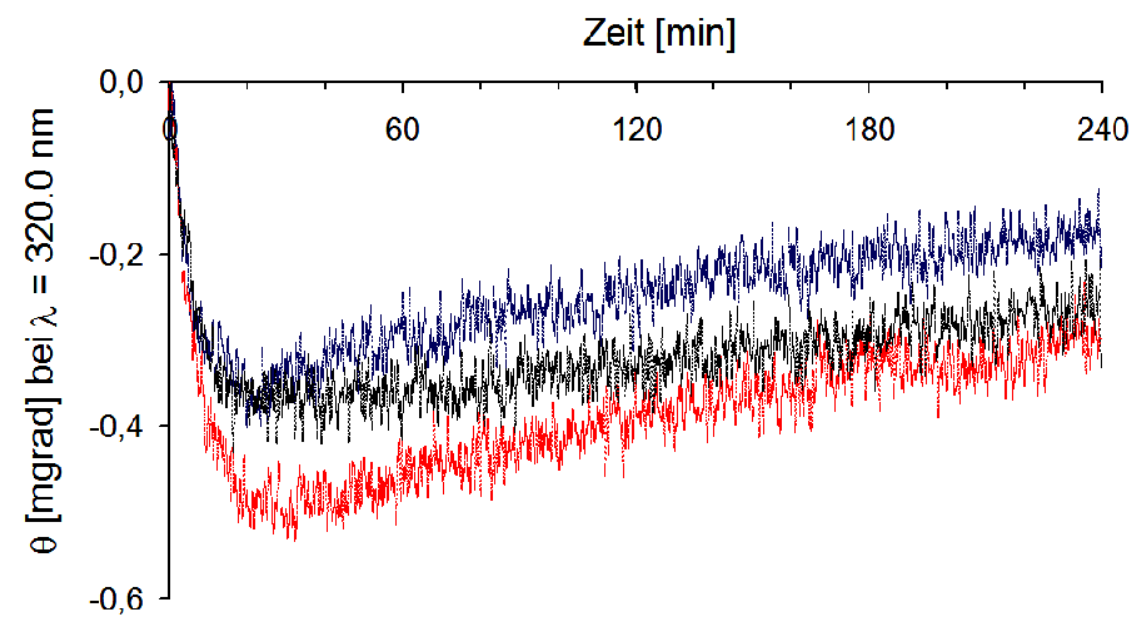

Abb. 136. Kinetik der Wechselwirkung des seco-Drugs (-)-(1R,10S)-34a mit dem DNAOligonukleotid ds-60 in Phosphatpuffer (Messung als Triplikat). 


\subsection{Untersuchung der Wechselwirkung verschiedener seco-Drugs mit dem Oligonukleotid ds-60}

Die Intensität des durch die Methyl-seco-CBI-DMAI-Analoga induzierten CD-Signals bei Wechselwirkung mit dem DNA-Doppelstrang ds-60 korreliert sehr gut mit der mittels massenspektrometrischen Untersuchungen bestimmten Alkylierungseffizienz dieser Verbindungen (s. Kap. 6). Um zu überprüfen, ob eine quantitative Beziehung zwischen der Zytotoxizität verschiedener seco-Drugs und der Intensität des durch diese Wirkstoffe verursachten CD-Signals besteht, wurden die Methyl-seco-CBIDerivate $(+)-(1 S, 10 R)-34 a-e$ mit dem DNA-Doppelstrang ds-60 (Abb. 137) inkubiert. Für einen Zeitraum von bis zu vier Stunden wurde die zeitabhängige Veränderung der CD-Spektren sowie des CD-Signals bei $\lambda=304.5 \mathrm{~nm}$ nach dem Start der Inkubation untersucht (Abb. 138, Tab. 44).

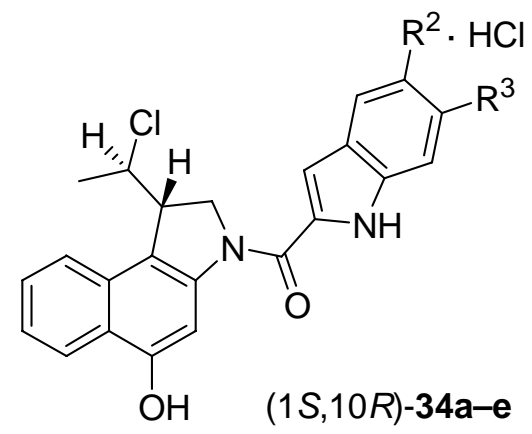

5'-CGG TCA ATT AGT CGC-3'
3'-GCC AGT TAA TCA GCG-5'
$\left.\begin{array}{l}(\mathrm{ON}-1) \\ (\mathrm{ON}-2)\end{array}\right\} \mathrm{ds}-60$

\begin{tabular}{ll}
\hline$R^{2}$ & $R^{3}$
\end{tabular}

a<smiles>CN(C)CCO[12CH3]</smiles>

$\mathrm{H}$

b

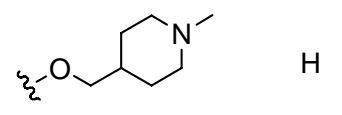

c $\quad \xi^{-N_{N}^{H}} \prod_{O}^{-} N_{1}^{N^{-}} \quad H$
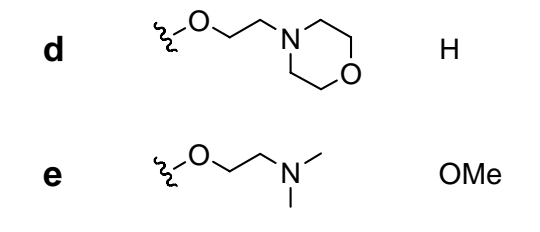

Abb. 137. Methyl-seco-CBI-Hydrochloride (+)-(1S,10R)-34a-e sowie die DNA ds-60.

Bei allen Methyl-seco-CBI-Hydrochloriden konnte ein signifikantes induziertes CDSignal beobachtet werden, dessen Intensität mit zunehmender Inkubationsdauer anstieg und nach zwei bis vier Stunden seinen Maximalwert erreichte. Hierbei war deutlich eine Verschiebung des Maximums der positiven induzierten CD-Bande von $\lambda=325 \mathrm{~nm}$ zu Beginn der Inkubation auf $\lambda=335 \mathrm{~nm}$ nach vierstündiger Inkubation zu erkennen, während die Lage des Minimums der negativen induzierten CD-Bande bei $\lambda=305 \mathrm{~nm}$ konstant blieb. Die Verschiebung der Lage des Maximums wird hierbei vermutlich durch den höher werdenden Anteil in den DNA-Doppelstrang 
eingelagerten Drugs im Vergleich zum Anteil noch ungebundenen Wirkstoffs verursacht.

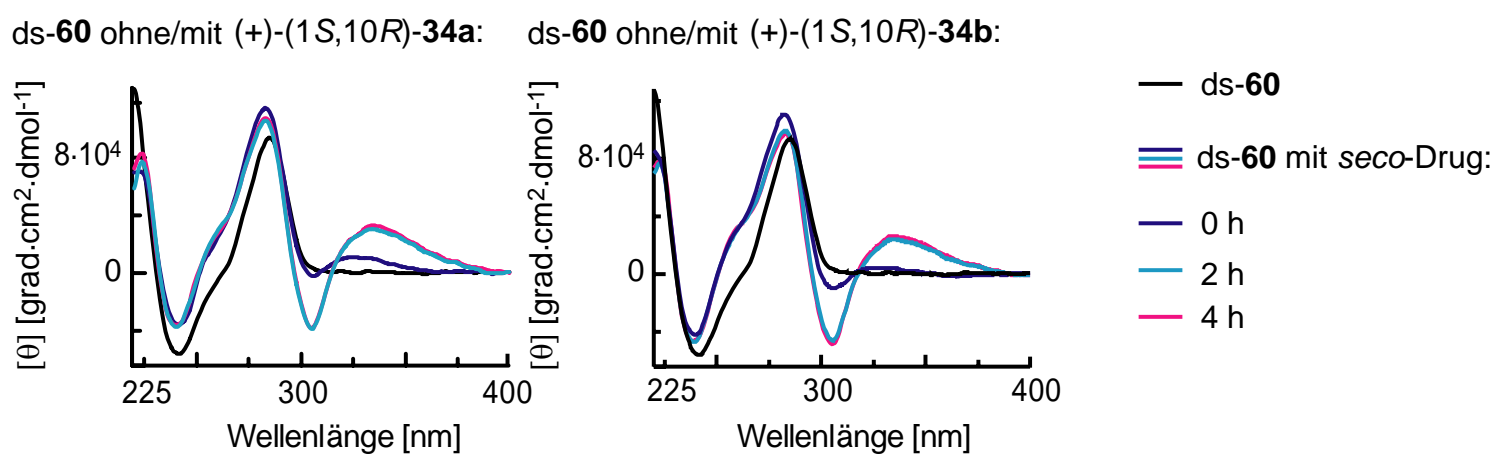

ds-60 ohne/mit (+)-(1S,10R)-34c: $\quad$ ds-60 ohne/mit (+)-(1S,10R)-34d: $\quad$ ds-60 ohne/mit (+)-(1S,10R)-34e:
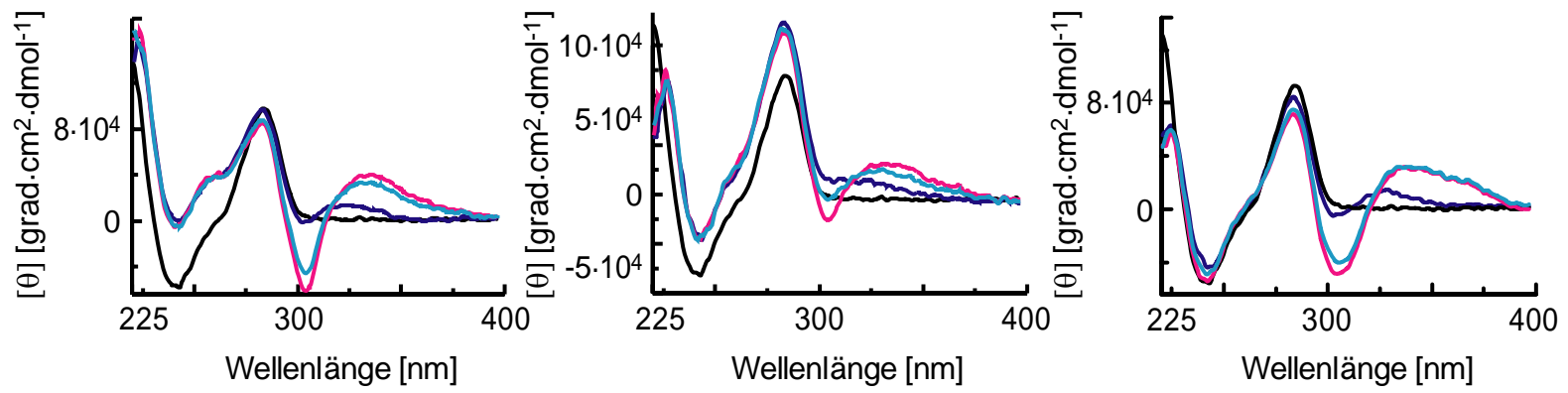

Abb. 138. CD-Spektren des Oligonukleotides ds-60 sowie von dessen Mischung mit den seco-Drug-Hydrochloriden (+)-(1S,10R)-34a-e im Verhältnis 1:1 in Phosphatpuffer (pH 7).

\begin{tabular}{ccccc}
\hline seco-Drug & $\begin{array}{c}\boldsymbol{I C}_{\mathbf{5 0}} \text { (A549) } \\
{[\mathbf{n M ]}}\end{array}$ & $\begin{array}{c}\Delta \boldsymbol{I C D} \\
{[\mathbf{m g r a d}]}\end{array}$ & $\begin{array}{c}\Delta \boldsymbol{\theta}(\boldsymbol{\lambda}=\mathbf{3 0 4 . 5} \mathbf{~ n m}) \\
{[\mathbf{m g r a d}]}\end{array}$ & $\begin{array}{c}\lambda_{\max }(\mathbf{0} \mathbf{~ h} \rightarrow \mathbf{4} \mathbf{~ h}) \\
{[\mathbf{n m}]}\end{array}$ \\
\hline$(+)-(1 S, 10 R)-34 \mathbf{a}$ & 0.75 & 4.6 & $-(3.5 \pm 0.4)$ & $325 \rightarrow 335$ \\
$(+)-(1 S, 10 R)-34 \mathbf{b}$ & 0.8 & 4.9 & -2.4 & $325 \rightarrow 335$ \\
$(+)-(1 S, 10 R)-34 \mathbf{c}$ & 3.8 & 5.1 & -2.9 & $325 \rightarrow 335$ \\
$(+)-(1 S, 10 R)-34 \mathbf{d}$ & 3.7 & 2.3 & -1.4 & $320 \rightarrow 335$ \\
$(+)-(1 S, 10 R)-34 \mathrm{e}$ & 0.20 & 5.5 & $-(2.8 \pm 0.2)$ & $330 \rightarrow 338$
\end{tabular}

Tab. 44. Zytotoxizitäten der Methyl-seco-CBI-Hydrochloride (+)-(1S,10R)-34a-e, $\triangle I C D$ Werte für $t=4 \mathrm{~h}(\Delta I C D=\theta(\lambda=335 \mathrm{~nm})-\theta(\lambda=305 \mathrm{~nm})), \Delta \theta$-Werte für $\lambda=304.5 \mathrm{~nm}$ $(\Delta \theta=\theta(4 \mathrm{~h})-\theta(0 \mathrm{~h}))$ sowie Verschiebung des Maximums der positiven CD-Bande nach $4 \mathrm{~h}$ Inkubation der Methyl-seco-CBI-Hydrochloride mit ds-60 im molaren Verhältnis 1:1 in Phosphatpuffer ( $\mathrm{pH}$ 7).

Die $\triangle I C D$-Werte $(\triangle I C D=\theta(\lambda=335 \mathrm{~nm})-\theta(\lambda=305 \mathrm{~nm}))$ der seco-Drugs mit Ausnahme des seco-Drugs $(+)-(1 S, 10 R)-34 d$ sind mit $\triangle I C D=(5 \pm 0.4)$ mgrad sehr 
ähnlich. Auch die Differenzen der Elliptizitäten $\Delta \theta=\theta(4 \mathrm{~h})-\theta(0 \mathrm{~h})$ bei $\lambda=304.5 \mathrm{~nm}$ sind mit $\Delta \theta=(2.9 \pm 0.5)$ mgrad für diese seco-Drugs in einer vergleichbaren Größenordnung. Die Einlagerung des seco-Drugs $(+)-(1 S, 10 R)-34 d$ bzw. des aus diesem in situ geformten Drugs 43d könnte aufgrund des erhöhten sterischen Anspruchs des Morpholino-Substituenten in der DNA-bindenen Untereinheit behindert werden. Dies korreliert mit der geringeren Zytotoxizität des seco-Drugs $(+)-(1 S, 10 R)-34 d$ in Invitro-Zytotoxizitätstests. Die hohe Affinität des seco-Drugs $(+)-(1 S, 10 R)-\mathbf{3 4 c}$ zu dem DNA-Doppelstrang korreliert allerdings nicht mit der ebenfalls niedrigen Zytotoxizität dieses Wirkstoffs im Vergleich zu $(+)-(1 S, 10 R)-34 \mathbf{a},(+)-(1 S, 10 R)-\mathbf{3 4 b}$ und $(+)-$ $(1 S, 10 R)-\mathbf{3 4 e}$.

Durch das Auftreten eines induzierten CD-Signals können demzufolge die toxischen Methyl-seco-CBI-Derivate wie die $(+)-(1 S, 10 R)$-seco-Drugs von den weniger giftigen Analoga wie den Prodrugs und den entsprechenden $(-)-(1 R, 10 S)$-seco-Drugs unterschieden werden. Die Messung der Intensität des induzierten CD-Signals erlaubt jedoch keine quantitative Abschätzung der Zytotoxizität.

Die Ergebnisse der CD-spektroskopischen Untersuchungen der Wechselwirkung der seco-CBI-Analoga (+)-(1S)-56a, $(-)-(1 R)-56 \mathbf{a},(-)-(1 S)-54 \mathbf{a}$ und $(+)-(1 S)-56 \mathbf{b}$ mit dem DNA-Oligonukleotid ds-60 zeigen, dass sowohl das Prodrug (-)-(1S)-54a als auch das seco-Drug $(-)-(1 R)-56 a$ mit der unnatürlichen Konfiguration keine bzw. nur eine vergleichbar schwache Wechselwirkung mit dem DNA-Doppelstrang ds-60 eingehen (Abb. 139, Tab. 45). Bei einer Wechselwirkung der seco-Drugs $(+)-(1 S)-56 a$ und $(+)-(1 S)-56 \mathbf{b}$ mit dem Oligonukleotid werden hingegen signifikante induzierte CDBanden beobachtet. Dies zeigt, dass auch für seco-CBI-Analoga eine grobe Abschätzung der Zytotoxizität mittels CD-Spektroskopie erfolgen kann.

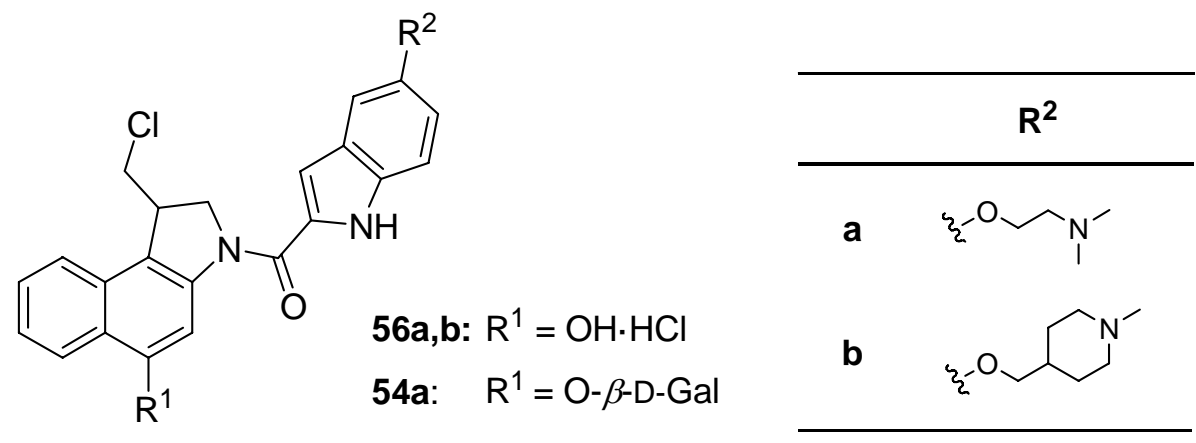

Abb. 139. seco-CBI-DMAI-Hydrochloride 56a,b sowie das seco-CBI-DMAI-Prodrug 54a.

Die $\triangle I C D$-Werte der seco-Drugs $(+)-(1 S)-56 \mathbf{a}$ und $(+)-(1 S)-56 \mathbf{b}$ sowie die Differenzen der Elliptizitäten nach vierstündiger Inkubationszeit bei $\lambda=304.5 \mathrm{~nm}$ 
unterscheiden sich jedoch deutlich voneinander, obwohl beide Verbindungen eine vergleichbar hohe Zytotoxizität aufweisen. Weiterhin zeigt (-)-(1S)-56a trotz einer im Vergleich zu den Methyl-seco-CBI-Hydrochloriden (+)-(1S,10R)-34a-e höheren Zytotoxizität nur ein verhältnismäßig schwaches induziertes CD-Signal bei Wechselwirkung mit ds-60. Dies bestätigt, dass die Intensität des induzierten CD-Signals nicht quantitativ mit der Zytotoxizität korreliert.

\begin{tabular}{|c|c|c|c|c|}
\hline seco-Drug & $\begin{array}{c}I C_{50}(\mathrm{~A} 549) \\
{[\mathrm{nM}]}\end{array}$ & $\begin{array}{c}\triangle I C D \\
{[\mathrm{mgrad}]}\end{array}$ & $\begin{array}{c}\Delta \theta(\lambda=304.5 \mathrm{~nm}) \\
{[\mathrm{mgrad}]}\end{array}$ & $\begin{array}{c}\lambda_{\max }(0 \mathrm{~h} \rightarrow 4 \mathrm{~h}) \\
{[\mathrm{nm}]}\end{array}$ \\
\hline$(+)-(1 S)-\mathbf{5 6 a}$ & 0.026 & 2.6 & -1.5 & 335 \\
\hline$(-)-(1 R)-56 \mathbf{a}$ & 11.5 & 0.2 & - & $355 \rightarrow 340$ \\
\hline$(-)-(1 S)-\mathbf{5 4 a}$ & 56.3 & - & - & 325 \\
\hline$(+)-(1 S)-\mathbf{5 6} \mathbf{b}$ & 0.014 & 7.1 & -3.5 & $320 \rightarrow 335$ \\
\hline
\end{tabular}

Tab. 45. Zytotoxizitäten der seco-CBI-Derivate (+)-(1S)-56a, (-)-(1R)-56a, (-)-(1S)-54a und $(+)-(1 S)-56 \mathbf{b}, \Delta I C D$-Werte für $t=4 \mathrm{~h}(\Delta I C D=\theta(\lambda=335 \mathrm{~nm})-\theta(\lambda=305 \mathrm{~nm})), \Delta \theta$-Werte für $\lambda=304.5 \mathrm{~nm}(\Delta \theta=\theta(4 \mathrm{~h})-\theta(0 \mathrm{~h}))$ sowie Verschiebung des Maximums der positiven CD-Bande nach 4-stündiger Inkubation der seco-CBI-Derivate mit ds-60 im molaren 1:1Verhältnis in Phosphatpuffer (pH 7).

Die seco-CBI-Hydrochloride $(+)-(1 S)-56 \mathbf{a}$ und $(+)-(1 S)-56 \mathbf{b}$ weisen im Vergleich zu den Methyl-seco-CBI-Hydrochloriden $(+)-(1 S, 10 R)-\mathbf{3 4 a}-\mathbf{e}$ bei einer Inkubation mit dem DNA-Doppelstrang ds-60 eine deutlich langsamere Zunahme des induzierten CDSignals auf (Abb. 138 und Abb. 140). So wurde das Maximum des induzierten CDSignals nicht nach maximal vier Stunden, sondern bei $(+)-(1 S)$-56a erst nach $24 \mathrm{~h}$ und bei $(+)-(1 S)$-56b erst nach $48 \mathrm{~h}$ erreicht.
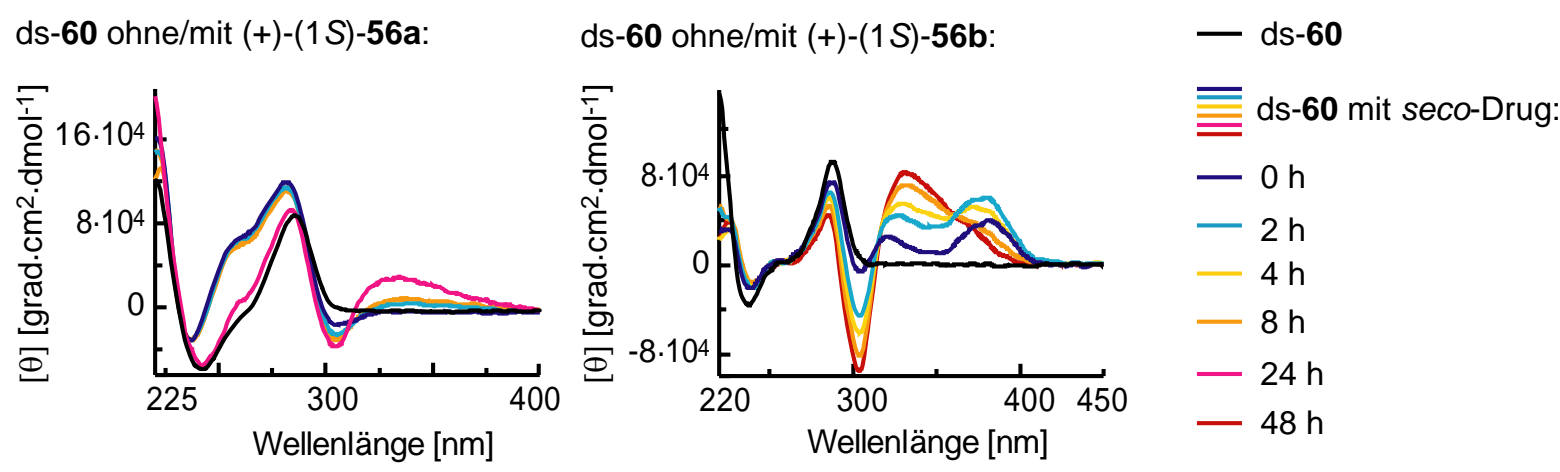

Abb. 140. CD-Spektren des Oligonukleotides ds-60 sowie von dessen Mischung mit den seco-Drug-Hydrochloriden (+)-(1S)-56a,b im 1:1-Verhältnis in Phosphatpuffer ( $\mathrm{pH} 7)$. 
Untersuchungen haben gezeigt, dass die seco-CBI-Hydrochloride in Abwesenheit von DNA mit etwa der gleichen Geschwindigkeit zu den entsprechenden Drugs zyklisieren wie die Methyl-seco-CBI-Hydrochloride. ${ }^{157,159}$ Somit kann die langsamere Zunahme des CD-Signals bei den seco-CBI-Derivaten nur durch eine Stabilisierung der secoForm durch den DNA-Doppelstrang und/oder eine langsamere oder weniger stabile Einlagerung des Drugs in den DNA-Doppelstrang verursacht werden.

Interessanterweise kann bei der Inkubation des seco-Drugs (+)-(1S)-56b mit dem DNA-Doppelstrang ds-60 nicht nur das für die Bindung des Drugs an den DNADoppelstrang charakteristische induzierte CD-Signal mit einem Minimum bei $\lambda=305 \mathrm{~nm}$ und einem Maximum bei $\lambda=335 \mathrm{~nm}$ beobachtet werden, sondern auch eine zusätzliche positive CD-Bande bei $\lambda=390 \mathrm{~nm}$ (Abb. 140). Die Intensität dieser CD-Bande nimmt in den ersten zwei Stunden nach Beginn der Inkubation schnell zu, um danach bei gleichzeitiger Vergrößerung des induzierten CD-Signals bei $\lambda=305 \mathrm{~nm}$ und $\lambda=335 \mathrm{~nm}$ wieder abzunehmen.

HPLC-Untersuchungen der Wechselwirkung der seco-Drugs (+)-(1S)-56a und $(+)-(1 S)$-56b mit dem DNA-Doppelstrang ds-60 hatten ergeben, dass das seco-Drug $(+)-(1 S)$-56b in beträchtlichem Maße durch eine Wechselwirkung mit dem DNADoppelstrang stabilisiert wird, während $(+)-(1 S)$-56a und die Methyl-seco-CBIHydrochloride $(+)-(1 S, 10 R)-\mathbf{3 4 a} \mathbf{a}, \mathbf{b}$ auch in Anwesenheit des DNA-Doppelstranges ds-60 schnell zum entsprechenden Drug zyklisieren (s. Kap. 7.2). Es wurde daher vermutet, dass die Bande um $\lambda=390 \mathrm{~nm}$ durch das seco-Drug verursacht wird. Um dies zu überprüfen, wurden CD-Spektren der Lösungen der seco-Drugs (+)-(1S)-56a,b und $(+)-(1 S, 10 R)-34 a, b$ in Puffer gemessen (Abb. 141).

Bei $\lambda=390 \mathrm{~nm}$ konnte für die seco-Drugs $(+)-(1 S)-56 \mathbf{b}$ und $(+)-(1 S, 10 R)-\mathbf{3 4 b}$ mit einer MPI-DNA-bindenen Einheit ein signifikantes CD-Signal detektiert werden, dessen Intensität innerhalb von 1-1.5 Stunden so stark abnahm, dass es nicht mehr detektiert werden konnte. Am stärksten ausgeprägt war dieses Signal für (+)-(1S)-56b. Aufgrund der rapiden Intensitätsabnahme konnte das CD-Signal bei $\lambda=390 \mathrm{~nm}$ nur dem schnell zum entsprechenden Drug zyklisierenden seco-Drug zugeordnet werden, denn die Drugs, und hier insbesondere die CBI-Drugs 84a,b, weisen eine hohe Stabilität auf.

Bei den beiden seco-Drugs $(+)-(1 S)$-56a und $(+)-(1 S, 10 R)$-34a mit einer DMAI-DNAbindenen Einheit konnte das CD-Signal bei $\lambda=390 \mathrm{~nm}$ nicht detektiert werden. Dies 
ist vermutlich auf eine schnellere Zyklisierung der seco-Drugs zu den entsprechenden Drugs und eine geringere Signalintensität zurückzuführen.
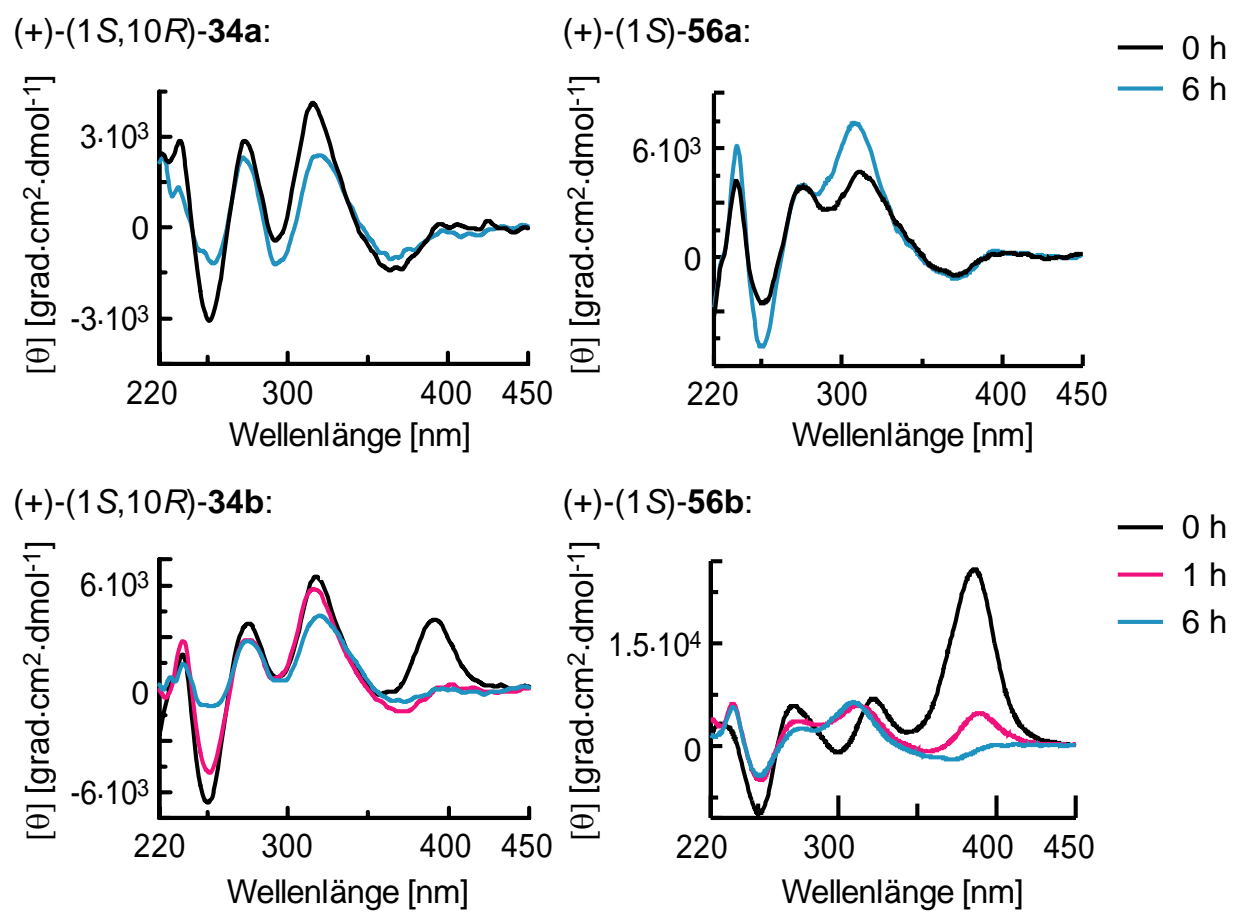

Abb. 141. CD-Spektren der seco-Drug-Hydrochloride (+)-(1S,10R)-34a, (+)-(1S)-56a, $(+)-(1 S, 10 R)-34 b$ und $(+)-(1 S)-56 b$ nach $0 \mathrm{~h}, 1 \mathrm{~h}$ und $6 \mathrm{~h}$ Inkubation in PBS (pH 7.4).

Die bei der Inkubation des seco-Drugs ( + -) $(1 S)-\mathbf{5 6 b}$ mit ds-60 beobachtete anfängliche Intensitätszunahme des CD-Signals bei $\lambda=390 \mathrm{~nm}$ (Abb. 140) kann durch eine Wechselwirkung des seco-Drugs mit der DNA erklärt werden, bei der durch Kopplungen der elektronischen Übergänge des seco-Drugs und der DNAKomponenten eine Intensitätserhöhung des CD-Signals bewirkt wird. Vermutlich erfolgt die Stabilisierung der seco-Form durch die Wechselwirkung mit der DNA nicht durch eine Einlagerung in die kleine Furche des DNA-Doppelstranges.

Da die beiden Methyl-seco-CBI-Derivate $(+)-(1 S, 10 R)-34 \mathbf{a}$ und $(+)-(1 S, 10 R)-34 \mathbf{b}$ bei Inkubation mit verschiedenen DNA-Oligonukleotiden nicht signifikant stabilisiert werden (s. Kap. 7.2) und die Signalintensität der Bande bei $\lambda=390 \mathrm{~nm}$ nur eine relativ geringe Intensität hat, wurde für diese Verbindungen keine intensive CD-Bande bei einer Inkubation mit den entsprechenden DNA-Oligonukleotiden erwartet und beobachtet.

Bei entsprechenden HPLC-Untersuchungen der Inkubation des seco-Drug-Hydrochlorids $(+)-(1 S)$-56a mit dem DNA-Doppelstrang ds-64 wurde stattdessen analog zu 
$(+)-(1 S)-56 b$ eine Stabilisierung der seco-Form beobachtet (s. Kap. 7.2). Da eine Wechselwirkung des seco-Drugs mit diesem DNA-Oligonukleotid die Signalintensität bei $\lambda=390 \mathrm{~nm}$ durch eine Induktion erhöhen könnte, wurden die CD-Spektren einer entsprechenden Reaktionslösung in Puffer und Wasser als Lösungsmittel gemessen (Abb. 142).
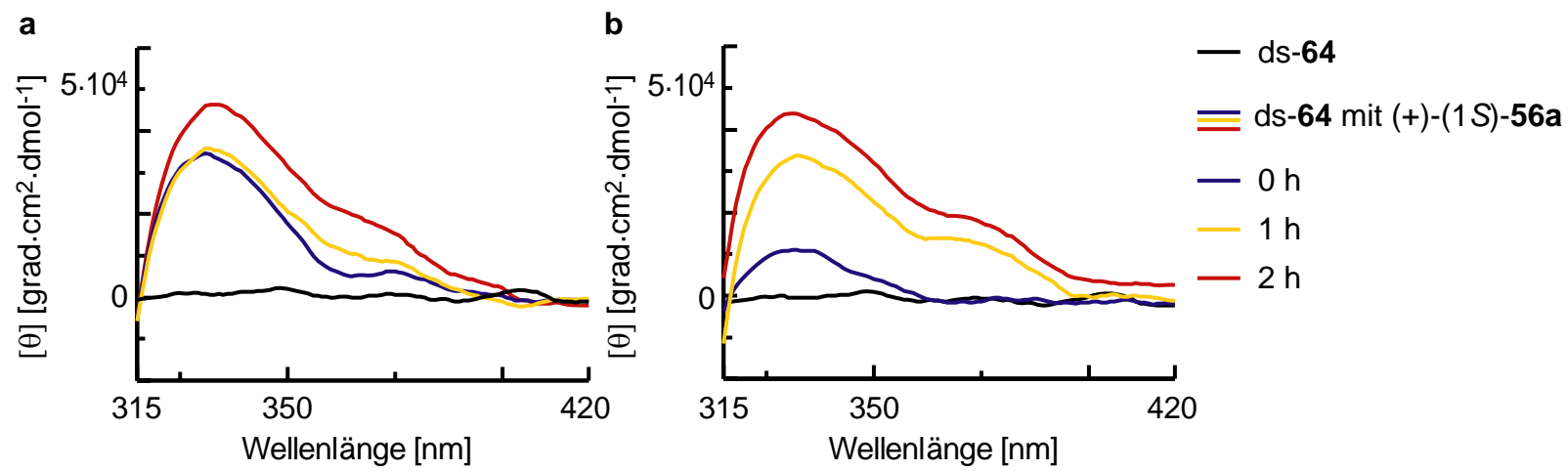

Abb. 142. CD-Spektren des Oligonukleotide ds-64 sowie dessen Mischung mit dem secoDrug-Hydrochlorid (+)-(1S)-56a im Verhältnis 1:1 in Wasser (a) und Phosphatpuffer (b).

Die dem seco-Drug zugeordnete Bande um $\lambda=390 \mathrm{~nm}$ ist sowohl bei einer Inkubation in Wasser als auch bei einer Inkubation in Puffer als Schulter der positiven Bande um $\lambda=335 \mathrm{~nm}$ zu erkennen. Hierbei kann, wie bei einer Inkubation von (+)-(1S)-56b mit ds-60, eine Intensitätszunahme in den ersten 2 Stunden der Inkubation beobachtet werden.

Wird (+)-(1S)-56a mit zellulärer DNA inkubiert, so kann nach einer Inkubationszeit von einer Stunde deutlich eine positive, durch eine Wechselwirkung des seco-Drugs mit der DNA induzierte CD-Bande um $\lambda=390 \mathrm{~nm}$ detektiert werden (Abb. 143).

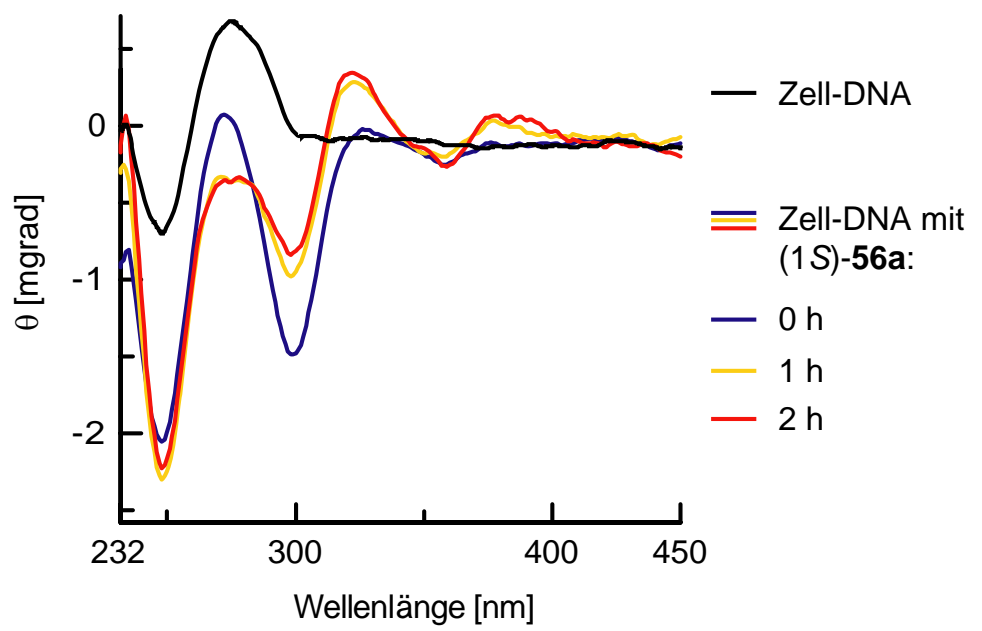

Abb. 143. CD-Spektren zellulärer DNA sowie einer Mischung selbiger mit dem seco-DrugHydrochlorid (+)-(1S)-56a in Wasser. 
Diese Bande ist intensiver als die bei einer Inkubation mit synthetischen DNA-Oligonukleotiden beobachtete Bande und zeigt deutlich, dass eine signifikante Stabilisierung des seco-Dugs durch eine Wechselwirkung mit der zellulären DNA stattfindet.

Sowohl (+)-(1S)-56a als auch $(+)-(1 S)-56 \mathbf{b}$ werden demzufolge im Gegensatz zu $(+)-(1 S, 10 R)-34 \mathbf{a}$ und $(+)-(1 S, 10 R)-34 \mathbf{b}$ durch eine Wechselwirkung mit doppelsträngiger DNA in ihrer seco-Form stabilisiert und dies manifestiert sich CD-spektroskopisch in einer positiven Bande um $\lambda=390 \mathrm{~nm}$. 


\section{Untersuchung der Aufnahme verschiedener Zytostatika in Zellen mittels CD-Spektroskopie}

Die seco-Drugs $(+)-(1 S, 10 R)-34 \mathbf{a}, \mathbf{b}$ und $(+)-(1 S)-56 \mathbf{a}, \mathbf{b}$ bzw. die aus diesen in situ gebildeten Drugs 43a,b bzw. 84a,b (Abb. 144) alkylieren geeignete DNADoppelstränge in Lösung mit einer mäßigen bis hohen Alkylierungseffizienz, zeigen gegenüber einzelsträngiger DNA, doppelsträngiger RNA oder kleinen Peptiden wie Glutathion aber nur eine geringe Reaktivität. Es wurde daher postuliert, dass die hohe Zytotoxizität dieser Wirkstoffe durch eine Alkylierung der zellulären DNA und einen in der Folge ausgelösten Zelltod verursacht sein könnte.
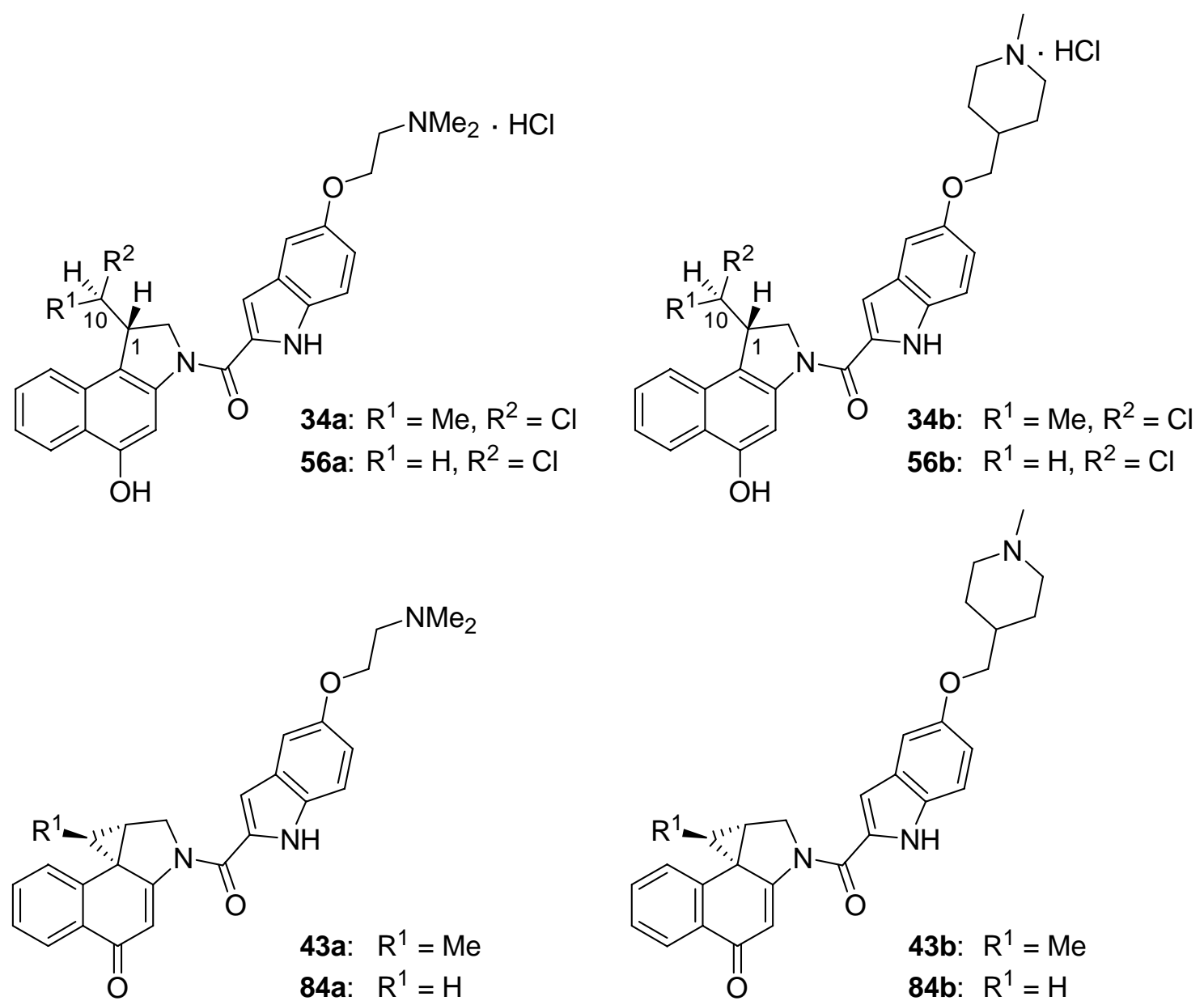

Abb. 144. Seco-Drug-Hydrochloride $(+)-(1 S, 10 R)-\mathbf{3 4 a}, \mathbf{b}$ und $(+)-(1 S)-56 \mathbf{a}, \mathbf{b}$ sowie entsprechende Drugs 43a,b bzw. 84a,b.

$(+)-(1 S, 10 R)-34 \mathbf{a}, \mathbf{b}$ und $(+)-(1 S)-56 \mathbf{a}, \mathbf{b}$ zeigen ein charakteristisches induziertes CDSignal (ICD) mit einem Minimum bei $\lambda=305 \mathrm{~nm}$ und einem Maximum bei $\lambda=335 \mathrm{~nm}$, wenn sie mit doppelsträngigen DNA-Oligonukleotiden inkubiert werden, die über eine AT-reiche Basensequenz von mindestens vier Basenpaaren verfügen (Abb. 145). Das ICD wird hierbei durch die Einlagerung des in situ aus den seco- 
Drugs entstehenden Drugs in den DNA-Doppelstrang verursacht (s. Kap. 8.4). Werden die seco-Drugs durch die Wechselwirkung mit DNA-Oligonukleotiden stabilisiert, so kann zudem eine positive CD-Bande um $\lambda=390 \mathrm{~nm}$ detektiert werden (s. Kap. 8.4).
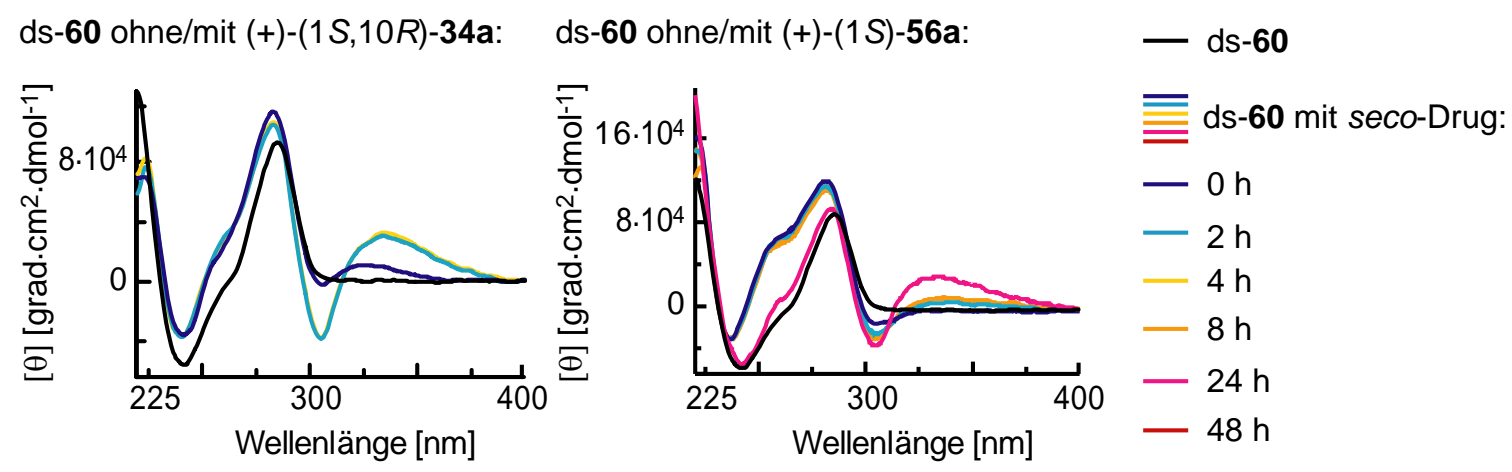

ds-60 ohne/mit (+)-(1S,10R)-34b: ds-60 ohne/mit (+)-(1S)-56b:
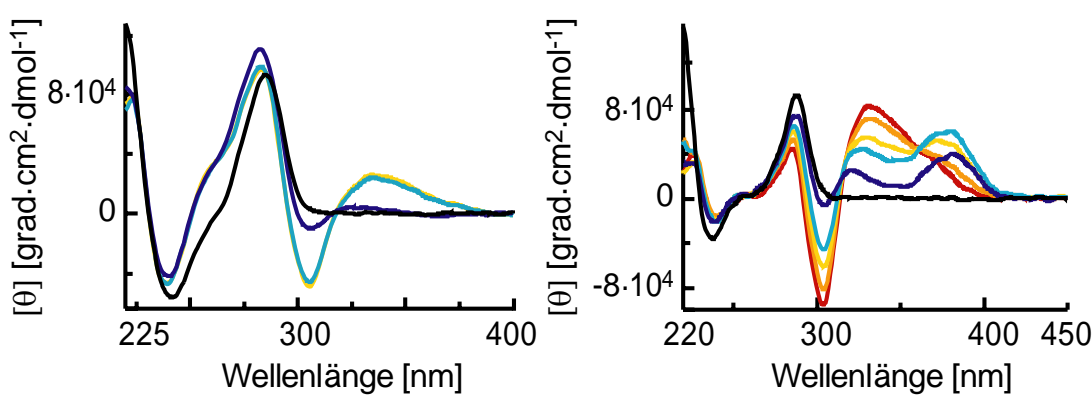

Abb. 145. CD-Spektren der seco-Drug-Hydrochloride $(+)-(1 S, 10 R)-34 \mathbf{a},(+)-(1 S, 10 R)-34 \mathbf{b}$, $(+)-(1 S)$-56a und $(+)-(1 S)-56 \mathbf{b}$ nach Inkubation mit der doppelsträngigen DNA ds-60 im 1:1-Verhältnis nach 0-48 h Inkubation in Phosphatpuffer ( $\mathrm{pH} 7)$.

Zur Überprüfung der Hypothese, dass die seco-Drugs eine Alkylierung der zellulären DNA verursachen, wurden in Anbetracht des charakteristischen induzierten CDSignals CD-spektroskopische Studien an Zellen durchgeführt. Als Zellen dienten hierbei in Suspension wachsende humane Lymphomzellen der Linie HL-60.

\subsection{CD-Spektroskopie an Zellen}

Ergebnisse einer CD-spektroskopischen Studie lebender Zellen wurden erstmals im Jahre 2001 von einer russischen Forschergruppe publiziert. ${ }^{199}$ Ziel dieser Studie war die Untersuchung der Änderung des CD-Spektrums $(\lambda=250-800 \mathrm{~nm})$ einer Suspension lebender Zellen nach Anregung durch Laser-Licht niedriger Intensität $(\lambda=820 \mathrm{~nm})$. Diese Änderung des CD-Spektrums wird vermutlich durch eine Konformationsänderung des Atmungskettenenzyms Cytochrom-c-Oxidase verursacht. 
Die Wechselwirkung linear polarisierten Lichtes mit den Zellen bedingte positive Banden im UV-, VIS- und nahen IR-Bereich. Während die zugrundeliegenden Absorptionen im UV-Bereich im Wesentlichen durch Proteine und Nukleinsäuren verursacht werden, sind die Absorptionsbanden im Bereich des sichtbaren und infraroten Lichtes hauptsächlich auf Chromophore der Atmungskettenenzyme zurückzuführen. ${ }^{200,201} \mathrm{CD}$-spektroskopische Studien zur Untersuchung der zellulären Aufnahme eines Wirkstoffs oder zur Aufklärung des Wirkmechanismus diverser Verbindungen in vitro wurden in der Literatur noch nicht beschrieben.

Die publizierten CD-spektroskopischen Untersuchungen an Zellen wurden mit speziell dafür entwickelten Apparaturen aufgezeichnet. ${ }^{199}$ Im Rahmen dieser Arbeit durchgeführte Versuche zeigten jedoch, dass bei Verwendung einer Schichtküvette CDSpektren lebender Zellen in einer Zellsuspension mit einem kommerziell erhältlichen Spektropolarimeter aufgezeichnet werden können. Hierbei wurde im Wellenlängenbereich $\lambda=200-250 \mathrm{~nm}$ eine intensive negative CD-Bande und im Wellenlängenbereich $\lambda=250-300 \mathrm{~nm}$ eine schwache positive CD-Bande beobachtet (Abb. 146a). Die Intensität der negativen Bande nahm mit zunehmender Anzahl der suspendierten Zellen signifikant zu. Im Wellenlängenbereich $\lambda=300-450 \mathrm{~nm}$ konnte stattdessen kein signifikantes CD-Signal detektiert werden.

a

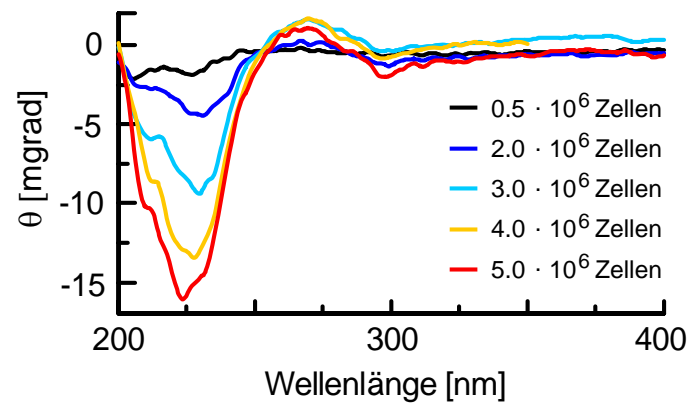

b

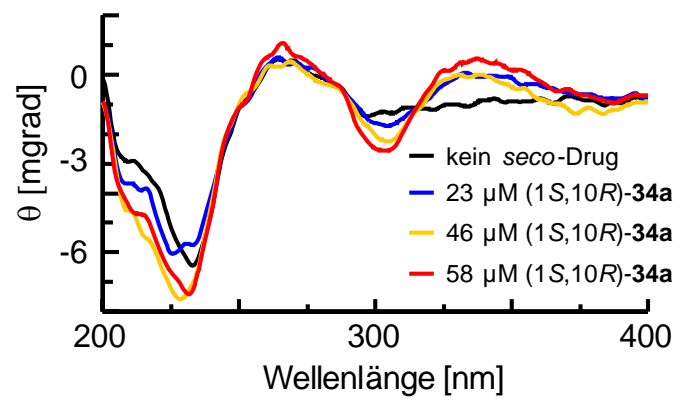

Abb. 146. CD-Spektren von Zellsuspensionen. a) Elliptizität der Suspension verschiedener Anzahlen an Zellen (HL-60) in je $70 \mu \mathrm{L}$ PBS, b) Elliptizität einer Suspension von $3.0 \cdot 10^{6}$ Zellen nach Präinkubation mit verschiedenen Konzentrationen des seco-Drug-Hydrochlorides $(+)-(1 S, 10 R)-34 \mathbf{a}$.

Die im UV-Bereich des Spektrums zu beobachtenden CD-Banden werden im Wesentlichen durch Proteine und Nukleinsäuren verursacht. B-DNA bewirkt eine positive CD-Bande mit einem Zentrum bei $\lambda=275 \mathrm{~nm}$ und eine negative CD-Bande um $\lambda=240 \mathrm{~nm}$. Der Nulldurchgang erfolgt bei $\lambda=258 \mathrm{~nm}$. Wird B-DNA gestreckt, wie dies z.B. in den zellulären Nucleosomen der Fall ist, nimmt die Intensität bei 
$\lambda=275 \mathrm{~nm}$ drastisch ab. Diese Änderung sowie die Überlagerung der durch DNA und Proteine verursachten Signale bedingen die unsymmetrische Form des CD-Spektrums der Zellsuspensionen (Abb. 146).

Werden die Zellen vor der Messung für $4.5 \mathrm{~h}$ mit zunehmenden Konzentrationen des seco-Drugs $(+)-(1 S, 10 R)-34 a$ inkubiert und im Anschluss mehrmals sorgfältig gewaschen, so kann deutlich das für die Wechselwirkung des seco-Drugs mit doppelsträngiger DNA charakteristische induzierte CD-Signal (ICD) mit einem Minimum bei $\lambda=305 \mathrm{~nm}$ und einem Maximum bei $\lambda=335 \mathrm{~nm}$ detektiert werden (Abb. 146b). Hierbei korreliert die Intensität des CD-Signals mit der Konzentration des seco-Drugs in der Inkubationslösung. Eventuell zusätzlich auftretende Änderungen im UV-Bereich können aufgrund der Überlagerung induzierter CD-Signale mit den für Zellen typischen CD-Signalen nicht zur Abschätzung der Drug-Konzentrationen verwendet werden.

\subsection{CD-Spektroskopie mit den seco-Drugs $(+)-(1 S, 10 R)-34 a, b$ und (+)-(1S)-56a,b präinkubierter Zellen}

Nachdem sich in Vorversuchen 3.0 $10^{6}$ Zellen und eine seco-Drug-Konzentration von $58 \mu \mathrm{M}$ als optimal erwiesen hatten, wurde die Kinetik der zellulären Aufnahme der seco-Drugs $(+)-(1 S, 10 R)-\mathbf{3 4 a}, \mathbf{b}$ und $(+)-(1 S)-56 \mathbf{a}, \mathbf{b}$ in HL-60-Zellen CD-spektroskopisch untersucht. Hierzu wurden die Zellen in 6er-Multischalen ausgesät und mit einer Lösung des Wirkstoffs in DMSO und Zellkulturmedium oder mit reinem DMSO und Zellkulturmedium versetzt. Die DMSO-Konzentration in der Inkubationslösung betrug hierbei einheitlich 1 Volumen-\%. (+)-(1S,10R)-34a,b und (1S)-56a wurden in einer Konzentration von $58 \mu \mathrm{M}$ eingesetzt. Aufgrund der hohen Zytotoxizität konnte diese Konzentration bei $(+)-(1 S)-56 \mathbf{b}$ nicht verwendet werden. Stattdessen wurde $(+)-(1 S)-56 b$ in einer Konzentration von $41 \mu \mathrm{M}$ eingesetzt.

Sofort nach dem Beginn der Inkubation sowie nach jeder vollen Stunde wurde bis zu einer Inkubationszeit von sechs Stunden jeweils der Inhalt eines Napfes in ein Zentrifugationsgefäß überführt, nach der Zentrifugation die Inkubationslösung verworfen und die Zellen dreimal mit PBS gewaschen. Anschließend wurden die Zellen in PBS suspendiert, die Suspension in die Vertiefung einer Schichtküvette überführt und unmittelbar danach ein CD-Spektrum der Zellsuspension bei $\lambda=200-400 \mathrm{~nm}$ bzw. $\lambda=200-450 \mathrm{~nm}$ gemessen. 
Neben den für die Zellsuspension typischen CD-Signalen unterhalb von $\lambda=300 \mathrm{~nm}$ konnte bei den mit den Wirkstoffen vorbehandelten Zellen ein signifikantes induziertes CD-Signal mit einem Minimum bei $\lambda=305 \mathrm{~nm}$ und einem Maximum bei $\lambda=335 \mathrm{~nm}$ detektiert werden, das bei unbehandelten Zellen nicht beobachtet werden konnte (Abb. 147).

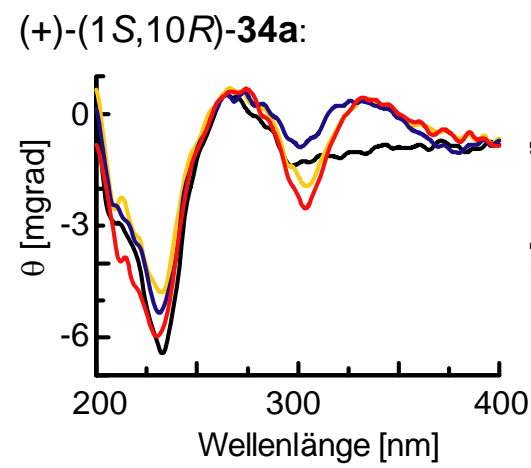

(+)-(1S)-56a:

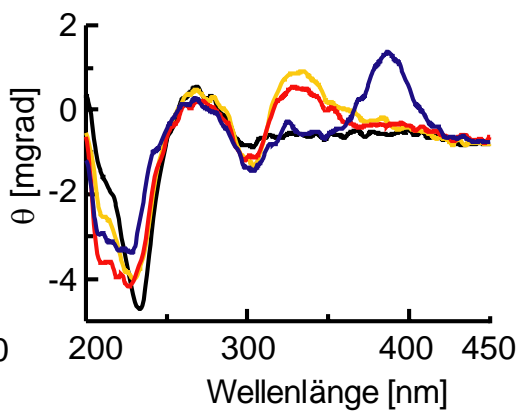

(+)-(1S)-56b:
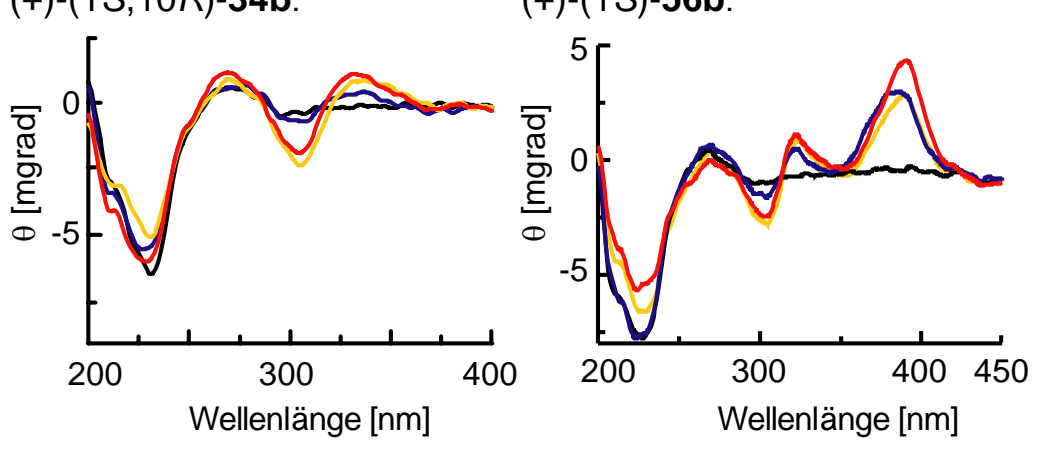

- Inkubation ohne seco-Drug

$\equiv$ Inkubation mit seco-Drug:

$-0 \mathrm{~h}$

$-4 \mathrm{~h}$

$-6 \mathrm{~h}$

Abb. 147. CD-Spektren von Zellsuspensionen unbehandelter Zellen (HL-60) und mit den seco-Drug-Hydrochloriden $(+)-(1 S, 10 R)-\mathbf{3 4 a}, \mathbf{b}$ und $(+)-(1 S)-\mathbf{5 6} \mathbf{a}, \mathbf{b}$ präinkubierter Zellen (HL-60) in PBS (pH 7.4).

Die Intensität dieses induzierten CD-Signals nahm mit zunehmender Inkubationsdauer zu. Dies ist ein eindeutiger Hinweis darauf, dass die seco-Drugs bzw. die aus diesen in situ generierten Drugs die Zellmembran der Zellen penetrierten und eine Wechselwirkung mit der zellulären DNA eingingen. Bei allen seco-Drugs konnte hierbei bereits nach einer nur sehr kurzen Inkubationszeit $(t=0 \mathrm{~h})$ ein signifikantes induziertes CD-Signal beobachtet werden, d.h. die Wirkstoffe penetrierten sehr schnell die Zellmembran.

Zusätzlich zu den CD-Banden um $\lambda=305 \mathrm{~nm}$ und $\lambda=335 \mathrm{~nm}$ konnte für die secoCBI-Hydrochloride $(+)-(1 S)-56 \mathbf{a}$ und $(+)-(1 S)$-56b das für die seco-Form charakteristische CD-Signal bei $\lambda=390 \mathrm{~nm}$ detektiert werden. Dieses CD-Signal war für $(+)-(1 S)-56 \mathbf{a}$ ab dem Inkubationsstart zu beobachten, erreichte nach einer Stunde ein 
Maximum und war ab einer Inkubationszeit von drei Stunden nicht mehr eindeutig nachweisbar (Tab. 46). Das entsprechende CD-Signal des stärker zytotoxischen secoDrugs (+)-(1S)-56b erreichte zwar ebenfalls nach einer Inkubationszeit von einer Stunde ein Maximum, war aber bis zu sechs Stunden nach dem Beginn der Inkubation noch zu detektieren (Tab. 46).

\begin{tabular}{|c|c|c|}
\hline Inkubationszeit [h] & $\begin{array}{c}(+)-(1 S)-56 a \\
I C D(\lambda=390 \mathrm{~nm})[\mathrm{mgrad}]\end{array}$ & $\begin{array}{c}(+)-(1 S)-56 \mathrm{~b} \\
I C D(\lambda=390 \mathrm{~nm})[\mathrm{mgrad}]\end{array}$ \\
\hline 0 & $2.0 \pm 0.8$ & $3.0 \pm 1.1$ \\
\hline 1 & $2.7 \pm 0.3$ & $4.4 \pm 0.6$ \\
\hline 2 & $1.4 \pm 0.5$ & $3.7 \pm 0.8$ \\
\hline 3 & $0.8 \pm 0.7$ & $3.7 \pm 0.7$ \\
\hline 4 & $0.0 \pm 0.4$ & $3.5 \pm 1.2$ \\
\hline 5 & $0.4 \pm 0.4$ & $2.5 \pm 1.3$ \\
\hline 6 & $-(0.5 \pm 0.5)$ & $2.8 \pm 0.8$ \\
\hline
\end{tabular}

Tab. 46. Induziertes CD-Signal (ICD) bei $\lambda=390 \mathrm{~nm}$ nach Inkubation von Zellen (HL-60) mit den seco-Drug-Hydrochloriden $(+)-(1 S)$-56a,b. Die Intensität der induzierten CD-Signale wurde durch Subtraktion der Elliptizität bei Messung unbehandelter Zellen von der Elliptizität bei Messung mit den seco-Drug-Hydrochloriden $(+)-(1 S)-\mathbf{5 6} \mathbf{a}, \mathbf{b}$ behandelter Zellen berechnet.

Während die Interaktion der Methyl-seco-CBI-Derivate $(+)-(1 S, 10 R)-34 a, b$ mit der zellulären DNA demzufolge ohne eine vorherige stabilisierende Wechselwirkung des seco-Drugs durch die DNA erfolgt, werden die toxischeren seco-CBI-Derivate $(+)-(1 S)-56 a, b$ zunächst von der DNA stabilisiert. Diese Stabilisierung ist für das zytotoxischere seco-Drug (+)-(1S)-56b stärker als für das weniger zytotoxische $(+)-(1 S)$-56a. Das ICD bei $\lambda=390 \mathrm{~nm}$ ist zudem ein Hinweis darauf, dass die Wirkstoffe bereits in ihrer seco-Form in die Zellen aufgenommen werden.

\subsection{CD-Spektroskopie isolierter zellulärer DNA aus mit den seco-Drugs $(+)-(1 S, 10 R)-34 a, b$ und $(+)-(1 S)-56 a, b$ präinkubierten Zellen}

Zur Bestätigung der These, dass das bei Präinkubation der HL-60-Zellen mit den secoDrugs $(+)-(1 S, 10 R)-\mathbf{3 4 a} \mathbf{a}, \mathbf{b}$ und $(+)-(1 S)-\mathbf{5 6} \mathbf{a}, \mathbf{b}$ beobachtete ICD tatsächlich durch eine 
Wechselwirkung der Drugs mit der zellulären DNA verursacht wurde, wurde die zelluläre DNA nach einer Vorbehandlung der Zellen mit den seco-Drugs isoliert, in Wasser gelöst und CD-spektroskopisch untersucht. Der hierzu verwendete DNAIsolierungs-Kit der Firma Qiagen ist für die Isolierung der DNA aus maximal 5.0 $10^{6}$ Zellen geeignet. ${ }^{202} \mathrm{Um}$ ausreichende Mengen isolierter DNA zu garantieren, wurden die Versuche mit dieser Zellzahl durchgeführt. Die Zellen wurden hierbei in 6erMultischalen ausgesät und mit einer Lösung des Wirkstoffs in DMSO und Zellkulturmedium oder mit reinem DMSO und Zellkulturmedium versetzt. Die DMSOKonzentration in der Inkubationslösung betrug hierbei einheitlich 1 Volumen-\%. Die Wirkstoff-Konzentrationen wurden den Löslichkeiten und Zytotoxizitäten der Verbindungen angepasst: $(+)-(1 S, 10 R)-34 a$ wurde in einer Konzentration von $97 \mu \mathrm{M}$, $(+)-(1 S, 10 R)-34 a$ und $(+)-(1 S)-56 a$ wurden in einer Konzentration von $68 \mu \mathrm{M}$ und $(+)-(1 S)-56 \mathbf{b}$ wurde in einer Konzentration von $48 \mu \mathrm{M}$ eingesetzt.

Sofort nach dem Beginn der Inkubation sowie nach jeder vollen Stunde wurde bis zu einer Inkubationszeit von sechs Stunden jeweils der Inhalt eines Napfes in ein Zentrifugationsgefäß überführt, nach der Zentrifugation die Inkubationslösung verworfen und die Zellen dreimal mit PBS gewaschen. Anschließend wurden die Zellen in PBS suspendiert. Mit einem Aliquot der Suspensionslösung wurde mittels einer Trypanblau-Färbung der Anteil toter Zellen in der Suspension bestimmt und parallel dazu mit dem anderen Aliquot der Zellsuspension die Isolierung der zellulären DNA vorgenommen. Nach einer Zytolyse in Anwesenheit RNA-abbauender Enzyme wurde hierbei die DNA mit Ethanol ausgefällt und im Anschluss an eine Membran gebunden. In mehreren Waschschritten wurden dann Proteine und andere Zellbestandteile entfernt und am Ende die DNA mit bidestilliertem Wasser von der Membran eluiert. Die auf diese Weise isolierte genomische und mitochondriale DNA sollte frei von RNA, Proteinen sowie Nucleasen sein und eine Größe unter $50 \mathrm{~kb}\left(1 \mathrm{~kb}=10^{3}\right.$ Basen $)$ mit einer Prädominanz von Fragmenten mit circa $20-30 \mathrm{~kb}$ aufweisen. Nach photometrischer Einstellung einer DNA-Konzentration von $23 \mu \mathrm{g} / \mathrm{mL}$ oder $30 \mu \mathrm{g} / \mathrm{mL}$ $\left(A_{260}=1.0 \text { entspricht einer DNA-Konzentration von circa } 50 \mathrm{mg} / \mathrm{mL}\right)^{203}$ wurde ein CD-Spektrum der jeweiligen DNA-Lösungen gemessen.

Abbildung 148 zeigt die nach Inkubation der Zellen mit $(+)-(1 S, 10 R)-34 a, b$ und $(+)-(1 S)-56 \mathbf{a}, \mathbf{b}$ erhaltenen CD-Spektren der isolierten DNA. Neben den für B-DNA typischen CD-Signalen unterhalb von $\lambda=300 \mathrm{~nm}$ konnte bei der DNA mit Wirkstoffen vorbehandelter Zellen ein signifikantes induziertes CD-Signal mit einem Minimum bei $\lambda=305 \mathrm{~nm}$ und einem Maximum bei $\lambda=335 \mathrm{~nm}$ detektiert werden. 
Dieses wurde bei der DNA unbehandelter Zellen nicht beobachtet. Die Intensität des induzierten CD-Signals nahm mit zunehmender Inkubationsdauer zu. Dies beweist, dass die seco-Drugs bzw. die aus diesen in situ generierten Drugs die Zellmembran der Zellen penetrierten und danach kovalente Addukte mit der zellulären DNA bildeten.
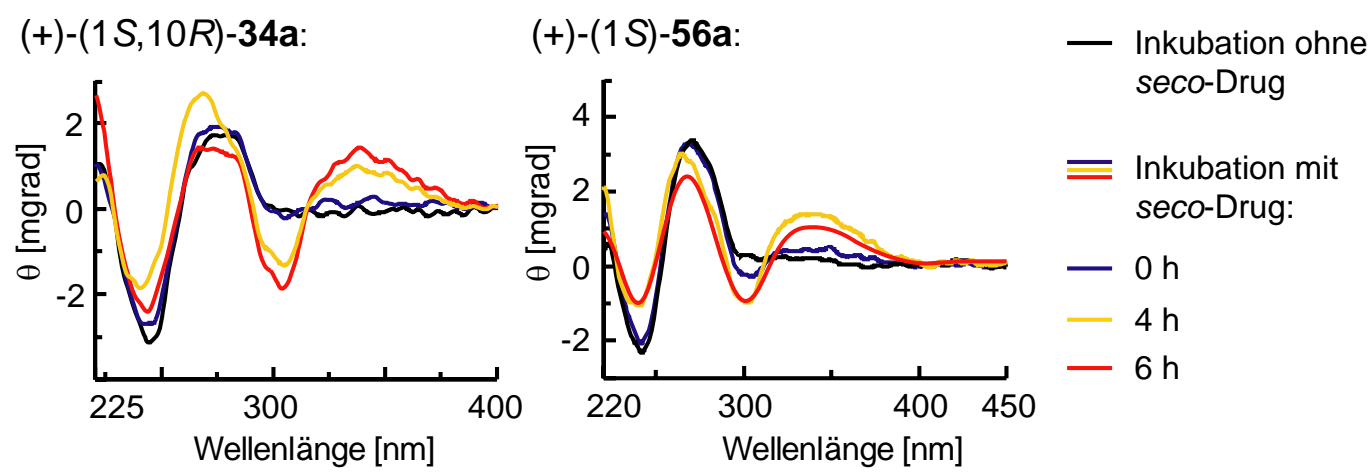

(+)-(1S,10R)-34b:

$(+)-(1 S)-56 b$ :
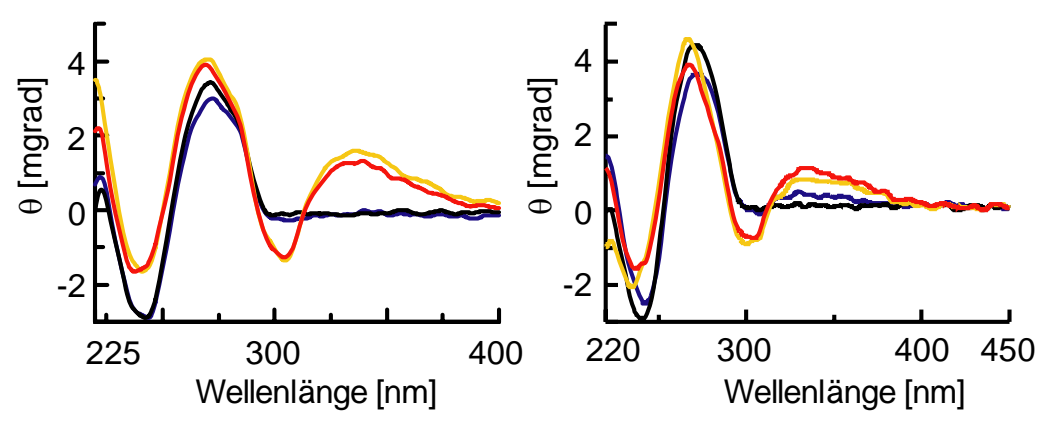

Abb. 148. CD-Spektren isolierter DNA unbehandelter Zellen (HL-60) und mit den secoDrug-Hydrochloriden $(+)-(1 S, 10 R)-34 \mathbf{a}, \mathbf{b}$ und $(+)-(1 S)-56 \mathbf{a}, \mathbf{b}$ präinkubierter Zellen.

Das für die seco-Form charakteristische CD-Signal bei $\lambda=390 \mathrm{~nm}$ konnte nicht detektiert werden, da nicht-kovalent gebundene Wirkstoffmoleküle während der DNAIsolierung und Reinigung entfernt wurden.

Alle CD-Messungen der Zellsuspensionen wurden für jeden Wirkstoff und jede Inkubationszeit dreimal und im Fall der DNA-Isolierung je viermal durchgeführt. Aus den jeweiligen CD-Spektren wurden dann die Intensitäten der induzierten CD-Signale mit einem Minimum bei $\lambda=305 \mathrm{~nm}$ und einem Maximum bei $\lambda=335 \mathrm{~nm}$ berechnet. Als Maß der Intensität des induzierten CD-Signals diente die als $\triangle I C D$ bezeichnete Differenz der Elliptizität an den Kurvenmaxima, d.h. der Elliptizität bei $\lambda=335 \mathrm{~nm}$ und bei $\lambda=305 \mathrm{~nm}$, da die Differenz dieser Werte zuverlässigere Aussagen über die Veränderung der Intensität des CD-Signals konsekutiver Messungen erlaubt als die Bestimmung des CD-Signals bei einer Wellenlänge (3). Die Ergebnisse sind in Abbildung 149 dargestellt. 


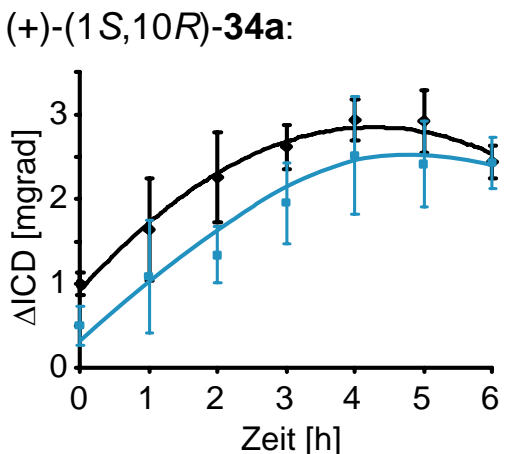

$(+)-(1 S, 10 R)-34 b$ :

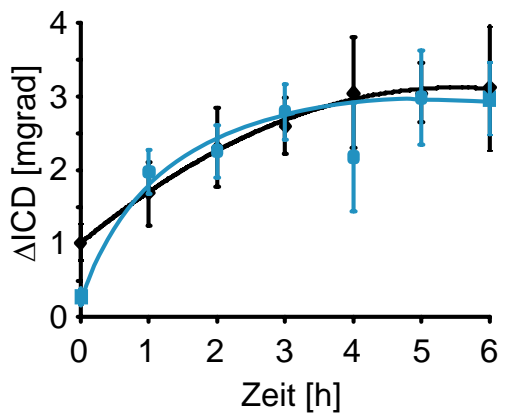

$(+)-(1 S)-56 a:$

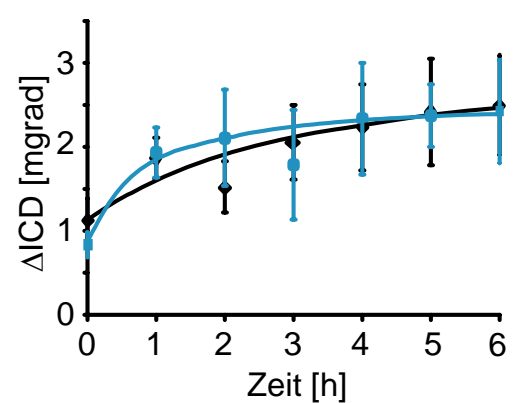

$(+)-(1 S)-56 b$ :

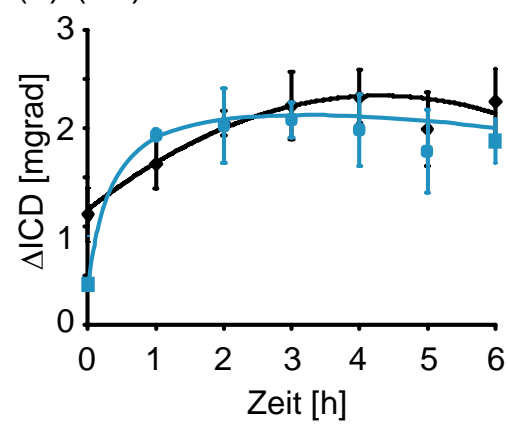

Abb. 149. Intensität des induzierten CD-Signals $(\triangle I C D=\theta(\lambda=335 \mathrm{~nm})-\theta(\lambda=305 \mathrm{~nm}))$ der Zellsuspensionen oder der isolierten zellulären DNA nach Inkubation der Zellen (HL-60) mit den seco-Drug-Hydrochloriden $(+)-(1 S, 10 R)-\mathbf{3 4 a}, \mathbf{b}$ und $(+)-(1 S)-\mathbf{5 6} \mathbf{a}, \mathbf{b}$.

Bei allen seco-Drugs ähneln sich im Rahmen der Fehler die $\triangle I C D$-Verläufe für die Messungen der lebenden Zellen und der aus diesen Zellen isolierten DNA. Hierbei fällt auf, dass die Intensität des ICD der isolierten DNA nach einer sehr kurzen Inkubationszeit $(t=0 \mathrm{~h})$ nahezu Null ist, während das ICD der Zellen bereits deutlich ausgeprägt ist. Bereits im Laufe sehr kurzer Inkubationszeiten penetrieren die secoDrugs demnach die Zellmembran und binden in den folgenden 10-15 Minuten, in denen die Zellen gewaschen werden, an die zelluläre DNA. Da diese Bindung nach der kurzen Inkubationszeit vorwiegend nicht-kovalent und reversibel ist, werden die meisten Drugs im Rahmen der DNA-Isolierung entfernt und können daher bei den entsprechenden CD-Messung der isolierten DNA nicht beobachtet werden. Nach längeren Inkubationszeiten ist der Unterschied zwischen den $\triangle I C D$-Werten der Zellen und der zellulären DNA kleiner, was auf einen höheren Anteil kovalent gebundenen Wirkstoffs hinweist.

Weiterhin deutet sich nach etwa vier Stunden Inkubation mit den Wirkstoffen eine Stagnation bzw. ein Abfall der Signalintensität an. Dies kann auf eine zunehmende Zahl toter Zellen zurückgeführt werden, die nach dem Absterben zerfallen und daher während des Waschens der Zellen entfernt werden. Kürzlich gestorbene Zellen gehen 
während der Reinigungsschritte nicht verloren und ihr Anteil an der Gesamtzahl der Zellen kann daher den Zustand der Zellpopulation repräsentieren.

Trypanblau ist ein saurer Farbstoff, der durch intakte Zellmembranen vitaler Zellen ausgeschlossen wird, defekte Zellmembranen absterbender oder toter Zellen jedoch durchdringen kann. ${ }^{204}$ Die durch das Anion des Trypanblau verursachte Anfärbung zytosolischer Proteine erlaubt daher die Detektion toter Zellen. Abbildung 150 zeigt den mittels Trypanblau-Färbung bestimmten Anteil toter Zellen in den Zellsuspensionen nach dem dreimaligen Waschen der Zellen. Deutlich ist hierbei eine Zunahme des Anteils toter Zellen nach einer Inkubationszeit von etwa vier Stunden zu erkennen, die mit der danach erfolgenden Abnahme der Intensität des induzierten CDSignals (Abb. 149) korreliert.

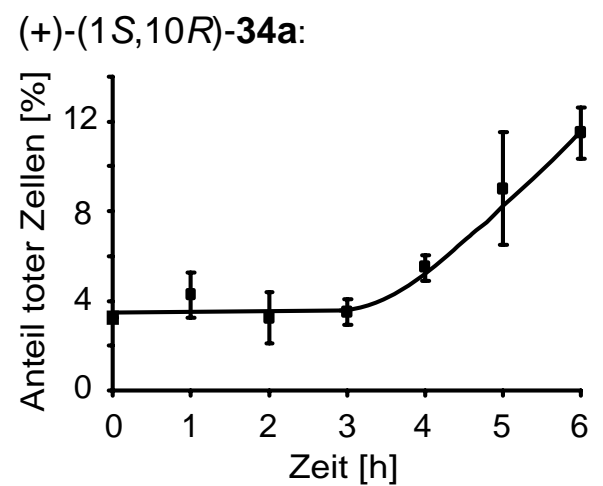

$(+)-(1 S, 10 R)-34 b$ :

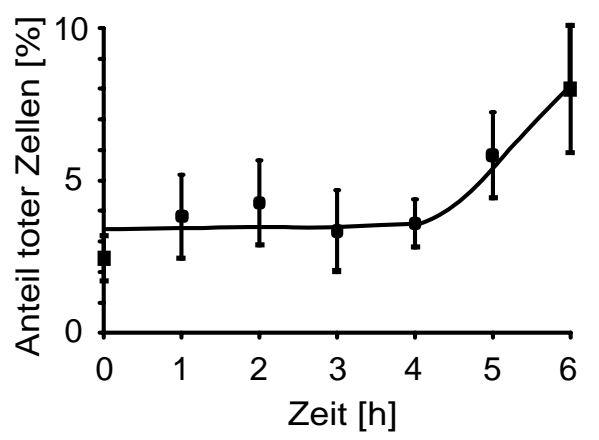

(+)-(1S)-56a:

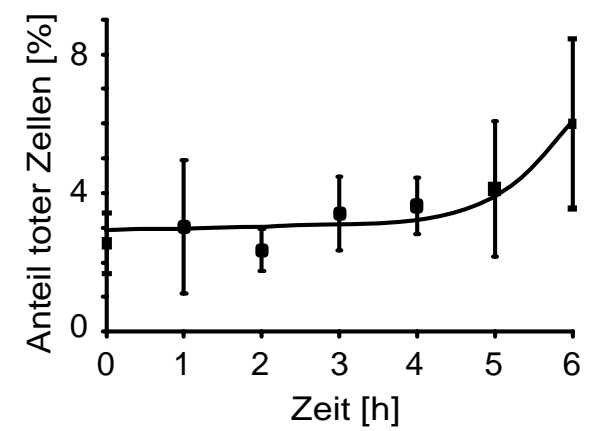

(+)-(1S)-56b:

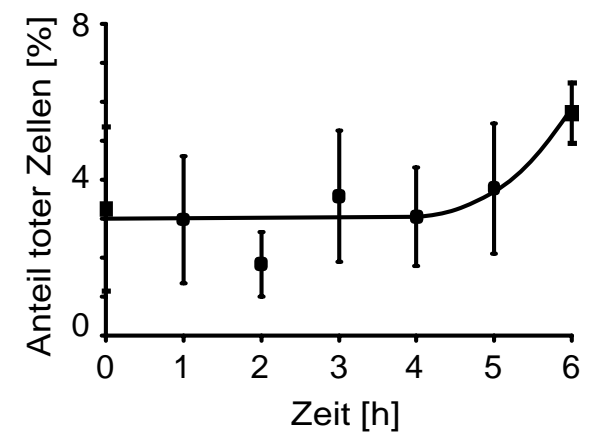

Abb. 150. Anteil toter Zellen (HL-60) nach Inkubation selbiger mit den seco-DrugHydrochloriden $(+)-(1 S, 10 R)-\mathbf{3 4 a}, \mathbf{b}$ und $(+)-(1 S)-\mathbf{5 6} \mathbf{a}, \mathbf{b}$.

Der Vergleich des zeitlichen Verlaufes der Intensität des induzierten CD-Signales mit dem Verlauf des Anteils toter Zellen beweist, dass die Zellen erst nach der Aufnahme der Wirkstoffe absterben. Das ICD wird somit eindeutig durch die Aufnahme des Wirkstoffes in lebende und nicht in tote Zellen verursacht. 
Insgesamt zeigen die Ergebnisse der vorgestellten CD-Messungen eindeutig, dass die seco-Drugs und Drugs sehr schnell die Zellmembran lebender Zellen durchdringen und an die zelluläre DNA als Wirkort binden. Hierbei findet nach einer vorübergehenden nicht-kovalenten Einlagerung in den DNA-Doppelstrang eine kovalente Reaktion mit der DNA statt, die zu einem stabilen Addukt führt.

Die Zytotoxizität der seco-Drugs nimmt in der Reihenfolge (+)-(1S)-56b > $(+)-(1 S)-56 \mathbf{a}>(+)-(1 S, 10 R)-34 \mathbf{a}, \mathbf{b}$ ab. Dies kann einerseits auf eine höhere Stabilität der aus $(+)-(1 S)-56 \mathbf{a}, \mathbf{b}$ in situ generierten CBI-Drugs gegenüber den aus den MethylAnaloga $(+)-(1 S, 10 R)-34 a, b$ gebildeten Methyl-CBI-Drugs zurückgeführt werden. Letztere sind wesentlich hydrolyseempfindlicher und reaktiver und erreichen daher vermutlich in geringeren Konzentrationen den intrazellulären Wirkort.

Da (+)-(1S)-56b durch eine Wechselwirkung mit der DNA stärker stabilisiert wird als $(+)-(1 S)-56 \mathbf{a}$ und die beiden Methyl-seco-CBI-Derivate $(+)-(1 S, 10 R)-34 \mathbf{a}, \mathbf{b}$ keine detektierbare Stabilisierung der seco-Form erfahren, kann zum anderen eine vorübergehende Speicherung und Stabilisierung des seco-Drugs durch die DNA eine langsamere, aber wesentlich stärkere Alkylierung der zellulären DNA - und somit einen stärkeren zytotoxischen Effekt- verursachen.

Die vorgestellten Studien beweisen, dass die Messung zeitabhängiger CD-Spektren mit Wirkstoffen präinkubierter Zellen die Detektion ihrer Aufnahme in die Zellen und ihrer Interaktion mit zellulären Zielstrukturen erlaubt. Hierbei ermöglicht eine Auswertung der gewonnenen Daten zudem eine fundierte Rationalisierung der Zytotoxizitätsunterschiede verschiedener Wirkstoffe.

Die neue Methode ist im Vergleich zu herkömmlichen Techniken der Untersuchung der Aufnahme und des Wirkmechanismus biologisch aktiver Verbindungen wie der Markierung mit Radioisotopen ${ }^{205}$ oder mit Fluoreszenzfarbstoffen ${ }^{206}$ von Vorteil, da die Moleküle nicht in Ihrer Struktur verändert werden müssen oder besondere Vorsichtsmaßnahmen bezüglich des Strahlenschutzes notwendig sind. Da achirale Wirkstoffe bei einer Interaktion mit chiralen Biomolekülen ebenfalls ein induziertes CD-Signal zeigen können, ist die Methode zudem nicht auf die Untersuchung chiraler Moleküle beschränkt, sondern könnte zur Untersuchung des Wirkmechanismus einer Vielzahl weiterer Verbindungen eingesetzt werden. 


\subsection{CD-spektroskopische Untersuchung der Aufnahme des fluoreszenz- markierten seco-Drugs $(1 S, 10 R)-76$ in Zellen}

Das fluoreszenzmarkierte seco-Drug (1S,10R)-76 (Abb. 151) alkyliert doppelsträngige DNA, zeigt hierbei jedoch eine geringere Alkylierungseffizienz als das entsprechende nicht fluoreszenzmarkierte seco-Drug $(1 S, 10 R)$-34a (s. Kap. 7). Des Weiteren ist der Anteil stabil in den DNA-Doppelstrang eingelagerten Wirkstoffs geringer (s. Kap. 8).

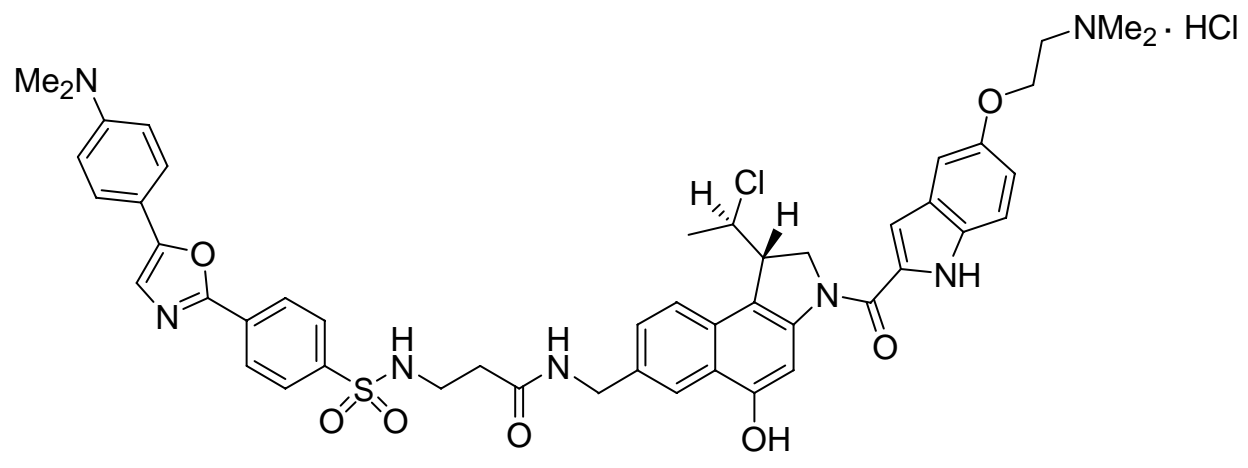

$(1 S, 10 R)-76$

Abb. 151. Struktur des fluoreszenzmarkierten seco-Drugs (1S,10R)-76.

Um zu überprüfen, ob eine mögliche Aufnahme des seco-Drugs $(1 S, 10 R)-76$ in lebende Zellen mittels CD-Spektroskopie verfolgt werden kann, wurden zunächst CDspektroskopische Messungen einer Lösung des seco-Drugs in Puffer sowohl in Anwesenheit als auch in Abwesenheit des DNA-Doppelstranges ds-60 durchgeführt. Hierbei konnte bei Inkubation des Wirkstoffs mit ds-60 ein signifikantes induziertes CD-Signal mit einem Minimum bei $\lambda=305 \mathrm{~nm}$ und einem Maximum bei $\lambda=335 \mathrm{~nm}$ detektiert werden (Abb. 152a). Die Intensität des ICD nahm im Vergleich zum nichtfluoreszenzmarkierten seco-Drug $(1 S, 10 R)$-34a deutlich langsamer zu und erreichte erst etwa 48 Stunden nach dem Beginn der Inkubation ein Maximum. Das CD-Signal des ohne DNA in PBS gelösten seco-Drugs $(1 S, 10 R)$-76 war im Vergleich zum induzierten CD-Signal nur schwach, wies aber ähnliche Minima und Maxima auf (Abb. 152b).

Zur Messung der Aufnahme von $(1 S, 10 R)$-76 in lebende Zellen wurde die neu entwickelte CD-spektroskopische Methode verwendet. 

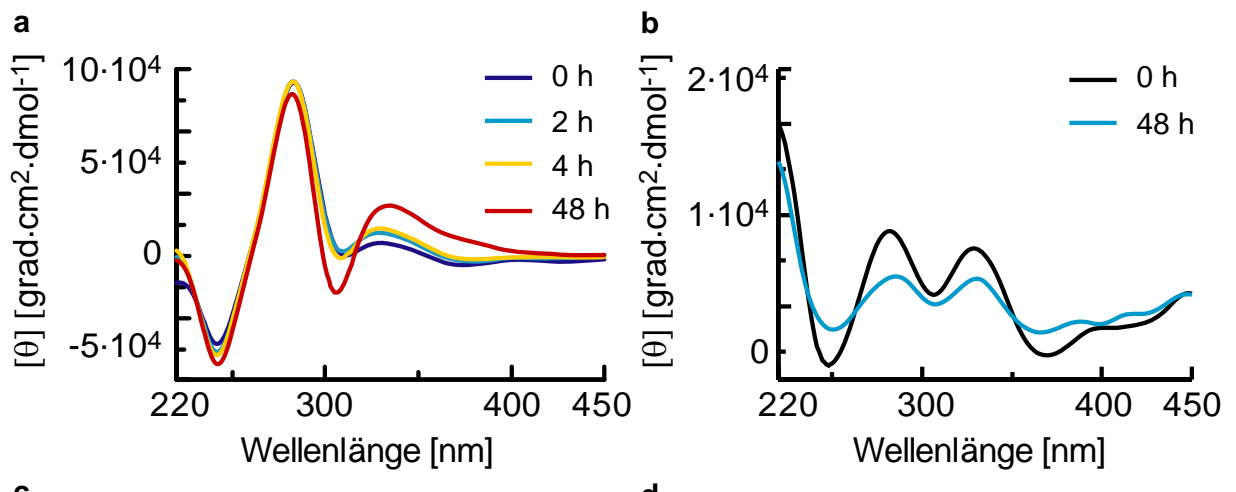

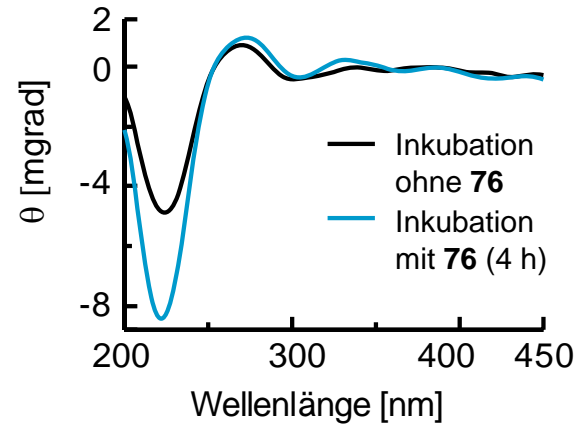

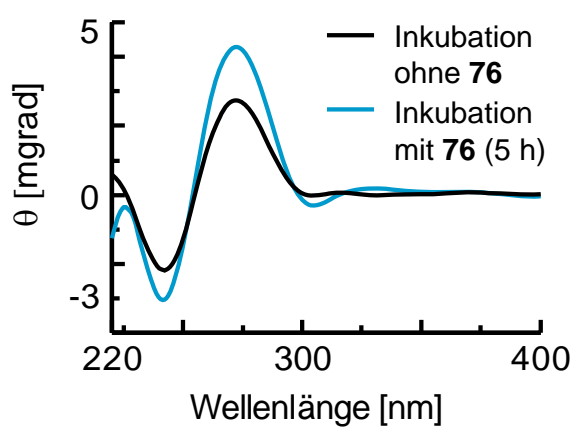

Abb. 152. Molare Elliptizität $[\theta]$ bzw. Elliptizität $\theta$ von a) einer Mischung aus $(1 S, 10 R)-76$ und der ds-DNA ds-60 im Verhältnis 1:1 nach 0-48 h Inkubation in PBS (pH 7.4); b) $(1 S, 10 R)$-76 nach $0 \mathrm{~h}$ und $48 \mathrm{~h}$ Inkubation in PBS (pH 7.4); c) einer Zellsuspensionen unbehandelter Zellen (HL-60) und mit $(1 S, 10 R)$-76 präinkubierter Zellen (HL-60) in PBS $(\mathrm{pH} 7.4) ; \mathrm{d})$ isolierter DNA unbehandelter Zellen (HL-60) und mit $(1 S, 10 R)-76$ präinkubierter Zellen.

Nach vier Stunden Inkubation der HL-60-Zellen mit $(1 S, 10 R)-76$ konnte ein schwaches induziertes CD-Signal mit einem Minimum bei $\lambda=305 \mathrm{~nm}$ und einem Maximum bei $\lambda=335 \mathrm{~nm}$ beobachtet werden, das bei unbehandelten Zellen nicht $\mathrm{zu}$ detektieren war (Abb. 152c). Das CD-Spektrum der DNA aus Zellen, die fünf Stunden mit dem seco-Drug inkubiert worden waren, zeigte ebenfalls ein sehr schwaches induziertes CD-Signal (Abb. 152d).

Obwohl das induzierte CD-Signal aufgrund der langsamen Reaktion der Verbindung mit der DNA nur sehr schwach ist, zeigt es dennoch, dass eine Aufnahme des secoDrugs in die Zellen sowie eine Wechselwirkung mit der zellulären DNA erfolgte. 


\subsection{CD-spektroskopische Untersuchung der Aufnahme anderer Zyto- statika in Zellen}

Nachdem die Aufnahme mehrerer seco-Drugs in Zellen und deren Interaktion mit der zellulären DNA mittels CD-Spektroskopie gezeigt werden konnte, sollte die Frage geklärt werden, ob analoge Untersuchungen auch mit anderen Zytostatika wie Doxorubicin (11), Melphalan (79) oder Mitomycin (99) erfolgen könnten (Abb. 153).

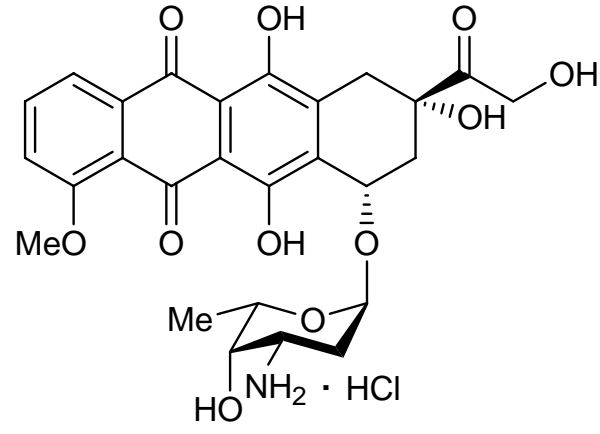

Doxorubicin (11)

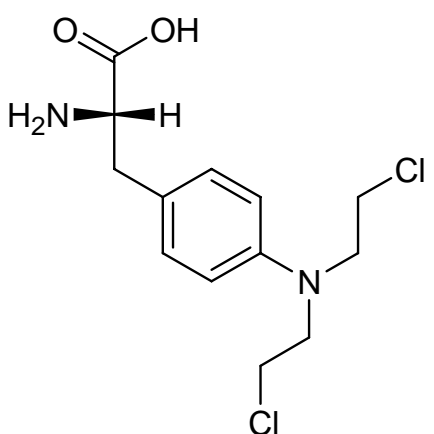

Melphalan (79)

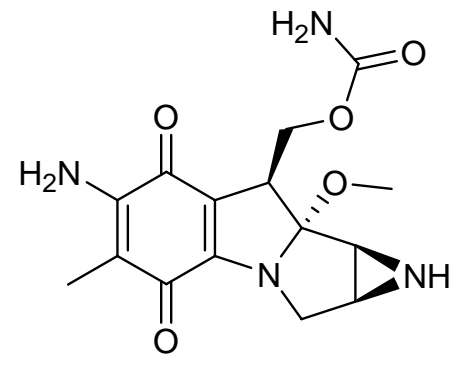

Mitomycin C (99)

Abb. 153. Doxorubicin (11), Melphalan (79) und Mitomycin C (99).

Diese drei klinisch eingesetzten Tumortherapeutika entfalten ihre Wirkung vermutlich durch eine Wechselwirkung mit der zellulären DNA. Während Doxorubicin in den DNA-Doppelstrang interkaliert und durch Radikalbildung Doppelstrangbrüche verursacht, stellen Melphalan und Mitomycin Alkylantien dar, die unter Ausbildung kovalenter Bindungen u.a. mit der DNA reagieren und somit Quervernetzungen der DNA, abnorme Basenpaarungen oder Strangbrüche auslösen. ${ }^{207}$ Mitomycin (99) muss hierbei zunächst enzymatisch zu einem reaktiven Metaboliten aktiviert werden, der dann mit Guaninbasen doppelsträngiger DNA reagiert (bevorzugte Sequenz: CG). ${ }^{208}$

Mitomycin C (99) selbst zeigte in Lösung ein CD-Spektrum mit einem Minimum bei $\lambda=370 \mathrm{~nm}$ und einem Maximum bei $\lambda=400 \mathrm{~nm}$ (Abb. 154). Wurde der Wirkstoff mit dem GC-reichen doppelsträngigen DNA-Oligonukleotid ds-69 inkubiert, so veränderte sich ab dem Inkubationsbeginn bis $\mathrm{zu}$ acht Stunden Inkubation das CDSpektrum nicht. Wurden die DNA und Mitomycin C (99) im 1:1-Verhältnis eingesetzt, so konnte keine signifikante Änderung des CD-Spektrums gegenüber den Spektren der Einzelkomponenten beobachtet werden. Bei einem zehnfachen Überschuss an 99 trat jedoch eine starke Veränderung auf: das Minimum bei $\lambda=370 \mathrm{~nm}$ wurde durch ein Minimum bei $\lambda=305 \mathrm{~nm}$ ersetzt und die für B-DNA charakteristischen Banden 
unterhalb von $\lambda=300 \mathrm{~nm}$ verloren stark an Intensität. Die Wechselwirkung von 99 mit der DNA hatte somit eine merkliche Strukturänderung der DNA bewirkt. Diese beruhte aufgrund des sofortigen Eintritts der Änderung nach der Substanzzugabe vermutlich nicht auf einer kovalenten Reaktion des Wirkstoffs mit der DNA.

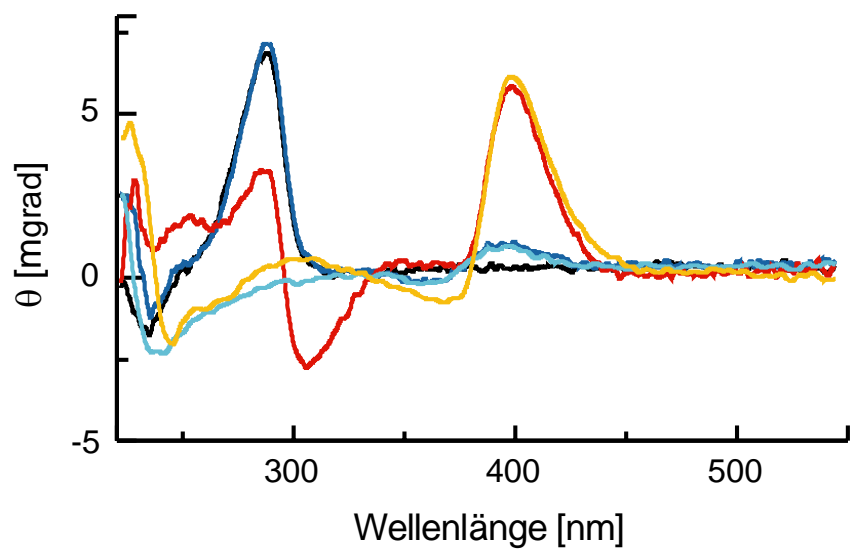

- $99(6 \mu \mathrm{M})$

- $99(60 \mu \mathrm{M})$

- ds-69

- ds $-69 / 99=1: 1$

$(6 \mu \mathrm{M})$

- ds-69 / $99=1: 10$

$(6 \mu \mathrm{M}: 60 \mu \mathrm{M})$

Abb. 154. CD-Spektren des DNA-Doppelstranges ds-69, des Zytostatikums Mitomycin C (99) und einer Mischung selbiger im molaren Verhältnis 1:1 bzw 1:10 in Phosphatpuffer (pH 7).

Die bei hohen Mitomycin-Konzentrationen in Lösung beobachtbaren CD-Signale könnten eine Untersuchung der zellulären Aufnahme des Wirkstoffs erlauben, wenn die innerhalb der Inkubationszeit in die Zellen aufgenommene Substanzmenge hinreichend wäre.

Je $3 \cdot 10^{6}$ Zellen der Linie HL-60 wurden daher mit Mitomycin C (99) inkubiert, wobei hohe Konzentrationen von $400 \mu \mathrm{M}$ oder $500 \mu \mathrm{M}$ gewählt wurden. Nach 3-, 4- und 24-stündiger Inkubation konnte kein signifikantes CD-Signal detektiert werden. Dies kann auf eine unzureichende Mitomycin-Konzentration in den Zellen oder eine Strukturveränderung des Moleküls zurückgeführt werden. Eine zu niedrige Konzentration könnte durch eine langsame Aufnahme oder ein effizientes Ausschleusen des Wirkstoffs aus der Zelle hinweisen. Eine signifikante Strukturveränderung und somit eine signifikante Änderung des CD-Spektrums könnte weiterhin durch die enzymatische Aktivierung des Wirkstoffs und dessen nachfolgende Reaktion mit DNA oder anderen Zielstrukturen innerhalb der Zelle erfolgt sein (Abb. 155). ${ }^{208}$ 
<smiles>CO[C@]12C(COC(N)=O)C3=C(C(=O)C(C)=C(N)C3=O)N1C[C@@H]1N[C@@H]12</smiles>

Mitomycin C (99)<smiles>CC=C(C)C</smiles>

100<smiles></smiles>

101

Abb. 155. Reduktive Aktivierung von Mitomycin C (99) zu 100 und nachfolgende Reaktion mit DNA zum kovalenten Addukt 101.

Melphalan (79) muss nicht enzymtisch aktiviert werden, denn das reaktive intermediäre Aziridiniumion (102) entsteht spontan aus 79 durch Chloridabspaltung (Abb. 156). ${ }^{207}$

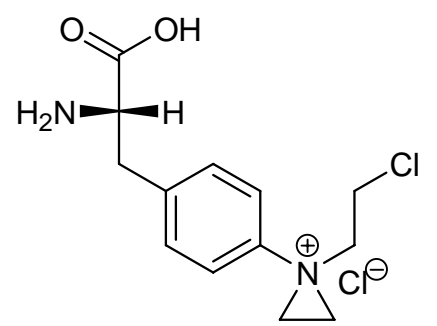

102

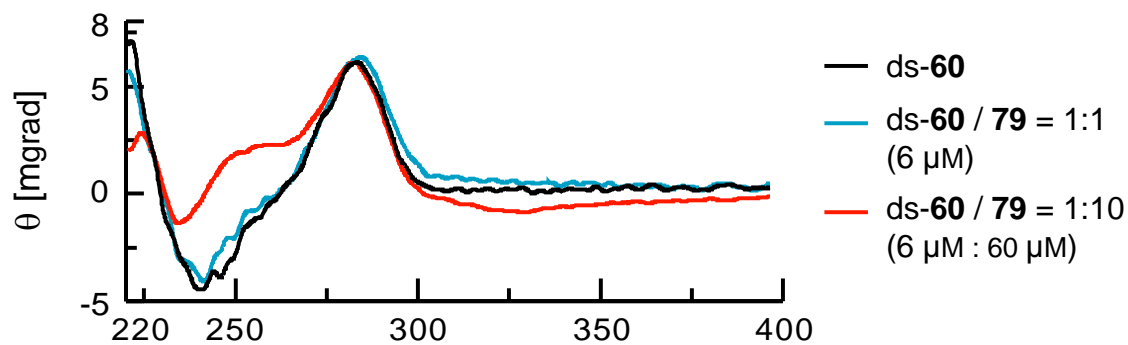

Wellenlänge [nm]

Abb. 156. Struktur des reaktiven Aziridiniumions 102 und CD-Spektren des DNA-Doppelstranges ds-60, des Zytostatikums Melphalan (79) und einer Mischung selbiger im molaren Verhältnis 1:1 bzw 1:10 in Phosphatpuffer (pH 7).

Weder Melphalan (79) noch eine Mischung von 79 mit dem DNA-Doppelstrang ds-60 zeigten in einem Inkubationsintervall von null bis sechs Stunden ein für den Wirkstoff oder dessen Konjugat mit der DNA charakteristisches und signifikantes CD-Signal. Die zelluläre Aufnahme dieses Wirkstoffs konnte daher nicht mittels CD-Spektroskopie untersucht werden.

Doxorubicin (11) verursachte in Phosphatpuffer $(\mathrm{pH} 7)$ ein CD-Spektrum mit einem Minimum bei $\lambda=292 \mathrm{~nm}$ und einem Maximum bei $\lambda=341 \mathrm{~nm}$. Die Intensität dieser Signale war auch bei einer hohen Konzentration von $63 \mu \mathrm{M}$ nur sehr schwach. Wurde der Wirkstoff allerdings mit dem doppelsträngigen DNA-Oligonukleotid ds-60 inkubiert, so konnte ein charakteristisches Minimum bei $\lambda=303 \mathrm{~nm}$ und ein Maximum bei $\lambda=370 \mathrm{~nm}$ beobachtet werden (Abb. 157). Die Intensität dieser Signale stieg mit zunehmender Konzentration des Wirkstoffs an. Gleichzeitig veränderte sich 
das CD-Spektrum unterhalb von $\lambda=300 \mathrm{~nm}$ signifikant. Dies deutet auf eine Strukturveränderung der DNA unter Verlust der B-Form hin.

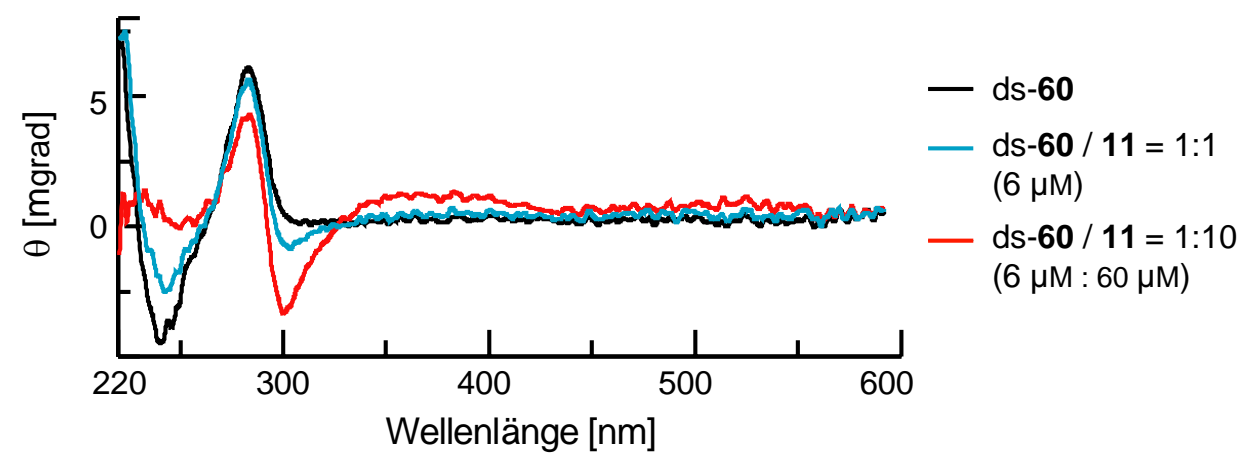

Abb. 157. CD-Spektren des DNA-Doppelstranges ds-60, des Zytostatikums Doxorubicin (11) und einer Mischung selbiger im molaren Verhältnis 1:1 bzw 1:10 in Phosphatpuffer (pH 7).

Aufgrund der geringen Intensität des durch Doxorubicin verursachten CD-Signals wurden die CD-spektroskopischen Untersuchungen zur zellulären Aufnahme des Wirkstoffs mit Konzentrationen von $75-1500 \mu \mathrm{M}$ und Inkubationszeiten von 2-48 Stunden durchgeführt. Hierbei konnte bei Konzentrationen von $300 \mu \mathrm{M}$ bzw. $1500 \mu \mathrm{M}$ eine signifikante Aufnahme des Wirkstoffs in die Zellen und eine Wechselwirkung des Drugs mit der DNA CD-spektroskopisch nachgewiesen werden (Abb. 158).

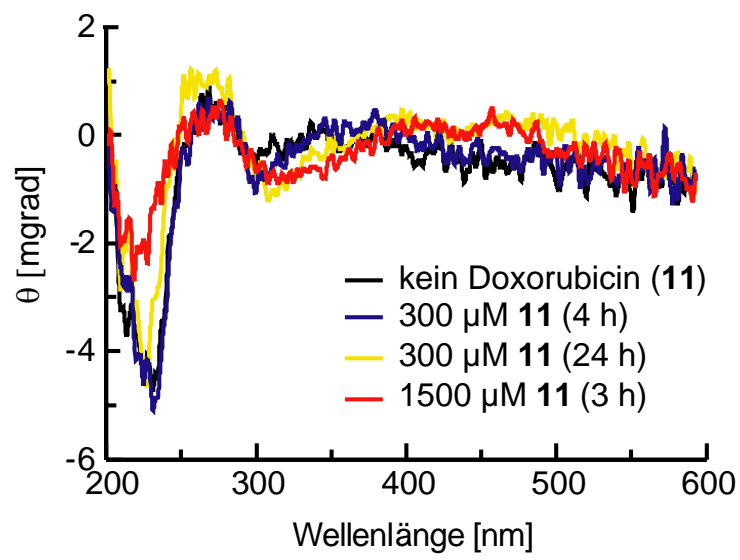

Abb. 158. Elliptizität $\theta$ von Zellsuspensionen unbehandelter Zellen (HL-60) und mit Doxorubicin (11) präinkubierter Zellen (HL-60) in PBS (pH 7.4).

Die vorgestellte CD-spektroskopische Methode ist demzufolge prinzipiell für In-vitroUntersuchungen zur Aufnahme von Duocarmycin-Analoga und anderer ausgewählter biologisch aktiver Substanzen in lebende Zellen und zur Studie des Wirkmechanismus dieser Verbindungen geeignet. 


\section{Untersuchung der Fluoreszenzeigenschaften und der zellulä- ren Aufnahme fluoreszenzmarkierter anti-Methyl-seco-CBI- DMAI-Derivate}

Alle fluoreszenzmikroskopischen Untersuchungen erfolgten in Zusammenarbeit mit Dr. Mišo Mitkovski am Max-Planck-Institut für experimentelle Medizin in Göttingen.

\subsection{Fluorimetrische Untersuchung der fluoreszenzmarkierten Analoga}

Zunächst wurden die Absorptions- und Fluoreszenzemissionsspektren der neuen Dapoxyl ${ }^{\circledR}$-Derivate 75 und 76 (Abb. 159) mit einem Fluorimeter aufgezeichnet.<smiles>[R20]c1cc2c(c3ccc(CNC(=O)CCNS(=O)(=O)c4ccc(-c5ncc(-c6ccc(NC)cc6)o5)cc4)cc13)[C@@H](C(C)Cl)CN2C(=O)c1cc2cc(OCCNC)ccc2[nH]1</smiles>

$(-)-(1 S, 10 R)-75: R=0-\beta-D-G a l \cdot \mathrm{CF}_{3} \mathrm{COOH}$ $(1 \mathrm{~S}, 10 R)-76: \mathrm{R}=\mathrm{OH} \cdot \mathrm{HCl}$<smiles>CNc1ccc(-c2cnc(-c3ccc(S(=O)(=O)NCCC(=O)O)cc3)o2)cc1</smiles>

103<smiles>CC(Cl)COCCN(C)CC(=O)O</smiles><smiles>CCOc1ccc(-c2nc3cc(-c4nc5cc(N6CCN(C)CC6)ccc5[nH]4)ccc3[nH]2)cc1</smiles>

40

Abb. 159. Fluoreszenzmarkierte anti-Methyl-seco-CBI-DMAI-Analoga (-)-(1S,10R)-75 und $(1 S, 10 R)-76$, Fluoreszenzfarbstoff-Derivat D10162 (39) nach Hydrolyse des aktivierten NHSEsters (103), seco-Drug (+)-(1S,10R)-34a und Hoechst 33342 (40). 
Abbildung 160 zeigt die Spektren des fluoreszenzmarkierten Prodrugs (-)-(1S,10R)-75 in Methanol und wässrigem Bildgebungspuffer ( $\mathrm{pH}$ 7.4) in einem Wellenlängenbereich von $\lambda=200-800 \mathrm{~nm}$. Das Absorptionsspektrum weist ein Maximum im blauen Bereich des sichtbaren Lichtes bei $\lambda_{\text {exc }}=355$ in Methanol bzw. $\lambda_{\text {exc }}=378 \mathrm{~nm}$ in Puffer auf. Das Maximum der bei $\lambda_{\mathrm{exc}}=378 \mathrm{~nm}$ angeregten Fluoreszenzemission liegt mit $\lambda_{\mathrm{em}}=570 \mathrm{~nm}$ in Methanol und $\lambda_{\mathrm{em}}=560 \mathrm{~nm}$ in Puffer (pH 7.4) im grüngelben Bereich des sichtbaren Lichtes.
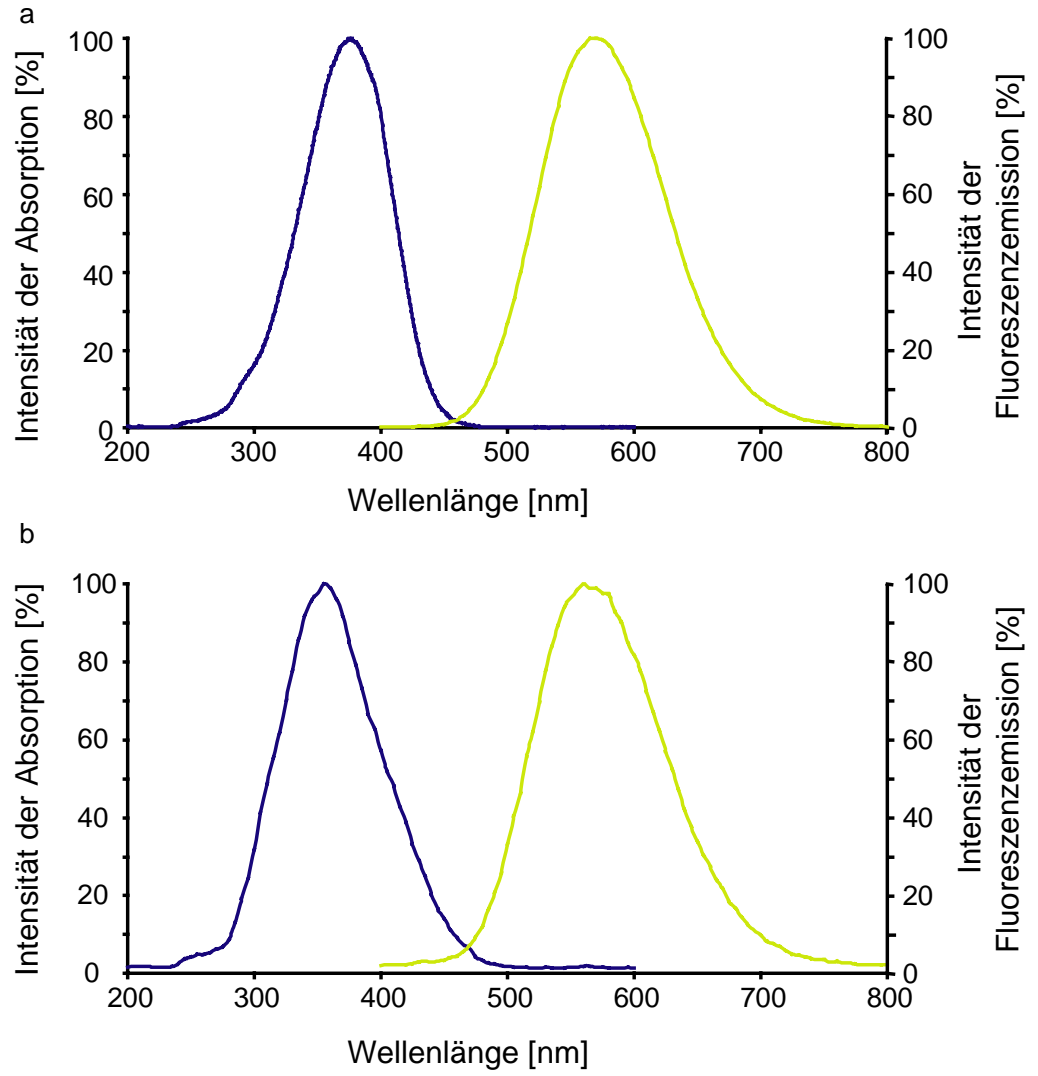

Abb. 160. Absorptions- und Fluoreszenzemissionspektren des fluoreszenzmarkierten Prodrugs (-)-(1S,10R)-75 in a) Methanol und b) wässrigem Puffer ( $\mathrm{pH} 7.4)$.

Die Absorptionsspektren des fluoreszenzmarkierten seco-Drugs $(1 S, 10 R)-76$ in Methanol und Puffer (Abb. 161) unterscheiden sich durch das Vorkommen einer zweiten Absorptionsbande mit einem Maximum bei $\lambda_{\mathrm{exc}}=525 \mathrm{~nm}$ von jenen des Prodrugs (-)-(1S,10R)-75. Während das Maximum der Fluoreszenzemission für $\mathbf{7 6}$ in Methanol bei $\lambda_{\mathrm{em}}=570 \mathrm{~nm}$ zu beobachten ist, liegt es im Puffer mit pH 7.4 und pH 12 bei $\lambda_{\mathrm{em}}=540 \mathrm{~nm}$ und im Puffer mit pH 3 bei $\lambda_{\mathrm{em}}=500 \mathrm{~nm}$ (Abb. 162). 

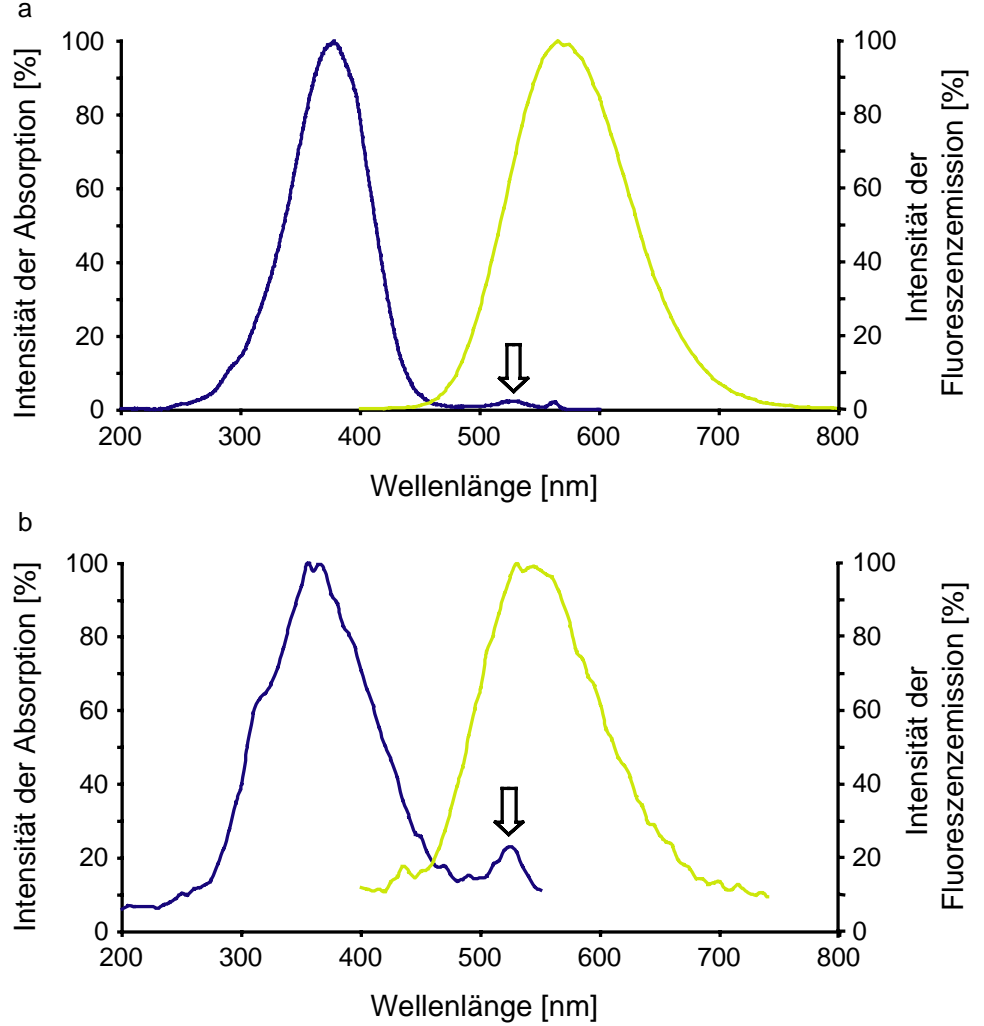

Abb. 161. Absorptions- und Fluoreszenzemissionspektren des fluoreszenzmarkierten secoDrugs (1S,10R)-76 in a) Methanol und b) wässrigem Puffer ( $\mathrm{pH}$ 7.4). Pfeil: zusätzliche Absorptionsbande um $\lambda_{\text {exc }}=525 \mathrm{~nm}$.

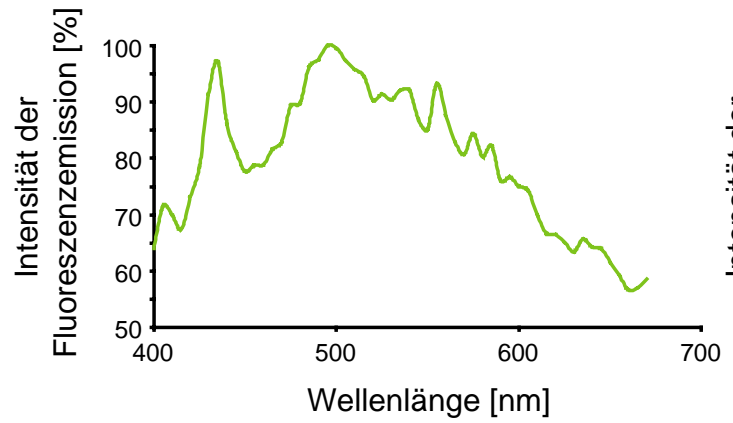

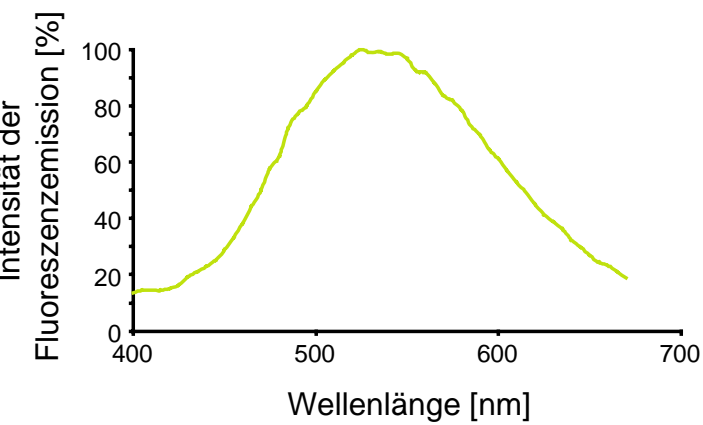

Abb. 162. Fluoreszenzemissionspektren des fluoreszenzmarkierten seco-Drugs $(1 S, 10 R)-76$ in a) wässrigem Puffer ( $\mathrm{pH} 3$ ) und b) wässrigem Puffer ( $\mathrm{pH} 12)$ bei $\lambda_{\mathrm{exc}}=378 \mathrm{~nm}$.

Der nicht an einen Wirkstoff gebundene, mit Wasser hydrolysierte NHS-Ester des Dapoxyl ${ }^{\circledR}$-Farbstoffes 103 zeigt analog zu dem Prodrug (-)-(1S,10R)-75 bei $\lambda_{\mathrm{exc}}=378 \mathrm{~nm}$ ein Absorptionsmaximum und in Methanol als Lösungsmittel bei $\lambda_{\mathrm{em}}=570 \mathrm{~nm}$ das entsprechende Fluoreszenzemissionsmaximum (Abb. 163). In Puffer mit pH 7.4 als Lösungsmittel ist das Emissionsmaximum im Vergleich zu 75 und 76 deutlich zu kleineren Wellenlängen verschoben und liegt bei etwa $500 \mathrm{~nm}$. Eine 
Absorptionsbande bei $525 \mathrm{~nm}$ kann nicht beobachtet werden und stellt somit ein Charakteristikum des fluoreszenzmarkierten seco-Drugs $\mathbf{7 6}$ dar.
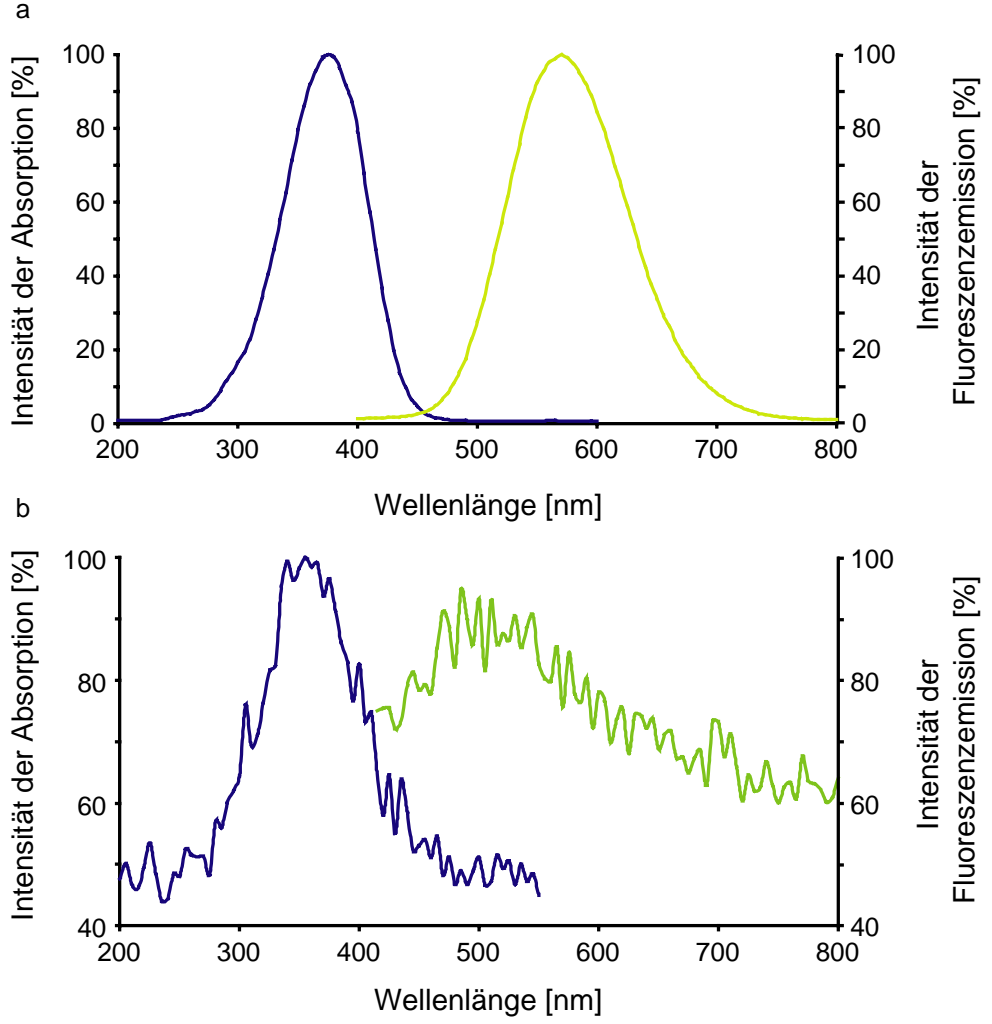

Abb. 163. Absorptions- und Fluoreszenzemissionspektren des hydrolysierten Dapoxyl ${ }^{\circledR}$ Fluoreszenzfarbstoffs D10162 (103) in a) Methanol und b) wässrigem Puffer ( $\mathrm{pH}$ 7.4).

Generell ist die Intensität der Fluoreszenzemission für alle untersuchten Dapoxyl ${ }^{\circledR}$ Derivate in wässrigem Puffer deutlich geringer als in Methanol und im stark sauren Milieu so schwach, dass sie kaum detektiert werden kann.

Das nicht fluoreszenzmarkierte seco-Drug (+)-(1S,10R)-34a zeigt in Methanol eine sehr schwache Fluoreszenz bei einer Anregung von $\lambda_{\mathrm{exc}}=350 \mathrm{~nm}$ und einer Fuoreszenzemission von $\lambda_{\mathrm{em}}=455 \mathrm{~nm}$. Diese kann im Puffer jedoch nicht beobachtet werden.

Nachdem erste fluoreszenzmikroskopische Untersuchungen gezeigt hatten, dass bei Inkubation von Zellen mit $(1 S, 10 R)$-76 wider Erwarten keine Fluoreszenzemission im Zellkern detektiert werden konnte, wurde eine mögliche Fluoreszenzlöschung durch eine Bindung des Wirkstoffs oder seiner Intermediate an DNA untersucht. Hierzu wurden synthetische DNA-Oligonukleotide und aus HL-60-Zellen isolierte zelluläre DNA mit dem seco-Drug 76 für 24 Stunden in Wasser inkubiert und im Anschluss die Absorptions- und Emissionsspektren aufgezeichnet. Dies erfolgte im Vergleich zur 
entsprechenden DNA-Lösung, einer Lösung von $\mathbf{7 6}$ und den entsprechenden frisch angesetzten Mischungen. Abb. 164 zeigt eine Auswahl der Spektren nach 24 Stunden Inkubation von 76 in Wasser oder in einer wässrigen Lösung zellulärer DNA mit den DNA-Konzentrationen $7.5 \mu \mathrm{g} / \mathrm{mL}, 15 \mu \mathrm{g} / \mathrm{mL}$ und $30 \mu \mathrm{g} / \mathrm{mL}$ für eine Fluoreszenzemission von $\lambda_{\mathrm{em}}=500 \mathrm{~nm}$ und $\lambda_{\mathrm{em}}=560 \mathrm{~nm}$.
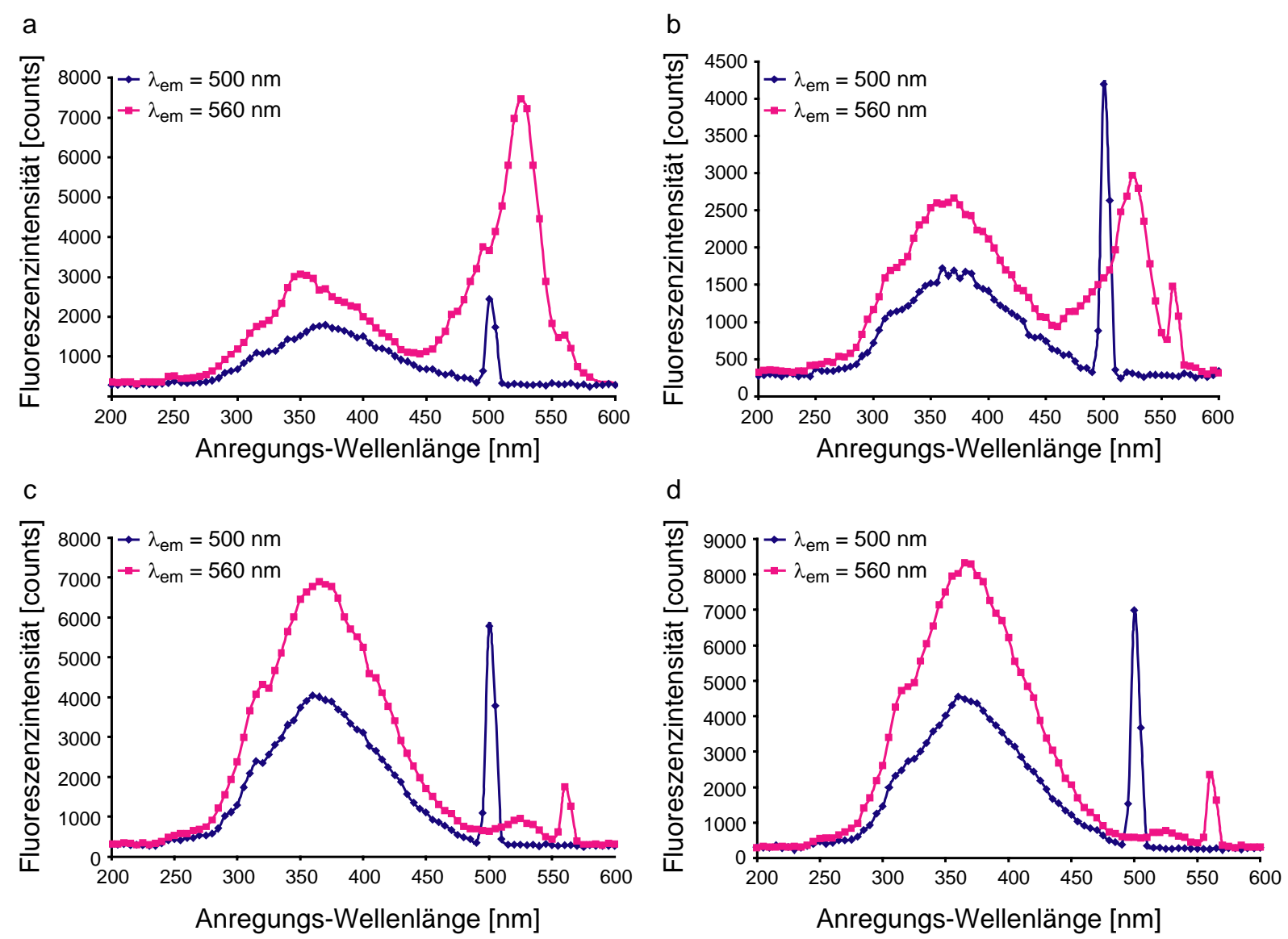

Abb. 164. Absorptionsspektren des fluoreszenzmarkierten seco-Drugs (1S,10R)-76 bezüglich einer Fluoreszenzemission von $\lambda_{\mathrm{em}}=500 \mathrm{~nm}$ und $\lambda_{\mathrm{em}}=560 \mathrm{~nm}$ nach $24 \mathrm{~h}$ Inkubation in a) Wasser oder b-d) einer wässrigen Lösung isolierter zellulärer DNA der Konzentration $7.5 \mu \mathrm{g} / \mathrm{mL}$ (b), $15 \mu \mathrm{g} / \mathrm{mL}$ (c) bzw. $30 \mu \mathrm{g} / \mathrm{mL}$ (d).

Deutlich ist zu erkennen, dass die Intensität der durch $\lambda_{\mathrm{exc}}=525 \mathrm{~nm}$ angeregten Fluoreszenzemission bei $\lambda_{\mathrm{em}}=560 \mathrm{~nm}$ mit zunehmender DNA-Konzentration stark abnimmt (Abb. 164). Umgekehrt nimmt jedoch die durch $\lambda_{\text {exc }}=378 \mathrm{~nm}$ angeregte Fluoreszenz für die beiden beobachteten Emissionswellenlängen $\lambda_{\mathrm{em}}=500 \mathrm{~nm}$ und $\lambda_{\mathrm{em}}=560 \mathrm{~nm}$ mit zunehmender DNA-Konzentration zu. Diese gegenläufige Tendenz wurde auch für synthetische Oligonukleotide und Plasmid-DNA beobachtet und war für die entsprechenden frisch angesetzten Lösungen schwächer als für die Lösungen, die 24 Stunden inkubiert worden waren. Die DNA selbst zeigt keine signifikante 
Fluoreszenz im untersuchten Wellenlängenbereich, weshalb der Effekt durch die Bindung des Wirkstoffs an die DNA verursacht sein muss. Sollte $\mathbf{7 6}$ an zelluläre DNA binden, so wäre diesen Untersuchungen zufolge zwar eine Schwächung der Fluoreszenzemission bei Anregung mit Laserlicht der Wellenlänge $\lambda_{\mathrm{exc}}=514 \mathrm{~nm}$ zu erwarten, aber gleichzeitig auch eine Zunahme der Fluoreszenzemission bei Anregung mit $\lambda_{\text {exc }}=405 \mathrm{~nm}$.

Zur Untersuchung der postulierten Bindung in der kleinen Furche zellulärer DNA wurden Studien zur zeitabhängigen Änderung der Fluoreszenzintensität des DNAbindenden Fluorophors Hoechst 33342 (40) bei dessen Zugabe zu nativer oder mit dem seco-Drug 76 vorinkubierter zellulärer DNA durchgeführt. Abb. 165 zeigt eine Darstellung dieser Versuchsreihe anhand einer DNA-Lösung der Konzentration $3 \mu \mathrm{g} / \mathrm{mL}$.

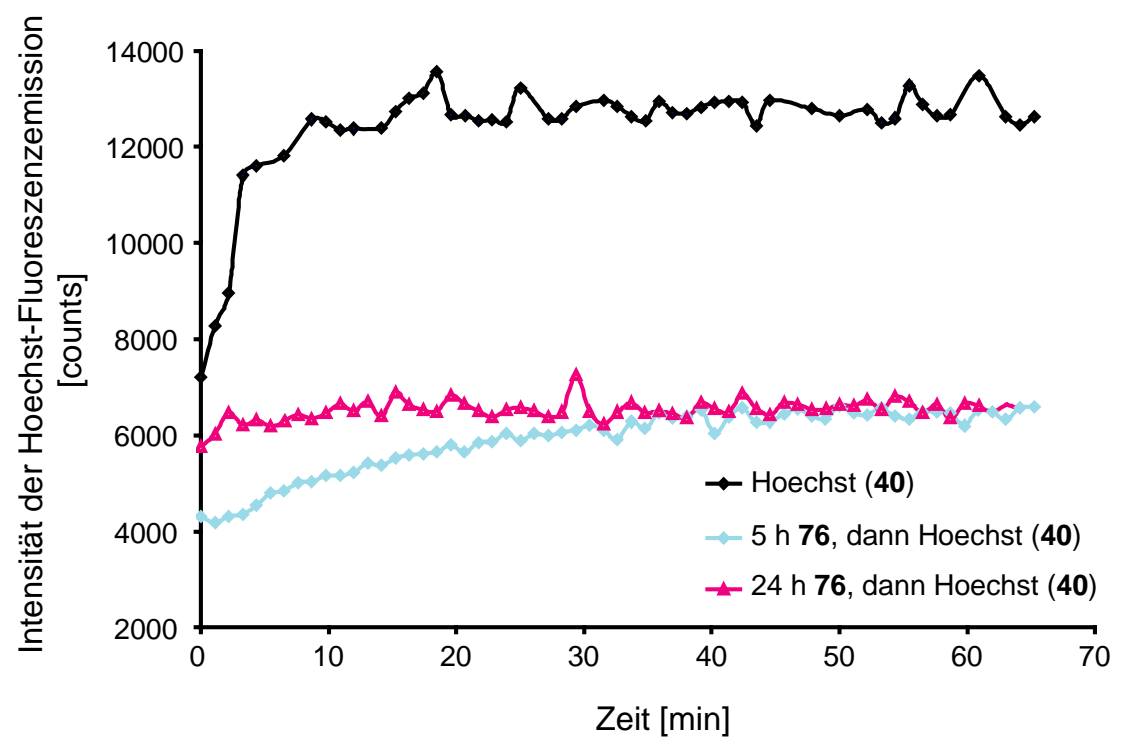

Abb. 165. Zeitliche Änderung der Intensität der Fluoreszenzemission von Hoechst 33342 (40) nach Zugabe zu einer wässrigen Lösung isolierter zellulärer DNA (Konzentration: $3 \mu \mathrm{g} / \mathrm{mL}$ ) ohne oder mit vorheriger Inkubation der DNA mit dem fluoreszenzmarkierten seco$\operatorname{Drug}(1 S, 10 R)-76$.

Wurde Hoechst mit einer Lösung der unbehandelten DNA in Wasser inkubiert, so nahm die für Hoechst charakteristische Fluoreszenz bei $\lambda_{\text {exc }}=365 \mathrm{~nm}$ und $\lambda_{\mathrm{em}}=450 \mathrm{~nm}$ sehr schnell auf das Doppelte der Anfangsintensität zu. Wurde die DNA-Lösung zuvor fünf Stunden mit dem seco-Drug 76 präinkubiert, so erfolgte der Anstieg der Fluoreszenzintensität langsamer und erreichte nicht die gleiche Intensität. Wurde die DNA 24 Stunden mit $\mathbf{7 6}$ präinkubiert, so konnte nur noch eine sehr schwache Zunahme der Hoechst-Fluoreszenzemission detektiert werden. 
Dieser Effekt wurde analog bei DNA-Konzentrationen von $1.5 \mu \mathrm{g} / \mathrm{mL}$ und $0.75 \mu \mathrm{g} / \mathrm{mL}$ sowie nach einer Präinkubation mit dem entsprechenden nicht-fluoreszenzmarkierten seco-Drug $(+)-(1 S, 10 R)-34$ a beobachtet.

Die Hoechst-Fluoreszenzintensität nimmt gemeinhin erst nach einer Bindung des Farbstoffs in die kleine Furche AT-reicher Abschnitte doppelsträngiger DNA zu. ${ }^{209}$ Eine Schwächung der Zunahme der Fluoreszenzintensität oder deren Ausbleiben bei einer Präinkubation mit den seco-Drugs $(1 S, 10 R)-76$ und $(+)-(1 S, 10 R)-34 a$ ist demzufolge ein eindeutiger Hinweis auf die Bindung der Wirkstoffe in der kleinen Furche der DNA in AT-reichen Abschnitten. Nach fünf Stunden Inkubation ist der Anteil kovalent gebundenen seco-Drugs noch niedrig und nicht-kovalent gebundener Wirkstoff kann teilweise durch Hoechst 33342 (40) verdrängt werden. Aufgrund des höheren Anteils kovalent gebundener Drugs nach längerer Inkubation ist eine Verdrängung des seco-Drugs aus der kleinen Furche durch 40 nach $24 \mathrm{~h}$ nicht mehr möglich und die mit der Hoechst-Einlagerung verbundene Zunahme der Fluoreszenzemission bleibt aus. Eine Bindung der Drugs in der kleinen Furche doppelsträngiger DNA ist somit belegt.

\subsection{Untersuchung der zellulären Aufnahme fluoreszenzmarkierter anti- Methyl-seco-CBI-DMAI-Derivate}

Die Untersuchungen zur zellulären Aufnahme der fluoreszenzmarkierten Verbindungen erfolgten mit einem konfokalen Fluoreszenz-Mikroskop und einem SpinningDisc-Fluoreszenz-Mikroskop an lebenden, nicht fixierten Zellen. Tote oder absterbende Zellen wurden hierbei durch eine Färbung mit Trypanblau sichtbar gemacht. Trypanblau ist ein saurer Farbstoff, der durch intakte Zellmembranen ausgeschlossen wird, die defekte Zellmembran absterbender oder toter Zellen jedoch durchdringt. ${ }^{204}$ Die durch das Anion des Trypanblau verursachte Anfärbung zytosolischer Proteine kann im Durchlicht an der blauen Farbe und mit einem Fluoreszenzmikroskop anhand der roten Fluoreszenz detektiert werden.

In Vorversuchen, die im Rahmen dieser Arbeit mit dem FITC-markierten Galactosid (1S,10R)-74 (Abb. 51) an humanen Bronchialkarzinomzellen der Linie A549 durchgeführt wurden, konnte auch bei Inkubation von Zellen mit hohen Konzentrationen von $(1 S, 10 R)-74(100 \mu \mathrm{M})$ in einem Zeitraum von bis zu fünf Stunden keine Aufnahme des Prodrugs in lebende Zellen beobachtet werden. Ab einer Konzentration von $5 \mu \mathrm{M}$ war jedoch eine deutliche Färbung des Zellkerns toter Zellen zu erkennen, in die 
das Prodrug aufgrund einer geschädigten Zellmembran hineindiffundieren konnte. Hierbei wurde kein Unterschied in An- und Abwesenheit von $\beta$-D-Galactosidase festgestellt. Dies ist darauf zurückzuführen, dass die glykosidische Bindung in (1S,10R)-74 nicht durch das Enzym gespalten wird (s. Kap. 5.8).

Die Untersuchungsergebnisse bestätigten, dass das Prodrug aufgrund der Zuckereinheit die Zellmembran lebender Zellen nicht durchdringen konnte. Um allerdings auszuschließen, dass es sich hierbei um einen Effekt des Fluoreszenzfarbstoffs handelte, wurde ein neues fluoreszenzmarkiertes Prodrug mit einem anderen Fluorophor synthetisiert. Zum Vergleich wurde zusätzlich das entsprechende fluoreszenzmarkierte seco-Drug hergestellt, welches aufgrund des Fehlens des Zuckerausteins in der Lage sein sollte, die Zellmembran zu durchdringen und an die zelluläre DNA zu binden.

Untersuchungen mit dem neuen seco-Drug $(1 S, 10 R)$-76 in Zellen der Linie A549 ergaben, dass eine Konzentration von $2 \mu \mathrm{M}$ bei einer Inkubationszeit von $1.5 \mathrm{~h}$ ausreichend war, um eine hohe Intensität des Fluoreszenzsignals in den Zellen zu erreichen. Alle Folgeuntersuchungen der zellulären Aufnahme des seco-Drugs $(1 S, 10 R)-76$ sowie des Prodrugs (-)-( $1 S, 10 R)-75$ erfolgten daher mit Konzentrationen von 2-10 $\mu \mathrm{M}$. Unter den vergleichbaren Bedingungen konnte keine Fluoreszenz in Zellen detektiert werden, die als Kontrolle mit der gleichen Konzentration des analogen nicht fluoreszenzmarkierten seco-Drugs $(+)-(1 S, 10 R)-34 a$, des hydrolysierten Farbstoffs 39 (103) oder mit DMSO behandelt worden waren.

Wurden Bronchialkarzinomzellen (A549) mit dem Prodrug (-)-(1S,10R)-75 inkubiert, so wurde in den ersten Stunden nach Inkubationsbeginn eine starke blau-grüne Färbung der gesamten Zellmembran der lebenden Zellen beobachtet (Abb. 166a).

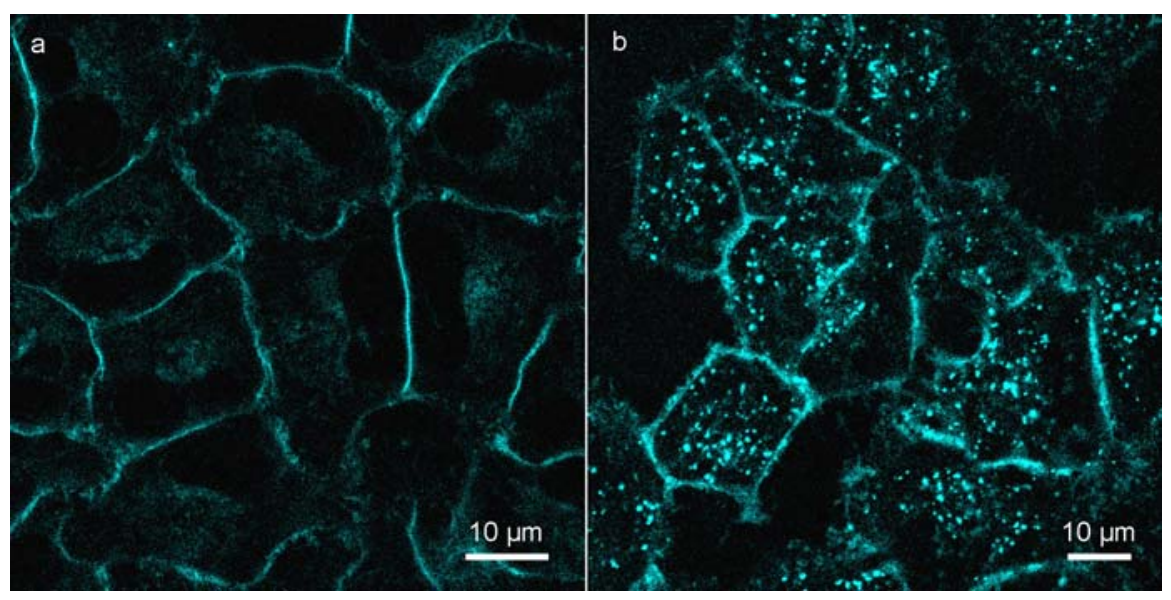

Abb. 166. Fluoreszenzmikroskopische Aufnahmen nach Inkubation von Zellen (A549) mit dem Prodrug (-)-(1S,10R)-75. a) 1 h Inkubationszeit, b) 4 h Inkubationszeit. 
In toten Zellen war zudem eine blaugrüne Färbung des Zytosols zu erkennen. Eine Verlängerung der Inkubationszeit auf vier Stunden führte schließlich zum Auftreten blaugrün gefärbter runder Strukturen im Zellinneren der lebenden Zellen (Abb. 166b). Co-Lokalisationsexperimente mit Endosomenmarkern (pEGFP-Endo) zeigten, dass es sich hierbei teils um Endosomen handelte (vide infra).

Eine optimale Anregung von (-)-(1S,10R)-75 erfolgte bei $\lambda_{\mathrm{exc}}=405 \mathrm{~nm}$, während bei $\lambda_{\text {exc }}=514 \mathrm{~nm}$ keine Fluoreszenz beobachtet werden konnte (Tab. 47). Die Fluoreszenzemission des Prodrugs hatte sowohl an der Zellmembran als auch in den runden zellulären Strukturen ein Maximum von $\lambda_{\mathrm{em}}=500 \mathrm{~nm}$. Dies ist im Vergleich zu der Fluoreszenzemission in Methanol $\left(\lambda_{\mathrm{em}}=560 \mathrm{~nm}\right)$ stark in Richtung kürzerer Wellenlängen verschoben und könnte ein Indiz dafür sein, dass das Prodrug mit einem hydrophoben Ende in das ebenfalls hydrophobe Innere der Zell- bzw. Organellmembran eingebettet wurde.

\begin{tabular}{ccc}
\hline$\lambda_{\text {exc }}[\mathbf{n m}]$ & $\lambda_{\text {em }}[\mathbf{n m}]$ & Lokalisation \\
\hline 405 & 500 & Zellmembran, später Endosomen, u.U. Lysosomen \\
514 & - & - \\
\hline
\end{tabular}

Tab. 47 Anregungs- und Emissionswellenlänge sowie Lokalisation für (-)-(1S,10R)-75.

Bei einer Inkubation von Zellen (A549 und HeLa SS6) mit dem seco-Drug (1S,10R)-76 konnte nach einer anfänglichen Färbung der Zellmembran bereits nach wenigen Minuten eine sehr intensive Fluoreszenz in verschiedenen intrazellulären Organellen beobachtet werden (Abb. 167). Mit Hilfe einer Trypanblau-Färbung konnten hierbei zwei Zellpopulationen unterschieden werden:

Bei dem ersten Zelltyp handelte es sich um tote Zellen, die mit Trypanblau angefärbt werden konnten. Sie zeigten nur bei einer Anregung mit Laserlicht der Wellenlänge $\lambda_{\text {exc }}=405 \mathrm{~nm}$ eine blaugrüne Fluoreszenzemission, die recht diffus im Zytosol der Zellen, aber auch in kleinen runden Strukturen sichtbar war (Abb. 167a). Diese Zellen erschienen im Durchlicht bläulich, hatten einen rötlichen Zellkern und neigten zum Ausbilden von Membranausstülpungen.

Zellen des zweiten Zelltyps waren vital und wirkten im Durchlicht bräunlich. Hier erfolgte bei einer Anregung mit $\lambda_{\mathrm{exc}}=405 \mathrm{~nm}$ eine blaugrüne Fluoreszenzemission mit 
einem Maximum bei $\lambda_{\mathrm{em}}=500 \mathrm{~nm}$ und bei $\lambda_{\mathrm{exc}}=514 \mathrm{~nm}$ eine gelbgrüne Fluoreszenzemission mit einem Maximum bei $\lambda_{\mathrm{em}}=560 \mathrm{~nm}$ (Abb. 167, Tab. 48).
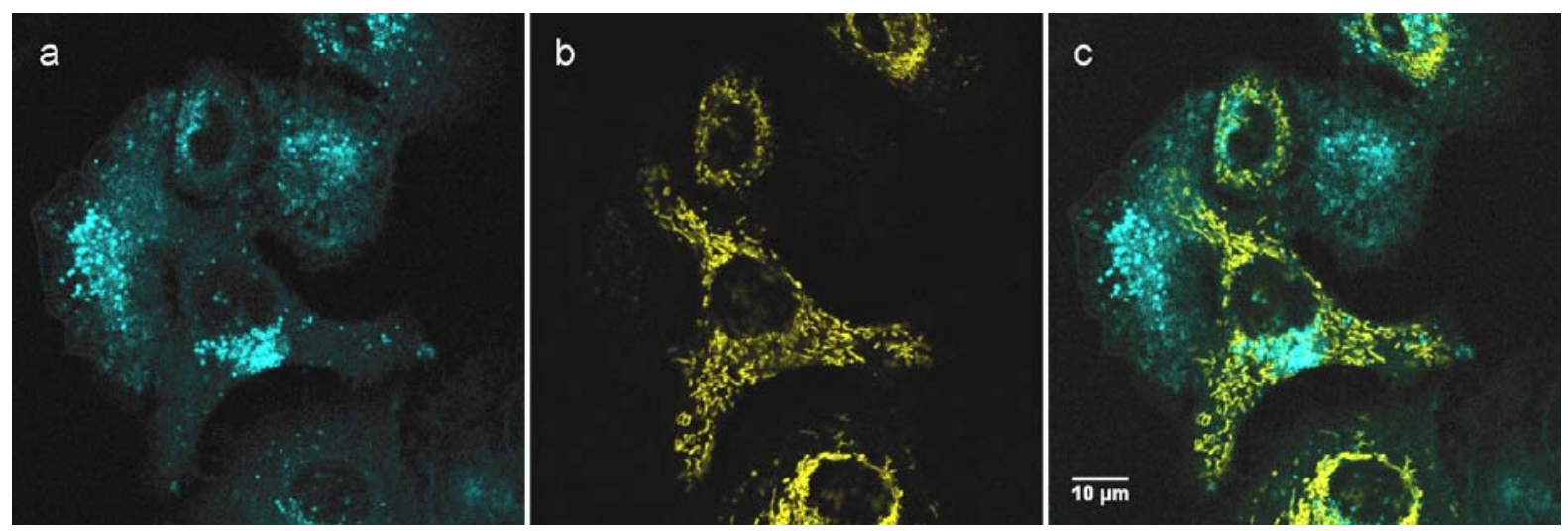

Abb. 167. Fluoreszenzmikroskopische Aufnahmen der zwei Zelltypen, die nach Inkubation der Zellen (A549) mit dem seco-Drug (1S,10R)-76 unterschieden werden können. a) vitale und tote Zellen, $\lambda_{\mathrm{em}}=500 \mathrm{~nm}$ (blau); b) vitale Zellen, $\lambda_{\mathrm{em}}=560 \mathrm{~nm}$ (gelb); c) Überlagerung der Emissionen bei $\lambda_{\mathrm{em}}=500 \mathrm{~nm}$ (blau) und $\lambda_{\mathrm{em}}=560 \mathrm{~nm}$ (gelb).

\begin{tabular}{ccc}
\hline$\lambda_{\text {exc }}[\mathbf{n m}]$ & $\lambda_{\text {em }}[\mathbf{n m}]$ & Lokalisation \\
\hline 405 & 500 & Zellmembran, Endosomen, u.U. Lysosomen, Golgi-Apparat, \\
& & Endoplasmatisches Retikulum \\
514 & 560 & Mitochondrien \\
\hline
\end{tabular}

Tab. 48 Anregungs- und Emissionswellenlänge sowie Lokalisation für $(1 S, 10 R)-76$.

Die blaugrüne Emission mit $\lambda_{\mathrm{em}}=500 \mathrm{~nm}$ konnte an der Zellmembran sowie in Organellen beobachtet werden, bei denen es sich vermutlich um Endosomen, Lysosomen, den Golgi-Apparat oder auch um Endoplasmatisches Retikulum handelte. Die größte Intensität war hierbei jeweils in einer Ansammlung in Kernnähe zu beobachten. Bei den zahlreichen länglichen Strukturen, die als einzige eine gelbgrüne Fluoreszenzemission von $\lambda_{\mathrm{em}}=560 \mathrm{~nm}$ zeigten, handelte es sich vermutlich um Mitochondrien, da die entsprechenden Organellen eine charakteristische Form aufwiesen und zudem bei Bestrahlung mit Laserlicht hoher Leistung schnell zerstört wurden.

Entgegen aller Erwartungen stellte sich heraus, dass der Zellkern nicht angefärbt wurde. Stattdessen war er deutlich als große ungefärbte Struktur im Inneren der Zellen zu erkennen (Abb. 168). 

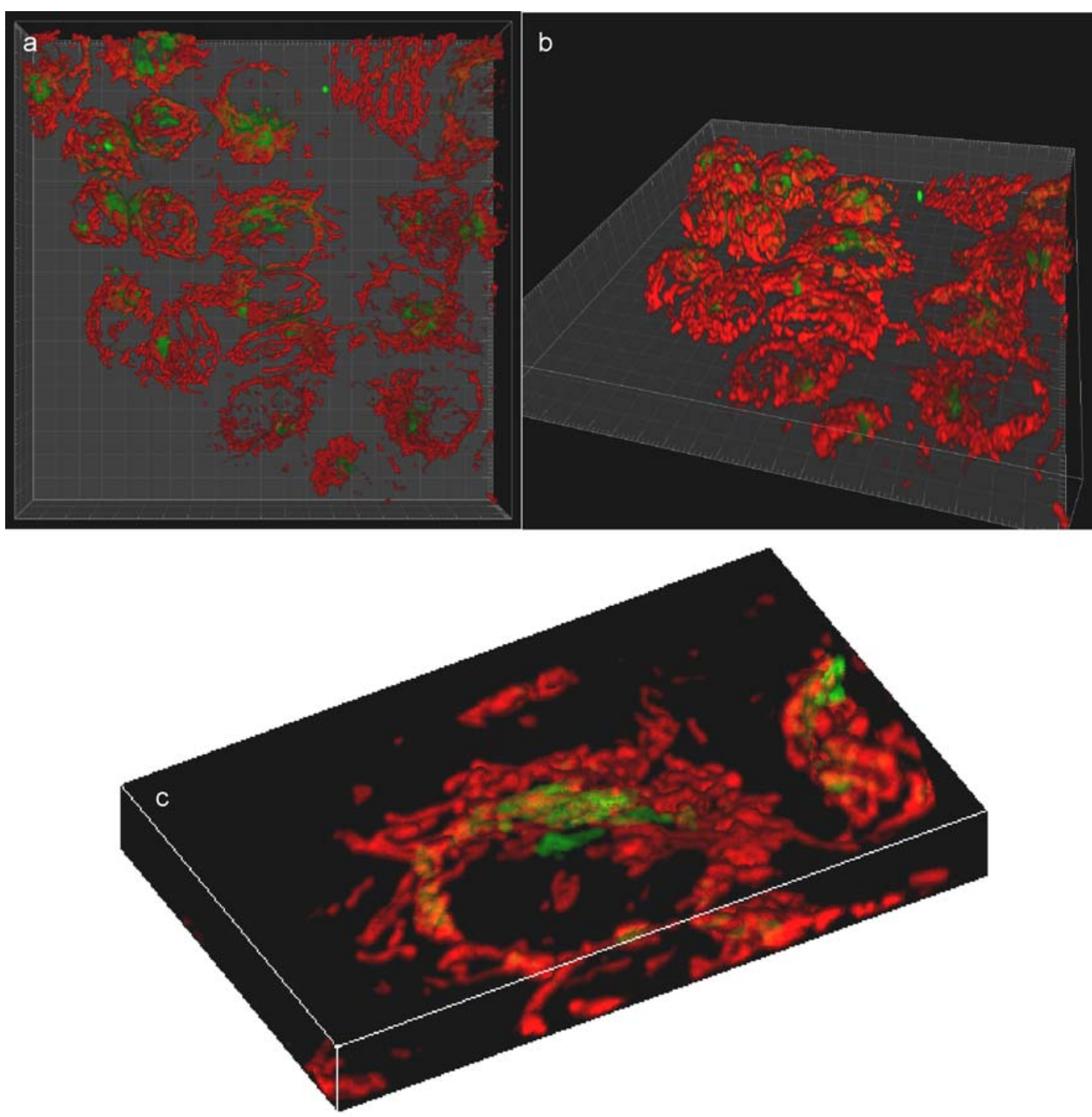

Abb. 168. Fluoreszenzmikroskopische Aufnahmen (Spinning-Disc-Mikroskop) nach 10minütiger Inkubation der Zellen (HeLa SS6) mit dem seco-Drug (1S,10R)-76. grün: $\lambda_{\mathrm{em}}=500 \mathrm{~nm}$, rot: $\lambda_{\mathrm{em}}=560 \mathrm{~nm}$. a) Aufsicht; b) Ansicht aus der Vogelperspektive; c) Vergrößerung einer Zelle, Ansicht aus der Vogelperspektive.

Bei einer Zugabe des blauen DNA-Farbstoffs Hoechst 33342 (40) zu Zellen, die bereits acht Stunden mit dem seco-Drug $(1 S, 10 R)$-76 inkubiert worden waren, wurden der Zellkernrand und der Rand nucleoliartiger Strukturen im Zellkerninneren angefärbt (Abb. 169a). Bei unbehandelten Zellen wurde hingegen eine gleichmäßigere Färbung des gesammten Zellkerns erzielt (Abb. 169b). Dies könnte darauf zurückzuführen sein, dass durch die Inkubation mit dem seco-Drug eine Apoptose ausgelöst wurde, die in der Folge zu einer Chromatinkondensation im Zellkern führte. ${ }^{210}$ Das Auslösen der Apoptose müsste hierbei nicht zwangsläufig durch eine Bindung des Wirkstoffs an die Kern-DNA verursacht worden sein, sondern könnte beispielsweise auch die Folge 
einer Schädigung der Mitochondrien sein. Auf der anderen Seite wäre eine Fluoreszenzlöschung nach Bindung des seco-Drugs $(1 S, 10 R)-76$ bzw. des entsprechenden Drugs an die DNA denkbar. Dass der Wirkstoff in den Zellkern eingelagert wurde, könnte aus dem Ausbleiben einer Färbung durch Hoechst 33342 (40) ersehen werden, das ebenfalls in der kleinen Furche AT-reicher DNA-Regionen bindet.

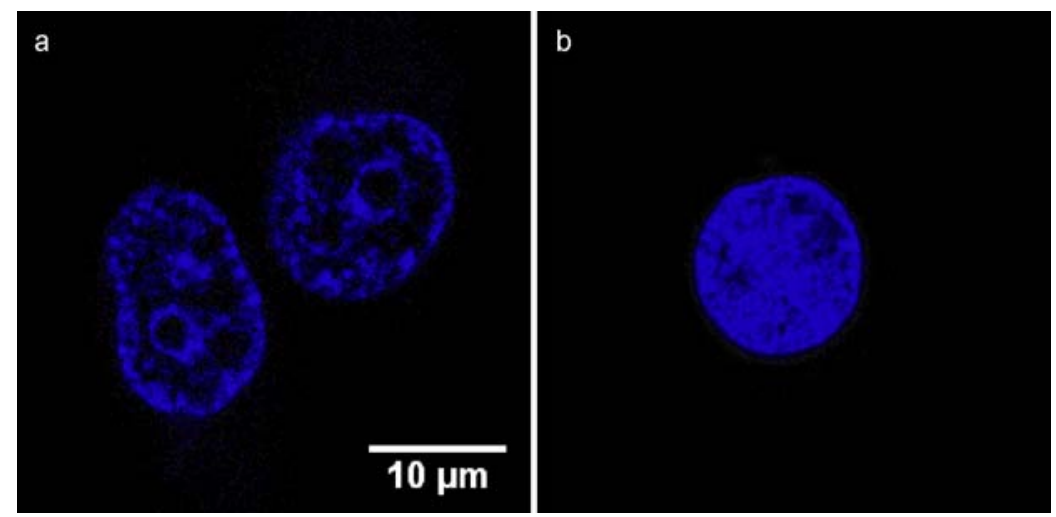

Abb. 169. Fluoreszenzmikroskopische Aufnahmen der Zellkerne a) mit $(1 S, 10 R)-76$ präinkubierter Zellen (A549) und b) unbehandelter Zellen (A549) nach Anfärbung mit Hoechst 33342 (40).

Um die Frage zu klären, ob es sich bei den länglichen Organellen, die eine gelbgrüne Fluoreszenzemission von $\lambda_{\mathrm{em}}=560 \mathrm{~nm}$ zeigten, tatsächlich um Mitochondrien handelte, wurde ein Co-Lolokalisationsexperiment mit dem Mitochondrien-selektiven Farbstoff MitoTracker ${ }^{\circledR}$ Deep Red (41) der Firma Invitrogen durchgeführt. 41 erlaubte aufgrund seiner stark rot-verschobenen Fluoreszenzemission hierbei nicht nur die gleichzeitige Beobachtung mit dem seco-Drug $(1 S, 10 R)$-76, welches im blaugrünen und gelbgrünen Bereich fluoreszierte, dem blau fluoreszierenden Hoechst (40) und dem rot fluoreszierenden Trypanblau, sondern auch die Erkennung vitaler Zellen.

Die Aufnahme der meisten Mitochondrien-selektiven Farbstoffe, wie die der MitoTracker $^{\circledR}$, ist abhängig vom Membranpotential der Mitochondrien. ${ }^{149}$ Aufgrund der Anreicherung von Protonen an der Außenseite der inneren Mitochondrienmembran kommt es zur Anreicherung negativ geladener Ionen an der Innenseite der inneren Mitochondrienmembran in vitalen Zellen. Kationische lipophile Farbstoffe wie die MitoTracker ${ }^{\circledR}$ werden daher nach einer passiven Diffussion durch die Membranen in der Matrix der Mitochondrien festgehalten. Aufgrund des Zusammenbruchs des Membranpotentials in einer frühen Phase der Apoptose werden die MitoTracker ${ }^{\circledR}$ nicht in Mitochondrien apoptotischer Zellen angereichert und erlauben so eine Differenzierung zwischen vitalen Zellen und apoptotischen bzw. toten Zellen. ${ }^{149,150}$ Eine 
gegenüber Thiolen reaktive Chlormethylgruppe in den MitoTrackern ${ }^{\circledR}$ bedingt vermutlich deren unter Zellfixierungsbedingungen zu beobachtende Retention in den Mitochondrien. ${ }^{149}$

Vorversuche zur Ermittlung der optimalen MitoTracker ${ }^{\circledR}$-Konzentration ergaben, dass bereits bei $25 \mathrm{nM}$ zwei Zellpopulationen unterschieden werden konnten. Analog zu den Beobachtungen nach Inkubation mit $(1 S, 10 R)$-76 zeigten Zellen eines Typs nur eine schwache, diffuse und punktförmige Anfärbung mit 41, während Zellen eines zweiten Typs eine starke Färbung der Mitochondrien aufwiesen. Nur letztere waren vitale Zellen mit intakten Mitochondrien und wurden durch Trypanblau nicht angefärbt. Bei einer Anregung mit $\lambda_{\mathrm{exc}}=633 \mathrm{~nm}$ erfolgte die Fluoreszenz bei $\lambda_{\mathrm{em}}=680 \mathrm{~nm}$, während bei $\lambda_{\text {exc }}=405 \mathrm{~nm}$ und $\lambda_{\text {exc }}=514 \mathrm{~nm}$ keine Fluoreszenz detektiert wurde (Tab. 49).

\begin{tabular}{ccc}
\hline$\lambda_{\text {exc }}[\mathbf{n m}]$ & $\lambda_{\text {em }}[\mathbf{n m}]$ & Lokalisation \\
\hline 633 & 680 & Mitochondrien \\
\hline
\end{tabular}

Tab. 49 Anregungs- und Emissionswellenlänge sowie Lokalisation des MitoTrackers ${ }^{\circledR} 41$.

Die Co-Lokalisationsexperimente mit dem MitoTracker ${ }^{\circledR} 41$ zeigten deutlich, dass das seco-Drug $(1 S, 10 R)-76$ in den Mitochondrien lebender Zellen angereichert wurde (Abb. 170b und Abb. 170c, obere 2/3 der Zellen, 76: grün dargestellt, 41: rot dargestellt, Abb. 170e, Überlagerung von 76 und 41: gelb dargestellt). Bei diesen lebenden Zellen waren durch Trypanblau (Abb. 170d, hellblau dargestellt) nur die Zellmembranen angefärbt. In den Mitochondrien durch Trypanblau deutlich im Zytosol angefärbter toter Zellen (Abb. 170b-e, unteres 1/3 der Zellen) konnten 41 und 76 stattdessen nur mit sehr schwachen Intensitäten nachgewiesen werden.

Bemerkenswert war, dass ein zunehmender Anteil der Zellen wenige Stunden nach einer seco-Drug-Inkubation Zeichen einer Apoptose zeigten (Abb. 170d). Es kam zur Ausbildung von Membranausstülpungen und zum Zusammenbruch des Membranpotentials in den Mitochondrien betroffener Zellen, sodass die Mitochondrien dieser Zellen nicht mehr durch den MitoTracker ${ }^{\circledR} 41$ angefärbt werden konnten.

Die blaugrüne Fluoreszenz des seco-Drugs (1S,10R)-76 (Abb. 170a, blau dargestellt) konnte in zytosolischen Organellen lebender und toter Zellen, hierbei insbesondere in Kernnähe, detektiert werden. Da die Fluoreszenz des DNA-Farbstoffs Hoechst 33342 (40) bei ähnlichen Wellenlängen wie die blaugrüne Fluoreszenz des seco-Drugs angeregt und detektiert wurde, war die Färbung der Zellkerne durch 40 (Abb. 170a, 
blau dargestellt) nur durch die Lokalisation der Färbung im Kern von der blaugrünen

Fluoreszenz des seco-Drugs in den zytosolischen Organellen zu unterscheiden.
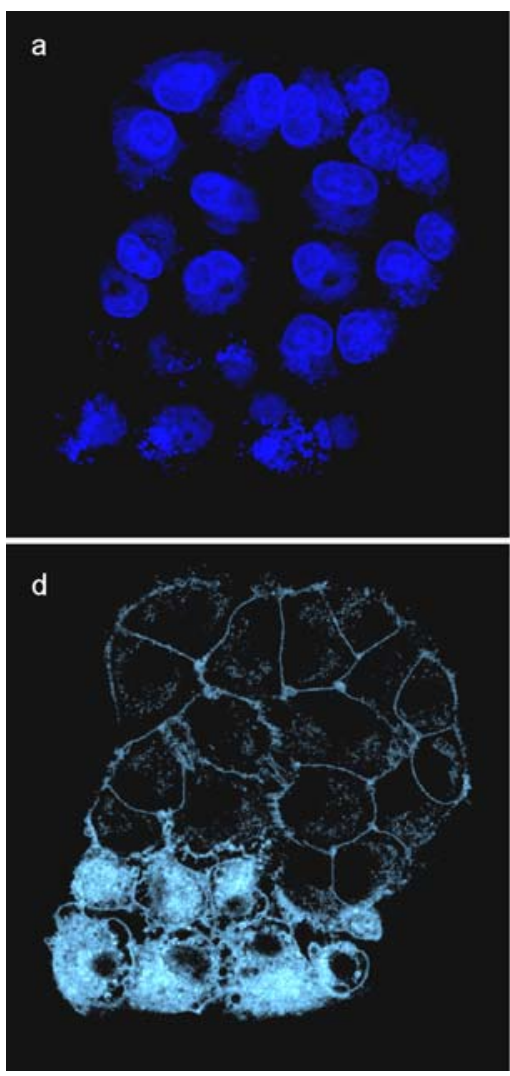
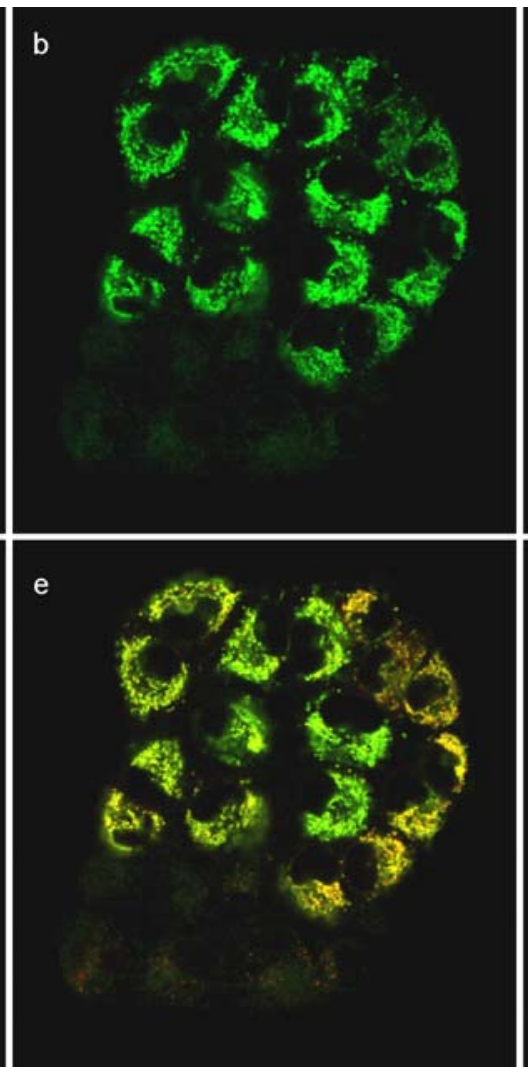
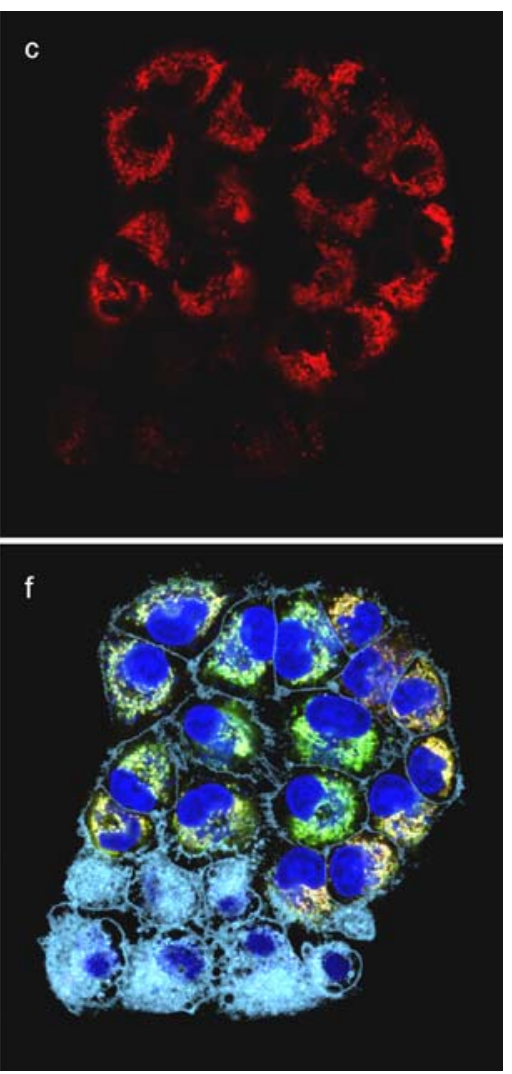

Abb. 170. Fluoreszenzmikroskopische Aufnahme vitaler und toter Zellen (A549) nach Inkubation mit $(1 S, 10 R)-76$. a) $\lambda_{\mathrm{exc}}=405 \mathrm{~nm}, \lambda_{\mathrm{em}}=460-500 \mathrm{~nm}$, Darstellung in blau: durch Hoechst 33342 (40) gefärbte Zellkerne und durch 76 gefärbte zytosolische Organellen; b) $\lambda_{\mathrm{exc}}=514 \mathrm{~nm}, \lambda_{\mathrm{em}}=560 \mathrm{~nm}$, Darstellung in grün: durch $(1 S, 10 R)-76$ gefärbte Mitochondrien vitaler Zellen (obere $2 / 3$ der Zellen); c) $\lambda_{\text {exc }}=633 \mathrm{~nm}, \lambda_{\mathrm{em}}=680 \mathrm{~nm}$, Darstellung in rot: durch MitoTracker ${ }^{\circledR}$ Deep Red (41) gefärbte Mitochondrien vitaler Zellen (obere 2/3 der Zellen); d) $\lambda_{\mathrm{exc}}=561 \mathrm{~nm}, \lambda_{\mathrm{em}}=630 \mathrm{~nm}$, Darstellung in hellblau: durch Trypanblau gefärbte Zellmembranen vitaler Zellen (obere $2 / 3$ der Zellen) und angefärbtes Zytosol toter Zellen (unteres 1/3 der Zellen); e) Überlagerung der Fluoreszenz von (1S,10R)-76 (grün) und MitoTracker Deep Red 41 (rot) zu gelb; f) Überlagerung von a-d.

Die Fluoreszenzemission von Trypanblau wurde bei $\lambda_{\mathrm{exc}}=561 \mathrm{~nm}$ und $\lambda_{\mathrm{em}}=630 \mathrm{~nm}$ detektiert (Tab. 50).

\begin{tabular}{ccc}
\hline$\lambda_{\text {exc }}[\mathbf{n m}]$ & $\lambda_{\text {em }}[\mathbf{n m}]$ & Lokalisation \\
\hline 561 & 630 & Zytosol toter Zellen, Zellmembran \\
\hline
\end{tabular}

Tab. 50. Anregungs- und Emissionswellenlänge sowie Lokalisation von Trypanblau. 
In zusätzlichen Phasenkontrastaufnahmen $(\lambda=514 \mathrm{~nm})$ waren tote Zellen anhand des dunkler gefärbten Zytosols und des dunkel erscheinenden Zellkerns gut von lebenden Zellen zu unterscheiden (Abb. 171a).
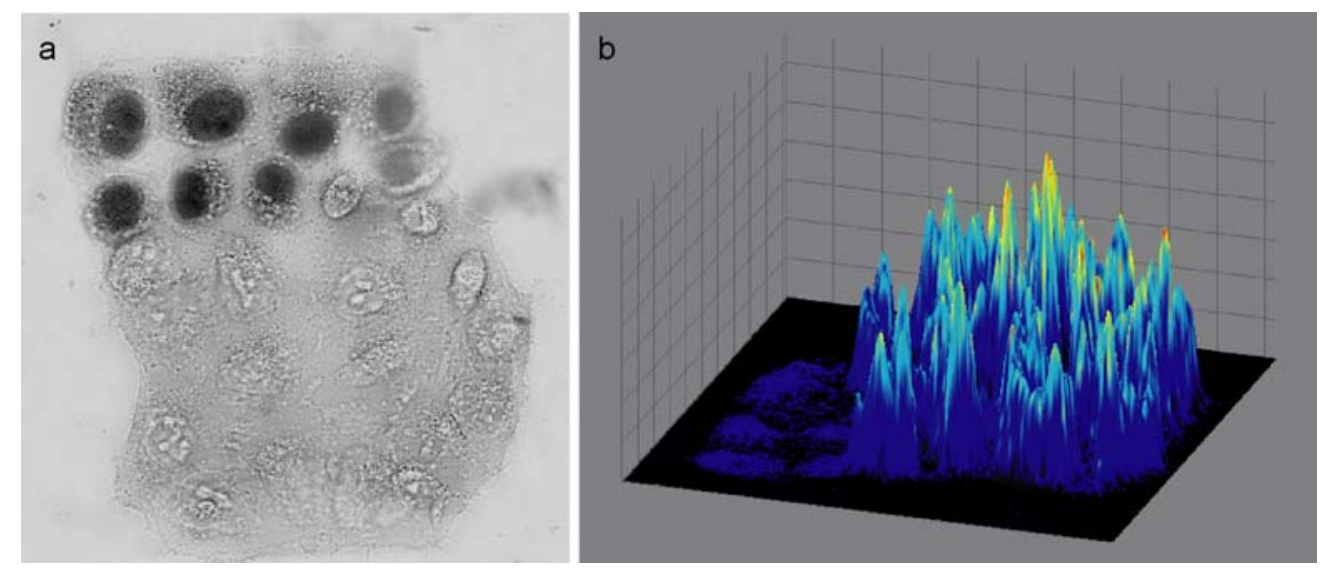

Abb. 171. Phasenkontrast-Aufnahme (a) und 3D-Darstellung der Intensität der Fluoreszenzemission von $(1 S, 10 R)-76$ bei $\lambda_{\mathrm{em}}=560 \mathrm{~nm}$ (b) der in Abb. 170 gezeigten vitalen und toten Zellen (A549) nach Inkubation mit $(1 S, 10 R)-76$. a) durch Trypanblau angefärbte tote Zellen (hier: oberes $1 / 3$ der Zellen) und intrazellulär ungefärbte vitale Zellen (hier: untere $2 / 3 \mathrm{der}$ Zellen); b) 3D-Darstellung der Intensität der Fluoreszenzemission von $(1 S, 10 R)-76$ bei $\lambda_{\mathrm{em}}=560 \mathrm{~nm}$. Schwache Intensität in toten Zellen (hier: linkes 1/3 der Zellen) und hohe Intensität in den Mitochondrien vitaler Zellen (hier: rechte 2/3 der Zellen).

76 reicherte sich vermutlich aus den gleichen Gründen wie 41 in lebenden Mitochondrien an: es penetrierte in ungeladenem Zustand die Zell- und Mitochondrienmembranen, wurde im Inneren der Mitochondrien protoniert und dort vom negativen Membranpotential festgehalten. Die lipophile Umgebung der Mitochondrienmatrix, in dem der Fettstoffwechsel stattfindet, beeinflusste hierbei wahrscheinlich das spektrale Verhalten des Fluorophors, dessen Emissionsmaximum hier bei $560 \mathrm{~nm}$ lag.

Zur Klärung der Frage, ob es sich bei den sphärischen, durch (-)-(1S,10R)-75 und $(1 S, 10 R)-76$ angefärbten Strukturen mit $\lambda_{\mathrm{em}}=500 \mathrm{~nm}$ um Endosomen handelte, wurden HeLa SS6-Zellen mit pEGFP-Endo transfiziert und anschließend mit 75 oder 76 inkubiert. pEGFP-Endo ist ein plasmidischer Vektor eines Fusionsproteins der humanen RhoB-GTPase mit einer $N$-terminalen c-Myc Sequenz und einer modifizierten Variante des grün-fluoreszierendes Proteins (GFP), die auch als EGFP (enhanced green fluorescent protein) bezeichnet wird. ${ }^{211}$ EGFP weist im Vergleich zu GFP eine rotverschobene Fluoreszenzemission, eine stärkere Fluoreszenzintensität und eine höhere Expression in Säugetierzellen auf. Nachdem die für pEGFP-Endo kodierende 
Gensequenz durch Transfektion in die Zellen eingebaut worden ist, wird das Gen abgelesen und das Fusionsprotein auf der Oberfläche von frühen endozytotischen Vesikeln und prälysosomalen Kompartimenten exprimiert. Seine bei $\lambda_{\text {exc }}=488 \mathrm{~nm}$ angeregte Fluoreszenz erfolgt bei $\lambda_{\mathrm{em}}=507 \mathrm{~nm}$.

Nach Inkubation der mit pEGFP-Endo transfizierten Zellen mit dem Prodrug $(-)-(1 S, 10 R)-75$ konnten mehrere kernnahe angefärbte runde Strukturen als Endosomen identifiziert werden. In der Peripherie befindliche gefärbte Organellen konnten stattdessen nicht den Endosomen zugeordnet werden. Es könnte sich hierbei um Lysosomen handeln. Wurden die mit pEGFP-Endo transfizierten Zellen mit dem seco-Drug $(1 S, 10 R)-76$ inkubiert, so konnte ein großer Teil der durch $\mathbf{7 6}$ angefärbten Strukturen mit $\lambda_{\mathrm{em}}=500 \mathrm{~nm}$ mit Endosomen korreliert werden (Abb. 172).

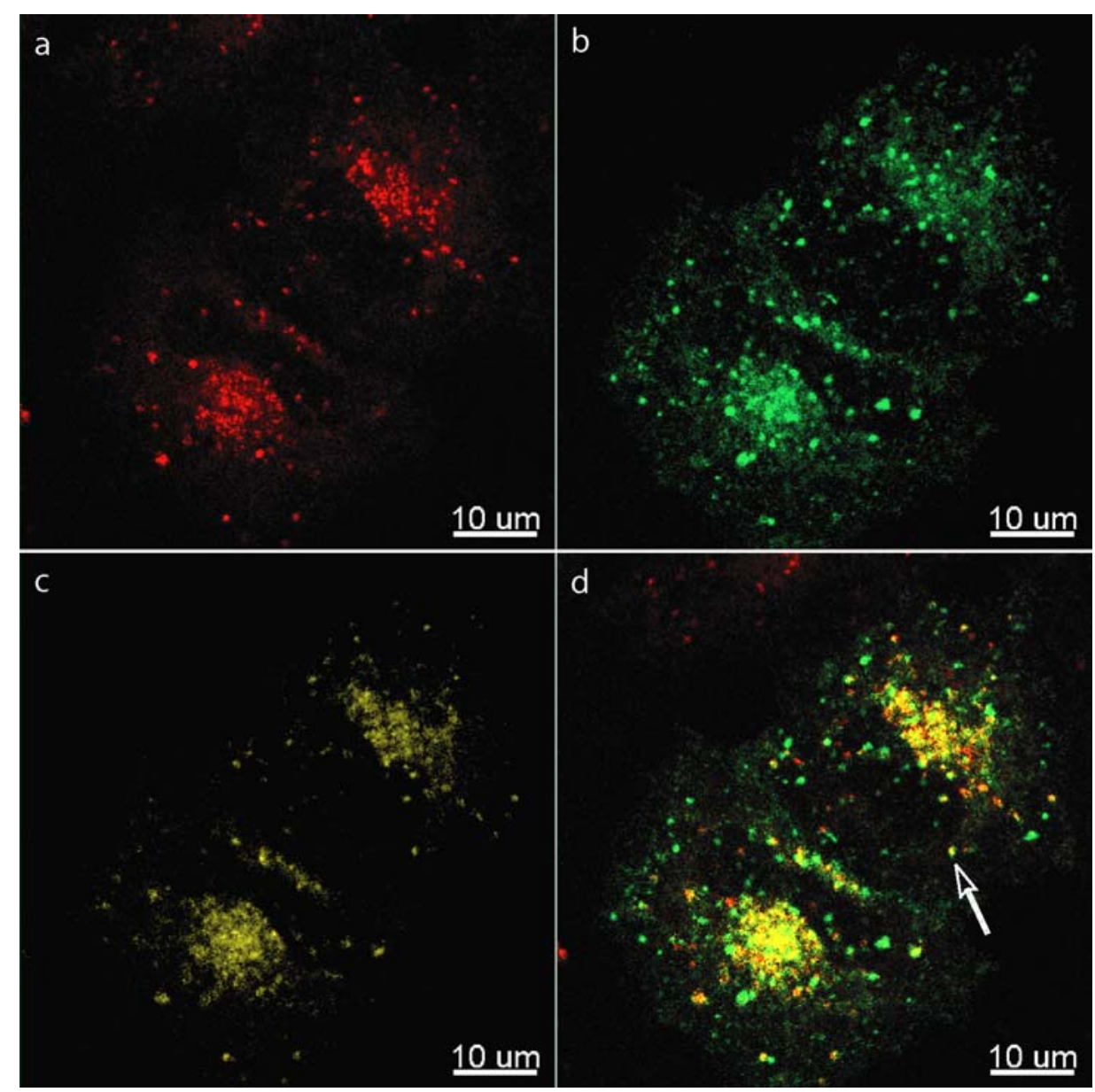

Abb. 172. Fluoreszenzmikroskopische Aufnahme mit pEGFP-Endo transfizierter Zellen (HeLa SS6) nach Inkubation mit $(1 S, 10 R)-76$. a) $\lambda_{\mathrm{exc}}=405 \mathrm{~nm}, \lambda_{\mathrm{em}}=500 \mathrm{~nm}$, Darstellung in rot: durch 76 gefärbte zytosolische Organellen; b) $\lambda_{\mathrm{exc}}=488 \mathrm{~nm}, \lambda_{\mathrm{em}}=510 \mathrm{~nm}$, Darstellung in grün: durch pEGFP-Endo gefärbte Endosomen; c) Darstellung in gelb: Co-lokalisierte Fluoreszenzemission von $(1 S, 10 R)-76$ und pEGFP-Endo; d) Überlagerung von a-c. Pfeil: Für zeitaufgelöste Co-Lokalisation (Abb. 173) ausgewähltes Endosom. 
Zur Absicherung des Ergebnisses wurde die zeitabhängige Bewegung mehrerer Endosomen im zweidimensionalen Raum durch eine Bilderfolge untersucht und zu jedem Zeitpunkt die Fluoreszenz des betrachteten Organells für $\lambda_{\text {exc }}=405 \mathrm{~nm}$ (76) und $\lambda_{\text {exc }}=488 \mathrm{~nm}$ (pEGFP-Endo) bestimmt. Für das in Abbildung 172 durch einen Pfeil markierte Endosom ist die zeitabhängige Bewegung in Abbildung 173 dargestellt. Da die dem seco-Drug entsprechende blaugrüne Fluoreszenz (blau dargestellt) sich zeitlich und räumlich mit der grünen Fluoreszenz des pEGFP-Endo (grün dargestellt) bewegte, ist eine Co-Lokalisation beider Substanzen in diesem Organell eindeutig belegt. Während sich viele Endosomen in Zellkernnähe nicht über weite Distanzen bewegten, konnte bei einigen Endosomen eine rasche Bewegung in Richtung der Zellperipherie beobachtet werden. Dies ist ein Hinweis dafür, dass das in Endosomen angereicherte seco-Drug aus der Zelle hinaus transportiert werden sollte.

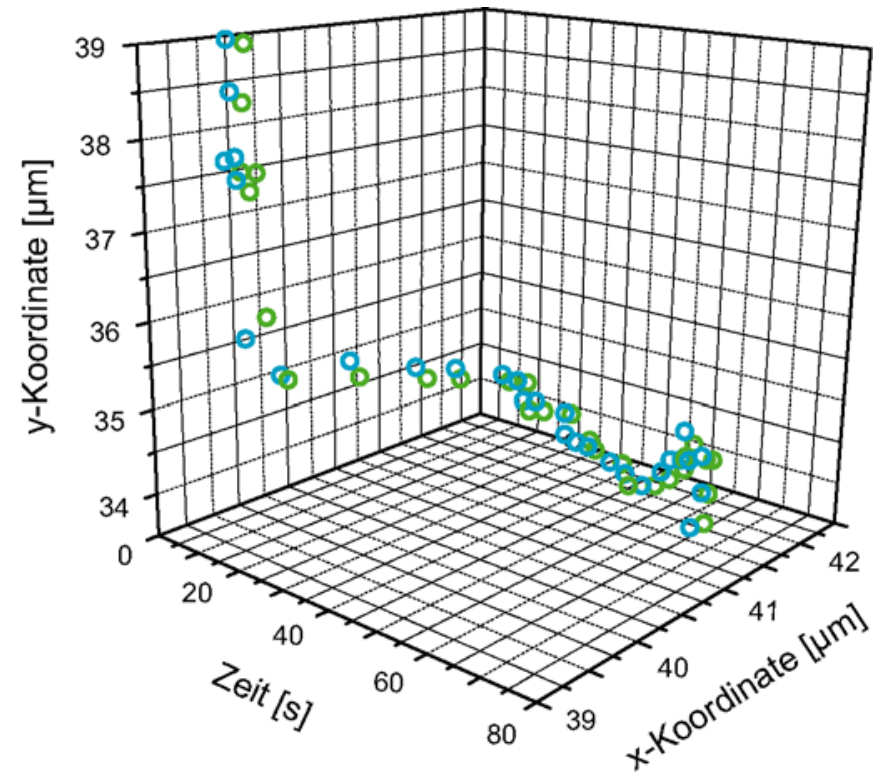

Abb. 173. Zeitliche und räumliche Co-Lokalisation der Fluoreszenzemission von 76 (blau) und pEGFP-Endo (grün) in dem in Abb. 172 durch einen Pfeil markierten Endosom.

Bei einem Teil der Endosomen könnte es sich um Lysosomen handeln, denn es ist allgemein bekannt, dass schwach basische Amine in zellulären Kompartimenten mit niedrigem internen $\mathrm{pH}$ wie den Lysosomen akkumulieren. ${ }^{212} \mathrm{Zu}$ diesen Farbstoffen gehört auch das Dapoxyl ${ }^{\circledR}$-Derivat LysoTracker ${ }^{\circledR}$ Blue-White DPX (104, Abb. 174), das analog zu (-)-(1S,10R)-75 und (1S,10R)-76 über einen Dapoxylrest und eine $N, N$ Dimethylaminofunktionalität verfügt. Der Mechanismus der Retention in den Lysosomen ist wahrscheinlich die Protonierung des Amins innerhalb der sauren Organelle gefolgt von einer ladungsbedingt verringerten Membranpenetration. 


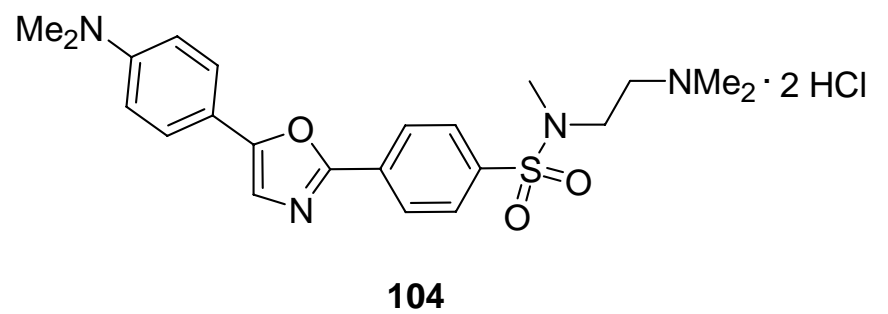

Abb. 174. Der Lysosomen-Farbstoff LysoTracker ${ }^{\circledR}$ Blue-White DPX (104).

Zur Klärung der Frage, ob die Substanzen an zelluläre DNA binden, wurden neben den bereits in Kap. 10.1 beschriebenen Experimenten zur Fluoreszenzlöschung durch DNA-Bindung einige In-vitro-Experimente an Zellen durchgeführt. Hierbei wurden die Zellen zunächst mit DMSO, den fluoreszenzmarkierten Analoga (-)-(1S,10R)-75 bzw. (1S,10R)-76 oder dem nicht-fluoreszenzmarkierten seco-Drug $(+)-(1 S, 10 R)-34 \mathbf{a}$ inkubiert und die Zellen danach gewaschen. Während einer anschließenden Inkubation mit dem DNA-Farbstoff Hoechst 33342 (40) wurde die zeitliche Änderung der Intensität der Hoechst-Fluoreszenz für alle beobachteten Zellen (etwa 400) gemessen und pro Zeitpunkt und Substanz ein Mittelwert gebildet (Abb. 175). Hoechst 33342 (40) bindet an AT-reiche Regionen doppelsträngiger DNA und seine Bindung sollte durch bereits eingelagerte Duocarmycin-Analoga behindert werden. Abb. 175 zeigt die Auftragung einer Kinetik ab einem Zeitpunkt von 75 Minuten nach der Hoechstzugabe.

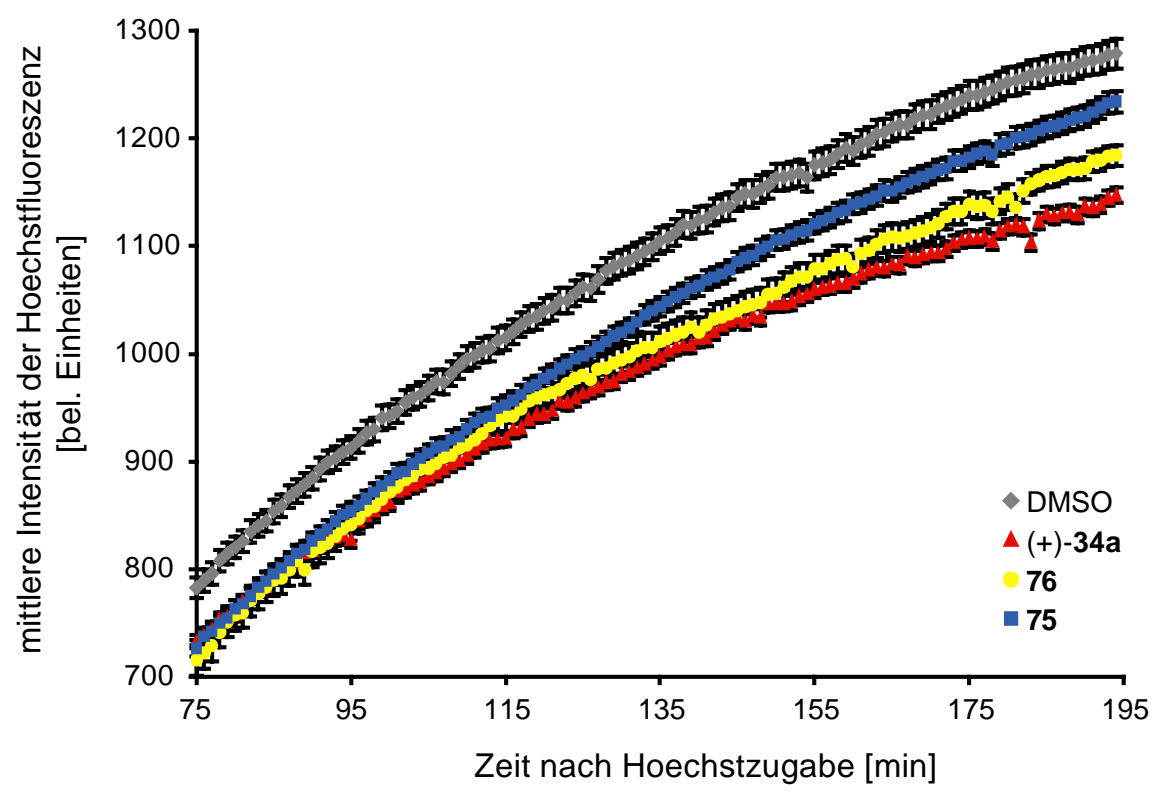

Abb. 175. Kinetik der Hoechstaufnahme nach Präinkubation der Zellen (A549) mit DMSO, dem seco-Drug (+)-34a oder den fluoreszenzmarkierten Analoga 75 bzw. 76. Fehlerbalken repräsentieren Standardfehler des Mittelwertes. 
Es ist deutlich zu erkennen, dass bei nur mit DMSO behandelten Zellen die mittlere Fluoreszenzintensität deutlich höher war als bei den mit Wirkstoffen inkubierten Zellen. Während die Steigung der Kurve DMSO-behandelter Zellen der mit dem fluoreszenzmarkierten Prodrug $\mathbf{7 5}$ ähnelt, ist die Steigung für das fluoreszenzmarkierte seco-Drug $(1 S, 10 R)$-76 geringer. Am niedrigsten ist sie für das nicht-markierte secoDrug (+)-34a. Diese Beobachtung korreliert mit den Zytotoxizitäten der Verbindungen und lässt folgende Hypothese zu: Während das seco-Drug (+)-34a sehr gut an die DNA bindet, ist die Affinität des fluoreszenzmarkierten seco-Drugs $(1 S, 10 R)-76$ geringer. Das fluoreszenz-markierte Prodrug $(-)-(1 S, 10 R)-\mathbf{7 5}$ wird nur in geringen Mengen in die Zellen aufgenommen und zeigt keine Reaktion mit der DNA.

Analoge Messungen, bei denen die Zellen zunächst mit Hoechst 33342 (40) und anschließend mit den Wirkstoffen oder DMSO inkubiert wurden, führten nicht zu reproduzierbaren Ergebnissen. Begründete Hinweise auf eine Verdrängung von Hoechst durch die Wirkstoffe konnten durch diese Experimente nicht gewonnen werden, was vermutlich auf die Zytotoxizität von Hoechst und eine möglicherweise langsame Verdrängung von Hoechst aus der Kern-DNA zurückzuführen ist.

Insgesamt ergaben die fluoreszenzmikroskopischen In-vitro-Untersuchungen, dass das fluoreszenzmarkierte Prodrug (-)-(1S,10R)-75 von der äußeren Zellmembran zurückgehalten wird und erst nach einer Inkubationszeit von mehreren Stunden in Form sphärischer Vesikel in den Zellen detektiert werden kann (Abb. 166). Das analoge seco-Drug $(1 S, 10 R)$-76 wird stattdessen sehr schnell in die Zellen aufgenommen, sodass bereits nach einigen Minuten eine hohe Intensität in Endosomen, Mitochondrien sowie anderen Organellen beobachtet werden kann (Abb. 170 und 172).

Nicht nur die deutlich niedrigere Alkylierungseffizienz der Prodrugs, sondern auch ihre signifikant verringerte Fähigkeit zur Penetration der Zellmembran trägt vermutlich zum hohen Zytotoxizitätsunterschied zwischen den Prodrugs und den entsprechenden seco-Drugs bei. Im Rahmen des ADEPT-Konzeptes ist es von großem Vorteil, wenn das Prodrug kaum in gesunde Körperzellen aufgenommen wird und das im Tumorgewebe generierte seco-Drug schnell in die Krebszellen hineindiffundieren kann. So bleibt die Wirkung der Zytostatika weitestgehend auf das Tumorgewebe beschränkt.

$\mathrm{Ob}$ das fluoreszenzmarkierte seco-Drug bzw. das entsprechende Drug in lebenden Zellen an die Kern-DNA bindet, konnte durch die durchgeführten Experimente nicht eindeutig bewiesen werden, ist aber als sehr wahrscheinlich anzusehen. 
Eine Bindung an die Kern-DNA muss hierbei nicht allein für die Zytotoxizität der Verbindungsklasse verantwortlich sein. Vielmehr liegt durch die Ergebnisse der vorgestellten Experimente ein Hinweis darauf vor, dass die hohe Zytotoxizität der Duocarmycin-Analoga und der entsprechenden Naturstoffe auch oder zusätzlich durch eine Schädigung der zellulären Mitochondrien erfolgen könnte. Diese enthalten plasmidische DNA, die durch das Drug alkyliert werden könnte. Für einen Einfluss der Mitochondrienschädigung sprechen die mit dem fluoreszenzmarkierten seco-Drug (1S,10R)-76 gemachten Beobachtungen (Abb. 170) und die Tatsache, dass eine Schädigung der Mitochondrien eine Apoptose auslösen kann. ${ }^{213}$ Mäuse, die mit hohen Dosen CC-1065 behandelt wurden, starben innerhalb von 12 Tagen durch hepatische Nekrose. Bei niedrigen Dosen trat ein verzögerter Tod (etwa 50 Tage nach der Injektion) auf, der mit einer starken Veränderung in der Struktur hepatischer Mitochondrien einherging. ${ }^{214}$ Auch dies ist ein Zeichen für die Wirkung der Substanzen auf die Mitochondrien. Nicht zuletzt könnte eine Schädigung der Mitochondrien auch die Frage beantworten, warum die Substanzen bereits in Dosen toxisch sind, in denen noch kein Effekt auf die Kern-DNA nachgewiesen werden konnte. $^{114}$

Insgesamt deuten die Ergebnisse deuten darauf hin, dass sowohl die Mitochondrien als auch die zelluläre DNA durch CC-1065- und Duocarmycin-Derivate geschädigt werden. Der Effekt auf die Mitochondrien könnte hierbei ausschlaggebend für die Zytotoxizität bei Applikation geringer Dosen sein. 


\section{ZUSAMMENFASSUNG}

Die Chemotherapie ist eine wichtige Behandlungsmethode bösartiger Tumoren. Trotz beachtlicher Fortschritte in der Entwicklung neuer und effizienter Krebstherapien verursachen die meisten derzeit in der klinischen Anwendung genutzten Chemotherapeutika immer noch starke Nebenwirkungen, da ihre zytotoxische Aktivität nicht auf entartete Zellen beschränkt ist und demzufolge auch Zellen schnell proliferierender gesunder Gewebe wie des blutbildenen Systems und des Magen-Darm-Traktes massiv beeinträchtigt werden. Ein Ziel der modernen Arzneimittelforschung ist daher die Entwicklung selektiver Tumortherapien, in denen genotypische oder phänotypische Unterschiede zwischen malignen und gesunden Zellen dazu genutzt werden, die zytotoxische Wirkung der Chemotherapeutika auf die Krebszellen zu limitieren.

Ein sehr vielversprechender Ansatz ist die Antibody-directed Enzyme Prodrug Therapie (ADEPT), bei der in therapeutischen Dosen ungiftige Transportformen (Prodrugs) verabreicht werden, die gezielt im Tumorgewebe von dort gebundenen Antikörper-Enzym-Konjugaten in hochgiftige Wirkstoffe (Drugs) umgewandelt werden. Im Arbeitskreis L. F. Tietze wurden in den letzten Jahren verschiedene Verbindungen für einen Einsatz im Rahmen des ADEPT-Konzeptes entwickelt, deren Struktur sich an derjenigen zytotoxischer Naturstoffe wie des CC-1065 und des Duocarmycin SA (19) orientiert (Abb. 176).

Als pharmakophore Gruppe weisen die Naturstoffe und die analogen Drugs eine als Elektrophil dienende Spirocyclopropylcyclohexadienon-Einheit auf, die mit nukleophilen Molekülen innerhalb der Zelle reagieren kann. Die Wirkstoffe werden daher innerhalb der Zytostatika der Gruppe der Alkylantien zugeordnet. Die von den Drugs abgeleiteten Prodrugs und seco-Drugs hingegen verfügen über eine phenolische Vorstufe der genannten pharmakophoren Einheit und somit über eine deutlich geringere Elektrophilie. Während die seco-Drugs in gepufferter Lösung innerhalb weniger Minuten unter Abspaltung von $\mathrm{HCl}$ nahezu vollständig zu den entsprechenden Drugs zyklisieren, verhindert in den Prodrugs eine Schützung der phenolischen Hydroxygruppe durch ein Glykosid wie $\beta$-D-Galactose die entsprechende Spirozyklisierung (Abb. 176). Die Prodrugs weisen daher eine signifikant reduzierte Zytotoxizität auf. In Anwesenheit der entsprechenden Glykohydrolase werden die Zuckerbausteine jedoch effizient abgespalten und aus dem intermediär enstehenden secoDrug bildet sich umgehend das entsprechende zytotoxische Drug. 
<smiles>COC(=O)c1cc2c([nH]1)C(=O)C=C1C2=C[C@H]2CCN1C2</smiles>

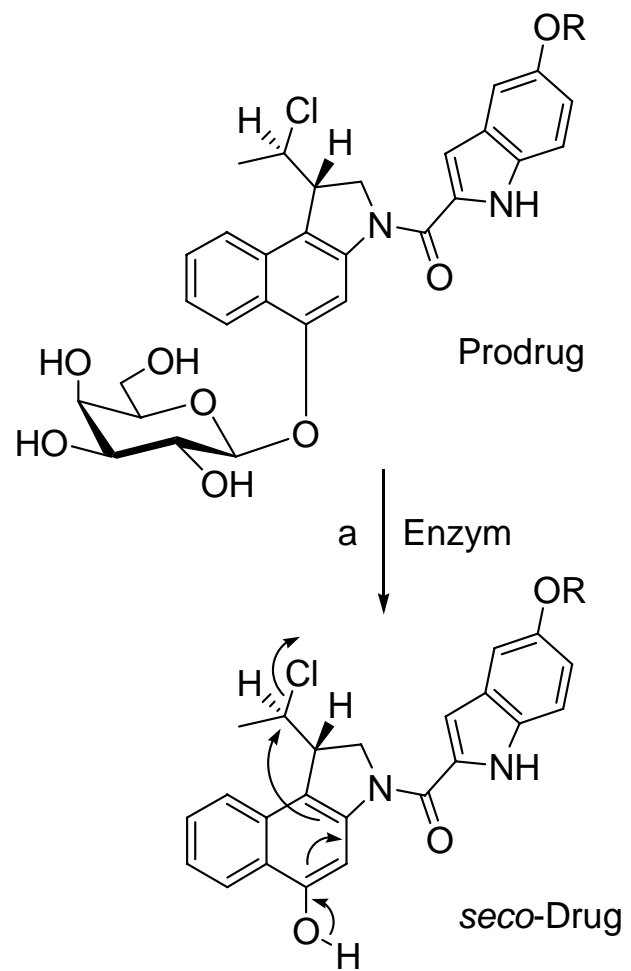

Abb. 176. Enzymatische Toxifizierung eines glykosidischen Prodrugs geringer Zytotoxizität zu dem entsprechenden seco-Drug (a) und schnelle In-situ-Zyklisierung unter Abspaltung von $\mathrm{HCl}$ zu dem hochgiftigen Drug (b), das ein Analogon des Duocarmycin SA (19) darstellt.

In der vorliegenden Arbeit wurden basierend auf der Struktur des Duocarmycin SA (19) neue seco-Drugs, ein neues glykosidisches Prodrug, eine den seco-Drugs analoge Verbindung ohne Chloratom sowie ein fluoreszenzmarkiertes Prodrug und ein fluoreszenzmarkiertes seco-Drug synthetisiert. Des Weiteren wurde die In-vitro-Zytotoxizität der neuen Verbindungen bestimmt und der Wirkmechanismus der Analoga mittels ESI-FTICR-MS, HPLC, HPLC-MS, CD-Spektroskopie und Fluoreszenzmikroskopie untersucht.

Zur Synthese des anti-Methyl-seco-CBI-DMAI-Hydrochlorids $(+)-(1 S, 10 R)-34 a$ aus rac-44 erfolgte zunächst eine Trennung der Enantiomere mittels präparativer HPLC an chiraler stationärer Phase (Chiralpak ${ }^{\circledR}$ IA) (Abb. 177). (+)-(1S,10R)-44 wurde hierbei mit 99.9\% ee erhalten. Nach Abspaltung der Boc-Schutzgruppe in (+)-(1S,10R)-44 mit $4 \mathrm{M} \mathrm{HCl}$ in Essigester erfolgte die Einführung der DNA-bindenden Seitenkette durch EDC $\cdot \mathrm{HCl}$-vermittelte Kupplung des freien Amins mit dem DMAI-CarbonsäureHydrochlorid (46a). Anschließend wurde die tertiäre Aminofunktionalität der DMAISeitenkette in das entsprechende Hydrochlorid überführt und die Benzylschutzgruppe durch katalytische Transferhydrierung abgespalten. Das seco-Drug (+)-(1S,10R)-34a wurde so in einer Ausbeute von 68\% über drei Stufen erhalten. 


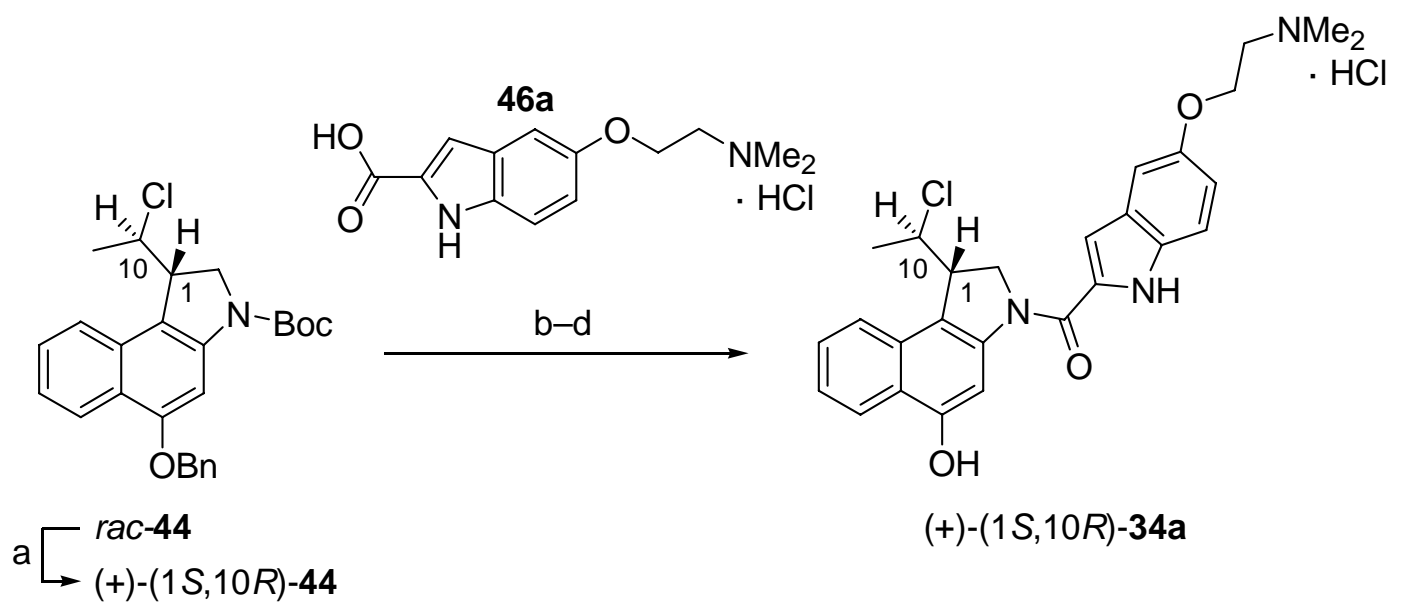

Abb. 177. Synthese des anti-Methyl-seco-CBI-DMAI-Hydrochlorids (+)-(1S,10R)-34a aus rac-44. a) Trennung der Enantiomere von rac-44: Chiralpak ${ }^{\circledR}$ IA $(250 \times 20 \mathrm{~mm}$, Partikelgröße: $5 \mu \mathrm{m}), \quad n$-Heptan $/ \mathrm{CH}_{2} \mathrm{Cl}_{2}=4: 1$, Fluss: $18 \mathrm{~mL} \mathrm{~min}^{-1}$, (+)-(1S,10R)-44: $99.9 \%$ ee; b) $4 \mathrm{M} \mathrm{HCl} / \mathrm{EE}, \mathrm{RT}, 3.5 \mathrm{~h}$; c) 46a, $\mathrm{EDC} \cdot \mathrm{HCl}, \mathrm{DMF}, \mathrm{RT}, 21 \mathrm{~h}, 76 \%$ über 2 Stufen; d) $4 \mathrm{M} \mathrm{HCl} / \mathrm{EE}, \mathrm{RT}, 2 \mathrm{~h}$, dann $\mathrm{Pd} / \mathrm{C} / \mathrm{NH}_{4} \mathrm{HCO}_{2}$, THF, $40{ }^{\circ} \mathrm{C}, 2 \mathrm{~h}, 90 \%$.

Zur Untersuchung des Einflusses des Chloratoms an C-10 auf die Zytotoxizität und die Wechselwirkung mit DNA wurde das enantiomerenreine dechlorierte Methyl-secoCBI-DMAI-Analogon (+)-(1S)-49 synthetisiert (Abb. 178). Im ersten Schritt erfolgte hierbei eine reduktive Dehalogenierung von rac-44 mit Tris(trimethylsilyl)silan (TTMSS) und AIBN als Radikalstarter zu rac-45.

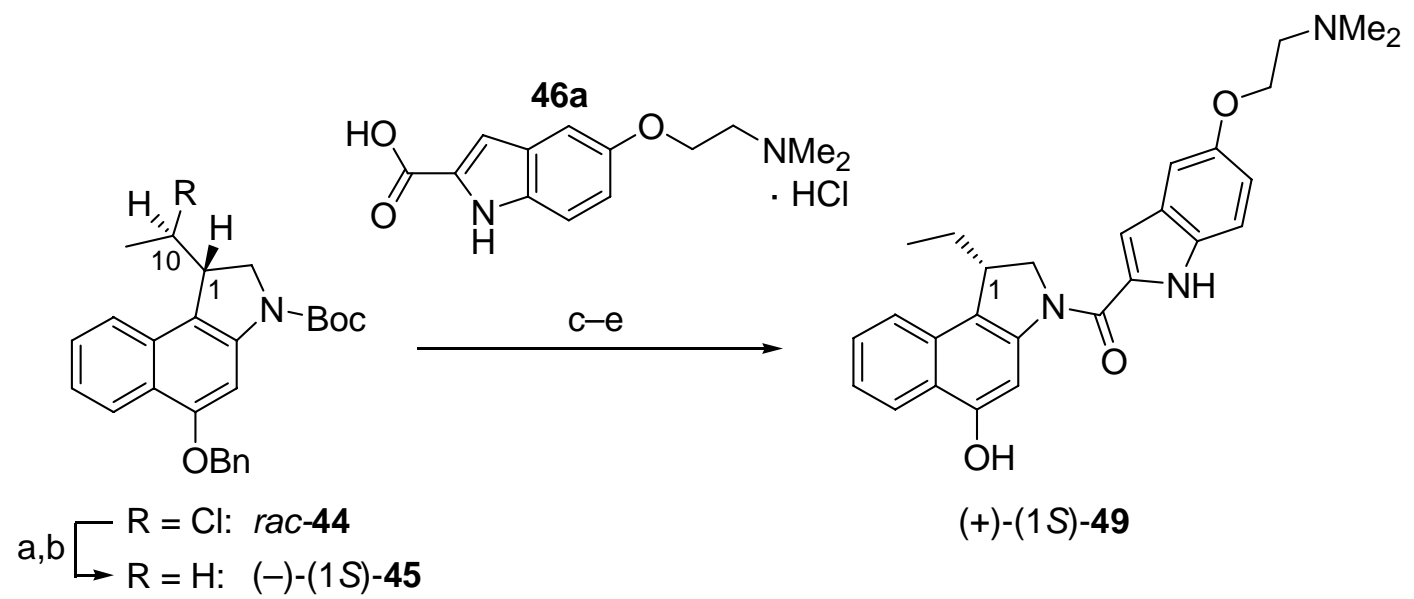

Abb. 178. Synthese des dechlorierten Analogons (+)-(1S)-49. a) TTMSS, AIBN, Toluol, $80^{\circ} \mathrm{C}, 7 \mathrm{~h}, 87 \%$; b) Trennung der Enantiomere von rac-45: Chiralpak ${ }^{\circledR}$ IA $(250 \times 20 \mathrm{~mm}$, Partikelgröße: $5 \mu \mathrm{m}), n$-Hexan $/ \mathrm{CH}_{2} \mathrm{Cl}_{2}=95: 5$, Fluss: $18 \mathrm{~mL} \mathrm{~min}{ }^{-1},(-)-(1 S)-45: 99.9 \%$ ee; c) $4 \mathrm{M} \mathrm{HCl} / \mathrm{EE}, \mathrm{RT}, 3.5 \mathrm{~h}$; d) 46a, EDC $\cdot \mathrm{HCl}, \mathrm{DMF}, \mathrm{RT}, 20 \mathrm{~h} ; 95 \%$ über 2 Stufen; e) $\mathrm{Pd} / \mathrm{C} / \mathrm{NH}_{4} \mathrm{HCO}_{2}$, THF, RT, 1 h, $96 \%$. 
rac-45 wurde anschließend durch präparative HPLC an chiraler stationärer Phase $\left(\right.$ Chiralpak $^{\circledR}$ IA) in die Enantiomere (-)-(1S)-45 und (+)-(1R)-45 getrennt, die jeweils mit $99.9 \%$ ee erhalten wurden. Die Einführung der DNA-bindenden Seitenkette erfolgte nach Abspaltung der Boc-Schutzgruppe in (-)-(1S)-45 mit $4 \mathrm{M} \mathrm{HCl}$ in Essigester durch EDC·HCl-vermittelte Kupplung des freien Amins mit dem DMAI-Carbonsäure-Hydrochlorid (46a). Anschließend wurde die Benzylschutzgruppe durch katalytische Transferhydrierung abgespalten und (+)-(1S)-49 so in einer Gesamtausbeute von 91\% über drei Stufen erhalten. Die In-vitro-Zytotoxizität des Ethylderivates an humanen Bronchialkarzinomzellen (A549) war mit einem $I C_{50}$-Wert von $6900 \mathrm{nM}$ deutlich geringer als jene des seco-Drugs $(+)-(1 S, 10 R)-34 a\left(I C_{50}=0.75 \mathrm{nM}\right)$. Dies unterstreicht die wichtige Rolle der Alkylierung für die Zytotoxizität der Wirkstoffe.

Obwohl die meisten anti-Methyl-seco-CBI-DMAI-Verbindungen für eine Anwendung im Rahmen des ADEPT-Konzeptes sehr gut geeignet sind (IC $C_{50}$ (Prodrug) / IC $C_{50}$ (Prodrug in Anwesenheit des Enzyms) $>1000, I C_{50}($ seco-Drug $\left.)<10 \mathrm{nM}\right)$, ist die Zytotoxizität des seco-Drugs $(+)-(1 S, 10 R)-34 \mathbf{a}\left(I C_{50}=0.75 \mathrm{nM}\right)$ deutlich geringer als die des Duocarmycin SA $\left(I C_{50}=10 \mathrm{pM}\right)$. Um die Wirksamkeit der seco-Drugs zu erhöhen, wurden daher die analogen seco-CBI-DMAI-Derivate mit einer Chlormethyl anstelle einer 1-Chlorethyl-Funktionalität synthetisiert (Abb. 179).

Zunächst wurde hierzu durch katalytische Transferhydrierung die Benzylschutzgruppe der bekannten Vorstufe rac-57 abgespalten, da sich eine Enantiomerentrennung mittels präparativer HPLC an chiraler stationärer Phase auf der Stufe von rac-57 als nicht praktikabel erwiesen hatte. Aufgrund der hohen Empfindlichkeit des primären Chlorids gegenüber einer reduktiven Dehalogenierung musste hierbei der Reaktionsverlauf sorgfältig kontrolliert werden. Durch präparative HPLC an chiraler stationärer Phase (Chiralpak ${ }^{\circledR}$ IA) wurde $r a c-55$ anschließend in die Enantiomere (+)-(1R)-55 und $(-)-(1 S)-55$ getrennt, die jeweils mit 99.9\% ee erhalten wurden. Die abschließende Synthese der seco-Drug-Hydrochloride rac-56a, (-)-(1R)-56a und (+)-(1S)-56a erfolgte mit 89\% - 98\% Ausbeute über zwei Stufen durch eine Abspaltung der BocSchutzgruppe in rac-55, (+)-(1R)-55 und (-)-(1S)-55 mit $4 \mathrm{M} \mathrm{HCl}$ in Essigester und anschließende EDC $\cdot \mathrm{HCl}$-vermittelte Kupplung der freien Amine mit dem DMAICarbonsäure-Hydrochlorid (46a). Bei der Aufarbeitung wurden die seco-Drugs 56a mit konzentrierter Salzsäure versetzt, um die tertiäre Aminofunktionalität der DMAISeitenkette in das entsprechende Hydrochlorid zu überführen und somit die Wasserlöslichkeit zu erhöhen sowie eine Zyklisierung der Wirkstoffe zu den aktiven Drugs während der Aufarbeitung zu verhindern. Die Zytotoxizität der enantiomerenreinen 
seco-Drugs war mit $I C_{50}$-Werten von $0.026 \mathrm{nM}((+)-(1 S)$-56a) bzw. $11.5 \mathrm{nM}((-)-(1 R)$ -

56a) wie erwartet deutlich höher als jene der analogen Methyl-seco-CBI-DMAIHydrochloride $(+)-(1 S, 10 R)-34 \mathbf{a}$ und $(-)-(1 R, 10 S)-\mathbf{3 4 a} .^{141 \mathrm{f}}$

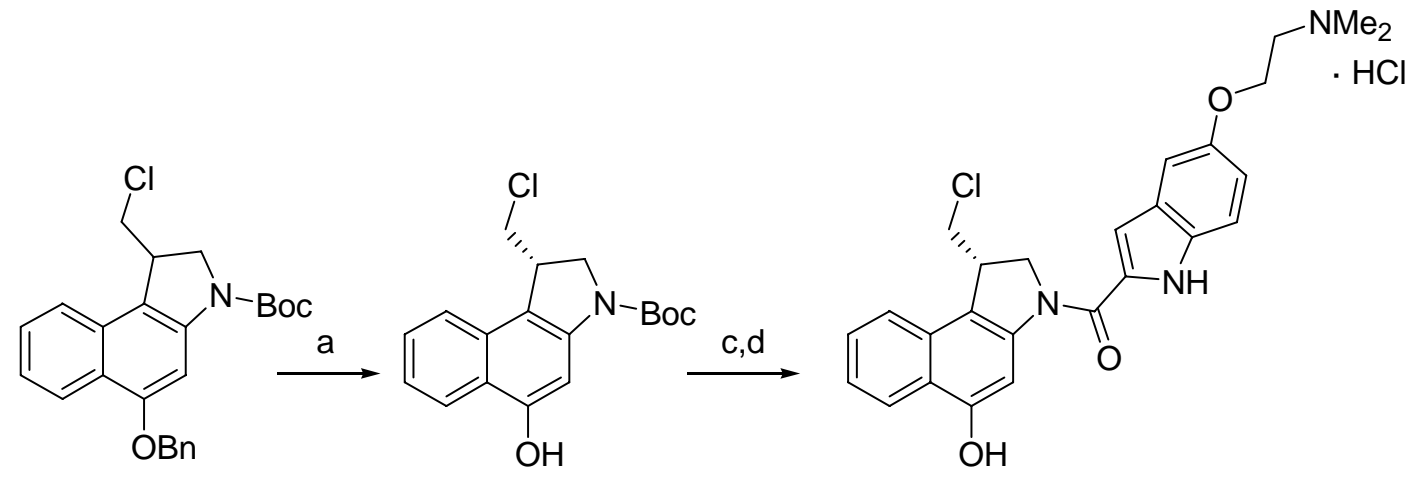

rac-57

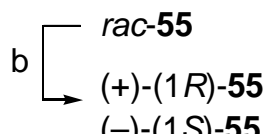

rac-56a: $\quad 98 \%$

$(-)-(1 R)-56 \mathbf{a}: \quad 89 \%$

$(+)-(1 S)-56 \mathbf{a}: \quad 91 \%$

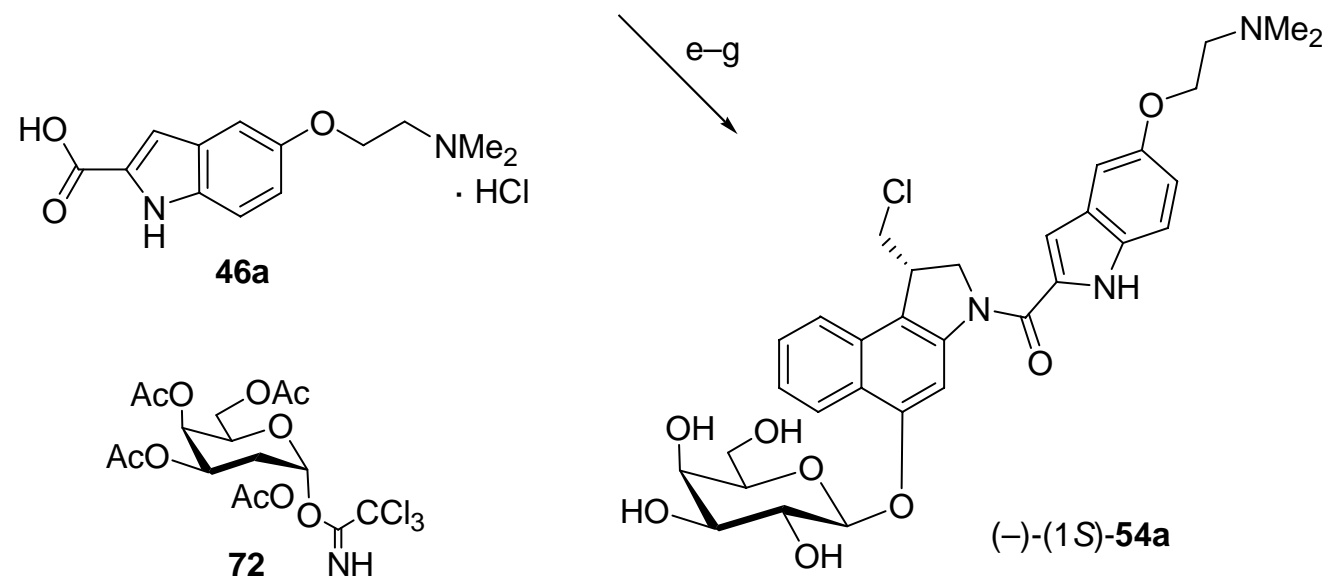

Abb. 179. Synthese der seco-CBI-DMAI-Derivate rac-56a, $(-)-(1 R)-56 \mathbf{a}$ und $(+)-(1 S)$-56a sowie des seco-CBI-DMAI-Prodrugs (-)-(1S)-54a. a) $\mathrm{Pd} / \mathrm{C} / \mathrm{NH}_{4} \mathrm{HCO}_{2}$, THF, RT, $1 \mathrm{~h}, 97 \%$; b) Trennung der Enantiomere von $\mathrm{rac}^{-55}$ : Chiralpak ${ }^{\circledR} \mathrm{IA}(250 \times 20 \mathrm{~mm}$, Partikelgröße: $5 \mu \mathrm{m}), n$-Hexan / Isopropanol $=97: 3$, Fluss: $18 \mathrm{~mL} \mathrm{~min}^{-1},(+)-(1 R)-55$ : 99.9\% ee, $(-)-(1 S)-55$ : 99.9\% ee; c) $4 \mathrm{M} \mathrm{HCl} / \mathrm{EE}, \mathrm{RT}, 3 \mathrm{~h}$; d) 46a, EDC·HCl, DMF, RT, 18-20 h, dann konz. HCl; e) 72, $\mathrm{BF}_{3} \cdot \mathrm{OEt}_{2}, \mathrm{CH}_{2} \mathrm{Cl}_{2}$, MS $(4 \AA),-10{ }^{\circ} \mathrm{C}, 3.5 \mathrm{~h}$, dann $\mathrm{BF}_{3} \cdot \mathrm{OEt}_{2}, \mathrm{RT}, 5.5 \mathrm{~h}$; f) $46 \mathbf{a}, \mathrm{EDC} \cdot \mathrm{HCl}$, DMF, RT, 21 h, 41\%; g) NaOMe/MeOH, RT, 2 h, 64\%.

Die Synthese des seco-CBI-DMAI- $\beta$-D-Galactosides (-)-(1S)-54a mit natürlicher Konfiguration erfolgte durch Glykosidierung von (-)-(1S)-55 mit 72 nach der von R. R. Schmidt ${ }^{160}$ entwickelten Trichloracetimidatmethode, nachfolgende $\mathrm{BF}_{3} \cdot \mathrm{OEt}_{2}$-vermittelte Boc-Entschützung und Kupplung des gebildeten freien sekundären Amins mit dem DMAI-Carbonsäure-Hydrochlorid (46a). Die abschließende basenkatalysierte Solvolyse der Acetylschutzgruppen lieferte das gewünschte Galactosid (-)-(1S)-54a in einer Ausbeute von 26\% über drei Stufen. 
Das neue Prodrug (-)-(1S)-54a ist etwa 3500-fach geringer toxisch als das entsprechende Drug, das in Anwesenheit des Enzyms $\beta$-D-Galactosidase aus diesem freigesetzt wird und eine sehr hohe Zytotoxizität von $I C_{50}=0.016 \mathrm{nM}$ aufweist. Zudem zeigt (-)-(1S)-54a eine gute Wasserlöslichkeit sowie eine sehr hohe Stabilität in wässriger Lösung und erfüllt daher alle Voraussetzungen für eine erfolgreiche Anwendung im Rahmen des ADEPT-Konzeptes. Aufgrund der vielversprechenden Eigenschaften wird das therapeutische Potential von $(-)-(1 S)$-54a derzeit in präklinischen Studien an Mäusen evaluiert.

Zur Untersuchung der Aufnahme verschiedener seco-Drugs in Zellen wurde in Anlehnung an die Synthese des seco-CBI-DMAI-Drugs (+)-(1S)-56a das seco-CBI-MPIDrug (+)-(1S)-56b mit einem $N$-Methylpiperidin-Substituenten in der DNA-bindenen Seitenkette synthetisiert (Abb. 180). Nach präparativer HPLC wurde $(+)-(1 S)$-56b hierbei in einer Gesamtausbeute von 63\% ausgehend von (-)-(1S)-55 erhalten. Die Invitro-Zytotoxizität von $(+)-(1 S)-56 \mathbf{b}$ ist mit einem $I C_{50}$-Wert von $0.014 \mathrm{nM}$ sehr hoch.

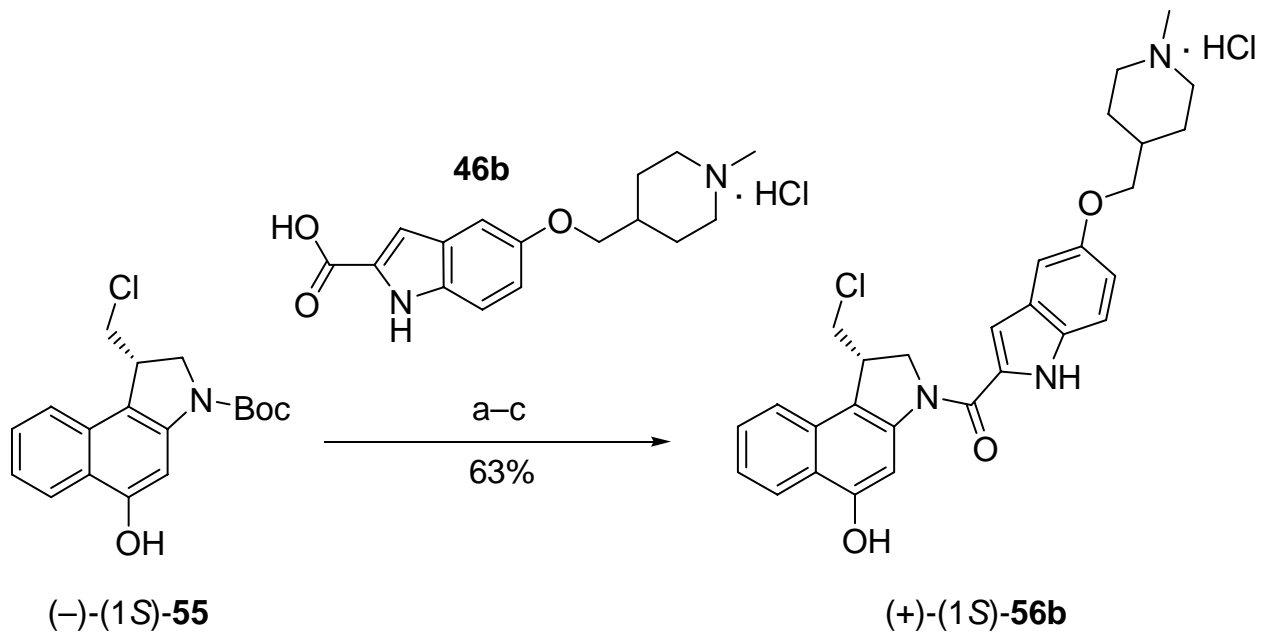

Abb. 180. Synthese des seco-CBI-MPI-Hydrochlorids (+)-(1S)-56b. a) $4 \mathrm{M} \mathrm{HCl} / \mathrm{EE}, \mathrm{RT}, 3 \mathrm{~h}$; b) 46b, EDC $\cdot \mathrm{HCl}$, DMF, RT, 19 h, dann konz. $\mathrm{HCl}$; c) präp. HPLC: Kromasil $100 \mathrm{C} 18, \mathrm{H}_{2} \mathrm{O}$ $(0.06 \%$ konz. $\mathrm{HCl}) / \mathrm{MeOH}=50 / 50 \rightarrow 25 / 75$ in 20 Minuten, Fluss: $12 \mathrm{~mL} \mathrm{m^{-1 }}$.

Die Synthese des fluoreszenzmarkierten anti-Methyl-seco-CBI-DMAI-Prodrugs $(-)-(1 S, 10 R)-75$ erfolgte ausgehend von der bekannten Vorstufe $(-)-(1 S, 10 R)-51$ durch eine Verknüpfung der Aminomethylfunktionalität an C-7 mit dem als NHS-Ester aktivierten, kommerziell erhältlichen Fluoreszenzfarbstoff D10162 (39) der Firma Invitrogen (Abb. 181). Nach präparativer HPLC konnte $(-)-(1 S, 10 R)-75$ in einer sehr guten Ausbeute von $89 \%$ erhalten werden. Das fluoreszenzmarkierte seco-Drug $(1 S, 10 R)-76$ wurde durch Abspaltung des Zuckerbausteins in $(-)-(1 S, 10 R)-75$ unter sauren Be- 
dingungen sowie nachfolgende präparative HPLC in 69\% erhalten (Abb. 181). Die fluoreszenzmarkierten Analoga (-)-(1S,10R)-75 und $(1 S, 10 R)-\mathbf{7 6}$ weisen eine etwas geringere In-vitro-Zytotoxizität auf als die entsprechenden nicht-fluoreszenzmarkierten Analoga. Weiterhin kann das fluoreszenzmarkierte Prodrug enzymatisch nicht zu dem entsprechenden seco-Drug aktiviert werden.

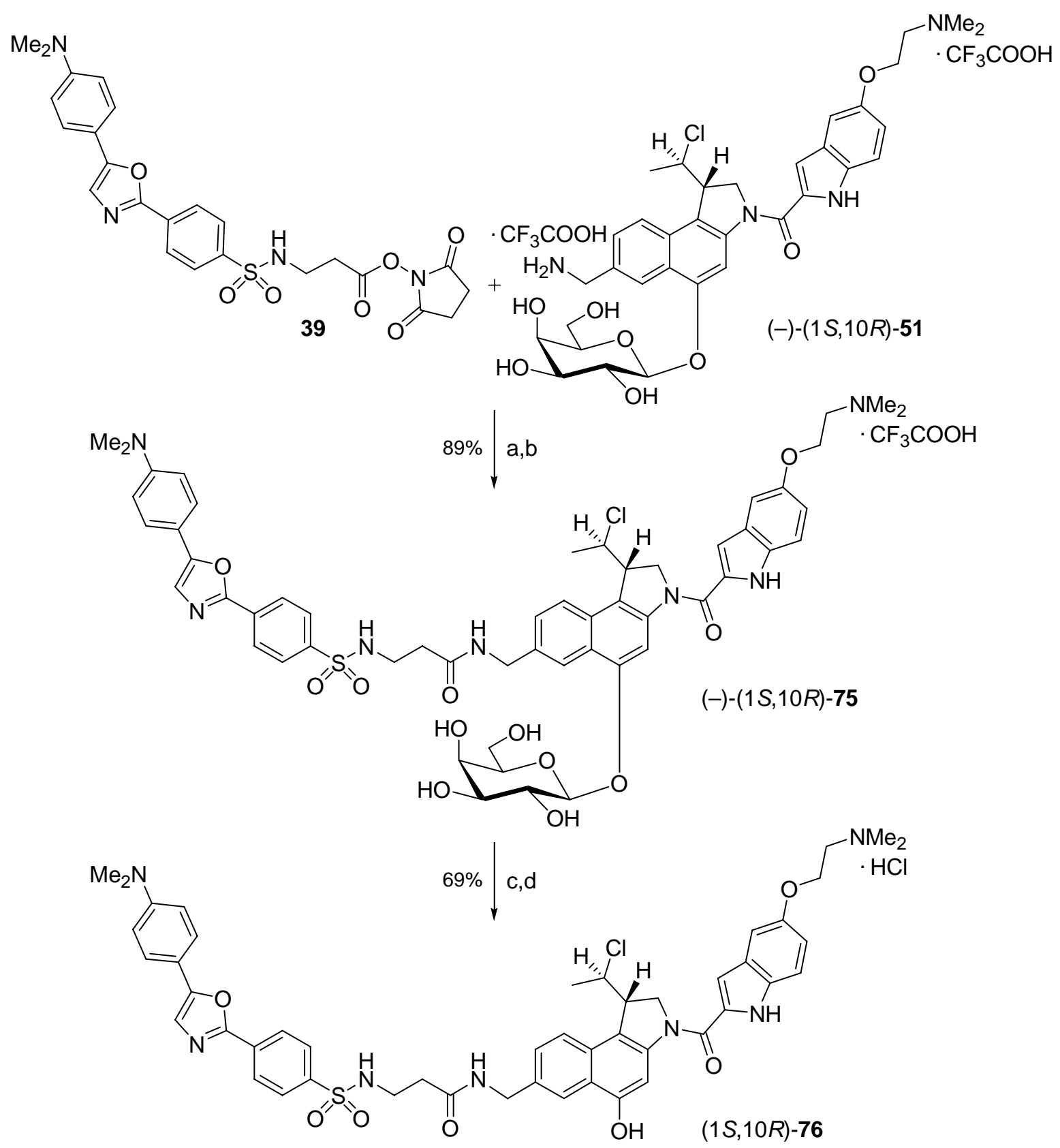

Abb. 181. Synthese der fluoreszenzmarkierten Analoga (-)-(1S,10R)-75 und (1S,10R)-76. a) $i \operatorname{Pr}_{2} \mathrm{NEt}$, DMF, RT, $9 \mathrm{~h}$; b) präp. HPLC: Kromasil $100 \mathrm{C} 18, \mathrm{H}_{2} \mathrm{O}(0.1 \% \mathrm{TFA}) / \mathrm{CH}_{3} \mathrm{CN}$ $=83 / 17 \rightarrow 50 / 50$ in 60 Minuten, Fluss: $12 \mathrm{~mL} \mathrm{~min}^{-1}$; c) konz. $\mathrm{HCl}, \mathrm{MeOH}, \mathrm{RT}, 3 \mathrm{~d}$; d) präp. HPLC: Kromasil $100 \mathrm{C} 18, \mathrm{H}_{2} \mathrm{O}(0.06 \%$ konz. $\mathrm{HCl}) / \mathrm{MeOH}=50 / 50 \rightarrow 25 / 75$ in 20 Minuten, Fluss: $12 \mathrm{~mL} \mathrm{~min}^{-1}$. 
Zur Aufklärung des Wirkmechanismus der Verbindungsklasse wurde die Wechselwirkung mehrerer seco-Drugs (Abb. 182), Prodrugs und analoger Verbindungen mit DNA-Oligonukleotiden (Abb. 183) untersucht. (+)-(1S,10R)-34a wurde zudem mit doppelsträngiger RNA und dem Tripeptid Glutathion (58) umgesetzt (Abb. 183).

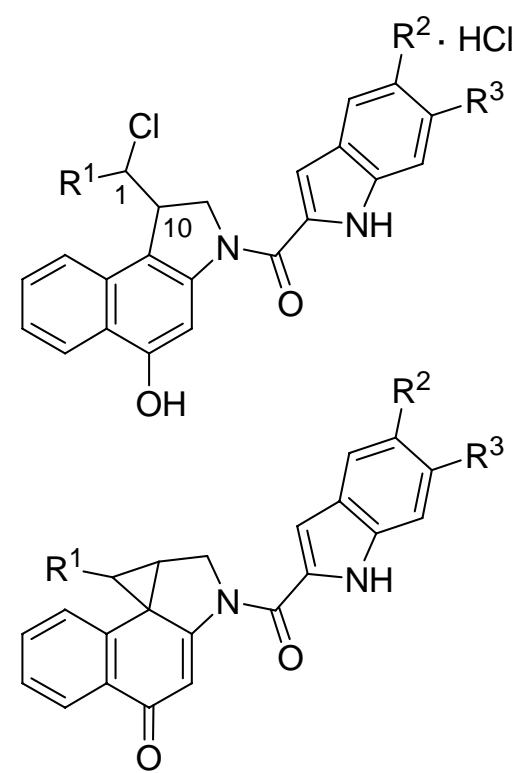

d d

Abb. 182. Anti-Methyl-seco-CBI-Hydrochloride 34a-e, die entsprechenden Drugs 43a-e sowie seco-CBI-Hydrochloride 56a,b und die entsprechenden Drugs 86a,b.<smiles>N[C@@H](CCC(=O)N[C@@H](CS)C(=O)NCC(=O)O)C(=O)O</smiles>

58 34a-e: $R^{1}=M e$

56a,b: $\quad R^{1}=H$

43a-e: $R^{1}=M e$

86a,b: $R^{1}=H$
5'-CGG UCA AUU AGU CGG-3' (ON-1) 3'-GCC AGU UAA UCA GCC-5' (ON-2) ds-59

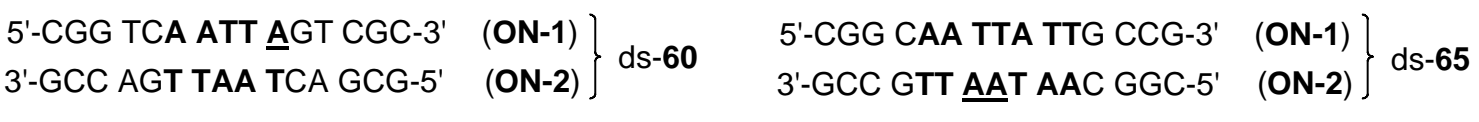

$$
\begin{aligned}
& \left.\left.\begin{array}{ll}
\text { 5'-TCG CCG GTC AAT TÁG-3' } & (\text { ON-1) } \\
\text { 3'-AGC GGC CAG TTA ATC-5' } & (\text { ON-2) }
\end{array}\right\} \text { ds-61 } \quad \begin{array}{ll}
\text { 5'-CCG GCT ATT AGG CCG-3' } & \text { (ON-1) } \\
\text { 3'-GGC CGA TAA TCC GGC-5' } & \text { (ON-2) }
\end{array}\right\} \text { ds-66 }
\end{aligned}
$$

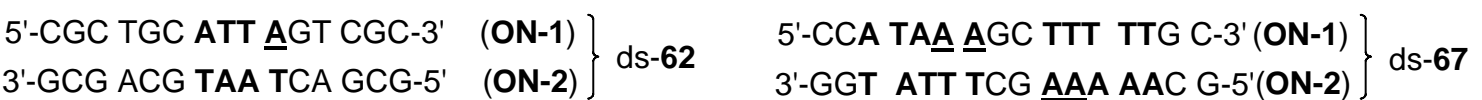

$$
\begin{aligned}
& \left.\left.\begin{array}{ll}
\text { 5'-CGC TCG AAT TGG CGC-3' } & (\text { ON-1) } \\
3^{\prime}-\text {-GCG AGC TTA ACC GCG-5' } & (\text { ON-2) }
\end{array}\right\} \text { ds-63 } \quad \begin{array}{lll}
\text { 5'-CGG CTT ATA TGA CCG-3' } & (\text { ON-1) } \\
3^{\prime}-\text { GCC GAA TAT ACT GGC-5' } & \text { (ON-2) }
\end{array}\right\} \text { ds-68 } \\
& \left.\begin{array}{ll}
\text { 5'-CGC GCT AAA AGA CCG-3' } & \text { (ON-1) } \\
\text { 3'-GCG CGA TTT TCT GGC-5' } & \text { (ON-2) }
\end{array}\right\} \text { ds-64 } \quad \begin{array}{l}
\text { 5'-TGG CTG CGA GCA CCT-3' } \\
\text { 3'-ACC GAC GCT CGT GGA-5' }
\end{array}
\end{aligned}
$$

Abb. 183. Glutathion (58), das RNA-Oligonukleotid ds-59 und die DNA-Oligonukleotide ds-60 - ds-69. Alkylierungspositionen sind durch Unterstriche gekennzeichnet. 
Die massenspektrometrischen Untersuchungen erfolgten direkt aus der Reaktionslösung mittels ESI-FTICR-MS ohne die bei ähnlichen Untersuchungen bisher notwendige chromatographische Reinigung und Anreicherung der alkylierten DNA. Neben der Detektion der alkylierten Oligonukleotide konnte durch Variation der Messbedingungen eine Fragmentierung der Addukte im Bereich der Alkylierungsstelle induziert werden, die eine genaue Lokalisation der Bindungsstelle ermöglichte (Abb. 184).
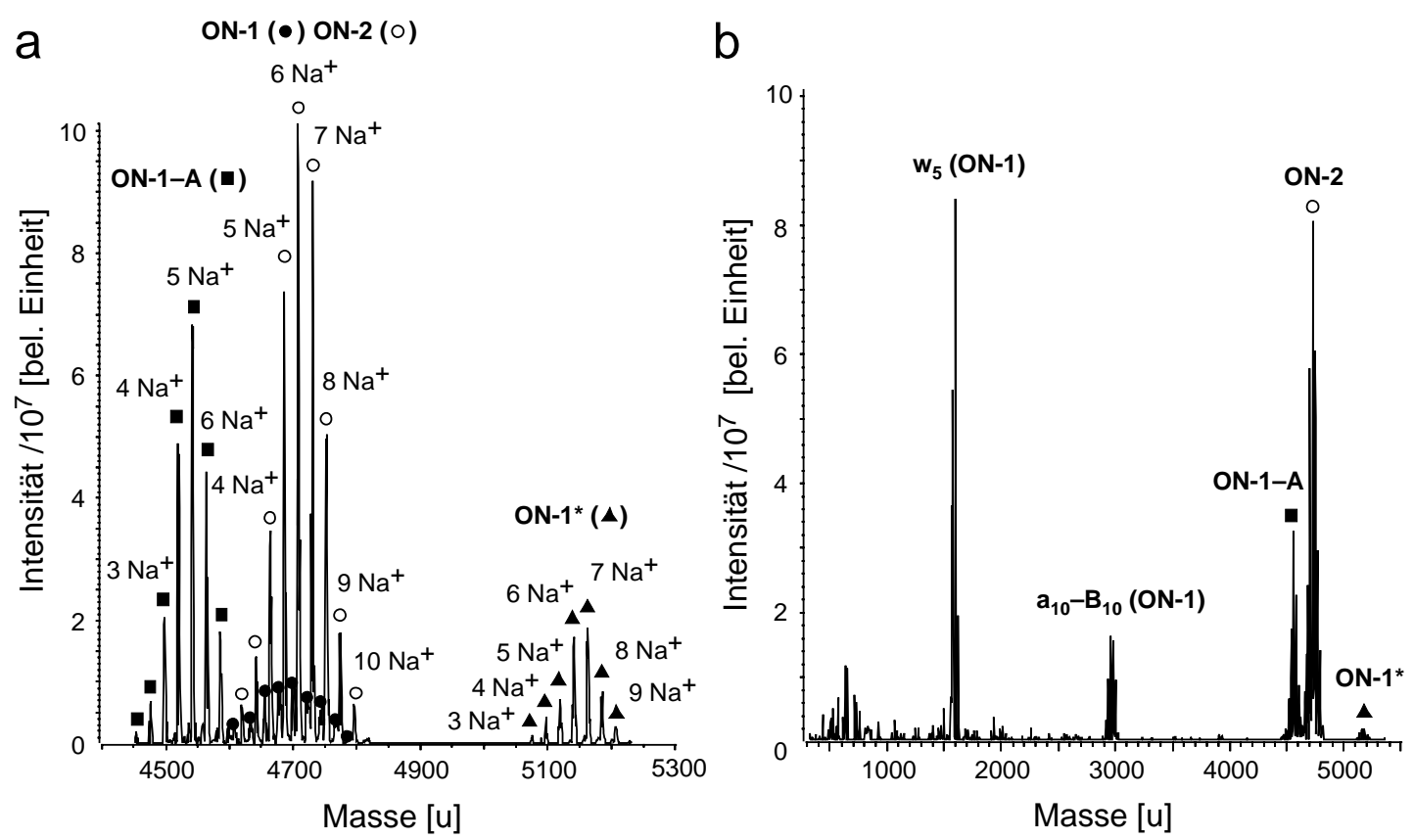

Abb. 184. Dekonvolierte Massenspektren nach Inkubation des DNA-Oligonukleotides ds-60 mit dem seco-Drug (+)-(1S,10R)-34a im molaren Verhältnis 1:1. a) $24 \mathrm{~h}$ Inkubation, $U_{\mathrm{C}}=-100 \mathrm{~V}$; b) $24 \mathrm{~h}$ Inkubation, $U_{\mathrm{C}}=-150 \mathrm{~V}$. Natriumaddukte der DNA-Oligonukleotide ON-1 (•) und ON-2 (०), des alkylierten Oligonukleotides ON-1*(^), des Oligonukleotides ON-1 nach Abspaltung der Nukleobase Adenin (ON-1-A ( $\mathbf{(})$ ) und der für eine Alkylierung am Adenin $\mathrm{A}_{10}(\mathrm{ON}-1)$ charakteristischen Bruchstücke $\mathbf{w}_{\mathbf{5}}(\mathbf{O N}-\mathbf{1})$ und $\mathbf{a}_{\mathbf{1 0}}-\mathbf{B}_{\mathbf{1 0}}(\mathbf{O N}-\mathbf{1})$.

Die zytotoxischen seco-Drugs zeigen eine hohe Alkylierungseffizienz und Sequenzselektivität bezüglich doppelsträngiger DNA und bilden kovalente Addukte mit einem Adenin am 3'-Ende AT-reicher Basensequenzen einer Länge von mindestens vier Basenpaaren (Abb. 183). Adenin wird an den ersten drei Positionen, die der Alkylierungsstelle am selben Strang in 5'-Richtung folgen, gegenüber Thymin bevorzugt. Des Weiteren werden Purinbasen an der ersten Position, die der Alkylierungsstelle am selben Strang in 3'-Richtung folgt, gegenüber Pyrimidinbasen bevorzugt. Die Alkylierungseffizienz der seco-Drugs gegenüber einzelsträngiger DNA, doppelsträngiger RNA oder einem Tripeptid wie Glutathion (58) ist wesentlich geringer, so dass erst bei einem deutlichen Wirkstoff-Überschuss eine signifikante Alkylierung 
detektiert werden kann. Die seco-Drugs mit einer deutlich geringeren Zytotoxizität sowie die relativ ungiftigen Prodrugs zeigen gegenüber doppelsträngiger DNA eine geringere Alkylierungseffizienz und Sequenzselektivität. Die Alkylierungseffizienz analoger Wirkstoffe korreliert demzufolge qualitativ mit der In-vitro-Zytotoxizität der Verbindungen.

Mittels HPLC und CD-Spektroskopie konnte eine der kovalenten Bindung vorausgehende Wechselwirkung der seco-Drugs bzw. der in situ aus diesen gebildeten Drugs mit den DNA-Oligonukleotiden detektiert werden (Abb. 185). Sowohl die Stabilisierung der seco-Drugs als auch die Einlagerung der aus diesen in situ gebildeten Drugs in die kleine Furche AT-reicher Regionen des DNA-Doppelstranges konnte hierbei durch die zeitliche Veränderung signifikanter induzierter CD-Signale und der entsprechenden Veränderungen der HPLC-Spektren verfolgt werden.
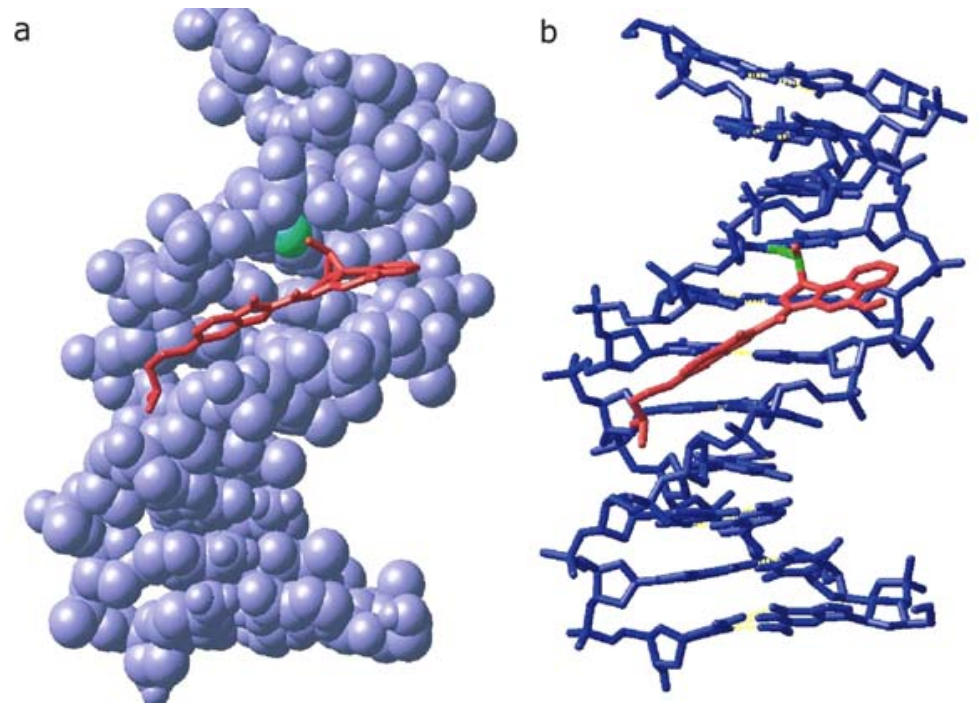

Abb. 185. Modell des nicht-kovalenten und kovalenten Adduktes des Drugs 43a mit dem doppelsträngigen DNA-Oligonukleotid 5'-d(GTCAATTAGTC)-3'·3'-d(CAGTTAATCAG)-5'.

Die Untersuchung verschiedener Methyl-seco-CBI- und seco-CBI-Derivate zeigte, dass die seco-Drugs der zytotoxischeren CBI-Verbindungen durch eine Wechselwirkung mit bestimmten doppelsträngigen DNA-Oligonukleotiden stabilisiert werden und dass sie stabilere Drugs bilden. Im Vergleich zu den analogen Methyl-seco-CBIDerivaten resultiert für die seco-CBI-Derivate hieraus eine langsamere Spirozyklisierung zum reaktiven Drug und eine niedrigere Alkylierungsgeschwindigkeit.

Die vollständige Einlagerung des aus dem Methyl-seco-Drug (+)-(1S,10R)-34a gebildeten Drugs 43a in den DNA-Doppelstrang ds-60 erfolgt beispielsweise 
innerhalb von etwa einer Stunde und die Geschwindigkeit der folgenden Alkylierung beträgt circa $10 \%$ pro Stunde. Interessanterweise können bei einem zweifachen Überschuss des Methyl-seco-Drugs (+)-(1S,10R)-34a zudem zwei Drug-Moleküle in den DNA-Doppelstrang eingelagert werden, was sich in einer doppelten Intensität des induzierten CD-Signals, einer verringerten DNA-Schmelztemperatur und einer verringerten Alkylierungseffizienz manifestiert. Bei dem analogen seco-CBI-Drug $(+)-(1 S)-56 a$ erfolgen sowohl die Zyklisierung des seco-Drugs zum Drug als auch die Einlagerung des Drugs in die kleine Furche der DNA sowie die Alkylierung deutlich langsamer als bei $(+)-(1 S, 10 R)-34 a$. Eine Erhöhung der seco-Drug-Konzentration führt bei (+)-(1S)-56a zudem zu einem Anstieg des Anteils alkylierter DNA.

Das starke induzierte CD-Signal, das bei einer Wechselwirkung der Drugs mit DNA beobachtet werden kann, wurde zur Untersuchung der Aufnahme der Wirkstoffe in lebende Zellen verwendet. Nach einer Inkubation mit dem jeweiligen seco-Drug wurden die Zellen gewaschen und die CD-Spektren einer Suspension der Zellen in PBS mittels eines handelsüblichen CD-Spektropolarimeters aufgezeichnet (Abb. 186).

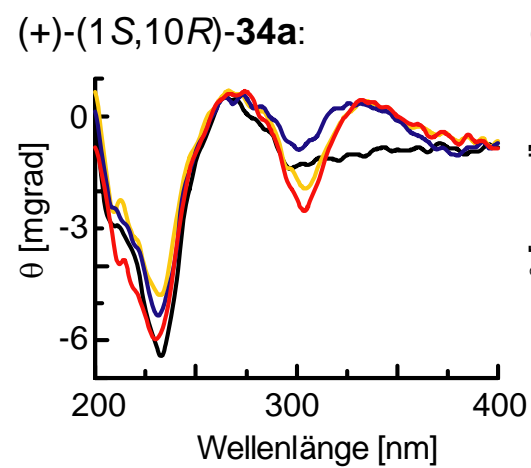

(+)-(1S)-56a:

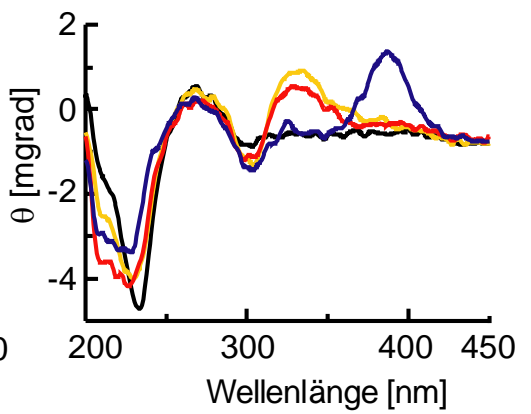

(+)-(1S)-56b:

(+)-(1S,10R)-34b:
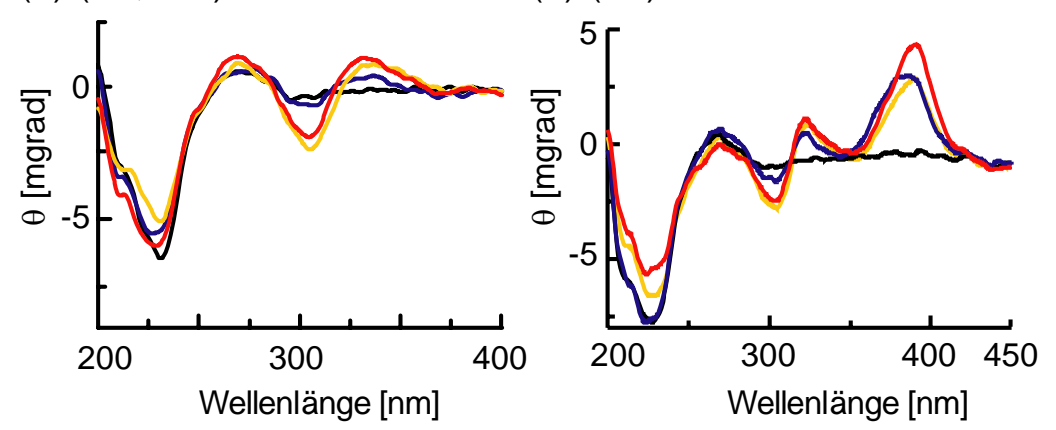

Abb. 186. CD-Spektren von Zellsuspensionen (HL-60 in PBS (pH 7.4)) unbehandelter Zellen und mit den seco-Drugs $(+)-(1 S, 10 R)-34 \mathbf{a}, \mathbf{b}$ oder $(+)-(1 S)-56 \mathbf{a}, \mathbf{b}$ präinkubierter Zellen.

Sowohl die CD-Spektren der mit den seco-Drugs präinkubierten Zellen als auch die CD-Spektren der aus diesen Zellen isolierten DNA zeigen das für eine Wechsel- 
wirkung der Drugs mit doppelsträngiger DNA charakteristische induzierte CD-Signal mit einem Minimum bei $\lambda=305 \mathrm{~nm}$ und einem Maximum bei $\lambda=335 \mathrm{~nm}$. Das im Fall der toxischeren seco-Drugs (+)-(1S)-56a,b in den CD-Spektren der Zellen sichtbare CD-Signal um $\lambda=390 \mathrm{~nm}$ weist zudem auf eine signifikante Stabilisierung der jeweiligen seco-Form in den Zellen hin. Dieses Signal kann bei CD-Messungen der aus den Zellen isolierten DNA nicht beobachtet werden, da die seco-Drugs nur eine schwache nicht-kovalente Wechselwirkung mit der DNA eingehen und im Laufe der DNA-Aufreinigung entfernt werden. Die untersuchten seco-Drugs penetrieren demzufolge die Zellmembran lebender Zellen sehr schnell und binden an die zelluläre DNA als ihre Zielstruktur. Die seco-Drugs mit einer höheren In-vitro-Zytotoxizität zeigen hierbei eine ausgeprägtere Stabilisierung der entsprechenden seco-Form, eine geringere Hydrolyse der stabileren Drugs und eine niedrigere DNA-Alkylierungsgeschwindigkeit letzterer. Eine langsamere, aber aufgrund der geringeren Inaktivierung durch Hydrolyse ausgeprägtere DNA-Alkylierung könnte demzufolge für die höhere Zytotoxizität der seco-CBI-Verbindungen (+)-(1S)-56a,b im Vergleich zu den analogen Methyl-seco-CBI-Verbindungen $(+)-(1 S, 10 R)-\mathbf{3 4 a}, \mathbf{b}$ verantwortlich sein.

Mit den durchgeführten Messungen gelang erstmals eine In-vitro-Untersuchung der zellulären Aufnahme und des Wirkmechanismus biologisch aktiver Verbindungen mittels CD-Spektroskopie. Die neue Methode ist im Vergleich zu herkömmlichen Techniken wie der Markierung mit Radioisotopen oder Fluoreszenzfarbstoffen vorteilhaft, weil die Wirkstoffe unverändert eingesetzt werden können. Da achirale Wirkstoffe bei einer Interaktion mit chiralen Biomolekülen ebenfalls ein induziertes CDSignal zeigen können, ist die Technik zudem nicht auf die Untersuchung chiraler Moleküle beschränkt, sondern könnte zur Untersuchung des Wirkmechanismus weiterer Verbindungen eingesetzt werden. Dies wurde am Beispiel des Zytostatikums Doxorubicin gezeigt.

Eine Untersuchung der zellulären Aufnahme der fluoreszenzmarkierten Wirkstoffanaloga mittels eines konfokalen Fluoreszenzmikroskopes zeigte, dass das Prodrug $(-)-(1 S, 10 R)-75$ zunächst von den Membranen lebender Zellen zurückgehalten wird und erst nach einigen Stunden unspezifisch in die Zellen aufgenommen wird (Abb. 187). Das fluoreszenzmarkierte seco-Drug (1S,10R)-76 penetriert hingegen innerhalb weniger Minuten die Zellmembran lebender Zellen und reichert sich in den Mitochondrien, Endosomen und anderen Kompartimenten an (Abb. 188). In den Zellkernen der Zellen wurde $(1 S, 10 R)$-76 erstaunlicherweise nicht detektiert. Der Grund hierfür könnte eine durch die DNA verursachte Fluoreszenzlöschung sein. 


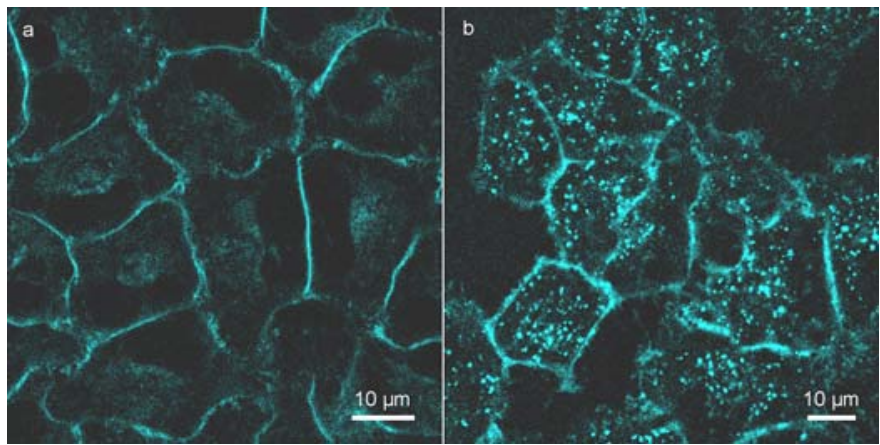

Abb. 187. Fluoreszenzmikroskopische Aufnahmen nach Inkubation von Zellen (A549) mit dem Prodrug (-)-(1S,10R)-75. a) 1 h Inkubationszeit, b) 4 h Inkubationszeit.
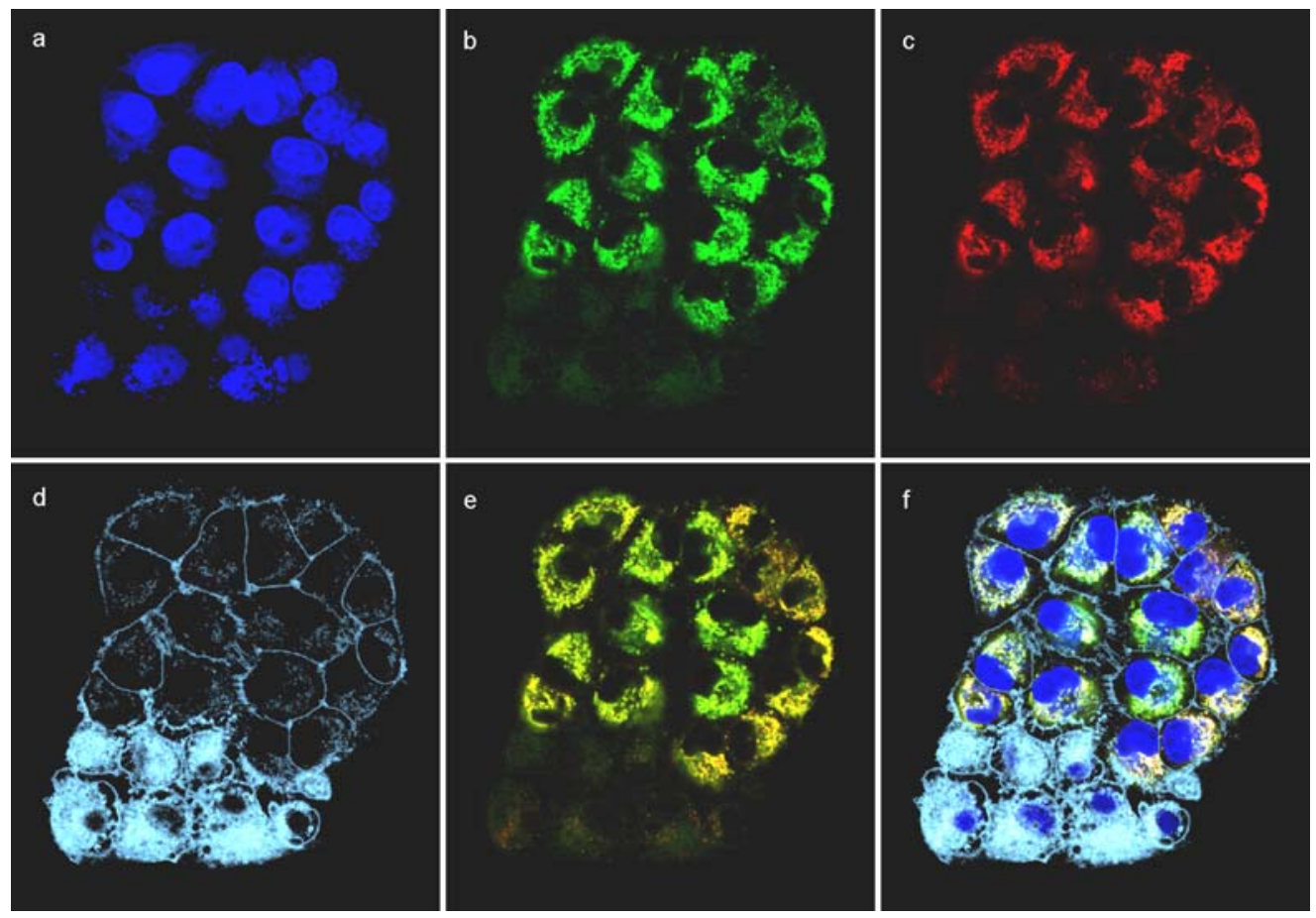

Abb. 188. Fluoreszenzmikroskopische Aufnahmen vitaler und toter Zellen (A549) nach Inkubation mit $(1 S, 10 R)$-76. a) Darstellung in blau: durch Hoechst 33342 (40) gefärbte Zellkerne und durch 76 gefärbte zytosolische Organellen; b) Darstellung in grün: durch $(1 S, 10 R)$-76 gefärbte Mitochondrien vitaler Zellen (obere $2 / 3$ der Zellen); c) Darstellung in rot: durch MitoTracker ${ }^{\circledR}$ Deep Red (41) gefärbte Mitochondrien vitaler Zellen (obere 2/3 der Zellen); d) Darstellung in hellblau: durch Trypanblau gefärbte Zellmembranen vitaler Zellen (obere 2/3 der Zellen) und angefärbtes Zytosol toter Zellen (unteres 1/3 der Zellen); e) Überlagerung der Fluoreszenz von (1S,10R)-76 (grün) und MitoTracker ${ }^{\circledR}$ Deep Red 41 (rot) zu gelb; f) Überlagerung von $\mathrm{a}-\mathrm{d}$.

Neben einer Alkylierung der zellulären DNA könnte eine Schädigung der Mitochondrien für die hohe Zytotoxizität der seco-Drugs verantwortlich sein. Die geringe Zytotoxizität der Prodrugs wird demgegenüber vermutlich durch die geringe Aufnahme in die Zellen und eine niedrige DNA-Alklyierungseffizienz verursacht. 


\section{EXPERIMENTELLER TEIL}

\section{Allgemeine Methoden}

Die Umsetzungen wurden soweit nötig in ausgeheizten Glasapparaturen unter einem leichten Argon-Überdruck durchgeführt. Die Lösungsmittel wurden entsprechend den üblichen Laboratoriumsmethoden getrocknet und destilliert. ${ }^{215}$ Käufliche Produkte wurden ohne weitere Reinigung eingesetzt. Das Entgasen von Lösungsmitteln geschah durch längeres Einleiten eines Argon-Gasstroms.

\section{$1.1 \quad$ Verwendete Geräte}

Drehwerte: Polarimeter Modell 241 der Firma Perkin-Elmer.

Infrarotspektren: Modell Vector 22 der Firma Bruker. Feststoffe wurden als KBr-Presslinge, Flüssigkeiten als Film zwischen KBr-Platten gemessen. Zur Kalibrierung diente die Polystyrolbande bei $1601 \mathrm{~cm}^{-1}$.

UV/VIS-Spektren: Modell Lambda 2 der Firma Perkin-Elmer.

${ }^{1}$ H-NMR-Spektren: Modelle Mercury-200 (200 MHz), Mercury-300 und Unity-300 (je $300 \mathrm{MHz})$ sowie Unity Inova-600 (600 MHz) der Firma Varian. Die chemischen Verschiebungen sind in Einheiten der $\delta$-Skala angegeben. Tetramethylsilan $\left(\delta_{\mathrm{TMS}}=0.00 \mathrm{ppm}\right)$ oder das angegebene Lösungsmittel dienten als interner Standard. Zur Kennzeichnung der Multiplizitäten der Signale werden folgende Abkürzungen verwendet: $\mathrm{s}$ (Singulett), d (Dublett), $\mathrm{t}$ (Triplett), q (Quartett), $\mathrm{m}$ (Multiplett), $\mathrm{m}_{\mathrm{c}}$ (zentriertes Multiplett), br (breites Signal). Zur Bezeichnung aromatischer Protonen oder Kohlenstoffatome werden folgende Abkürzungen verwendet: $i$ (ipso), $o$ (ortho), $m$ (meta), $p$ (para). Die Spektren wurden in der Regel erster Ordnung entsprechend interpretiert. Die Kopplungskonstanten $J$ sind in Hertz $(\mathrm{Hz})$ angegeben.

${ }^{13}$ C-NMR-Spektren: Modelle Mercury-200 (50 MHz), Mercury-300 und Unity-300 (je $75 \mathrm{MHz})$ sowie Unity Inova-600 (150 MHz). Als interner Standard diente Tetramethylsilan oder das angegebene Lösungsmittel. Die chemischen Verschiebungen sind den ${ }^{1}$ H-breitbandentkoppelten Spektren entnommen, die Multiplizitäten der Signale wurden in multiplett-selection-Experimenten (APT-Pulsfolge) bestimmt.

Massenspektren: Zur Aufnahme der EI-Spektren diente ein doppelfokussierendes Sektorfeld-Massenspektrometer MAT 95 der Firma Finnigan. ESI-Spektren wurden mit einem Ion-Trap-Massenspektrometer LCQ der Firma Finnigan aufgenommen. 
Angegeben werden die Quotienten aus Masse zu Ladung sowie in Klammern die relativen Intensitäten bezogen auf den Basispeak $(I=100)$. Die Messung der ESIHRMS-Spektren erfolgte an einem 7 Tesla-Fourier Transform Ion Cyclotron Resonance (FTICR)-Massenspektrometer APEX IV der Firma Bruker, das mit einer Apollo-ESI-Quelle der Firma Bruker und einer Spritzenpumpe 74900 series der Firma Cole-Parmer ausgestattet ist. Der Fluss der Spritzenpumpe betrug $2 \mu \mathrm{L} / \mathrm{min}$. Zur Aufnahme der Spektren und zur Auswertung diente das Programm XMASS der Firma Bruker.

Fluorimetrie: Zur Aufnahme der Anregungs- und Emissionsspektren diente ein Spektrofluorometer Quanta Master der Firma PTI (Photon Technology International) ausgerüstet mit 2 Photomultiplier Detektoren 814 der Firma PTI. Verwendung fanden das Programm FeliX32 und eine Präzisionsküvette (Schichtdicke: $10 \mathrm{~mm}$ ) der Firma Hellma. Zur Aufnahme des Absorptionsspektrums des Prodrugs (-)-(1S,10R)-75 diente zudem ein Spektrometer Cary 5E der Firma Varian und zur Aufnahme des Emissionsspektrums ein Spektrometer Fluorolog der Firma Jabin Yvon.

UV-Absorption: Modell Genesys 10UV der Firma Thermo Electron Corporation.

CD-Spektren: Alle CD-Spectren wurden bei $25^{\circ} \mathrm{C}$ mit einem Jasco J-810 Spectropolarimeter der Firma Jasco ausgestattet mit einem Peltiercontroller PCT-423S der Firma Jasco aufgenommen. Die Bezeichnung $C D$ [mgrad] entspricht hierbei der Elliptizität $\theta$ [mgrad]. Die Einstellungen bei Wahl des Programmes Spectrum Measurement waren: data mode: $\mathrm{CD}$ and $\mathrm{Abs}$, band width: $1.0 \mathrm{~nm}$, response: $1 \mathrm{sec}$, sensitivity: $100 \mathrm{mgrad}$, step resolution: $0.1 \mathrm{~nm}$, scan speed: $100 \mathrm{~nm} / \mathrm{min}$, accumulations: 4, scanning mode: continuous. Als Referenz diente das Spektrum des jeweiligen Lösungsmittels. Die Einstellungen bei Wahl des Programmes Time Course Measurement waren: data mode: $\mathrm{CD}$ and Abs, wavelength: $304.5 \mathrm{~nm}$, measuring time: $4 \mathrm{~h}$, data pitch: $1.0 \mathrm{sec}$, band width: $1.0 \mathrm{~nm}$, response: $1 \mathrm{sec}$, sensitivity: $100 \mathrm{mgrad}$, accumulations: 1 .

Zentrifuge: Verwendung fand eine Zentrifuge 5417R der Firma Eppendorf.

Mikrowellenreaktor: Reaktionen unter Mikrowellenbestrahlung wurden in einem SmithCreator Mikrowellenreaktor der Firma Personal Chemistry unter Verwendung von $5 \mathrm{~mL}$ Druckgefäßen durchgeführt. 


\subsection{Chromatographische Methoden}

Dünnschichtchromatographie (DC): Es wurden DC-Fertigfolien SIL G/UV254 der Firma Macherey-Nagel \& Co. (Schichtdicke $0.25 \mathrm{~mm}$ ) verwendet. Angegeben sind $\mathrm{R}_{f^{-}}$ Werte (Laufhöhe relativ zur Laufmittelfront). Als Abkürzungen für die verwendeten Lösungsmittel werden benutzt: EE (Essigsäureethylester), PE (Petrolether des Siedebereiches $40-75^{\circ} \mathrm{C}$ ), $\mathrm{CH}_{2} \mathrm{Cl}_{2}$ (Dichlormethan), $\mathrm{MeOH}$ (Methanol). Neben der UVDetektion dienten eine Vanillin-Schwefelsäure-Lösung (0.5 g Vanillin, $3 \mathrm{~mL}$ konz. Schwefelsäure, $85 \mathrm{~mL}$ Methanol und $10 \mathrm{~mL}$ Essigsäure) und eine Molybdatophosphorsäure-Lösung (5\% in Methanol) als Anfärbereagenzien.

Säulenchromatographie: Alle säulenchromatographischen Trennungen wurden mit Kieselgel 60 (Korngröße: 0.032-0.063 mm) der Firma Merck durchgeführt.

\section{Hochdruckflüssigkeitschromatographie (HPLC):}

Analytische HPLC: Analytische Trennungen mit Ausnahme der OligonukleotidExperimente wurden auf einer HPLC-Anlage der Firma Jasco, ausgestattet mit einer Lösungsmittelpumpe PU-2080, einer Mischkammer LG-1590-04, einem Multiwellenlängendetektor MD-2010 Plus und der Steuerung LC-Net II/ADC, vorgenommen. Zusätzlich war ein automatischer Probenwechsler (Autosampler AS-2055) derselben Firma angeschlossen. Zur Bedienung, Datenerfassung und Datenauswertung wurden die Computerprogramme Borwin PDA, HSS 2000 und Borwin Chromatography der Firma Jasco eingesetzt. Für die analytischen Messungen wurden die Fertigsäulen Chiralcel $^{\circledR}$ OD $(250 \times 4.6 \mathrm{~mm}$, Partikelgröße: $10 \mu \mathrm{m})$ der Firma Daicel Chemical Industries Ltd. sowie Kromasil $100 \mathrm{C} 18(5 \mu \mathrm{m}, 250 \times 4 \mathrm{~mm})$ der Firma Jasco verwendet. Als Lösungsmittel dienten $n$-Hexan, Dichlormethan und Isopropanol in HPLC-Qualität (Chiralcel ${ }^{\circledR}$ OD) sowie bidestilliertes Wasser (Zusatz von 0.1 Vol.-\% Trifluoressigsäure zur Peptidsynthese oder 0.06 Vol.-\% konzentrierte Salzsäure) und Acetonitril bzw. Methanol in HPLC-Qualität (Kromasil 100 C18). Alle Proben wurden membranfiltriert und die Lösungsmittel entgast.

Präparative HPLC: Präparative Trennungen wurden auf einem HPLC-System der Firma Jasco, ausgestattet mit zwei Lösungsmittelpumpen Modell PU-2087 PLUS und einem UV-Detektor Modell UV-2075 PLUS, vorgenommen. Eingesetzt wurden eine Fertigsäule Chiralpak ${ }^{\circledR}$ IA $(250 \times 20 \mathrm{~mm}$, Partikelgröße: $5 \mu \mathrm{m})$ sowie eine Fertigsäule des Typs Kromasil $100 \mathrm{C} 18(7 \mu \mathrm{m}, 250 \times 20 \mathrm{~mm})$ der Firma Jasco in Verbindung mit einer Vorsäule des Typs Kromasil $100 \mathrm{C} 18(5 \mu \mathrm{m}, 50 \times 20 \mathrm{~mm})$ der Firma Jasco. Als 
Lösungsmittel dienten $n$-Heptan, $n$-Hexan und Dichlormethan in HPLC-Qualität (Chiralpak ${ }^{\circledR}$ IA) sowie bidestilliertes Wasser (Zusatz von 0.1 Vol.-\% Trifluoressigsäure zur Peptidsynthese) und Acetonitril bzw. Methanol in HPLC-Qualität (Kromasil 100 C18). Alle Proben wurden membranfiltriert und die Lösungsmittel entgast.

\subsection{Materialien und Geräte für HPLC-MS-Messungen}

Medium: Verwendung fand das serumfreie Medium UltraCulture ${ }^{\circledR}$ der Firma Lonza, welches mit 2 mM L-Glutamin der Firma Gibco versetzt war.

Enzym: $\beta$-D-Galactosidase (E.C. 3.2.1.23) von Eschericha coli G 5635 (Sigma), Aktivität: 250-600 Einheiten (Units (U)) pro mg Protein bei $\mathrm{pH} 7.3$ und $37^{\circ} \mathrm{C}$, $1 \mathrm{U}=1 \mu \mathrm{mol}$ Substratumsatz pro Minute.

Lösungsmittel: DMSO der Firma Merck, MeOH in HPLC-Qualität der Firma VWR.

Filter: Zur Abtrennung des Enzyms mittels Ultrafiltrationszentrifugation dienten Montage-PCR-Zentrifugen-Filter-Einsätze (Bestellnummer: UFC7PCR50) der Firma Millipore.

HPLC-MS: Die analytischen Trennungen wurden auf einer HPLC-Anlage bestehend aus einer Lösungsmittelpumpe Rheos 4000, einem Degaser ERC-3415 $\alpha$ der Firma Flux Instruments, einem Autosampler 851-AS der Firma Jasco und einem Diodenarray-Detektor der Firma Thermo vorgenommen. Eingesetzt wurde die Säule Synergi Max-RP C12 $(150 \times 2$ mm, Partikelgröße $4 \mu \mathrm{m})$ der Firma phenomenex. Zur Bedienung, Datenerfassung und Datenauswertung wurden die Computerprogramme Janeiro und Xcalibur verwendet. Als Laufmittelkomponenten dienten Wasser (Laufmittel A) und Methanol (Laufmittel B) der Firma VWR. Zur Verbesserung der Peakschärfe enthielten beide Laufmittel $0.05 \%$ Ameisensäure der Firma Roth. Die Lösungsmittelgemische wurden auf der Niederdruckseite erzeugt. Die Flussrate betrug $300 \mu \mathrm{L} / \mathrm{min}$ bei folgendem Gradienten (A/B):

\begin{tabular}{cc}
\hline Zeit $[\mathrm{min}]$ & $\mathrm{A} / \mathrm{B}$ \\
\hline 0 & $70 / 30$ \\
$0-15$ & $70 / 30 \rightarrow 0 / 100$ \\
$15-22$ & $0 / 100$ \\
$22-23$ & $0 / 100 \rightarrow 70 / 30$ \\
$23-29$ & $70 / 30$ \\
\hline
\end{tabular}


Die der analytischen Trennung online folgende Aufnahme von ESI-Massenspektren wurde an einem Ion-Trap-Massenspektrometer LCQ der Firma Finnigan durchgeführt. Die UV-Detektion erfolgte im Bereich von 200-800 nm und die Massen-Detektion im Bereich von 100-2000 m/z. Die Kapillartemperatur betrug $220^{\circ} \mathrm{C}$, die Sprayspannung $4.5 \mathrm{kV}$ und der Sheath-Gas-Fluss 80 (beliebige Einheit).

\subsection{Materialien und Geräte zur Untersuchung der Wechselwirkung von Zytostatika mit DNA, RNA und Glutathion}

DNA-Oligonukleotide: Zur Untersuchung der Bildung von DNA-Addukten dienten HPLC- und teils PAGE-gereinigte einzel- oder doppelsträngige DNA-Oligonukleotide der Firma $I B A$. Die Konzentration der in Wasser gelösten DNA betrug $0.1 \mathrm{nmol} / \mu \mathrm{L}$.

RNA-Oligonukleotide: Verwendung fand HPLC-gereinigte doppelsträngige RNA der Firma $I B A$ mit einer Konzentration der in Wasser gelösten RNA von $0.1 \mathrm{nmol} / \mu \mathrm{L}$.

Alle Reaktionen mit RNA erfolgten in sterilen und RNase-freien Multiply ${ }^{\circledR}$-Pro 0.5 mL-Amplifikationsgefäßen der Firma Sarstedt unter Nutzung steriler, RNase-freier Biosphere ${ }^{\circledR}-10 \mu$ L-Pipettenspitzen mit Filtern der Firma Sarstedt.

Glutathion: $\gamma$-L-Glutamyl-L-cysteinyl-glycin (58, G4251) der Firma Sigma-Aldrich.

Phosphatpuffer: Lösung von $\mathrm{Na}_{2} \mathrm{HPO}_{4} / \mathrm{NaH}_{2} \mathrm{PO}_{4}(10 \mathrm{mM})$ und $\mathrm{NaCl}(0.1 \mathrm{M})$ in bidestilliertem Wasser, $\mathrm{pH}$ 7.0.

ESI-HRMS: Die massenspektrometrische Untersuchung der Addukte erfolgte an einem Fourier Transform Ion Cyclotron Resonance (FTICR)-Massenspektrometer APEX IV im negativen (DNA, RNA) bzw. positiven (Glutathion) Ionenmodus. Im negativen Ionenmodus betrug die Kapillarspannung $4.2 \mathrm{kV}$, die End-Platten-Spannung $3.8 \mathrm{kV}$ und die Capillary-Skimmer-Spannung (Kapillarausgangsspannung, $U_{\mathrm{C}}$ ) bei geringer Fragmentierung $-100 \mathrm{~V}$ und unter Fragmentierungsbedingungen $-150 \mathrm{~V}$. Als Trockengas diente Stickstoff mit einer Temperatur von $100^{\circ} \mathrm{C} \mathrm{bzw.} 250^{\circ} \mathrm{C}$. Untersucht wurde der Massenbereich 398-2000 m/z unter Hochauflösung. Die hohe Auflösung der gemessenen Spektren erlaubte die Dekonvolution der durch das Auftreten mehrfach geladener Ionen komplexen Signalsätze zu einfacheren Spektren der entsprechenden neutralen Verbindungen. Angegeben sind jeweils die berechneten und gefundenen monoisotopischen Massen der neutralen Spezies in der atomaren Masseneinheit (u). Kovalente Addukte sind mit * gekennzeichnet und in Klammern ist das Duocarmycin-Analogon genannt, das bei der entsprechenden Reaktion eingesetzt 
wurde. Die Oligonukleotid-Fragmente sind nach einer auf dem Vorschlag von S. A. McLuckey basierenden Nomenklatur bezeichnet (Abb. 189). ${ }^{180}$

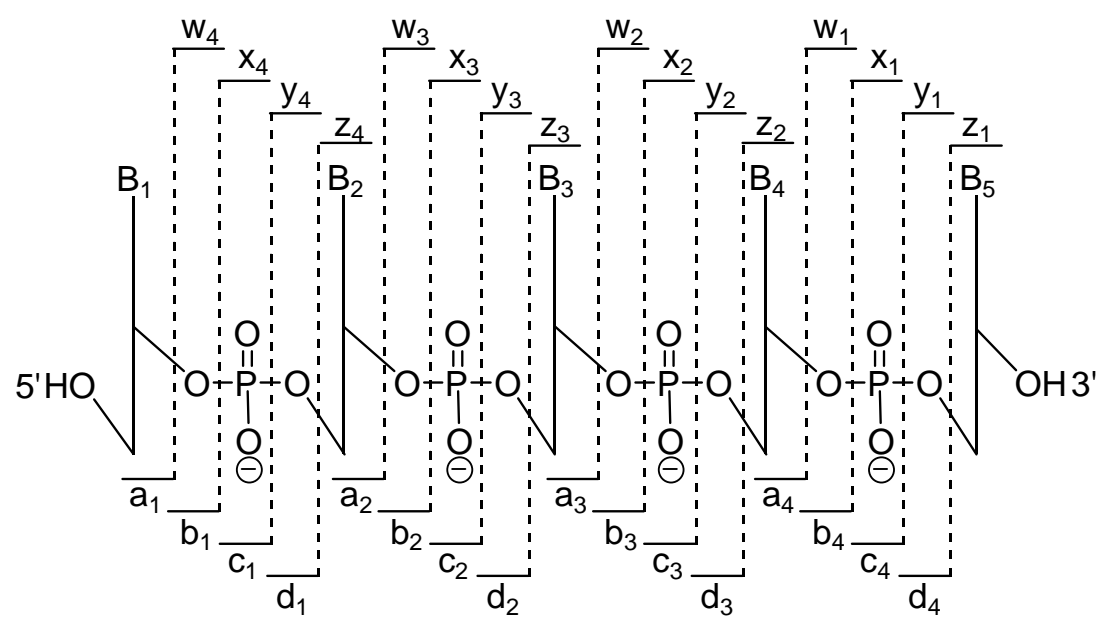

Abb. 189. Nomenklatur der Oligonukleotid-Fragmente basierend auf einem Vorschlag von S. A. McLuckey. ${ }^{180}$

Analytische und semipräparative HPLC: Trennungen von Reaktionsmischungen mit DNA-Oligonukleotiden erfolgten mit einer HPLC-Anlage vom Typ Agilent 1200 Series mit DAD der Firma Agilent Technologies unter Nutzung der Software Agilent LC Series ChemStation B.03.01 der Firma Agilent Technologies. Eingesetzt wurden die Säulen Aquapore OD-300 $(220 \times 4.6 \mathrm{~mm}$, Partikelgröße $7 \mu \mathrm{m})$ der Firma Perkin Elmer und Bondapak ${ }^{\circledR}$ C18 $(300 \times 3.9$ mm, Partikelgröße $10 \mu \mathrm{m}$, Porengröße $125 \AA)$ der Firma Waters. Als Laufmittelkomponenten dienten Wasser mit $0.1 \mathrm{M}$ Triethylammoniumacetat-Puffer der Firma Fluka, pH 7 (Laufmittel A) und Wasser/Acetonitril $=20 / 80$ mit 0.1 M Triethylammoniumacetat-Puffer der Firma Fluka, pH 7 (Laufmittel B). Die Säulentemperatur betrug $28^{\circ} \mathrm{C}$ und die Flussrate $1 \mathrm{~mL} / \mathrm{min}$ (Aquapore OD300) bzw. $2 \mathrm{~mL} / \mathrm{min}$ (Bondapak ${ }^{\circledR} \mathrm{C} 18$ ) bei folgendem Gradienten (A/B):

\begin{tabular}{cc}
\hline Zeit $[\mathrm{min}]$ & $\mathrm{A} / \mathrm{B}$ \\
\hline $0-2$ & $95 / 5$ \\
$2-22$ & $95 / 5 \rightarrow 80 / 20$ \\
$22-45$ & $80 / 20 \rightarrow 20 / 80$ \\
$45-50$ & $20 / 80$ \\
$50-60$ & $20 / 80 \rightarrow 95 / 5$ \\
\hline
\end{tabular}

Die Detektion erfolgte bei den Wellenlängen $\lambda=254 \mathrm{~nm}, 260 \mathrm{~nm}, 280 \mathrm{~nm}, 300 \mathrm{~nm}$ und $350 \mathrm{~nm}$. Duocarmycin-Analoga und deren Derivate einschließlich der kovalenten 
und nicht-kovalenten Verbindungen mit Oligonukleotiden absorbieren bei $\lambda=350 \mathrm{~nm}$, während Oligonukleotide bei dieser Wellenlänge keine Absorption zeigen. Die Auswertung erfolgte daher durch Integration der Absorptionsspur bei $\lambda=350 \mathrm{~nm}$ und Berechnung des prozentualen Anteils der jeweiligen Spezies am Gesamtintegral. Die kovalenten und nicht-kovalenten Addukte werden mit ${ }^{(*)}$ gekennzeichnet.

Schmelztemperaturbestimmung: DNA-Schmelzkurven wurden an einem PerkinElmer Lambda 10 UV/VIS Spectrophotometer mit einem angeschlossenen PerkinElmer PTP-1 Peltiersystem aufgenommen. Die Messung erfolgte bei den Wellenlängen $\lambda=250 \mathrm{~nm}, 260 \mathrm{~nm}, 270 \mathrm{~nm}$ und $280 \mathrm{~nm}$ in einer Quarzküvette mit $d=1 \mathrm{~cm}$ und einer DNA-Konzentration von $6 \mu \mathrm{M}$. Dabei wurde folgendes Temperaturprogramm gewählt:

\begin{tabular}{cc}
\hline Zeit $[\mathrm{h}]$ & Temperatur $\left[{ }^{\circ} \mathrm{C}\right]$ \\
\hline $0-3$ & 0 \\
$3-6$ & $-2 \rightarrow 85$ \\
$6-9$ & $85 \rightarrow-2$ \\
\hline
\end{tabular}

Die Schmelztemperatur $T_{m}$ eines DNA-Oligomers entspricht der halbmaximalen Zunahme der Hyperchromizität $H$. Die Hyperchromizität bei einer Temperatur $T$ kann nach folgender Formel aus der temperaturabhängigen Absorption $A(T)$ und dem kleinsten gemessenen Absorptionswert des entsprechenden Experimentes $\left(A_{0}\right)$ berechnet werden:

$$
H(T)[\%]=\frac{\left(A(T)-A_{0}\right) \cdot 100}{A_{0}}
$$

Molecular Modelling: Verwendet wurde das Programm MacroModel. ${ }^{195}$ Energieminimierungen erfolgten mit dem Kraftfeld Amber ${ }^{196}$ und konformationelle Studien mit der Methode MCMM. ${ }^{216}$ Als Lösungsmittel diente Wasser und die dielektrische Feldkonstante wurde als 1.0 angenommen. Grundlage der Modellierung war die mittels NMR-Spektroskopie aufgeklärte Struktur eines kovalenten DNA-Duocarmycin SA-Komplexes (Zugangscode: 1dsa). ${ }^{178}$ 


\subsection{Materialien für In-vitro-Zytotoxizitätstests und In-vitro-Mechanis- musstudien}

\section{Zelllinien:}

A549, ATCC-CCL 185 (American Type Culture Collection Certified Cell Lines), eine 1972 aus einem cancerogenen Tumorexplanat der Lunge eines 58-jährigen männlichen Patienten etablierte, epithelähnliche, adhärent in Monolayern wachsende Zelllinie. Herkunft: Institut für Zellbiologie der Universität Essen.

HL-60, ATCC CCL-240, die promyelocytische Zelllinie wächst in Suspension und wurde 1976 aus dem peripheren Blut einer 35-jährigen Frau mit akuter myeloischer Leukämie (AML) etabliert. Herkunft: Abteilung Immunologie des Universitätsklinikums Göttingen.

HeLa SS6, ATCC CCL-2, eine 1951 aus dem Zervixkarzinom einer 31-jährigen Frau etablierte, epitheliale, adhärent in Monolayern wachsende Zelllinie. Herkunft: Abteilung Zelluläre Biochemie des Max-Planck-Institutes für biophysikalische Chemie, Göttingen

Medien: Alle Pulvermedien wurden in bidestilliertem Wasser angesetzt, mit $\mathrm{HCl}$ auf pH 7.4 titriert und sterilfiltriert.

Kulturmedium für A549: DMEM (Dulbecco `s Modified Eagles Medium) mit $4.5 \mathrm{~g} / 1$ Glucose (Biochrom, T043-10). Das Medium wurde mit 4 mM L-Glutamin und $3.7 \mathrm{~g} / 1$ Natriumhydrogencarbonat supplementiert.

Kulturmedium für HL-60: RPMI 1640 (Roswell Park Memorial Institute), (Biochrom, T121-10). Das Medium wurde mit 2 mM L-Glutamin und 2.0 g/l Natriumhydrogencarbonat supplementiert.

Kulturmedium für HeLa SS6: DMEM (Dulbecco`s Modified Eagles Medium), (Gibco/Invitrogen, 41966). Das Medium wurde mit $0.4 \mathrm{mM} \mathrm{L-Glutamin}$ und $0.2 \mathrm{mM}$ Natriumpyruvat supplementiert.

Medium-Zusätze: 10\% FKS (Fötales Kälberserum) der Firma Biochrom, 30 min inaktiviert bei $56^{\circ} \mathrm{C}$. 
Inkubationsmedium für die Toxinexposition: Als serumfreies Medium für die Toxinexposition wurde UltraCulture ${ }^{\circledR}$ der Firma Lonza eingesetzt.

Enzym: $\beta$-D-Galactosidase (E.C. 3.2.1.23) von Eschericha coli G 5635 (Sigma), Aktivität: 250-600 Einheiten (Units (U)) pro mg Protein bei $\mathrm{pH} 7.3$ und $37^{\circ} \mathrm{C}$, $1 \mathrm{U}=1 \mu \mathrm{mol}$ Substratumsatz pro Minute.

Zellzählkammer: Netzeinteilung nach Bürker der Firma Assistent.

Testplatten: 6-well Testplatten der Firma TPP (über Biochrom).

Zellablösungsreagenz: Trypsin-EDTA-Lösung für die Passagierung von Monolayerkulturen der Firma Biochrom. 0.05-0.02\% in PBS (Phosphat-buffered-Saline) ohne $\mathrm{Ca}^{2+}, \mathrm{Mg}^{2+}$.

PBS-Puffer: Lösung der PBS-Trockensubstanz (Phosphate Buffered Saline) der Firma Biochrom $K G$ in bidestilliertem Wasser. Salzkonzentrationen in der Pufferlösung mit pH 7.4: $137.0 \mathrm{mM} \mathrm{NaCl}, 2.7 \mathrm{mM} \mathrm{KCl}, 8.1 \mathrm{mM} \mathrm{Na}_{2} \mathrm{HPO}_{4}, 1.1 \mathrm{mM} \mathrm{KH}_{2} \mathrm{PO}_{4}$.

Trypanblau: Gebrauchsfertige Lösung der Firma Biochrom von 0.5\% (w/v) Trypanblau in physiologischer Kochsalzlösung.

DNA-Isolierung: Zur Isolierung der zellulären DNA diente ein QIAamp ${ }^{\circledR}$ DNA Mini Kit der Firma Qiagen. Die Vorgehensweise zur Isolation der DNA aus je 5 Millionen HL-60-Zellen erfolgte nach dem im mitgelieferten Handbuch beschriebenen Protokoll. Zur Entfernung von RNA-Verunreinigungen diente RNase A der Firma Qiagen und die Elution im letzten Schritt erfolgte mit $200 \mu \mathrm{L}$ bidestilliertem Wasser.

Fluoreszenzfarbstoff der Verbindungen (-)-(1S,10R)-75 und (1S,10R)-76: Zur Kupplung des Farbstoffs Dapoxyl ${ }^{\circledR}-3$-Sulfonamidpropionsäure an die freie Amino-

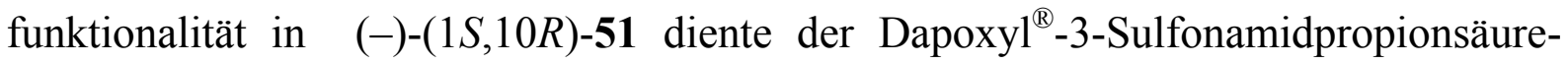
succinimidylester D10162 (39) der Firma Invitrogen.

Mitochondrien-selektiver Fluoreszenzfarbstoff: Zum Anfärben der Mitochondrien vitaler Zellen diente MitoTracker ${ }^{\circledR}$ Deep Red 633 FM (41) der Firma Invitrogen.

Zellkern-selektiver Fluoreszenzfarbstoff: Zum Anfärben der Kern-DNA diente Hoechst 33342 (40) der Firma Sigma-Aldrich.

Fluoreszenzmarkierung der Endosomen: Endozytotische Vesikel wurden durch die Expression des Vektors pEGFP-Endo (Clontech, Katalognr. 6935-1) in adhärenten 
Zellen visualisiert. Die Transfektion erfolgte mit Lipofectamine 2000 (Invitrogen) nach dem mitgelieferten Protokoll.

Bildgebungspuffer: Mit $\mathrm{NaOH}$ auf $\mathrm{pH} 7.4$ titrierte Lösung von $\mathrm{NaCl}(135 \mathrm{mM}), \mathrm{KCl}$ (5.37 mM), $\mathrm{MgCl}_{2}(1.66 \mathrm{mM}), \mathrm{CaCl}_{2}(1.8 \mathrm{mM})$, HEPES (10 mM) und Glukose $(5.55 \mathrm{mM})$ in bidestilliertem Wasser.

Fluoreszenzmikroskopie: Verwendung fanden ein Konfokales LaserscanningMikroskop des Typs Leica SP2 der Firma Leica, ein Spinning-Disc-Mikroskop des Typs UltraVIEW VoX der Firma Perkin Elmer und ein mit einer Hamamatsu ORCAER Kamera ausgestattetes inverses Weitfeld-Mikroskop des Typs Zeiss Axiovert 200M der Firma Zeiss. Die Bearbeitung der Daten nach der Datenerfassung erfolgte mit den Programmen ImageJ, Imaris 6.2, Volocity und IgorPro 4.05A Carbon.

Die Detektion der Fluoreszenzemission des Farbstoffs Hoechst 33342 (40) am Weitfeld-Mikroskop erfolgte mit einem 10-fach Objektiv des Typs Plan-Neofluar 10x / 0.30 Ph1 und dem Filter Set 49 (DAPI) der Firma Zeiss.

Die folgende Tabelle zeigt die Anregungswellenlängen sowie die ungefähre Lage der Maxima der Fluoreszenzemission bei Detektion mit dem Konfokalen LaserscanningMikroskop bzw. die detektierten Wellenlängenbereiche der Fluoreszenzemission bei Untersuchungen mit dem Spinning-Disc-Mikroskop.

\begin{tabular}{cccc}
\hline Verbindung & $\lambda_{\text {exc }}[\mathbf{n m}]$ & $\lambda_{\text {em }}[\mathbf{n m}]^{\mathbf{a}}$ & $\lambda_{\text {em }}[\mathbf{n m}]^{\mathbf{b}}$ \\
\hline$(-)-(1 S, 10 R)-75$ & 405 & 500 & - \\
$(1 S, 10 R)-76$ & 405 & 500 & $477 \pm 45$ \\
& 514 & 560 & $575 \pm 100$ \\
hydrolysiertes D10162 (103) & 405 & 500 & - \\
MitoTracker ${ }^{\circledR}$ Deep Red 633 FM (41) & 633 & 680 & - \\
Hoechst 33342 (40) $_{\text {Trypanblau }}$ & 405 & 460,485 & - \\
pEGFP-Endo & 561,594 & 630 & $705 \pm 90$ \\
\hline
\end{tabular}

Tab. 60. Anregungswellenlängen, Maxima der Emissionswellenlängen oder Detektionsbereiche für fluoreszenzmikroskopische Untersuchungen an lebenden Zellen. a: konfokales Laserscanning-Mikroskop, b: Spinning-Disc-Mikroskop. 


\section{Synthese der anti-Methyl-seco-CBI-Derivate}

2.1 Trennung der Enantiomere von rac-\{(1S,10R)-5-Benzyloxy-3-(tertbutyloxycarbonyl)-1-(10-chlor-ethyl)-1,2-dihydro-3H-benz[e]indol\} (rac-44)

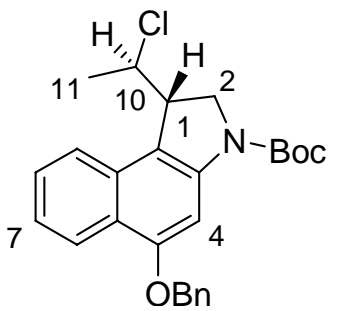

Rac-44 (1.1 g, $2.5 \mathrm{mmol})$ wurde in einem Gemisch aus Heptan / Dichlormethan = 1:1 $(22 \mathrm{~mL}$ ) gelöst. Je $1 \mathrm{~mL}$ dieser Probelösung (entsprechend $50 \mathrm{mg}$ bzw. $0.11 \mathrm{mmol}$ des racemischen Gemisches) wurden in das präparative HPLC-System (Säule: Chiralpak IA $^{\circledR}, 250 \times 20 \mathrm{~mm}$, Partikelgröße: $5 \mu \mathrm{m}$, mobile Phase: Heptan $/$ Dichlormethan $=4: 1$,

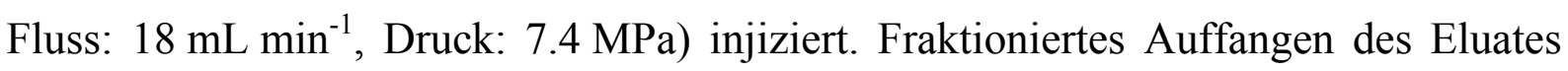
(UV-Detektor: $\lambda=250 \mathrm{~nm}$ ) lieferte die beiden Enantiomere $(+)-(1 S, 10 R)-44$ und $(-)-(1 R, 10 S)-44$.

\section{Analytische Daten für $(+)-(1 S, 10 R)-44:$}

HPLC (präparativ): $t_{\mathrm{R}}: \quad 5.2 \mathrm{~min}$

Fraktion: $3.5-5.9 \mathrm{~min}$

HPLC (analytisch): Säule: Chiralcel OD

Eluens: $\quad 1 \%$ Isopropanol in $n$-Hexan

Fluss: $\quad 0.8 \mathrm{~mL} \mathrm{~min}^{-1}$

$t_{\mathrm{R}}: \quad 13.6 \mathrm{~min}, 99.9 \%$ ee.

$[\alpha]_{\mathbf{D}}^{20}=+28.0^{\circ}\left(\mathrm{c}=0.8, \mathrm{CHCl}_{3}\right)$.

UV $\left(\mathrm{CH}_{3} \mathrm{CN}\right): \lambda_{\max }(\lg \varepsilon)=207.5 \mathrm{~nm}$ (4.432), 218.0 (4.381), 255.0 (4.845), 302.5 (3.973), 314.0 (4.059), 341.0 (3.555).

IR $(\mathrm{KBr}): \widetilde{v}\left(\mathrm{~cm}^{-1}\right)=3445,2974,2923,1699,1625,1579,1455,1409,1387,1367$, 1336, 1273, 1147, 1047, 911, 846, 757, 735, 694. 
${ }^{1} \mathrm{H}-\mathrm{NMR}\left(300 \mathrm{MHz}\right.$, Tetrachlorethan- $\left.\mathrm{d}_{2}, 100{ }^{\circ} \mathrm{C}\right): \delta=1.65\left(\mathrm{~s}, 9 \mathrm{H}, \mathrm{C}\left(\mathrm{CH}_{3}\right)_{3}\right), 1.66(\mathrm{~d}$, $\left.J=6.7 \mathrm{~Hz}, 3 \mathrm{H}, 11-\mathrm{H}_{3}\right), 3.82-3.93\left(\mathrm{~m}_{\mathrm{c}}, 1 \mathrm{H}, 1-\mathrm{H}\right), 4.12(\mathrm{dd}, J=11.4,9.4 \mathrm{~Hz}, 1 \mathrm{H}$, $\left.2-\mathrm{H}_{\mathrm{a}}\right), 4.40\left(\mathrm{dd}, J=11.4,2.5 \mathrm{~Hz}, 1 \mathrm{H}, 2-\mathrm{H}_{\mathrm{b}}\right), 4.62(\mathrm{dq}, J=6.7,4.2 \mathrm{~Hz}, 1 \mathrm{H}, 10-\mathrm{H})$, $5.33\left(\mathrm{~m}_{\mathrm{c}}, 2 \mathrm{H}, \mathrm{OCH}_{2} \mathrm{Ph}\right), 7.33-7.62(\mathrm{~m}, 7 \mathrm{H}, 7-\mathrm{H}, 8-\mathrm{H}, 5 \times \mathrm{Ph}-\mathrm{H}), 7.69(\mathrm{~d}, J=8.4 \mathrm{~Hz}$, $1 \mathrm{H}, 9-\mathrm{H}), 7.76$ (s, $1 \mathrm{H}, 4-\mathrm{H}), 8.34$ (d, $J=8.4 \mathrm{~Hz}, 1 \mathrm{H}, 6-\mathrm{H})$.

${ }^{13}$ C-NMR $\left(75 \mathrm{MHz}\right.$, Tetrachlorethan- $\left.\mathrm{d}_{2}, 100{ }^{\circ} \mathrm{C}\right): \delta=23.3(\mathrm{C}-11), 28.4\left(\mathrm{C}\left(\mathrm{CH}_{3}\right)_{3}\right)$, 46.0 (C-1), 51.0 (C-2), 60.1 (C-10), $70.5\left(\mathrm{OCH}_{2}\right), 80.8\left(\underline{\mathrm{C}}\left(\mathrm{CH}_{3}\right)_{3}\right), 97.3(\mathrm{C}-4), 115.4$ (C-9b), 122.0 (C-5a), 122.6, 122.7, 123.4 (C-6, C-7, C-9), 127.0 (C-8), 127.3, 127.7, $128.3(5 \times \mathrm{Ph}-\underline{\mathrm{CH}}), 130.5(\mathrm{C}-9 \mathrm{a}), 136.9\left(\mathrm{Ph}-\mathrm{C}_{i}\right), 141.7(\mathrm{C}-3 \mathrm{a}), 152.0(\mathrm{C}=\mathrm{O}), 155.8$ (C-5).

MS (ESI): $m / z(\%)=460(100)[\mathrm{M}+\mathrm{Na}]^{+}$.

$\mathbf{C}_{26} \mathrm{H}_{28} \mathrm{CINO}_{3}$ (437.97).

Analytische Daten für $(-)-(1 R, 10 S)-44:$

HPLC (präparativ): $t_{\mathrm{R}}: \quad 7.1 \mathrm{~min}$

Fraktion: $\quad 6.3-8.4 \mathrm{~min}$

HPLC (analytisch): Säule: Chiralcel OD

Eluens: $\quad 1 \%$ Isopropanol in $n$-Hexan

Fluss: $\quad 0.8 \mathrm{~mL} \mathrm{~min}^{-1}$

$t_{\mathrm{R}}: \quad 17.4 \mathrm{~min}, 99.9 \%$ ee .

$[\alpha]_{\mathrm{D}}^{20}=-27.0^{\circ}\left(\mathrm{c}=0.8, \mathrm{CHCl}_{3}\right)$. 
$2.2(+)-\{(1 S, 10 R)-5-B e n z y l o x y-1-(10-c h l o r-e t h y l)-3-[(5-(2-(N, N$-dimethylamino)ethoxy)indol-2-yl)carbonyl]-1,2-dihydro-3H-benz $[e]$ indol $\}$ $((+)-(1 S, 10 R)-47)$

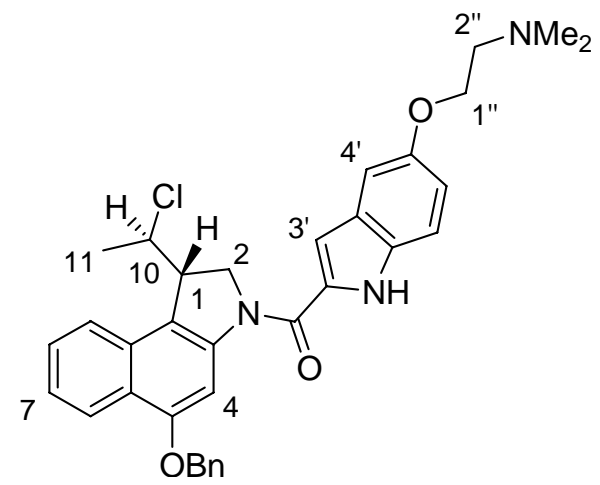

(+)-(1S,10R)-44 (150 mg, $342 \mu \mathrm{mol}, 1.0$ Äq.) wurde in $4 \mathrm{M} \mathrm{HCl} / \mathrm{EE}(11 \mathrm{~mL})$ suspendiert, die Reaktionsmischung $3.5 \mathrm{~h}$ bei Raumtemperatur gerührt und anschließend das Lösungsmittel im Vakuum entfernt. Der Rückstand wurde $1 \mathrm{~h}$ im Vakuum getrocknet, in DMF $(8 \mathrm{~mL})$ gelöst, die Lösung auf $0{ }^{\circ} \mathrm{C}$ gekühlt und mit $\mathrm{EDC} \cdot \mathrm{HCl}$ (197 mg, $1.03 \mathrm{mmol}, 3.0$ Äq.) sowie DMAI-CO ${ }_{2} \mathrm{H} \cdot \mathrm{HCl}$ (46a) $(127 \mathrm{mg}, 445 \mu \mathrm{mol}$, 1.3 Äq.) versetzt. Nach 21 h Inkubationsdauer bei Raumtemperatur wurde die Reaktionslösung mit Essigester $(50 \mathrm{~mL})$, Wasser $(50 \mathrm{~mL})$ sowie gesättigter $\mathrm{NaHCO}_{3^{-}}$ Lösung $(50 \mathrm{~mL})$ versetzt und anschließend mit Essigester $(4 \times 150 \mathrm{~mL})$ extrahiert. Die vereinigten organischen Phasen wurden mit gesättigter NaCl-Lösung $(4 \times 100 \mathrm{~mL})$ gewaschen, über $\mathrm{MgSO}_{4}$ getrocknet und das Lösungsmittel im Vakuum entfernt. Säulenchromatographie an Kieselgel $\left(\mathrm{CH}_{2} \mathrm{Cl}_{2} / \mathrm{MeOH}=10: 1\right)$ lieferte die Titelverbindung (+)-(1S,10R)-47 als weißen Feststoff (148 mg, $261 \mu \mathrm{mol}, 76 \%)$.

$\mathbf{R}_{f}=0.40\left(\mathrm{CH}_{2} \mathrm{Cl}_{2} / \mathrm{MeOH}=10: 1\right)$.

$[\alpha]_{\mathrm{D}}^{20}=+43.2^{\circ}\left(\mathrm{c}=0.5, \mathrm{CHCl}_{3}\right)$.

UV $\left(\mathrm{CH}_{3} \mathrm{CN}\right): \lambda_{\max }(\lg \varepsilon)=207.0 \mathrm{~nm}$ (4.826), 249.5 (4.434), 290.0 (4.446), 300.0 (4.606), 339.5 (4.519).

IR (KBr): $\widetilde{v}\left(\mathrm{~cm}^{-1}\right)=3452,2937,1621,1518,1456,1414$.

${ }^{1} \mathrm{H}-\mathrm{NMR}\left(300 \mathrm{MHz}, \mathrm{CDCl}_{3}\right): \delta=1.62\left(\mathrm{~d}, J=6.8 \mathrm{~Hz}, 3 \mathrm{H}, 11-\mathrm{H}_{3}\right), 2.37(\mathrm{~s}, 6 \mathrm{H}$, $\mathrm{NMe}_{2}$ ), 2.77 (t, $\left.J=5.7 \mathrm{~Hz}, 2 \mathrm{H}, 2 "-\mathrm{H}_{2}\right), 3.88-3.97(\mathrm{~m}, 1 \mathrm{H}, 1-\mathrm{H}), 4.10$ (t, $J=5.7 \mathrm{~Hz}$, $\left.2 \mathrm{H}, 1 "-\mathrm{H}_{2}\right), 4.46-4.60\left(\mathrm{~m}, 2 \mathrm{H}, 2-\mathrm{H}_{\mathrm{a}}, 10-\mathrm{H}\right), 4.84\left(\mathrm{~m}_{\mathrm{c}}, 1 \mathrm{H}, 2-\mathrm{H}_{\mathrm{b}}\right), 5.24\left(\mathrm{~m}_{\mathrm{c}}, 2 \mathrm{H}\right.$, $\left.\mathrm{OC} \underline{\mathrm{H}}_{2} \mathrm{Ph}\right), 6.94-7.04$ (m, $\left.2 \mathrm{H}, 3^{\prime}-\mathrm{H}, 6^{\prime}-\mathrm{H}\right), 7.12$ (d, $\left.J=2.2 \mathrm{~Hz}, 1 \mathrm{H}, 4^{\prime}-\mathrm{H}\right), 7.28-7.44$, 
7.45-7.55 (2 × m, 8 H, 7-H, 7'-H, 8-H, $5 \times$ Ph-H), 7.67 (d, $J=8.3$ Hz, 1 H, 9-H), 8.18 ( $\left.\mathrm{s}_{\mathrm{br}}, 1 \mathrm{H}, 4-\mathrm{H}\right), 8.35(\mathrm{~d}, J=8.3 \mathrm{~Hz}, 1 \mathrm{H}, 6-\mathrm{H}), 9.81\left(\mathrm{~s}_{\mathrm{br}}, 1 \mathrm{H}, \mathrm{NH}\right)$.

${ }^{13}$ C-NMR $\left(75 \mathrm{MHz}, \mathrm{CDCl}_{3}\right): \delta=24.0(\mathrm{C}-11), 45.8\left(\mathrm{NMe}_{2}\right), 47.5(\mathrm{C}-1), 53.6(\mathrm{C}-2)$, 58.3 (C-2"), 59.9 (C-10), 66.5 (C-1"), $70.3\left(\mathrm{OCCH}_{2} \mathrm{Ph}\right), 98.2$ (C-4), 103.5 (C-4'), 105.9 (C-3'), 112.7 (C-7'), 117.1, 117.2 (C-6', C-5a), 122.5, 123.7, 123.7, 123.8 (C-6, C-7, C-9, C-9b), 127.4, 127.6, 127.9, 128.1, 128.5 (C-3a', C-8, $5 \times$ Ph- $-\mathrm{H}), 130.0,130.8$, 131.4 (C-2', C-7a', C-9a), 136.7 (Ph-C ${ }_{i}$ ), 142.4 (C-3a), 153.8 (C-5'), 155.6 (C-5), 160.5 $(\mathrm{C}=\mathrm{O})$.

MS (ESI): $m / z(\%)=1135.5(11)[2 \mathrm{M}+\mathrm{H}]^{+}, 568.2(100)[\mathrm{M}+\mathrm{H}]^{+}$.

$\mathrm{C}_{34} \mathrm{H}_{34} \mathrm{ClN}_{3} \mathrm{O}_{3}$ (568.11). $\quad$ ber.: 568.2362 gef.: 568.2362 (ESI-HRMS).

\section{$2.3(+)-\{(1 S, 10 R)-1-(10-C h l o r-e t h y l)-3-[(5-(2-(N, N-d i m e t h y l a m i n o)-$ ethoxy)indol-2-yl)carbonyl]-5-hydroxy-1,2-dihydro-3H-benz[e]indol- Hydrochlorid\} ((+)-(1S,10R)-34a)}

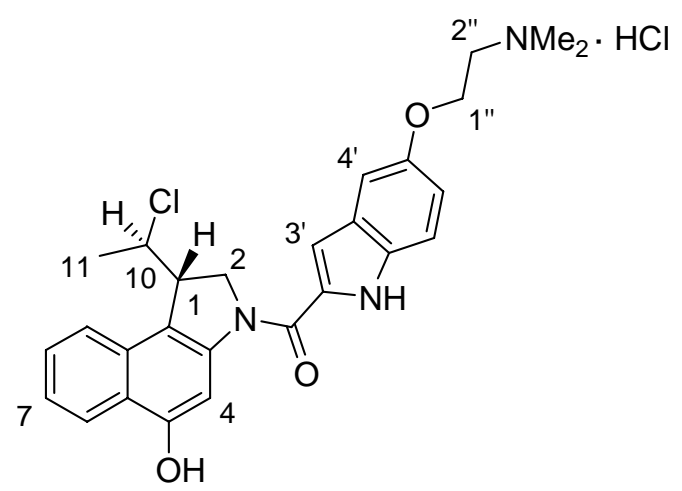

Der Benzylether (+)-(1S,10R)-47 (88.0 mg, $155 \mu$ mol, 1.0 Äq.) wurde in $4 \mathrm{M} \mathrm{HCl/EE}$ $(9 \mathrm{~mL})$ gelöst und $2 \mathrm{~h}$ bei Raumtemperatur gerührt. Anschließend wurde die Lösung im Vakuum eingeengt, $1 \mathrm{~h}$ im Vakuum getrocknet und der Rückstand in THF (7 mL) suspendiert. Zu der Suspension wurde bei Raumtemperatur Palladium auf Aktivkohle (10\%-ig, $34 \mathrm{mg}, 31 \mu \mathrm{mol}, 0.20$ Äq. bez. Pd) und Ammoniumformiat (25\% aq.Lösung, $0.34 \mathrm{~mL}$ ) gegeben. Nach $2 \mathrm{~h}$ Rühren bei $40^{\circ} \mathrm{C}$ wurde über Celite vom Feststoff abfiltriert, gründlich mit Methanol $(300 \mathrm{~mL})$ gewaschen und das Filtrat im Vakuum eingeengt. Säulenchromatographische Reinigung an Kieselgel $\left(\mathrm{CH}_{2} \mathrm{Cl}_{2} /\right.$ $\mathrm{MeOH}=5: 1,1 \%$ konz. $\mathrm{HCl})$ lieferte die Zielverbindung $(+)-(1 S, 10 R)-\mathbf{3 4 a}$ als grünen Feststoff (72.0 mg, $140 \mu \mathrm{mol}, 90 \%)$. 
$\mathbf{R}_{\boldsymbol{f}}=0.43\left(\mathrm{CH}_{2} \mathrm{Cl}_{2} / \mathrm{MeOH}=5: 1\right)$.

$[\alpha]_{\mathrm{D}}^{20}=+25.0^{\circ}(\mathrm{c}=0.4, \mathrm{MeOH})$.

UV $\left(\mathrm{CH}_{3} \mathrm{CN}\right): \lambda_{\max }(\lg \varepsilon)=207.0 \mathrm{~nm}$ (4.454), 248.0 (4.212), 303.0 (4.281), 338.0 (4.192).

IR $(\mathrm{KBr}): \widetilde{v}\left(\mathrm{~cm}^{-1}\right)=3213,1587,1517,1473,1414,1234,1177$.

${ }^{1}$ H-NMR $\left(300 \mathrm{MHz}, \mathrm{DMSO}-\mathrm{d}_{6}\right): \delta=1.62\left(\mathrm{~d}, J=6.6 \mathrm{~Hz}, 3 \mathrm{H}, 11-\mathrm{H}_{3}\right), 2.84(\mathrm{~d}$, $\left.J=5.0 \mathrm{~Hz}, 6 \mathrm{H}, \mathrm{NMe}_{2}\right), 3.51\left(\mathrm{t}, J=4.9 \mathrm{~Hz}, 2 \mathrm{H}, 2^{\prime \prime}-\mathrm{H}_{2}\right), 4.17\left(\mathrm{~m}_{\mathrm{c}}, 1 \mathrm{H}, 1-\mathrm{H}\right), 4.42$ (t, $\left.J=4.9 \mathrm{~Hz}, 2 \mathrm{H}, 1 "-\mathrm{H}_{2}\right), 4.57\left(\mathrm{~m}_{\mathrm{c}}, 1 \mathrm{H}, 2-\mathrm{H}_{\mathrm{a}}\right), 4.67-4.80\left(\mathrm{~m}, 2 \mathrm{H}, 2-\mathrm{H}_{\mathrm{b}}, 10-\mathrm{H}\right), 7.00$ (dd, $\left.J=9.0,2.2 \mathrm{~Hz}, 1 \mathrm{H}, 66^{\prime}-\mathrm{H}\right), 7.16$ ( $\mathrm{s}, 1 \mathrm{H}, 3$ '-H), 7.26 (d, J=2.2 Hz, $\left.1 \mathrm{H}, 4^{\prime}-\mathrm{H}\right)$, $7.35(\mathrm{dd}, 2 \times J=8.2 \mathrm{~Hz}, 1 \mathrm{H}, 7-\mathrm{H}), 7.45$ (d, $\left.J=9.0 \mathrm{~Hz}, 1 \mathrm{H}, 7{ }^{\prime}-\mathrm{H}\right), 7.50$ (dd, $2 \times J=8.2 \mathrm{~Hz}, 1 \mathrm{H}, 8-\mathrm{H}), 7.88(\mathrm{~d}, J=8.2 \mathrm{~Hz}, 1 \mathrm{H}, 9-\mathrm{H}), 7.97$ ( $\left.\mathrm{s}_{\mathrm{br}}, 1 \mathrm{H}, 4-\mathrm{H}\right), 8.12(\mathrm{~d}$, $J=8.2 \mathrm{~Hz}, 1 \mathrm{H}, 6-\mathrm{H}), 10.4(\mathrm{~s}, 1 \mathrm{H}, \mathrm{OH}), 10.9\left(\mathrm{~s}_{\mathrm{br}}, 1 \mathrm{H}, \mathrm{NH}^{+}\right), 11.6\left(\mathrm{~s}_{\mathrm{br}}, 1 \mathrm{H}, \mathrm{NH}\right)$.

${ }^{13}$ C-NMR (75 MHz, DMSO-d $\left.{ }_{6}\right): \delta=23.4$ (C-11), $42.6\left(\mathrm{NMe}_{2}\right), 45.8$ (C-1), 51.8 (C-2), 55.2 (C-2"), 61.5 (C-10), 63.0 (C-1"), 100.4 (C-4), 104.0 (C-4'), 105.2 (C-3'), 113.2 (C-7'), 115.5 (C-6'), 115.8 (C-5a), 122.2 (C-9b), 122.8 (C-9), 122.9 (C-7), 123.1 (C-6), 126.9 (C-8), 127.4 (C-3a'), 129.8, 131.3, 131.9 (C-2', C-7a', C-9a), 142.1 (C-3a), 152.0 $\left(\mathrm{C}-5{ }^{\prime}\right), 153.9(\mathrm{C}-5), 159.8(\mathrm{C}=\mathrm{O})$.

MS (EI, $70 \mathrm{eV}): m / z(\%)=478.2(100)[\mathrm{M}-\mathrm{Cl}]^{+}, 442.2(26)[\mathrm{M}-\mathrm{HCl}-\mathrm{Cl}]^{+}$.

$\mathbf{C}_{27} \mathbf{H}_{29} \mathbf{C l}_{2} \mathbf{N}_{3} \mathbf{O}_{3}$ (514.44). $\quad$ ber.: 478.1892

gef.: 478.1892, [M-HCl-Cl $]^{+}($ESI-HRMS).

\section{$2.4(-)-\{(1 R, 10 S)-5-B e n z y l o x y-1-(10-c h l o r-e t h y l)-3-[(5-(2-(N, N-d i m e t h y l-$ amino)ethoxy)indol-2-yl)carbonyl]-1,2-dihydro-3H-benz $[e]$ indol\} $((-)-(1 R, 10 S)-47)$}

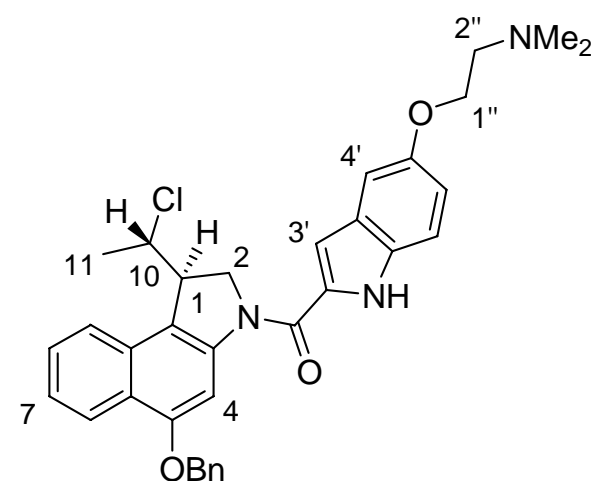


$(-)-(1 R, 10 S)-44(100 \mathrm{mg}, 228 \mu \mathrm{mol}, 1.0$ Äq.) wurde in $4 \mathrm{M} \mathrm{HCl} / \mathrm{EE}(7 \mathrm{~mL})$ suspendiert, die Reaktionsmischung $3 \mathrm{~h}$ bei Raumtemperatur gerührt und anschließend das Lösungsmittel im Vakuum entfernt. Der Rückstand wurde $1.5 \mathrm{~h}$ im Vakuum getrocknet, in DMF $(5 \mathrm{~mL})$ gelöst, die Lösung auf $0{ }^{\circ} \mathrm{C}$ gekühlt und mit $\mathrm{EDC} \cdot \mathrm{HCl}$ (131 mg, $684 \mu \mathrm{mol}, 3.0$ Äq.) sowie DMAI-CO ${ }_{2} \mathrm{H} \cdot \mathrm{HCl}$ (46a) $(84.5 \mathrm{mg}, 296 \mu \mathrm{mol}$, 1.3 Äq.) versetzt. Nach $2 \mathrm{~d}$ Inkubationsdauer bei Raumtemperatur wurde die Reaktionslösung mit Essigester $(50 \mathrm{~mL})$, Wasser $(50 \mathrm{~mL})$ sowie gesättigter $\mathrm{NaHCO}_{3}$ Lösung $(50 \mathrm{~mL})$ versetzt und anschließend mit Essigester $(4 \times 150 \mathrm{~mL})$ extrahiert. Die vereinigten organischen Phasen wurden mit gesättigter NaCl-Lösung $(4 \times 100 \mathrm{~mL})$ gewaschen, über $\mathrm{MgSO}_{4}$ getrocknet und das Lösungsmittel im Vakuum entfernt. Säulenchromatographie an Kieselgel $\left(\mathrm{CH}_{2} \mathrm{Cl}_{2} / \mathrm{MeOH}=10: 1\right)$ lieferte die Titelverbindung (-)-(1R,10S)-47 als weißen Feststoff (96.2 mg, $169 \mu \mathrm{mol}, 74 \%)$.

$\mathbf{R}_{f}=0.26\left(\mathrm{CH}_{2} \mathrm{Cl}_{2} / \mathrm{MeOH}=10: 1\right)$.

${ }^{1}$ H-NMR $\left(300 \mathrm{MHz}, \mathrm{CDCl}_{3}\right): \delta=1.62\left(\mathrm{~d}, J=6.8 \mathrm{~Hz}, 3 \mathrm{H}, 11-\mathrm{H}_{3}\right), 2.37(\mathrm{~s}, 6 \mathrm{H}$, $\mathrm{NMe}_{2}$ ), 2.77 (t, $\left.J=5.7 \mathrm{~Hz}, 2 \mathrm{H}, 2 "-\mathrm{H}_{2}\right), 3.88-3.97$ (m, $\left.1 \mathrm{H}, 1-\mathrm{H}\right), 4.10$ (t, $J=5.7 \mathrm{~Hz}$, $\left.2 \mathrm{H}, 1 "-\mathrm{H}_{2}\right), 4.46-4.60\left(\mathrm{~m}, 2 \mathrm{H}, 2-\mathrm{H}_{\mathrm{a}}, 10-\mathrm{H}\right), 4.84\left(\mathrm{~m}_{\mathrm{c}}, 1 \mathrm{H}, 2-\mathrm{H}_{\mathrm{b}}\right), 5.24\left(\mathrm{~m}_{\mathrm{c}}, 2 \mathrm{H}\right.$, $\left.\mathrm{OC}_{2} \mathrm{Ph}\right), 6.94-7.04\left(\mathrm{~m}, 2 \mathrm{H}, 3^{\prime}-\mathrm{H}, 66^{\prime}-\mathrm{H}\right), 7.12\left(\mathrm{~d}, J=2.2 \mathrm{~Hz}, 1 \mathrm{H}, 4^{\prime}-\mathrm{H}\right), 7.28-7.44$, 7.45-7.55 (2 × m, 8 H, 7-H, 7'-H, 8-H, $5 \times$ Ph-H), 7.67 (d, $J=8.3$ Hz, 1 H, 9-H), 8.18 ( $\left.\mathrm{s}_{\mathrm{br}}, 1 \mathrm{H}, 4-\mathrm{H}\right), 8.35(\mathrm{~d}, J=8.3 \mathrm{~Hz}, 1 \mathrm{H}, 6-\mathrm{H}), 9.81$ ( $\left.\mathrm{s}_{\mathrm{br}}, 1 \mathrm{H}, \mathrm{NH}\right)$.

${ }^{13}$ C-NMR $\left(75 \mathrm{MHz}, \mathrm{CDCl}_{3}\right): \delta=24.0(\mathrm{C}-11), 45.8\left(\mathrm{NMe}_{2}\right), 47.5(\mathrm{C}-1), 53.6(\mathrm{C}-2)$, 58.3 (C-2"), 59.9 (C-10), 66.5 (C-1"), $70.3\left(\mathrm{OCH}_{2} \mathrm{Ph}\right), 98.2$ (C-4), 103.5 (C-4'), 105.9 (C-3'), 112.7 (C-7'), 117.1, 117.2 (C-6', C-5a), 122.5, 123.7, 123.7, 123.8 (C-6, C-7, C-9, C-9b), 127.4, 127.6, 127.9, 128.1, 128.5 (C-3a', C-8, $5 \times$ Ph- $-\mathrm{H}), 130.0,130.8$, 131.4 (C-2', C-7a', C-9a), 136.7 (Ph-C ${ }_{i}$ ), 142.4 (C-3a), 153.8 (C-5'), 155.6 (C-5), 160.5 $(\mathrm{C}=\mathrm{O})$.

MS (ESI): $m / z(\%)=1135.5(11)[2 \mathrm{M}+\mathrm{H}]^{+}, 568.2(100)[\mathrm{M}+\mathrm{H}]^{+}$.

$\mathrm{C}_{34} \mathrm{H}_{34} \mathrm{CIN}_{3} \mathrm{O}_{3}$ (568.11). 


\section{5 (1R,10S)-5-Benzyloxy-1-(10-Chlor-ethyl)-3-[(5-(2-( $N, N, N$-trimethyl-} ammonium)ethoxy)-indol-2-yl)carbonyl]-1,2-dihydro-3H-benz[e]indol-Iodid $((1 R, 10 S)-70)$

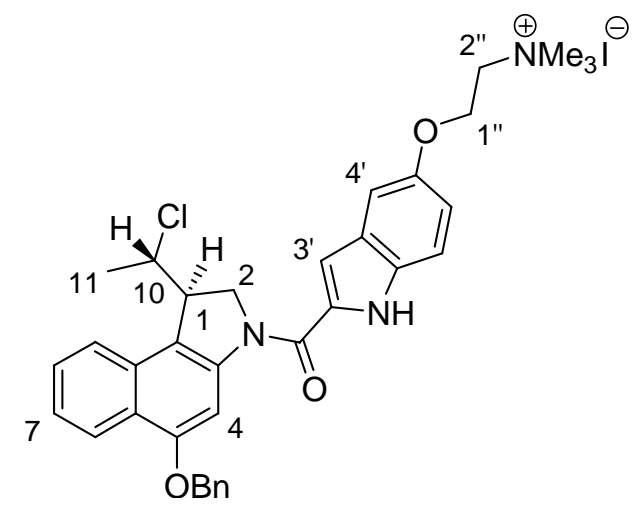

Der Benzylether (-)-(1R,10S)-47 (10 mg, $18 \mu$ mol, 1.0 Äq.) wurde in Dichlormethan $(1.2 \mathrm{~mL})$ gelöst. Die Reaktionsmischung wurde dreimal mit Methyliodid $(2.8 \mathrm{mg}$, $1.2 \mu \mathrm{L}, 19 \mu \mathrm{mol}, 1.1$ Äq.) versetzt und jeweils $60 \mathrm{~min}$ bei $60^{\circ} \mathrm{C}$ im Mikrowellenreaktor gerührt. Nach weiteren $0.5 \mathrm{~h}$ Rühren bei Raumtemperatur wurde das überschüssige Methylodid mit Methanol $(10 \mathrm{~mL})$ vernichtet, die Reaktionsmischung im Vakuum getrocknet und das Produkt $(1 R, 10 S)$-70 ohne weitere Aufreinigung als hellgelber Feststoff (12 mg, $17 \mu \mathrm{mol}, 94 \%)$ erhalten.

$\mathbf{R}_{f}=\left(\mathrm{CH}_{2} \mathrm{Cl}_{2} / \mathrm{MeOH}=10: 1\right)$.

${ }^{1}$ H-NMR $\left(300 \mathrm{MHz}\right.$, DMSO-d $\left.{ }_{6}\right): \delta=1.65\left(\mathrm{~d}, J=6.8 \mathrm{~Hz}, 3 \mathrm{H}, 11-\mathrm{H}_{3}\right), 3.20(\mathrm{~s}, 9 \mathrm{H}$, $\left.\mathrm{NMe}_{3}{ }^{+}\right), 3.82\left(\mathrm{~m}_{\mathrm{c}}, 2 \mathrm{H}, 2^{\prime \prime}-\mathrm{H}_{2}\right), 4.25\left(\mathrm{~m}_{\mathrm{c}}, 1 \mathrm{H}, 1-\mathrm{H}\right), 4.49\left(\mathrm{~m}_{\mathrm{c}}, 2 \mathrm{H}, 1 "-\mathrm{H}_{2}\right), 4.62$ (dd, $\left.J=11.0,2.0 \mathrm{~Hz}, 1 \mathrm{H}, 2-\mathrm{H}_{\mathrm{a}}\right), 4.71-4.85\left(\mathrm{~m}, 2 \mathrm{H}, 2-\mathrm{H}_{\mathrm{b}}, 10-\mathrm{H}\right), 5.31\left(\mathrm{~m}_{\mathrm{c}}, 2 \mathrm{H}, \mathrm{OC}_{2} \mathrm{Ph}\right)$, 7.00 (dd, $\left.J=8.8,2.2 \mathrm{~Hz}, 1 \mathrm{H}, 6{ }^{\prime}-\mathrm{H}\right), 7.19$ (d, $\left.J=2.2 \mathrm{~Hz}, 1 \mathrm{H}, 3^{\prime}-\mathrm{H}\right), 7.30$ (d, $\left.J=2.4 \mathrm{~Hz}, 1 \mathrm{H}, 4^{\prime}-\mathrm{H}\right), 7.33-7.49,7.53-7.63\left(2 \times \mathrm{m}, 8 \mathrm{H}, 7-\mathrm{H}, 8-\mathrm{H}, 7{ }^{\prime}-\mathrm{H}, 5 \times \mathrm{Ph}-\mathrm{H}\right)$, $7.98(\mathrm{~d}, J=8.2 \mathrm{~Hz}, 1 \mathrm{H}, 9-\mathrm{H}), 8.11(\mathrm{~s} \mathrm{br}, 1 \mathrm{H}, 4-\mathrm{H}), 8.23(\mathrm{~d}, J=8.2 \mathrm{~Hz}, 1 \mathrm{H}, 6-\mathrm{H})$, $11.69\left(\mathrm{~s}_{\mathrm{br}}, 1 \mathrm{H}, \mathrm{NH}\right)$.

MS (ESI): $\mathrm{m} / \mathrm{z}(\%)=582.3(100)[\mathrm{M}-\mathrm{I}]^{+}$.

$\mathrm{C}_{35} \mathrm{H}_{37} \mathrm{CIIN}_{3} \mathrm{O}_{3}$ (710.04). 


\section{$2.6(+)-\{(1 S, 10 R)-5-B e n z y l o x y-1-(10-C h l o r-e t h y l)-3-[(5-(2-(N, N, N-$ trimethylammonium)ethoxy)-indol-2-yl)carbonyl]-1,2-dihydro-3H- benz $[e]$ indol-Iodid $\}((+)-(1 S, 10 R)-70)$}

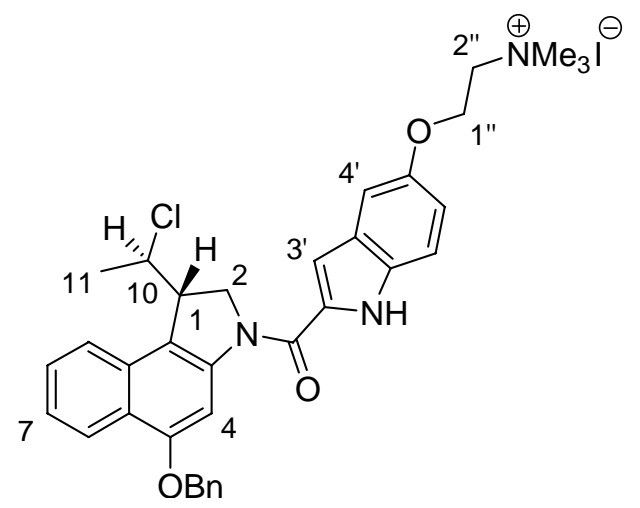

Der Benzylether (+)-(1S,10R)-47 (10 mg, $18 \mu$ mol, 1.0 Äq.) wurde in Dichlormethan $(1.5 \mathrm{~mL})$ gelöst. Die Reaktionsmischung wurde mit Methyliodid $(8.4 \mathrm{mg}, 3.6 \mu \mathrm{L}$, $58 \mu \mathrm{mol}, 3.3$ Äq.) versetzt und $60 \mathrm{~min}$ bei $100^{\circ} \mathrm{C}$ im Mikrowellenreaktor gerührt. Nach weiteren $0.5 \mathrm{~h}$ Rühren bei Raumtemperatur wurde das überschüssige Methylodid mit Methanol $(10 \mathrm{~mL})$ vernichtet, die Reaktionsmischung im Vakuum getrocknet und das Produkt $(1 S, 10 R)-70$ nach Säulenfiltration an Kieselgel $\left(\mathrm{CH}_{2} \mathrm{Cl}_{2} / \mathrm{MeOH}=5: 1\right)$ als hellgelber Feststoff (12 mg, $17 \mu \mathrm{mol}, 94 \%)$ erhalten.

$\mathbf{R}_{f}=0.17(\mathrm{DCM} / \mathrm{MeOH}=5: 1)$.

$[\alpha]_{\mathrm{D}}^{20}=+35.5^{\circ}(\mathrm{c}=0.22, \mathrm{MeOH})$.

UV (MeOH): $\lambda_{\max }(\lg \varepsilon)=207.5 \mathrm{~nm}$ (4.758), 301.0 (4.440), 335.5 (4.369).

IR $(\mathrm{KBr}): \widetilde{v}\left(\mathrm{~cm}^{-1}\right)=3417,2922,1623,1586,1515,1458,1405,1289,1266,1232$, 1174, 1126, 969, 842, 698 .

${ }^{1}$ H-NMR (300 MHz, DMSO-d $\left.)_{6}\right): \delta=1.65\left(\mathrm{~d}, J=6.6 \mathrm{~Hz}, 3 \mathrm{H}, 11-\mathrm{H}_{3}\right), 3.22(\mathrm{~s}, 9 \mathrm{H}$, $\left.\mathrm{NMe}_{3}{ }^{+}\right), 3.83\left(\mathrm{~m}_{\mathrm{c}}, 2 \mathrm{H}, 2^{\prime \prime}-\mathrm{H}_{2}\right), 4.25(\mathrm{dt}, J=9.4,2.4 \mathrm{~Hz}, 1 \mathrm{H}, 1-\mathrm{H}), 4.49\left(\mathrm{~m}_{\mathrm{c}}, 2 \mathrm{H}\right.$, 1"- $\left.\mathrm{H}_{2}\right), 4.62\left(\mathrm{dd}, J=11.0,2.4 \mathrm{~Hz}, 1 \mathrm{H}, 2-\mathrm{H}_{\mathrm{a}}\right), 4.77\left(\mathrm{t}, J=11.0 \mathrm{~Hz}, 1 \mathrm{H}, 2-\mathrm{H}_{\mathrm{b}}\right), 4.81$ (dq, $J=6.6,2.4 \mathrm{~Hz}, 1 \mathrm{H}, 10-\mathrm{H}), 5.31\left(\mathrm{~m}_{\mathrm{c}}, 2 \mathrm{H}, \mathrm{OCH}_{2} \mathrm{Ph}\right), 7.00(\mathrm{dd}, J=9.0,2.4 \mathrm{~Hz}$, $\left.1 \mathrm{H}, 66^{\prime}-\mathrm{H}\right), 7.20$ (d, $\left.J=1.8 \mathrm{~Hz}, 1 \mathrm{H}, 3^{\prime}-\mathrm{H}\right), 7.30$ (d, $\left.J=2.2 \mathrm{~Hz}, 1 \mathrm{H}, 4^{\prime}-\mathrm{H}\right), 7.37\left(\mathrm{~m}_{\mathrm{c}}\right.$, $\left.1 \mathrm{H}, \mathrm{Ph}-\mathrm{H}_{p}\right), 7.43-7.47\left(\mathrm{~m}, 4 \mathrm{H}, 7-\mathrm{H}, 7^{\prime}-\mathrm{H}, 2 \times \mathrm{Ph}-\mathrm{H}\right), 7.55-7.61(\mathrm{~m}, 3 \mathrm{H}, 8-\mathrm{H}$, $2 \times \mathrm{Ph}-\mathrm{H}), 7.98(\mathrm{~d}, J=8.2 \mathrm{~Hz}, 1 \mathrm{H}, 9-\mathrm{H}), 8.12\left(\mathrm{~s}_{\mathrm{br}}, 1 \mathrm{H}, 4-\mathrm{H}\right), 8.23(\mathrm{~d}, J=8.2 \mathrm{~Hz}, 1 \mathrm{H}$, 6-H), 11.7 (s, $1 \mathrm{H}, \mathrm{NH})$. 
${ }^{13}$ C-NMR (125 MHz, $\left.\mathrm{CDCl}_{3}\right): \delta=23.4$ (C-11), 45.9 (C-1), $52.0(\mathrm{C}-2), 53.2\left(\mathrm{NMe}_{3}{ }^{+}\right)$, 61.4 (C-10), 62.1 (C-1"), 64.2 (C-2"), 69.6 (O대글 $\mathrm{Ph}), 98.4$ (C-4), 104.1 (C-4'), 105.3 (C-3'), 113.2 (C-7'), 115.5 (C-6'), 117.6 (C-5a), 122.6 (C-6, C-9b), 123.1 (C-9), 123.8 (C-7), 127.4, 127.9, 128.5 (C-8, C-3a', $5 \times$ Ph- $\underline{\mathrm{CH}}$ ), 129.6, 131.2, 132.0 (C-2', C-7a', C-9a), $136.8\left(\mathrm{Ph}_{i}\right), 142.0$ (C-3a), $151.8\left(\mathrm{C}-5^{\prime}\right), 154.2(\mathrm{C}-5), 160.0(\mathrm{C}=\mathrm{O})$.

MS (ESI): $\mathrm{m} / \mathrm{z}(\%)=582.3(100)[\mathrm{M}-\mathrm{I}]^{+}$.

$\mathrm{C}_{35} \mathrm{H}_{37} \mathrm{ClIN}_{3} \mathrm{O}_{3}(710.04)$.

ber.: 582.2518

gef.: 582.2516, [M-I] $]^{+}($ESI-HRMS).

\section{7 (1S)-1-(10-Hydroxy-ethyl)-3-[(5-(2-( $N, N$-dimethylamino)-ethoxy)- indol-2-yl)carbonyl]-1,2-dihydro-3H-benz[e]indol-5-yl]- $\beta$-D-galacto- pyranosid (85a)}

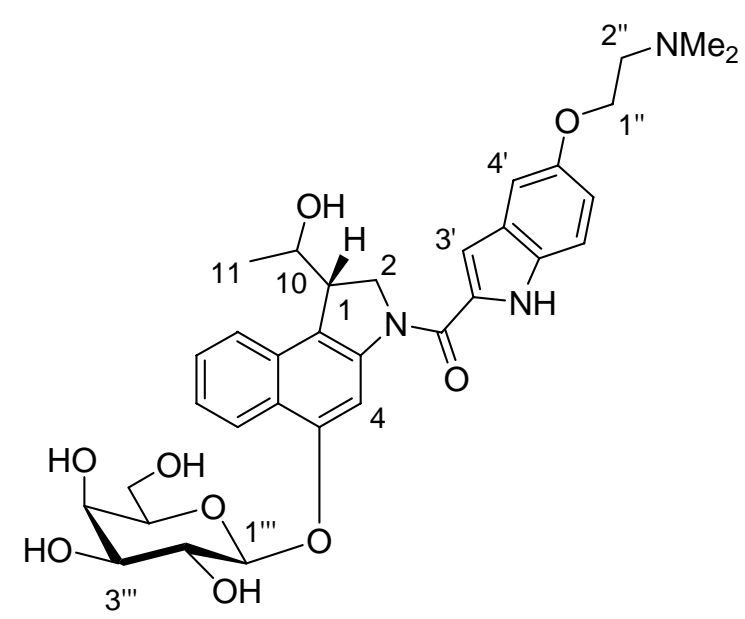

(1S,10R)-33a (16 mg, $25 \mu \mathrm{mol})$ wurde in DMSO $(300 \mu \mathrm{L})$ gelöst und mit $0.9 \%$-iger Kochsalzlösung (154 mM aq.-Lösung von NaCl, $30 \mathrm{~mL}$ ) versetzt. Nach 3 Wochen bei Raumtemperatur wurde das Lösungsmittel im Vakuum entfernt. Säulenchromatographische Reinigung des Rohproduktes an Kieselgel $\left(\mathrm{CH}_{2} \mathrm{Cl}_{2} / \mathrm{MeOH}=1: 1\right)$ lieferte das Produkt 85a in quantitativer Ausbeute.

$\mathbf{R}_{\boldsymbol{f}}=0.20\left(\mathrm{CH}_{2} \mathrm{CL}_{2} / \mathrm{MeOH}=1: 1\right)$.

${ }^{1}$ H-NMR $\left(600 \mathrm{MHz}, \mathrm{DMSO}_{-} \mathrm{d}_{6}\right): \delta=1.14\left(\mathrm{~d}, J=6.4 \mathrm{~Hz}, 3 \mathrm{H}, 11-\mathrm{H}_{3}\right), 2.81(\mathrm{~s}, 6 \mathrm{H}$,

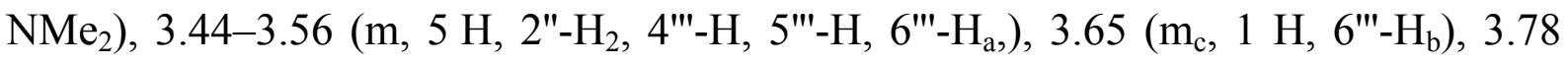
$\left(\mathrm{m}_{\mathrm{c}}, 2 \mathrm{H}, 2\right.$ '"-H, 1-H), 3.83 ( $\left.\mathrm{m}_{\mathrm{c}}, 1 \mathrm{H}, 3^{\prime \prime}-\mathrm{H}\right), 4.12\left(\mathrm{~m}_{\mathrm{c}}, 1 \mathrm{H}, 10-\mathrm{H}\right), 4.39\left(\mathrm{~m}_{\mathrm{c}}, 2 \mathrm{H}\right.$, $\left.1 "-\mathrm{H}_{2}\right), 4.59-4.69$ (m, $\left.3 \mathrm{H}, 2-\mathrm{H}_{2}, \mathrm{OH}\right), 4.72\left(\mathrm{~m}_{\mathrm{c}}, 1 \mathrm{H}, \mathrm{OH}\right), 4.75\left(\mathrm{~m}_{\mathrm{c}}, 1 \mathrm{H}, \mathrm{OH}\right), 4.87-$ 
4.92 (m, 2 H, 1"'-H, OH), 5.29 (m, 1 H, OH), 6.98 (dd, J=8.8, 2.2 Hz, 1 H, 6'-H), 7.14 (s, $1 \mathrm{H}, 4$ 4'-H) $^{\prime} 7.25\left(\mathrm{~s}, 1 \mathrm{H}, 3^{\prime}-\mathrm{H}\right), 7.39(\mathrm{dd}, 2 \times J=7.5 \mathrm{~Hz}, 1 \mathrm{H}, 7-\mathrm{H}), 7.43(\mathrm{~d}$, $\left.J=9.2 \mathrm{~Hz}, 1 \mathrm{H}, 7^{\prime}-\mathrm{H}\right), 7.52(\mathrm{dd}, 2 \times J=7.5 \mathrm{~Hz}, 1 \mathrm{H}, 8-\mathrm{H}), 7.93(\mathrm{~d}, J=8.6 \mathrm{~Hz}, 1 \mathrm{H}$, 9-H), 8.25 ( $\left.\mathrm{s}_{\mathrm{br}}, 1 \mathrm{H}, 4-\mathrm{H}\right), 8.32$ (d, $\left.J=8.6 \mathrm{~Hz}, 1 \mathrm{H}, 6-\mathrm{H}\right), 9.17$ ( $\left.\mathrm{s}_{\mathrm{br}}, 1 \mathrm{H}, \mathrm{NH}\right), 11.7$ (s, $\left.1 \mathrm{H}, \mathrm{NH}^{+}\right)$.

${ }^{13}$ C-NMR $\left(150 \mathrm{MHz}\right.$, DMSO-d $\left.{ }_{6}\right): \delta=21.7(\mathrm{C}-11), 42.8\left(\mathrm{NMe}_{2}\right), 46.3$ (C-1), 52.3 (C-2), 55.4 (C-2"), 59.3 (C-6"'), 63.2 (C-1"), 67.2 (C-10), 67.3 (C-3"'), 70.6 (C-2"'), 73.3 (C-4"'), 75.1 (C-5"'), 102.2 (2 Signale, C-4, C-1"'), 103.9 (C-3'), 105.1 (C-4'), 113.2 (C-7'), 115.4 (C-6'), 120.8 (C-5a), 123.1 (2 Signale), 123.3, 123.7 (C-9, C-9b, C-6, C-7), 126.7 (C-8), 127.4 (C-3a), 129.9, 131.5, 131.9 (C-7a', C-2', C-9a), 141.9 (C-3a), $152.0\left(\mathrm{C}-5^{\prime}\right), 153.0(\mathrm{C}-5), 160.0(\mathrm{C}=\mathrm{O})$.

MS (ESI): $m / z(\%)=622.4(100)[\mathrm{M}+\mathrm{H}]^{+}$.

$\mathrm{C}_{33} \mathrm{H}_{39} \mathrm{~N}_{3} \mathrm{O}_{9}$ (621.67).

\section{Synthese des dechlorierten Methyl-seco-CBI-DMAI-Derivates}

\section{1 (-)-\{(1S)-5-Benzyloxy-3-(tert-butyloxycarbonyl)-1-ethyl-1,2-dihydro- $3 H$-benz $[e]$ indol\} $((-)-(1 S)-45)$}

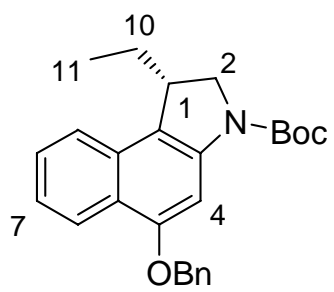

Eine Lösung des Chlorids (+)-(1S,10R)-44 (50.0 mg, $114 \mu \mathrm{mol}, 1.0$ Äq.) in Toluol $(5 \mathrm{~mL})$ wurde durch Einleiten eines Argon-Gasstromes entgast, mit TTMSS $(0.20 \mathrm{~mL}$, $0.64 \mathrm{mmol}, 5.6$ Äq.) sowie AIBN (0.20 mg, $0.12 \mathrm{mmol}, 1.1$ Äq.) versetzt und $7.0 \mathrm{~h}$ bei $80^{\circ} \mathrm{C}$ gerührt. Nach dem Abkühlen auf Raumtemperatur wurde das Reaktionsgemisch mit einer 10\%-igen KF-Lösung $(5 \mathrm{~mL})$ versetzt und $30 \mathrm{~min}$ bei Raumtemperatur gerührt. Die Phasen wurden getrennt, die organische Phase über $\mathrm{MgSO}_{4}$ getrocknet und das Lösungsmittel im Vakuum entfernt. Säulenchromatographie an Kieselgel $(\mathrm{PE} / \mathrm{EE}=10: 1)$ lieferte das Produkt $(-)-(1 S)-45$ als weißen Feststoff (40 mg, $99 \mu \mathrm{mol}, 87 \%)$. 
HPLC (analytisch): Säule: Chiralpak $^{\circledR}$ IA

Eluens: $\quad$ Hexan $/$ Dichlormethan $=90: 10$

Fluss: $\quad 0.8 \mathrm{~mL} \mathrm{~min}^{-1}$

$t_{\mathrm{R}}: \quad 18 \mathrm{~min}, 99.9 \%$ ee.

$\mathbf{R}_{f}=0.42(\mathrm{PE} / \mathrm{EE}=10: 1)$.

$[\alpha]_{\mathrm{D}}^{20}=-2.3^{\circ}\left(\mathrm{c}=0.22, \mathrm{CHCl}_{3}\right)$.

UV $\left(\mathrm{CH}_{3} \mathrm{CN}\right): \lambda_{\max }(\lg \varepsilon)=207.5 \mathrm{~nm}$ (4.414), 217.5 (4.394), 254.5 (4.841), 303.0 (3.994), 314.0 (4.068), 337.5 (3.558).

IR $(\mathrm{KBr}): \widetilde{v}\left(\mathrm{~cm}^{-1}\right)=2958,1694,1625,1580,1459,1408,1379,1367,1343,1267$, 1229, 1177, 1146, 1082, 1055, 908, 848, 756, 699.

${ }^{1} \mathbf{H}-\mathbf{N M R}\left(300 \mathrm{MHz}\right.$, Tetrachlorethan- $\left.\mathrm{d}_{2}, 100{ }^{\circ} \mathrm{C}\right): \delta=1.00\left(\mathrm{t}, J=7.4 \mathrm{~Hz}, 3 \mathrm{H}, 11-\mathrm{H}_{3}\right.$ ), 1.60-1.77 (m, $\left.10 \mathrm{H}, \mathrm{C}\left(\mathrm{CH}_{3}\right)_{3}, 10-\mathrm{H}_{\mathrm{a}}\right), 1.89-2.05\left(\mathrm{~m}, 1 \mathrm{H}, 10-\mathrm{H}_{\mathrm{b}}\right), 3.62$ (dddd, $J=2 \times 9.0,2 \times 3.0 \mathrm{~Hz}, 1 \mathrm{H}, 1-\mathrm{H}), 3.99\left(\mathrm{dd}, J=11.4 \mathrm{~Hz}, 3.0 \mathrm{~Hz}, 1 \mathrm{H}, 2-\mathrm{H}_{\mathrm{a}}\right), 4.15(\mathrm{dd}$, $\left.J=11.4,9.0 \mathrm{~Hz}, 1 \mathrm{H}, 2-\mathrm{H}_{\mathrm{b}}\right), 5.32\left(\mathrm{~s}, 2 \mathrm{H}, \mathrm{OCH}_{2} \mathrm{Ph}\right), 7.31-7.53(\mathrm{~m}, 5 \mathrm{H}, 7-\mathrm{H}, 8-\mathrm{H}$, $\left.\mathrm{Ph}-\mathrm{H}_{p}, 2 \times \mathrm{Ph}-\mathrm{H}_{m}\right), 7.59\left(\mathrm{~m}_{\mathrm{c}}, 2 \mathrm{H}, 2 \times \mathrm{Ph}-\mathrm{H}_{o}\right), 7.72(\mathrm{~d}, J=8.4 \mathrm{~Hz}, 1 \mathrm{H}, 9-\mathrm{H}), 7.75\left(\mathrm{~s}_{\mathrm{br}}\right.$, $1 \mathrm{H}, 4-\mathrm{H}), 8.32$ (d, $J=8.4 \mathrm{~Hz}, 1 \mathrm{H}, 6-\mathrm{H})$.

${ }^{13}$ C-NMR (75 MHz, Tetrachlorethan- $\left.\mathrm{d}_{2}, 100{ }^{\circ} \mathrm{C}\right): \delta=10.4(\mathrm{C}-11), 27.5(\mathrm{C}-10), 28.4$ $\left(\mathrm{C}\left(\underline{\mathrm{CH}}_{3}\right)_{3}\right), 39.5(\mathrm{C}-1), 54.0(\mathrm{C}-2), 70.5\left(\mathrm{OCH}_{2} \mathrm{Ph}\right), 80.5\left(\underline{\mathrm{C}}\left(\mathrm{CH}_{3}\right)_{3}\right), 97.3(\mathrm{C}-4), 119.3$ (C-9b), 122.3 (C-5a), 122.5 (C-9), 122.6 (C-7), 123.1 (C-6), 126.7 (C-8), 127.3 $\left(2 \times \mathrm{Ph}_{-} \mathrm{C}_{o}\right), 127.6\left(\mathrm{Ph}-\mathrm{C}_{p}\right), 128.3\left(2 \times \mathrm{Ph}_{-} \mathrm{C}_{m}\right), 130.4(\mathrm{C}-9 \mathrm{a}), 137.0\left(\mathrm{Ph}-\mathrm{C}_{i}\right), 140.2$ (C-3a), $152.3(\mathrm{C}=\mathrm{O}), 154.9(\mathrm{C}-5)$.

MS (ESI): $m / z(\%)=404(65)[\mathrm{M}+\mathrm{H}]^{+}, 426(100)[\mathrm{M}+\mathrm{Na}]^{+}$.

$\mathrm{C}_{26} \mathrm{H}_{29} \mathrm{NO}_{3}$ (403.51).

ber.: 403.2147

gef.: $403.2147[\mathrm{M}]^{+}$(EI-HRMS). 


\section{2 rac-\{5-Benzyloxy-3-(tert-butyloxycarbonyl)-1-ethyl-1,2-dihydro-3H- benz[e]indol\} (rac-45)}

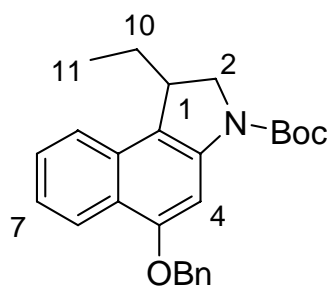

Eine Lösung des Chlorids rac-44 (50.0 mg, $110 \mu \mathrm{mol}, 1.0$ Äq.) in Toluol (5 mL) wurde durch Einleiten eines Argon-Gasstromes entgast, mit TTMSS $(0.20 \mathrm{~mL}$, $0.64 \mathrm{mmol}, 5.6$ Äq.) sowie AIBN (0.20 mg, $0.12 \mathrm{mmol}, 1.1$ Äq.) versetzt und $7 \mathrm{~h}$ bei $80^{\circ} \mathrm{C}$ gerührt. Nach dem Abkühlen auf Raumtemperatur wurde das Reaktionsgemisch mit einer 10\%-igen KF-Lösung $(5 \mathrm{~mL})$ versetzt und 30 min bei Raumtemperatur gerührt. Die Phasen wurden getrennt, die organische Phase über $\mathrm{MgSO}_{4}$ getrocknet und das Lösungsmittel im Vakuum entfernt. Säulenchromatographie an Kieselgel $(\mathrm{PE} / \mathrm{EE}=10: 1)$ lieferte das Produkt rac-45 als weißen Feststoff (40 mg, $99 \mu \mathrm{mol}, 87 \%)$.

$\mathbf{R}_{f}=0.42(\mathrm{PE} / \mathrm{EE}=10: 1)$.

UV $\left(\mathrm{CH}_{3} \mathrm{CN}\right): \lambda_{\max }(\lg \varepsilon)=207.5 \mathrm{~nm}$ (4.414), 217.5 (4.394), 254.5 (4.841), 303.0 (3.994), 314.0 (4.068), 337.5 (3.558).

IR $(\mathrm{KBr}): \widetilde{v}\left(\mathrm{~cm}^{-1}\right)=2958,1694,1625,1580,1459,1408,1379,1367,1343,1267$, 1229, 1177, 1146, 1082, 1055, 908, 848, 756, 699.

${ }^{1}$ H-NMR (300 MHz, Tetrachlorethan- $\mathrm{d}_{2}, 100{ }^{\circ} \mathrm{C}$ ): $\delta=1.00$ (t, $J=7.4 \mathrm{~Hz}, 3 \mathrm{H}, 11-\mathrm{H}_{3}$ ), 1.60-1.77 (m, $\left.10 \mathrm{H}, \mathrm{C}\left(\mathrm{CH}_{3}\right)_{3}, 10-\mathrm{H}_{\mathrm{a}}\right), 1.89-2.05\left(\mathrm{~m}, 1 \mathrm{H}, 10-\mathrm{H}_{\mathrm{b}}\right), 3.62$ (dddd, $J=2 \times 9.0,2 \times 3.0 \mathrm{~Hz}, 1 \mathrm{H}, 1-\mathrm{H}), 3.99\left(\mathrm{dd}, J=11.4 \mathrm{~Hz}, 3.0 \mathrm{~Hz}, 1 \mathrm{H}, 2-\mathrm{H}_{\mathrm{a}}\right), 4.15(\mathrm{dd}$, $J=11.4,9.0 \mathrm{~Hz}, 1 \mathrm{H}, 2-\mathrm{H}_{\mathrm{b}}$ ), 5.32 (s, $\left.2 \mathrm{H}, \mathrm{OC}_{2} \mathrm{Ph}\right), 7.31-7.53$ (m, $5 \mathrm{H}, 7-\mathrm{H}, 8-\mathrm{H}$, $\left.\mathrm{Ph}-\mathrm{H}_{p}, 2 \times \mathrm{Ph}-\mathrm{H}_{m}\right), 7.59\left(\mathrm{~m}_{\mathrm{c}}, 2 \mathrm{H}, 2 \times \mathrm{Ph}-\mathrm{H}_{o}\right), 7.72(\mathrm{~d}, J=8.4 \mathrm{~Hz}, 1 \mathrm{H}, 9-\mathrm{H}), 7.75\left(\mathrm{~s}_{\mathrm{br}}\right.$, $1 \mathrm{H}, 4-\mathrm{H}), 8.32$ (d, $J=8.4 \mathrm{~Hz}, 1 \mathrm{H}, 6-\mathrm{H})$.

${ }^{13}$ C-NMR (75 MHz, Tetrachlorethan- $\mathrm{d}_{2}, 100{ }^{\circ} \mathrm{C}$ ): $\delta=10.4$ (C-11), $27.5(\mathrm{C}-10), 28.4$ $\left(\mathrm{C}\left(\underline{\mathrm{CH}}_{3}\right)_{3}\right), 39.5(\mathrm{C}-1), 54.0(\mathrm{C}-2), 70.5\left(\mathrm{OCH}_{2} \mathrm{Ph}\right), 80.5\left(\underline{\mathrm{C}}\left(\mathrm{CH}_{3}\right)_{3}\right), 97.3(\mathrm{C}-4), 119.3$ (C-9b), 122.3 (C-5a), 122.5 (C-9), 122.6 (C-7), 123.1 (C-6), 126.7 (C-8), 127.3 $\left(2 \times \mathrm{Ph}_{-} \mathrm{C}_{o}\right), 127.6\left(\mathrm{Ph}-\mathrm{C}_{p}\right), 128.3\left(2 \times \mathrm{Ph}^{-\mathrm{C}_{m}}\right), 130.4(\mathrm{C}-9 \mathrm{a}), 137.0\left(\mathrm{Ph}-\mathrm{C}_{\mathrm{i}}\right), 140.2$ (C-3a), $152.3(\mathrm{C}=\mathrm{O}), 154.9(\mathrm{C}-5)$. 
MS (ESI): $m / z(\%)=404(65)[\mathrm{M}+\mathrm{H}]^{+}, 426(100)[\mathrm{M}+\mathrm{Na}]^{+}$.

$\mathrm{C}_{26} \mathrm{H}_{29} \mathrm{NO}_{3}(403.51)$.

ber.: 403.2147

gef.: $403.2147[\mathrm{M}]^{+}$(EI-HRMS).

\subsection{Trennung der Enantiomere von rac-\{5-Benzyloxy-3-(tert-butyloxy- carbonyl)-1-ethyl)-1,2-dihydro-3H-benz[e]indol\} (rac-45)}

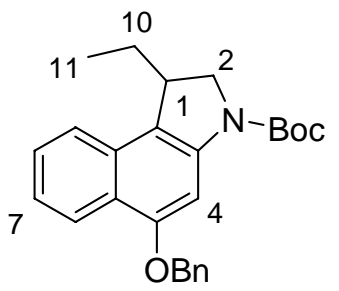

rac-45 (170 mg, $420 \mu \mathrm{mol})$ wurde in einem Gemisch aus Hexan/Dichlormethan = 95:5 $(3.5 \mathrm{~mL})$ gelöst. Je $0.7 \mathrm{~mL}$ dieser Probelösung (entsprechend $34 \mathrm{mg}$ bzw. $84 \mu$ mol des racemischen Gemisches) wurden in das präparative HPLC-System (Säule: Chiralpak ${ }^{\circledR}$ IA, $250 \times 20 \mathrm{~mm}$, Partikelgröße: $5 \mu \mathrm{m}$, mobile Phase: Hexan / Dichlormethan $=95: 5$, Fluss: $18 \mathrm{~mL} \mathrm{~min}^{-1}$, Druck: 5.9 MPa) injiziert. Fraktioniertes Auffangen des Eluates (UV-Detektor: $\lambda=250 \mathrm{~nm}$ ) lieferte die Enantiomere $(-)-(1 S)-\mathbf{4 5}$ und $(+)-(1 R)-45$.

\section{Analytische Daten für $(-)-(1 S)-45:$}

HPLC (präparativ): $t_{\mathrm{R}}: \quad 15 \mathrm{~min}$

Fraktion: $11.0-19.0 \mathrm{~min}$

HPLC (analytisch): Säule: $\quad$ Chiralpak $^{\circledR}$ IA

Eluens: $\quad$ Hexan $/$ Dichlormethan $=90: 10$

Fluss: $\quad 0.8 \mathrm{~mL} \mathrm{~min}^{-1}$

$t_{\mathrm{R}}: \quad 18 \mathrm{~min}, 99.9 \%$ ee.

$[\alpha]_{\mathrm{D}}^{20}=-3.2^{\circ}\left(\mathrm{c}=0.22, \mathrm{CHCl}_{3}\right)$.

UV $\left(\mathrm{CH}_{3} \mathrm{CN}\right): \lambda_{\max }(\lg \varepsilon)=207.5 \mathrm{~nm}$ (4.432), 218.0 (4.381), 255.0 (4.845), 302.5 (3.973), 314.0 (4.059), 341.0 (3.555). 
IR $(\mathrm{KBr}): \widetilde{v}\left(\mathrm{~cm}^{-1}\right)=3445,2974,2923,1699,1625,1579,1455,1409,1387,1367$, 1336, 1273, 1147, 1047, 911, 846, 757, 735, 694.

${ }^{1} \mathrm{H}-\mathrm{NMR}\left(300 \mathrm{MHz}\right.$, Tetrachlorethan- $\left.\mathrm{d}_{2}, 100{ }^{\circ} \mathrm{C}\right): \delta=1.65\left(\mathrm{~s}, 9 \mathrm{H}, \mathrm{C}\left(\mathrm{CH}_{3}\right)_{3}\right), 1.66(\mathrm{~d}$, $\left.J=6.7 \mathrm{~Hz}, 3 \mathrm{H}, 11-\mathrm{H}_{3}\right), 3.82-3.93\left(\mathrm{~m}_{\mathrm{c}}, 1 \mathrm{H}, 1-\mathrm{H}\right), 4.12(\mathrm{dd}, J=11.4,9.4 \mathrm{~Hz}, 1 \mathrm{H}$, $\left.2-\mathrm{H}_{\mathrm{a}}\right), 4.40\left(\mathrm{dd}, J=11.4,2.5 \mathrm{~Hz}, 1 \mathrm{H}, 2-\mathrm{H}_{\mathrm{b}}\right), 4.62(\mathrm{dq}, J=6.7,4.2 \mathrm{~Hz}, 1 \mathrm{H}, 10-\mathrm{H})$, $5.33\left(\mathrm{~m}_{\mathrm{c}}, 2 \mathrm{H}, \mathrm{OCH}_{2} \mathrm{Ph}\right), 7.33-7.62(\mathrm{~m}, 7 \mathrm{H}, 7-\mathrm{H}, 8-\mathrm{H}, 5 \times \mathrm{Ph}-\mathrm{H}), 7.69(\mathrm{~d}, J=8.4 \mathrm{~Hz}$, $1 \mathrm{H}, 9-\mathrm{H}), 7.76$ (s, $1 \mathrm{H}, 4-\mathrm{H}), 8.34$ (d, $J=8.4 \mathrm{~Hz}, 1 \mathrm{H}, 6-\mathrm{H})$.

${ }^{13}$ C-NMR $\left(75 \mathrm{MHz}\right.$, Tetrachlorethan- $\left.\mathrm{d}_{2}, 100{ }^{\circ} \mathrm{C}\right): \delta=23.3(\mathrm{C}-11), 28.4\left(\mathrm{C}\left(\mathrm{CH}_{3}\right)_{3}\right)$, 46.0 (C-1), $51.0(\mathrm{C}-2), 60.1(\mathrm{C}-10), 70.5\left(\mathrm{OCH}_{2} \mathrm{Ph}\right), 80.8\left(\underline{\mathrm{C}}\left(\mathrm{CH}_{3}\right)_{3}\right), 97.3(\mathrm{C}-4), 115.4$ (C-9b), 122.0 (C-5a), 122.6, 122.7, 123.4 (C-6, C-7, C-9), 127.0 (C-8), 127.3, 127.7, $128.3(5 \times \mathrm{Ph}-\underline{\mathrm{C}} \mathrm{H}), 130.5(\mathrm{C}-9 \mathrm{a}), 136.9\left(\mathrm{Ph}^{-} \mathrm{C}_{i}\right), 141.7(\mathrm{C}-3 \mathrm{a}), 152.0(\mathrm{C}=\mathrm{O}), 155.8$ (C-5).

MS (ESI): $m / z(\%)=460(100)[\mathrm{M}+\mathrm{Na}]^{+}$.

\section{Analytische Daten für $(+)-(1 R)-45:$}

HPLC (präparativ): $t_{\mathrm{R}}: \quad 23 \mathrm{~min}$

Fraktion: $20.0-34.0 \mathrm{~min}$

HPLC (analytisch): Säule: $\quad$ Chiralpak $^{\circledR}$ IA

Eluens: $\quad$ Hexan $/$ Dichlormethan $=90: 10$

Fluss: $\quad 0.8 \mathrm{~mL} \mathrm{~min}^{-1}$

$t_{\mathrm{R}}: \quad 25 \min , 99.9 \%$ ee.

$[\alpha]_{\mathrm{D}}^{20}=+3.2^{\circ}\left(\mathrm{c}=0.22, \mathrm{CHCl}_{3}\right)$. 


\section{4 (+)-\{(1S)-5-Benzyloxy-3-[(5-(2-( $N, N$-dimethylamino)ethoxy)indol-2-} yl)carbonyl]-1-ethyl-1,2-dihydro-3H-benz[e]indol\} $((+)-(1 S)-48)$

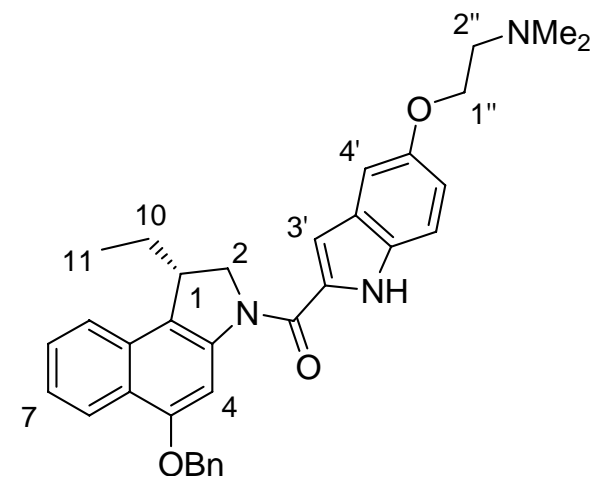

Eine Suspension aus (-)-(1S)-45 (65.0 mg, $161 \mu \mathrm{mol}, 1.0$ Äq.) in $4 \mathrm{M} \mathrm{HCl} / \mathrm{EE}$ $(4.0 \mathrm{~mL})$ wurde $3.5 \mathrm{~h}$ bei Raumtemperatur gerührt und anschließend das Lösungsmittel im Vakuum entfernt. Der Rückstand wurde $1 \mathrm{~h}$ im Vakuum getrocknet, in DMF (3.0 mL) gelöst, die Lösung auf $0{ }^{\circ} \mathrm{C}$ gekühlt und mit EDC $\cdot \mathrm{HCl}(94.2 \mathrm{mg}, 484 \mu \mathrm{mol}$, 3.0 Äq.) sowie DMAI-CO ${ }_{2} \mathrm{H} \cdot \mathrm{HCl}($ 46a) $(60.4 \mathrm{mg}, 210 \mu \mathrm{mol}, 1.3$ Äq.) versetzt. Nach 20 h Rühren bei Raumtemperatur wurde die Reaktionslösung mit Essigester $(20 \mathrm{~mL})$, Wasser $(20 \mathrm{~mL})$ sowie gesättigter $\mathrm{NaHCO}_{3}$-Lösung $(20 \mathrm{~mL})$ versetzt und anschließend mit Essigester $(4 \times 60 \mathrm{~mL})$ extrahiert. Die vereinigten organischen Phasen wurden mit gesättigter NaCl-Lösung $(4 \times 40 \mathrm{~mL})$ gewaschen, über $\mathrm{MgSO}_{4}$ getrocknet und das Lösungsmittel im Vakuum entfernt. Säulenchromatographie an Kieselgel $\left(\mathrm{CH}_{2} \mathrm{Cl}_{2} /\right.$ $\mathrm{MeOH}=10: 1)$ lieferte die Titelverbindung $(+)-(1 S)-48$ als weißen Feststoff $(81.2 \mathrm{mg}$, $152 \mu \mathrm{mol}, 95 \%)$.

$\mathbf{R}_{f}=0.29\left(\mathrm{CH}_{2} \mathrm{Cl}_{2} / \mathrm{MeOH}=10: 1\right)$.

$[\alpha]_{\mathbf{D}}^{20}=+13.3^{\circ}(\mathrm{c}=0.24, \mathrm{MeOH})$.

UV (MeOH): $\lambda_{\max }(\lg \varepsilon)=206.5 \mathrm{~nm}$ (4.757), 245.0 (4.360), 301.0 (4.486), 340.5 (4.423).

IR $(\mathrm{KBr}): \widetilde{v}\left(\mathrm{~cm}^{-1}\right)=3260,2930,1623,1587,1515,1457,1404,1287,1266,1231$, 1178, 1129, 1028, 842, 801, 756, 696.

${ }^{1} \mathrm{H}-\mathrm{NMR}\left(600 \mathrm{MHz}, \mathrm{CDCl}_{3}\right): \delta=0.94\left(\mathrm{t}, J=7.5 \mathrm{~Hz}, 3 \mathrm{H}, 11-\mathrm{H}_{3}\right), 1.68\left(\mathrm{~m}_{\mathrm{c}}, 1 \mathrm{H}\right.$, 10- $\mathrm{H}_{\mathrm{a}}$ ), $1.94\left(\mathrm{~m}_{\mathrm{c}}, 1 \mathrm{H}, 10-\mathrm{H}_{\mathrm{b}}\right), 2.37$ (s, $\left.6 \mathrm{H}, \mathrm{NMe}_{2}\right), 2.78$ (t, $\left.J=6.0 \mathrm{~Hz}, 2 \mathrm{H}, 2 "-\mathrm{H}_{2}\right)$, $3.60\left(\mathrm{~m}_{\mathrm{c}}, 1 \mathrm{H}, 1-\mathrm{H}\right), 4.12\left(\mathrm{t}, J=6.0 \mathrm{~Hz}, 2 \mathrm{H}, 1 "-\mathrm{H}_{2}\right), 4.47$ (dd, $J=10.2,2.0 \mathrm{~Hz}, 1 \mathrm{H}$, $\left.2-\mathrm{H}_{\mathrm{a}}\right), 4.64\left(\mathrm{~m}_{\mathrm{c}}, 1 \mathrm{H}, 2-\mathrm{H}_{\mathrm{b}}\right), 5.29\left(\mathrm{~m}_{\mathrm{c}}, 2 \mathrm{H}, \mathrm{OC}_{2} \mathrm{Ph}\right), 7.00(\mathrm{~d}, J=8.5,1.6 \mathrm{~Hz}, 1 \mathrm{H}$, 3'-H), 7.03 (dd, $\left.J=8.9,2.4 \mathrm{~Hz}, 1 \mathrm{H}, 6^{\prime}-\mathrm{H}\right), 7.13$ (d, $\left.J=2.4 \mathrm{~Hz}, 1 \mathrm{H}, 4^{\prime}-\mathrm{H}\right), 7.31-7.41$, 
7.45-7.58 (2 × m, 8 H, 7-H, 8-H, 7'-H, $5 \times$ Ph-H), $7.74(\mathrm{~d}, J=8.5 \mathrm{~Hz}, 1 \mathrm{H}, 9-\mathrm{H}), 8.18$ ( $\left.\mathrm{s}_{\mathrm{br}}, 1 \mathrm{H}, 4-\mathrm{H}\right), 8.33(\mathrm{~d}, J=8.5 \mathrm{~Hz}, 1 \mathrm{H}, 6-\mathrm{H}), 9.42(\mathrm{~s}, 1 \mathrm{H}, \mathrm{NH})$.

${ }^{13}$ C-NMR (150 MHz, $\left.\mathrm{CDCl}_{3}\right): \delta=11.0(\mathrm{C}-11), 27.6(\mathrm{C}-10), 41.3(\mathrm{C}-1), 45.9\left(\mathrm{NMe}_{2}\right)$, 56.4 (C-2), 58.4 (C-2"), 66.5 (C-1"), $70.3\left(\mathrm{OCH}_{2} \mathrm{Ph}\right), 98.3$ (C-4), 103.6 (C-4'), 105.8 (C-3'), 112.6 (C-7'), 117.1 (C-6'), 121.1 (C-9b), 122.9 (C-9), 123.5 (C-6), 123.7 (C-7), 123.8 (C-5a), $127.1(\mathrm{C}-8), 127.6\left(2 \times \mathrm{Ph}^{-} \mathrm{C}_{o}\right), 127.9\left(\mathrm{Ph}-\mathrm{C}_{p}\right), 128.3\left(\mathrm{C}-3 \mathrm{a}^{\prime}\right), 128.6$ $\left(2 \times \mathrm{Ph}_{-} \mathrm{C}_{m}\right), 129.9,131.0,131.2\left(\mathrm{C}-2\right.$ ', C-7a', C-9a), $137.0\left(\mathrm{Ph}-\mathrm{C}_{i}\right), 140.9(\mathrm{C}-3 \mathrm{a})$, $153.8\left(\mathrm{C}-5^{\prime}\right), 154.8(\mathrm{C}-5), 160.4(\mathrm{C}=\mathrm{O})$.

MS (ESI): $m / z(\%)=1067.5(6)[2 \mathrm{M}+\mathrm{H}]^{+}, 534.3(100)[\mathrm{M}+\mathrm{H}]^{+}$.

$\mathbf{C}_{34} \mathbf{H}_{35} \mathbf{N}_{3} \mathbf{O}_{3}$ (533.66). $\quad$ ber.: 534.2751 gef.: $534.2751[\mathrm{M}+\mathrm{H}]^{+}(\mathrm{ESI}-\mathrm{HRMS})$.

\section{$3.5(+)-\{(1 S)-3-[(5-(2-(N, N$-dimethylamino $)$ ethoxy $)$ indol-2-yl)carbonyl]-1- ethyl)-5-hydroxy-1,2-dihydro-3H-benz $[e]$ indol\} $((+)-(1 S)-49)$}

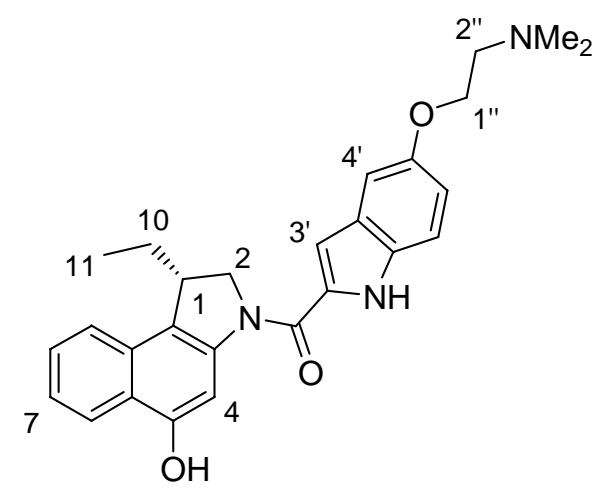

Eine Suspension des Benzylethers (+)-(1S)-48 (65.0 mg, $122 \mu \mathrm{mol}, 1.0$ Äq.) in THF $(4.0 \mathrm{~mL})$ wurde bei Raumtemperatur mit Palladium auf Aktivkohle (10\%-ig, $26 \mathrm{mg}$, $24 \mu \mathrm{mol}, 0.20$ Äq. bez. Pd) und Ammoniumformiat ( $25 \%$ aq.-Lösung, $0.26 \mathrm{~mL}$ ) versetzt. Die Reaktionsmischung wurde $1 \mathrm{~h}$ bei Raumtemperatur gerührt, der Feststoff über Celite abfiltriert und gründlich mit Methanol $(300 \mathrm{~mL})$ gewaschen. Das Filtrat wurde im Vakuum eingeengt. Säulenchromatographische Reinigung an Kieselgel $\left(\mathrm{CH}_{2} \mathrm{Cl}_{2} / \mathrm{MeOH}=5: 1\right)$ lieferte die Zielverbindung $(+)-(1 S)-49$ als gelben Feststoff (51.9 mg, $117 \mu \mathrm{mol}, 96 \%$ ).

$\mathbf{R}_{f}=0.27\left(\mathrm{CH}_{2} \mathrm{Cl}_{2} / \mathrm{MeOH}=5: 1\right)$. 
$[\alpha]_{\mathrm{D}}^{20}=+15.0^{\circ}(\mathrm{c}=0.26, \mathrm{MeOH})$.

UV $(\mathrm{MeOH}): \lambda_{\max }(\lg \varepsilon)=202.0 \mathrm{~nm}$ (4.504), 204.5 (4.505), 242.5 (4.166), 303.0 (4.167), 344.5 (4.192).

IR (KBr): $\widetilde{v}\left(\mathrm{~cm}^{-1}\right)=3406,2961,2825,1651,1607,1518,1386,1266,1232,790$.

${ }^{1}$ H-NMR $\left(300 \mathrm{MHz}\right.$, DMSO-d $\left.{ }_{6}\right): \delta=0.84\left(\mathrm{t}, J=7.4 \mathrm{~Hz}, 3 \mathrm{H}, 11-\mathrm{H}_{3}\right), 1.51-1.66(\mathrm{~m}$, $\left.1 \mathrm{H}, 10-\mathrm{H}_{\mathrm{a}}\right), 1.75-1.89\left(\mathrm{~m}, 1 \mathrm{H}, 10-\mathrm{H}_{\mathrm{b}}\right), 2.35\left(\mathrm{~s}, 6 \mathrm{H}, \mathrm{NMe}_{2}\right), 2.81(\mathrm{t}, J=5.8 \mathrm{~Hz}, 2 \mathrm{H}$, 2"- $\left.\mathrm{H}_{2}\right), 3.74\left(\mathrm{~m}_{\mathrm{c}}, 1 \mathrm{H}, 1-\mathrm{H}\right), 4.12\left(\mathrm{t}, J=5.8 \mathrm{~Hz}, 2 \mathrm{H}, 1 "-\mathrm{H}_{2}\right), 4.32(\mathrm{dd}, J=10.6,2.0 \mathrm{~Hz}$, $\left.1 \mathrm{H}, 2-\mathrm{H}_{\mathrm{a}}\right), 4.68\left(\mathrm{dd}, J=10.6,9.6 \mathrm{~Hz}, 1 \mathrm{H}, 2-\mathrm{H}_{\mathrm{b}}\right), 6.92\left(\mathrm{dd}, J=9.0,2.2 \mathrm{~Hz}, 1 \mathrm{H}, 6{ }^{\prime}-\mathrm{H}\right)$, $7.10\left(\mathrm{~d}, \quad J=1.8 \mathrm{~Hz}, \quad 1 \mathrm{H}, \quad 3^{\prime}-\mathrm{H}\right), 7.17$ (d, $\left.J=2.4 \mathrm{~Hz}, 1 \mathrm{H}, \quad 4^{\prime}-\mathrm{H}\right), 7.33$ (dd, $2 \times J=8.4 \mathrm{~Hz}, 1 \mathrm{H}, 7-\mathrm{H}), 7.40\left(\mathrm{~d}, J=9.0 \mathrm{~Hz}, 1 \mathrm{H}, 7^{\prime}-\mathrm{H}\right), 7.49(\mathrm{dd}, 2 \times J=8.4,1.0 \mathrm{~Hz}$, $1 \mathrm{H}, 8-\mathrm{H}), 7.78$ (d, $J=8.4 \mathrm{~Hz}, 1 \mathrm{H}, 9-\mathrm{H}), 7.96(\mathrm{~s}, 1 \mathrm{H}, 4-\mathrm{H}), 8.12$ (d, $J=8.4 \mathrm{~Hz}, 1 \mathrm{H}$, 6-H), 8.22 (s, $1 \mathrm{H}, \mathrm{OH}), 11.6\left(\mathrm{~s}_{\mathrm{br}}, 1 \mathrm{H}, \mathrm{NH}\right)$.

${ }^{13}$ C-NMR $\left(75 \mathrm{MHz}\right.$, DMSO-d $\left.\mathrm{d}_{6}\right): \delta=10.4$ (C-11), 27.1 (C-10), 39.9 (C-1), 45.0 ( $\mathrm{NMe}_{2}$ ), 56.0 (C-2), 57.3 (C-2"), 65.7 (C-1"), 100.4 (C-4), 103.4 (C-4'), 105.1 (C-3'), 113.1 (C-7'), 115.6 (C-6'), 119.1 (C-9b), 122.2 (C-5a), 122.7, 122.9, 123.0 (C-6, C-7, C-9), 126.7 (C-8), 127.5 (C-3a'), 129.8, 131.2, 131.6 (C-2', C-7a', C-9a), 140.9 (C-3a), 152.7, $153.1\left(\mathrm{C}-5, \mathrm{C}-5^{\prime}\right), 160.0(\mathrm{C}=\mathrm{O})$.

MS (ESI): $m / z(\%)=444.2(100)[\mathrm{M}+\mathrm{H}]^{+}$.

$\mathbf{C}_{27} \mathrm{H}_{29} \mathbf{N}_{3} \mathbf{O}_{3}$ (443.54). $\quad$ ber.: 444.22817

gef.: $444.22813[\mathrm{M}+\mathrm{H}]^{+}$(ESI-HRMS).

\section{Synthese der seco-CBI-DMAI-Derivate}

4.1 rac-\{3-(tert-Butyloxycarbonyl)-1-chlormethyl-5-hydroxy-1,2-dihydro$3 \mathrm{H}$-benz $[e]$ indol $\}$ (rac-55)

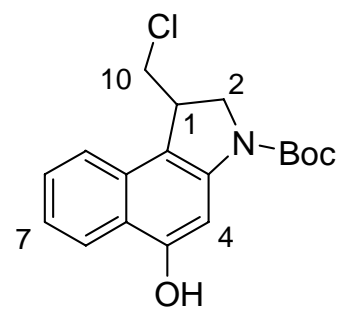


$\mathrm{Zu}$ einer Lösung des mit dem dechlorierten Benzylether verunreinigten Benzylethers rac-57 (100 mg, 236 $\mu$ mol, 1.0 Äq.) in THF $(10 \mathrm{~mL})$ wurden bei Raumtemperatur Palladium auf Aktivkohle (10\%-ig, $50 \mathrm{mg}, 47 \mu \mathrm{mol}, 0.2$ Äq. bez. Pd) und Ammoniumformiat ( $25 \%$ aq.-Lösung, $0.50 \mathrm{~mL}$ ) gegeben. Nach $35 \mathrm{~min}$ Rühren bei Raumtemperatur wurde über eine Celite-Schicht vom Feststoff abfiltriert, gründlich mit Aceton $(300 \mathrm{~mL})$ nachgespült und das Filtrat im Vakuum konzentriert. Säulenchromatographie an Kieselgel $(\mathrm{PE} / \mathrm{EE}=5: 1)$ lieferte ein Gemisch des dechlorierten Phenols und des Produktes rac-55 (77.0 mg, $230 \mu \mathrm{mol}, 97 \%$ ).

$\mathbf{R}_{f}=0.30(\mathrm{PE} / \mathrm{EE}=5: 1)$.

${ }^{1}$ H-NMR $\left(200 \mathrm{MHz}, \mathrm{CDCl}_{3}\right): \delta=1.62\left(\mathrm{~s}, 9 \mathrm{H}, \mathrm{C}\left(\mathrm{CH}_{3}\right)_{3}\right), 3.41(\mathrm{dd}, 2 \times J=11.0 \mathrm{~Hz}$, $\left.1 \mathrm{H}, 10-\mathrm{H}_{\mathrm{a}}\right), 3.90-4.00\left(\mathrm{~m}, 2 \mathrm{H}, 1-\mathrm{H}, 10-\mathrm{H}_{\mathrm{b}}\right), 4.10\left(\mathrm{dd}, 2 \times J=11.0 \mathrm{~Hz}, 1 \mathrm{H}, 2-\mathrm{H}_{\mathrm{a}}\right)$, $4.26\left(\mathrm{~d}, J=11.0 \mathrm{~Hz}, 1 \mathrm{H}, 2-\mathrm{H}_{\mathrm{b}}\right), 6.61\left(\mathrm{~s}_{\mathrm{br}}, 1 \mathrm{H}, \mathrm{OH}\right), 7.31(\mathrm{ddd}, 2 \times J=8.0,1.0 \mathrm{~Hz}$, 7-H), 7.47 (ddd, $2 \times J=8.0,1.0 \mathrm{~Hz}, 1 \mathrm{H}, 8-\mathrm{H}), 7.61(\mathrm{~d}, J=8.0 \mathrm{~Hz}, 1 \mathrm{H}, 9-\mathrm{H}), 7.78$ $\left(\mathrm{s}_{\mathrm{br}}, 1 \mathrm{H}, 4-\mathrm{H}\right), 8.20(\mathrm{~d}, J=8.0 \mathrm{~Hz}, 1 \mathrm{H}, 6-\mathrm{H})$.

${ }^{13} \mathrm{C}-\mathrm{NMR}\left(50 \mathrm{MHz}, \mathrm{CDCl}_{3}\right): \delta=28.5\left(\mathrm{C}\left(\mathrm{C}_{3}\right)_{3}\right), 41.7(\mathrm{C}-1), 46.5(\mathrm{C}-10), 53.1(\mathrm{C}-2)$, $81.8\left(\underline{\mathrm{C}}\left(\mathrm{CH}_{3}\right)_{3}\right), 99.1(\mathrm{C}-4), 114.0(\mathrm{C}-9 \mathrm{~b}), 121.5$ (C-5a), 121.7, 122.7, 123.6 (C-6, C-7, C-9), 127.5 (C-8), 130.3 (C-9a), 141.1 (C-3a), 153.3 (C=O), 154.1 (C-5).

$\mathrm{C}_{18} \mathrm{H}_{20} \mathrm{ClNO}_{3}$ (333.82).

\subsection{Trennung der Enantiomere von rac-\{3-(tert-Butyloxycarbonyl)-1- chlormethyl-5-hydroxy-1,2-dihydro-3H-benz[e]indol\} (rac-55)}

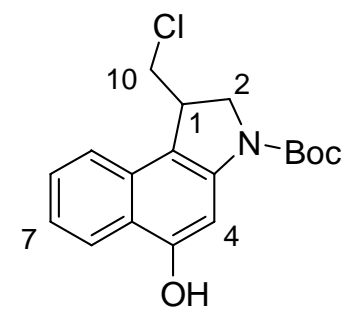

rac-55 wurde in einem Gemisch aus $n$-Hexan/ Isopropanol $=1: 1$ gelöst. Je $0.8 \mathrm{~mL}$ dieser Lösung (Konzentration: $23 \mathrm{mg} / \mathrm{mL}$ ) wurde in das präparative HPLC-System (Säule: Chiralpak ${ }^{\circledR}$ IA, $250 \times 20 \mathrm{~mm}$, Partikelgröße: $5 \mu \mathrm{m}$, mobile Phase: $n$-Hexan / Isopropanol $=97: 3$, Fluss: $18 \mathrm{~mL} \mathrm{~min}^{-1}$, Druck: $5.7 \mathrm{MPa}$ ) injiziert. Fraktioniertes Auffangen des Eluates (UV-Detektor: $\lambda=254 \mathrm{~nm}$ ) lieferte die Enantiomere $(+)-(1 R)-55$ und $(-)-(1 S)-55$. 


\section{Analytische Daten für $(+)-(1 R)-55:$}

HPLC (präparativ): $t_{\mathrm{R}}: \quad 12.9 \mathrm{~min}$

Fraktion: $12.0-14.0 \mathrm{~min}$

HPLC (analytisch): Säule: Chiralcel OD

Eluens: $\quad 2 \%$ Isopropanol in $n$-Hexan

Fluss: $\quad 0.8 \mathrm{~mL} \mathrm{~min}^{-1}$

$t_{\mathrm{R}}: \quad 11.4 \mathrm{~min}, 99.9 \%$ ee.

$\mathbf{R}_{\boldsymbol{f}}=0.30(\mathrm{PE} / \mathrm{EE}=5: 1)$.

$[\alpha]_{\mathrm{D}}^{20}=+48.6^{\circ}\left(\mathrm{c}=0.28, \mathrm{CHCl}_{3}\right)$.

${ }^{1}$ H-NMR $\left(200 \mathrm{MHz}, \mathrm{CDCl}_{3}\right): \delta=1.62\left(\mathrm{~s}, 9 \mathrm{H}, \mathrm{C}\left(\mathrm{CH}_{3}\right)_{3}\right), 3.41(\mathrm{dd}, 2 \times J=11.0 \mathrm{~Hz}$, $\left.1 \mathrm{H}, 10-\mathrm{H}_{\mathrm{a}}\right), 3.90-4.00\left(\mathrm{~m}, 2 \mathrm{H}, 1-\mathrm{H}, 10-\mathrm{H}_{\mathrm{b}}\right), 4.10\left(\mathrm{dd}, 2 \times J=11.0 \mathrm{~Hz}, 1 \mathrm{H}, 2-\mathrm{H}_{\mathrm{a}}\right)$, $4.26\left(\mathrm{~d}, J=11.0 \mathrm{~Hz}, 1 \mathrm{H}, 2-\mathrm{H}_{\mathrm{b}}\right), 6.61(\mathrm{~s} \mathrm{br}, 1 \mathrm{H}, \mathrm{OH}), 7.31(\mathrm{dd}, 2 \times J=8.0,1.0 \mathrm{~Hz}$, 7-H), $7.47(\mathrm{dd}, 2 \times J=8.0,1.0 \mathrm{~Hz}, 1 \mathrm{H}, 8-\mathrm{H}), 7.61(\mathrm{~d}, J=8.0 \mathrm{~Hz}, 1 \mathrm{H}, 9-\mathrm{H}), 7.78\left(\mathrm{~s}_{\mathrm{br}}\right.$, $1 \mathrm{H}, 4-\mathrm{H}), 8.20$ (d, $J=8.0 \mathrm{~Hz}, 1 \mathrm{H}, 6-\mathrm{H})$.

${ }^{13} \mathrm{C}-\mathrm{NMR}\left(50 \mathrm{MHz}, \mathrm{CDCl}_{3}\right): \delta=28.5\left(\mathrm{C}\left(\underline{\mathrm{CH}}_{3}\right)_{3}\right), 41.7(\mathrm{C}-1), 46.5$ (C-10), 53.1 (C-2), $81.8\left(\underline{\mathrm{C}}\left(\mathrm{CH}_{3}\right)_{3}\right), 99.1$ (C-4), 114.0 (C-9b), 121.5 (C-5a), 121.7, 122.7, 123.6 (C-6, C-7, C-9), 127.5 (C-8), 130.3 (C-9a), 141.1 (C-3a), 153.3 (C=O), 154.1 (C-5).

$\mathrm{C}_{18} \mathrm{H}_{20} \mathrm{CINO}_{3}$ (333.82).

\section{Analytische Daten für (-)-(1S)-55:}

HPLC (präparativ): $t_{\mathrm{R}}: \quad 15.3 \mathrm{~min}$

Fraktion: $15.0-17.0 \mathrm{~min}$

HPLC (analytisch): Säule: Chiralcel OD

Eluens: $\quad 2 \%$ Isopropanol in $n$-Hexan

Fluss: $\quad 0.8 \mathrm{~mL} \mathrm{~min}^{-1}$

$t_{\mathrm{R}}: \quad 15.2 \mathrm{~min}, 99.9 \%$ ee.

$[\alpha]_{\mathrm{D}}^{20}=-45.8^{\circ}\left(\mathrm{c}=0.24, \mathrm{CHCl}_{3}\right)$. 


\section{3 rac-\{1-Chlormethyl-3-[(5-(2-( $N, N$-dimethylamino $)$ ethoxy)indol-2-yl)- carbonyl]-5-hydroxy-1,2-dihydro-3H-benz[e]indol-Hydrochlorid\} (rac-56a)}

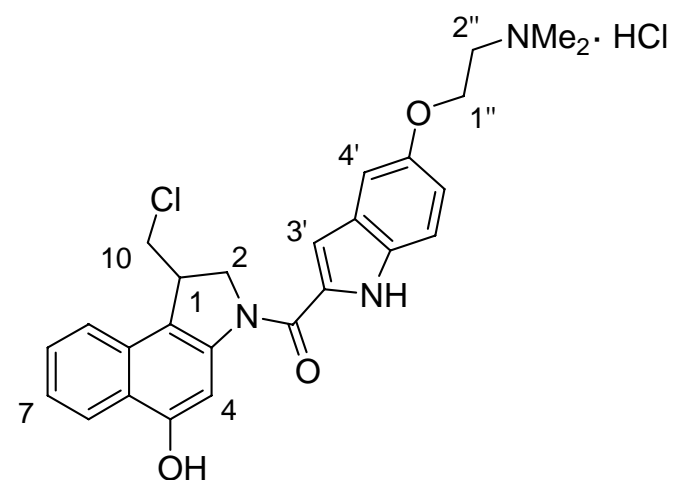

Das mit dem dechlorierten Phenol verunreinigte Phenol rac-55 (74.0 mg, 222 $\mu \mathrm{mol}$, 1.0 Äq.) wurde in $4 \mathrm{M} \mathrm{HCl} / \mathrm{EE}(5 \mathrm{~mL})$ suspendiert, die Reaktionsmischung $3 \mathrm{~h}$ bei Raumtemperatur gerührt und anschließend das Lösungsmittel im Vakuum entfernt. Der Rückstand wurde $1 \mathrm{~h}$ im Vakuum getrocknet, in DMF (3.5 mL) gelöst, die Lösung auf $0{ }^{\circ} \mathrm{C}$ gekühlt und mit $\mathrm{EDC} \cdot \mathrm{HCl}(130 \mathrm{mg}, 670 \mu \mathrm{mol}, 3.0 \mathrm{Äq}$.) sowie DMAI$\mathrm{CO}_{2} \mathrm{H} \cdot \mathrm{HCl}$ (46a) $(82.0 \mathrm{mg}, 290 \mu \mathrm{mol}, 1.3$ Äq.) versetzt. Nach $18 \mathrm{~h}$ Rühren bei Raumtemperatur wurde konzentrierte $\mathrm{HCl}(1 \mathrm{~mL})$ zugegeben und das Lösungsmittel im Vakuum entfernt. Säulenchromatographische Reinigung an Kieselgel $\left(\mathrm{CH}_{2} \mathrm{Cl}_{2} / \mathrm{MeOH}=5: 1, \quad 1 \%\right.$ konz. $\left.\mathrm{HCl}\right)$ lieferte das mit der entsprechenden dechlorierten Verbindung verunreinigte Produkt rac-56a (109 mg, $218 \mu \mathrm{mol}, 98 \%$ ) als hellgelben Feststoff.

$\mathbf{R}_{f}=0.29\left(\mathrm{CH}_{2} \mathrm{Cl}_{2} / \mathrm{MeOH}=5: 1,1 \%\right.$ konz. $\left.\mathrm{HCl}\right)$.

UV (MeOH): $\lambda_{\max }(\lg \varepsilon)=207.0 \mathrm{~nm}$ (4.361), 247.5 (4.127), 302.5 (4.162), 336.0 (4.082).

IR $(\mathrm{KBr}): \widetilde{v}\left(\mathrm{~cm}^{-1}\right)=3416,1626,1518,1471,1413,1284,1233,1178$.

${ }^{1}$ H-NMR $\left(300 \mathrm{MHz}, \mathrm{MeOH}-\mathrm{d}_{4}\right): \delta=2.99\left(\mathrm{~s}, 6 \mathrm{H}, \mathrm{NMe}_{2}\right), 3.55-3.65\left(\mathrm{~m}, 3 \mathrm{H}, 2 "-\mathrm{H}_{2}\right.$, $\left.10-\mathrm{H}_{\mathrm{a}}\right), 3.96\left(\mathrm{dd}, J=11.2,3.0 \mathrm{~Hz}, 1 \mathrm{H}, 10-\mathrm{H}_{\mathrm{b}}\right), 4.12\left(\mathrm{~m}_{\mathrm{c}}, 1 \mathrm{H}, 1-\mathrm{H}\right), 4.35(\mathrm{t}$, $\left.J=5.0 \mathrm{~Hz}, 2 \mathrm{H}, 1 "-\mathrm{H}_{2}\right), 4.61-4.67$ (m, $\left.2 \mathrm{H}, 2-\mathrm{H}_{2}\right), 7.04$ (dd, $\left.J=8.8,2.2 \mathrm{~Hz}, 1 \mathrm{H}, 6{ }^{\prime}-\mathrm{H}\right)$, 7.07 (s, $\left.1 \mathrm{H}, 3^{\prime}-\mathrm{H}\right), 7.26$ (d, $\left.J=2.2 \mathrm{~Hz}, 1 \mathrm{H}, 4^{\prime}-\mathrm{H}\right), 7.35$ (dd, $\left.2 \times J=7.6 \mathrm{~Hz}, 1 \mathrm{H}, 7-\mathrm{H}\right)$, $7.44\left(\mathrm{~d}, J=8.9 \mathrm{~Hz}, 1 \mathrm{H}, 7^{\prime}-\mathrm{H}\right), 7.51$ (dd, $\left.2 \times J=7.6 \mathrm{~Hz}, 1 \mathrm{H}, 8-\mathrm{H}\right), 7.76(\mathrm{~d}, J=8.6 \mathrm{~Hz}$, 
$1 \mathrm{H}, 9-\mathrm{H}), 7.81\left(\mathrm{~s}_{\mathrm{br}}, 1 \mathrm{H}, 4-\mathrm{H}\right), 8.19(\mathrm{~d}, J=8.6 \mathrm{~Hz}, 1 \mathrm{H}, 6-\mathrm{H}), 10.41(\mathrm{~s}, 1 \mathrm{H}, \mathrm{OH})$, $10.64\left(\mathrm{~s}_{\mathrm{br}}, 1 \mathrm{H}, \mathrm{NH}^{+}\right), 11.64(\mathrm{~s}, 1 \mathrm{H}, \mathrm{NH})$.

${ }^{13}$ C-NMR (75 MHz, MeOH-d 4 ): $\delta=43.5(\mathrm{C}-1), 43.9\left(\mathrm{NMe}_{2}\right), 47.5$ (C-10), $56.8(\mathrm{C}-2)$, 57.8 (C-2"), 63.7 (C-1"), 101.4 (C-4), 105.2 (C-4'), 107.2 (C-3'), 114.2 (C-7'), 117.1, 117.2 (C-5a, C-6'), 123.5 (C-9), 124.3, 124.5, 124.6 (C-6, C-7, C-9a), 128.6 (C-8), 129.2, 131.5, 132.5, 133.9 (C-2', C-3a', C-7a', C-9b), 143.1 (C-3a), 153.8 (C-5'), 155.8 (C-5), $162.6(\mathrm{C}=\mathrm{O})$.

MS (ESI): $m / z(\%)=926.7(32)[2 \mathrm{M}-\mathrm{HCl}-\mathrm{Cl}]^{+}, 464.1(100)[\mathrm{M}-\mathrm{Cl}]^{+}$.

$\mathbf{C}_{26} \mathbf{H}_{27} \mathbf{C l}_{2} \mathbf{N}_{3} \mathbf{O}_{3}$ (500.41). $\quad$ ber.: 464.1736 gef.: 464.1736, [M-Cl] ${ }^{+}$(ESI-HRMS).

\section{4 (-)-\{(1R)-1-Chlormethyl-3-[(5-(2-(,$N$-dimethylamino)ethoxy)indol-2- yl)carbonyl]-5-hydroxy-1,2-dihydro-3H-benz[e]indol-Hydrochlorid\} $((-)-(1 R)-56 a)$}

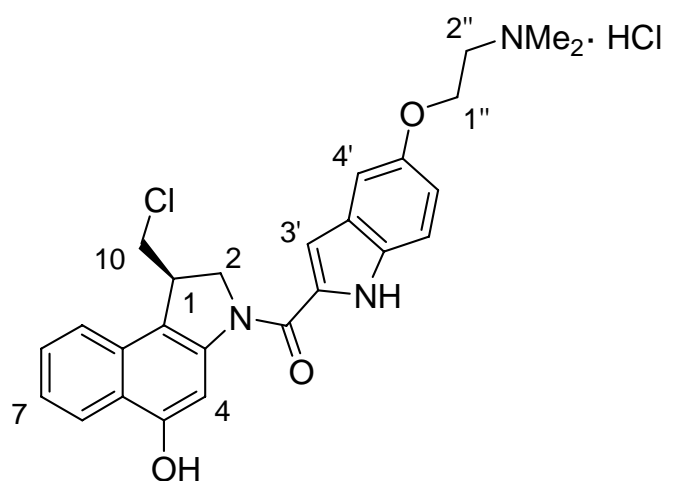

Das Phenol (+)-(1R)-55 (70.0 mg, $210 \mu \mathrm{mol}, 1.0$ Äq.) wurde in $4 \mathrm{M} \mathrm{HCl} / \mathrm{EE}(5 \mathrm{~mL})$ suspendiert, die Reaktionsmischung $3 \mathrm{~h}$ bei Raumtemperatur gerührt und anschließend das Lösungsmittel im Vakuum entfernt. Der Rückstand wurde $1 \mathrm{~h}$ im Vakuum getrocknet, in DMF $(3.5 \mathrm{~mL})$ gelöst, die Lösung auf $0{ }^{\circ} \mathrm{C}$ gekühlt und mit $\mathrm{EDC} \cdot \mathrm{HCl}$ (121 mg, $630 \mu \mathrm{mol}, 3.0$ Äq.) sowie DMAI- $\mathrm{CO}_{2} \mathrm{H} \cdot \mathrm{HCl}$ (46a) $(76.0 \mathrm{mg}, 273 \mu \mathrm{mol}$, 1.3 Äq.) versetzt. Nach $20 \mathrm{~h}$ Rühren bei Raumtemperatur wurde konzentrierte $\mathrm{HCl}$ (1.5 mL) zugegeben und das Lösungsmittel im Vakuum entfernt. Säulenchromatographische Reinigung an Kieselgel $\left(\mathrm{CH}_{2} \mathrm{Cl}_{2} / \mathrm{MeOH}=5: 1,1 \%\right.$ konz. $\left.\mathrm{HCl}\right)$ lieferte das Produkt (-)-(1R)-56a (95.4 mg, $191 \mu \mathrm{mol}, 91 \%)$ als hellgelben Feststoff.

$\mathbf{R}_{f}=0.36\left(\mathrm{CH}_{2} \mathrm{Cl}_{2} / \mathrm{MeOH}=5: 1,1 \%\right.$ konz. $\left.\mathrm{HCl}\right)$. 
$[\alpha]_{\mathbf{D}}^{20}=-18.0^{\circ}(\mathrm{c}=0.2, \mathrm{MeOH})$.

UV (MeOH): $\lambda_{\max }(\lg \varepsilon)=205.5 \mathrm{~nm}$ (4.420), 247.5 (4.186), 302.5 (4.239), 335.5 (4.164).

IR (KBr): $\widetilde{v}\left(\mathrm{~cm}^{-1}\right)=3396,2687,1626,1587,1517,1471,1411,1283,1233,1177$.

${ }^{1}$ H-NMR $\left(300 \mathrm{MHz}, \mathrm{DMSO}_{-} \mathrm{d}_{6}\right): \delta=2.83\left(\mathrm{~s}, 6 \mathrm{H}, \mathrm{NMe}_{2}\right), 3.48(\mathrm{t}, J=5.0 \mathrm{~Hz}, 2 \mathrm{H}$, 2"- $\mathrm{H}_{2}$ ), 3.84 (dd, $J=11.0,7.6 \mathrm{~Hz}, 1 \mathrm{H}, 10-\mathrm{H}_{\mathrm{a}}$ ), 4.03 (dd, $J=11.0,3.0 \mathrm{~Hz}, 1 \mathrm{H}, 10-\mathrm{H}_{\mathrm{b}}$ ), $4.22\left(\mathrm{~m}_{\mathrm{c}}, 1 \mathrm{H}, 1-\mathrm{H}\right), 4.39$ (t, $\left.J=5.0 \mathrm{~Hz}, 2 \mathrm{H}, 1 "-\mathrm{H}_{2}\right), 4.54$ (dd, $J=11.0,1.8 \mathrm{~Hz}, 1 \mathrm{H}$, 2- $\left.\mathrm{H}_{\mathrm{a}}\right), 4.79\left(\mathrm{dd}, J=11.0,9.4 \mathrm{~Hz}, 1 \mathrm{H}, 2-\mathrm{H}_{\mathrm{b}}\right), 7.00\left(\mathrm{dd}, J=8.8,2.2 \mathrm{~Hz}, 1 \mathrm{H}, 6{ }^{\prime}-\mathrm{H}\right), 7.11$ (s, $\left.1 \mathrm{H}, 3^{\prime}-\mathrm{H}\right), 7.26\left(\mathrm{~d}, J=2.2 \mathrm{~Hz}, 1 \mathrm{H}, 4^{\prime}-\mathrm{H}\right), 7.36(\mathrm{dd}, 2 \times J=7.4 \mathrm{~Hz}, 1 \mathrm{H}, 7-\mathrm{H}), 7.45$ $\left(\mathrm{d}, J=8.8 \mathrm{~Hz}, 1 \mathrm{H}, 7^{\prime}-\mathrm{H}\right), 7.52(\mathrm{dd}, 2 \times J=7.4 \mathrm{~Hz}, 1 \mathrm{H}, 8-\mathrm{H}), 7.84(\mathrm{~d}, J=8.4 \mathrm{~Hz}, 1 \mathrm{H}$, 9-H), 7.97 (s, $1 \mathrm{H}, 4-\mathrm{H}), 8.13$ (d, $J=8.4 \mathrm{~Hz}, 1 \mathrm{H}, 6-\mathrm{H}), 10.43$ (s, $1 \mathrm{H}, \mathrm{OH}), 10.93\left(\mathrm{~s}_{\mathrm{br}}\right.$, $\left.1 \mathrm{H}, \mathrm{NH}^{+}\right), 11.64(\mathrm{~s}, 1 \mathrm{H}, \mathrm{NH})$.

${ }^{13}$ C-NMR (75 MHz, DMSO-d ${ }_{6}$ ): $\delta=41.2(\mathrm{C}-1), 42.8\left(\mathrm{NMe}_{2}\right), 47.5$ (C-10), 54.9 (C-2), 55.4 (C-2"), 63.0 (C-1"), 100.3 (C-4), 104.0 (C-4'), 105.1 (C-3'), 113.2 (C-7'), 114.9 (C-6'), 115.6 (C-5a), 122.1, 122.7, 123.0, 123.1 (C-6, C-7, C-9, C-9a), 127.2 (C-8), 127.3 (C-3a'), 129.8, 131.3, 131.9 (C-2', C-7a', C-9b), 142.2 (C-3a), 152.0 (C-5'), $154.1(\mathrm{C}-5), 160.0(\mathrm{C}=\mathrm{O})$.

MS (ESI): $m / z(\%)=926.8(32)[2 \mathrm{M}-\mathrm{HCl}-\mathrm{Cl}]^{+}, 464.2(100)[\mathrm{M}-\mathrm{Cl}]^{+}$.

$\mathbf{C}_{26} \mathbf{H}_{27} \mathrm{Cl}_{2} \mathbf{N}_{3} \mathbf{O}_{3}(500.41)$. ber.: 464.1736 gef.: 464.1736, [M-Cl] $]^{+}$(ESI-HRMS).

\section{$4.5(+)-\{(1 S)-1-C h l o r m e t h y l-3-[(5-(2-(N, N$-dimethylamino)ethoxy)indol-2- yl)carbonyl]-5-hydroxy-1,2-dihydro-3H-benz[e]indol-Hydrochlorid\} $((+)-(1 S)-56 a)$}

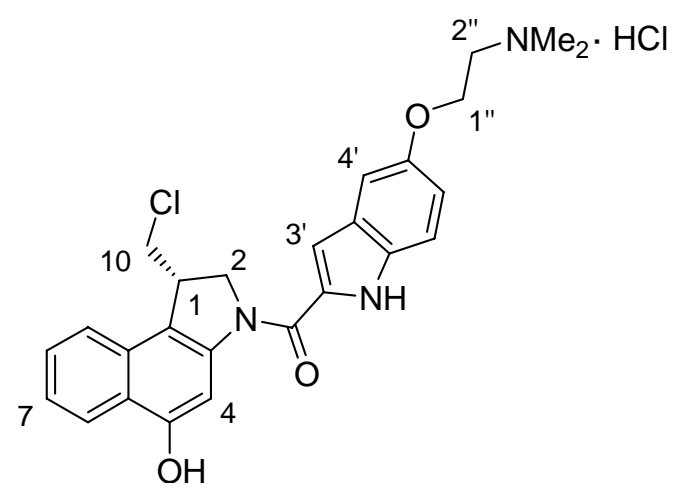


Das Phenol (-)-(1S)-55 (70.0 mg, $210 \mu \mathrm{mol}, 1.0$ Äq.) wurde in $4 \mathrm{M} \mathrm{HCl} / \mathrm{EE}(5 \mathrm{~mL})$ suspendiert, die Reaktionsmischung $3 \mathrm{~h}$ bei Raumtemperatur gerührt und anschließend das Lösungsmittel im Vakuum entfernt. Der Rückstand wurde $1 \mathrm{~h}$ im Vakuum getrocknet, in DMF $(3.5 \mathrm{~mL})$ gelöst, die Lösung auf $0{ }^{\circ} \mathrm{C}$ gekühlt und mit $\mathrm{EDC} \cdot \mathrm{HCl}$ (121 mg, $630 \mu \mathrm{mol}, 3.0$ Äq.) sowie DMAI-CO ${ }_{2} \mathrm{H} \cdot \mathrm{HCl}$ (46a) $(77.5 \mathrm{mg}, 273 \mu \mathrm{mol}$, 1.3 Äq.) versetzt. Nach $20 \mathrm{~h}$ Rühren bei Raumtemperatur wurde konzentrierte $\mathrm{HCl}$ $(0.5 \mathrm{~mL})$ zugegeben und das Lösungsmittel im Vakuum entfernt. Säulenchromatographische Reinigung an Kieselgel $\left(\mathrm{CH}_{2} \mathrm{Cl}_{2} / \mathrm{MeOH}=5: 1,1 \%\right.$ konz. $\left.\mathrm{HCl}\right)$ lieferte das Produkt (+)-(1S)-56a (93.2 mg, $186 \mu \mathrm{mol}, 89 \%)$ als hellgelben Feststoff, der anschließend mittels präparativer HPLC (s.u.) weiter aufgereinigt wurde.

HPLC (analytisch):

Säule: $\quad$ Kromasil 100 C18

\begin{tabular}{ccc}
\cline { 2 - 3 } Gradient: & Zeit $[\mathrm{min}]$ & $\mathrm{H}_{2} \mathrm{O}(0.06 \%$ konz. $\mathrm{HCl}) / \mathrm{MeOH}$ \\
\cline { 2 - 3 } & 0 & $60 / 40$ \\
$0-15$ & $60 / 40 \rightarrow 0 / 100$ \\
$15-22$ & $0 / 100$ \\
$22-23$ & $0 / 100 \rightarrow 60 / 40$ \\
$23-30$ & $60 / 40$ \\
\hline
\end{tabular}

Fluss: $\quad 0.8 \mathrm{~mL} \mathrm{~min}^{-1}$

$t_{\mathrm{R}}: \quad 12.8 \mathrm{~min}$

HPLC (präparativ):

Säule: $\quad$ Kromasil 100 C18

\begin{tabular}{lcc}
\cline { 2 - 3 } Gradient: & Zeit [min] & $\mathrm{H}_{2} \mathrm{O}(0.06 \%$ konz. $\mathrm{HCl}) / \mathrm{MeOH}$ \\
\cline { 2 - 3 } & 0 & $60 / 40$ \\
& $0-15$ & $60 / 40 \rightarrow 0 / 100$ \\
& $15-22$ & $0 / 100$ \\
& $22-23$ & $0 / 100 \rightarrow 60 / 40$ \\
Fluss: & $23-30$ & $60 / 40$ \\
$t_{\mathrm{R}}:$ & $18 \mathrm{~mL} \mathrm{\text {min}^{-1 }}$ \\
Fraktion: & $9.0-11.5 \mathrm{~min}$ & \\
\end{tabular}


$\mathbf{R}_{f}=0.42\left(\mathrm{CH}_{2} \mathrm{Cl}_{2} / \mathrm{MeOH}=5: 1,1 \%\right.$ konz. $\left.\mathrm{HCl}\right)$.

$[\alpha]_{\mathbf{D}}^{\mathbf{2 0}}=+20.2^{\circ}(\mathrm{c}=0.213, \mathrm{MeOH})$.

UV (MeOH): $\lambda_{\max }(\lg \varepsilon)=200.5 \mathrm{~nm}$ (4.627), 202.5 (4.632), 204.5 (4.634), 247.5 (4.367), 302.5 (4.454), 337.5 (4.365).

IR $(\mathrm{KBr}): \widetilde{v}\left(\mathrm{~cm}^{-1}\right)=3406,3190,2643,1623,1585,1517,1470,1410,1282,1232$, $1175,1118,1059,991,758$.

${ }^{1}$ H-NMR $\left(300 \mathrm{MHz}\right.$, DMSO-d $\left.\mathrm{d}_{6}\right): \delta=2.86\left(\mathrm{~s}, 6 \mathrm{H}, \mathrm{NMe}_{2}\right), 3.52(\mathrm{t}, J=5.0 \mathrm{~Hz}, 2 \mathrm{H}$, 2"- $\left.\mathrm{H}_{2}\right), 3.85$ (dd, $\left.J=11.2,8.0 \mathrm{~Hz}, 1 \mathrm{H}, 10-\mathrm{H}_{\mathrm{a}}\right), 4.03\left(\mathrm{dd}, J=11.2,3.0 \mathrm{~Hz}, 1 \mathrm{H}, 10-\mathrm{H}_{\mathrm{b}}\right.$ ), $4.22\left(\mathrm{~m}_{\mathrm{c}}, 1 \mathrm{H}, 1-\mathrm{H}\right), 4.38\left(\mathrm{t}, J=5.0 \mathrm{~Hz}, 2 \mathrm{H}, 1 "-\mathrm{H}_{2}\right), 4.55$ (dd, $J=10.8,1.6 \mathrm{~Hz}, 1 \mathrm{H}$, 2- $\left.\mathrm{H}_{\mathrm{a}}\right), 4.79\left(\mathrm{dd}, J=10.8,9.6 \mathrm{~Hz}, 1 \mathrm{H}, 2-\mathrm{H}_{\mathrm{b}}\right), 7.01\left(\mathrm{dd}, J=9.0,2.2 \mathrm{~Hz}, 1 \mathrm{H}, 6 \mathbf{6}^{\prime}-\mathrm{H}\right), 7.11$ (s, $\left.1 \mathrm{H}, 3^{\prime}-\mathrm{H}\right), 7.27\left(\mathrm{~d}, J=2.2 \mathrm{~Hz}, 1 \mathrm{H}, 4^{\prime}-\mathrm{H}\right), 7.37(\mathrm{dd}, 2 \times J=7.6 \mathrm{~Hz}, 1 \mathrm{H}, 7-\mathrm{H}), 7.45$ $\left(\mathrm{d}, J=9.0 \mathrm{~Hz}, 1 \mathrm{H}, 7^{\prime}-\mathrm{H}\right), 7.53(\mathrm{dd}, 2 \times J=7.6 \mathrm{~Hz}, 1 \mathrm{H}, 8-\mathrm{H}), 7.85(\mathrm{~d}, J=8.4 \mathrm{~Hz}, 1 \mathrm{H}$, 9-H), 7.97 (s, $1 \mathrm{H}, 4-\mathrm{H}), 8.13$ (d, $J=8.4 \mathrm{~Hz}, 1 \mathrm{H}, 6-\mathrm{H}), 10.41$ (s, $1 \mathrm{H}, \mathrm{OH}), 10.45$ ( $\mathrm{s}_{\mathrm{br}}$, $\left.1 \mathrm{H}, \mathrm{NH}^{+}\right), 11.65(\mathrm{~s}, 1 \mathrm{H}, \mathrm{NH})$.

${ }^{13}$ C-NMR (125 MHz, DMSO-d $\left.{ }_{6}\right): \delta=41.2(\mathrm{C}-1), 42.8\left(\mathrm{NMe}_{2}\right), 47.5$ (C-10), 54.9 (C-2), 55.4 (C-2"), 62.9 (C-1"), 100.3 (C-4), 104.0 (C-4'), 105.1 (C-3'), 113.2 (C-7'), 114.9 (C-5a), 115.5 (C-6'), 122.1 (C-9a), 122.7 (C-9), 123.0 (C-7), 123.1 (C-6), 127.2 (C-8), 127.3 (C-3a'), 129.8, 131.3, 131.9 (C-2', C-7a', C-9b), 142.1 (C-3a), 152.0 $\left(\mathrm{C}-5^{\prime}\right), 154.1(\mathrm{C}-5), 160.0(\mathrm{C}=\mathrm{O})$.

MS (ESI): $m / z(\%)=926.8(30)[2 \mathrm{M}-2 \mathrm{Cl}-\mathrm{H}]^{+}, 464.2(100)[\mathrm{M}-\mathrm{Cl}]^{+}$.

$\mathrm{C}_{26} \mathrm{H}_{27} \mathrm{Cl}_{2} \mathbf{N}_{3} \mathbf{O}_{3}(500.41)$. ber.: 464.1736 gef.: 464.1736, [M-Cl] $]^{+}$(ESI-HRMS). 


\section{6 (1S)-[1-Chlormethyl-3-[(5-(2-( $N, N$-dimethylamino)ethoxy)indol-2-yl)- carbonyl]-1,2-dihydro-3H-benz[e]indol-5-yl]-2,3,4,6-tetra-O-acetyl- $\beta$ - D-galactopyranosid ((1S)-73)}

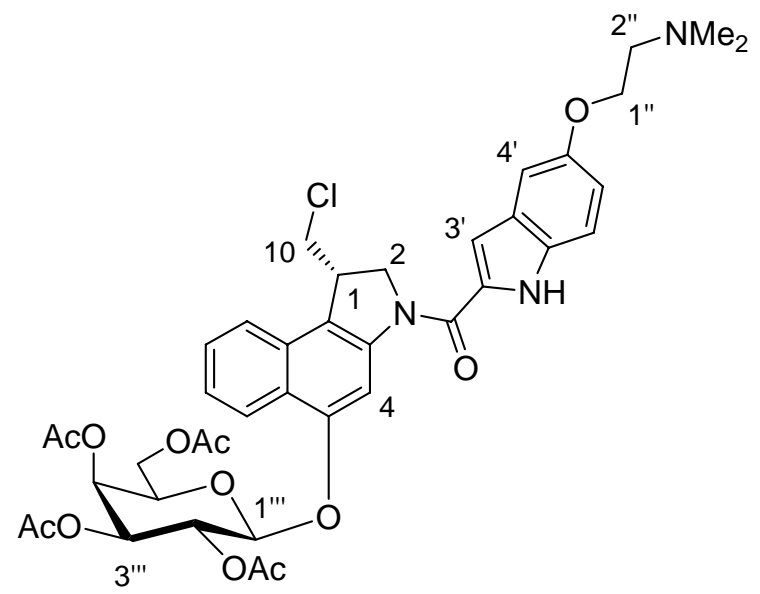

$\mathrm{Zu}$ einer Lösung des Phenols (-)-(1S)-55 (95.0 mg, $285 \mu \mathrm{mol}, 1.0$ Äq.) in absolutem $\mathrm{CH}_{2} \mathrm{Cl}_{2}(13 \mathrm{~mL})$ wurde aktiviertes Molsieb $4 \AA(0.61 \mathrm{~g})$ gegeben und $30 \mathrm{~min}$ bei Raumtemperatur gerührt. Nach Zugabe des $O$-(2,3,4,6-Tetra- $O$-acetyl- $\alpha$-D-galactopyranosyl)-trichloracetimidats (72) (147 mg, $299 \mu \mathrm{mol}, 1.05$ Äq.) wurde die Lösung auf $-10{ }^{\circ} \mathrm{C}$ gekühlt und langsam eine Lösung von $\mathrm{BF}_{3} \cdot \mathrm{OEt}_{2}(18.0 \mu \mathrm{L}, 143 \mu \mathrm{mol}$, 0.5 Äq.) in absolutem $\mathrm{CH}_{2} \mathrm{Cl}_{2}(1.5 \mathrm{~mL})$ zugetropft. Nach $3.5 \mathrm{~h}$ Rühren bei $-10{ }^{\circ} \mathrm{C}$ wurde weiteres $\mathrm{BF}_{3} \cdot \mathrm{OEt}_{2}\left(108 \mu \mathrm{L}, 855 \mu \mathrm{mol}, 3.0 \mathrm{Äq}\right.$.) in absolutem $\mathrm{CH}_{2} \mathrm{Cl}_{2}(1.3 \mathrm{~mL})$ hinzugefügt und anschließend auf Raumtemperatur erwärmt. Nach $5.5 \mathrm{~h}$ wurde das Reaktionsgemisch via Transferkanüle in einen zweiten Kolben überführt und so vom Molsieb abgetrennt. Das Molsieb wurde gründlich mit $\mathrm{CH}_{2} \mathrm{Cl}_{2}(2 \times 10 \mathrm{~mL})$ gewaschen und anschließend das Lösungsmittel im Vakuum entfernt. Der erhaltene Rückstand wurde $1 \mathrm{~h}$ im Vakuum getrocknet und in absolutem DMF $(14 \mathrm{~mL})$ aufgenommen. Die Lösung wurde auf $0{ }^{\circ} \mathrm{C}$ gekühlt und mit $\mathrm{EDC} \cdot \mathrm{HCl}(164 \mathrm{mg}, 855 \mu \mathrm{mol}, 3.0$ Äq.) sowie DMAI- $\mathrm{CO}_{2} \mathrm{H} \cdot \mathrm{HCl}$ (46a) (122 mg, $428 \mu \mathrm{mol}, 1.5$ Äq.) versetzt. Nach 21 h Rühren bei Raumtemperatur wurde die Reaktionslösung mit Essigester $(25 \mathrm{~mL})$, Wasser $(25 \mathrm{~mL})$ sowie gesättigter $\mathrm{NaHCO}_{3}$-Lösung $(25 \mathrm{~mL})$ versetzt und anschließend mit Essigester $(4 \times 50 \mathrm{~mL})$ extrahiert. Die vereinigten organischen Phasen wurden mit gesättigter $\mathrm{NaCl}$-Lösung $(4 \times 100 \mathrm{~mL})$ gewaschen, über $\mathrm{MgSO}_{4}$ getrocknet und das Lösungsmittel im Vakuum entfernt. Säulenchromatographische Reinigung an Kieselgel $\left(\mathrm{CH}_{2} \mathrm{Cl}_{2} / \mathrm{MeOH}=10: 1\right)$ lieferte das Produkt (1S)-73 (93.5 mg, $\left.118 \mu \mathrm{mol}, 41 \%\right)$ als gelben Feststoff. 
$\mathbf{R}_{f}=0.22\left(\mathrm{CH}_{2} \mathrm{Cl}_{2} / \mathrm{MeOH}=10: 1\right)$.

MS (ESI): $m / z(\%)=1588.5(26)[2 \mathrm{M}+\mathrm{H}]^{+}, 794.3(100)[\mathrm{M}+\mathrm{H}]^{+}$.

$\mathbf{C}_{40} \mathbf{H}_{44} \mathbf{C I N}_{3} \mathbf{O}_{12}$ (794.24). $\quad$ ber.: 794.2692 gef.: 794.2686, $[\mathrm{M}+\mathrm{H}]^{+}$(ESI-HRMS).

\section{7 (-)-\{(1S)-1-Chlormethyl-3-[(5-(2-( $N, N$-dimethylamino)ethoxy)indol-2- yl)carbonyl]-1,2-dihydro-3H-benz[e]indol-5-yl]- $\beta$-D-galactopyra- nosid\} ((-)-(1S)-54a)}

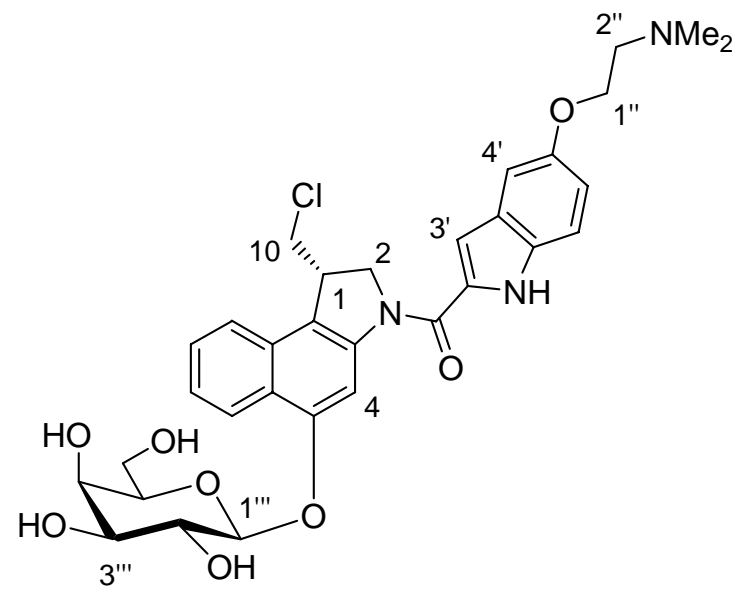

Das acetylgeschützte Galactosid (1S)-73 $(90.0 \mathrm{mg}, 113 \mu \mathrm{mol}, 1.0$ Äq.) wurde in absolutem Methanol $(6 \mathrm{~mL})$ gelöst und bei $0{ }^{\circ} \mathrm{C}$ mit NaOMe in Methanol $(42.0 \mu \mathrm{L}$ einer 5.4 M Lösung, $226 \mu$ mol, 2.0 Äq.) versetzt. Nach Erwärmen auf Raumtemperatur und $2 \mathrm{~h}$ Rühren bei dieser Temperatur wurde die Reaktionslösung mit Methanol $(1.5 \mathrm{~mL})$ sowie Wasser $(1.5 \mathrm{~mL})$ verdünnt und so lange saurer Ionentauscher (Amberlite-IR 120) hinzugegeben, bis die Lösung neutral war $(\mathrm{pH}=7)$. Der Ionenaustauscher wurde abgetrennt und mit Methanol $(2 \times 50 \mathrm{~mL})$ gewaschen. Die organischen Phasen wurden vereinigt, das Lösungsmittel im Vakuum entfernt und nach säulenchromatographischer Reinigung an Kieselgel $\left(\mathrm{CH}_{2} \mathrm{Cl}_{2} / \mathrm{MeOH}=1: 1\right)$ das Produkt (-)-(1S)-54a (45 mg, $72 \mu \mathrm{mol}, 64 \%)$ als hellgelber Feststoff erhalten.

$\mathbf{R}_{f}=0.22\left(\mathrm{CH}_{2} \mathrm{Cl}_{2} / \mathrm{MeOH}=1: 1\right)$.

$[\alpha]_{\mathrm{D}}^{20}=-8.1^{\circ}(\mathrm{c}=0.235$, DMSO $)$.

UV $\left(\mathrm{CH}_{3} \mathrm{CN}\right): \lambda_{\max }(\lg \varepsilon)=206.0 \mathrm{~nm}$ (4.651), 246.0 (4.349), 298.5 (4.517), 336.0 (4.455). 
IR $(\mathrm{KBr}): \widetilde{v}\left(\mathrm{~cm}^{-1}\right)=3407,2944,2871,1624,1590,1517,1461,1413,1266,1231$, $1178,1077$.

${ }^{1}$ H-NMR (600 MHz, DMSO-d $\left.{ }_{6}\right): \delta=2.24\left(\mathrm{~s}, 6 \mathrm{H}, \mathrm{NMe}_{2}\right), 2.66(\mathrm{t}, J=6.0 \mathrm{~Hz}, 2 \mathrm{H}$,

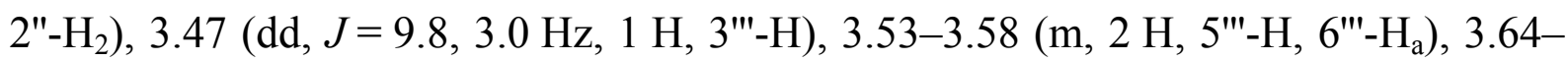
3.69 (m, 1 H, 6"'-H $)$, 3.76-3.83 (m, 2 H, 4"'-H, 2"'-H), 3.92 (dd, $J=11.2,7.6$ Hz, 1 H, $\left.10-\mathrm{H}_{\mathrm{a}}\right), 4.05-4.08\left(\mathrm{~m}, 3 \mathrm{H}, 1 "-\mathrm{H}_{2}, 10-\mathrm{H}_{\mathrm{b}}\right), 4.30\left(\mathrm{~m}_{\mathrm{c}}, 1 \mathrm{H}, 1-\mathrm{H}\right), 4.55-4.61(\mathrm{~m}, 3 \mathrm{H}$, $\left.2 \times \mathrm{OH}, 2-\mathrm{H}_{\mathrm{a}}\right), 4.82\left(\mathrm{dd}, J=10.8,9.6 \mathrm{~Hz}, 1 \mathrm{H}, 2-\mathrm{H}_{\mathrm{b}}\right), 4.93\left(\mathrm{~d}, J=7.8 \mathrm{~Hz}, 1 \mathrm{H}, 1{ }^{\prime \prime}-\mathrm{H}\right)$, $5.31(\mathrm{~s} b r, 1 \mathrm{H}, \mathrm{OH}), 6.92\left(\mathrm{dd}, J=9.0,2.6 \mathrm{~Hz}, 1 \mathrm{H}, 6{ }^{\prime}-\mathrm{H}\right), 7.10(\mathrm{~d}, J=2.0 \mathrm{~Hz}, 1 \mathrm{H}$, 3'-H), 7.17 (d, $\left.J=2.6 \mathrm{~Hz}, 1 \mathrm{H}, 4^{\prime}-\mathrm{H}\right), 7.40$ (d, $\left.J=9.0 \mathrm{~Hz}, 1 \mathrm{H}, 7^{\prime}-\mathrm{H}\right), 7.43$ (dd, $2 \times J=8.6 \mathrm{~Hz}, 1 \mathrm{H}, 7-\mathrm{H}), 7.58(\mathrm{dd}, 2 \times J=8.6 \mathrm{~Hz}, 1 \mathrm{H}, 8-\mathrm{H}), 7.92(\mathrm{~d}, J=8.6 \mathrm{~Hz}, 1 \mathrm{H}$, 9-H), 8.23 ( $\left.\mathrm{s}_{\mathrm{br}}, 1 \mathrm{H}, 4-\mathrm{H}\right), 8.35$ (d, $\left.J=8.6 \mathrm{~Hz}, 1 \mathrm{H}, 6-\mathrm{H}\right), 11.63$ (s, $\left.1 \mathrm{H}, \mathrm{NH}\right)$.

${ }^{13}$ C-NMR (125 MHz, DMSO-d 6 ): $\delta=41.2(\mathrm{C}-1), 45.5\left(\mathrm{NMe}_{2}\right), 47.4(\mathrm{C}-10), 54.9$ (C-2), 57.8 (C-2"), 59.5 (C-6"'), 66.3 (C-1"), 67.5 (C-4"'), 70.5 (C-2'"), 73.2 (C-3"'), 75.1 (C-5"'), 101.8 (C-4), 102.1 (C-1"'), 103.2 (C-4'), 105.2 (C-3'), 113.1 (C-7'), 115.8 (C-6'), 117.9 (C-5a), 122.7 (C-9), 122.9 (C-9b), 123.3 (C-6), 123.7 (C-7), 127.4 (C-3a', C-8), 129.4 (C-9a), 130.8, 131.6 (C-2', C-7a'), 142.1 (C-3a), 153.0 (C-5'), 153.7 (C-5), $160.2(\mathrm{C}=\mathrm{O})$.

MS (ESI): $m / z(\%)=1275.0(14)[2 \mathrm{M}+\mathrm{Na}]^{+}, 1252.8(36)[2 \mathrm{M}+\mathrm{H}]^{+}, 939.4(21)$ $[3 \mathrm{M}+2 \mathrm{H}]^{2+}, 626.2(100)[\mathrm{M}+\mathrm{H}]^{+}$.

$\mathbf{C}_{32} \mathrm{H}_{36} \mathrm{ClN}_{3} \mathbf{O}_{\mathbf{8}}(626.10)$. ber.: 626.2269

gef.: $626.2264,[\mathrm{M}+\mathrm{H}]^{+}$(ESI-HRMS). 


\section{Synthese des (1S)-seco-CBI-MPI-Drugs}

\section{1 (+)-\{(1S)-1-(10-Chlormethyl)-5-hydroxy-3-[(5-(1-methylpiperidin-4-} yl-methoxy)indol-2-yl)carbonyl]-1,2-dihydro-3H-benz[e]indol-Hydrochlorid\} ((+)-(1S)-56b)

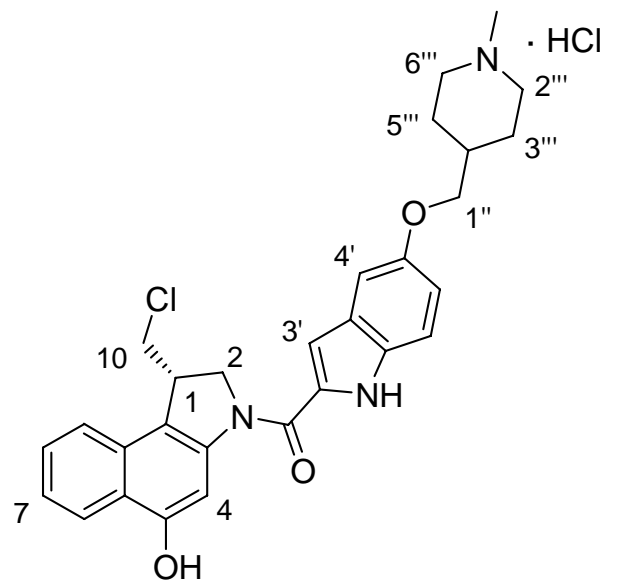

Das Phenol (-)-(1S)-55 (20.0 mg, $60.0 \mu \mathrm{mol}, 1.0$ Äq.) wurde in $4 \mathrm{M} \mathrm{HCl} / \mathrm{EE}(5 \mathrm{~mL})$ suspendiert, die Reaktionsmischung $3 \mathrm{~h}$ bei Raumtemperatur gerührt und anschließend das Lösungsmittel im Vakuum entfernt. Der Rückstand wurde $1 \mathrm{~h}$ im Vakuum getrocknet, in DMF $(3 \mathrm{~mL})$ gelöst, die Lösung auf $0{ }^{\circ} \mathrm{C}$ gekühlt und mit $\mathrm{EDC} \cdot \mathrm{HCl}$ (23.0 mg, $120 \mu \mathrm{mol}, 2.0$ Äq.) sowie $\mathrm{MPI}-\mathrm{CO}_{2} \mathrm{H} \cdot \mathrm{HCl}$ (46b) $(25.3 \mathrm{mg}, 77.9 \mu \mathrm{mol}$, 1.3 Äq.) versetzt. Nach 19 h Rühren bei Raumtemperatur wurde konzentrierte $\mathrm{HCl}$ $(0.5 \mathrm{~mL})$ zugegeben und das Lösungsmittel im Vakuum entfernt. Säulenchromatographische Reinigung an Kieselgel $\left(\mathrm{CH}_{2} \mathrm{Cl}_{2} / \mathrm{MeOH}=5: 1,1 \%\right.$ konz. $\left.\mathrm{HCl}\right)$ gefolgt von einer Reinigung mittels präparativer HPLC (s.u.) lieferte (+)-(1S)-56b (20.4 mg, $37.7 \mu \mathrm{mol}, 63 \%$ ) als hellgelben Feststoff.

HPLC (analytisch):

Säule: $\quad$ Kromasil 100 C18

\begin{tabular}{|c|c|c|}
\hline \multirow[t]{6}{*}{ Gradient: } & Zeit [min] & $\mathrm{H}_{2} \mathrm{O}(0.06 \%$ konz. $\mathrm{HCl}) / \mathrm{MeOH}$ \\
\hline & 0 & $50 / 50$ \\
\hline & $0-15$ & $50 / 50 \rightarrow 0 / 100$ \\
\hline & $15-22$ & $0 / 100$ \\
\hline & $22-23$ & $0 / 100 \rightarrow 50 / 50$ \\
\hline & $23-30$ & $50 / 50$ \\
\hline
\end{tabular}


Fluss: $\quad 0.8 \mathrm{~mL} \mathrm{~min}^{-1}$

$t_{\mathrm{R}}$ :

$11.3 \mathrm{~min}$

HPLC (präparativ):

Säule: $\quad$ Kromasil 100 C18

Gradient:

\begin{tabular}{cc}
\hline Zeit $[\mathrm{min}]$ & $\mathrm{H}_{2} \mathrm{O}(0.06 \%$ konz. $\mathrm{HCl}) / \mathrm{MeOH}$ \\
\hline 0 & $50 / 50$ \\
$0-20$ & $50 / 50 \rightarrow 25 / 75$ \\
$20-23$ & $0 / 100$ \\
$23-25$ & $0 / 100 \rightarrow 50 / 50$ \\
$25-30$ & $50 / 50$ \\
\hline
\end{tabular}

Fluss: $\quad 18 \mathrm{~mL} \mathrm{~min}^{-1}$

$t_{\mathrm{R}}: \quad 14 \mathrm{~min}$

Fraktion: $\quad 13.2-16.6 \mathrm{~min}$

$\mathbf{R}_{\boldsymbol{f}}=0.38\left(\mathrm{CH}_{2} \mathrm{Cl}_{2} / \mathrm{MeOH}=5: 1,1 \%\right.$ konz. $\left.\mathrm{HCl}\right)$.

UV $(\mathrm{MeOH}): \lambda_{\max }(\lg \varepsilon)=205.5 \mathrm{~nm}$ (4.567), 247.5 (4.316), 303.0 (4.365), 335.0 (4.300).

IR $(\mathrm{KBr}): \widetilde{v}\left(\mathrm{~cm}^{-1}\right)=3405,2952,2677,1624,1587,1517,1411,1232,759$.

${ }^{1}$ H-NMR $\left.(600 \text { MHz, DMSO-d })_{6}\right): \delta=1.61\left(\mathrm{~m}_{\mathrm{c}}, 2 \mathrm{H}, 33^{\prime \prime}-\mathrm{H}_{\mathrm{ax}}, 5^{\prime \prime}-\mathrm{H}_{\mathrm{ax}}\right), 1.93-2.08(\mathrm{~m}$,

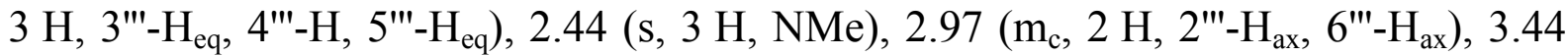
$\left(\mathrm{m}_{\mathrm{c}}, 2 \mathrm{H}, 2\right.$ "'- $-\mathrm{H}_{\mathrm{eq}}, 6$ 6"'-H $\left._{\mathrm{eq}}\right), 3.84\left(\mathrm{dd}, J=11.3,7.8 \mathrm{~Hz}, 1 \mathrm{H}, 10-\mathrm{H}_{\mathrm{a}}\right), 3.90\left(\mathrm{~m}_{\mathrm{c}}, 2 \mathrm{H}\right.$, $\left.1 "-\mathrm{H}_{2}\right), 4.03$ (dd, $\left.J=11.3,3.3 \mathrm{~Hz}, 1 \mathrm{H}, 10-\mathrm{H}_{\mathrm{b}}\right), 4.22\left(\mathrm{~m}_{\mathrm{c}}, 1 \mathrm{H}, 1-\mathrm{H}\right), 4.55$ (dd, $J=10.8$, $\left.2.0 \mathrm{~Hz}, 1 \mathrm{H}, 2-\mathrm{H}_{\mathrm{a}}\right), 4.78\left(\mathrm{dd}, J=10.8,9.4 \mathrm{~Hz}, 1 \mathrm{H}, 2-\mathrm{H}_{\mathrm{b}}\right), 6.93(\mathrm{dd}, J=9.0,2.2 \mathrm{~Hz}$, $\left.1 \mathrm{H}, 6^{\prime}-\mathrm{H}\right), 7.07$ (s, $\left.1 \mathrm{H}, 3^{\prime}-\mathrm{H}\right), 7.19$ (d, J=2.2 Hz, $1 \mathrm{H}, 4$ '-H), 7.37 (m, 2 H, 7-H), 7.41 (d, $\left.J=9.0 \mathrm{~Hz}, 1 \mathrm{H}, 7^{\prime}-\mathrm{H}\right), 7.53$ (m $\left., 1 \mathrm{H}, 8-\mathrm{H}\right), 7.85$ (d, $\left.J=8.4 \mathrm{~Hz}, 1 \mathrm{H}, 9-\mathrm{H}\right), 7.96$ ( $\left.\mathrm{s}_{\mathrm{br}}, 1 \mathrm{H}, 4-\mathrm{H}\right), 8.13(\mathrm{~d}, J=8.4 \mathrm{~Hz}, 1 \mathrm{H}, 6-\mathrm{H}), 9.93\left(\mathrm{~s}_{\mathrm{br}}, 1 \mathrm{H}, \mathrm{NH}^{+}\right), 10.4(\mathrm{~s}, 1 \mathrm{H}, \mathrm{OH})$, 11.6 (s, $1 \mathrm{H}, \mathrm{NH})$.

${ }^{13}$ C-NMR (125 MHz, DMSO-d 6 ): $\delta=26.0$ (C-3"', C-5"'), 32.7 (C-4"'), 41.2 (C-1), 42.7 (NMe), 47.5 (C-10), 53.1 (C-2"', C-6"'), 54.9 (C-2), 71.6 (C-1"), 100.3 (C-4), 103.5 (C-4'), 105.1 (C-3'), 113.1 (C-7'), 114.9 (C-5a), 115.6 (C-6'), 122.1 (C-9b), 122.7 
(C-9), 123.0 (C-7), 123.1 (C-6), 127.2 (C-8), 127.4 (C-3a'), 129.8, 131.1, 131.6 (C-2',

C-7a', C-9a), 142.2 (C-3a), 152.9 (C-5'), 154.1 (C-5), 160.1 (C=O).

MS (ESI): $m / z(\%)=1007.4(17)[2 \mathrm{M}-\mathrm{HCl}-\mathrm{Cl}]^{+}, 504.2(100)[\mathrm{M}-\mathrm{Cl}]^{+}$.

$\mathbf{C}_{29} \mathbf{H}_{31} \mathbf{C l}_{2} \mathbf{N}_{3} \mathbf{O}_{3}$ (540.48). $\quad$ ber.: 504.2049

gef.: 504.2051, [M-Cl] $]^{+}$(ESI-HRMS).

6 Synthese der fluoreszenzmarkierten anti-Methyl-seco-CBIDMAI-Derivate

6.1 (-)-\{3-[4-(5-(4-Dimethylaminophenyl)oxazol-2-yl)benzolsulfonylamino]propionsäure-[(1S,10R)-1-(10-chlor-ethyl)-3-[(5-(2-(N,N-dimethylamino)ethoxy)indol-2-yl)carbonyl]-5- $O$ - $\beta$-D-galactopyranosyl1,2-dihydro-3H-benz[e] indol-7-ylmethyl]amid-trifluoracetat $\}$ $((-)-(1 S, 10 R)-75)$

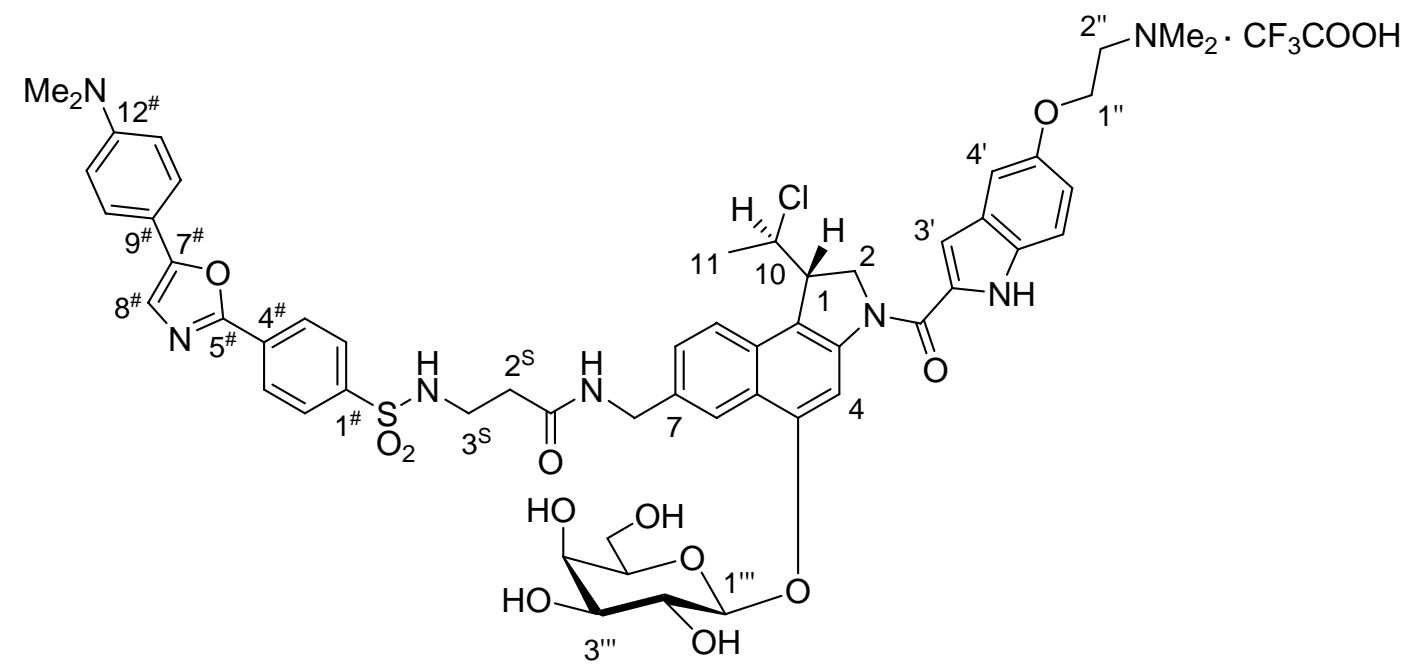

$\mathrm{Zu}$ einer Lösung des NHS-Esters (39) $(12.3 \mathrm{mg}, 24.0 \mu \mathrm{mol}, 1.0$ Äq.) in absolutem DMF $(200 \mu \mathrm{L})$ wurde eine Lösung des Galactosides (-)-(1S,10R)-51 (25.0 mg, $27.9 \mu \mathrm{mol}, 1.2$ Äq.) und $i$ - $\operatorname{Pr}_{2} \mathrm{NEt}(23.0 \mu \mathrm{L}, 139 \mu \mathrm{mol}, 5.8$ Äq.) in absolutem DMF $(150 \mu \mathrm{L})$ getropft. Nach $9 \mathrm{~h}$ Rühren bei Raumtemperatur wurde die Reaktionslösung mit bidestilliertem Wasser $(0.1 \%$ TFA, $3.0 \mathrm{~mL})$ und $\mathrm{CH}_{3} \mathrm{CN}(2.5 \mathrm{~mL})$ verdünnt. Je $2 \mathrm{~mL}$ dieser Lösung wurden in das präparative HPLC-System (s. u.) injiziert. Fraktioniertes Auffangen des Eluats, Entfernung der Lösungsmittel unter verminder- 
tem Druck sowie Entfernung des restlichen Lösungsmittels mittels Gefriertrocknung lieferte das fluoreszenzmarkierte glykosidische Prodrug (-)-(1S,10R)-75 als gelben Feststoff (27.8 mg, $21.5 \mu \mathrm{mol}, 89 \%)$.

HPLC (analytisch):

Säule: $\quad$ Kromasil 100 C18

\begin{tabular}{|c|c|c|}
\hline \multirow[t]{5}{*}{ Gradient: } & Zeit [min] & $\mathrm{H}_{2} \mathrm{O}(0.1 \%$ TFA $) / \mathrm{CH}_{3} \mathrm{CN}$ \\
\hline & 0 & $83 / 17$ \\
\hline & $0-60$ & $83 / 17 \rightarrow 50 / 50$ \\
\hline & $60-80$ & $50 / 50$ \\
\hline & $80-90$ & $50 / 50 \rightarrow 83 / 17$ \\
\hline
\end{tabular}

Fluss: $\quad 0.8 \mathrm{~mL} \mathrm{~min}^{-1}$

$t_{\mathrm{R}}: \quad 31.0 \mathrm{~min}$

HPLC (präparativ):

Säule: $\quad$ Kromasil $100 \mathrm{C} 18$

Gradient:

\begin{tabular}{cc}
\hline Zeit $[\mathrm{min}]$ & $\mathrm{H}_{2} \mathrm{O}(0.1 \%$ TFA $) / \mathrm{CH}_{3} \mathrm{CN}$ \\
\hline 0 & $83 / 17$ \\
$0-60$ & $83 / 17 \rightarrow 50 / 50$ \\
$60-70$ & $50 / 50 \rightarrow 83 / 17$ \\
\hline
\end{tabular}

Fluss: $\quad 12 \mathrm{~mL} \mathrm{~min}^{-1}$

$t_{\mathrm{R}}: \quad 38.5 \mathrm{~min}$

Fraktion: $\quad 38.0-41.0 \mathrm{~min}$

$[\alpha]_{\mathbf{D}}^{20}=-14.0^{\circ}(\mathrm{c}=0.15, \mathrm{MeOH})$.

UV (MeOH): $\lambda_{\max }(\lg \varepsilon)=202.5 \mathrm{~nm}$ (4.821), 252.0 (4.514), 289.0 (4.546), 299.5 (4.582), 349.0 (4.627).

IR $(\mathrm{KBr}): \widetilde{v}\left(\mathrm{~cm}^{-1}\right)=3406,2924,2819,1675,1616,1510,1407,1161,800$.

${ }^{1}$ H-NMR (600 MHz, DMSO-d $\left.6,80{ }^{\circ} \mathrm{C}\right): \delta=1.63\left(\mathrm{~d}, J=6.6 \mathrm{~Hz}, 3 \mathrm{H}, 11-\mathrm{H}_{3}\right), 2.40(\mathrm{t}$, $\left.J=7.4 \mathrm{~Hz}, 2 \mathrm{H}, 2^{\mathrm{S}}-\mathrm{H}_{2}\right), 2.93\left(\mathrm{~s}, 6 \mathrm{H}, 2^{\prime \prime}-\mathrm{NMe}_{2}\right), 2.98$ (s, $\left.6 \mathrm{H}, 12^{\#}-\mathrm{NMe}_{2}\right), 3.14$ (t, 


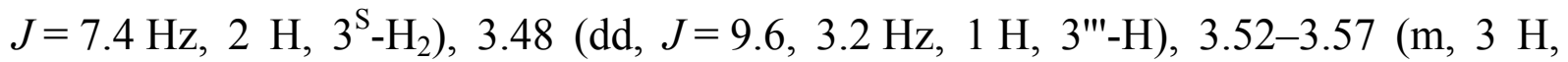

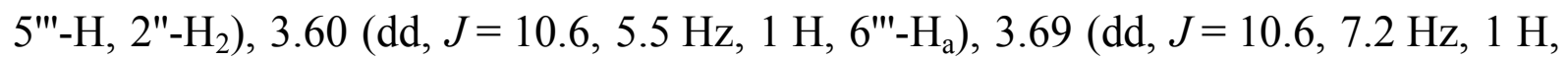
6"'-H $\mathrm{H}_{\mathrm{b}}, 3.81-3.86$ (m, 2 H, 2"'-H, 4"'-H), 4.20 (dt, $\left.J=9.4,2.6 \mathrm{~Hz}, 1 \mathrm{H}, 1-\mathrm{H}\right), 4.36$ (t, $\left.J=5.0 \mathrm{~Hz}, 2 \mathrm{H}, 1 "-\mathrm{H}_{2}\right), 4.42\left(\mathrm{~m}_{\mathrm{c}}, 2 \mathrm{H}, 12-\mathrm{H}_{2}\right), 4.62\left(\mathrm{dd}, J=11.0,2.6 \mathrm{~Hz}, 1 \mathrm{H}, 2-\mathrm{H}_{\mathrm{a}}\right)$, $4.70\left(\mathrm{dd}, J=11.0,9.4 \mathrm{~Hz}, 1 \mathrm{H}, 2-\mathrm{H}_{\mathrm{b}}\right), 4.79(\mathrm{dq}, J=6.6,3.0 \mathrm{~Hz}, 1 \mathrm{H}, 10-\mathrm{H}), 4.92(\mathrm{~d}$, $J=7.8 \mathrm{~Hz}, 1 \mathrm{H}, 1 " '-\mathrm{H}), 6.83$ (d, $J=9.0 \mathrm{~Hz}, 2 \mathrm{H}, 2 \times \mathrm{Ar}-\mathrm{H}), 7.01$ (dd, $J=9.0,2.2 \mathrm{~Hz}$, $\left.1 \mathrm{H}, 66^{\prime}-\mathrm{H}\right), 7.12\left(\mathrm{~d}, J=2.0 \mathrm{~Hz}, 1 \mathrm{H}, 3^{\prime}-\mathrm{H}\right), 7.28$ (d, $\left.J=2.2 \mathrm{~Hz}, 1 \mathrm{H}, 4^{\prime}-\mathrm{H}\right), 7.45-7.48$ (m, $\left.2 \mathrm{H}, 77^{\prime}-\mathrm{H}, 8-\mathrm{H}\right), 7.54-7.56\left(\mathrm{~m}, 2 \mathrm{H}, 3^{\mathrm{S}}-\mathrm{NH}, 8^{\#}-\mathrm{H}\right), 7.65(\mathrm{~d}, J=9.0 \mathrm{~Hz}, 2 \mathrm{H}$, $2 \times \mathrm{Ar}-\mathrm{H}), 7.89(\mathrm{~d}, J=8.5 \mathrm{~Hz}, 1 \mathrm{H}, 9-\mathrm{H}), 7.96(\mathrm{~d}, J=8.4 \mathrm{~Hz}, 2 \mathrm{H}, 2 \times \mathrm{Ar}-\mathrm{H}), 8.18$ (s, $1 \mathrm{H}, 12-\mathrm{NH}), 8.20-8.23$ (m, $4 \mathrm{H}, 4-\mathrm{H}, 6-\mathrm{H}, 2 \times \mathrm{Ar}-\mathrm{H}), 9.64\left(\mathrm{~s}_{\mathrm{br}}, 1 \mathrm{H}, \mathrm{NH}^{+}\right), 11.5(\mathrm{~s}, 1$ $\left.\mathrm{H}, 1^{\prime}-\mathrm{NH}\right)$.

${ }^{13}$ C-NMR $\left(125 \mathrm{MHz}\right.$, DMSO-d $\left.{ }_{6}\right): \delta=23.4(\mathrm{C}-11), 35.5\left(\mathrm{C}-2^{\mathrm{S}}\right), 38.7\left(\mathrm{C}-3^{\mathrm{S}}\right), 40.1$ (12 $-\mathrm{NMe}_{2}$ ), 42.5 (C-12), 42.9 (2"-NMe $), 46.0$ (C-1), 52.0 (C-2), 55.7 (C-2"), 59.5 (C-6"'), 61.4 (C-10), 62.7 (C-1"), 67.5 (C-4"'), 70.5 (C-2"'), 73.1 (C-3"'), 75.2 (C-5"'), 101.8 (C-9b), 102.1 (C-1"'), 104.0 (C-4'), 105.4 (C-3'), 112.1 (2 × Ar-C), 113.3 (C-7'), $114.6\left(\underline{\mathrm{CF}}_{3} \mathrm{CO}_{2}\right), 115.6(\mathrm{C}-6), 118.9(\mathrm{C}-5 \mathrm{a}), 121.4\left(\mathrm{C}-8^{\#}\right), 121.7$ (C-4, C-6), 122.7 (C-7), 123.3 (C-9), 125.5 ( $2 \times$ Ar-C), 126.1 ( $2 \times$ Ar-C), 127.4 (C-8), 127.4 ( $2 \times$ Ar-C), $128.5\left(\mathrm{C}-4^{\#}\right), 130.2\left(\mathrm{C}-9^{\#}\right), 131.2$ (C-9a), $132.0\left(\mathrm{C}-3 \mathrm{a}^{\prime}\right), 134.7$ (C-7a'), 141.1 (C-2', C-1 $\left.{ }^{\#}\right), 141.6(\mathrm{C}-3 \mathrm{a}), 150.1\left(\mathrm{C}-7^{\#}\right), 152.0\left(\mathrm{C}-12^{\#}\right), 152.7\left(\mathrm{C}-5^{\prime}\right), 153.4(\mathrm{C}-5), 157.5$ $\left(\mathrm{C}-5^{\#}, 1^{\prime}-\mathrm{C}=\mathrm{O}\right), 160.0\left(\mathrm{CF}_{3} \mathrm{CO}_{2}\right), 169.6\left(2^{\mathrm{S}}-\mathrm{C}=\mathrm{O}\right)$.

MS (ESI): $m / z(\%)=1066.4(100)\left[\mathrm{M}-\mathrm{CF}_{3} \mathrm{CO}_{2}\right]^{+}, 533.7(80)\left[\mathrm{M}-\mathrm{CF}_{3} \mathrm{CO}_{2}+\mathrm{H}\right]^{2+}, 452.7$ (41) $\left[\mathrm{M}-\mathrm{CF}_{3} \mathrm{CO}_{2}-\mathrm{C}_{6} \mathrm{H}_{11} \mathrm{O}_{5}+\mathrm{H}\right]^{2+}$.

$\mathbf{C}_{56} \mathbf{H}_{61} \mathbf{C I F}_{3} \mathbf{N}_{7} \mathbf{O}_{14} \mathbf{S}(1180.64)$. $\quad$ ber.: 1066.3782 gef.: $1066.3778,\left[\mathrm{M}-\mathrm{CF}_{3} \mathrm{CO}_{2}\right]^{+}$(ESI-HRMS). 


\subsection{3-[4-(5-(4-Dimethylaminophenyl)oxazol-2-yl)benzolsulfonylamino]- propionsäure-[(1S,10R)-1-(10-chlor-ethyl)-3-[(5-(2-( $N, N$-dimethyl- amino)ethoxy)indol-2-yl)carbonyl]-5-hydroxy-1,2-dihydro-3H- benz[e]indol-7-ylmethyl]amid-Hydrochlorid $((1 S, 10 R)-76)$}

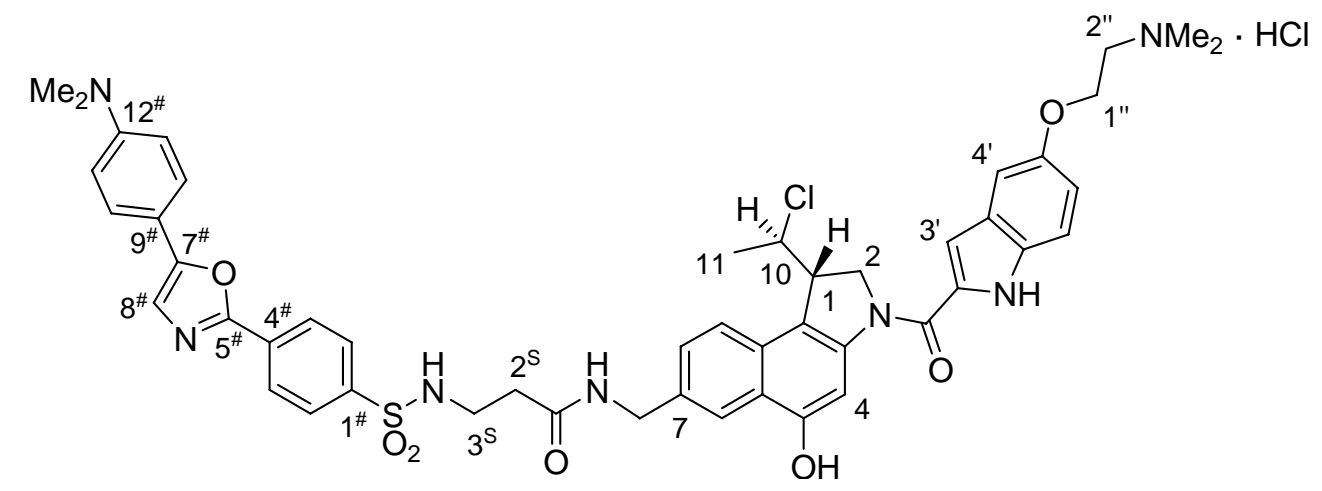

Eine Lösung des fluoreszenzmarkierten Prodrugs (-)-(1S,10R)-75 (5.0 mg, $3.9 \mu \mathrm{mol})$ in Methanol $(3 \mathrm{~mL})$ wurde mit konz. $\mathrm{HCl}(0.3 \mathrm{~mL})$ versetzt und die Reaktionsmischung 3 Tage bei Raumtemperatur gerührt. Das Lösungsmittel wurde unter vermindertem Druck entfernt, der Rückstand in Methanol gelöst und mittels präparativer HPLC (s.u.) das Produkt vom Edukt getrennt. Das restliche Edukt wurde in Methanol (4 mL) gelöst, mit konz. $\mathrm{HCl}(4 \mathrm{~mL})$ versetzt und 4 Tage bei Raumtemperatur gerührt. Das Lösungsmittel wurde entfernt und erneut das restliche Edukt mittels präparativer HPLC (s.u.) vom Produkt getrennt. Vereinigung der Produktfraktionen lieferte das Zielmolekül (1S,10R)-76 (2.6 mg, $2.7 \mu \mathrm{mol}, 69 \%)$ als gelben Feststoff.

HPLC (analytisch):

Säule: $\quad$ Kromasil 100 C18

Gradient:

\begin{tabular}{cc}
\hline Zeit $[\mathrm{min}]$ & $\mathrm{H}_{2} \mathrm{O}(0.06 \%$ konz. $\mathrm{HCl}) / \mathrm{MeOH}$ \\
\hline $0-15$ & $50 / 50 \rightarrow 0 / 100$ \\
$15-22$ & $0 / 100$ \\
$22-23$ & $0 / 100 \rightarrow 50 / 50$ \\
$23-30$ & $50 / 50$ \\
\hline
\end{tabular}

Fluss: $\quad 0.8 \mathrm{~mL} \mathrm{~min}^{-1}$

$t_{\mathrm{R}}: \quad 11.6 \mathrm{~min}$ 
HPLC (präparativ):

Säule: $\quad$ Kromasil 100 C18

Gradient:

\begin{tabular}{cc}
\hline Zeit $[\mathrm{min}]$ & $\mathrm{H}_{2} \mathrm{O}(0.06 \%$ konz. $\mathrm{HCl}) / \mathrm{MeOH}$ \\
\hline $0-20$ & $50 / 50 \rightarrow 25 / 75$ \\
$20-23$ & $0 / 100$ \\
$23-25$ & $0 / 100 \rightarrow 50 / 50$ \\
$25-30$ & $50 / 50$ \\
\hline
\end{tabular}

Fluss: $\quad 18 \mathrm{~mL} \mathrm{~min}^{-1}$

$t_{\mathrm{R}}: \quad 15 \mathrm{~min}$

Fraktion: $\quad 14.2-17.0 \mathrm{~min}$

${ }^{1}$ H-NMR $\left(600 \mathrm{MHz}\right.$, DMSO-d $\left.\mathrm{d}_{6}\right): \delta=1.61\left(\mathrm{~d}, J=6.7 \mathrm{~Hz}, 3 \mathrm{H}, 11-\mathrm{H}_{3}\right), 2.37(\mathrm{t}$, $\left.J=7.2 \mathrm{~Hz}, 2 \mathrm{H}, 2^{\mathrm{S}}-\mathrm{H}_{2}\right), 2.88$ (d, $J=5.0 \mathrm{~Hz}, 6 \mathrm{H}, 2^{\prime \prime}-\mathrm{NMe}_{2}$ ), 2.98 (s, $6 \mathrm{H}, 12^{\#}-\mathrm{NMe}_{2}$ ), 3.07 (dt, $\left.J=7.2,6.0 \mathrm{~Hz}, 2 \mathrm{H}, 3^{\mathrm{S}}-\mathrm{H}_{2}\right), 3.54\left(\mathrm{~m}_{\mathrm{c}}, 2 \mathrm{H}, 2^{2}-\mathrm{H}_{2}\right), 4.14\left(\mathrm{~m}_{\mathrm{c}}, 1 \mathrm{H}, 1-\mathrm{H}\right), 4.33-$ $4.41\left(\mathrm{~m}_{\mathrm{c}}, 4 \mathrm{H}, 1 "-\mathrm{H}_{2}, 12-\mathrm{H}_{2}\right), 4.56\left(\mathrm{dd}, J=11.0,2.0 \mathrm{~Hz}, 1 \mathrm{H}, 2-\mathrm{H}_{\mathrm{a}}\right), 4.68-4.76(\mathrm{~m}, 2 \mathrm{H}$, 2- $\left.\mathrm{H}_{\mathrm{b}}, 10-\mathrm{H}\right), 6.83(\mathrm{~d}, J=8.8 \mathrm{~Hz}, 2 \mathrm{H}, 2 \times \mathrm{Ar}-\mathrm{H}), 7.00$ (dd, $\left.J=9.0,2.4 \mathrm{~Hz}, 1 \mathrm{H}, 66^{\prime}-\mathrm{H}\right)$, $7.16\left(\mathrm{~d}, J=1.8 \mathrm{~Hz}, 1 \mathrm{H}, 3^{\prime}-\mathrm{H}\right), 7.26\left(\mathrm{~d}, J=2.4 \mathrm{~Hz}, 1 \mathrm{H}, 4^{\prime}-\mathrm{H}\right), 7.39$ (dd, $J=8.5$, $1.4 \mathrm{~Hz}, 1 \mathrm{H}, 8-\mathrm{H}), 7.44$ (d, J=9.0 Hz, $\left.1 \mathrm{H}, 7^{\prime}-\mathrm{H}\right), 7.62\left(\mathrm{~s}, 1 \mathrm{H}, 8^{\#}-\mathrm{H}\right), 7.67$ (d, $J=8.8 \mathrm{~Hz}, 2 \mathrm{H}, 2 \times \mathrm{Ar}-\mathrm{H}), 7.79\left(\mathrm{t}, J=6.0 \mathrm{~Hz}, 1 \mathrm{H}, 3^{\mathrm{S}}-\mathrm{NH}\right), 7.84(\mathrm{~d}, J=8.5 \mathrm{~Hz}, 1 \mathrm{H}$, 9-H), 7.94-7.99 (m, 4 H, 4-H, 6-H, $2 \times$ Ar-H), 8.23 (d, $J=8.4$ Hz, 2 H, $2 \times$ Ar-H), $8.45(\mathrm{t}, J=6.0 \mathrm{~Hz}, 1 \mathrm{H}, 12-\mathrm{NH}), 10.2,10.3\left(2 \times \mathrm{s}_{\mathrm{br}}, 2 \mathrm{H}, \mathrm{OH}, \mathrm{NH}^{+}\right), 11.6(\mathrm{~s}, 1 \mathrm{H}$, $\left.1^{\prime}-\mathrm{NH}\right)$.

MS (ESI): $m / z(\%)=904.3(100)[\mathrm{M}-\mathrm{Cl}]^{+}$.

$\mathbf{C}_{48} \mathbf{H}_{51} \mathbf{C l}_{2} \mathbf{N}_{7} \mathbf{O}_{7} \mathbf{S}$ (940.93). $\quad$ ber.: 904.3254

gef.: 904.3250, [M-Cl] $]^{+}$(ESI-HRMS). 


\section{Untersuchung der Wechselwirkung verschiedener Duocarmy- cin-Analoga mit DNA, RNA und Glutathion mittels Massen- spektrometrie}

\subsection{AAV 7.1: Allgemeine Arbeitsvorschrift zur massenspektrometrischen Untersuchung der Wechselwirkung verschiedener Duocarmycin- Analoga mit einzel- oder doppelsträngigen DNA-Oligonukleotiden}

Doppel- oder einzelsträngige DNA-Oligonukleotide wurden als wässrige Lösungen $(0.1 \mathrm{mM})$ der entsprechenden Natrium- oder Ammoniumsalze eingesetzt. 1 Aliquot der Stammlösung eines Duocarmycin-Analogons in DMSO wurde in die Lösung des ausgewählten DNA-Oligonukleotides pipettiert und die Reaktionsmischung $24 \mathrm{~h}$ bei $25^{\circ} \mathrm{C}$ inkubiert. $\mathrm{Zu}$ den angegebenen Zeitpunkten nach dem Start der Inkubation wurde ein Aliquot der Reaktionsmischung entnommen und die Lösung direkt analysiert oder tiefgefroren $\left(-20^{\circ} \mathrm{C}\right)$ und zu einem späteren Zeitpunkt untersucht.

Analyse: Die Reaktionslösungen wurden mit dem gleichen Volumen Methanol versetzt und unmittelbar danach massenspektrometrisch untersucht (ESI-FTICR-MS, negativer Ionenmodus, Kapillartemperatur: $100^{\circ} \mathrm{C}$ ).

7.2 AAV 7.2: Allgemeine Arbeitsvorschrift zur massenspektrometrischen Untersuchung der Wechselwirkung verschiedener DuocarmycinAnaloga mit einzel- oder doppelsträngigen DNA-Oligonukleotiden im Verhältnis $n: 1(n=1,2,5)$

1 Aliquot der Stammlösung eines Duocarmycin-Analogons in DMSO $(1 \mu \mathrm{L}$, $(5 \times \mathrm{n})$ nmol, n Äq.) wurde nach AAV 7.1 in die Lösung des ausgewählten DNAOligonukleotides ( $50 \mu \mathrm{L}, 5 \mathrm{nmol}, 1 \mathrm{Äq}$.) pipettiert und die Reaktionsmischung $24 \mathrm{~h}$ bei $25^{\circ} \mathrm{C}$ inkubiert. $\mathrm{Zu}$ den Zeitpunkten $t=0 \mathrm{~h}$ und $t=24 \mathrm{~h}$ wurde die Reaktionsmischung nach AAV 7.1 massenspektrometrisch untersucht. 


\subsection{AAV 7.3: Allgemeine Arbeitsvorschrift zur Bestimmung des Anteils alkylierter DNA}

Wurde nur einer der zwei Oligonukleotide eines untersuchten DNA-Doppelstranges alkyliert (z.B. ON-1), so wurde der Anteil des umgesetzten Oligonukleotides zum Zeitpunkt $t$ wie folgt berechnet:

Zunächst wurde für die jeweilige Messung $x$ die Peakhöhe je eines Isotopes jedes Natriumadduktes beider Oligonukleotide bestimmt (z.B.: $\mathrm{I}_{1, \mathrm{x}}\left(2 \mathrm{Na}^{+}\right)=$Intensität des Einzelstranges $\mathrm{ON}-1$ mit $2 \mathrm{Na}^{+}$bei Messung $x$ ). Die Peakhöhen entsprechender Natriumaddukte und Isotope des ersten und zweiten Oligonukleotids wurden dann zueinander durch Division in Beziehung gesetzt (z.B.: $\mathrm{I}_{1, \mathrm{x}}\left(2 \mathrm{Na}^{+}\right) / \mathrm{I}_{2, \mathrm{x}}\left(2 \mathrm{Na}^{+}\right)$). Aus den so erhaltenen $m_{x}-m_{0, \mathrm{x}}$ (in der Regel 7 bis 10) Einzelwerten wurde dann der Mittelwert für alle Natriumaddukte dieser Messung berechnet:

$$
Q_{x}^{t}=\frac{\sum_{n=m_{0, x}}^{m_{x}} \frac{I_{1, x}^{t}\left(n \cdot N a^{+}\right)}{I_{2, x}^{t}\left(n \cdot N a^{+}\right)}}{\left|m_{x}-m_{0, x}\right|} .
$$

Dieses Verfahren wurde für 2 bis 4 Messungen derselben Reaktionsmischung angewandt und aus den Mittelwerten der Einzelmessungen der Mittelwert aller Messungen errechnet:

$$
\overline{Q^{t}}=\frac{\sum_{x} Q_{x}^{t}}{x} .
$$

Analog wurde für das jeweilige doppelsträngige Oligonukleotid das Verhältnis der beiden Einzelstränge vor der Reaktion bestimmt (verwendet wurden für diese Messungen die reine DNA oder Mischungen der DNA und der Substanz zum Zeitpunkt $t=0 \mathrm{~h})$ :

$$
\overline{Q^{0}}=\frac{\sum_{x} Q_{x}^{0}}{x} .
$$

Der Anteil umgesetzten Oligonukleotides errechnete sich dann gemäß:

$$
A^{t}=1-\frac{\overline{Q^{t}}}{\overline{Q^{0}}} .
$$




\subsection{Massenspektrometrische Untersuchung der Wechselwirkung des} seco-Drugs $(+)-(1 S, 10 R)-34$ a mit DNA-Oligonukleotiden

\subsection{1 ds-60 / (1S,10R)-34a $=1: 1$}

Die Wechselwirkung von $(1 S, 10 R)$-34a mit dem DNA-Oligonukleotid ds-60 wurde nach AAV $7.2(\mathrm{n}=1)$ untersucht.

\begin{tabular}{|c|c|c|c|}
\hline Verbindung & Summenformel & berechnet & gefunden \\
\hline $43 a$ & $\mathrm{C}_{27} \mathrm{H}_{27} \mathrm{O}_{3} \mathrm{~N}_{3}$ & 441.21 & 441.21 \\
\hline$(1 S, 10 R)-\mathbf{3 4 a}$ & $\mathrm{C}_{27} \mathrm{H}_{28} \mathrm{O}_{3} \mathrm{~N}_{3} \mathrm{Cl}$ & 477.18 & 477.19 \\
\hline ON-1 (ds-60) & $\mathrm{C}_{146} \mathrm{H}_{180} \mathrm{O}_{89} \mathrm{~N}_{55} \mathrm{P}_{14} \mathrm{Na}_{5}$ & 4675.71 & 4675.74 \\
\hline ON-2 (ds-60) & $\mathrm{C}_{146} \mathrm{H}_{179} \mathrm{O}_{87} \mathrm{~N}_{58} \mathrm{P}_{14} \mathrm{Na}_{5}$ & 4684.72 & 4684.76 \\
\hline Verbindung & Summenformel & berechnet & gefunden \\
\hline $43 a$ & $\mathrm{C}_{27} \mathrm{H}_{27} \mathrm{O}_{3} \mathrm{~N}_{3}$ & 441.21 & 441.21 \\
\hline$A *(34 a)$ & $\mathrm{C}_{32} \mathrm{H}_{32} \mathrm{O}_{3} \mathrm{~N}_{8}$ & 576.26 & 576.27 \\
\hline $\mathrm{w}_{5}(\mathrm{ON}-1$ (ds-60)) & $\mathrm{C}_{48} \mathrm{H}_{63} \mathrm{O}_{32} \mathrm{~N}_{18} \mathrm{P}_{5}$ & 1558.25 & 1558.27 \\
\hline$a_{10}-B_{10}(\mathrm{ON}-1(\mathrm{ds}-60))$ & $\mathrm{C}_{93} \mathrm{H}_{112} \mathrm{O}_{57} \mathrm{~N}_{32} \mathrm{P}_{9} \mathrm{Na}_{5}$ & 2982.40 & 2982.43 \\
\hline ON-1-A (ds-60) & $\mathrm{C}_{141} \mathrm{H}_{175} \mathrm{O}_{89} \mathrm{~N}_{50} \mathrm{P}_{14} \mathrm{Na}_{5}$ & 4540.65 & 4540.69 \\
\hline ON-1 (ds-60) & $\mathrm{C}_{146} \mathrm{H}_{180} \mathrm{O}_{89} \mathrm{~N}_{55} \mathrm{P}_{14} \mathrm{Na}_{5}$ & 4675.71 & 4675.76 \\
\hline ON-2 (ds-60) & $\mathrm{C}_{146} \mathrm{H}_{179} \mathrm{O}_{87} \mathrm{~N}_{58} \mathrm{P}_{14} \mathrm{Na}_{5}$ & 4684.72 & 4684.79 \\
\hline $\mathrm{ON}-1 *(\mathrm{ds}-60,34 \mathrm{a})$ & $\mathrm{C}_{173} \mathrm{H}_{207} \mathrm{O}_{92} \mathrm{~N}_{58} \mathrm{P}_{14} \mathrm{Na}_{5}$ & 5116.91 & 5116.96 \\
\hline
\end{tabular}

Alkylierung ON-1 (berechnet nach AAV 7.3): 75\%.

Alkylierungsposition: $\mathrm{A}_{10}(\mathrm{ON}-1)$.

CID-MS/MS:

\begin{tabular}{|c|c|c|c|}
\hline ON-1-A (ds-60) & Summenformel & berechnet & gefunden \\
\hline $\mathrm{ON}-1-\mathrm{A}(\mathrm{ds}-60)$ & $\mathrm{C}_{141} \mathrm{H}_{175} \mathrm{O}_{89} \mathrm{~N}_{50} \mathrm{P}_{14} \mathrm{Na}_{5}$ & 4540.65 & 4540.68 \\
\hline $\mathrm{w}_{5}(\mathrm{ON}-1$ (ds-60)) & $\mathrm{C}_{48} \mathrm{H}_{63} \mathrm{O}_{32} \mathrm{~N}_{18} \mathrm{P}_{5}$ & 1558.25 & 1558.29 \\
\hline$a_{10}-B_{10}(\mathrm{ON}-1(\mathrm{ds}-60))$ & $\mathrm{C}_{93} \mathrm{H}_{112} \mathrm{O}_{57} \mathrm{~N}_{32} \mathrm{P}_{9} \mathrm{Na}_{5}$ & 2982.34 & 2982.43 \\
\hline
\end{tabular}


Messung mit interner Kalibrierung $(\mathrm{m} / \mathrm{z}$ 388.81770, $\mathrm{m} / \mathrm{z}$ 1033.98811, $\mathrm{m} / \mathrm{z}$ 1633.94979):

$24 \mathrm{~h}:$

\begin{tabular}{llll}
\hline Verbindung & Summenformel & berechnet & gefunden \\
\hline $\mathbf{A}^{*}$ (34a) & $\mathrm{C}_{32} \mathrm{H}_{32} \mathrm{O}_{3} \mathrm{~N}_{8}$ & 576.2597 & 576.2598 \\
$\mathbf{w}_{\mathbf{5}}$ (ON-1 (ds-60)) & $\mathrm{C}_{48} \mathrm{H}_{63} \mathrm{O}_{32} \mathrm{~N}_{18} \mathrm{P}_{5}$ & 1558.254 & 1558.256 \\
$\mathbf{a}_{10}-\mathbf{B}_{10}(\mathbf{O N}-1$ (ds-60)) & $\mathrm{C}_{93} \mathrm{H}_{112} \mathrm{O}_{57} \mathrm{~N}_{32} \mathrm{P}_{9} \mathrm{Na}_{5}$ & 2894.470 & 2894.471 \\
ON-1-A (ds-60) & $\mathrm{C}_{141} \mathrm{H}_{178} \mathrm{O}_{89} \mathrm{~N}_{50} \mathrm{P}_{14} \mathrm{Na}_{2}$ & 4474.706 & 4474.712 \\
ON-1 (ds-60) & $\mathrm{C}_{146} \mathrm{H}_{182} \mathrm{O}_{89} \mathrm{~N}_{55} \mathrm{P}_{14} \mathrm{Na}_{3}$ & 4640.754 & 4640.754 \\
ON-2 (ds-60) & $\mathrm{C}_{146} \mathrm{H}_{179} \mathrm{O}_{87} \mathrm{~N}_{58} \mathrm{P}_{14} \mathrm{Na}_{5}$ & 4684.718 & 4684.717 \\
ON-1* (ds-60, 34a) & $\mathrm{C}_{173} \mathrm{H}_{207} \mathrm{O}_{92} \mathrm{~N}_{58} \mathrm{P}_{14} \mathrm{Na}_{5}$ & 5116.9 .12 & 5116.917 \\
\hline
\end{tabular}

\subsection{2 ds-60 / $(1 S, 10 R)-34 \mathrm{a}=1: \mathrm{n}(\mathrm{n}=2,4,5)$}

Die Wechselwirkung von $(1 S, 10 R)$-34a mit dem DNA-Oligonukleotid ds-60 wurde nach AAV $7.2(\mathrm{n}=2,4,5)$ untersucht. Ergebnisse für $t=24 \mathrm{~h}$ :

\begin{tabular}{|c|c|c|c|c|}
\hline \multirow[t]{9}{*}{$\mathrm{n}=2$ : } & Verbindung & Summenformel & berechnet & gefunden \\
\hline & $43 a$ & $\mathrm{C}_{27} \mathrm{H}_{27} \mathrm{O}_{3} \mathrm{~N}_{3}$ & 441.21 & 441.21 \\
\hline & $A *(34 a)$ & $\mathrm{C}_{32} \mathrm{H}_{32} \mathrm{O}_{3} \mathrm{~N}_{8}$ & 576.26 & 576.27 \\
\hline & $\mathrm{w}_{5}(\mathrm{ON}-1$ (ds-60)) & $\mathrm{C}_{48} \mathrm{H}_{63} \mathrm{O}_{32} \mathrm{~N}_{18} \mathrm{P}_{5}$ & 1558.25 & 1558.27 \\
\hline & $a_{10}-B_{10}(\mathrm{ON}-1(\mathrm{ds}-60))$ & $\mathrm{C}_{93} \mathrm{H}_{112} \mathrm{O}_{57} \mathrm{~N}_{32} \mathrm{P}_{9} \mathrm{Na}_{5}$ & 2982.40 & 2982.43 \\
\hline & ON-1-A (ds-60) & $\mathrm{C}_{141} \mathrm{H}_{175} \mathrm{O}_{89} \mathrm{~N}_{50} \mathrm{P}_{14} \mathrm{Na}_{5}$ & 4540.65 & 4540.71 \\
\hline & ON-1 (ds-60) & $\mathrm{C}_{146} \mathrm{H}_{180} \mathrm{O}_{89} \mathrm{~N}_{55} \mathrm{P}_{14} \mathrm{Na}_{5}$ & 4675.71 & 4675.76 \\
\hline & ON-2 (ds-60) & $\mathrm{C}_{146} \mathrm{H}_{179} \mathrm{O}_{87} \mathrm{~N}_{58} \mathrm{P}_{14} \mathrm{Na}_{5}$ & 4684.72 & 4684.77 \\
\hline & ON-1* (ds-60, 34a) & $\mathrm{C}_{173} \mathrm{H}_{207} \mathrm{O}_{92} \mathrm{~N}_{58} \mathrm{P}_{14} \mathrm{Na}_{5}$ & 5116.91 & 5116.97 \\
\hline
\end{tabular}

Alkylierung ON-1 (berechnet nach AAV 7.3): 50\%.

Alkylierungsposition: $\mathrm{A}_{10}(\mathrm{ON}-1)$.

\begin{tabular}{|c|c|c|c|c|}
\hline \multirow{7}{*}{$\mathrm{n}=4$} & Verbindung & Summenformel & berechnet & gefunden \\
\hline & $43 \mathbf{a}$ & $\mathrm{C}_{27} \mathrm{H}_{27} \mathrm{O}_{3} \mathrm{~N}_{3}$ & 441.21 & 441.21 \\
\hline & $(1 S, 10 R)-\mathbf{3 4 a}$ & $\mathrm{C}_{27} \mathrm{H}_{28} \mathrm{O}_{3} \mathrm{~N}_{3} \mathrm{Cl}$ & 477.18 & 477.19 \\
\hline & $A *(34 a)$ & $\mathrm{C}_{32} \mathrm{H}_{32} \mathrm{O}_{3} \mathrm{~N}_{8}$ & 576.26 & 576.27 \\
\hline & $w_{5}(\mathrm{ON}-1$ (ds-60)) & $\mathrm{C}_{48} \mathrm{H}_{63} \mathrm{O}_{32} \mathrm{~N}_{18} \mathrm{P}_{5}$ & 1558.25 & 1558.27 \\
\hline & $a_{10}-B_{10}(\mathrm{ON}-1(\mathrm{ds}-60))$ & $\mathrm{C}_{93} \mathrm{H}_{112} \mathrm{O}_{57} \mathrm{~N}_{32} \mathrm{P}_{9} \mathrm{Na}_{5}$ & 2982.40 & 2982.43 \\
\hline & ON-1-A (ds-60) & $\mathrm{C}_{141} \mathrm{H}_{175} \mathrm{O}_{89} \mathrm{~N}_{50} \mathrm{P}_{14} \mathrm{Na}_{5}$ & 4540.65 & 4540.71 \\
\hline
\end{tabular}




\begin{tabular}{llll} 
ON-1 (ds-60) & $\mathrm{C}_{146} \mathrm{H}_{180} \mathrm{O}_{89} \mathrm{~N}_{55} \mathrm{P}_{14} \mathrm{Na}_{5}$ & 4675.71 & 4675.76 \\
ON-2 (ds-60) & $\mathrm{C}_{146} \mathrm{H}_{179} \mathrm{O}_{87} \mathrm{~N}_{58} \mathrm{P}_{14} \mathrm{Na}_{5}$ & 4684.72 & 4684.78 \\
ON-1* (ds-60, 34a) & $\mathrm{C}_{173} \mathrm{H}_{207} \mathrm{O}_{92} \mathrm{~N}_{58} \mathrm{P}_{14} \mathrm{Na}_{5}$ & 5116.91 & 5116.98 \\
\hline
\end{tabular}

Alkylierung ON-1 (berechnet nach AAV 7.3): 75\%.

Alkylierungsposition: $\mathrm{A}_{10}(\mathrm{ON}-1)$.

\begin{tabular}{|c|c|c|c|c|}
\hline $\mathrm{n}=5$ & Verbindung & Summenformel & berechnet & gefunden \\
\hline & $43 \mathbf{a}$ & $\mathrm{C}_{27} \mathrm{H}_{27} \mathrm{O}_{3} \mathrm{~N}_{3}$ & 441.21 & 441.21 \\
\hline & $84 a$ & $\mathrm{C}_{27} \mathrm{H}_{29} \mathrm{O}_{4} \mathrm{~N}_{3}$ & 459.22 & 459.22 \\
\hline & $(1 S, 10 R)-\mathbf{3 4 a}$ & $\mathrm{C}_{27} \mathrm{H}_{28} \mathrm{O}_{3} \mathrm{~N}_{3} \mathrm{Cl}$ & 477.18 & 477.19 \\
\hline & $A^{*}(34 a)$ & $\mathrm{C}_{32} \mathrm{H}_{32} \mathrm{O}_{3} \mathrm{~N}_{8}$ & 576.26 & 576.26 \\
\hline & $G *(34 a)$ & $\mathrm{C}_{32} \mathrm{H}_{32} \mathrm{O}_{4} \mathrm{~N}_{8}$ & 592.25 & 592.26 \\
\hline & $\mathrm{w}_{5}(\mathrm{ON}-1$ (ds-60)) & $\mathrm{C}_{48} \mathrm{H}_{63} \mathrm{O}_{32} \mathrm{~N}_{18} \mathrm{P}_{5}$ & 1558.25 & 1558.28 \\
\hline & $a_{10}-B_{10}(\mathrm{ON}-1(\mathrm{ds}-60))$ & $\mathrm{C}_{93} \mathrm{H}_{112} \mathrm{O}_{57} \mathrm{~N}_{32} \mathrm{P}_{9} \mathrm{Na}_{5}$ & 2982.34 & 2982.47 \\
\hline & ON-1-A (ds-60) & $\mathrm{C}_{141} \mathrm{H}_{175} \mathrm{O}_{89} \mathrm{~N}_{50} \mathrm{P}_{14} \mathrm{Na}_{5}$ & 4540.65 & 4540.70 \\
\hline & ON-1 (ds-60) & $\mathrm{C}_{146} \mathrm{H}_{180} \mathrm{O}_{89} \mathrm{~N}_{55} \mathrm{P}_{14} \mathrm{Na}_{5}$ & 4675.71 & 4675.75 \\
\hline & ON-2 (ds-60) & $\mathrm{C}_{146} \mathrm{H}_{179} \mathrm{O}_{87} \mathrm{~N}_{58} \mathrm{P}_{14} \mathrm{Na}_{5}$ & 4684.72 & 4684.79 \\
\hline & ON-1*(ds-60, 34a) & $\mathrm{C}_{173} \mathrm{H}_{207} \mathrm{O}_{92} \mathrm{~N}_{58} \mathrm{P}_{14} \mathrm{Na}_{5}$ & 5116.91 & 5117.0 \\
\hline & ON-1*/ON-2 (ds-60, 34a) & $\mathrm{C}_{319} \mathrm{H}_{381} \mathrm{O}_{179} \mathrm{~N}_{116} \mathrm{P}_{28} \mathrm{Na}_{15}$ & 9911.54 & 9911.64 \\
\hline
\end{tabular}

Alkylierung ON-1 (berechnet nach AAV 7.3): 90\%.

Alkylierungsposition: $\mathrm{A}_{10}(\mathrm{ON}-1)$.

\subsubsection{Kinetik ds-60 / (1S,10R)-34a $=1: 1,0-24 \mathrm{~h}$}

1 Aliquot der Stammlösung von $(1 S, 10 R)$-34a $(4 \mu \mathrm{L}, 20$ nmol, 1 Äq.) wurde nach AAV 7.1 in die Lösung des DNA-Oligonukleotides ds-60 (200 $\mu \mathrm{L}, 20 \mathrm{nmol}, 1$ Äq.) pipettiert und die Reaktionsmischung $24 \mathrm{~h}$ bei $25{ }^{\circ} \mathrm{C}$ inkubiert. $\mathrm{Zu}$ den Zeitpunkten $t=0 \mathrm{~h}$ bis $t=6 \mathrm{~h}$ wurde stündlich und anschließend zum Zeitpunkt $t=24 \mathrm{~h}$ ein Aliquot der Reaktionslösung ( $20 \mu \mathrm{L})$ entnommen und die Reaktionsmischung massenspektrometrisch untersucht. Die Messreihe wurde dreimal wiederholt und für jeden Zeitpunkt jeder Messreihe nach AAV 7.3 der Anteil der Alkylierung des Stranges ON-1 berechnet. 


\begin{tabular}{ccccc}
\hline$t[\mathrm{~h}]$ & $\begin{array}{c}\text { Alkylierung [\%] } \\
\text { Messreihe 1 }\end{array}$ & $\begin{array}{c}\text { Alkylierung [\%] } \\
\text { Messreihe 2 }\end{array}$ & $\begin{array}{c}\text { Alkylierung [\%] } \\
\text { Messreihe 3 }\end{array}$ & $\begin{array}{c}\text { Alkylierung [\%] } \\
\text { Mittelwert } \pm \boldsymbol{\sigma}\end{array}$ \\
\hline $\mathbf{0}$ & 0 & 0 & 0 & 0 \\
$\mathbf{1}$ & 11 & 12 & 18 & $14 \pm 4$ \\
$\mathbf{2}$ & 19 & 23 & 33 & $25 \pm 7$ \\
$\mathbf{3}$ & 32 & 30 & 41 & $34 \pm 6$ \\
$\mathbf{4}$ & 41 & 38 & 47 & $42 \pm 5$ \\
$\mathbf{5}$ & 49 & 49 & 57 & $52 \pm 5$ \\
$\mathbf{6}$ & 56 & 54 & 67 & $59 \pm 7$ \\
$\mathbf{2 4}$ & 72 & 68 & 76 & $72 \pm 4$ \\
\hline
\end{tabular}

\subsection{4 ds-60 / (1S,10R)-34a = 1:1, nicht-kovalente Wechselwirkungen}

Die nicht-kovalente Wechselwirkung von $(1 S, 10 R)$-34a mit dem DNA-Oligonukleotid ds-60 wurde nach AAV $7.2(\mathrm{n}=1)$ untersucht. Hierbei wurde die Reaktionslösung direkt nach dem Ansetzen mit Wasser / Ammoniumacetat (10 mM aq.-Lösg.)/Isopropanol $=3 / 1 / 1(50 \mu \mathrm{L})$ versetzt und die Lösung bei einer Kapillartemperatur von $100{ }^{\circ} \mathrm{C}$ und einer Spannung von $U_{\mathrm{C}}=-80 \mathrm{~V}$ massenspektrometrisch untersucht.

\begin{tabular}{|c|c|c|c|c|}
\hline \multirow{9}{*}{$t=0 \mathrm{~h}:$} & Verbindung & Summenformel & berechnet & gefunden \\
\hline & $43 a$ & $\mathrm{C}_{27} \mathrm{H}_{27} \mathrm{O}_{3} \mathrm{~N}_{3}$ & 441.21 & 441.21 \\
\hline & $84 a$ & $\mathrm{C}_{27} \mathrm{H}_{29} \mathrm{O}_{4} \mathrm{~N}_{3}$ & 459.22 & 459.22 \\
\hline & $(1 S, 10 R)-\mathbf{3 4 a}$ & $\mathrm{C}_{27} \mathrm{H}_{28} \mathrm{O}_{3} \mathrm{~N}_{3} \mathrm{Cl}$ & 477.18 & 477.19 \\
\hline & ON-1 (ds-60) & $\mathrm{C}_{146} \mathrm{H}_{180} \mathrm{O}_{89} \mathrm{~N}_{55} \mathrm{P}_{14} \mathrm{Na}_{5}$ & 4675.71 & 4675.75 \\
\hline & ON-2 (ds-60) & $\mathrm{C}_{146} \mathrm{H}_{179} \mathrm{O}_{87} \mathrm{~N}_{58} \mathrm{P}_{14} \mathrm{Na}_{5}$ & 4684.72 & 4684.79 \\
\hline & ON-1* (ds-60, 34a) & $\mathrm{C}_{173} \mathrm{H}_{207} \mathrm{O}_{92} \mathrm{~N}_{58} \mathrm{P}_{14} \mathrm{Na}_{5}$ & 5116.91 & 5117.0 \\
\hline & ds-60 & $\mathrm{C}_{292} \mathrm{H}_{356} \mathrm{O}_{176} \mathrm{~N}_{113} \mathrm{P}_{28} \mathrm{Na}_{13}$ & 9426.37 & 9426.55 \\
\hline & ds-60 $0^{(*)}(34 a)$ & $\mathrm{C}_{319} \mathrm{H}_{385} \mathrm{O}_{179} \mathrm{~N}_{116} \mathrm{P}_{28} \mathrm{Na}_{11}$ & 9823.61 & 9823.82 \\
\hline
\end{tabular}

Intensitäten: $t=0 \mathrm{~h}: \quad \mathbf{O N} / \mathbf{O N}-\mathbf{1} * \sim 87: 1, \mathbf{O N} / \mathrm{ds}-\mathbf{6 0} \sim 14: 1$, ON $/$ ds-60 ${ }^{(*)} \sim 58: 1$, ds-60 / ds-60 ${ }^{(*)} \sim 4: 1$.

$t=3 \mathrm{~h}: \quad$ ON $/$ ON-1* $\sim 2: 1, \mathbf{O N} / \mathrm{ds}-60 \sim 43: 1, \mathbf{O N} / \mathrm{ds}-60^{(*)} \sim 5.5: 1$, ds-60 / ds- $60^{(*)} \sim 1: 7.5$. 


\subsubsection{ON-1 (ds-60) / (1S,10R)-34a $=1: n(n=1,5)$}

Die Wechselwirkung von $(1 S, 10 R)$-34a mit dem DNA-Oligonukleotid ON-1 (ds-60) wurde nach AAV $7.2(\mathrm{n}=1,5)$ untersucht.

$0 \mathrm{~h}:$

\begin{tabular}{cccc}
\hline Verbindung & Summenformel & berechnet & gefunden \\
\hline$(1 S, 10 R)-34 a$ & $\mathrm{C}_{27} \mathrm{H}_{28} \mathrm{O}_{3} \mathrm{~N}_{3} \mathrm{Cl}$ & 477.18 & 477.19 \\
$\mathbf{4 3 a}$ & $\mathrm{C}_{27} \mathrm{H}_{27} \mathrm{O}_{3} \mathrm{~N}_{3}$ & 441.21 & 441.21 \\
$\mathbf{O N - 1}$ (ds-60) & $\mathrm{C}_{146} \mathrm{H}_{185} \mathrm{O}_{89} \mathrm{~N}_{55} \mathrm{P}_{14}$ & 4565.80 & 4565.86 \\
\hline
\end{tabular}

\begin{tabular}{|c|c|c|c|c|}
\hline \multirow[t]{16}{*}{$24 \mathrm{~h}(\mathrm{n}=1)$} & Verbindung & Summenformel & berechnet & gefunden \\
\hline & $43 a$ & $\mathrm{C}_{27} \mathrm{H}_{27} \mathrm{O}_{3} \mathrm{~N}_{3}$ & 441.21 & 441.21 \\
\hline & $84 a$ & $\mathrm{C}_{27} \mathrm{H}_{29} \mathrm{O}_{4} \mathrm{~N}_{3}$ & 459.22 & 459.22 \\
\hline & $A *(34 a)$ & $\mathrm{C}_{32} \mathrm{H}_{32} \mathrm{O}_{3} \mathrm{~N}_{8}$ & 576.26 & 576.26 \\
\hline & $G *(34 a)$ & $\mathrm{C}_{32} \mathrm{H}_{32} \mathrm{O}_{4} \mathrm{~N}_{8}$ & 592.25 & 592.26 \\
\hline & $\mathrm{w}_{2}(\mathrm{ON}-1$ (ds-60)) & $\mathrm{C}_{19} \mathrm{H}_{26} \mathrm{O}_{13} \mathrm{~N}_{8} \mathrm{P}_{2}$ & 636.11 & 636.11 \\
\hline & $a_{3}-B_{3}(O N-1($ ds-60) $)$ & $\mathrm{C}_{24} \mathrm{H}_{30} \mathrm{O}_{14} \mathrm{~N}_{8} \mathrm{P}_{2}$ & 716.14 & 716.14 \\
\hline & $\mathrm{w}_{4}(\mathrm{ON}-1$ (ds-60)) & $\mathrm{C}_{38} \mathrm{H}_{51} \mathrm{O}_{26} \mathrm{~N}_{13} \mathrm{P}_{4}$ & 1229.20 & 1229.22 \\
\hline & $w_{5}(\mathrm{ON}-1(\mathrm{ds}-60))$ & $\mathrm{C}_{48} \mathrm{H}_{63} \mathrm{O}_{32} \mathrm{~N}_{18} \mathrm{P}_{5}$ & 1558.25 & 1558.27 \\
\hline & $\mathbf{a}_{7}-\mathbf{B}_{7}(\mathrm{ON}-1$ (ds-60)) & $\mathrm{C}_{63} \mathrm{H}_{79} \mathrm{O}_{38} \mathrm{~N}_{23} \mathrm{P}_{6}$ & 1951.34 & 1951.36 \\
\hline & $\mathrm{w}_{8}(\mathrm{ON}-1$ (ds-60)) & $\mathrm{C}_{78} \mathrm{H}_{101} \mathrm{O}_{51} \mathrm{~N}_{42} \mathrm{P}_{12}$ & 2479.40 & 2479.44 \\
\hline & $\mathrm{w}_{12}(\mathrm{ON}-1$ (ds-60)) & $\mathrm{C}_{117} \mathrm{H}_{150} \mathrm{O}_{74} \mathrm{~N}_{27} \mathrm{P}_{8}$ & 3698.61 & 3698.67 \\
\hline & ON-1-A (ds-60) & $\mathrm{C}_{141} \mathrm{H}_{180} \mathrm{O}_{89} \mathrm{~N}_{50} \mathrm{P}_{14}$ & 4430.74 & 4430.81 \\
\hline & ON-1-G (ds-60) & $\mathrm{C}_{141} \mathrm{H}_{180} \mathrm{O}_{88} \mathrm{~N}_{50} \mathrm{P}_{14}$ & 4414.75 & 4414.81 \\
\hline & ON-1 (ds-60) & $\mathrm{C}_{146} \mathrm{H}_{185} \mathrm{O}_{89} \mathrm{~N}_{55} \mathrm{P}_{14}$ & 4565.80 & 4565.87 \\
\hline & ON-1* (ds-60, 34a) & $\mathrm{C}_{173} \mathrm{H}_{212} \mathrm{O}_{92} \mathrm{~N}_{58} \mathrm{P}_{14}$ & 5007.00 & 5007.10 \\
\hline
\end{tabular}

Intensitäten: $\mathbf{O N}-1 / \mathbf{O N}-\mathbf{1}^{*} \sim 5 / 1$.

Alkylierungsposition: $\mathrm{G}_{3}(\mathrm{ON}-1)>\mathrm{A}_{7}(\mathrm{ON}-1)$.

\begin{tabular}{rllll}
$24 \mathrm{~h}(\mathrm{n}=5):$ & Verbindung & Summenformel & berechnet & gefunden \\
\hline 43a & $\mathrm{C}_{27} \mathrm{H}_{27} \mathrm{O}_{3} \mathrm{~N}_{3}$ & 441.21 & 441.21 \\
$\mathbf{8 4 a}$ & $\mathrm{C}_{27} \mathrm{H}_{29} \mathrm{O}_{4} \mathrm{~N}_{3}$ & 459.22 & 459.22 \\
$(1 S, 10 R)-\mathbf{3 4 a}$ & $\mathrm{C}_{27} \mathrm{H}_{28} \mathrm{O}_{3} \mathrm{~N}_{3} \mathrm{Cl}$ & 477.18 & 477.18 \\
& $\mathbf{G}^{*}(\mathbf{3 4 a})$ & $\mathrm{C}_{32} \mathrm{H}_{32} \mathrm{O}_{4} \mathrm{~N}_{8}$ & 592.25 & 592.26 \\
& $\mathbf{a}_{3}-\mathbf{B}_{3}(\mathbf{O N}-\mathbf{1}(\mathbf{d s - 6 0 )})$ & $\mathrm{C}_{24} \mathrm{H}_{30} \mathrm{O}_{14} \mathrm{~N}_{8} \mathrm{P}_{2}$ & 716.14 & 716.14
\end{tabular}




\begin{tabular}{llll}
$\mathbf{w}_{\mathbf{4}}$ (ON-1 (ds-60)) & $\mathrm{C}_{38} \mathrm{H}_{51} \mathrm{O}_{26} \mathrm{~N}_{13} \mathrm{P}_{4}$ & 1229.20 & 1229.22 \\
$\mathbf{w}_{\mathbf{5}}(\mathbf{O N}-1$ (ds-60)) & $\mathrm{C}_{48} \mathrm{H}_{63} \mathrm{O}_{32} \mathrm{~N}_{18} \mathrm{P}_{5}$ & 1558.25 & 1558.27 \\
ON-1 (ds-60) & $\mathrm{C}_{146} \mathrm{H}_{185} \mathrm{O}_{89} \mathrm{~N}_{55} \mathrm{P}_{14}$ & 4565.80 & 4565.88 \\
ON-1* (ds-60, 34a) & $\mathrm{C}_{173} \mathrm{H}_{212} \mathrm{O}_{92} \mathrm{~N}_{58} \mathrm{P}_{14}$ & 5007.00 & 5007.08 \\
\hline
\end{tabular}

Intensitäten: $\mathbf{O N}-\mathbf{1} / \mathbf{O N}-\mathbf{1} * \sim 1 / 1$.

\subsection{6 ds-61 / $(1 S, 10 R)-34 \mathrm{a}=1: \mathrm{n}(\mathrm{n}=1,2)$}

Die Wechselwirkung von $(1 S, 10 R)$-34a mit dem DNA-Oligonukleotid ds-61 wurde nach AAV $7.2(\mathrm{n}=1,2)$ untersucht. Ergebnisse für $t=24 \mathrm{~h}$ :

\begin{tabular}{|c|c|c|c|c|}
\hline \multirow{9}{*}{$\mathrm{n}=1,2$ : } & Verbindung & Summenformel & berechnet & gefunden \\
\hline & $\mathrm{w}_{1}(\mathrm{ON}-1$ (ds-61)) & $\mathrm{C}_{10} \mathrm{H}_{14} \mathrm{O}_{7} \mathrm{~N}_{5} \mathrm{P}$ & 347.06 & 347.06 \\
\hline & $43 a$ & $\mathrm{C}_{27} \mathrm{H}_{27} \mathrm{O}_{3} \mathrm{~N}_{3}$ & 441.21 & 441.20 \\
\hline & $A *(34 a)$ & $\mathrm{C}_{32} \mathrm{H}_{32} \mathrm{O}_{3} \mathrm{~N}_{8}$ & 576.26 & 576.26 \\
\hline & $a_{14}-B_{14}(\mathrm{ON}-1(\mathrm{ds}-61))$ & $\mathrm{C}_{131} \mathrm{H}_{161} \mathrm{O}_{82} \mathrm{~N}_{45} \mathrm{P}_{13} \mathrm{Na}_{5}$ & 4193.59 & 4193.63 \\
\hline & ON-1-A (ds-61) & $\mathrm{C}_{141} \mathrm{H}_{175} \mathrm{O}_{89} \mathrm{~N}_{50} \mathrm{P}_{14} \mathrm{Na}_{5}$ & 4540.65 & 4540.71 \\
\hline & ON-1 (ds-61) & $\mathrm{C}_{146} \mathrm{H}_{180} \mathrm{O}_{89} \mathrm{~N}_{55} \mathrm{P}_{14} \mathrm{Na}_{5}$ & 4675.71 & 4675.76 \\
\hline & ON-2 (ds-61) & $\mathrm{C}_{146} \mathrm{H}_{179} \mathrm{O}_{87} \mathrm{~N}_{58} \mathrm{P}_{14} \mathrm{Na}_{5}$ & 4684.72 & 4684.77 \\
\hline & ON-1* (ds-61, 34a) & $\mathrm{C}_{173} \mathrm{H}_{207} \mathrm{O}_{92} \mathrm{~N}_{58} \mathrm{P}_{14} \mathrm{Na}_{5}$ & 5116.91 & 5116.97 \\
\hline
\end{tabular}

Alkylierung ON-1 (berechnet nach AAV 7.3): 60\% $(\mathrm{n}=1)$ bzw. $\sim 40 \%(\mathrm{n}=2)$. Alkylierungsposition: $\mathrm{A}_{14}(\mathrm{ON}-1)$.

\subsection{7 ds-62 / $(1 S, 10 R)-34 a=1: n(n=1,2)$}

Die Wechselwirkung von $(1 S, 10 R)$-34a mit dem DNA-Oligonukleotid ds-62 wurde nach AAV $7.2(\mathrm{n}=1,2)$ untersucht. Ergebnisse für $t=24 \mathrm{~h}$ :

\begin{tabular}{|c|c|c|c|c|}
\hline \multirow[t]{6}{*}{$\mathrm{n}=1,2$} & Verbindung & Summenformel & berechnet & gefunden \\
\hline & $(1 S, 10 S)-\mathbf{4 3 a}$ & $\mathrm{C}_{27} \mathrm{H}_{27} \mathrm{O}_{3} \mathrm{~N}_{3}$ & 441.21 & 441.21 \\
\hline & $A^{*}(34 a)$ & $\mathrm{C}_{32} \mathrm{H}_{32} \mathrm{O}_{3} \mathrm{~N}_{8}$ & 576.26 & 576.26 \\
\hline & $\mathrm{w}_{5}(\mathrm{ON}-1$ (ds-62)) & $\mathrm{C}_{48} \mathrm{H}_{63} \mathrm{O}_{32} \mathrm{~N}_{18} \mathrm{P}_{5}$ & 1558.25 & 1558.25 \\
\hline & $a_{10}-B_{10}(\mathrm{ON}-1(\mathrm{ds}-62))$ & $\mathrm{C}_{92} \mathrm{H}_{112} \mathrm{O}_{58} \mathrm{~N}_{30} \mathrm{P}_{9} \mathrm{Na}_{5}$ & 2958.39 & 2958.43 \\
\hline & ON-1-A (ds-62) & $\mathrm{C}_{140} \mathrm{H}_{175} \mathrm{O}_{90} \mathrm{~N}_{48} \mathrm{P}_{14} \mathrm{Na}_{5}$ & 4516.64 & 4516.70 \\
\hline
\end{tabular}




$\begin{array}{llll}\text { ON-1 (ds-62) } & \mathrm{C}_{145} \mathrm{H}_{180} \mathrm{O}_{90} \mathrm{~N}_{53} \mathrm{P}_{14} \mathrm{Na}_{5} & 4651.70 & 4651.75 \\ \text { ON-2 (ds-62) } & \mathrm{C}_{146} \mathrm{H}_{178} \mathrm{O}_{86} \mathrm{~N}_{61} \mathrm{P}_{14} \mathrm{Na}_{5} & 4709.72 & 4709.78 \\ \text { ON-1* (ds-62, 34a) } & \mathrm{C}_{172} \mathrm{H}_{207} \mathrm{O}_{93} \mathrm{~N}_{56} \mathrm{P}_{14} \mathrm{Na}_{5} & 5092.90 & 5092.96\end{array}$

Alkylierung ON-1 (berechnet nach AAV 7.3): 55\% $(\mathrm{n}=1)$ bzw. $\sim 30 \%(\mathrm{n}=2)$.

Alkylierungsposition: $\mathrm{A}_{10}(\mathrm{ON}-1)$.

\subsection{8 ds-63 / $(1 S, 10 R)-34 a=1: n(n=1,2)$}

Die Wechselwirkung von $(1 S, 10 R)$-34a mit dem DNA-Oligonukleotid ds-63 wurde nach AAV $7.2(\mathrm{n}=1,2)$ untersucht. Ergebnisse für $t=24 \mathrm{~h}$ :

\begin{tabular}{|c|c|c|c|c|}
\hline \multirow{8}{*}{$\mathrm{n}=1,2$ : } & Verbindung & Summenformel & berechnet & gefunden \\
\hline & $43 a$ & $\mathrm{C}_{27} \mathrm{H}_{27} \mathrm{O}_{3} \mathrm{~N}_{3}$ & 441.21 & 441.21 \\
\hline & $84 a$ & $\mathrm{C}_{27} \mathrm{H}_{29} \mathrm{O}_{4} \mathrm{~N}_{3}$ & 459.22 & 459.21 \\
\hline & $G^{*}(34 a)$ & $\mathrm{C}_{32} \mathrm{H}_{32} \mathrm{O}_{4} \mathrm{~N}_{8}$ & 592.25 & 592.26 \\
\hline & $\mathrm{w}_{2}(\mathrm{ON}(\mathrm{ds}-63))$ & $\mathrm{C}_{19} \mathrm{H}_{26} \mathrm{O}_{13} \mathrm{~N}_{8} \mathrm{P}_{2}$ & 636.11 & 636.11 \\
\hline & $a_{3}-B_{3}(\mathrm{ON}-2(\mathrm{ds}-63))$ & $\mathrm{C}_{24} \mathrm{H}_{30} \mathrm{O}_{14} \mathrm{~N}_{8} \mathrm{P}_{2}$ & 716.14 & 716.14 \\
\hline & ON-1 (ds-63) & $\mathrm{C}_{145} \mathrm{H}_{179} \mathrm{O}_{89} \mathrm{~N}_{56} \mathrm{P}_{14} \mathrm{Na}_{5}$ & 4676.70 & 4676.80 \\
\hline & ON-2 (ds-63) & $\mathrm{C}_{145} \mathrm{H}_{178} \mathrm{O}_{87} \mathrm{~N}_{59} \mathrm{P}_{14} \mathrm{Na}_{5}$ & 4685.71 & 4685.80 \\
\hline
\end{tabular}

Schwache Alkylierung an G.

\subsection{9 ds-64 / $(1 S, 10 R)-34 a=1: n(n=1,2)$}

Die Wechselwirkung von $(1 S, 10 R)$-34a mit dem DNA-Oligonukleotid ds-64 wurde nach AAV $7.2(\mathrm{n}=1,2)$ untersucht. Ergebnisse für $t=24 \mathrm{~h}$ :

\begin{tabular}{|c|c|c|c|c|}
\hline \multirow[t]{9}{*}{$\mathrm{n}=1,2:$} & Verbindung & Summenformel & berechnet & gefunden \\
\hline & $43 \mathbf{a}$ & $\mathrm{C}_{27} \mathrm{H}_{27} \mathrm{O}_{3} \mathrm{~N}_{3}$ & 441.21 & 441.21 \\
\hline & $84 a$ & $\mathrm{C}_{27} \mathrm{H}_{29} \mathrm{O}_{4} \mathrm{~N}_{3}$ & 459.22 & 459.22 \\
\hline & $A^{*}(34 a)$ & $\mathrm{C}_{32} \mathrm{H}_{32} \mathrm{O}_{3} \mathrm{~N}_{8}$ & 576.26 & 576.26 \\
\hline & $w_{5}(\mathrm{ON}-1$ (ds-64)) & $\mathrm{C}_{48} \mathrm{H}_{62} \mathrm{O}_{30} \mathrm{~N}_{21} \mathrm{P}_{5}$ & 1567.27 & 1567.28 \\
\hline & $\mathrm{w}_{5}(\mathrm{ON}-2(\mathrm{ds}-64))$ & $\mathrm{C}_{48} \mathrm{H}_{62} \mathrm{O}_{31} \mathrm{~N}_{21} \mathrm{P}_{5}$ & 1583.26 & 1583.27 \\
\hline & $a_{10}-B_{10}(\mathrm{ON}-1(\mathrm{ds}-64))$ & $\mathrm{C}_{92} \mathrm{H}_{114} \mathrm{O}_{54} \mathrm{~N}_{36} \mathrm{P}_{9} \mathrm{Na}$ & 2888.48 & 2888.50 \\
\hline & $a_{10}-B_{10}(\mathrm{ON}-2(\mathrm{ds}-64))$ & $\mathrm{C}_{93} \mathrm{H}_{117} \mathrm{O}_{61} \mathrm{~N}_{26} \mathrm{P}_{9} \mathrm{Na}_{2}$ & 2898.43 & 2898.50 \\
\hline & ON-1-A (ds-64) & $\mathrm{C}_{140} \mathrm{H}_{172} \mathrm{O}_{84} \mathrm{~N}_{57} \mathrm{P}_{14} \mathrm{Na}_{5}$ & 4543.68 & 4543.70 \\
\hline
\end{tabular}




\begin{tabular}{llll} 
ON-2-A (ds-64) & $\mathrm{C}_{141} \mathrm{H}_{181} \mathrm{O}_{92} \mathrm{~N}_{47} \mathrm{P}_{14} \mathrm{Na}_{5}$ & 4547.64 & 4547.65 \\
ON-1 (ds-64) & $\mathrm{C}_{145} \mathrm{H}_{177} \mathrm{O}_{84} \mathrm{~N}_{62} \mathrm{P}_{14} \mathrm{Na}_{5}$ & 4678.73 & 4678.76 \\
ON-2 (ds-64) & $\mathrm{C}_{146} \mathrm{H}_{181} \mathrm{O}_{92} \mathrm{~N}_{52} \mathrm{P}_{14} \mathrm{Na}_{5}$ & 4682.69 & 4682.74 \\
ON-1* (ds-64, 34a) & $\mathrm{C}_{172} \mathrm{H}_{204} \mathrm{O}_{87} \mathrm{~N}_{65} \mathrm{P}_{14} \mathrm{Na}_{5}$ & 5119.94 & 5120.01 \\
\hline
\end{tabular}

Alkylierungsposition: $\mathrm{A}_{10}(\mathrm{ON}-1) \gg>\mathrm{A}_{10}(\mathrm{ON}-2)$.

Intensität: $\mathbf{w}_{5}(\mathbf{O N}-1) / \mathbf{w}_{5}(\mathbf{O N}-2) \sim \mathbf{a}_{10}-\mathbf{B}_{10}(\mathbf{O N}-1) / \mathbf{a}_{10}-\mathbf{B}_{10}(\mathbf{O N}-2) \sim 4: 1$.

Alkylierungseffizienz $(n=1)>$ Alkylierungseffizienz $(n=2)$.

\subsubsection{0 ds-65 / $(1 S, 10 R)-34 a=1: n(n=1,2)$}

Die Wechselwirkung von $(1 S, 10 R)$-34a mit dem DNA-Oligonukleotid ds-65 wurde nach AAV $7.2(\mathrm{n}=1,2)$ untersucht. Ergebnisse für $t=24 \mathrm{~h}$ :

\begin{tabular}{|c|c|c|c|c|}
\hline \multirow[t]{13}{*}{$\mathrm{n}=1,2$} & Verbindung & Summenformel & berechnet & gefunden \\
\hline & $43 a$ & $\mathrm{C}_{27} \mathrm{H}_{27} \mathrm{O}_{3} \mathrm{~N}_{3}$ & 441.21 & 441.21 \\
\hline & $84 a$ & $\mathrm{C}_{27} \mathrm{H}_{29} \mathrm{O}_{4} \mathrm{~N}_{3}$ & 459.22 & 459.22 \\
\hline & $A *(34 a)$ & $\mathrm{C}_{32} \mathrm{H}_{32} \mathrm{O}_{3} \mathrm{~N}_{8}$ & 576.26 & 576.27 \\
\hline & $G^{*}(34 a)$ & $\mathrm{C}_{32} \mathrm{H}_{32} \mathrm{O}_{4} \mathrm{~N}_{8}$ & 592.25 & 592.26 \\
\hline & $w_{6}(\mathrm{ON}(\mathrm{ds}-65))$ & $\mathrm{C}_{58} \mathrm{H}_{76} \mathrm{O}_{39} \mathrm{~N}_{20} \mathrm{P}_{6}$ & 1862.30 & 1862.31 \\
\hline & $w_{7}(\mathrm{ON}-2(\mathrm{ds}-65))$ & $\mathrm{C}_{68} \mathrm{H}_{88} \mathrm{O}_{44} \mathrm{~N}_{25} \mathrm{P}_{7}$ & 2175.36 & 2175.37 \\
\hline & $a_{8}-B_{8}(\mathrm{ON}-2(\mathrm{ds}-65))$ & $\mathrm{C}_{73} \mathrm{H}_{91} \mathrm{O}_{43} \mathrm{~N}_{28} \mathrm{P}_{7}$ & 2264.40 & 2264.40 \\
\hline & $a_{9}-B_{9}(\mathrm{ON}-2(\mathrm{ds}-65))$ & $\mathrm{C}_{83} \mathrm{H}_{100} \mathrm{O}_{48} \mathrm{~N}_{33} \mathrm{P}_{8} \mathrm{Na}_{3}$ & 2643.40 & 2643.43 \\
\hline & ON-1-A (ds-65) & $\mathrm{C}_{141} \mathrm{H}_{175} \mathrm{O}_{89} \mathrm{~N}_{50} \mathrm{P}_{14} \mathrm{Na}_{5}$ & 4540.65 & 4540.72 \\
\hline & ON-2-A (ds-65) & $\mathrm{C}_{141} \mathrm{H}_{174} \mathrm{O}_{87} \mathrm{~N}_{53} \mathrm{P}_{14} \mathrm{Na}_{5}$ & 4549.66 & 4549.72 \\
\hline & ON-1 (ds-65) & $\mathrm{C}_{146} \mathrm{H}_{185} \mathrm{O}_{89} \mathrm{~N}_{55} \mathrm{P}_{14} \mathrm{Na}_{5}$ & 4675.71 & 4675.76 \\
\hline & ON-2 (ds-65) & $\mathrm{C}_{146} \mathrm{H}_{179} \mathrm{O}_{87} \mathrm{~N}_{58} \mathrm{P}_{14} \mathrm{Na}_{5}$ & 4684.72 & 4684.77 \\
\hline
\end{tabular}

Alkylierung ON-2 (berechnet nach AAV 7.3): 30\% $(\mathrm{n}=1)$ bzw. $\sim 18 \%(\mathrm{n}=2)$.

Alkylierungsposition: $\mathrm{A}_{8}(\mathrm{ON}-2)>>\mathrm{A}_{9}(\mathrm{ON}-2)$.

Intensität: $\mathbf{a}_{8}-\mathbf{B}_{\mathbf{8}}(\mathbf{O N}-2) / \mathbf{a}_{9}-\mathbf{B}_{\mathbf{9}}(\mathbf{O N}-\mathbf{2}) \sim 4: 1$. 


\subsubsection{1 ds-66 / $(1 S, 10 R)-34 a=1: n(n=1,2)$}

Die Wechselwirkung von $(1 S, 10 R)$-34a mit dem DNA-Oligonukleotid ds-66 wurde nach AAV $7.2(\mathrm{n}=1,2)$ untersucht. Ergebnisse für $t=24 \mathrm{~h}$ :

\begin{tabular}{|c|c|c|c|c|}
\hline \multirow{12}{*}{$\mathrm{n}=1,2$ : } & Verbindung & Summenformel & berechnet & gefunden \\
\hline & $43 \mathbf{a}$ & $\mathrm{C}_{27} \mathrm{H}_{27} \mathrm{O}_{3} \mathrm{~N}_{3}$ & 441.21 & 441.21 \\
\hline & $84 a$ & $\mathrm{C}_{27} \mathrm{H}_{29} \mathrm{O}_{4} \mathrm{~N}_{3}$ & 459.22 & 459.22 \\
\hline & $A *(34 a)$ & $\mathrm{C}_{32} \mathrm{H}_{32} \mathrm{O}_{3} \mathrm{~N}_{8}$ & 576.26 & 576.26 \\
\hline & $w_{5}(\mathrm{ON}(\mathrm{ds}-66))$ & $\mathrm{C}_{48} \mathrm{H}_{62} \mathrm{O}_{31} \mathrm{~N}_{21} \mathrm{P}_{5}$ & 1583.26 & 1583.26 \\
\hline & $a_{10}-B_{10}(\mathrm{ON}-1(\mathrm{ds}-66))$ & $\mathrm{C}_{92} \mathrm{H}_{114} \mathrm{O}_{58} \mathrm{~N}_{30} \mathrm{P}_{9} \mathrm{Na}_{3}$ & 2914.42 & 2914.45 \\
\hline & $a_{10}-B_{10}(\mathrm{ON}-2(\mathrm{ds}-66))$ & $\mathrm{C}_{92} \mathrm{H}_{114} \mathrm{O}_{56} \mathrm{~N}_{33} \mathrm{P}_{9} \mathrm{Na}_{2}$ & 2901.45 & 2901.49 \\
\hline & ON-1-A (ds-66) & $\mathrm{C}_{140} \mathrm{H}_{174} \mathrm{O}_{89} \mathrm{~N}_{51} \mathrm{P}_{14} \mathrm{Na}_{5}$ & 4541.65 & 4541.70 \\
\hline & ON-2-A (ds-66) & $\mathrm{C}_{141} \mathrm{H}_{173} \mathrm{O}_{87} \mathrm{~N}_{54} \mathrm{P}_{14} \mathrm{Na}_{5}$ & 4550.66 & 4550.71 \\
\hline & ON-1 (ds-66) & $\mathrm{C}_{145} \mathrm{H}_{179} \mathrm{O}_{89} \mathrm{~N}_{56} \mathrm{P}_{14} \mathrm{Na}_{5}$ & 4676.70 & 4676.75 \\
\hline & ON-2 (ds-66) & $\mathrm{C}_{145} \mathrm{H}_{178} \mathrm{O}_{87} \mathrm{~N}_{59} \mathrm{P}_{14} \mathrm{Na}_{5}$ & 4685.71 & 4685.76 \\
\hline & ON-2* (ds-66, 34a) & $\mathrm{C}_{172} \mathrm{H}_{203} \mathrm{O}_{90} \mathrm{~N}_{62} \mathrm{P}_{14} \mathrm{Na}_{7}$ & 5170.88 & 5170.95 \\
\hline
\end{tabular}

Alkylierungsposition: $\mathrm{A}_{10}(\mathrm{ON}-2) / \mathrm{A}_{10}(\mathrm{ON}-1) \sim 2: 1$.

Intensität: $\mathbf{a}_{10}-\mathbf{B}_{10}(\mathbf{O N}-2) / \mathbf{a}_{10}-\mathbf{B}_{10}(\mathbf{O N}-1) \sim 2: 1$.

Alkylierungseffizienz $(\mathrm{n}=1)>$ Alkylierungseffizienz $(\mathrm{n}=2)$.

\subsubsection{2 ds-67 / $(1 S, 10 R)-34 a=1: n(n=1,2)$}

Die Wechselwirkung von $(1 S, 10 R)$-34a mit dem DNA-Oligonukleotid ds-67 wurde nach AAV $7.2(\mathrm{n}=1,2)$ untersucht. Ergebnisse für $t=24 \mathrm{~h}$ :

\begin{tabular}{|c|c|c|c|c|}
\hline \multirow[t]{9}{*}{$\mathrm{n}=1,2$ : } & Verbindung & Summenformel & berechnet & gefunden \\
\hline & $(1 S, 10 S)-\mathbf{4 3 a}$ & $\mathrm{C}_{27} \mathrm{H}_{27} \mathrm{O}_{3} \mathrm{~N}_{3}$ & 441.21 & 441.20 \\
\hline & $A^{*}(34 a)$ & $\mathrm{C}_{32} \mathrm{H}_{32} \mathrm{O}_{3} \mathrm{~N}_{8}$ & 576.26 & 576.27 \\
\hline & $a_{6}-B_{6}(O N-1(d s-67))$ & $\mathrm{C}_{53} \mathrm{H}_{66} \mathrm{O}_{31} \mathrm{~N}_{18} \mathrm{P}_{5} \mathrm{Na}$ & 1628.27 & 1628.29 \\
\hline & $a_{6}-B_{6}(O N-2(d s-67))$ & $\mathrm{C}_{54} \mathrm{H}_{65} \mathrm{O}_{29} \mathrm{~N}_{23} \mathrm{P}_{5} \mathrm{Na}$ & 1677.29 & 1677.31 \\
\hline & $a_{7}-B_{7}(O N-1(d s-67))$ & $\mathrm{C}_{63} \mathrm{H}_{76} \mathrm{O}_{36} \mathrm{~N}_{23} \mathrm{P}_{6} \mathrm{Na}_{3}$ & 1985.29 & 1985.33 \\
\hline & $a_{7}-B_{7}(O N-2(d s-67))$ & $\mathrm{C}_{64} \mathrm{H}_{77} \mathrm{O}_{34} \mathrm{~N}_{28} \mathrm{P}_{6} \mathrm{Na}$ & 1990.34 & 1990.37 \\
\hline & $\mathrm{w}_{9}(\mathrm{ON}-1$ (ds-67)) & $\mathrm{C}_{88} \mathrm{H}_{112} \mathrm{O}_{60} \mathrm{~N}_{26} \mathrm{P}_{9} \mathrm{Na}_{3}$ & 2840.38 & 2840.43 \\
\hline & $w_{9}(\mathrm{ON}-2$ (ds-67)) & $\mathrm{C}_{89} \mathrm{H}_{109} \mathrm{O}_{58} \mathrm{~N}_{31} \mathrm{P}_{9} \mathrm{Na}_{5}$ & 2933.37 & 2933.41 \\
\hline
\end{tabular}




\begin{tabular}{llll}
$\mathbf{w}_{10}(\mathbf{O N}-1$ (ds-67)) & $\mathrm{C}_{98} \mathrm{H}_{127} \mathrm{O}_{65} \mathrm{~N}_{31} \mathrm{P}_{10} \mathrm{Na}_{5}$ & 3197.41 & 3197.45 \\
$\mathbf{w}_{10}(\mathbf{O N}-2$ (ds-67)) & $\mathrm{C}_{99} \mathrm{H}_{121} \mathrm{O}_{63} \mathrm{~N}_{36} \mathrm{P}_{10} \mathrm{Na}_{5}$ & 3246.42 & 3246.46 \\
ON-1-A (ds-67) & $\mathrm{C}_{153} \mathrm{H}_{187} \mathrm{O}_{92} \mathrm{~N}_{59} \mathrm{P}_{15} \mathrm{Na}_{5}$ & 4803.70 & 4803.75 \\
ON-2-A (ds-67) & $\mathrm{C}_{153} \mathrm{H}_{187} \mathrm{O}_{92} \mathrm{~N}_{59} \mathrm{P}_{15} \mathrm{Na}_{5}$ & 4901.73 & 4901.79 \\
ON-1 (ds-67) & $\mathrm{C}_{156} \mathrm{H}_{194} \mathrm{O}_{96} \mathrm{~N}_{54} \mathrm{P}_{15} \mathrm{Na}_{5}$ & 4938.75 & 4938.80 \\
ON-1* (ds-67, 34a) & $\mathrm{C}_{183} \mathrm{H}_{219} \mathrm{O}_{99} \mathrm{~N}_{57} \mathrm{P}_{15} \mathrm{Na}_{7}$ & 5423.92 & 5423.03 \\
ON-2* (ds-67, 34a) & $\mathrm{C}_{185} \mathrm{H}_{217} \mathrm{O}_{95} \mathrm{~N}_{67} \mathrm{P}_{15} \mathrm{Na}_{7}$ & 5521.95 & 5522.04 \\
\hline
\end{tabular}

Alkylierungsposition: $\mathrm{A}_{7}(\mathrm{ON}-2)>\mathrm{A}_{7}(\mathrm{ON}-1)>\mathrm{A}_{6}(\mathrm{ON}-2) \sim \mathrm{A}_{6}(\mathrm{ON}-1)$.

Alkylierungseffizienz $(n=1)>$ Alkylierungseffizienz $(n=2)$.

\subsubsection{3 ds-68 / $(1 S, 10 R)-34 a=1: n(n=1,2)$}

Die Wechselwirkung von $(1 S, 10 R)$-34a mit dem DNA-Oligonukleotid ds-68 wurde nach AAV $7.2(\mathrm{n}=1,2)$ untersucht. Ergebnisse für $t=24 \mathrm{~h}$ :

\begin{tabular}{|c|c|c|c|c|}
\hline \multirow{12}{*}{$\mathrm{n}=1,2$} & Verbindung & Summenformel & berechnet & gefunden \\
\hline & $43 a$ & $\mathrm{C}_{27} \mathrm{H}_{27} \mathrm{O}_{3} \mathrm{~N}_{3}$ & 441.21 & 441.21 \\
\hline & $84 a$ & $\mathrm{C}_{27} \mathrm{H}_{29} \mathrm{O}_{4} \mathrm{~N}_{3}$ & 459.22 & 459.22 \\
\hline & $A *(34 a)$ & $\mathrm{C}_{32} \mathrm{H}_{32} \mathrm{O}_{3} \mathrm{~N}_{8}$ & 576.26 & 576.27 \\
\hline & $w_{4}(\mathrm{ON}-2(\mathrm{ds}-68))$ & $\mathrm{C}_{38} \mathrm{H}_{50} \mathrm{O}_{25} \mathrm{~N}_{16} \mathrm{P}_{4}$ & 1254.21 & 1254.23 \\
\hline & $w_{5}(\mathrm{ON}(\mathrm{ds}-68))$ & $\mathrm{C}_{48} \mathrm{H}_{61} \mathrm{O}_{30} \mathrm{~N}_{21} \mathrm{P}_{5} \mathrm{Na}$ & 1589.25 & 1589.27 \\
\hline & $a_{10}-B_{10}(\mathrm{ON}-2(\mathrm{ds}-68))$ & $\mathrm{C}_{93} \mathrm{H}_{113} \mathrm{O}_{57} \mathrm{~N}_{32} \mathrm{P}_{9} \mathrm{Na}_{4}$ & 2960.41 & 2960.45 \\
\hline & $a_{11}-B_{11}(\mathrm{ON}-2(\mathrm{ds}-68))$ & $\mathrm{C}_{103} \mathrm{H}_{125} \mathrm{O}_{62} \mathrm{~N}_{37} \mathrm{P}_{10} \mathrm{Na}_{4}$ & 3273.47 & 3273.51 \\
\hline & ON-2-A (ds-68) & $\mathrm{C}_{141} \mathrm{H}_{174} \mathrm{O}_{87} \mathrm{~N}_{53} \mathrm{P}_{14} \mathrm{Na}_{5}$ & 4549.66 & 4549.72 \\
\hline & ON-1 (ds-68) & $\mathrm{C}_{146} \mathrm{H}_{180} \mathrm{O}_{89} \mathrm{~N}_{55} \mathrm{P}_{14} \mathrm{Na}_{5}$ & 4675.72 & 4675.77 \\
\hline & ON-2 (ds-68) & $\mathrm{C}_{146} \mathrm{H}_{179} \mathrm{O}_{87} \mathrm{~N}_{58} \mathrm{P}_{14} \mathrm{Na}_{5}$ & 4684.72 & 4684.78 \\
\hline & ON-2* (ds-68, 34a) & $\mathrm{C}_{173} \mathrm{H}_{203} \mathrm{O}_{90} \mathrm{~N}_{61} \mathrm{P}_{14} \mathrm{Na}_{8}$ & 5191.87 & 5191.96 \\
\hline
\end{tabular}

Alkylierung ON-2 (berechnet nach AAV 7.3): 77\% $(\mathrm{n}=1), \sim 58 \%(\mathrm{n}=2)$.

Alkylierungsposition: $\mathrm{A}_{10}(\mathrm{ON}-2) \sim \mathrm{A}_{11}(\mathrm{ON}-2)$. 
7.4.14 ds-69 / $(1 S, 10 R)-34 a=1: n(n=1,2)$

Die Wechselwirkung von $(1 S, 10 R)$-34a mit dem DNA-Oligonukleotid ds-69 wurde nach AAV $7.2(\mathrm{n}=1,2)$ untersucht. Ergebnisse für $t=24 \mathrm{~h}$ :

\begin{tabular}{|c|c|c|c|c|}
\hline \multirow[t]{6}{*}{$\mathrm{n}=1,2$ : } & Verbindung & Summenformel & berechnet & gefunden \\
\hline & $43 a$ & $\mathrm{C}_{27} \mathrm{H}_{27} \mathrm{O}_{3} \mathrm{~N}_{3}$ & 441.21 & 441.21 \\
\hline & $84 a$ & $\mathrm{C}_{27} \mathrm{H}_{29} \mathrm{O}_{4} \mathrm{~N}_{3}$ & 459.22 & 459.26 \\
\hline & $G^{*}(34 a)$ & $\mathrm{C}_{32} \mathrm{H}_{32} \mathrm{O}_{4} \mathrm{~N}_{8}$ & 592.25 & 592.26 \\
\hline & ON-1 (ds-69) & $\mathrm{C}_{145} \mathrm{H}_{179} \mathrm{O}_{89} \mathrm{~N}_{56} \mathrm{P}_{14} \mathrm{Na}_{5}$ & 4676.70 & 4676.72 \\
\hline & ON-2 (ds-69) & $\mathrm{C}_{145} \mathrm{H}_{178} \mathrm{O}_{87} \mathrm{~N}_{59} \mathrm{P}_{14} \mathrm{Na}_{5}$ & 4685.71 & 4685.74 \\
\hline
\end{tabular}

Schwache Alkylierung an G.

\subsection{Massenspektrometrische Untersuchung der Wechselwirkung des seco-Drugs $(+)-(1 S, 10 R)-34 a$ mit dem RNA-Oligonukleotid ds-59}

\subsection{1 ds-59 / $(1 S, 10 R)-34 a=1: n(n=1,5)$}

1 Aliquot der Stammlösung von $(1 S, 10 R)$-34a in DMSO (n $\mu \mathrm{L},(5 \times \mathrm{n}) \mathrm{nmol}, \mathrm{n}$ Äq.) wurde nach AAV 7.1 in die Lösung des RNA-Oligonukleotides (50 $\mu \mathrm{L}, 5$ nmol, 1 Äq.) pipettiert und die Reaktionsmischung $24 \mathrm{~h}$ bei $25{ }^{\circ} \mathrm{C}$ inkubiert. $\mathrm{Zu}$ den Zeitpunkten $t=0 \mathrm{~h}$ und $t=24 \mathrm{~h}$ wurde die Reaktionsmischung massenspektrometrisch untersucht.

\begin{tabular}{|c|c|c|c|}
\hline Verbindung & Summenformel & berechnet & gefunden \\
\hline $43 \mathbf{a}$ & $\mathrm{C}_{27} \mathrm{H}_{27} \mathrm{O}_{3} \mathrm{~N}_{3}$ & 441.21 & 441.21 \\
\hline$(1 S, 10 R)-\mathbf{3 4 a}$ & $\mathrm{C}_{27} \mathrm{H}_{28} \mathrm{O}_{3} \mathrm{~N}_{3} \mathrm{Cl}$ & 477.18 & 477.19 \\
\hline ON-1 (ds-59) & $\mathrm{C}_{142} \mathrm{H}_{171} \mathrm{O}_{102} \mathrm{~N}_{56} \mathrm{P}_{14} \mathrm{Na}_{7}$ & 4886.55 & 4886.61 \\
\hline ON-2 (ds-59) & $\mathrm{C}_{143} \mathrm{H}_{170} \mathrm{O}_{104} \mathrm{~N}_{57} \mathrm{P}_{14} \mathrm{Na}_{7}$ & 4943.54 & 4943.59 \\
\hline $\begin{array}{l}\text { ON-1 (ds-59) } \\
(1 S, 10 R)-\mathbf{3 4 a}\end{array}$ & $\mathrm{C}_{169} \mathrm{H}_{199} \mathrm{O}_{105} \mathrm{~N}_{59} \mathrm{P}_{14} \mathrm{Na}_{7} \mathrm{Cl}$ & 5420.72 & 5420.83 \\
\hline $\begin{array}{l}\text { ON-2 (ds-59) } \\
(1 S, 10 R)-34 \mathbf{a}\end{array}$ & $\mathrm{C}_{170} \mathrm{H}_{198} \mathrm{O}_{107} \mathrm{~N}_{60} \mathrm{P}_{14} \mathrm{Na}_{7} \mathrm{Cl}$ & 5363.73 & 5363.89 \\
\hline ON-1/ON-2 (ds-59) & $\mathrm{C}_{285} \mathrm{H}_{336} \mathrm{O}_{206} \mathrm{~N}_{113} \mathrm{P}_{28} \mathrm{Na}_{19}$ & 9940.00 & 9940.16 \\
\hline $\begin{array}{l}\text { ON-1/ON-2 (ds-59) } \\
(1 S, 10 R)-34 \mathbf{a}\end{array}$ & $\mathrm{C}_{312} \mathrm{H}_{364} \mathrm{O}_{209} \mathrm{~N}_{116} \mathrm{P}_{28} \mathrm{Na}_{19} \mathrm{Cl}$ & 10417.18 & 10417.31 \\
\hline
\end{tabular}




\begin{tabular}{lllll}
$24 \mathrm{~h}(\mathrm{n}=1):$ & Verbindung & Summenformel & berechnet & gefunden \\
\cline { 2 - 4 } $\mathbf{8 4 a}$ & $\mathrm{C}_{27} \mathrm{H}_{29} \mathrm{O}_{4} \mathrm{~N}_{3}$ & 459.22 & 459.22 \\
ON-1 (ds-59) & $\mathrm{C}_{142} \mathrm{H}_{171} \mathrm{O}_{102} \mathrm{~N}_{56} \mathrm{P}_{14} \mathrm{Na}_{7}$ & 4886.55 & 4886.61 \\
ON-2 (ds-59) & $\mathrm{C}_{143} \mathrm{H}_{170} \mathrm{O}_{104} \mathrm{~N}_{57} \mathrm{P}_{14} \mathrm{Na}_{7}$ & 4943.54 & 4943.59 \\
ON-1/ON-2 (ds-59) & $\mathrm{C}_{285} \mathrm{H}_{336} \mathrm{O}_{206} \mathrm{~N}_{113} \mathrm{P}_{28} \mathrm{Na}_{19}$ & 9940.00 & 9940.15 \\
\hline
\end{tabular}

Keine Alkylierung.

\begin{tabular}{|c|c|c|c|c|}
\hline \multirow[t]{12}{*}{$24 \mathrm{~h}(\mathrm{n}=5)$} & Verbindung & Summenformel & berechnet & gefunden \\
\hline & $43 a$ & $\mathrm{C}_{27} \mathrm{H}_{27} \mathrm{O}_{3} \mathrm{~N}_{3}$ & 441.21 & 441.21 \\
\hline & $(1 S, 10 R)-\mathbf{3 4 a}$ & $\mathrm{C}_{27} \mathrm{H}_{28} \mathrm{O}_{3} \mathrm{~N}_{3} \mathrm{Cl}$ & 477.18 & 477.19 \\
\hline & $84 a$ & $\mathrm{C}_{27} \mathrm{H}_{29} \mathrm{O}_{4} \mathrm{~N}_{3}$ & 459.22 & 459.22 \\
\hline & $G^{*}(34 a)$ & $\mathrm{C}_{32} \mathrm{H}_{32} \mathrm{O}_{4} \mathrm{~N}_{8}$ & 592.25 & 592.26 \\
\hline & ON-1 (ds-59) & $\mathrm{C}_{142} \mathrm{H}_{171} \mathrm{O}_{102} \mathrm{~N}_{56} \mathrm{P}_{14} \mathrm{Na}_{7}$ & 4886.55 & 4886.62 \\
\hline & ON-2 (ds-59) & $\mathrm{C}_{143} \mathrm{H}_{170} \mathrm{O}_{104} \mathrm{~N}_{57} \mathrm{P}_{14} \mathrm{Na}_{7}$ & 4943.54 & 4943.60 \\
\hline & ON-1* (ds-59, 34a) & $\mathrm{C}_{169} \mathrm{H}_{203} \mathrm{O}_{105} \mathrm{~N}_{59} \mathrm{P}_{14} \mathrm{Na}_{2}$ & 5217.85 & 5217.91 \\
\hline & ON-2* (ds-59, 34a) & $\mathrm{C}_{170} \mathrm{H}_{202} \mathrm{O}_{107} \mathrm{~N}_{60} \mathrm{P}_{14} \mathrm{Na}_{2}$ & 5274.83 & 5274.90 \\
\hline & $\begin{array}{l}\text { ON-1*(ds-59, 34a) } \\
\cdot(1 S, 10 R)-\mathbf{3 4 a}\end{array}$ & $\mathrm{C}_{196} \mathrm{H}_{228} \mathrm{O}_{108} \mathrm{~N}_{62} \mathrm{P}_{14} \mathrm{Na}_{5} \mathrm{Cl}$ & 5760.98 & 5761.09 \\
\hline & $\begin{array}{l}\mathbf{O N}-2 *(\mathbf{d s}-59) \\
(1 S, 10 R)-\mathbf{3 4 a}\end{array}$ & $\mathrm{C}_{197} \mathrm{H}_{227} \mathrm{O}_{110} \mathrm{~N}_{63} \mathrm{P}_{14} \mathrm{Na}_{5} \mathrm{Cl}$ & 5817.96 & 5818.10 \\
\hline & ON-1/ON-2 (ds-59) & $\mathrm{C}_{285} \mathrm{H}_{336} \mathrm{O}_{206} \mathrm{~N}_{113} \mathrm{P}_{28} \mathrm{Na}_{19}$ & 9940.00 & 9940.24 \\
\hline
\end{tabular}

Intensitäten: $\mathbf{O N}-\mathbf{1} * \sim \mathbf{O N}-\mathbf{2} *, \mathbf{O N} / \mathbf{O N}^{*}>9: 1$.

\subsection{Massenspektrometrische Untersuchung der Alkylierung des Tripeptides Glutathion durch das seco-Drug $(+)-(1 S, 10 R)-34 a$}

Glutathion $(\mathbf{5 8}, 30.7 \mathrm{mg}, 100 \mu \mathrm{mol})$ wurde unter Schutzatmosphäre in bidestilliertem und mit Argon gesättigtem Wasser $(1 \mathrm{~mL})$ gelöst $\left(c_{1}=100 \mathrm{mM}\right)$ und durch Verdünnen mit bidestilliertem und mit Argon gesättigtem Wasser weitere Lösungen niedrigerer Glutathion-Konzentration hergestellt $\left(c_{2}=10.0 \mathrm{mM}, \quad c_{3}=1.00 \mathrm{mM}, \quad c_{4}=100 \mu \mathrm{M}\right.$, $\left.c_{5}=50.0 \mu \mathrm{M}, c_{6}=10.0 \mu \mathrm{M}\right)$. Je $100 \mu \mathrm{L}$ der Glutathion-Lösungen der Konzentrationen $c_{1}$ bis $c_{4}$ und je $50 \mu \mathrm{L}$ der Glutathionlösungen $c_{4}$ bis $c_{6}$ wurden mit einem Aliquot der Stammlösung von $(1 S, 10 R)$-34a in DMSO $(1 \mu \mathrm{L}, 5 \mathrm{nmol})$ versetzt und die Reaktionsmischungen $24 \mathrm{~h}$ bei $25^{\circ} \mathrm{C}$ unter Argonatmosphäre inkubiert. Nach $24 \mathrm{~h}$ Inkubation wurden je $10 \mu \mathrm{L}$ der Inkubationslösung mit $90 \mu \mathrm{L}$ einer Mischung aus Wasser/ 
$\mathrm{MeOH}=1 / 1$ (Zusatz von $0.2 \%$ Ameisensäure) versetzt und massenspektrometrisch untersucht (positiver Ionenmodus). I [\%] = rel. Intensität [\%].

\begin{tabular}{ccc}
\hline Konzentration von 58 & $\mathbf{5 8} /(1 S, 10 R)-\mathbf{3 4 a}$ & Verbindungen $(\mathbf{I}[\%])$ \\
\hline $100 \mathrm{mM}$ & $2000: 1$ & $\mathbf{5 8}(100), \mathbf{8 4 a}(8), \mathbf{9 2}(5), \mathbf{5 8} *(0.8)$ \\
$10.0 \mathrm{mM}$ & $200: 1$ & $\mathbf{5 8}(100), \mathbf{8 4 a}(14), \mathbf{9 2}(3)$ \\
$1.00 \mathrm{mM}$ & $20: 1$ & $\mathbf{5 8}(100), \mathbf{8 4 a}(47), \mathbf{9 2}(9)$ \\
$0.10 \mathrm{mM}$ & $2: 1$ & $\mathbf{8 4 a}(100), \mathbf{5 8}(23), \mathbf{9 2}(3)$ \\
$0.10 \mathrm{mM}$ & $1: 1$ & $\mathbf{8 4 a}(100), \mathbf{5 8}(10), \mathbf{9 2}(3)$ \\
$50.0 \mu \mathrm{M}$ & $1: 2$ & $\mathbf{8 4 a}(100), \mathbf{5 8}(5), \mathbf{9 2}(1)$ \\
$10.0 \mu \mathrm{M}$ & $1: 5$ & $\mathbf{8 4 a}(100), \mathbf{5 8}(3), \mathbf{9 2}(1)$ \\
\hline
\end{tabular}

$24 \mathrm{h:}$\begin{tabular}{llll}
\hline Ion & Summenformel & berechnet & gefunden \\
\hline$[\mathbf{5 8}+\mathbf{H}]^{+}$ & $\mathrm{C}_{10} \mathrm{H}_{18} \mathrm{O}_{6} \mathrm{~N}_{3} \mathrm{~S}^{+}$ & 308.091 & 308.091 \\
{$[\mathbf{9 2 +}+\mathbf{H}]^{+}$} & $\mathrm{C}_{20} \mathrm{H}_{33} \mathrm{O}_{12} \mathrm{~N}_{6} \mathrm{~S}_{2}^{+}$ & 613.159 & 613.159 \\
{$\left[\mathbf{8 4 a}^{+}+\mathbf{H}\right]^{+}$} & $\mathrm{C}_{27} \mathrm{H}_{30} \mathrm{O}_{4} \mathrm{~N}_{3}^{+}$ & 460.224 & 460.223 \\
{$\left[\mathbf{5 8}^{*}+\mathbf{H}\right]^{+}$} & $\mathrm{C}_{37} \mathrm{H}_{45} \mathrm{O}_{9} \mathrm{~N}_{6} \mathrm{~S}^{+}$ & 749.296 & 749.298 \\
\hline
\end{tabular}

\subsection{Massenspektrometrische Untersuchung der Wechselwirkung des seco-Drugs $(+)-(1 S, 10 R)-34 b$ mit DNA-Oligonukleotiden}

\subsection{1 ds-60 / $(1 S, 10 R)-34 b=1: 1$}

Die Wechselwirkung von $(1 S, 10 R)-34 \mathbf{b}$ mit dem DNA-Oligonukleotid ds-60 wurde nach AAV $7.2(\mathrm{n}=1)$ untersucht.

\begin{tabular}{|c|c|c|c|}
\hline Verbindung & Summenformel & berechnet & gefunden \\
\hline $43 b$ & $\mathrm{C}_{30} \mathrm{H}_{31} \mathrm{O}_{3} \mathrm{~N}_{3}$ & 481.24 & 481.24 \\
\hline$A^{*}(34 b)$ & $\mathrm{C}_{35} \mathrm{H}_{36} \mathrm{O}_{3} \mathrm{~N}_{8}$ & 616.29 & 616.30 \\
\hline $\mathrm{w}_{5}(\mathrm{ON}-1(\mathrm{ds}-60))$ & $\mathrm{C}_{48} \mathrm{H}_{63} \mathrm{O}_{32} \mathrm{~N}_{18} \mathrm{P}_{5}$ & 1558.25 & 1558.29 \\
\hline$a_{10}-B_{10}(O N-1(d s-60))$ & $\mathrm{C}_{93} \mathrm{H}_{112} \mathrm{O}_{57} \mathrm{~N}_{32} \mathrm{P}_{9} \mathrm{Na}_{5}$ & 2982.40 & 2982.47 \\
\hline ON-1-A (ds-60) & $\mathrm{C}_{141} \mathrm{H}_{175} \mathrm{O}_{89} \mathrm{~N}_{50} \mathrm{P}_{14} \mathrm{Na}_{5}$ & 4540.65 & 4540.74 \\
\hline ON-1 (ds-60) & $\mathrm{C}_{146} \mathrm{H}_{180} \mathrm{O}_{89} \mathrm{~N}_{55} \mathrm{P}_{14} \mathrm{Na}_{5}$ & 4675.71 & 4675.76 \\
\hline ON-2 (ds-60) & $\mathrm{C}_{146} \mathrm{H}_{179} \mathrm{O}_{87} \mathrm{~N}_{58} \mathrm{P}_{14} \mathrm{Na}_{5}$ & 4684.72 & 4684.79 \\
\hline ON-1* (ds-60, 34b) & $\mathrm{C}_{176} \mathrm{H}_{211} \mathrm{O}_{92} \mathrm{~N}_{58} \mathrm{P}_{14} \mathrm{Na}_{5}$ & 5156.94 & 5157.04 \\
\hline
\end{tabular}


Alkylierung ON-1 (berechnet nach AAV 7.3): 53\%.

Alkylierungsposition: $\mathrm{A}_{10}(\mathrm{ON}-1)$.

\subsubsection{ON-1 (ds-60) / (1S,10R)-34b $=1: 1$}

Die Wechselwirkung von $(1 S, 10 R)-34 b$ mit dem DNA-Oligonukleotid ON-1 (ds-60) wurde nach AAV $7.2(\mathrm{n}=1)$ untersucht.

$24 \mathrm{~h}:$\begin{tabular}{llll}
\hline Verbindung & Summenformel & berechnet & gefunden \\
\hline ON-1 (ds-60) & $\mathrm{C}_{146} \mathrm{H}_{185} \mathrm{O}_{89} \mathrm{~N}_{55} \mathrm{P}_{14}$ & 4565.80 & 4565.87 \\
ON-1* (ds-60, 34b) & $\mathrm{C}_{173} \mathrm{H}_{212} \mathrm{O}_{92} \mathrm{~N}_{58} \mathrm{P}_{14}$ & 5047.03 & 5047.13 \\
\hline
\end{tabular}

Intensitäten: $\mathbf{O N}-\mathbf{1} / \mathbf{O N}-1 * \sim 3 / 1$.

\subsection{3 ds-61 / (1S,10R)-34b $=1: 1$}

Die Wechselwirkung von $(1 S, 10 R)$-34b mit dem DNA-Oligonukleotid ds-61 wurde nach AAV $7.2(\mathrm{n}=1)$ untersucht.

\begin{tabular}{|c|c|c|c|}
\hline Verbindung & Summenformel & berechnet & gefunden \\
\hline $\mathrm{w}_{1}(\mathrm{ON}-1$ (ds-61)) & $\mathrm{C}_{10} \mathrm{H}_{14} \mathrm{O}_{7} \mathrm{~N}_{5} \mathrm{P}$ & 347.06 & 347.07 \\
\hline $43 b$ & $\mathrm{C}_{30} \mathrm{H}_{31} \mathrm{O}_{3} \mathrm{~N}_{3}$ & 481.24 & 481.24 \\
\hline$A *(34 b)$ & $\mathrm{C}_{35} \mathrm{H}_{36} \mathrm{O}_{3} \mathrm{~N}_{8}$ & 616.29 & 616.30 \\
\hline$a_{14}-B_{14}(\mathrm{ON}-1(\mathrm{ds}-61))$ & $\mathrm{C}_{131} \mathrm{H}_{161} \mathrm{O}_{82} \mathrm{~N}_{45} \mathrm{P}_{13} \mathrm{Na}_{5}$ & 4193.59 & 4193.71 \\
\hline ON-1-A (ds-61) & $\mathrm{C}_{141} \mathrm{H}_{175} \mathrm{O}_{89} \mathrm{~N}_{50} \mathrm{P}_{14} \mathrm{Na}_{5}$ & 4540.65 & 4540.73 \\
\hline ON-1 (ds-61) & $\mathrm{C}_{146} \mathrm{H}_{180} \mathrm{O}_{89} \mathrm{~N}_{55} \mathrm{P}_{14} \mathrm{Na}_{5}$ & 4675.71 & 4675.79 \\
\hline ON-2 (ds-61) & $\mathrm{C}_{146} \mathrm{H}_{179} \mathrm{O}_{87} \mathrm{~N}_{58} \mathrm{P}_{14} \mathrm{Na}_{5}$ & 4684.72 & 4684.80 \\
\hline ON-1* (ds-61, 34b) & $\mathrm{C}_{176} \mathrm{H}_{211} \mathrm{O}_{92} \mathrm{~N}_{58} \mathrm{P}_{14} \mathrm{Na}_{5}$ & 5156.94 & 5157.04 \\
\hline
\end{tabular}

Alkylierung ON-1 (berechnet nach AAV 7.3): 66\% .

Alkylierungsposition: $\mathrm{A}_{14}(\mathrm{ON}-1)$. 


\subsection{4 ds-62 / (1S,10R)-34b $=1: 1$}

Die Wechselwirkung von $(1 S, 10 R)$-34b mit dem DNA-Oligonukleotid ds-62 wurde nach AAV $7.2(\mathrm{n}=1)$ untersucht.

\begin{tabular}{|c|c|c|c|}
\hline Verbindung & Summenformel & berechnet & gefunden \\
\hline $43 b$ & $\mathrm{C}_{30} \mathrm{H}_{31} \mathrm{O}_{3} \mathrm{~N}_{3}$ & 481.24 & 481.24 \\
\hline$A *(34 b)$ & $\mathrm{C}_{35} \mathrm{H}_{36} \mathrm{O}_{3} \mathrm{~N}_{8}$ & 616.29 & 616.30 \\
\hline $\mathrm{w}_{5}(\mathrm{ON}-1$ (ds-62)) & $\mathrm{C}_{48} \mathrm{H}_{63} \mathrm{O}_{32} \mathrm{~N}_{18} \mathrm{P}_{5}$ & 1558.25 & 1558.27 \\
\hline$a_{10}-B_{10}(\mathrm{ON}-1(\mathrm{ds}-62))$ & $\mathrm{C}_{92} \mathrm{H}_{117} \mathrm{O}_{58} \mathrm{~N}_{30} \mathrm{P}_{9}$ & 2848.48 & 2848.50 \\
\hline ON-1-A (ds-62) & $\mathrm{C}_{140} \mathrm{H}_{175} \mathrm{O}_{90} \mathrm{~N}_{48} \mathrm{P}_{14} \mathrm{Na}_{5}$ & 4516.64 & 4516.69 \\
\hline ON-1 (ds-62) & $\mathrm{C}_{145} \mathrm{H}_{180} \mathrm{O}_{90} \mathrm{~N}_{53} \mathrm{P}_{14} \mathrm{Na}_{5}$ & 4651.70 & 4651.75 \\
\hline ON-2 (ds-62) & $\mathrm{C}_{146} \mathrm{H}_{178} \mathrm{O}_{86} \mathrm{~N}_{61} \mathrm{P}_{14} \mathrm{Na}_{5}$ & 4709.72 & 4709.77 \\
\hline ON-1* (ds-62, 34b) & $\mathrm{C}_{175} \mathrm{H}_{211} \mathrm{O}_{93} \mathrm{~N}_{56} \mathrm{P}_{14} \mathrm{Na}_{5}$ & 5132.93 & 5133.00 \\
\hline
\end{tabular}

Alkylierung ON-1 (berechnet nach AAV 7.3): 67\%.

Alkylierungsposition: $\mathrm{A}_{10}(\mathrm{ON}-1)$.

\subsection{5 ds-63 / (1S,10R)-34b $=1: 1$}

Die Wechselwirkung von $(1 S, 10 R)$-34b mit dem DNA-Oligonukleotid ds-63 wurde nach AAV $7.2(\mathrm{n}=1)$ untersucht.

\begin{tabular}{|c|c|c|c|}
\hline Verbindung & Summenformel & berechnet & gefunden \\
\hline $43 b$ & $\mathrm{C}_{30} \mathrm{H}_{31} \mathrm{O}_{3} \mathrm{~N}_{3}$ & 481.24 & 481.24 \\
\hline $84 b$ & $\mathrm{C}_{30} \mathrm{H}_{33} \mathrm{O}_{4} \mathrm{~N}_{3}$ & 499.25 & 499.25 \\
\hline$G^{*}(34 b)$ & $\mathrm{C}_{35} \mathrm{H}_{36} \mathrm{O}_{4} \mathrm{~N}_{8}$ & 632.29 & 632.29 \\
\hline$w_{2}(O N(d s-63))$ & $\mathrm{C}_{19} \mathrm{H}_{26} \mathrm{O}_{13} \mathrm{~N}_{8} \mathrm{P}_{2}$ & 636.11 & 636.11 \\
\hline$a_{3}-B_{3}(O N-2(d s-63))$ & $\mathrm{C}_{24} \mathrm{H}_{30} \mathrm{O}_{14} \mathrm{~N}_{8} \mathrm{P}_{2}$ & 716.14 & 716.14 \\
\hline ON-1 (ds-63) & $\mathrm{C}_{145} \mathrm{H}_{179} \mathrm{O}_{89} \mathrm{~N}_{56} \mathrm{P}_{14} \mathrm{Na}_{5}$ & 4676.70 & 4676.80 \\
\hline ON-2 (ds-63) & $\mathrm{C}_{145} \mathrm{H}_{178} \mathrm{O}_{87} \mathrm{~N}_{59} \mathrm{P}_{14} \mathrm{Na}_{5}$ & 4685.71 & 4685.80 \\
\hline
\end{tabular}

schwache Alkylierung an G. 


\subsection{6 ds-64 / (1S,10R)-34b $=1: 1$}

Die Wechselwirkung von $(1 S, 10 R)$-34b mit dem DNA-Oligonukleotid ds-64 wurde nach AAV $7.2(\mathrm{n}=1)$ untersucht.

\begin{tabular}{|c|c|c|c|}
\hline Verbindung & Summenformel & berechnet & gefunden \\
\hline $43 b$ & $\mathrm{C}_{30} \mathrm{H}_{31} \mathrm{O}_{3} \mathrm{~N}_{3}$ & 481.24 & 481.24 \\
\hline $84 b$ & $\mathrm{C}_{30} \mathrm{H}_{33} \mathrm{O}_{4} \mathrm{~N}_{3}$ & 499.25 & 499.25 \\
\hline$A *(34 b)$ & $\mathrm{C}_{35} \mathrm{H}_{36} \mathrm{O}_{3} \mathrm{~N}_{8}$ & 616.29 & 616.30 \\
\hline$w_{5}(\mathrm{ON}-1$ (ds-64)) & $\mathrm{C}_{48} \mathrm{H}_{62} \mathrm{O}_{30} \mathrm{~N}_{21} \mathrm{P}_{5}$ & 1567.27 & 1567.28 \\
\hline$w_{5}(\mathrm{ON}-2(\mathrm{ds}-64))$ & $\mathrm{C}_{48} \mathrm{H}_{62} \mathrm{O}_{31} \mathrm{~N}_{21} \mathrm{P}_{5}$ & 1583.26 & 1583.27 \\
\hline$a_{10}-B_{10}(O N-1(d s-64))$ & $\mathrm{C}_{92} \mathrm{H}_{114} \mathrm{O}_{54} \mathrm{~N}_{36} \mathrm{P}_{9} \mathrm{Na}$ & 2888.48 & 2888.52 \\
\hline$a_{10}-B_{10}(O N-2(d s-64))$ & $\mathrm{C}_{93} \mathrm{H}_{117} \mathrm{O}_{61} \mathrm{~N}_{26} \mathrm{P}_{9} \mathrm{Na}_{2}$ & 2898.43 & 2898.50 \\
\hline ON-1-A (ds-64) & $\mathrm{C}_{140} \mathrm{H}_{172} \mathrm{O}_{84} \mathrm{~N}_{57} \mathrm{P}_{14} \mathrm{Na}_{5}$ & 4543.68 & 4543.73 \\
\hline ON-2-A (ds-64) & $\mathrm{C}_{141} \mathrm{H}_{181} \mathrm{O}_{92} \mathrm{~N}_{47} \mathrm{P}_{14} \mathrm{Na}_{5}$ & 4547.64 & 4547.69 \\
\hline ON-1 (ds-64) & $\mathrm{C}_{145} \mathrm{H}_{177} \mathrm{O}_{84} \mathrm{~N}_{62} \mathrm{P}_{14} \mathrm{Na}_{5}$ & 4678.73 & 4678.79 \\
\hline ON-2 (ds-64) & $\mathrm{C}_{146} \mathrm{H}_{181} \mathrm{O}_{92} \mathrm{~N}_{52} \mathrm{P}_{14} \mathrm{Na}_{5}$ & 4682.69 & 4682.74 \\
\hline ON-1* (ds-64, 34b) & $\mathrm{C}_{175} \mathrm{H}_{208} \mathrm{O}_{87} \mathrm{~N}_{65} \mathrm{P}_{14} \mathrm{Na}_{5}$ & 5159.97 & 5160.02 \\
\hline $\mathrm{ON}-2 *(\mathrm{ds}-64,34 \mathrm{~b})$ & $\mathrm{C}_{176} \mathrm{H}_{212} \mathrm{O}_{95} \mathrm{~N}_{55} \mathrm{P}_{14} \mathrm{Na}_{5}$ & 5163.93 & 5164.01 \\
\hline
\end{tabular}

Alkylierungsposition: $\mathrm{A}_{10}(\mathrm{ON}-1) \sim \mathrm{A}_{10}(\mathrm{ON}-2)$.

Intensität: $\mathbf{w}_{5}(\mathbf{O N}-1) / \mathbf{w}_{5}(\mathbf{O N}-2) \sim \mathbf{a}_{10}-\mathbf{B}_{10}(\mathbf{O N}-1) / \mathbf{a}_{10}-\mathbf{B}_{10}(\mathrm{ON}-2) \sim 1: 1$.

\subsection{7 ds-65 / (1S,10R)-34b $=1: 1$}

Die Wechselwirkung von $(1 S, 10 R)$-34b mit dem DNA-Oligonukleotid ds-65 wurde nach AAV $7.2(\mathrm{n}=1)$ untersucht.

\begin{tabular}{lllll}
\hline $24 \mathrm{~h}:$ & Verbindung & Summenformel & berechnet & gefunden \\
\hline $\mathbf{4 3 b}$ & $\mathrm{C}_{30} \mathrm{H}_{31} \mathrm{O}_{3} \mathrm{~N}_{3}$ & 481.24 & 481.24 \\
$\mathbf{8 4 b}$ & $\mathrm{C}_{30} \mathrm{H}_{33} \mathrm{O}_{4} \mathrm{~N}_{3}$ & 499.25 & 499.25 \\
$\mathbf{A}^{*}(\mathbf{3 4 b})$ & $\mathrm{C}_{35} \mathrm{H}_{36} \mathrm{O}_{3} \mathrm{~N}_{8}$ & 616.29 & 616.30 \\
$\mathbf{G}^{*}(\mathbf{3 4 b})$ & $\mathrm{C}_{35} \mathrm{H}_{36} \mathrm{O}_{4} \mathrm{~N}_{8}$ & 632.29 & 632.29 \\
$\mathbf{w}_{\mathbf{3}}(\mathbf{O N}$ (ds-65)) & $\mathrm{C}_{28} \mathrm{H}_{38} \mathrm{O}_{19} \mathrm{~N}_{11} \mathrm{P}_{3}$ & 925.16 & 925.16 \\
$\mathbf{w}_{\mathbf{6}}(\mathbf{O N}-\mathbf{2}$ (ds-65)) & $\mathrm{C}_{58} \mathrm{H}_{76} \mathrm{O}_{39} \mathrm{~N}_{20} \mathrm{P}_{6}$ & 1862.30 & 1862.31 \\
$\mathbf{w}_{7}(\mathbf{O N}-2$ (ds-65)) & $\mathrm{C}_{68} \mathrm{H}_{88} \mathrm{O}_{44} \mathrm{~N}_{25} \mathrm{P}_{7}$ & 2175.36 & 2175.37
\end{tabular}




$\begin{array}{llll}\mathbf{a}_{8}-\mathrm{B}_{8}(\mathbf{O N}-2 \text { (ds-65)) } & \mathrm{C}_{73} \mathrm{H}_{90} \mathrm{O}_{43} \mathrm{~N}_{28} \mathrm{P}_{7} \mathrm{Na} & 2286.38 & 2286.41 \\ \mathbf{a}_{9}-\mathbf{B}_{9}(\mathbf{O N}-2 \text { (ds-65)) } & \mathrm{C}_{83} \mathrm{H}_{100} \mathrm{O}_{48} \mathrm{~N}_{33} \mathrm{P}_{8} \mathrm{Na}_{3} & 2643.40 & 2643.43 \\ \text { ON-1-A (ds-65) } & \mathrm{C}_{141} \mathrm{H}_{175} \mathrm{O}_{89} \mathrm{~N}_{50} \mathrm{P}_{14} \mathrm{Na}_{5} & 4540.65 & 4540.71 \\ \text { ON-2-A (ds-65) } & \mathrm{C}_{141} \mathrm{H}_{174} \mathrm{O}_{87} \mathrm{~N}_{53} \mathrm{P}_{14} \mathrm{Na}_{5} & 4549.66 & 4549.72 \\ \text { ON-1 (ds-65) } & \mathrm{C}_{146} \mathrm{H}_{185} \mathrm{O}_{89} \mathrm{~N}_{55} \mathrm{P}_{14} \mathrm{Na}_{5} & 4675.71 & 4675.76 \\ \text { ON-2 (ds-65) } & \mathrm{C}_{146} \mathrm{H}_{179} \mathrm{O}_{87} \mathrm{~N}_{58} \mathrm{P}_{14} \mathrm{Na}_{5} & 4684.72 & 4684.77\end{array}$

Alkylierung ON-2 (berechnet nach AAV 7.3): 20\%.

Alkylierungsposition: $\mathrm{A}_{8}(\mathrm{ON}-2)>\mathrm{A}_{9}(\mathrm{ON}-2)$.

\subsection{8 ds-66 / $(1 S, 10 R)-34 b=1: 1$}

Die Wechselwirkung von $(1 S, 10 R)$-34b mit dem DNA-Oligonukleotid ds-66 wurde nach AAV $7.2(\mathrm{n}=1)$ untersucht.

\begin{tabular}{|c|c|c|c|}
\hline Verbindung & Summenformel & berechnet & gefunden \\
\hline $43 b$ & $\mathrm{C}_{30} \mathrm{H}_{31} \mathrm{O}_{3} \mathrm{~N}_{3}$ & 481.24 & 481.24 \\
\hline $84 b$ & $\mathrm{C}_{30} \mathrm{H}_{33} \mathrm{O}_{4} \mathrm{~N}_{3}$ & 499.25 & 499.25 \\
\hline$A *(34 b)$ & $\mathrm{C}_{35} \mathrm{H}_{36} \mathrm{O}_{3} \mathrm{~N}_{8}$ & 616.29 & 616.30 \\
\hline$G *(34 b)$ & $\mathrm{C}_{35} \mathrm{H}_{36} \mathrm{O}_{4} \mathrm{~N}_{8}$ & 632.29 & 632.29 \\
\hline $\mathrm{w}_{5}(\mathrm{ON}(\mathrm{ds}-66))$ & $\mathrm{C}_{48} \mathrm{H}_{62} \mathrm{O}_{31} \mathrm{~N}_{21} \mathrm{P}_{5}$ & 1583.26 & 1583.27 \\
\hline$a_{10}-B_{10}(\mathrm{ON}-1(\mathrm{ds}-66))$ & $\mathrm{C}_{92} \mathrm{H}_{114} \mathrm{O}_{58} \mathrm{~N}_{30} \mathrm{P}_{9} \mathrm{Na}_{3}$ & 2914.42 & 2914.46 \\
\hline$a_{10}-B_{10}(\mathrm{ON}-2(\mathrm{ds}-66))$ & $\mathrm{C}_{92} \mathrm{H}_{114} \mathrm{O}_{56} \mathrm{~N}_{33} \mathrm{P}_{9} \mathrm{Na}_{2}$ & 2901.45 & 2901.48 \\
\hline ON-1-A (ds-66) & $\mathrm{C}_{140} \mathrm{H}_{174} \mathrm{O}_{89} \mathrm{~N}_{51} \mathrm{P}_{14} \mathrm{Na}_{5}$ & 4541.65 & 4541.70 \\
\hline ON-2-A (ds-66) & $\mathrm{C}_{141} \mathrm{H}_{173} \mathrm{O}_{87} \mathrm{~N}_{54} \mathrm{P}_{14} \mathrm{Na}_{5}$ & 4550.66 & 4550.71 \\
\hline ON-1 (ds-66) & $\mathrm{C}_{145} \mathrm{H}_{179} \mathrm{O}_{89} \mathrm{~N}_{56} \mathrm{P}_{14} \mathrm{Na}_{5}$ & 4676.70 & 4676.75 \\
\hline ON-2 (ds-66) & $\mathrm{C}_{145} \mathrm{H}_{178} \mathrm{O}_{87} \mathrm{~N}_{59} \mathrm{P}_{14} \mathrm{Na}_{5}$ & 4685.71 & 4685.76 \\
\hline ON-2*(ds-66, 34b) & $\mathrm{C}_{175} \mathrm{H}_{207} \mathrm{O}_{90} \mathrm{~N}_{62} \mathrm{P}_{14} \mathrm{Na}_{7}$ & 5210.91 & 5210.99 \\
\hline
\end{tabular}

Alkylierungsposition: $\mathrm{A}_{10}(\mathrm{ON}-2) / \mathrm{A}_{10}(\mathrm{ON}-1) \sim 2: 1$.

Intensität: $\mathbf{a}_{10}-\mathbf{B}_{10}(\mathbf{O N}-2) / \mathbf{a}_{10}-\mathbf{B}_{10}(\mathbf{O N}-1) \sim 2: 1$. 


\subsection{9 ds-67 / (1S,10R)-34b $=1: 1$}

Die Wechselwirkung von $(1 S, 10 R)$-34b mit dem DNA-Oligonukleotid ds-67 wurde nach AAV $7.2(\mathrm{n}=1)$ untersucht.

\begin{tabular}{|c|c|c|c|}
\hline Verbindung & Summenformel & berechnet & gefunden \\
\hline $43 b$ & $\mathrm{C}_{30} \mathrm{H}_{31} \mathrm{O}_{3} \mathrm{~N}_{3}$ & 481.24 & 481.24 \\
\hline $84 b$ & $\mathrm{C}_{30} \mathrm{H}_{33} \mathrm{O}_{4} \mathrm{~N}_{3}$ & 499.25 & 499.25 \\
\hline$A *(34 b)$ & $\mathrm{C}_{35} \mathrm{H}_{36} \mathrm{O}_{3} \mathrm{~N}_{8}$ & 616.29 & 616.30 \\
\hline $\mathbf{a}_{7}-\mathrm{B}_{7}(\mathrm{ON}-1$ (ds-67)) & $\mathrm{C}_{63} \mathrm{H}_{76} \mathrm{O}_{36} \mathrm{~N}_{23} \mathrm{P}_{6} \mathrm{Na}_{3}$ & 1985.29 & 1985.32 \\
\hline$a_{7}-B_{7}(O N-2(d s-67))$ & $\mathrm{C}_{64} \mathrm{H}_{77} \mathrm{O}_{34} \mathrm{~N}_{28} \mathrm{P}_{6} \mathrm{Na}$ & 1990.34 & 1990.37 \\
\hline$w_{9}(\mathrm{ON}-1$ (ds-67)) & $\mathrm{C}_{88} \mathrm{H}_{112} \mathrm{O}_{60} \mathrm{~N}_{26} \mathrm{P}_{9} \mathrm{Na}_{3}$ & 2840.38 & 2840.41 \\
\hline$w_{9}(\mathrm{ON}-2$ (ds-67)) & $\mathrm{C}_{89} \mathrm{H}_{109} \mathrm{O}_{58} \mathrm{~N}_{31} \mathrm{P}_{9} \mathrm{Na}_{5}$ & 2933.37 & 2933.41 \\
\hline ON-1-A (ds-67) & $\mathrm{C}_{153} \mathrm{H}_{187} \mathrm{O}_{92} \mathrm{~N}_{59} \mathrm{P}_{15} \mathrm{Na}_{5}$ & 4803.70 & 4803.75 \\
\hline ON-2-A (ds-67) & $\mathrm{C}_{153} \mathrm{H}_{187} \mathrm{O}_{92} \mathrm{~N}_{59} \mathrm{P}_{15} \mathrm{Na}_{5}$ & 4901.73 & 4901.79 \\
\hline ON-1 (ds-67) & $\mathrm{C}_{156} \mathrm{H}_{194} \mathrm{O}_{96} \mathrm{~N}_{54} \mathrm{P}_{15} \mathrm{Na}_{5}$ & 4938.75 & 4938.80 \\
\hline
\end{tabular}

Alkylierungsposition: $\mathrm{A}_{7}(\mathrm{ON}-2) \sim \mathrm{A}_{7}(\mathrm{ON}-1)$.

\subsubsection{0 ds-68 / (1S,10R)-34b = 1:1}

Die Wechselwirkung von $(1 S, 10 R)$-34b mit dem DNA-Oligonukleotid ds-68 wurde nach AAV $7.2(\mathrm{n}=1)$ untersucht.

\begin{tabular}{|c|c|c|c|}
\hline Verbindung & Summenformel & berechnet & gefunden \\
\hline $43 b$ & $\mathrm{C}_{30} \mathrm{H}_{31} \mathrm{O}_{3} \mathrm{~N}_{3}$ & 481.24 & 481.24 \\
\hline $84 b$ & $\mathrm{C}_{30} \mathrm{H}_{33} \mathrm{O}_{4} \mathrm{~N}_{3}$ & 499.25 & 499.25 \\
\hline$A *(34 b)$ & $\mathrm{C}_{35} \mathrm{H}_{36} \mathrm{O}_{3} \mathrm{~N}_{8}$ & 616.29 & 616.30 \\
\hline $\mathrm{w}_{4}(\mathrm{ON}-2(\mathrm{ds}-68))$ & $\mathrm{C}_{38} \mathrm{H}_{50} \mathrm{O}_{25} \mathrm{~N}_{16} \mathrm{P}_{4}$ & 1254.21 & 1254.22 \\
\hline $\mathrm{w}_{5}(\mathrm{ON}-2(\mathrm{ds}-68))$ & $\mathrm{C}_{48} \mathrm{H}_{61} \mathrm{O}_{30} \mathrm{~N}_{21} \mathrm{P}_{5} \mathrm{Na}$ & 1589.25 & 1589.26 \\
\hline$a_{10}-B_{10}(\mathrm{ON}-2(\mathrm{ds}-68))$ & $\mathrm{C}_{93} \mathrm{H}_{113} \mathrm{O}_{57} \mathrm{~N}_{32} \mathrm{P}_{9} \mathrm{Na}_{4}$ & 2960.41 & 2960.46 \\
\hline ON-2-A (ds-68) & $\mathrm{C}_{141} \mathrm{H}_{174} \mathrm{O}_{87} \mathrm{~N}_{53} \mathrm{P}_{14} \mathrm{Na}_{5}$ & 4549.66 & 4549.72 \\
\hline ON-1 (ds-68) & $\mathrm{C}_{146} \mathrm{H}_{180} \mathrm{O}_{89} \mathrm{~N}_{55} \mathrm{P}_{14} \mathrm{Na}_{5}$ & 4675.72 & 4675.77 \\
\hline ON-2 (ds-68) & $\mathrm{C}_{146} \mathrm{H}_{179} \mathrm{O}_{87} \mathrm{~N}_{58} \mathrm{P}_{14} \mathrm{Na}_{5}$ & 4684.72 & 4684.78 \\
\hline $\mathrm{ON}-2 *(\mathrm{ds}-68,34 \mathrm{~b})$ & $\mathrm{C}_{176} \mathrm{H}_{209} \mathrm{O}_{90} \mathrm{~N}_{61} \mathrm{P}_{14} \mathrm{Na}_{6}$ & 5187.94 & 5188.02 \\
\hline
\end{tabular}

Alkylierung ON-2 (berechnet nach AAV 7.3): 82\%.

Alkylierungsposition: $\mathrm{A}_{10}(\mathrm{ON}-2)>>\mathrm{A}_{11}(\mathrm{ON}-2)$. 


\subsubsection{1 ds-69 / (1S,10R)-34b $=1: 1$}

Die Wechselwirkung von $(1 S, 10 R)$-34b mit dem DNA-Oligonukleotid ds-69 wurde nach AAV $7.2(\mathrm{n}=1)$ untersucht.

\begin{tabular}{|c|c|c|c|}
\hline Verbindung & Summenformel & berechnet & gefunden \\
\hline $84 b$ & $\mathrm{C}_{30} \mathrm{H}_{33} \mathrm{O}_{4} \mathrm{~N}_{3}$ & 499.25 & 499.25 \\
\hline$A *(34 b)$ & $\mathrm{C}_{35} \mathrm{H}_{36} \mathrm{O}_{3} \mathrm{~N}_{8}$ & 616.29 & 616.30 \\
\hline$G^{*}(34 b)$ & $\mathrm{C}_{35} \mathrm{H}_{36} \mathrm{O}_{4} \mathrm{~N}_{8}$ & 632.29 & 632.29 \\
\hline ON-1 (ds-69) & $\mathrm{C}_{145} \mathrm{H}_{179} \mathrm{O}_{89} \mathrm{~N}_{56} \mathrm{P}_{14} \mathrm{Na}_{5}$ & 4676.70 & 4676.72 \\
\hline ON-2 (ds-69) & $\mathrm{C}_{145} \mathrm{H}_{178} \mathrm{O}_{87} \mathrm{~N}_{59} \mathrm{P}_{14} \mathrm{Na}_{5}$ & 4685.71 & 4685.74 \\
\hline ON-1* (ds-69, 34b) & $\mathrm{C}_{175} \mathrm{H}_{211} \mathrm{O}_{92} \mathrm{~N}_{59} \mathrm{P}_{14} \mathrm{Na}_{4}$ & 5135.96 & 5136.01 \\
\hline
\end{tabular}

schwache Alkylierung an $\mathrm{G}>>\mathrm{A}$.

\subsection{Massenspektrometrische Untersuchung der Wechselwirkung des seco-Drugs (+)-(1S)-56a mit DNA-Oligonukleotiden}

\subsection{1 ds-60 / $(1 S)-56 \mathrm{a}=1: \mathrm{n}(\mathrm{n}=1,2)$}

Die Wechselwirkung von (1S)-56a mit dem DNA-Oligonukleotid ds-60 wurde nach AAV $7.2(n=1,2)$ untersucht.

\begin{tabular}{|c|c|c|c|c|}
\hline \multirow[t]{10}{*}{$\mathrm{n}=1:$} & Verbindung & Summenformel & berechnet & gefunden \\
\hline & $86 a$ & $\mathrm{C}_{26} \mathrm{H}_{25} \mathrm{O}_{3} \mathrm{~N}_{3}$ & 427.19 & 427.19 \\
\hline & $(1 S)-\mathbf{5 6 a}$ & $\mathrm{C}_{26} \mathrm{H}_{26} \mathrm{O}_{3} \mathrm{~N}_{3} \mathrm{Cl}$ & 463.17 & 463.17 \\
\hline & $A *(56 a)$ & $\mathrm{C}_{31} \mathrm{H}_{30} \mathrm{O}_{3} \mathrm{~N}_{8}$ & 562.24 & 562.25 \\
\hline & $\mathrm{w}_{5}(\mathrm{ON}-1$ (ds-60)) & $\mathrm{C}_{48} \mathrm{H}_{63} \mathrm{O}_{32} \mathrm{~N}_{18} \mathrm{P}_{5}$ & 1558.25 & 1558.28 \\
\hline & $a_{10}-B_{10}(\mathrm{ON}-1(\mathrm{ds}-60))$ & $\mathrm{C}_{93} \mathrm{H}_{112} \mathrm{O}_{57} \mathrm{~N}_{32} \mathrm{P}_{9} \mathrm{Na}_{5}$ & 2982.40 & 2982.44 \\
\hline & ON-1-A (ds-60) & $\mathrm{C}_{141} \mathrm{H}_{175} \mathrm{O}_{89} \mathrm{~N}_{50} \mathrm{P}_{14} \mathrm{Na}_{5}$ & 4540.65 & 4540.71 \\
\hline & ON-1 (ds-60) & $\mathrm{C}_{146} \mathrm{H}_{180} \mathrm{O}_{89} \mathrm{~N}_{55} \mathrm{P}_{14} \mathrm{Na}_{5}$ & 4675.71 & 4675.76 \\
\hline & ON-2 (ds-60) & $\mathrm{C}_{146} \mathrm{H}_{179} \mathrm{O}_{87} \mathrm{~N}_{58} \mathrm{P}_{14} \mathrm{Na}_{5}$ & 4684.72 & 4684.77 \\
\hline & ON-1* (ds-60, 56a) & $\mathrm{C}_{172} \mathrm{H}_{205} \mathrm{O}_{92} \mathrm{~N}_{58} \mathrm{P}_{14} \mathrm{Na}_{5}$ & 5102.90 & 5102.94 \\
\hline
\end{tabular}

Alkylierung ON-1 (berechnet nach AAV 7.3): 46\%.

Alkylierungsposition: $\mathrm{A}_{10}(\mathrm{ON}-1)$. 


\begin{tabular}{|c|c|c|c|}
\hline Verbindung & Summenformel & berechnet & gefunden \\
\hline $86 a$ & $\mathrm{C}_{26} \mathrm{H}_{25} \mathrm{O}_{3} \mathrm{~N}_{3}$ & 427.19 & 427.19 \\
\hline$(1 S)-\mathbf{5 6 a}$ & $\mathrm{C}_{26} \mathrm{H}_{26} \mathrm{O}_{3} \mathrm{~N}_{3} \mathrm{Cl}$ & 463.17 & 463.17 \\
\hline$A *(56 a)$ & $\mathrm{C}_{31} \mathrm{H}_{30} \mathrm{O}_{3} \mathrm{~N}_{8}$ & 562.24 & 562.26 \\
\hline $\mathrm{w}_{5}(\mathrm{ON}-1$ (ds-60)) & $\mathrm{C}_{48} \mathrm{H}_{63} \mathrm{O}_{32} \mathrm{~N}_{18} \mathrm{P}_{5}$ & 1558.25 & 1558.28 \\
\hline$a_{10}-B_{10}(O N-1(d s-60))$ & $\mathrm{C}_{93} \mathrm{H}_{112} \mathrm{O}_{57} \mathrm{~N}_{32} \mathrm{P}_{9} \mathrm{Na}_{5}$ & 2982.40 & 2982.44 \\
\hline ON-1-A (ds-60) & $\mathrm{C}_{141} \mathrm{H}_{175} \mathrm{O}_{89} \mathrm{~N}_{50} \mathrm{P}_{14} \mathrm{Na}_{5}$ & 4540.65 & 4540.71 \\
\hline ON-1 (ds-60) & $\mathrm{C}_{146} \mathrm{H}_{180} \mathrm{O}_{89} \mathrm{~N}_{55} \mathrm{P}_{14} \mathrm{Na}_{5}$ & 4675.71 & 4675.76 \\
\hline ON-2 (ds-60) & $\mathrm{C}_{146} \mathrm{H}_{179} \mathrm{O}_{87} \mathrm{~N}_{58} \mathrm{P}_{14} \mathrm{Na}_{5}$ & 4684.72 & 4684.77 \\
\hline ON-1* (ds-60, 56a) & $\mathrm{C}_{172} \mathrm{H}_{205} \mathrm{O}_{92} \mathrm{~N}_{58} \mathrm{P}_{14} \mathrm{Na}_{5}$ & 5102.90 & 5102.95 \\
\hline
\end{tabular}

Alkylierung ON-1 (berechnet nach AAV 7.3): 55\%.

Alkylierungsposition: $\mathrm{A}_{10}(\mathrm{ON}-1)$.

\subsubsection{ON-1 (ds-60) / (1S)-56a $=1: 1$}

Die Wechselwirkung von (1S)-56a mit dem DNA-Oligonukleotid ON-1 (ds-60) wurde nach AAV $7.2(\mathrm{n}=1)$ untersucht.

\begin{tabular}{lllll}
$24 \mathrm{~h}:$ & Verbindung & Summenformel & berechnet & gefunden \\
\cline { 2 - 2 } & $\mathrm{C}_{146} \mathrm{H}_{185} \mathrm{O}_{89} \mathrm{~N}_{55} \mathrm{P}_{14}$ & 4565.80 & 4565.87 \\
ON-1 (ds-60) $\cdot(1 S)-56 a$ & $\mathrm{C}_{172} \mathrm{H}_{210} \mathrm{O}_{90} \mathrm{~N}_{61} \mathrm{P}_{14} \mathrm{Cl}$ & 5028.96 & 5029.01 \\
\hline
\end{tabular}

Keine Alkylierung.

\subsection{3 ds-61 / (1S)-56a $=1: 1$}

Die Wechselwirkung von (1S)-56a mit dem DNA-Oligonukleotid ds-61 wurde nach AAV $7.2(n=1)$ untersucht.

\begin{tabular}{|c|c|c|c|}
\hline Verbindung & Summenformel & berechnet & gefunden \\
\hline $\mathrm{w}_{1}(\mathrm{ON}-1$ (ds-61)) & $\mathrm{C}_{10} \mathrm{H}_{14} \mathrm{O}_{7} \mathrm{~N}_{5} \mathrm{P}$ & 347.06 & 347.06 \\
\hline $86 a$ & $\mathrm{C}_{26} \mathrm{H}_{25} \mathrm{O}_{3} \mathrm{~N}_{3}$ & 427.19 & 427.19 \\
\hline$A *(56 a)$ & $\mathrm{C}_{31} \mathrm{H}_{30} \mathrm{O}_{3} \mathrm{~N}_{8}$ & 562.24 & 562.25 \\
\hline ON-1-A (ds-61) & $\mathrm{C}_{141} \mathrm{H}_{175} \mathrm{O}_{89} \mathrm{~N}_{50} \mathrm{P}_{14} \mathrm{Na}_{5}$ & 4540.65 & 4540.73 \\
\hline ON-1 (ds-61) & $\mathrm{C}_{146} \mathrm{H}_{180} \mathrm{O}_{89} \mathrm{~N}_{55} \mathrm{P}_{14} \mathrm{Na}_{5}$ & 4675.71 & 4675.79 \\
\hline
\end{tabular}




\begin{tabular}{llll} 
ON-2 (ds-61) & $\mathrm{C}_{146} \mathrm{H}_{179} \mathrm{O}_{87} \mathrm{~N}_{58} \mathrm{P}_{14} \mathrm{Na}_{5}$ & 4684.72 & 4684.80 \\
ON-1* (ds-61, 56a) & $\mathrm{C}_{172} \mathrm{H}_{205} \mathrm{O}_{92} \mathrm{~N}_{58} \mathrm{P}_{14} \mathrm{Na}_{5}$ & 5102.90 & 5102.93 \\
\hline
\end{tabular}

Alkylierung ON-1 (berechnet nach AAV 7.3): 9\% .

Alkylierungsposition: $\mathrm{A}_{14}(\mathrm{ON}-1)$.

\subsection{4 ds-62 / (1S)-56a $=1: 1$}

Die Wechselwirkung von (1S)-56a mit dem DNA-Oligonukleotid ds-62 wurde nach AAV $7.2(n=1)$ untersucht.

\begin{tabular}{|c|c|c|c|}
\hline Verbindung & Summenformel & berechnet & gefunden \\
\hline $86 a$ & $\mathrm{C}_{26} \mathrm{H}_{25} \mathrm{O}_{3} \mathrm{~N}_{3}$ & 427.19 & 427.19 \\
\hline$A *(56 a)$ & $\mathrm{C}_{31} \mathrm{H}_{30} \mathrm{O}_{3} \mathrm{~N}_{8}$ & 562.24 & 562.25 \\
\hline $\mathrm{w}_{5}(\mathrm{ON}-1(\mathrm{ds}-62))$ & $\mathrm{C}_{48} \mathrm{H}_{63} \mathrm{O}_{32} \mathrm{~N}_{18} \mathrm{P}_{5}$ & 1558.25 & 1558.27 \\
\hline$a_{10}-B_{10}(\mathrm{ON}-1(\mathrm{ds}-62))$ & $\mathrm{C}_{92} \mathrm{H}_{117} \mathrm{O}_{58} \mathrm{~N}_{30} \mathrm{P}_{9}$ & 2848.48 & 2848.50 \\
\hline ON-1-A (ds-62) & $\mathrm{C}_{140} \mathrm{H}_{175} \mathrm{O}_{90} \mathrm{~N}_{48} \mathrm{P}_{14} \mathrm{Na}_{5}$ & 4516.64 & 4516.69 \\
\hline ON-1 (ds-62) & $\mathrm{C}_{145} \mathrm{H}_{180} \mathrm{O}_{90} \mathrm{~N}_{53} \mathrm{P}_{14} \mathrm{Na}_{5}$ & 4651.70 & 4651.75 \\
\hline ON-2 (ds-62) & $\mathrm{C}_{146} \mathrm{H}_{178} \mathrm{O}_{86} \mathrm{~N}_{61} \mathrm{P}_{14} \mathrm{Na}_{5}$ & 4709.72 & 4709.77 \\
\hline $\mathrm{ON}-1 *(\mathrm{ds}-62,56 \mathrm{a})$ & $\mathrm{C}_{171} \mathrm{H}_{208} \mathrm{O}_{93} \mathrm{~N}_{56} \mathrm{P}_{14} \mathrm{Na}_{2}$ & 5012.94 & 5012.99 \\
\hline
\end{tabular}

Alkylierung ON-1 (berechnet nach AAV 7.3): 29\%.

Alkylierungsposition: $\mathrm{A}_{10}(\mathrm{ON}-1)$.

\subsection{5 ds-63 / (1S)-56a $=1: 1$}

Die Wechselwirkung von (1S)-56a mit dem DNA-Oligonukleotid ds-63 wurde nach AAV $7.2(n=1)$ untersucht.

\begin{tabular}{|c|c|c|c|}
\hline Verbindung & Summenformel & berechnet & gefunden \\
\hline $86 a$ & $\mathrm{C}_{26} \mathrm{H}_{25} \mathrm{O}_{3} \mathrm{~N}_{3}$ & 427.19 & 427.19 \\
\hline$(1 S)-\mathbf{5 6} \mathbf{a}$ & $\mathrm{C}_{26} \mathrm{H}_{26} \mathrm{O}_{3} \mathrm{~N}_{3} \mathrm{Cl}$ & 463.17 & 463.17 \\
\hline$G^{*}(56 a)$ & $\mathrm{C}_{31} \mathrm{H}_{30} \mathrm{O}_{4} \mathrm{~N}_{8}$ & 578.24 & 578.24 \\
\hline$w_{2}(\mathrm{ON}(\mathrm{ds}-63))$ & $\mathrm{C}_{19} \mathrm{H}_{26} \mathrm{O}_{13} \mathrm{~N}_{8} \mathrm{P}_{2}$ & 636.11 & 636.12 \\
\hline$w_{3}(O N(d s-63))$ & $\mathrm{C}_{28} \mathrm{H}_{38} \mathrm{O}_{19} \mathrm{~N}_{11} \mathrm{P}_{3}$ & 925.16 & 925.16 \\
\hline$a_{3}-B_{3}(O N-2(d s-63))$ & $\mathrm{C}_{24} \mathrm{H}_{30} \mathrm{O}_{14} \mathrm{~N}_{8} \mathrm{P}_{2}$ & 716.14 & 716.14 \\
\hline
\end{tabular}




$\begin{array}{llll}\text { ON-1 (ds-63) } & \mathrm{C}_{145} \mathrm{H}_{179} \mathrm{O}_{89} \mathrm{~N}_{56} \mathrm{P}_{14} \mathrm{Na}_{5} & 4676.70 & 4676.80 \\ \text { ON-2 (ds-63) } & \mathrm{C}_{145} \mathrm{H}_{178} \mathrm{O}_{87} \mathrm{~N}_{59} \mathrm{P}_{14} \mathrm{Na}_{5} & 4685.71 & 4685.80 \\ \text { ON-1* (ds-63, 56a) } & \mathrm{C}_{171} \mathrm{H}_{203} \mathrm{O}_{92} \mathrm{~N}_{59} \mathrm{P}_{14} \mathrm{Na}_{6} & 5125.87 & 5125.93\end{array}$

schwache Alkylierung an G.

\subsection{6 ds-64 / (1S)-56a $=1: 1$}

Die Wechselwirkung von (1S)-56a mit dem DNA-Oligonukleotid ds-64 wurde nach AAV $7.2(n=1)$ untersucht.

\begin{tabular}{|c|c|c|c|}
\hline Verbindung & Summenformel & berechnet & gefunden \\
\hline $86 a$ & $\mathrm{C}_{26} \mathrm{H}_{25} \mathrm{O}_{3} \mathrm{~N}_{3}$ & 427.19 & 427.19 \\
\hline$(1 S)-\mathbf{5 6 a}$ & $\mathrm{C}_{26} \mathrm{H}_{26} \mathrm{O}_{3} \mathrm{~N}_{3} \mathrm{Cl}$ & 463.17 & 463.17 \\
\hline$A^{*}(56 a)$ & $\mathrm{C}_{31} \mathrm{H}_{30} \mathrm{O}_{3} \mathrm{~N}_{8}$ & 562.24 & 562.25 \\
\hline $\mathrm{w}_{5}(\mathrm{ON}-1$ (ds-64)) & $\mathrm{C}_{48} \mathrm{H}_{62} \mathrm{O}_{30} \mathrm{~N}_{21} \mathrm{P}_{5}$ & 1567.27 & 1567.28 \\
\hline $\mathrm{w}_{5}(\mathrm{ON}-2(\mathrm{ds}-64))$ & $\mathrm{C}_{48} \mathrm{H}_{62} \mathrm{O}_{31} \mathrm{~N}_{21} \mathrm{P}_{5}$ & 1583.26 & 1583.27 \\
\hline ON-1 (ds-64) & $\mathrm{C}_{145} \mathrm{H}_{177} \mathrm{O}_{84} \mathrm{~N}_{62} \mathrm{P}_{14} \mathrm{Na}_{5}$ & 4678.73 & 4678.79 \\
\hline ON-2 (ds-64) & $\mathrm{C}_{146} \mathrm{H}_{181} \mathrm{O}_{92} \mathrm{~N}_{52} \mathrm{P}_{14} \mathrm{Na}_{5}$ & 4682.69 & 4682.74 \\
\hline
\end{tabular}

schwache Alkylierung an A.

Alkylierungsposition: $\mathrm{A}_{10}(\mathrm{ON}-1) \sim \mathrm{A}_{10}(\mathrm{ON}-2)$.

\subsection{7 ds-65 / (1S)-56a $=1: 1$}

Die Wechselwirkung von (1S)-56a mit dem DNA-Oligonukleotid ds-65 wurde nach AAV $7.2(n=1)$ untersucht.

\begin{tabular}{|c|c|c|c|}
\hline Verbindung & Summenformel & berechnet & gefunden \\
\hline $86 \mathbf{a}$ & $\mathrm{C}_{26} \mathrm{H}_{25} \mathrm{O}_{3} \mathrm{~N}_{3}$ & 427.19 & 427.19 \\
\hline$(1 S)-\mathbf{5 6 a}$ & $\mathrm{C}_{26} \mathrm{H}_{26} \mathrm{O}_{3} \mathrm{~N}_{3} \mathrm{Cl}$ & 463.17 & 463.17 \\
\hline$A *(56 a)$ & $\mathrm{C}_{31} \mathrm{H}_{30} \mathrm{O}_{3} \mathrm{~N}_{8}$ & 562.24 & 562.25 \\
\hline$w_{3}(O N(d s-65))$ & $\mathrm{C}_{28} \mathrm{H}_{38} \mathrm{O}_{19} \mathrm{~N}_{11} \mathrm{P}_{3}$ & 925.16 & 925.16 \\
\hline $\mathrm{w}_{6}(\mathrm{ON}-2(\mathrm{ds}-65))$ & $\mathrm{C}_{58} \mathrm{H}_{76} \mathrm{O}_{39} \mathrm{~N}_{20} \mathrm{P}_{6}$ & 1862.30 & 1862.30 \\
\hline $\mathrm{w}_{7}(\mathrm{ON}-2$ (ds-65)) & $\mathrm{C}_{68} \mathrm{H}_{88} \mathrm{O}_{44} \mathrm{~N}_{25} \mathrm{P}_{7}$ & 2175.36 & 2175.37 \\
\hline$a_{8}-B_{8}(\mathrm{ON}-2(\mathrm{ds}-65))$ & $\mathrm{C}_{73} \mathrm{H}_{88} \mathrm{O}_{43} \mathrm{~N}_{28} \mathrm{P}_{7} \mathrm{Na}_{3}$ & 2330.34 & 2330.36 \\
\hline ON-1-A (ds-65) & $\mathrm{C}_{141} \mathrm{H}_{175} \mathrm{O}_{89} \mathrm{~N}_{50} \mathrm{P}_{14} \mathrm{Na}_{5}$ & 4540.65 & 4540.71 \\
\hline
\end{tabular}




$\begin{array}{llll}\text { ON-2-A (ds-65) } & \mathrm{C}_{141} \mathrm{H}_{174} \mathrm{O}_{87} \mathrm{~N}_{53} \mathrm{P}_{14} \mathrm{Na}_{5} & 4549.66 & 4549.72 \\ \text { ON-1 (ds-65) } & \mathrm{C}_{146} \mathrm{H}_{185} \mathrm{O}_{89} \mathrm{~N}_{55} \mathrm{P}_{14} \mathrm{Na}_{5} & 4675.71 & 4675.76 \\ \text { ON-2 (ds-65) } & \mathrm{C}_{146} \mathrm{H}_{179} \mathrm{O}_{87} \mathrm{~N}_{58} \mathrm{P}_{14} \mathrm{Na}_{5} & 4684.72 & 4684.77\end{array}$

Alkylierung ON-1 (berechnet nach AAV 7.3): 17\%.

Alkylierungsposition: $\mathrm{A}_{8}(\mathrm{ON}-2)>\mathrm{A}_{9}(\mathrm{ON}-2)$.

\subsection{8 ds-66 / (1S)-56a $=1: 1$}

Die Wechselwirkung von (1S)-56a mit dem DNA-Oligonukleotid ds-66 wurde nach AAV $7.2(n=1)$ untersucht.

\begin{tabular}{|c|c|c|c|}
\hline Verbindung & Summenformel & berechnet & gefunden \\
\hline $86 a$ & $\mathrm{C}_{26} \mathrm{H}_{25} \mathrm{O}_{3} \mathrm{~N}_{3}$ & 427.19 & 427.19 \\
\hline$(1 S)-\mathbf{5 6} \mathbf{a}$ & $\mathrm{C}_{26} \mathrm{H}_{26} \mathrm{O}_{3} \mathrm{~N}_{3} \mathrm{Cl}$ & 463.17 & 463.17 \\
\hline$A *(56 a)$ & $\mathrm{C}_{31} \mathrm{H}_{30} \mathrm{O}_{3} \mathrm{~N}_{8}$ & 562.24 & 562.25 \\
\hline $\mathrm{w}_{5}(\mathrm{ON}(\mathrm{ds}-66))$ & $\mathrm{C}_{48} \mathrm{H}_{62} \mathrm{O}_{31} \mathrm{~N}_{21} \mathrm{P}_{5}$ & 1583.26 & 1583.28 \\
\hline$a_{10}-B_{10}(\mathrm{ON}-1(\mathrm{ds}-66))$ & $\mathrm{C}_{92} \mathrm{H}_{113} \mathrm{O}_{58} \mathrm{~N}_{30} \mathrm{P}_{9} \mathrm{Na}_{4}$ & 2936.40 & 2936.45 \\
\hline$a_{10}-B_{10}(\mathrm{ON}-2(\mathrm{ds}-66))$ & $\mathrm{C}_{92} \mathrm{H}_{112} \mathrm{O}_{56} \mathrm{~N}_{33} \mathrm{P}_{9} \mathrm{Na}_{4}$ & 2967.40 & 2967.45 \\
\hline ON-1-A (ds-66) & $\mathrm{C}_{140} \mathrm{H}_{174} \mathrm{O}_{89} \mathrm{~N}_{51} \mathrm{P}_{14} \mathrm{Na}_{5}$ & 4541.65 & 4541.70 \\
\hline ON-2-A (ds-66) & $\mathrm{C}_{141} \mathrm{H}_{173} \mathrm{O}_{87} \mathrm{~N}_{54} \mathrm{P}_{14} \mathrm{Na}_{5}$ & 4550.66 & 4550.71 \\
\hline ON-1 (ds-66) & $\mathrm{C}_{145} \mathrm{H}_{179} \mathrm{O}_{89} \mathrm{~N}_{56} \mathrm{P}_{14} \mathrm{Na}_{5}$ & 4676.70 & 4676.75 \\
\hline ON-2 (ds-66) & $\mathrm{C}_{145} \mathrm{H}_{178} \mathrm{O}_{87} \mathrm{~N}_{59} \mathrm{P}_{14} \mathrm{Na}_{5}$ & 4685.71 & 4685.76 \\
\hline $\mathrm{ON}-2 *(\mathrm{ds}-66)$ & $\mathrm{C}_{171} \mathrm{H}_{202} \mathrm{O}_{90} \mathrm{~N}_{62} \mathrm{P}_{14} \mathrm{Na}_{6}$ & 5134.88 & 5134.95 \\
\hline
\end{tabular}

Alkylierungsposition: $\mathrm{A}_{10}(\mathrm{ON}-1) \sim \mathrm{A}_{10}(\mathrm{ON}-2)$.

Intensität: $\mathbf{a}_{10}-\mathbf{B}_{10}(\mathbf{O N}-1) / \mathbf{a}_{10}-\mathbf{B}_{10}(\mathbf{O N}-2) \sim 1: 1$.

\subsection{9 ds-67 / (1S)-56a $=1: 1$}

Die Wechselwirkung von (1S)-56a mit dem DNA-Oligonukleotid ds-67 wurde nach AAV $7.2(\mathrm{n}=1)$ untersucht.

\begin{tabular}{|c|c|c|c|}
\hline Verbindung & Summenformel & berechnet & gefunden \\
\hline $86 a$ & $\mathrm{C}_{26} \mathrm{H}_{25} \mathrm{O}_{3} \mathrm{~N}_{3}$ & 427.19 & 427.19 \\
\hline$(1 S)-\mathbf{5 6 a}$ & $\mathrm{C}_{26} \mathrm{H}_{26} \mathrm{O}_{3} \mathrm{~N}_{3} \mathrm{Cl}$ & 463.17 & 463.17 \\
\hline$A *(56 a)$ & $\mathrm{C}_{31} \mathrm{H}_{30} \mathrm{O}_{3} \mathrm{~N}_{8}$ & 562.24 & 562.25 \\
\hline
\end{tabular}




\begin{tabular}{llll} 
ON-1 (ds-67) & $\mathrm{C}_{156} \mathrm{H}_{194} \mathrm{O}_{96} \mathrm{~N}_{54} \mathrm{P}_{15} \mathrm{Na}_{5}$ & 4938.75 & 4938.80 \\
ON-2 (ds-67) & $\mathrm{C}_{158} \mathrm{H}_{190} \mathrm{O}_{92} \mathrm{~N}_{64} \mathrm{P}_{15} \mathrm{Na}_{5}$ & 4992.82 & 4992.89 \\
\hline
\end{tabular}

Schwache Alkylierung an A.

\subsubsection{0 ds-68 / (1S)-56a $=1: 1$}

Die Wechselwirkung von (1S)-56a mit dem DNA-Oligonukleotid ds-68 wurde nach AAV $7.2(\mathrm{n}=1)$ untersucht.

\begin{tabular}{|c|c|c|c|}
\hline Verbindung & Summenformel & berechnet & gefunden \\
\hline $86 a$ & $\mathrm{C}_{26} \mathrm{H}_{25} \mathrm{O}_{3} \mathrm{~N}_{3}$ & 427.19 & 427.19 \\
\hline$(1 S)-\mathbf{5 6 a}$ & $\mathrm{C}_{26} \mathrm{H}_{26} \mathrm{O}_{3} \mathrm{~N}_{3} \mathrm{Cl}$ & 463.17 & 463.17 \\
\hline$A *(56 a)$ & $\mathrm{C}_{31} \mathrm{H}_{30} \mathrm{O}_{3} \mathrm{~N}_{8}$ & 562.24 & 562.25 \\
\hline $\mathrm{w}_{4}(\mathrm{ON}-2(\mathrm{ds}-68))$ & $\mathrm{C}_{38} \mathrm{H}_{50} \mathrm{O}_{25} \mathrm{~N}_{16} \mathrm{P}_{4}$ & 1254.21 & 1254.22 \\
\hline $\mathrm{w}_{5}(\mathrm{ON}-2(\mathrm{ds}-68))$ & $\mathrm{C}_{48} \mathrm{H}_{61} \mathrm{O}_{30} \mathrm{~N}_{21} \mathrm{P}_{5} \mathrm{Na}$ & 1589.25 & 1589.26 \\
\hline$a_{10}-B_{10}(\mathrm{ON}-2(\mathrm{ds}-68))$ & $\mathrm{C}_{93} \mathrm{H}_{113} \mathrm{O}_{57} \mathrm{~N}_{32} \mathrm{P}_{9} \mathrm{Na}_{4}$ & 2960.41 & 2960.46 \\
\hline ON-2-A (ds-68) & $\mathrm{C}_{141} \mathrm{H}_{174} \mathrm{O}_{87} \mathrm{~N}_{53} \mathrm{P}_{14} \mathrm{Na}_{5}$ & 4549.66 & 4549.72 \\
\hline ON-1 (ds-68) & $\mathrm{C}_{146} \mathrm{H}_{180} \mathrm{O}_{89} \mathrm{~N}_{55} \mathrm{P}_{14} \mathrm{Na}_{5}$ & 4675.72 & 4675.77 \\
\hline ON-2 (ds-68) & $\mathrm{C}_{146} \mathrm{H}_{179} \mathrm{O}_{87} \mathrm{~N}_{58} \mathrm{P}_{14} \mathrm{Na}_{5}$ & 4684.72 & 4684.78 \\
\hline ON-2* (ds-68, 56a) & $\mathrm{C}_{176} \mathrm{H}_{209} \mathrm{O}_{90} \mathrm{~N}_{61} \mathrm{P}_{14} \mathrm{Na}_{6}$ & 5187.94 & 5188.02 \\
\hline
\end{tabular}

Alkylierung ON-2 (berechnet nach AAV 7.3): 21\%.

Alkylierungsposition: $\mathrm{A}_{10}(\mathrm{ON}-2)>>\mathrm{A}_{11}(\mathrm{ON}-2)$.

\subsubsection{1 ds-69 / (1S)-56a $=1: 1$}

Die Wechselwirkung von (1S)-56a mit dem DNA-Oligonukleotid ds-69 wurde nach AAV $7.2(\mathrm{n}=1)$ untersucht.

\begin{tabular}{|c|c|c|c|}
\hline Verbindung & Summenformel & berechnet & gefunden \\
\hline $86 \mathbf{a}$ & $\mathrm{C}_{26} \mathrm{H}_{25} \mathrm{O}_{3} \mathrm{~N}_{3}$ & 427.19 & 427.19 \\
\hline$A *(56 a)$ & $\mathrm{C}_{31} \mathrm{H}_{30} \mathrm{O}_{3} \mathrm{~N}_{8}$ & 562.24 & 562.25 \\
\hline ON-1 (ds-69) & $\mathrm{C}_{145} \mathrm{H}_{179} \mathrm{O}_{89} \mathrm{~N}_{56} \mathrm{P}_{14} \mathrm{Na}_{5}$ & 4676.70 & 4676.72 \\
\hline ON-2 (ds-69) & $\mathrm{C}_{145} \mathrm{H}_{178} \mathrm{O}_{87} \mathrm{~N}_{59} \mathrm{P}_{14} \mathrm{Na}_{5}$ & 4685.71 & 4685.74 \\
\hline
\end{tabular}

schwache Alkylierung an A. 


\subsection{Massenspektrometrische Untersuchung der Wechselwirkung des seco-Drugs (+)-(1S)-56b mit DNA-Oligonukleotiden}

\subsection{1 ds-60 / (1S)-56b $=1: 1$}

Die Wechselwirkung von (1S)-56b mit dem DNA-Oligonukleotid ds-60 wurde nach AAV $7.2(n=1)$ untersucht.

\begin{tabular}{|c|c|c|c|}
\hline Verbindung & Summenformel & berechnet & gefunden \\
\hline $86 b$ & $\mathrm{C}_{29} \mathrm{H}_{29} \mathrm{O}_{3} \mathrm{~N}_{3}$ & 467.22 & 467.22 \\
\hline$(1 S)-\mathbf{5 6 b}$ & $\mathrm{C}_{29} \mathrm{H}_{30} \mathrm{O}_{3} \mathrm{~N}_{3} \mathrm{Cl}$ & 503.20 & 503.20 \\
\hline$A^{*}(56 b)$ & $\mathrm{C}_{34} \mathrm{H}_{34} \mathrm{O}_{3} \mathrm{~N}_{8}$ & 602.28 & 602.28 \\
\hline $\mathrm{w}_{5}(\mathrm{ON}-1(\mathrm{ds}-60))$ & $\mathrm{C}_{48} \mathrm{H}_{63} \mathrm{O}_{32} \mathrm{~N}_{18} \mathrm{P}_{5}$ & 1558.25 & 1558.26 \\
\hline$a_{10}-B_{10}(\mathrm{ON}-1(\mathrm{ds}-60))$ & $\mathrm{C}_{93} \mathrm{H}_{115} \mathrm{O}_{57} \mathrm{~N}_{32} \mathrm{P}_{9} \mathrm{Na}_{2}$ & 2916.45 & 2916.49 \\
\hline ON-1-A (ds-60) & $\mathrm{C}_{141} \mathrm{H}_{175} \mathrm{O}_{89} \mathrm{~N}_{50} \mathrm{P}_{14} \mathrm{Na}_{5}$ & 4540.65 & 4540.69 \\
\hline ON-1 (ds-60) & $\mathrm{C}_{146} \mathrm{H}_{182} \mathrm{O}_{89} \mathrm{~N}_{55} \mathrm{P}_{14} \mathrm{Na}_{3}$ & 4631.74 & 4631.78 \\
\hline ON-2 (ds-60) & $\mathrm{C}_{146} \mathrm{H}_{181} \mathrm{O}_{87} \mathrm{~N}_{58} \mathrm{P}_{14} \mathrm{Na}_{3}$ & 4640.75 & 4640.79 \\
\hline ON-1*(ds-60, 56b) & $\mathrm{C}_{175} \mathrm{H}_{209} \mathrm{O}_{92} \mathrm{~N}_{58} \mathrm{P}_{14} \mathrm{Na}_{5}$ & 5142.93 & 5142.98 \\
\hline
\end{tabular}

Alkylierung ON-1 (berechnet nach AAV 7.3): 28\%.

Alkylierungsposition: $\mathrm{A}_{10}(\mathrm{ON}-1)$.

\subsubsection{ON-1 (ds-60) / (1S)-56b $=1: 1$}

Die Wechselwirkung von (1S)-56b mit dem DNA-Oligonukleotid ON-1 (ds-60) wurde nach AAV $7.2(\mathrm{n}=1)$ untersucht.

\begin{tabular}{lllll}
\cline { 2 - 4 } $\mathrm{h}:$ & Summenformel & berechnet & gefunden \\
\hline $\mathbf{8 6 b}$ & $\mathrm{C}_{29} \mathrm{H}_{29} \mathrm{O}_{3} \mathrm{~N}_{3}$ & 467.22 & 467.22 \\
$(1 S)-56 b$ & $\mathrm{C}_{29} \mathrm{H}_{30} \mathrm{O}_{3} \mathrm{~N}_{3} \mathrm{Cl}$ & 503.20 & 503.20 \\
ON-1 (ds-60) & $\mathrm{C}_{146} \mathrm{H}_{185} \mathrm{O}_{89} \mathrm{~N}_{55} \mathrm{P}_{14}$ & 4565.80 & 4565.89 \\
\hline
\end{tabular}

Keine Alkylierung. 


\subsection{3 ds-61 / (1S)-56b $=1: 1$}

Die Wechselwirkung von (1S)-56b mit dem DNA-Oligonukleotid ds-61 wurde nach AAV $7.2(n=1)$ untersucht.

\begin{tabular}{|c|c|c|c|}
\hline Verbindung & Summenformel & berechnet & gefunden \\
\hline $\mathrm{w}_{1}(\mathrm{ON}-1$ (ds-61)) & $\mathrm{C}_{10} \mathrm{H}_{14} \mathrm{O}_{7} \mathrm{~N}_{5} \mathrm{P}$ & 347.06 & 347.06 \\
\hline $86 b$ & $\mathrm{C}_{29} \mathrm{H}_{29} \mathrm{O}_{3} \mathrm{~N}_{3}$ & 467.22 & 467.22 \\
\hline$(1 S)-56 b$ & $\mathrm{C}_{29} \mathrm{H}_{30} \mathrm{O}_{3} \mathrm{~N}_{3} \mathrm{Cl}$ & 503.20 & 503.20 \\
\hline$A *(56 b)$ & $\mathrm{C}_{34} \mathrm{H}_{34} \mathrm{O}_{3} \mathrm{~N}_{8}$ & 602.28 & 602.28 \\
\hline$a_{14}-B_{14}(\mathrm{ON}-1(\mathrm{ds}-61))$ & $\mathrm{C}_{131} \mathrm{H}_{161} \mathrm{O}_{82} \mathrm{~N}_{45} \mathrm{P}_{13} \mathrm{Na}_{5}$ & 4193.59 & 4193.66 \\
\hline ON-1-A (ds-61) & $\mathrm{C}_{141} \mathrm{H}_{175} \mathrm{O}_{89} \mathrm{~N}_{50} \mathrm{P}_{14} \mathrm{Na}_{5}$ & 4540.65 & 4540.72 \\
\hline ON-1 (ds-61) & $\mathrm{C}_{146} \mathrm{H}_{180} \mathrm{O}_{89} \mathrm{~N}_{55} \mathrm{P}_{14} \mathrm{Na}_{5}$ & 4675.71 & 4675.78 \\
\hline ON-2 (ds-61) & $\mathrm{C}_{146} \mathrm{H}_{179} \mathrm{O}_{87} \mathrm{~N}_{58} \mathrm{P}_{14} \mathrm{Na}_{5}$ & 4684.72 & 4684.79 \\
\hline ON-1*(ds-61, 56b) & $\mathrm{C}_{175} \mathrm{H}_{209} \mathrm{O}_{92} \mathrm{~N}_{58} \mathrm{P}_{14} \mathrm{Na}_{5}$ & 5142.93 & 5142.99 \\
\hline
\end{tabular}

Alkylierung ON-1 (berechnet nach AAV 7.3): 31\%.

Alkylierungsposition: $\mathrm{A}_{14}(\mathrm{ON}-1)$.

\subsection{4 ds-62 / (1S)-56b $=1: 1$}

Die Wechselwirkung von (1S)-56b mit dem DNA-Oligonukleotid ds-62 wurde nach AAV $7.2(n=1)$ untersucht.

\begin{tabular}{|c|c|c|c|}
\hline Verbindung & Summenformel & berechnet & gefunden \\
\hline $86 b$ & $\mathrm{C}_{29} \mathrm{H}_{29} \mathrm{O}_{3} \mathrm{~N}_{3}$ & 467.22 & 467.22 \\
\hline$(1 S)-\mathbf{5 6 b}$ & $\mathrm{C}_{29} \mathrm{H}_{30} \mathrm{O}_{3} \mathrm{~N}_{3} \mathrm{Cl}$ & 503.20 & 503.20 \\
\hline$A^{*}(56 b)$ & $\mathrm{C}_{34} \mathrm{H}_{34} \mathrm{O}_{3} \mathrm{~N}_{8}$ & 602.28 & 602.27 \\
\hline $\mathrm{w}_{5}(\mathrm{ON}-1(\mathrm{ds}-62))$ & $\mathrm{C}_{48} \mathrm{H}_{63} \mathrm{O}_{32} \mathrm{~N}_{18} \mathrm{P}_{5}$ & 1558.25 & 1558.27 \\
\hline$a_{10}-B_{10}(\mathrm{ON}-1$ (ds-62)) & $\mathrm{C}_{92} \mathrm{H}_{112} \mathrm{O}_{58} \mathrm{~N}_{30} \mathrm{P}_{9} \mathrm{Na}_{5}$ & 2958.39 & 2958.43 \\
\hline ON-1-A (ds-62) & $\mathrm{C}_{140} \mathrm{H}_{175} \mathrm{O}_{90} \mathrm{~N}_{48} \mathrm{P}_{14} \mathrm{Na}_{5}$ & 4516.64 & 4516.69 \\
\hline ON-1 (ds-62) & $\mathrm{C}_{145} \mathrm{H}_{180} \mathrm{O}_{90} \mathrm{~N}_{53} \mathrm{P}_{14} \mathrm{Na}_{5}$ & 4651.70 & 4651.76 \\
\hline ON-2 (ds-62) & $\mathrm{C}_{146} \mathrm{H}_{178} \mathrm{O}_{86} \mathrm{~N}_{61} \mathrm{P}_{14} \mathrm{Na}_{5}$ & 4709.72 & 4709.78 \\
\hline ON-1* (ds-62, 56b) & $\mathrm{C}_{174} \mathrm{H}_{209} \mathrm{O}_{93} \mathrm{~N}_{56} \mathrm{P}_{14} \mathrm{Na}_{5}$ & 5118.92 & 5118.99 \\
\hline
\end{tabular}

Alkylierung ON-1 (berechnet nach AAV 7.3): 32\%.

Alkylierungsposition: $\mathrm{A}_{10}(\mathrm{ON}-1)$. 
7.9.5 ds-63 / (1S)-56b $=1: 1$

Die Wechselwirkung von (1S)-56b mit dem DNA-Oligonukleotid ds-63 wurde nach AAV $7.2(\mathrm{n}=1)$ untersucht.

\begin{tabular}{|c|c|c|c|}
\hline Verbindung & Summenformel & berechnet & gefunden \\
\hline $86 b$ & $\mathrm{C}_{29} \mathrm{H}_{29} \mathrm{O}_{3} \mathrm{~N}_{3}$ & 467.22 & 467.22 \\
\hline$(1 S)-\mathbf{5 6} \mathbf{b}$ & $\mathrm{C}_{29} \mathrm{H}_{30} \mathrm{O}_{3} \mathrm{~N}_{3} \mathrm{Cl}$ & 503.20 & 503.20 \\
\hline $\mathrm{w}_{2}(\mathrm{ON}(\mathrm{ds}-63))$ & $\mathrm{C}_{19} \mathrm{H}_{26} \mathrm{O}_{13} \mathrm{~N}_{8} \mathrm{P}_{2}$ & 636.11 & 636.11 \\
\hline $\mathrm{w}_{4}(\mathrm{ON}-1$ (ds-63)) & $\mathrm{C}_{38} \mathrm{H}_{50} \mathrm{O}_{25} \mathrm{~N}_{16} \mathrm{P}_{4}$ & 1254.21 & 1254.21 \\
\hline ON-1 (ds-63) & $\mathrm{C}_{145} \mathrm{H}_{179} \mathrm{O}_{89} \mathrm{~N}_{56} \mathrm{P}_{14} \mathrm{Na}_{5}$ & 4676.70 & 4676.76 \\
\hline ON-2 (ds-63) & $\mathrm{C}_{145} \mathrm{H}_{178} \mathrm{O}_{87} \mathrm{~N}_{59} \mathrm{P}_{14} \mathrm{Na}_{5}$ & 4685.71 & 4685.78 \\
\hline ON-1* (ds-63, 56b) & $\mathrm{C}_{174} \mathrm{H}_{208} \mathrm{O}_{92} \mathrm{~N}_{59} \mathrm{P}_{14} \mathrm{Na}_{5}$ & 5143.92 & 5143.99 \\
\hline
\end{tabular}

Alkylierung ON-1 (berechnet nach AAV 7.3): 32\%.

\subsection{6 ds-64 / (1S)-56b $=1: 1$}

Die Wechselwirkung von (1S)-56b mit dem DNA-Oligonukleotid ds-64 wurde nach AAV $7.2(n=1)$ untersucht.

\begin{tabular}{|c|c|c|c|}
\hline Verbindung & Summenformel & berechnet & gefunden \\
\hline $86 b$ & $\mathrm{C}_{29} \mathrm{H}_{29} \mathrm{O}_{3} \mathrm{~N}_{3}$ & 467.22 & 467.22 \\
\hline$(1 S)-\mathbf{5 6 b}$ & $\mathrm{C}_{29} \mathrm{H}_{30} \mathrm{O}_{3} \mathrm{~N}_{3} \mathrm{Cl}$ & 503.20 & 503.20 \\
\hline$A *(56 b)$ & $\mathrm{C}_{34} \mathrm{H}_{34} \mathrm{O}_{3} \mathrm{~N}_{8}$ & 602.28 & 602.28 \\
\hline$w_{5}(\mathrm{ON}-1$ (ds-64)) & $\mathrm{C}_{48} \mathrm{H}_{62} \mathrm{O}_{30} \mathrm{~N}_{21} \mathrm{P}_{5}$ & 1567.27 & 1567.28 \\
\hline$a_{10}-B_{10}(O N-1(d s-64))$ & $\mathrm{C}_{92} \mathrm{H}_{110} \mathrm{O}_{54} \mathrm{~N}_{36} \mathrm{P}_{9} \mathrm{Na}_{5}$ & 2976.41 & 2976.46 \\
\hline ON-1-A (ds-64) & $\mathrm{C}_{140} \mathrm{H}_{171} \mathrm{O}_{84} \mathrm{~N}_{57} \mathrm{P}_{14} \mathrm{Na}_{6}$ & 4565.67 & 4565.73 \\
\hline ON-1 (ds-64) & $\mathrm{C}_{145} \mathrm{H}_{177} \mathrm{O}_{84} \mathrm{~N}_{62} \mathrm{P}_{14} \mathrm{Na}_{5}$ & 4678.73 & 4678.79 \\
\hline ON-2 (ds-64) & $\mathrm{C}_{146} \mathrm{H}_{181} \mathrm{O}_{92} \mathrm{~N}_{52} \mathrm{P}_{14} \mathrm{Na}_{5}$ & 4682.69 & 4682.73 \\
\hline $\mathrm{ON}-1 *(\mathrm{ds}-64,56 \mathrm{~b})$ & $\mathrm{C}_{174} \mathrm{H}_{206} \mathrm{O}_{87} \mathrm{~N}_{65} \mathrm{P}_{14} \mathrm{Na}_{5}$ & 5145.95 & 5146.03 \\
\hline
\end{tabular}

Alkylierung ON-1 (berechnet nach AAV 7.3): 6\%.

Alkylierungsposition: $\mathrm{A}_{10}(\mathrm{ON}-1)$. 


\subsection{7 ds-65 / (1S)-56b $=1: 1$}

Die Wechselwirkung von (1S)-56b mit dem DNA-Oligonukleotid ds-65 wurde nach AAV $7.2(n=1)$ untersucht.

\begin{tabular}{|c|c|c|c|}
\hline Verbindung & Summenformel & berechnet & gefunden \\
\hline $86 b$ & $\mathrm{C}_{29} \mathrm{H}_{29} \mathrm{O}_{3} \mathrm{~N}_{3}$ & 467.22 & 467.22 \\
\hline$(1 S)-\mathbf{5 6 b}$ & $\mathrm{C}_{29} \mathrm{H}_{30} \mathrm{O}_{3} \mathrm{~N}_{3} \mathrm{Cl}$ & 503.20 & 503.20 \\
\hline$A *(56 b)$ & $\mathrm{C}_{34} \mathrm{H}_{34} \mathrm{O}_{3} \mathrm{~N}_{8}$ & 602.28 & 602.28 \\
\hline$w_{6}(\mathrm{ON}-2(\mathrm{ds}-65))$ & $\mathrm{C}_{58} \mathrm{H}_{76} \mathrm{O}_{39} \mathrm{~N}_{20} \mathrm{P}_{6}$ & 1862.30 & 1862.31 \\
\hline $\mathrm{w}_{7}(\mathrm{ON}-2(\mathrm{ds}-65))$ & $\mathrm{C}_{68} \mathrm{H}_{88} \mathrm{O}_{44} \mathrm{~N}_{25} \mathrm{P}_{7}$ & 2175.36 & 2175.38 \\
\hline$a_{8}-B_{8}(\mathrm{ON}-2(\mathrm{ds}-65))$ & $\mathrm{C}_{73} \mathrm{H}_{88} \mathrm{O}_{43} \mathrm{~N}_{28} \mathrm{P}_{7} \mathrm{Na}_{3}$ & 2330.34 & 2330.39 \\
\hline ON-1-A (ds-65) & $\mathrm{C}_{141} \mathrm{H}_{175} \mathrm{O}_{89} \mathrm{~N}_{50} \mathrm{P}_{14} \mathrm{Na}_{5}$ & 4540.65 & 4540.72 \\
\hline ON-2-A (ds-65) & $\mathrm{C}_{141} \mathrm{H}_{174} \mathrm{O}_{87} \mathrm{~N}_{53} \mathrm{P}_{14} \mathrm{Na}_{5}$ & 4549.66 & 4549.72 \\
\hline ON-1 (ds-65) & $\mathrm{C}_{146} \mathrm{H}_{185} \mathrm{O}_{89} \mathrm{~N}_{55} \mathrm{P}_{14} \mathrm{Na}_{5}$ & 4675.71 & 4675.76 \\
\hline ON-2 (ds-65) & $\mathrm{C}_{146} \mathrm{H}_{179} \mathrm{O}_{87} \mathrm{~N}_{58} \mathrm{P}_{14} \mathrm{Na}_{5}$ & 4684.72 & 4684.79 \\
\hline
\end{tabular}

Alkylierung ON-2 (berechnet nach AAV 7.3): 13\%.

Alkylierungsposition: $\mathrm{A}_{8}(\mathrm{ON}-2) \sim \mathrm{A}_{9}(\mathrm{ON}-2)$.

\subsection{8 ds-66 / (1S)-56b $=1: 1$}

Die Wechselwirkung von (1S)-56b mit dem DNA-Oligonukleotid ds-66 wurde nach AAV $7.2(n=1)$ untersucht.

\begin{tabular}{|c|c|c|c|}
\hline Verbindung & Summenformel & berechnet & gefunden \\
\hline $86 b$ & $\mathrm{C}_{29} \mathrm{H}_{29} \mathrm{O}_{3} \mathrm{~N}_{3}$ & 467.22 & 467.22 \\
\hline$(1 S)-\mathbf{5 6 b}$ & $\mathrm{C}_{29} \mathrm{H}_{30} \mathrm{O}_{3} \mathrm{~N}_{3} \mathrm{Cl}$ & 503.20 & 503.20 \\
\hline$A *(56 b)$ & $\mathrm{C}_{34} \mathrm{H}_{34} \mathrm{O}_{3} \mathrm{~N}_{8}$ & 602.28 & 602.28 \\
\hline $\mathrm{w}_{5}(\mathrm{ON}(\mathrm{ds}-66))$ & $\mathrm{C}_{48} \mathrm{H}_{62} \mathrm{O}_{31} \mathrm{~N}_{21} \mathrm{P}_{5}$ & 1583.26 & 1583.28 \\
\hline$a_{10}-B_{10}(O N-1(d s-66))$ & $\mathrm{C}_{92} \mathrm{H}_{115} \mathrm{O}_{58} \mathrm{~N}_{30} \mathrm{P}_{9} \mathrm{Na}_{2}$ & 2892.44 & 2892.50 \\
\hline$a_{10}-B_{10}(O N-2(d s-66))$ & $\mathrm{C}_{92} \mathrm{H}_{115} \mathrm{O}_{56} \mathrm{~N}_{33} \mathrm{P}_{9} \mathrm{Na}$ & 2879.47 & 2879.52 \\
\hline ON-1-A (ds-66) & $\mathrm{C}_{140} \mathrm{H}_{174} \mathrm{O}_{89} \mathrm{~N}_{51} \mathrm{P}_{14} \mathrm{Na}_{5}$ & 4541.65 & 4541.73 \\
\hline ON-2-A (ds-66) & $\mathrm{C}_{141} \mathrm{H}_{173} \mathrm{O}_{87} \mathrm{~N}_{54} \mathrm{P}_{14} \mathrm{Na}_{5}$ & 4550.66 & 4550.74 \\
\hline ON-1 (ds-66) & $\mathrm{C}_{145} \mathrm{H}_{179} \mathrm{O}_{89} \mathrm{~N}_{56} \mathrm{P}_{14} \mathrm{Na}_{5}$ & 4676.70 & 4676.75 \\
\hline ON-2 (ds-66) & $\mathrm{C}_{145} \mathrm{H}_{178} \mathrm{O}_{87} \mathrm{~N}_{59} \mathrm{P}_{14} \mathrm{Na}_{5}$ & 4685.71 & 4685.76 \\
\hline ON-2* (ds-66, 56b) & $\mathrm{C}_{174} \mathrm{H}_{207} \mathrm{O}_{90} \mathrm{~N}_{62} \mathrm{P}_{14} \mathrm{Na}_{5}$ & 5152.93 & 5152.95 \\
\hline
\end{tabular}


Alkylierungsposition: $\mathrm{A}_{10}(\mathrm{ON}-2)>\mathrm{A}_{10}(\mathrm{ON}-1)$.

Intensität: $\mathbf{a}_{10}-\mathbf{B}_{\mathbf{1 0}}(\mathbf{O N}-2) / \mathbf{a}_{10}-\mathbf{B}_{\mathbf{1 0}}(\mathbf{O N}-1) \sim 3: 1$.

\subsection{9 ds-67 / (1S)-56b $=1: 1$}

Die Wechselwirkung von (1S)-56b mit dem DNA-Oligonukleotid ds-67 wurde nach AAV $7.2(\mathrm{n}=1)$ untersucht.

\begin{tabular}{|c|c|c|c|}
\hline Verbindung & Summenformel & berechnet & gefunden \\
\hline $86 b$ & $\mathrm{C}_{29} \mathrm{H}_{29} \mathrm{O}_{3} \mathrm{~N}_{3}$ & 467.22 & 467.22 \\
\hline$(1 S)-56 \mathbf{b}$ & $\mathrm{C}_{29} \mathrm{H}_{30} \mathrm{O}_{3} \mathrm{~N}_{3} \mathrm{Cl}$ & 503.20 & 503.20 \\
\hline$A *(56 b)$ & $\mathrm{C}_{34} \mathrm{H}_{34} \mathrm{O}_{3} \mathrm{~N}_{8}$ & 602.28 & 602.28 \\
\hline$a_{7}-B_{7}(\mathrm{ON}-1(\mathrm{ds}-67))$ & $\mathrm{C}_{63} \mathrm{H}_{79} \mathrm{O}_{36} \mathrm{~N}_{23} \mathrm{P}_{6}$ & 1919.35 & 1919.39 \\
\hline$a_{7}-B_{7}(\mathrm{ON}-2(\mathrm{ds}-67))$ & $\mathrm{C}_{64} \mathrm{H}_{77} \mathrm{O}_{34} \mathrm{~N}_{28} \mathrm{P}_{6} \mathrm{Na}$ & 1990.34 & 1990.38 \\
\hline $\mathrm{w}_{9}(\mathrm{ON}-1$ (ds-67)) & $\mathrm{C}_{88} \mathrm{H}_{114} \mathrm{O}_{60} \mathrm{~N}_{26} \mathrm{P}_{9} \mathrm{Na}$ & 2796.42 & 2796.45 \\
\hline $\mathrm{w}_{9}(\mathrm{ON}-2$ (ds-67)) & $\mathrm{C}_{89} \mathrm{H}_{112} \mathrm{O}_{58} \mathrm{~N}_{31} \mathrm{P}_{9} \mathrm{Na}_{2}$ & 2867.41 & 2867.47 \\
\hline ON-1-A (ds-67) & $\mathrm{C}_{153} \mathrm{H}_{187} \mathrm{O}_{92} \mathrm{~N}_{59} \mathrm{P}_{15} \mathrm{Na}_{5}$ & 4803.70 & 4803.75 \\
\hline ON-2-A (ds-67) & $\mathrm{C}_{153} \mathrm{H}_{187} \mathrm{O}_{92} \mathrm{~N}_{59} \mathrm{P}_{15} \mathrm{Na}_{5}$ & 4901.73 & 4901.79 \\
\hline ON-1 (ds-67) & $\mathrm{C}_{156} \mathrm{H}_{194} \mathrm{O}_{96} \mathrm{~N}_{54} \mathrm{P}_{15} \mathrm{Na}_{3}$ & 4894.79 & 4894.86 \\
\hline ON-2 (ds-67) & $\mathrm{C}_{158} \mathrm{H}_{190} \mathrm{O}_{92} \mathrm{~N}_{64} \mathrm{P}_{15} \mathrm{Na}_{5}$ & 4992.82 & 4992.89 \\
\hline ON-1* (ds-67, 56b) & $\mathrm{C}_{185} \mathrm{H}_{223} \mathrm{O}_{99} \mathrm{~N}_{57} \mathrm{P}_{15} \mathrm{Na}_{5}$ & 5405.97 & 5406.05 \\
\hline ON-2*(ds-67, 56b) & $\mathrm{C}_{187} \mathrm{H}_{221} \mathrm{O}_{95} \mathrm{~N}_{67} \mathrm{P}_{15} \mathrm{Na}_{5}$ & 5504.01 & 5504.13 \\
\hline
\end{tabular}

Alkylierungsposition: $\mathrm{A}_{7}(\mathrm{ON}-1) \sim \mathrm{A}_{7}(\mathrm{ON}-2)$.

\subsubsection{0 ds-68 / (1S)-56b = 1:1}

Die Wechselwirkung von (1S)-56b mit dem DNA-Oligonukleotid ds-68 wurde nach AAV $7.2(n=1)$ untersucht.

\begin{tabular}{|c|c|c|c|}
\hline Verbindung & Summenformel & berechnet & gefunden \\
\hline $86 b$ & $\mathrm{C}_{29} \mathrm{H}_{29} \mathrm{O}_{3} \mathrm{~N}_{3}$ & 467.22 & 467.22 \\
\hline$(1 S)-\mathbf{5 6 b}$ & $\mathrm{C}_{29} \mathrm{H}_{30} \mathrm{O}_{3} \mathrm{~N}_{3} \mathrm{Cl}$ & 503.20 & 503.20 \\
\hline$A *(56 b)$ & $\mathrm{C}_{34} \mathrm{H}_{34} \mathrm{O}_{3} \mathrm{~N}_{8}$ & 602.28 & 602.28 \\
\hline$w_{5}(\mathrm{ON}-2(\mathrm{ds}-68))$ & $\mathrm{C}_{48} \mathrm{H}_{62} \mathrm{O}_{30} \mathrm{~N}_{21} \mathrm{P}_{5}$ & 1567.26 & 1567.26 \\
\hline$a_{10}-B_{10}(O N-2(d s-68))$ & $\mathrm{C}_{93} \mathrm{H}_{116} \mathrm{O}_{57} \mathrm{~N}_{32} \mathrm{P}_{9} \mathrm{Na}$ & 2894.47 & 2894.52 \\
\hline
\end{tabular}




\begin{tabular}{llll} 
ON-2-A (ds-68) & $\mathrm{C}_{141} \mathrm{H}_{174} \mathrm{O}_{87} \mathrm{~N}_{53} \mathrm{P}_{14} \mathrm{Na}_{5}$ & 4549.66 & 4549.74 \\
ON-1 (ds-68) & $\mathrm{C}_{146} \mathrm{H}_{180} \mathrm{O}_{89} \mathrm{~N}_{55} \mathrm{P}_{14} \mathrm{Na}_{5}$ & 4675.72 & 4675.77 \\
ON-2 (ds-68) & $\mathrm{C}_{146} \mathrm{H}_{179} \mathrm{O}_{87} \mathrm{~N}_{58} \mathrm{P}_{14} \mathrm{Na}_{5}$ & 4684.72 & 4684.79 \\
ON-2* (ds-68, 56b) & $\mathrm{C}_{173} \mathrm{H}_{206} \mathrm{O}_{90} \mathrm{~N}_{61} \mathrm{P}_{14} \mathrm{Na}_{5}$ & 5151.94 & 5151.95 \\
\hline
\end{tabular}

Alkylierung ON-2 (berechnet nach AAV 7.3): 30\%.

Alkylierungsposition: $\mathrm{A}_{10}(\mathrm{ON}-2)$.

\subsubsection{1 ds-69 / (1S)-56b $=1: 1$}

Die Wechselwirkung von (1S)-56b mit dem DNA-Oligonukleotid ds-69 wurde nach AAV $7.2(n=1)$ untersucht.

\begin{tabular}{|c|c|c|c|}
\hline Verbindung & Summenformel & berechnet & gefunden \\
\hline $86 b$ & $\mathrm{C}_{29} \mathrm{H}_{29} \mathrm{O}_{3} \mathrm{~N}_{3}$ & 467.22 & 467.22 \\
\hline$(1 S)-\mathbf{5 6} \mathbf{b}$ & $\mathrm{C}_{29} \mathrm{H}_{30} \mathrm{O}_{3} \mathrm{~N}_{3} \mathrm{Cl}$ & 503.20 & 503.20 \\
\hline$A *(56 b)$ & $\mathrm{C}_{34} \mathrm{H}_{34} \mathrm{O}_{3} \mathrm{~N}_{8}$ & 602.28 & 602.28 \\
\hline$w_{3}(\mathrm{ON}-1$ (ds-69)) & $\mathrm{C}_{28} \mathrm{H}_{39} \mathrm{O}_{20} \mathrm{~N}_{8} \mathrm{P}_{3}$ & 900.15 & 900.16 \\
\hline$a_{12}-B_{12}(\mathrm{ON}-1(\mathrm{ds}-69))$ & $\mathrm{C}_{112} \mathrm{H}_{136} \mathrm{O}_{69} \mathrm{~N}_{43} \mathrm{P}_{11} \mathrm{Na}_{4}$ & 3619.51 & 3619.61 \\
\hline ON-1 (ds-69) & $\mathrm{C}_{145} \mathrm{H}_{179} \mathrm{O}_{89} \mathrm{~N}_{56} \mathrm{P}_{14} \mathrm{Na}_{5}$ & 4676.70 & 4676.72 \\
\hline ON-2 (ds-69) & $\mathrm{C}_{145} \mathrm{H}_{178} \mathrm{O}_{87} \mathrm{~N}_{59} \mathrm{P}_{14} \mathrm{Na}_{5}$ & 4685.71 & 4685.74 \\
\hline ON-1* (ds-69, 56b) & $\mathrm{C}_{174} \mathrm{H}_{208} \mathrm{O}_{92} \mathrm{~N}_{59} \mathrm{P}_{14} \mathrm{Na}_{5}$ & 5143.92 & 5144.01 \\
\hline
\end{tabular}

Schwache Alkylierung ON-1.

Alkylierungsposition: $\mathrm{A}_{12}(\mathrm{ON}-1)$.

\subsection{Massenspektrometrische Untersuchung der Wechselwirkung ande- rer seco-Drugs mit den Oligonukleotiden ds-60 und ON-1 (ds-60)}

\subsection{1 ds-60 / $(1 R, 10 S)-34 \mathrm{a}=1: \mathrm{n}(\mathrm{n}=1,2,5)$}

Die Wechselwirkung von $(1 R, 10 S)$-34a mit dem DNA-Oligonukleotid ds-60 wurde nach AAV $7.2(\mathrm{n}=1,2,5)$ untersucht. 


\begin{tabular}{|c|c|c|c|c|}
\hline \multirow[t]{9}{*}{$\mathrm{n}=1,2$ : } & Verbindung & Summenformel & berechnet & gefunden \\
\hline & $43 a$ & $\mathrm{C}_{27} \mathrm{H}_{27} \mathrm{O}_{3} \mathrm{~N}_{3}$ & 441.21 & 441.21 \\
\hline & $84 a$ & $\mathrm{C}_{27} \mathrm{H}_{29} \mathrm{O}_{4} \mathrm{~N}_{3}$ & 459.22 & 459.22 \\
\hline & $(1 R, 10 S)-\mathbf{3 4 a}$ & $\mathrm{C}_{27} \mathrm{H}_{28} \mathrm{O}_{3} \mathrm{~N}_{3} \mathrm{Cl}$ & 477.18 & 477.18 \\
\hline & $G^{*}(34 a)$ & $\mathrm{C}_{32} \mathrm{H}_{32} \mathrm{O}_{4} \mathrm{~N}_{8}$ & 592.25 & 592.26 \\
\hline & ON-1 (ds-60) & $\mathrm{C}_{146} \mathrm{H}_{180} \mathrm{O}_{89} \mathrm{~N}_{55} \mathrm{P}_{14} \mathrm{Na}_{5}$ & 4675.71 & 4675.77 \\
\hline & ON-2 (ds-60) & $\mathrm{C}_{146} \mathrm{H}_{179} \mathrm{O}_{87} \mathrm{~N}_{58} \mathrm{P}_{14} \mathrm{Na}_{5}$ & 4684.72 & 4684.80 \\
\hline & ON-1* (ds-60, 34a) & $\mathrm{C}_{173} \mathrm{H}_{206} \mathrm{O}_{92} \mathrm{~N}_{58} \mathrm{P}_{14} \mathrm{Na}_{6}$ & 5138.89 & 5138.95 \\
\hline & ON-2* (ds-60, 34a) & $\mathrm{C}_{173} \mathrm{H}_{206} \mathrm{O}_{90} \mathrm{~N}_{61} \mathrm{P}_{14} \mathrm{Na}_{5}$ & 5125.92 & 5125.98 \\
\hline
\end{tabular}

Sehr schwache Alkylierung an G, beide Einzelstränge.

Intensität: $\mathbf{O N} / \mathbf{O N}^{*} \sim 60: 1(\mathrm{n}=1)$.

\begin{tabular}{llll}
\hline $\mathrm{n}=5:$ & Summenformel & berechnet & gefunden \\
\hline 43a & $\mathrm{C}_{27} \mathrm{H}_{27} \mathrm{O}_{3} \mathrm{~N}_{3}$ & 441.21 & 441.21 \\
$\mathbf{8 4 a}$ & $\mathrm{C}_{27} \mathrm{H}_{29} \mathrm{O}_{4} \mathrm{~N}_{3}$ & 459.22 & 459.22 \\
$(1 R, 10 S)$-34a & $\mathrm{C}_{27} \mathrm{H}_{28} \mathrm{O}_{3} \mathrm{~N}_{3} \mathrm{Cl}$ & 477.18 & 477.18 \\
$\mathbf{G *}$ (34a) & $\mathrm{C}_{32} \mathrm{H}_{32} \mathrm{O}_{4} \mathrm{~N}_{8}$ & 592.25 & 592.26 \\
ON-1-A (ds-60) & $\mathrm{C}_{141} \mathrm{H}_{176} \mathrm{O}_{89} \mathrm{~N}_{50} \mathrm{P}_{14} \mathrm{Na}_{4}$ & 4518.67 & 4518.67 \\
ON-2-A (ds-60) & $\mathrm{C}_{141} \mathrm{H}_{174} \mathrm{O}_{87} \mathrm{~N}_{53} \mathrm{P}_{14} \mathrm{Na}_{5}$ & 4549.66 & 4549.68 \\
ON-1 (ds-60) & $\mathrm{C}_{146} \mathrm{H}_{180} \mathrm{O}_{89} \mathrm{~N}_{55} \mathrm{P}_{14} \mathrm{Na}_{5}$ & 4675.71 & 4675.77 \\
ON-2 (ds-60) & $\mathrm{C}_{146} \mathrm{H}_{179} \mathrm{O}_{87} \mathrm{~N}_{58} \mathrm{P}_{14} \mathrm{Na}_{5}$ & 4684.72 & 4684.80 \\
ON-1* (ds-60, 34a) & $\mathrm{C}_{173} \mathrm{H}_{207} \mathrm{O}_{92} \mathrm{~N}_{58} \mathrm{P}_{14} \mathrm{Na}_{5}$ & 5116.91 & 5117.04 \\
ON-2* (ds-60, 34a) & $\mathrm{C}_{173} \mathrm{H}_{206} \mathrm{O}_{90} \mathrm{~N}_{61} \mathrm{P}_{14} \mathrm{Na}_{5}$ & 5125.92 & 5126.04 \\
\hline
\end{tabular}

Schwache Alkylierung an G, beide Einzelstränge.

Intensität: $\mathbf{O N}-1^{*} \sim \mathbf{O N}-2 *, \mathbf{O N} / \mathbf{O N}^{*} \sim 50: 1$.

\subsubsection{ON-1 (ds-60) / (1R,10S)-34a $=1: 1$}

Die Wechselwirkung von $(1 R, 10 S)$-34a mit dem DNA-Oligonukleotid ON-1 (ds-60) wurde nach AAV $7.2(\mathrm{n}=1)$ untersucht.

\begin{tabular}{lllll} 
& 24 h: & Summenformel & berechnet & gefunden \\
\cline { 2 - 4 } & 43a & $\mathrm{C}_{27} \mathrm{H}_{27} \mathrm{O}_{3} \mathrm{~N}_{3}$ & 441.21 & 441.21 \\
$\mathbf{8 4 a}$ & $\mathrm{C}_{27} \mathrm{H}_{29} \mathrm{O}_{4} \mathrm{~N}_{3}$ & 459.22 & 459.22
\end{tabular}




$\begin{array}{llll}(1 R, 10 S)-34 a & \mathrm{C}_{27} \mathrm{H}_{28} \mathrm{O}_{3} \mathrm{~N}_{3} \mathrm{Cl} & 477.18 & 477.18 \\ \text { ON-1 (ds-60) } & \mathrm{C}_{146} \mathrm{H}_{185} \mathrm{O}_{89} \mathrm{~N}_{55} \mathrm{P}_{14} & 4565.80 & 4565.85 \\ \text { ON-1* (ds-60, 34a) } & \mathrm{C}_{173} \mathrm{H}_{212} \mathrm{O}_{92} \mathrm{~N}_{58} \mathrm{P}_{14} & 5007.00 & 5007.05\end{array}$

Intensität: $\mathbf{O N}-\mathbf{1} / \mathbf{O N}-1 * \sim 11: 1$.

\subsection{3 ds-60 / $(1 R)-56 \mathrm{a}=1: \mathrm{n}(\mathrm{n}=1,2)$}

Die Wechselwirkung von $(1 R)$-56a mit dem DNA-Oligonukleotid ds-60 wurde nach AAV $7.2(\mathrm{n}=1,2)$ untersucht.

\begin{tabular}{|c|c|c|c|c|}
\hline \multirow[t]{10}{*}{$\mathrm{n}=1,2$} & Verbindung & Summenformel & berechnet & gefunden \\
\hline & $86 a$ & $\mathrm{C}_{26} \mathrm{H}_{25} \mathrm{O}_{3} \mathrm{~N}_{3}$ & 427.19 & 427.20 \\
\hline & $(1 R)-\mathbf{5 6 a}$ & $\mathrm{C}_{26} \mathrm{H}_{26} \mathrm{O}_{3} \mathrm{~N}_{3} \mathrm{Cl}$ & 463.17 & 463.17 \\
\hline & $A *(56 a)$ & $\mathrm{C}_{31} \mathrm{H}_{30} \mathrm{O}_{3} \mathrm{~N}_{8}$ & 562.24 & 562.26 \\
\hline & $\mathrm{w}_{8}(\mathrm{ON}-2(\mathrm{ds}-60))$ & $\mathrm{C}_{78} \mathrm{H}_{99} \mathrm{O}_{49} \mathrm{~N}_{30} \mathrm{P}_{5} \mathrm{Na}$ & 2510.40 & 2510.45 \\
\hline & $a_{7}-B_{7}(O N-2(d s-60))$ & $\mathrm{C}_{63} \mathrm{H}_{78} \mathrm{O}_{38} \mathrm{~N}_{23} \mathrm{P}_{6} \mathrm{Na}$ & 1973.32 & 1973.37 \\
\hline & ON-2-A (ds-60) & $\mathrm{C}_{141} \mathrm{H}_{179} \mathrm{O}_{87} \mathrm{~N}_{53} \mathrm{P}_{14}$ & 4439.75 & 4439.84 \\
\hline & ON-1 (ds-60) & $\mathrm{C}_{146} \mathrm{H}_{180} \mathrm{O}_{89} \mathrm{~N}_{55} \mathrm{P}_{14} \mathrm{Na}_{5}$ & 4675.71 & 4675.76 \\
\hline & $\mathrm{ON}-2(\mathrm{ds}-60)$ & $\mathrm{C}_{146} \mathrm{H}_{179} \mathrm{O}_{87} \mathrm{~N}_{58} \mathrm{P}_{14} \mathrm{Na}_{5}$ & 4684.72 & 4684.79 \\
\hline & ON-2* (ds-60, 56a) & $\mathrm{C}_{172} \mathrm{H}_{204} \mathrm{O}_{90} \mathrm{~N}_{61} \mathrm{P}_{14} \mathrm{Na}_{5}$ & 5111.91 & 5112.01 \\
\hline
\end{tabular}

Alkylierung ON-2 (berechnet nach AAV 7.3): 41\% $(n=1), 60 \%(n=2)$.

Alkylierungsposition: $\mathrm{A}_{7}(\mathrm{ON}-2)$.

\subsection{4 ds-60 / (+)-89=1:n $(n=1,5)$}

Die Wechselwirkung von (+)-89 mit dem DNA-Oligonukleotid ds-60 wurde nach $\operatorname{AAV} 7.2(\mathrm{n}=1,5)$ untersucht. Ergebnis für $t=24 \mathrm{~h}$ :

\begin{tabular}{lllll}
$\mathrm{n}=1,5:$ & Verbindung & Summenformel & berechnet & gefunden \\
\cline { 2 - 5 } $\mathbf{9 0}$ & $\mathrm{C}_{22} \mathrm{H}_{23} \mathrm{O}_{3} \mathrm{~N}_{3}$ & 377.17 & 377.17 \\
$(+)-89$ & $\mathrm{C}_{22} \mathrm{H}_{24} \mathrm{O}_{3} \mathrm{~N}_{3} \mathrm{Cl}$ & 413.15 & 413.15 \\
$\mathbf{O N}-1$ (ds-60) & $\mathrm{C}_{146} \mathrm{H}_{180} \mathrm{O}_{89} \mathrm{~N}_{55} \mathrm{P}_{14} \mathrm{Na}_{5}$ & 4675.71 & 4675.73 \\
$\mathbf{O N - 2}($ ds-60) & $\mathrm{C}_{146} \mathrm{H}_{179} \mathrm{O}_{87} \mathrm{~N}_{58} \mathrm{P}_{14} \mathrm{Na}_{5}$ & 4684.72 & 4684.74 \\
\hline
\end{tabular}

Keine Alkylierung. 
7.10.5 ds-60 / (-)-89 = 1:n $(n=1,5)$

Die Wechselwirkung von (-)-89 mit dem DNA-Oligonukleotid ds-60 wurde nach AAV $7.2(\mathrm{n}=1,5)$ untersucht. Ergebnis für $t=24 \mathrm{~h}$ :

\begin{tabular}{|c|c|c|c|c|}
\hline \multirow[t]{5}{*}{$\mathrm{n}=1,5:$} & Verbindung & Summenformel & berechnet & gefunden \\
\hline & 90 & $\mathrm{C}_{22} \mathrm{H}_{23} \mathrm{O}_{3} \mathrm{~N}_{3}$ & 377.17 & 377.17 \\
\hline & $(-)-89$ & $\mathrm{C}_{22} \mathrm{H}_{24} \mathrm{O}_{3} \mathrm{~N}_{3} \mathrm{Cl}$ & 413.15 & 413.15 \\
\hline & ON-1 (ds-60) & $\mathrm{C}_{146} \mathrm{H}_{180} \mathrm{O}_{89} \mathrm{~N}_{55} \mathrm{P}_{14} \mathrm{Na}_{5}$ & 4675.71 & 4675.73 \\
\hline & ON-2 (ds-60) & $\mathrm{C}_{146} \mathrm{H}_{179} \mathrm{O}_{87} \mathrm{~N}_{58} \mathrm{P}_{14} \mathrm{Na}_{5}$ & 4684.72 & 4684.74 \\
\hline
\end{tabular}

Keine Alkylierung.

\subsection{Massenspektrometrische Untersuchung der Wechselwirkung der Methyl-seco-CBI-Hydrochloride (1S,10R)-34a, (1S,10R)-34e, $(1 S, 10 R)-34 c$ und (1S,10R)-34d mit dem DNA-Oligonukleotid ds-60 im Vergleich}

\subsection{1 ds-60 / seco-Drugs $=1: 1$}

Die Wechselwirkung von $(1 S, 10 R)-\mathbf{3 4 a}, \quad(1 S, 10 R)-\mathbf{3 4 b x}, \quad(1 S, 10 R)-\mathbf{3 4 \mathbf { c }}$ und $(1 S, 10 R)-34 d$ mit dem DNA-Oligonukleotid ds-60 wurde nach AAV $7.2(\mathrm{n}=1)$ untersucht und der Anteil der Alkylierung eines Einzelstranges nach AAV 7.3 berechnet. Ergebnisse für $t=24 \mathrm{~h}$ :

\begin{tabular}{ccc}
\hline seco-Drug & Alkylierung ON-1 (ds-60) [\%] & Alkylierungsposition \\
\hline$(1 S, 10 R)-34 \mathbf{a}$ & 75 & $\mathrm{~A}_{10}(\mathrm{ON}-1)$ \\
$(1 S, 10 R)-34 \mathbf{e}$ & 90 & $\mathrm{~A}_{10}(\mathrm{ON}-1)$ \\
$(1 S, 10 R)-34 \mathbf{c}$ & 93 & $\mathrm{~A}_{10}(\mathrm{ON}-1)$ \\
$(1 S, 10 R)-34 d$ & 57 & $\mathrm{~A}_{10}(\mathrm{ON}-1)$ \\
\hline
\end{tabular}

\begin{tabular}{lllll}
\cline { 2 - 5 }$(1 S, 10 R)-34 a:$ & Verbindung & Summenformel & berechnet & gefunden \\
\cline { 2 - 5 } & $\mathbf{4 3 a}$ & $\mathrm{C}_{27} \mathrm{H}_{27} \mathrm{O}_{3} \mathrm{~N}_{3}$ & 441.21 & 441.21 \\
& $\mathbf{A}^{*}(\mathbf{3 4 a})$ & $\mathrm{C}_{32} \mathrm{H}_{32} \mathrm{O}_{3} \mathrm{~N}_{8}$ & 576.26 & 576.27 \\
& $\mathbf{w}_{\mathbf{5}}(\mathbf{O N}-\mathbf{1}(\mathbf{d s - 6 0}))$ & $\mathrm{C}_{48} \mathrm{H}_{63} \mathrm{O}_{32} \mathrm{~N}_{18} \mathrm{P}_{5}$ & 1558.25 & 1558.27 \\
& $\mathbf{a}_{\mathbf{1 0}}-\mathbf{B}_{\mathbf{1 0}}(\mathbf{O N - 1}(\mathbf{d s}-\mathbf{6 0}))$ & $\mathrm{C}_{93} \mathrm{H}_{112} \mathrm{O}_{57} \mathrm{~N}_{32} \mathrm{P}_{9} \mathrm{Na}_{5}$ & 2982.40 & 2982.43
\end{tabular}




\begin{tabular}{|c|c|c|c|c|}
\hline & ON-1-A (ds-60) & $\mathrm{C}_{141} \mathrm{H}_{175} \mathrm{O}_{89} \mathrm{~N}_{50} \mathrm{P}_{14} \mathrm{Na}_{5}$ & 4540.65 & 4540.69 \\
\hline & ON-1 (ds-60) & $\mathrm{C}_{146} \mathrm{H}_{180} \mathrm{O}_{89} \mathrm{~N}_{55} \mathrm{P}_{14} \mathrm{Na}_{5}$ & 4675.71 & 4675.76 \\
\hline & ON-2 (ds-60) & $\mathrm{C}_{146} \mathrm{H}_{179} \mathrm{O}_{87} \mathrm{~N}_{58} \mathrm{P}_{14} \mathrm{Na}_{5}$ & 4684.72 & 4684.79 \\
\hline & ON-1* (ds-60, 34a) & $\mathrm{C}_{173} \mathrm{H}_{207} \mathrm{O}_{92} \mathrm{~N}_{58} \mathrm{P}_{14} \mathrm{Na}_{5}$ & 5116.91 & 5116.96 \\
\hline$(1 S, 10 R)-34 \mathbf{e}:$ & Verbindung & Summenformel & berechnet & gefunden \\
\hline & $43 e$ & $\mathrm{C}_{28} \mathrm{H}_{29} \mathrm{O}_{4} \mathrm{~N}_{3}$ & 471.22 & 471.22 \\
\hline & $A^{*}(34 \mathrm{e})$ & $\mathrm{C}_{33} \mathrm{H}_{34} \mathrm{O}_{4} \mathrm{~N}_{8}$ & 606.27 & 606.28 \\
\hline & $\mathrm{w}_{5}(\mathrm{ON}-1$ (ds-60)) & $\mathrm{C}_{48} \mathrm{H}_{63} \mathrm{O}_{32} \mathrm{~N}_{18} \mathrm{P}_{5}$ & 1558.25 & 1558.28 \\
\hline & $a_{10}-B_{10}(\mathrm{ON}-1(\mathrm{ds}-60))$ & $\mathrm{C}_{93} \mathrm{H}_{112} \mathrm{O}_{57} \mathrm{~N}_{32} \mathrm{P}_{9} \mathrm{Na}_{5}$ & 2982.40 & 2982.45 \\
\hline & ON-1-A (ds-60) & $\mathrm{C}_{141} \mathrm{H}_{175} \mathrm{O}_{89} \mathrm{~N}_{50} \mathrm{P}_{14} \mathrm{Na}_{5}$ & 4540.65 & 4540.72 \\
\hline & ON-1 (ds-60) & $\mathrm{C}_{146} \mathrm{H}_{185} \mathrm{O}_{89} \mathrm{~N}_{55} \mathrm{P}_{14}$ & 4565.80 & 4565.86 \\
\hline & ON-2 (ds-60) & $\mathrm{C}_{146} \mathrm{H}_{184} \mathrm{O}_{87} \mathrm{~N}_{58} \mathrm{P}_{14}$ & 4574.81 & 4574.88 \\
\hline & ON-1* (ds-60, 34e $)$ & $\mathrm{C}_{174} \mathrm{H}_{204} \mathrm{O}_{93} \mathrm{~N}_{58} \mathrm{P}_{14} \mathrm{Na}_{5}$ & 5146.92 & 5147.00 \\
\hline$(1 S, 10 R)-\mathbf{3 4 c :}$ & Verbindung & Summenformel & berechnet & gefunden \\
\hline & $43 c$ & $\mathrm{C}_{27} \mathrm{H}_{26} \mathrm{O}_{3} \mathrm{~N}_{4}$ & 454.20 & 454.20 \\
\hline & $A *(34 c)$ & $\mathrm{C}_{32} \mathrm{H}_{31} \mathrm{O}_{3} \mathrm{~N}_{9}$ & 589.26 & 589.26 \\
\hline & $\mathrm{w}_{5}(\mathrm{ON}-1$ (ds-60)) & $\mathrm{C}_{48} \mathrm{H}_{63} \mathrm{O}_{32} \mathrm{~N}_{18} \mathrm{P}_{5}$ & 1558.25 & 1558.28 \\
\hline & $a_{10}-B_{10}(\mathrm{ON}-1(\mathrm{ds}-60))$ & $\mathrm{C}_{93} \mathrm{H}_{112} \mathrm{O}_{57} \mathrm{~N}_{32} \mathrm{P}_{9} \mathrm{Na}_{5}$ & 2982.40 & 2982.45 \\
\hline & ON-1-A (ds-60) & $\mathrm{C}_{141} \mathrm{H}_{175} \mathrm{O}_{89} \mathrm{~N}_{50} \mathrm{P}_{14} \mathrm{Na}_{5}$ & 4540.65 & 4540.74 \\
\hline & ON-1 (ds-60) & $\mathrm{C}_{146} \mathrm{H}_{185} \mathrm{O}_{89} \mathrm{~N}_{55} \mathrm{P}_{14}$ & 4565.80 & 4565.87 \\
\hline & ON-2 (ds-60) & $\mathrm{C}_{146} \mathrm{H}_{184} \mathrm{O}_{87} \mathrm{~N}_{58} \mathrm{P}_{14}$ & 4574.81 & 4574.88 \\
\hline & ON-1* (ds-60, 34c) & $\mathrm{C}_{173} \mathrm{H}_{201} \mathrm{O}_{92} \mathrm{~N}_{59} \mathrm{P}_{14} \mathrm{Na}_{5}$ & 5129.91 & 5130.02 \\
\hline
\end{tabular}

\begin{tabular}{|c|c|c|c|c|}
\hline \multirow[t]{9}{*}{$(1 S, 10 R)-\mathbf{3 4 d}:$} & Verbindung & Summenformel & berechnet & gefunden \\
\hline & $43 d$ & $\mathrm{C}_{29} \mathrm{H}_{29} \mathrm{O}_{4} \mathrm{~N}_{3}$ & 483.22 & 483.22 \\
\hline & $A *(34 d)$ & $\mathrm{C}_{34} \mathrm{H}_{34} \mathrm{O}_{4} \mathrm{~N}_{8}$ & 618.27 & 618.28 \\
\hline & $w_{5}(\mathrm{ON}-1$ (ds-60)) & $\mathrm{C}_{48} \mathrm{H}_{63} \mathrm{O}_{32} \mathrm{~N}_{18} \mathrm{P}_{5}$ & 1558.25 & 1558.28 \\
\hline & $a_{10}-B_{10}(\mathrm{ON}-1(\mathrm{ds}-60))$ & $\mathrm{C}_{93} \mathrm{H}_{112} \mathrm{O}_{57} \mathrm{~N}_{32} \mathrm{P}_{9} \mathrm{Na}_{5}$ & 2982.40 & 2982.50 \\
\hline & ON-1-A (ds-60) & $\mathrm{C}_{141} \mathrm{H}_{175} \mathrm{O}_{89} \mathrm{~N}_{50} \mathrm{P}_{14} \mathrm{Na}_{5}$ & 4540.65 & 4540.74 \\
\hline & ON-1 (ds-60) & $\mathrm{C}_{146} \mathrm{H}_{185} \mathrm{O}_{89} \mathrm{~N}_{55} \mathrm{P}_{14}$ & 4565.80 & 4565.87 \\
\hline & ON-2 (ds-60) & $\mathrm{C}_{146} \mathrm{H}_{184} \mathrm{O}_{87} \mathrm{~N}_{58} \mathrm{P}_{14}$ & 4574.81 & 4574.91 \\
\hline & ON-1* (ds-60, 34d $)$ & $\mathrm{C}_{175} \mathrm{H}_{204} \mathrm{O}_{93} \mathrm{~N}_{58} \mathrm{P}_{14} \mathrm{Na}_{5}$ & 5158.92 & 5159.02 \\
\hline
\end{tabular}


7.11.2 ds-60 / seco-Drug $x /$ seco-Drug y $=1$ :n:n $(n=1,0.5,1.2)$

Die Wechselwirkung von $(1 S, 10 R)-\mathbf{3 4 a},(1 S, 10 R)-\mathbf{3 4 e},(1 S, 10 R)-\mathbf{3 4 \mathbf { c }}$ und $(1 S, 10 R)-\mathbf{3 4 d}$ mit dem DNA-Oligonukleotid ds-60 wurde nach AAV 7.2 untersucht, wobei jeweils 2 seco-Drugs gleichzeitig mit dem Oligonukleotid im Verhältnis 1:1:1, 1:0.5:0.5 oder 1:1.2:1.2 inkubiert wurden. Ergebnisse für $t=24 \mathrm{~h}$ :

\begin{tabular}{|c|c|c|c|c|}
\hline seco-Drug x & seco-Drug y & ds- $60 / x / y$ & $\begin{array}{c}\text { Alkylierung ON-1 } \\
\text { (ds-60) [\%] }\end{array}$ & $\begin{array}{l}\text { Produkt- } \\
\text { verhältnis }\end{array}$ \\
\hline \multirow[t]{7}{*}{$(1 S, 10 R)-\mathbf{3 4 a}$} & $(1 S, 10 R)-\mathbf{3 4} \mathbf{e}$ & $1: 1: 1$ & 98 & $\mathbf{A}^{*}(\mathbf{a})<\mathbf{A}^{*}$ (b) \\
\hline & & $1: 0.5: 0.5$ & 99 & \\
\hline & $(1 S, 10 R)-\mathbf{3 4 c}$ & $1: 1: 1$ & 93 & $\mathbf{A}^{*}(\mathbf{a})<\mathbf{A} *(\mathbf{b})$ \\
\hline & & $1: 0.5: 0.5$ & 82 & \\
\hline & $(1 S, 10 R)-\mathbf{3 4 d}$ & $1: 1: 1$ & 88 & $\mathbf{A}^{*}(\mathbf{a})>\mathbf{A}^{*}(\mathbf{b})$ \\
\hline & & $1: 0.5: 0.5$ & 56 & \\
\hline & & $1: 1.2: 1.2$ & 86 & \\
\hline
\end{tabular}

\subsection{Massenspektrometrische Untersuchung der Wechselwirkung verschiedener Prodrugs mit den DNA-Oligonukleotiden ds-60 und ON-1 (ds-60)}

\subsection{1 ds-60 / $(1 S, 10 R)-33 a=1: n(n=1,5)$}

Die Wechselwirkung von $(1 S, 10 R)$-33a mit dem DNA-Oligonukleotid ds-60 wurde nach AAV $7.2(\mathrm{n}=1,5)$ untersucht. Ergebnisse für $t=24 \mathrm{~h}$ :

\begin{tabular}{|c|c|c|c|}
\hline Verbindung & Summenformel & berechnet & gefunden \\
\hline$(1 S, 10 R)-\mathbf{3 3 a}$ & $\mathrm{C}_{33} \mathrm{H}_{38} \mathrm{O}_{8} \mathrm{~N}_{3} \mathrm{Cl}$ & 639.23 & 639.24 \\
\hline$A *(33 a)$ & $\mathrm{C}_{38} \mathrm{H}_{42} \mathrm{O}_{8} \mathrm{~N}_{8}$ & 738.31 & 738.32 \\
\hline ON-1 (ds-60) & $\mathrm{C}_{146} \mathrm{H}_{180} \mathrm{O}_{89} \mathrm{~N}_{55} \mathrm{P}_{14} \mathrm{Na}_{5}$ & 4675.71 & 4675.75 \\
\hline ON-2 (ds-60) & $\mathrm{C}_{146} \mathrm{H}_{179} \mathrm{O}_{87} \mathrm{~N}_{58} \mathrm{P}_{14} \mathrm{Na}_{5}$ & 4684.72 & 4684.76 \\
\hline $\mathrm{ON}-1 *(\mathrm{ds}-60,33 \mathrm{a})$ & $\mathrm{C}_{179} \mathrm{H}_{217} \mathrm{O}_{97} \mathrm{~N}_{58} \mathrm{P}_{14} \mathrm{Na}_{5}$ & 5278.96 & 5279.02 \\
\hline $\mathrm{ON}-2 *(\mathrm{ds}-60,33 \mathrm{a})$ & $\mathrm{C}_{179} \mathrm{H}_{216} \mathrm{O}_{95} \mathrm{~N}_{61} \mathrm{P}_{14} \mathrm{Na}_{5}$ & 5287.98 & 5288.04 \\
\hline
\end{tabular}

Intensität: $\mathbf{O N - 1 *} \sim \mathbf{O N - 2 *}, \mathbf{O N} / \mathbf{O N}^{*} \sim 60: 1$. 


\begin{tabular}{|c|c|c|c|}
\hline Verbindung & Summenformel & berechnet & gefunden \\
\hline$(1 S, 10 R)-\mathbf{3 3 a}$ & $\mathrm{C}_{33} \mathrm{H}_{38} \mathrm{O}_{8} \mathrm{~N}_{3} \mathrm{Cl}$ & 639.23 & 639.24 \\
\hline$A *(33 a)$ & $\mathrm{C}_{38} \mathrm{H}_{42} \mathrm{O}_{8} \mathrm{~N}_{8}$ & 738.31 & 738.33 \\
\hline $\mathrm{w}_{5}(\mathrm{ON}-1$ (ds-60)) & $\mathrm{C}_{48} \mathrm{H}_{63} \mathrm{O}_{32} \mathrm{~N}_{18} \mathrm{P}_{5}$ & 1558.25 & 1558.27 \\
\hline $\mathbf{a}_{7}-\mathbf{B}_{7}(\mathrm{ON}-2(\mathrm{ds}-60))$ & $\mathrm{C}_{63} \mathrm{H}_{78} \mathrm{O}_{38} \mathrm{~N}_{23} \mathrm{P}_{6} \mathrm{Na}$ & 1973.32 & 1973.34 \\
\hline $\mathrm{w}_{8}(\mathrm{ON}-2$ (ds-60)) & $\mathrm{C}_{78} \mathrm{H}_{98} \mathrm{O}_{49} \mathrm{~N}_{30} \mathrm{P}_{5} \mathrm{Na}_{2}$ & 2532.40 & 2532.41 \\
\hline$a_{10}-B_{10}(\mathrm{ON}-2(\mathrm{ds}-60))$ & $\mathrm{C}_{93} \mathrm{H}_{112} \mathrm{O}_{57} \mathrm{~N}_{32} \mathrm{P}_{9} \mathrm{Na}_{5}$ & 2982.40 & 2982.43 \\
\hline ON-1-A (ds-60) & $\mathrm{C}_{141} \mathrm{H}_{176} \mathrm{O}_{89} \mathrm{~N}_{50} \mathrm{P}_{14} \mathrm{Na}_{4}$ & 4518.67 & 4518.71 \\
\hline ON-2-A (ds-60) & $\mathrm{C}_{141} \mathrm{H}_{174} \mathrm{O}_{87} \mathrm{~N}_{53} \mathrm{P}_{14} \mathrm{Na}_{5}$ & 4549.66 & 4549.71 \\
\hline ON-1 (ds-60) & $\mathrm{C}_{146} \mathrm{H}_{180} \mathrm{O}_{89} \mathrm{~N}_{55} \mathrm{P}_{14} \mathrm{Na}_{5}$ & 4675.71 & 4675.76 \\
\hline ON-2 (ds-60) & $\mathrm{C}_{146} \mathrm{H}_{179} \mathrm{O}_{87} \mathrm{~N}_{58} \mathrm{P}_{14} \mathrm{Na}_{5}$ & 4684.72 & 4684.77 \\
\hline ON-1* (ds-60, 33a) & $\mathrm{C}_{179} \mathrm{H}_{215} \mathrm{O}_{97} \mathrm{~N}_{58} \mathrm{P}_{14} \mathrm{Na}_{7}$ & 5322.92 & 5322.98 \\
\hline $\mathrm{ON}-2 *(\mathrm{ds}-60,33 a)$ & $\mathrm{C}_{179} \mathrm{H}_{214} \mathrm{O}_{95} \mathrm{~N}_{61} \mathrm{P}_{14} \mathrm{Na}_{7}$ & 5331.94 & 5331.99 \\
\hline
\end{tabular}

Alkylierung an $\mathrm{A}_{10}(\mathrm{ON}-1) \sim \mathrm{A}_{7}(\mathrm{ON}-2)$.

Intensität: $\mathbf{O N - 1 *} \sim \mathbf{O N - 2 *}, \mathbf{O N} / \mathbf{O N}^{*} \sim 10: 1$.

\subsubsection{ON-1 (ds-60) / (1S,10R)-33a $=1: 1$}

Die Wechselwirkung von $(1 S, 10 R)$-33a mit dem DNA-Oligonukleotid ON-1 (ds-60) wurde nach AAV $7.2(\mathrm{n}=1)$ untersucht.

\begin{tabular}{|c|c|c|c|}
\hline Verbindung & Summenformel & berechnet & gefunden \\
\hline$(1 S, 10 R)-\mathbf{3 3 a}$ & $\mathrm{C}_{33} \mathrm{H}_{38} \mathrm{O}_{8} \mathrm{~N}_{3} \mathrm{Cl}$ & 639.23 & 639.24 \\
\hline $85 a$ & $\mathrm{C}_{33} \mathrm{H}_{39} \mathrm{O}_{9} \mathrm{~N}_{3}$ & 621.27 & 621.28 \\
\hline$G^{*}(33 a)$ & $\mathrm{C}_{38} \mathrm{H}_{42} \mathrm{O}_{9} \mathrm{~N}_{8}$ & 754.31 & 754.32 \\
\hline ON-1 (ds-60) & $\mathrm{C}_{146} \mathrm{H}_{185} \mathrm{O}_{89} \mathrm{~N}_{55} \mathrm{P}_{14}$ & 4565.80 & 4565.88 \\
\hline ON-1* (ds-60, 33a) & $\mathrm{C}_{179} \mathrm{H}_{222} \mathrm{O}_{97} \mathrm{~N}_{58} \mathrm{P}_{14}$ & 5169.05 & 5169.17 \\
\hline $\begin{array}{l}\text { ON-1 (ds-60) } \\
(1 S, 10 R)-33 \mathbf{a}\end{array}$ & $\mathrm{C}_{179} \mathrm{H}_{223} \mathrm{O}_{97} \mathrm{~N}_{58} \mathrm{P}_{14} \mathrm{Na}_{5} \mathrm{Cl}$ & 5205.03 & 5205.14 \\
\hline
\end{tabular}

Schwache Alkylierung an G. Intensität: ON-1 / ON-1* 30:1. 
7.12.3 ds-60 / (1S)-54a = 1:n $(\mathrm{n}=1,5)$

Die Wechselwirkung von (1S)-54a mit dem DNA-Oligonukleotid ds-60 wurde nach AAV $7.2(\mathrm{n}=1,5)$ untersucht. Ergebnisse für $t=24 \mathrm{~h}$ :

\begin{tabular}{|c|c|c|c|c|}
\hline \multirow[t]{6}{*}{$\mathrm{n}=1$ : } & Verbindung & Summenformel & berechnet & gefunden \\
\hline & $(1 S)-54 a$ & $\mathrm{C}_{32} \mathrm{H}_{36} \mathrm{O}_{8} \mathrm{~N}_{3} \mathrm{Cl}$ & 625.22 & 625.22 \\
\hline & ON-1 (ds-60) & $\mathrm{C}_{146} \mathrm{H}_{180} \mathrm{O}_{89} \mathrm{~N}_{55} \mathrm{P}_{14} \mathrm{Na}_{5}$ & 4675.71 & 4675.76 \\
\hline & ON-2 (ds-60) & $\mathrm{C}_{146} \mathrm{H}_{179} \mathrm{O}_{87} \mathrm{~N}_{58} \mathrm{P}_{14} \mathrm{Na}_{5}$ & 4684.72 & 4684.79 \\
\hline & ON-1 (ds-60) $\cdot(1 S)-54 a$ & $\mathrm{C}_{178} \mathrm{H}_{221} \mathrm{O}_{97} \mathrm{~N}_{58} \mathrm{P}_{14} \mathrm{Na}_{5} \mathrm{Cl}$ & 5300.93 & 5301.09 \\
\hline & ON-2 (ds-60) $\cdot(1 S)-54 a$ & $\mathrm{C}_{178} \mathrm{H}_{220} \mathrm{O}_{95} \mathrm{~N}_{61} \mathrm{P}_{14} \mathrm{Na}_{5} \mathrm{Cl}$ & 5309.94 & 5310.09 \\
\hline \multirow[t]{6}{*}{$\mathrm{n}=5:$} & Verbindung & Summenformel & berechnet & gefunden \\
\hline & $(1 S)-\mathbf{5 4 a}$ & $\mathrm{C}_{32} \mathrm{H}_{36} \mathrm{O}_{8} \mathrm{~N}_{3} \mathrm{Cl}$ & 625.22 & 625.22 \\
\hline & ON-1 (ds-60) & $\mathrm{C}_{146} \mathrm{H}_{180} \mathrm{O}_{89} \mathrm{~N}_{55} \mathrm{P}_{14} \mathrm{Na}_{5}$ & 4675.71 & 4675.76 \\
\hline & ON-2 (ds-60) & $\mathrm{C}_{146} \mathrm{H}_{179} \mathrm{O}_{87} \mathrm{~N}_{58} \mathrm{P}_{14} \mathrm{Na}_{5}$ & 4684.72 & 4684.79 \\
\hline & ON-1 (ds-60) $\cdot(1 S)-54 a$ & $\mathrm{C}_{178} \mathrm{H}_{221} \mathrm{O}_{97} \mathrm{~N}_{58} \mathrm{P}_{14} \mathrm{Na}_{5} \mathrm{Cl}$ & 5300.93 & 5301.09 \\
\hline & ON-2 (ds-60) $\cdot(1 S)-54 a$ & $\mathrm{C}_{178} \mathrm{H}_{220} \mathrm{O}_{95} \mathrm{~N}_{61} \mathrm{P}_{14} \mathrm{Na}_{5} \mathrm{Cl}$ & 5309.94 & 5310.09 \\
\hline
\end{tabular}

Zusätzlich: ON-1 (ds-60) • (2-4) (1S)-54a und ON-2 (ds-60) • (2-4) (1S)-54a für n = 5.

\subsection{Massenspektrometrische Untersuchung der Wechselwirkung fluoreszenzmarkierter Duocarmycin-Analoga mit der DNA ds-60}

\subsection{1 ds-60 / $(1 S, 10 R)-76=1: n(n=1,5)$}

Die Wechselwirkung von $(1 S, 10 R)-\mathbf{7 6}$ mit dem DNA-Oligonukleotid ds-60 wurde nach AAV $7.2(\mathrm{n}=1,5)$ untersucht. Ergebnisse für $t=24 \mathrm{~h}$ :

\begin{tabular}{|c|c|c|c|c|}
\hline \multirow{7}{*}{$\mathrm{n}=1,5:$} & Verbindung & Summenformel & berechnet & gefunden \\
\hline & BK71 & $\mathrm{C}_{48} \mathrm{H}_{49} \mathrm{O}_{7} \mathrm{~N}_{7} \mathrm{~S}$ & 867.34 & 867.35 \\
\hline & $(1 S, 10 R)-\mathbf{7 6}$ & $\mathrm{C}_{48} \mathrm{H}_{50} \mathrm{O}_{7} \mathrm{~N}_{7} \mathrm{SCl}$ & 903.32 & 903.33 \\
\hline & $A *(76)$ & $\mathrm{C}_{53} \mathrm{H}_{54} \mathrm{O}_{7} \mathrm{~N}_{12} \mathrm{~S}$ & 1002.40 & 1002.41 \\
\hline & $\mathrm{w}_{5}(\mathrm{ON}-1$ (ds-60)) & $\mathrm{C}_{48} \mathrm{H}_{63} \mathrm{O}_{32} \mathrm{~N}_{18} \mathrm{P}_{5}$ & 1558.25 & 1558.28 \\
\hline & $a_{10}-B_{10}(O N-1(d s-60))$ & $\mathrm{C}_{93} \mathrm{H}_{112} \mathrm{O}_{57} \mathrm{~N}_{32} \mathrm{P}_{9} \mathrm{Na}_{5}$ & 2982.40 & 2982.45 \\
\hline & ON-1-A (ds-60) & $\mathrm{C}_{141} \mathrm{H}_{175} \mathrm{O}_{89} \mathrm{~N}_{50} \mathrm{P}_{14} \mathrm{Na}_{5}$ & 4540.65 & 4540.71 \\
\hline
\end{tabular}




\begin{tabular}{cccc} 
ON-1 (ds-60) & $\mathrm{C}_{146} \mathrm{H}_{180} \mathrm{O}_{89} \mathrm{~N}_{55} \mathrm{P}_{14} \mathrm{Na}_{5}$ & 4675.71 & 4675.77 \\
ON-2 (ds-60) & $\mathrm{C}_{146} \mathrm{H}_{179} \mathrm{O}_{87} \mathrm{~N}_{58} \mathrm{P}_{14} \mathrm{Na}_{5}$ & 4684.72 & 4684.78 \\
ON-1* (ds-60, 76) & $\mathrm{C}_{194} \mathrm{H}_{229} \mathrm{O}_{96} \mathrm{~N}_{62} \mathrm{SP}_{14} \mathrm{Na}_{5}$ & 5543.05 & 5543.12 \\
\hline
\end{tabular}

Alkylierung ON-1 (berechnet nach AAV 7.3): 20\% $(n=1)$.

Alkylierungsposition: $\mathrm{A}_{10}(\mathrm{ON}-1)$.

\subsection{2 ds-60 / $(1 S, 10 R)-75=1: n(n=1,5)$}

Die Wechselwirkung von $(1 S, 10 R)-\mathbf{7 5}$ mit dem DNA-Oligonukleotid ds-60 wurde nach AAV $7.2(\mathrm{n}=1,5)$ untersucht. Ergebnisse für $t=24 \mathrm{~h}$ :

\begin{tabular}{|c|c|c|c|c|}
\hline \multirow[t]{6}{*}{$\mathrm{n}=1,5$} & Verbindung & Summenformel & berechnet & gefunden \\
\hline & $(1 S, 10 R)-75$ & $\mathrm{C}_{54} \mathrm{H}_{60} \mathrm{O}_{12} \mathrm{~N}_{7} \mathrm{SCl}$ & 1065.37 & 1065.36 \\
\hline & ON-1 (ds-60) & $\mathrm{C}_{146} \mathrm{H}_{180} \mathrm{O}_{89} \mathrm{~N}_{55} \mathrm{P}_{14} \mathrm{Na}_{5}$ & 4675.71 & 4675.77 \\
\hline & ON-2 (ds-60) & $\mathrm{C}_{146} \mathrm{H}_{179} \mathrm{O}_{87} \mathrm{~N}_{58} \mathrm{P}_{14} \mathrm{Na}_{5}$ & 4684.72 & 4684.78 \\
\hline & $\begin{array}{l}\text { ON-1 (ds-60) } \\
(1 S, 10 R)-75\end{array}$ & $\mathrm{C}_{200} \mathrm{H}_{238} \mathrm{O}_{101} \mathrm{~N}_{62} \mathrm{SClP}_{14} \mathrm{Na}_{7}$ & 5785.04 & 5785.14 \\
\hline & $\begin{array}{l}\text { ON-2 (ds-60) } \\
(1 S, 10 R)-75\end{array}$ & $\mathrm{C}_{200} \mathrm{H}_{237} \mathrm{O}_{99} \mathrm{~N}_{65} \mathrm{SClP}_{14} \mathrm{Na}_{7}$ & 5794.05 & 5794.18 \\
\hline
\end{tabular}

Keine Alkylierung. ON / ON $\cdot(1 S, 10 R)-\mathbf{7 5} \sim 40: 1(\mathrm{n}=1)$. 


\section{Untersuchung der Wechselwirkung neuer Duocarmycin- Analoga mit DNA-Oligonukleotiden mittels HPLC}

\subsection{AAV 8.1: Allgemeine Arbeitsvorschrift zur Untersuchung der Wechselwirkung neuer Duocarmycin-Analoga mit doppelsträngigen DNA-Oligonukleotiden mittels HPLC}

Doppelsträngige DNA-Oligonukleotide wurden als wässrige Lösungen $(0.1 \mathrm{mM}) \mathrm{der}$ entsprechenden Natriumsalze eingesetzt. 1 Aliquot der Stammlösung eines Duocarmycin-Analogons in DMSO wurde in die Lösung des ausgewählten Oligonukleotides pipettiert und die Reaktionsmischung bei $25^{\circ} \mathrm{C}$ inkubiert. $\mathrm{Zu}$ den angegebenen Zeiten nach dem Start der Inkubation wurde ein Aliquot der Reaktionsmischung entnommen und die Lösung direkt analysiert oder tiefgefroren $\left(-20^{\circ} \mathrm{C}\right)$ und zu einem späteren Zeitpunkt untersucht.

Analyse: Die Reaktionslösungen wurden ohne weitere Aufarbeitung in das HPLCSystem injiziert und die Komponenten mittels einer Gradientenelution aufgetrennt. Die Auswertung der HPLC-Messungen erfolgte durch Integration der Absorptionsspur bei $\lambda=350 \mathrm{~nm}$. Der Anteil jeder Spezies in der Reaktionslösung wurde über den prozentualen Anteil des entsprechenden Integrals am Gesamtintegral abgeschätzt.

\subsection{AAV 8.2: Allgemeine Arbeitsvorschrift zur Untersuchung der Wechselwirkung neuer Duocarmycin-Analoga mit doppelsträngigen DNA-Oligonukleotiden im Verhältnis 1:1 mittels HPLC}

1 Aliquot der Stammlösung des seco-Drugs in DMSO (1 $\mu \mathrm{L}, 5 \mathrm{nmol}, 1$ Äq.) wurde nach AAV 8.1 mit einem Oligonukleotid ( $50 \mu \mathrm{L}, 5 \mathrm{nmol}, 1$ Äq.) bei $25{ }^{\circ} \mathrm{C}$ inkubiert und die Reaktionsmischung zu dem Zeitpunkt $t=24 \mathrm{~h}$ mittels analytischer HPLC untersucht. 


\subsection{AAV 8.3: Allgemeine Arbeitsvorschrift zur Untersuchung der Wechselwirkung neuer Duocarmycin-Analoga mit doppelsträngigen DNA-Oligonukleotiden in Phosphatpuffer mittels HPLC}

Doppel- oder einzelsträngige DNA-Oligonukleotide wurden als wässrige Lösungen (0.1 mM) der entsprechenden Natrium- oder Ammoniumsalze eingesetzt. 1 Aliquot der Stammlösung eines Duocarmycin-Analogons in DMSO wurde in die Lösung des ausgewählten Oligonukleotides pipettiert, ein zum Lösungsvolumen äquivalentes Volumen Phosphatpuffer ( $\mathrm{pH} 7$ ) zugegeben und die Reaktionsmischung bei $25^{\circ} \mathrm{C}$ inkubiert. $\mathrm{Zu}$ den angegebenen Zeiten nach dem Start der Inkubation wurde ein Aliquot der Reaktionsmischung entnommen und die Lösung direkt analysiert oder tiefgefroren $\left(-20^{\circ} \mathrm{C}\right)$ und zu einem späteren Zeitpunkt untersucht.

Analyse: Die Reaktionslösungen wurden ohne weitere Aufarbeitung in das HPLCSystem injiziert und die Komponenten mittels einer Gradientenelution aufgetrennt.

\subsection{AAV 8.4: Allgemeine Arbeitsvorschrift zur Untersuchung der Wechselwirkung neuer Duocarmycin-Analoga mit doppelsträngigen DNA-Oligonukleotiden mittels semi-präparativer HPLC gefolgt von ESI-FTICR-Massenspektrometrie}

Doppelsträngige DNA-Oligonukleotide wurden als wässrige Lösungen $(0.1 \mathrm{mM})$ der entsprechenden Natriumsalze eingesetzt. 1 Aliquot der Stammlösung eines Duocarmycin-Analogons in DMSO wurde in die Lösung des ausgewählten Oligonukleotides pipettiert, falls angegeben Phosphatpuffer $(\mathrm{pH} 7)$ zugefügt und die Reaktionsmischung bei $25^{\circ} \mathrm{C}$ inkubiert. $\mathrm{Zu}$ einem bestimmten Zeitpunkt nach dem Start der Inkubation wurde die Reaktionsmischung tiefgefroren und lyophilisiert. Zur semi-präparativen Trennung mittels HPLC wurde das Lyophilisat in bidestilliertem Wasser $(60-100 \mu \mathrm{L})$ gelöst, die Lösung in das HPLC-System injiziert und die Fraktionen gesammelt, tiefgefroren und lyophilisiert.

Analyse mittels ESI-FTICR-MS (negativer Ionenmodus): Das jeweilige Lyophilisat wurde in Wasser $/ \mathrm{MeOH}=1: 1(40 \mu \mathrm{L})$ gelöst und die Lösung massenspektrometrisch untersucht. Die Kapillartemperatur betrug $250{ }^{\circ} \mathrm{C}$. 


\subsection{Kinetik der Wechselwirkung des seco-Drugs (+)-(1S,10R)-34a mit ds- 60 im Verhältnis 1:1 in Wasser und in Phosphatpuffer}

1 Aliquot der Stammlösung von $(1 S, 10 R)-34 a$ in DMSO ( $1 \mu \mathrm{L}, 5$ nmol, 1 Äq.) wurde nach AAV 8.1 mit ds-60 (50 $\mu \mathrm{L}, 5 \mathrm{nmol}, 1$ Äq.) oder nach AAV 8.3 mit einer Mischung aus ds-60 (50 $\mu \mathrm{L}, 5 \mathrm{nmol}, 1$ Äq.) und Phosphatpuffer ( $\mathrm{pH} 7,50 \mu \mathrm{L})$ bei $25^{\circ} \mathrm{C}$ inkubiert und die Reaktionsmischung zu den Zeitpunkten $t=0 \mathrm{~h}, 1 \mathrm{~h}, 2 \mathrm{~h}, 3 \mathrm{~h}$ und $4 \mathrm{~h}$ mittels analytischer HPLC (Säule: Bondapak ${ }^{\circledR}$ ) untersucht.

\begin{tabular}{|c|c|c|c|c|}
\hline \multirow[t]{7}{*}{ Inkubation in Wasser: } & $t[\mathrm{~h}]$ & ds-60 ${ }^{(*)}[\%]$ & $43 a[\%]$ & $(1 S, 10 R)-34 \mathrm{a}[\%]$ \\
\hline & 0 & - & 17 & 83 \\
\hline & 1 & 59 & 8 & 33 \\
\hline & 2 & 87 & - & 13 \\
\hline & 3 & 96 & - & 4 \\
\hline & 4 & 100 & - & - \\
\hline & $t_{\mathrm{R}}[\min ]$ & 18.3 & 36.7 & 40.4 \\
\hline \multirow[t]{7}{*}{ Inkubation in Puffer: } & $t[\mathbf{h}]$ & ds-60 ${ }^{(*)}[\%]$ & 43a $[\%]$ & $(1 S, 10 R)-34 \mathrm{a}[\%]$ \\
\hline & $\overline{0}$ & - & 26 & 74 \\
\hline & 1 & 85 & 6 & 9 \\
\hline & 2 & 100 & - & - \\
\hline & 3 & 100 & - & - \\
\hline & 4 & 100 & - & - \\
\hline & $t_{\mathrm{R}}[\min ]$ & 18.9 & 36.7 & 40.4 \\
\hline
\end{tabular}

\subsection{Untersuchung der Wechselwirkung des seco-Drugs $(+)-(1 S, 10 R)-34 a$ mit ds-60 im Verhältnis 1:1 nach Inkubation in Phosphatpuffer mittels semi-präparativer HPLC gefolgt von ESI-FTICR-MS}

1 Aliquot der Stammlösung von $(1 S, 10 R)$-34a in DMSO (3 $\mu \mathrm{L}, 15 \mathrm{nmol}, 1$ Äq.) wurde mit einer Mischung aus ds-60 (150 $\mu \mathrm{L}, 15$ nmol, 1 Äq.) und Phosphatpuffer (pH 7, $150 \mu \mathrm{L}$ ) bei $25^{\circ} \mathrm{C}$ inkubiert und die Reaktionsmischung nach $1 \mathrm{~h}$ Inkubation nach AAV 8.4 (Säule: Bondapak ${ }^{\circledR}$ ) untersucht. Zusätzlich wurde 1 Aliquot der Stammlösung von $(1 S, 10 R)$-34a in DMSO (1 $\mu \mathrm{L}, 5 \mathrm{nmol}, 1$ Äq.) mit einer Mischung aus 
ds-60 (50 $\mu \mathrm{L}, 5 \mathrm{nmol}, 1$ Äq.) und Phosphatpuffer (pH 7, $50 \mu \mathrm{L})$ bei $25^{\circ} \mathrm{C}$ inkubiert und die Reaktionsmischung nach 5 h Inkubation nach AAV 8.4 (Säule: Bondapak ${ }^{\circledR}$ ) untersucht.

$1 \mathrm{~h}$ Inkubation:

\begin{tabular}{ccccc}
\cline { 2 - 4 } HPLC: & $\boldsymbol{t}[\mathbf{h}]$ & $\mathbf{d s - 6 0} \mathbf{0}^{(*)}[\mathbf{\%}]$ & $\mathbf{4 3 a}[\mathbf{\%}]$ & $(1 S, 10 R)-\mathbf{3 4 a}[\mathbf{\%}]$ \\
\cline { 2 - 5 } & 68 & 9 & 23 \\
\hline $\boldsymbol{t}_{\mathbf{R}}[\mathbf{m i n}]$ & 18.5 & 36.8 & 40.6 \\
\hline
\end{tabular}

\begin{tabular}{|c|c|c|c|c|}
\hline ds- $60^{(*)}$ & Summenformel & berechnet & gefunden & Intensität [\%] \\
\hline ON-1 (ds-60) & $\mathrm{C}_{146} \mathrm{H}_{185} \mathrm{O}_{89} \mathrm{~N}_{55} \mathrm{P}_{14}$ & 4565.80 & 4565.83 & 88 \\
\hline ON-2 (ds-60) & $\mathrm{C}_{146} \mathrm{H}_{184} \mathrm{O}_{87} \mathrm{~N}_{58} \mathrm{P}_{14}$ & 4574.80 & 4575.84 & 100 \\
\hline ON-1* (ds-60, 34a) & $\mathrm{C}_{173} \mathrm{H}_{212} \mathrm{O}_{92} \mathrm{~N}_{58} \mathrm{P}_{14}$ & 5007.00 & 5007.01 & 4 \\
\hline ON-1-A (ds-60) & $\mathrm{C}_{141} \mathrm{H}_{180} \mathrm{O}_{89} \mathrm{~N}_{50} \mathrm{P}_{14}$ & 4430.74 & 4430.75 & 4 \\
\hline
\end{tabular}

Alkylierung ON-1: 10\%.

Alkylierungsposition: $\mathrm{A}_{10}(\mathrm{ON}-1)$.

$\underline{5 \mathrm{~h} \text { Inkubation: }}$

\begin{tabular}{|c|c|c|c|c|}
\hline \multirow[t]{3}{*}{ HPLC: } & $t[\mathbf{h}]$ & ds-60 ${ }^{(*)}[\%]$ & $43 a[\%]$ & $(1 S, 10 R)-\mathbf{3 4 a}[\mathbf{0}]$ \\
\hline & 5 & 97 & - & 3 \\
\hline & $t_{\mathrm{R}}[\min ]$ & 18.9 & - & 40.6 \\
\hline
\end{tabular}

\begin{tabular}{|c|c|c|c|c|}
\hline ds- $60^{(*)}$ & Summenformel & berechnet & gefunden & Intensität [\%] \\
\hline ON-1 (ds-60) & $\mathrm{C}_{146} \mathrm{H}_{185} \mathrm{O}_{89} \mathrm{~N}_{55} \mathrm{P}_{14}$ & 4565.80 & 4565.87 & 53 \\
\hline ON-2 (ds-60) & $\mathrm{C}_{146} \mathrm{H}_{184} \mathrm{O}_{87} \mathrm{~N}_{58} \mathrm{P}_{14}$ & 4574.80 & 4574.87 & 100 \\
\hline ON-1-A (ds-60) & $\mathrm{C}_{141} \mathrm{H}_{180} \mathrm{O}_{89} \mathrm{~N}_{50} \mathrm{P}_{14}$ & 4430.74 & 4430.80 & 4 \\
\hline $\mathrm{w}_{5}(\mathrm{ON}-1$ (ds-60)) & $\mathrm{C}_{48} \mathrm{H}_{63} \mathrm{O}_{32} \mathrm{~N}_{18} \mathrm{P}_{5}$ & 1558.25 & 1557.95 & 10 \\
\hline$d_{9}(\mathrm{ON}-1$ (ds-60)) & $\mathrm{C}_{88} \mathrm{H}_{133} \mathrm{O}_{56} \mathrm{~N}_{32} \mathrm{P}_{9}$ & 2792.46 & 2792.50 & 3 \\
\hline
\end{tabular}

Alkylierung ON-1: 50\%.

Alkylierungsposition: $\mathrm{A}_{10}(\mathrm{ON}-1)$. 
8.7 Untersuchung der Wechselwirkung des seco-Drugs $(+)-(1 S, 10 R)-34 a$ mit ds-60 im Verhältnis 1:1 nach $24 \mathrm{~h}$ Inkubation bei $25^{\circ} \mathrm{C}$ und $2 \mathrm{~h}$ Erhitzen auf $95{ }^{\circ} \mathrm{C}$ mittels semi-präparativer HPLC gefolgt von ESIFTICR-MS

1 Aliquot der Stammlösung von (1S,10R)-34a in DMSO (5 $\mu \mathrm{L}, 25 \mathrm{nmol}, 1$ Äq.) wurde mit ds-60 (250 $\mu \mathrm{L}, 25 \mathrm{nmol}, 1 \mathrm{Äq}$.) $24 \mathrm{~h}$ bei $25^{\circ} \mathrm{C}$ inkubiert und die Reaktionsmischung dann $2 \mathrm{~h}$ auf $95{ }^{\circ} \mathrm{C}$ erhitzt. Anschließend wurde die Reaktionsmischung nach AAV 8.4 (Säule: Aquapore) untersucht.

$24 \mathrm{~h}$ bei $25^{\circ} \mathrm{C}$ und $2 \mathrm{~h}$ bei $95^{\circ} \mathrm{C}$ :

\begin{tabular}{|c|c|c|c|c|c|c|}
\hline$t[\mathrm{~h}]$ & $\mathrm{w}_{5}(\mathrm{ON}-1)$ & $d_{9}(\mathrm{ON}-1)$ & ON-2 & ds-60*(34a) & ds-60 & $A^{*}(34)$ \\
\hline$t_{\mathrm{R}}[\min ]$ & 12.4 & 17.1 & 18.1 & 19.7 & 19.9 & 34.1 \\
\hline
\end{tabular}

\begin{tabular}{|c|c|c|c|c|}
\hline$w_{5}(\mathrm{ON}-1(\mathrm{ds}-60))$ & Summenformel & berechnet & gefunden & Intensität [\%] \\
\hline$w_{5}(O N-1(d s-60))$ & $\mathrm{C}_{48} \mathrm{H}_{63} \mathrm{O}_{32} \mathrm{~N}_{18} \mathrm{P}_{5}$ & 1558.25 & 1558.26 & 100 \\
\hline$\left[w_{5}(\mathrm{ON}-1(\mathrm{ds}-60))\right]_{2}$ & $\mathrm{C}_{96} \mathrm{H}_{126} \mathrm{O}_{64} \mathrm{~N}_{36} \mathrm{P}_{10}$ & 3116.50 & 3116.53 & 1 \\
\hline
\end{tabular}

MS: \begin{tabular}{lllll}
\hline d9 $_{\mathbf{9}}(\mathrm{ON}-\mathbf{1}(\mathbf{d s}-60))$ & Summenformel & berechnet & gefunden & Intensität [\%] \\
\hline $\mathbf{d}_{\mathbf{9}}(\mathbf{O N}-\mathbf{1}(\mathbf{d s}-60))$ & $\mathrm{C}_{88} \mathrm{H}_{133} \mathrm{O}_{56} \mathrm{~N}_{32} \mathrm{P}_{9}$ & 2792.46 & 2792.48 & 100 \\
\hline
\end{tabular}

\begin{tabular}{|c|c|c|c|c|}
\hline ON-2 (ds-60) & Summenformel & berechnet & gefunden & Intensität [\%] \\
\hline ON-2 (ds-60) & $\mathrm{C}_{146} \mathrm{H}_{184} \mathrm{O}_{87} \mathrm{~N}_{58} \mathrm{P}_{14}$ & 4574.80 & 4574.88 & 100 \\
\hline $\mathrm{w}_{14}(\mathrm{ON}-2(\mathrm{ds}-60))$ & $\mathrm{C}_{136} \mathrm{H}_{173} \mathrm{O}_{84} \mathrm{~N}_{53} \mathrm{P}_{14}$ & 4325.72 & 4325.78 & 92 \\
\hline
\end{tabular}

\begin{tabular}{|c|c|c|c|c|}
\hline $\begin{array}{l}\mathrm{ON}-1-\mathrm{A}+\mathrm{H}_{2} \mathrm{O} / \mathrm{ON}-2 \\
(\mathrm{ds}-60)\end{array}$ & Summenformel & berechnet & gefunden & Intensität [\%] \\
\hline ON-2 (ds-60) & $\mathrm{C}_{146} \mathrm{H}_{184} \mathrm{O}_{87} \mathrm{~N}_{58} \mathrm{P}_{14}$ & 4574.80 & 4574.87 & 84 \\
\hline $\mathrm{w}_{5}(\mathrm{ON}-1(\mathrm{ds}-60))$ & $\mathrm{C}_{48} \mathrm{H}_{63} \mathrm{O}_{32} \mathrm{~N}_{18} \mathrm{P}_{5}$ & 1558.25 & 1558.27 & 100 \\
\hline dg $_{9}(\mathrm{ON}-1$ (ds-60)) & $\mathrm{C}_{88} \mathrm{H}_{133} \mathrm{O}_{56} \mathrm{~N}_{32} \mathrm{P}_{9}$ & 2792.46 & 2792.49 & 60 \\
\hline
\end{tabular}




\begin{tabular}{|c|c|c|c|c|}
\hline $\begin{array}{l}\text { ON-1/ON-2 } \\
\text { (ds-60) }\end{array}$ & Summenformel & berechnet & gefunden & Intensität [\%] \\
\hline ON-2 (ds-60) & $\mathrm{C}_{146} \mathrm{H}_{184} \mathrm{O}_{87} \mathrm{~N}_{58} \mathrm{P}_{14}$ & 4574.80 & 4574.91 & 98 \\
\hline ON-1 (ds-60) & $\mathrm{C}_{146} \mathrm{H}_{185} \mathrm{O}_{89} \mathrm{~N}_{55} \mathrm{P}_{14}$ & 4565.80 & 4565.90 & 100 \\
\hline
\end{tabular}

\begin{tabular}{lllll}
\hline MS: & Summenformel & berechnet & gefunden & Intensität [\%] \\
\hline $\mathbf{A}^{*}(\mathbf{3 4 a})$ & $\mathrm{C}_{32} \mathrm{H}_{32} \mathrm{O}_{3} \mathrm{~N}_{8}$ & 576.26 & 576.26 & 100 \\
{$\left[\mathbf{A}^{*} \text { (34a) }\right]_{2}$} & $\mathrm{C}_{64} \mathrm{H}_{64} \mathrm{O}_{6} \mathrm{~N}_{16}$ & 1152.52 & 1152.50 & 54 \\
{$\left[\mathbf{A}^{*} \mathbf{( 3 4 a )}\right]_{3}$} & $\mathrm{C}_{96} \mathrm{H}_{96} \mathrm{O}_{9} \mathrm{~N}_{24}$ & 1728.78 & 1728.82 & 8 \\
\hline
\end{tabular}

\subsection{Untersuchung der Wechselwirkung des seco-Drugs $(+)-(1 S, 10 R)-34 a$ mit ds-60 im Verhältnis 1:1 bis 5:1 in Wasser und Phosphatpuffer}

1 Aliquot der Stammlösung von $(1 S, 10 R)$-34a in DMSO $(\mathrm{n} \mu \mathrm{L},(5 \times \mathrm{n}) \mathrm{nmol}, \mathrm{n}$ Äq.) wurde nach AAV 8.1 mit ds-60 ( $50 \mu \mathrm{L}, 5$ nmol, 1 Äq.) oder nach AAV 8.3 mit einer Mischung aus ds-60 (50 $\mu \mathrm{L}, 5 \mathrm{nmol}, 1$ Äq.) und Phosphatpuffer (pH 7, $50 \mu \mathrm{L}$ ) bei $25^{\circ} \mathrm{C}$ inkubiert und die Reaktionsmischung zu den Zeitpunkten $t=0 \mathrm{~h}$ und $24 \mathrm{~h}$ mittels analytischer HPLC (Säule: Bondapak $\left.{ }^{\circledR}\right)$ untersucht. Ergebnisse für $(t=24 \mathrm{~h})$ :

\begin{tabular}{|c|c|c|c|c|c|}
\hline \multirow[t]{7}{*}{$\begin{array}{l}\text { Inkubation } \\
\text { in Wasser: }\end{array}$} & $(1 S, 10 R)-34 a / d s-60$ & $\begin{array}{c}\text { ds-60(*) }(34 a) \\
{[\%]} \\
\end{array}$ & $\begin{array}{c}d s-60 * *(34 a) \\
{[\%]} \\
\end{array}$ & $\begin{array}{l}43 a \\
{[\%]}\end{array}$ & $\begin{array}{l}84 a \\
{[\%]} \\
\end{array}$ \\
\hline & $1: 1$ & 99 & - & - & 1 \\
\hline & $2: 1$ & 90 & - & - & 10 \\
\hline & $3: 1$ & 71 & 2 & - & 27 \\
\hline & $4: 1$ & 55 & 3 & - & 42 \\
\hline & $5: 1$ & 46 & 3 & - & 51 \\
\hline & $t_{\mathrm{R}}[\min ]$ & 18.3 & 25.0 & - & 35.6 \\
\hline \multirow[t]{7}{*}{$\begin{array}{l}\text { Inkubation } \\
\text { in Puffer: }\end{array}$} & $(1 S, 10 R)-34 a / d s-60$ & $\begin{array}{c}\text { ds-60(*) }(34 a) \\
{[\%]}\end{array}$ & $\begin{array}{c}\text { ds-60**(34a) } \\
{[\%]}\end{array}$ & $\begin{array}{l}43 a \\
{[\%]}\end{array}$ & $\begin{array}{l}\text { 84a } \\
{[\%]}\end{array}$ \\
\hline & $1: 1$ & 100 & - & - & - \\
\hline & $2: 1$ & 100 & - & - & - \\
\hline & $3: 1$ & 73 & 15 & - & 12 \\
\hline & $4: 1$ & 53 & 27 & - & 20 \\
\hline & $5: 1$ & 43 & 32 & - & 26 \\
\hline & $t_{\mathrm{R}}[\min ]$ & 18.4 & 25.1 & - & 35.5 \\
\hline
\end{tabular}


8.9 Untersuchung der Wechselwirkung des seco-Drugs $(+)-(1 S, 10 R)-34 a$ mit ds-60 im Verhältnis 5:1 nach $24 \mathrm{~h}$ Inkubation in Phosphatpuffer mittels semi-präparativer HPLC gefolgt von ESI-FTICR-MS

1 Aliquot der Stammlösung von (1S,10R)-34a in DMSO ( $25 \mu \mathrm{L}, 125$ nmol, 5 Äq.) wurde mit einer Mischung aus ds-60 (250 $\mu \mathrm{L}, 25 \mathrm{nmol}, 1$ Äq.) und Phosphatpuffer $(\mathrm{pH} 7,250 \mu \mathrm{L}) 24 \mathrm{~h}$ bei $25^{\circ} \mathrm{C}$ inkubiert und die Reaktionsmischung nach AAV 8.4 (Säule: Bondapak $\left.{ }^{\circledR}\right)$ untersucht. Ergebnisse für $(t=24$ h):

\begin{tabular}{|c|c|c|c|c|c|}
\hline \multirow[t]{2}{*}{ HPLC: } & $t[h]$ & ON-1-A (ds-60) & ds- $60^{(*)}(34 a)$ & ds- $60^{(* *)}(34 a)$ & $84 a$ \\
\hline & $t_{R}[\mathrm{~min}]$ & 16.2 & 18.0 & 24.9 & 33.9 \\
\hline
\end{tabular}

\begin{tabular}{llllll}
\cline { 2 - 2 }$:$ & ON-1-A (ds-60) & Summenformel & berechnet & gefunden & Intensität [\%] \\
\cline { 2 - 6 } & $\mathbf{w}_{\mathbf{5}}(\mathbf{O N}-1$ (ds-60)) & $\mathrm{C}_{48} \mathrm{H}_{63} \mathrm{O}_{32} \mathrm{~N}_{18} \mathrm{P}_{5}$ & 1558.25 & 1558.22 & 100 \\
d $_{9}(\mathbf{O N}-1$ (ds-60)) & $\mathrm{C}_{88} \mathrm{H}_{133} \mathrm{O}_{56} \mathrm{~N}_{32} \mathrm{P}_{9}$ & 2792.46 & 2792.48 & 24 \\
\hline
\end{tabular}

\begin{tabular}{|c|c|c|c|c|}
\hline ds-60 $60^{(*)}(34 a)$ & Summenformel & berechnet & gefunden & $\begin{array}{l}\text { Intensität } \\
{[\%]}\end{array}$ \\
\hline ON-2 (ds-60) & $\mathrm{C}_{146} \mathrm{H}_{184} \mathrm{O}_{87} \mathrm{~N}_{58} \mathrm{P}_{14}$ & 4574.80 & 4574.86 & 100 \\
\hline ON-1* (ds-60, 34a) & $\mathrm{C}_{173} \mathrm{H}_{212} \mathrm{O}_{92} \mathrm{~N}_{58} \mathrm{P}_{14}$ & 5007.00 & 5007.00 & 8 \\
\hline $\mathrm{w}_{5}(\mathrm{ON}-1(\mathrm{ds}-60))$ & $\mathrm{C}_{48} \mathrm{H}_{63} \mathrm{O}_{32} \mathrm{~N}_{18} \mathrm{P}_{5}$ & 1558.25 & 1558.26 & 49 \\
\hline$d_{9}(\mathrm{ON}-1$ (ds-60)) & $\mathrm{C}_{88} \mathrm{H}_{133} \mathrm{O}_{56} \mathrm{~N}_{32} \mathrm{P}_{9}$ & 2792.46 & 2792.49 & 32 \\
\hline
\end{tabular}

\begin{tabular}{llllll}
\cline { 2 - 2 } MS & ds-60**(34a) & Summenformel & berechnet & gefunden & $\begin{array}{l}\text { Intensität } \\
{[\%]}\end{array}$ \\
\cline { 2 - 2 } & $\mathrm{C}_{146} \mathrm{H}_{184} \mathrm{O}_{87} \mathrm{~N}_{58} \mathrm{P}_{14}$ & 4574.80 & 4574.84 & 100 \\
$\mathbf{O N - 1 * * ( d s - 6 0 , 3 4 a )}$ & $\mathrm{C}_{200} \mathrm{H}_{239} \mathrm{O}_{95} \mathrm{~N}_{61} \mathrm{P}_{14}$ & 5448.21 & 5448.29 & 29 \\
$\mathbf{w}_{\mathbf{5}}(\mathbf{O N - 1}(\mathbf{d s - 6 0 )})$ & $\mathrm{C}_{48} \mathrm{H}_{63} \mathrm{O}_{32} \mathrm{~N}_{18} \mathrm{P}_{5}$ & 1558.25 & 1558.26 & 25 \\
\hline
\end{tabular}


8.10 Kinetik der Wechselwirkung der seco-Drugs (+)-(1S,10R)-34a, $(+)-(1 S, 10 R)-34 b$, $(+)-(1 S)-56 a$ und $(+)-(1 S)-56 b$ mit ds-60 im

\section{Verhältnis 1:1 in Phosphatpuffer}

1 Aliquot der Stammlösung des jeweiligen seco-Drugs in DMSO $(1 \mu \mathrm{L}, 5 \mathrm{nmol}$, 1 Äq.) wurde nach AAV 8.3 mit einer Mischung aus ds-60 (50 $\mu \mathrm{L}, 5$ nmol, 1 Äq.) und Phosphatpuffer ( $\mathrm{pH} 7,50 \mu \mathrm{L}$ ) bei $25^{\circ} \mathrm{C}$ inkubiert und die Reaktionsmischung zu den Zeitpunkten $t=0 \mathrm{~h}, 2 \mathrm{~h}, 4 \mathrm{~h}$ und $6 \mathrm{~h}$ mittels analytischer HPLC (Säule: Bondapak ${ }^{\circledR}$ ) untersucht.

$(1 S, 10 R)-\mathbf{3 4 a}$ :

\begin{tabular}{cccc}
\hline $\boldsymbol{t}[\mathbf{h}]$ & $\mathbf{d s - 6 0}^{(*)}(\mathbf{3 4 a})[\%]$ & $\mathbf{4 3 a}[\mathbf{\%}]$ & $\mathbf{( 1 S , 1 0 R ) - 3 4 a ~ [ \% ] ~}$ \\
\hline 0 & - & 22 & 78 \\
2 & 100 & - & - \\
4 & 100 & - & - \\
6 & 100 & - & - \\
\hline $\boldsymbol{t}_{\mathrm{R}}[\mathbf{m i n}]$ & 20.4 & 39.2 & 43.3 \\
\hline
\end{tabular}

$(1 S, 10 R)-\mathbf{3 4 b}$ :

\begin{tabular}{cccc}
\hline $\boldsymbol{t}[\mathbf{h}]$ & $\mathbf{d s - 6 0}^{(*)}(\mathbf{3 4 b})[\mathbf{\%}]$ & $\mathbf{4 3 b}[\mathbf{\%}]$ & $\mathbf{( 1 S , 1 0 R ) - 3 4 b ~ [ \% ] ~}$ \\
\hline 0 & - & 11 & 89 \\
2 & 100 & - & - \\
4 & 100 & - & - \\
6 & 100 & - & - \\
\hline $\boldsymbol{t}_{\mathrm{R}}[\mathbf{m i n}]$ & 20.1 & 42.7 & 46.5 \\
\hline
\end{tabular}

(1S)-56a:

\begin{tabular}{cccc}
\hline $\boldsymbol{t}[\mathbf{h}]$ & $\mathbf{d s - 6 0}^{(*)} \mathbf{( 5 6 a )}[\mathbf{\%}]$ & $\mathbf{8 6 a}[\mathbf{\%}]$ & $\mathbf{( 1 S ) - 5 6 a ~ [ \% ] ~}$ \\
\hline 0 & 0 & 26 & 74 \\
2 & 35 & 20 & 45 \\
4 & 67 & 14 & 19 \\
6 & 88 & 0 & 12 \\
\hline $\boldsymbol{t}_{\mathrm{R}}[\mathbf{m i n}]$ & 18.8 & 40.9 & 46.0 \\
\hline
\end{tabular}


$(1 S)-\mathbf{5 6 b}$ :

\begin{tabular}{cccc}
\hline $\boldsymbol{t}[\mathbf{h}]$ & $\mathbf{d s - 6 0}^{(*)} \mathbf{( 5 6 b )}[\mathbf{\%}]$ & $\mathbf{8 6 b}[\%]$ & $\mathbf{( 1 S )}-\mathbf{5 6 b}[\%]$ \\
\hline 0 & 0 & 24 & 76 \\
2 & 29 & 20 & 51 \\
4 & 49 & 17 & 34 \\
6 & 62 & 19 & 19 \\
\hline $\boldsymbol{t}_{\mathrm{R}}[\mathbf{m i n}]$ & 18.6 & 44.4 & 49.9 \\
\hline
\end{tabular}

8.11 Untersuchung der Wechselwirkung des seco-Drugs (+)-(1S,10R)-34a mit DNA-Oligonukleotiden im Verhältnis 1:1 in Wasser und Phosphatpuffer

1 Aliquot der Stammlösung von $(1 S, 10 R)-34 a$ in DMSO (1 $\mu \mathrm{L}, 5$ nmol, 1 Äq.) wurde nach AAV 8.1 mit dem angegebenen doppelsträngigen Oligonukleotid $(50 \mu \mathrm{L}, 5 \mathrm{nmol}$, 1 Äq.) oder nach AAV 8.3 mit einer Mischung aus dem angegebenen doppelsträngigen Oligonukleotid (50 $\mu \mathrm{L}, 5 \mathrm{nmol}, 1$ Äq.) und Phosphatpuffer (pH 7, $50 \mu \mathrm{L}$ ) bei $25^{\circ} \mathrm{C}$ inkubiert und die Reaktionsmischung zu den Zeitpunkten $t=0 \mathrm{~h}$ und $t=24 \mathrm{~h}$ mittels analytischer HPLC (Säule: Bondapak ${ }^{\circledR}$ ) untersucht.

Inkubation in Wasser $(t=24 \mathrm{~h})$ :

\begin{tabular}{|c|c|c|c|c|}
\hline ds & $d s^{(*)}(34 a)[\%]$ & 43a $[\%]$ & $(1 S, 10 R)-34 a[\%]$ & $t_{\mathrm{R}}\left(\mathrm{ds} \mathrm{s}^{(*)}(34 \mathrm{a})\right)[\mathrm{min}]$ \\
\hline ds-60 & 100 & - & - & 19.9 \\
\hline ds-61 & 98 & 2 & - & 22.5 \\
\hline ds-62 & 99 & 1 & - & 19.8 \\
\hline ds-63 & 36 & 64 & - & 20.0 \\
\hline ds-64 & 99 & 1 & - & 19.3 \\
\hline ds-65 & 73 & 27 & - & 19.3 \\
\hline ds-66 & 97 & 3 & - & 19.1 \\
\hline ds-67 & 100 & - & - & 19.4 \\
\hline ds- 68 & 99 & 1 & - & 18.8 \\
\hline ds-69 & 37 & 63 & - & $19-23$ \\
\hline$t_{\mathrm{R}}[\min ]$ & s. Extraspalte & 35 & 37.6 & \\
\hline
\end{tabular}


Inkubation in Phosphatpuffer $(t=24 \mathrm{~h})$ :

\begin{tabular}{|c|c|c|c|c|}
\hline ds & $d s^{(*)}(34 a)[\%]$ & $43 \mathbf{a}[\%]$ & $(1 S, 10 R)-34 a[\%]$ & $t_{\mathrm{R}}\left(\mathrm{ds}^{(*)}(34 \mathrm{a})\right)[\mathrm{min}]$ \\
\hline ds-60 & 100 & - & - & 19.9 \\
\hline ds-61 & 97 & 3 & - & 23.4 \\
\hline ds-62 & 98 & 2 & - & 20.7 \\
\hline ds-63 & 24 & 76 & - & 20.4 \\
\hline ds-64 & 99 & 1 & - & 20.0 \\
\hline ds- 65 & 97 & 3 & - & 19.6 \\
\hline ds-66 & 99 & 1 & - & 19.4 \\
\hline ds-67 & 99 & 1 & - & 19.8 \\
\hline ds-68 & 100 & - & - & 19.3 \\
\hline ds-69 & 45 & 55 & - & $19-23$ \\
\hline$t_{\mathrm{R}}[\mathrm{min}]$ & s. Extraspalte & 36.1 & 38.0 & \\
\hline
\end{tabular}

\subsection{Untersuchung der Wechselwirkung des seco-Drugs $(+)-(1 S, 10 R)-34 b$ mit DNA-Oligonukleotiden im Verhältnis 1:1}

Die Wechselwirkung von $(1 S, 10 R)$-34b mit den Oligonukleotiden ds-60 bis ds-69 wurde nach AAV 8.2 untersucht (Säule: Bondapak ${ }^{\circledR}$ ). Ergebnisse für $t=24 \mathrm{~h}$ :

\begin{tabular}{ccccc}
\hline $\mathbf{d s}$ & $\mathbf{d s}^{(*)} \mathbf{( 3 4 b )}[\mathbf{\%}]$ & $\mathbf{4 3 b}[\mathbf{\%}]$ & $\mathbf{( 1 S , 1 0 R ) - 3 4 b ~ [ \% ]}$ & $\boldsymbol{t}_{\mathbf{R}}\left(\mathbf{d s} \mathbf{s}^{(*)} \mathbf{( 3 4 b ) )}[\mathbf{m i n}]\right.$ \\
\hline $\mathbf{d s - 6 0}$ & 97 & 1 & 2 & 18.1 \\
$\mathbf{d s - 6 1}$ & 89 & 2 & 9 & 20.8 \\
$\mathbf{d s - 6 2}$ & 96 & 4 & - & 18.2 \\
$\mathbf{d s - 6 3}$ & 38 & 62 & - & 18.1 \\
$\mathbf{d s - 6 4}$ & 96 & 1 & 3 & 17.8 \\
$\mathbf{d s - 6 5}$ & 60 & 40 & - & $16-25$ \\
$\mathbf{d s - 6 6}$ & 97 & 3 & - & 17.4 \\
$\mathbf{d s - 6 7}$ & 97 & 1 & 2 & 18.1 \\
$\mathbf{d s - 6 8}$ & 99 & 1 & - & 17.4 \\
$\mathbf{d s - 6 9}$ & 60 & 40 & - & $18-25$ \\
\hline $\boldsymbol{t}_{\mathbf{R}}[\mathbf{m i n}]$ & s. Extraspalte & 35.9 & 39.8 & \\
\hline
\end{tabular}


8.13 Untersuchung der Wechselwirkung des seco-Drugs (+)-(1S)-56a mit DNA-Oligonukleotiden im Verhältnis 1:1

Die Wechselwirkung von (1S)-56a mit den Oligonukleotiden ds-60 bis ds-69 wurde nach AAV 8.2 untersucht (Säule: Aquapore). Ergebnisse für $t=24 \mathrm{~h}$ :

\begin{tabular}{cccccc}
\hline ds & $\begin{array}{c}\text { Fragmente } \\
{[\%]}\end{array}$ & $\begin{array}{c}\mathbf{d s}^{(*)}(\mathbf{5 6 a}) \\
{[\%]}\end{array}$ & $\begin{array}{c}\mathbf{8 6 a} \\
{[\%]}\end{array}$ & $(\mathbf{1 S})-\mathbf{5 6 a}[\%]$ & $\boldsymbol{t}_{\mathbf{R}}\left(\mathbf{d s} \mathbf{s}^{(*)}(\mathbf{5 6 a})\right)[\mathbf{m i n}]$ \\
\hline ds-60 & - & 99 & - & 1 & 18.6 \\
ds-61 & - & 87 & - & 13 & 20.9 \\
ds-62 & - & 92 & - & 8 & 18.9 \\
ds-63 & - & 17 & 68 & 15 & 18.9 \\
ds-64 & - & 41 & - & 59 & 18.5 \\
ds-65 & 30 & 53 & 13 & 4 & 18.3 \\
ds-66 & 13 & 73 & 11 & 3 & 18.3 \\
ds-67 & - & 95 & - & 5 & 18.8 \\
ds-68 & 15 & 83 & - & 2 & 18.3 \\
ds-69 & - & 18 & 53 & 29 & 18.9 \\
\hline $\boldsymbol{t}_{\mathbf{R}}[\mathbf{m i n}]$ & 3.8 & s. Extraspalte & 34.7 & 39.7 & \\
\hline
\end{tabular}

\subsection{Untersuchung der Wechselwirkung des seco-Drugs (+)-(1S)-56b mit DNA-Oligonukleotiden im Verhältnis 1:1}

Die Wechselwirkung von (1S)-56b mit den Oligonukleotiden ds-60 bis ds-69 wurde nach AAV 8.2 untersucht (Säule: Aquapore). Ergebnisse für $t=24 \mathrm{~h}$ :

\begin{tabular}{cccccc}
\hline ds & $\begin{array}{c}\text { Fragmente } \\
{[\%]}\end{array}$ & $\begin{array}{c}\mathbf{d} \mathbf{s}^{(*)}(\mathbf{5 6 b}) \\
{[\%]}\end{array}$ & $\begin{array}{c}\mathbf{8 6 b} \\
{[\%]}\end{array}$ & $(\mathbf{1 S})-\mathbf{5 6 b}[\%]$ & $\boldsymbol{t}_{\mathbf{R}}\left(\mathbf{d s} \mathbf{s}^{(*)}(\mathbf{5 6 b})\right)[\mathbf{m i n}]$ \\
\hline ds-60 & - & 52 & 3 & 45 & 18.3 \\
ds-61 & - & 81 & 2 & 17 & 21.1 \\
ds-62 & - & 78 & 3 & 19 & 19.1 \\
ds-63 & - & 13 & 68 & 19 & 19.1 \\
ds-64 & - & 34 & 3 & 63 & 18.8 \\
ds-65 & 17 & 48 & 8 & 27 & 18.6
\end{tabular}




\begin{tabular}{cccccc} 
ds-66 & 7 & 84 & 2 & 7 & 18.4 \\
ds-67 & - & 67 & 3 & 30 & 18.8 \\
ds-68 & 6 & 70 & 3 & 21 & 18.4 \\
ds-69 & - & 26 & 41 & 33 & $19-20$ \\
\hline $\boldsymbol{t}_{\mathbf{R}}[\mathbf{m i n}]$ & 3.8 & s. Extraspalte & 36.5 & 41.2 & \\
\hline
\end{tabular}

\subsection{Untersuchung der Wechselwirkung weiterer Duocarmycin-Analoga mit DNA-Oligonukleotiden}

1 Aliquot der Stammlösung des Duocarmycin-Analogons in DMSO $(1 \mu \mathrm{L}, 5 \mathrm{nmol}$,

1 Äq. bzw. $1 \mu \mathrm{L}, 25$ nmol, 5 Äq.) wurde nach AAV 8.1 mit ds-60 $(50 \mu \mathrm{L}, 5 \mathrm{nmol}$, 1 Äq.) bei $25^{\circ} \mathrm{C}$ inkubiert und die Reaktionsmischung nach $t=24 \mathrm{~h}$ mittels analytischer HPLC (Säule: Bondapak ${ }^{\circledR}$ ) untersucht. Ergebnisse für $t=24 \mathrm{~h}$ :

\begin{tabular}{cccc}
\hline $\mathbf{( 1 S , 1 0 R ) - 3 3 a ~ / ~ d s - 6 0 ~}$ & ds-60 $^{(*)} \mathbf{( 3 3 a ) ~}[\%]$ & $\mathbf{8 5 a}[\%]$ & $(\mathbf{1 S , 1 0 R ) - 3 3 a ~ [ \% ] ~}$ \\
\hline $1: 1$ & 12 & 12 & 76 \\
$5: 1$ & 14 & 17 & 69 \\
\hline $\boldsymbol{t}_{\mathrm{R}}[\mathbf{m i n}]$ & 18.3 & 29.3 & 32.6 \\
\hline
\end{tabular}

\begin{tabular}{cccc}
\hline $\mathbf{( 1 S ) - 5 4 a ~ / ~ d s - 6 0 ~}$ & ds-60 $^{(*)}(\mathbf{5 4 a )}[\%]$ & $\mathbf{8 8 a}[\%]$ & $(\mathbf{1 S )})-54 a[\%]$ \\
\hline $1: 1$ & - & - & 100 \\
$5: 1$ & - & - & 100 \\
\hline $\boldsymbol{t}_{\mathrm{R}}[\mathrm{min}]$ & - & - & 32.5 \\
\hline
\end{tabular}

\begin{tabular}{cccc}
\hline $\mathbf{( 1 R , 1 0 S ) - 3 4 a ~ / ~ d s - 6 0 ~}$ & ds-60 $^{(*)}(\mathbf{3 4 a})[\%]$ & $\mathbf{8 4 a}[\%]$ & $(\mathbf{1 R , 1 0 S ) - 3 4 a ~ [ \% ] ~}$ \\
\hline $1: 1$ & - & 100 & - \\
$5: 1$ & 8 & 73 & 19 \\
\hline $\boldsymbol{t}_{\mathbf{R}}[\mathbf{m i n}]$ & 26.3 & 33.6 & 37.5 \\
\hline
\end{tabular}

\begin{tabular}{cccc}
\hline $\mathbf{( 1 R ) - 5 6 a ~ / ~ d s - 6 0 ~}$ & ds-60 $^{(*)}(\mathbf{5 6 a )}[\%]$ & $\mathbf{8 6 a}[\%]$ & $(\mathbf{1 R ) - 5 6 a ~ [ \% ] ~}$ \\
\hline $1: 1$ & 49 & 28 & 23 \\
$5: 1$ & 33 & 29 & 38 \\
\hline $\boldsymbol{t}_{\mathbf{R}}[\mathbf{m i n}]$ & 18.4 & $33-34.5$ & 37.4 \\
\hline
\end{tabular}




\begin{tabular}{ccc}
\hline $\mathbf{( 1 S ) - 4 9 ~ / ~ d s - 6 0 ~}$ & ds-60 $^{(*)}(\mathbf{4 9 )}[\mathbf{\%}]$ & $\mathbf{( 1 S ) - 4 9 ~ [ \% ] ~}$ \\
\hline $1: 1$ & - & 100 \\
$5: 1$ & 1 & 99 \\
$\boldsymbol{t}_{\mathbf{R}}[\mathbf{m i n}]$ & 23.3 & 33.9 \\
\hline
\end{tabular}

\begin{tabular}{cccc}
\hline $\mathbf{( 1 S , 1 0 R ) - 7 5 ~ / ~ d s - 6 0 ~}$ & ds-60 $^{(*)}(\mathbf{7 5 )}[\%]$ & $\mathbf{9 4}[\%]$ & $(\mathbf{1 S}, \mathbf{1 0 R})-\mathbf{7 5}[\%]$ \\
\hline $1: 1$ & - & - & 100 \\
$5: 1$ & - & - & 100 \\
\hline $\boldsymbol{t}_{\mathrm{R}}[\mathrm{min}]$ & - & - & 39.8 \\
\hline
\end{tabular}

\begin{tabular}{cccc}
\hline $\mathbf{( 1 S , 1 0 R ) - 7 6 ~ / d s - 6 0}$ & $\mathbf{d s}^{-60} \mathbf{( * )}^{(\mathbf{7 6})}[\mathbf{\%}]$ & $\mathbf{9 7}[\mathbf{\%}]$ & $\mathbf{( 1 S , 1 0 R ) - 7 6 ~ [ \% ] ~}$ \\
\hline $1: 1$ & 23 & 19 & 58 \\
$5: 1$ & 12 & 19 & 69 \\
\hline $\boldsymbol{t}_{\mathrm{R}}[\mathrm{min}]$ & 27.8 & 42.4 & 43.8 \\
\hline
\end{tabular}




\section{Untersuchung der Wechselwirkung neuer Duocarmycin- Analoga und anderer Zytostatika mit DNA-Oligonukleotiden mittels CD-Spektroskopie}

$\Delta I C D=\theta(\lambda=335 \mathrm{~nm})-\theta(\lambda=305 \mathrm{~nm})$.

\subsection{AAV 9.1: Allgemeine Arbeitsvorschrift zur Untersuchung des CD von Zytostatika in Phospatpuffer (pH 7, T $\left.=25^{\circ} \mathrm{C}\right)$}

1 Aliquot der Stammlösung eines Duocarmycin-Analogons oder anderen Zytostatikums in DMSO wurde in Phosphatpuffer ( $\mathrm{pH} 7$ ) pipettiert und die Reaktionsmischung gut durchmischt. Die Lösung wurde sofort in eine Küvette $(d=1 \mathrm{~cm})$ überführt und bei $25^{\circ} \mathrm{C}$ inkubiert. $\mathrm{Zu}$ den angegebenen Zeitpunkten nach dem Ansetzen der Reaktionmischung wurde ein CD-Spektrum gemessen. Als Referenz diente der verwendete Phosphatpuffer.

\subsection{AAV 9.2: Allgemeine Arbeitsvorschrift zur Untersuchung des CD von Zytostatika in PBS (pH 7.4, $T=37^{\circ} \mathrm{C}$ )}

1 Aliquot der Stammlösung eines Duocarmycin-Analogons in DMSO wurde in PBS (pH 7.4) gelöst ( $c=58 \mu \mathrm{M})$ und die Reaktionsmischung gut durchmischt. Die Lösung wurde sofort in eine Küvette $(d=1 \mathrm{~cm})$ überführt und bei $37^{\circ} \mathrm{C}$ inkubiert. Nach den Inkubationszeiten $t=0 \mathrm{~h}, 0.5 \mathrm{~h}, 1 \mathrm{~h}, 2 \mathrm{~h}, 3 \mathrm{~h}, 4 \mathrm{~h}, 6 \mathrm{~h}$ und $8 \mathrm{~h}$ wurde ein CD-Spektrum im Wellenlängenbereich $\lambda=220-450 \mathrm{~nm}$ gemessen. Als Referenz diente PBS.

\subsection{AAV 9.3: Allgemeine Arbeitsvorschrift zur Untersuchung der Wechselwirkung von Zytostatika mit einzel- oder doppelsträngigen DNA-Oligonukleotiden mittels CD-Spektroskopie}

Doppel- oder einzelsträngige DNA-Oligonukleotide wurden als wässrige Lösungen $(0.1 \mathrm{mM})$ der entsprechenden Natrium- oder Ammoniumsalze eingesetzt. 1 Aliquot der Stammlösung eines Duocarmycin-Analogons oder anderen Zytostatikums in DMSO $(1 \mu \mathrm{L})$ wurde in eine Mischung der wässrigen Lösung des ausgewählten Oligonukleotides $(50 \mu \mathrm{L})$ und Phosphatpuffer $(\mathrm{pH} 7,0.75 \mathrm{~mL})$ pipettiert und die Reaktionsmischung gut durchmischt. Die Lösung wurde sofort in eine Küvette 
$(d=1 \mathrm{~cm})$ überführt und bei $25^{\circ} \mathrm{C}$ inkubiert. Je nach Fragestellung wurde zu den angegebenen Zeitpunkten nach dem Ansetzen der Reaktionmischung ein CDSpektrum gemessen oder über einen Zeitraum von mehreren Stunden bei einer festen Wellenlänge die zeitliche Änderung des CD-Signals aufgezeichnet. Als Referenz diente der verwendete Phosphatpuffer. $\mathrm{Zu}$ Vergleichszwecken wurde ein CDSpektrum des jeweiligen DNA-Oligonukleotides $(50 \mu \mathrm{L})$ in Phosphatpuffer $(\mathrm{pH} 7$, $0.75 \mathrm{~mL})$ nach Zugabe von DMSO $(1 \mu \mathrm{L})$ gemessen.

\subsubsection{AAV 9.3a: ds-DNA / Wirkstoff $=1: n(n=1-10), \lambda=220-400 \mathrm{~nm}$}

1 Aliquot $(\mathrm{n} \mu \mathrm{L},(5 \times \mathrm{n}) \mathrm{nmol}, \mathrm{n}$ Äq.) der Stammlösung des Wirkstoffs in DMSO $(5 \mathrm{nmol} / \mu \mathrm{L})$ wurde nach AAV 9.3 mit einer Lösung aus dem doppelsträngigen Oligonukleotid (50 $\mu \mathrm{L}, 5 \mathrm{nmol}, 1$ Äq.) in Phosphatpuffer $(0.75 \mu \mathrm{L})$ gemischt, die Reaktionsmischung bei $25^{\circ} \mathrm{C}$ inkubiert und zu den Zeitpunkten $t=0 \mathrm{~h}, 0.25 \mathrm{~h}, 0.5 \mathrm{~h}$, $0.75 \mathrm{~h}, 1 \mathrm{~h}, 1.5 \mathrm{~h}, 2 \mathrm{~h}$ und $4 \mathrm{~h}$ ein CD-Spektrum im Wellenlängenbereich $\lambda=220$ $400 \mathrm{~nm}$ gemessen.

\subsubsection{AAV 9.3b: ds-DNA / Wirkstoff $=1: 1, \lambda=220-350 \mathrm{~nm}$}

1 Aliquot (1 $\mu \mathrm{L}, 5$ nmol, 1 Äq.) der Stammlösung des Wirkstoffs in DMSO $(5 \mathrm{nmol} / \mu \mathrm{L})$ wurde nach AAV 9.3 mit einer Lösung aus dem doppelsträngigen Oligonukleotid (50 $\mu \mathrm{L}, 5 \mathrm{nmol}, 1$ Äq.) in Phosphatpuffer $(0.75 \mu \mathrm{L})$ gemischt, die Reaktionsmischung bei $25^{\circ} \mathrm{C}$ inkubiert und im Zeitraum $t=0-2 \mathrm{~h}$ alle 10 Minuten sowie im Zeitraum $t=2-6 \mathrm{~h}$ jede Stunde ein CD-Spektrum im Wellenlängenbereich $\lambda=220-350 \mathrm{~nm}$ gemessen.

\subsubsection{AAV 9.3c: ds-DNA / Wirkstoff $=1: n(n=1-5), \lambda=304.5 \mathrm{~nm}$}

1 Aliquot $(\mathrm{n} \mu \mathrm{L},(5 \times \mathrm{n}) \mathrm{nmol}, \mathrm{n}$ Äq. $)$ der Stammlösung des Wirkstoffs in DMSO ( $5 \mathrm{nmol} / \mu \mathrm{L}$ ) wurde nach AAV 9.3 mit einer Lösung aus dem doppelsträngigen Oligonukleotid ( $50 \mu \mathrm{L}, 5 \mathrm{nmol}, 1$ Äq.) in Phosphatpuffer $(0.75 \mu \mathrm{L})$ gemischt, die Reaktionsmischung bei $25{ }^{\circ} \mathrm{C}$ inkubiert und im Zeitraum $t=0-4 \mathrm{~h}$ die zeitliche Änderung des CD-Signals bei $\lambda=304.5 \mathrm{~nm}$ aufgezeichnet. 


\subsection{CD nach Inkubation der Wirkstoffe in Phophatpuffer (pH 7)}

\subsubsection{Inkubation von (1S,10R)-34a in Phosphatpuffer}

1 Aliquot der Stammlösung von $(1 S, 10 R)-34 a$ in DMSO $(5 \mathrm{nmol} / \mu \mathrm{L})$ wurde in Phosphatpuffer ( $\mathrm{pH} 7,0.8 \mathrm{~mL}$ ) pipettiert und nach AAV $9.1 \mathrm{im}$ Zeitraum $t=0-2 \mathrm{~h}$ alle 10 Minuten sowie im Zeitraum $t=2-6 \mathrm{~h}$ jede Stunde ein CD-Spektrum im Wellenlängenbereich $\lambda=220-350 \mathrm{~nm}$ gemessen.

$0 \mathrm{~h}: \lambda_{\max }[\mathrm{nm}](\theta[\mathrm{mgrad}]): 230(0.0), 266(-0.5), 320(-0.7)$.

$\lambda_{\text {min }}[\mathrm{nm}](\theta[\mathrm{mgrad}]): 254(-0.9), 290(-1.9)$.

$1 \mathrm{~h}: \lambda_{\max }[\mathrm{nm}](\theta[\mathrm{mgrad}]): 230(0.2), 266(-0.5), 320(-0.4)$.

$\lambda_{\min }[\mathrm{nm}](\theta[\mathrm{mgrad}]): 254(-1.1), 290(-1.6)$.

$6 \mathrm{~h}: \lambda_{\max }[\mathrm{nm}](\theta[\mathrm{mgrad}]): 230(0.0), 266(-0.4), 320(-0.6)$.

$\lambda_{\min }[\mathrm{nm}](\theta[\mathrm{mgrad}]): 254(-1.0), 290(-1.8)$.

\subsubsection{Inkubation von Doxorubicin (11) in Phosphatpuffer}

1 Aliquot der Stammlösung von Doxorubicin (11) in DMSO $(5 \mathrm{nmol} / \mu \mathrm{L})$ wurde in Phosphatpuffer ( $\mathrm{pH} 7,0.8 \mathrm{~mL})$ pipettiert und nach AAV 9.1 ein CD-Spektrum für die Doxorubicin-Konzentrationen $6.3 \mu \mathrm{M}$ und $62.5 \mu \mathrm{M}$ im Wellenlängenbereich $\lambda=220-600 \mathrm{~nm}$ gemessen.

$62.5 \mu \mathrm{M}: \lambda_{\max }[\mathrm{nm}](\theta$ [mgrad]): 341 (1.6).

$\lambda_{\min }[\mathrm{nm}](\theta[\mathrm{mgrad}]): 292(-0.55)$.

\subsubsection{Inkubation von Melphalan (79) in Phosphatpuffer}

1 Aliquot der Stammlösung von Melphalan (79) in DMSO (5 nmol/ $\mu \mathrm{L})$ wurde in Phosphatpuffer ( $\mathrm{pH} 7,0.8 \mathrm{~mL}$ ) pipettiert und nach AAV 9.1 ein CD-Spektrum für die Melphalan-Konzentrationen $6.3 \mu \mathrm{M}$ und $62.5 \mu \mathrm{M}$ im Wellenlängenbereich $\lambda=220-400 \mathrm{~nm}$ gemessen.

Es konnte kein signifikantes CD-Signal beobachtet werden. 


\subsubsection{Inkubation von Mitomycin (99) in Phosphatpuffer}

1 Aliquot der Stammlösung von Mitomycin (99) in DMSO ( $5 \mathrm{nmol} / \mu \mathrm{L})$ wurde in Phosphatpuffer ( $\mathrm{pH} 7,0.8 \mathrm{~mL}$ ) pipettiert und nach AAV 9.1 nach den Inkubationszeiten $t=0 \mathrm{~h}, 0.5 \mathrm{~h}, 1 \mathrm{~h}, 2 \mathrm{~h}, 3 \mathrm{~h}, 5 \mathrm{~h}$ und $6 \mathrm{~h}$ ein CD-Spektrum für die MitomycinKonzentrationen $6.3 \mu \mathrm{M}$ und $62.5 \mu \mathrm{M}$ im Wellenlängenbereich $\lambda=220-800 \mathrm{~nm}$ gemessen.

$6.3 \mu \mathrm{M}: \quad \lambda_{\max }[\mathrm{nm}](\theta[\mathrm{mgrad}]): 400(0.64)$.

$$
\lambda_{\min }[\mathrm{nm}](\theta[\mathrm{mgrad}]): 370(-0.32) .
$$

$62.5 \mu \mathrm{M}: \lambda_{\max }[\mathrm{nm}](\theta[\mathrm{mgrad}]): 400(5.5)$.

$$
\lambda_{\min }[\mathrm{nm}](\theta[\mathrm{mgrad}]): 370(-0.64) .
$$

Es konnte im untersuchten Zeitintervall keine Änderung des CD-Spektrums beobachtet werden.

\subsection{CD nach Inkubation der Wirkstoffe in PBS (pH 7.4, $\left.T=37^{\circ} \mathrm{C}\right)$}

\subsubsection{Inkubation des seco-Drugs $(1 S, 10 R)-34 a$ in PBS}

$(1 S, 10 R)-34 a$ wurde nach AAV 9.2 untersucht.

$0 \mathrm{~h}: \lambda_{\max }[\mathrm{nm}](\theta[\mathrm{mgrad}]): 275$ (1.9), $320(2.8)$.

$\lambda_{\text {min }}[\mathrm{nm}](\theta[\mathrm{mgrad}]): 250(-2.0), 290(-0.30), 370(-0.94)$.

$8 \mathrm{~h}: \lambda_{\max }[\mathrm{nm}](\theta[\mathrm{mgrad}]): 275$ (1.3), 320 (1.6).

$\lambda_{\min }[\mathrm{nm}](\theta$ [mgrad]): $250(-0.63), 290(-0.50), 370(-0.56)$.

\subsubsection{Inkubation des seco-Drugs (1S)-56a in PBS}

(1S)-56a wurde nach AAV 9.2 untersucht.

$0 \mathrm{~h}: \lambda_{\max }[\mathrm{nm}](\theta[\mathrm{mgrad}]): 275$ (2.5), $310(3.0), 390(0.1)$.

$\lambda_{\min }[\mathrm{nm}](\theta$ [mgrad]): $250(-1.5), 290(1.7), 370(-0.70)$. 
$8 \mathrm{~h}: \lambda_{\max }[\mathrm{nm}](\theta[\mathrm{mgrad}]): 275$ (2.7), 310 (4.8), 390 (0.4).

$\lambda_{\text {min }}[\mathrm{nm}](\theta[\mathrm{mgrad}]): 250(-3.0), 370(-0.70)$.

\subsubsection{Inkubation des seco-Drugs $(1 S, 10 R)-34 b$ in PBS}

$(1 S, 10 R)$-34b wurde nach AAV 9.2 untersucht.

0 h: $\lambda_{\max }[\mathrm{nm}](\theta[\mathrm{mgrad}]): 275$ (2.5), 320 (4.1), 390 (2.6).

$\lambda_{\text {min }}[\mathrm{nm}](\theta[\mathrm{mgrad}]): 250(-4.2), 290(0.3)$.

$8 \mathrm{~h}: \lambda_{\max }[\mathrm{nm}](\theta[\mathrm{mgrad}]): 275(0.8), 320(0.3)$.

$\lambda_{\min }[\mathrm{nm}](\theta[\mathrm{mgrad}]): 250(-0.2), 290(-1.5)$.

\subsubsection{Inkubation des seco-Drugs (1S)-56b in PBS}

(1S)-56b wurde nach AAV 9.2 untersucht.

$0 \mathrm{~h}: \lambda_{\max }[\mathrm{nm}](\theta[\mathrm{mgrad}]): 275$ (3.8), 320 (4.6), 390 (16.9).

$\lambda_{\min }[\mathrm{nm}](\theta$ [mgrad]): $250(-6.4), 300(0.51), 345$ (1.3).

$8 \mathrm{~h}: \lambda_{\max }[\mathrm{nm}](\theta[\mathrm{mgrad}]): 275(1.3), 310(4.1)$.

$\lambda_{\min }[\mathrm{nm}](\theta[\mathrm{mgrad}]): 250(-3.3), 370(-1.3)$.

9.6 Untersuchung der Wechselwirkung von Zytostatika mit einzel- oder doppelsträngigen DNA-Oligonukleotiden mittels CD-Spektroskopie

\subsection{1 (1S,10R)-34a, $\lambda=220-400 \mathrm{~nm}$}

\subsubsection{1 ds-60 / (1S,10R)-34a = 1:1 in Phosphatpuffer}

Die Wechselwirkung von $(1 S, 10 R)-34 a$ und ds-60 wurde nach AAV 9.3a $(\mathrm{n}=1)$ untersucht.

$0 \mathrm{~h}: \lambda_{\max }[\mathrm{nm}](\theta[\mathrm{mgrad}]): 285(6.9), 325(0.8)$.

$\lambda_{\min }[\mathrm{nm}](\theta[\mathrm{mgrad}]): 240(-2.2), 305(-0.2)$. 
$\Delta \mathrm{ICD}(0 \mathrm{~h})=0.8 \mathrm{mgrad}$.

$2 \mathrm{~h}: \lambda_{\max }[\mathrm{nm}](\theta$ [mgrad]): 285 (6.9), 335 (2.2).

$\lambda_{\text {min }}[\mathrm{nm}](\theta[\mathrm{mgrad}]): 240(-2.2), 305(-2.3)$.

$\Delta \operatorname{ICD}(2 \mathrm{~h})=4.5 \mathrm{mgrad}$.

$4 \mathrm{~h}: \lambda_{\max }[\mathrm{nm}](\theta[\mathrm{mgrad}]): 285$ (6.9), 335 (2.3).

$\lambda_{\min }[\mathrm{nm}](\theta[\mathrm{mgrad}]): 240(-2.2), 305(-2.3)$.

$\Delta \operatorname{ICD}(4 \mathrm{~h})=4.6 \mathrm{mgrad}$.

\subsubsection{2 ds-60 / (1S,10R)-34a = 1:1 mit/ohne Vorinkubation des seco-Drugs im Puffer}

1 Aliquot (1 $\mu \mathrm{L}, 5$ nmol, 1 Äq.) der Stammlösung von $(1 S, 10 R)-34 \mathbf{a}$ in DMSO $(5 \mathrm{nmol} / \mu \mathrm{L})$ wurde in Phosphatpuffer $(\mathrm{pH} 7,0.45 \mathrm{~mL})$ gelöst und direkt oder nach $2 \mathrm{~h}$ Inkubation bei $25^{\circ} \mathrm{C}$ eine wässrige Lösung von ds-60 (50 $\mu \mathrm{L}, 5$ nmol, 1 Äq.) zu der Reaktionsmischung pipettiert sowie gut durchmischt. Die Lösung wurde sofort in eine Küvette $(d=1 \mathrm{~cm})$ überführt und bei $25^{\circ} \mathrm{C}$ inkubiert. $\mathrm{Zu}$ den Zeitpunkten $t=0 \mathrm{~h}$, $0.25 \mathrm{~h}, 0.5 \mathrm{~h}, 0.75 \mathrm{~h}, 1 \mathrm{~h}, 1.5 \mathrm{~h}, 2 \mathrm{~h}$ und $4 \mathrm{~h}$ nach der Zugabe des Oligonukleotides wurde ein CD-Spektrum im Wellenlängenbereich $\lambda=220-400 \mathrm{~nm}$ gemessen. Als Referenz diente der verwendete Phosphatpuffer.

$\underline{(1 S, 10 R)-34 a / \text { ds-60 }=1: 1 \text { mit Vorinkubation im Puffer: }}$

$0 \mathrm{~h}: \quad \lambda_{\max }[\mathrm{nm}](\theta[\mathrm{mgrad}]): 285$ (5.8), 325 (1.4).

$\lambda_{\min }[\mathrm{nm}](\theta[\mathrm{mgrad}]): 240(-1.4), 305(-0.3)$.

$\Delta \mathrm{ICD}=1.6$ mgrad

0.5-4 h: $\quad \lambda_{\max }[\mathrm{nm}](\theta[\mathrm{mgrad}]): 285(5.1), 335$ (2.0).

$\lambda_{\min }[\mathrm{nm}](\theta[\mathrm{mgrad}]): 240(-1.4), 305(-2.0)$.

$\Delta \mathrm{ICD}=4.0 \mathrm{mgrad}$.

$\underline{(1 S, 10 R)-34 \mathbf{a} / \mathrm{ds}-60=1: 1 \text { ohne Vorinkubation im Puffer: }}$

$0 \mathrm{~h}: \quad \lambda_{\max }[\mathrm{nm}](\theta[\mathrm{mgrad}]): 285(6.4), 325(0.6)$. 
$\lambda_{\text {min }}[\mathrm{nm}](\theta$ [mgrad] $): 240(-2.0), 305(-0.1)$.

$\Delta \mathrm{ICD}=0.8 \mathrm{mgrad}$.

$0.5 \mathrm{~h}: \quad \lambda_{\max }[\mathrm{nm}](\theta[\mathrm{mgrad}]): 285(6.4), 330(1.4)$.

$\lambda_{\text {min }}[\mathrm{nm}](\theta[\mathrm{mgrad}]): 240(-2.0), 305(-1.3)$.

$\Delta \mathrm{ICD}=2.5$ mgrad

$4 \mathrm{~h}: \quad \lambda_{\max }[\mathrm{nm}](\theta[\mathrm{mgrad}]): 285(6.4), 335(1.7)$.

$\lambda_{\min }[\mathrm{nm}](\theta[\mathrm{mgrad}]): 240(-2.0), 305(-1.7)$.

$\Delta \mathrm{ICD}=3.4$ mgrad

\subsubsection{3 ds-60 / (1S,10R)-34a = 1:1 mit/ohne Inkubation im Puffer}

1 Aliquot (1 $\mu \mathrm{L}, 5 \mathrm{nmol}, 1$ Äq.) der Stammlösung von $(1 S, 10 R)$-34a in DMSO ( $5 \mathrm{nmol} / \mu \mathrm{L})$ wurde mit einer wässrigen Lösung von ds-60 (50 $\mu \mathrm{L}, 5 \mathrm{nmol}, 1$ Äq.) versetzt. Direkt danach oder nach $2 \mathrm{~h}$ Inkubation bei $25^{\circ} \mathrm{C}$ wurde zu der Reaktionsmischung Phosphatpuffer (pH 7, $0.45 \mathrm{~mL}$ ) gegeben und gut durchmischt. Die Lösung wurde sofort in eine Küvette $(d=1 \mathrm{~cm})$ überführt und bei $25^{\circ} \mathrm{C}$ inkubiert. Beide Lösungen wurden $2 \mathrm{~h}$ nach dem Mischen des seco-Drugs mit der DNA CD-spektrometrisch (Wellenlängenbereich $\lambda=220-400 \mathrm{~nm}$ ) untersucht. Beide Lösungen wurden danach weitere $2 \mathrm{~h}$ im Puffer inkubiert und erneut ein CD-Spektrum gemessen. Als Referenz diente der verwendete Phosphatpuffer.

\section{$\underline{(1 S, 10 R)-\mathbf{3 4 a} / \mathrm{ds}-\mathbf{6 0}=1: 1 \text { nach Inkubation ohne Puffer: }}$}

$2 \mathrm{~h}: \lambda_{\max }[\mathrm{nm}](\theta[\mathrm{mgrad}]): 280(6.7), 325(1.2)$.

$\lambda_{\min }[\mathrm{nm}](\theta[\mathrm{mgrad}]): 240(-3.0), 305(-0.3)$.

$\Delta \mathrm{ICD}=1.4$ mgrad

$\underline{(1 S, 10 R)-34 a / \text { ds-60 }=1: 1 \text { nach Inkubation im Puffer: }}$

$2 \mathrm{~h}: \lambda_{\max }[\mathrm{nm}](\theta[\operatorname{mgrad}]): 280(6.9), 335$ (1.5).

$\lambda_{\text {min }}[\mathrm{nm}](\theta[\mathrm{mgrad}]): 240(-3.6), 305(-1.3)$.

$\Delta \mathrm{ICD}=2.8 \mathrm{mgrad}$. 
$\underline{(1 S, 10 R)-34 a / \text { ds- } 60=1: 1 \text { nach Inkubation mit/ohne Puffer: }}$

Die Spektren beider Lösungen sind nahezu identisch.

$\lambda_{\max }[\mathrm{nm}](\theta[\mathrm{mgrad}]): 280(6.0), 335$ (1.4).

$\lambda_{\text {min }}[\mathrm{nm}](\theta[\mathrm{mgrad}]): 240(-4.0), 305(-2.5)$.

$\Delta \mathrm{ICD}=3.9 \mathrm{mgrad}$

ds-60:

$\lambda_{\max }[\mathrm{nm}](\theta[\mathrm{mgrad}]): 280(7.0)$.

$\lambda_{\text {min }}[\mathrm{nm}](\theta[\mathrm{mgrad}]): 240(-4.0)$.

\subsubsection{4 ds-60 / (1S,10R)-34a $=1: 1 \rightarrow 1: 5$ in Phosphatpuffer}

1 Aliquot (1 $\mu \mathrm{L}, 5 \mathrm{nmol}, 1$ Äq.) der Stammlösung von $(1 S, 10 R)-34 a$ in DMSO $(5 \mathrm{nmol} / \mu \mathrm{L})$ wurde in Phosphatpuffer $(\mathrm{pH} 7,0.45 \mathrm{~mL})$ gelöst und bei $25^{\circ} \mathrm{C}$ eine wässrige Lösung von ds-60 (50 $\mu \mathrm{L}, 5 \mathrm{nmol}, 1$ Äq.) zu der Reaktionsmischung pipettiert sowie gut durchmischt. Die Lösung wurde sofort in eine Küvette $(d=1 \mathrm{~cm})$ überführt und bei $25^{\circ} \mathrm{C}$ inkubiert. Nach den Zeiten $t=0 \mathrm{~h}, 1 \mathrm{~h}$ und $2 \mathrm{~h}$ wurde ein CDSpektrum im Wellenlängenbereich $\lambda=220-400 \mathrm{~nm}$ gemessen. Anschließend wurde bis zum Verhältnis ds-60/ $(1 S, 10 R)-\mathbf{3 4 a}=1: 5$ jeweils 1 weiteres Äquivalent seco-Drug (1S,10R)-34a (je $1 \mu \mathrm{L}, 5 \mathrm{nmol}, 1$ Äq.) zu der Reaktionsmischung pipettiert, durchmischt und erneut nach $t=0 \mathrm{~h}, 1 \mathrm{~h}$ und $2 \mathrm{~h}$ ein CD-Spektrum im Wellenlängenbereich $\lambda=220-400 \mathrm{~nm}$ gemessen. Als Referenz diente der verwendete Phosphatpuffer.

\begin{tabular}{cccc}
\hline ds-60/(1S,10R)-34a & $\begin{array}{c}\Delta \text { ICD }(\mathbf{0} \text { h) } \\
{[\mathbf{m g r a d}]}\end{array}$ & $\begin{array}{c}\Delta \text { ICD }(\mathbf{2} \text { h) } \\
{[\mathbf{m g r a d}]}\end{array}$ & $\begin{array}{c}\text { Zunahme } \Delta \text { ICD } \\
{[\mathbf{m g r a d}]}\end{array}$ \\
\hline $1: 1$ & 1.15 & 6.44 & 5.29 \\
$1: 2$ & 6.47 & 11.33 & 4.86 \\
$1: 3$ & 9.37 & 10.60 & 1.23 \\
$1: 4$ & 8.28 & 8.40 & 0.12 \\
$1: 5$ & 6.55 & 6.55 & 0.00 \\
\hline
\end{tabular}




\subsubsection{5 ds-60 / (1S,10R)-34a $=1: 1$ in PBS $\left(\mathrm{pH} 7.4, \mathrm{~T}=25^{\circ} \mathrm{C}\right)$}

1 Aliquot (1 $\mu \mathrm{L}, 5 \mathrm{nmol}, 1$ Äq.) der Stammlösung von $(1 S, 10 R)-34 \mathbf{a}$ in DMSO $(5 \mathrm{nmol} / \mu \mathrm{L})$ wurde in eine Mischung der wässrigen Lösung von ds-60 (50 $\mu \mathrm{L}, 5 \mathrm{nmol}$, 1 Äq.) und Phosphatpuffer (pH 7.4, $0.75 \mathrm{~mL}$ ) pipettiert und die Reaktionsmischung gut durchmischt. Die Lösung wurde sofort in eine Küvette $(d=1 \mathrm{~cm})$ überführt und bei $25^{\circ} \mathrm{C}$ inkubiert. Nach den Inkubationszeiten $t=0 \mathrm{~h}, 1 \mathrm{~h}$ und $2 \mathrm{~h}$ wurde ein CDSpektrum im Wellenlängenbereich $\lambda=220-400 \mathrm{~nm}$ gemessen.

$\mathrm{Zu}$ Vergleichszwecken wurde zusätzlich ein CD-Spektrum des DNA-Oligonukleotides ds-60 sowie des seco-Drugs ohne DNA aufgezeichnet. Hierzu wurde ds-60 (50 $\mu \mathrm{L}$, $5 \mathrm{nmol})$ in Phosphatpuffer ( $\mathrm{pH} 7,0.75 \mathrm{~mL})$ gelöst und nach Zugabe von DMSO $(1 \mu \mathrm{L})$ ein CD-Spektrum im Wellenlängenbereich $\lambda=220-400 \mathrm{~nm}$ gemessen. Danach wurde 1 Aliquot $(1 \mu \mathrm{L}, 5 \mathrm{nmol})$ der Stammlösung von $(1 S, 10 R)-34 a$ in DMSO $(5 \mathrm{nmol} / \mu \mathrm{L})$ in PBS $(0.80 \mathrm{~mL})$ gelöst und die Reaktionsmischung bei $25^{\circ} \mathrm{C}$ inkubiert. Nach den Inkubationszeiten $t=0 \mathrm{~h}$ und $0.5 \mathrm{~h}$ wurde ein CD-Spektrum im Wellenlängenbereich $\lambda=220-400 \mathrm{~nm}$ gemessen.

Als Referenz für alle Messungen diente PBS.

$(1 S, 10 R)-\mathbf{3 4 a} / \mathrm{ds}-60=1: 1:$

$0 \mathrm{~h}: \lambda_{\max }[\mathrm{nm}](\theta[\mathrm{mgrad}]): 285$ (3.6), $320(0.83)$.

$\lambda_{\text {min }}[\mathrm{nm}](\theta$ [mgrad]): $240(-1.6), 304(-0.50)$.

$2 \mathrm{~h}: \lambda_{\max }[\mathrm{nm}](\theta[\mathrm{mgrad}]): 285$ (3.6), $335(1.9)$.

$\lambda_{\min }[\mathrm{nm}](\theta[\mathrm{mgrad}]): 240(-1.9), 304(-2.4)$.

ds-60:

$\lambda_{\max }[\mathrm{nm}](\theta$ [mgrad] $): 285$ (4.6).

$\lambda_{\min }[\mathrm{nm}](\theta[\mathrm{mgrad}]): 240(-2.8)$.

$\underline{(1 S, 10 R)-34 a:}$

$\lambda_{\max }[\mathrm{nm}](\theta$ [mgrad]): 270 (0.67), 318 (1.2).

$\lambda_{\text {min }}[\mathrm{nm}](\theta[\mathrm{mgrad}]): 290(-0.17)$. 


\subsection{2 (1S,10R)-34a, $\lambda=220-350 \mathrm{~nm}$}

\subsubsection{1 ds-60 / (1S,10R)-34a $=1: 1$ in Phosphatpuffer}

Die Wechselwirkung von $(1 S, 10 R)-34 a$ und ds-60 wurde nach AAV 9.3b untersucht.

$0 \mathrm{~h}: \lambda_{\max }[\mathrm{nm}](\theta[\mathrm{mgrad}]): 285(1.3), 328(-0.4)$.

$\lambda_{\min }[\mathrm{nm}](\theta$ [mgrad]): $240(-5.9), 305(-2.3)$.

$1 \mathrm{~h}: \lambda_{\max }[\mathrm{nm}](\theta[\mathrm{mgrad}]): 285(0.9), 330(1.5)$.

$\lambda_{\min }[\mathrm{nm}](\theta[\mathrm{mgrad}]): 240(-5.9), 305(-5.4)$.

$6 \mathrm{~h}: \lambda_{\max }[\mathrm{nm}](\theta[\mathrm{mgrad}]): 285$ (1.1), 335 (1.6).

$\lambda_{\min }[\mathrm{nm}](\theta$ [mgrad]): $240(-5.9), 305(-5.7)$.

\subsubsection{2 ds-69 / (1S,10R)-34a $=1: 1$ in Phosphatpuffer}

Die Wechselwirkung von $(1 S, 10 R)-34 a$ und ds-69 wurde nach AAV 9.3b untersucht.

$0 \mathrm{~h}: \lambda_{\max }[\mathrm{nm}](\theta[\mathrm{mgrad}]): 285(4.8), 320(0.5)$.

$\lambda_{\min }[\mathrm{nm}](\theta[\operatorname{mgrad}]): 240(-1.9), 305(0.3)$.

$1 \mathrm{~h}: \lambda_{\max }[\mathrm{nm}](\theta[\mathrm{mgrad}]): 285$ (4.9), $320(0.8)$.

$\lambda_{\min }[\mathrm{nm}](\theta[\mathrm{mgrad}]): 240(-1.6), 305(0.5)$.

$6 \mathrm{~h}: \lambda_{\max }[\mathrm{nm}](\theta[\mathrm{mgrad}]): 285(4.7), 320(0.5)$.

$\lambda_{\min }[\mathrm{nm}](\theta[\mathrm{mgrad}]): 240(-1.3), 305(0.3)$.

\subsubsection{ON-1 (ds-60) / (1S,10R)-34a $=1: 1$ in Phosphatpuffer}

Die Wechselwirkung von $(1 S, 10 R)$-34a und ON-1 (ds-60) wurde nach AAV 9.3b untersucht.

$0 \mathrm{~h}: \lambda_{\max }[\mathrm{nm}](\theta[\mathrm{mgrad}]): 280(4.8), 320$ (2.2).

$\lambda_{\min }[\mathrm{nm}](\theta[\mathrm{mgrad}]): 240(-2.9), 305$ (1.3).

$1 \mathrm{~h}: \lambda_{\max }[\mathrm{nm}](\theta[\mathrm{mgrad}]): 280$ (4.9), 320 (2.8).

$\lambda_{\min }[\mathrm{nm}](\theta[\mathrm{mgrad}]): 240(-3.0), 305(0.5)$. 
$6 \mathrm{~h}: \lambda_{\max }[\mathrm{nm}](\theta[\mathrm{mgrad}]): 280(4.7), 320(2.2)$.

$$
\lambda_{\text {min }}[\mathrm{nm}](\theta \text { [mgrad]): } 240 \text { (-2.9), } 305 \text { (1.3). }
$$

\subsection{3 (1S,10R)-34a, $\lambda=304.5 \mathrm{~nm}$}

\subsubsection{1 (1S,10R)-34a in Phosphatpuffer}

1 Aliquot (1 $\mu \mathrm{L}, 5 \mathrm{nmol}, 1$ Äq.) der Stammlösung von $(1 S, 10 R)-34 a$ in DMSO $(5 \mathrm{nmol} / \mu \mathrm{L})$ wurde in Phosphatpuffer $(\mathrm{pH} 7,0.80 \mathrm{~mL})$ gegeben. Die Lösung wurde in eine Küvette $(d=1 \mathrm{~cm})$ überführt, bei $25^{\circ} \mathrm{C}$ inkubiert und im Zeitraum $t=0 \mathrm{~h}$ bis $t=4 \mathrm{~h}$ die zeitliche Änderung des CD-Signals bei $\lambda=304.5 \mathrm{~nm}$ aufgezeichnet. Die Messung wurde dreimal wiederholt.

$\theta(4 \mathrm{~h})-\theta(0 \mathrm{~h})=(0.5 \pm 0.1) \mathrm{mgrad}$.

\subsubsection{2 ds-60 / (1S,10R)-34a $=1: 1$ in Phosphatpuffer}

Die Wechselwirkung von $(1 S, 10 R)-\mathbf{3 4 a}$ und ds-60 wurde dreimal nach AAV3c $(\mathrm{n}=1)$ untersucht.

$\theta(4 \mathrm{~h})-\theta(0 \mathrm{~h})=-(3.5 \pm 0.4) \mathrm{mgrad}$.

\subsubsection{3 ds-60 / (1S,10R)-34a $=1: 1$ mit/ohne $2 \mathrm{~h}$ Vorinkubation in Phosphat- puffer}

1 Aliquot (1 $\mu \mathrm{L}, 5 \mathrm{nmol}, 1$ Äq.) der Stammlösung von $(1 S, 10 R)-34 \mathbf{a}$ in DMSO $(5 \mathrm{nmol} / \mu \mathrm{L})$ wurde in Phosphatpuffer $(\mathrm{pH} 7,0.45 \mathrm{~mL})$ gegeben und direkt oder nach $2 \mathrm{~h}$ Inkubation bei $25^{\circ} \mathrm{C}$ mit einer wässrigen Lösung von ds-60 (50 $\mu \mathrm{L}, 5 \mathrm{nmol}, 1$ Äq.) versetzt. Die Lösung wurde in eine Küvette $(d=1 \mathrm{~cm})$ überführt, bei $25^{\circ} \mathrm{C}$ inkubiert und der Verlauf des CD-Signals bei $304.5 \mathrm{~nm}$ im Zeitraum $t=0 \mathrm{~h}$ bis $t=4 \mathrm{~h}$ gemessen.

$(1 S, 10 R)-\mathbf{3 4 a} /$ ds-60 = 1:1 mit Vorinkubation im Puffer:

$\theta(4 \mathrm{~h})-\theta(0 \mathrm{~h})=-2.8 \mathrm{mgrad}$.

$\underline{(1 S, 10 R)-34 a / \text { ds-60 }=1: 1 \text { ohne Vorinkubation im Puffer: }}$

$\theta(4 \mathrm{~h})-\theta(0 \mathrm{~h})=-1.9 \mathrm{mgrad}$. 


\subsubsection{4 ds-60 / (1S,10R)-34a $=1: 1$ in Wasser $(\mathrm{pH} 5)$}

Die Wechselwirkung von $(1 S, 10 R)-34 a$ und ds-60 wurde zweimal nach AAV 9.3c $(\mathrm{n}=1)$ mit Wasser $(\mathrm{pH}$ 5) anstelle des Phosphatpuffers untersucht.

$\theta(4 \mathrm{~h})-\theta(0 \mathrm{~h})=-(0.4 \pm 0.2)$ mgrad

\subsubsection{5 ds-69 / (1S,10R)-34a $=1: 1$ in Phosphatpuffer}

Die Wechselwirkung von $(1 S, 10 R)$-34a und ds-69 wurde dreimal nach AAV 9.3c $(\mathrm{n}=1)$ untersucht.

$\theta(4 \mathrm{~h})-\theta(0 \mathrm{~h})=(0.5 \pm 0.2)$ mgrad

\subsubsection{ON-1 (ds-60) $/(1 S, 10 R)-34 a=1: 1$ in Phosphatpuffer}

Die Wechselwirkung von $(1 S, 10 R)$-34a und ON-1 (ds-60) wurde dreimal nach AAV $9.3 \mathrm{c}(\mathrm{n}=1)$ untersucht.

$\theta(4 \mathrm{~h})-\theta(0 \mathrm{~h})=(0.5 \pm 0.1)$ mgrad

\subsubsection{7 ds-60 / (1S,10R)-34a $=1: 2$ in Phosphatpuffer}

Die Wechselwirkung von $(1 S, 10 R)$-34a und ds-60 wurde dreimal nach AAV 9.3c $(\mathrm{n}=2)$ untersucht.

$\theta(4 \mathrm{~h})-\theta(0 \mathrm{~h})=-(5.0 \pm 0.2)$ mgrad

\subsubsection{8 ds-60 / (1S,10R)-34a $=1: 1 \rightarrow 1: 2$ in Phosphatpuffer}

Die Wechselwirkung von $(1 S, 10 R)$-34a und ds-60 wurde dreimal nach AAV 9.3c $(\mathrm{n}=1)$ untersucht. Unmittelbar nach Ende der Inkubationszeit von $4 \mathrm{~h}$ wurde $\mathrm{zu}-$ sätzlich jeweils ein weiteres Aliquot ( $1 \mu \mathrm{L}, 5$ nmol, 1 Äq.) der Stammlösung des Toxins in DMSO $(5 \mathrm{nmol} / \mu \mathrm{L})$ zu der Reaktionslösung pipettiert, gemischt und erneut im Zeitraum $t=0 \mathrm{~h}$ bis $t=4 \mathrm{~h}$ die zeitliche Änderung des CD-Signals bei $\lambda=304.5 \mathrm{~nm}$ aufgezeichnet.

$$
\begin{array}{ll}
\text { ds-60 } /(1 S, 10 R)-34 a=1: 1: & \theta(4 \mathrm{~h})-\theta(0 \mathrm{~h})=-(2.8 \pm 0.6) \text { mgrad } \\
\text { ds-60 } /(1 S, 10 R)-34 \mathbf{a}=1: 1 \rightarrow 1: 2: & \theta(4 \mathrm{~h})-\theta(0 \mathrm{~h})=-(2.5 \pm 0.3) \text { mgrad } .
\end{array}
$$




\subsection{4 (1S,10R)-34bx}

\subsubsection{1 ds-60 / (1S,10R)-34bx $=1: 1, \lambda=220-400 \mathrm{~nm}$}

Die Wechselwirkung von $(1 S, 10 R)-\mathbf{3 4 b x}$ und ds-60 wurde nach AAV 9.3a $(\mathrm{n}=1)$ untersucht.

$0 \mathrm{~h}: \lambda_{\max }[\mathrm{nm}](\theta[\mathrm{mgrad}]): 285(5.3), 330(0.9)$.

$\lambda_{\min }[\mathrm{nm}](\theta[\mathrm{mgrad}]): 240(-2.8), 304(-0.3)$.

$\Delta \mathrm{ICD}(0 \mathrm{~h})=1.1 \mathrm{mgrad}$.

$2 \mathrm{~h}: \lambda_{\max }[\mathrm{nm}](\theta[\mathrm{mgrad}]): 285(4.4), 338(2.0)$.

$\lambda_{\text {min }}[\mathrm{nm}](\theta[\mathrm{mgrad}]): 240(-3.3), 306(-3.2)$.

$\Delta \mathrm{ICD}(2 \mathrm{~h})=5.2 \mathrm{mgrad}$.

$4 \mathrm{~h}: \lambda_{\max }[\mathrm{nm}](\theta[\mathrm{mgrad}]): 285(4.4), 338(2.1)$.

$\lambda_{\min }[\mathrm{nm}](\theta[\mathrm{mgrad}]): 240(-3.3), 306(-3.2)$.

$\Delta \mathrm{ICD}(4 \mathrm{~h})=5.5 \mathrm{mgrad}$.

\subsubsection{2 ds-60 / (1S,10R $)-34 \mathrm{bx}=1: 1, \lambda=304.5 \mathrm{~nm}$}

Die Wechselwirkung von $(1 S, 10 R)-\mathbf{3 4 b x}$ und ds-60 wurde nach AAV 9.3c $(\mathrm{n}=1)$ untersucht.

$\theta(4 \mathrm{~h})-\theta(0 \mathrm{~h})=-2.6 \mathrm{mgrad}$

\subsection{5 $(1 S, 10 R)-34 \mathrm{c}$}

\subsubsection{1 ds-60 / (1S,10R)-34c $=1: 1, \lambda=220-400 \mathrm{~nm}$}

Die Wechselwirkung von $(1 S, 10 R)-34 c$ und ds-60 wurde nach AAV 9.3a $(\mathrm{n}=1)$ untersucht.

$0 \mathrm{~h}: \lambda_{\max }[\mathrm{nm}](\theta[\mathrm{mgrad}]): 280(6.3), 325(0.7)$.

$\lambda_{\min }[\mathrm{nm}](\theta[\mathrm{mgrad}]): 240(-2.0), 305(0)$.

$\Delta \operatorname{ICD}(0 \mathrm{~h})=0.6 \mathrm{mgrad}$ 
$2 \mathrm{~h}: \lambda_{\max }[\mathrm{nm}](\theta[\mathrm{mgrad}]): 280$ (5.6), 335 (2.1).

$\lambda_{\min }[\mathrm{nm}](\theta[\mathrm{mgrad}]): 240(-2.3), 305(-2.6)$.

$\Delta \operatorname{ICD}(2 \mathrm{~h})=4.7 \mathrm{mgrad}$.

$4 \mathrm{~h}: \lambda_{\max }[\mathrm{nm}](\theta[\mathrm{mgrad}]): 280(5.5), 335$ (2.2).

$\lambda_{\min }[\mathrm{nm}](\theta$ [mgrad]): $240(-2.4), 305(-2.9)$.

$\Delta \operatorname{ICD}(4 \mathrm{~h})=5.1 \mathrm{mgrad}$.

\subsection{6 (1S,10R)-34d}

\subsubsection{1 ds-60 / (1S,10R)-34d $=1: 1, \lambda=220-400 \mathrm{~nm}$}

Die Wechselwirkung von $(1 S, 10 R)-34 d$ und ds-60 wurde nach AAV 9.3a $(\mathrm{n}=1)$ untersucht.

$0 \mathrm{~h}: \quad \lambda_{\max }[\mathrm{nm}](\theta[\mathrm{mgrad}]): 285(6.9)$.

$\lambda_{\min }[\mathrm{nm}](\theta[\mathrm{mgrad}]): 240(-1.5)$.

$\Delta \operatorname{ICD}(0 \mathrm{~h})=-0.3 \mathrm{mgrad}$.

$0.5 \mathrm{~h}: \quad \lambda_{\max }[\mathrm{nm}](\theta[\mathrm{mgrad}]): 285(6.9), 320(1.0)$.

$\lambda_{\min }[\mathrm{nm}](\theta[\mathrm{mgrad}]): 240(-1.5), 305(0.5)$.

$\Delta \mathrm{ICD}(0 \mathrm{~h})=0.3 \mathrm{mgrad}$.

$2 \mathrm{~h}: \quad \lambda_{\max }[\mathrm{nm}](\theta[\mathrm{mgrad}]): 285(6.2), 335$ (1.3).

$\lambda_{\min }[\mathrm{nm}](\theta[\mathrm{mgrad}]): 240(-1.5), 305(-0.5)$.

$\Delta \operatorname{ICD}(2 \mathrm{~h})=1.8 \mathrm{mgrad}$.

$4 \mathrm{~h}: \quad \lambda_{\max }[\mathrm{nm}](\theta[\mathrm{mgrad}]): 285(6.1), 335$ (1.5).

$\lambda_{\text {min }}[\mathrm{nm}](\theta[\mathrm{mgrad}]): 240(-1.5), 305(-0.9)$.

$\Delta \mathrm{ICD}(4 \mathrm{~h})=2.3 \mathrm{mgrad}$. 


\subsection{7 (1S,10R)-34b}

\subsubsection{1 ds-60 / (1S,10R $)-34 b=1: 1, \lambda=220-400 \mathrm{~nm}$}

Die Wechselwirkung von $(1 S, 10 R)-34 b$ und ds-60 wurde nach AAV 9.3a $(\mathrm{n}=1)$ untersucht.

$0 \mathrm{~h}: \lambda_{\max }[\mathrm{nm}](\theta[\mathrm{mgrad}]): 280(6.9), 325(0.02)$.

$\lambda_{\min }[\mathrm{nm}](\theta[\mathrm{mgrad}]): 240(-2.8), 305(-0.8)$.

$\Delta \operatorname{ICD}(0 \mathrm{~h})=0.8 \mathrm{mgrad}$.

$2 \mathrm{~h}: \lambda_{\max }[\mathrm{nm}](\theta[\mathrm{mgrad}]): 280(6.2), 335$ (1.6).

$\lambda_{\text {min }}[\mathrm{nm}](\theta[\mathrm{mgrad}]): 240(-2.8), 305(-3.0)$.

$\Delta \operatorname{ICD}(2 \mathrm{~h})=4.6 \mathrm{mgrad}$.

$4 \mathrm{~h}: \lambda_{\max }[\mathrm{nm}](\theta[\mathrm{mgrad}]): 280(6.1), 335(1.7)$.

$\lambda_{\min }[\mathrm{nm}](\theta[\mathrm{mgrad}]): 240(-2.8), 305(-3.2)$.

$\Delta \mathrm{ICD}(4 \mathrm{~h})=4.9 \mathrm{mgrad}$.

\subsection{8 (1S)-56a}

9.6.8.1 ds-60 / (1S)-56a $=1: 1, \lambda=220-400 \mathrm{~nm}$

Die Wechselwirkung von (1S)-56a und ds-60 wurde nach AAV 9.3a $(\mathrm{n}=1)$ untersucht. Ergänzend wurde ein CD-Spektrum bei $t=6 \mathrm{~h}, 8 \mathrm{~h}$ und $24 \mathrm{~h}$ gemessen.

$0 \mathrm{~h}: \lambda_{\max }[\mathrm{nm}](\theta[\mathrm{mgrad}]): 280(7.3), 335(-0.3)$.

$\lambda_{\min }[\mathrm{nm}](\theta$ [mgrad] $): 240(-2.0), 305(-1.1)$.

$\Delta \mathrm{ICD}(0 \mathrm{~h})=0.8 \mathrm{mgrad}$.

$2 \mathrm{~h}: \lambda_{\max }[\mathrm{nm}](\theta[\mathrm{mgrad}]): 280(7.3), 335(0.2)$.

$\lambda_{\text {min }}[\mathrm{nm}](\theta[\mathrm{mgrad}]): 240(-2.0), 305(-1.7)$

$\Delta \operatorname{ICD}(2 \mathrm{~h})=1.9 \mathrm{mgrad}$.

$4 \mathrm{~h}: \lambda_{\max }[\mathrm{nm}](\theta[\operatorname{mgrad}]): 280(7.3), 335(0.4)$. 
$\lambda_{\text {min }}[\mathrm{nm}](\theta[\mathrm{mgrad}]): 240(-2.0), 305(-1.8)$.

$\Delta \mathrm{ICD}(4 \mathrm{~h})=2.2 \mathrm{mgrad}$.

$8 \mathrm{~h}: \lambda_{\max }[\mathrm{nm}](\theta[\mathrm{mgrad}]): 280(7.2), 335(0.5)$.

$\lambda_{\text {min }}[\mathrm{nm}](\theta[\mathrm{mgrad}]): 240(-2.0), 305(-2.1)$.

$\Delta \mathrm{ICD}(4 \mathrm{~h})=2.6 \mathrm{mgrad}$.

\subsubsection{2 ds-60 / (1S)-56a $=1: 1, \lambda=304.5 \mathrm{~nm}$}

Die Wechselwirkung von (1S)-56a und ds-60 wurde zweimal nach AAV 9.3c $(\mathrm{n}=1)$ untersucht, wobei das Zeitintervall um $4 \mathrm{~h}$ auf eine Gesamtzeit von $8 \mathrm{~h}$ verlängert wurde.

$\theta(4 \mathrm{~h})-\theta(0 \mathrm{~h})=-(1.5 \pm 0.1) \mathrm{mgrad}$

$\theta(8 \mathrm{~h})-\theta(4 \mathrm{~h})=-(0.5 \pm 0.1) \mathrm{mgrad}$

\subsubsection{3 ds-64 / (1S)-56a $=1: 1, \lambda=220-400 \mathrm{~nm}$}

Die Wechselwirkung von (1S)-56a und ds-64 wurde nach AAV 9.3a $(\mathrm{n}=1)$ untersucht.

Zusätzlich wurde 1 Aliquot ( $5 \mu \mathrm{L}, 25 \mathrm{nmol}, 1$ Äq.) der Stammlösung des Toxins in DMSO (5 nmol/ $\mu \mathrm{L})$ nach AAV 9.3 mit einer Lösung aus dem doppelsträngigen Oligonukleotid ds-64 (250 $\mu \mathrm{L}, 25 \mathrm{nmol}, 1$ Äq.) in Wasser $(0.55 \mu \mathrm{L})$ gemischt, die Reaktionsmischung bei $25^{\circ} \mathrm{C}$ inkubiert und zu den Zeitpunkten $t=0 \mathrm{~h}$ und $1 \mathrm{~h}$ ein CD-Spektrum im Wellenlängenbereich $\lambda=220-400 \mathrm{~nm}$ gemessen.

ds-64:

$\lambda_{\max }[\mathrm{nm}](\theta[\mathrm{mgrad}]): 270(1.0)$.

$\lambda_{\text {min }}[\mathrm{nm}](\theta[\mathrm{mgrad}]): 245(-8.3)$.

ds-64 / (1S)-56a in Puffer:

$0 \mathrm{~h}: \lambda_{\max }[\mathrm{nm}](\theta[\mathrm{mgrad}]): 270(-2.0), 330(0.3), 380(0)$.

$\lambda_{\min }[\mathrm{nm}](\theta[\mathrm{mgrad}]): 245(-7.2), 302(-4.2)$.

$1 \mathrm{~h}: \lambda_{\max }[\mathrm{nm}](\theta[\operatorname{mgrad}]): 270(-1.8), 330(2.2), 380$ (1.0). 
$\lambda_{\min }[\mathrm{nm}](\theta[\mathrm{mgrad}]): 245(-6.7), 302(-3.5)$.

ds-64 / (1S)-56a in Wasser:

0 h: $\lambda_{\max }[\mathrm{nm}](\theta[\mathrm{mgrad}]): 264$ (-2.7), 295 (-2.7), $330(2.0), 380$ (0.7).

$\lambda_{\min }[\mathrm{nm}](\theta$ [mgrad]): $286(-3.7), 305(-3.9), 363(0.4)$.

\subsection{9 (1S)-56b}

\subsubsection{1 ds-60 / (1S) $-56 \mathrm{~b}=1: 1, \lambda=220-400 \mathrm{~nm}$}

Die Wechselwirkung von (1S)-56b und ds-60 wurde nach AAV 9.3a $(\mathrm{n}=1)$ untersucht. Ergänzend wurde ein CD-Spektrum bei $\mathrm{t}=6 \mathrm{~h}, 8 \mathrm{~h}$ und $48 \mathrm{~h}$ gemessen.

$0 \mathrm{~h}: \lambda_{\max }[\mathrm{nm}](\theta[\mathrm{mgrad}]): 285$ (4.7), 320 (1.5), 380 (2.5).

$\lambda_{\min }[\mathrm{nm}](\theta$ [mgrad]): $240(-1.1), 305(-0.3), 350(0.7)$.

$\Delta \operatorname{ICD}(0 \mathrm{~h})=1.4 \mathrm{mgrad}$.

$4 \mathrm{~h}: \lambda_{\max }[\mathrm{nm}](\theta[\mathrm{mgrad}]): 285$ (3.9), 330 (3.5), 380 (3.1).

$\lambda_{\min }[\mathrm{nm}](\theta$ [mgrad]): $240(-1.1), 305(-3.8), 350$ (2.6).

$\Delta \mathrm{ICD}(4 \mathrm{~h})=7.1 \mathrm{mgrad}$.

$8 \mathrm{~h}: \lambda_{\max }[\mathrm{nm}](\theta[\mathrm{mgrad}]): 285$ (3.3), 330 (4.4).

$\lambda_{\min }[\mathrm{nm}](\theta[\mathrm{mgrad}]): 240(-1.1), 305(-5.0)$.

$\Delta \operatorname{ICD}(0 \mathrm{~h})=9.3 \mathrm{mgrad}$.

$48 \mathrm{~h}: \lambda_{\max }[\mathrm{nm}](\theta[\mathrm{mgrad}]): 285$ (2.8), 330 (5.2).

$\lambda_{\min }[\mathrm{nm}](\theta$ [mgrad]): $240(-1.1), 305(-5.9)$.

$\Delta \mathrm{ICD}(0 \mathrm{~h})=11.0 \mathrm{mgrad}$.

\subsubsection{2 ds-60 / (1S)-56b $=1: 1, \lambda=304.5 \mathrm{~nm}$}

Die Wechselwirkung von (1S)-56b und ds-60 wurde nach AAV 9.3c $(\mathrm{n}=1)$ untersucht, wobei das Zeitintervall um $4 \mathrm{~h}$ auf eine Gesamtzeit von $8 \mathrm{~h}$ verlängert wurde. 
$\theta(4 \mathrm{~h})-\theta(0 \mathrm{~h})=-3.5 \mathrm{mgrad}$

$\theta(8 \mathrm{~h})-\theta(4 \mathrm{~h})=-1.0 \mathrm{mgrad}$

\subsubsection{0 (1S)-49}

\subsubsection{1 ds-60 / (1S)-49 $=1: 1, \lambda=220-400 \mathrm{~nm}$}

Die Wechselwirkung von (1S)-49 und ds-60 wurde nach AAV 9.3a $(\mathrm{n}=1)$ untersucht.

$0 \mathrm{~h}: \lambda_{\max }[\mathrm{nm}](\theta[\mathrm{mgrad}]): 280(6.9), 335(0.3)$.

$\lambda_{\min }[\mathrm{nm}](\theta[\mathrm{mgrad}]): 240(-4.1), 308(-0.3)$.

$\Delta \operatorname{ICD}(0 \mathrm{~h})=0.5$ mgrad

$4 \mathrm{~h}: \lambda_{\max }[\mathrm{nm}](\theta[\mathrm{mgrad}]): 280(6.8), 328(0.1)$.

$\lambda_{\min }[\mathrm{nm}](\theta[\operatorname{mgrad}]): 240(-4.1), 308(-0.5)$.

$\Delta \operatorname{ICD}(4 \mathrm{~h})=0.2 \mathrm{mgrad}$.

Im untersuchten Zeitintervall konnte nur ein sehr schwaches ICD beobachtet werden.

\subsubsection{2 ds-60 / (1S)-49 $=1: 1$ und 1:10 in Phosphatpuffer, $\lambda=304.5 \mathrm{~nm}$}

Die Wechselwirkung von (1S)-49 und ds-60 wurde nach AAV 9.3c $(\mathrm{n}=1,10)$ untersucht.

ds-60 / (1S)-49=1:1: $\quad \theta(4 \mathrm{~h})-\theta(0 \mathrm{~h})=0.1 \mathrm{mgrad}$

ds-60 / (1S)-49 = 1:10: $\quad \theta(4 \mathrm{~h})-\theta(0 \mathrm{~h})=-0.6 \mathrm{mgrad}$

\subsubsection{1 (1R,10S)-34a}

\subsubsection{1 ds-60 / (1R,10S)-34a $=1: 1, \lambda=220-400 \mathrm{~nm}$}

Die Wechselwirkung von $(1 R, 10 S)-34 a$ und ds-60 wurde nach AAV 9.3a $(\mathrm{n}=1)$ untersucht.

$0 \mathrm{~h}: \lambda_{\max }[\mathrm{nm}](\theta[\mathrm{mgrad}]): 280(8.8), 354(0.6)$.

$\lambda_{\min }[\mathrm{nm}](\theta[\operatorname{mgrad}]): 240(0.0), 320(0.2)$.

$4 \mathrm{~h}: \lambda_{\max }[\mathrm{nm}](\theta[\mathrm{mgrad}]): 280(8.8), 354(0.7)$. 
$\lambda_{\text {min }}[\mathrm{nm}](\theta[\mathrm{mgrad}]): 240(0.0), 320(0.05)$.

Im untersuchten Zeitintervall konnte nur ein sehr schwaches ICD beobachtet werden.

9.6.11.2 ds-60 / $(1 R, 10 S)-34 \mathrm{a}=1: 1, \lambda=304.5 \mathrm{~nm}$

Die Wechselwirkung von $(1 R, 10 S)$-34a und ds-60 wurde dreimal nach AAV 9.3c $(\mathrm{n}=1)$ untersucht.

$\theta(4 \mathrm{~h})-\theta(0 \mathrm{~h})=-(0.2 \pm 0.1) \mathrm{mgrad}$

\subsubsection{2 $(1 S, 10 R)-33 \mathrm{a}$}

\subsubsection{1 ds-60 / (1S,10R)-33a $=1: 1$ in Phosphatpuffer, $\lambda=220-400 \mathrm{~nm}$}

Die Wechselwirkung von $(1 S, 10 R)-33 a$ und ds-60 wurde nach AAV 9.3a $(\mathrm{n}=1)$ untersucht.

$0 \mathrm{~h}: \lambda_{\max }[\mathrm{nm}](\theta[\mathrm{mgrad}]): 280(5.0), 325(0.1)$.

$\lambda_{\min }[\mathrm{nm}](\theta[\mathrm{mgrad}]): 240(-2.9), 305(-0.3)$.

$4 \mathrm{~h}: \lambda_{\max }[\mathrm{nm}](\theta[\mathrm{mgrad}]): 280(5.0), 325(0.2)$.

$\lambda_{\text {min }}[\mathrm{nm}](\theta[\mathrm{mgrad}]): 240(-2.9), 305(-0.2)$.

Im untersuchten Zeitintervall konnte kein signifikantes ICD beobachtet werden.

\subsubsection{2 ds-60 / (1S,10R)-33a $=1: 1$ in Phosphatpuffer, $\lambda=220-350 \mathrm{~nm}$}

Die Wechselwirkung von $(1 S, 10 R)-33 a$ und ds-60 wurde nach AAV 9.3b untersucht.

$0 \mathrm{~h}: \lambda_{\max }[\mathrm{nm}](\theta[\mathrm{mgrad}]): 285(3.9), 325(0.5)$.

$\lambda_{\min }[\mathrm{nm}](\theta[\mathrm{mgrad}]): 240(-3.2), 305(-0.6)$.

$6 \mathrm{~h}: \lambda_{\max }[\mathrm{nm}](\theta[\mathrm{mgrad}]): 285(3.9), 325(0.6)$.

$\lambda_{\min }[\mathrm{nm}](\theta[\mathrm{mgrad}]): 240(-3.2), 305(-0.9)$.

Im untersuchten Zeitintervall konnte kein signifikantes ICD beobachtet werden.

\subsubsection{3 (1S)-54a}

9.6.13.1 $\quad$ ds-60 $/(1 S)-54 a=1: 1, \lambda=220-400 \mathrm{~nm}$ 
Die Wechselwirkung von (1S)-54a und ds-60 wurde nach AAV 9.3a $(\mathrm{n}=1)$ untersucht.

Ergänzend wurde ein CD-Spektrum bei $t=6 \mathrm{~h}$ und $8 \mathrm{~h}$ gemessen.

$\lambda_{\max }[\mathrm{nm}](\theta$ [mgrad] $): 280(6.9), 325$ (1.0).

$\lambda_{\min }[\mathrm{nm}](\theta$ [mgrad] $): 240(-2.1), 305(-0.2)$.

Im untersuchten Zeitintervall konnte kein signifikantes ICD beobachtet werden.

\subsubsection{4 (1R)-56a}

\subsubsection{1 ds-60 / (1R)-56a $=1: 1, \lambda=220-400 \mathrm{~nm}$}

Die Wechselwirkung von (1R)-56a und ds-60 wurde nach AAV 9.3a $(\mathrm{n}=1)$ untersucht. Ergänzend wurde ein CD-Spektrum bei $t=6 \mathrm{~h}$ und $8 \mathrm{~h}$ gemessen.

$0 \mathrm{~h}: \lambda_{\max }[\mathrm{nm}](\theta$ [mgrad]): $280(6.4), 355(0.0)$.

$\lambda_{\min }[\mathrm{nm}](\theta$ [mgrad] $): 240(-3.3), 330(-0.1)$.

$\Delta \operatorname{ICD}(0 \mathrm{~h})=-0.66 \mathrm{mgrad}$.

$4 \mathrm{~h}: \lambda_{\max }[\mathrm{nm}](\theta[\mathrm{mgrad}]): 280(6.0), 340(0.4)$.

$\lambda_{\min }[\mathrm{nm}](\theta[\mathrm{mgrad}]): 240(-3.1), 311(-0.1)$.

$\Delta \operatorname{ICD}(0 \mathrm{~h})=0.2 \mathrm{mgrad}$

$8 \mathrm{~h}: \lambda_{\max }[\mathrm{nm}](\theta[\mathrm{mgrad}]): 280(5.9), 340(0.6)$.

$\lambda_{\min }[\mathrm{nm}](\theta[\mathrm{mgrad}]): 240(-2.9), 306(-0.2)$.

$\Delta \operatorname{ICD}(0 \mathrm{~h})=0.3$ mgrad

\subsubsection{5 (1S,10R)-76}

\subsubsection{1 ds-60 / (1S,10R)-76 = 1:1 in PBS (pH 7.4), $\lambda=220-400 \mathrm{~nm}$}

1 Aliquot $(0.5 \mu \mathrm{L}, 5 \mathrm{nmol}, 1$ Äq.) der Stammlösung von $(1 S, 10 R)-76$ in DMSO $(10 \mathrm{nmol} / \mu \mathrm{L})$ wurde in eine Mischung der wässrigen Lösung von ds-60 $(50 \mu \mathrm{L}$,

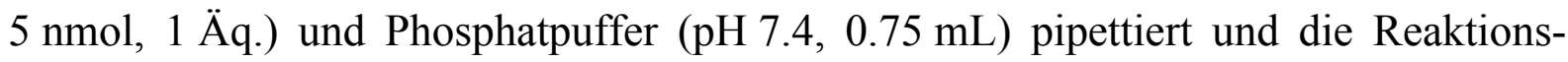
mischung gut durchmischt. Die Lösung wurde sofort in eine Küvette $(d=1 \mathrm{~cm})$ überführt und bei $25^{\circ} \mathrm{C}$ inkubiert. Nach den Inkubationszeiten $t=0 \mathrm{~h}, 0.5 \mathrm{~h}, 1 \mathrm{~h}, 2 \mathrm{~h}$, 
$3 \mathrm{~h}, 4 \mathrm{~h}$ und $48 \mathrm{~h}$ wurde ein CD-Spektrum im Wellenlängenbereich $\lambda=220-550 \mathrm{~nm}$ gemessen.

$\mathrm{Zu}$ Vergleichszwecken wurde zusätzlich ein CD-Spektrum des seco-Drugs ohne DNA aufgezeichnet. Hierzu wurde 1 Aliquot $(0.5 \mu \mathrm{L}, 5 \mathrm{nmol})$ der Stammlösung von $(1 S, 10 R)-76$ in DMSO $(10 \mathrm{nmol} / \mu \mathrm{L})$ in PBS $(0.80 \mathrm{~mL})$ gelöst und die Reaktionsmischung bei $25^{\circ} \mathrm{C}$ inkubiert. Nach den Inkubationszeiten $t=0 \mathrm{~h}, 0.5 \mathrm{~h}, 1 \mathrm{~h}, 2 \mathrm{~h}, 3 \mathrm{~h}$, $4 \mathrm{~h}$ und $48 \mathrm{~h}$ wurde ein CD-Spektrum im Wellenlängenbereich $\lambda=220-550 \mathrm{~nm}$ gemessen.

Als Referenz für alle Messungen diente PBS.

\section{$\underline{(1 S, 10 R)-76 / \text { ds-60 }=1: 1:}$}

$0 \mathrm{~h}: \lambda_{\max }[\mathrm{nm}](\theta[\mathrm{mgrad}]): 280(5.6), 330(0.4)$.

$$
\lambda_{\text {min }}[\mathrm{nm}](\theta[\mathrm{mgrad}]): 240(-2.8), 310(0.00), 375(-0.3) .
$$

$4 \mathrm{~h}: \lambda_{\max }[\mathrm{nm}](\theta[\mathrm{mgrad}]): 285(5.5), 330(0.9)$.

$$
\lambda_{\min }[\mathrm{nm}](\theta[\mathrm{mgrad}]): 240(-3.2), 308(-0.1), 375(-0.1) .
$$

$48 \mathrm{~h}: \lambda_{\max }[\mathrm{nm}](\theta[\mathrm{mgrad}]): 280(5.1), 335$ (1.6).

$\lambda_{\min }[\mathrm{nm}](\theta[\mathrm{mgrad}]): 240(-3.4), 305(-1.2)$.

$\Delta \mathrm{ICD}(0 \mathrm{~h})=2.8 \mathrm{mgrad}$.

\section{$\underline{(1 S, 10 R)-76:}$}

$48 \mathrm{~h}: \lambda_{\max }[\mathrm{nm}](\theta[\mathrm{mgrad}]): 285(0.16), 330(0.15), 447$ (0.07).

$$
\lambda_{\text {min }}[\mathrm{nm}](\theta[\mathrm{mgrad}]): 250(-0.12), 305(0.02), 370(-0.14) .
$$

\subsubsection{Doxorubicin (11)}

1 Aliquot der Stammlösung von Doxorubicin (11) in DMSO ( $5 \mathrm{nmol} / \mu \mathrm{L})$ wurde nach AAV 9.3 mit einer Lösung von ds-60 gemischt, bei $25^{\circ} \mathrm{C}$ inkubiert und im Zeitraum $t=0-2 \mathrm{~h}$ alle $20 \mathrm{~min}$ ein CD-Spektrum im Wellenlängenbereich $\lambda=220-600 \mathrm{~nm}$ für die Doxorubicin-Konzentrationen $6.3 \mu \mathrm{M}$ (Doxorubicin / ds-60=1:1) bis $62.5 \mu \mathrm{M}$ (Doxorubicin / ds-60 = 10:1) gemessen. 
$\underline{11 / d s-60=1: 1:}$

$\lambda_{\max }[\mathrm{nm}](\theta[\operatorname{mgrad}]): 285(6.0), 370(0.33)$.

$\lambda_{\min }[\mathrm{nm}](\theta[\operatorname{mgrad}]): 240(-3.0), 303(-0.67)$.

Es konnte eine schwache, zeitlich konstante Änderung des CD-Spektrums im Vergleich zu den Spektren der Einzelkomponenten beobachtet werden.

$\underline{11 / \mathrm{ds}-60=10: 1:}$

$\lambda_{\max }[\mathrm{nm}](\theta$ [mgrad] $): 285$ (4.2), $370(1.1)$.

$\lambda_{\min }[\mathrm{nm}](\theta[\mathrm{mgrad}]): 303(-3.7)$.

Es konnte eine signifikante, aber zeitlich konstante Änderung des CD-Spektrums im Vergleich zu den Spektren der Einzelkomponenten beobachtet werden.

\subsubsection{Melphalan (79)}

1 Aliquot der Stammlösung von Melphalan (79) in DMSO (5 nmol/ $\mu \mathrm{L})$ wurde nach AAV 9.3 mit einer einer Lösung von ds-60 gemischt, bei $25^{\circ} \mathrm{C}$ inkubiert und in der ersten Stunde nach dem Beginn der Inkubation alle 10 Minuten und danach zu den Inkubationszeiten $t=1.5 \mathrm{~h}, 2 \mathrm{~h}, 3 \mathrm{~h}, 5 \mathrm{~h}$ und $6 \mathrm{~h}$ ein CD-Spektrum im Wellenlängenbereich $\lambda=220-400 \mathrm{~nm}$ für die Melphalan-Konzentrationen 6.3 $\mu \mathrm{M}$ (Melphalan / ds-60 = 1:1) und 62.5 $\mu \mathrm{M}($ Melphalan / ds-60 = 10:1) gemessen.

$\underline{79 / \text { ds- }-60=1: 1:}$

$\lambda_{\max }[\mathrm{nm}](\theta$ [mgrad $\left.]\right): 285(6.1)$.

$\lambda_{\min }[\mathrm{nm}](\theta[\operatorname{mgrad}]): 240(-4.4)$.

Es konnte im untersuchten Zeitintervall keine Änderung des CD-Spektrums und kein ICD beobachtet werden.

$\underline{79 / \text { ds-60 }=10: 1:}$

$\lambda_{\max }[\mathrm{nm}](\theta[\mathrm{mgrad}]): 285$ (5.8).

$\lambda_{\min }[\mathrm{nm}](\theta[\mathrm{mgrad}]): 234(-1.4), 320(-1.0)$.

Es konnte eine schwache Änderung des CD-Spektrums beobachtet werden. 


\subsubsection{Mitomycin C (99)}

1 Aliquot der Stammlösung von Mitomycin C (99) in DMSO ( $5 \mathrm{nmol} / \mu \mathrm{L})$ wurde nach AAV3 mit einer Oligonukleotidlösung (ds-60 oder ds-69) gemischt, bei $25^{\circ} \mathrm{C}$ inkubiert und nach den Inkubationszeiten $t=0$ h, 0.25 h, 0.5 h, 0.75 h, 1 h, 2 h, 4 h, $6 \mathrm{~h}$ und $8 \mathrm{~h}$ ein CD-Spektrum im Wellenlängenbereich $\lambda=220-550 \mathrm{~nm}$ für die Mitomycin C-Konzentrationen $6.3 \mu \mathrm{M} \quad(\mathbf{9 9} /$ ds-DNA = 1:1) und $62.5 \mu \mathrm{M} \quad(\mathbf{9 9} /$ ds-DNA $=10: 1)$ gemessen.

$\underline{99} /$ ds- $60=1: 1:$

$\lambda_{\max }[\mathrm{nm}](\theta$ [mgrad]): $280(8.3), 400(0.75)$.

$\lambda_{\text {min }}[\mathrm{nm}](\theta[\mathrm{mgrad}]): 240(-0.22), 370(-0.15)$.

Es konnte im untersuchten Zeitintervall keine Änderung des CD-Spektrums und kein ICD beobachtet werden.

$\underline{99} /$ ds-69=1:1:

$\lambda_{\max }[\mathrm{nm}](\theta$ [mgrad]): 280 (7.2), $400(0.70)$.

$\lambda_{\text {min }}[\mathrm{nm}](\theta$ [mgrad]): $240(-1.4), 370(-0.48)$.

Es konnte im untersuchten Zeitintervall keine Änderung des CD-Spektrums und kein ICD beobachtet werden.

$\underline{99 / d s-69=10: 1:}$

$0 \mathrm{~h}: \lambda_{\max }[\mathrm{nm}](\theta[\mathrm{mgrad}]): 280(3.0), 400(5.5)$.

$\lambda_{\min }[\mathrm{nm}](\theta[\mathrm{mgrad}]): 305(-3.0)$.

$7 \mathrm{~h}: \lambda_{\max }[\mathrm{nm}](\theta[\mathrm{mgrad}]): 280(3.5), 400(5.3)$.

$\lambda_{\min }[\mathrm{nm}](\theta[\mathrm{mgrad}]): 305(-2.3)$.

Es konnte eine schwache zeitabhängige Änderung des CD-Spektrums beobachtet werden. 


\section{Untersuchung der Aufnahme verschiedener Zytostatika in Zellen mittels CD-Spektroskopie}

Alle Versuche wurden mit humanen Lymphomzellen der Linie HL-60 durchgeführt.

$\Delta \mathrm{ICD}=\theta(\lambda=335 \mathrm{~nm})-\theta(\lambda=305 \mathrm{~nm})$.

\subsection{AAV 10.1: Allgemeine Arbeitsvorschrift zur Messung des CD intakter Zellen nach vorheriger Inkubation mit Zytostatika}

In R10F (RPMI 1640 mit 10\% fötalem Kälberserum, 2 mM L-Glutamin und $2.0 \mathrm{~g} / 1$ Natriumhydrogencarbonat) kultivierte Zellen der Linie HL-60 wurden mit serumfreiem Zellkulturmedium (UltraCulture ${ }^{\circledR}$ ) gewaschen und eine Suspension der Zellen in UltraCulture ${ }^{\circledR}$ in 6-well-Multischalen pipettiert, so dass eine Konzentration von $3 \times 10^{6}$ Zellen pro Kammer erzielt wurde. Die Zellen wurden daraufhin mit einer Lösung aus UltraCulture ${ }^{\circledR}$ Medium $(1.98 \mathrm{~mL})$ und der Stammlösung eines Zytostatikums in DMSO $(20 \mu \mathrm{L})$ bei $37{ }^{\circ} \mathrm{C}$ und $7.5 \% \mathrm{CO}_{2}$ inkubiert. Die als Kontrolle dienenden Zellen wurden mit einer Lösung aus UltraCulture ${ }^{\circledR}$ Medium $(1.98 \mathrm{~mL})$ und DMSO $(20 \mu \mathrm{L})$ bei $37{ }^{\circ} \mathrm{C}$ und $7.5 \% \mathrm{CO}_{2}$ inkubiert. Direkt nach dem Beginn der Inkubation und nach den angegebenen Inkubationszeiten wurde die Testsubstanz entfernt und die Zellen wurden dreimal mit PBS (pH 7.4, $1.0 \mathrm{~mL}$ ) gewaschen (Zentrifugation: je 3 min bei $350 \times \mathrm{g}$ ). Das nach dem 3 . Waschen erhaltene Zellpellet wurde in PBS ( $\mathrm{pH} 7.4,70 \mu \mathrm{L}$ ) resuspendiert, die Suspension in die Vertiefung einer $0.1 \mathrm{~mm}$ Schichtküvette pipettiert und ein CD-Spektrum der Suspension aufgenommen.

\subsection{AAV 10.2: Allgemeine Arbeitsvorschrift zur Isolation zellulärer DNA, zur Bestimmung des Anteils toter Zellen und zur Messung des CD der isolierten DNA nach vorheriger Inkubation der Zellen mit Zytostatika}

In R10F (RPMI 1640 mit 10\% fötalem Kälberserum, 2 mM L-Glutamin und 2.0 g/l Natriumhydrogencarbonat) kultivierte Zellen der Linie HL-60 wurden mit serumfreiem Zellkulturmedium (UltraCulture ${ }^{\circledR}$ ) gewaschen und eine Suspension der Zellen in UltraCulture ${ }^{\circledR}$ in 6-well-Multischalen pipettiert, so dass eine Konzentration von $5 \times 10^{6}$ Zellen pro Kammer erzielt wurde. Die Zellen wurden daraufhin mit einer Lösung aus UltraCulture ${ }^{\circledR}$ Medium $(1.98 \mathrm{~mL})$ und der Stammlösung eines Zytostatikums in DMSO $(20 \mu \mathrm{L})$ bei $37^{\circ} \mathrm{C}$ und $7.5 \% \mathrm{CO}_{2}$ inkubiert. Die als Kontrolle 
dienenden Zellen wurden mit einer Lösung aus UltraCulture ${ }^{\circledR}$ Medium $(1.98 \mathrm{~mL})$ und DMSO $(20 \mu \mathrm{L})$ bei $37{ }^{\circ} \mathrm{C}$ und $7.5 \% \mathrm{CO}_{2}$ inkubiert. Direkt nach dem Starten der Inkubation und nach den angegebenen Inkubationszeiten wurde die Testsubstanz entfernt und die Zellen wurden dreimal mit PBS (pH 7.4, $1.0 \mathrm{~mL}$ ) gewaschen (Zentrifugation: je $3 \mathrm{~min}$ bei $350 \times \mathrm{g}$ ). Das nach dem 3. Waschen erhaltene Zellpellet wurde in PBS (pH 7.4, $200 \mu \mathrm{L}$ ) resuspendiert.

Ein Anteil der Zellsuspension $(8 \mu \mathrm{L})$ wurde mit PBS $(198 \mu \mathrm{L})$ verdünnt, mit einer Lösung von Trypanblau in physiologischer Kochsalzlösung $(0.5 \%(\mathrm{w} / \mathrm{v}), 50 \mu \mathrm{L})$ versetzt und nach kurzer Inkubationszeit ( $2 \mathrm{~min})$ der Anteil toter Zellen bestimmt.

Die restliche Zellsuspension wurde zur Isolation der zellulären DNA unter Nutzung eines QIAamp ${ }^{\circledR}$ DNA Mini Kits der Firma Qiagen verwendet. Hierzu erfolgte im ersten Schritt die Zugabe von Proteinase K (20 $\mu$ L, Stammlösung Bestandteil des Kits) und RNase A ( $4 \mu \mathrm{L}, 100 \mathrm{mg} / \mathrm{mL}, 7000 \mathrm{U} / \mathrm{mL}$, nicht Bestandteil des Kits). Nach Durchmischung mit einem Vortexgerät wurde zu der Reaktionslösung AL-Puffer (200 $\mu \mathrm{L}$, Bestandteil des Kits) pipettiert, die Mischung $15 \mathrm{~s}$ mit einem Vortexgerät durchmischt und anschließend $10 \mathrm{~min}$ bei $56^{\circ} \mathrm{C}$ inkubiert. Nach der folgenden Zugabe von Ethanol (96\%-ig, $200 \mu \mathrm{L}$ ) und $15 \mathrm{~s}$ Durchmischen mit einem Vortexgerät wurde die Reaktionsmischung in einem spezielles Zentrifugationsröhrchen mit einem Sammelgefäß (QIAamp ${ }^{\circledR}$ Spin column, Sammelgefäß: $2 \mathrm{~mL}$, beide Bestandteil des Kits) zentrifugiert $(1 \mathrm{~min}$ bei $20817 \times \mathrm{g})$. Das Zentrifugationsröhrchen wurde in einem neuen Sammelgefäß (2 mL) platziert, mit AW1-Puffer (500 $\mu \mathrm{L}$, Bestandteil des Kits) gefüllt und erneut zentrifugiert $(1 \mathrm{~min}$ bei $20817 \times \mathrm{g}$ ). Das Zentrifugationsröhrchen wurde in einem weiteren Sammelgefäß $(2 \mathrm{~mL})$ platziert, mit AW2-Puffer $(500 \mu \mathrm{L}$, Bestandteil des Kits) gefüllt und erneut zentrifugiert ( 3 min bei $20817 \times \mathrm{g}$ ). Nach Platzieren des Zentrifugenröhrchens in einem Probengefäß $(1.5 \mathrm{~mL})$ wurde bidestilliertes Wasser $(200 \mu \mathrm{L})$ eingefüllt und nach 5-minütiger Inkubation bei Raumtemperatur die DNA durch Zentrifugation eluiert $(1 \mathrm{~min}$ bei $20817 \times \mathrm{g})$.

Nach Bestimmung der DNA-Konzentration mittels UV-Absorptionsmessung $\left(A_{260}\right)$ und Einstellen der angegebenen Konzentration wurde ein CD-Spektrum der in bidestilliertem Wasser gelösten isolierten DNA aufgenommen.

\subsection{CD-Spektren unbehandelter Zellen in Suspension}

Unterschiedliche Anzahlen in R10F (RPMI 1640 mit 10\% fötalem Kälberserum, 2 mM L-Glutamin und 2.0 g/l Natriumhydrogencarbonat) kultivierter Zellen der Linie 
HL-60 wurden mit serumfreiem Zellkulturmedium (UltraCulture ${ }^{\circledR}$ ) und dreimal mit PBS (pH 7.4, $1.0 \mathrm{~mL}$ ) gewaschen (Zentrifugation: je 3 min bei $350 \times \mathrm{g}$ ). Das nach dem 3. Waschen erhaltene Zellpellet wurde in PBS (pH 7.4, 70 $\mu \mathrm{L})$ resuspendiert, die Suspension in die Vertiefung einer $0.1 \mathrm{~mm}$ Schichtküvette pipettiert und ein CDSpektrum der Suspension aufgenommen.

\subsection{Untersuchung der zellulären Aufnahme des seco-Drugs $(+)-(1 S, 10 R)-34 a$}

\subsubsection{Zeit- und Konzentrationsabhängigkeit des CD intakter Zellen nach Inkubation mit (1S,10R)-34a}

Je ein Aliquot einer Stammlösung des seco-Drugs (1S,10R)-34a in DMSO $(c=6.0 \mu \mathrm{g} / \mu \mathrm{L}$ bzw. $11.7 \mathrm{nmol} / \mu \mathrm{L})$ wurde mit DMSO verdünnt und nach AAV 10.1 der Einfluss verschiedener Konzentrationen des seco-Drugs und unterschiedlicher Inkubationszeiten auf das CD-Spektrum bestimmt. Untersucht wurden die folgenden Konzentrationen und Inkubationszeiten:

\begin{tabular}{ccc}
\hline $\begin{array}{c}\text { Konzentration } \\
{[\boldsymbol{\mu} \mathbf{M}]}\end{array}$ & $\begin{array}{c}\text { Inkubationszeit } \\
{[\mathbf{h}]}\end{array}$ & Beobachtung \\
\hline 0.49 & 24 & Zellzahl erniedrigt, kein ICD detektierbar \\
2.92 & 24 & Zellzahl erniedrigt, kein ICD detektierbar \\
5.83 & 4 und 5 & Zellzahl $\sim$ konstant, $\Delta I C D=1.0 \mathrm{mgrad}$ \\
5.83 & 6 & Zellzahl erniedrigt, $\Delta I C D=0.7 \mathrm{mgrad}$ \\
11.7 & 4 und 5 & Zellzahl $\sim$ konstant, $\triangle I C D=1.3 \mathrm{mgrad}$ \\
23.3 & 4.5 & Zellzahl $\sim$ konstant, $\triangle I C D=1.7 \mathrm{mgrad}$ \\
35.0 & 4.5 & Zellzahl $\sim$ konstant, $\Delta I C D=2.3 \mathrm{mgrad}$ \\
46.7 & 4.5 & Zellzahl $\sim$ konstant, $\Delta I C D=2.6 \mathrm{mgrad}$ \\
58.3 & 4.5 & Zellzahl $\sim$ konstant, $\triangle I C D=3.2 \mathrm{mgrad}$ \\
\hline
\end{tabular}




\subsubsection{Zeitabhängigkeit des CD intakter Zellen nach Inkubation mit} $(1 S, 10 R)-34 a$

Je ein Aliquot einer Stammlösung des seco-Drugs $(1 S, 10 R)$-34a in DMSO $(c=6.0 \mu \mathrm{g} / \mu \mathrm{L}$ bzw. $11.7 \mathrm{nmol} / \mu \mathrm{L})$ wurde mit DMSO verdünnt und nach AAV 10.1 die Änderung des CD-Spektrums der Zellen $(\lambda=200-400 \mathrm{~nm})$ nach Inkubation mit $(1 S, 10 R)-34 \mathbf{a}(c=58 \mu \mathrm{M})$ in Abhängigkeit von der Inkubationszeit $(t=0-6 \mathrm{~h})$ untersucht. Die Messreihe wurde dreimal durchgeführt.

Ergebnisse bezüglich des $\triangle I C D$ siehe 10.4.4.

\subsubsection{Zeitabhängigkeit des CD isolierter zellulärer DNA nach Inkubation mit $(1 S, 10 R)-34 a$}

Je ein Aliquot einer Stammlösung des seco-Drugs $(1 S, 10 R)-34 a$ in DMSO $(c=10.0 \mu \mathrm{g} / \mu \mathrm{L}$ bzw. $19.5 \mathrm{nmol} / \mu \mathrm{L})$ wurde mit DMSO verdünnt und nach AAV 10.2 die Änderung des CD-Spektrums isolierter zellulärer DNA $(\lambda=220-400 \mathrm{~nm})$ sowie der Anteil toter Zellen nach Inkubation der Zellen mit $(1 S, 10 R)-34 a(c=97 \mu \mathrm{M})$ in Abhängigkeit von der Inkubationszeit $(t=0-6 \mathrm{~h})$ untersucht. Die nach der Elution zur Messung des CD-Spektrums eingestellte DNA-Konzentration betrug $23 \mu \mathrm{g} / \mathrm{mL}$ $\left(A_{260}=0.46 \pm 0.05\right)$. Die Messreihe wurde viermal durchgeführt.

Ergebnisse bezüglich des $\triangle I C D$ siehe 10.4.4.

\subsubsection{Ergebnisse nach Inkubation von Zellen mit (1S,10R)-34a}

\begin{tabular}{cccc}
\hline $\begin{array}{c}\text { Inkubationszeit } \\
{[\mathbf{h}]}\end{array}$ & $\begin{array}{c}\Delta \text { ICD (Zellen) } \\
{[\mathbf{m g r a d}]}\end{array}$ & $\begin{array}{c}\Delta \text { ICD }(\mathbf{D N A}) \\
{[\mathbf{m g r a d}]}\end{array}$ & $\begin{array}{c}\text { Anteil toter Zellen } \\
{[\%]}\end{array}$ \\
\hline 0 & $1.0 \pm 0.1$ & $0.5 \pm 0.2$ & $3 \pm 1$ \\
1 & $1.6 \pm 0.6$ & $1.1 \pm 0.7$ & $4 \pm 2$ \\
2 & $2.3 \pm 0.5$ & $1.3 \pm 0.3$ & $3 \pm 1$ \\
3 & $2.6 \pm 0.3$ & $1.9 \pm 0.5$ & $4 \pm 1$ \\
4 & $2.9 \pm 0.2$ & $2.5 \pm 0.7$ & $6 \pm 2$ \\
5 & $2.9 \pm 0.4$ & $2.4 \pm 0.5$ & $9 \pm 2$ \\
6 & $2.4 \pm 0.2$ & $2.4 \pm 0.3$ & $12 \pm 3$ \\
\hline Kontrolle & $0.2 \pm 0.1$ & $0.00 \pm 0.06$ & $3 \pm 1$ \\
\hline
\end{tabular}




\subsection{Untersuchung der zellulären Aufnahme des seco-Drugs (+)-(1S)-56a}

\subsubsection{Zeitabhängigkeit des CD intakter Zellen nach Inkubation mit (1S)-56a}

Je ein Aliquot einer Stammlösung des seco-Drugs $(1 S)$-56a in DMSO $(c=5.9 \mu \mathrm{g} / \mu \mathrm{L}$ bzw. $11.7 \mathrm{nmol} / \mu \mathrm{L})$ wurde mit DMSO verdünnt und nach AAV 10.1 die Änderung des CD-Spektrums der Zellen $(\lambda=200-450 \mathrm{~nm})$ nach Inkubation mit (1S)-56a $(c=58 \mu \mathrm{M})$ in Abhängigkeit von der Inkubationszeit $(t=0-6 \mathrm{~h})$ untersucht. Die Messreihe wurde dreimal durchgeführt.

Ergebnisse bezüglich des $\triangle I C D$ siehe 10.5.3.

Zusätzlich zu den induzierten CD-Signalen bei $\lambda=305 \mathrm{~nm}$ und $\lambda=335 \mathrm{~nm}$ konnte ein starkes und zeitabhängiges ICD bei $\lambda=390 \mathrm{~nm}$ beobachtet werden.

\begin{tabular}{cc}
\hline Inkubationszeit $[\mathbf{h}]$ & $\left.\boldsymbol{I C D}_{\mathbf{3}} \mathbf{( 3 9 0} \mathbf{~ n m}\right)^{\mathbf{a}}[\mathbf{m g r a d}]$ \\
\hline 0 & $2.0 \pm 0.8$ \\
1 & $2.7 \pm 0.3$ \\
2 & $1.4 \pm 0.5$ \\
3 & $0.8 \pm 0.7$ \\
4 & $0.0 \pm 0.4$ \\
5 & $0.4 \pm 0.4$ \\
6 & $-0.5 \pm 0.5$
\end{tabular}

a: $I C D=\theta(\lambda=390 \mathrm{~nm}$, Zellen mit Wirkstoff $)-\theta(\lambda=390 \mathrm{~nm}$, Zellen ohne Wirkstoff $)$.

\subsubsection{Zeitabhängigkeit des CD isolierter zellulärer DNA nach Inkubation mit (1S)-56a}

Je ein Aliquot einer Stammlösung des seco-Drugs $(1 S)$-56a in DMSO $(c=9.75 \mu \mathrm{g} / \mu \mathrm{L}$ bzw. $19.5 \mathrm{nmol} / \mu \mathrm{L}$ ) wurde mit DMSO verdünnt und nach AAV 10.2 die Änderung des CD-Spektrums isolierter zellulärer DNA $(\lambda=200-450 \mathrm{~nm})$ sowie der Anteil toter Zellen nach Inkubation der Zellen mit $(1 S)$-56a $(c=68 \mu \mathrm{M})$ in Abhängigkeit von der Inkubationszeit $(t=0-6 \mathrm{~h})$ untersucht. Die nach Elution für die Messung des CD- 
Spektrums eingestellte DNA-Konzentration betrug $23 \mu \mathrm{g} / \mathrm{mL}\left(A_{260}=0.46 \pm 0.05\right)$. Die Messreihe wurde viermal durchgeführt.

Ergebnisse bezüglich des $\triangle I C D$ siehe 10.5.3.

Zusätzlich zu den induzierten CD-Signalen bei $\lambda=305 \mathrm{~nm}$ und $\lambda=335 \mathrm{~nm}$ konnte kein ICD bei $\lambda=390 \mathrm{~nm}$ beobachtet werden

10.5.3 Ergebnisse nach Inkubation von Zellen mit (1S)-56a

\begin{tabular}{cccc}
\hline $\begin{array}{c}\text { Inkubationszeit } \\
{[\mathbf{h}]}\end{array}$ & $\begin{array}{c}\Delta \boldsymbol{I C D}(\text { Zellen) } \\
{[\mathbf{m g r a d}]}\end{array}$ & $\begin{array}{c}\Delta \boldsymbol{I C D}(\mathbf{D N A}) \\
{[\mathbf{m g r a d}]}\end{array}$ & $\begin{array}{c}\text { Anteil toter Zellen } \\
{[\%]}\end{array}$ \\
\hline 0 & $1.1 \pm 0.3$ & $0.8 \pm 0.2$ & $3 \pm 1$ \\
1 & $1.9 \pm 0.2$ & $1.9 \pm 0.3$ & $3 \pm 2$ \\
2 & $1.5 \pm 0.3$ & $2.1 \pm 0.6$ & $2 \pm 1$ \\
3 & $2.1 \pm 0.4$ & $1.8 \pm 0.6$ & $3 \pm 1$ \\
4 & $2.2 \pm 0.5$ & $2.3 \pm 0.7$ & $4 \pm 1$ \\
5 & $2.4 \pm 0.6$ & $2.4 \pm 0.4$ & $4 \pm 2$ \\
6 & $2.5 \pm 0.6$ & $2.4 \pm 0.6$ & $6 \pm 2$ \\
\hline Kontrolle & $0.2 \pm 0.1$ & $0.1 \pm 0.1$ & $2 \pm 1$ \\
\hline
\end{tabular}

\subsubsection{CD einer Mischung isolierter zellulärer DNA und (1S)-56a}

Ein Aliquot einer Stammlösung des seco-Drugs (1S)-56a in DMSO (1 $\mu \mathrm{L}, 5 \mathrm{nmol})$ wurde zu einer Lösung zellulärer DNA in Wasser $(0.2 \mathrm{~mL}, 30 \mu \mathrm{g} / \mathrm{mL})$ und Phosphat-

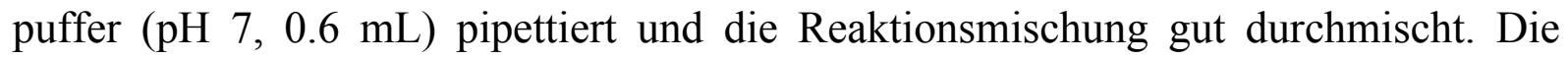
Lösung wurde sofort in eine Küvette $(d=1 \mathrm{~cm})$ überführt und bei $25^{\circ} \mathrm{C}$ inkubiert. $\mathrm{Zu}$ den angegebenen Zeiten nach dem Ansetzen der Reaktionmischung wurde ein CDSpektrum gemessen Als Referenz diente der verwendete Phosphatpuffer.

$0 \mathrm{~h}: \quad \lambda_{\max }[\mathrm{nm}](\theta[\mathrm{mgrad}]): 270(0.0), 320(0.1), 385(-0.1)$.

$\lambda_{\min }[\mathrm{nm}](\theta[\mathrm{mgrad}]): 248(-2.6), 298(-1.9), 360(-0.3)$.

$2.5 \mathrm{~h}: \quad \lambda_{\max }[\mathrm{nm}](\theta[\mathrm{mgrad}]): 270(0.4), 320(0.4), 385(-0.2)$.

$\lambda_{\min }[\mathrm{nm}](\theta$ [mgrad]): $248(-2.2), 298(-0.8), 360$ (-0.2). 
10.6 Untersuchung der zellulären Aufnahme des seco-Drugs $(+)-(1 S, 10 R)-34 b$

\subsubsection{Zeitabhängigkeit des CD intakter Zellen nach Inkubation mit} $(1 S, 10 R)-34 b$

Je ein Aliquot einer Stammlösung des seco-Drugs $(1 S, 10 R)-34 \mathbf{b}$ in DMSO $(c=6.5 \mu \mathrm{g} / \mu \mathrm{L}$ bzw. $11.7 \mathrm{nmol} / \mu \mathrm{L})$ wurde mit DMSO verdünnt und nach AAV 10.1 die Änderung des CD-Spektrums der Zellen $(\lambda=200-400 \mathrm{~nm})$ nach Inkubation mit $(1 S, 10 R)-34 \mathbf{b} \quad(c=58 \mu \mathrm{M})$ in Abhängigkeit von der Inkubationszeit $(t=0-6 \mathrm{~h})$ untersucht. Die Messreihe wurde dreimal durchgeführt.

Ergebnisse bezüglich des $\triangle I C D$ siehe 10.6.4.

\subsubsection{Zeit- und Konzentrationsabhängigkeit der Anzahl toter Zellen nach Inkubation mit (1S,10R)-34b}

Je ein Aliquot einer Stammlösung des seco-Drugs $(1 S, 10 R)-34 \mathbf{b}$ in DMSO $(c=6.5 \mu \mathrm{g} / \mu \mathrm{L}$ bzw. $11.7 \mathrm{nmol} / \mu \mathrm{L})$ wurde mit DMSO verdünnt und nach AAV 10.2 der Einfluss verschiedener Konzentrationen des seco-Drugs und unterschiedlicher Inkubationszeiten auf die Antahl toter Zellen bestimmt. Untersucht wurde eine Inkubationszeit von $2 \mathrm{~h}$ und $4 \mathrm{~h}$ mit den folgenden Konzentrationen:

\begin{tabular}{ccc}
\hline $\begin{array}{c}\text { Konzentration } \\
\text { [nM] }\end{array}$ & $\begin{array}{c}\text { Anteil toter Zellen nach 2 h } \\
\text { Inkubationszeit [\%] }\end{array}$ & $\begin{array}{c}\text { Anteil toter Zellen nach 4 h } \\
\text { Inkubationszeit [\%] }\end{array}$ \\
\hline 58.6 & 2 & 3 \\
67.6 & 2 & 4 \\
76.6 & 3 & 19 \\
85.7 & 8 & 20 \\
97.4 & 23 & 31 \\
\hline Kontrolle & 2 & 2 \\
\hline
\end{tabular}


10.6.3 Zeitabhängigkeit des CD isolierter zellulärer DNA nach Inkubation mit $(1 S, 10 R)-34 b$

Je ein Aliquot einer Stammlösung des seco-Drugs $(1 S, 10 R)-34 b$ in DMSO $(c=6.5 \mu \mathrm{g} / \mu \mathrm{L}$ bzw. $11.7 \mathrm{nmol} / \mu \mathrm{L})$ wurde mit DMSO verdünnt und nach AAV 10.2 die Änderung des CD-Spektrums isolierter zellulärer DNA $(\lambda=220-400 \mathrm{~nm})$ sowie der Anteil toter Zellen nach Inkubation der Zellen mit $(1 S, 10 R)-34 b(c=68 \mu \mathrm{M})$ in Abhängigkeit von der Inkubationszeit $(t=0-6 \mathrm{~h})$ untersucht. Die zur Messung des CD eingestellte DNA-Konzentration betrug $30 \mu \mathrm{g} / \mathrm{mL}\left(A_{260}=0.60 \pm 0.05\right)$. Die Messreihe wurde viermal durchgeführt.

Ergebnisse bezüglich des $\triangle I C D$ siehe 10.6.4.

\subsubsection{Ergebnisse nach Inkubation von Zellen mit $(1 S, 10 R)-34 b$}

\begin{tabular}{cccc}
\hline $\begin{array}{c}\text { Inkubationszeit } \\
{[\mathbf{h}]}\end{array}$ & $\begin{array}{c}\Delta \text { ICD (Zellen) } \\
{[\mathbf{m g r a d}]}\end{array}$ & $\begin{array}{c}\Delta \text { ICD (DNA) } \\
{[\mathbf{m g r a d}]}\end{array}$ & $\begin{array}{c}\text { Anteil toter Zellen } \\
{[\%]}\end{array}$ \\
\hline 0 & $1.0 \pm 0.3$ & $0.3 \pm 0.1$ & $3 \pm 1$ \\
1 & $1.7 \pm 0.4$ & $2.0 \pm 0.3$ & $4 \pm 1$ \\
2 & $2.3 \pm 0.5$ & $2.3 \pm 0.4$ & $4 \pm 1$ \\
3 & $2.6 \pm 0.4$ & $2.8 \pm 0.4$ & $3 \pm 1$ \\
4 & $3.1 \pm 0.8$ & $2.2 \pm 0.7$ & $4 \pm 1$ \\
5 & $3.1 \pm 0.4$ & $3.0 \pm 0.7$ & $6 \pm 1$ \\
6 & $3.1 \pm 0.8$ & $3.0 \pm 0.5$ & $8 \pm 2$ \\
\hline Kontrolle & $0.2 \pm 0.1$ & $0.1 \pm 0.1$ & $2 \pm 1$ \\
\hline
\end{tabular}

\subsection{Untersuchung der zellulären Aufnahme des seco-Drugs (+)-(1S)-56b}

\subsubsection{Zeitabhängigkeit des CD intakter Zellen nach Inkubation mit (1S)-56b}

Je ein Aliquot einer Stammlösung des seco-Drugs (1S)-56b in DMSO $(c=6.3 \mu \mathrm{g} / \mu \mathrm{L}$ bzw. $11.7 \mathrm{nmol} / \mu \mathrm{L})$ wurde mit DMSO verdünnt und nach AAV 10.1 die Änderung des CD-Spektrums $(\lambda=200-500 \mathrm{~nm})$ der Zellen nach Inkubation mit $(1 S)-\mathbf{5 6 b}$ 
$(c=41 \mu \mathrm{M})$ in Abhängigkeit von der Inkubationszeit $(t=0-6 \mathrm{~h})$ untersucht. Die Messreihe wurde dreimal durchgeführt.

Ergebnisse bezüglich des $\triangle I C D$ siehe 10.7.3.

Zusätzlich zu den induzierten CD-Signalen bei $\lambda=305 \mathrm{~nm}$ und $\lambda=335 \mathrm{~nm}$ konnte ein starkes und zeitabhängiges ICD bei $\lambda=390 \mathrm{~nm}$ beobachtet werden.

\begin{tabular}{cc}
\hline Inkubationszeit $[\mathbf{h}]$ & $\boldsymbol{I C D}_{\mathbf{( 3 9 0} \mathbf{~ n m})^{\mathbf{a}}[\mathbf{m g r a d}]}$ \\
\hline 0 & $3.0 \pm 1.1$ \\
1 & $4.4 \pm 0.6$ \\
2 & $3.7 \pm 0.8$ \\
3 & $3.7 \pm 0.7$ \\
4 & $3.5 \pm 1.2$ \\
5 & $2.5 \pm 1.3$ \\
6 & $2.8 \pm 0.8$ \\
\hline
\end{tabular}

a: $I C D=\theta(\lambda=390 \mathrm{~nm}$, Zellen mit Wirkstoff $)-\theta(\lambda=390 \mathrm{~nm}$, Zellen ohne Wirkstoff $)$.

\subsubsection{Zeitabhängigkeit des CD isolierter zellulärer DNA nach Inkubation mit (1S)-56b}

Je ein Aliquot einer Stammlösung des seco-Drugs (1S)-56b in DMSO $(c=6.5 \mu \mathrm{g} / \mu \mathrm{L}$ bzw. $11.7 \mathrm{nmol} / \mu \mathrm{L}$ ) wurde mit DMSO verdünnt und nach AAV 10.2 die Änderung des CD-Spektrums isolierter zellulärer DNA $(\lambda=220-450 \mathrm{~nm})$ sowie der Anteil toter Zellen nach Inkubation der Zellen mit $(1 S)-56 b(c=48 \mu \mathrm{M})$ in Abhängigkeit von der Inkubationszeit $(t=0-6 \mathrm{~h})$ untersucht. Die nach der Elution zur Messung des CDSpektrums eingestellte DNA-Konzentration betrug $30 \mu \mathrm{g} / \mathrm{mL}\left(A_{260}=0.60 \pm 0.05\right)$. Die Messreihe wurde viermal durchgeführt.

Ergebnisse bezüglich des $\triangle I C D$ siehe 10.7.3.

Zusätzlich zu den induzierten CD-Signalen bei $\lambda=305 \mathrm{~nm}$ und $\lambda=335 \mathrm{~nm}$ konnte kein ICD bei $\lambda=390 \mathrm{~nm}$ beobachtet werden. 
10.7.3 Ergebnisse nach Inkubation von Zellen mit (1S)-56b

\begin{tabular}{cccc}
\hline $\begin{array}{c}\text { Inkubationszeit } \\
{[\mathbf{h}]}\end{array}$ & $\begin{array}{c}\Delta \text { ICD (Zellen) } \\
{[\text { mgrad] }}\end{array}$ & $\begin{array}{c}\Delta \text { ICD (DNA) } \\
{[\text { mgrad] }}\end{array}$ & $\begin{array}{c}\text { Anteil toter Zellen } \\
{[\%]}\end{array}$ \\
\hline 0 & $1.1 \pm 0.3$ & $0.5 \pm 0.2$ & $3 \pm 2$ \\
1 & $1.6 \pm 0.2$ & $1.9 \pm 0.1$ & $3 \pm 2$ \\
2 & $2.1 \pm 0.1$ & $2.1 \pm 0.4$ & $2 \pm 1$ \\
3 & $2.2 \pm 0.3$ & $2.1 \pm 0.4$ & $4 \pm 2$ \\
4 & $2.3 \pm 0.3$ & $1.9 \pm 0.4$ & $3 \pm 1$ \\
5 & $2.0 \pm 0.4$ & $1.9 \pm 0.5$ & $4 \pm 2$ \\
6 & $2.3 \pm 0.3$ & $1.8 \pm 0.2$ & $6 \pm 1$ \\
\hline Kontrolle & $0.3 \pm 0.3$ & $0.1 \pm 0.1$ & $3 \pm 1$ \\
\hline
\end{tabular}

\subsection{Untersuchung der zellulären Aufnahme des fluoreszenzmarkierten seco-Drugs $(1 S, 10 R)-76$}

\subsubsection{CD intakter Zellen nach 4 h Inkubation mit (1S,10R)-76}

Ein Aliquot einer Stammlösung des seco-Drugs $(1 S, 10 R)-76$ in DMSO $(c=10 \mathrm{nmol} / \mu \mathrm{L})$ wurde mit DMSO verdünnt und nach AAV 10.1 die Änderung des CD-Spektrums der Zellen $(\lambda=200-500 \mathrm{~nm})$ nach Inkubation mit $(1 S, 10 R)-76$ $(c=58 \mu \mathrm{M}$ ) bei einer Inkubationszeit von $t=4 \mathrm{~h}$ untersucht (2 Messungen).

Zellen mit $(1 S, 10 R)-76:$

$4 \mathrm{~h}: \lambda_{\max }[\mathrm{nm}](\theta[\mathrm{mgrad}]): 270(1.2), 333(0.3)$.

$\lambda_{\min }[\mathrm{nm}](\theta[\mathrm{mgrad}]): 220(-10.5), 300(-0.6)$.

$\Delta \operatorname{ICD}(4 \mathrm{~h})=\theta(335 \mathrm{~nm})-\theta(305 \mathrm{~nm})=(1.0 \pm 0.1) \operatorname{mgrad}$.

Zellen ohne $(1 S, 10 R)-76$ :

$4 \mathrm{~h}: \lambda_{\max }[\mathrm{nm}](\theta[\mathrm{mgrad}]): 270(0.7), 338(-0.2)$.

$\lambda_{\min }[\mathrm{nm}](\theta[\mathrm{mgrad}]): 220(-6.0), 300(-0.7)$.

$\Delta \operatorname{ICD}(0 \mathrm{~h})=\theta(335 \mathrm{~nm})-\theta(305 \mathrm{~nm})=0.3 \mathrm{mgrad}$. 


\subsubsection{CD isolierter zellulärer DNA nach 5 h Inkubation mit (1S,10R)-76}

Je ein Aliquot einer Stammlösung des seco-Drugs $(1 S, 10 R)-76$ in DMSO $(c=10 \mathrm{nmol} / \mu \mathrm{L})$ wurde mit DMSO verdünnt und nach AAV 10.2 die Änderung des CD-Spektrums isolierter zellulärer DNA $(\lambda=200-500 \mathrm{~nm})$ sowie der Anteil toter Zellen nach Inkubation der Zellen mit $(1 S, 10 R)-76(c=97 \mu \mathrm{M})$ für eine Inkubationszeit von $t=5 \mathrm{~h}$ untersucht. Die nach Elution für die Messung des CD eingestellte DNA-Konzentration betrug $30 \mu \mathrm{g} / \mathrm{mL}\left(A_{260}=0.60 \pm 0.05\right)$ und der Anteil toter Zellen jeweils $3 \%$.

DNA aus Zellen mit $(1 S, 10 R)-76$ :

$5 \mathrm{~h}: \lambda_{\max }[\mathrm{nm}](\theta[\mathrm{mgrad}]): 275$ (4.3), $330(0.2)$.

$\lambda_{\min }[\mathrm{nm}](\theta[\mathrm{mgrad}]): 240(-3.0), 305(-0.3)$.

$\Delta \operatorname{ICD}(5 \mathrm{~h})=\theta(335 \mathrm{~nm})-\theta(305 \mathrm{~nm})=0.5 \operatorname{mgrad}$.

DNA aus Zellen ohne $(1 S, 10 R)-76$ :

$5 \mathrm{~h}: \lambda_{\max }[\mathrm{nm}](\theta[\mathrm{mgrad}]): 275$ (2.7).

$\lambda_{\min }[\mathrm{nm}](\theta[\mathrm{mgrad}]): 240(-2.1)$.

$\Delta \operatorname{ICD}(0 \mathrm{~h})=\theta(335 \mathrm{~nm})-\theta(305 \mathrm{~nm})=0.0 \operatorname{mgrad}$.

\subsection{Untersuchung der zellulären Aufnahme von Doxorubicin (11)}

\subsubsection{Zeit- und Konzentrationsabhängigkeit des CD intakter Zellen nach Inkubation mit 11}

Je ein Aliquot einer Stammlösung von Doxorubicin (11) in DMSO $(c=50 \mathrm{nmol} / \mu \mathrm{L}$ bzw. $150 \mathrm{nmol} / \mu \mathrm{L}$ ) wurde mit DMSO verdünnt und nach AAV 10.1 der Einfluss verschiedener Konzentrationen des Zytostatikums und unterschiedlicher Inkubationszeiten auf das CD-Spektrum $(\lambda=200-600 \mathrm{~nm})$ bestimmt. Untersucht wurden die folgenden Konzentrationen und Inkubationszeiten: 


\begin{tabular}{ccc}
\hline $\begin{array}{c}\text { Konzentration } \\
{[\boldsymbol{\mu} \mathbf{M}]}\end{array}$ & $\begin{array}{c}\text { Inkubationszeit } \\
{[\mathbf{h}]}\end{array}$ & Beobachtung $^{\text {a }}$ \\
\hline 75.0 & 4 & Zellzahl $\sim$ konstant, kein ICD detektierbar \\
75.0 & 48 & Zellzahl gering, kein ICD detektierbar \\
225 & 48 & Zellzahl gering, kein ICD detektierbar \\
300 & 6 & Zellzahl $\sim$ konstant, ICD schwach \\
300 & 24 & Zellzahl $\sim$ konstant, ICD schwach \\
300 & 48 & Zellzahl sehr gering, kein ICD detektierbar \\
450 & 4 & Zellzahl gering, ICD schwach \\
450 & 48 & Zellzahl sehr gering, kein ICD detektierbar \\
750 & 3 & Zellzahl $\sim$ konstant, ICD schwach \\
1500 & 3 & Zellzahl gering, ICD schwach \\
\hline
\end{tabular}

a: Bei allen Konzentrationen war das Zellpellet rot gefärbt und die Zellen waren morphologisch im Vergleich zur Kontrolle abgerundet.

\subsection{Untersuchung der zellulären Aufnahme von Mitomycin C (99)}

\subsubsection{Zeit- und Konzentrationsabhängigkeit des CD intakter Zellen nach Inkubation mit 99}

Je ein Aliquot einer Stammlösung von Mitomycin C (99) in DMSO ( $c=50 \mathrm{nmol} / \mu \mathrm{L})$ wurde mit DMSO verdünnt und nach AAV 10.1 der Einfluss verschiedener Konzentrationen des Zytostatikums und unterschiedlicher Inkubationszeiten auf das CD-Spektrum $(\lambda=200-500 \mathrm{~nm})$ bestimmt. Untersucht wurden die folgenden Konzentrationen und Inkubationszeiten:

\begin{tabular}{ccc}
\hline $\begin{array}{c}\text { Konzentration } \\
{[\boldsymbol{\mu} \mathbf{M}]}\end{array}$ & $\begin{array}{c}\text { Inkubationszeit } \\
{[\mathbf{h}]}\end{array}$ & Beobachtung \\
\hline 400 & 3 & Zellzahl $\sim$ konstant, kein ICD detektierbar \\
400 & 24 & Zellzahl $\sim$ konstant, kein ICD detektierbar \\
500 & 4 & Zellzahl $\sim$ konstant, kein ICD detektierbar \\
\hline
\end{tabular}




\section{Untersuchung der Fluoreszenzeigenschaften und der zellulä- ren Aufnahme fluoreszenzmarkierter anti-Methyl-seco-CBI- DMAI-Derivate}

Alle fluoreszenzmikroskopischen Untersuchungen und Studien am Fluorimeter erfolgten in Kooperation mit Dr. Mišo Mitkovski, Abteilung Molekulare Biologie Neuronaler Signale des Max-Planck-Institutes für experimentelle Medizin in Göttingen, unter Leitung von Prof. Dr. W. Stühmer.

\subsection{Charakterisierung der Fluoreszenzeigenschaften von anti-Methyl- seco-CBI-DMAI-Derivaten}

\subsubsection{AAV 11.1.1. Allgemeine Arbeitsvorschrift zur Bestimmung der Fluores- zenzintensität bei festgelegter Wellenlänge in Abhängigkeit von der Anregungswellenlänge (Absorption-Scan)}

1 Aliquot der Stammlösung $(c=1 \mathrm{mM})$ der zu untersuchenden Substanz in DMSO ( $2 \mu \mathrm{L}, 2 \mathrm{nmol})$ wurde im gewählten Lösungsmittel (200 $\mu \mathrm{L}$, Lösungsmittel: Methanol, Bildgebungspuffer oder Wasser) gelöst, die Lösung mit einem Vortexgerät durchmischt und in eine Quarz-Küvette pipettiert. Mit einem Fluorimeter wurde die Fluoreszenzintensität der Emissionen bei $\lambda_{\mathrm{em}}=500 \mathrm{~nm}$ und $\lambda_{\mathrm{em}}=560 \mathrm{~nm}$ für einen Anregungswellenlängenbereich von $\lambda_{\text {exc }}=200-600 \mathrm{~nm}$ gemessen.

Parameter: Excitation scan, digital cfg, Exc.: 200-600 nm, length: $400 \mathrm{~nm}$, Em1: $500 \mathrm{~nm}, \mathrm{Em} 2: 560 \mathrm{~nm}$, Step size: $5 \mathrm{~nm}$ (bzw. $1 \mathrm{~nm}$ ), Integration: $1 \mathrm{sec}$, Averages: 1.

\subsubsection{AAV 11.1.2. Allgemeine Arbeitsvorschrift zur Messung des Fluoreszenz- emissionsspektrums bei festgelegter Anregungswellenlänge (Emission- Scan)}

1 Aliquot der Stammlösung $(c=1 \mathrm{mM})$ der zu untersuchenden Substanz in DMSO (2 $\mu \mathrm{L}, 2 \mathrm{nmol})$ wurde im gewählten Lösungsmittel (200 $\mu \mathrm{L}$, Lösungsmittel: Methanol, Bildgebungspuffer oder Wasser) gelöst, die Lösung mit einem Vortexgerät durchmischt und in eine Küvette pipettiert. Mit einem Fluorimeter wurde die Fluoreszenzintensität bei einer Anregung mit Laserlicht der Wellenlänge $\lambda_{\mathrm{exc}}=350 \mathrm{~nm}$ (bzw. 
$378 \mathrm{~nm}, 405 \mathrm{~nm}$ oder $514 \mathrm{~nm}$ ) für einen Emissionsbereich von $\lambda_{\mathrm{em}}=400-800 \mathrm{~nm}$ gemessen.

Parameter: Emission scan, digital cfg, Exc.: $350 \mathrm{~nm}$ (bzw. $378 \mathrm{~nm}, 405 \mathrm{~nm}$ oder $514 \mathrm{~nm}$ ), Em1 und Em2: 400-800 nm, Step size: $5 \mathrm{~nm}$, Integration: $1 \mathrm{sec}$, Averages: 1.

\subsubsection{AAV 11.1.3. Allgemeine Arbeitsvorschrift zur Untersuchung der Änderung der Fluoreszenzeigenschaften der anti-Methyl-seco-CBI- DMAI-Derivate durch DNA-Bindung}

1 Aliquot der Stammlösung $(c=10 \mathrm{mM})$ der jeweils zu untersuchenden Substanz $((1 S, 10 R)-34 \mathbf{a},(1 S, 10 R)-76$ oder $(1 S, 10 R)-75)$ in DMSO $(2 \mu \mathrm{L}, 20 \mathrm{nmol})$ wurde mit einer Lösung zellulärer oder plasmidischer DNA in bidestilliertem Wasser $(400 \mu \mathrm{L})$ oder mit bidestilliertem Wasser $(400 \mu \mathrm{L})$ versetzt. Die Konzentration zellulärer DNA betrug $30 \mu \mathrm{g} / \mathrm{mL}, 15 \mu \mathrm{g} / \mathrm{mL}$ oder $7.5 \mu \mathrm{g} / \mathrm{mL}$ und die Konzentration plasmidischer DNA $32 \mu \mathrm{g} / \mathrm{mL}$. 1 Aliquot $(200 \mu \mathrm{L})$ der Reaktionslösung wurde sofort tiefgefroren und das andere Aliquot $(200 \mu \mathrm{L}) 24 \mathrm{~h}$ bei $25{ }^{\circ} \mathrm{C}$ inkubiert und anschließend tiefgefroren. Zum Vergleich wurden die Lösungen der reinen zellulären oder plasmidischen DNA mit DMSO $(200 \mu \mathrm{L}, 1 \%$ DMSO, Konzentration der zellulären DNA: $30 \mu \mathrm{g} / \mathrm{mL}, 15 \mu \mathrm{g} / \mathrm{mL}$ oder $7.5 \mu \mathrm{g} / \mathrm{mL}$, Konzentration der plasmidischen DNA: $32 \mu \mathrm{g} / \mathrm{mL}$ ) verwendet.

Für alle Lösungen wurde nach dem Auftauen zunächst nach AAV 11.1.1 ein Absorption-Scan und anschließend nach AAV 11.1.2 ein Emission-Scan durchgeführt.

\subsubsection{AAV 11.1.4. Allgemeine Arbeitsvorschrift zur Untersuchung der zeit- lichen Änderung der Intensität der Hoechstfluoreszenz bei DNA-Bindung nach Vorinkubation der DNA mit anti-Methyl-seco-CBI-DMAI-Derivaten}

Die nach AAV 11.1.3 untersuchten Lösungen wurden mit Wasser (800 $\mu \mathrm{L})$ verdünnt und mit einem Aliquot einer Lösung des Kernfarbstoffs Hoechst 33342 (40) in Wasser $(1 \mu \mathrm{L}$, Konzentration der Stammlösung: $18 \mu \mathrm{M}, 18 \mathrm{pmol})$ versetzt $\left(c_{\text {final }}=18 \mathrm{nM}\right)$. Die

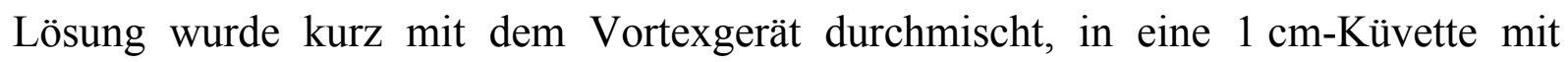
Rührvorrichtung pipettiert und umgehend (1-2 min nach dem Ansatz) unter ständigem Rühren die zeitliche Änderung der Fluoreszenzemission bei $\lambda_{\mathrm{em}}=500 \mathrm{~nm}$ und $\lambda_{\mathrm{em}}=560 \mathrm{~nm}$ für eine Anregung bei $\lambda_{\mathrm{exc}}=365 \mathrm{~nm}, 405 \mathrm{~nm}$ und $514 \mathrm{~nm}$ aufgezeichnet. 
Parameter: Exc. 365 nm: Em1: 500 nm, Em2: 560 nm; Exc. 405 nm: Em1: 500 nm, Em2: 560 nm; Exc. 514 nm: Em1: 500 nm, Em2: 560 nm; Messung: $1 \mathrm{sec}$, alle $60 \mathrm{sec}$; Messzeit: $3661 \mathrm{sec}$; Integration: $1 \mathrm{sec}$.

\subsection{Fluoreszenzmikroskopische Untersuchung der Aufnahme und intra- zellulären Verteilung fluoreszenzmarkierter anti-Methyl-seco-CBI- DMAI-Derivate}

\subsubsection{AAV 11.2.1. Allgemeine Arbeitsvorschrift zur Vorbereitung der A549- Zellen zur Untersuchung der zellulären Aufnahme fluoreszenzmarkierter anti-Methyl-seco-CBI-DMAI-Derivate am konfokalen Laserscanning- Mikroskop}

Als Zelllinie diente das adhärent wachsende humane Bronchialkarzinom der Linie A549. Die Aussaat der Tumorzellen erfolgte in D10F (DMEM mit Zusatz von 10\% fötalem Kälberserum, $44 \mathrm{mM} \mathrm{NaHCO} 3$ und $4 \mathrm{mM}$ Glutamin) in einer Konzentrationen von $25 \times 10^{3}$ Zellen in $500 \mu \mathrm{L}$ Medium pro Kammer des Deckgläschens (Nunc ${ }^{\circledR}$ LabTek $^{\circledR}$ Chamber Slide mit 4 wells auf Permanox). Die Zellen wurden für 24 h bei $37^{\circ} \mathrm{C}$ und 7.5\% $\mathrm{CO}_{2}$ adheriert. Alternativ wurden die Zellen in einer Konzentration von $5 \times 10^{3}$ Zellen in $500 \mu \mathrm{L}$ Medium pro Kammer des Deckgläschens ausgesät und für 3 Tage bei $37^{\circ} \mathrm{C}$ und $7.5 \% \mathrm{CO}_{2}$ adheriert.

\subsubsection{AAV 11.2.2. Allgemeine Arbeitsvorschrift zur Vorbereitung der} HeLa SS6-Zellen zur Untersuchung der zellulären Aufnahme fluoreszenzmarkierter anti-Methyl-seco-CBI-DMAI-Derivate am Spinning-DiscMikroskop

Als Zelllinie dienten adhärent wachsende Zervixkarzinomzellen der Linie HeLa SS6. Die Aussaat der Tumorzellen erfolgte in D10F (DMEM mit Zusatz von 10\% fötalem Kälberserum, $0.4 \mathrm{mM}$ Glutamin und $0.2 \mathrm{mM}$ Natriumpyruvat) in einer Konzentrationen von $25 \times 10^{3}$ Zellen in $500 \mu \mathrm{L}$ Medium pro Kammer des Deckgläschens (Nunc ${ }^{\circledR}$ Lab-Tek ${ }^{\circledR}$ Chamber Slide mit 4 wells auf Permanox). Die Zellen wurden für $24 \mathrm{~h}$ bei $37{ }^{\circ} \mathrm{C}$ und $5 \% \mathrm{CO}_{2}$ adheriert. 


\subsubsection{AAV 11.2.3. Allgemeine Arbeitsvorschrift zur Vorbereitung der HeLa SS6-Zellen zur Untersuchung der Lokalisation fluoreszenz- markierter anti-Methyl-seco-CBI-DMAI-Derivate in Endosomen am konfokalen Laserscanning-Mikroskop}

Als Zelllinie dienten Zellen des adhärent wachsenden Zervixkarzimoms der Linie HeLa SS6. Die Aussaat der Tumorzellen erfolgte in D10F (DMEM mit Zusatz von $10 \%$ fötalem Kälberserum, $0.4 \mathrm{mM}$ Glutamin und $0.2 \mathrm{mM}$ Natriumpyruvat) in einer Konzentration von $25 \times 10^{3}$ Zellen in $500 \mu \mathrm{L}$ Medium pro Kammer des Deckgläschens (Nunc ${ }^{\circledR}$ Lab-Tek ${ }^{\circledR}$ Chamber Slide mit 4 wells auf Permanox). Die Zellen wurden für $24 \mathrm{~h}$ bei $37^{\circ} \mathrm{C}$ und $5 \% \mathrm{CO}_{2}$ adheriert und unter Nutzung des Vektors pEGFP-Endo nach dem Protokoll der Firma Invitrogen mit Lipofectamine 2000 transfiziert.

\subsubsection{AAV 11.2.4. Allgemeine Arbeitsvorschrift zur Untersuchung der zellulären Aufnahme fluoreszenzmarkierter anti-Methyl-seco-CBI- DMAI-Derivate inklusive des Waschens der Zellen nach Inkubation}

Die nach AAV 11.2.1-3 vorbereiteten Zellen wurden mit serumfreiem UltraCulture ${ }^{\circledR}$ Medium $(2 \times 1 \mathrm{~mL})$ gewaschen und mit einer Lösung der zu untersuchenden Substanz in DMSO und UltraCulture ${ }^{\circledR}$ Medium $(500 \mu \mathrm{L}, 1 \%$ DMSO) oder mit einer Lösung aus DMSO in UltraCulture ${ }^{\circledR}$ Medium (500 $\mu \mathrm{L}, 1 \%$ DMSO) versetzt. Die Konzentration der Verbindungen in der Inkubationslösung betrug $10 \mu \mathrm{M}((1 S, 10 R)-75,(1 S, 10 R)-76$, 103, (1S,10R)-34a) oder $25 \mathrm{nM}(\mathbf{4 1})$. Nach einer bestimmten Inkubationszeit (45 min $2.5 \mathrm{~h}$ ) bei $37^{\circ} \mathrm{C}$ und $7.5 \% \mathrm{CO}_{2}$ wurden die Zellen mit UltraCulture ${ }^{\circledR}$ Medium ( $\left.1 \mathrm{~mL}\right)$ sowie mit dem Bildgebungspuffer $(2 \times 1 \mathrm{~mL})$ gewaschen und im Bildgebungspuffer mittels eines konfokalen Fluoreszenzmikroskopes untersucht.

\subsubsection{AAV 11.2.5. Allgemeine Arbeitsvorschrift zur Untersuchung der zellulären Aufnahme fluoreszenzmarkierter anti-Methyl-seco-CBI- DMAI-Derivate ohne Waschen der Zellen nach Inkubation}

Die nach AAV 11.2.1-3 vorbereiteten Zellen wurden mit serumfreiem UltraCulture ${ }^{\circledR}$ Medium $(2 \times 1 \mathrm{~mL})$ und mit dem Bildgebungspuffer $(2 \times 1 \mathrm{~mL})$ gewaschen und mit einer Lösung der zu untersuchenden Substanz in DMSO und dem Bildgebungspuffer (500 $\mu \mathrm{L}, 1 \%$ DMSO) oder mit einer Lösung aus DMSO im Bildgebungspuffer $(500 \mu \mathrm{L}, 1 \%$ DMSO) versetzt. Die Konzentration der Verbindungen in der Inkuba- 
tionslösung betrug 2-10 $\mu \mathrm{M}((1 S, 10 R)-\mathbf{7 5},(1 S, 10 R)-\mathbf{7 6}, \mathbf{1 0 3})$ oder $25 \mathrm{nM}(\mathbf{4 1})$. Nach einer bestimmten Inkubationszeit bei $37{ }^{\circ} \mathrm{C}$ und $7.5 \% \mathrm{CO}_{2}$ wurden die Zellen mittels eines konfokalen Fluoreszenzmikroskopes untersucht.

\subsubsection{AAV 11.2.6. Allgemeine Arbeitsvorschrift zur Anfärbung mit} Hoechst 33342 (40), Trypanblau und/oder dem Mitochondrienfarbstoff 41

Zur Anfärbung der Zellkerne wurde eine Lösung des Farbstoffs Hoechst 33342 (40) in Puffer ( $1 \mu \mathrm{L}$, Konzentration der Stammlösung: $36 \mathrm{~mm}, 36 \mathrm{nmol})$ mit dem Bildgebungspuffer in den Kammern vermischt $\left(c_{\text {final }}=72 \mu \mathrm{M}\right)$ und die Zellen vor der Beobachtung einige Minuten bei Raumtemperatur inkubiert.

Zur Anfärbung toter Zellen und zum Färben der Zellmembranen wurde eine Lösung des Farbstoffs Trypanblau in physiologischem Puffer $(5-25 \mu \mathrm{L})$ mit dem Bildgebungspuffer in den Kammern vermischt und die Zellen vor der Beobachtung einige Minuten bei Raumtemperatur inkubiert.

Zur Co-Lokalisation des seco-Drugs $(1 S, 10 R)$-34a mit dem Mitochondrienfarbstoff 41 wurde eine Lösung von 41 in DMSO (1-1.25 $\mu$, Konzentration der Stammlösung: $10 \mu \mathrm{M})$ mit dem Bildgebungspuffer in den Kammern vermischt $\left(c_{\text {final }}=20-25 \mathrm{nM}\right)$ und die Zellen vor der Beobachtung bei Raumtemperatur $30 \mathrm{~min}-1.5 \mathrm{~h}$ inkubiert.

\subsection{Fluoreszenzmikroskopische Untersuchung der zeitlichen Änderung der Intensität der Hoechst 33342 (40)-Fluoreszenz während und nach Inkubation von Zellen mit anti-Methyl-seco-CBI-DMAI-Derivaten}

\subsubsection{AAV 11.3.1. Allgemeine Arbeitsvorschrift zur zeitlichen Änderung der Hoechst 33342 (40)-Fluoreszenzintensität nach Inkubation der Zellen mit anti-Methyl-seco-CBI-DMAI-Derivaten}

Zellen der Linie A549 wurden nach AAV 11.2.1 für die Untersuchung vorbereitet. Die Zellen wurden mit serumfreiem UltraCulture ${ }^{\circledR}$ Medium $(2 \times 1 \mathrm{~mL})$ gewaschen und mit einer Lösung der zu untersuchenden Substanz in DMSO und UltraCulture ${ }^{\circledR}$ Medium (500 $\mu \mathrm{L}, 1 \%$ DMSO) oder mit einer Lösung aus DMSO in UltraCulture ${ }^{\circledR}$ Medium $(500 \mu \mathrm{L}, 1 \% \mathrm{DMSO})$ versetzt. Die Konzentration der Verbindungen $(1 S, 10 R)-\mathbf{7 5}$, $(1 S, 10 R)-76$ oder $(1 S, 10 R)$-34a in der Inkubationslösung betrug $2 \mu \mathrm{M}$. Nach einer 
Inkubationszeit von $2.5 \mathrm{~h}$ bei $37^{\circ} \mathrm{C}$ und $7.5 \% \mathrm{CO}_{2}$ wurden die Zellen mit Bildgebungspuffer $(2 \times 1 \mathrm{~mL})$ gewaschen und mit Bildgebungspuffer $(500 \mu \mathrm{L})$ versetzt. Kurz vor dem Beginn der Messung wurde eine Lösung des Farbstoffs Hoechst 33342 (40) im Bildgebungspuffer (500 $\mu \mathrm{L}$, Konzentration der Lösung: $18 \mu \mathrm{M})$ mit dem Bildgebungspuffer in den Kammern vermischt $\left(c_{\text {final }}=9 \mu \mathrm{M}\right)$ und unmittelbar nach Festlegung der Beobachtungspositionen die zeitliche Änderung der Intensität der Hoechstfluoreszenz mittels eines Fluoreszenzmikroskopes untersucht. Die Messung erfolgte parallel für alle Ansätze und für einen Beobachtungszeitraum von bis zu 193 Minuten.

Parameter: Aufnahmefrequenz pro Ansatz: $1 \mathrm{~min}^{-1}$, Belichtungszeit: $30 \mathrm{~ms}$, Bildtyp: 16 bit, Objektiv: 10x, Filter-Set: DAPI.

\subsubsection{AAV 11.3.2. Allgemeine Arbeitsvorschrift zur zeitlichen Änderung der Hoechst 33341 (40)-Fluoreszenzintensität während Inkubation der Zellen mit anti-Methyl-seco-CBI-DMAI-Derivaten}

Zellen der Linie A549 wurden nach AAV 11.2.1 für die Untersuchung vorbereitet. Die Zellen wurden mit serumfreiem UltraCulture ${ }^{\circledR}$ Medium $(2 \times 1 \mathrm{~mL})$ sowie mit dem Bildgebungspuffer $(2 \times 1 \mathrm{~mL})$ gewaschen und mit einer Lösung des Kernfarbstoffs Hoechst 33342 (40) im Bildgebungspuffer $(500 \mu \mathrm{L}, c=9 \mu \mathrm{M})$ versetzt. Nach einer Inkubationszeit von $1.0 \mathrm{~h}$ bei $37^{\circ} \mathrm{C}$ und $7.5 \% \mathrm{CO}_{2}$ wurde die Hoechst-Lösung entfernt und die Zellen mit einer Lösung der zu untersuchenden Substanz in DMSO und im Bildgebungspuffer ( $500 \mu \mathrm{L}, 1 \%$ DMSO) oder mit einer Lösung aus DMSO im Bildgebungspuffer ( $500 \mu \mathrm{L}, 1 \% \mathrm{DMSO})$ versetzt. Die Konzentration der Verbindungen $(1 S, 10 R)-75,(1 S, 10 R)-76$ oder $(1 S, 10 R)-34 a$ in der Inkubationslösung betrug $2 \mu \mathrm{M}$. Unmittelbar nach Festlegung der Beobachtungspositionen wurde die zeitliche Änderung der Intensität der Hoechstfluoreszenz mittels eines Fluoreszenzmikroskopes untersucht. Die Messung erfolgte parallel für alle Ansätze und für einen Beobachtungszeitraum von $2 \mathrm{~h}$.

Parameter: Aufnahmefrequenz pro Ansatz: $1 \mathrm{~min}^{-1}$, Belichtungszeit: $30 \mathrm{~ms}$, Bildtyp: 16 bit, Objektiv: 10x, Filter-Set: DAPI. 


\subsubsection{AAV 11.3.3. Allgemeine Arbeitsvorschrift zur Auswertung der nach AAV 11.3.1 und AAV 11.3.2 gewonnenen Daten}

Die nach AAV 11.3.1 und AAV 11.3.2 aufgezeichneten Bilder wurden mit dem Programm Image J geöffnet und jedes Bild mittels eines Mittelwertfilters (Median Filter, Radius: 1 Pixel) bearbeitet. Anschließend wurden Verschiebungen der Aufnahmeposition innerhalb einer Bildserie durch eine Ausrichtung mittels des Plugins Stagrag ausgeglichen. Nachdem für alle Bilder aller zu vergleichenden Bilderserien derselbe minimale Intensitätswert festgelegt wurde, wurden die Aufnahmen in Binärdateien umgewandelt. Nach einer Festlegung der Zellgrenzen mittels einer automatischen Partikelanalyse wurde die zeitabhängige Intensitätszunahme innerhalb aller erkannten Zellkerne einzeln erfasst. Die zeitabhängige Intensitätszunahme wurde mittels des Programmes IgorPro 4.05A Carbon für alle Kerne einer Serie aufgetragen und Ausreisser, die von Beginn an eine sehr hohe Fluoreszenzintensität zeigten oder deren Intensität sprunghaft anstieg oder abfiel, wurden von der anschließenden Berechnung des Mittelwertes sowie des Standardfehlers des Mittelwertes ausgeschlossen. 


\section{Ergänzende Untersuchungen}

\subsection{Untersuchung der Löslichkeit verschiedener Duocarmycin-Analoga in Applikationsmedien}

Verwendete Symbole und ihre Bedeutung:

+ : gut löslich

o : mäßig löslich

- : nicht löslich

12.1.1 Löslichkeit der anti-Methyl-seco-CBI-DMAI-Analoga (1S,10R)-33a und $(1 S, 10 R)-34 a$ in isotoner Kochsalzlösung

$(1 S, 10 R)-33 a(7.0 \mathrm{mg}, 11 \mu \mathrm{mol})$ wurde in DMSO $(7 \mu \mathrm{L})$ und $(1 S, 10 R)-34 a(5.0 \mathrm{mg}$, $11 \mu \mathrm{mol})$ wurde in DMSO $(5 \mu \mathrm{L})$ gelöst. $1 \mu \mathrm{L}$ der jeweiligen Stammlösung wurde mit verschiedenen Mengen DMSO verdünnt. Je $1 \mu \mathrm{L}$ der resultierenden Lösungen wurde mit $99 \mu \mathrm{L}$ isotoner Kochsalzlösung (154 $\mathrm{mM} \mathrm{NaCl}$ in Wasser) versetzt, mit einem Vortexgerät durchmischt und die Löslichkeit ermittelt.

Galactosid $(1 S, 10 R)-33 \mathbf{a}:$

\begin{tabular}{l|cccccccccc} 
Konzentration $[\mathrm{mM}]$ & 15.6 & 7.8 & 3.9 & 1.9 & 1.4 & 1.2 & 1.1 & $\mathbf{1 . 0}$ & 0.9 & 0.5 \\
\hline $\mathrm{NaCl}(0.9 \%)$ & - & - & - & - & - & - & 0 & + & + & +
\end{tabular}

$\underline{\operatorname{seco}-\operatorname{Drug}(1 S, 10 R)-\mathbf{3 4 a}:}$

\begin{tabular}{l|cccccccc} 
Konzentration $[\mathrm{mm}]$ & 19.0 & 9.5 & 5.8 & 2.9 & 1.9 & 1.5 & 1.0 & 0.6 \\
\hline $\mathrm{NaCl}(0.9 \%)$ & + & + & + & + & + & + & + & +
\end{tabular}

12.1.2 Löslichkeit der anti-Methyl-seco-CBI-DMAI-Analoga (1S,10R)-35 und $(1 S, 10 R)-34$ a sowie des seco-CBI-DMAI-Analogons (1S)-56a in isotoner Kochsalzlösung, PBS und Zellkulturmedium

(1S,10R)-35 (384 $\mu \mathrm{g}, 600 \mathrm{nmol}),(1 S, 10 R)-34 \mathrm{a}(309 \mu \mathrm{g}, 600 \mathrm{nmol})$ und (1S)-56a $(300 \mu \mathrm{g}, 600 \mathrm{nmol})$ wurden jeweils in DMSO $(6 \mu \mathrm{L})$ gelöst und aus den Stamm- 
lösungen durch Zugabe von DMSO weitere Stammlösungen hergestellt. Je $1 \mu \mathrm{L}$ der resultierenden Lösungen wurde mit $99 \mu \mathrm{L}$ isotoner Kochsalzlösung (154 mM NaCl in Wasser), UltraCulture ${ }^{\circledR}$ Zellmedium (UC) oder PBS (pH 7.4) versetzt, der Ansatz mit einem Vortexgerät durchmischt und die Löslichkeit ermittelt.

Mannosid $(1 S, 10 R)-\mathbf{3 5}$ :

\begin{tabular}{l|cccccccccc} 
Konzentration $[\mathrm{mM}]$ & 1.0 & 0.75 & 0.50 & 0.40 & 0.30 & 0.20 & 0.15 & $\mathbf{0 . 1 0}$ & 0.05 & 0.01 \\
\hline $\mathrm{NaCl}(0.9 \%)$ & - & - & - & - & - & 0 & 0 & + & + & + \\
$\mathrm{UC}$ & - & - & & - & - & 0 & 0 & + & + & + \\
$\mathrm{PBS}$ & - & & & - & - & & 0 & + & & +
\end{tabular}

seco-Drug $(1 S, 10 R)-34 \mathbf{a}$ :

\begin{tabular}{|c|c|c|c|c|c|c|c|c|c|c|}
\hline Konzentration [mM] & 1.0 & 0.75 & 0.50 & 0.40 & 0.30 & 0.20 & 0.15 & 0.10 & 0.05 & 0.01 \\
\hline $\mathrm{NaCl}(0.9 \%)$ & + & + & + & + & + & + & + & + & + & + \\
\hline $\mathrm{UC}$ & - & - & & o & & + & & + & & + \\
\hline PBS & & & & o & & & & + & & + \\
\hline
\end{tabular}

seco-Drug (1S)-56a:

\begin{tabular}{l|cccccccccc} 
Konzentration $[\mathrm{mM}]$ & 1.0 & 0.75 & 0.50 & 0.40 & 0.30 & 0.20 & 0.15 & $\mathbf{0 . 1 0}$ & 0.05 & 0.01 \\
\hline $\mathrm{NaCl}(0.9 \%)$ & + & + & + & + & + & + & + & + & + & + \\
$\mathrm{UC}$ & - & - & & - & & 0 & & + & & + \\
$\mathrm{PBS}$ & & & & & & & & & & \\
\end{tabular}

\subsection{Kinetik der Zyklisierung des seco-Drugs $(+)-(1 S, 10 R)-34 a$ in Wasser (pH 7)}

$(1 S, 10 R)-34 a(1.0 \mathrm{mg}, 1.9 \mu \mathrm{mol})$ wurde in DMSO $(40 \mu \mathrm{L})$ gelöst. 1 Aliquot dieser Stammlösung (10 $\mu \mathrm{L}, 0.48 \mathrm{nmol})$ wurde in Wasser $(\mathrm{pH} 7)$ gelöst, die Reaktionsmischung mit dem Vortexgerät durchmischt und für $24 \mathrm{~h}$ bei $37^{\circ} \mathrm{C}$ inkubiert. Zu den Zeitpunkten $t=0 \mathrm{~h}, 0.5 \mathrm{~h}, 1 \mathrm{~h}, 1.5 \mathrm{~h}, 2 \mathrm{~h}, 3 \mathrm{~h}, 4 \mathrm{~h}, 5 \mathrm{~h}, 6 \mathrm{~h}$ und $24 \mathrm{~h}$ wurde ein Aliquot der Lösung $(90 \mu \mathrm{L})$ entnommen und mittels HPLC-MS analysiert. 
Angegeben/Aufgetragen ist der prozentuale Anteil des Ionenstromintegrals jeder Spezies (AUC [\%]) in Abhängigkeit von der Inkubationszeit.

\begin{tabular}{cccc}
\hline $\boldsymbol{t}[\mathbf{h}]$ & $\begin{array}{c}\text { seco-Drug (1S,10R)-34a } \\
\text { AUC [\%] }\end{array}$ & $\begin{array}{c}\text { Drug 43a } \\
\text { AUC [\%] }\end{array}$ & $\begin{array}{c}\text { hydrolysiertes Drug 84a } \\
\text { AUC [\%] }\end{array}$ \\
\hline 0.0 & 82.9 & 5.3 & 11.9 \\
0.5 & 45.5 & 25.7 & 28.8 \\
1.0 & 23.3 & 20.8 & 55.9 \\
1.5 & 12.2 & 12.4 & 75.4 \\
2.0 & 7.8 & 5.8 & 86.4 \\
3.0 & 3.1 & 1.5 & 95.4 \\
4.0 & 1.1 & 0.8 & 98.1 \\
5.0 & 0.6 & 0.4 & 99.0 \\
6.0 & 0.0 & 0.0 & 100.0 \\
24.0 & 0.0 & 0.0 & 100.0 \\
\hline
\end{tabular}

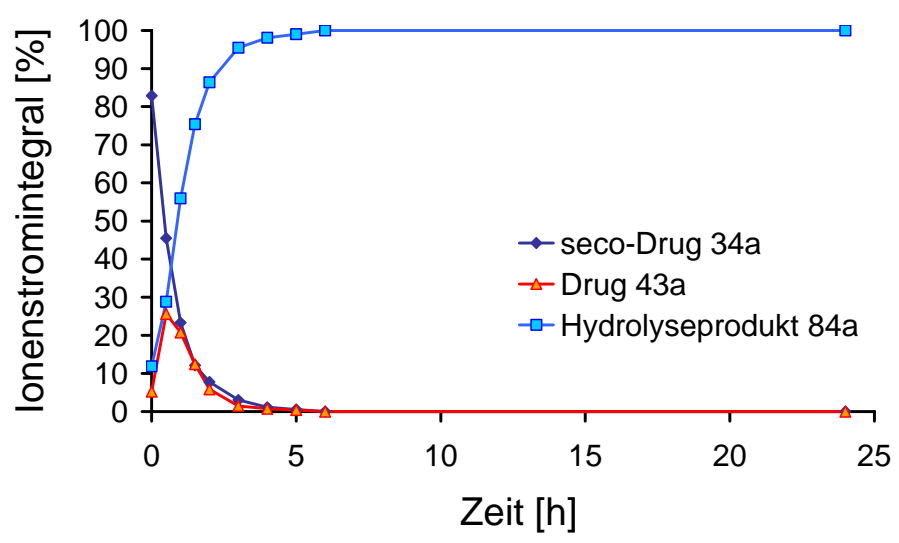

\subsection{Untersuchung der enzymatischen Spaltung fluoreszenzmarkierter Prodrugs mittels HPLC-MS}

\subsubsection{Untersuchung der enzymatischen Spaltung des Galactosids (1S,10R)-74}

Je 1 Aliquot der Stammlösung des Galactosids $(1 S, 10 R)-74(1 \mu \mathrm{L}, 10 \mathrm{nmol})$ in DMSO $(c=10 \mu \mathrm{M})$ wurde mit einer Lösung des Enzyms $\beta$-D-Galactosidase $(0 \mathrm{U}, 0.15 \mathrm{U}$, 
$0.71 \mathrm{U}, 3.6 \mathrm{U}, 7.1 \mathrm{U}, 14.3 \mathrm{U}, 47.3 \mathrm{U}, 60.0 \mathrm{U}, 120.0 \mathrm{U})$ in UltraCulture $^{\circledR}$ Medium $(100 \mu \mathrm{L})$ versetzt und die Lösung mit einem Vortexgerät durchmischt. Zur HPLC-MSMessung wurden umgehend $50 \mu \mathrm{L}$ der Reaktionslösung entnommen, das Enzym durch Ultrafiltrationszentrifugation ( 5 min bei $3000 \times \mathrm{g})$ abgetrennt und mit $\mathrm{MeOH}(50 \mu \mathrm{L})$ nachgespült sowie zentrifugiert $(10 \mathrm{~min}$ bei $3000 \times \mathrm{g})$. Die vom Enzym abgetrennte Reaktionslösung wurde mittels HPLC-MS untersucht. Die verbliebene Reaktionslösung wurde $24 \mathrm{~h}$ bei $37^{\circ} \mathrm{C}$ inkubiert, das Enzym durch Ultrafiltrationszentrifugation $(5 \mathrm{~min}$ bei $3000 \times \mathrm{g})$ abgetrennt, mit $\mathrm{MeOH}(50 \mu \mathrm{L})$ nachgespült sowie zentrifugiert $(10 \mathrm{~min}$ bei $3000 \times \mathrm{g})$ und die Lösung mittels HPLC-MS untersucht.

Zur Auswertung wurden für die zwei untersuchten Zeiten die Ionenströme des Substrates sowie der bei der Reaktion gebildeten Intermediate und Produkte in Abhängigkeit von der Elutionszeit aufgetragen und die jeweiligen Kurven integriert. Erst bei hohen Enzymkonzentrationen $(>40 \mathrm{U} / 100 \mu \mathrm{L})$ konnte eine signifikante Spaltung des Prodrugs zum seco-Drug festgestellt werden, die jedoch bei den untersuchten Enzymkonzentrationen nie vollständig war.

Aufgetragen ist das prozentuale Verhältnis aus dem Ionenstromintegral (AUC) des Prodrugs nach $24 \mathrm{~h}$ und $0 \mathrm{~h}$ Inkubation in Abhängigkeit von der Enzymmenge.

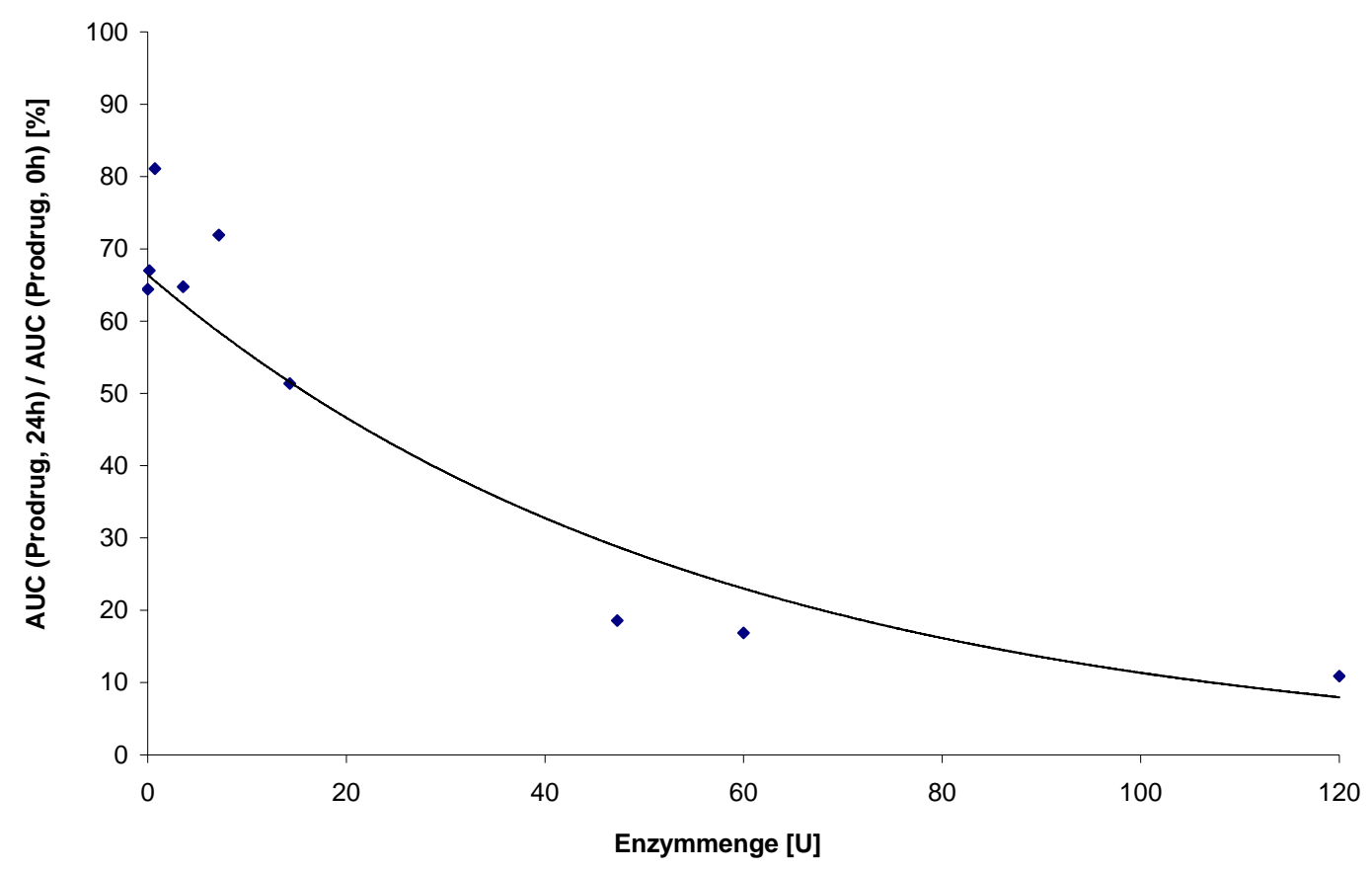




\subsubsection{Untersuchung der enzymatischen Spaltung des Galactosids (1S,10R)-75}

1 Aliquot der Stammlösung des Galactosids $(1 S, 10 R)-75(1 \mu \mathrm{L}, 10 \mathrm{nmol})$ in DMSO wurde mit einer Lösung des Enzyms $\beta$-D-Galactosidase (150 U) und $\mathrm{MgCl}_{2}(40 \mu \mathrm{g})$ in PBS $(100 \mu \mathrm{L})$ versetzt und die Lösung mit einem Vortexgerät durchmischt. Zur HPLC-MS-Messung wurden umgehend $50 \mu \mathrm{L}$ der Reaktionslösung entnommen, das Enzym durch Ultrafiltrationszentrifugation $(5 \mathrm{~min}$ bei $3000 \times \mathrm{g}$ ) abgetrennt und mit $\mathrm{MeOH}(50 \mu \mathrm{L})$ nachgespült sowie zentrifugiert $(10 \mathrm{~min}$ bei $3000 \times \mathrm{g})$. Die vom Enzym abgetrennte Reaktionslösung wurde mittels HPLC-MS untersucht. Die verbliebene Reaktionslösung $(50 \mu \mathrm{L})$ wurde $24 \mathrm{~h}$ bei $37^{\circ} \mathrm{C}$ inkubiert, das Enzym durch Ultrafiltrationszentrifugation $(5 \mathrm{~min}$ bei $3000 \times \mathrm{g}$ ) abgetrennt, mit $\mathrm{MeOH}$ $(50 \mu \mathrm{L})$ nachgespült sowie zentrifugiert $(10 \mathrm{~min}$ bei $3000 \times \mathrm{g})$ und die Lösung mittels HPLC-MS untersucht.

Es konnte keine Spaltung des Prodrugs $(1 S, 10 R)$-75 zum seco-Drug $(1 S, 10 R)$-76 beobachtet werden.

\subsection{Bestimmung der Schmelztemperatur doppelsträngiger DNA nach Inkubation mit (1S,10R)-34a}

1 Aliquot der Stammlösung des seco-Drugs $(1 S, 10 R)$-34a in DMSO (n $\mu \mathrm{L}$, $(5 \times \mathrm{n}) \mathrm{nmol}, \mathrm{n}$ Äq.) wurde in eine Mischung der wässrigen Lösung des Oligonukleotides ds-60 (50 $\mu \mathrm{L}, 5 \mathrm{nmol}, 1$ Äq.) pipettiert, die Reaktionsmischung gut durchmischt und $24 \mathrm{~h}$ bei $25^{\circ} \mathrm{C}$ inkubiert. Die Lösung wurde mit Phosphatpuffer (pH 7, $0.75 \mathrm{~mL}$ ) verdünnt, in eine Quarzküvette überführt und die temperaturabhängige UV-Absoprtion aufgezeichnet.

$\mathrm{Zu}$ Vergleichszwecken wurde die Schmelzkurve des DNA-Oligonukleotides (50 $\mu \mathrm{L}$, $5 \mathrm{nmol}$ ) in Phosphatpuffer ( $\mathrm{pH} 7,0.75 \mathrm{~mL}$ ) gemessen.

$$
\begin{array}{ll}
\mathrm{T}_{\mathrm{m}}(\mathrm{ds}-60): & (56 \pm 1)^{\circ} \mathrm{C} \\
\mathrm{T}_{\mathrm{m}}(\mathrm{ds}-\mathbf{6 0}+(1 S, 10 R)-\mathbf{3 4 a}=1: 1): & (59 \pm 1)^{\circ} \mathrm{C} \\
\mathrm{T}_{\mathrm{m}}(\text { ds-60 }+(1 S, 10 R)-\mathbf{3 4 a}=1: 2): & (47 \pm 1)^{\circ} \mathrm{C},(61 \pm 1){ }^{\circ} \mathrm{C}(2 \text { kooperative Übergänge }) \\
\mathrm{T}_{\mathrm{m}}(\text { ds-60 }+(1 S, 10 R)-\mathbf{3 4 a}=1: 5): & (47 \pm 1)^{\circ} \mathrm{C},(60 \pm 1){ }^{\circ} \mathrm{C}(2 \text { kooperative Übergänge })
\end{array}
$$




\section{ANHANG}

\section{Abkürzungen und Akronyme}

A

Ac

ADEPT

$\ddot{A q q}$.

AIBN

APT

ber.

$\mathrm{Bn}$

Boc

$\mathrm{Bu}$

C

CBI

CBQ

CCBI

CD

CI

CID

COSY

CPI

CPyI

CSD

CTL

DA

DSA

DAI

DC

$\triangle I C D$

DMAI

DMEM
Adenin

Acetyl

Antibody-Directed Enzyme Prodrug Therapy

Äquivalente

$\alpha, \alpha^{\prime}$-Aza-bis-isobutyronitril

Attached Proton Test

berechnet

Benzyl

tert-Butyloxycarbonyl

Butyl

Cytosin

Cyclopropabenzoindol

Cyclopropabenzochinolin

7-Cyano-CBI

Circular-Dichroismus

Cyclopropaindol

Collison Induced Dissociation, kollisionsbedingte Dissoziation

Correlated Spectroscopy

Cyclopropapyrroloindol

7-Methoxycarbonyl-cyclopropapyridoindol

Capillary-Skimmer-Dissoziation

Zytotoxische Lymphozyten

Duocarmycin A

Duocarmycin Stable A

5-(2-N,N-Dimethylamino-acetylamino)- $1 H$-indol

Dünnschichtchromatographie

Differenz zweier CD-Werte als Maß der Intensität des ICD (hier: $\triangle I C D=\theta(\lambda=335 \mathrm{~nm})-\theta(\lambda=305 \mathrm{~nm})$ )

5-[2-(N,N-Dimethylamino)-ethoxy]-1H-indol

Dulbeccos Modified Eagles Medium 


\begin{tabular}{|c|c|}
\hline $\mathrm{DMF}$ & Dimethylformamid \\
\hline DMMI & 5-(2-N,N-Dimethylaminoethoxy)-6-methoxy-1H-indol \\
\hline DMSO & Dimethylsulfoxid \\
\hline DNA & Desoxyribonukleinsäure \\
\hline ds-59 & doppelsträngiges RNA-Oligonukleotid der Nummer 59 \\
\hline ds-60 - ds-69 & doppelsträngige DNA-Oligonukleotide der Nummern 60 - 69 \\
\hline $\mathrm{EDC} \cdot \mathrm{HCl}$ & $\begin{array}{l}N \text {-(3-Dimethylaminopropyl)- } N \text { '-ethylcarbodiimid-Hydro- } \\
\text { chlorid }\end{array}$ \\
\hline EDTA & Ethylendiamintetraessigsäure \\
\hline$e e$ & Enantiomerenüberschuß \\
\hline $\mathrm{EE}$ & Essigsäureethylester \\
\hline en & Ethylendiamin \\
\hline ESI & Elektronen-Spray-Ionisation \\
\hline Et & Ethyl \\
\hline $\mathrm{EtOH}$ & Ethanol \\
\hline FITC & Fluorescein-Isothiocyanat \\
\hline FKS & Fötales Kälberserum \\
\hline $\mathrm{G}$ & Guanin \\
\hline Gal & Galactose \\
\hline GDEPT & Gene-Directed Enzyme Prodrug Therapy \\
\hline gef. & gefunden \\
\hline ges. & gesättigt \\
\hline GFP & Grün-fluoreszierendes Protein \\
\hline HPLC & High Performance (Pressure) Liquid Chromatography \\
\hline HRMS & High Resolution Mass Spectrometry \\
\hline HTCFA & Human Tumor Colony Forming Ability \\
\hline $\mathrm{Hz}$ & Hertz \\
\hline$i$ & ipso \\
\hline$i-\operatorname{Pr}$ & Isopropyl \\
\hline$I C_{50}$ & $\begin{array}{l}\text { Inhibitory Concentration; Toxinkonzentration, bei der das } \\
\text { Zellwachstum um } 50 \% \text { unterbunden wird }\end{array}$ \\
\hline $\mathrm{ICD}$ & Induzierter Circular-Dichroismus \\
\hline $\operatorname{Ind}_{2}$ & Bisindol- \\
\hline$i . v$. & intravenös \\
\hline
\end{tabular}


in vitro

in vivo

IR

$m$

kat.

konz.

MAR

MCBI

MCCPI

$\mathrm{Me}$

MEI

$\mathrm{MeOH}$

MMI

MPI

Ms

MS

MTT

MW

NHS

NMR

$o$

ON-1 (bzw. ON-2)

$p$

PAGE

PBS

PCR

PDE

PE

pEGFP-Endo

$\mathrm{Ph}$

$Q I C_{50}$ außerhalb lebender Organismen; hier: Versuche an lebenden Zellen in Zellkultur

im lebenden Organismus

Infrarot-Spektroskopie

meta

katalytische Mengen

konzentriert

matrix attachment regions, Matrix-Anknüpfugsstellen

7-Methoxy-CBI

Methoxycarbonyl-CPI

Methyl

5-(2-Morpholin-4-yl-ethoxy)-1H-indol

Methanol

5-Methoxy-1 $H$-indol

5-(1-Methylpiperidin-4-yl-methoxy)- $1 H$-indol

Molsieb

Massenspektrometrie

3-(4,5-Dimethylthiazol-2-yl)-2,5-diphenyltetrazoliumbromid

Mikrowellenreaktor

$N$-Hydroxysuccinimid

Nuclear Magnetic Resonance

ortho

Oligonukleotid 1 (bzw. Oligonukleotid 2)

para

Polyacrylamid-Gelelektrophorese

Phosphate Buffered Saline, phosphatgepufferte NaCl-Lösung

Polymerase-Kettenreaktion

Pyrrolodihydroindol

Petrolether des Siedebereiches $40-80{ }^{\circ} \mathrm{C}$

Plasmidischer Vektor eines Fusionsproteins zur Fluoreszenzmarkierung früher Endosomen und prälysosomaler Kompartimente

Phenyl

$I C_{50}$ (Prodrug) $/ I C_{50}$ (Prodrug in Anwesenheit des aktivierenden Enzyms) 


$\begin{array}{ll}\mathrm{R}_{f} & \text { Retentionswert für DC } \\ t_{\mathrm{R}} & \text { Retentionszeit für HPLC } \\ \text { RNA } & \text { Ribonukleinsäure } \\ \text { RT } & \text { Raumtemperatur } \\ \text { SVDP } & \text { Schlangengift-Phosphodiesterase I } \\ \text { T } & \text { Thymin } \\ \text { TBAI } & \text { Tetrabutylammoniumiodid } \\ \text { tert } & \text { tertiär } \\ \text { TFA } & \text { Trifluoressigsäure } \\ \text { THF } & \text { Tetrahydrofuran } \\ \text { TMAI } & 5 \text {-[2-(N,N,N-Trimethylammonium)-ethoxy]-1H-indol } \\ T_{\mathrm{m}} & \text { Schmelztemperatur doppelsträngiger DNA } \\ \text { TMI } & 5,6,7-T r i m e t h o x y-1 H \text {-indol } \\ \text { TMS } & \text { Trimethylsilyl } \\ \text { TTMSS } & \text { Tris(trimethylsilyl)silan } \\ \mathrm{u} & \text { Atomare Masseneinheit, 1 u = 1,660 538 782 (83) } 10^{-27} \mathrm{~kg} \\ U_{\mathrm{C}} & \text { Kapillarausgangsspannung, CapExit Voltage, auch: Capillary- } \\ \text { UV } & \text { Skimmer-Spannung } \\ & \text { Ultraviolett-Spektroskopie }\end{array}$




\section{Literatur}

1 a) H. W. Doerr, Forschung Frankfurt 2004, 1, 54-58; b) F. Stern, Angew. Chem. 2004, 116, 4352-4359.

2 http://nobelprize.org/nobel_prizes/medicine/laureates/1908/ehrlich-bio.html.

3 a) F. Winau, O. Westphal, R. Winau, Microbes Infect. 2004, 6, 786-789; b) R. S. Schwartz, N. Engl. J. Med. 2004, 350, 1079-1080.

4 P. Ehrlich, Experimental researches on specific therapeutics, Hoeber-Verlag, New York, 1909.

5 C. Voegtlin, Physiol. Rev. 1925, 5, 63-94.

6 Informationen der WHO, 2008: a) http://www.who.int/mediacentre/factsheets/ fs297/en/; b) http://www.who.int/mediacentre/factsheets/fs310/en/.

7 Daten des statistischen Bundesamtes für 2007: http://www.destatis.de/jetspeed/ portal/cms/Sites/destatis/Internet/DE/Content/Statistiken/Gesundheit/Todesursac hen/Aktuell.psml.

a) F. Kratz, I. A. Müller, C. Ryppa, A. Warnecke, ChemMedChem 2008, 3, 20 53; b) W. A. Denny, Aust. J. Chem. 2004, 57, 821-828.

a) L. F. Tietze, Nachr. Chem. Tech. Lab. 1988, 36, 728-737; b) L. F. Tietze, Molecular Aspects of Chemotherapy, E. Borowskyyi, D. Shugar (Herausg.), Pergamon Press, New York, 1990; c) L. F. Tietze, M. Lieb, T. Herzig, F. Haunert, I. Schuberth, Bioorg. Med. Chem. 2001, 9, 1929-1939; d) L. F. Tietze, T. Herzig, A. Fecher, F. Haunert, I. Schuberth, ChemBioChem 2001, 2, 758-765; e) L. F. Tietze, T. Feuerstein, A. Fecher, F. Haunert, O. Panknin, U. Borchers, I. Schuberth, F. Alves, Angew. Chem. 2002, 114, 785-787; f) L. F. Tietze, T. Herzig, T. Feuerstein, I. Schuberth, Eur. J. Org. Chem. 2002, 1634-1645; g) L. F. Tietze, T. Feuerstein, Aust. J. Chem. 2003, 56, 841-854.

10 a) S. Grimm, Chem. Unserer Zeit 2003, 37, 172-178; b) A. Lawen, Bioassays 2003, 25, 888-896; c) A. Gewies, ApoReview 2003, 1-26.

C. Lengauer, K. W. Kinzler, B. Vogelstein, Nature 1998, 396, 643-649. H.-G. Neumann, Chemie in unserer Zeit 1991, 25, 102-107. D. M. Prescott, A. S. Flexer, Krebs, Spektrum der Wissenschaft Verlagsgesellschaft, Heidelberg, 1990. W. Burkart, Spektrum der Wissenschaft 1994, 12, 112-120. L. M. Coussens, Z. Werb, Nature 2002, 420, 860-867. 
16

17

G. Löffler, Basiswissen Biochemie mit Pathobiochemie, Springer Verlag, Berlin, 2000.

P. Tiollais, M. Buendia in Krebs - Forschung, Diagnostik, Therapie, Spektrum Akademischer Verlag, Heidelberg, 1992.

a) R. A. Weinberg in Spektrum der Wissenschaft Spezial: Krebsmedizin, Spektrum der Wissenschaft Verlagsgesellschaft, Heidelberg, 1996; b) W. W. Gibbs in Spektrum der Wissenschaft Spezial: Krebsmedizin II, Spektrum der Wissenschaft Verlagsgesellschaft, Heidelberg, 2003.

H. Varmus, R. A. Weinberg, Gene und Krebs - Biologische Wurzeln der Tumorentstehung, Spektrum Akademischer Verlag, Heidelberg, 1996.

a) R. A. Weinberg, Science 1985, 230, 770-776; b) L. Römer, C. Klein, A. Dehner, H. Kessler, J. Buchner, Angew. Chem. 2006, 118, 6590-6611.

K. E. Hellstrom, I. Hellstrom, Tumor Antigens. in J. R. Bertino, Enzyclopedia of Cancer, Vol. 1, Academic Press, San Diego, 1997.

L. J. van't Veer, R. Bernards, Nature 2008, 452, 564-570.

a) S. Kumar, M. Shelley, C. Harrison, B. Coles, T. J. Wilt, M. D. Mason, Cochrane database Syst. Rev. 2006, 4, CD006019; b) C.-H. Lai, H.-J- Huang, Curr. Opin. Obstetr. and Gynecol. 2006, 18, 29-34; c) S. B. Decruze, J. A. Green, Int. J. Gynecol. Canc. 2007, 17, 964-978; d) R. E. Greene, J. Pharmacy Practice 2008, 21, 36-45.

a) Spektrum der Wissenschaft Spezial 5: Krebsmedizin, Spektrum Akademischer Verlag, Heidelberg, 1996; b) E. Jäger, D. Jäger, A. Knuth, Int. J. Cancer 2003, 106, 817-820; c) L. Gattinoni, D. J. Powell Jr.; S. A. Rosenberg, N. P. Restifo, Nat. Rev. Immunol. 2006, 6, 383-393.

a) C. Nieder, N. Wieden Andratschke, M. Molls, Cancer Treatment Rev. 2003, 32, 348-364; b) C. Verhoef, J. H. W. de Wilt, H. M. W. Verheul, Curr. Pharm. Des. 2006, 12, 2623-2630; c) F. Hillen, A. W. Griffioen, Cancer and Metastasis Rev. 2007, 26, 489-502.

a) S. P. Davies, H. Reddy, M. Caivano, P. Cohen, Biochem. J. 2000, 351, 95105; b) M. Deininger, E. Buchdunger, B. J. Druker, Blood 2005, 105, 26402653; c) V. Gandhi, J. M. Kilpatrick, W. Plunkett, M. Ayres, L. Harman, M. Du, S. Bantia, J. Davisson, W. G. Wierda, S. Faderl, H. Kantarjian, D. Thomas, Blood 2005, 106, 4253-4260. 
27

30

a) O. M. Friedman, A. M. Seligman, J. Am. Chem. Soc. 1954, 76, 655-658; b) H. Arnold, F. Bourseaux, Angew. Chem. 1958, 70, 539-544; c) H. Arnold, F. Bourseaux, N. Brock, Nature 1958, 181, 931.

a) A. I. Pinto, S. J. Lippard, Biochim. Biophys. Acta 1985, 780, 167-180; b) S. E. Sherman, S. J. Lippard, Chem. Rev. 1987, 87, 1153-1181; c) J. P. Caradonna, S. J. Lippard, Inorg. Chem. 1988, 27, 1454-1466.

C. Bystroff, S. J. Oatley, J. Kraut, Biochemistry 1990, 29, 3263-3277.

E. K. Rowinsky, R. C. Donehower, Pharmac. Ther. 1991, 52, 35-84.

a) J. Rohr, Angew. Chem. 1997, 109, 2284-2289; b) K. C. Nicolaou, R. K. Guy, P. Potier, Sci. Am. 1996, 272, 84-88; c) M. E. Wall, M. C. Wani, Cancer Res. 1995, 55, 753-760; d) K. C. Nicolaou, W.-M. Dai, R. K. Guy, Angew. Chem. Int. Ed. Engl. 1994, 33, 15-44; e) A. G. Chaudhary, M. M. Gharpure, J. M. Rimoldi, M. D. Chordia, A. A. L. Gunatilaka, D. G. I. Kingston, S. Grover, C. M. Lin, E. Hamel, J. Am. Chem. Soc. 1994, 116, 4097-4098; f) K. C. Nicolaou, W.-M. Dai, R. K. Guy, Angew. Chem. 1994, 106, 38-69; g) D. G. I. Kingston, Pharmac. Ther. 1991, 52, 1-34; h) S. B. Horwitz, I. Ringel, J. Nat. Cancer Inst. 1991, 83, 288-291; i) M. C. Wani, H. L. Taylor, M. E. Wall, P. Coggon, A. T. McPhail, J. Am. Chem. Soc. 1971, 93, 2325-2327.

R. C. Young, R. F. Ozols, C. E. Myers, New Eng. J. Med. 1981, 305, 139-153.

H. zur Hausen in Krebs - Forschung, Diagnostik, Therapie, Spektrum Akademischer Verlag, Heidelberg, 1992.

H. Plattner, J. Hentschel, Taschenlehrbuch Zellbiologie, Thieme Verlag, Stuttgart, 1997.

a) P. C. Cander, Nutr. Rev. 1998, 56, 70-83; b) T. Boon, P. G. Coulie, B. Van den Eynde, Immunology Today 1997, 18, 267-268.

J. S. Ross, K. Gray, D. Schenkein, B. Greene, Gary S. Gray, J. Shulok, P. J. Worland, A. Celniker, M. Rolfe, Expert Rev. Anticancer Ther. 2003, 3, 107-121.

G. Köhler, C. Milstein, Nature 1975, 256, 495-497.

H. Kirchner, A. Kruse, P. Neustock, L. Rink, Cytokine und Interferone, Spektrum Akademischer Verlag, Heidelberg, 1994.

D. Ockert, M. Schmitz, M. Hampl, E. P. Rieber, Immunology Today 1999, 20, 63-65.

R. T. Costello, L.-A. Gastaut, D. Olive, Immunology Today 1999, 20, 488-493. 
41 P. Sanderson, G. G. MacPherson, C. H. Jenkins, P. C. Calder, J. Leuk. Biol. 1997, 62, 771-777.

42 A. Kugler, G. Stuhler, Nature Medicine 2000, 6, 332-336.

a) G. A. Piertersz, A. Rowland, M. J. Smyth, I. F. C. McKenzie, Adv. Immunol. 1994, 56, 301-387; b) G. A. Piertersz, I. F. C. McKenzie, Immun. Rev. 1992, 129, 57-80; c) P. A. Trail, H. D. King, G. M. Dubowchik, Cancer Immunol. Immunother. 2003, 52, 328-337.

a) E. L. Sievers, F. R. Appelbaum, R. T. Spielberger, S. J. Forman, D. Flowers, F. O. Smith, K. Shannon-Dorcy, M. S. Berger, I. D. Bernstein, Blood 1999, 93, 3678-3684; b) P. R. Hamann, L. M. Hinman, I. Hollander, C. F. Beyer, D. Lindh, R. Holcomb, W. Hallett H. R. Tsou, J. Upeslacis, D. Shochat, A. Mountain, D. A. Flowers, I. Bernstein, Bioconjugate Chem. 2002, 13, 47-58.

a) L. N. Jungheim, T. A. Shepherd, Chem. Rev. 1994, 94, 1553-1566; b) K. D. Bagshawe, Mol. Med. Today 1995, 424-431; c) R. G. Melton, R. F. Sherwood, J. Natl. Cancer Inst. 1996, 88, 153-165; d) T. W. Doyle, Pharmacology \& Therapeutics 1999, 83, 67-123; e) P. D: Senter, C. J. Springer, Adv. Drug Delivery Rev. 2001, 53, 247-264.

T. L. Cheng, S. L. Wei, B. M. Chen, J. W. Chern, M. F. Wu, P. W. Liu, S. R. Roffler, Br. J. Cancer 1999, 79, 1378-1385.

a) J. C. Reubi, H. R. Mäcke, E. P. Krenning, J. Nucl. Med. 2005, 46, 67S-75S; b) M. Dyba, N. I. Tarasova, C. J. Michejda, Curr. Pharm. Des. 2004, 10, 23112334; c) J. C. Reubi, Endocrine Reviews 2003, 24, 389-427; d) J. C. Reubi, B. Waser, Eur. J. Nucl. Med. 2003, 30, 781-793; e) M. Langer, A. G. BeckSickinger, Curr. Med. Chem. 2001, 1, 71-93; f) W. A. P. Breeman, M. de Jong, D. J. Kwekkeboom, R. Valkema, W. H. Bakker, P. P. M. Kooij, T. J. Visser, E. P. Krenning, Eur. J. Nucl. Med. 2001, 28, 1421-1429; g) A. Heppeler, S. Froidevaux, A. N. Eberle, H. R. Maecke, Curr. Med. Chem. 2000, 7, 971-994; h) A. V. Schally, A. Nagy, Eur. J. Endocrin. 1999, 141, 1-14; h) G. S. Baldwin, A. Shulkes, Gut 1998, 42, 581-584.

O. Warburg, The Metabolism of Tumors, Constable, London, 1930.

a) R. K. Jain, Spektrum der Wissenschaft 1994, 9, 48-55; b) P. Vaupel, F. Kallinowski, P. Okunieff, Cancer Res. 1989, 49, 6449-6465.

M. von Ardenne, P. G. Reitnauer, Acta Biol. Med. Germ. 1970, 25, 483-493. 
a) S. P. Osinsky, L. N. Bubnovskaja, T. Sergienko, Anticancer Res. 1987, 7, 199-201; b) S. P. Osinsky, L. N. Bubnovskaja, Arch. Geschwulstforschung 1984, 54, 463-469; c) E. Jähde, M. F. Rajewsky, Cancer Res. 1982, 42, 1505-1512; d) M. von Ardenne, P. G. Reitnauer, Arch. Geschwulstforschung 1975, 45, 135145.

a) L. F. Tietze, T. Feuerstein, Curr. Pharm. Des. 2003, 9, 2155-2175, b) L. F. Tietze, M. Beller, R. Fischer, M. Lögers, E. Jähde, K. H. Glüsenkamp, M. F. Rajewsky, Angew. Chem. 1990, 102, 812-813; c) L. F. Tietze, R. Fischer, M. Beller, R. Seele, Liebigs Ann. Chem. 1990, 151-157; d) L. F. Tietze, R. Fischer, H. J. Guder, M. Neumann, Liebigs Ann. Chem. 1987, 847-856; e) L. F. Tietze, R. Fischer, H. J. Guder, A. Goerlach, M. Neumann, T. Krach, Carbohydr. Res. 1987, 164, 177-194 ; f) L. F. Tietze, R. Fischer, Angew. Chem. 1981, 93, 1002. K. D. Bagshawe, Br. J. Cancer 1987, 56, 531-532.

a) W. A. Denny, Cancer Investig. 2004, 22, 604-619; b) L. F. Tietze, T. Feuerstein, Curr. Pharm. Des. 2003, 9, 2155-2175; c) L. F. Tietze, T. Feuerstein, Aust. J. Chem. 2003, 56, 841-854; d) M. Jung, Mini-Rev. Med. Chem. 2001, 1, 399-407; e) G. Xu, H. L. McLeod, Clin. Cancer Res. 2001, 7, 3314-3324; f) K. N. Syrigos, A. A. Epenetos, Anticancer Res. 1999, 19, 605-613; g) G. M. Dubowchik, M. A. Walker, Pharmacol. Ther. 1999, 83, 67-123; h) C. J. Springer, I. Niculescu-Duvaz, Adv. Drug Deliv. Rev. 1997, 26, 151-172; i) L. N. Jungheim, T. A. Shepherd, Chem. Rev. 1994, 94, 1553-1566.

a) R. J. Francis, S. J. Mather, K. Chester, S. K. Sharma, J. Bhatia, R. B. Pedley, R. Waibel, A. J. Green, R. H. Begent, Eur. J. Nucl. Med. and Mol. Imaging 2004, 31, 1090-1096; b) K. Chester, B. Pedley, B. Tolner, J. Violet, A. Mayer, S. Sharma, G. Boxer, A. Green, S. Nagl, R. Begent, Tumor Biol. 2004, 25, 91-98.

a) C. J. Springer, P. Antoniw, K. D. Bagshawe, F. Searle, G. M. F. Bisset, M. Jarman, J. Med. Chem. 1990, 33, 677-681; b) K. D. Bagshaw et al., Cell Biophys. 1993, 22, 1-8; c) K. D. Bagshawe, Adv. Pharmacol. 1993, 24, 99-121; d) I. Niculescu-Duvaz, F. Friedlos, D. Niculescu-Duvaz, L. Davies, C. J. Springer, Anticancer Drug Des. 1999, 19, 517-538; e) L. A. Wolfe et al., Bioconj. Chem. 1999, 10, 38-48.

K. N. Syrigos, A. A. Epenetos, Anticancer Res. 1999, 19, 605.

a) E. Bakina, Z. Wu, M. Rosenblum, D. Farquhar, J. Med. Chem. 1997, 40, 4013-4018; b) P. H. J. Houba, E. Boven, I. H. Van der Meulen-Muileman, R. G. 
Leenders, J. W. Scheeren, H. M. Pinedo, H. J. Haisma, Int. J. Cancer 2001, 91, 550-554; c) A. El Alaoui, N. Saha, F. Schmidt, C. Monneret, J.-C. Florent, Bioorg. Med. Chem. 2006, 14, 5012-5019; d) Z. M. Prijovich, Y.-L. Leu, S. R. Roffler, Cancer Chemother. Pharmacol. 2007, 60, 7-17; e) L. F. Tietze, H. J. Schuster, K. Schmuck, I. Schuberth, F. Alves. Bioorg. Med. Chem. 2008, 16, 6312-6318.

a) H. B. Bosmann, T. C. Hall, Proc. Natl. Acad. Sci. U.S.A. 1974, 71, 18331837; b) M. Y. Torgov, S. C. Alley, C. G. Cerveny, D. Farquhar, P. D. Senter, Bioconjugate Chem. 2005, 16, 717-721; c) L. Fang et al., J. Med. Chem. 2006, 49, 6290-6297; d) H. Devalapally, R. S. Navath, V. Yenamandra, R. R. Akkinepally, R. K. Devarakonda, Ach. Pharm. Res. 2007, 6, 723-732. W. A. Denny, Eur. J. Med. Chem. 2001, 36, 577-595.

a) M. L. Rodrigues, P. Carter, C. Wirth, S. Mullins, A. Lee, B. K. Blackburn, Chem. Biol. 1995, 2, 223-227; b) U. M. Vrudhula, H. P. Svensson, K. A. Kennedy, P. M. Senter, P. M. Wallace, Bioconj. Chem. 1993, 4, 334-340.

a) K. Bosslet, R. Straub, M. Blumrich, J. Czech, M. Gerken, B. Sperker, H. K. Kroemer, J.-P. Gesson, M. Koch, C. Monneret, Cancer Res. 1998, 58, 11951201; b) R. V. J. Chari, Adv. Drug Delivery Rev. 1998, 31, 89-104; c) F. M. H. De Groot, E. W. P. Damen, H. W. Scheeren, Curr. Med. Chem, 2001, 8, 10931122.

a) A. Sinhababu, D. Thakker, Adv. Drug Deliv Rev. 1996, 19, 241-273; b) T. E. Mürdter, G. Friedel, J. T. Backmann, M. McClellan, M. Schick, M. Gerken, K. Bosslet, P. Fritz, H. Toomes, H. K. Kroemer, B. Sperker, J. Pharmacol. Exp. Ther. 2002, 301, 223-228.

a) M. Langer, F. Kratz, B. Rothen-Ruishauser, H. Wunderli-Allenspach, A. G. Beck-Sickinger, J. Med. Chem. 2001, 44, 1341-1348; b) L. F. Tietze, O. Panknin, F. Major, B. Krewer, Chem. Eur. J. 2008, 14, 2811-2818, c) L. F. Tietze, O. Panknin, B. Krewer, F. Major, I. Schuberth, Int. J. Mol. Sci. 2008, 9, 821-837.

K. D. Bagshawe, Br. J. Cancer 1989, 60, 275-281.

C. J. Springer, K. D. Bagshawe, S. K. Sharma et al., Eur. J. Cancer 1991, 27, 1361-1366.

K. D. Bagshawe, Expert. Rev. Anticancer Ther. 2006, 6, 1421-1431. 
a) S. K. Sharma, K. D. Bagshawe, C. J. Springer et. al. Dis. Markers 1991, 9, 225-231; b) S. K. Sharma, J. A. Boden, C. J. Springer, P. J. Burke, K. D. Bagshawe, Cell Biophys. 1994, 219-228; c) S. K. Sharma, K. D. Bagshawe, P. J. Burke, J. A. Boden, G. T. Rogers, C. J. Springer, R. G. Melton, R. F. Sherwood, Cancer Supplement 1994, 73, 1114-1120.

a) L. F. Tietze, F. Major, I. Schuberth, D. A. Spiegl, B. Krewer, K. Maksimenka, G. Bringmann, J. Magull, Chem. Eur. J. 2007, 13, 4396-4409; b) L. F. Tietze, F. Major, I. Schuberth, Angew. Chem. 2006, 118, 6724-6727; Angew. Chem., Int. Ed. 2006, 45, 6574-6577; c) L. F. Tietze, B. Krewer, H. Frauendorf, F. Major, I. Schuberth, Angew. Chem. 2006, 118, 6720-6724; Angew. Chem., Int. Ed. 2006, 45, 6570-6574; d) L. F. Tietze, F. Major, Eur. J. Org. Chem. 2006, 2314-2321. M. Zientkowska, Doktorarbeit, Göttingen, 2007.

a) K. D. Bagshawe, S. K. Sharma, C. J. Spriner, P. Antoniw. Tumor Targeting 1995, 1, 17-29; b) K. D. Bagshawe, R. H. J. Begent, Adv. Drug Deliv. Rev. 1996, $22,365-367$.

J. Martin et al., Cancer Chemother. Pharmacol. 1997, 40, 189-201.

a) C. J. Springer, R. Dowell, P. J. Burke, E. Hadley, D. H. Davis, D. C. Blakey, R. G. Melton, I. Niculescu-Duvaz, J. Med. Chem. 1995, 38, 5051-5065 ; b) D. C. Blakey et al., Cancer Res. 1996, 56, 3287-3292.

a) M. P. Napier et al., Clin. Cancer Res. 2000, 6, 765-772 ; b) R. J. Francis et al., Br. J. Cancer 2002, 87, 600-607.

S. K. Sharma et al., Clin. Cancer Res. 2005, 11, 814-528.

A. Mayer et al., Clin. Cancer Res. 2006, 12, 6509-6516.

a) L. J. Hanka, A. Dietz, S. A. Gerpheide, S. L. Kuentzel, D. G. Martin, J. Antibiot. 1978, 31, 1211-1217; b) D. G. Martin, C. Biles, S. A. Gerpheide, L. J. Hanka, W. C. Krueger, J. P. McGovren, S. A. Mizsak, G. L. Neil, J. C. Stewart, J. Visser, J. Antibiot. 1981, 34, 1119-1125.

J. P. McGroven, G. L. Clarke, E. A. Pratt, T. F. DeKoning, J. Antibiot. 1984, 37, 63-70.

M. Ichimura, T. Ogawa, K. Takahashi, E. Kobayashi, I. Kawamoto, T. Yasuzawa, I. Takahashi, H. Nakano, J. Antibiot. 1990, 43, 1037-1038.

a) Y. Igarashi, K. Futamata, T. Fujita, A. Sekine, H. Senda, H. Naoki, T. Furumai, J. Antibiot. 2003, 56, 107, b) J. P. Parrish, D. B. Kastrinsky, S. E. Wolkenberg, Y. Igarashi, D. L. Boger, J. Am. Chem. Soc 2003, 125, 10971-10976; c) M. 
S. Tichenor, D. B. Kastrinsky, D. L. Boger, J. Am. Chem. Soc. 2004, 126, 83968398.

a) L. H. Hurley, C.-S. Lee, J. P. McGovren, M. A. Warpehoski, M. A. Mitchell, R. C. Kelly, P. A. Aristoff, Biochemistry 1988, 27, 3886-3892; b) L. H. Hurley, M. A. Warpehoski, C.-S. Lee, J. P. McGovren, T. A. Scahill, R. C. Kelly, M. A. Mitchell, N. A. Wicnienski, I. Gebhard, P. D. Joohnson, V. S. Bradford, J. Am. Chem. Soc. 1990, 112, 4633-4649.

a) Y. Ambroise, D. L. Boger, Bioorg. Med. Chem. 2002, 12, 303-306; b) K. Spiegel, Doktorarbeit, Triest, 2004; c) K. Spiegel, U. Rothlisberger, P. Carloni, J. Phys. Chem. B 2006, 110, 3647-3660.

a) D. L. Boger, D. L. Hertzog, B. Bollinger, D. S. Johnson, H. Cai, J. Goldberg, P. Turnbull, J. Am. Chem. Soc. 1997, 119, 4977-4986; b) D. L. Boger, B. Bollinger, D. L. Hertzog, D. S. Johnson, H. Cai, P. Mésini, R. M. Garbaccio, Q. Jin, P. A. Kitos, J. Am. Chem. Soc. 1997, 119, 4987-4998; c) D. L. Boger, R. M. Garbaccio, Acc. Chem. Res. 1999, 32, 1043-1052.

a) K. N. Kirschner, M. Lee, R. C. Stanley, J. P. Bowen, Bioorg. Med. Chem. 2000, 8, 329-335; b) P. Cimino, G. Bifulco, R. Riccio, L. Gomez-Paloma, V. Barone, Org. Biomol. Chem. 2006, 4, 1242-1251.

A. V. Vargiu, P. Ruggerone, A. Magistrato, P. Carloni, Biophys. J. 2008, 94, $550-561$.

J. P. McGovren, G. L. Clarke, E. A. Pratt, T. F. DeKoning, J. Antibiot. 1984, 37, $63-70$.

a) J. P. McGovern, G. L. Clarke, E. A. Pratte, T. F. deKoning, J. Antibiot. 1983, 37, 63-70; b) S. Nagamura, A. Asai, E. Kobayashi, K. Gomi, H. Saito, Bioorg. Med. Chem. 1997, 5, 623-630; c) B. Cacciari, R. Romagnoli, P. G. Baraldi, T. Da Ros, G. Spalluto, Exp. Opin. Ther. Pat. 2000, 10, 1853-1871; d) A. Sato, L. McNulty, K. Cox, S. Kim, A. Scott, K. Daniell, K. Summerville, C. Price, S. Hudson, K. Kiakos, L. A. Hartley, T. Asao, M. Lee, J. Med. Chem. 2005, 48, 3903-3918; e) P. G. Baraldi, A. Bovero, F. Fruttarolo, D. Preti, M. A. Tabrizi, M. G. Pavani, R. Romagnoli, Med. Res. Rev. 2004, 24, 475-528; f) W. A. Denny, Curr. Med. Chem. 2001, 8, 533-544; g) B. S. P. Reddy, S. K. Sharma, J. P. W. Lown, Curr. Med. Chem. 2001, 8, 475-508. 
88

a) D. L. Boger, C. W. Boyce, R. M. Garbaccio, J. A. Goldberg, Chem. Rev. 1997, 97, 787-828; b) D. L. Boger, D. S. Johnson, Angew. Chem. 1996, 108, 15421580; c) S. E. Wolkenberg, D. L. Boger, Chem. Rev. 2002, 102, 2477-2496.

a) J. P. Parrish, T. V. Hughes, I. Hwang, D. L. Boger, J. Am. Chem. Soc. 2004, 126, 80-81; b) M. S. Tichenor, K. S. MacMillen, J. S. Stover, S. E. Wolkenberg, M. G. Pavani, L. Zanella, A. N. Zaid, G. Spalluto, T. J. Rayl, I. Hwang, P. G. Baraldi, D. L. Boger, J. Am Chem. Soc. 2007, 129, 14092-14099.

a) D. L. Boger, S. Johnson, Angew. Chem. 1996, 108, 1542-1580; Angew. Chem. Int. Ed. Engl. 1996, 35, 1438-1474; b) P. G. Baraldi et al., J. Med. Chem. 2001, 44, 2536-2543; c) J. P. Parrish, D. B. Kastrinsky, F. Stauffer, M. P. Hedrick, I. Hwang, D. L. Boger, Bioorg. Med. Chem. 2003, 11, 3815-3838; d) Y. Wang et al., J. Med. Chem. 2003, 46, 634-637.

a) D. L. Boger, T. Ishizaki, Tetrahedron Lett. 1990, 31, 793-796; b) D. B. Kastrinsky, D. L. Boger, J. Org. Chem. 2004, 69, 2284-2289.

a) R. I. Pinto, S. J. Lippard, Biochem. Biophys. Acta 1985, 780, 167-180, b) S. E. Sherman, S. J. Lippard, Chem. Rev. 1987, 87, 1153-1181; c) J. P. Caradonna, S. J. Lippard, Inorg. Chem. 1988, 27, 1454, -1466; d) D. L. Boger, D. S. Johnson, Angew. Chem. 1996, 108, 1542-1580.

a) J. P. Parrish, D. B. Kastrinsky, S. E. Wolkenberg, Y. Igarashi, D. L. Boger, J. Am. Chem. Soc. 2003, 125, 10971-10976; b) M. S. Tichenor, K. S. MacMillan, J. D. Trzupek, T. J. Rayl, I. Hwang, D. L. Boger, J. Am. Chem. Soc. 2007, 129, 10858-10869; c) M. S. Tichenor, J. D. Trzupek, D. B. Kastrinsky, F. Shiga, I. Hwang, D. L. Boger, J. Am. Chem. Soc. 2006, 128, 15683-15696.

a) R. D. Hightower, B. U. Sevin, J. P. Pevras, M. Untch, R. Angioli, H. Averette, Gynecol. Oncol. 1992, 42, 186-190; b) B. J. Foster, P. M. Larusso, E. Poplin, M. Zalupski, M. Valdivieso, A. Wozniak, L. Flaherty, D. A. Kasunic, R. H. Earhart, L. H. Baker, Invest. New Drugs 1996, 13, 321-326; c) H. A. Burris, V. C. Dleras, M. Tunca, R. H. Earhart, J. R. Echardt, G. I. Rodriguez, D. S. Shaffer, S. M. Fields, E. Campbell, L. Scaaf, D. Kasunic, D. D. Von Hoff, Anticancer Drugs 1997, 8, 588-596.

a) L. H. Li, T. F. deKoning, R. C. Kelly, W. C. Krueger, J. P. McGovren, G. E. Padbury, G. L. Petzold, T. L. Wallace, R. J. Ouding, M. D. Prairie, I. Gebhard, Canc. Res. 1992, 52, 4904-4913; b) I. Wolff, K. Bench, J. S. Beijnen, U. Bruntsch, F. Cavalli, J. de Jong, Y. Groot, O. van Tellingen, J. Wanders, C. 
Sessa, Clin. Canc. Res. 1996, 2, 1717-1723; c) O. van Telligen, C. J. A. Punt, A. Awada, D. J. T. Wagener, M. J. Piccart, Y. Groot, L. J. Scaaf, R. E. C. Henrar, W. J. Nooijen, J. H. Beijnen, Cancer Chemother. Pharmacol. 1998, 41, 377-384.

a) H. C. Pitot, C. Erlichman, J. M. Reid, J. A. Sloan, M. M. Ames, P. G. Bagniewski, P. Atherton-Skaff, A. A. Adjei, J. Rubin, D. Rayson, R. M. Goldberg, Proc. Am. Assoc. Cancer Res. 1999, 40, 91; b) H. C. Pitot, J. M. Reid, J. A. Sloan, M. M. Ames, A. A. Adjei, J. Rubin, P. G. Bagniewski, P. Atherton, D. Rayson, R. M. Goldberg, C. Ehrlichman, Clin. Cancer Res. 2002, 8, 712-717; c) G. H. Schwartz, A. Patnaik, L. A. Hammond, J. Rizzo, K. Berg, D. D. Von Hoff, E. K. Rowinsky, Ann. Oncol. 2003, 14, 775-782.

a) S. R. Alberts, C. Ehrlichman, J. M. Reid, J. A. Sloan, M. M. Ames, R. L. Richardson, R. M. Goldberg, Clin. Canc. Res. 1998, 4, 2111-2117, b) A. Asai, S. Nagamura, E. Kobayashi, K. Gomi, H. Saito, Bioorg. Med. Chem. Lett. 1999, 9, 2995-2998; c) J. Rubin, S. Alberts, V. Suman, H. Pitot, M. Greene, J. Camoriano, Proc. Am. Soc. Clin. Oncol. 2000, 19, abstr. 1198; d) S. N. Markovic, V. J. Suman, A. M. Vokov, T. R. Fitch, D. W. Hillman, A. A. Adjei, S. R. Alberts, J. S. Kaur, T. A. Braich, J. M. Leitch, E. T. Creagan, Am. J. Clin. Oncol. 2002, 25, 308-312.

S. Nagamura, H. Saito Chem. of Heterocyclic Compounds 1998, 34, 1386-1405.

a) S. Nagamura, E. Kobayashi, K. Gomi, H. Saito, Bioorg. Med. Chem. Lett. 1996, 6, 2147-2150; b) S. Nagamura, E. Kobayashi, K. Gomi, H. Saito, Bioorg. Med. Chem. 1996, 4, 1379-1391; c) A. Asai, S. Nagamura, S. Saito, J. Am. Chem. Soc. 1994, 116, 4171-4177.

100 E. Kobayashi, A. Okamoto, M. Asada, M. Okabe, S. Nagamura, A. Asai, S. Hiromitsu, K. Gomi, T. Hirata, Cancer Res. 1994, 54, 2404-2410.

101 C. S. Lee, N. W. Gibson, Canc. Res. 1991, 51, 6586-6591.

102 a) L. H. Hurley, V. S. Reynolds, D. H. Swenson, G. L. Petzold, T. A. Scahill, Sience 1984, 226, 843-844; b) L. H. Hurley, D. R. Needham-VanDevanter, Acc. Chem. Res. 1986, 19, 230-237; c) D. L. Boger, B. Bollinger, D. L. Hertzog, D. S. Johnson, H. Cai, P. Mésini, R. M. Garbaccio, Q. Jin, P. A. Kitos, J. Am. Chem. Soc. 1997, 119, 4987-4998.

103 W. T. Tse, D. L. Boger, Chem. \& Biol. 2004, 11, 1607-1617.

104 a) Z.-F. Tao, T. Fujiwara, I. Saito, H. Sugiyama, Angew. Chem. Int. Ed. 1999, 38, 650-653; a) K.-I. Shinohara, T. Bando, S. Sasaki, Y. Sakakibara, M. Minoshima, 
H. Sugiyama, CancerSci 2006, 97, 3, 219-225; b) K.-I. Shinohara, S. Sasaki, M. Minoshima, T. Bando, H. Sugiyama, Nucleic Acids Res. 2006, 34, 1189-1195.

A. J. Ruiz-Chica, M. A. Medina, F. Sánchez-Jiménez, F. J. Ramírez, J. Mol. Struct. 2005, 744-747, 619-698.

a) R. M. Brosh, J. K. Karow, E. J. White, N. D. Shaw, I. D. Hickson, V. A. Bohr, Nucleic Acids Res. 2000, 28, 2420-2430; b) M. Gniadowski, W. A. Denny, S. M. Nelson, M. Czyz, Curr. Med. Chem. 2003,10, 909-924.

S. Y. Chiang, J. Welch, F. J. Rauscher, T. A. Beerman, Biochemistry 1994, 33, 7033-7040.

108 a) J. M. Woynarowski, A. V. Trevino, K. A. Rodriguez, S. C. Hardies, C. J. Benham, J. Biol. Chem. 2001, 276, 44, 40555-40566; b) J. M. Woynarowski, Biochim. Biophys. Acta 2002, 1587, 300-308; c) J. M. Woynarowski, Curr. Cancer Drug Targets 2004, 4, 219-234.

J. M. Woynarowski, C. Napier, A. V. Trevino, B. Arnett, Biochemistry 2000, 39, 9917-9927.

110 S. M. Nelson, L. R. Ferguson, W. A. Denny, Chem. Res. Toxicol. 2005, 18, 239248.

111 a) P. H. Clinton, I. U. de Silva, P. J. McHugh, F. J. Ghadessy, M. J. Tilby, D. E. Thurston, J. A. Hartley, Nucleic Acids Res. 2005, 33, 3283-3291; b) O. D. Schärer, Angew. Chem. Int. Ed. 2003, 42, 2946-2974.

112 P.-R. C, M. M. McHugh, T. Melendy, T. Beerman, Mol. Cancer Ther. 2003, 2, 651-659.

113 a) S. M. Nelson, L. R. Ferguson, W. A. Denny, Cell \& Chromosome 2004, 3, 2;

b) L. C. J. Gillet, O. D. Schärer, Chem. Rev. 2006, 106, 253-276.

114 a) B. K. Bhuyan, K. A. Newell, S. L. Crampton, D. D. von Hoff, Canc. Res. 1982, 42, 3532-3537; b) L. H. Li, D. H. Swenson, S. L. F. Schpok, S. L. Kuentzel, B. D. Dayton, W. C. Krueger, Canc. Res. 1982, 42, 999-1004; c) E. A. Adams, G. J. Badiner, B. K. Bhuyan, Cancer Res. 1988, 48, 109-116.

115 B. K. Bhuyan, S. L. Crampton, E. G. Adams, Cancer Res. 1983, 43, 4227-4232.

116 a) W. C. Krueger, M. D. Prairie, Chem.-Biol. Interactions 1992, 82, 31-46; b) W. C. Krueger, N. T. Hatzenbuhler, M. D. Prairie, M. H. Shea, Chem.-Biol. Interactions 1991, 79, 265-286.

117 D. H. Swenson, G. L. Petzold, M. G. Williams, L. H. Li, M. D. Prairie, W. C. Krueger, Chem.-Biol. Interactions 1988, 67, 199-213. 
118 D. H. Swenson, G. L. Petzold, M. G. Williams, L. H. Li, M. D. Prairie, W. C. Krueger, Chem.-Biol. Interactions 1988, 67, 199-213.

119 W. C. Krueger, M. D. Prairie, Chem.-Biol. Interactions 1987, 62, 281-295.

120 W. C. Krueger, M. D. Prairie, Chem.-Biol. Interactions 1991, 79, 137-149.

121 A. Moscowitz, K. Mislow, J. Am Chem. Soc. 1962, 84, 4605.

122 a) N. C. Garbett, P. A. Ragazzon, J. B. Chaires, Nat. Protoc. 2007, 2, 3166-3172;

b) B. Nordén, T. Kurucsev, J. Mol. Recogn. 1994, 7, 141-156.

N. Y. Thériault, W. C. Krueger, M. D. Prairie, Chem.-Biol. Interactions 1988, 65, 187-201.

124 W. C. Krueger, D. J. Duchamp, L. H. Li, A. Moscowitz, G. L. Petzold, M. D. Prairie, D. H. Swenson, Chem.-Biol. Interactions 1986, 59, 55-72.

B. C. Moy, M. D. Prairie, W. C. Krueger, B. K. Bhuyan, Canc. Res. 1998, 49, 1983-1988.

126 V. L. Reynolds, J. P. McGovren, L. H. Hurley, J. Antibiot. 1986, 319-334.

127 A. Skladanowski, M. Koba, J. Konopa, Biochem. Pharmacol. 2001, 61, 67-72.

128 J. D. Trzupek, J. M. Gottesfeld, D. L. Boger, Nat. Chem Biol. 2006, 2, 79-81.

129 R. Baird, S. Winstein, J. Am. Chem. Soc. 1963, 85, 567-578.

130 a) L. F. Tietze, M. Lieb, T. Herzig, F. Haunert, I. Schuberth, Bioorg. Med. Chem. 2001, 9, 1929-1939; b) M. P. Hay, R. F. Anderson, D. M. Ferry, W. R. Wilson, W. A. Denny, J. Med. Chem. 2003, 46, 5533-5545; c) S. C. Jeffrey, M. Y. Torgov, J. B. Andreyka, L. Boddington, C. G. Cerveny, W. A. Denny, K. A. Gordon, D. Gustin, J. Haugen, T. Kline, M. T. Nguyen, P. D. Senter, J. Med. Chem. 2004, JM040137Q.

131 Denny, W. A. J. of Biomed. and Biotech. 2003, 1, 48-70.

132 Hay, M. P.; Sykes, B. M.; Denny, W. A.; Wilson, W. R. Bioorg. Med. Chem. Lett. 1999, 9, 2237-2242.

133 M. P. Hay, G. J. Atwell, W. R. Wilson, S. M. Pullen, W. A. Denny, J. Med. Chem. 2003, 46, 2456-2466.

134 a) G. J. Atwell, M. Tercel, M. Boyd, W. R. Wilson, W. A. Denny, J. Org. Chem. 1998, 63, 9414-9420; b) G. J. Atwell, J. B. J. Milbank, W. R. Wilson, A. Hogg, A., W. A. Denny, J. Med. Chem. 1999, 42, 3400-3411; c) W. Jin, J. D. Trzupek, T. J. Rayl, M. A. Broward, G. A. Vielhauer, S. J. Weir, I. Hwang, D. L. Boger, J. Am. Chem. Soc. 2007, 129, 15391-15397. 
135 a) Y. Wang, J. Jiang, X. Jiang, S. Cai, H. Han, L. Li, Z. Tian, W. Jiang, Z. Zhang, Y. Xiao, S. W. Wright, J. W. Larrick, Bioorg. Med. Chem. 2008, 16, 6552-6559; b) Y. Wang, L. Li, Z. Tiang, W. Jiang, J. W. Larrick, Bioorg. Med. Chem. 2006, 14, 7854-7861.

136 P. R. Hamann, Expert Opinion on Therapeutic Patents 2005, 15, 1078-1103.

137 a) Y. Wang,; S. C. Wright, J. W. Larrick, United States Patent, Number 5843937 , 1998; b) Y. Wang, H. Yuan, S. C. Wright, H. Wang, J. W. Larrick, Bioorg. Med. Chem. 2003, 11, 1569-1575.

138 a) L. N. Jungheim, T. A. Shepherd, J. K. Kling, Heterocycles 1993, 35, 339-348;

b) Y. Wang, H. Yuan, S. C. Wright, H. Wang, J. W. Larrick, BMC Chem. Biol. 2001, 1:4.

139 a) T. Suzawa, S. Nagamura, H. Saito, S. Ohta, N. Hanai, M. Yamasaki, Bioorg. Med. Chem. 2000, 8, 2175-5184, b) Y. V. Kovtun, C. A. Audette, Y. Ye, H. Xie, M. F. Ruberti, S. J. Phinney, B. A. Leece, T. Chittenden, W. A. Blättler, V. S. Goldmacher, Cancer Res. 2006, 66, 3214-3220.

S. C. Jeffrey et al., J. Am. Chem. Soc. 2004, 1344-1358.

a) A. Fecher, Dissertation, Göttingen 2000; b) T. Herzig, Dissertation, Göttingen 2000; c) T. Feuerstein, Dissertation, Göttingen 2003; d) O. Panknin, Dissertation, Göttingen 2004; e) X. Chen, Dissertation, Göttingen 2006; f) F. Major, Dissertation, Göttingen, 2006; g) F. Colunga, Dissertation, Göttingen 2007; h) H. Schuster, Dissertation, Göttingen, 2008.

L. F. Tietze, H. J. Schuster, B. Krewer, I. Schuberth, J. Med. Chem. 2008, in press.

143 Informationen zur Fluoreszenzmikroskopie: http://de.wikipedia.org/wiki/ Fluoreszenzmikroskopie.

$144 \mathrm{http} / /$ products.invitrogen.com/ivgn/en/US/adirect/invitrogen?cmd=IVGNcat DisplayCategory\&catKey $=72201$.

145 a) O. Shimomura, F. H. Johnson und Y. Saiga. Journal of Cellular and Comparative Physiology 1962, 59, 223-239; b) O. Shimomura. Journal of Microscopy 2005, 217, 1-15.

B. G. Giepmans, S. R. Adams, M. H. Ellisman, R. Y. Tsien, Science 2006, 312, 217-224.

147 http://probes.invitrogen.com/handbook/sections/0107.html. 
148 a) http://probes.invitrogen.com/handbook/sections/0806.html; b) S. A. Latt, G. Stetten, J. Histochem. and Cytochem. 1976, 24, 24-33; c) G. A. Daxhelet, M. M. Coene, P.P. Hoet, G. C. Cocito, Anal Biochem. 1989, 179, 401-403; c) F. G. Loontiens, P. Regenfuss, A. Zechel, L. Dumortier, R. M. Clegg, Biochemistry 1990, 29, 9029-9039.

149 a) http://probes.invitrogen.com/handbook/sections/1202.html;

b) http://probes.invitrogen.com/media/pis/mp07510.pdf.

150 a) A. Macho, D. Decaudin, M. Castedo, T. Hirsch, S. A. Susin, N. Zamzami, G. Kroemer, Cytometry 1996, 25, 333-340; b) M. Castedo, T. Hirsch, S. A. Susin, N. Zamzami, P. Marchetti, A. Macho, G. Kroemer. J. of Immunol. 1996, 512521.

151 F. Alves, M. Zientkowska, unveröffentlichte Ergebnisse.

152 http://www.mpin-koeln.mpg.de/index.php?id=77.

153 a) J. Krneta, J. Kroll, F. Alves, C. Prahst, F. Sananbenesi, C. Dullin, S. Kimmina, D. J. Phillips, H. G. Augustin, Cancer Res. 2006, 66, 5686-5694; b) N. V. Evgenov, Z. Medarova, G. Dai, S. Bonner-Weir, A. Moore, Nat. Med. 2006, 12, 144-148; c) S. H. Thorne, R. S. Negrin, C. H. Contag, Science 2006, 311, 17801784; d) L. A. Pardo, C. Contreras-Jurado, M. Zientkowska, F. Alves, W. Stühmer, J. Membrane Biol. 2005, 205, 115-124; e) X. Chen, P. S. Conti, R. A. Moats, Cancer Res. 2004, 64, 8009-8014; f) C.-H. Tung, Q. Zeng, K. Shah, D.E. Kim, D. Schellingerhout, R. Weissleder, Cancer Res. 2004, 64, 1579-1583.

154 a) R. M. Hoffman, Nature 2005, 5, 796-806; b) G. Seitz, S. W. Warmann, J. Fuchs, H. Heitmann, J. Mahrt, A.-C. Busse, P. Ruck, R. M. Hoffman, J. T. Wessels. Cell Prolif. 2008, 41, 365-374; c) M. Yang, G. Luiken, E. Baranov, R. M. Hofman, BioTechniques 2005, 39, 170-172.

155 F. F. Jobsis, Science 1977, 198, 1264-1267.

156 a) G. Wei, N. A. Loktionova, A. E. Pegg, R. C. Moschel, J. Med.Chem. 2005, 48, 256-261; b) H. Cheng, X. Cao, M. Xian, L. Fang, T. B. Cai, J. J. Ji, J. B. Tunac, D. Sun, P. G. Wang, J. Med. Chem. 2005, 48, 645-652; c) M. Y. Torgov, S. C. Alley, C. G. Cerveny,D. Farquhar, P. D. Senter, Bioconjugate Chem. 2005, 16, 717-721; d) E. Bouvier, S. Thirot, F. Schmidt, C. Monneret, Bioorg. Med. Chem. 2004, 12, 969-977; e) T. Kline, M. Y. Torgov, B. A. Mendelsohn, C. G. Cerveny, P. D. Senter, Mol. Pharm. 2004, 1, 9-22; f) E. Bouvier, S. Thirot, F. Schmidt, C. Monneret, Org. Biomol. Chem. 2003, 1, 3343-3352; g) H. Townes, 
K. Summerville, B. Purnell, M. Hooker, E. Madsen, S. Hudson, M. Lee, Med. Chem. Res. 2002, 12, 248-253; h) N. Amishiro, S. Nagamura, C. Murakata, A. Okamoto, E. Kobayashi, M. Asada, K. Gomi, T. Tamaoki, M. Okabe, N. Yamaguchi, K. Yamaguchi, H. Saito, Bioorg. Med. Chem. 2000, 8, 381-391.

B. Krewer, Diplomarbeit, Göttingen, 2005.

J. B. J. Milbank, M. Tercel, G. J. Atwell, W. R. Wilson, A. Hogg, W. A. Denny, J. Med. Chem. 1999, 42, 649-658.

a) J. M. von Hof, Diplomarbeit, Göttingen, 2006; b) J. M. von Hof, unveröffentlichte Ergebnisse.

a) R. R. Schmidt, Angew. Chem. 1986, 98, 213-236; Angew. Chem. Int. Ed. Engl. 1986, 25, 212-235; b) W. Dullenkopf, J. C. Castro-Palomino, L. Manzoni, R. R. Schmidt, Carbohydr. Res. 1996, 296, 135-147.

a) G. Damia, M. D’Incalci, Cytotechnology 1998, 27, 165-173; b) P. Mistry, L.

R. Kelland, G. Abel, S. Sidhar, K. R. Harrap, Br. J. Cancer 1991, 64, 215-220;

c) M.-H. David-Cordonnier, Eur. J. Biochem. 2003, 270, 2848-2859.

D. A. Spiegl, Diplomarbeit, Göttingen, 2004.

D. L. Boger, W. Yun, N. Han, Bioorg. Med. Chem. 1995, 3, 1429-1453.

a) S. Ram, L. D. Spicer, Tetrahedron Lett. 1987, 28, 515-516; b) T. Bieg, W. Szeja, Synthesis 1985, 76-77.

B. Helferich, E. Schmitz-Hillebrecht, Ber. Dtsch. Chem. Ges. 1933, 66, 378-383.

E. Fischer, K. Raske, Ber. Dtsch. Chem. Ges. 1909, 42, 1465-1476.

a) H. Paulsen, Angew. Chem. 1982, 94, 184-201; b) W. Königs, E. Knorr, Ber. Dtsch. Chem. Ges. 1901, 34, 957-981.

a) L. F. Tietze, R. Fischer, H.-J. Guder, Tetrahedron Lett. 1982, 23, 4661-4664;

b) L. F. Tietze, R. Fischer, Angew. Chem. 1981, 108, 1002.

S. J. Danishefsky, M. T. Bilodeau, Angew. Chem. 1996, 108, 1482-1522.

P. Zimmermann, R. Bommer, T. Bär, R. R. Schmidt, J. Carbohydr. Chem. 1988, 7, 435-452.

G. Zemplen, E. Pascu, Ber. Dtsch. Chem. Ges. 1929, 62, 1613-1614.

a) L. M. Greene, J. L. Reade, C. F. Ware, J. Immunol. Meth. 1984, 70, 257-268;

b) T- Mosmann, J. Immunol. Meth. 1983, 65, 55-63.

L. F. Tietze, J. M. von Hof, B. Krewer, M. Müller, F. Major, H. J. Schuster, I. Schuberth. F. Alves, ChemMedChem 2008, in press.

L. F. Tietze, F. Major, Eur. J. Org. Chem. 2006, 2314-2321. 
175 a) D. L. Boger, D. L. Hertzog, B. Bollinger, D. S. Johnson, H. Cai, J. Goldberg, P. Turnbull, J. Am. Chem. Soc. 1997, 119, 4977-4986; b) D. L. Boger, B. Bollinger, D. L. Hertzog, D. S. Johnson, H. Cai, P. Mésini, R. M. Garbaccio, Q. Jin, P. A. Kitos, J. Am. Chem. Soc. 1997, 119, 4987-4998.

N. B. Ulyanov, W. R. Bauer, T. L. James, J. of Biomol. NMR 2002, 22, 265-280. a) D. L. Boger, D. S. Johnson, W. Yun, C. M. Tarby, Bioorg. Med. Chem. 1994, 2, 115-135; b) D. L. Boger, R. S. Coleman, B. J. Invergo, S. M. Sakya, T. Ishizaki, S. A. Munk, H. Zarrinmayeh, P. A. Kitos, S. C. Thompson, J. Am. Chem. Soc. 1990, 112, 4623-4632.

W. J. Chazin et al., J. Mol. Biol. 1997, 272, 237-252.

179 a) P. Iannitti, M. M. Sheil, G. Wickham, J. Am. Chem. Soc. 1997, 119, 14901491; b) L. A. Marzilli, D. Wang, W. R. Kobertz, J. M. Essigmann, P. Vouros, J. Am. Soc. Mass. Spectrom. 1998, 9, 676-682; c) P. Iannitti-Tito, A. Weimann, G. Wickham, M. M. Sheil, Analyst 2000, 125, 627-634; d) J. L. Beck, M. L. Colgrave, S. F. Ralph, M. M. Sheil, Mass Spectrom. Rev. 2001, 20, 61-87; e) M. L. Colgrave, P. Iannitti-Tito, G. Wickham, M. M. Sheil, Aust. J. Chem. 2003, 56, 401-413; f) R. Singh, P. B. Farmer, Carcinogenesis 2006, 2, 178-196.

a) S. A. McLuckey, S. Habibi-Goudarzi, J. Am. Chem. Soc. 1993, 115, 1208512095; b) E. Nordhoff, F. Kirpekar, P. Roepstorff, Mass Spectrom. Rev. 1996, 15, 67-138; c) J. H. Banoub, R. P. Newton, E. Esmans, D. F. Ewing, G. Mackenzie, Chem. Rev. 2005, 105, 1869-1915; d) J. P. Barry, P. Vouros, A. V. Schepdael, S.-J- Law, J. Mass Spectrom. 2005, 30, 993-1006; e) S. A. Hofstadler, K. A. Sannes-Lowery, J. C. Hannis, Mass Spectrom. Rev. 2005, 24, 265-285.

a) C. H. Lin, D. J. Patel, J. Mol. Biol. 1995, 248, 162-179; b) P. S. Eis, J. A. Smith, J. M. Rydzewski, D. A. Case, D. L. Boger, W. J. Chazin, J. Mol. Biol. 1997, 272, 237-252; c) J. A. Smith, G. Bifulco, D. A. Case, D. L. Boger, L. Gomez-Paloma, W. J. Chazin, J. Mol. Biol. 2000, 300, 1195-1204.

182 O. Kennard, W. N. Hunter, Angew. Chem. 1991, 103, 1280-1304; Angew. Chem. Int. Ed. Engl. 1991, 30, 1254-1277.

a) T. Bando, A. Narita, S. Sasaki, H. Sugiyama, J. Am. Chem. Soc. 2005, 127, 13890-13895; b) S. Kupchinsky, S. Centioni, T. Howard, J. Trzupek, S. Roller, V. Carnahan, H. Townes, B. Purnell, C. Price, H. Handl, K. Summerville, K. Johnson, J. Toth, S. Hudson, K. Kiakos, J. A. Hartley, M. Lee, Bioorg. Med. 
Chem. 2004, 12, 6221-6236; c) D. L. Boger, H. W. Schmitt, B. E. Fink, M. P. Hedrick, J. Org. Chem. 2001, 66, 6654-6661; d) Z. Zhang, M. C. Poirier, Chem. Res. Toxicol. 1997, 10, 971-977; e) Y. Pommier, G. Kohlhagen, C. Bailly, M. Waring, A. Mazumder, K. W. Kohn, Biochemistry 1996, 35, 13303-13309.

A) D. G. Gale, R. D. Smith, J. Am. Soc. Mass Spectrom. 1995, 6, 1154-1164; b) K. X. Wan, M. L. Gross, J. Am. Soc. Mass Spectrom. 2000, 11, 450-457; c) S. A. Hofstadler, R. H. Griffey, Chem Rev. 2001, 101, 377-390.

a) H. Sugiyama, K. Ohmori, K. L. Chan, M. Hosoda, A. Asai, H. Saito, I. Saito, Tetrahedron Lett. 1993, 34, 2179-2182; b) K. Yamamoto, H. Sugiyama, S. Kawanishi, Biochemistry 1993, 32, 1059-1066; c) A. Asai, S. Nagamura, H. Saito, J. Am. Chem. Soc. 1994, 116, 4171-4177.

a) W. H. Habig et al., J. Biomol. Chem. 1974, 249, 7130-7139; b) D. M. Townsend, K. D. Tew, Oncogene 2003, 22, 7369-7357; c) A. Pompella, A. Visvikis, A. Paolicchi, V. de Tata, A. F. Casini, Biochem. Pharmacol. 2003, 66, 1499-1503.

A. Pastore, G. Federici, E. Bestini, F. Piemonte, Clinica Chimica Acta 2003, 333, 19-39.

Merck Index, 11. Ausgabe, Eintrag 4369.

a) R. Stevens, L. Stevens, N. C. Price, Biochem. Education 1983, 11, 70; b) R. M. C. Dawson in Data for Biochemical Research, 3. Ausgabe, Oxford University Press, New York, 1987, S. 16-17.

a) M. A. Warpehoski, D. E. Harper, M. A. Mitchell, T. J. Monroe, Biochemistry 1992, 31, 2502-2508; b) D. L. Boger, W. Yun, J. Am. Chem. Soc. 1993, 115, 9872-9873; c) D. L. Boger, D. S. Johnson, W. Yun, J. Am. Chem. Soc. 1994, $116,1635-1656$.

a) N. Berova, L. Di Bari, G. Pescitelli, Chem. Soc. Rev. 2007, 36, 914-931; b) S. R. Martin, M. J. Schilstra, Methods Cell Biol. 2008, 84, 263-293; c) G. D. Fasman (Editor), Circular Dichroism and the Conformational Analysis of Biomolecules, Plenum Press, New York, 1996; d) N. Berova, K. Nakanishi R., W. Woody, R. W. (Editoren), Circular Dichroism: Principles and Applications, 2. Auflage, Wiley-VCH, New York, 2000.

Als Elliptizität wird der Winkel bezeichnet, dessen Tangens gleich dem Verhältnis zwischen der kleinen und der großen Achse des elliptisch polarisierten Lichtes ist. 
193

194

195
a) S. J. Weiner, P. A. Kollmann,

1986, 7, 230-252; b) R. Schwesinger et al., J. Comput. Chem. 1991, 12, 620; c)

M. A. Alisi et al., Tetrahedron Lett. 1992, 33, 7793-7796.

196

a) J. P. Pelton, D. E. Wemmer, Proc. Natl. Acad. Sci. USA 1989, 86, 5723-5727;

b) X.-L. Yang, C. Kaenzig, M. Lee, A. H.-J. Wang, Eur. J. Biochem. 1999, 263, 646-655; c) P. B. Dervan, Bioorg. Med. Chem. 2001, 9, 2215-2235.

197

a) T. Bando, A. Marita, K. Asada, H. Ayame, H. Sugiyama, J. Am. Chem. Soc. 2004, 126, 8948-8955; b) T. Bando, A. Narita, S. Sasaki, H. Sugiyama, J. Am. Chem. Soc. 2005, 127, 13890-13895.

H. Sugiyama, C. Lian, M. Isomura, I. Saito, A. H.-J. Wang, Proc. Natl. Acad. Sci. USA 1996, 93, 14405-14410.

S. F. Kol'yakov, L. V. Pyatibrat, E. L. Mikhailov, O. N. Kompanets, T. I. Karu, Doklady Biochemistry and Biophysics 2001, 377, 128-131.

P. Nicholls, W. B. Elliot, in Iron Biochemistry and Medicine, New York, Academic 1974, 221-272.

P. Hallén, P. Brzezinski, Biochim. Biophys. Acta 1994, 1184, 207-218.

Qiagen, QIAamp ${ }^{\circledR}$ DNA Mini and Blood Mini Handbook, 2. Auflage, 2007.

J. Sambrook, D. W. Russell. Molecular Cloning: A Laboratory Manual, 3. Auflage, Cold Spring Harbor Laboratory Press, Cold Spring Harbor, New York, 2001.

http://www.molim.uni-erlangen.de/lehrInfo/F1_neubauer1.pdf.

G. Lappin, S. Temple, Radiotracers in Drug Development, CRC Press, Boca Raton, 2006.

J.-J. Aaron, S. Trajkovska, Curr. Drug Targets 2006, 7, 1067-1081.

W. Forth, D. Henschler, W. Rummel, U. Förstermann, K. Starke (Herausgeber), Allgemeine und spezielle Pharmakologie und Toxikologie, 8. Auflage, Urban und Fischer Verlag, München, 2001.

a) M. Nishiyama, K. Suzuki, T. Kumazaki, W. Yamamoto, T. Toge, T. Okamura, K. Kurisu, Int. J. Cancer 1997, 72, 649-656; b) S. E. Wolkenberg, D. L. Boger, Chem. Rev. 2002, 7, 2477-2495; c) U. Galm, M. H. Hager, S. G. Van Lanen, J. 
Ju, J. S. Thorson, B. Shen, Chem. Rev. 2005, 105, 739-758 ; d) D. M. Noll, T. McGregor Mason, P. S. Miller, Chem. Rev. 2006, 106, 277-301.

209 J. Portugal, M. J. Waring, $B B A$ 1988, 949, 158-168.

210 a) M. Kubbies, Cytometry 1990, 11, 386-394; b) H. A. Crissman, M. E. Wilder, R. A. Tobey, Cancer Res. 1988, 48, 5742-5746.

211 a) D. C. Prasher, V. K. Eckenrode, W. W. Ward, F. G. Prendergast, M. J. Cormier, Gene 1992, 111, 229-233; b) P. Adamson, H. F. Paterson, A. Hall, J. Cell Biol. 1992, 119, 617-627; c) M. Chalfie, Y. Tu, G. Euskirchen, W. W. Ward, D. C. Prasher, Science 1994, 263, 802-805; d) S. Inouye, F. I. Tsuji, FEBS Letters 1994, 341, 277-280; e) B. Cormack, R. Valdivia, S. Falkow, Gene 1996, 173, 33-38.

212 a) http://probes.invitrogen.com/handbook/sections/1203.html; b) A. Hambrock, C. Löffler-Walz, U. Quast, Br. J. Pharmacol. 2002, 136, 995-1004; c) K. E. Fogarty, J. F. Kidd, A. Turner, J. N. Skepper, J. Carmichael, P. Thorn, J. Biol. Chem. 2000, 275, 22487-22494.

a) A. Cossarizza, S. Salvioli, Methods Cell Biol. 2001, 63, 467-486; b) C. Brenner, G. Kroemer, Science 2000, 289, 1150-1151.

V. L. Reynolds, J. P. McGovren, L. H. Hurley, J. Antibiot. 1986, 319-334.

D. D. Perrin, W. L. F. Arnarego, Purification of Laboratory Chemicals, $3^{\text {rd }}$ Ed., Pergamon Press, Oxford, 1988.

216 a) G. Chang, W. C. Guida, W. C. Still, J. Am. Chem. Soc. 1989, 111, 4379-4386;

b) M. Saunders, K. N. Houk, Y. D. Wu, W. C. Still, M. Lipton, G. Chang, W. C. Guida, J. Am. Chem. Soc. 1990, 112, 1419-1427. 


\section{Danksagung}

Zuerst möchte ich mich bei allen Mitarbeitern der analytischen Abteilungen des Instituts für Organische und Biomolekulare Chemie bedanken, ohne deren professionelle Arbeit die Anfertigung dieser Dissertation nicht möglich gewesen wäre.

Für die Aufnahme der Massenspektren und die Hilfsbereitschaft danke ich Frau Györgyi Sommer-Udvarnoki, Frau Gabriele Krökel und Herrn Dr. Holm Frauendorf. Dr. Holm Frauendorf gilt zudem mein besonderer Dank für die Unterstützung bezüglich der HPLC-MS-Messungen und für die vielen interessanten, gemeinsam durchgeführten Untersuchungen am ESI-FTICR-MS. Vielen Dank für die tolle Zusammenarbeit!

Für die Aufnahme der Kernresonanzspektren möchte ich mich bei der NMR-Abteilung unseres Instituts bedanken, deren Mitarbeiter mir auch bei Abgabe geringer Substanzmengen immer fabelhafte Spektren aufnahmen. Vielen Dank daher an Herrn Ulrich Leonhardt, Herrn Reinhard Machinek, Frau Christiane Siebert, Herrn Martin Weitemeyer und Frau Carola Zolke.

Ein großes Dankeschön geht an Herrn Olaf Senge und den ehemaligen Auszubildenden Daniel Lohrberg für die tatkräftige Unterstützung bei der Durchführung diverser HPLC-Messungen. Herrn Frank Hambloch danke ich für die Sicherung meiner an den Massenspektrometern gewonnenen Daten und Herrn G. Busse (MPI für biophysikalische Chemie Göttingen) für die Unterstützung bei einer Fluoreszenzspektroskopieuntersuchung. Weiterhin danke ich Frau Evelyn Pfeil für das Messen zahlreicher UVund IR-Spektren sowie der Drehwerte.

Mein ganz besonderer Dank gilt Dr. Ingrid Schuberth, Anja Herdlitschke und Angela Rübeling aus der Zellbiologie unseres Institutes für die gewissenhafte Durchführung und Auswertung der In-vitro-Zytotoxizitätsuntersuchungen sowie die tatkräftige Unterstützung bei der Durchführung aller Versuche mit Zellen. Ihr hattet immer ein offenes Ohr für meine Fragen und habt mich immer vorbildlich unterstützt. Die Zusammenarbeit mit Euch hat mir sehr viel Spass gemacht und ich werde Euch wirklich vermissen!

Für die Möglichkeit zur Nutzung des CD-Spektropolarimeters, des UV-Gerätes und des Modellierungsarbeitsplatzes im Computerraum möchte ich mich bei Prof. U. Diederichsen und seiner Arbeitsgruppe bedanken. Sehr dankbar bin ich insbesondere Dr. Andrea Elsner, die mir die Bedienung des CD-Spektrometers und des 
UV-Gerätes erklärte und die ersten Messungen zusammen mit mir durchführte. Ein zusätzlicher Dank gebührt ihr für die Modellierungsstudien. Vielen Dank für Dein Engagement!

Ein Dankeschön geht auch an Frau G. Schmidt, die als Ansprechpartnerin der Firma Jasco jederzeit kompetente Auskünfte und praktische Hilfe rund um das Thema HPLC erteilen konnte. Herrn J. Küßner und Herrn E. Kirchner der Firma Bruker Daltonik $G m b H$ danke ich für die großzügige Bereitstellung des Programmes Xmass, die mir eine zeitlich flexible Bearbeitung meiner Massenspektren erlaubte.

Herrn Prof. L. F. Tietze, Herrn Prof. A. Zeeck und Frau PD. S. Grond möchte ich für das Vertrauen danken, Übungsgruppen leiten zu dürfen und bei der Organisation von Lehrveranstaltungen mitwirken zu dürfen.

Bei allen Mitgliedern der Abteilungen Tietze und Werz möchte ich mich für die angenehme Arbeitsatmosphäre, die Hilfsbereitschaft, die gute Zusammenarbeit und die Geduld während meiner oftmals langen Arbeitsberichte bedanken.

Mein besonderer Dank gilt Dr. Felix Major für die Bereitstellung vieler Substanzen, die ich als Ausgangsmaterial für meine Synthesen nutzen konnte oder die ich als solche zur Untersuchung des Wirkmechanismus der Verbindungsklasse einsetzen konnte. Vielen Dank! Besonders danke ich auch Jan Marian von Hof für die Bereitstellung wertvollen Ausgangsmaterials für die Prodrug- und seco-Drug-Synthesen und die gute Zusammenarbeit in diversen (Kooperations-)Projekten. In diesem Zusammenhang möchte ich auch Dr. Heiko Schuster für die Bereitstellung des DMAI-DNABinders und für die Möglichkeit zur Stabilitätsuntersuchung seiner Prodrugs danken. Ein Dank geht weiterhin an alle anderen (ehemaligen) Kollegen der CC-1065-Gruppe (Chen, Frank, Franzisco, Galina, Kianga, Michael, Rasmus und Sonja) für das Teilen der Chemikalien und die interessanten Gespräche.

Christian, Felix, Florian, Frank, Katja und Thomas, d.h. meinen Kollegen aus Labor 406, danke ich für das äußerst angenehme Arbeitsklima, die vielen guten Tipps (z.B. wo die Acetondestille steht...) und die netten Unterhaltungen. Ihr werdet mir fehlen!

Christian Raith und Dr. Florian Stecker danke ich explizit für die gute und produktive Zusammenarbeit bei der Übungsgruppenleitung zu den Vorlesungen Experimentalchemie und Synthesemethoden.

Dr. Niels Böhnke und Linda Nacke gilt mein Dank für die oft zeitraubende Tätigkeit als Materialwart. Nina Tölle, Marian von Hof und Christian Raith sei gedankt für die 
Hilfe im Bereich der analytischen und präparativen HPLC. Des Weiteren danke ich Martina Pretor (Du bist unsere Rettung!), Dr. Sascha Hellkamp, Dr. Tom Kinzel und Frank Behrendt für ihre sofortige und kompetente Hilfe bei Computerproblemen jeglicher Art und unserer Sekretärin Sabine Schacht für die effiziente Koordination in Herrn Tietzes Vorzimmer.

Ein Dank gebührt auch unseren ehemaligen SFB-Sekretärinnen Jessica Frömmel und Heike Drebing sowie unseren Hausmeistern Frank Peters und Wolfram Matthies für Ihre stete Hilfsbereitschaft.

Für das schnelle und sorgfältige Korrekturlesen dieser Arbeit sowie die guten Tipps bedanke ich mich ganz herzlich bei Arne Heins, Christian Raith, Frank Behrendt, Henning Böckemeier, Kianga Schmuck, Linda Nacke, Marian von Hof sowie Dr. Holm Fauendorf und Dr. Ingrid Schuberth. Christian Raith, Dr. Felix Major, Dr. Florian Stecker und Dr. Tom Kinzel danke ich zudem für das Korrekturlesen diverser Anträge und Veröffentlichungen. Ihr habt mir sehr geholfen, vielen Dank!

Ein großer Dank gilt meinen/unseren Kooperationspartnern an anderen Instituten:

PD Dr. Frauke Alves von der Abteilung Hämatologie und Onkologie des Universitätsklinikums Göttingen danke ich für die Möglichkeit, an der Testung unserer Wirkstoffe in präklinischen Studien mitarbeiten zu dürfen und für den Einblick ins Optical Imaging. Marta Zientkowska und Joanna Napp gilt mein Dank für den praktischen Einblick in die präklinischen Studien und die gute Kooperation. Allen weiteren Kooperationspartnern dieses Projektes vom Universitätsklinikum Göttingen und vom Max-Plack-Institut für experimentelle Medizin in Göttingen danke ich für die gewinnbringenden Diskussionen und das gemeinsame Voranbringen des Projektes.

Meinen Kooperationspartnern Professor Dr. Walter Stühmer und Dr. Mišo Mitkovski am MPI für experimentelle Medizin in Göttingen danke ich für die gute Zusammenarbeit bezüglich der fluoreszenzmikroskopischen Untersuchungen der neuen Analoga. Dr. Mišo Mitkovski danke ich zudem für die vielen gemeinsamen Messungen, die immer sehr interessante Ergebnisse lieferten (unbelievable) sowie die interessanten Diskussionen und 3D-Ansichten. Vielen Dank!

Unseren Kooperationspartnern Dr. Surinder K. Sharma und Professor Dr. K. Bagshawe des UCL Cancer Institutes in London danke ich für die Testung zweier vielversprechender ADEPT-Kandidaten in vitro und in vivo. 
Der Bayer HealthCare und insbesondere Herrn H.-G. Lerchen danke ich für die Durchführung präklinischer Studien und die Untersuchungen des Metabolismus einer Reihe interessanter ADEPT-Verbindungen.

Unserem neuesten Kooperationspartner Dr. Jochen Stritzker der Genelux Corporation (San Diego) und Gastwisenschaftler der Universität Würzburg danke ich für die interessanten Studien zu einem Einsatz unserer Prodrugs in einem neuen und sehr vielversprechenden Ansatz selektiver Tumortherapien mit Viren.

Der Deutsche Telekom Stiftung danke ich für die finanzielle und ideelle Förderung während meiner Promotion. Inbesondere möchte ich in diesem Zusammenhang Frau C. Frense-Heck, die Ihre Aufgabe als Ansprechpartnerin und Stipendiatenbetreuerin vorbildlich erfüllt, für ihr Verständnis sowie die unbürokratische und schnelle Unterstützung bei größeren und kleineren Problemen danken.

Ganz besonders danke ich meiner Familie, die mich in vielerlei Hinsicht während meines Studiums und der Promotion unterstützt hat. Meine Schwester Ulrike verdient dabei ein Extra-Dankeschön für die wertvollen Tipps im Hinblick auf meine Publikationen (Es lebe das Krewer-Netzwerk!).

Ein herzlicher Dank gilt Dir, Stefano, für die Unterstützung während des gesamten Studiums und der Doktorarbeit und für Deine Liebe und Dein Verständnis.

Vielen Dank.

Meine akademischen Lehrer waren u. a. die folgenden Professoren und Dozenten:

F. Alves, G. Beuermann, P. Botschwina, J. Brockmöller, A. de Meijere, U. Diederichsen, W. Hack, W. Felsch, L. Fitjer, C. Griesinger, S. Grond, U. Klingebiel, H. Laatsch， J. Magull, F. Meyer, H. W. Roesky, C. Schneider, J. Schroeder, G. M. Sheldrick， R. Signorell， M. Suhm， I. Úson， L. F. Tietze，F. Vetterlein und A. Zeeck. 


\section{Lebenslauf}

\section{Persönliche Daten}

Name:

Birgit Krewer

Geburtstag:

08.09.1977

Geburtsort:

Bitburg

Eltern:

Johannes Krewer und Agnes Krewer, geb. Schnorrenberg

Staatsangehörigkeit:

deutsch

Familienstand:

ledig

\section{Schulausbildung und Freiwilliges Soziales Jahr}

1984-1988

$1988-1997$

07.1997

09.1996-08.1998

\section{Studium}

04.1999

04.2001

05.2003

03.2005

$12.2004-05.2005$

07.2005

08.2005-08.2008

22.01.2009
Grundschule, Aach-Newel

Angela-Merici-Gymnasium, Trier

Allgemeine Hochschulreife

Freiwilliges Soziales Jahr beim ASB, Erlangen

Beginn des Studiums der Medizin an der Georg-August-Universität Göttingen

Beginn des Studiums der Chemie an der Georg-August-Universität Göttingen

Diplomvorprüfung Chemie

Fremdsprachenzertifikat Italienisch

Diplomarbeit am Institut für Organische und Biomolekulare Chemie der Georg-August-Universität Göttingen unter der Leitung von Prof. Dr. Dr. h. c. Lutz F. Tietze über das Thema „Synthese und kinetische Untersuchungen der Transformationen von anti-Methyl-seco-CBI-DMAI-Verbindungen für eine selektive Krebstherapie"

Diplomprüfung im Studiengang Chemie

Dissertation am Institut für Organische und Biomolekulare Chemie der Georg-August-Universität Göttingen unter der Leitung von Prof. Dr. Dr. h. c. Lutz F. Tietze über das Thema „Synthese, biologische Evaluation und Untersuchung des Wirkmechanismus neuartiger Duocarmycin-Analoga für eine selektive Krebstherapie"

Rigorosum 